
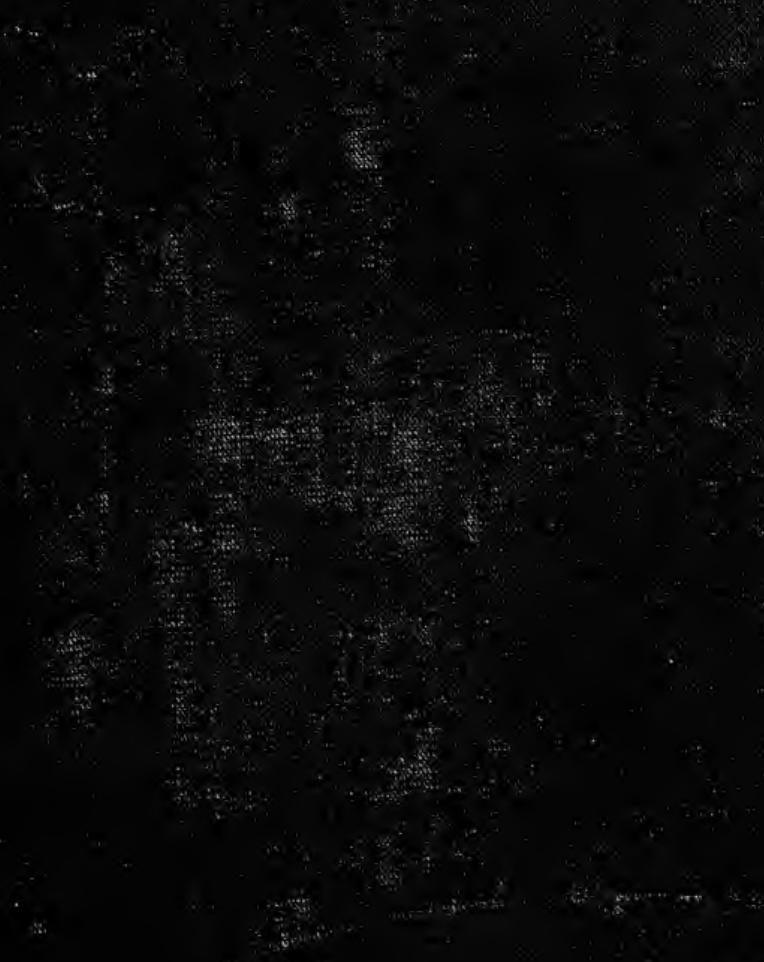


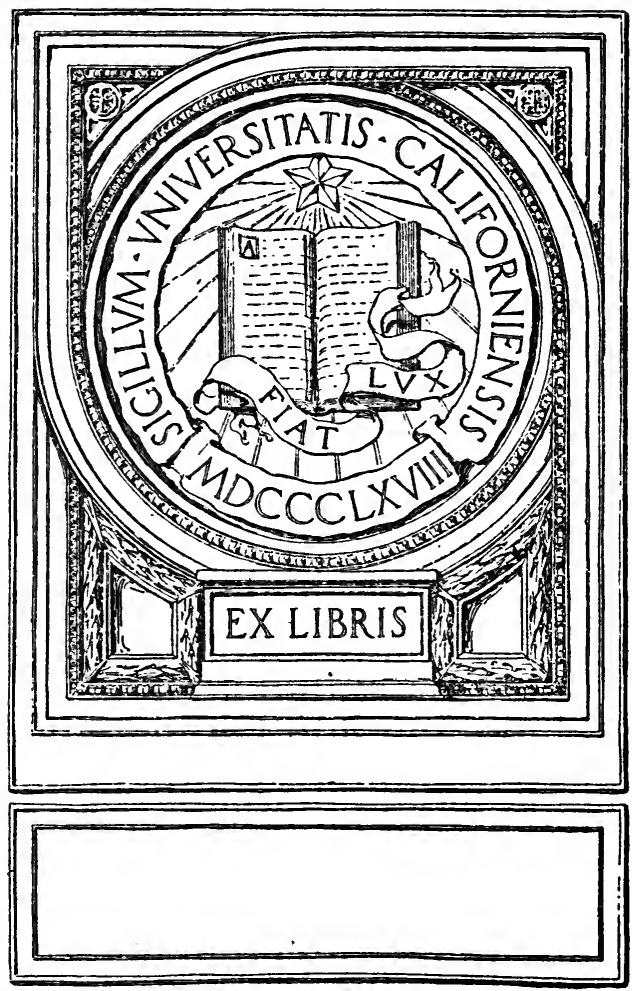




\section{Digitized by the Internet Archive in 2007 with funding from Microsoft Corporation}




\section{TEXT-BOOK ON NAVIGATION - AND}

NAUTICAL ASTRONOMY 



\title{
TEXT-BOOK ON NAVIGATION
}

AND

\section{NAUTICAL ASTRONOMY}

\author{
BY \\ J. GILL, F.R.A.S.
}

REVISED AND ENLARGED

BY

W. V. MERRIFIELD, B.A., F.R.A.S.

HEAD-MASTER OF THE LIVERPOOL CORPORATION NAUTICAL COLLEGE

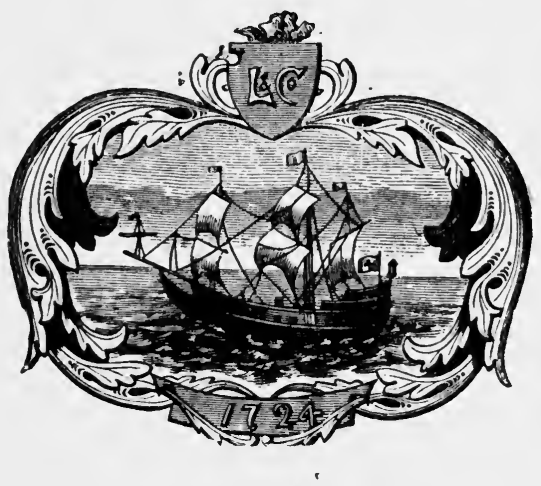

NEW EDITION

LONGMANS, GREEN AND CO.

39 PATERNOSTER ROW, LONDON FOURTH AVENUE \& 30TH STREET, NEW YORK

BOMBAY, CALCUTTA, AND MADRAS

1918

All rights reserved 


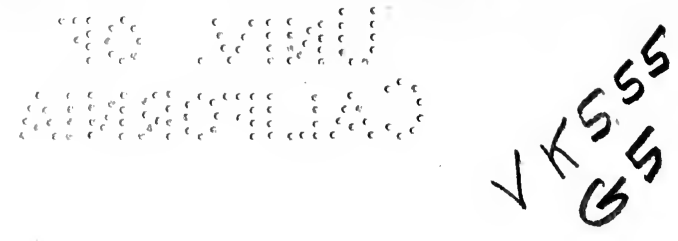




\section{PREFACE TO NEW EDITION}

THIS work is designed to meet the special requirements of officers of the Merchant Service, and to be a complete TextBook on Navigation, etc., for the general student.

Candidates for Board of Trade Certificates will find in it all that is needed to cope with the new regulations for the Examinations of Mates and Masters, from the lowest to the highest grades, as regards both practice and principles.

The new features in this edition are-

(1) Rearrangement, by which the proofs of the various problems are inserted at the beginning of the separate chapter instead of being collected in one chapter at the end of the book. This gives the student a better chance of comprehending each problem.

(2) All the astronomical examples are fresh, the necessary rules are given for working them, and, where possible, an example is worked direct from the figure, without using special formula; this will be found of great assistance to those contemplating going in for the "extra" examination.

(3) The necessary elements from the "Nautical Almanac" are embodied in the book in the form found in the "N.A.," and so will afford as good practice in extracting the data as the possession of the Almanac itself.

(4) The chapters on Trigonometry have been entirely rewritten, and the student is shown how to construct both Plane and Spherical Triangles to scale. 
For further information in this important subject he is recommended to consult a recognised School Text-Book.

(5) New chapters have been introduced on the Projections, by which any figure may be drawn to scale, and on the Correction of Altitudes.

(6) The chapters on the Tides and Tidal Soundings have been rewritten to suit the recent Tide Tables, extracts from which are found at the end of the book.

The candidate is warned that the abridged "Nautical Almanac" is in use at the examination room, and so must be on his guard when correcting all data, as the entries are arranged in such a manner that they may be extracted at sight.

For the number of page in the new edition of Norie corresponding to the number of table as given in this book, the student is referred to the Index of that work.

Chart work and the Construction of Charts have been more fully dealt with, and it is hoped that the alterations made will ensure the appreciation of the student.

W. V. MERRIFIELD.

LiverPoOL, 1918. 


\title{
C O N T E N T S
}

\author{
PART I.
}

CHA PTER

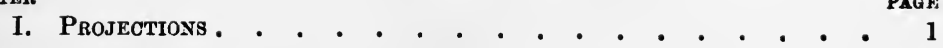

II. Definitions and Instruments . . . . . . . . . . . 7

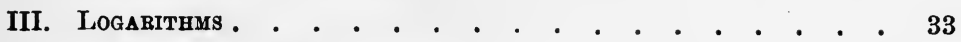

IV. Solution of Plane Triangles . . . . . . . . . . . . 43

V. Solution of Spherical Triangles . . . . . . . . . . 60

VI. The Sailings • • . . . . . . . . . . . . . . 71

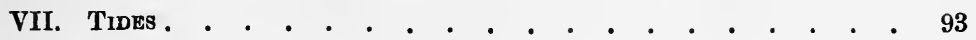

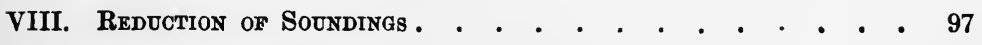

IX. TIME - . . . . . . . . . . . . . . . 107

X. Elgments from the "Nautical Almanac" • . • . • . . 117

XI. Sidereal and Solar Time . . . . . . . . . . . 127

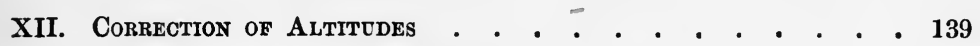

XiII. Latitude by Meridian Altitude . • . • . . . . . 145

XIV. Latitude by Ex-Meridian Altitude . . . . . . . . . 157

XV. Compass Error by Amplitudes . . . . • • • . . . . 168

XVI. Compass Error bT Azimoths . . . . . . . . . . . 173

XVII. Longitude by Chronometer . . . . . • . . . . . . 183

XVIII. Sumner's Method of Projection . . . . . . . . . . . 195

XIX. The Chart . . . . . . . . . . . . . . . . 201

XX. Use of Napier's Diagrai . • • • . • • • . . . . 208

XXI. Great Circle Salling . . . . . . . . . . 216 
CHAPTER PAGR

XXII. Latitude by Double Altitudes . . . . . . . . . 227

XXIII. Finding Error of Chronometer . . . . . . . . . . 241

XXIV. Calculation of Altitudes . . . . . . . . . . . 246

XXV. Longitdde by Lonar Distances . . . . . . . . . 250

\section{PART II.}

XXVi. Construction of Charts . . . . . . . . . . . . 263

XXVII. LAws of Storms . . . . . . . . . . . . . . . 271

XXVili. Magnetism and Detiation of the Compass . . . . . . 278

XXIX. Syllabus . . . . . . . . . . . . . . . . . 299

XXX. Miscellaneous Problems . . . . . . . . . . . . 331

APPENDIX . . . . . . . . . . . . . . . . 343

Answers . . . . . . . . . . . . . . 403

Tide Tables . . . . . . . . . . . . at end 1-12 


\section{PART I.}

\section{CHAPTER I.}

PROJECTIONS.

A WELL-DRAWN figure is at all times a great help to a student in the solution of a problem, and for a clear understanding of new terms made use of in a fresh subject. For this some knowledge of projection is required.

Projection is the art of representing a solid body on any surface by means of lines drawn according to definite laws. In Nautical Astronomy the solid is a sphere, and the surface a plane. These projections are either Natural or Artificial : Natural when the drawings are such as they would appear to the eye situated at a given point; Artificial when they are not perspective representations. According to the relative positions of the eye, sphere and plane of projection or primitive, the methods employed in Natural Projections receive different names, of which the most important are the Orthographic, Gnomonic, and Stereographic.

In the Orthographic, the eye is supposed so distant from the sphere that the visual rays are parallel to one another, the primitive is perpendicular to this direction.

In the Gnomonic, the eye is supposed to be at the centre of the sphere, and the primitive is a tangent plane to the sphere.

In the Stereographic, the eye is on the circumference of the sphere, and the primitive is a plane cutting the sphere in a great circle, which has the eye as its pole.

Since the primitive may be parallel to the Equator, Meridian, or Horizon, the above projections may be further distinguished as Equatorial, Meridional, or Horizontal.

The one used throughout this work is the Horizontal Stereographic Projection, and its important properties are: (1) all circles on the sphere project into either circles or straight lines ; (2) any figure on the sphere projects into a similar figure on the primitive.

(a) Projection on the Plane of the Equinoctial.-Here the primitive is the equinoctial, and the pole $\mathrm{P}$ the projecting point. The concentric circles are parallels of declination. Hour circles 
are répiresented: byy straight lines, since their planes pass through the projecting point. 'NPS is the celestial meridian, and EPW

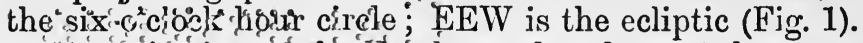

A projection of the Earth on the plane of the equator shows

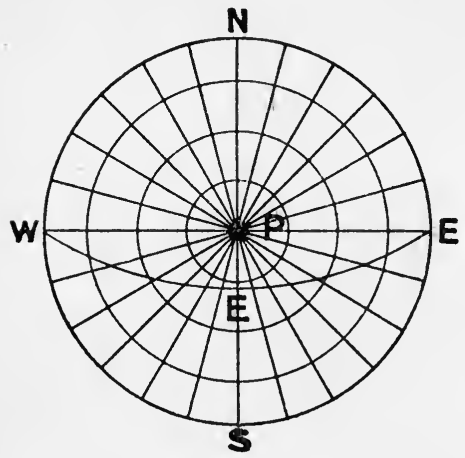

FIG. 1.

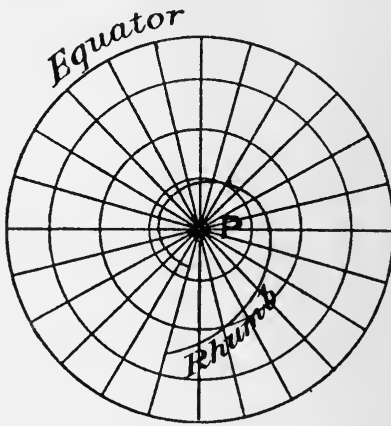

FIG. 2.

the meridians of longitude as straight lines, and the parallels of latitude as concentric circles whose common centre is the pole. This is useful for showing the course of a rhumb line, also for mapping the circumpolar regions (Fig. 2).

(b) Projection on the Plane of the Meridian (Figs. 3 and

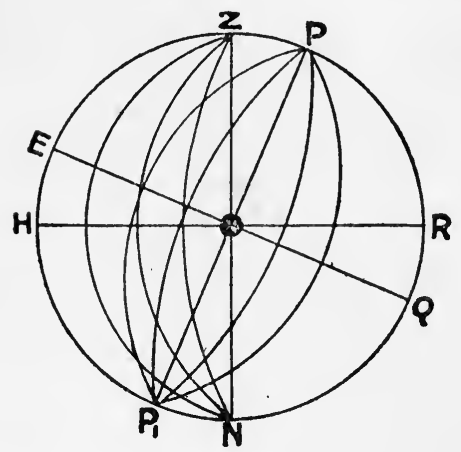

Fig. 3.

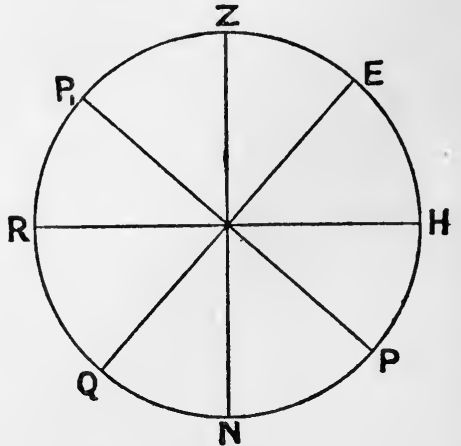

FIG. 4.

4).-The primitive circle represents the celestial meridian, the projecting point $\mathrm{O}$ being the east or west point of the horizon; $\mathrm{Z}$ and $\mathrm{N}$ are the zenith and nadir; $\mathrm{P}$ and $\mathrm{P}_{1}$, the north and souti poles respectively; $\mathrm{HR}$ (at right angles to $\mathrm{ZN}$ ) is the horizon; and $\mathrm{EQ}$ (at right angles to $\mathrm{PP}_{1}$ ) is the equinoctial. The elevation of the upper pole $\mathrm{P}$ above the horizon, viz. the arc $R P$, is equal to the latitude of the observer's position. The arc EZ also equals the 
latitude. Supposing $\mathrm{R}$ to be the north point of the horizon, then $P$ is the north pole (Fig. 3), and the latitude is north. For south latitude, the south pole $\mathrm{P}_{1}$ must be above the horizon (Fig. 4).

Hour circles are represented by ares from $\mathrm{P}$ to $\mathrm{P}_{1}$, and vertical or altitude circles by arcs from $\mathrm{Z}$ to $\mathrm{N}$.

(c) Projection on the Plane of the Horizon (Fig. 5.)-Here the primitive circle is the horizon, N., E., S., W. being the cardinal points. The zenith $(Z)$ is the projecting point, hence all vertical circles appear as straight lines passing through Z, NZs' being the celestial meridian, and WZE the prime vertical. $P$ is the north pole, at a distance from $N$. equal to the latitude. The arc $\mathrm{ZQ}$ is also equal to the latitude, and $\mathrm{PZ}$ is the co-latitude; WQE is the equator, cutting the horizon in the E. and $\mathrm{W}$. points; $\mathrm{P} p_{1}, \mathrm{P} p_{2}$, etc.,

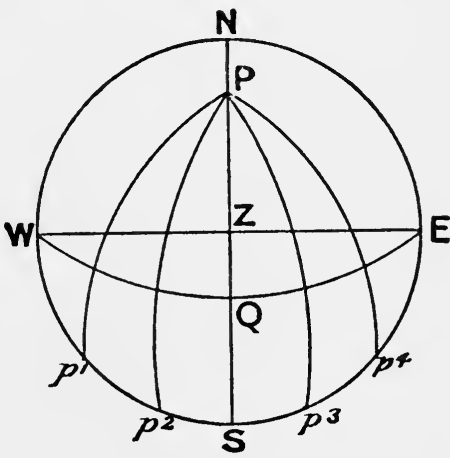

Fia. 5. are hour circles.

The projection on the plane of the horizon has some advantages over that on the plane of the meridian for illustrating most of the problems of nautical astronomy, and is therefore more commonly employed.

To draw a figure to scale, a "Gunter" rule is necessary; the following illustration explains the connection between the lines marked Rum., Cho., Sin., Tan., and S.T. on the rule (Fig. 6).

With centre $\mathrm{O}$, distance $\mathrm{OA}$, describe a semicircle. $\mathrm{AOB}$ is

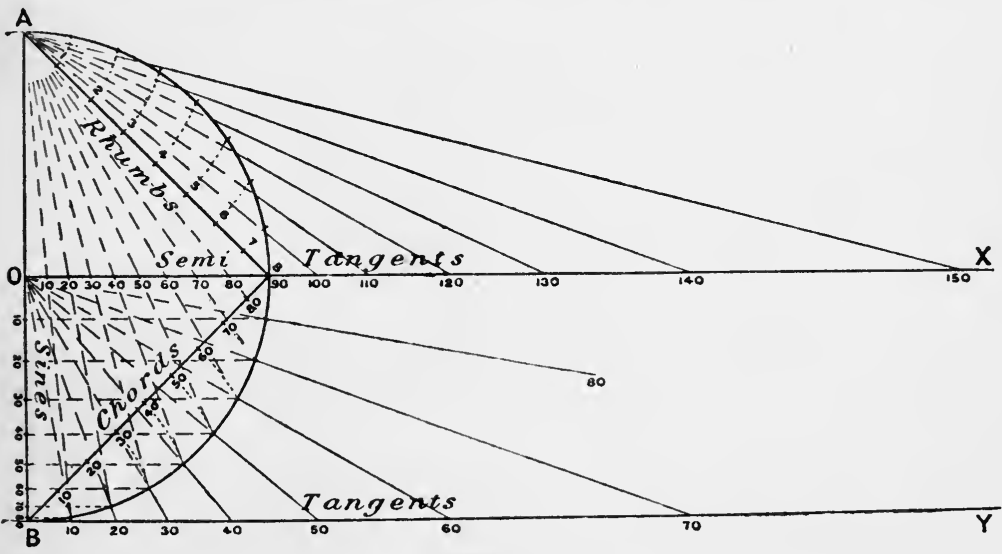

Fia. 6. 
a vertical diameter; OX, a horizontal line through centre; $\mathrm{BY}$, a tangent at $B$. OX divides the figure into two quadrants; the upper one is divided into eight equal parts, and with $A$ as centre and distance the different chords from $A$ to each point; the distances are brought back on the chord of $90^{\circ}$, forming the line of Rhumbs (RUM.). A3 is thus the chord of a circle described with radius $\mathrm{OA}$, which subtends an angle of three points at

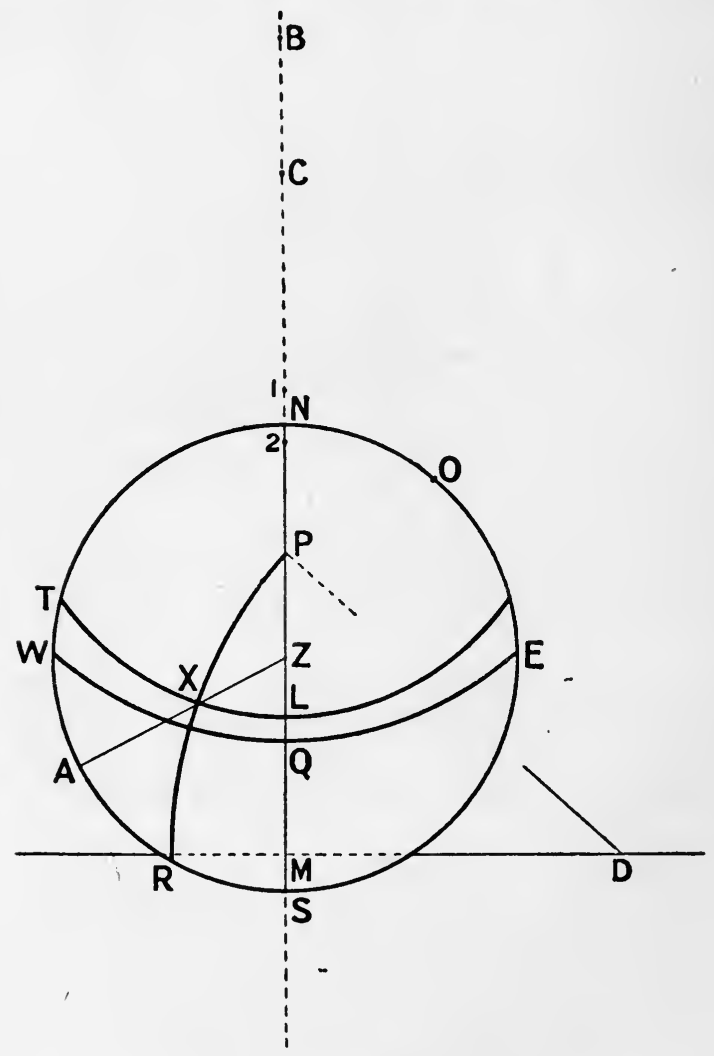

Frg. 7.

centre 0 . The line of Chords (CHо.) is similarly formed on the lower quadrant, but the quadrant is here divided into nine equal parts instead of eight, and thus gives divisions to $10^{\circ}$, which can be further subdivided. We can now see that the chord of $60^{\circ}$ is the radius that must be used to describe the circle. For the line of Tangents (TAN.) through $\mathrm{O}$ and points of division in lower quadrant, draw straight lines meeting $\mathrm{BY}$ in required points. For the line of Semi-Tangents (S.T.) through A, and 
points of division in lower quadrant, and also corresponding points in upper quadrant, draw lines to cut $O X$ in required points.

Example.-Draw a figure from following data : Latitude $40^{\circ} \mathrm{N}$.; western hour angle $2^{\mathrm{h}} 48^{\mathrm{m}}$; declination $10^{\circ} \mathrm{N}$.; and take off the Amplitude at setting, Azimuth and Altitude (Fig. 7).

With centre $Z$, and radius the chord of $60^{\circ}$, describe a circle N.E.S.W.; draw SZNB vertically, and lay off $\mathbf{E}$. and W. as the extremities of a horizontal diameter through $\mathrm{Z}$. Make $\mathrm{ZM}=40^{\circ}$ (Lat.) from scale of tangents, and through $\mathbf{M}$ draw a line perpendicular to $M Z$; in this line are the centres of all hour circles. Make NO $=$ chord of $40^{\circ}$ (Lat.), where the line OW cuts the vertical line is the elevated pole $P$. At $\mathbf{P}$ to the right make an angle $=$ complement hour angle that is $48^{\circ}$; this line cuts the line through $M$ in $\mathrm{D}$, and is the centre for describing the hour circle required PXR. For the equinoctial, add the colat to $90^{\circ}=140^{\circ}$; subtract the colat from $90^{\circ}=40^{\circ}$, and from scale of S.T. make $\mathrm{ZB}=140^{\circ}$, and $\mathrm{ZQ}=40^{\circ}$; bisect $\mathrm{BQ}$ in 1 , this is centre for describing equinoctial WQE.

For the declination parallel, add colat to polar distance $=130^{\circ}$, subtract colat from polar distance $=30^{\circ}$; from S.T. scale make $\mathrm{ZC}=130^{\circ}$, and $\mathrm{ZL}=30^{\circ}$; bisect $\mathrm{CL}$ in 2 ; this is centre for describing the parallel TXL, where the parallel cuts the hour circle is $\mathrm{X}$, the position of the object. Draw ZXA the vertical circle through the object.

Measure WT on the scale of chords for the Amplitude $=15^{\circ}$, or $\mathrm{W} .15^{\circ} \mathrm{N}$.

Measure SA on the scale of chords for the Azimuth $=63^{\circ}$, or $\mathrm{S} .63^{\circ} \mathrm{W}$.

Measure ZX on the S.T. scale for the Zenith Distance $=49^{\circ}$, or Altitude $=41^{\circ}$.

For South Latitude set off ZM to the north, and construct the figure downwards instead of upwards.

The only Artificial Projection to be considered is Mercator's (Fig. 8).

Mercator's Projection.-This is the kind of projection used in the construction of Navigating Charts, and represents the Earth's surface as a plane. The meridians of longitude are drawn as parallel straight lines, and the divisions of latitude are expanded in the same proportion as the meridian distances are lengthened. The effect of this is to make the rhumb course a straight line, which is of great advantage to the navigator.

The distance from the equator of any given parallel of latitude, and the amount of expansion of a degree of latitude, can be found from the table of Meridional Parts; for example, the parallel of $30^{\circ}$ is 1800 geographical miles from

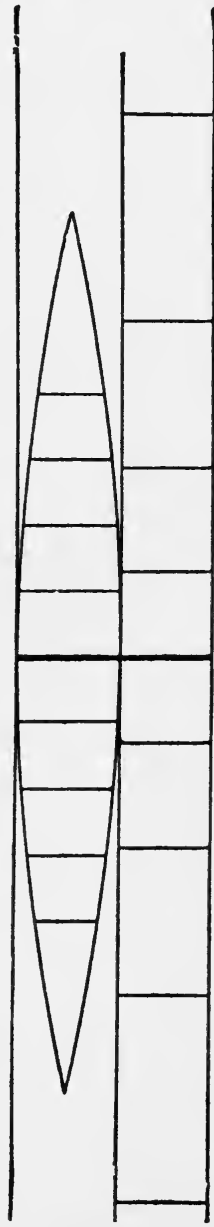

Fia. 8. the equator on the globe, but the meridional parts for $30^{\circ}=1888$, 
which means that on a Mercator's chart drawn to the same scale this parallel would be 1888 geographical miles from the equator. Again, the meridional parts for $3 \mathrm{~L}^{\circ}=1958$, and $1958-1888=70$ miles, which would be the length of the expanded degree from $30^{\circ}$ to $31^{\circ}$.

The meridional parts for any given latitude may be calculated by adding together the secants of all minutes of latitude up to the given latitude; thus-

$$
\sec 0^{\prime}+\sec 1^{\prime}+\sec 2^{\prime}+\sec 3^{\prime} \text {, etc. }
$$

or they may be calculated independently from the formula-

$\log$ of mer. parts $=3.8984895+\log \left(\log \cot \frac{1}{2}\right.$ co-lat. -10$)$ 


\section{CHAPTER II.}

\section{DEFINITIONS AND INSTRUMENTS.}

1. Great Circles.-Circles whose planes pass through the centre of a sphere or globe.

2. Vertex of a Great Circle.-That point in it which is farthest from the Equator.

3. Small Circles.-Circles whose planes do not pass through the centre of the sphere.

$A V B$ and $C^{\prime} D$ are great circles. $\mathrm{V}$ and $\mathrm{V}^{\prime}$ are vertices. EOF, a small circle.

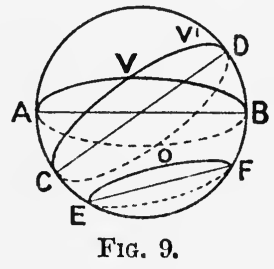

4. Right Anglc.-An angle measuring $90^{\circ}$, or one quarter of a circle.

5. Oblique Angle.-An angle not a right angle.

6. Obtuse Angle.-An angle greater than a right angle.

7. Acute Angle.-An angle less than a right angle.

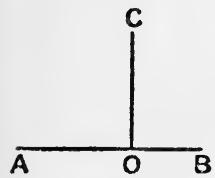

Fig. 10.

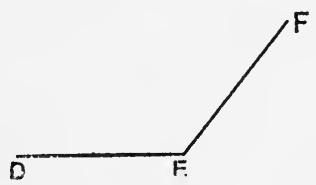

FIG. 11.

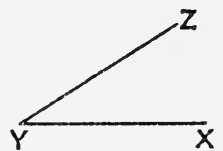

Fig. 12.

$\mathrm{AOC}$ and $\mathrm{BOC}$ are right angles.

DEF and XYZ are oblique angles.

DEF is an obtuse angle.

$\mathrm{XYZ}$ is an acute angle.

8. Spherical Angle.-An angle included between two great circles of a sphere (Fig. 13).

$\mathrm{AOC}$ and $\mathrm{BOC}$ are spherical angles.

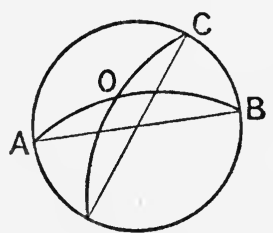

Fig. 13. 
9. Arc.-A part of the circumference of a circle.

10. Complement of an Arc or Angle.-Its difference from $90^{\circ}$.

11. Supplement of an Arc or Angle.-Its difference from $180^{\circ}$.

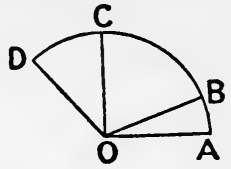

Fig. 14.

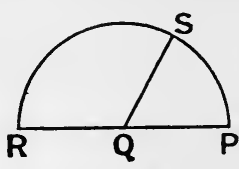

Fia. 15.
$\mathrm{AB}, \mathrm{BC}, \mathrm{CD}$ are arcs.

BOC is complement of BOA.

$\mathrm{BC}$ is complement of $\mathrm{BA}$.

COD is complement of AOD.
PS and SR are arcs.

SR is supplement of PS.

RQS is supplement of SQP.

12. The Poles.-The points where the earth's axis meets the surface.

13. Equator.-A great circle of the earth $90^{\circ}$ distant from the poles.

14. A Meridian.-Half a great circle extending from pole to pole of the earth.

15. Parallels of Latitude.-Circles whose planes are parallel to the plane of the Equator.

16. Tropics.-Two parallels of latitude distant $23^{\circ} 28^{\prime}$ on each side of the Equator: Cancer on the north, and Capricorn on the South.

17. Difference of Latitude.-The arc of a meridian intercepted between the parallels of latitude on which the places stand.

18. Prime Meridian.-The meridian from which longitudes are measured; in this country it is the meridian of Greenwich.

19. Longitude.-Distance in arc east or west of the meridian of Greenwich. It is measured on the Equator, or on a graduated parallel. up to $180^{\circ}$

20. Difference of Longitude.-An arc of the Equator intercepted between two meridians of longitude (Fig. 16).

$\mathbf{P}$ and $\mathbf{P}^{\prime}$ are the poles.

$\mathrm{EQ}$ is the equator.

$\mathrm{PAP}^{\prime}$ and $\mathrm{PBP}^{\prime}$ are meridians.

$\mathrm{POP}^{\prime}$ the prime meridian.

$\mathrm{LL}^{\prime}, \mathrm{TT}^{\prime}, \mathrm{RR}^{\prime}$ are' parallels of latitude.

'TT' is tropic of Cancer.

$\mathrm{RR}^{\prime}$ is tropic of Capricorn.

$\mathrm{XY}$ is difference of latitude when places are on same side of equator, on parallels LL' and ' $\mathrm{TT}$ '.

$\mathrm{XZ}$ is difference of latitude when places are on opposite sides of equator, on parallels $\mathbf{L L}^{\prime}$ and $\mathbf{R R}$.

$\mathrm{OA}$ and $\mathrm{OB}$ are Longitudes of places on meridians PAP' and PBP'.

$\mathrm{AB}$ is difference of longitude, between places on meridians PAP' $^{\prime}$ and PBP' $^{\prime}$

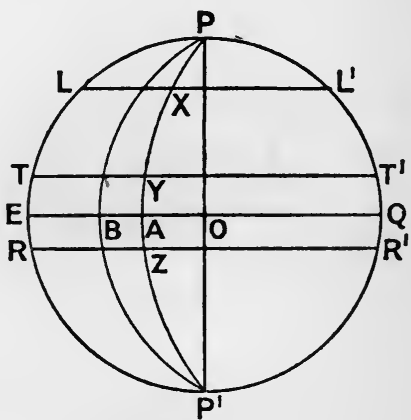

FIG. 16. 
21. Meridional Parts. - The distance from the Equator in geographical miles of a given latitude on Mercator's Chart (Fig. 17).

$$
\begin{aligned}
& a b=\text { parallel on globe. } \\
& c d=\text { same parallel on chart. } \\
& e c=\text { meridional parts for } \\
& \text { lat. } e a .
\end{aligned}
$$

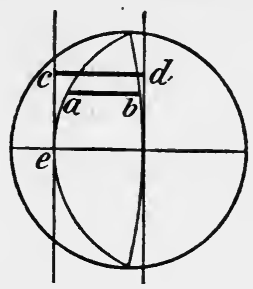

Fig. 17.

22. Departure.-The distance in geographical miles between two places in the same latitude. In the traverse table, it is the number of miles of easting or westing made on a given course and distance.

23. Nautical Mile.-The one-sixtieth part of a degree measured on a meridian. It varies slightly with the latitude, and its mean value is taken at 6080 feet.

24. Rhumb Liné.-A line which makes equal angles with all the meridians it crosses.

25. Zenith.-The point in the heavens vertically over the observer's head.

26. Nadir.-The point in the heavens diametrically opposite to the Zenith.

27. Equinoctial.-A great circle in the heavens $90^{\circ}$ from the celestial poles.

28. Ecliptic.-A great circle in the heavens representing the sun's annual apparent path.

29. First Point of Aries.-The point where the sun crosses the Equinoctial about the 21st of March.

30. Celestial Meridian of Observer.-The vertical circle which cuts the Horizon in the true North and South points (Fig. 18).

NESW., Plane of horizon.

$\mathrm{Z}$ is zenith.

EQW is equinoctial.

C $\boldsymbol{r C}^{\prime}$ is ecliptic.

$\boldsymbol{T}$ is first point of Aries.

NPZS is celestial meridian of observer.

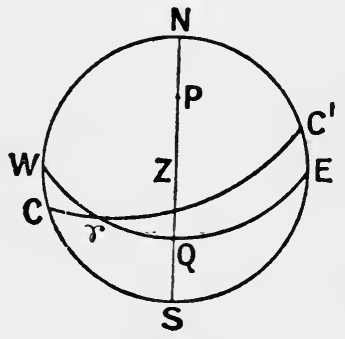

FIG. 18.

31. Azimuth.-The bearing of an elevated object reckoned from the N. or S. point. 
32. Amplitude.-The bearing of an object when rising or setting, reckoned from the E. or W. point.

33. Vertical Circles.-Circles passing through the Zenith and Nadir, and therefore perpendicular to the Horizon. They are also called "altitude circles" and "azimuth circles."

34. Prime Vertical.-The vertical circle which cuts the Horizon in the true East and West points.

35. Declination.-Distance in arc north or south from the Equinoctial measured on an Hour Circle.

36. Polar Distance.-The distance in arc from the elevated pole, and therefore the complement of the Declination, measured on an Hour Circle.

37. Hour Circles.-Halves of great circles which pass through the celestial poles, one hour being equal to $15^{\circ}$ (Fig. 19).

NESW, Plane of horizon.

NPZS, Celestial meridian.

$P$, Elevated pole.

$\mathrm{X}$, a heavenly body on parallel of declination LL'.

NZA or arc NA is Azimuth of X.

WL, Amplitude of $X$ at setting.

ZXA, Vertical circle through $\mathbf{X}$.

WZE, Prime vertical.

$\mathrm{XD}$, Declination of $\mathrm{X}$.

$\mathrm{PX}$, Polar distance of $\mathrm{X}$.

PXD, Hour circle through X.

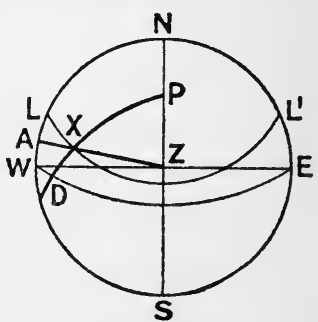

FIG. 19.

38. Right Ascension.-Distance eastward from the first, point of Aries measured on the Equinoctial and expressed in Time.

39. Hour Angle.-The angle at the pole between the observer's Celestial Meridian and an Hour Circle.

40. Civil Time.-The time used in civil life. The day begins at midnight, and is divided into two parts of twelve hours each, a.m. from midnight to noon, and p.m. from noon to midnight.

41. Astronomical Time.-Time used for astronomical calculations. The day begins at noon, and the hours count from 0 to 24 .

42. Mean Time.-The Westerly hour angle of the Mean Sun, it is the time shown by a correctly going timepiece.

The Mean Sun is an imaginary body which is supposed to move along the equinoctial with the average velocity of the True Sun in the ecliptic.

43. Apparent Time.--The Westerly hour angle of the true Sun.

44. Equation of Time.-The difference between Mean and Apparent Times; and therefore used to convert one time to the other.

The Equation of Time is least about April 15th, June 15th, August 31st, and December 24th: and greatest about February 10th, May 14th, July 26th, and November 2nd in each year. 
45. Sidereal Time.-The Westerly hour angle of the first point of Aries (Fig. 20).

Figure as before on horizon plano.

$\mathrm{CrC}^{\prime}$ is Ecliptic.

$r$ is first point of Aries.

$M$ is mean Sun.

$\mathrm{T}$ is true Sun.

$\mathrm{X}$ is any heavenly object.

Then

$r A$ is right ascension of $\mathrm{X}$.

QPA is easterly hour angle of $X$.

QPM is westerly hour angle of mean sun, or Mean Time.

QP'T is westerly hour angle of true sun, or Apparent Time.

QPr is westerly hour angle of $r$, or Sidereal Time.

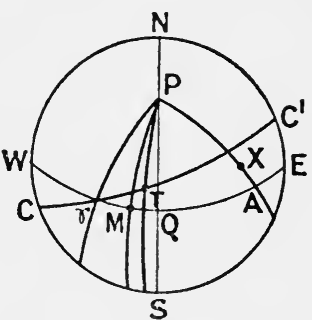

FIG. 20.

TPM is Equation of Time.

46. Visible Horizon. - The circle which bounds the observer's view at sea.

47. Sensible Horizon.-A plane touching the Earth at the observer's position and extended to the Heavens.

48. Rational Horizon. - A plane passing through the Earth's Centre parallel to the Sensible Horizon and extended to the Heavens.

49. Artificial Horizon.-A horizontal reflecting surface used for observing altitudes in the absence of a good sea-horizon.

50. Dip.-The angular depression of the Visible horizon below the Sensible, due to the observer's elevated position.

51. Observed Altitude.-The angular height of an object above the Visible horizon as measured by a Sextant.

52. Apparent Altitude.-The angular height of an object above the Sensible horizon, found by correcting the observed altitude for Index Error and Dip.

53. True Altitude.-The angular height of an object above the Rational Horizon, found by correcting the Apparent Altitude for Refraction and Parallax (Fig. 21).

$A B$ is visible horizon.

MIOA = angle OA makes with sensible horizon is Dip.

AOX $=$ observed altitude.

MOX = apparent altitude.

$\mathrm{XCN}=$ true altitude.

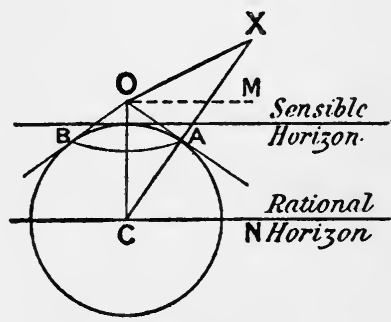

FIG. 21. 
54. Refraction.-The error of altitude caused by the bending of rays of light in passing through the atmosphere (Fig. 22).

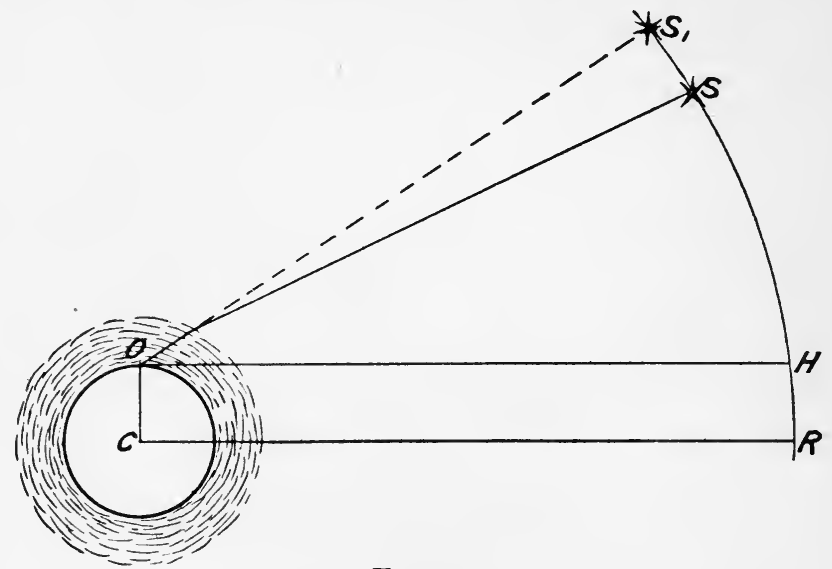

FIG. 22.

O, Observer's position.

$\mathrm{S}$, True position of star.

OH, Horizon.

$\mathrm{S}_{1}$, Apparent position of star.

$\mathrm{HS}_{1}$. Apparent altitude of a star.

$\mathrm{SS}_{1}$, Refraction.

RS, True altitude of a star.

55. Parallax is the angle at the centre of the object subtended by the earth's radius at the position of the observer. It is a correction for reducing an observation to the earth's centre (Fig. 23).

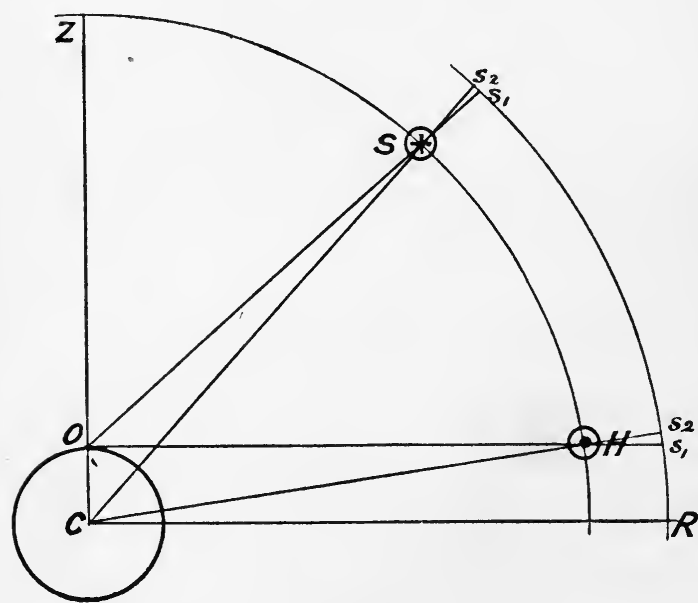

O, Observer's position.

$\odot$ H, Sun's position on horizon.

$\bigoplus \mathrm{S}$, Sun's position in altitude.

$\angle$ OHC, Horizontal parallax.

$\angle$ OSC, Parallax in altitude.

$Z$, The zenith of observer.

Fia. 23. 
56. Semidiameter.-The angle subtended at the earth's centre by the radius of the sun, moon, or planet.

57. Augmentation of Moon's Semidiameter. - An apparent increase in the moon's semidiameter due to the fact that her distance from the observer decreases as her altitude increases (Fig. 24).

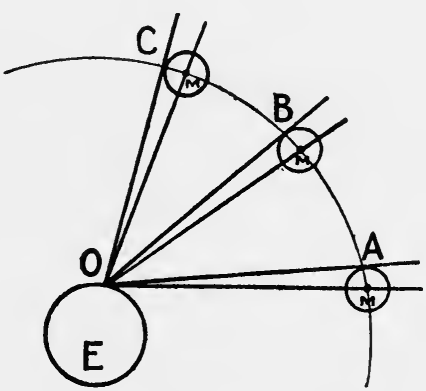

Fig. 24.

E, Contre of earth.

O, Observer's position.

MA, Position of moon on horizon.

MB, MC, Other positions of moon in altitude: her centre being at fixed distance from $\mathrm{E}$. As she rises her distance from $\mathbf{O}$ decreases. MOA, Semidiameter of moon on horizon.

MOB and MOC, Semidiameters when in altitude.

MOB-MOA and MOC-MOA, Augmentation of semidiameter when in altitude.

58. Reduction of Horizontal Parallax.-A correction necessary on account of the shortening of the earth's radii towards the poles (Fig, 25).

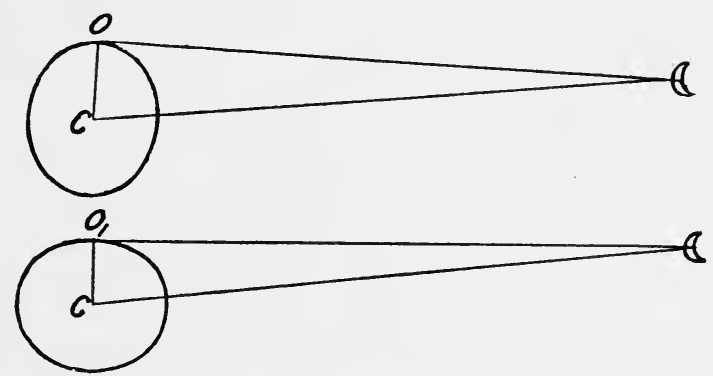

FIG. 25.

0 , Observer's position on longest diameter of earth.

$\mathrm{O}_{1}$, Position on a shorter diameter.

$\mathrm{O}$ \& C, Equatorial horizontal parallax.

$\mathrm{O}_{1}$, \& C, Horizontal parallax for latitude of observer, which is less because subtended by a shorter radius. 
59. Zenith Distance.-The angular distance from the Zenith, or the complement of the true altitude measured on a vertical circle.

60. Magnetic Meridian at a place is a great circle in whose plane a compass-needle lies when under the earth's influence only.

61. Variation.-The angle between the True and Magnetic meridians, measured from True North.

62. Deviation.-The angle between the Compass-needle and the Magnetic meridian.

63. Error of the Compass.-The angle between the Compassneedle and the True meridian (Fig. 26).

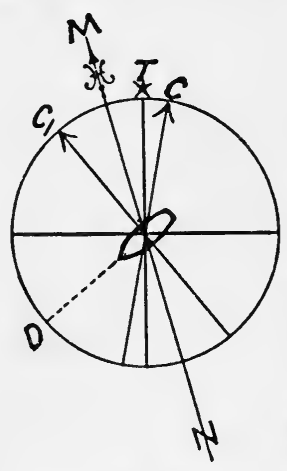

FIG. 26.

T. True north.

MN, Magnetic meridian.

$\mathrm{C}$ and $\mathrm{C}_{1}$, Different directions of compass north.

TM, Variation (west).

MC, Deviation (east).

$\mathrm{MC}_{1}$, , (west).

TC, Error of compass (east).

$\mathrm{TC}_{1}$, $\ddot{\text {, }}, \quad$ (west).

$\mathrm{CD}$ or $\mathrm{C}_{1} \dddot{\mathrm{D}}$, Compass course from north.

TI), True course from north.

IID, Magnetic course from north.

64. Leeway.-The angle between the ship's keel and her "wake" (Fig. 27).

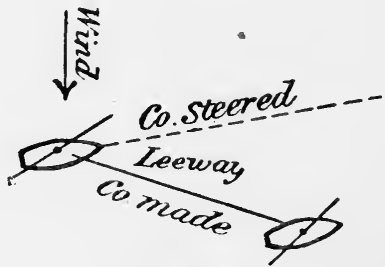

Fig. 27.

NotE.-The foregoing comprise the defuitions required by the Board of Trade Regulations for the examination of mates and masters.

65. Latitude.-Distance in arc north or south from the Equator measured on a Meridian.

66. Arctic Circle.-The parallel of $66^{\circ} 32^{\prime} \mathrm{N}$. lat.

67. Antarctic Circle.-The parallel of $66^{\circ} 32^{\prime} \mathrm{S}$. lat.

68. Obliquity of Ecliptic.-The angle between the planes of the Ecliptic and Equinoctial. 
69. Equinoxes.-The points where the Ecliptic intersects the Equinoctial. The Vernal Equinox is where the sun crosses the Equinoctial in March, and the Autumnal where it crosses in September.

70. Precession.-A slow motion of the Equinoxes along the Equinoctial westwards, amounting to about $50^{\prime \prime}$ annually.

71. Solstices.-The points on the Ecliptic farthest from the Equinoctial.

N.B.-The terms "Equinoxes" (Spring and Autumn) and "Solstices" (Summer and Winter) are also applied to the times of the year when the sun is on the Equinoctial or at the Solstices.

72. Celestial Latitude.-Distance in arc north or south from the Ecliptic.

73. Celestial Longitude.-Distance in arc from the "first point of Aries " measured on the Ecliptic.

74. Circumpolar Stars. - Stars whose polar distance is less than the latitude of the place, and consequently never set.

\section{Questions on Variation and Deviation, from the Board of Trade Regulations.}

1. Q.-Does the variation change with time?

A.- Yes; it slowly changes in amount. At London it now decreases about $9^{\prime}$ annually.

2. Q.- Is the variation the same all over the world?

A.-No; all amounts from $0^{\circ}$ to $180^{\circ}$ may be found.

3. Q.-Where do you find the variation?

A.- On a variation chart.

4. Q.-Does the deviation change? if so, when?

A.- It changes with a change of course; also, for the same course with lapse of time, because the magnetic condition of the ship is liable to change, and from change of cargo.

5. Q.-Where is the north magnetic pole situated ? A.- - In about $70^{\circ} \mathrm{N}$. lat. and $92^{\circ} \mathrm{W}$. long.

6. Q.-Where is the south magnetic pole situated ?

A.- In about lat. $75^{\circ} \mathrm{S}$., and long. $150^{\circ} \mathrm{E}$.

7. Q.-Should the compass-needle point to the magnetic or the true pole of the earth?

A.-To the magnetic pole.

8. Q.-When is the altitude of an object most seriously affected by refraction?

$A$.-When nearest to the horizon.

9. Q.-Whore is the pole star situated ?

$A$.-At the distance of $1^{\circ} 12^{\prime}$ from the true celestial pole.

10. Q.-Which is the most favourable time for determining the hour angle of a celestial body, and thence the longitude, and state the reason why?

A.-When it is on the prime vertical, because the hour angle is then least affected by errors in altitude or latitude. 


\section{INSTRUMENTS.}

Mariner's Compass.-The Mariner's Compass consists of three parts :-Bowl, Card, and Needles. The Bowl is a hollow hemisphere of brass, weighted at its lowest part to keep it horizontal. On its inside a vertical line is painted called the "lubber" line, which indicates on the card the Course of the ship. "From the centre of the bottom of the bowl springs a support which holds a sharp pivot tipped with iridium to render it hard and nonrustable. The pivot fits into a brass cap having an agate or ruby centre to work on. From the cap by means of silk threads the card is suspended.

The card is circular, made of thin paper with the centre part cut out to lessen the weight, and having a band of aluminium round its circumference to strengthen it, and is graduated to quarter-points and degrees.

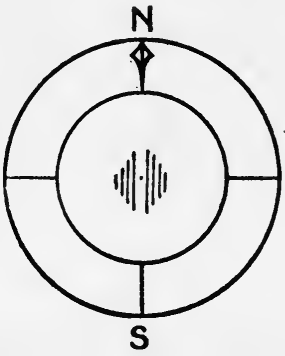

Fig. 28.

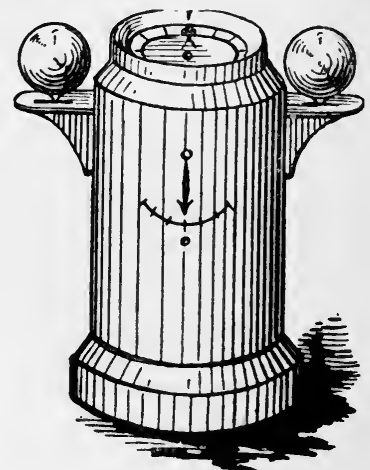

Fig. 29.

From the card hang the magnetised needles, which are generally 8 in number, arranged symmetrically, parallel to one another, and to the N. and S. points of the card (Fig. 28). The needles are about the size of a large knitting-needle, the longest pair with a $10^{\prime \prime}$ compass card being $3{ }_{4}^{1 \prime}$ long.

The whole instrument is mounted on gimbals, with strong wire supports to take off the vibration of the ship as much as possible, and is placed in a binnacle (Fig. 29). Two brackets at the side support cast-iron correctors, and provision is made inside the binnacle for compensating magnets. A brass cylindrical box on the outside is provided for a Flinders Bar. A Clinometer shows the angle of "heeling."

Azimuth Compass.-The Azimuth Compass is like an ordinary Steering-compass in the mounting of the needles and card. There is a movable ring on the bowl, provided with sightvanes at opposite ends of a diameter. One of these should have 
a reflecting prism for reading the graduations on the card, and the other a mirror for reflecting elevated objects (Fig. 30).

It is mounted in a box or on a tripod, and in using it the observer looks through the narrow slit, and moves the ring round until the object is bisected by the wire in the other sight-vane, and then reads off the bearing by means of the prism.

Sometimes a vertical style is fixed on the centre of the glass cover of an ordinary compass, for showing the sun's compass bearing by means of the shadow.

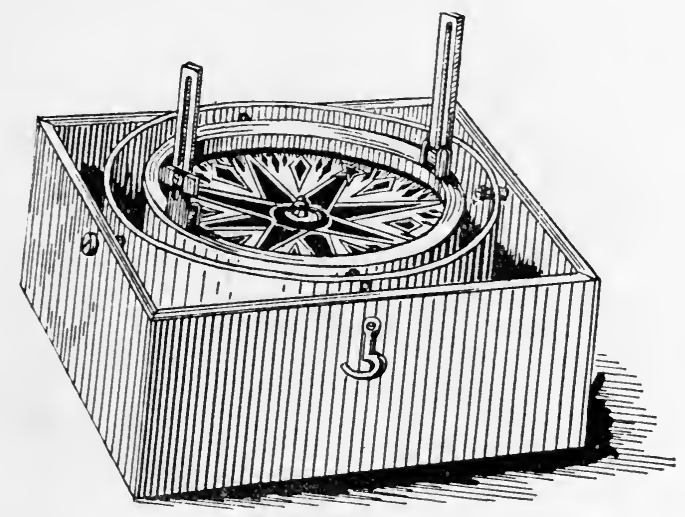

FIG. 30.

Pelorus.-The "Pelorus" resembles an Azimuth Compass, but has neither magnets nor bowl. The "card," usually of metal, is not suspended, but is free to move round its centre, and is mounted on gimbals and weighted to keep it horizontal. A bar carrying the two sight-vanes is pivoted at the centre of the card, and may be clamped in any position." Four "lubberpoints," $90^{\circ}$ distant, are usually marked outside the edge of the "card" (Fig. 31).

The uses of the "Pelorus" are-

(a) To find the Deviation on any course. The sight-vane being clamped to the known correct magnetic bearing of a distant object, the card is turned round until, on looking through the slit, the object is seen bisected by the wire. The correct magnetic course is shown at the lubber-point, and the difference between this course and the course by compass is the Deviation.

(b) To place the ship's head in any desired direction for the purpose of compensating the compasses.

The sight-vanes being clamped to a known correct magnetic bearing, and the card turned round until the desired direction of ship's head is at the lubber-point, then the ship is swung until 
the object is seen bisected by the wire. Her head is now on the desired point, and the magnets or correctors may be placed in position so that the Compass shall show the same course as the Pelorus.

(c) For taking Bearings when the Standard Compass is not available.

Care must be taken that the ship is upright, and that a line

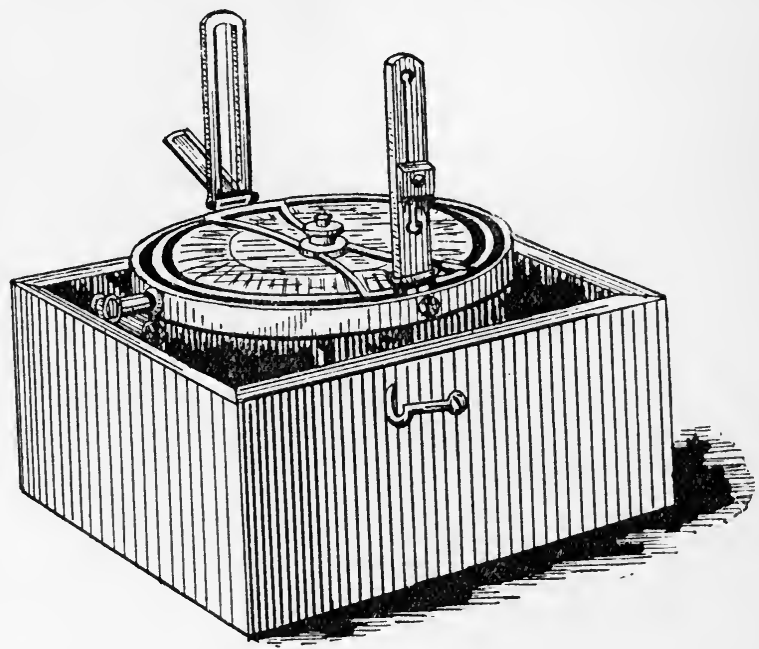

Fig. 31.

through the centre of the card and the lubber-point shall be parallel to the line of the keel.

Barometers.- The atmosphere surrounds the earth to a height of two hundred miles or more, and presses on the surface with an average weight of nearly $15 \mathrm{lbs}$. on a square inch, and its average pressure at sea-level is nearly 1000 millibars. A cubic foot of atmospheric air under ordinary circumstances weighs approximately an ounce and a quarter and its density increases one per cent. with an increase of ten millibars of pressure, and decreases one per cent. with an increase of temperature of $5^{\circ} \mathrm{F}$. (see "Barometer Manual"). The pressure varies with changes of temperature and moisture and from other causes, and decreases from the sea-level upwards. A Barometer is an instrument for measuring this pressure.

Barometers are generally of two kinds, viz. "Aneroid," meaning without liquid, and "Mercurial."

The Aneroid Barometer has a shallow metal cylinder with a flexible cover, and partially exhausted of air. The tendency to collapse in consequence of the partial vacuum is balanced by a 
strong spring attached to the cover and fastened to the bottom of the containing box. As the pressure of the atmosphere varies, the movements of the flexible cover inwards and outwards are, by a mechanical contrivance, conveyed to a pointer which shows on a dial the pressure of the atmosphere (Fig. 32).

The readings from an aneroid cannot be depended upon, and should be compared from time to time with those taken from a mercurial barometer, and adjusted by means of a screw at the back of the instrument, and index error recorded.

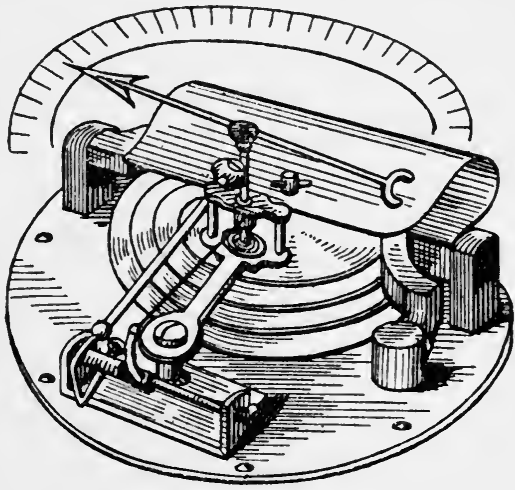

Fig. 32.

It is very portable, convenient for reading, and the readings recorded require no correction for temperature or latitude, but must be corrected for height above sea-level and index error.

The dial of the barometer is graduated on three concentric circles, the outer showing the reading in millibars, the centre in inches and tenths, and the inner in millimetres.

The converters for the three scales may be obtained from the fact that 100 centibars or 1000 millibars correspond to 29.53 inches of mercury at $32^{\circ} \mathrm{Fahr}$, and $45^{\circ}$ lat. and to 750 millimetres at $0^{\circ} \mathrm{C}$. and $45^{\circ}$ lat. A table for this purpose is found in the "Seaman's Hand Book on Meteorology," and may be obtained by the student as follows :-

One inch of mercury corresponds to $33 \cdot 86$ millibars.

Hence to convert "inches" to " mbars." multiply reading in inches by $33 \cdot 86$.

To convert " millibars " to " inches," divide reading in " mbars." by $33 \cdot 86$.

Again 03937 inch equals 1 millimetre.

Hence to convert "inches" to "mms." divide reading in inches by 03937 .

To convert "mms." to inches, multiply reading in "mms." by 03937 .

And since 1000 mbars. correspond to $750 \mathrm{mms}$.,

To convert mbars. to "mins." subtract one-quarter of reading in mbars. for corresponding " $\mathrm{mms."}$

To convert "mms." to mbars. add one-third of reading in "mms." for corresponding "mbars."

The Mercurial Barometer consists of a glass tube about 33 in. 
long (whose open end dips into a quantity of mercury contained in a trough or "cistern"), enclosing a column of mercury of varying height. The height of this column measured from the surface of the mercury in the cistern at any moment is the measure of the pressure of the atmosphere on a surface equal to the section of the tube. This pressure is indicated in inches of mercury and mbars. on scales near the top. Between the top of the column, and the top of the tube there is a space called the

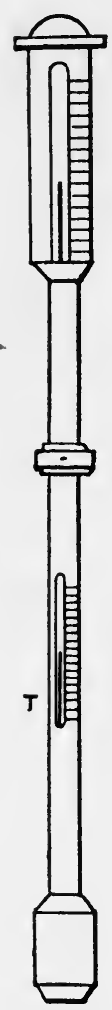

Fig. 33. FIG. 34 . Torricellian vacuum, because of the experiments made in 1643 by an Italian called Torricelli ( $v$, Fig. 34).

The portable barometers (Fig. 33) used at sea have the glass tube protected by a casing of wood or iron, and the mercury in the cistern is prevented from escaping by a cover or bag of washleather, which, however, does not interfere with the air-pressure. In this form of barometer the "inches" on the scale are shortened, so as to compensate for the changing level of the mercury in the cistern as the column rises or falls.

For scientific purposes, corrections of the barometer-readings are made for temperature height above sea-level, and latitude.

Thermometer.-A Thermometer is an instrument for measuring temperatures. The common Thermometer is a glass tube of exceedingly small bore, blown out at one end into a bulb, which is filled with mercury, the other end being hermetically sealed after the air is driven out. As the mercury in the bulb expands with heat and contracts with cold to a greater degree than the glass envelope, this causes the column in the tube to advance or retire. The degree of the scale indicated by the end of the column is the temperature.

in use.

Three different scales of temperature are

(a) The Fahrenheit thermometer ${ }^{1}$ (Fig. 35, a), which is the one generally used in this country, marks the freezing-point of water $32^{\circ}$ and the boiling-point $212^{\circ}$, when the barometer reads 29.905 inches at $32^{\circ}$ Fahr., a difference of $180^{\circ}$. Zero (0) on this scale is the temperature of a mixture of salt and snow.

${ }^{1}$ So called because Fahrenheit, a German, in 1721 , first suggested this method of graduation. 
(b) The Centigrade or Celsius ${ }^{1}$ thermometer (Fig. 35, b) marks the freezing-point zero (0) and the boiling-point $100^{\circ}$.

(c) The Réaumur thermometer ${ }^{2}$ (Fig. $35, c$ ) marks freezingpoint zero (0) and boiling-point $80^{\circ}$.

The attached thermometer in the barometer (T, Fig. 33) has two scales, one graduated to give the temperature Fahrenheit, the other graduated in Centigrade degrees, showing the temperature reckoned from absolute zero, which is $-273^{\circ}$ C. or $-459^{\circ}$ Fahr., and is the temperature at which permanent gases following the ordinary rate of contraction on decrease of temperature would occupy no volume and meet no pressure.

Mercury is the liquid generally in use in thermometers because of its low freezing-point $\left(-40^{\circ}\right.$ C.), high boilingpoint $\left(358^{\circ} \mathrm{C}\right.$.), and its steady rate of expansion through long ranges of tem-
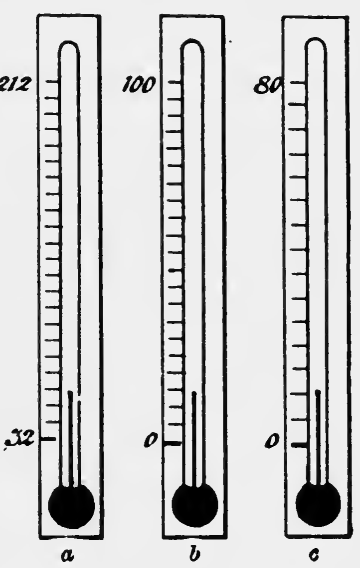

Fig. 35. perature; other advantages are its opacity and the fact that it does not wet the glass envelope. For lower temperatures alcohol is used instead of mercury, as it solidifies at $-130^{\circ} \mathrm{C}$. and boils at $78^{\circ} \mathrm{C}$., the alcohol being coloured to render it visible.

The number of divisions on the three scales between freezing and boiling-points are therefore in the ratio of 180, 100, and 80 , or $9,5,4$, from which it is easy to compare the readings of any one of these instruments with each of the other two.

Examples.-1. What are the readings of the Centigrade and the Réaumur scales corresponding to $72^{\circ}, 18^{\circ}$ and $-40^{\circ} \mathrm{Fahr}$.?

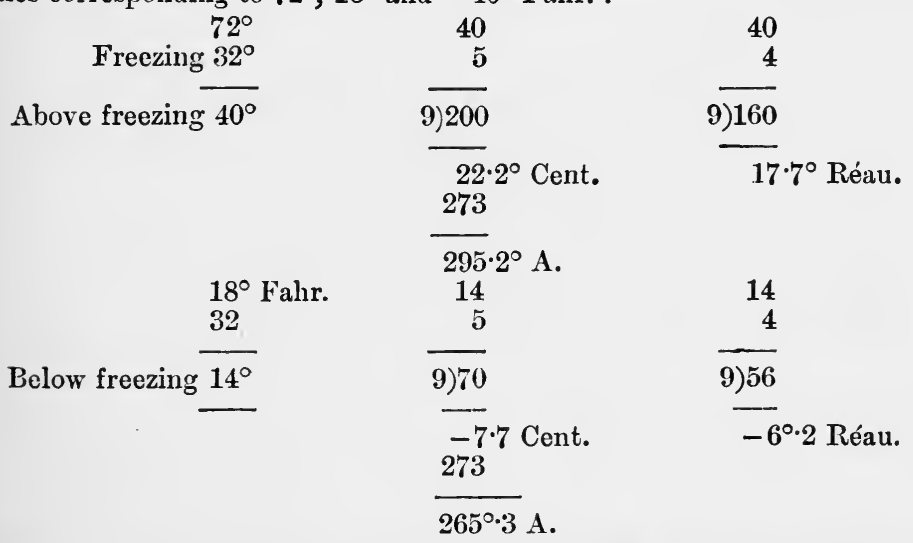

1 Named after Celsius, a Swede, who, about 1743, suggested this method of graduation.

${ }_{2}$ Called after its proposer, Réaumur, a Frenchman, about 1743. 


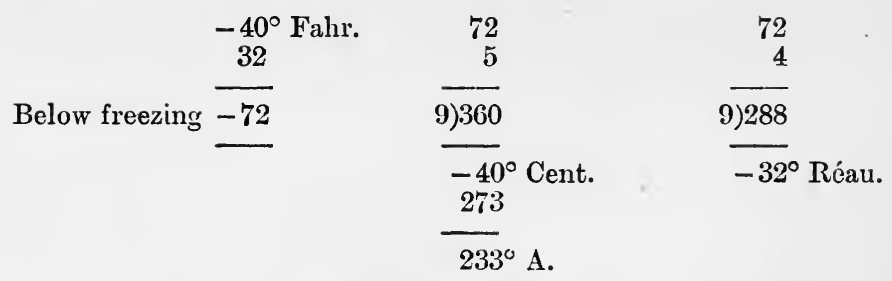

The amounts marked "A." being the readings when the thermometer graduations commence at absolute zero.

2. Convert $32^{\circ}$ Cent. and $20^{\circ}$ Réaumur into the corresponding Falırenleit temperatures.

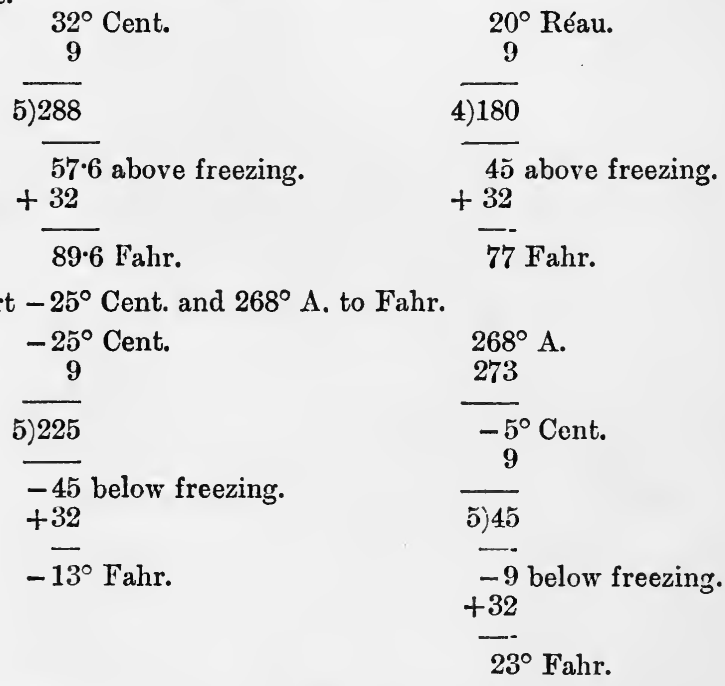

Chronometer (Fig. 36).-A chronometer is an accurately made and compensated timepiece with its balance so constructed that any change of temperature produces the smallest change in its error from day to day; this difference of error is called its daily rate. Most commonly it is made to work for two days, and on its face is an index hand showing how long since the instrument was wound. The winding should take place every day at the same hour in order that the operation may become a habit, and as a guarantee that a constant interval elapses between the operations, and is performed by six or seven halfturns of the key.

The keyhole at the back is protected by a sliding cap. The instrument is mounted on gimbals in a mahogany case having a glass roof and outer cover. In the case is a clamp by means of which it can be prevented from swinging in the gimbals when conveyed from ship to shore. 
Its use is to obtain correct mean time at Greenwich (the error and rate being known), and thence the longitude.

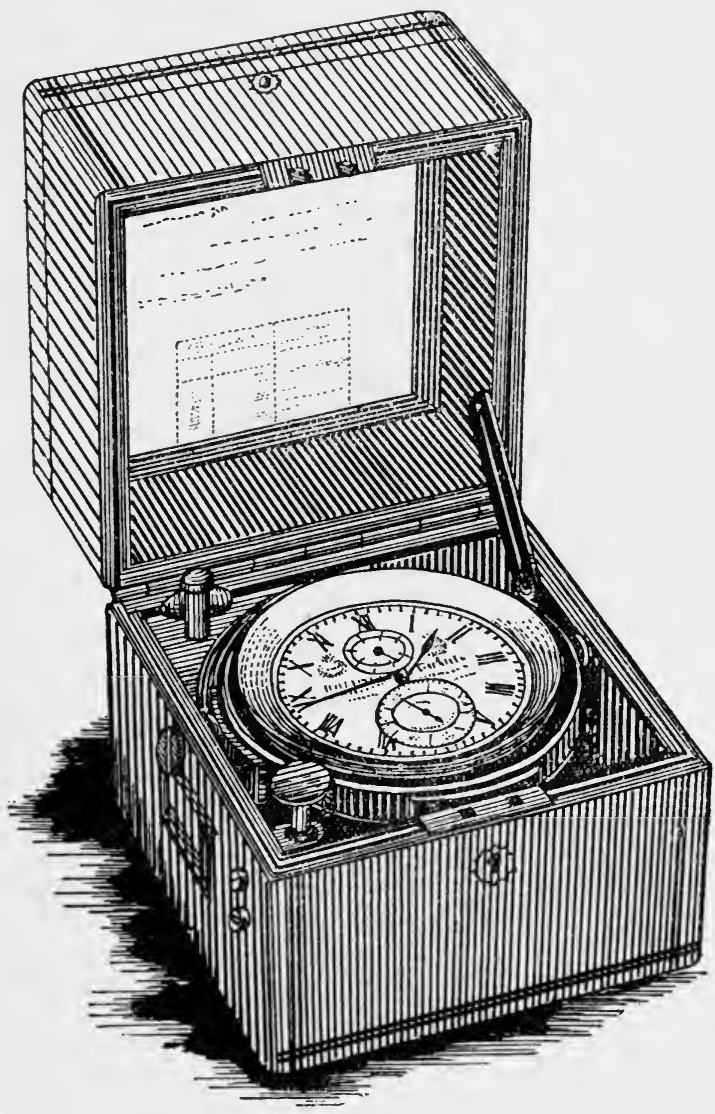

FIG. 36.

Hydrometer.-The Hydrometer is an instrument for measuring Density or Specific Gravity (Fig. 37).

Specific gravity of a solid or liquid is its weight compared with the weight of an equal bulk or volume of distilled water at the temperature of $62^{\circ} \mathrm{Fahr}$., or, as some scientists prefer, $39^{\circ} \cdot 2$ Fahr., which is the point of maximum density.

The hydrometer used on board ship for obtaining the density of sea-water, and the water in docks or rivers, is a glass or metal stem with two bulbs, the lower of which is weighted with mercury or small shot to make the instrument float upright. The scale on the stem reads from 0 downwards. It is seen that 
in using this hydrometer we displace constant weights of different volumes: the instrument is graduated so that the S.G. may be read directly from the scale, which is effected by shortening the divisions from 0 downwards.

When in distilled water (temp. $62^{\circ}$ ), the level of the

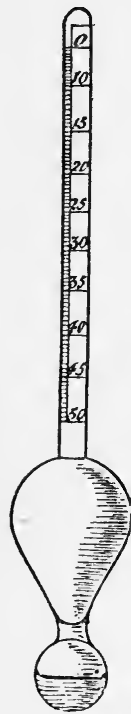
water is at 0 , but in sea-water at about 26 . In brackish water it will be somewhere between those marks, according to the degree of saltness.

One thousand must be added to the figures on the scale when stating the S.G.

Hence the S.G. of distilled water (temp. $62^{\circ}$ Fahr.) is 1000 , and the S.G. of sea-water 1025 or 1026 , whilst the S.G. of the water in a river or estuary or dock where fresh water enters might be anything between these two limits.

These facts have an important bearing on the loading of ships, since the law fixes the load-line for seagoing vessels.

It is obvious that a ship may be loaded deeper than her "load-mark" in fresh or brackish water, for she will "rise to her marks" when she goes to sea.

The S.G. of the water at the loading-place may be obtained by a Hydrorneter, and, her draught being known, a simple proportion will give the "sea draught" nearly. Also when the "draught" at sea is known, FIG. 37. the "draught" in dock or river can be found.

Examples.-1. The S.G. of the water in the dock is 1015, and the ship's draught $23 \mathrm{ft} .6$ in. : required her draught at sea. Taking S.G. of sea-water as 1025 -

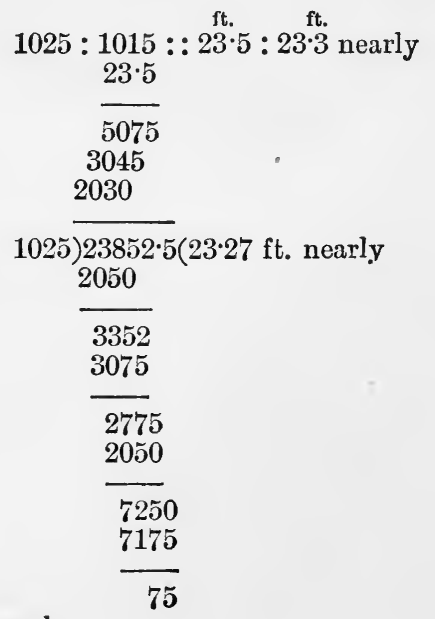

Answer, $23 \cdot 3 \mathrm{ft}$. nearly. 
2. At sea a ship draws $26 \mathrm{ft} .9 \mathrm{in}$. : what will her draught be in dock, where the S.G. is 1010 ?

ft. in. ft. in.

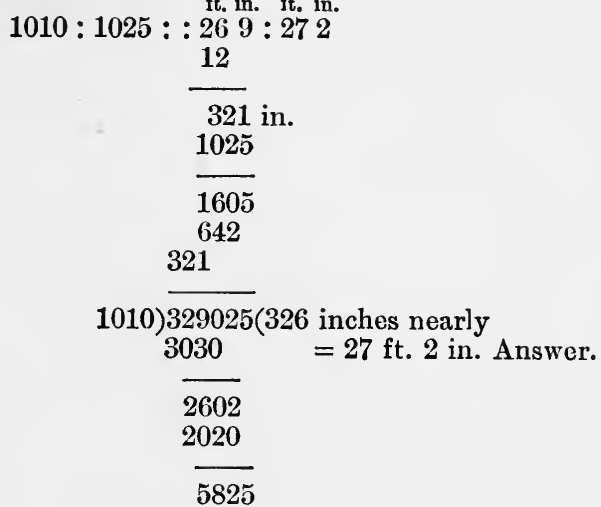

3. The number of inches between the F. W. mark and centre of disc is given on the load-line certificate as 7.5: how much may the Plimsoll mark be submerged in dock when Hydrometer reads 9 ?

In diagram density at $\mathbf{F}$.W. is 0 at centre of disc 25 : vessel floats in 9 . Hence for a difference in saltness of 25 , the mark is put down $7 \cdot 5$ inches: how much will it be put down for a difference in saltness of $25-9=16$ ?

$$
\begin{aligned}
& =\frac{7.5 \times 16}{25} \text { inches } \\
& =4.8 \text { inches, }
\end{aligned}
$$

and F.W. mark would be out of water $2 \cdot 7$ inches.

4. The tons per inch in sea water is 40 : what would it be in water where Hydrometer reads 16 ?

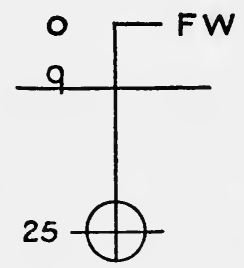

FIG. 37A.

As the water is lighter, fewer tons will sink her one inch.

$$
\begin{aligned}
& =\frac{40 \times 1016}{1025} \\
& =39.65 \text { tons per inch. }
\end{aligned}
$$

The Station Pointer.-The Station Pointer is a graduated circle having three radial arms, one of which is fixed, and the other two moveable, the latter being provided with verniers and clamp and tangent screws (Fig. 38).

The use of the Station Pointer is to locate the ship's position on a chart from the angles subtended by three lighthouses or other fixed objects on shore.

With a sextant, the horizontal angles between the middle object and each of the other two are measured, and the moveable arms are set to these angles.

Then the instrument is laid on the chart with the bevelled edge of the fixed arm on the middle object, and moved about 
until the bevelled edges of the other two arms fall on the other two objects. The centre of the circle gives the ship's position.

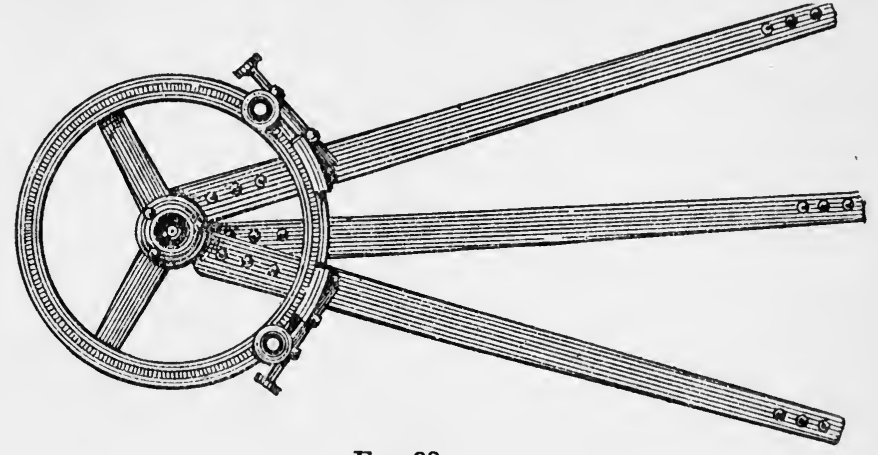

Fia. 38.

The Sextant (Fig. 39).-The "full" Sextant for sea use consists of a metal frame in the form of a Sector of about $60^{\circ}$, with an arc or limb graduated to degrees and $10^{\prime}$ spaces. An index bar, pivoted at the centre of the circle, carries the silvered Index Glass, and at the other end a Vernier or Nonius for subdividing to $10^{\prime \prime}$. The index bar is provided with clamp and tangent screws, and carries a reading microscope. The Horizon Glass-half of which is silvered-stands on the frame. Both glasses are provided with screens for taking off the glare of a strong light when the instrument is used. A handle at the back of the frame is convenient for holding, and a collar, which is moveable towards or from the frame by means of a milledhead screw, serves to hold a plain tube or a telescope.

When in correct adjustment, the index and horizon glasses are

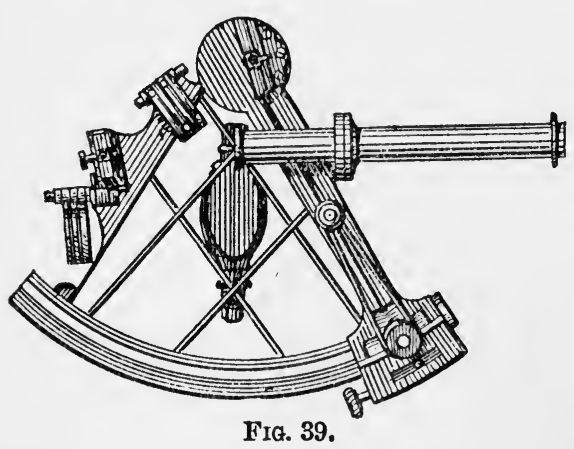

perpendicular to the plane of the instrument (the upper surface of the frame), and parallel to each other when the pointer on the vernier indicates 0 on the arc. The axis of the telescope when screwed into the collar is parallel to the plane of the instrument.

The first two adjustments are essential, but if the glasses are slightly out of parallelism, it is of little consequence, for the "index error" can be easily determined and applied. Screws are provided for making all the adjustments. 
Questions on the Adjustments of the Sextant in Board of Trade Examinations for Mates and Masters.

1. What is the first adjustment of the sextant ?

2. How do you make that adjustment?

3. What is the second adjustment?

4. Describe how to make that adjustment.

5. What is the third adjustment?

6. How would you make the third adjustment?

7. In the absence of a screw, how would you proceed?

8. How would you find the index error by the horizon?

9. How is it to be applied?

10. Place the index at error of minutes to be added, clamp it and leave it

NorE.-The examiner will see that it is correct.

11. The examiner will then place the zero of the vernier on the arc, not near any of the marked divisions, and the candidate will read it.

Note.-In all cases the applicant will name or otherwise point out the screws used in the various adjustments.

12. How do you find the index error by the sun?

13. How is the same applied?

Suppose the reading on the arc to be

to be , find the index error.

, and the reading off the arc

14. What proof have you that those measurements or angles have beer taken with tolerable accuracy?

15. Describe the fourth adjustment.

Answers to the Questions on the Sextaxt.

1. To set the Index Glass perpendicular to the plane of the sextant.

2. 'The index should be clamped at about $60^{\circ}$, and the sextant held face upwards with the limb from the observer; then, on looking into the index glass towards the limb, if the reflected and real arcs do not coincide, turn the adjusting screws at the back of the glass until they do coincide.

3. To set the Horizon Glass perpendicular to the plane of the sextant.

4. The index being clamped at 0 , the sextant should be held horizontally, face upwards-then, on looking through the telescope collar towards the horizon, if the reflected and real horizons do not coincide, turn the upper adjusting screw at the 'back of the glass until they do coincide. By night, look at a star and see if its reflection passes up and down through the star, if it does the horizon glass is truly perpendicular, if not, use the upper screw to make it do so.

5. To set the Horizon Glass parallel to the Index Glass when the index is at 0 on the arc.

6. The index being clamped at 0 , the sextant should be held vertically; then, on looking through the tube or telescope at the horizon, if the reflected and real horizons do not coincide, turn the lower adjusting screw at the back of the glass until they do coincide.

7. Find the Index Error.

8. Placing the index at 0 , and holding the sextant as for the third adjustment, make the reflected and real horizons coincide by means of the Tangent Screw. By night, if when the index is at 0 , the true and reflected stars do not coincide, make them do so by means of the tangent screw. The reading "On" or "Off" is the Index Error.

9. It is subtractive if "on," and additive if "off."

10 and 11 are practical and require no written answer.

12. Clamping the index at 40 " "on" the arc and looking through the sight-tube or telescope at the sun, make the limbs of the reflected and real suns touch by means of the tangent screw, and note the reading; then clamp at 40 " "off," and again make the contact and note the reading. Half the lifference of the readings is the Index Error. 

additive.

13. If the greater reading is "on," the error is subtractive; if "off," it is

14. One-fourth the sum of the readings should be the Sun's Semidiameter, as in the Nautical Almanac for the given day.

15. The Fourth Adjustment is to set the line of collimation or axis of the telescope parallel to the plane of the instrument. The adjustment is made as follows: Screw on the Inverting Telescope, and, getting it in correct focus, turn the eye-piece round until two parallel wires in the tube are parallel to the plane of the sextant. Then select two celestial objects not less than $90^{\circ}$ apart, and holding the sextant with its face in the plane of the objects, move the index forward until the reflected image of one object comes into view in the centre of the field of the telescope with the direct image of the other. Bring both images in contact on the wire nearest the frame, and by slightly moving the instrument get them on the other wire : if they remain in contact, the adjustment is perfect; if they separate, the object end inclines towards the frame; but if they overlap, it declines from it. The adjustment is made by means of two screws in the collar which holds the telescope.

The effect of the collimation error is to make the observed angle too-great.

Any error of centering is an essential defect of the instrument, and may be detected by comparing the distance of two stars as measured by the sextant, and as measured by a standard instrument, or deduced from calculation.

Any error due to eccentricity of the limb may be determined by Lord Ellenborough's method.

Select two stars of nearly equal zenith distances on opposite sides of the zenith, and from their altitudes calculate the latitudes. If the latitudes agree there is no error, otherwise half the difference of the latitudes is the error, additive when the latitude from the star on the equatorial side is greater, and subtractive if less.

For suitable stars to observe see "Stars and Sextants," by J. A. Sprigge and others.

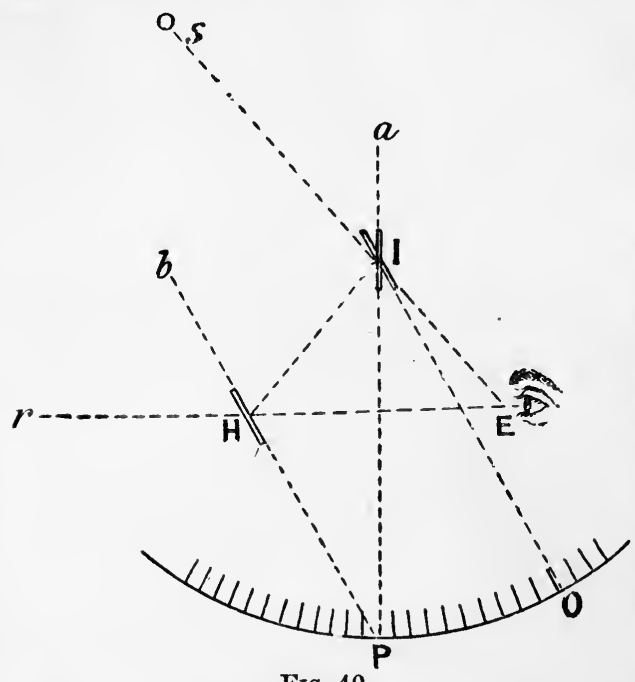

Principle of the Sextant.-The principle of the sextant is based on the optical fact that the angle of incidence of a ray of light upon a mirror is equal to the angle of reflection, and hence "The angle between the first and last directions of a ray which has suffered two reflections in one plane is equal to twice the inclination of the reflecting surfaces to one another."

Let $\mathrm{I}$ and $\mathrm{H}$ repre-

Fig. 40. sent the index and horizon glasses of a sextant. Light from $\mathrm{S}$ falling on $\mathrm{I}$ is reflected at an equal angle to $\mathrm{H}$, 
and thence reflected to the eye at $\mathrm{E}$, so that the object $\mathrm{S}$ would be seen by reflection in the direction $\mathrm{E} r$, and if $r$ were the horizon, the object's image would be seen on the horizon.

IO represents the index bar when the mirrors are parallel, and IP when it has been moved to P. Produce PI to $a, \mathrm{PH}$ to $b$, and $\mathrm{EH}$ to $r$.

Now, since $\angle \mathrm{HIP}=\angle \mathrm{SI} a=\angle \mathrm{EIP}$ (Euc. I. 15), the $\angle \mathrm{HIE}$ is bisected by IP, making $\angle \mathrm{HIP}=\angle \mathrm{EIP}$.

Also, since $\angle b \mathrm{HI}=\angle \mathrm{EHP}=\angle b \mathrm{H} r$ (Euc. I. 15), the $\angle r \mathrm{HI}$ is bisected by $b \mathrm{H}$, making $\angle r \mathrm{H} b=\angle b \mathrm{HI}$.

The $\angle r \mathrm{HI}=\angle \mathrm{HIE}+\angle \mathrm{HEI}$ (Euc. I. 32); therefore $\angle r \mathrm{H} b=\frac{1}{2} \angle \mathrm{HIE}+\frac{1}{2} \angle \mathrm{HEI}=\angle \mathrm{HIP}+\frac{1}{2} \angle \mathrm{HEI}$.

Again, $\angle r \mathrm{H} b(=b \mathrm{HI})=\angle \mathrm{HIP}+\angle \mathrm{HPI}$; therefore HIP $+\mathrm{HPI}=\mathrm{HIP}+\frac{1}{2} \mathrm{HEI}$.

Taking away the common angle HIP, there remains $\angle \mathrm{HPI}$ $=\frac{1}{2} \angle \mathrm{HEI}$; and as $\angle \mathrm{OIP}=\angle \mathrm{HPI}$, because $\mathrm{IO}$ and $\mathrm{HP}$ are parallel, it follows that the angle through which the idex bar IP has moved from zero is half the angle described by the image of the object. For this reason an arc of $\frac{1}{2}^{\circ}$ on the limb is read as $1^{\circ}$, and an arc of $60^{\circ}$ will measure $120^{\circ}$.

ART. 87. Principle of the Vernier, or Nonius.-The value of the smallest division on an ordinary sextant is 10 , but the

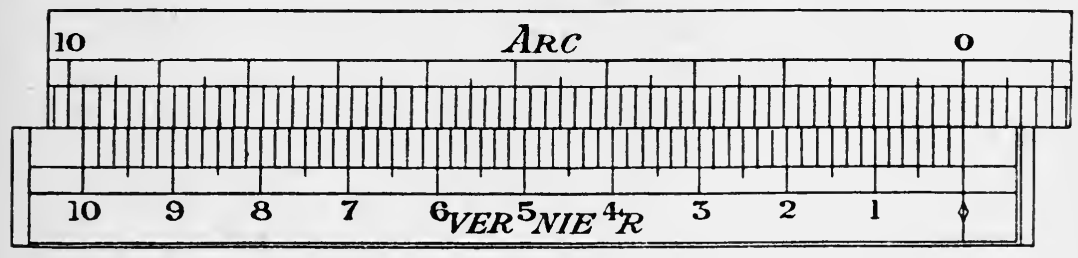

Fig. 41.

vernier attached to the index bar subdivides into single minutes and 10, 20,30, etc. seconds.

This is accomplished by taking 59 divisions of the limb for the length of the vernier, and dividing it into 60 equal parts;

$$
\text { Thus, } \begin{aligned}
60 \mathrm{~V} & =59 \mathrm{~L} \\
\therefore \mathrm{IV} & =\frac{59}{60} \mathrm{~L}=\mathrm{L}-\frac{\mathrm{L}}{60}
\end{aligned}
$$

that is, one division on the vernier is $\frac{1}{60}$ of $10^{\prime}=10^{\prime \prime}$ shorter than one on the limb. Six of these vernier divisions are marked 1 , and the whole length reads $10^{\prime}$.

When the pointer or 0 on the vernier coincides with a cut on the limb, the next vernier cut falls short of the one above it on the limb by $10^{\prime \prime}$, the second one by $20^{\prime \prime}$, the third by $30^{\prime \prime}$, etc. So that if the index is moved forward until the first, second, 
third, etc., cut coincides with the one above it on the limb, the pointer will have moved $10^{\prime \prime}, 20^{\prime \prime}, 30^{\prime \prime}$, etc., and so on to the end of the vernier scale. When the $10^{\prime}$ cut coincides, the pointer will have moved a whole division of the limb, i.e. 10'. Therefore, to find how far the pointer or 0 has moved from the last limb division, it is only necessary to see what cut on the vernier coincides with a cut on the limb.

The same rule holds good when the reading is "off" the arc, only in this case both scales must be read from left to right.

Star Maps and Planispheres.-A knowledge of the Star-groups or Constellations and the names of the principal bright Stars is essential to the Navigator who would make use of these objects to find the Latitude and Longitude at sea.

Many Star-maps and "Planispheres" are in use, but it is unnecessary to mention here more than the following:-

Proctor's Star Atlas.

Philip's Planisphere.

Poole's Celestial Planisphere.

On a Star-map or a Celestial Globe, the position of a star can be found from its R.A. and Dec. in the same manner as a place is located on a globe or chart by the Latitude and Longitude.

Planispheres are designed to show the principal star-groups above the Horizon at a given hour. Philip's Planisphere consists of a moveable disc turning in a leather frame about the pole as centre. On the dise is a map of the heavens, hour circles being drawn for every two hours, the equinoctial, ecliptic, and circles of declination are also shown. On the circumference of the disc the days of the month are printed. Out of the leather frame an oval is cut, and around the edge of the frame are printed the hours of the day and night. To find the stars visible at any time, turn the disc until the date is abreast the hour; the stars visible in the oval are those above the horizon at the time, and in the place for which the planisphere is constructed.

A wire stretched across the middle of the ellipse represents the Meridian.

The Planisphere gives by inspection the approximate Time of Meridian Passage of a star as well as the times of Rising and Setting. It can also be used to find by inspection what bright stars are within a given time from the Meridian at any given hour of Greenwich or local Time.

Tables of Meridian Passage of Stars.-Table xuIv. of Norie gives the apparent times of Mer. Pass. of the principal stars at intervals of five days, and as a star crosses the Meridian about $4^{\mathrm{m}}$ earlier on each successive day, it is easy to find the time for intermediate days.

Table 27 of Raper gives the time of Mer. Pas. of fifty-five bright stars on the first day of each month, and by subtract- 
ing $4^{\mathrm{m}}$ for each day elapsed, as before, the required time is approximately found for any day, or correction found in Table $27 \mathrm{~A}$.

The Meridian Altitude of a selected star being computed from its Dec. and the Approximate Latitude, the sextant can be set to this angle; and as the approximate time of Mer. Pass. is known, the observer can be in readiness to measure the altitude at the moment the star is on the Meridian, and so obtain the Correct Latitude.

\section{Exercises.}

1. The meridional parts for lat. $38^{\circ} 25^{\prime}$ are 2500.08 . Calculate those for $38^{\circ} 31^{\prime}$.

2. The meridional parts for lat. $57^{\circ} 46^{\prime}$ are 4267.97 . Calculate those for $57^{\circ} 50^{\prime}$.

Ans. $4275 \cdot 5$.

3. The vernier of a sextant, the limb of which is divided to $10^{\prime}$, has 40 divisions, coinciding with 119 divisions on the limb. With what accuracy may the instrument be read?

Ans. 15".

4. The limb of a sextant is divided to $15^{\prime}$, and 59 divisions on the limb are formed into 60 divisions on the vernier. With what accuracy may it be read? Ans. 15".

5. If every inch on a barometer scale be divided into 10 parts, show how to form a vernier such that the reading of the instrument may be taken to 005 of an inch. Ans. Take 9 divisions and divide into 20 equal parts.

6. Describe Philip's Planisphere.

7. Where may the Meridian Passage of a star be found? Is it given in mean or apparent time?

8. On the arc readings, $34^{\prime} 50^{\prime \prime}, 34^{\prime} 20^{\prime \prime}, 34^{\prime} 20^{\prime \prime}$; off the arc readings, $29^{\prime} 40^{\prime \prime}, 29^{\prime} 0^{\prime \prime}, 29^{\prime} 20^{\prime \prime}$; find the Index Error and Semidiameter.

9. On the arc reading, $28^{\prime} 50^{\prime \prime}$; off the arc, $34^{\prime} 40^{\prime \prime}$; find Index Error and Semidiameter. Ans. $+2^{\prime} 55^{\prime \prime}: 15^{\prime} 52 \cdot \circ^{\prime \prime}$.

10. When the hydrometer marks 16 , a ship's draught is $25 \mathrm{ft} .8 \mathrm{in}$. : find her draught at sea. Ans. $25 \mathrm{ft} .5$ in.

11. At sea a ship draws $18 \mathrm{ft}$. $10 \mathrm{in}$. : what will her draught be in a dock where the reading on the hydrometer is 12 ? Ans. $19 \mathrm{ft} .1$ in.

12. Between the F.W. mark and centre of disc, the distance is 6 inches. How much can the Plimsoll mark be submerged in dock, where hydrometer reads 9? How much is F.W. mark above water level?

Ans. $3 \cdot 8$ in. : $2 \cdot 2$ in.

13. Ship's displacement is 10,000 tons. Her tons per inch in salt water 40. What will be her change in draught on entering dock where hydrometer reads 10 ? Ans. $3 \cdot 7$ ins.

14. The area of a ship at load water level is 15,120 sq. ft. How many tons will sink her 1 inch in salt water? Ans. 36 tons.

15. Barometer reads 29.92 in. : find what pressure per sq. in. this is equivalent to, taking the Specific Gravity of mercury to be 13.598.

16. Barometer reads $29 \cdot 65$ inches : find corresponding readings in $\mathrm{mm}$. and mbars. Ans. $753 \cdot 1 \mathrm{~mm}$.; 1003.9 mbars.

17. Express a barometrical reading of $745.6 \mathrm{~mm}$. in inches and mbars. Ans. $29 \cdot 35$ ins. ; $994 \cdot 1$ mbars. 
18. Convert a reading of 983.4 mbars. to $\mathrm{mm}$. and ins.

Ans. $29 \cdot 04$ ins. ; $737.6 \mathrm{~mm}$.

19. The temperature of the maximum density of water is $39.4^{\circ} \mathrm{F}$, and at which salt water freezes is $26^{\circ} \mathrm{F}$. Express these as Cent. and Absolute readings.

Ans. $4 \cdot 1^{\circ} \mathrm{C}$. and $277 \cdot 1^{\circ} \mathrm{A}$. ; $-33^{\circ} \mathrm{C} ., 2692^{\circ} \mathrm{A}$.

20. Alcohol boils at $68^{\circ} \mathrm{C}$.; absolute zero is $-273 \mathrm{C}$. What are the corresponding temperatures Fahr.?

Ans. $1544^{\circ} \mathrm{F}$. ; $-459 \cdot 4^{\circ} \mathrm{F}$. 


\section{CHAPTER III.}

\section{LOGARITHMS.}

ART. 1.-In the expression $\mathrm{N}=a^{x}$; " $\mathrm{N}$ " is the number obtained by raising " $a$ " to the power of " $x$ "; keeping " $a$ " fixed in value, and finding all the values of " $\mathrm{N}$ " obtained by performing the operation $a^{x}$ : where " $x$ " may be anything fractional or integral, results in a table of logarithms: the fixed, or constant, number is called the "Base," the power chosen the "Logarithm": thus a Logarithm is the index to which the Base must be raised to give the number. In common logs the base is always 10, hence the logs used in our problems represent the power to which 10 must be raised to equal the number. Logs are chiefly fractional, since very few numbers are exact powers of 10 : the whole number, or integral part of the log., is called the index, and the decimal part the mantissa. It is the decimal part that is found on pages 2-16 in Norie's Tables, or any other nautical tables. The index is added by the computer, and is found by subtracting unity, " 1 ," from the number of figures in the integral part of the quantity; this is evident from the following considerations :-

$$
10^{0}=1,10^{1}=1,10^{2}=100,10^{3}=1000 .
$$

Thus from definition-

$$
\begin{aligned}
& \log 1=0 \\
& \log 10=1 \\
& \log 100=2 \\
& \log 1000=3 ; \quad \text { and so on. }
\end{aligned}
$$

Hence the logs of all numbers between 1 and 10, those which only have one digit in the whole number part, fall between 0 and 1 , and so are wholly decimal, having 0 for index. Again, the logs of all numbers between 100 and 1000, which are expressed by three digits in the whole number part, fall between 2 and 3, and so always have 2 for the index.

The index of a wholly decimal number is negative, and is found by adding unity, " 1 ," to the number of cyphers immediately after the decimal point, and before the first significant figure, and putting a minus sign (-) over it. 
Logs of all numbers which are expressed by the same figures, but differ only in the position of the decimal point, have the same mantissa.

A minus index is made positive by adding 10 to it.

ART 2.-Finding the Logarithms of Numbers.-In Table, pp. 2-16, Norie, the first column is headed "No."; here are entered all numbers from 100 to 999 . The other columns are headed 0 to 9 ; and the end one "Diff." : the first three figures of the number whose log is required are found under "No."; the fourth figure represents the column to be used; the number found in this column abreast the figures under "No." is the mantissa of log required. The index must be placed as indicated above. Should there be fewer than four figures in the number, add cyphers to make up four and take out mantissa, using index corresponding to original number.

\section{Examples.-}

\begin{tabular}{llll}
$\begin{array}{l}\text { Numbers. } \\
\text { 1. } 6\end{array}$ & & & Logarithms. \\
2.34 & $\ldots$ & $\ldots$ & $0 \cdot 778151$ \\
3.420 & $\ldots$ & $\ldots$ & $1 \cdot 531479$ \\
4. $7 \cdot 856$ & $\ldots$ & $\ldots$ & $2 \cdot 623249$ \\
5.38270 & $\ldots$ & $\ldots$ & $0 \cdot 895201$ \\
6.5 & $\ldots$ & $\ldots$ & $4 \cdot 582858$ \\
7.065 & $\ldots$ & $\ldots$ & $\frac{1}{1} \cdot 698970$ \\
8. 00013 & $\ldots$ & $\ldots$ & $\frac{2}{3} \cdot 812913$ \\
9. $\cdot 00000671$ & $\ldots$ & $\ldots$ & $\frac{3}{6} \cdot 113943$ \\
\hline
\end{tabular}

Nore.-The negative index is generally_changed into a positive for Nautical Computations by adding 10 , so that $\overline{1}$ becomes $9, \overline{2}$ becomes 8 , etc.

When the number contains more than four figures, take out the log. of the first four; then find the correction for the remaining figures by multiplying the "Diff." by these figures, and cutting off as many to the right. The remaining quantity is the correction to be added.

Examples.-

\begin{tabular}{|c|c|c|c|c|}
\hline \multirow[t]{2}{*}{ 1. $2 \cdot 340401$} & ... & $\ldots$ & $\begin{array}{r}\text { Logarithms. } \\
0.369216 \\
74\end{array}$ & Diff. $\begin{array}{r}185 \\
401 \\
\frac{185}{740}\end{array}$ \\
\hline & & & 0.369290 & 74,185 \\
\hline 2. 55300.017 & ... & ... & $4 \cdot 742725$ & Diff. ${ }_{0017}^{78}$ \\
\hline & & & $4 \cdot 742725$ & $\begin{array}{l}546 \\
78\end{array}$ \\
\hline
\end{tabular}

3. $86430000 \quad \ldots \quad \ldots \quad 7 \cdot 936664$

Note.-There is no correction for 0 's at the end of a number. 
EXERCISES.

1. Find the Logarithms of the following numbers:-

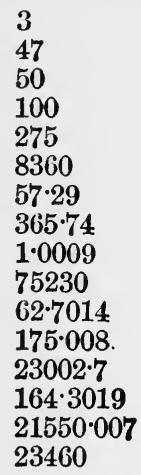

3409
$7 \cdot 5$
$163 \cdot 45$
$704 \cdot 009$
$32636 \cdot 04$
$\cdot 5$
$\cdot 049$
$\cdot 0036$
$\cdot 001204$
$\cdot 006728$
$\cdot 00028041$
$\cdot 0000753$
$\cdot 0346009$
$\cdot 075604$
$\cdot 3670007$

ART. 3.-Finding the Numbers corresponding to Given Logarithms. -When searching for the number corresponding to a log., no account is taken of the index, the mantissa is looked out in the tables, and will be found to either correspond exactly with an entry there, or fall between two entries. In the event of exact coincidence, the figures in the "No." column and at the top of the column where the log. is found, give the first four figures of the Number required: the place of the decimal point depends on the Index, and is found by counting off from the left one more than the number of figures in the index. Should the index call for more than four digits in the Number, cyphers are added to make up the required quantity.

Should the log. not agree, as is more often the case, the next less entry is taken from the tables and subtracted from the given log., cyphers are added to this difference and then divided by the number abreast in the "Diff." column. The figures in the dividend are extra ones to be placed to the right after the four figures taken from the tables corresponding to the less entry used.

Examples.-

\begin{tabular}{cccc} 
Given logs. & & \multicolumn{2}{c}{ Numbers. } \\
1. $0 \cdot 113943$ & $\ldots$ & $\ldots$ & $1 \cdot 3$ \\
2. $1 \cdot 791480$ & $\ldots$ & $\ldots$ & $61 \cdot 87$ \\
3. $2 \cdot 724931$ & $\ldots$ & $\ldots$ & $530 \cdot 8$
\end{tabular}

When the Index exceeds three, and more than four figures are required, the log. next less in the tables is taken out, and the remainder divided (as in Division of Decimals) by the "Diff." gives the additional figures required. 
Examples. -

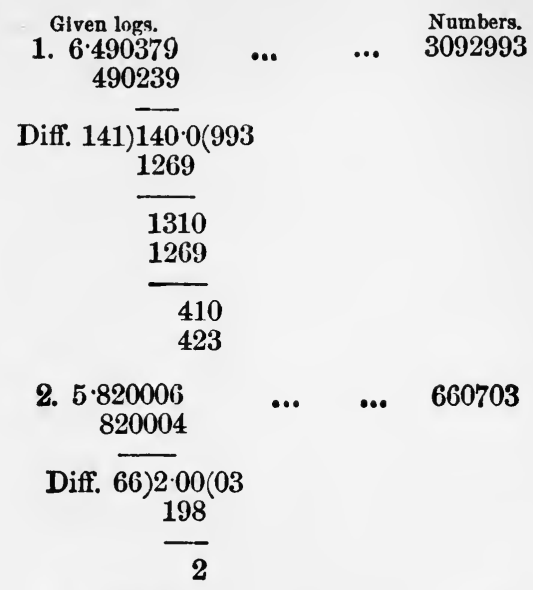

3. $4.875003 \quad$... $\quad \ldots \quad 74990$

When the index is negative, and the number therefore a decimal, the position of the first figure (of value) is indicated by the index; thus, $\overline{1}$ shows it will occupy the first place after the decimal point, $\overline{2}$ requires the first figure (of value) in the second place, etc.

Examples.-

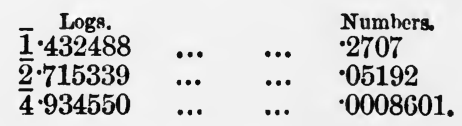

Nore.-These index numbers when increased by 10 become $9,8,6$.

EXERCISES.

2. Find the numbers of which the following are the Logarithms :-

$3 \cdot 203577$
$2 \cdot 145818$
$1 \cdot 700271$
$0 \cdot 715920$
$0 \cdot 004382$
$4 \cdot 681484$
$5 \cdot 690196$
$6 \cdot 148900$
$7 \cdot 040203$
$4 \cdot 806044$

$5 \cdot 175801$
$6 \cdot 531481$
$7 \cdot 000435$
$5 \cdot 361917$
$4 \cdot 041393$
$6 \cdot 049606$
$0 \cdot 000434$
$3 \cdot 670154$
$7 \cdot 276003$
$5 \cdot 380032$

Nore.-Since logarithms are merely the powers of " 10 ," which would make the numbers, to multiply quantities, we do as in Algebra, add the powers.

To divide quantities, subtract the powers.

To perform Involution, multiply the log. by the power.

To perform Evolution, divide the log. by the root. 
ArT. 4. Multiplication by Logarithms.

Rule.-Add together the logarithms of the numbers, and find the number corresponding to the sum of logarithms.

Examples.-

1. Multiply 234 by $1 \cdot 76$ by common logarithms.

$234 \log 2 \cdot 369216$

$1.76 \log 0 \cdot 245513$

Ans. $411 \cdot 8 \log 2 \cdot 614729$

2. Multiply 32640 by $\cdot 00876$.

$32640 \log 4 \cdot 513750$

$.00876 \log 7 \cdot 942504$

Ans. $285 \cdot 9 \log 2 \cdot \mathbf{4 5 6 2 5 4}$

3. Multiply together $3 \cdot 17,24 \cdot 781$, and $\cdot 067$.

$3 \cdot 17 \log 0 \cdot 501059$

$24 \cdot 781 \log 1 \cdot 394119$

$.067 \log 8 \cdot 826075$

Ans. $5 \cdot 263 \log \overline{0 \cdot 721253}$

4. Multiply $760 \cdot 56$ by $\cdot 0001877$.

$760 \cdot 56 \log 2 \cdot 881133$

$\cdot 0001877 \log 6 \cdot 273464$

Ans. $1427 \log 9 \cdot 154597$

5. Multiply $\cdot 89472$ by $\cdot 003708$.

$\begin{array}{rr}.89472 & \log 9 \cdot 951687 \\ .003708 & \log \frac{7 \cdot 569140}{.003318}\end{array}$

Remark.-It is evident that the product of a whole number by a whole number is a whole number, and the product of a decimal by a decimal is a decimal; but when a whole number and a decimal are multiplied together, the answer contains a whole number if the sum of indexes amounts to ten or more (in which case ten is rejected); but if the sum is less than ten, the answer is a decimal.

\section{Exercises.}

1. Multiply 479 by 41 .

2 . , 4672 by 5 .

3. $\quad " \quad 1037 \cdot 5$ by 269 .

4. , , 35890 by 10 .

5. , $\quad 16 \cdot 536$ by $42 \cdot 90$.

6. , $12 \cdot 4 \check{5}$ by 3.84 .

7. $\quad " \quad 7 \cdot 5642$ by $279 \cdot 003$.

8. $\quad, \quad 2 \cdot 3467$ by 123.006 .

9 . ", $164 \cdot 3019$ by $21550 \cdot 007$. 
10. Multiply $356 \cdot 8$ by $\cdot 0167$.

11. " 001204 by $\cdot 006728$.

12.,$\quad 32415 \cdot 5$ by $\cdot 0002$.

13. $", \quad 046009$ by $\cdot 00028041$.

14. $", \quad \cdot 1000012$ by $\cdot 00259$.

15. ", 100 by $\cdot 005$.

16. ", $7642 \cdot 005$ by $3 \cdot 26507$.

17. $" \quad 999999$ by $\cdot 1$.

18. ", 0867 by 235.6004 .

$19 . \quad$ " 98421 by 234 .

20 . ,, 00765 by $\cdot 23461$.

21 . " 28550 by $\cdot 0444$.

22 . $" 30000000$ by $\cdot 00765$.

23 . Find the product of $2.36 \times 19 \cdot 742 \times \cdot 3897$.

24. " " $104.26 \times .018 \times 95.41 \times 8$.

\section{ArT. 5. Division by Logarithms.}

Rule.-Subtract the log of the Divisor from the $\log$ of the Dividend, and then find the corresponding number.

\section{Examples.-}

1. Divide 37640 by 4705 .

$$
\begin{array}{rr}
37640 & \log 4 \cdot 575650 \\
4705 & \log 3 \cdot 672560 \\
\text { Ans. } 8.000 & \log 0.903090
\end{array}
$$

2. Divide $246 \cdot 78$ by $\cdot 0272$.

$$
\begin{array}{rr}
246 \cdot 78 & \log 2 \cdot 392310 \\
\cdot 0272 & \log 8 \cdot 434569 \\
\text { Ans. } 9073 & \log 3 \cdot 957741
\end{array}
$$

3. Divide $\cdot 14$ by $\cdot 09876$.

$$
\begin{array}{rr}
\cdot 14 & \log 9 \cdot 146128 \\
.09876 & \log 8 \cdot 994581 \\
\text { Ans. } 1 \cdot 418 & \log \frac{0 \cdot 151547}{}
\end{array}
$$

4. Divide $207 \cdot 4$ by $3709 \cdot 1$.

$207 \cdot 4 \quad \log 2 \cdot 316809$

$3709 \cdot 1 \log 3 \cdot 569269$

Ans. $05592 \log 8 \cdot 747540$

5. Divide $\cdot 0076438$ by $\cdot 92$.

$$
\begin{array}{rr}
.0076438 & \log 7 \cdot 883310 \\
.92 & \log 9 \cdot 963788
\end{array}
$$

Ans. $\cdot 008308 \log 7 \cdot 919522$

Remark.-The answer always contains whole numbers (one more than the index) when the Divisor is less than the Dividend, but is all decimals when the Divisor is the greater. 
EXERCISES.
1. Divide $32636 \cdot 04$ by $704 \cdot 009$.
2. ,, $\quad 687 \cdot 31$ by $2 \cdot 34$.
3. , $45 \cdot 2$ by 005 .
4. ,, 985.712 by $\cdot 0056$.
5. ," 923 by 2001 .
6. ", 64238 by $\cdot 026$.
7. " $\quad 99$ by "0000745.
8. " $35161 \cdot 9$ by $34 \cdot 24$.
$9 . \quad, \quad 746202$ by 52496 .
10. " " $197 \cdot 65773$ by 00139 .
11., 35 by $34 \cdot 24063$.
12. " 9 by 874303 .
13. „ $16192 \cdot 2$ by 01086 .
14. ", 1.3 by 0000000290003 .
15. ", 001 by 1000 .
16. ", 000876 by $\cdot 0000438$.
17.,$\quad 012$ by 009847 .
18. ," 76591 by $\cdot 13$.
19. Find the value of $\frac{198 \cdot 79}{3 \cdot 46}$.

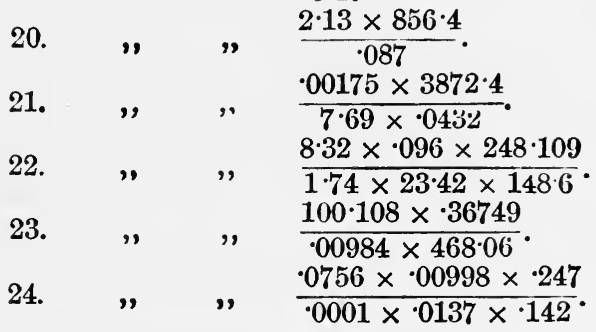

ART. 6. Involution by Logarithms.

Rule.-Multiply the $\log$ of the number by the required Power, and then find the corresponding number.

Example.-Required the 7th power of 1.09.

$1.09 \log 0.037426$

Ans. $1.828 \log \frac{7}{0 \cdot 261982}$

Exercises.

1. Required the square or 2 nd power of $23 \cdot 4$.

2 .,$\quad$ cube or 3 rd power of 1.876 .

3. $\quad, \quad$ 5th power of $\cdot 08967$.

4. $\quad$ ", 9th power of $\cdot 1039$.

5. $\quad, \quad$ 13th power of 367 .

ART. 7. Evolution by Logarithms.

Rule.-Divide the log of the given number by the required Root, and then find the corresponding number. 
Examples.-

1. Required the square root of $\mathbf{1 0 8 1 6}$.

$$
\begin{array}{rr}
10816 & \log 2) 4034066 \\
\text { Ans. } 104 & \log \frac{2 \cdot 017033}{}
\end{array}
$$

2. Required the cube root of 42875 .

$$
\begin{array}{rr}
42875 & \log 3) 4 \cdot 632204 \\
\text { Ans. } 35 & \log \frac{1 \cdot 544068}{1 \cdot 5}
\end{array}
$$

3. Required the 5 th root of $9 \cdot 618$.

$$
\begin{array}{rr}
9.618 & \log 5) 0.983085 \\
\text { Ans. } 1.573 & \log \frac{0.196617}{0.0}
\end{array}
$$

4. Required the 7 th root of $234 \cdot 68$.

$234.68 \log 7) 2 \cdot 370476$

$$
\text { Ans. } 2 \cdot 181 \log \overline{0.338639}
$$

5. Required the cube (or 3 rd) root of ${ }^{\circ} 004913$.

$$
\begin{array}{cc}
.004913 \log 3) \overline{3} \cdot 691347 \\
\text { Ans. } \cdot 17 \log \frac{1}{\overline{1} \cdot 230449}
\end{array}
$$

6. Required the cube root of 0.06174 .

$$
\begin{gathered}
\cdot 06174 \log \overline{2} \cdot 790567 \text { or }-3+1 \cdot 790567 \\
\text { Ans. } \frac{3952 \log \overline{1} \cdot 596856}{1 \cdot 790567}
\end{gathered}
$$

7. Required the 5 th root of $\cdot 007652$.

$$
\begin{aligned}
& .007652 \log 5) \overline{3} \cdot 883775 \\
& \text { Ans. } \cdot 3774 \log \overline{\overline{1}} \cdot 576755
\end{aligned}
$$

\section{Exercises.}

1. Required the square root of $306 \cdot 25$.

$2 . \quad$ cube , $" 46 \cdot 656$.

$3 . \quad$ " $\quad$ 5th $\quad ", 002435$.

4. ", cube ", 12167000 .

$5 . \quad, \quad 7$ th $", 00000002097152$.

Remark.-With a Table of Logarithms containing only six places of figures, such as is used for Navigation, the answers in the preceding exercises cannot be expected to be correct to more than four or five places.

Of course, it must be understood that whenever logs are added in the calculations of problems in Navigation and Nautical Astronomy, it means that the terms are multiplied togetber, and when logs are subtracted, it means division. This is important to remember when one of the terms is zero (or 0 ). 
Additional Exercises.

Find by logs the values of the following:-

1. $\sqrt{20675} ; \quad \sqrt{769 \cdot 52} ; \quad \sqrt[3]{46976482}$.

2. $(29 \cdot 865)^{2}$ and $(98 \cdot 7652)^{2}$.

3. $(91.543)^{2} \times \sqrt[3]{8794.027} ; \sqrt{\frac{4682}{99 \times 37987}}$.

4. $\frac{\sqrt{8794 \cdot 08}}{\sqrt[3]{276509}}$

ART. 8. To find the Logarithm of a Given Ratio (Sin, Cos, Tan, etc.).-InTable Xxv.,pp. 264-353, Norie, are entered the logarithms of the Sines, Cosines, Tangents, etc., of the various angles from $0^{\circ}$ to $90^{\circ}$, given to every half-minute, two pages being reserved for each degree : on the top of the page the degrees from $0^{\circ}$ to $44^{\circ}$ in consecutive order, the minutes and half-minutes being entered in the column on the left-hand side, the names of the ratios at the top; and in columns between two ratios the differences for each second of arc to 30". At the bottom of the page the degrees from $45^{\circ}$ to $89^{\circ}$ are entered, the names of the ratios, and on the right-hand side reading upwards the minutes and half-minutes of arc. In order that there shall be no minus indices, 10 is added to each index before tabulation. Pages 240-263 at the beginning of the table are devoted to the Sines of small angles from $0^{\circ}$ to $4^{\circ}$ to each second of arc, and to the Cosines of large angles from $86^{\circ}$.to $90^{\circ}$. To find a log, turn up the number of degrees on the top of the page if the angle is less than $44^{\circ}$, at the bottom of the page if the angle exceeds $44^{\circ}$; find the minutes on the left if the degrees are at the top, and on the right if the degrees are at the bottom, and abreast the minutes in the column corresponding to the ratio required is the log.

Examples.-

$\begin{array}{ll}\mathrm{L} \sin & 23^{\circ} 25^{\prime}=9 \cdot 599244 \\ \mathrm{~L} \sin & 58^{\circ} 36^{\prime}=9 \cdot 931229 \\ \mathrm{~L} \sin & 27^{\circ} 433^{\prime}=9 \cdot 667666 \\ \mathrm{~L} \sin & 64^{\circ} 144^{\prime}=9 \cdot 954549 \\ \mathrm{~L} \operatorname{cosec} & 75^{\circ} 56^{\prime}=10 \cdot 013222 \\ \mathrm{~L} \cot & 37^{\circ} 28 \frac{1}{2}^{\prime}=10 \cdot 115412\end{array}$

$\mathrm{L} \cos \quad 40^{\circ} 36^{\prime}=9.880397$

$\mathrm{L} \tan 47^{\circ} 28^{\prime}=10.037440$

$\mathrm{L} \cos \quad 65^{\circ} 22 \frac{1}{2}^{\prime}=9 \cdot 619800$

$\mathrm{L}$ sec $14^{\circ} 19^{\prime}=10 \cdot 013701$

$\mathrm{L} \operatorname{cosec} 51^{\circ} 40^{\prime}=10 \cdot 105454$

$\mathrm{L} \tan 13^{\circ} 47^{\prime}=9.389724$

If the angle exceeds $90^{\circ}$, subtract the amount from $180^{\circ}$ and take out the same ratio of the remainder; or take $90^{\circ}$ from the angle and take out the complementary ratio of the remainder.

Examples.-

$\mathrm{L} \sin 102^{\circ} 47^{\prime}=\mathrm{L} \sin \quad 77^{\circ} 13^{\prime}=\mathrm{L} \cos 12^{\circ} 47^{\prime}=9 \cdot 989100$

$\mathrm{L} \operatorname{cosec} 111^{\circ} 15^{\prime}=\mathrm{L} \operatorname{cosec} 68^{\circ} 45^{\prime}=\mathrm{L} \sec 21^{\circ} 15^{\prime}=10 \cdot 030580$

$\mathrm{L} \cot \quad 98^{\circ} 32^{\prime}=\mathrm{L} \cot 81^{\circ} 28^{\prime}=\mathrm{L} \tan 8^{\circ} 32^{\prime}=9 \cdot 176224$

To correct for odd seconds in an angle, find the amount in 
the proper " Diff." column corresponding to the seconds required, add to the log for sines, tangents, and secants, and subtract for cosines, cotangents, and cosecants.

Remark. - The beginning part of this table gives the L Sines of small angles $\left(0^{\circ}\right.$ to $\left.4^{\circ}\right)$ to seconds of arc: or the $\mathrm{L}$ Cos of large angles $\left(86^{\circ}\right.$ to $\left.90^{\circ}\right)$ : seeing that sines and cosecants are complementary, and that the sines and tangents, also the cosecants and cotangents of small angles are approximately equal, by subtracting the $\mathrm{L}$ Sines from 20 we have the corresponding L Cosec, and when the angle is very small $\left(0^{\circ}\right.$ to $\left.0^{\circ} 30^{\prime}\right)$ the L Cot.; this avoids using the very large differences tabulated for $30^{\prime \prime}$.

Examples.-

$\mathrm{L} \sin 56^{\circ} 37^{\prime} 25^{\prime \prime}=9 \cdot 921726$ corr. for $25^{\prime \prime}=+35$
$\mathrm{~L} \cos \quad 37^{\circ} 26^{\prime} 47^{\prime \prime}=9 \cdot 899779 \quad,, \quad 17^{\prime \prime}=-27$
$\mathrm{~L} \sec 55^{\circ} 14^{\prime} 38^{\prime \prime}=10 \cdot 244061 \quad,, \quad 8^{\prime \prime}=+24$
$\mathrm{~L} \operatorname{cosec} 104^{\circ} 17^{\prime} 20^{\prime \prime}=10 \cdot 013648 \quad, \quad 1^{\prime \prime}=-5$
$\mathrm{~L} \cos 88^{\circ} 12^{\prime} 26^{\prime \prime}=8 \cdot 495333$ (large "cos "table).

ART. 9. To find the Angle corresponding to a Logarithm.Reverse the above process, looking out the log in its proper column, and taking the next less log to subtract from the given $\log$ in the case of sines, secs, and tans, and the next greater one in the case of cosines, cosecs, and cots, to subtract the given log from; this difference referred to the corresponding "Diff." column gives the extra seconds.

Examples.-

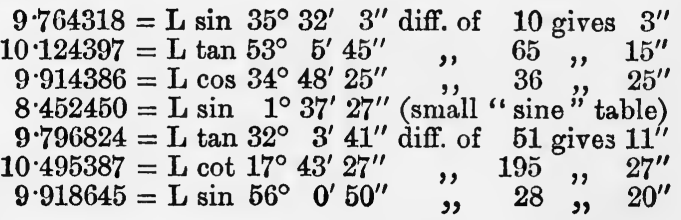




\section{CHAPTER IV.}

\section{SOLUTION OF PLANE TRIANGLES.}

ART. 10. Trigonometrical Ratios-Comparisons can only be made between two quantities which refer to the same kind of thing. A Ratio is the comparison of two quantities, and in Trigonometry the quantities compared are the lengths of the sides, or functions of the angles. A Ratio may be expressed by writing the two quantities with two dots (:) between them, or by forming a vulgar or decimal fraction of them. In every triangle there are three sides, and since two are used to form the ratio, it follows that these can be arranged in "six" different ways ; and hence there are "six" Trigonometrical Ratios. Each one has received a definite name; thus there are sines, cosines, tangents, cotangents, secants, and cosecants.

In any right-angled triangle the side opposite the right angle is always called the Hypotenuse. The side which with the hypotenuse forms the angle is called the BASE. The side opposite the angle under consideration is called the PERPENDICULAR.

$$
\begin{aligned}
& \text { The ratio } \frac{\text { perp }}{\text { hyp }} \text { is called "sine" or shortly "sin." }
\end{aligned}
$$

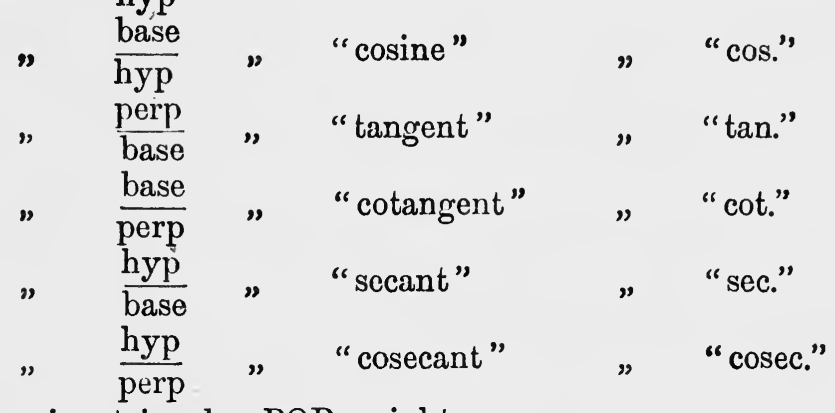

Thus in triangle $\mathrm{PQR}$, right angled at $\mathrm{Q}$, the hypotenuse is always $\mathrm{PR}$; and when the ratios of $\mathrm{P}$ are considered,

$\mathrm{PQ}$ is the base,

$\mathrm{RQ}$ is the perpendicular.

- But when the ratios of $R$ are under consideration, then-

$\mathrm{RQ}$ is the base,

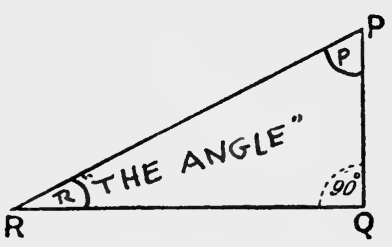

FIG. 42.

$\mathrm{PQ}$ is the perpendicular. 
Thus from definition-

$$
\begin{aligned}
& \sin \mathrm{P}=\frac{\mathrm{RQ}}{\mathrm{PR}} \quad \text { and } \quad \sin \mathrm{R}=\frac{\mathrm{PQ}}{\mathrm{PR}} \\
& \cos \mathrm{P}=\frac{\mathrm{PQ}}{\mathrm{PR}} \quad, \quad \cos \mathrm{R}=\frac{\mathrm{RQ}}{\mathrm{PR}} \\
& \tan P=\frac{R Q}{P Q} \quad \text {, } \quad \tan R=\frac{P Q}{R Q} \\
& \cot P=\frac{P Q}{R Q} \quad \text { " } \quad \cot R=\frac{R Q}{P Q} \\
& \sec \mathrm{P}=\frac{\mathrm{PR}}{\mathrm{PQ}} \quad \text { " } \quad \text { sec } \mathrm{R}=\frac{\mathrm{PR}}{\mathrm{RQ}} \\
& \operatorname{cosec} P=\frac{P R}{R Q} \quad \text {, } \operatorname{cosec} R=\frac{P R}{P Q}
\end{aligned}
$$

and since $P$ and $R$ are complementary, this is expressed by saying that-

The sine of an angle is equal to the cosine of its complement, and vice versa.

The cosine of an angle is equal to the sine of its complement.

And so with tan and cot : sec and cosec. It will be seen that since-

$$
\operatorname{cosec}=\frac{1}{\sin } \quad \sec =\frac{1}{\cos } \quad \cot =\frac{1}{\tan }
$$

the cosec is the reciprocal of the sin, sec of the cos, and cot of the tan. This fact is useful, as it enables a divisor to be replaced by a multiplier in a formula; the same result being obtained whether we divide by sin, cos, or tan; or multiply by their reciprocals cosec, sec, or cot.

ART. 11.-Changes in Sign and Magnitude of Angles.-Consider

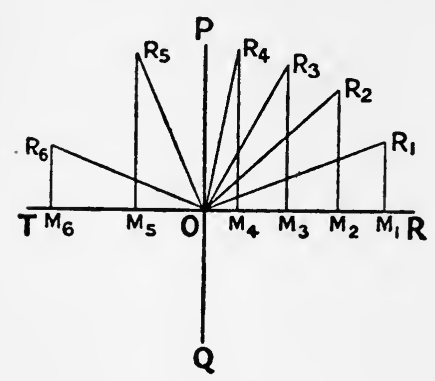

FIG. 43. two lines POQ and ROT meeting in $\mathrm{O}$ at right angles. It is necessary, in order to know in what direction a line is drawn, that some difference should be made when a line is drawn perpendicularly to TR up or down, or when perpendicularly to $P Q$ towards $R$ or $T$; this is done by the use of the signs + and -. Lines drawn perpendicularly up from TR are considered + , down - . Lines drawn perpendicularly to $P Q$ to the right are considered + , to the left - . 
Let a line with centre $O$ revolve from the position $O R$, in a direction against the hands of a clock. In going from OR to OP, it traces out all angles from $0^{\circ}$ to $90^{\circ}$, and in going from OP to OT all angles from $90^{\circ}$ to $180^{\circ}$; larger values need not be considered, as the angles and arcs dealt with in this book do not exceed $180^{\circ}$.

Suppose the revolving line to take up positions indicated by $R_{1}, R_{2}, R_{3}, R_{4}, R_{5}, R_{6}$. Draw perpendiculars from these points meeting TR in $M_{1}, M_{2}, M_{3}, M_{4}, M_{5}, M_{6}$;

Then-

$$
\begin{aligned}
\sin \mathrm{R}_{1} \mathrm{OM}_{1} & =\frac{\mathrm{R}_{1} \mathrm{M}_{1}}{\mathrm{OR}_{1}} \\
\sin \mathrm{R}_{2} \mathrm{OM}_{2} & =\frac{\mathrm{R}_{2} \mathrm{M}_{2}}{\mathrm{OR}_{2}} \\
\sin \mathrm{R}_{6} \mathrm{OM}_{6} & =\frac{\mathrm{R}_{6} \mathrm{M}_{6}}{\mathrm{OR}_{6}}
\end{aligned}
$$

Since $\mathrm{OR}_{1}=\mathrm{OR}_{2}=\ldots \mathrm{OR}_{6}$, it follows that the above fractions, which represent the values the sin has as the angle increases, also increase as the line revolves from $O R$ to $O P$, and decrease as the line revolves from OP to OT. In the position OR or OT the perpendicular vanishes, consequently-

$$
\begin{aligned}
\sin 0^{\circ} & =0 \\
\sin 180^{\circ} & =0
\end{aligned}
$$

Also, when the revolving line coincides with $\mathrm{OP}$, the perpendicular coincides with and is equal to it, or-

$$
\sin 90^{\circ}=1
$$

All the time, however, the perpendicular has been above TR and is reckoned + .

We arrive at the following conclusions :-

As the angle increases from $0^{\circ}$ to $90^{\circ}$, the sine takes all values from 0 to 1.

As the angle increases from $90^{\circ}$ to $180^{\circ}$, the sine takes all values from 1 to 0 .

In both the above cases the sine is positive.

$$
\text { Again- } \quad \begin{aligned}
\cos \mathrm{R}_{1} \mathrm{OM}_{1} & =\frac{\mathrm{OM}_{1}}{\mathrm{OR}_{1}} \\
\cos \mathrm{R}_{4} \mathrm{OM}_{4} & =\frac{\mathrm{OM}_{4}}{\mathrm{OR}_{4}} \\
\cos \mathrm{R}_{6} \mathrm{OM}_{6} & =\frac{\mathrm{OM}_{6}}{\mathrm{OR}_{6}}
\end{aligned}
$$

The value of the cosine depends on the base, and it is seen from the figure that as the angle increases from $0^{\circ}$ to $90^{\circ}$ the base gradually diminishes, and the cosine with it; also when the angle increases from $90^{\circ}$ to $180^{\circ}$ the base increases, but is now 
drawn in a contrary direction, and so of opposite sign. Hence in this case-

As the angle increases from $0^{\circ}$ to $90^{\circ}$, the cosine takes all values from 1 to 0 .

As the angle increases from $90^{\circ}$ to $180^{\circ}$, the cosine takes all values from 0 to -1 .

The tangent depending on the ratio of perpendicular to base follows the same rule as the sine in increasing as the angle increases; and follows the cosine by becoming a negative value in the quadrant from $90^{\circ}$ to $180^{\circ}$. Reciprocals of ratios follow the same rule as the ratios themselves, only as regards sign.

ART. 12. Supplementary Angles.-Make angle TOS = angle $\mathrm{ROM}$, where $\mathrm{OR}=\mathrm{OS} ; \mathrm{ST}$ and RM

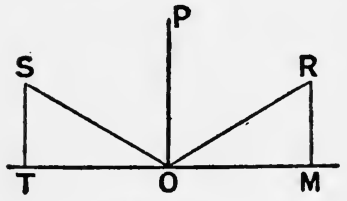

Fig. 44. perpendiculars.

The angles ROM and SOM are supplementary. $\operatorname{Sin} \mathrm{ROM}=\frac{\mathrm{RM}}{\mathrm{OR}}, \sin \mathrm{SOM}=\frac{\mathrm{ST}}{\mathrm{OS}}=\frac{\mathrm{RM}}{\mathrm{OR}}$ $\therefore \sin \mathrm{ROM}=\sin \mathrm{SOM}$.

Again-

$$
\cos R O M=\frac{O M}{U R}, \cos S O M=\frac{O T}{O S}=\frac{-O M}{O S}
$$

$$
\therefore \cos \mathrm{ROM}=-\cos \mathrm{SOM} \text {; }
$$

or sine of an angle equals the sine of its supplement; but cosinc of an angle equals the cosine of its supplement with - sign prefixed.

ART. 13.-Summary.-As angles increase, the sines, tangents, and secants increase.

As angles increase, the cosines, cotangents, and cosecants decrease.

All ratios are positive $(t)$ when angles fall between $0^{\circ}$ and $90^{\circ}$.

When angles fall between $90^{\circ}$ and $180^{\circ}$ all ratios except sines and cosecants are negative $(-)$; these two are positive $(+)$.

$$
\begin{aligned}
\operatorname{Sin} A & =\cos (\operatorname{comp} . A) \\
\operatorname{Cos} A & =\sin (\operatorname{comp} . A) \\
\operatorname{Tan} A & =\cot (\operatorname{comp} . A) \\
\operatorname{Cot} A & =\tan (\operatorname{comp} . A) \\
\operatorname{Sin} A & =\sin (\operatorname{supp} . A) \\
\operatorname{Cos} A & =-\cos (\operatorname{supp} . A) \\
\operatorname{Cosec} A & =\frac{1}{\sin A} \\
\operatorname{Sec} A & =\frac{1}{\cos A} \\
\operatorname{Cot} A & =\frac{1}{\tan A}
\end{aligned}
$$


ART. 14. Solution of Right-angled Triangles. - In all triangles there are six parts (three sides and three angles). In a plane triangle the sum of the three angles is $180^{\circ}$; if three parts be given (one given part must be a side), the other parts may be determined. In right-angled triangles a knowledge of the ratios enables any one to effect the solution; one of the given parts being a right angle, the other two parts which are given can only be (1) two sides, or (2) one side and an angle. The tables are needed, because in them are tabulated the logarithms of all ratios of angles from $0^{\circ}$ to $90^{\circ}$; consequently, when an angle is given, the log of any ratio of that angle may be found; or if an angle is required, knowing the log of the ratio, the angle may be looked up.

Considering the first case where two sides are given. These sides put in the form of a fraction will make four different ratios of the two acute angles, and there are four different ways of starting the solution, all equally correct.

Remark.-All plane triangles should be drawn to scale. To do this the student requires a pen or pencil bow and a six-inch boxwood protractor. The advantage is that the problem may be solved graphically, and the answer obtained is a useful check on the numerical calculation, and so serious mistakes avoided. Angles are laid off or measured as with a Field's parallel rule, by placing the plain edge on the line, and the centre point at the point at which the angle with the line is to be made or measured. On the space at disposal depends the scale of the figure, and this scale should be entered at the side. Thus if we wish to represent a length of 215 inches, and choose a scale of $\frac{1}{10}$ inch to 10 inches, the total length of the line would be $21 \frac{1}{2}$ tenths of inches, or $2 \cdot 15$ inches. Again, to represent a length of 425 miles on a scale of $\frac{1}{10}$ inch to 25 miles, the length would be $\frac{425}{25} \times \frac{1}{10}$ inches $=1.7$ inches : or if in such a figure the length of a side is 2.6 inches, its actual size would be $\frac{2.6 \times 25}{\frac{1}{10}}$ miles $=650$ miles.

Example 1.-In triangle $\mathrm{ABC}, \mathrm{B}=90^{\circ}, \mathrm{AB}=368, \mathrm{BC}=215$. Find the angles, and $\mathrm{AC}$.

Graphical Solution.-Draw horizontal line AB and make it $368 \mathrm{~mm}$. $=36.8 \mathrm{~mm}$. in length : at $\mathrm{B}$ draw $\mathrm{BC}$ perpendicular to $\mathrm{AB}$ and make it $\frac{215}{10}=21.5 \mathrm{~mm}$. in length. Join $A C$.

$$
\begin{array}{rlrl}
\text { Measure } \quad \mathrm{AC} & =42.5 \mathrm{~mm} . \quad \therefore \mathrm{AC}=425 \\
, & \mathrm{~B} \hat{\mathrm{AC}} & =30^{\circ} \\
, & \mathrm{B} \hat{\mathrm{CA}} & =60^{\circ}
\end{array}
$$


Trigonometrical Solution.-Since $\mathrm{AB}$ and $\mathrm{BC}$ are known, we may say-

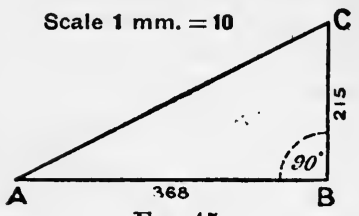

Fig. 45.

$$
\begin{aligned}
\frac{A B}{B C} & =\cot A \text { or } \frac{A B}{B C}=\tan C \\
\text { or } \frac{B C}{A B} & =\tan A \text { or } \frac{B C}{A B}=\cot C .
\end{aligned}
$$

Using the first ratio-

$$
\cot \mathrm{A}=\frac{\mathrm{AB}}{\mathrm{BC}}=\frac{368}{215}
$$

Apply logs, and adding 10 to top index, since tabular cotangent log has been increased by 10 -

$$
\begin{aligned}
& \begin{array}{lllll}
\mathrm{AB} & \ldots & 368 & \log =12.565848
\end{array} \\
& \begin{array}{lllll}
\mathrm{BC} & \ldots & 215 & \log =2 \cdot 332438
\end{array} \\
& 30^{\circ} 17^{\prime} 42^{\prime \prime} \mathrm{L} \text { cot }=\overrightarrow{10 \cdot 233410} \\
& \begin{aligned}
\therefore \mathrm{A} & =\frac{90}{30^{\circ} 17^{\prime} 42^{\prime \prime}} \\
\text { and } \mathrm{C} & =\frac{594218}{5942}
\end{aligned}
\end{aligned}
$$

To find AC, we form a fraction, putting side wanted in the numerator and side known in the denominator, and writing down the name of ratio so formed. This gives rise to several ways of solution, as we may say-

$$
\frac{A C}{A B}=\sec A \text { or } \frac{A C}{B C}=\operatorname{cosec} A \text { or } \frac{A C}{A B}=\operatorname{cosec} C \text { or } \frac{A C}{B C}=\sec C
$$

$\therefore \mathrm{AC}=\mathrm{AB} \times \sec \mathrm{A}$

Apply logs, rejecting 10 from index, added to make a tabular secant.

$$
\begin{array}{ccccc}
\mathrm{AB} & \ldots & \ldots & 368 & \log =2.565848 \\
\mathrm{~A} & \ldots & 30^{\circ} 17^{\prime} 42^{\prime \prime} \mathrm{L} \text { sec }=10.063768 \\
\mathrm{AC} & \ldots & \ldots & 426.2 \quad \log =\frac{42 \cdot 629616}{\prime 2} \\
\text { Ans. } \mathrm{A}=30^{\circ} 17^{\prime} 42^{\prime \prime} ; \mathrm{C}=59^{\circ} 42^{\prime} 18^{\prime \prime} ; \mathrm{AC}=426.2 .
\end{array}
$$

Example 2.-In triangle $\mathrm{PQR}, \mathrm{Q}=90^{\circ}, \mathrm{PR}=17 \cdot 8, \mathrm{PQ}=15 \cdot 5$. Solve.

Graphical Solution.-Draw a horizontal line $\mathrm{RQ}$; at $\mathrm{Q}$ make $\mathrm{QP}$ perpendicular to $R Q$ and $\frac{15 \cdot 5}{16}$ of an inch in length. Take $\frac{17 \cdot 8}{16}$ of an inch as a radius, and with $P$ as centre, cut $R Q$ in $R$. Then $R P Q$ is triangle.

$$
\begin{array}{rlrl}
\text { Measure } & \mathrm{RQ} & =8 \cdot 8 \text { sixteenths } & \therefore \mathrm{RQ}=8 \cdot 8 \\
, \quad & \mathrm{R} \hat{\mathrm{P} Q} & =30^{\circ} \\
\text { " } & \mathrm{PR} Q & =60 .
\end{array}
$$

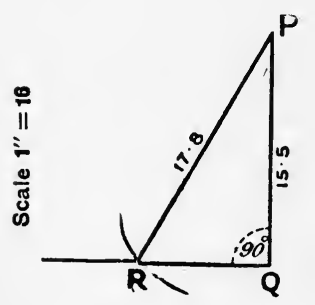

Fia. 46.

Trigonometrical Solution.-

Apply logs.

$$
\operatorname{Sin} R=\frac{P Q}{P R}
$$

$$
\begin{aligned}
& \begin{array}{lllll}
\mathrm{PQ} & \ldots & \ldots & 15 \cdot 5 & \log =11 \cdot 190332
\end{array} \\
& \begin{array}{llllll}
\mathrm{PR} & \ldots & \ldots & \ldots & 17 \cdot 8 & \log =1 \cdot 250420
\end{array} \\
& \mathrm{R} \quad \ldots \quad 60^{\circ} 33^{\prime} 1^{\prime \prime} \mathrm{L} \sin =9 \cdot 939912 \\
& \text { Again- } \\
& \mathrm{P}=90-\mathrm{R}=29^{\circ} 26^{\prime} 59^{\prime \prime} \\
& \frac{\mathrm{RQ}}{\overline{\mathrm{PQ}}}=\cot \mathrm{R} \\
& \therefore \mathrm{RQ}=\mathrm{PQ} \times \cot \mathrm{R}
\end{aligned}
$$


Apply logs.

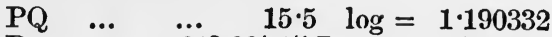

$$
\begin{aligned}
& \text { R } \quad \ldots \quad 60^{\circ} 33^{\prime} 1^{\prime \prime} \mathrm{L} \text { cot }=9 \cdot 751752 \\
& \text { RQ } \quad \ldots \quad \ldots \quad 8.751 \quad \log =\overline{70.942084} \\
& \text { Ans. } \mathrm{P}=29^{\circ} 26^{\prime} 59^{\prime \prime} ; \mathrm{R}=60^{\circ} 33^{\prime} 1^{\prime \prime} ; \mathrm{RQ}=8 \cdot 751 \text {. }
\end{aligned}
$$

The second case, where one side and an angle are given, is solved by remembering that the ratio to work from is formed by placing the side wanted in the numerator and the side known in the denominator. As before, there are four different ways, all equally right, of starting.

Example 3.-In triangle LMN, M = $90^{\circ}, \mathrm{N}=55^{\circ} 15^{\prime}, \mathrm{LM}=1342$. Solve.

Graphical Solution.-Draw a horizontal line NM: at M draw ML perpendicular to $\mathrm{MN}$ and make it equal to $\frac{1342}{1000}$ inch $=1.342$ inch. At any point $O$ in $M N$ make an angle $=55^{\circ} 15^{t}$ : through $L$ draw $L N$ parallel to this line. Then $\mathrm{LN} M=55^{\circ} 15^{\prime}$.

$$
\begin{aligned}
& \text { Measure NL }=1.62 \text { inch } \quad \therefore \mathrm{NL}=1620 \\
& " \quad \mathrm{MN}=.92 \quad, \quad \therefore \mathrm{MN}=920
\end{aligned}
$$

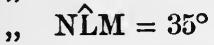

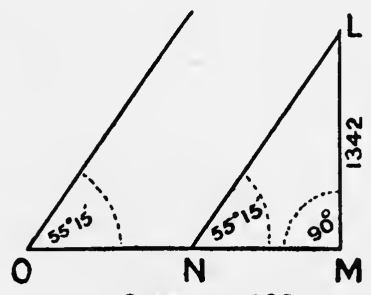

Scale $1 "=1000$

Fig. 47.

Trigonometrical Solution -

$$
\begin{aligned}
& \text { LM ... } 1342 \log =3 \cdot 127752 \\
& \mathrm{~N} 55^{\circ} 15^{\prime} \mathrm{L} \operatorname{cosec}=10 \cdot 085315 \\
& \log =3 \cdot 127752 \\
& \mathrm{~L} \cot =\mathbf{9} \cdot 841187 \\
& 1633 \quad \log =\$ 3 \cdot 213067 \quad 931 \quad \log =\not 2 \cdot 968939 \\
& \mathrm{~L}=90^{\circ}-\mathrm{N}=34^{\circ} 45^{\prime} \\
& \text { Ans. } \mathrm{L}=34^{\circ} 45^{\prime} ; \mathrm{LN}=1633 ; \mathrm{MN}=931 \text {. }
\end{aligned}
$$$$
\therefore \mathrm{LN}=\mathrm{LM} \times \operatorname{cosec} \mathrm{N} \text {, and } \mathrm{MN}=\mathrm{LM} \times \cot \mathrm{N}
$$

$$
\frac{\mathrm{LN}}{\mathrm{LM}}=\operatorname{cosec} \mathrm{N} \text {, and } \frac{\mathrm{MN}}{\mathrm{LM}}=\cot \mathrm{N}
$$

\section{Exercises.-Right-angled Triangles (Plane).}

1. In triangle $\mathrm{ABC}, \mathrm{AB}=503, \mathrm{AC}=357, \mathrm{C}=90^{\circ}$. Find $\mathrm{A}, \mathrm{B}$, and $\mathrm{BC}$.

2. In triangle $\mathrm{PQR}, \mathrm{PQ}=371, \mathrm{QR}=204, \mathrm{Q}=90^{\circ}$. Find $\mathrm{P}, \mathrm{R}$, and $\mathrm{PR}$.

3. In triangle $\mathrm{OPB}, \mathrm{OP}=125 \cdot 7, \mathrm{~PB}=695, \mathrm{O}=90^{\circ}$. Find $\mathrm{P}, \mathrm{B}$, and $\mathrm{OB}$.

4. In triangle $\mathrm{ABC}, \mathrm{A}=64^{\circ} 41^{\prime}, \mathrm{C}=90^{\circ}, \mathrm{AB}=1037$. Find $\mathrm{AC}$ and $\mathrm{BC}$.

5. In triangle $\mathrm{ABC}, \mathrm{B}=34^{\circ} 17^{\prime}, \mathrm{C}=90^{\circ}, \mathrm{BC}=905$. Find $\mathrm{AB}$ and $\mathrm{AC}$.

6. In triangle $A B C, A B=147, B C=116, C=90^{\circ}$. Find $A, B$, and $A C$.

7. In triangle $P Q R, P=33^{\circ} 14^{\prime}, P Q=4372, Q=90^{\circ}$. Find $P R$ and $R Q$.

8. In triangle $\mathrm{ABC}, \mathrm{C}=90^{\circ}, \mathrm{AC}=706, \mathrm{BC}=981$. Find $\mathrm{A}, \mathrm{B}$, and $\mathrm{AB}$.

9. At $145 \mathrm{ft}$. from the base of a flagstaff its angle of elevation is observed to be $32^{\circ} 16^{\prime}$. Find the height.

10. The difference of latitude made good is 236.5 miles south, the departure 215.7 miles west. Find the course, and distance sailed.

11. The length of the shadow cast by a vertical post is $39 \mathrm{ft}$. $6 \mathrm{in}$. when the sun has an elevation of $21^{\circ} 32^{\prime}$. Find the height of the post.

12. From a ship a promontory was observed to be $3 \frac{1}{2}$ points on the bow, 
and after making 7 miles on her course, it was found to be abeam. What distance was the vessel from the point at the two bearings?

13. A lighthouse, whose top is $200 \mathrm{ft}$. above the sea-level, marks a danger situated at three cables' length from the shore. Required the vertical "danger angle."

14. From a reef awash at low water, the angle of elevation to the summit of a hill distant 2050 yards in a horizontal direction is $1^{\circ} 12^{\prime}$; height of the eye, $6 \mathrm{ft}$.; tidal rise, $21 \mathrm{ft}$. Required the height of the hill above high water.

ART. 15. Solution of Oblique-angled Plane Triangles.-Triangles which do not contain a right angle are called oblique-angled. Facts to be remembered in connection with triangles are-

The sum of the angles is $180^{\circ}$.

Equal angles are subtended by equal sides.

The greater side is opposite the greater angle.

Any two sides are together greater than the third side.

According to the parts given the solution falls into three different cases.

1. Given two sides and an angle opposite to one of the known sides.

Or, given two angles and a side.

2. Given three sides. sides.

3. Given two sides and the angle contained by the known

CASE I.-For the first case, the following property is used: Sides are proportional to the sines of the opposite angles.

$\mathrm{ACB}$ is a triangle: draw $\mathrm{CD}$ at right angles to $\mathrm{AB}$.

Then $-\frac{C D}{A C}=\sin A$. . . . I.

and $-\quad \frac{\mathrm{CD}}{\mathrm{BC}}=\sin \mathrm{B} . . . \quad$. II.

Divide I. by II.

$$
\therefore \frac{\mathrm{CD}}{\mathrm{AC}} \div \frac{\mathrm{CD}}{\mathrm{BC}}=\frac{\sin \mathrm{A}}{\sin \mathrm{B}}
$$

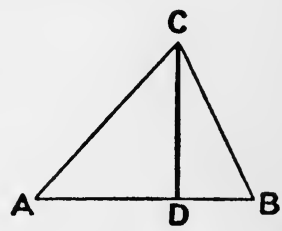

Fig. 48.

that-

$$
\frac{\mathrm{CD}}{\mathrm{AC}} \times \frac{\mathrm{BC}}{\mathrm{CD}}=\frac{\sin \mathrm{A}}{\sin \mathrm{B}}
$$

or, cancelling $\mathrm{CD}_{-}-$

$$
\frac{\mathrm{BC}}{\mathrm{AC}}=\frac{\sin \mathrm{A}}{\sin \mathrm{B}}
$$

Now, if a perpendicular were dropped from A on BC, it might be proved in a similar manner that-

$$
\frac{\mathrm{AC}}{\mathrm{AB}}=\frac{\sin \mathrm{B}}{\sin \mathrm{C}}
$$

Hence the proposition is established. 
Example 1.-Given $P Q=350, P R=367$, and $Q=54^{\circ} 30^{\prime}$. Solve.

Draw a horizontal line $R Q$, and at $Q$ make angle $54^{\circ} 30^{\prime}$, also on a scale of $1 \cdot 1$ inch to 350 make $P Q 1 \cdot 1$ inch long. Find length of $P R$ on our scale $=\frac{1.1 \times 367}{350}=1.15 \mathrm{inch}$, take this length in compass, and with $\mathrm{P}$ as centre draw an arc cutting $\mathrm{QR}$ in $\mathrm{R}$. 'Then $\mathrm{PQR}$ is triangle.

$$
\begin{aligned}
\mathrm{PRQ} & =51^{\circ} \\
\mathrm{RPQ} & =75^{\circ} \\
\mathrm{RQ} & =1.38 \text { inch } \quad \therefore \mathrm{RQ}=439 .
\end{aligned}
$$

Two sides and an angle opposite to a given side; hence the part to be found is the angle opposite to the other given side; here we form a fraction having for its numerator the

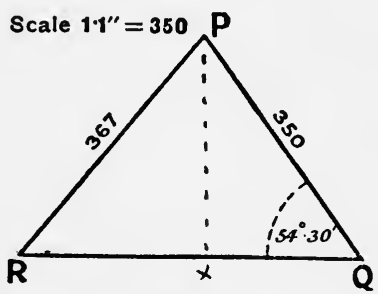

F1G. 49. sine of the angle wanted, and for its denominator the sine of the given angle. This fraction is equal to one formed from preceding proof.

Thus-

$$
\begin{aligned}
\frac{\sin R}{\sin Q} & =\frac{P Q}{P R} \\
\therefore \sin R & =\frac{P Q \times \sin Q}{P R}
\end{aligned}
$$

Apply logs.

$$
\begin{aligned}
& \mathrm{PQ} \quad \ldots \quad \ldots \quad 350 \quad \log =2 \cdot 544068 \\
& \mathrm{Q} \quad \ldots \quad \dddot{54}^{\circ} 30^{\prime} \mathrm{L} \sin =9 \cdot 910686 \\
& 12 \cdot 454754 \\
& \begin{array}{llllll}
\mathrm{PR} & \ldots & \ldots & 367 & \log =25564666
\end{array} \\
& \text { R } \quad \ldots 50^{\circ} 55^{\prime} 57^{\prime \prime} \mathrm{L} \sin =9890038 \\
& \mathrm{Q}=54^{\circ} 30^{\prime} 0^{\prime \prime} \\
& \mathrm{R}=505557 \\
& \mathrm{Q}+\mathrm{R}_{0}^{\prime}=\underset{180}{1052557} \\
& \mathrm{P}=\begin{array}{lll}
74 & 34 & 3
\end{array}
\end{aligned}
$$

Again, to find the third side RQ: form a fraction with the side wanted (RQ) as numerator, and one of the given sides (PR) as denominator ; this fraction equals one formed by placing sine of angle opposite $R Q(\sin P)$ in numerator and sine of angle opposite $\mathrm{PR}(\sin Q)$ in denominator.

$$
\begin{aligned}
& \mathrm{RQ}=\frac{\sin \mathrm{P}}{\sin \mathrm{Q}} \\
& \therefore \mathrm{RQ}=\frac{\mathrm{PR} \times \sin \mathrm{P}}{\sin \mathrm{Q}}=\mathrm{PR} \times \sin \mathrm{P} \times \operatorname{cosec} \mathrm{Q}
\end{aligned}
$$

In order to make all the $\operatorname{logs}$ added, $\sin Q$ as a divisor is changed into cosec $Q$ as a multiplier-

$$
\text { since } \operatorname{cosec} Q=\frac{1}{\sin Q}
$$




$$
\begin{aligned}
& \text { PR } \quad \ldots \quad \ldots \quad 367 \quad \log =2 \cdot 564666 \\
& \mathrm{P} \quad \cdots \quad 7^{\circ} 34^{\prime} 3^{\prime \prime} \mathrm{L} \text { sin }=9.984052 \\
& \mathrm{Q} \quad \ldots \quad 54^{\circ} 30^{\prime} \mathrm{L} \operatorname{cosec}=10.089314 \\
& \text { RQ } \quad \ldots \quad \ldots \quad 434.5 \quad \log =\overline{22.638032} \\
& \text { Ans. } \mathrm{P}=74^{\circ} 34^{\prime} 3^{\prime \prime} ; \mathrm{R}=50^{\circ} 55^{\prime} 57^{\prime \prime} ; \mathrm{RQ}=434 \cdot 5 \text {. }
\end{aligned}
$$

Example 2.-Given $\mathrm{C}=118^{\circ} 30^{\prime}, \mathrm{B}=21^{\circ} 22^{\prime}$, and $\mathrm{AC}=67 \cdot 5$. Solve. Graphical Solution.-Draw horizontal line AC of length $\frac{67.5}{100}$ inches $=\cdot 68$ inch. At $\mathrm{C}$ draw $\mathrm{CB}$ making an angle of $118^{\circ} 30^{\prime}$ with $\mathrm{AC}$, and through A draw AD parallel to CB. At A draw AB

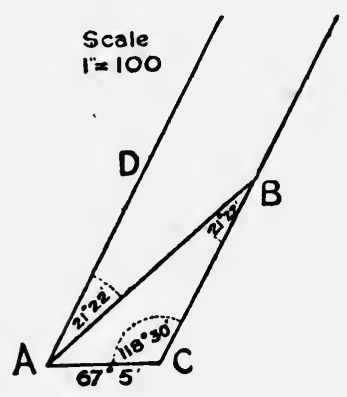

Fig. 50. making an angle $21^{\circ} 22^{\prime}$ with $\mathrm{AD}$, to meet $\mathrm{CB}$ in $\mathrm{B}$. Then $\mathrm{ABC}$ is triangle.

$$
\begin{aligned}
& \text { Measure } \mathrm{A}=40^{\circ} \\
& \text { ", } \quad \mathrm{AB}=1 \cdot 6 \text { inch } \quad \therefore \mathrm{AB}=160 \\
& " \quad \mathrm{BC}=1 \cdot 2, \quad \therefore \mathrm{BC}=120
\end{aligned}
$$

Trigonometrical Solution.-

$$
\begin{aligned}
\mathrm{A}+\mathrm{B}+\mathrm{C} & =180^{\circ} \\
\therefore \mathrm{A} & =180^{\circ}-(\mathrm{B}+\mathrm{C}) \\
& =180^{\circ}-139^{\circ} 52^{\prime} \\
& =40^{\circ} 8^{\prime}
\end{aligned}
$$

To find $\mathrm{BC}-$

$$
\frac{B C}{A C}=\frac{\sin A}{\sin B}
$$

$$
\therefore \mathrm{BC}=\frac{\mathrm{AC} \times \sin \mathrm{A}}{\sin \mathrm{B}}=\mathrm{AC} \times \sin \mathrm{A} \times \operatorname{cosec} \mathrm{B}
$$

$$
\begin{array}{lllll}
\mathrm{AC} & \ldots & \ldots & 67.5 \quad \log =1 \cdot 829304 \\
\mathrm{~A} & \ldots & \multicolumn{4}{c}{40^{\circ} 8^{\prime} \mathrm{L} \sin =9 \cdot 809269} \\
\mathrm{~B} & \ldots & 21^{\circ} 22^{\prime} \mathrm{L} \operatorname{cosec}=10 \cdot 438499 \\
\mathrm{BC} & \ldots & \ldots & 119 \cdot 4 \quad \log =22 \cdot 077072
\end{array}
$$

To find $\mathrm{AB}-$

$$
\begin{aligned}
\frac{\mathrm{AB}}{\overline{A C}} & =\frac{\sin \mathrm{C}}{\sin \mathrm{B}} \\
\therefore \mathrm{AB} & =\frac{\mathrm{AC} \times \sin \mathrm{C}}{\sin \mathrm{B}}=\mathrm{AC} \times \sin \mathrm{C} \times \operatorname{cosec} \mathrm{B}
\end{aligned}
$$

$$
\begin{aligned}
& \begin{array}{llllll}
\mathrm{AC} & \ldots & \ldots & 67.5 \quad \log =1.829304
\end{array} \\
& \text { C } \quad \ldots \quad 118^{\circ} 30^{\prime} \mathrm{L} \sin =9.943899 \quad \ldots \quad \text { (Use } \sin 61^{\circ} 30^{\prime} \text {, the } \\
& \text { B } \quad \ldots \quad 21^{\circ} 22^{\prime} \mathrm{L} \text { cosec }=10^{\circ} 438499 \quad \ldots \quad \text { supplement.) }
\end{aligned}
$$

$$
\mathrm{AB} \quad \ldots \quad 162 \cdot 8 \quad \log =\overline{22 \cdot 211702}
$$

$$
\text { Ans. } \mathrm{A}=40^{\circ} 8^{\prime} ; \mathrm{AB}=162 \cdot 8 ; \mathrm{BC}=119 \cdot 4 \text {. }
$$

Example 3.-Given AP $=1134 ; \mathrm{PM}=875 ; \mathrm{A}=35^{\circ} 20^{\prime}$. Solve.

Here is given the angle opposite to the smaller side, and when the triangle is drawn to scale, it is found that two triangles can be drawn from the data; there are thus two solutions, and it is known as the ambiguous case.

Graphical Solution.-Lay off a horizontal line of unlimited length, and at one end $\mathrm{A}$ make an angle equal to the given angle, viz. $\mathrm{MAP}=35^{\circ} 20^{\prime}$. 
Along AP measure the longer side $=1134$, that is 1.13 inch ; and with centre $\mathbf{P}$ and distance equal to the shorter side 875 , that is 87 inch ; describe an arc cutting $\mathbf{A M}$ in $\mathbf{M}$ and $\mathbf{M}^{\prime}$. Thus both $P M$ and $\mathrm{PM}^{\prime}=875$. Hence there are two triangles, PAM and PAM', which satisfy the given conditions.

Measure AM $=\mathbf{1 . 5}$ inch, that is $\mathbf{1 5 0 4}$ $\mathbf{A M}^{\prime}=\cdot 3 \tilde{5}$ inch, that is 350 .

Trigonometrical Solution.-To find $\mathbf{M}$ in triangle APM-

$$
\begin{aligned}
& \frac{\sin \mathrm{M}}{\sin \mathrm{A}}=\frac{\mathrm{AP}}{\mathrm{PM}}
\end{aligned}
$$

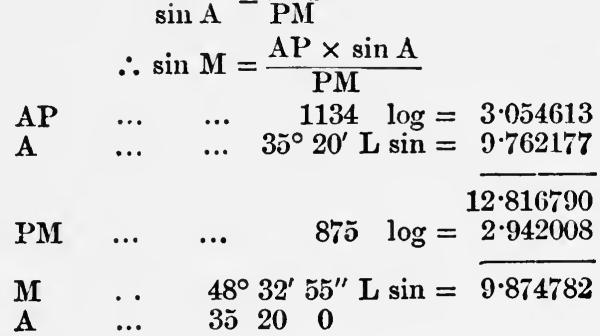

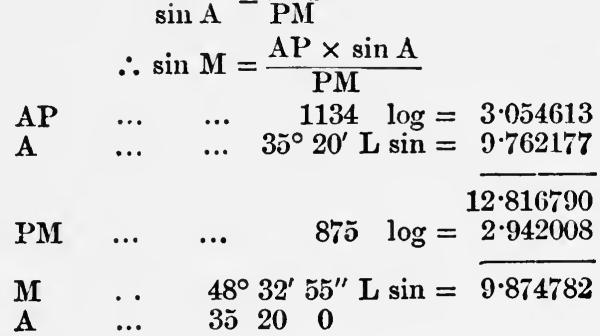

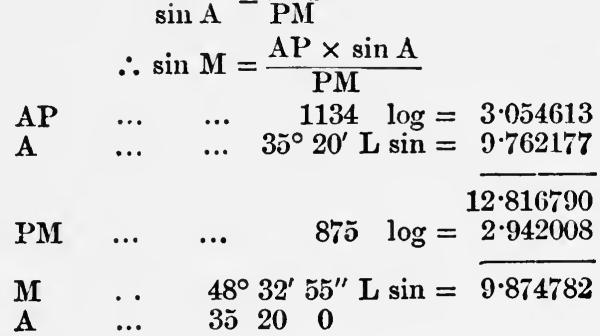

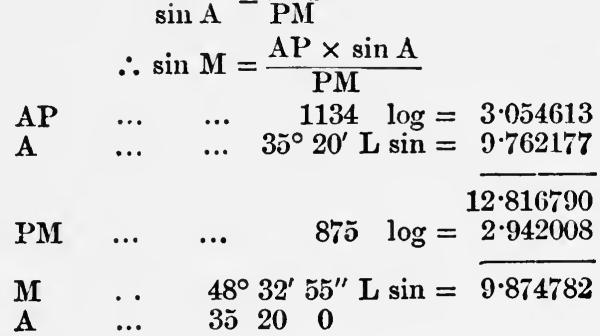

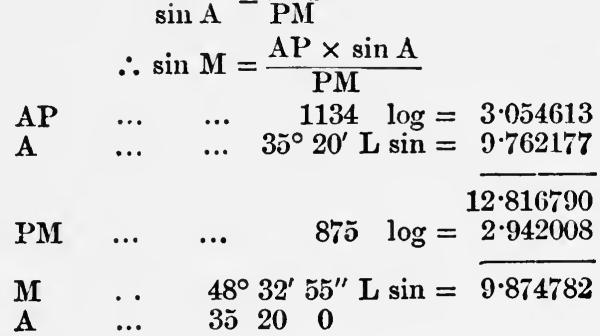

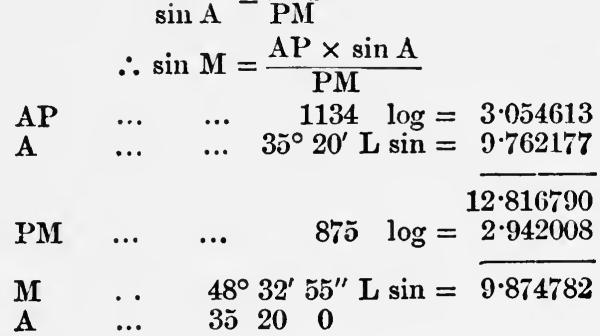

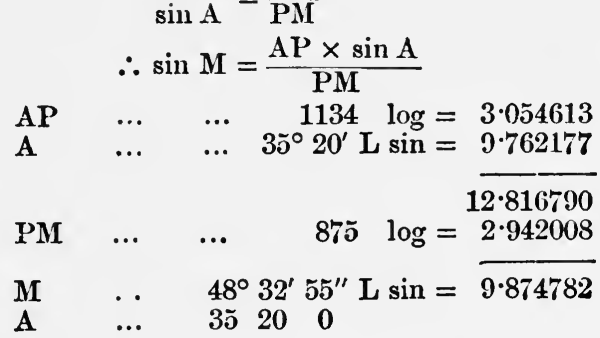$$
A+M \quad \cdots \quad 835255
$$$$
\text { P } \quad \ldots \quad \longdiv { 9 6 \quad 5 }
$$

To find $A M$ in triangle AMP-

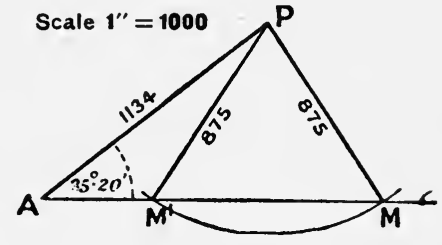

FIG. 51.

$$
\begin{aligned}
\frac{A M}{P M} & =\frac{\sin \mathbf{P}}{\sin A} \\
\therefore A M & =\frac{P M \times \sin P}{\sin A}=P M \times \sin P \times \operatorname{cosec} A \\
P M & \ldots \quad \ldots \quad 875 \quad \log =2.942008
\end{aligned}
$$$$
\mathrm{P} \quad \cdots \quad \cdots \quad 96^{\circ} 7^{\prime} 5^{\prime \prime} \mathrm{L} \sin =9.997519
$$$$
\text { A } \quad \cdots \quad 35^{\circ} 20^{\prime} \mathrm{L} \text { cosec }=10.237823
$$$$
\text { AM } \quad \ldots \quad \ldots \quad 1504 \quad \text { log }=\overline{\$ 3 \cdot 177350}
$$

To find $\mathbf{M}^{\prime}$ in $\mathrm{APM}^{\prime}$ -

Since $\mathbf{P M}=\mathbf{P M}^{\prime}$, angle $\mathbf{P M} \mathbf{M}^{\prime}=$ angle $\mathbf{P M} \mathbf{I}^{\prime} \mathbf{M}$

$$
\begin{aligned}
\text { Hence } \mathbf{M}^{\prime} & =180-\mathbf{M} \\
& =131^{\circ} 27^{\prime} 5^{\prime \prime} \\
\mathbf{A} & =\frac{3520}{\mathbf{M}^{\prime}+\mathrm{A}}=\frac{166475}{180} \\
\mathbf{P} & =\overline{131255}
\end{aligned}
$$

To find $\mathrm{AM}^{\prime}$ in triangle $\mathrm{APM}^{\prime}-$

$$
\begin{aligned}
\frac{A M^{\prime}}{P M^{\prime}} & =\frac{\sin \mathbf{P}}{\sin \mathbf{A}} \\
\therefore A M^{\prime} & =\frac{P M^{\prime} \times \sin P}{\sin A}=P M^{\prime} \times \sin P \times \operatorname{cosec} \mathbf{A}
\end{aligned}
$$




$$
\begin{array}{lllll}
\mathrm{YM}^{\prime} & \ldots & \ldots & 875 & \log =2942008 \\
\mathrm{P} & \ldots & 13^{\circ} 12^{\prime} 55^{\prime \prime} \mathrm{L} \sin =9 \cdot 359096 \\
\mathrm{~A} & \ldots & 35^{\circ} 20^{\prime} \mathrm{L} \operatorname{cosec}=10 \cdot 237823 \\
\mathrm{AMI} & \ldots & \ldots & 345.9 & \log =22.538927
\end{array}
$$

Ans. $\mathrm{N}=48^{\circ} 32^{\prime} 55^{\prime \prime}, \mathrm{P}=96^{\circ} 7^{\prime} 5^{\prime \prime}, \mathrm{AM}=1504$

$$
\text { or } 131275 ; \quad \text { or } 131255 \text {, or } 345.9
$$

CASE II.-Given three sides, to find the angles. The half sum of the three sides is denoted by the letter s. If $\mathrm{ABC}$ is a triangle, the formula for finding an angle is-

$$
\cos \frac{\mathrm{A}}{2}=\sqrt{\frac{s \cdot(s-\mathrm{BC})}{\mathrm{AB} \cdot \mathrm{AC}}}
$$

$$
\text { where } s=\frac{1}{2}(\mathrm{AB}+\mathrm{AC}+\mathrm{BC})
$$

This is proved in any "Trigonometry," and may be expressed in writing thus-

Cosine of half an angle is equal to the square root of the amount obtained by dividing the product of the half sum of sides and the remainder by the product of the sides which contain the angles.

The remainder is obtained by subtracting the side opposite the angle required from the half sum of the sides.

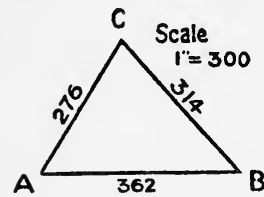

Fic. 52.

Example 4.-Given $\mathrm{AB}=362, \mathrm{BC}=314, \mathrm{AC}$ $=276$. Solve.

Graphical Solution.-Draw a horizontal line AB in length $=\frac{362}{300}$ inch $=1 \cdot 21$ inch. With centre $A$, radius $=\frac{278}{300}=\cdot 92$ inch, describe an arc, and with centre $\mathrm{B}$, radius $=314=1.05$ inch, describe another arc cutting first arc in $\mathrm{C}$. Then $\mathrm{ABC}$ is the triangle.

A measures $57 \frac{1}{2}^{\circ}$

$\begin{array}{lll}\text { B } \quad, & 47 \frac{10}{2} \\ \text { C } & , & 74^{\circ}\end{array}$

Trigonometrical Solution. - To find C-

$$
\begin{aligned}
& \cos \frac{\mathrm{C}}{2}=\sqrt{\frac{s \cdot(s-\mathrm{AB})}{\mathrm{AC} \cdot \mathrm{BC}}} \\
& \mathrm{AB}=362 \\
& \mathrm{AC}=276 \quad \ldots \quad \ldots \quad \log 2 \cdot 440909 \\
& \mathrm{BC}=314 \quad \ldots \quad \ldots \quad \text { log } 24496930 \\
& \text { 2) } 952 \\
& s=476 \quad \log 2 \cdot 677607 \\
& s-\mathrm{AB}=114 \log 2.056905 \\
& 24 \cdot 734512 \\
& 4 \cdot 937839 \\
& \text { 2) } 19 \cdot 796673 \\
& 37^{\circ} 41^{\prime} 37^{\prime \prime} \mathrm{L} \cos =9.898336 \\
& 2 \\
& \mathrm{C}=75 \quad 23 \quad 14
\end{aligned}
$$


Again, to find $\mathrm{B}$ -

$$
\begin{gathered}
\cos \frac{\mathrm{B}}{2}=\sqrt{\frac{s \cdot(s-\mathrm{AC})}{\mathrm{AB} \cdot \mathrm{BC}}} \\
\mathrm{AB}=362 \quad \ldots \quad \ldots \quad \log =2 \cdot 558709 \\
\mathrm{BC}=314 \quad \ldots \quad \ldots \quad \log =2 \cdot 496930 \\
s=476 \quad \log =2 \cdot 677607 \\
s-\mathrm{AC}=200 \quad \log =\frac{2 \cdot 301030}{24 \cdot 978637} \quad \overline{5 \cdot 055639} \\
\frac{5 \cdot 055639}{2) 19 \cdot 922998} \\
\mathrm{~B}=\frac{9 \cdot 961499}{473230} \\
\mathrm{~A}=180^{\circ}-(\mathrm{B}+\mathrm{C})=180^{\circ}-122^{\circ} 55^{\prime} 44^{\prime \prime}=57^{\circ} 4^{\prime} 16^{\prime \prime} \\
\mathrm{Ans.} \mathrm{A}=57^{\circ} 4^{\prime} 16^{\prime \prime} ; \mathrm{B}=47^{\circ} 32^{\prime} 30^{\prime \prime} ; \mathrm{C}=75^{\circ} 23^{\prime} 14^{\prime \prime} .
\end{gathered}
$$

Case III.-Given two sides and the contained angle; to solve the triangle. The solution depends on the following property. In any triangle, the tangent of half the difference of two angles bears the same ratio to the tangent of half the sum of the same two angles as the difference of the sides opposite the angles bears to the sum of the same sides.

This is expressed as a formula, thus-

$$
\begin{aligned}
\frac{\tan \frac{1}{2}(A-B)}{\tan \frac{1}{2}(A+B)} & =\frac{B C-A C}{B C+A C} \\
\therefore \tan \frac{A-B}{2} & =\frac{B C-A C}{B C+A C} \cdot \tan \frac{A+B}{2} \\
\frac{A+B}{2} & =90-\frac{C}{2} \\
\therefore \tan \frac{A+B}{2} & =\cot \frac{C}{2}
\end{aligned}
$$

and since-

and the formula used for the solution reduces to-

$$
\tan \frac{A-B}{2}=\frac{B C-A C}{B C+A C} \cdot \cot \frac{C}{2}
$$

Example 5.-Given $\mathrm{BC}=145 \cdot 5, \mathrm{AC}=98 \cdot 1$, and $\mathrm{C}=87^{\circ} 20^{\prime}$. Solve the triangle.

Graphical Solution.-Draw a horizontal line BC $=1.46 \mathrm{inch} ;$ at $\mathrm{C}$ make angle $=87^{\circ} 20^{\prime}$ by drawing $\mathrm{CA}=\frac{98 \cdot 1}{100}=\cdot 98$ inch long.

$$
\begin{array}{ccc}
\text { Measure } & \mathrm{A} & =58^{\circ} \\
, & \mathrm{B} & =35^{\circ} \\
, & \mathrm{AB} & =1 \cdot 71 \text { inch }=171
\end{array}
$$

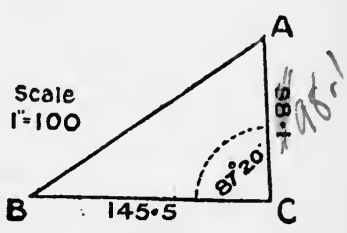

Fig, 53. 
Trigonometrical Solution.-

$$
\begin{aligned}
& \frac{\mathrm{A}+\mathrm{B}}{2}=90^{\circ}-\frac{\mathrm{C}}{2} \\
& =90^{\circ}-43^{\circ} 40^{\prime} \\
& \tan \frac{\mathrm{A}-\mathrm{B}}{2}=\frac{46^{\circ} 20^{\prime}}{\mathrm{BC}+\mathrm{AC}} \cdot \cot \frac{\mathrm{C}}{2} \\
& =\frac{145 \cdot 5-98 \cdot 1}{145 \cdot 5+98 \cdot 1} \cdot \cot 43^{\circ} 40^{\prime} \\
& =\frac{47 \cdot 4}{243 \cdot 6} \cdot \cot 43^{\circ} 40^{\prime} \\
& \mathrm{BC}-\mathrm{AC} \quad \ldots \quad \ldots \quad 47.4 \quad \log =1.675778 \\
& \frac{\mathrm{C}}{2} \quad \ldots \quad \ldots \quad \ldots 43^{\circ} 40^{\prime} \mathrm{L} \cot =\underline{10.020220} \\
& 11 \cdot 695998 \\
& \mathrm{BC}+\mathrm{AC} \quad \ldots \quad \ldots \quad 243 \cdot 6 \quad \log =2 \cdot 386677 \\
& \frac{\mathrm{A}-\mathrm{B}}{2} \ldots \quad \ldots \quad 11^{\circ} 31^{\prime} 20^{\prime \prime} \mathrm{L} \tan =\overline{9 \cdot 309321} \\
& \begin{array}{cccccc}
\mathrm{A}+\mathrm{B} & \ldots & \ldots & 46 \quad 20 \quad 0
\end{array}
\end{aligned}
$$$$
\begin{array}{rrrrrrr}
\mathrm{B} & \cdots & \cdots & 57 & 51 & 20 \\
\text { To find } & \cdots & \cdots & 34 & 48 & 40
\end{array}
$$

$$
\begin{aligned}
\frac{\mathrm{AB}}{\mathrm{AC}} & =\frac{\sin \mathrm{C}}{\sin \mathrm{B}} \\
\therefore \mathrm{AB} & =\frac{\mathrm{AC} \times \sin \mathrm{C}}{\sin \mathrm{B}}=\mathrm{AC} \times \sin \mathrm{C} \times \operatorname{cosec} \mathrm{B}
\end{aligned}
$$$$
\begin{array}{lllrr}
\mathrm{AC} & \ldots & \ldots & \ldots 98 \cdot 1 \quad \log =1 \cdot 991669 \\
\mathrm{C} & \ldots & \ldots & 87^{\circ} 20^{\prime} \mathrm{L} \sin =9 \cdot 999529 \\
\mathrm{~B} & \ldots & 34^{\circ} & 48^{\prime} 40^{\prime \prime} \mathrm{L} \operatorname{cosec}=10 \cdot 243461
\end{array}
$$$$
\mathrm{AB} \quad \ldots \quad \ldots \quad 171 \cdot 7 \quad \log =\$ 2 \cdot 234659
$$

Ans. $\mathrm{A}=57^{\circ} 51^{\prime} 20^{\prime \prime} ; \mathrm{B}=34^{\circ} 48^{\prime} 40^{\prime \prime} ; \mathrm{AB}=171 \cdot 7$.

ART. 16.--The proofs of the rules used in the two last cases are inserted here for the benefit of any student who may not have a "Trigonometry" handy.

To express the cosine of an angle in terms of the sides.-

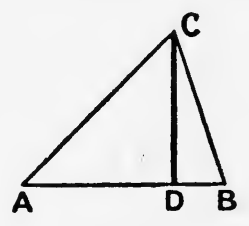

Fig. 54.

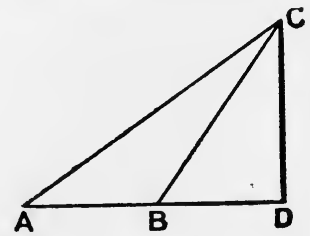

Fig. 55 .

Let $\mathrm{ABC}$ be a triangle; one figure represents $\mathrm{B}$ acute, the other $\mathrm{B}$ obtuse. Draw $\mathrm{CD}$ at right angles to $\mathrm{AB}$ or $\mathrm{AB}$ produced.

By Euclid II. 13 and 12$\mathrm{AC}^{2}=\mathrm{AB}^{2}+\mathrm{BC}^{2}-2 \mathrm{AB} \cdot \mathrm{BD}$ or $\mathrm{AC}^{2}=\mathrm{AB}^{2}+\mathrm{BC}^{2}+2 \mathrm{AB} \cdot \mathrm{BD}$ using small letters for sides and observing that- 
$\frac{\mathrm{BD}}{\mathrm{BC}}=\cos \mathrm{B}$

$\therefore \mathrm{BD}=\mathrm{BC} \cdot \cos \mathrm{B}=a \cdot \cos \mathrm{B}$

$$
\text { also } \begin{aligned}
\frac{\mathrm{BD}}{\mathrm{BC}} & =\cos \mathrm{CBD} \\
\therefore \mathrm{BD} & =\mathrm{BC} \cdot \cos \mathrm{CBD} \\
& =-a \cdot \cos \mathrm{B}
\end{aligned}
$$

Insert these values for $\mathrm{BD}$ -

$\therefore b^{2}=c^{2}+a^{2}-2 c a \cos \mathrm{B} \quad$ or $b^{2}=c^{2}+a^{2}-2 c . a \cos \mathrm{B}$

Hence-

$$
\cos \mathrm{B}=\frac{c^{2}+a^{2}-b^{2}}{2 c a}
$$

Similarly for $\cos \mathrm{A}$ and $\cos \mathrm{C}$.

$$
\text { To show that } \cos \frac{\mathrm{A}}{2}=\sqrt{\frac{s \cdot(s-a)}{b c}}
$$

Now-

$$
\begin{aligned}
\cos \mathrm{A} & =\frac{b^{2}+c^{2}-a^{2}}{2 b c} \\
1+\cos \mathrm{A} & =1+\frac{b^{2}+c^{2}-a^{2}}{2 b c} \\
& =\frac{2 b c+b^{2}+c^{2}-a^{2}}{2 b c} \\
& =\frac{(b+c)^{2}-a^{2}}{2 b c} \\
& =\frac{(b+c+a)(b+c-a)}{2 b c}
\end{aligned}
$$

Let $s=\frac{1}{2}(b+c+a)$

Hence-

$$
\text { then } s-a=\frac{1}{2}(b+c-a)
$$

$$
\begin{aligned}
& \text { or- } \\
& 1+\cos \mathrm{A}=\frac{2 s \cdot \mathscr{2}(s-a)}{2 b c} \\
& 2 \cos ^{2} \frac{\mathrm{A}}{2}=\frac{2 s(s-a)}{b c}
\end{aligned}
$$

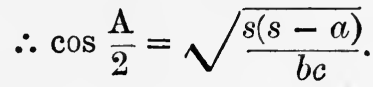

Again-

To show that $\tan \frac{\mathrm{A}-\mathrm{B}}{2}=\frac{a-b}{a+b} \cdot \tan \frac{\mathrm{A}+\mathrm{B}}{2}$.

Since- 
Divide II. by I.

$$
\begin{aligned}
\text { Hence- } \frac{\sin \mathrm{A}-\sin \mathrm{B}}{\sin \mathrm{A}+\sin \mathrm{B}} & =\frac{a-b}{a+b} \\
\frac{2 \cos \frac{\mathrm{A}+\mathrm{B}}{2} \cdot \sin \frac{\mathrm{A}-\mathrm{B}}{2}}{2 \sin \frac{\mathrm{A}+\mathrm{B}}{2} \cdot \cos \frac{\mathrm{A}-\mathrm{B}}{2}} & =\frac{a-b}{a+b} \\
\therefore \tan \frac{\mathrm{A}-\mathrm{B}}{2} & =\frac{a-b}{a+b} \cdot \tan \frac{\mathrm{A}+\mathrm{B}}{2}
\end{aligned}
$$

\section{Exercises.-Oblique-angled Plane Triangles.}

If $\mathrm{ABC}$ be any triangle, complete the solution in the following cases :-
1. $a=1056, b=359, c=1267$.
2. $a=364, b=217, c=494$.
3. $a=96, b=80, c=63$.
4. $\mathrm{A}=37^{\circ} 54^{\prime}, \mathrm{B}=74^{\circ} 25^{\prime}, a=104 \cdot 6$.
5. $\mathrm{B}=14^{\circ} 20^{\prime}, \mathrm{C}=101^{\circ} 13^{\prime}, b=296$.
6. $\mathrm{A}=97^{\circ} 34^{\prime}, \mathrm{C}=50^{\circ} 16^{\prime}, \mathrm{c}=16$.
7. $a=6954, b=4865, \mathrm{C}=39^{\circ} 40^{\prime}$.
8. $a=267, c=341, \mathrm{~B}=68^{\circ} 46^{\prime}$.
9. $b=61, c=49, \mathrm{~A}=97^{\circ} 18^{\prime}$.
10. $a=865, b=742, \mathrm{~A}=52^{\circ} 26^{\prime}$.
11. $b=469, c=348, \mathrm{C}=39^{\circ} 4^{\prime}$.
12. $a=1065, c=897, \mathrm{~A}=49^{\circ} 36^{\prime}$.
13. $a=587, b=925, \mathrm{~A}=21^{\circ} 23^{\prime}$.
14. $a=7, b=8, c=9$.
15. $a=600, b=500, c=1000$.
16. $a=50, b=60, c=70$.
17. $\mathrm{A}=18^{\circ} 20^{\prime}, \mathrm{B}=150^{\circ}, b=10,000$.
18. $\mathrm{A}=78^{\circ} 40^{\prime}, \mathrm{C}=39^{\circ} 55^{\prime}, c=135$.
19. $b=237.09, c=130.96, A=57^{\circ} 59^{\prime}$.
20. $c=2265^{\circ} 4, a=1779, \mathrm{~B}=58^{\circ} 17^{\prime}$.
21. $a=1300, b=500, \mathrm{~A}-\mathrm{B}=30^{\circ} 22^{\prime}$.
22. $a=1586 \cdot 6, b=5374 \cdot 5, \mathrm{~A}=15^{\circ} 11^{\prime}$.
23. $a=200, b=300, \mathrm{~A}=35^{\circ} 15^{\prime}$.

24. The angular elevation of a tower at a place $A$ due south of it is $45^{\circ}$, and at a place $\mathrm{B}$, due west of $\mathrm{A}$, the elevation is $30^{\circ} ; \mathrm{AB}=300 \mathrm{ft}$. Find height of tower.

25. $\mathrm{AB}$ is a line $250 \mathrm{ft}$. long, in the same horizontal plane as the foot $\mathrm{D}$ of a tower CD; the angles DAB and DBA are respectively $61^{\circ} 23^{\prime}$ and $47^{\circ} 14^{\prime}$; the angle of elevation $\mathrm{CAD}$ is $34^{\circ} 50^{\prime}$. Find height of tower.

\section{Miscelianeous Problems.}

1. The difference between the base and perpendicular of a right-angled triangle is one-fifth of their sum. Find the angles.

2. $\mathrm{P}$ and $\mathrm{Q}$ are two stations 1000 yards apart on a straight stretch of seashore which bears east and west. At $P$ a rock bears $S_{.} 42^{\circ}$ W., at $Q$ it bears S. $35^{\circ} \mathrm{E}$. Find distance of rock from shore.

3. A person on a ship, which is sailing on a straight course observes two lighthouses, one of which, $\mathrm{L}$, is due north of the other, $M$. When $M$ is due 
east, $\mathrm{L}$ bears $45^{\circ}$ to the east of north, and when $\mathrm{L}$ is due east, $\mathrm{M}$ bears $60^{\circ}$ to the east of south. Find direction of ship's course.

4. $A B$ is a vertical pole 50 feet high, $A$ being above $B ; B C$ is inclined upward at an angle of $20^{\circ}$ to the horizontal line, $\mathrm{BD}$, so that $\mathrm{ABC}$ is an angle of $70^{\circ}$; the shadow of $\mathrm{AB}$ on $\mathrm{BC}$ is 50 feet long. If the shadow fell on $\mathrm{BD}$, what would be its length?

5. From the top of a vertical cliff $100 \mathrm{ft}$. high, forming one bank of a river, the angles of depression of the top and bottom of a vertical cliff, which forms the opposite bank of the river, are $28^{\circ} 40^{\prime}$ and $64^{\circ} 30^{\prime}$ respectively. Find height of opposite cliff and width of river.

6. The summit of a spire is vertically over the middle point of a horizontal square enclosure, side $=1000 \mathrm{ft}$. When the shadow of the spire just reaches a corner of the square the altitude of the sun is $27^{\circ} 29^{\prime} 50^{\prime \prime}$. Find height of spire.

7. A tower near the coast is 197 feet high. From a rock the angle of elevation of the top of the tower is $8^{\circ} 15^{\prime}$. A ship steams so as to clear the rock by 1.5 cables. What is the angle of elevation of tower from ship ?

8. At two boats $600 \mathrm{yds}$. apart, the angles of elevation of a hydroplane flying directly between the boats are observed to be $57^{\circ}$ and $65^{\circ} 30^{\prime}$. Find the height of the hydroplane.

9. Two ships, $A$ and $B$, leave harbour together. A sails S. $12^{\circ} \mathrm{W}$. at a rate of 10.5 knots, and B S. $67^{\circ} \mathrm{E}$. at 8 knots. How far apart will they be in $2 \frac{1}{2}$ hours, and what will be the bearing of $A$ from $B$ ?

10. From a ship the bearings of two objects, $A$ and $B$, are N. $30^{\circ}$ E., and N. $20^{\circ} \mathrm{W}$. After the ship has sailed 5 miles due N., the bearings are N. $60^{\circ}$ E. and N. $40^{\circ} \mathrm{W}$. Find distance and bearing of A from B.

11. The foot, Q, of a tower and two stations, $A$ and $B$, are in the same horizontal plane. The angular elevation of the tower at $\mathrm{A}$ is $60^{\circ}$, and at $B$ is $45^{\circ}$, the distance from $A$ to $B$ is 100 feet, and the angle AQB is $60^{\circ}$. Find height of tower.

12. From $P$ the bearing and distance of $A$ is NE. 5 miles, and of $B$, $\mathrm{S} .70^{\circ} \mathrm{E}$. From $\mathrm{Q}$, due east of $\mathrm{P}$, the bearing of $\mathrm{A}$ is $\mathrm{N} .25^{\circ} \mathrm{E}$. If $\mathrm{B}$ is due south of $A$, what is the bearing of $B$ from $Q$ ?

13. The hypotenuse of a right-angled triangle is 1000 feet long, and the difference between the other two sides is 240 feet : calculate the other sides and angles.

14. The height of a tower is 67.375 yds. At $P$, which is $5.35 \mathrm{yds}$. above the level of its base, the angle subtenuled by the tower is $74^{\circ} 40^{\prime}$. Find the angle of elevation of the top of the tower as seen from $\mathrm{P}$, and horizontal distance of $\mathbf{P}$ from tower. 


\section{CHAPTER V. \\ SOLUTION OF SPHERICAL TRIANGLES.}

ART. 17.-A spherical triangle is a portion of the surface of a sphere bounded by arcs of three great circles, and, like a plane triangle, has three sides and three angles. The sides, being arcs of circles, are measured like angles, in degrees, minutes, and seconds $\left({ }^{\circ} \prime \prime \prime\right)$.

When one of the angles is $90^{\circ}$, the triangle is right-angled; when one side is $90^{\circ}$, it is quadrantal; and when no side or angle is $90^{\circ}$, it is an oblique-angled triangle.

Unlike a plane triangle, a spherical triangle may have two or three right angles, or one, two, or three sides of $90^{\circ}$, but no angle or side can be as much as $180^{\circ}$.

The sum of any two sides is greater than the third side.

The sum of the three angles of a spherical triangle is always more than $180^{\circ}$, but less than $540^{\circ}$, and the sum of the three sides is less than $360^{\circ}$.

The greater angle is opposite to the greater side, as in plane triangles.

The angles at the base of an isosceles triangle are equal, as in plane triangles.

ART. 18. Solution of Right-angled Spherical Triangles.-Here one of the given parts is the right angle; any other two parts being given, the triangle can be solved. In order to simplify the solution, instead of using the five remaining parts of the triangle, Napier devised rules which refer only to his "Circular Parts."

Napier's Circular Parts.-These are five in number, and are the two sides which contain the right angle, the complement of

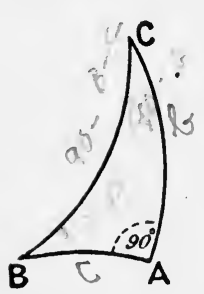

Fig. 56. the hypotenuse, and the complements of the two angles. Thus in triangle $\mathrm{ABC}$, right-angled at $A$, the circular parts are-

$$
\mathrm{AB} ; \mathrm{AC} ; \text { Co. C ; Co. BC; Co. B }
$$

These are split into three groups, consisting of-

1 middle,

2 adjacents,

2 opposites.

Any part may be taken as middle. 
Thus-

\begin{tabular}{l|l|l}
\hline \multicolumn{1}{|c|}{ Middle. } & \multicolumn{1}{|c|}{ Adjacents. } & \multicolumn{1}{|c}{ Opposites. } \\
\hline AC & AB; co. C & Co. B; co. BC \\
Co. C & AC; co. BC & Co. B; AB \\
Co. BC & Co. B; co. C & AB ; AC \\
\hline
\end{tabular}

\section{Napier's Rules.-}

I. Sine mid part $=$ tangents of adjacents multiplied.

II. Sine mid part $=$ cosines of opposites multiplied.

Each of these rules connects three parts. When used it must be arranged that two are given parts; also that the given parts are the only ones used to find the others. To do this, always start by considering whether the given parts are adjacents or opposites; then take as middle each given part in succession, and use the Rule which will connect the given parts.

Hence

$$
\begin{aligned}
\sin A C & =\tan A B \cdot \tan c o . C \\
& =\tan A B \cdot \cot C
\end{aligned}
$$

and $\sin \mathrm{AC}=\cos \mathrm{co} . \mathrm{B} . \cos \operatorname{co} . \mathrm{BC}$

$$
=\sin \mathrm{B} \cdot \sin \mathrm{BC}
$$

Again $\quad \sin c o . B C=\tan c o . B . \tan c o . C$

or $\cos \mathrm{BC}=\cot \mathrm{B} \cdot \cot \mathrm{C}$

and $\sin \cos \mathrm{BC}=\cos \mathrm{AB} \cdot \cos \mathrm{AC}$

or $\cos B C=\cos A B \cdot \cos A C$

ART 19.-Hints on construction of Spherical Triangles.

Draw a circle as a primitive, with radius of sphere, we shall use one inch; but the larger the radius the better the result will be; with the Gunter rule it would be two inches.

Let $\mathrm{C}$ be the centre, then any diameter drawn will represent a great circle at right angles to the primitive : thus ACB (Fig. 57) is a right circle.

Draw DCE at right angles to $\mathrm{AB}$. Then $\mathrm{D}$ and $\mathrm{E}$ are the Poles of ACB. The centres of all oblique circles through $\mathrm{A}$ and $\mathrm{B}$ lie on the line DCE. Thus with any centre $\mathrm{F}$ and radius FA describe an arc of a circle, then AGB is an oblique circle. To find its

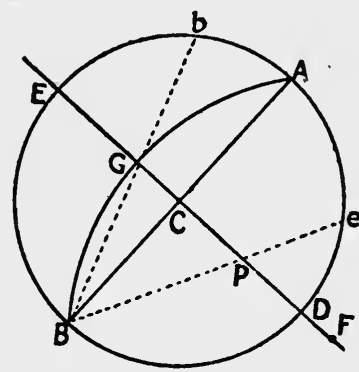

FIG. 57. pole, join $\mathrm{BG}$ and produce to $b$, make be equal to $\mathrm{EA}\left(90^{\circ}\right)$, join $e \mathrm{~B}$ cutting $\mathrm{DE}$ in $\mathrm{P}$ : then $\mathrm{P}$ is the pole of $\mathrm{AGB}$.

N.B.-Great circles at right angles to AGB must pass through its pole $\mathrm{P}$.

Hence great circles can be drawn through a point on or within the primitive, or through two points, one on, the other 
inside the primitive. Thus in Fig. 58 let $\mathrm{A}$ and $\mathrm{B}$ be two points, $A$ on, and $B$ inside. Draw diameter $A C D$, and a line through $\mathrm{C}$, as $\mathrm{CO}$, at right angles. Join $\mathrm{AB}$, and bisect it by a line cutting $\mathrm{CO}$ in $\mathrm{X}$. Then $\mathrm{X}$ is centre of great circle through $\mathrm{A}$ and $\mathrm{B}$.

If an oblique circle is to be drawn through any two points inside the primitive as through $\mathrm{A}$ and $\mathrm{B}$, Fig. 59, proceed
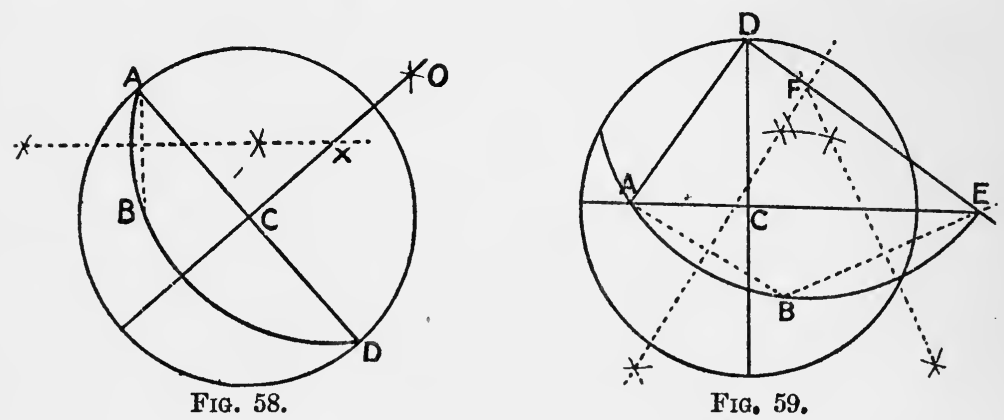

thus-Draw diameter $\mathrm{AC}$, and $\mathrm{CD}$ through $\mathrm{C}$ at right angles to $\mathrm{AC}$. Join $\mathrm{AD}$, make $\mathrm{ADE}$ a right angle, cutting $\mathrm{AC}$ in $\mathrm{E}$ : join $\mathrm{AB}, \mathrm{BE}$, bisect these by lines at right angles intersecting in $\mathrm{F}$. $\mathrm{F}$ will be the centre for describing oblique circle required.

To draw a great circle at right angles to a given oblique circle through a given point, first find the pole of the given oblique circle; then by the preceding examples draw a great circle through the given point and this pole; this will be at right angles to the given oblique circle, the given point may be either on the primitive, or on the oblique circle.

A great circle is drawn making a given angle with the primitive (say $35^{\circ}$ ) through a given point as follows :-

From centre with radius $=\tan 35^{\circ}$ describe a small arc, and with given point as centre and radius $=\sec 35^{\circ}$ : draw another arc, this intersects the first arc at the centre from which the great circle is to be drawn with sec $35^{\circ}$ as radius.

N.B.-With a radius of one inch, the $\tan$ and sec of any angle may be obtained from the traverse table thus-Take angle (say $35^{\circ}$ ) as course and radius (1.00) in lat. col., then sec (1.22) is found in dist. col. and $\tan (0 \cdot 7)$ in dep. col., the semi-tangent $=$ tangent of half the angle $=0.31$. In Fig. $60, \mathrm{~A}$ is given point, and $o$ is centre of required great circle.

If $o \mathrm{C}$ be drawn as a diameter, the arc $a b$ measures the angle: $\mathrm{C} a=0.52$; in traverse table find 1 in lat. 0.52 in dep.; angle $=27 \frac{1}{2}^{\circ}$, hence $\mathrm{C} a$ on scale of semi-tangents $=55^{\circ}$, or $a b=35^{\circ}$.

A small circle parallel to the primitive and at any distance from it is drawn from the centre of primitive, with radius = semi-tangent of complement of required distance. 
A small circle through any point parallel to a right circle at a given distance is drawn thus: let $\mathrm{A}$ be given point, and $35^{\circ}$ given distance; then with sec $\left(\mathrm{Co} .35^{\circ}\right)$, that is sec $55^{\circ}$, as radius sweep an arc from centre $C$, where this arc intersects an arc drawn from $A$ as centre and $\tan 55^{\circ}$ as radius is the centre for describing the small circle (Fig. 61).

On scale-

$\operatorname{Sec} 55^{\circ}=1 \cdot 74^{\prime \prime}$

$\operatorname{Tan} 55^{\circ}=1 \cdot 43^{\prime \prime}$.

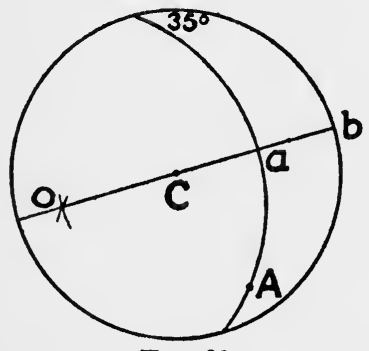

Fig. 60.

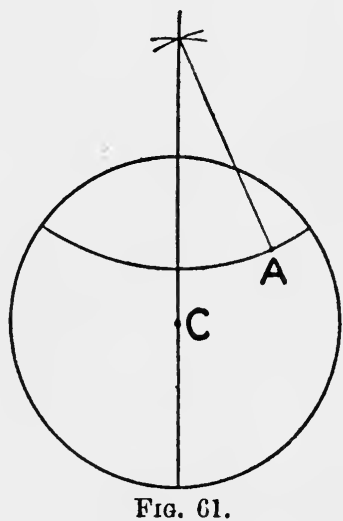

To measure any arc of an oblique circle, say arc $\mathrm{AB}$ (Fig. 62).

Find pole $\mathrm{P}$ of oblique circle, join $\mathrm{PA}, \mathrm{PB}$, and produce to meet primitive in $a$ and $b$, then $a b$ measured on the scale of chords is the length of $\mathrm{AB}$.

Similarly, to measure an angle at the intersection of two great circles, first find their poles, join the point of intersection of the

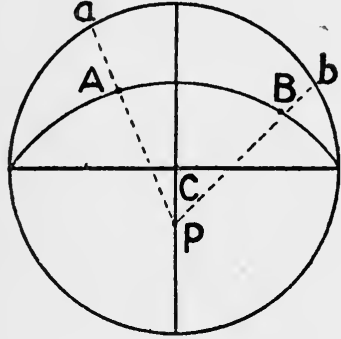

Fig. 62.

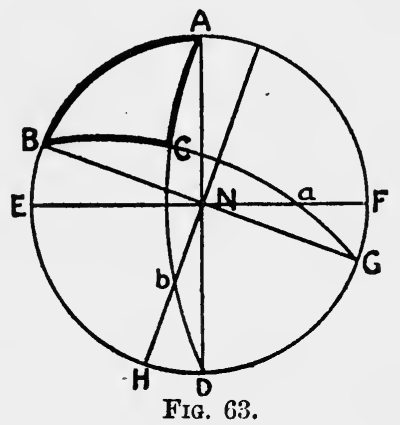

FIG. 63.

circles by lines passing through the poles, and produced to cut the primitive. The measure of this arc of the primitive on the scale of chords is the measure of the angle.

Example 1.-Given $\mathrm{A}=64^{\circ} 30^{\prime}, \mathrm{B}=56^{\circ} 26^{\prime}, \mathrm{C}=90^{\circ}$. Solve.

Construction (Fig. 63). - Draw primitive, AD and EF, diameters at right angles. At $\mathrm{A}$ make angle of $64^{\circ} 30^{\prime}$ with primitive, centre of circle is on EF produced, radius $=\sec 64^{\circ} 30^{\prime}=2 \cdot 32$. Find pole $a$ of circle ACD. Then 
with $\mathrm{N}$ as centre and radius $=$ semi-tangent of angle $\mathrm{B} 56^{\circ} 25^{\prime}=0.53$ describe an arc cutting ACD in $b$, this point is pole of circle required. Draw diameter $b \mathrm{~N}$ and $\mathrm{BG}$ at right angles. Since $\mathrm{C}$ is to be a right angle, the circle drawn through $\mathrm{B} a \mathrm{G}$ is one required ; this cuts $\mathrm{ACD}$ at $\mathrm{C}$. $\mathrm{ABC}$ is triangle.

$\mathrm{By}$ measurement $\mathrm{AB}=71^{\circ}$

$$
\begin{aligned}
& \mathrm{BC}=60^{\circ} \\
& \mathrm{AC}=51^{\circ}
\end{aligned}
$$

Calculation.-Here the given parts are opposites. We therefore use co. A with its opposites, and then co. B with its opposites. Finally, to find AB, we use adjacents.

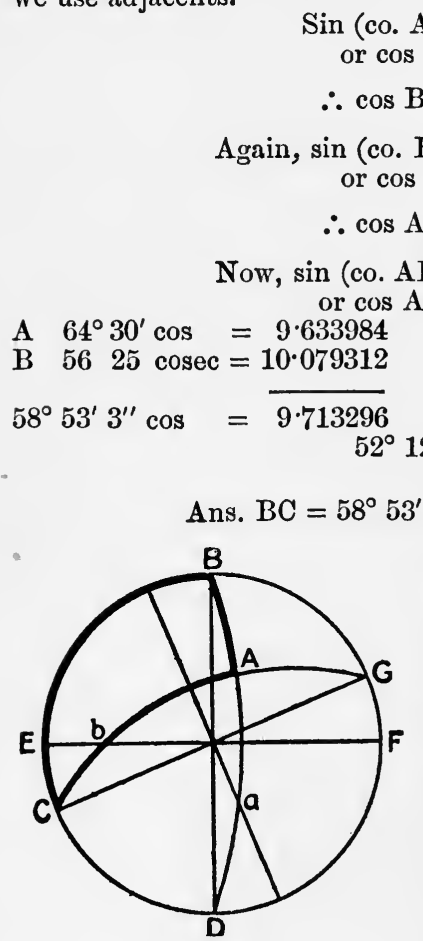

Fig. 64.

$$
52^{\circ} 12^{\prime} 15^{\prime \prime} \cos =\overline{9 \cdot 787354}
$$

$$
71^{\circ} 32^{\prime} 11^{\prime \prime} \cos =\overline{9 \cdot 500650}
$$

. . III. $\cot =9 \cdot 678496$ $\cot =9 \cdot 822154$

Example 2.-Given $\mathrm{A}=90^{\circ}, \mathrm{B}=117^{\circ}$ $20^{\prime}, \mathrm{BC}=113^{\circ} 40^{\prime}$. Solve.

Construction (Fig. 64). -Draw primitive, diameters $\mathrm{BD}$ and $\mathrm{EF}$ at right angles. At $\mathrm{B}$ make an angle $117^{\circ} 20^{\prime}$ with primitive ; sec $=2 \cdot 21$ as radius, draw circle $\mathrm{BAD}$, find its pole $b$. Make $\mathrm{BC}=113^{\circ} 40^{\prime}$, through $\mathrm{C}$ draw diameter $\mathrm{CG}$ and through $\mathrm{CbG}$ describe a circle cutting $\mathrm{BAD}$ in $\mathrm{A}$. Then $\mathrm{ABC}$ is triangle. Pole of $\mathrm{C} b \mathrm{G}$ is at $a$.

By measurement

radius for $\mathrm{C} b \mathrm{G}=1.63=$ sec. $52^{\circ} \mathrm{C}=52^{\circ}$

$$
\begin{aligned}
& \mathrm{AB}=45^{\circ} \\
& \mathrm{AC}=127^{\circ}
\end{aligned}
$$

Calculation.-Here the given parts are adjacents. We therefore use co. B with its adjacents ; then co. BC with its adjacents. Lastly, to find AC, we use opposites.

$\operatorname{Sin}(\cos B)=\tan A B \cdot \tan (\cos B C)$

or $\cos B=\tan A B \cdot \cot B C$

$\therefore \tan ^{+} \mathrm{AB}=\frac{\cos \mathrm{B}}{\cot \mathrm{BC}}=\cos ^{-} \mathrm{B} \cdot \tan ^{-} \mathrm{BC}$

Again, $\sin (\cos B C)=\tan (\cos B) \cdot \tan (\cos C)$

or $\cos \mathrm{BC}=\cot \mathrm{B} \cdot \cot \mathrm{C}$

$$
\therefore \cot ^{+} \mathrm{C}=\frac{\cos \mathrm{BC}}{\cot \mathrm{B}}=\cos ^{-} \mathrm{BC} \cdot \tan ^{-} \mathrm{B} \text {. }
$$

And $\sin ^{+} \mathrm{AC}=\cos (\cos \mathrm{B}) \cdot \cos (\operatorname{co} . \mathrm{BC})$

$$
=\sin ^{+} \mathrm{B} \cdot \sin ^{+} \mathrm{BC} \text {. }
$$




$$
\begin{aligned}
& B=117^{\circ} 20^{\prime} \quad \cos =9.661970 \quad \tan =10.286614 \quad \sin =9 \cdot 948584 \\
& \mathrm{BC}=11340 \quad \tan =10.358253 \\
& \cos =9 \cdot 603594 \\
& \sin =9 \cdot 961846 \\
& 46^{\circ} 20^{\prime} 1^{\prime \prime} \tan =10 \cdot 020223 \\
& 52^{\circ} 9^{\prime} 59^{\prime \prime} \cot =\overline{9 \cdot 890208} \\
& 54^{\circ} 27^{\prime} 10^{\prime \prime} \sin =\overline{9 \cdot 910430}
\end{aligned}
$$

In the case of $\mathrm{AB}$ and $\mathrm{C}$, notice that they are marked + , so these angles are in the first quadrant, and the values are those obtained direct from the tables; in the case of $\mathrm{AC}$, which is marked +, the value might be the tabular value or its supplement. As angle B opposite to it exceeds $90^{\circ}$, use the supplement.

$$
\text { Ans. } \mathrm{AB}=46^{\circ} 20^{\prime} 1^{\prime \prime} ; \mathrm{C}=52^{\circ} 9^{\prime} 59^{\prime \prime} ; \mathrm{AC}=125^{\circ} 32^{\prime} 50^{\prime \prime} \text {. }
$$

ART 20.-In solving these triangles, observe-

1. Angles and opposite sides are of the same affection, that is, are both over, or both under, $90^{\circ}$.

2. The hypotenuse is under $90^{\circ}$ when the angles or sides are of the same affection.

The hypotenuse is over $90^{\circ}$ when the angles or sides are of contrary affection.

3. When an angle and opposite side are given, the triangle admits of two solutions; this is called the Ambiguous case, and may be understood from the following figure. Let $\mathrm{AOB}$ and $\mathrm{AMB}$ be two arcs of great circles intersecting at $A$ and $B$. The angles at $A$ and $B$ are equal, and each arc is a semi-circle. Now let OM, another great circle arc, he drawn at right angles to AMB. Thus we have two right-angled triangles $\mathrm{AOM}$ and $\mathrm{BOM}$, in which angle $\mathrm{A}$ and

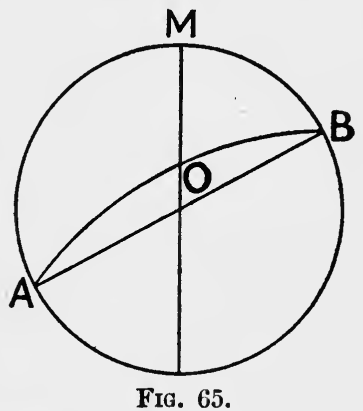
arc $\mathrm{OM}$ are equal to angle $\mathrm{B}$ and arc $\mathrm{OM}$. Hence with angle $=\mathrm{A}$ and $\operatorname{arc}=\mathrm{OM}$ given, there is nothing to indicate which of the triangles AOM or BOM is the required one.

\section{Exercises.-Right-aygled Spherical Triangles.}

Solve the following triangles :-
1. $\mathrm{C}=90^{\circ}, \mathrm{AC}=65^{\circ} 12^{\prime}, \mathrm{BC}=51^{\circ} 36^{\prime}$.
2. $\mathrm{A}=78^{\circ} 11^{\prime}, \mathrm{B}=39^{\circ} 49^{\prime}, \mathrm{C}=90^{\circ}$.
3. $\mathrm{AB}=84^{\circ} 13^{\prime}, \mathrm{BC}=61^{\circ} 44, \mathrm{C}=90^{\circ}$.
4. $\mathrm{AB}=79^{\circ} 27^{\prime}, \mathrm{A}=51^{\circ} 30^{\prime}, \mathrm{C}=90^{\circ}$.
5. $\mathrm{BC}=32^{\circ} 51^{\prime}, \mathrm{B}=56^{\circ} 17^{\prime}, \mathrm{C}=90^{\circ}$.
6. $\mathrm{BC}=54^{\circ} 37^{\prime}, \mathrm{A}=67^{\circ} 53^{\prime}, \mathrm{C}=90^{\circ}$.
7. $\mathrm{B}=90^{\circ}, \mathrm{AB}=70^{\circ} 29^{\prime}, \mathrm{BC}=102^{\circ} 38^{\prime}$.
8. $\mathrm{B}=90^{\circ}, \mathrm{AB}=110^{\circ} 17^{\prime}, \mathrm{BC}=98^{\circ} 46^{\prime}$.
9. $\mathrm{B}=90^{\circ}, \mathrm{C}=114^{\circ} 51^{\prime}, \mathrm{A}=67^{\circ} 32^{\prime}$.
10. $\mathrm{B}=90^{\circ}, \mathrm{C}=92^{\circ} 31^{\prime}, \mathrm{A}=118^{\circ} 44^{\prime}$.
11. $\mathrm{B}=90^{\circ}, \mathrm{AC}=107^{\circ} 19^{\prime}, \mathrm{AB}=69^{\circ} 8^{\prime}$.
12. $\mathrm{B}=90^{\circ}, \mathrm{AC}=88^{\circ} 36^{\prime}, \mathrm{BC}=101^{\circ} 25^{\prime}$.
13. $\mathrm{A}=90^{\circ}, \mathrm{AB}=97^{\circ} 20^{\prime}, \mathrm{BC}=94^{\circ} 13^{\prime}$.
14. $\mathrm{A}=90^{\circ}, \mathrm{BC}=113^{\circ} 10^{\prime}, \mathrm{C}=74^{\circ} 32^{\prime}$. 
15. $\mathrm{A}=90^{\circ}, \mathrm{BC}=83^{\circ} 12^{\prime}, \mathrm{C}=98^{\circ} 15^{\prime}$.

16. $\mathrm{A}=90^{\circ}, \mathrm{AB}=95^{\circ} 52^{\prime}, \mathrm{B}=76^{\circ} 13^{\prime}$.

17. $\mathrm{A}=90^{\circ}, \mathrm{AC}=106^{\circ} 27^{\prime}, \mathrm{C}=94^{\circ} 8^{\prime}$.

18. $\mathrm{A}=90^{\circ}, \mathrm{AB}=114^{\circ} 22^{\prime}, \mathrm{C}=108^{\circ} 19^{\prime}$.

ART. 21. Solution of Oblique-angled Spherical Triangles.-The object of this section is to give the student an insight into the solution of those triangles which refer particularly to the ordinary problems of Nautical Astronomy. Two cases only will be considered.

CASE I.-Given the three sides, to find the angles.

If $\mathrm{ABC}$ be a triangle, where the sides $\mathrm{AB}, \mathrm{AC}$, and $\mathrm{BC}$ are known.

$$
\text { Let } s=\frac{1}{2}(\mathrm{AB}+\mathrm{AC}+\mathrm{BC}) \text {. }
$$

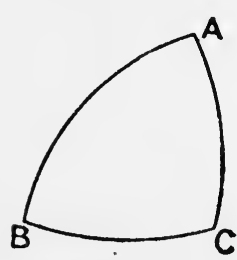

Fig. 66.

The formulæ used are-

$$
\begin{aligned}
& \cos \frac{\mathrm{A}}{2}=\sqrt{\frac{\sin s \cdot \sin (s-\mathrm{CB})}{\sin \mathrm{AB} \cdot \sin \mathrm{AC}}} \\
& \cos \frac{\mathrm{B}}{2}=\sqrt{\frac{\sin s \cdot \sin (s-\mathrm{AC})}{\sin \mathrm{AB} \cdot \sin \mathrm{BC}}} \\
& \cos \frac{\mathrm{C}}{2}=\sqrt{\frac{\sin s \cdot \sin (s-\mathrm{AB})}{\sin \mathrm{AC} \cdot \sin \mathrm{BC}}}
\end{aligned}
$$

Example 1.-In $\mathrm{PQR}$, given $\mathrm{PQ}=84^{\circ} 30^{\prime}, \mathrm{QR}=108^{\circ} 44^{\prime}, \mathrm{PR}=72^{\circ} 20^{\prime}$. Find the angles.

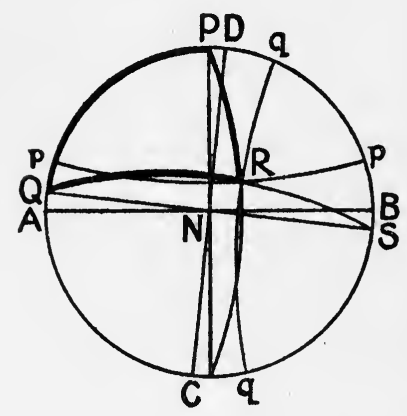

FIG. 67.

Construction (Fig. 67).-Draw primitive, lay off $\mathrm{PQ}=84^{\circ} 30^{\prime}$. Through $\mathrm{P}$ draw diameter, and another $\mathrm{AB}$ at right angles. Around $\mathbf{P}$ as pole describe small circle $p \mathrm{R} p$ distant $72^{\circ} 20^{\prime}$ from it or $17^{\circ} 40^{\prime}$ from $\mathrm{AB}$ : the centre for this small circle is on NP produced at distance sec $72^{\circ} 20^{\prime}=3 \cdot 24^{\prime \prime}$ from $\mathrm{N}$, radius $=\tan 72^{\circ} 20^{\prime}=3.08^{\prime \prime}$. Through $Q$ draw diameter, and another CD at right angles. Around $\mathrm{S}$ as pole describe small circle $q \mathbf{R} q$ distant supplement $108^{\circ} 44^{\prime}$ or $71^{\circ} 16^{\prime}$ from it or $18^{\circ} 44^{\prime}$ from CD : the centre for this small circle is on NS produced at distance sec $71^{\circ} 16^{\prime}$ from $\mathrm{N}$ $=3^{\circ} 07^{\prime \prime}$, and radius is $\tan 71^{\circ} 16^{\prime}=2 \cdot 9^{\prime \prime}$. Where these two small circles intersect is $R$. Through PR and QR draw oblique circles.

$\mathrm{PQR}$ is triangle required.

By measurement $\mathrm{QPR}=112^{\circ}$ semi-tangent $=0.19$ or $22^{\circ}$. $\mathrm{PQR}=70^{\circ}$ semi-tangent $=0.18$ or $20^{\circ}$.

$$
\begin{aligned}
& \begin{array}{ll}
, \prime & \mathrm{PQR}=78^{\circ} \\
, & \mathrm{PRQ}=78^{\circ} .
\end{array} \\
& \cos \frac{\mathrm{P}}{2}=\sqrt{\frac{\sin s \cdot \sin (s-\mathrm{QR})}{\sin \mathrm{PQ} \cdot \sin \mathrm{PR}}} \\
& \cos \frac{\mathrm{Q}}{2}=\sqrt{\frac{\sin s \cdot \sin (s-\mathrm{PR})}{\sin \mathrm{PQ} \cdot \sin \mathrm{QR}}} \\
& \cos \frac{\mathrm{R}}{2}=\sqrt{\frac{\sin s \cdot \sin (s-\mathrm{PQ})}{\sin \mathrm{PR} \cdot \sin \mathrm{QR}}}
\end{aligned}
$$


To make all the logs added, "sines" in denominators are changed to their reciprocals "cosecs."

${ }^{\circ} \mathrm{QR}=108^{\circ} 44^{\prime} \quad \ldots \quad \ldots \quad \ldots \quad \operatorname{cosec}=10.023639 \quad \operatorname{cosec}=10.023639$

$\mathrm{PQ}=8430$ cosec $=10.002004 \quad \operatorname{cosec}=10.002004$

$\mathrm{PR}=72 \quad 20 \operatorname{cosec}=10.020981 \quad \ldots \quad \ldots \quad \ldots \quad \operatorname{cosec}=10.020981$

2)265 34

$s=13247 \sin =9.865653$ sin $=9.865653 \sin =9.865653$

$s-\mathrm{QR}=24 \quad 3$ sin $=9.610164$

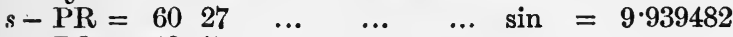

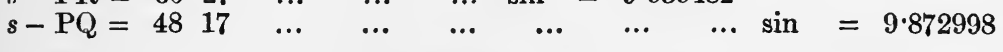

2) $19 \cdot 498802$

$$
\begin{aligned}
& \text { 2)19.830778 }
\end{aligned}
$$

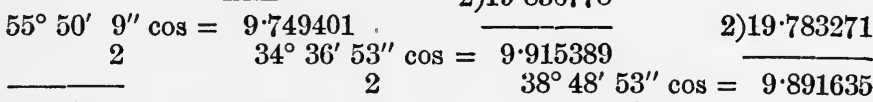

$$
\begin{aligned}
& \mathrm{P}=1114018 \quad \mathrm{Q}=\overline{69} \overline{1346} \quad \mathrm{R}=\overline{773746}
\end{aligned}
$$

Ans. $\mathrm{P}=111^{\circ} 40^{\prime} 18^{\prime \prime} ; \mathrm{Q}=69^{\circ} 13^{\prime} 46^{\prime \prime} ; \mathrm{R}=77^{\circ} 37^{\prime} 46^{\prime \prime}$.

CASE II.-Given two sides and the contained angle. In the above triangle $\mathrm{ABC}$, let $\mathrm{AB}, \mathrm{BC}$ be known and angle $\mathrm{B}$; suppose $A B$ greater than $B C$. The solution depends on Napier's Analogies.

$$
\begin{aligned}
& \tan \frac{1}{2}(C+A)=\frac{\cos \frac{1}{2}(A B-B C)}{\cos \frac{1}{2}(A B+B C)} \cdot \cot \frac{B}{2} \\
& \tan \frac{1}{2}(C-A)=\frac{\sin \frac{1}{2}(A B-B C)}{\sin \frac{1}{2}(A B+B C)} \cdot \cot \frac{B}{2}
\end{aligned}
$$

- These by addition and subtraction determine $\mathrm{C}$ and $\mathrm{A}$; the third side is obtained from Gauss' theorem.

$$
\cos \frac{\mathrm{AC}}{2}=\frac{\cos \frac{1}{2}(\mathrm{AB}+\mathrm{BC})}{\cos \frac{1}{2}(\mathrm{C}+\mathrm{A})} \cdot \sin \frac{\mathrm{B}}{2}
$$

Note that the reciprocals of the ratios in the denominators are used to make the logs added, and that the half sum of angles is of the same affection as the half sum of sides.

Example 2.-In $\mathrm{XYZ}$, given $\mathrm{XY}=88^{\circ}$ $20^{\prime}, \mathrm{YZ}=60^{\circ} 50^{\prime}$, angle $\mathrm{Y}=75^{\circ} 30^{\prime}$. Solve.

Construction.-Draw primitive, measure on it $\mathrm{YX}=88^{\circ} 20^{\prime}$. Draw the diameter through $\mathrm{Y}$ : and $\mathrm{AB}$ at right angles to it. At $\mathrm{Y}$ make angle with primitive $=75^{\circ} 30^{\prime}$ by drawing oblique circle YZ. Around $\mathrm{Y}$ as pole, draw a small circle $a \mathrm{Z} a$ distant $60^{\circ} 50^{\prime}$ from it at distance $\mathrm{sec}=2 \cdot 06^{\prime \prime}$, and radius $\tan =1 \cdot 8^{\prime \prime}$ : this cuts the oblique circle in $\mathrm{Z}$.

$\mathrm{XYZ}$ is triangle required.

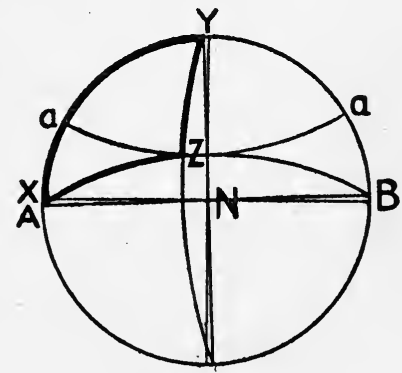

FIG. 68. 
By measurement

,

,

,

angle $\mathrm{X}=60^{\circ}$

semi-tangent $=0.26$ or $30^{\circ}$

angle $\mathrm{Z}=96^{\circ}$

$\mathrm{XZ}=77^{\circ}$

Calculation.-

$$
\begin{aligned}
\tan \frac{1}{2}(Z+X) & =\frac{\cos \frac{1}{2}(X Y-Y Z)}{\cos \frac{1}{2}(X Y+Y Z)} \cdot \cot \frac{Y}{2} \\
\tan \frac{1}{2}(Z-X) & =\frac{\sin \frac{1}{2}(X Y-Y Z)}{\sin \frac{1}{2}(X Y+Y Z)} \cdot \cot \frac{Y}{2} \\
\cos \frac{Z X}{2} & =\frac{\cos \frac{1}{2}(X Y+Y Z)}{\cos \frac{1}{2}(Z+X)} \cdot \sin \frac{Y}{2}
\end{aligned}
$$

$$
\begin{aligned}
& \mathrm{XY}=88^{\circ} 20^{\prime} \\
& \mathrm{YZ}=6050
\end{aligned}
$$

$\mathrm{XY}+\mathrm{YZ}=14910$

$\mathrm{XY}-\mathrm{YZ}=2730$

$\frac{1}{2}(X Y+Y Z)=7435$ sec $=10.575385 \operatorname{cosec}=10.015915 \cos =9.424615$

$\frac{1}{2}(X Y-Y Z)=1345 \cos =9.987372 \quad$ sin $=9.376003$

$$
\frac{\mathrm{Y}}{2}=3745 \cot =\underline{10 \cdot 111100} \quad \cot =10 \cdot 111100 \sin =9 \cdot 786906
$$

$\frac{1}{2}(Z+X)=78^{\circ} 2^{\prime} 8^{\prime \prime} \tan =\overline{10 \cdot 673857}$

$\frac{1}{2}(Z-X)$

$$
\begin{aligned}
& \mathrm{Z}=\overline{954156} \\
& \mathrm{X}=602220
\end{aligned}
$$$$
\tan =\overline{9 \cdot 503018}
$$$$
\text { sec }=10 \cdot 683391
$$

$$
\begin{gathered}
38^{\circ} 16^{\prime} 20^{\prime \prime} \cos =\overline{9 \cdot 894912} \\
\hline
\end{gathered}
$$

$76 \quad 3240$

Ans. $\mathrm{X}=60^{\circ} 22^{\prime} 20^{\prime \prime} ; \mathrm{Z}=95^{\circ} 41^{\prime} 56^{\prime \prime} ; \mathrm{XZ}=76^{\circ} 32^{\prime} 40^{\prime \prime}$.

ART. 22.-To express the cosine of an angle of a spherical triangle in terms of the sines and cosines of the sides.

Let $O$ be the centre of the sphere, and PQR a spherical triangle. Let tangent at $\mathrm{P}$ to arc $\mathrm{PR}$ meet OR produced in $\mathrm{T}$; and let tangent at $P$ to arc $P Q$ meet $O Q$ produced in S. Join ST. Thus angle TPS is angle $\mathrm{P}$ of spherical triangle, and TOS measures the side RQ; SOP the side $P Q$; and TOP the side PR.

In triangle SPT-

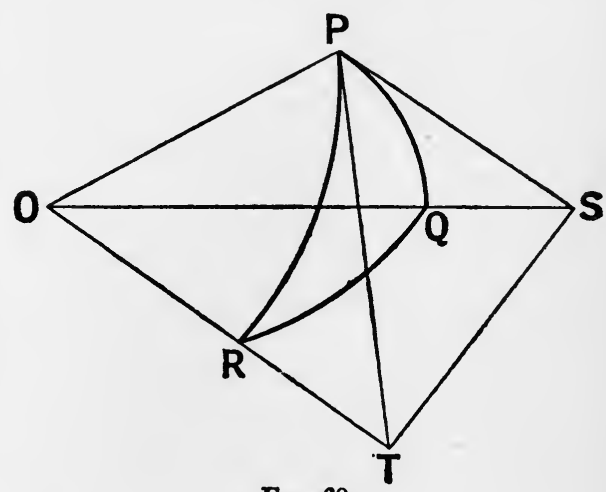

Fig. 69.

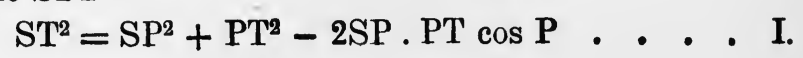


Again, in triangle TOS-

$$
\begin{aligned}
\mathrm{ST}^{2} & =\mathrm{SO}^{2}+\mathrm{OT}^{2}-2 \mathrm{SO} . \mathrm{OT} \cos \mathrm{SOT} \\
& =\mathrm{SP}^{2}+\mathrm{PO}^{2}+\mathrm{PT}^{2}+\mathrm{PO}^{2}-2 \mathrm{SO} . \mathrm{OT} \cdot \cos \mathrm{RQ}
\end{aligned}
$$

since OPS and OPT are right angles-

Subtract I. from II.

$$
=2 \mathrm{PO}^{2}+\mathrm{SP}^{2}+\mathrm{PT}^{2}-2 \mathrm{SO} . \mathrm{OT} \cos \mathrm{RQ} \text { II. }
$$

$$
\therefore 0=2 \mathrm{PO}^{2}+2 \mathrm{SP} \text {. PT } \cos \mathrm{P}-2 \mathrm{SO} . \mathrm{OT} \cos \mathrm{RQ}
$$

Hence $\cos \mathrm{RQ}=\frac{\mathrm{PO}}{\mathrm{OT}} \cdot \frac{\mathrm{PO}}{\mathrm{SO}}+\frac{\mathrm{PT}}{\mathrm{OT}} \cdot \frac{\mathrm{SP}}{\mathrm{SO}} \cos \mathrm{P}$

$=\cos \mathrm{TOP} \cdot \cos \mathrm{POS}+\sin \mathrm{TOP} \cdot \sin \mathrm{POS} \cdot \cos \mathrm{P}$

$=\cos \mathrm{PR} \cdot \cos \mathrm{PQ}+\sin \mathrm{PR} \cdot \sin \mathrm{PQ} \cdot \cos \mathrm{P}$.

This is the fundamental formula, and, where $A B C$ is the triangle and sides denoted by $a, b, c$, is expressed-

$$
\cos a=\cos b \cdot \cos c+\sin b \cdot \sin c \cdot \cos A .
$$

The formula used in Case $I$. is derived from this in the following manner :-

$$
\begin{aligned}
\cos a & =\cos b \cdot \cos c+\sin b \cdot \sin c \cdot \cos A \\
\therefore \cos A & =\frac{\cos a-\cos b \cdot \cos c}{\sin b \cdot \sin c}
\end{aligned}
$$

Hence $1+\cos A=1+\frac{\cos a-\cos b \cdot \cos c}{\sin b \cdot \sin c}$

$$
\text { or } \begin{aligned}
2 \cos ^{2} \frac{A}{2} & =\frac{\sin b \cdot \sin c+\cos a-\cos b \cdot \cos c}{\sin b \cdot \sin c} \\
& =\frac{\cos a-\cos (b+c)}{\sin b \cdot \sin c} \\
& =\frac{2 \sin \frac{1}{2}(a+b+c) \cdot \sin \frac{1}{2}(b+c-a)}{\sin b \cdot \sin c}
\end{aligned}
$$

Let $s=\frac{1}{2}(a+b+c) \quad \therefore s-a=\frac{1}{2}(b+c-a)$

$$
\begin{aligned}
& \therefore \cos ^{2} \frac{\mathrm{A}}{2}=\frac{\sin s \cdot \sin (s-a)}{\sin b \cdot \sin c} \\
& \text { or } \cos \frac{\mathrm{A}}{2}=\sqrt{\frac{\sin s \cdot \sin (s-a)}{\sin b \cdot \sin c}}
\end{aligned}
$$

Exercises.-Oblique-angled Spherical Triangles.

1. If $\mathrm{BC}=82^{\circ} 26^{\prime}, \mathrm{AC}=92^{\circ} 2^{\prime}, \mathrm{AB}=104^{\circ} 28^{\prime}$. Solve.

2. If $\mathrm{BC}=140^{\circ}, \mathrm{AC}=70^{\circ}, \mathrm{AB}=80^{\circ}$. Solve.

3. If $\mathrm{BC}=113^{\circ} 2^{\prime}, \mathrm{AC}=82^{\circ} 40^{\prime}$, and $\mathrm{C}=138^{\circ} 50^{\prime}$. Solve.

4. If $\mathrm{AC}=60^{\circ}, \mathrm{AB}=84^{\circ} 22^{\prime}$, and $\mathrm{A}=95^{\circ}$. Find $\mathrm{BC}$.

5. If $\mathrm{BC}=115^{\circ} 20^{\prime}, \mathrm{AB}=84^{\circ} 42^{\prime}$, and $\mathrm{B}=65^{\circ} 30^{\prime}$. Find $\mathrm{A}$ and $\mathrm{C}$.

6. If $\mathrm{BC}=90^{\circ}, \mathrm{AC}=75^{\circ} 29^{\prime}, \mathrm{AB}=84^{\circ} 13^{\prime}$. Find $\mathrm{A}$. long.

7. Sun's R.A. and Dec. being $1^{\mathrm{b}} 30^{\mathrm{m}} 10^{\circ}$, and $9^{\circ} 26^{\prime} 30^{\prime \prime} \mathrm{N}$. Find his

8. The R.A. of a star is $16^{\mathrm{h}} 49^{\mathrm{m}} 48^{\mathrm{s}}$, and its Dec. is $7^{\circ} 23^{\prime} 10^{\prime \prime} \mathrm{N}$. ; find its long. and lat., the obliquity of the ecliptic being taken to be $23^{\circ} 27^{\prime} 30^{\prime \prime}$. 
9. In a right-angled spherical triangle $\mathrm{C}=90^{\circ}$, show $\tan a=\tan c \cdot \cos \mathrm{B}$ $=\tan \mathbf{A} \cdot \sin b$; also if $\mathbf{B}=b$, show triangle must be isosceles.

10. Two ports $A$ and $B$, both in northern hemisphere, are in long. $90^{\circ} \mathrm{W}$. and $10^{\circ} \mathrm{W}$. Two ships leave $A$ and $B$ respectively, proceeding each upon the great circle which touches the parallel of the port at the point of departure.

Ship from A steams to the eastward at uniform rate of $12 \mathrm{knots}$, that from $B$ to the westward at 17 knots ; they meet each other in 5 days. Find lat. and long. of point of meeting. 


\section{CHAPTER VI.}

\section{THE SAILINGS.}

Art. 23. Parallel Sailing.-In parallel sailing, the ship's course is supposed to continue on the same parallel of latitude. There are three things concerned, viz. the Latitude, the Departure or Meridian Distance, and the Difference of Longitude.

Definitions.-(1) Latitude: the distance of the ship north or south from the Equator.

(2) Departure (or Meridian Distance) : the distance in geographical miles between two places on the same parallel of latitude.

(3) Difference of Longitude: the arc of the Equator corresponding to the Meridian Distance.

Illustration $-\mathrm{AB}$ and $\mathrm{CD}$ are Departures at different distances from the Equator; EQ is the D. long., or corresponding Arc of the Equator.

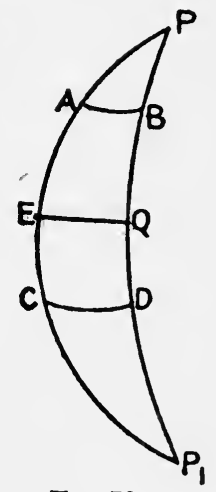

Fig. 70.

Remark.-It is seen that the Meridian Distance decreases as the Latitude increases, and vanishes altogether at the Poles.

The formulæ which express the relation between the three terms are-

1. D. long. $=$ dep. $\times$ sec lat.

2. Dep. ${ }^{\prime}=$ diff. long. $\times \cos$ lat.

3. Sec lat. $=\frac{\text { diff. long. }}{\text { dep. }}$

These are the three cases in Parallel Sailing, and show how the D. long. or Dep. or Lat. may be found when the other two terms are given.

Let $\mathrm{P}$ be the pole, $\mathrm{PE}$ and $\mathrm{PQ}$ meridians of longitude, $\mathrm{EQ}$ 
an arc of the Equator, DL an arc of a parallel of latitude, and C the centre of the Earth.

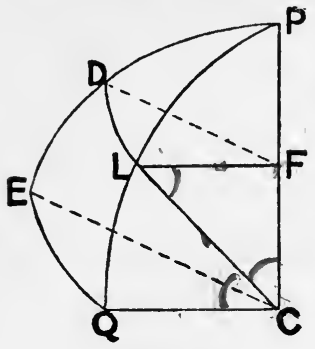

Fig. 71.

Then QL or ED will represent the lat. of the parallel $\mathrm{DL}, \mathrm{EQ}$ is the diff. long., and DL the departure. PC.

Join CL, and draw FL perpendicular to

It is evident that $\mathrm{FL}$ is a radius of the small circle of which DL is a part, and $\mathrm{CQ}$ a radius of the great circle of which $\mathrm{EQ}$ is a part; that is, a radius of the Earth. And since the arcs are proportional to the radii of the two circles-

Arc DL : are EQ : : rad. FL : rad. CQ

therefore DL : EQ : : FL : CL

because CL is also a radius of the Earth ;

$$
\text { or } \frac{\mathrm{DL}}{\mathrm{EQ}}=\frac{\mathrm{FL}}{\mathrm{CL}}=\sin \mathrm{FCL} \text {, or } \cos \mathrm{QCL}
$$

because CFL is a plane right-angled triangle, and QCL is the complement of FCL.

Now, the angle QCL is measured by the arc QL, which is the latitude of the parallel DL-

$$
\text { therefore } \frac{\text { dep. }}{\text { D. long. }}=\cos \text { lat. . . . . . }
$$

from which are derived the formulæ-

$$
\text { Dep. }=\text { D. long. } \times \text { cos lat. . . . . . }
$$

D. long. $=\frac{\text { dep. }}{\text { cos lat. }}$ or dep. $\times$ sec lat. . . .

Now, the formula $\frac{\text { dep. }}{\text { D. long. }}=\cos$ lat. expresses the relation

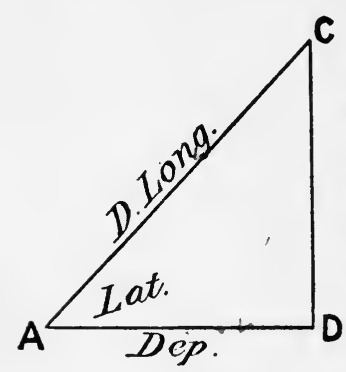

Fia. 72. between the base, hypotenuse, and angle at the base of a right-angled plane triangle. Such a triangle may therefore be used to derive the formulæ of parallel sailing, by calling the base departure, the hypotenuse diff. of longitude, and the angle at the base latitude.

$$
\begin{aligned}
& \text { Then } \frac{\text { dep. }}{\text { D. long. }}=\text { cos lat. . . . } \\
& \text { and } \frac{\text { D. long. }}{\text { dep. }}=\text { sec lat. . . . }
\end{aligned}
$$

From (1) dep. = D. long. $\times$ cos lat. (3) from (2) D. long. = dep. $\times$ sec lat. .

which are the same as those derived from the sphere. 
ART. 24. Middle-latitude Sailing.--This is a combination of plane and parallel sailing, the dep. being common to both, but the latitude used is the " middle lat.," or mean of the two latitudes, for in this case the ship does not sail on a parallel of latitude.

It is evident that the formulæ for rightangled triangles will solve every case, but this method is only made use of in modern navigation for the purpose of finding the $D$. long. in the "day's work," the formula em. ployed being-

D. long. $=$ dep. $\times$ sec of middle lat. The mean is not the true "middle lat.," being too small, but is sufficiently near for short distances.

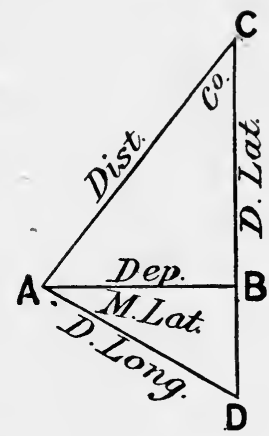

Fig. 73.

Examples. -

1. In lat. $46^{\circ} 45^{\prime}$ the Departure made good was 110.5 miles : required the Difference of Longitude.

Construction. - In Fig. 74, scale $\frac{1}{10}$ inch $=10$ miles. Draw horizontal line $\mathbf{A} \mathbf{B}=\mathbf{1} \cdot 1$ inches for departure, make angle $\mathrm{BAC}=46^{\circ} 45^{\prime}$, and draw $\mathrm{BC}$ perpendicular to $\mathrm{AB}$ : then $\mathrm{AC}$ represents $\mathrm{D}$. long.

Measure $\mathrm{AC}=1.6$ inches or 160 miles.

$$
\begin{array}{llll}
\text { Dep. } 110 \cdot 5 & \ldots & \log 2 \cdot 043362 \\
\text { Lat. } 46^{\circ} 45^{\prime} & \ldots & \text { sec } 10 \cdot 164193 \\
\text { D. long. }=161 \cdot 3 \ldots & \log 2 \cdot 207555
\end{array}
$$

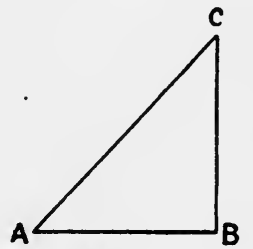

Fig 74.

2. In lat. $53^{\circ} 14^{\prime}$ the $\mathrm{D}$. long. being $3^{\circ} 16^{\prime}$, required the Meridian Distance or Departure.

In Fig. 75 draw horizontal line $\mathrm{AB}$. Make angle $\mathrm{BAC}=$ $53^{\circ} 14^{\prime}$, and $A C=0.98$ inch; scale $\frac{1}{10}$ inch $=20$ miles. From $\mathrm{C}$ draw $\mathrm{CB}$ perpendicular to $\mathrm{AB}$ : then $\mathrm{AB}$ represents Dep. Measure $\mathrm{AB}=\mathbf{0 . 6}$ inch or 120 miles.

$$
\begin{array}{llll}
\text { D. long. 196' } & \ldots & \ldots & \log 2 \cdot 292256 \\
\text { Lat. 53 } 14^{\prime} & \ldots & \ldots & \cos 9 \cdot 777106 \\
\text { Dep. }=117 \cdot 3 & \ldots & \ldots & \log 2 \cdot 069362
\end{array}
$$

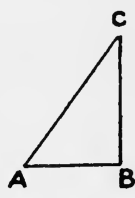

Fic. 75.

3. On what parallel of latitude would a Meridian Distance of 245 miles give a difference of longitude of $5^{\circ} 54^{\prime}$ ?

In Fig. 76, scale $\frac{1}{10}$ inch $=20$ miles, draw $A B=1.2$ long, at $\mathrm{B}$ draw a perpendicular to $\mathbf{A B}$, and with $\mathrm{A}$ as centre, radius $=1.77$ inch, draw an arc, cutting this perpendicular in $\mathrm{C}$ : then $\mathrm{BAC}$ represents lat.

$$
\begin{aligned}
& \begin{array}{llllll}
\text { D. long. } 3 \tilde{5} 4 & \ldots & \ldots & \ldots & \ldots & \log 2 \cdot 549003
\end{array} \\
& \begin{array}{llllll}
\text { Dep. } 24 \overline{0} & \ldots & \ldots & \ldots & \ldots & \log 2 \cdot 389166
\end{array} \\
& \text { Lat. } 46^{\circ} 12^{\prime} \quad \ldots \quad \ldots \quad \ldots \quad \ldots \quad \text { sec } \overline{10 \cdot 159837}
\end{aligned}
$$

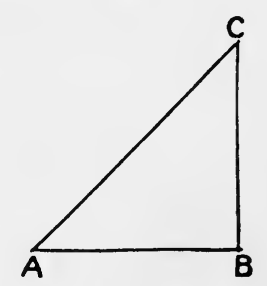

Fig. 76.

Remark.-In the first two cases 10 is rejected from the sum of indexes, and in the third case 10 is added to the upper index, because in the Table of $\log$ Sines, etc., the proper index is always increased by 10 . 


\section{Exercises.}

1. In lat. $16^{\circ} 30^{\prime} \mathrm{N}$. the dep. made good was $167 \cdot 6$ miles : what will the difference of.longitude be by parallel sailing ?

2. The difference of longitude between two places in lat. $63^{\circ} 19^{\prime} 30^{\prime \prime}$ is $4^{\circ} 20^{\prime}$ : required the distance as measured along the parallel.

3. In lat. $11^{\circ} 56^{\prime} \mathrm{N}$. the dep. made good was 365 miles : required the difference of longitude in minutes.

4. In what latitude is 200 miles of dep. equal to 600 minutes of longitude?

5 . In lat. $35^{\circ} 40^{\prime} \mathrm{S}$. the dep. made good was $9 \cdot 76$ : required the difference of longitude measured on the parallel.

6. What is the difference of latitude between two parallels of latitude on different sides of the Equator, when between the same two meridians the dep. on the northern parallel is 250 miles, on the southern 350 miles, and on the Equator 470 miles?

7. On the parallel of $48^{\circ} 12^{\prime}$ ran true west 1005 miles : if the longitude left was $9^{\circ} 30^{\prime} \mathrm{W}$., what was the longitude in?

8. From two ports in lat. $40^{\circ} 20^{\prime} \mathrm{N}$., distant 300 minutes of longitude, two ships sail N. for 300 miles : how many miles apart will they be, and in what latitude?

9. In lat. $33^{\circ} 15^{\prime} \mathrm{N}$. ran east 10.95 miles : how many minutes of longitude will that represent?

10. If two ships in lat. $51^{\circ} \mathrm{S}$. should sail directly north until the departure changes from 400 to 500 minutes, what latitude will they be in?

11. In lat. $72^{\circ} 59^{\prime}$ the dep. was 370.5 miles: convert that into minutes of longitude.

12. In what latitude does 300 miles of dep. correspond to 600 minutes of longitude?

13. The latitude by Mer. alt. was $36^{\circ} 35^{\prime} \mathrm{N}$.; longitude by afternoon sights, $137^{\circ} 38^{\prime}$ E. ; run since noon due east, 39 miles : find noon Jongitude.

14: A vessel sailed due east along the parallel of $45^{\circ} 24^{\prime} \mathrm{S}$. for 29 miles from long. $43^{\circ} 40^{\prime} \mathrm{E}$. : what is her longitude in?

15. What distance must a vessel sail on the parallel $48^{\circ} 25^{\prime} \mathrm{N}$. to change her longitude $2^{\circ} 25^{\prime}$ ?

16. A vessel sailing due east finds her difference of longitude to be $1^{\circ} 19^{\prime}$, and distance made good $50^{\prime}$ : what is her latitude?

17. How far on the parallel of $38^{\circ} \mathrm{S}$. must a vessel sail from long. $47^{\circ} 29^{\prime}$ E. to reach long. $49^{\circ} 27^{\prime} \mathrm{E}$. ?

18. For every $1^{\circ}$ diff. long. I have to sail 45 miles due west: along what parallel am I sailing ?

ART. 25. Plane and Traverse Sailings.-For short distances, the surface of the Earth may be regarded as a plane. In plane

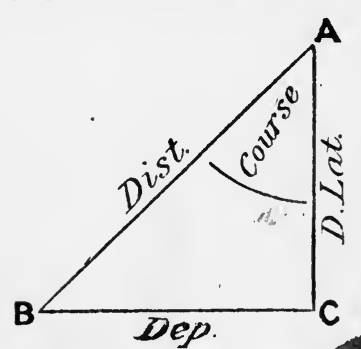

Fig. 77. and traverse sailings no notice is taken of the curvature, and all cases may be solved by the formulæ for right-angled triangr'es.

Thus in sailing from $A$ to $B$, the hypotenuse represents the distance, the perpendicular the departure, and the base the $\mathrm{D}$. lat., whilst the angle which AB makes with $\mathrm{AC}$ (lying true $\mathrm{N}$. and S.) is the course.

In the Traverse Table the values of D. lat. and $D$. in miles are given for every degree of course 
up to $89^{\circ}$ and all distances up to 600 miles, being computed from the formulæ-

$$
\begin{aligned}
\frac{\text { D. lat. }}{\text { dist. }} & =\cos \text { course } \\
\frac{\text { dep. }}{\text { dist. }} & =\text { in course } \\
\text { whence D. lat. } & =\text { dist. } \times \text { cos course } . . . \\
\text { and dep. } & =\text { dist. } \times \text { sin course . . . . }
\end{aligned}
$$

When D. lat. and dep. are given, the course and distance made good may be found from the formula-

$$
\begin{aligned}
& \text { tan course }=\frac{\text { dep. }}{\text { D. lat. }} \cdot \text {. . . . . . . } \\
& \text { distance }=\text { D. lat. } \times \text { sec course } . .
\end{aligned}
$$

ART. 25. The Day's Work and Traverse Sailing.-The purpose of the Day's Work is to find the position of the ship at noon by "Dead reckoning," that is, from the courses and distances sailed since the preceding noon. The direct course and distance made good are also determined.

The courses given are by compass as per ship's Log Book, but the true courses must be found for computing a "Traverse Table."

Directions for finding the True Courses.-(a) Allow the leeway to the Right (R.) when the wind blows on the left or Port Side of the ship, and to the Left (L.) when on the Right or Starboard Side. (b) Allow E. deviation and variation (or total correction) to the Right (R.), and W. to the Left (L.).

Notw.-The Leeway may be determined by towing the log-ship astern and observing the angle the line makes with the keel, but it is often merely estimated.

The Deviation is found by reference to the Deviation Card, and the Variation from a chart.

When the Departure is taken from a known point of land or light, the opposite course to the bearing of the point or light from the ship is called the "Departure Course," and the distance off is the distance belonging to that course.

The "Set" and "Drift" of the current are found by chart, and are treated as a course and distance made by the ship, because the effect is the same on the Day's Work.

Note.-Should the "Set" and "Drift" of the current be required, it is the course and distance calculated by Mercator from the D.R. position found by Traverse to the observation position given in the question.

They may also be found by turning $D$. long. into Dep.: then with the D. lat. and Dep. find Co. and Dist. in Traverse Table, for Set and Prift required. 
Illustrations and Minor Calculations.
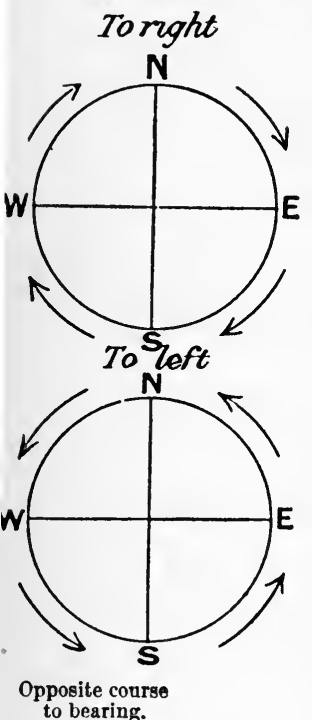

(1) S. $45^{\circ} \mathrm{R}$ Corr. 11 R.

S. $\overline{56} R$.

(2) N. $65^{\circ} \mathrm{L}$. Leeway $20 \mathrm{~L}$. N. $\overline{85} \mathrm{~L}$. Corr. 3 R. N. $\overline{82} \mathrm{~L}$.

(3) N. $77^{\circ} \mathrm{R}$. $17 \mathrm{R}$. N. $\overline{94} R$. $12 \mathrm{~K}$.

N. $\overline{106} \mathrm{R}$. 180

S. 74 E.

(4) N. $57^{\circ} \mathrm{I}$ $16 \mathrm{~L}$. N. 73 I. N. $\begin{array}{rr}23 & \text { L. } \\ 2 & \text { L. }\end{array}$ N. $\overline{75} \mathrm{~L}$.

(5) S. $90^{\circ} \mathrm{L}$. $19 R$. S."̈̄i I. 21 R.

S. $\overline{50} \mathrm{~L}$.

(6) N. $52^{\circ} \mathrm{L}$. $14 \mathrm{~L}$. N. $\overline{66}$ L. Corr. 0 N. $\overline{66}$ L.

\section{Example 1.}

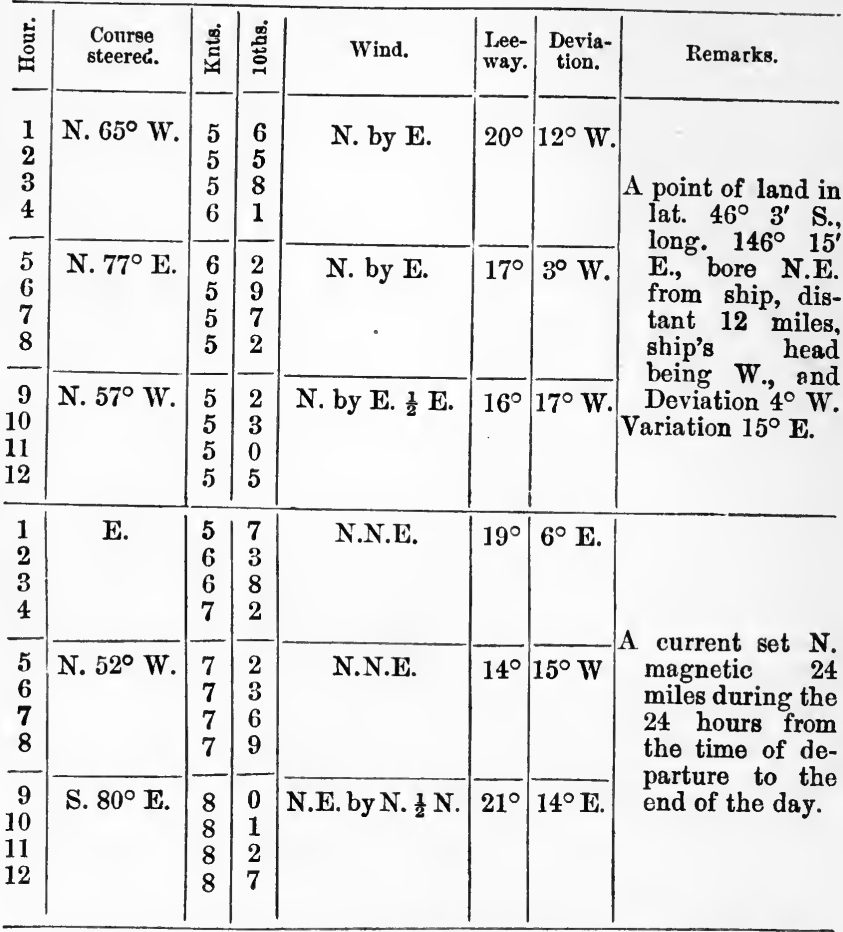

Correct the courses, and find the course and distance made good; also the Latitude and Longitude in by inspection.

Traverse Table.

\begin{tabular}{|c|c|c|c|c|c|}
\hline \multirow{2}{*}{ True courses. } & \multirow{2}{*}{ Distance. } & \multicolumn{2}{|c|}{ D. Lat. } & \multicolumn{2}{|c|}{ Dep. } \\
\hline & & N. & s. & E. & W. \\
\hline \multirow[t]{3}{*}{$\begin{array}{l}\text { S. } 56^{\circ} \mathrm{W} . \\
\text { N. } 82^{\circ} \mathrm{W} . \\
\text { S. } 74^{\circ} \mathrm{E} . \\
\text { N. } 75^{\circ} \mathrm{W} . \\
\text { S. } 50^{\circ} \mathrm{E} . \\
\text { N. } 66^{\circ} \mathrm{W} . \\
\text { S. } 30^{\circ} \mathrm{E} . \\
\text { N. } 15^{\circ} \mathrm{E} .\end{array}$} & \multirow[t]{3}{*}{$\begin{array}{l}12 \\
23 \\
23 \\
21 \\
26 \\
30 \\
33 \\
24\end{array}$} & $\begin{array}{r}3 \cdot 2 \\
5 \cdot 4 \\
12 \cdot 2 \\
23 \cdot 2\end{array}$ & $\begin{array}{r}6 \cdot 7 \\
6 \cdot 3 \\
16 \cdot 7 \\
28 \cdot 6\end{array}$ & $\begin{array}{r}22 \cdot 1 \\
19 \cdot 9 \\
16 \cdot 5 \\
6 \cdot 2\end{array}$ & $\begin{array}{r}9 \cdot 9 \\
22 \cdot 8 \\
\\
20 \cdot 3 \\
\\
27 \cdot 4\end{array}$ \\
\hline & & $44 \cdot 0$ & $\begin{array}{l}58 \cdot 3 \\
44 \cdot 0\end{array}$ & $64 \cdot 7$ & $\begin{array}{l}80 \cdot 4 \\
64 \cdot 7\end{array}$ \\
\hline & & \multicolumn{2}{|c|}{ D. lat. $14: 3$} & \multicolumn{2}{|c|}{ Dep. 15.7} \\
\hline
\end{tabular}

The D. lat. and dep. are found nearest together under the course 48 
and dist. 21 miles, which are the course and distance made good (course S. $48^{\circ}$ W.).

Lat. left $46^{\circ} 3^{\prime} \mathrm{S}$. Long. left $146^{\circ} 15^{\prime} \mathrm{E}$.

D. lat. $14^{\prime} \mathrm{S} . \quad$ D. long. $23^{\prime} \mathrm{W}$.

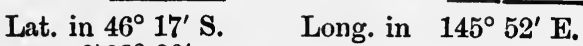
2) $92^{\circ} 20^{\prime}$

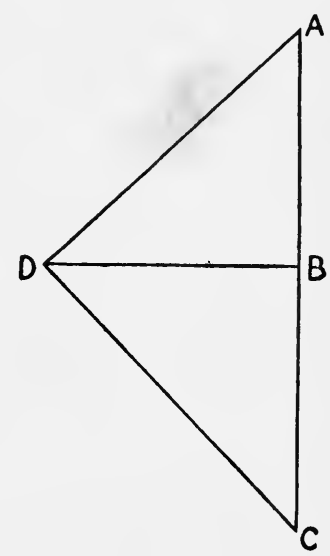

Fia. 77A.
Diff. long. $22 \cdot 67$

... $\quad$ sec $10 \cdot 159541$

... $\quad \log 1 \cdot 195900$

Dep. $15 \cdot 7$

\% $\quad \log 1 \cdot 355441$ colunin.

In Fig. $77 \mathrm{~A}$, scale 1 inch $=10$ miles, let $\mathrm{ABC}$ represent portion of meridian.

$\mathrm{AB}=1.43$ inch is $\mathrm{D}$. lat.

$\mathrm{BD}=1.57$ inch is Dep.

where $A B D$ is $90^{\circ}$.

Lay off $\mathrm{BDC}=46^{\circ} \mathrm{Mid}$. lat.

Then $\mathrm{BAD}$ is course $=48^{\circ}$.

$\mathrm{AD}$ is Dist. $=2 \cdot 1 \mathrm{inch}$.

$$
=21 \text { miles. }
$$

$\mathrm{DC}$ is $\mathrm{D}$. long $=2 \cdot 3$ inch.
Minor

Calculations.

(7) S. 80 L.

$21 R$.

S. $\overline{59}$ L.

$29 \mathrm{R}$.

S. $\overline{30}$ L.

(8) Current.

N. 00

$15 \mathrm{R}$.

N. $\overline{16}$ R.

Example 2.

\begin{tabular}{|c|c|c|c|c|c|c|c|}
\hline Hour. & Course steered. & Knts. & 10ths. & Wind. & $\begin{array}{l}\text { Lee- } \\
\text { way, }\end{array}$ & $\begin{array}{l}\text { Devia- } \\
\text { tion. }\end{array}$ & Remarks. \\
\hline $\begin{array}{l}1 \\
2 \\
3 \\
4\end{array}$ & S.W. & $\begin{array}{l}8 \\
8 \\
9 \\
9\end{array}$ & $\begin{array}{l}2 \\
4 \\
2 \\
2\end{array}$ & S.E. by S. & $\begin{array}{l}\text { Pts. } \\
1 \frac{1}{2}\end{array}$ & $6^{\circ} \mathrm{W}$. & \multirow{3}{*}{$\begin{array}{l}\text { A point of land } \\
\text { in lat. } 49^{\circ} 57^{\prime} \\
\mathrm{N} ., \text { long. } 5^{\circ} 12^{\prime} \\
\text { W., bore by } \\
\text { compass N.W. } \\
\frac{1}{2} \mathrm{~N} \text {., distant } \\
20 \text { miles, ship's } \\
\text { head being S.W., } \\
\text { and Deviation as } \\
\text { per log. } \\
\text { Variation } 19^{\circ} \mathrm{W} \text {. }\end{array}$} \\
\hline $\begin{array}{l}5 \\
6 \\
7 \\
8\end{array}$ & S.W. by W. & $\begin{array}{l}8 \\
8 \\
7 \\
7\end{array}$ & $\begin{array}{l}9 \\
5 \\
6 \\
0\end{array}$ & S.S.E. & $1 \frac{3}{4}$ & $3^{\circ} \mathrm{W}$. & \\
\hline $\begin{array}{r}9 \\
10 \\
11 \\
12\end{array}$ & S.W. by S. & $\begin{array}{l}6 \\
6 \\
6 \\
5\end{array}$ & $\begin{array}{l}7 \\
5 \\
2 \\
6\end{array}$ & S.E. & $1 \frac{1}{2}$ & $2^{\circ} \mathrm{E}$. & \\
\hline $\begin{array}{l}1 \\
2 \\
3 \\
4\end{array}$ & S.S E. & $\begin{array}{l}7 \\
7 \\
8 \\
9\end{array}$ & $\begin{array}{l}5 \\
9 \\
5 \\
1\end{array}$ & S.W. & 2 & $7^{\circ} \mathrm{E}$. & \multirow{3}{*}{$\begin{array}{l}\text { A current set } \mathrm{E} \text {. } \\
\text { by } \mathrm{N} . \frac{1}{2} \mathrm{~N} \text {. (corr. } \\
\text { mag.) } 30 \text { miles, } \\
\text { during the } 24 \\
\text { hours. }\end{array}$} \\
\hline $\begin{array}{l}5 \\
6 \\
7 \\
8\end{array}$ & S. by W. $\frac{1}{2}$ W. & $\begin{array}{l}10 \\
10 \\
10 \\
10\end{array}$ & $\begin{array}{l}0 \\
1 \\
3 \\
6\end{array}$ & W. & $1 \frac{8}{4}$ & $4^{\circ} \mathrm{E}$ & \\
\hline $\begin{array}{r}9 \\
10 \\
11 \\
12\end{array}$ & S. $\frac{1}{4} \mathrm{E}$. & $\begin{array}{l}11 \\
11 \\
11 \\
12\end{array}$ & $\begin{array}{l}3 \\
6 \\
7 \\
4\end{array}$ & W. by $\mathbf{N}$. & $\frac{1}{2}$ & $2^{\circ} \mathrm{E}$. & \\
\hline
\end{tabular}

Required the course and distance made good, and the Latitude and Longitude in. 
Minor

Calculations,

1) S. $39^{\circ} \mathrm{L}$. Corr. $25 \mathrm{~L}$.

S. 64 L.

S. $62^{\circ} \mathrm{R}$. Corr. $25 \mathrm{~L}$.

S. $\overline{37}$ R.

S. $76^{\circ} \mathrm{R}$.

$22 \mathrm{~L}$.

S. $\overline{54} R$.

S. $51^{\circ} \mathrm{L}$.

$17 \mathrm{~L}$.

S. $\overline{31} \mathrm{R}$.

S. $45^{\circ} \mathrm{L}$. 12 L.

S. $\overline{57}$ L.

S. $3^{\circ} \mathrm{L}$. 15 L.

S. $\overline{18} \mathrm{~L}$.

S. $8^{\circ} \mathrm{L}$.

$17 \mathrm{~L}$.

S. $\overline{25} \mathrm{~L}$.

rent $\mathrm{N} .73^{\circ} \mathrm{R}$. Var. $19 \mathrm{~L}$.

N. $\overline{54} \mathrm{R}$.

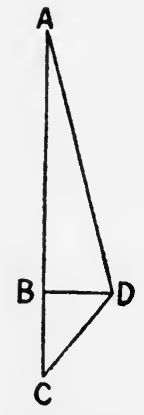

FIG. 78.
Traverse Table.

\begin{tabular}{|c|c|c|c|c|c|}
\hline \multirow{2}{*}{ True courses. } & \multirow{2}{*}{ Distance. } & \multicolumn{2}{|c|}{ D. Lat. } & \multicolumn{2}{|c|}{ Dep. } \\
\hline & & N. & s. & E. & W. \\
\hline \multirow[t]{3}{*}{$\begin{array}{l}\text { S. } 64^{\circ} \mathrm{E} . \\
\text { S. } 37^{\circ} \mathrm{W} . \\
\text { S. } 54^{\circ} \mathrm{W} . \\
\text { S. } 34^{\circ} \mathrm{W} . \\
\text { S. } 57^{\circ} \text { E. } \\
\text { S. } 18^{\circ} \text { E. } \\
\text { S. } 25^{\circ} \text { E. } \\
\text { N. } 54^{\circ} \text { E. }\end{array}$} & \multirow[t]{3}{*}{$\begin{array}{l}20 \\
35 \\
32 \\
25 \\
33 \\
41 \\
47 \\
30\end{array}$} & $17 \cdot 6$ & $\begin{array}{r}8 \cdot 8 \\
28 \cdot 0 \\
18 \cdot 8 \\
20 \cdot 7 \\
18 \cdot 0 \\
39 \cdot 0 \\
42 \cdot 6\end{array}$ & $\begin{array}{l}27 \cdot 7 \\
12 \cdot 7 \\
19 \cdot 9 \\
21 \cdot 3\end{array}$ & $\begin{array}{l}21 \cdot 1 \\
25 \cdot 9 \\
14 \cdot 0\end{array}$ \\
\hline & & $17 \cdot 6$ & $\begin{array}{r}175 \cdot 9 \\
17 \cdot 6\end{array}$ & $\begin{array}{r}102 \cdot 6 \\
61 \cdot 0\end{array}$ & $61 \cdot 0$ \\
\hline & & & $158 \cdot 3$ & $41 \cdot 6$ & \\
\hline
\end{tabular}

Course and dist. made good S. $15^{\circ}$ E. 164 miles.

Lat. left $49^{\circ} 57^{\prime} \mathrm{N}$.

D. lat. $2^{\circ} 38^{\prime} \mathrm{S}$.

Long. left $5^{\circ} 12^{\prime} \mathrm{W}$.

D. long. $1^{\circ} 3^{\prime} \mathrm{E}$.

Lat. in $47^{\circ} 19^{\prime} \mathrm{N}$. 2) $97^{\circ} 16^{\prime}$

Long in $4^{\circ} 9^{\prime} \mathrm{W}$.

Mid. lat. $48^{\circ} 38^{\prime} \quad \ldots \quad \ldots \quad \ldots \quad$ sec $10 \cdot 179880$

Dep. $41 \cdot 6 \quad$.. $\quad \ldots \quad \ldots \quad \quad \ldots \quad \log 1 \cdot 619093$

D. long. $62.95 \quad \ldots \quad \ldots \quad \ldots \quad \quad \ldots \quad \log 1 \cdot 798973$

In Fig. 78 scale 1 inch $=100$ miles, $A B C$ represents meridian.

$\mathrm{AB}=1.58$ inch is $\mathrm{D}$. lat.

$\mathrm{BD}=0.42$ inch is Dep.

$\mathrm{ABD}=90^{\circ}$.

Make $B D C=48 \frac{1}{2}=$ Mid. lat.

Then BAD is course $=15^{\circ}$.

$\mathrm{AD}$ is Dist. $=1.64$ inch.

$=164$ miles.

CD is D. long $=0.63$ inch.

$=63$ miles.

Note 1.-The D. long. can also be found by inspection thus: Take the mid. lat. as a course and find dep. in D. lat. column; the dist. corresponding is the D. long.

Nоте 2.-When course and leeway are in "points," it is most convenient to allow the leeway before changing points into degrees, then apply the correction.

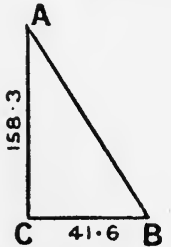

FIG. 79.

$\mathrm{A}=14^{\circ} 43^{\prime} 26^{\prime \prime}$

$41 \cdot 6 \log =11 \cdot 619093$

$158 \cdot 3 \log =2 \cdot 199481$

$\tan =\overline{9 \cdot 419612}$

Find-

Now-
D. lat. $158 \cdot 3 \mathrm{~S}$., dep. $41 \cdot 6 \mathrm{E}$.

In triangle $\mathrm{ABC}, \mathrm{C}=90, \mathrm{AC}=158 \cdot 3, \mathrm{BC}=41 \cdot 6$.

$$
\begin{aligned}
\mathbf{A} & =\text { ccurse } \\
\mathbf{A B} & =\text { distance. }
\end{aligned}
$$

$$
\tan A=\frac{B C}{A C}=\frac{41 \cdot 6}{158 \cdot 3} \text { and } \frac{A B}{A C}=\sec A
$$

$$
\therefore \mathrm{AB}=\mathrm{AC} \times \sec \mathrm{A}
$$

Course S. $14^{\circ} 43^{\prime} 26^{\prime \prime}$ E., distance $163 \cdot 7$ miles. 
Exercises.

1.

\begin{tabular}{|c|c|c|c|c|c|c|c|}
\hline Hour. & Course steered. & Knts. & 10ths. & Wind. & $\begin{array}{l}\text { Lee- } \\
\text { way. }\end{array}$ & $\begin{array}{c}\text { Deซ̄ia- } \\
\text { tion. }\end{array}$ & Remarks. \\
\hline $\begin{array}{l}1 \\
2 \\
3 \\
4\end{array}$ & N.N.W. & $\begin{array}{l}17 \\
16 \\
14 \\
13\end{array}$ & $\begin{array}{l}1 \\
2 \\
3 \\
4\end{array}$ & W. $\frac{1}{4} \mathrm{~S}$. & $\begin{array}{c}\text { Pis. } \\
1\end{array}$ & $7^{\circ} \mathrm{E}$ & \multirow{3}{*}{$\begin{array}{l}\text { A point of land in } \\
\text { lat. } 0^{\circ} 34^{\prime} \mathrm{S} \text {., } \\
\text { long. } 0^{\circ} 17^{\prime} \mathrm{W} \text {., } \\
\text { bearing by com- } \\
\text { pass S. } \mathrm{E} \text {, } \\
\text { distant } 49 \text { miles, } \\
\text { with the ship's } \\
\text { head at N.N.W. } \\
\text { Deviation as per } \\
\text { log. } \\
\text { Variation } 30^{\circ} \mathrm{W} \text {. }\end{array}$} \\
\hline $\begin{array}{l}5 \\
6 \\
7 \\
8\end{array}$ & N. by W. & $\begin{array}{l}13 \\
15 \\
17 \\
16\end{array}$ & $\begin{array}{l}2 \\
5 \\
6 \\
7\end{array}$ & N.W. by W. $\frac{3}{4}$ W. & 2 & $36^{\circ} \mathrm{E}$. & \\
\hline $\begin{array}{r}9 \\
10 \\
11 \\
12\end{array}$ & N.N.E. & $\begin{array}{l}15 \\
10 \\
12 \\
16\end{array}$ & $\begin{array}{l}8 \\
9 \\
1 \\
2\end{array}$ & East & 3 & $19^{\circ} \mathrm{W}$. & \\
\hline $\begin{array}{l}1 \\
2 \\
3 \\
4\end{array}$ & N.E. by E. $\frac{1}{2}$ E. & $\begin{array}{l}13 \\
17 \\
10 \\
15\end{array}$ & $\begin{array}{l}3 \\
4 \\
5 \\
8\end{array}$ & S.E. by E. & $3 \frac{1}{2}$ & $5^{\circ} \mathrm{W}$ & \multirow{3}{*}{$\begin{array}{l}\text { A current set cor- } \\
\text { rect magnetic } \\
\text { South } 4 \text { miles } \\
\text { from the time } \\
\text { departure was } \\
\text { taken to the end } \\
\text { of the day. }\end{array}$} \\
\hline $\begin{array}{l}5 \\
6 \\
7 \\
8\end{array}$ & S.W. $\frac{1}{4}$ W. & $\begin{array}{l}14 \\
13 \\
15 \\
17\end{array}$ & $\begin{array}{l}\mathbf{9} \\
\mathbf{3} \\
\mathbf{9} \\
\mathbf{9}\end{array}$ & S. by E. $\frac{1}{2}$ E. & $\frac{1}{2}$ & $4^{\circ} \mathrm{E}$ & \\
\hline $\begin{array}{r}9 \\
10 \\
11 \\
12\end{array}$ & S.S.W. & $\begin{array}{l}11 \\
14 \\
13 \\
16\end{array}$ & $\begin{array}{l}4 \\
9 \\
8 \\
9\end{array}$ & West & 2 & $5^{\circ} \mathrm{E}$. & \\
\hline
\end{tabular}

Correct the courses for Deviation, Variation, and Leeway, and find the course and distance from the given point, and the Latitude and Longitude in.

2.

\begin{tabular}{|c|c|c|c|c|c|c|c|}
\hline Hour. & Course steered. & Kints. & 10 ths. & Wind. & $\begin{array}{l}\text { Lee- } \\
\text { way. }\end{array}$ & $\begin{array}{c}\text { Devi i- } \\
\text { tion. }\end{array}$ & Remarks. \\
\hline $\begin{array}{r}1 \\
2 \\
3 \\
4 \\
5 \\
6 \\
7 \\
8 \\
9 \\
10 \\
11 \\
12\end{array}$ & N. $85^{\circ} \mathrm{W}$. & $\begin{array}{l}12 \\
12 \\
12 \\
12 \\
12 \\
12 \\
12 \\
12 \\
12 \\
12 \\
12 \\
12\end{array}$ & $\begin{array}{l}6 \\
7 \\
4 \\
2 \\
8 \\
5 \\
4 \\
5 \\
6 \\
3 \\
\end{array}$ & S.S.IV. & - & $14^{\circ} \mathrm{E}$. & $\begin{array}{l}\text { A point in lat. } 55^{\circ} \\
1^{\prime} \text { N., long. } 8^{\circ} \\
20^{\prime} \text { W., bearing } \\
\text { by compass } \mathrm{S} .23^{\circ} \\
\text { l., ship's head } \\
\text { N. } 85^{\circ} \mathrm{W} \text {. Devi- } \\
\text { ation as per log., } \\
\text { distant } 7 \text { miles. }\end{array}$ \\
\hline
\end{tabular}




\begin{tabular}{|c|c|c|c|c|c|c|c|}
\hline Hour. & Course steered. & Knts. & 10ths. & Wind. & $\begin{array}{l}\text { Lee- } \\
\text { way. }\end{array}$ & $\begin{array}{c}\text { Devia- } \\
\text { tion. }\end{array}$ & Remarks. \\
\hline $\begin{array}{r}1 \\
2 \\
3 \\
4 \\
5 \\
6 \\
7 \\
8 \\
9 \\
10 \\
11 \\
12\end{array}$ & N. $82^{\circ} \mathrm{W}$. & $\begin{array}{l}11 \\
11 \\
11 \\
11 \\
12 \\
12 \\
12 \\
12 \\
12 \\
12 \\
11 \\
11\end{array}$ & $\begin{array}{l}9 \\
8 \\
6 \\
9 \\
1 \\
4 \\
5 \\
3 \\
2 \\
9 \\
4\end{array}$ & S.IV. & 一 & $12^{\circ} \mathrm{E}$ & $\begin{array}{l}\text { Variation during } \\
\text { first } 8 \text { hours, } 28^{\circ} \\
\text { W.; during se- } \\
\text { cond } 8 \text { hours, } 30^{\circ} \\
\text { W.; during third } \\
8 \text { hours, } 32^{\circ} \text { W. } \\
\text { A current set cor- } \\
\text { rect magnetic } \\
\text { S.S.E. } \frac{1}{2} \text { E. } 2 \frac{1}{2} \\
\text { miles per hour for } \\
\text { all day. }\end{array}$ \\
\hline
\end{tabular}

Find the course and distance made good; Latitude and Longitude of the ship.

3.

\begin{tabular}{|c|c|c|c|c|c|c|c|}
\hline Hour & Course steered. & Knts. & 10 ths. & Wind. & $\begin{array}{l}\text { Lee. } \\
\text { way }\end{array}$ & $\begin{array}{c}\text { Devia- } \\
\text { tion. }\end{array}$ & Remarks. \\
\hline $\begin{array}{l}1 \\
2 \\
3 \\
4\end{array}$ & N. by E. $\frac{1}{2}$ E. & $\begin{array}{l}\mathbf{9} \\
\mathbf{9} \\
\mathbf{9} \\
\mathbf{8}\end{array}$ & $\begin{array}{l}\mathbf{1} \\
\mathbf{3} \\
\mathbf{9} \\
\mathbf{7}\end{array}$ & S.E. by E. & $\begin{array}{c}\text { Pts. } \\
\frac{1}{4}\end{array}$ & $18^{\circ} \mathrm{E}$. & \multirow{3}{*}{$\begin{array}{l}\text { A point of land in } \\
\text { lat. } 18^{\circ} 59^{\prime} \mathrm{S} \text {, } \\
\text { long. } 179^{\circ} 53^{\prime} \\
\text { W., bearing by } \\
\text { compass E.S.E., } \\
\text { distant } 19 \text { miles, } \\
\text { with the ship's } \\
\text { head at N. by } \\
\mathrm{E} . \frac{1}{4} \mathrm{E} \text {. Devia- } \\
\text { tion as per log. } \\
\text { Variation } 9^{\circ} \mathrm{E} \text {. }\end{array}$} \\
\hline $\begin{array}{l}5 \\
6 \\
7 \\
8\end{array}$ & S.E. by E. & $\begin{array}{l}6 \\
\text { i } \\
6 \\
6\end{array}$ & $\begin{array}{l}4 \\
1 \\
3 \\
2\end{array}$ & S. by IV. & $1 \frac{1}{2}$ & $23^{\circ} \mathrm{W}$. & \\
\hline $\begin{array}{r}9 \\
10 \\
11 \\
12\end{array}$ & E. by N. $\frac{1}{4} \mathbf{N}$. & $\begin{array}{l}\mathbf{6} \\
\mathbf{5} \\
\mathbf{5} \\
\mathbf{5}\end{array}$ & $\begin{array}{l}0 \\
\mathbf{9} \\
8 \\
\mathbf{3}\end{array}$ & N. $\frac{1}{2}$ E. & $1 \frac{3}{4}$ & $3^{\circ} \mathrm{W}$. & \\
\hline $\begin{array}{l}1 \\
2 \\
3 \\
4\end{array}$ & S.W. $\frac{3}{4}$ W. & $\begin{array}{l}\mathbf{5} \\
\mathbf{5} \\
\mathbf{5} \\
\mathbf{5}\end{array}$ & $\begin{array}{l}3 \\
1 \\
2 \\
4\end{array}$ & S.S.E. & $2 !$ & 0 & \multirow{3}{*}{$\begin{array}{l}\text { A current set cor } \\
\text { rect niagnetic } \\
\text { S.S.E. } \frac{3}{4} \text { E., } 15 \\
\text { miles from the } \\
\text { time departure } \\
\text { was taken to the } \\
\text { end of the day. }\end{array}$} \\
\hline $\begin{array}{l}5 \\
6 \\
7 \\
8\end{array}$ & S.S.W. & $\begin{array}{r}7 \\
8 \\
8 \\
, 9\end{array}$ & $\begin{array}{l}9 \\
2 \\
4 \\
5\end{array}$ & W. by N. & 1 & $11^{\circ} \mathrm{W}$. & \\
\hline $\begin{array}{r}9 \\
10 \\
11 \\
12\end{array}$ & N.N.E. & $\begin{array}{r}9 \\
10 \\
10 \\
10\end{array}$ & $\begin{array}{l}6 \\
0 \\
3 \\
1\end{array}$ & N.W $\frac{1}{2}$ W. & $1 \frac{1}{4}$ & $16^{\circ} \mathrm{E}$. & \\
\hline
\end{tabular}

Correct the courses for Deviation, Variation, and Leeway, and find the eourse and distance from the given point, and the Latitude and Longitude in. 
4.

\begin{tabular}{|c|c|c|c|c|c|c|c|}
\hline Hour. & Course steered. & Knts. & 10ths. & Wind. & $\begin{array}{l}\text { Lee- } \\
\text { way. }\end{array}$ & $\begin{array}{c}\text { Devia- } \\
\text { tíon. }\end{array}$ & Remarks. \\
\hline $\begin{array}{l}1 \\
2 \\
3 \\
4\end{array}$ & S. by W. $\frac{1}{2}$ W. & $\begin{array}{r}16 \\
17 \\
10 \\
9\end{array}$ & $\begin{array}{l}3 \\
1 \\
2 \\
4\end{array}$ & W. $\frac{1}{2} \mathrm{~S}$. & $\begin{array}{r}\text { Pts. } \\
1 \frac{1}{4}\end{array}$ & $7^{\circ} \mathrm{E}$ & \multirow{3}{*}{$\begin{array}{l}\text { A point of land in } \\
\text { lat. } 58^{\circ} 30^{\prime} \mathrm{S} \text {., } \\
\text { long. } 64^{\circ} 54^{\prime} \text { W., } \\
\text { bearing by com- } \\
\text { pass N.W. } \frac{1}{4} \mathrm{~N} \text {., } \\
\text { distaut } 60 \text { miles, } \\
\text { with the ship's } \\
\text { head at S. by } \\
\text { W. } \frac{1}{2} \text { W. Devia- } \\
\text { tion as per log. } \\
\text { Variation } 21^{\circ} \text { E. }\end{array}$} \\
\hline $\begin{array}{l}5 \\
6 \\
7 \\
8\end{array}$ & W. by S. $\frac{1}{4} \mathrm{~S}$. & $\begin{array}{l}11 \\
12 \\
13 \\
14\end{array}$ & $\begin{array}{l}9 \\
0 \\
0 \\
1\end{array}$ & N.W. by N. & $\frac{3}{4}$ & $9^{\circ} \mathrm{E}$ & \\
\hline $\begin{array}{r}9 \\
10 \\
11 \\
12\end{array}$ & S.W. $\frac{1}{4}$ W. & $\begin{array}{l}16 \\
14 \\
12 \\
13\end{array}$ & $\begin{array}{l}9 \\
8 \\
8 \\
5\end{array}$ & S.S.E & $\frac{1}{4}$ & $8^{\circ} \mathrm{W}$ & \\
\hline $\begin{array}{l}1 \\
2 \\
3 \\
4\end{array}$ & N.E. by N. & $\begin{array}{l}10 \\
11 \\
12 \\
13\end{array}$ & $\begin{array}{l}9 \\
8 \\
8 \\
5\end{array}$ & W.S.W. & 0 & $11^{\circ} \mathrm{W}$. & \multirow{3}{*}{$\begin{array}{l}\text { A current set cor- } \\
\text { rect magnetic } \\
\text { W. } \frac{1}{2} \text { S. } 39 \text { miles, } \\
\text { from the time } \\
\text { departure was } \\
\text { taken to the end } \\
\text { of the day. }\end{array}$} \\
\hline $\begin{array}{l}5 \\
6 \\
7 \\
8\end{array}$ & N. by E. & $\begin{array}{l}14 \\
15 \\
16 \\
17\end{array}$ & $\begin{array}{l}8 \\
8 \\
8 \\
6\end{array}$ & N.W. by W. & $\frac{1}{2}$ & $12^{\circ} \mathrm{W}$. & \\
\hline $\begin{array}{r}9 \\
10 \\
11 \\
12\end{array}$ & W. by N. & $\begin{array}{l}9 \\
1 \\
2 \\
6\end{array}$ & $\begin{array}{l}7 \\
7 \\
7 \\
9\end{array}$ & S.W. by S. & $\frac{1}{4}$ & $41^{\circ} \mathrm{W}$. & \\
\hline
\end{tabular}

Correct the courses for Deviation, Variation, and Leeway, and find the course and distauce from the given point, and the Latitude and Longitude in.

5.

\begin{tabular}{|c|c|c|c|c|c|c|c|}
\hline Hour. & Course steered. & Knts. & 10ths. & Wind. & $\begin{array}{l}\text { Lee- } \\
\text { way. }\end{array}$ & $\begin{array}{c}\text { Devia- } \\
\text { tion. }\end{array}$ & Remarks. \\
\hline $\begin{array}{l}1 \\
2 \\
3 \\
4\end{array}$ & N.N.W. $\frac{1}{2}$ W. & $\begin{array}{l}4 \\
\mathbf{3} \\
\mathbf{3} \\
\mathbf{1}\end{array}$ & $\begin{array}{l}\mathbf{1} \\
\mathbf{3} \\
\mathbf{1} \\
\mathbf{5}\end{array}$ & N.E. & $\begin{array}{l}\text { Pts. } \\
1 \frac{3}{4}\end{array}$ & $2^{\circ} \mathrm{W}$. & \multirow{3}{*}{$\begin{array}{l}\text { A point in lat. } 29^{\circ} \\
59^{\prime} \mathrm{N} ., \text { long. } 132^{\circ} \\
54^{\prime} \text { E., bearing by } \\
\text { compass N.N.E. } \\
\frac{1}{2} \text { E., ship's head } \\
\text { N.W. by W. De- } \\
\text { viation } 6^{\circ} \text { W., } \\
\text { distant } 15 \text { miles. }\end{array}$} \\
\hline $\begin{array}{l}5 \\
6 \\
7 \\
8\end{array}$ & E.S.E. & $\begin{array}{l}\mathbf{2} \\
3 \\
\mathbf{3} \\
\mathbf{4}\end{array}$ & $\begin{array}{l}1 \\
1 \\
1 \\
7\end{array}$ & N.E. & 2 & $7^{\circ} \mathrm{E}$. & \\
\hline $\begin{array}{r}9 \\
10 \\
11 \\
12\end{array}$ & S. $\frac{3}{4} \mathrm{E}$. & $\begin{array}{l}6 \\
6 \\
5 \\
6\end{array}$ & $\begin{array}{l}3 \\
9 \\
4 \\
4\end{array}$ & E.S.E. & $2 \frac{1}{4}$ & $2^{\circ} \mathrm{W}$. & \\
\hline
\end{tabular}

(Continued on next page.) 


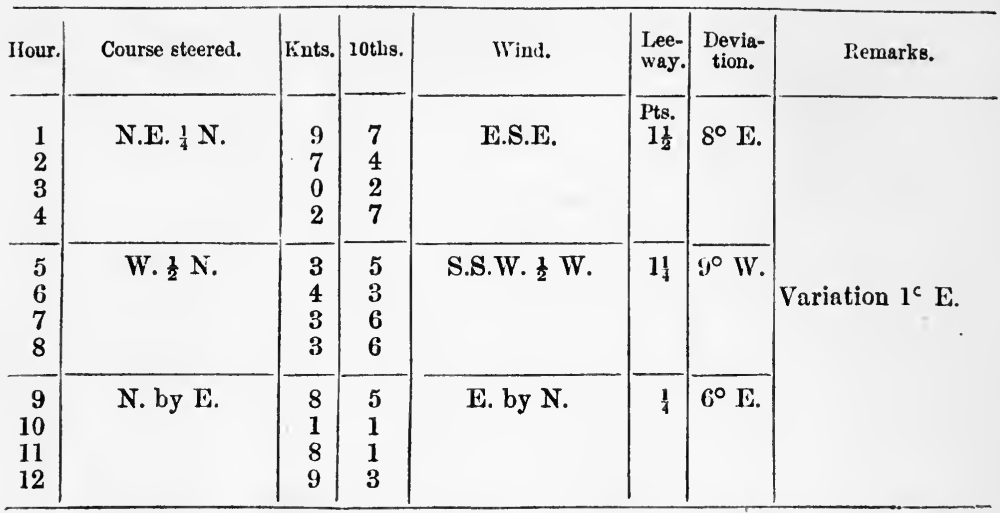

The position by observation was found to be lat. $30^{\circ} 25^{\prime} \mathrm{N}$., long. $133^{?} 7^{\prime} \mathrm{E}$. Find the set and drift of the current.

6.

\begin{tabular}{|c|c|c|c|c|c|c|c|}
\hline Hour. & Course steered. & Knots. & 10ths. & Winds. & $\begin{array}{l}\text { Lee- } \\
\text { way. }\end{array}$ & $\begin{array}{c}\text { Devia- } \\
\text { tion. }\end{array}$ & Remarks. \\
\hline $\begin{array}{l}1 \\
\mathbf{2} \\
3 \\
4\end{array}$ & S. by W. & $\begin{array}{l}12 \\
13 \\
11 \\
12\end{array}$ & $\begin{array}{l}1 \\
2 \\
3 \\
4\end{array}$ & W. by S. & 3 pt. & $9^{\circ} \mathrm{W}$ & \multirow{6}{*}{\begin{tabular}{|l} 
A point in lat. $54^{c}$ \\
$22^{\prime} \mathrm{N} .$, long. $178^{\circ}$ \\
$26^{\prime}$ E., bearing \\
by compass N.W. \\
$\frac{1}{2}$ W., ship's head \\
N. 3 E. Devia- \\
tion as per log, \\
distant 8 miles. \\
Variation $12^{\circ} \mathrm{E}$.
\end{tabular}} \\
\hline $\begin{array}{l}5 \\
6 \\
7 \\
8\end{array}$ & N. ${ }_{4}^{3} \mathrm{E}$. & $\begin{array}{l}12 \\
13 \\
14 \\
11\end{array}$ & $\begin{array}{l}9 \\
8 \\
7 \\
6\end{array}$ & East & $\frac{1}{4} \mathrm{pt}$. & $6^{\circ} \mathrm{E}$ & \\
\hline $\begin{array}{r}9 \\
10 \\
11 \\
12\end{array}$ & East & $\begin{array}{l}11 \\
12 \\
12 \\
13\end{array}$ & $\begin{array}{l}2 \\
2 \\
2 \\
4\end{array}$ & S.S.E. & $\frac{1}{2} \mathrm{pt}$. & $19^{\circ} \mathrm{E}$ & \\
\hline $\begin{array}{l}1 \\
2 \\
3 \\
4\end{array}$ & S.E. & $\begin{array}{r}9 \\
11 \\
12 \\
10\end{array}$ & $\begin{array}{l}3 \\
4 \\
7 \\
6\end{array}$ & S.S.W. & $\frac{3}{4} \mathrm{pt}$. & $11^{\circ} \mathrm{E}$ & \\
\hline $\begin{array}{l}5 \\
6 \\
7 \\
8\end{array}$ & S.S.W. $\frac{1}{4}$ W. & $\begin{array}{l}12 \\
11 \\
14 \\
15\end{array}$ & $\begin{array}{l}6 \\
2 \\
9 \\
3\end{array}$ & N.W. & - & $12^{\circ} \mathrm{W}$. & \\
\hline $\begin{array}{r}9 \\
10 \\
11 \\
12\end{array}$ & E. $\frac{3}{4}$ N. & $\begin{array}{l}13 \\
12 \\
11 \\
13\end{array}$ & $\begin{array}{l}\mathbf{9} \\
\mathbf{9} \\
\mathbf{9} \\
\mathbf{3}\end{array}$ & North & $\frac{1}{4} \mathrm{pt}$. & $18^{\circ} \mathrm{E}$ & \\
\hline
\end{tabular}

The ship by observation was found in lat. $51^{\circ} 59^{\prime} \mathrm{N}$., long. $178^{\circ} 5^{\prime} \mathrm{W}$. Find set and drift of current. 
ART. 27. Mercator's Sailing.-The problem in Mercator's Sailing commonly used, and the only one in the Board of Trade Examination for Mates and Masters, is to find the Course and Distance from place to place, the latitudes and longitudes of both places being given.

The data used in the calculation are-

The difference of latitude.

The difference of longitude.

The meridional difference of latitude.

Definitions.-(1) D. lat.: The sum or difference of the two latitudes (according as they are of different names or of the same name) reduced to miles.

(2) D. long.: The sum or difference of the two longitudes (according as they are of different names or of the same name) reduced to minutes of arc.

N.B.-When the sum of longitudes exceeds $180^{\circ}$, subtract from $360^{\circ}$.

(3) Mer. D. lat.: The sum or difference of the meridional parts for the two latitudes.

Formulce.-(1) To find the Course-

(2) To find the Distance-

$$
\text { Tangent of course }=\frac{\text { D. long. }}{\text { mer. D. lat. }}
$$

\section{Distance $=$ secant of course $\times$ D. lat.}

It may be graphically represented by two similar triangles, $\mathrm{DEC}$ and $\mathrm{ABC}$, the angle at $\mathrm{C}$ being the course, which is common to both triangles. The sides of the smaller triangle represent the elements of plane sailing. The extended meridian CB represents the meridional $\mathrm{D}$. lat. found from the meridional parts for the two latitudes; then the side $\mathrm{AB}$ will be the D. long. in its correct proportion to the departure. The object aimed at in Mercator's method is to find the rhumb course from point to point. For this purpose, the diff. lat. is extended

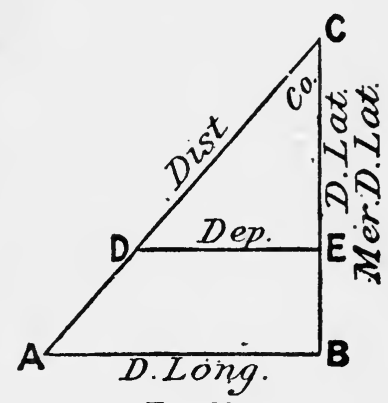

FIG. 80. by means of the meridional parts so as to bear the same proportion to the diff. long. as the true diff. lat. bears to the departure. In the right-angled triangle $\mathrm{ABC}-$

and in the triangle $\mathrm{DEC}$

$$
\text { Tan course }=\frac{\text { D. long. }}{\text { mer. D. lat. }} \cdot . \quad . \quad . .
$$

$$
\frac{\text { dist. }}{\text { D. lat. }}=\sec \text { course }
$$

therefore dist. $=$ D. lat. $\times$ sec course . . . 
These are the only formulæ required for computing the true rhumb course and the distance on that course. Evidently this distance is longer than the distance on a great circle, but the method has the advantage of leading to the destination without change of course.

\section{Examples.-}

1. Find the Course and Distance from A to D on Mercator's principle.

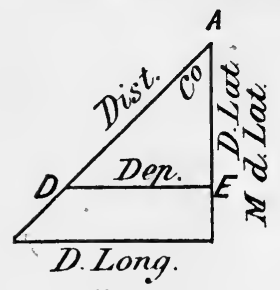

FIG. 81 .
Lat. of $\mathrm{A}, 51^{\circ} 36^{\prime} \mathrm{N}$.; long. of $\mathrm{A}, 8^{\circ} 32^{\prime} \mathrm{W}$. 51, D, $38^{\circ} 32^{\prime} \mathrm{N}$.; 510 N. Mer. parts $3832 \mathrm{~N}$.

134

60

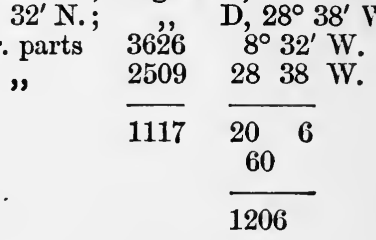
D. long. 1206
Course S. $47^{\circ} 11 \frac{1}{2}^{\prime}$ W. $\quad \ldots \quad \ldots \quad$ log $\tan \overline{10 \cdot 033294}$
Course $47^{\circ} 11 \frac{1}{2}^{\prime} \ldots . \quad \ldots . \quad \ldots \quad \ldots \quad \log \sec 10 \cdot 167780$
D. lat. $784 \ldots \quad \ldots \quad \ldots \quad \ldots \quad \ldots \log 2 \cdot 894316$
Distance 1154 miles $\quad \ldots \quad \ldots \quad \ldots \quad \log 3 \cdot 062096$

784

Note.-The Course is reckoned from $\mathrm{S}$ because $\mathrm{D}$ is south of $\mathrm{A}$, and towards W. because $\mathrm{D}$ is west of $\mathrm{A}$.

2. Find the Course and Distance from $\mathbf{P}$ (Hawraki) to $\mathbf{B}$ (Hawaii).

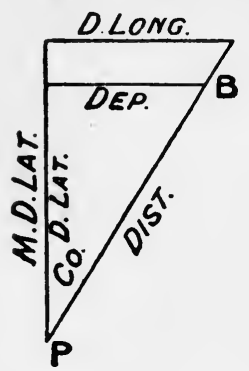

FIG. 82.
Lat. of $\mathrm{P}, 35^{\circ} 59^{\prime} \mathrm{S}$.; long. of $\mathrm{P}, 175^{\circ} 4^{\prime} \mathrm{E}$. , B, $19^{\circ} 50^{\prime} \mathrm{N}$.; , B, $156^{\circ} 40^{\prime} \mathrm{W}$.

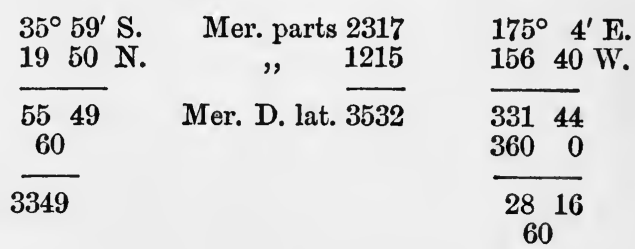

D. long. $\overline{1696}$

D. long. $1696 \quad \ldots \quad \ldots \quad \ldots \quad \ldots \quad \ldots \quad \log 3 \cdot 229426$

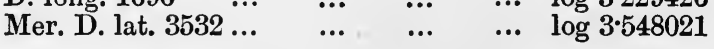

Course N. $25^{\circ} 39^{\prime}$ E. $\quad \ldots \quad \ldots \quad \ldots \quad \log \tan 9 \cdot 681405$

Course $25^{\circ} 39^{\prime} \quad \ldots \quad$... $\quad \ldots \quad \quad \log \sec 10.045056$

D. lat. $3349 \quad \ldots . \quad \ldots \quad \ldots \quad \ldots \quad$ log $3 \cdot 524915$

Distance $3715 \quad \ldots \quad \ldots \quad \ldots \quad \ldots \quad \log 3 \cdot 569971$

NotE.-The Course is reckoned from $\mathrm{N}$. because $\mathrm{B}$ is north of $\mathrm{P}$, and $\mathbf{E}$. because it crosses the meridian of $180^{\circ}$. 
3. Required the Course and Distance by Mercator from $\mathrm{A}$ to $\mathrm{B}$.

Lat. of $\mathrm{A}, 6^{\circ} 15^{\prime} \mathrm{N}$. ; long. of $\mathrm{A}, 79^{\circ} 30^{\prime} \mathrm{E}$.

Lat. $6^{\circ} 15^{\prime} \mathrm{N}$. Mer. parts 376 Long. $79^{\circ} 30^{\prime} \mathrm{E}$.

, $36^{\circ} 10^{\prime} \mathrm{S}$. , $2330 \quad, \quad 113^{\circ} 45^{\prime} \mathbf{E}$.

$\overline{4225} \quad$ Mer. D. lat. $\overline{2706} \quad \frac{34 \quad 15}{60}$

D. 32545

D. long. 2055

D. long. $2055 \quad \ldots \quad \ldots \quad \log 3 \cdot 312812$

Mer. D. lat. $2706 \quad \ldots . \quad \ldots \quad \log 3.432328$

Course S. $37^{\circ} 13^{\prime}$ E. $\quad \log \tan 9 \cdot 880484$

Course $37^{\circ} 13^{\prime} \quad \ldots \quad \log \sec 10 \cdot 098894$

D. lat. $2545 \quad \ldots \quad \ldots \quad \log 3405688$

Distance 3196 miles $\quad \ldots \quad \log 3 \cdot 504582$

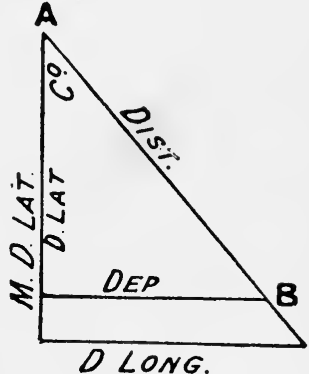

FIG. 83.

4. Required the Course and Distance by Mercator's principle from A, in lat. $57^{\circ} 42^{\prime} \mathrm{S}$.; long. $70^{\circ} 3^{\prime} \mathrm{W}$., to B. in lat. $46^{\circ} 58^{\prime} \mathrm{S}$.; long. $168^{\circ} 20^{\prime} \mathrm{E}$.; also the Course to steer by compass, supposing the variation to be $22^{\circ} \mathrm{E}$., and the deviation of the compass $7^{\circ} 30^{\prime} \mathrm{W}$.

In Fig. 84, ABC is portion of meridian. Scale 1 inch $=2000$ miles. $\mathrm{AC}=0.53$ inch is Mer. D. lat. $\mathrm{ACD}=90^{\circ}$. $\mathrm{CD}=3 \cdot 65$ inch is $\mathrm{D}$. long.

$\mathrm{AB}=0.32$ inch is $\mathrm{D}$. lat.

$\mathrm{BE}$ parallel to CD is Dep.

Then

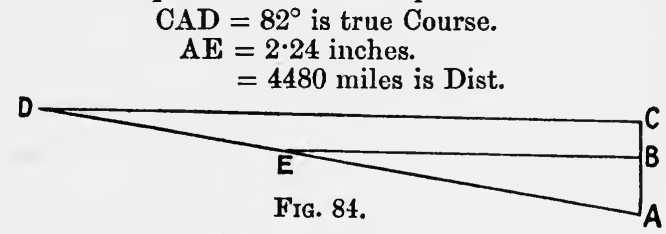

Lat. $57^{\circ} 42^{\prime}$ S. Mer. parts 4260 , $46^{\circ} 58^{\prime} \mathrm{S}$. $1 0 \longdiv { 4 4 }$ Mer. D. lat. $\overline{1060}$ 60

D.
lat. 644
Long. $70^{\circ} 3^{\prime} \mathrm{W}$. ,, $168^{\circ} 20^{\prime} \mathrm{E}$.

$238 \quad 23$

$360 \quad 0$

60

D. long. 7297

D. long. $7297 \quad \ldots \quad \ldots \quad \ldots \quad \ldots \log 3 \cdot 863144$

Mer. D. lat. $1060 \ldots \quad \ldots \quad \ldots \quad \ldots . \quad \ldots \quad \log 3 \cdot 025306$

N. $81^{\circ} 44^{\prime} 5^{\prime \prime} W . \ldots \quad \ldots \quad \ldots \quad \log \tan 10.837838$

Course $81^{\circ} 44^{\prime} 5^{\prime \prime} \quad \ldots \quad \ldots \quad$ log $\sec 10.842372$

74 gives $5^{\prime \prime}$

$\begin{array}{llllll}\text { D. lat. } 644 & \ldots & \ldots & \ldots & \ldots & \log 2 \cdot 808886\end{array}$

Distance 4480 miles $\quad \ldots \quad \ldots \quad \ldots \log 3651258$ 
Note. - When the Course is large, it may be advisable to work to seconds, as in this case, in order to ensure the accuracy of the distance within a mile.

To find the Course by compass :

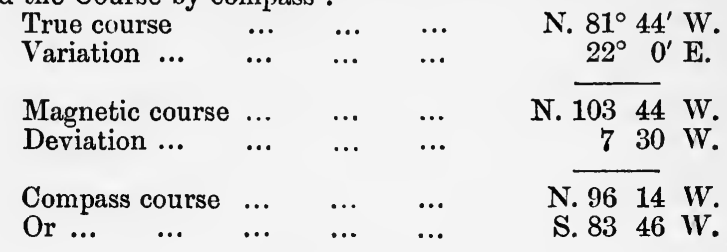

Exercises.

Required the Compass Course and Distance from A to B by calculation on Mercator's principle.

1. Lat. A, $50^{\circ} 49^{\prime}$ N. ; long. $A, 0^{\circ} 0^{\prime}$.

,, B, $48^{\circ} 17^{\prime} \mathrm{N}$.; , , B, $54^{\circ} 47^{\prime} \mathrm{W}$. Variation $19^{\circ} 45^{\prime}$ ' W. ; deviation $20^{\circ} \mathrm{W}$.

2. Lat. A, $11^{\circ} 11^{\prime}$ S. ; long. A, $0^{\circ} 37^{\prime} \mathrm{V}$. , B, $0^{\circ} 0^{\prime}$; $\quad$, B, $0^{\circ} 0^{\prime}$. Var. $23^{\circ} 30^{\prime}$ W.; dev. $10^{\circ} 17^{\prime} \mathrm{E}$.

3. Lat. A, $52^{\circ} 57^{\prime}$ N.; long. A, $158^{\circ} 33^{\prime}$ W. Var. $25^{\circ}$ E. ; dev. $15^{\circ}$ W.' $\quad$ B, $178^{\circ} 48^{\prime} \mathrm{E}$.

4. Lat. A, $14^{\circ} 9^{\prime}$ S.; long. A, $180^{\circ} 0^{\prime}$. , B, $0^{\circ} 0^{\prime} ; \quad 7^{\circ}, \mathrm{B}, 174^{\circ} 57^{\prime} \mathrm{E}$. Var. $9^{\circ}$ E. ; dev. $5^{\circ} 30^{\prime}$ E.

5. Lat. A, $35^{\circ} 15^{\prime}$ S.; long. A, $115^{\circ} 15^{\prime}$ E. , B, $51^{\circ} 30^{\prime} \mathrm{S}$.; Var. $7 \frac{10}{2}$ W.; dev. $15 \frac{10}{2}$ W.

6. Lat. A, $51^{\circ} 24^{\prime}$ N.; $\quad$ long. A, $9^{\circ} 36^{\prime} \mathrm{WV}$. " B, $38^{\circ} 36^{\prime} \mathrm{S}$.; Var. $25 \frac{1}{2}^{\circ}$ W. ; dev. $14 \frac{1}{2}{ }^{\prime \prime} \mathrm{E}$.

7. Lat. A, $0^{\circ} 0^{\prime}$; long. A, $81^{\circ} 27^{\prime}$ IV. , B, $61^{\circ} 10^{\prime} \mathrm{S}_{\text {; }}$; $\quad$,' B, $170^{\circ} 59^{\prime} \mathrm{E}$. Var. $2^{\circ} 20^{\prime}$ E.; dev. $20^{\circ} 40^{\prime} \mathrm{E}$.

8. Lat. A, $42^{\circ} 56^{\prime}$ S. ; long. A, $100^{\circ} 36^{\prime} \mathrm{W}$. , B, $10^{\circ} 36^{\prime} \mathrm{N}$.; , B, $180^{\circ} 0^{\prime}$. Var. $17^{\circ} 10^{\prime} \mathrm{W}$.; dev. $13^{\circ} 50^{\prime} \mathrm{E}$.

9. Lat. A, $36^{\circ} 19^{\prime} \mathrm{S}$.; $\quad$ long. A, $30^{\circ} 46^{\prime} \mathrm{W}$. , B, $36^{\circ} 12^{\prime} \mathrm{S}$; $\quad, \quad \mathrm{B}, 58^{\circ} 23^{\prime} \mathrm{W}$. Var. $31^{\circ} 15^{\prime} \mathrm{W}$.; dev. $14^{\circ} 26^{\prime} \mathrm{W}$.

10. Lat. $\mathrm{A}, 0^{\circ} 0^{\prime}$; long. $\mathrm{A}, 31^{\circ} 17^{\prime} \mathrm{W}$. , B, $63^{\circ} 28^{\prime} \mathrm{N}$.; $\quad \mathrm{B}, 28^{\circ} 16^{\prime} \mathrm{W}$. Var. $12^{\circ} 20^{\prime}$ W.; dev. $15^{\circ} 30^{\prime} \mathrm{E}$.

11. Lat. A, $32^{\circ} 22^{\prime} \mathrm{N}$.; long. A, $33^{\circ} 15^{\prime} \mathrm{E}$. ,, B, $37^{\circ} 4^{\prime} \mathrm{N}$.; $\quad$, B, $15^{\circ} 40^{\prime} \mathrm{E}$. Var. $5^{\circ} 35^{\prime} \mathrm{W}$.; dev. $12^{\circ} 29^{\prime} \mathrm{W}$.

12. Lat. A, $0^{\circ} 17^{\prime} \mathrm{S}$. ; long. A, $59^{\circ} 47^{\prime} \mathrm{W}$. ", B, $1^{\circ} 59^{\prime} \mathrm{N}$; ; $10^{\circ}$ ' $\mathrm{B}, 120^{\circ} 13^{\prime} \mathrm{E}$. Var. $6^{\circ} 40^{\prime}$ E.; dev. $13^{\circ} ' 50^{\prime} \mathrm{W}$. 
ART. 27.-Current Sailing.

1. Given the course and rate of sailing of a ship, and the

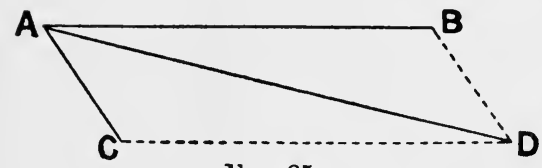

FIG. 85. "set" and "drift" of a current during the same interval of time, to find the course and distance made good.

Let $\mathrm{AB}$ represent the course and the distance sailed, and AC the "set" and "drift" of the current. Draw $C D$ parallel to $A B$, and $B D$ parallel to $A C$, and join $A D$; then $A D$ will represent the course and distance made good during the time elapsed.

Here the angle $\mathrm{BAC}$ is known, and therefore $\mathrm{ABD}$ is also known, because it is equal to $180^{\circ}-\mathrm{BAC}$. Also the sides $\mathrm{AB}$ and $\mathrm{BD}$ of the triangle $\mathrm{ABD}$ are known (because $\mathrm{BD}=\mathrm{AC}$ ). Hence two sides and included angle of the oblique-angled triangle ABD are known, from which the other angles and the third side $A D$ can be computed. From the given direction of $\mathrm{AB}$ and the angle $\mathrm{BAD}$ the course of $\mathrm{AD}$ may be found.

Example 1.-A ship steers E. by N. at 10 miles per hour in a current setting S. by W. 3 miles per hour. Find the course and distance made good.

The angle $\mathrm{BAC}=10$ points, therefore $\mathrm{ACD}=6$ points (or $67^{\circ} 30^{\prime}$ ), because the two together are equal to two right angles. Applying the formula for two sides and including angle-

$$
\begin{aligned}
& \tan \frac{1}{2}(A-D)=\frac{C D-A C}{C D+A C} \cdot \tan \frac{1}{2}(A+D) \\
& 180^{\circ} \quad 0^{\prime} \\
& 67 \quad 30 \\
& \text { A + D } 11230 \\
& \frac{1}{2}(\mathrm{~A}+\mathrm{D}) \overline{56 \quad 15} \\
& \text { CD } 10 \\
& \text { AC } 3 \\
& \mathrm{CD}+\mathrm{AC} \overline{\mathbf{1 3}} \\
& \mathrm{CD}-\mathrm{AC} \quad 7
\end{aligned}
$$

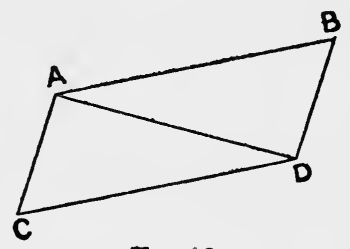

Fig. 86.

.. $\quad \tan 10 \cdot 175107$

... $\quad \log 0.845098$

11.020205

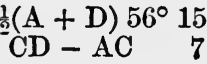$$
\mathrm{CD}+\mathrm{AC} \quad 13
$$$$
\text { ... } \quad \log 1 \cdot 113943
$$$$
\frac{1}{2}(\mathrm{~A}-\mathrm{D}) 3852
$$$$
\frac{1}{2}(\mathrm{~A}+\mathrm{D}) 56 \quad 15
$$

$\angle \mathrm{CDA} 1723$

Course of AB N. $7845 \mathrm{E}$.

\section{(being the lesser angle ( opposite to lesser side)}

$$
\begin{array}{rl}
\text { N. } 96 & 8 \mathrm{E} . \\
180 & 0
\end{array}
$$

Course made good S. 8352 E. 
To find distance made good (AD).

$$
\begin{aligned}
& \frac{\mathrm{AD}}{\mathrm{AC}}=\frac{\sin \mathrm{ACD}}{\sin \mathrm{CDA}} \\
& \text { therefore } \mathrm{AD}=\frac{\mathrm{AC} \times \sin \mathrm{ACD}}{\sin \mathrm{CDA}} \\
& \operatorname{ACD} 67^{\circ} 30^{\prime} \quad \ldots \quad \ldots \quad \sin 9.965615 \\
& \begin{array}{cccccc}
\mathrm{AC} & 3 & \ldots & \ldots & \log 0.477121 \\
\mathrm{CDA} & 17^{\circ} & 23^{\prime} & \ldots & & \operatorname{cosec} 10.524673
\end{array} \\
& \text { AD } 9 \cdot 3 \quad \ldots \quad \ldots \quad \log 0.967409
\end{aligned}
$$

2. Given the course to a given point, the set and drift of the current, and the rate of sailing of the ship; to find the course to steer and the distance made good towards the point in a given time.

Let $\mathrm{A}$ be the place of the ship, and $\mathrm{B}$ the destination, and $\mathrm{AC}$ the set and drift of the current.

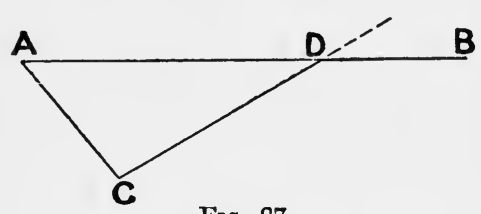

FIG. 87.

B From $\mathrm{C}$ set off CD equal to the distance the ship would sail in the given time, cutting $\mathrm{AB}$ in the point $D$. Then $C D$ gives the course to steer, and $\mathrm{AD}$ is the distance made good towards $B$.

In the triangle $\mathrm{ACD}$, the two sides $\mathrm{AC}$ and $\mathrm{CD}$ are given, and the angle at $\mathrm{A}$ opposite to the latter, from which the other angles and remaining side can be found by the rule of sines (Case I.).

Example.-Given the direct course from A to B, E. by S., and the set and drift of the current S.S.E. 4 miles per hour, the ship's rate of sailing being 7 miles per hour, required the course to steer in order to counteract the effect of the current, and the distance made good towards B in 2 hours?

Draw AC in a S.S.E. direction, and set off on it 8 miles (drift in 2 hours), and from $\mathrm{C}$ set off 14 miles (2 hours' sailing), cutting $\mathrm{AB}$ in the point $\mathrm{D}$, and

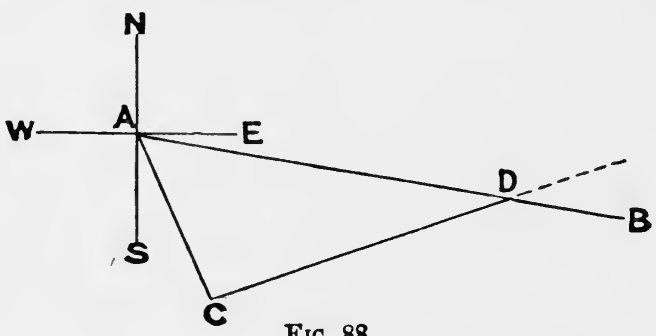

Fig. 88.

join $\mathrm{CD}$. The line $\mathrm{CD}$ will give the course to steer, and $\mathrm{AD}$ is the distance made good.

Here $\mathrm{AC}=8, \mathrm{CD}=14$, and the angle $\mathrm{CAD}$ (opposite to $\mathrm{CD}$ ) $=56^{\circ} 15^{\prime}$.

$$
\begin{aligned}
\text { Then } \frac{\sin D}{\sin A} & =\frac{A C}{C D} \\
\text { and } \sin D & =\frac{A C \times \sin A}{C D}
\end{aligned}
$$




$$
\begin{aligned}
& \begin{array}{lllll}
\mathrm{A} 56^{\circ} 15^{\prime} & \ldots & \ldots & \text { sine } & 9.919346
\end{array}
\end{aligned}
$$

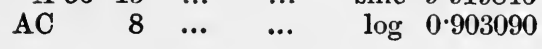

$$
\begin{aligned}
& 10 \cdot 822936 \\
& \begin{array}{llllll}
\mathrm{CD} & 14 & \ldots & \ldots & \log 1 \cdot 146128
\end{array} \\
& \text { D } 28^{\circ} 22^{\prime} \text { sine } \quad 9 \cdot 676808
\end{aligned}
$$

Course from A to B S. $7845 \mathrm{E}$.

$$
\begin{array}{rl}
\text { S. } 107 & 7 \mathrm{E} . \\
180 & 0
\end{array}
$$

Course to steer N. $7253 \mathrm{E}$.

To find AD.

$$
\begin{aligned}
& \mathrm{A}=56^{\circ} 15^{\prime} \\
& \mathrm{D}=\frac{2822}{8427} \quad \frac{\mathrm{AD}}{\overline{\mathrm{CD}}}=\frac{\sin \mathrm{C}}{\sin \mathrm{A}} \\
& 84 \quad 37 \\
& 180 \quad 0 \\
& \therefore \mathrm{AD}=\frac{\mathrm{CD} \times \sin \mathrm{C}}{\sin \mathrm{A}} \\
& \mathrm{C}=9523 \\
& \begin{array}{cccccc}
C & 95^{\circ} & 23^{\prime} & \ldots & \ldots & \sin 9 \cdot 998080 \\
\mathrm{CD} & 14 & \ldots & \ldots & \log 1 \cdot 146128 \\
\mathrm{~A} 56 & 15 & \ldots & &
\end{array}
\end{aligned}
$$

3. The ship's position by observation and by dead reckoning being known, the set and drift of the current may be found. (Solved by right-angled triangles.)

Example.-At noon on a certain day, according to dead reckoning from the previous noon, a ship was in lat. $45^{\circ} 30^{\prime} \mathrm{N}$., long. $28^{\circ} 15^{\prime} \mathrm{W}$.; but by observation she was found to be in lat. $46^{\circ} 15^{\prime} \mathrm{N}$., long. $27^{\circ} 8^{\prime} \mathrm{W}$. Required the set and drift of the current.

D.R. lat. $45^{\circ} 30^{\prime} \mathrm{N}$. $\stackrel{\text { M.pts. }}{3073}$ Long. $28^{\circ} 15^{\prime} \mathrm{WV}$. Obs. „, $4615 \mathrm{~N}$. 3137 " $27 \quad 8$ W.

$$
45 \mathrm{~N} \text {. } \frac{64}{67}
$$

D. long. $67 \quad \ldots \quad \log \quad 1 \cdot 826075$ M. D. lat. 64 ... $\log 1 \cdot 806180$

Set of current N. $46^{\circ} 19^{\prime}$ E. $\tan 10.019895$

$$
\text { D. lat. }{ }^{46^{\circ} 19^{\prime}} \quad \ldots \quad \text { sec } 10 \cdot 160728
$$

Drift in 24 hours $65 \cdot 1 . \quad \log 1 \cdot 813941$

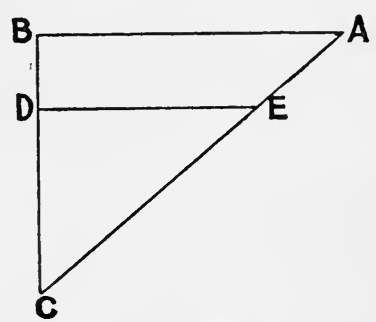

Fig. 89.

$$
\text { Rate per hour } \quad=\frac{65 \cdot 1}{24}=2 \cdot 7 \text { miles. }
$$

Note.-This is a case of finding a course and distance by Mercator, and is solved by the formulæ for right-angled triangles.

Examples 1 and 3 can be solved approximately by means of the Traverse Table. 
Example 1.-

\begin{tabular}{|c|c|c|c|c|c|}
\hline Courses. & Dist. & N. & S. & E. & w. \\
\hline \multirow[t]{3}{*}{$\begin{array}{l}\text { E. by N. } \\
\text { S. by W. }\end{array}$} & $\begin{array}{r}10 \\
3\end{array}$ & $2 \cdot 0$ & $\overline{2 \cdot 9}$ & $9 \cdot 8$ & $\overline{0 \cdot 6}$ \\
\hline & & \multirow[t]{2}{*}{$2 \cdot 0$} & $\begin{array}{l}2 \cdot 9 \\
2 \cdot 0\end{array}$ & $\begin{array}{l}9 \cdot 8 \\
0.6\end{array}$ & \multirow[t]{2}{*}{06} \\
\hline & & & 0.9 & $9 \cdot 2$ & \\
\hline
\end{tabular}

Course and distance made good, S. $84^{\circ}$ E. $9 \cdot 3$ miles.

Example 3.-D. lat. 64 and dep. 67 give course $46^{\circ}$

Course $46^{\circ}$, with D. lat. 45 , give dist. 65

Questions in current sailing may be varied in many ways, but all of them can be solved on the principles of the three foregoing examples.

ART. 28.-The "Danger Angle."-When sailing near the land where there are outlying dangers, a safe passage may be secured

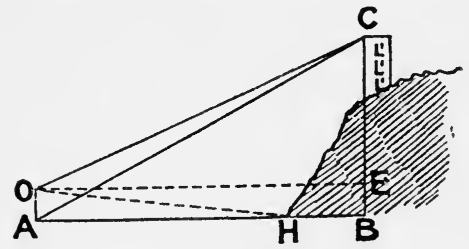

FIG. 90. by calculating the angle subtended at a safe distance by the height of the top of a lighthouse or cliff above sea-level. Setting this angle on the sextant, the navigator so shapes his course that this vertical angle is not exceeded, allowance being also made for the dip of the land horizon (page 191 Norie or 35 Raper).

Referring to the figure, the height $\mathrm{BC}$ and the safe distance $\mathrm{AB}$ being known (by the chart) -

$$
\operatorname{Tan} \angle \mathrm{BAC}=\frac{\mathrm{CB}}{\mathrm{AB}}
$$

Let $\mathrm{AO}$ be the height of observer's eye above sea-level, $\mathrm{OE}$ a horizontal line, and $H$ the base of the cliff or land horizon; then $\angle \mathrm{EOH}$ is the dip, $\mathrm{EB}=\mathrm{OA}$, and $\mathrm{CE}=\mathrm{CB}-\mathrm{EB}$.

Now, $\tan \angle \mathrm{COE}=\frac{\mathrm{CE}}{\mathrm{OE}}$, and the dip being added to $\angle \mathrm{COE}$, the danger angle $\mathrm{COH}$ is found.

Example.-The height of the top of a lighthouse which stands inland 500 feet is 725 feet, and, owing to the existence of a sunken rock, it is not safe to pass nearer the land than $1 \frac{1}{4}$ mile. Required the greatest vertical angle for safe navigation which the top of the lighthouse should make with the base of the cliff on which it stands, the height of eye being $20 \mathrm{ft}$. 
Referring to the figure-

$$
\begin{aligned}
& \mathrm{CE}=725-20=705 \mathrm{ft} \text {., } \mathrm{AH}=6600 \mathrm{ft} \text {. } \\
& \text { and } \mathrm{AB} \text { or } \mathrm{OE}=6600+500=7100 \mathrm{ft} \text {. } \\
& \text { Now, } \tan \mathrm{COE}=\frac{\mathrm{CE}}{\mathrm{OE}}=\frac{705}{7100} \\
& 705 \quad \ldots \quad \ldots \quad \log 2 \cdot 848189 \\
& \mathrm{COE}=5^{\circ} 40^{\prime} \quad \ldots \quad \ldots \quad \tan 8.996931 \\
& + \text { Dip } 10
\end{aligned}
$$

$\angle \mathrm{COH} 550$ the danger angle required.

\section{To find the Width of a River} or Channel.-Let $\mathrm{C}$ be a prominent object on the opposite bank, and $A$ and $B$ two stations whose distance apart is known, $\mathrm{B}$ being chosen so that the $\angle \mathrm{ABC}$ is a right angle. The horizontal angle at $A$, subtended by $B$ and $C$, can be measured by means of a sextant or prismatic compass.

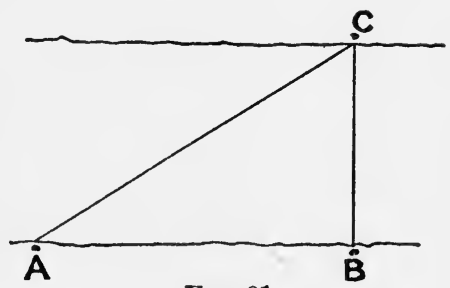

Fig. 91.

$$
\text { Then } \begin{aligned}
\frac{C B}{A B} & =\tan A \\
\text { and } \mathrm{CB} & =A B \times \tan A
\end{aligned}
$$

Example.-Given the distance $\mathrm{AB}=600$ yards, and the angle $\mathrm{CAB}=42^{\circ} 30^{\prime}$, required the width $(\mathrm{CB})$ of the river.

$$
\begin{array}{rrrrr}
\mathrm{A} & 42^{\circ} 30^{\prime} & \ldots & \ldots & \tan 9 \cdot 962052 \\
\mathrm{AB} & 600 & \ldots & \ldots & \log 2 \cdot 778151 \\
\mathrm{BC}= & 549 \cdot 8 & \ldots & \ldots & \log 2 \cdot 740203
\end{array}
$$

therefore the width of the river is 550 yards nearly.

\section{Miscellaneous Problems.}

1. Two ports in lats. $38^{\circ} \mathrm{S}$. and $50^{\circ} \mathrm{S}$. are on the same meridian; a vessel leaves the former, and, after sailing due W. 300 miles, steers due S. until the second parallel is reached. How far is she then distant from the second port?

2. Two places, $A$ and $B$, are in the same latitude, and in longs. $10^{\circ} \mathrm{W}$. and $20^{\circ} 20^{\prime} \mathrm{W}$. respectively; a ship, sailing 10 knots, took exactly 48 hours to pass from one to the other. Find the latitude.

3. A vessel sailed from lat. $35^{\circ} 20^{\prime} \mathrm{N}$., long. $30^{\circ} \mathrm{W}$., 250 miles due $\mathrm{N}$., 250 miles due W., 250 miles due S., and 250 miles due E. Required her latitude and longitude in.

4. A ship which sails 8 knots per hour, within 6 points of the wind, has to reach a port 120 miles S.S.W. of her, wind S.W. How long will she take?

5. A ship, after steaming S.E. by E. 12 knots per hour for 23 hours, from a position lat. $25^{\circ} 36^{\prime} \mathrm{S}$., long. $62^{\circ} 35^{\prime} \mathrm{E}$., found herself in lat. $27^{\circ} 25^{\prime} \mathrm{S}$., long. $66^{\circ} 45^{\prime}$ E. Find set and drift of current. 
6. A ship has to reach a port 30 miles N.N.W. of her ; the wind is $\mathrm{N}$. by $E$., and she can sail 7 knots within 6 points of the wind, making point leeway; she starts on the starboard tack, wishing to make her port in two tacks. After what interval must she go about?

7. An observer in a boat finds that the angle of elevation of the top of a righthouse standing upon a cliff is $32^{\circ}$; after the boat has been rowed 100 yards directly towards the lighthouse, the elevation of the same point is $71^{\circ}$. Find the distance of the boat from the foot of the cliff at both observations; and, if at both points of observation the angle subtended by the lighthouse is found to have the same value, find the heights of cliff and lighthouse.

8. The upper part of a mast is 30 feet long, and subtends, at a point 150 feet in a horizontal line from the base, the same angle as that subtended at the same point by a man 6 feet high standing at the base. Find height of the mast.

9. A steamer is being steered S.W. $\frac{1}{2} \mathrm{~W}$., at the rate of 12 miles per hour, in a known current setting W.N.W. $2 \frac{1}{2}$ miles per hour. Required the course and distance made good per hour.

10. Given the course and distance to a port, N. $75^{\circ} \mathrm{W} .196$ miles ; a steady current is setting $S .15^{\circ} \mathrm{W} .1 \cdot 9$ mile per hour, and the vessel steams $10 \mathrm{knots}$. What course should be steered to counteract the current, and what progress is made towards the port in 12 hours?

11. A ship's position is, by dead reckoning, lat. $48^{\circ} 21^{\prime} \mathrm{S}$., long. $43^{\circ} 28^{\prime} \mathrm{W}$. ; and by observation, lat. $47^{\circ} 16^{\prime}$, long. $41^{\circ} 3^{\prime} \mathrm{W}$. Assuming the discrepancy to be due to a current, what was its set and drift during the time elapsed since the previous observations?

12. The true course to destination is $\mathrm{N} .33^{\circ} \mathrm{W}$., and distance 75 miles; but after steaming 5 hours on that course at 14 miles per hour, it was found to bear $\mathrm{N}$. by W. (true), and distant by cross-bearings 10 miles. What was the effect of the current?

13. How long should it take a steamer to reach her destination, bearing W.N.W. 85 miles distant, if steering the proper course to counteract the effect of a steady current setting $\mathrm{S}$. $20^{\circ} \mathrm{W}$. at the rate of $23_{4}^{3}$ miles per hour, the ship's rate of steaming being 13 knots?

14. A departure is taken at 6 P.M., from a position determined by crossbearings in lat. $51^{\circ} 18^{\prime} \mathrm{N}$., long. $9^{\circ} 42^{\prime} \mathrm{W}$.; her course is set W. $\frac{1}{2} \mathrm{~S}$., and after steaming at the rate of 14 knots per hour until noon the following day, the position is found by observation to be lat. $51^{\circ} 5^{\prime} \mathrm{N}$., long. $16^{\circ} 20^{\prime} \mathrm{W}$. Required the set and drift of the current.

15. From a place $A$, two ships start at same time steaming 10 knots and 8 knots respectively due $\mathrm{E}$. After two hours the two ships bear $\mathrm{S} .46^{\circ} \mathrm{W}$. and $\mathrm{S}$. $66^{\circ} \mathrm{W}$. from a place $\mathrm{B}$ on the same parallel as and 30 miles E. of $\mathrm{A}$. Find set and drift of current.

16. From a ship at anchor a torpedo boat known to be steaming at $15 \mathrm{knots}$ was observed, at 9 A.M., to bear N. $20^{\circ}$ W., at $9^{\mathrm{h}} 10^{\mathrm{m}}$ she bore N. $5^{\circ}$ E., and at $9^{\mathrm{h}} 30^{\mathrm{m}}$ N. $35^{\circ}$ E. Determine course steamed by T. B. and her distance from ship in her last position. 


\section{CHAPTER VII.}

TIDES.

ART. 29.-Observation reveals the fact that the waters around our coast are not at the same height at all hours of the day. At times great tracts are uncovered which at other times have several feet of water over them. This is a consequence of what are known as the "Tides," and is due to the attraction by the moon and sun of the waters of the ocean, combined with the rotation of the earth on its axis. The changes in the distances and relative positions of these bodies account for the general variations in the character of the tides, but local influences modify their action, and make the determination of high and low water at any place a matter of extreme difficulty. The rise and fall occurs twice in about 243 hours, which is the mean value of the lunar day, and tends to show that the moon's influence plays the most important part, being more than twice that of the sun's.

Let the figure represent the earth surrounded by an envelope of water, shown by the dotted circle.

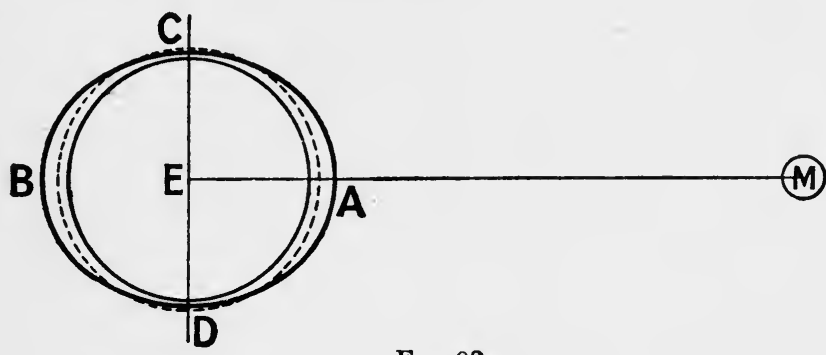

FIG. 92.

Under the action of the moon $M$, the waters assume an elliptical form, being piled up on the sides nearest to and furthest from the moon, and correspondingly reduced on the sides at right angles to this direction, thus causing the waters to be higher at $A$ and $B$, in the direction of the line of centres EM; and lower 
at $\mathrm{C}$ and $\mathrm{D}$ at right angles to this direction. As the earth rotates from west to east, this crest moves from east to west. The action of the sun is similar to the moon, and causes two solar tides in a day.

When the centres of the sun and moon are in a line, that is, at new moon, the bodies being in conjunction, or at full moon, when they are said to be in opposition, the solar and lunar effects correspond, and we have the highest or Spring tides.

When the bodies are $90^{\circ}$ apart or in quadrature, the solar low water corresponds with the lunar high water, and the lowest or Neap tides occur.

As the moon moves eastward faster than the sun, the combined effect will be to produce a crest to the westward of the moon during the first and third quarters, and thus the time of high water will be hastened; also an opposite effect during the second and fourth quarters, when the time of high water will be retarded. This is called the priming and lagging of the tides.

The middle between the levels of high water and low water at Springs is called the mean level of the sea (M.T.L.).

The datum line is the level of low water of ordinary Springs, (M.L.W.S.) and the height of a tide is measured above this line unless it is stated otherwise in the Admiralty Tide Tables, where full information is given at the foot of the page for each port showing what the zero of predictions is.

The interval which elapses between the moon's transit each day and the time of $\mathrm{H} . \mathrm{W}$. next following is the Lunitidal Interval; the mean of the lunitidal intervals for all days between new and full moon is the Corrected establishment of the Port; the lunitidal interval on the days of new and full moon is the Vulgar establishment, and is registered in Roman figures on Admiralty charts as H.W.F. and C.

ART. 31.- In the Admiralty Tide Tables are given the times of High and Low Water and Heights above the zero of predictions selected for the various ports, around the British Isles and at other places chosen through the world, called "standard" ports. The Tables are in two parts, at the end of Part I. is an index of all standard ports, and of ports referred to a particular standard, and full information is tabulated for each day of the month throughout the year on the pages mentioned. At the end of Part II. is a general index, and on referring to the proper pages the lat., long., H.W.F. and C., and rise at Springs and Neaps are found for each place. Part II. is used when insufficient, or no information is given in Part I. for the required place.

The tides in Part I. are entered in order of occurrence, P.M. times and heights in block type. 
The times given are STANDARD or mean time of certain meridians. Local and Greenwich times may be obtained by applying D. Long. in time. The "time differences" show how much earlier (if marked -) later (if marked +) high and low water occur at the required port than at the standard.

When no time difference is entered, or place not found in Part I., turn up index Part II. and on the page or pages will be found the Greenwich times of H.W.F. and C. at the required port and at the selected standard. The difference between these is the time difference, and is added $(t)$ when full and change at place is greater than that at standard, subtracted (-) when less.

The port to be selected as standard is the nearest one geographically to the ship.

REMARK.- When the difference is + , and the sum amounts to more than $12^{\mathrm{h}}$, reject $12^{\mathrm{h}}$ and change from A.M. to P.M. on the same day, or from P.M. to A.M. on the day after: it may be necessary to take the P.M. time of tide for the day before, in order to obtain the A.M. time of tide on the required day.

When the difference is -, and the time entered in the Tables is less than the difference, borrow $12^{\mathrm{h}}$, and change from P.M. to A.M. on the same day, or from A.M. on the day after to P.M. on the required day.

Examples.-

1. Find the M.T.G. and M.T.S. of H.W. on September 20th off Pembroke Dock.

$$
\begin{aligned}
& \text { M.T.G. H.W. Pemb. Dock No A.M. Noon. } \\
& \text { Long. }-20^{\mathrm{m}} \quad-20^{\mathrm{m}} \\
& \therefore \text { M.T.S. H.W. Pemb. Dock } 11^{\mathrm{h}} 40^{\mathrm{m}} \text { A.M., No P.M. }
\end{aligned}
$$

2. Find the M.T.G. and M.T.S. of H.W. on August 22nd off Llanelly.

M.T.G. H.W. Pemb. Dk. $0^{\mathrm{h}} 1^{\mathrm{m}}$ A.M.

$$
\text { Diff. }+1
$$

M.T.G. H.W. Llanelly 02 A.M.

Long. W. -17

M.T.S. H.W. Llanelly $\overline{1145 \text { P.M. }}$

$\therefore$ No A.M. $0^{\mathrm{h}} 36^{\mathrm{m}}$ P.M.

$+1$

037 P.M.

$-17$

020 P.M.

3. Find the M.T.G. of H.W. on July 22nd off Limerick.

Dublin T. H.W. Galway $10^{\mathrm{h}} \quad 1^{\mathrm{m}}$ A.M. $\quad 10^{\mathrm{h}} 30^{\mathrm{m}}$ P.Mr. Diff. +134

Dublin T. H.W. Limerick 11 35 A.M. Long. W. + 25 $+134$

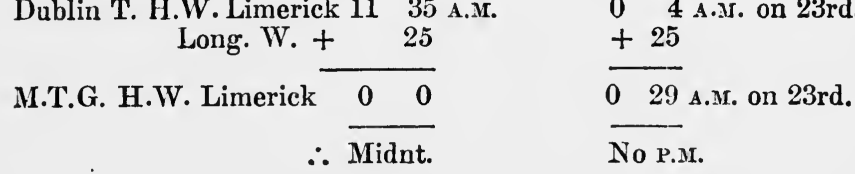


4. Find the M.T.G. of H.W. on Oct. 21st off St. Mary's.

$\begin{array}{ccc}\text { M.T.G. H.W. Devonport } & 0^{\mathrm{h}} 31^{\mathrm{m}} \text { A.M. } & 1^{\mathrm{h}} 9^{\mathrm{m}} \text { P.M. } \\ \text { Diff. }-117 & -117^{-}\end{array}$

M.T.G. H.W. St. Mary's $\overline{11} 14$ р.м. $\overline{1152}$ А.м.

No P.M.

5. Find the M.T.G. and M.T.S. of H.W. on Sept. 21st off Lizard Point.

H.W. F. \& C. Devonport $\quad 6^{\mathrm{h}} 0^{\mathrm{m}}$

" Lizard Point 521

$$
\text { Diff. }-\overline{039}
$$

M.T.G. H.W. Devonport $\quad 0^{\mathrm{h}} 30^{\mathrm{m}}$ P.M.

Diff. $\quad-0 \quad 39$

M.T.G. H.W.Lizard Point $\overline{1151}$ A.M. No P.M.

Long. W. -021

M.T.S. Lizard Point $\overline{1130}$ A.M. No P.M.

\section{ExerCises.}

1. Find the M.T.G. of high water-

at Bridlington on Nov. 29th.

„Spurn Point on Dec 18th.

"Dingle on Aug. 10th.

" Hilbre Island on Oct. 13th.

" Clydebank on Sept. 10th.

2. Find the M.T.S. of high water-

at Rotterdam on Jan. 19th and 20th.

"Ayr on Nov. 9th and 10th.

"Crinan on Dec. 21st and 22nd

"Port Carlisle on Sept. 28th and 29th.

"Wicklow on Sept. 30th and Oct. 1st.

3. Find the M.T.G. and M.T.S. of high water-

at Quaco on July 8th.

"Strangford Quay on Oct. 29th.

4. Find the M.T.G. of high water-

at Ardrishaig on Nov. 9th

H.W. F. and C. at Greenock $12^{\mathrm{h}} 24^{\mathrm{m}}$.

Also at "Southampton on Jan. 22 nd.

H.W. F. and C. at Portsmouth Dockyard $11^{\mathrm{h}} 45^{\mathrm{m}}$.

" "Southampton $\left\{\begin{array}{cc}0^{\mathrm{h}} & 39^{\mathrm{m}} \\ 11 & 2\end{array}\right.$

Times H.W. at Portsmouth $0^{\mathrm{h}} 44^{\mathrm{m}}$ A.M. $1^{\mathrm{h}} 1^{\mathrm{m}}$ P.M. 


\section{CHAPTER VIII.}

\section{REDUCTION OF SOUNDINGS.}

ART. 32.-Near to land in foggy weather, the greatest security for the navigator is the frequent use of the "lead," and feeling his way by "ground navigation." A line of soundings and specimens of the bottom (brought up by the "arming" of the lead) will generally enable him to fix his position on the chart, or give him due warning of danger.

In Board of Trade inquiries into cases of stranding, the first importance is properly attached to the taking of soundings, and woe to the captain who may be found to have neglected this precaution.

The soundings marked on charts are from the Mean Low-water Level of spring tides, but the actual depth at a place varies with Springs and Neaps and the interval from high water. The difference between the sea-level at the "time of cast" and the Mean Low water of Springs is the Reduction of Soundings.

The Heights of Tides in the Admiralty Tables are measured from the same zero or datum line as used for the chart soundings, but some local tables, e.g. the Liverpool or Holden's Tables, give the heights from a datum line five feet below the Mean Sea-level.

In the diagram, let $\mathrm{O}$ (zero) be the mean level of low water spring tides, $H$ the mean high water springs, and $\mathrm{M}$ the mean level of the sea or half-tide level; also let $h_{1}, h_{2}, h_{3}, h_{4}$ be the high-water marks of various tides, and $l_{1}, l_{2}, l_{3}, l_{4}$ the corresponding low-water marks, and $B$ the sea-bottom.

Now, if the lead were cast when the sealevel is at $O$, it would give the same sounding as the chart, but at other times there would be

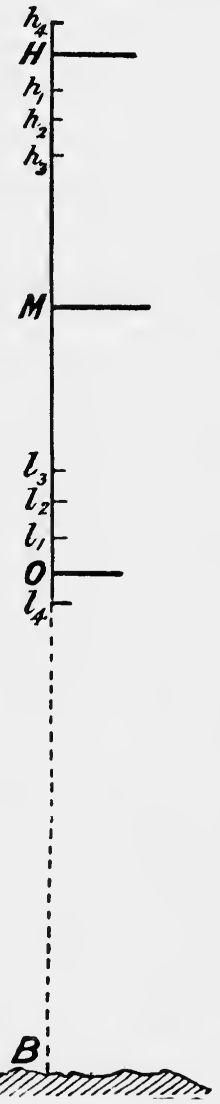

Fig. 93. a difference depending on the height of the tide in the tables and the interval from high water. This difference is the Reduction of Soundings. 
The Half Range of any tide is found by subtracting the half mean spring range (H.M.S.R.) from the height, e.g. $\mathrm{M} h_{1}=\mathrm{O} h_{1}$ - O.M.

When the half-range, the time from high water and the time occupied in rising or falling are known, reference to the Tidal Diagrams No. I. to V. in the Admiralty Tables, or a diagram drawn by the student himself, gives the difference of level between $M$ and the actual surface of the sea, which, being added to or taken from the H.M.S.R., gives the height above mean low water, or zero.

ART. 33.-In calculating a correction to a cast or reduction of soundings we proceed in the following order. Firstly.Obtain the interval between the time of cast and the time of H.W.: from this derive the angle of swing. Secondly.-Find the Mean Tide Level (M.T.L.) and Height of Tide at ship: their difference gives the half tidal range, or half diurnal range (H.D.R.). Thirdly.-With the angle and H.D.R. take either from the traverse table in the D.Lat. column using angle as Co., and H.D.R. as dist., or from the diagram drawn, distance ship is from M.T.L. Fourthly.-Apply this distance to the M.T.L. for the distance the ship is from datum, which gives Reduction.

To find Interval and Angle.-The Interval is the elapsed time between the times of H.W. at place, and of cast: both times being reckoned from the same meridian. The time any tide takes to Rise or Fall is given at foot of column for those ports where H.W. only is predicted ; at ports for which both H.W. and L.W. are predicted it is found by subtracting preceding time of L.W. from H.W. used, for time to Rise: and by subtracting time of H.W. used from time of succeeding L.W., for time to Fall.

Interval must always be less than time of Rise or Fall used.

Times in Tide Table are not necessarily G.M.T.

Since from H. to L.W. tide sweeps through $180^{\circ}$,

$$
\text { Angle }=\frac{\text { Interval in minutes } \times 180^{\circ}}{\text { Time of Rise or Fall in minutes }}
$$

Examples.-Find the interval and angle:-

1. On August 29 th at $9^{\text {h }} 14^{\mathrm{m}}$ A.M. M.T.S. off Tenby.

$$
\begin{aligned}
& \text { M.T.G. Pembroke Dock 29th } 6^{\text {h }} 46^{\text {m }} \text { A.s. } \\
& \text { Time Diff. } \quad-035 \\
& \text { M.T.G. H.W. Tenby 29th } \overline{611} \text { A.M. } \\
& \text { Tenby Long. W. }-019
\end{aligned}
$$

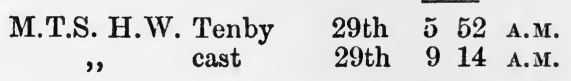


Time to fall $6^{\mathrm{h}} 15^{\mathrm{m}}$;

$$
\text { Hence angle }=\frac{202 \times 180}{375}=97^{\circ}
$$

2. On December 16th at $9^{\mathrm{h}} 40^{\mathrm{m}}$ A.M. M.T.G. off Lamlash.

M.T.G. H.W. Greenock, Dec. 16th $4^{\mathrm{h}} 27^{\mathrm{m}}$ P.M.

Time Diff. -015

$$
\begin{array}{rrrrr} 
& \text { Lamlash, Dec. 16th } & \overline{412} & \text { P.M. } \\
& \text { cast } & \text { Dec. 16th } & 940 & \text { A.M. } \\
& \text { Interval } & \overline{632} \text { before H.W. } \quad \therefore \text { Rising. }
\end{array}
$$

H.W. Greenock $4^{\mathrm{h}} 27^{\mathrm{m}}$ P.M.

preceding L.W. $\quad, \quad 9 \quad 47$ A.M.

$$
\begin{gathered}
\text { Time to rise } \overline{640} \\
\text { Angle }=\frac{392 \times 180}{400}=175^{\circ}
\end{gathered}
$$

N.B.-Since only Time Diff. for H.W. is given, time of rise or fall at ship is taken to be the same as at standard port.

3. On July 23rd at $8^{\mathrm{h}} 15^{\mathrm{m}}$ P.M. M.T.S. off Welchpool, N.B.

Stand. time H.W. St. John, July $23 \mathrm{rd} \quad 6^{\mathrm{h}} 38^{\mathrm{m}}$ P.M. Following L.W. $1^{\mathrm{h}} 6^{\mathrm{m}}$ A.M.

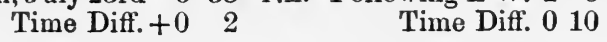

, , Welchpool $\ldots \overline{640}$ P.M. Welchp'l L.W. $\overline{116}$ A.s.

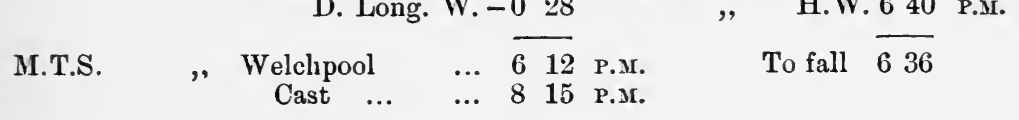

$$
\text { Interval } \overline{23}
$$

$$
\text { Angle }=\frac{123 \times 180}{396}=56^{\circ} \text { after H.W. } \quad \therefore \text { Falling. }
$$

N.B. (1) Since Time Differences for both H. and L.W. are givell, they must both be used to find time of fall at ship.

N.B. (2) Should no Time Difference be given, find its amount from H.W. F. and Cs. entered in Part II., and use 6 hours as time of rise or fall.

\section{Exercises:}

Find the Interval and Angle :-

1. On Dec. 24th at $11^{\mathrm{h}} 30^{\mathrm{m}}$ P.M. M.T.S. off Grimsby.

2. "Nov. 5th at $3^{\mathrm{h}} 10^{\mathrm{m}}$ P.M. M.T.S. off Spurn Point.

3. ", Oct. 25th at $10^{\mathrm{h}} 15^{\mathrm{m}}$ P.M. M.T.G. off Bridlington.

4. "Sept. 26th at $1^{\mathrm{h}} 10^{\mathrm{m}}$ P.M. M.T.S. off Donaghadee.

5. "Feb. 19th at $4^{\mathrm{h}} 15^{\mathrm{m}}$ A.M. M.T.S. off Beachy Head.

6. "Jan. 22nd at $8^{\mathrm{h}} 15^{\mathrm{m}}$ P.M. M.T.S. off Ramsgate.

To find the Mean Tide Level and Half Daily Range.-(a) The height of tides above Datum is entered for all standard ports at H.W., and at most ports for L.W. also. When H.W. heights only are predicted, the M.T.L. is given at the foot of the column. When both H.W. and L.W. heights are predicted the 
M.T.L. is half the sum of these heights, unless the L.W. height is * signifying below Datum, when half the difference must be taken. To find the H.D.R. subtract the M.T.L. from the height of tide.

Thus on Dec. 2nd, A.M., off Hull.

\begin{tabular}{llllr} 
Ht. H.W. & $\ldots$ & 17 & 11 \\
M.T.L. & $\ldots$ & 10 & 5 \\
\hline H.D.R. & $\ldots$ & 7 & 6
\end{tabular}

On Oct. 7th, A.M., off Liverpool, rise and fall.
ft. in.
ft. in.
ft. in.

Ht. H.W. 238

H.W. 238

ft. in. preceding L.W. $6 \quad 7 \quad$ M.T.L. $151 \frac{1}{2}$ following L.W. $7 \quad 3$

M.T.L. $155 \frac{1}{2}$

$$
\text { 2) } \overline{303} \text { H.D.R. } 8 \quad 6 \frac{1}{2}
$$

M.T.L. rise $151 \frac{1}{2}$

M.T.L. fall $15 \quad 5 \frac{1}{2}$

2)30 11 H.D.R. $82 \frac{1}{2}$

On Sept. 13th, P.M., off Liverpool, rise and fall.

Rise.

ft. in.

H. W. ft. in. $^{\text {in }}$

preceding L.W. *0 6 M.T.L. $149 \frac{1}{2}$

$$
\text { 2) } \overline{297} \text { H.D.R. } \overline{153 \frac{1}{2}}
$$

M.T.L. $149 \frac{1}{2}$
Fall.

H.W. 30 ft. $\stackrel{\text { in. }}{1}$ H.W. 30 ft. $\stackrel{\text { in. }}{1}$

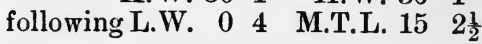

2)30 5 H.D.R. $1410 \frac{1}{2}$

(b) The height of tides for places referred to standard ports is found by applying the height differences according to sign to the heights at standard. These height differences are tabulated for Springs and Neaps, and, strictly speaking, are only correct for those days, which may be determined by reference to the Tables, when the days on which the highest H.W. occur are Springs, and those on which the lowest H.W. are entered are Neaps. These days may be on the days of full or new moon, or of quadrature, or one or two days after these phenomena. Astronomical data are entered at the beginning of the Tables. An interval of seven days may be allowed between Springs and Neaps, and so the correct height difference may be determined for any intermediate day by allowing $\frac{1}{7}$ th of the difference between the Spring and Neap difference for each day elapsed since last Spring or Neap. To find the M.T.L. for places referred to a standard at which only $\mathrm{H}$.W. is predicted, oR to a standard at which both H.W. and L.W. are predicted, but only the height differences for H.W. are given, apply $\frac{1}{2}$ SPRING Diff. to the M.T.L. at standard.

For places at which the Difference are given for both H.W. and L.W., find the corrected Height Difference and thence the heights of H. and L.W. at the place, from which the M.T.L. for the required port may be directly obtained as for a standard. 
Examples. - Find the M.T.L. and H.D.K. "off spurn Point on Dec. 13th, P.M.

On looking down the Tables, the days of Springs are seen to be on the 11 th and 27 th, our date is two days from Springs.

$$
\begin{array}{crrr}
\text { Spring Diff. } & -2 & 2 & \text { ft. } \\
\text { Neap ," } & -1 & 7 & 7 \\
\text { Diff. for 7 days } & -\overline{0} & 7 & 2 \\
2 \text {," } & -0 & 2 & 7) 14 \\
\text { Ht. Diff. for date } & \therefore 2 & 0 & -2
\end{array}
$$

M.T.L. Hull 10 it.

$\frac{1}{2}$ Spring Diff. -11

M.T.L. Spurn $\overline{9 \quad 4}$

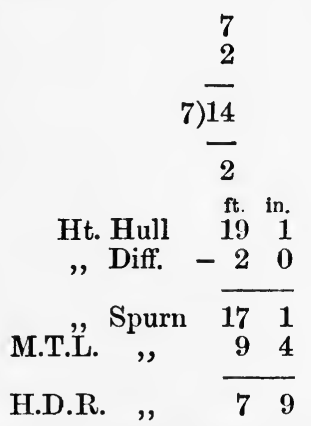

Off Dungeness on Feb. 9th, A.M., falling tide. Springs is on the 6th, hence three days from.

$$
\begin{array}{lrr}
\text { ft. } & \text { in. } \\
\text { S. Diff. }+3 & 7 \\
\text { N. }, \quad+4 & 8
\end{array}
$$

Diff. for 7 days $+\overline{1} 1$ $, \quad 3,, \quad+06$ Ht. diff. for date +41

H.W. Ht. Dover 18 in

$$
\begin{aligned}
& \text { L.W. , } \\
& \text { 2) } 5
\end{aligned}
$$

$\overline{9 \quad 21}$

7)39

$\overline{6}$

Diff. +41

Ht. Dungeness

M.T.L.

$22 \quad 2$

110

H.D.R. , ,

N.B. - Always use $\frac{1}{2}$ Spring Diff. to find M.T.L. at ship.

Off Ramsgate, January 6th, A.M., rising. Our date two days to springs.

Springs H.W. Diff. $-3 \quad 1$

Neaps

$-16$

Diff. for 7 days

$\overline{-17}$ " 2 " $\quad-0 \quad 5$

$\therefore$ Ht. Diff. H.W. $\quad-28$

Ht. H.W. Duver 189

Diff. -28

Ht. H.W. Ramsgate $16 \quad 1$

M.T.L.

710

H.D.R.

",

$\overline{83}$
L.W. Diff. $+0 \frac{\text { ft. }}{2}$

$$
\begin{aligned}
& \text {, } \quad-1 \quad 4 \\
& -16 \\
& \begin{array}{ll}
-0 & 5
\end{array}
\end{aligned}
$$

Ht. L.W. $\quad$ ft. in. Diff. $-0 \quad 3$

Ht. L.W. $\quad *^{0} \quad 5$

, H.W. 161

2)15 8 


\section{Exercises.}

Find the M.T.L. and H.D.R.-

1. On August 22nd, A.s., off Mellon.

2. "Sept. 12th, P.M., off Valentia.

3. "July 20th, A.M., off Foynes Island.

4. "Feb. 14th, P.M., rise and fall off Rye Bay.

5. "Jan. 8th, A.M., , , Hastings.

6. ", August 17th, A.M., ", ," Seal Cove.

7. " Oct. 22nd, P.M., ", ", Warren Point.

8. "Sept. 11th, A.M., rise off Amnan Foot.

To illustrate the working of the whole problem several examples will now be worked in full.

Example 1.-Find the Reduction of Soundings off Spurn Point on November 18th at $8^{\mathrm{h}} 38^{\mathrm{m}}$, P.M., M.T.G.

$$
\begin{aligned}
& \text { M.T.G. of H.W. Hull } \quad 0^{\mathrm{h}} \quad 3^{\mathrm{m}} \text { A.M. } \\
& \text { Time Diff. } \quad-1 \quad 4 \\
& \begin{array}{lllll} 
& \text { H.W. Spurn } & 10 & 59 & \text { P.M. } \\
\text { ") } & & 8 & 38 & \text { A.M. }
\end{array}
\end{aligned}
$$

Interval 221 before, $\therefore$ rising. Takes 6 hrs. to rise.

$$
\text { Hence angle }=\frac{141 \times 180}{360}=70^{\circ}{ }^{\circ}
$$

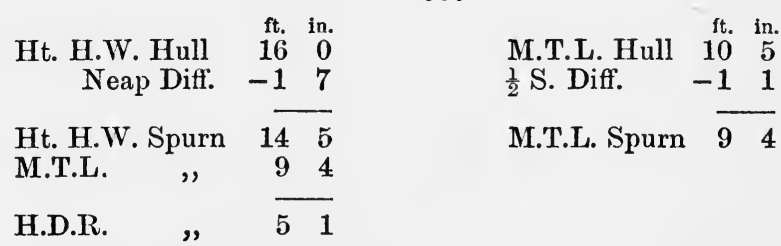

Now, see Fig. 94, draw a vertical line, and a horizontal line for the M.T.L.

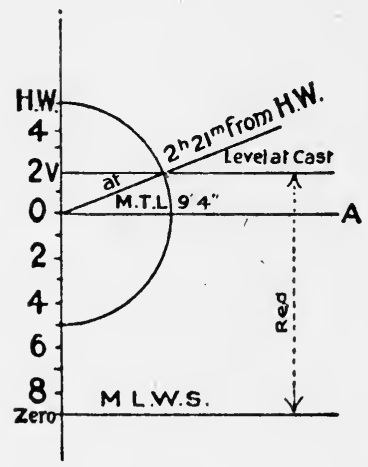

Fig. 94. as $\mathrm{OA}$; from $\mathrm{O}$ measure down $9^{\prime} 4^{\prime \prime}$ to scale for zero, and measure up $5^{\prime} 1^{\prime \prime}$ for $\mathrm{H}$.W.; with centre $O$, radius $=H . D . R$. draw semicircle. At $O$, draw $O B$ making $70 \frac{1}{2}^{\circ}$ with vertical cutting semicircle in a point through which draw a horizontal line for "level of tide at cast," meeting vertical in $\mathrm{V}$.

Measure $\mathrm{OV}=1^{\prime} 10^{\prime \prime}$, this is distance of ship at time of cast above M.T.L.

N.B. - Without the aid of a protractor, OV may be found in the D. lat. column of the Traverse Table, using angle $70 \frac{1}{2}$ as course, and H.D.R. $5^{\prime} 1^{\prime \prime}=61^{\prime \prime}$ as distance, this gives $22^{\prime \prime}$.

$$
\begin{gathered}
\text { M.T.L. } \quad 9^{\prime} 4^{\prime \prime} \\
\text { OV }+110
\end{gathered}
$$

Reduction to zero $\overline{112}$ to be subtracted from cast. 
Since the zero at Hull is the level of mean low water springs, this is also the reduction to M.L.W.S.

Example 2.-Find the correction to cast on July 14 th at $8^{\mathrm{h}} 5^{\mathrm{m}}$, P.M., M.T.S. off Dingle.

Dub. time H.W. Galway $4^{\text {h }} 3^{\mathrm{m}}$ P.M.

Diff. $\quad-39$

$$
" \quad \text { " D. Long. W. } \quad-16 \text { Pingle } 324 \text { p.M. }
$$

M.T.S. time H.W. Dingle $\overline{38}$ р.м. M.T.S. Cast 85 P.M.

$$
\text { Interval } 457 \text { (falling) }
$$

Takes $5^{\mathrm{h}} 55^{\mathrm{m}}$ to fall

$$
\therefore \text { angle }=\frac{297 \times 180}{35 \overline{5}}=151^{\circ} \text {. }
$$

f. ins.

Ht. H.W. Galway 152

Diff. $\quad-4 \quad 4$

$$
\begin{aligned}
& \text {,, M.T.L. Dingle } \overline{1010} \\
& \text { H.D.R. , , } \overline{51}
\end{aligned}
$$

Now draw figure (Fig. 95).

$$
\begin{array}{crc} 
& \text { ft. } & \text { ins } \\
\text { M.T.L. } & 5 & 9 \\
\text { OV } & -4 & 4
\end{array}
$$

Reduction to zero $\overline{15}$ to be subtracted.

Since the zero is 75 foot $=9$ inches below the level of M.L.W.S. the Reduction to M.L.W.S. is $8^{\prime \prime}$ to be subtracted from cast.

Fxample 3.-Find the Reduction on Sept. 27 th at $4^{\mathrm{h}} 10^{\mathrm{m}}$, P.M., M.T.S. off Wicklow.

$$
\begin{array}{lrr} 
& \text { ft. } & \text { ins. } \\
\text { M.T.L. Galway } & 8 & 2 \\
\frac{1}{2} \text { S. Diff. } & -2 & 5 \\
\text { M.T.L. Dingle } & \overline{5} & 9
\end{array}
$$

3 days to Springs.

$$
\begin{array}{llr}
\text { Sp. Diff. } & -4 & 9 \\
\text { Np. , } & -3 & 10 \\
\text { In } 7 \text { days } & - & 11 \\
, 3, & - & 5 \\
\text { Ht. Diff. } & -4 & 4
\end{array}
$$

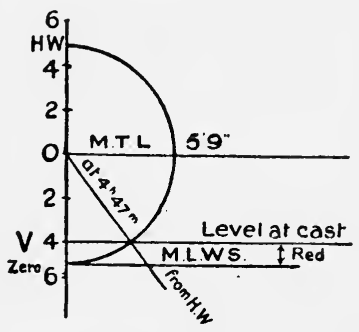

Fig. 95.

$$
\begin{aligned}
& \text { Stand, time H.W. Kingstown } 11^{\mathrm{h}} 4^{\mathrm{m}} \text { P.M. } \\
& \text { Diff. - } 43 \\
& \text {, , } \quad \text { Wicklow } \quad \overline{1021} \text { P.M. Long. E. } \\
& \text { M.T.S. Wicklow } 1022 \text { P.M. } \\
& \text { M.T.S. Cast } 410 \text { P.M. } \\
& \text { Interval } 612 \text { (rising) }
\end{aligned}
$$

To rise takes $6^{\mathrm{h}} 25^{\mathrm{m}}$.

$$
\text { Angle }=\frac{372 \times 180}{385}=174^{\circ} \text {. }
$$




\begin{tabular}{|c|c|c|c|c|c|c|}
\hline $\begin{array}{l}\text { Ht. L.W. Kingstown } \\
\text { "H.W. ", }\end{array}$ & $\begin{array}{r}\text { ft. } \\
1 \\
11\end{array}$ & $\begin{array}{l}\text { ins. } \\
0 \\
9\end{array}$ & H.W. K & $\begin{array}{l}\text { ingstown } \\
\text { Difl. }\end{array}$ & $\begin{array}{r}\text { ft. } \\
11 \\
-\quad 2\end{array}$ & $\begin{array}{c}\text { ius } \\
9 \\
9\end{array}$ \\
\hline & 2)12 & 9 & M.’.'L. & Wicklow & & $\begin{array}{l}0 \\
0\end{array}$ \\
\hline M.T.L. $\frac{1}{2}$ S." Diff. & $\begin{array}{r}6 \\
-1\end{array}$ & $\begin{array}{l}4 \frac{1}{2} \\
4 \frac{1}{2}\end{array}$ & & ", & & 0 \\
\hline M.T.L. Wicklow & 5 & 0 & & & & \\
\hline
\end{tabular}

Now draw Fig. 96.

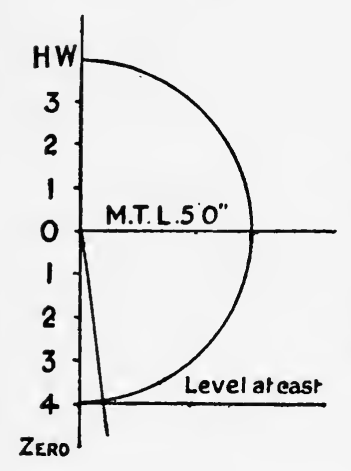

FIG. 96.

$$
\begin{array}{ccc}
\text { M.T.L. } & 5 & 0 \\
\text { O.V. } & 4 & 0
\end{array}
$$

Reduction to zero $\overline{10}$ to be subtracted

Since zero is 84 foot $=10$ inches below the level of M.L.W.S.

Reduction to that level is $2^{\prime \prime}$ to be subtracted from cast.

Example 4. - Find the Reduction on Sept. 12 th at $5^{\mathrm{b}}$, A.M., M.T.S. off Donaghadee.

Stand. time H.W. Kingstown $11^{\mathrm{b}} 1^{\mathrm{m}}$ A.M.

$$
\begin{aligned}
& \text { Diff. - } 2 \\
& \begin{array}{lll}
\text {, } \quad & \begin{array}{l}
\text { Donaghadee } \\
\text { D. Long. E. }
\end{array} \quad+3
\end{array} \\
& \text { M.T.S. ", " Cast } \quad \begin{array}{rll}
11 & 2 & \text { A.M. }
\end{array} \\
& \text { Interval } 62 \text { rising. }
\end{aligned}
$$

\begin{tabular}{|c|c|c|c|}
\hline $\begin{array}{r}\text { Ht. L.W. Kingstown } \\
\text { Diff. }\end{array}$ & $\begin{array}{rr}\text { ft. } & \text { ins. } \\
0 & 6 \\
-0 & 10\end{array}$ & H.W. & $\begin{array}{r}\text { ft. ins } \\
124 \\
+\quad 6\end{array}$ \\
\hline $\begin{array}{l}\text { Ht. L.W. Donaghadee } \\
\text { "H.W. ", }\end{array}$ & $\begin{array}{rr}-0 & 4 \\
12 & 10\end{array}$ & $\begin{array}{l}\text { H.W. } \\
\text { M.T.L. }\end{array}$ & $\begin{array}{rr}12 & 10 \\
6 & 3\end{array}$ \\
\hline & 2)12 6 & H.D.R. & 6 \\
\hline M.T.L. & $\begin{array}{ll}6 & 3\end{array}$ & & \\
\hline
\end{tabular}

To rise takes $6^{\mathrm{h}} 29^{\mathrm{m}}$

$$
\therefore \text { angle }=\frac{362 \times 180}{389}=168^{\circ}
$$

Now draw Fig. 97.

$$
\begin{aligned}
& \text { ft. ins. } \\
& \text { M.T.L. } 6 \quad 3 \\
& \text { OV. } 65 \\
& \text { Red. to zero } 2 \text { to add to cast }
\end{aligned}
$$

Since zero is $\mathbf{8 4}$ foot $=\mathbf{1 0}$ inches below the level of M.L.W.S. Reduction to M.L.W.S. is 1 foot to be added to the cast. 
This problem may also be utilised to find the depth of water to be found at any time at a given spot on a chart, by adding the Reduction found to the depth marked on the chart ; if from this the ship's draught is subtracted,

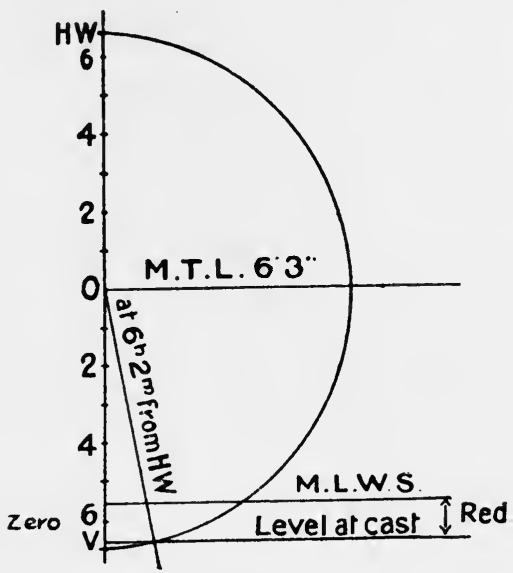

Fir. 97.

the depth of water under the ship's bottom may be found ; or, again, the time may be found when a vessel of given draught will find sufficient water to pass an obstruction.

\section{EXERCISES.}

Find the correction to be applied to the cast, in order to reduce the soundings to datum and M.L.W.S. :-

1. On Oct. 14th, at $5^{\mathrm{h}} 56^{\mathrm{m}}$ P.M., M.T.G. off Hull.

2. "July 24 th, at $4^{\mathrm{h}} 30^{\mathrm{m}}$ A.M., M.T.S. off Galway.

3. " Nov. 1st, at $1^{\mathrm{h}} 20^{\mathrm{m}}$ A.M., M.T G. off Grimsby.

4. " Aug. 15th, at $1^{\mathrm{h}} 10^{\mathrm{m}}$ A.M., M.T.S. off Limerick.

5. "Sept. 20 th, at $6^{\text {h }} 20^{\mathrm{m}}$ P.M., M.T.G. off Tenby.

6. ", Dec. 18th, at $10^{\mathrm{h}}$ P.M., M.T.G. off Spurn Point.

7. "Aug. 6th, at $2^{\text {h }} 10^{\mathrm{m}}$ A.M., M.T.S. off St. John (N.B.).

8. "Nov. 3rd, at $7^{\text {h }} 40^{\mathrm{m}}$ A.M. , M.T.G. off Abu Shahr.

9. "Sept. 28 th, at $4^{\text {h }} 45^{\mathrm{m}}$ A.M., M.T.G. off Fowey.

10. "Oct. 19th, at $5^{\text {h }} 20^{\mathrm{m}}$ P.M., M.T.S. off Exmouth.

11. "Oct. 23rd, at $7^{\text {h }} 10^{\mathrm{m}}$ P.M., M.T.S. off St. Mary's.

12. "Oct. 7 th, at $2^{\mathrm{h}} 40^{\mathrm{m}}$ P.M., M.T.G. off Beaumaris.

13. "Sept. 13th, at $6^{\mathrm{h}} 20^{\mathrm{m}}$ A.M., M.T.S. off Workington.

14. "Oct. 12th, at $0^{\mathrm{h}} 15^{\mathrm{m}}$ P.M., M.T.S. off Dartmouth.

15. "Sept. 13th, at $5^{\text {h }} 10^{\mathrm{m}}$ A.M., M.T.S. off Whitehaven.

16. "Nov. 20 th, at $5^{\text {h }} 15^{m}$ A.M., M.T.S. off Henjam Island.

17. "July 15th at $10^{\mathrm{h}} 16^{\mathrm{m}}$ P.M., M.T.G. off St. Andrews (N.B.).

18. " a Spring-tide day $1 \frac{1}{2}$ hours from H.W. off Al Basra.

19. " a Neap-tide day 2 hours from L.W. off Kuweit.

20. The depth of water on a bar at the entrance to a harbour at mean low water springs is $10 \mathrm{ft} .6 \mathrm{in}$. If the time of high water is $10^{\mathrm{h}} 51^{\mathrm{m}}$ A.M., find the depth of water on the bar at $9^{\text {h }}$ A.r., the height of tide for day being $20 \mathrm{ft}$. $3 \mathrm{in}$. Spring range $22 \mathrm{ft}$. 
21. On a certain day it is high water at Falmouth at $7^{\text {h }} 20^{\mathrm{m}}$ P.M. Height of tide $15 \mathrm{ft}$. 6 in.; mean tide level $8 \mathrm{ft}$. What is the earliest time in the afternoon when there will be not less than 20 feet of water over a shoal marked 2 fathoms on the chart?

22. At St. Helier, Jersey, the M.T.L. is $15 \mathrm{ft}^{\circ} 9$ in., and a certain tide rises $25 \mathrm{ft} .6 \mathrm{in}$. Find the height of the tide $1^{\mathrm{h}} 30^{\mathrm{m}}$ before high water.

23. On Deal Bank the depth marked on the chart is $18 \mathrm{ft}$. What depth of water would there be over it on Feb. 6 th at $1^{\mathrm{h}} 30^{\mathrm{m}}$ A.M. M.T.G. ? If a vessel's draught was $25 \mathrm{ft}$., what depth of water would she have under her?

24. A vessel whose draught is $23 \mathrm{ft}$. 6 in. wishes to berth at inner harbour where average depth on chart is 2 fathoms. Heights of tide at high and low water on the day are $14^{\prime} 10^{\prime \prime}$ and $1^{\prime} 10^{\prime \prime}$; time of H.W. $9^{\mathrm{h}} 56^{\mathrm{m}}$ A.M., previous time L.W. $3^{\mathrm{h}} 43^{\mathrm{m}}$ A.M. What is the earliest time on the day when there will be sufficient water? 


\section{CHAPTER IX.}

\section{TIME.}

ART. 34. Time and Arc.-It is often necessary to change Time ( $\left.{ }^{(\mathrm{m} \mathrm{s}}\right)$ into Arc $\left({ }^{\circ} \prime \prime\right)$, or the contrary.

Twenty-four hours are the equivalent of $360^{\circ}$;

therefore $1^{\mathrm{h}}$ is equivalent to $15^{\circ}$

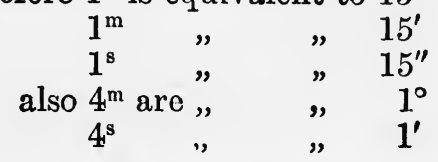

Two rules for converting Arc into Time are deduced from the above, viz.-
(1) Divide the ${ }^{\circ}$ " $"$ by 15.
(2) Multiply " " by 4, and divide by 60 .

Noтz:-The latter is generally preferred, because of the easier division.

Example.-Convert $34^{\circ} 16^{\prime} 30^{\prime \prime}$ into Time.

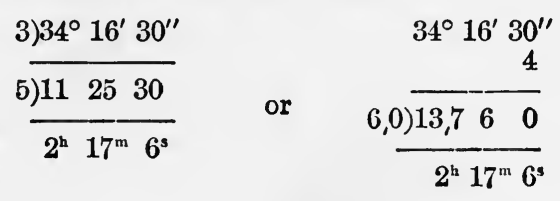

Exercises.

Find the equivalent values in Time of the following Arcs:-

$2^{\circ} 59^{\prime} 30^{\prime \prime} ; 179^{\circ} 0^{\prime} 45^{\prime \prime} ; 15^{\circ} 0^{\prime} 15^{\prime \prime} ; 67^{\circ} 52^{\prime} 55^{\prime \prime} ; 0^{\circ} 17^{\prime} 20^{\prime \prime} ; 10^{\circ} 19^{\prime} 40^{\prime \prime}$; $155^{\circ} 11^{\prime} 36^{\prime \prime} ; 93^{\circ} 0^{\prime} 45^{\prime \prime} ; 117^{\circ} 38^{\prime} 30^{\prime \prime} ; 144^{\circ} 54^{\prime} ; 176^{\circ} 39^{\prime} 35^{\prime \prime} ; 3^{\circ} 23^{\prime}$; $0^{\circ} 59^{\prime} 45^{\prime \prime} ; 0^{\circ} 0^{\prime} 15^{\prime \prime} ; 0^{\circ} 15^{\prime} ; 0^{\circ} 48^{\prime} ; 13^{\circ} ; 168^{\circ} 9^{\prime} ; 61^{\circ} 48^{\prime} 45^{\prime \prime}$.

By reversing the above rules, Time may be changed into Arc, viz.-

(1) Multiply by 15 .

(2) Multiply by 60 and divide by 4 . 
Example.-Change $7^{\mathrm{h}} 32^{\mathrm{m}} 15^{\mathrm{s}}$ into arc.

\begin{tabular}{cc}
$7^{\mathrm{h}} 32^{\mathrm{m}} 15^{\mathrm{s}}$ & $\frac{7^{\mathrm{h}} 32^{\mathrm{m}} 15^{\mathrm{s}}}{60}$ \\
\hline 223645 \\
$\frac{5}{113^{\circ} 3^{\prime} 45^{\prime \prime}}$
\end{tabular} or $\frac{4 \longdiv { 4 5 2 1 5 0 }}{113^{\circ} 3^{\prime} 45^{\prime \prime}}$

\section{Exercises.}

Change into Arc the following Time intervals :-

$1^{\mathrm{h}} 12^{\mathrm{m}} 30^{\mathrm{s}} ; 10^{\mathrm{h}} 19^{\mathrm{m}} 55^{\mathrm{s}} ; 8^{\mathrm{h}} 0^{\mathrm{m}} 10^{\mathrm{s}} ; 6^{\mathrm{h}} 59^{\mathrm{m}} 18^{\mathrm{s}} ; 11^{\mathrm{h}} 59^{\mathrm{m}} 58^{\mathrm{s}} ; 3^{\mathrm{h}} 0^{\mathrm{m}} 19^{\mathrm{s}}$; $5^{\mathrm{h}} 59^{\mathrm{m}} 22^{\mathrm{s}} ; 9^{\mathrm{h}} 1^{\mathrm{m}} 37^{\mathrm{s}} ; 0^{\mathrm{h}} 15^{\mathrm{m}} 15^{\mathrm{s}} ; 2^{\mathrm{h}} 25^{\mathrm{m}} ; 0^{\mathrm{h}} 10^{\mathrm{m}} 35^{\mathrm{s}} ; 0^{\mathrm{h}} 0^{\mathrm{m}} 45^{\mathrm{s}} ; 2^{\mathrm{h}} 24^{\mathrm{m}} 44^{\mathrm{s}} ;$ $11^{\mathrm{h}} 0^{\mathrm{m}} 19^{\mathrm{s}} ; 11^{\mathrm{h}} 13^{\mathrm{m}} 30^{\mathrm{s}} ; 5^{\mathrm{h}} 0^{\mathrm{m}} 5^{\mathrm{s}} ; 8^{\mathrm{h}} 28^{\mathrm{m}} 52^{\mathrm{s}} ; 10^{\mathrm{h}} 0^{\mathrm{m}} 12^{\mathrm{s}} ; 0^{\mathrm{h}} 0^{\mathrm{m}} 12^{\mathrm{s}}$; $0^{\mathrm{h}} 1^{\mathrm{m}} 40^{\mathrm{s}}$.

ART. 35. Time and Longitude.-The rules for Time and Arc may be employed to find-

(1) The difference between Greenwich Time and the Time at a place whose Longitude is given; and Time.

(2) The Longitude corresponding to a given difference of

But it must be borne in mind that, as the Earth rotates from west to east, places in E. longitude have sunlight earlier than Greenwich, and places in W. longitude later. Therefore the Time at a place in E. longitude is always fust of or greater than the Time at Greenwich, and at a place in W. longitude it is always slow of or less than Greenwich Time.

ART. 36.-Difference of Time due to Longitude.

\section{Examples.-}

1. What is the difference between the time at a place in $72^{\circ} 50^{\prime} \mathrm{E}$. long. and the time at Greenwich?

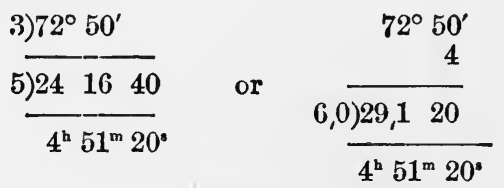

Ans. The time at place is $4^{\mathrm{h}} 51^{\mathrm{m}} 20^{\circ}$ fast of Greenwich time.

2. What is the difference between Greenwich time and the time at a place in $124^{\circ} 10^{\prime} 45^{\prime \prime} \mathrm{W}$. long. ?

$$
\frac{3) 124^{\circ} 10^{\prime} 45^{\prime \prime}}{5) 412335} \quad \text { or } \quad \frac{124^{\circ} 10^{\prime} 45^{\prime \prime}}{6,0) \frac{49460}{8^{\mathrm{h}} 16^{\mathrm{m}} 43^{\mathrm{s}}}}
$$

Ans. The time at place is $8^{\mathrm{h}} 16^{\mathrm{m}} 43^{\mathrm{s}}$ behind, or slow, of Greenwich time. 
EXERCISES.

Find the difference between time at Greenwich and corresponding time in the following longitudes, and say which is the greater :-

$10^{\circ} 20^{\prime}$ W. ; $17^{\circ} 45^{\prime}$ E. ; $110^{\circ} 17^{\prime}$ E. ; $172^{\circ} 36^{\prime}$ W. ; $100^{\circ} 16^{\prime} 30^{\prime \prime}$ E. ; $90^{\circ} 4^{\prime} 45^{\prime \prime}$ W. ; $0^{\circ} 7^{\prime} 15^{\prime \prime}$ E. ; $179^{\circ} 56^{\prime} 45^{\prime \prime}$ W. ; $1^{\circ} 2^{\prime} 15^{\prime \prime}$ W. ; $115^{\circ} 0^{\prime} 30^{\prime \prime}$ E. ; $0^{\circ} 2^{\prime} 45^{\prime \prime}$ E. ; $165^{\circ} 0^{\prime} 15^{\prime \prime}$ W.

\section{ART. 37.-Longitude from Difference of Time.}

\section{Examples.-}

1. The mean time at ship is January $5^{\mathrm{d}} 2^{\mathrm{h}} 14^{\mathrm{m}} 40^{\mathrm{s}}$, when mean time at Greenwich is January $5^{d} 9^{\mathrm{h}} 45^{\text {m }} 20^{\prime}$ : required the longitude.

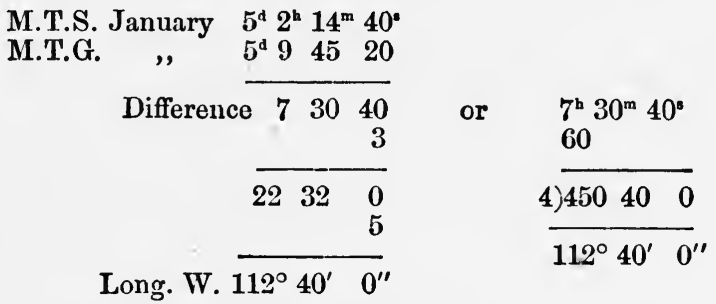

2. The mean time at ship is February $14^{\mathrm{d}} 17^{\mathrm{h}} 16^{\mathrm{m}} 25^{\mathrm{s}}$ when mean time at Greenwich is February $14^{\mathrm{d}} 17^{\mathrm{h}} 19^{\mathrm{m}} 14^{\mathrm{s}}$ : required the longitude.

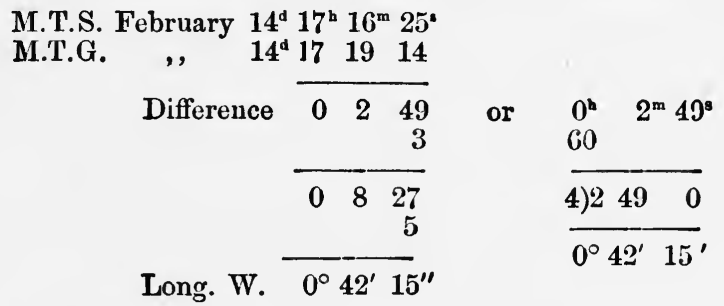

3. Given M.T.G. March $30^{\mathrm{d}} 2^{\mathrm{b}} 19^{\mathrm{m}} 55^{\mathrm{s}}$, and M.T.S. March $29^{\mathrm{d}} 21^{\mathrm{b}} 16^{\mathrm{m}} 58^{\mathrm{s}}$ : required the longitude.

$$
\begin{aligned}
& \text { M.T.G. March } 30^{d} 2^{\text {h }} 19^{m} 55^{\mathrm{a}} \\
& \text { M.T.S. } \quad \text {, } \quad 29^{\text {d }} 21 \quad 16 \quad 58
\end{aligned}
$$

\begin{tabular}{ll} 
Difference & $\frac{5}{60}$ \\
Long. W. & $\frac{457}{30257 \quad 0}$ \\
\hline $75^{\circ} 44^{\prime} 15^{\prime \prime}$
\end{tabular}

4. Given M.T.G. December $31^{\mathrm{d}} 19^{\mathrm{h}} 11^{\mathrm{m}} 25^{\mathrm{s}}$, and M.T.S. January $1^{\mathrm{d}} 3^{\mathrm{h}} 17^{\mathrm{m}} 50^{\mathrm{s}}$ : required the longitude. 
M.T.G. December $31^{\mathrm{d}} 19^{\mathrm{h}} 11^{\mathrm{m}} 25^{\mathrm{s}}$

M.T.S. January $1^{\text {d }} 3 \quad 17 \quad 50$

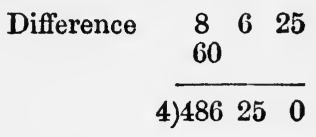

Long. E. $\overline{121^{\circ} 36^{\prime} 15^{\prime \prime}}$

5. Given M.T.S. July $2^{\mathrm{d}} 5^{\mathrm{h}} 15^{\mathrm{m}} 45^{\mathrm{s}}$, and M.T.G. July $1^{\mathrm{d}} 22^{\mathrm{h}} 20^{\mathrm{m}} 30^{\mathrm{s}}$ : required the longitude.

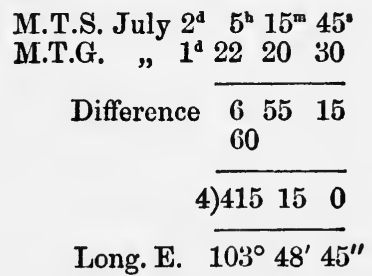
prefers.

NoтE.-The student may change Time into Longitude by any method he

ExERCises.

Find the Longitudes from the following Simultaneous Times at ship and Greenwich :-

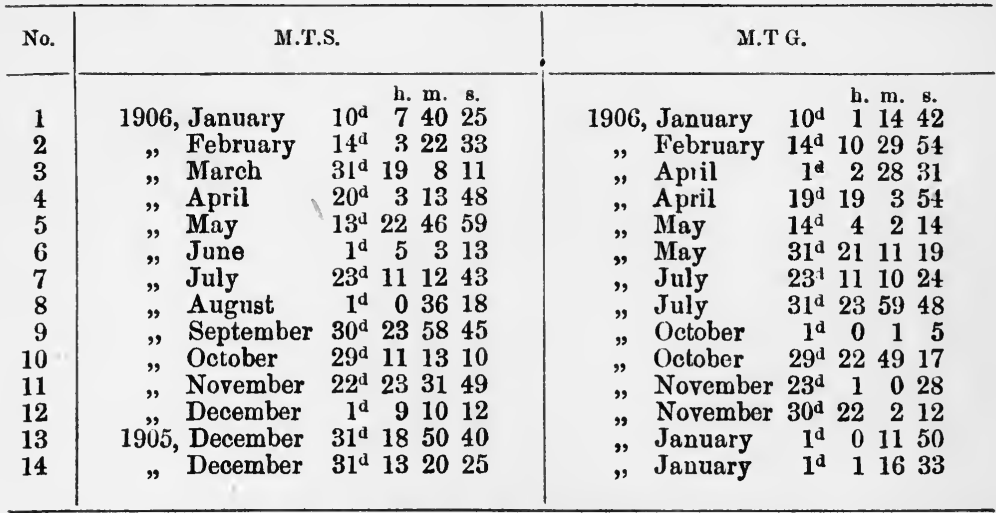

ART. 38.-To find the Time at Greenwich when the Time at a place or at ship and the Longitude are known.

Rule.-Add the difference of time for West Longitude, and subtract for East.

Examples.-

1. When it is apparent noon at ship on May 10th in long. $96^{\circ} \mathrm{W}$., what is the time at Greenwich?
A.T.S. May $10^{\mathrm{d}} 0^{\mathrm{h}} 0^{\mathrm{m}} 0^{\mathrm{s}}$
6240
$96^{\circ}$
A.T.G. May $\overline{10^{\mathrm{d}} 6240}$
$6,0) 38,4$ 
2. It is apparent noon at a place in $175^{\circ} 40^{\prime} \mathrm{E}$. on July $30 \mathrm{th}$ : required the time at Greenwich.
A.T. at place, July $30^{\mathrm{d}} 0^{\mathrm{h}} 0^{\mathrm{m}} 0^{\mathrm{s}}$
114240
A.T.G. July $\overline{29^{\mathrm{a}} 121720}$

$\begin{array}{r}175^{\circ} 40^{\prime} \\ \frac{4}{6,0)} \\ \hline \frac{70,240}{11^{\mathrm{h}} 42^{\mathrm{m}} 40^{\prime}}\end{array}$

3. The sun is on the Meridian of ship's place in long. $100^{\circ} 35^{\prime} \mathrm{E}$. on May 15th : required the time at Greenwich.
A.T.S. May $15^{\mathrm{d}} 0^{\mathrm{h}} 0^{\mathrm{m}} 0^{\mathrm{s}}$
$100^{\circ} 35^{\prime}$
A.T.G. May $\overline{14^{\mathrm{d}} 171740}$
Or 15th 51740 A.M.

$\frac{6,0) \overline{40,2} 20}{6^{\mathrm{h}} 42^{\mathrm{m}} 20^{\mathrm{s}}}$

4. When it is $6^{\text {h }} 50^{\mathrm{m}}$ P.M. apparent time on February 10 th at ship in long. $75^{\circ} 50^{\prime} \mathrm{W}$., what is the time at Greenwich?
A.T.S. February $10^{\mathrm{d}} 6^{\mathrm{h}} 50^{\mathrm{m}} 0^{\mathrm{a}}$
$5 \quad 320$
$75^{\circ} 50^{\prime}$
A.T.G. February $10^{\mathrm{d}} 115320$

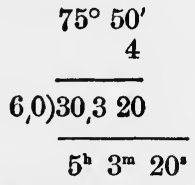

5. At a place in long. $115^{\circ} 56^{\prime}$ E. it is $7^{\mathrm{h}} 30^{\mathrm{m}}$ A.M. mean time on June 15th : required the Greenwich time.
M.T. at place, June $14^{\mathrm{d}} 19^{\mathrm{h}} 30^{\mathrm{m}} 0^{\mathrm{e}}$
74344
$115^{\circ} 56^{\prime}$
4
M.T.G. June $14^{d} 114616$

$$
\frac{6,0) \frac{\overline{46,344}}{7^{\mathrm{b}} 43^{\mathrm{m}} 44^{\mathrm{s}}}}{}
$$

Note.-A.M. Civil time is changed into Astronomical time by adding the interval of 12 hours between noon and midnight, which makes the Astronomical day one less than the Civil day ; but when it is P.M. the Astronomical day is the same as the Civil.

Astronomical time is always written thus : February $10^{\mathrm{d}} 6^{\mathrm{h}} 50^{\mathrm{m}} 0^{\mathrm{s}}$, or June $14^{\mathrm{d}} 19^{\mathrm{h}} 30^{\mathrm{m}} 0^{\mathrm{s}}$ being reckoned from noon onwards to 24 hours.

Civil time is written thus: February $10 \mathrm{th}, 6^{\mathrm{h}} 50^{\mathrm{m}} 0^{\mathrm{s}}$ P.M., or June 15th, $7^{\text {h }} 30^{\mathrm{m}} 0^{\mathrm{s}}$ A.M.

\section{ExerCises.}

To find the Astronomical Time at Greenwich. Civil time at ship. 1. May 16.
h. m. 8 .
… $\quad$... 31230 P.M.
2. May 1st $\quad \ldots . \quad \ldots \quad 5810$ A.M.
3. June 13th $\ldots . \quad \ldots \quad 82735$ P.M.
4. June 30 th $\ldots . \quad \ldots \quad 11249$ A.M.
5. June 1st $\ldots . \quad \ldots \quad 4 \quad 150$ P.M.
6. February 17 th $\quad \ldots \quad 74328$ P.M.
7. February 28th $\quad \ldots .101918$ A.M.
8. August 21st... $\quad \ldots \quad 61640$ A.M.
9. August 1st ... $\quad$... 25414 P.M.
10. August 10th $\quad \ldots \quad 11955$ P.M.
11. October 22 nd $\quad \ldots \quad 93812$ A.M.
12. October 29th $\quad \ldots \quad 105611$ P.M.
$591630 \mathrm{~W}$.
$1362250 \mathrm{~W}$.
$1741445 \mathrm{E}$.
$1053145 \mathrm{~W}$.
$961715 \mathrm{E}$.
744430 W.
$1121445 \mathrm{~W}$.
$431330 \mathrm{~W}$.
$165550 \mathrm{E}$.
$155015 \mathrm{E}$.
$155045 \mathrm{~W}$.
$821715 \mathrm{WV}$

Longitude of ship. 
ArT. 39.-To find the Time at Ship when the Time at Greenwich and the Longitude of Ship are known.

Rule.-Subtract the difference of time for West Longitude, and add for East, which is simply the reverse of the preceding rule. The reason has been previously explained (Art. 35).

\section{Examples.-}

1. Required the Time at ship in long. $65^{\circ}$ E., when the A.T.G. is August 5th, $10^{\mathrm{h}} 30^{\mathrm{m}}$ A.M.
A.T.G. August $4^{\mathrm{d}} 22^{\mathrm{h}} 30^{\mathrm{m}}$
$42^{20}$
\begin{tabular}{c}
$65^{\circ}$ \\
$\frac{4}{\overline{26,0}}$ \\
\hline$\frac{4^{\mathrm{h}}}{20^{\mathrm{m}}}$
\end{tabular}

2. What is the A.T.S. in long. $120^{\circ} 15^{\prime}$ W. when the A.T.G. is $2^{\mathrm{h}} 35^{\mathrm{m}}$ P.M. on January 2nd?
$\begin{array}{lll}\text { A.T.G. January } 2^{\mathrm{d}} & 2^{\mathrm{h}} & 35^{\mathrm{m}} \\ 8 & 1\end{array}$
$120^{\circ} 15^{\prime}$

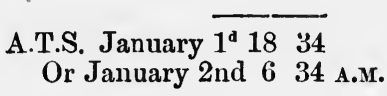
$\frac{6,0) \frac{48,1 \cdot 0}{8^{\mathrm{h}} 1^{\mathrm{m}}}}{\mathrm{W}^{\mathrm{m}}}$

3. Required the Mean Time at ship in long. $64^{\circ}$ W. when the M.T.G. is August $15^{\mathrm{d}} 5^{\mathrm{h}} 17^{\mathrm{m}} 35^{\mathrm{a}}$.

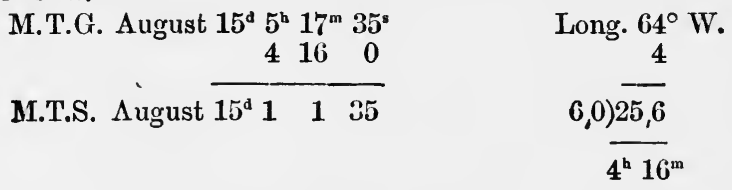

\section{Exercises.}

1. What is the mean time at ship in long. $123^{\circ} 27^{\prime} 30^{\prime \prime} \mathbf{E}$. when the M.T.G. is October $14^{\mathrm{d}} 9^{\mathrm{h}} 15^{\mathrm{m}} 24^{\mathrm{s}}$ ?

2. What is the M.T.S. in long. $35^{\circ}$ W. when the M.T.G. is May 6th $2^{\mathrm{h}} 3^{\mathrm{m}} 46^{\mathrm{s}}$ P.M. ?

3. Find the M.T.S. in long. $143^{\circ} 27^{\prime} 30^{\prime \prime}$ W. when the M.T.G. is September 1st $4^{\mathrm{h}} 37^{\mathrm{m}} 23^{\mathrm{s}}$ A.M.

4. When the M.T.G. is June 2 nd $11^{\mathrm{h}} 19^{\mathrm{m}} 14^{\mathrm{*}}$ P.M., what is the mean time at ship in long. $95^{\circ} 46^{\prime} \mathrm{E}$. ?

5. Required the M.T.S. in long. $97^{\circ} 16^{\prime} 45^{\prime \prime}$ E. when the M.T.G. is October 19 th $5^{\text {h }} 8^{\mathrm{m}} 40^{\mathrm{s}}$ P.M.

6. Find the M.T.S. when the M.T.G. is May 1 st $5^{\text {h }} 49^{\mathrm{m}} 54^{\mathrm{s}}$ A.M. in long. $164^{\circ} 48^{\prime} \mathrm{E}$.

ART. 40.-Rating Chronometers. The ship's chronometer is relied on at sea to give the Mean Time at Greenwich (M.T.G.), its error on leaving port and its rate of gaining or losing per day being known.

An "Error" and " Rate" are usually supplied when the chronometer leaves the shop, but as the Rate is liable to be affected by changes of temperature and other causes during a voyage, it 
is advisable to ascertain the correct Error when opportunity offers at ports the ship may visit.

"Rating a chronometer" means finding the rate at which it gains or loses per day by dividing the sum or difference of the errors on different dates by the number of days elapsed.

\section{Examples.-}

1. A chronometer was found to be $4^{\mathrm{m}} 30^{\circ}$ fast of mean noon at Gree1. wich on January 15th, 1906, and on March 30th, 1906, it was $7^{m} 35^{\circ}$ fast of mean noon at Greenwich. Required the rate.

m. 8.

Fast 430 on January 15.

Fast 735 on March 30 .

35 gaineu in 74 days. 60

74) $185<2^{\mathrm{s}} \cdot 5$ gain per day.

148

370

370

2. A chronometer was $14^{\mathrm{m}} 25^{\mathrm{A}}$ fast of mean noon at Greenwich on September 1st, 1906, and at mean noon at Greenwich on December 4th, 1906 , it was $13^{\mathrm{m}} 14^{\mathrm{n}} \cdot 5$ fast. Required the rate.

m. $\mathbf{s .}$

Fast 1425 on September 1.

Fast 1314.5 on December 4.

110.5 lost in 94 days.

60

$\overline{94)} \overline{70 \cdot 5}\left(\cdot 75^{\prime}\right.$ losing daily. 658

3. A chronometer was $1^{\mathrm{m}} 42^{\circ}$ slow of M.T.G. at mean noon on January 1st, 1906 , and on March 31st at mean noon Greenwich time it was $6^{\mathrm{m}} 9^{\mathrm{s}}$ slow. Required the rate.

m. s.

Slow 142 on January 1.

Slow 69 on March 31 .

427 lost in 89 days.

60

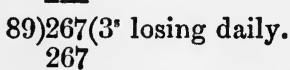

4. On leaving Liverpool, January 19th, 1904, the ship's chronometer was $4^{\mathrm{m}} 2^{\mathrm{s}}$.5 slow of mean noon at Greenwich, and at Sydney on May 28th it was found to be $3^{\mathrm{m}} 10^{n} 5$ slow of mean noon at Greenwich. Required the rate. 
m. 8 .

Slow 4.5 on January 19.

Slow 310.5 on May 28.

$52 \cdot 0$ gained in 130 days.

130) $52 \cdot 0\left(\cdot 4^{s}\right.$ gaining daily.

$52 \cdot 0$

5. At New York on February 27th, 1904, a ship's chronometer was 18* slow at mean noon Greenwich time, and at Southampton on March 6th, at Greenwich mean noon it was $14^{\mathrm{s}}$ fast. Required the rate.

B.

Slow 18 on February 27.

Fast 14 on March 6.

32 gained in 8 days.

8) 32

$4^{\mathrm{s}}$ gaining daily.

6. A chronometer was fast of mean noon at Greenwich $2^{\mathrm{m}} 17^{\mathrm{s}}$ on January 14th, 1906, and on June 1st it was $3^{\mathrm{m}} 55^{\mathrm{s}} \cdot 5$ slow of mean noon at Greenwich. Required the rate.

m. 8.

Fast 217 on January 14.

Slow 355.5 on June 1.

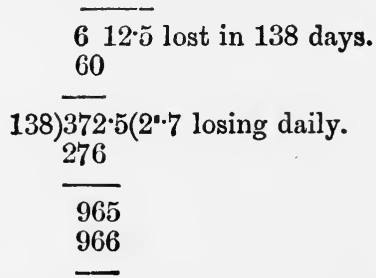

ART. 41. The time by chronometer being given, and two errors or one error and daily rate, to determine the correct G.M.T.

Find the rate as explained above, multiply this by the number of days and decimals elapsed between the date of second error, and date of chronometer time. This gives the accumulated rate. Now take the time by chronometer expressed astronomically, being careful to make it correspond as far as possible with the Greenwich Time deduced from the Ship Time and approximate longitude, apply the second error and accumulated rate to obtain the correct G.M.T.

\section{Examples.-}

1. February 24 th, about $8^{\mathrm{h}} 20^{\mathrm{m}}$ A.M. at ship ir long. by account $74^{\circ} 15^{\prime} \mathrm{W}$., the chronometer showed $1^{\mathrm{b}} 12^{\mathrm{m}} 20^{\mathrm{s}} 5$, and had been found $13^{\mathrm{m}} 35^{\mathrm{s}}$ slow of mean noon at Greenwich on October 30th, and on December 24th it was $10^{\mathrm{m}} 55^{\mathrm{*}} \cdot 5$ slow. Find G.M.T. 


\begin{tabular}{|c|c|}
\hline $\begin{array}{r}74^{\circ} 15^{\prime} \\
4\end{array}$ & $\begin{array}{l}\text { Ship time Feb. } 23^{\mathrm{d}} 20^{\mathrm{h}} 20^{\mathrm{m}} \\
\text { Long. W. }+457\end{array}$ \\
\hline 6,0$) 29,7 \quad 0$ & Greenwich time $24^{\text {d }} 117$ \\
\hline
\end{tabular}

Time by chron. Feb. $24^{\mathrm{d}} 1^{\mathrm{h}} 12^{\mathrm{m}} 205^{\mathrm{s}}$ Second error slow $10 \quad 55 \cdot 5$

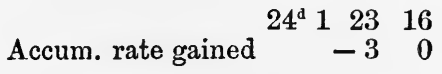
M.G.T. Feb. $24^{\mathrm{d}} 12016$
Slow Oct. 30th $13^{\text {m }} 35^{\text {s }}$ ," Dec. 24th $10 \quad 55.5$ Gain in 55 days $\overline{259.5}$ $55) 159 \cdot 5\left(2^{\prime} \cdot 9\right.$ 110 495 495

$$
\begin{array}{r}
\text { Elapsed time } \\
\text { rate } \begin{array}{c}
62 \cdot 05 \\
\frac{2 \cdot 9}{55845}
\end{array} \\
\frac{12410}{6,0) \overline{17,9 \cdot 945}} \\
\frac{2^{\mathrm{m}} 59^{\cdot} \cdot 9}{}
\end{array}
$$

2. October 18 th, at $2^{\mathrm{h}} 30^{\mathrm{m}}$ A.M., M.T. ship nearly in long. by D.R. $50^{\circ}$ E. ; the chronometer showed $11^{\mathrm{h}} 3^{\mathrm{m}} 22^{\mathrm{s}}$, which had been found $4^{\mathrm{m}} 13^{\mathrm{s}} \cdot 7$ fast on July 24 th, and losing daily $3^{\mathrm{a}} \cdot 4$. Find G.M.T.

$$
\begin{array}{rrr}
4 & \text { Ship time Oct. } & 17^{\mathrm{d}} 14^{\mathrm{h}} 30^{\mathrm{m}} \\
\text { Long E. } & -320 \\
\hline \mathbf{2 0 , 0} & \text { Oct. } & 17^{\mathrm{d}} 1110
\end{array}
$$

Elapsed time $85 \cdot 5$

rate $3 \cdot 4$

$$
6 \frac{\begin{array}{c}
3420 \\
2565
\end{array}}{\overline{29,0 \cdot 70}} \frac{4^{\mathrm{m}} 50^{\mathrm{s} \cdot 7}}{}
$$

Time by chron. Oct. $17^{\mathrm{d}} 11^{\mathrm{h}} 3^{\mathrm{m}} 22^{\mathrm{s}}$

Error fast

Oct. $17^{\mathrm{d}} 10 \quad 59 \quad 8 \cdot 3$

Accum. rate lost

$$
\begin{array}{r}
+450.7 \\
\hline
\end{array}
$$

$$
\text { M.T.G. Oct. } 17^{\mathrm{d}} 11 \quad 3 \quad 59
$$

3. February 3rd, approximate ship time $1^{\mathrm{h}} 8^{\mathrm{m}}$ A.M., in long. about $31^{\circ}$ W., when a chronometer, known to be $43^{\text {m }} 19^{\text {s }}$ fast on January 13 th, and gaiuing daily $2^{\mathrm{s}} 5$, showed $3^{\mathrm{b}} 55^{\mathrm{m}} 30^{\mathrm{s}} \cdot 5$. Find correct G.M.T.

$$
\begin{aligned}
& 31^{\circ} \quad \text { Ship time Feb. } 2^{\mathrm{d}} 13^{\mathrm{h}} 8^{\mathrm{m}} \quad \text { Elapsed time } \\
& \begin{array}{rrr}
\frac{4}{6,0) 1,24} & \text { Greenwich time } & 2^{\mathrm{d}} 1512 \\
2^{\mathrm{h}} 4^{\mathrm{m}} & &
\end{array} \\
& \text { rate } 2 \cdot 5 \\
& \text { Time by chron. Feb. } \quad 2^{\mathrm{d}} 15^{\mathrm{h}} 55^{\mathrm{m}} 30^{\mathrm{s}} \cdot 5 \\
& \text { Error fast } \quad-4319
\end{aligned}
$$

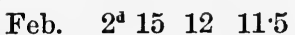

$$
\begin{aligned}
& \text { Accum. rate gained } \quad-51.5 \\
& \text { G.M.T. Feb. } \quad 2^{\mathrm{d}} 15 \quad 1120
\end{aligned}
$$$$
\begin{aligned}
& 1030 \\
& 412
\end{aligned}
$$$$
\overline{51 \cdot 50}
$$ 


\section{EXERCISES.}

Find the chronometer "Rate" from the following errors on Greenwich Mean Noon :-

\begin{tabular}{|c|c|c|c|c|}
\hline No. & 1st date. & Error. & 2nd date. & Error. \\
\hline $\begin{array}{l}1 \\
2 \\
3 \\
4 \\
5 \\
6 \\
7 \\
8\end{array}$ & $\begin{array}{l}\text { August 28th } \\
\text { September 30th } \\
\text { April 12th } \\
\text { April 1st } \\
\text { February 27th } \\
\text { December 27th } \\
\text { June 1st } \\
\text { June 16th }\end{array}$ & \begin{tabular}{crcc} 
b. & m. & s. \\
0 & 7 & $2 \cdot 1$ fast \\
1 & 21 & 19.0 slow \\
0 & 25 & 19.0 slow \\
0 & 10 & 24.0 fast \\
0 & 0 & 19.5 fast \\
& \multicolumn{3}{c}{ correct } \\
0 & 1 & 8.8 slow \\
0 & 14 & 26.9 fast
\end{tabular} & $\begin{array}{l}\text { December } 9 \text { th } \\
\text { January } 28 \text { th } \\
\text { July 1st } \\
\text { August 15th } \\
\text { July 31st } \\
\text { February 20th } \\
\text { September 30th } \\
\text { September 30tl }\end{array}$ & 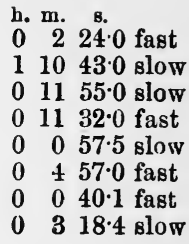 \\
\hline
\end{tabular}

9. November 27 th, at about $10^{\text {h }}$ A.M., at ship in long. $123^{\circ} 15^{\prime}$ E., when a chronometer showed $1^{\mathrm{h}} 53^{\mathrm{m}} 34^{\mathrm{s}} \cdot 6$, which was slow for G.M.N. $3^{\mathrm{m}} 13^{\mathrm{s}}$ on September 10th, and fast $2^{\mathrm{m}} 30^{\mathrm{s}}$ on October 20th. Find correct G.M.T.

10. October 31st, about $2^{\mathrm{h}} 15^{\mathrm{m}}$ P.M., at ship in long. $124^{\circ} \mathrm{W}$., when a chronometer showed $10^{\mathrm{h}} 7^{\mathrm{m}} 33^{\mathrm{s}}$, which was slow $10^{\mathrm{m}} 46^{\mathrm{s}} \cdot 8$ on September 29 th, and gaining $1^{*} \cdot 01$ daily. Find the G.M.T.

11. March 20th, about $4^{\text {b }}$ P.M., at ship in long. $63^{\circ} 45^{\prime}$ W., when a chronometer showed $7^{\mathrm{b}} 12^{\mathrm{m}} 1^{\mathrm{s}}$, which was slow $1^{\mathrm{b}} 2^{\mathrm{m}} 4^{\mathrm{s}}$ on January 2 nd, and on February 1st was slow $1^{\mathrm{h}} 3^{\mathrm{m}} 54^{\mathrm{s}}$. Find the G.M.T.

12. December 10th, about $2^{\mathrm{h}} 15^{\mathrm{m}}$ P.M., at ship in long. $161^{\circ} \mathrm{W}$., when a chronometer showed $2^{\mathrm{h}} 1^{\mathrm{m}} 23^{\mathrm{s}}$, which was fast $59^{\mathrm{m}} 16^{\mathrm{s}}$ on August 12 th, and on October 31st was fast $1^{\mathrm{h}} 2^{\mathrm{m}} 16^{\mathrm{s}}$ on G.M.N. Find G.M.T.

13. July 4th, at $7^{\mathrm{h}} 17^{\mathrm{m}}$ A.M., at ship in long. $75^{\circ} \mathrm{W}$., when a chronometer showed 12 o'clock, it was fast of G.M. noon $38^{\mathrm{s}}$ on April 15th, and gained $\cdot 75^{s}$ daily since. Find G.M.T.

14. November $27 \mathrm{th}$, at $7^{\mathrm{h}}$ A.M., at ship in long. $4^{\circ} 45^{\prime} \mathrm{W}$., when a chronometer showed $7^{\mathrm{h}} 17^{\mathrm{m}} 58^{\mathrm{s}} \cdot 5$, which had been found $6^{\mathrm{m}} 57^{\mathrm{s}}$ slow for G.M. noon on August 21st, and slow $6^{\mathrm{m}} 37^{\mathrm{s}} \cdot 5$ on September 20th. Find G.M.T.

15. December 14 th, about $4^{\mathrm{h}} 5^{\mathrm{m}}$ P.M., M.T.S. in long. $11^{\circ} 6^{\prime} \mathrm{W}$., when a chronometer showed $5^{\mathrm{h}} 20^{\mathrm{m}} 44^{\mathrm{z}}$, which was fast of G.M. noon $2^{\mathrm{m}} 38^{\mathrm{a}} \cdot 1$ on November 10 th, and on November 27 th was correct. Find G.M.T.

16. May 1st, about $6^{\mathrm{h}} 30^{\mathrm{m}}$ P.M., at ship in long. $91^{\circ}$ E., when a chronometer showed $12^{\mathrm{h}}$, and was slow $24^{\mathrm{m}} 54^{\mathrm{s}}$ on January 11 th for G.M. noon, and slow $24^{\mathrm{m}} \cdot 34^{\mathrm{s}}$ on March 2 nd. Find G.M.T.

17. April 16th, about $4^{\mathrm{h}}$. P.M., at ship in long. $131^{\circ} 25^{\prime}$ E., when a chronometer showed $7^{\mathrm{h}} 18^{\mathrm{m}} 56^{\mathrm{s}}$, which was slow of G.M. noon on February 9th $9^{\mathrm{m}} 21^{\cdot} \cdot 5$, and was slow $3^{\mathrm{m}} 19^{\mathrm{s}} \cdot 5$ on March 17 th. Find G.M.T. 


\section{CHAPTER X.}

\section{ELEMENTS FROM THE "NAUTICAL ALMANAC."}

ART. 42.-A great part of the labour involved in the calculation of problems in Nautical Astronomy is the Reduction of the Elements from the "Nautical Almanac;" therefore it is most important that the student should master this part of the work at the outset. The advantage of a thorough acquaintance with the "Nautical Almanac" is incalculable.

The necessary extracts for working all the problems in this Book will be found in the Appendix. In the case of the stars the "mean position " only is given, and this is the one used in the calculations, as the introduction of the "apparent places" would considerably enlarge the Appendix without giving a corresponding advantage.

The Sun's Elements.-These are given for Noon at Greenwich, therefore it is always necessary to know the Greenwich Astronomical Time.

When Apparent Time is given, the elements are taken from p. I. of the month; but when Mean Time is given, they are taken from $\mathrm{p}$. II.

The variations or changes in one hour are on p. I.

All minutes and seconds in the Greenwich time are reduced to decimals of an hour.

(1) Declination.

\section{Examples.-}

1. Find the sun's declination for August 16 th $8^{\mathrm{h}} 36^{\mathrm{m}}$ P.M. apparent time at Greenwich.

Declination at noon $13^{\circ} 57^{\prime} 28^{\prime \prime} \cdot 0 \mathrm{~N}$. H.V. $47 \cdot 03$ page I., app. time

Cor. $\quad-6445$

Dec. at $8^{\text {h }} 36^{\mathrm{m}} 13 \quad 50 \quad 43.5 \mathrm{~N}$.

28218

37624

$$
\frac{6,0 \overline{40,4 \cdot 458}}{6^{\prime} 44^{\prime \prime} \cdot 56}
$$

The correction is subtracted because the declination is decreasing. 
2. Find sun's declination for September 29 th $2^{\text {h }} 45^{\mathrm{m}}$ A.M. M.T.G. ; astro. M.'T.G. $28^{\mathrm{d}} 14^{\mathrm{h}} 45^{\mathrm{m}}$.

Dec. for $29^{\mathrm{d}}$ noon $2^{\circ} 9^{\prime} 24^{\prime \prime} \cdot 1 \mathrm{~S}$. Cor. -9003

Dec. for $28^{\mathrm{d}} 14^{\mathrm{h}} 45^{\mathrm{m}} \overline{2023 \cdot 8} \mathrm{~S}$.
H.V. $58 \cdot 41$ page I., mean time.

$9 \cdot 25$

$$
\frac{\begin{array}{c}
29205 \\
11682 \\
52569
\end{array}}{\frac{5,0) 54,0 \cdot 2925}{9^{\prime} 0^{\prime \prime} \cdot 3}}
$$

Here we work from nearest noon, and obtain multiplier for H.V. by subtracting the $14^{\mathrm{h}} 45^{\mathrm{m}}$ in G.M.T. from $24^{\mathrm{h}}=9^{\mathrm{h}} 15^{\mathrm{m}}$.

The correction is subtracted since the declination decreases from 29th to 28 th.

3. Find sun's declination for September $23 \mathrm{rd} 11^{\mathrm{h}} 48^{\mathrm{m}}$ P.M. M.T.G.

Dec. for $23^{\text {d }}$ noon $0^{\circ} 10^{\prime} 58^{\prime \prime} \cdot 1$ N. H.V. $58 \cdot 45$

$$
\text { Cor. }-1129 \cdot 7
$$

$11 \cdot 8$

Dec. for $23^{d} 11^{\text {h }} 4 S^{m} \quad 0 \quad 031 \cdot 6 \mathrm{~S}$.

$$
\begin{gathered}
\begin{array}{c}
46760 \\
64295
\end{array} \\
\frac{6,0) 68,9 \cdot 710}{11^{\prime} 29^{\prime \prime} \cdot 7}
\end{gathered}
$$

Since the declination changes in name from $N$. to $S$., it must decrease. The declination has a maximum value twice during the year, about June 21st and December 24 th, the value being about $23^{\circ} 27^{\prime} 15^{\prime \prime}$; it has no value about March 20th and September 23rd, the sun being on the equinoctial on those dates.

From March 20th to June 21st the sun's declination is $\mathrm{N}$. and increasing.

"June 21st to Sept. 23rd ,, , , , , decreasing.

"Sept. 23rd to Dec. 24th ", $\quad$," $\quad$ S. ", increasing.

"Dec. 24th to March 20th ," , ", ", decreasing.

(2) Equation of Time.

\section{Examples.-}

1. Find the Eq. of Time for September 24 th $8^{\mathrm{h}} 21^{\mathrm{m}}$ A.M. A.T.G.

Eq. of Time for Sept. $24^{\mathrm{d}}$ noon $7^{\mathrm{m}} 43^{\mathrm{s}} \cdot 36$

Cor. $\quad-3 \cdot 16$

$$
\text { ,, , Sept. } 23^{\mathrm{d}} 20^{\mathrm{h}} 21^{\mathrm{m}} \overline{740 \cdot 20}
$$

H. V. $\cdot 866$

$3 \cdot 65$ for nearest noon.

$$
\begin{gathered}
4330 \\
5196 \\
2598
\end{gathered}
$$

By looking on the top of the column, we may see how to apply this amount to A.T.G. in order to obtain M.T.G. A thick line divides the heading. There is a corresponding thick line in the Eq. of Time column between $\mathbf{1}^{\mathrm{d}}$ and $2^{d}$ : this shows that all amounts above the thick line must be applied as stated above the line in the heading, and vice vers $\hat{a}$; hence the amount found, $7^{\mathrm{m}} 40^{\mathrm{s}} \cdot 2$, must be subtracted from the given A.T.G.

Thus A.T.G. Sept. $23^{\mathrm{d}} 20^{\mathrm{h}} 21^{\mathrm{m}} 0^{\mathrm{s}}$

Eq. of Time $\quad-740.2$

M.T.G. Sept. $2 3 ^ { d } \longdiv { 2 0 \quad 1 3 1 9 . 8 }$ 
2. Find Eq. of Time for September 1st $8^{\mathrm{h}} 42^{\mathrm{m}}$ P.M. M.T.G.; and find A.T.G.

Eq. of Time Sept. 1st noon $0^{\mathrm{m}} 9^{\mathrm{s}} \cdot 13$

Cor. $\quad 6 \cdot 78$

" $\quad, \quad 1^{\mathrm{a}} 8^{\mathrm{h}} 42^{\mathrm{m}} \overline{0 \quad 2 \cdot 35}$

M.T.G. Sept. $1^{\mathrm{d}} 8^{\mathrm{h}} 42^{\mathrm{m}} 0^{\mathrm{a}}$

$$
\begin{aligned}
& \text { Eq. } \\
& \text { A.T.G. , } \quad 1^{\mathrm{d}} \frac{-2 \cdot 3 \tilde{5}}{4157 \cdot 65}
\end{aligned}
$$

\section{A.T.G. , $\quad 1^{\mathrm{d}} \overline{841 \quad \overline{57 \cdot 65}}$}

H.V. $\cdot 779$

$8 \cdot 7$

5453

6232

$6 \cdot 7773$

Correction is subtracted from Eq. because it is changing its name, and the total amount is subtracted from M.T.G. because it is above the black line in column. Had the correction been more than the original amount of Eq., the corrected amount would have turned out below the line and additive.

The Eq. of Time has 4 maxima during the year, on Feb. 11th, May 15th, July 27 th, Nov. 4 th.

The Eq. of Time has 4 minima during the year, on April 15th, June 15th, Sept. 1st, Dec. 25th.

On the days on which the Eq. of Time vanishes, the mean and apparent suns are on the same hour circle.

(3) Right Ascension.

\section{Examples.-}

1. Find the R.A. of the apparent sun on August 19th at $8^{\mathrm{h}} 27^{\mathrm{m}}$ P.M. M.T.G.

R.A. August 19 th noon $9^{\mathrm{h}} 51^{\mathrm{m}} 21^{\mathrm{n}} \cdot 31$

Cor. +118.62

$$
\text { , } \quad \text { " } 19^{\mathrm{d}} 8^{\mathrm{h}} 27^{\mathrm{m}} \overline{952 \quad 39 \cdot 93}
$$

H.V. 9·304

$$
\begin{gathered}
8 \cdot 45 \\
\begin{array}{c}
46520 \\
37216 \\
74432
\end{array}
\end{gathered}
$$

$78 \cdot 61880$ A.T.G.

2. Find the R.A. of the apparent sun on August 25th at $3^{\mathrm{b}} 15^{\mathrm{m}}$ A.M.

$$
\begin{aligned}
& \text { A.T.G. Augusi } 24^{\mathrm{d}} 15^{\mathrm{h}} 15^{\mathrm{m}} \\
& \text { R.A. August 25th noon } 10^{\mathrm{h}} 13^{\mathrm{m}} 33^{\mathrm{s}} \cdot 02 \\
& \begin{array}{lll}
\text { Cor. } & -1 & 20 \cdot 39
\end{array} \\
& \text {, , , } 24^{\mathrm{a}} 1 \tilde{5}^{\mathrm{h}} 15^{\mathrm{m}} \overline{10 \quad 12 \quad 12 \cdot 63}
\end{aligned}
$$
H.V. $9 \cdot 187$
$8 \cdot 75$
45935
64309
73496

In correcting the above elements, the H.V. as entered in the "Nautical Almanac" has been used without alteration; the H.V. differs, however, day by day, and therefore requires correcting itself; this is done by applying the amount that the H.V. changes in half the interval to be corrected for to the H.V. used: the element is then said to be corrected for 2 nd differences. 
Example.-Find the R.A., Dec., and Eq. of Time for August 1st, $8^{\mathrm{h}} 30^{\mathrm{m}}$ P.M. A.T.G., correcting for 2nd Differences.

\begin{tabular}{|c|c|c|c|c|c|c|c|}
\hline R.A. & & ist 1 & $\begin{array}{c}\text { st noon } 8^{\text {h }} 42^{\text {n }} \\
\text { Cor. }+1\end{array}$ & $\begin{array}{l}55^{s} \cdot 43 \\
22 \cdot 612\end{array}$ & $\begin{array}{l}\text { II.V. 1st } \\
\text { ", 2nd }\end{array}$ & $\begin{array}{l}9^{s} \cdot 724 \\
9 \cdot 698\end{array}$ & $\begin{array}{r}9^{s} \cdot 724 \\
\text { Cor. }-.005\end{array}$ \\
\hline R.A. & " & " & $8^{\mathrm{h}} 30^{\mathrm{m}} 844$ & $18 \cdot 042$ & $\frac{1}{2}$ Int. & $\begin{array}{l}\cdot 026 \\
4 \cdot 25\end{array}$ & $\begin{array}{r}9 \cdot 719 \\
8.5\end{array}$ \\
\hline & & & & & & $\begin{array}{l}2550 \\
850\end{array}$ & $\begin{array}{r}48595 \\
77752\end{array}$ \\
\hline & & & & & 24) ${ }^{*}$ & 11050 & $82 \cdot 6115$ \\
\hline & & & & & & & \\
\hline
\end{tabular}

Dec. for August 1st noon $18^{\circ} 11^{\prime} 45^{\prime \prime} \cdot 0$ N. $\quad$ II.V. 1st $37^{\prime \prime} \cdot 26$

$37^{\prime \prime} \cdot 26$

Cor. $-517 \cdot 8$

,2 2nd 38.00

Cor. $+\cdot 13$

Dec. " $\quad$ " $\quad 8^{\mathrm{h}} 30^{\mathrm{m}} \overline{18 \quad 6 \cdot 27 \cdot 2} \mathrm{~N}$.

74

$\frac{1}{2}$ Int. $4 \cdot 25$

$37 \cdot 39$

$8 \cdot 5$

18695

1700

2975

29912

$\overline{2 4 \longdiv { 3 \cdot 1 4 5 0 }}$

$317 \cdot 815$

$\cdot 13$

Eq. of Time August 1st noon $6^{\mathrm{m}} 10^{\mathrm{s}} \cdot 22$

Cor. $-1 \cdot 165$

H.V. 1st $\cdot 132$

$\cdot 132$

"2 2nd $\cdot 158$

Cor. $+\cdot 005$

$" \quad \quad \quad 8^{\mathrm{h}} 6^{\mathrm{m}} \overline{6.055}$

$\overline{026}$

137

$\frac{1}{2}$ Int. $4 \cdot 25$

8.5

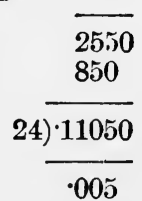

Nore. - The Polar Distance of an object is its distance from the elevated pole, and is the complement of the declination. It is found by adding $90^{\circ}$ to the dec. when dec. and lat. are of opposite names, and by subtracting the dec. from $90^{\circ}$ when dec. and lat. are of same name.

\section{Exercises.}

Correct the declination, equation of time, and right ascension for the following Greenwich times.

1. Apparent time Aug. $3^{\mathrm{a}} \quad 5^{\mathrm{h}} 48^{\mathrm{m}}$.

2. $\quad, \quad$ Aug. $7^{\mathrm{d}} 954$.

3. $" \quad$ Aug $14^{\mathrm{d}} 1436$.

\begin{tabular}{|c|c|}
\hline Mean time & Sept. 14 \\
\hline & \\
\hline$"$ & pt. $23^{\mathrm{d}}$ \\
\hline & Sept. $23^{\mathrm{d}}$ \\
\hline ", & Sept. $23^{\mathrm{d}}$ \\
\hline ,, & Sept. $29^{d}$ \\
\hline
\end{tabular}


10. Find the A.T. ship when the Greenwich mean time is August 20d $16^{\mathrm{h}} 5^{\mathrm{m}} 30^{\mathrm{s}}$ in long. $64^{\circ} \mathrm{E}$.

11. Find the M.T. ship when the A.T.G. is September $30^{\mathrm{d}} 8^{\mathrm{h}} 42^{\mathrm{m}}$ in long. $164^{\circ} 30^{\prime} \mathrm{W}$.

12. If the A.T.S. is September 25 th $3^{\mathrm{h}} 19^{\mathrm{m}} 25^{\mathrm{s}}$ A.M., in long. $84^{\circ} 20^{\prime}$ E., find the M.T.G.

ART. 43. Sidereal Time.-This is tabulated for noon of each day on p. II., and is the Sidereal Time at mean noon; another name for it is Right Ascension of the Mean Sun. Since the Mean Sun is supposed to move uniformly in the equinoctial, the H.V. is constant. A table for correcting the Sidereal Time is found in the "Nautical Almanac;" or in Norie, table xxxviii. The equivalents taken from the "Nautical Almanac" are given in the Appendix.

Example.-Find the correct Sid. Time for August $25^{\mathrm{d}} 13^{\mathrm{h}} 15^{\mathrm{m}} 25^{\mathrm{s}}$, M.T.G.

$$
\begin{aligned}
& \text { S.T. for August } 25^{\mathrm{d}} \text { noon } \quad 10^{\mathrm{h}} 11^{\mathrm{m}} 21^{\mathrm{s}} \cdot 50 \\
& \begin{array}{lll}
\text { Accel. for } 13^{\text {h }} & 2 & 8 \cdot 13
\end{array} \\
& \begin{array}{lrr}
, & 15^{\mathrm{m}} & 2 \cdot 46 \\
, & 25^{\mathrm{s}} & \cdot 07
\end{array}
\end{aligned}
$$

R.A.M. Sun $10 \quad 13 \quad 32 \cdot 16$

\section{Exercises.}

Correct the Sid. Times for following G.M.T.'s.
1. August
$19^{\mathrm{d}} 18^{\mathrm{h}} 10^{\mathrm{m}} 32^{\mathrm{s}}$.
2. $\quad, \quad 28 \quad 3 \quad 4 \quad 47$.
3. September $514 \quad 5414$.
4. ,, 2924924 .

ART. 44. Moon's Elements-(1) Semi-diameter. (2) Horizontal Parallax. These are entered on p. III. of "Nautical Almanac" for "noon" and "midnight" of each day. The difference between any two consecutive entries is the variation in twelve hours, from which by proportion may be found the variation corresponding to the required interval. After being corrected for "time," the S.D. requires a further amount called " Augmentation" to be added to it, in consequence of the apparent increase in the disc of the moon, due to her approach to the observer as she increases her altitude. This is found in Table D, Norie. The H.P. also requires an amount called "Reduction" to be subtracted from it, because the H.P. entered in the almanac is the Equatorial H.P., and the observer is in some latitude where the earth's radius is shorter than the equatorial radius, and so the H.P. is reduced. This correction is found in Table E, Norie. 
Example.-August $16^{\text {d }}$ at $5^{\text {h }} 14^{\mathrm{m}} 24^{\mathrm{s}}$ M.T.G. in lat. $35^{\circ}$ S.; app. alt. moon, $47^{\circ}$. Find corrected S.D. and H.P.

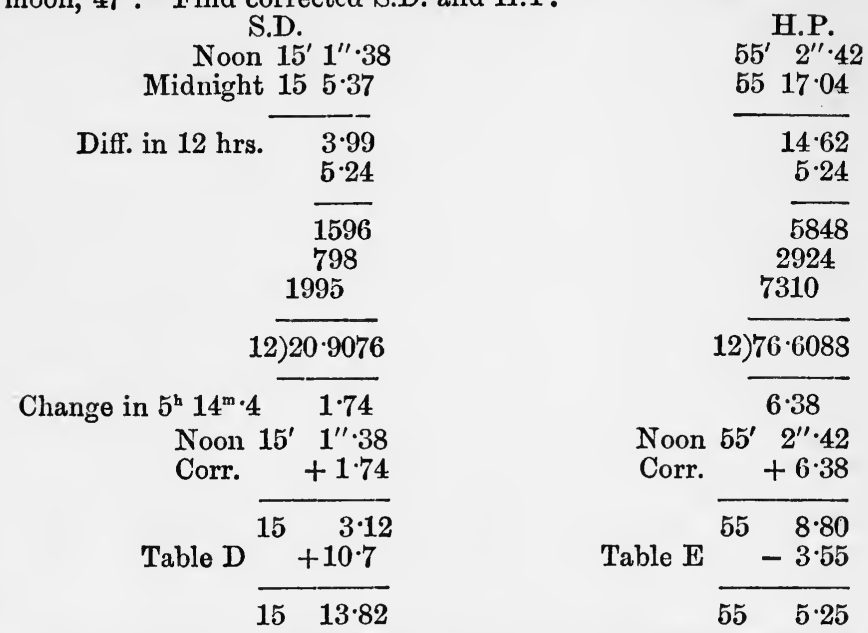

Should the time exceed 12 hours, that is, fall between midnight and noon, the element is taken out for midnight and corrected towards the next day noon, using as a multiplier the hours in the Greenwich time reduced by 12.

Exercises.

Find the S.D. and H.P. of the Moon under the following conditions :-

1. August $7^{\mathrm{d}} 7^{\mathrm{h}} 24^{\mathrm{m}}$ M.T.G. in lat. $40^{\circ}$ N. Alt. $26^{\circ}$.

2. $, \quad 17^{\mathrm{d}} 1615 \quad, \quad, \quad 50^{\circ} \mathrm{S}$, , $36^{\circ}$.

3. " $24^{\mathrm{d}} 2036$ ", ", $30^{\circ} \mathrm{N}$. " $46^{\circ}$.

4. $\quad$ " $31^{\mathrm{d}} 545 \quad, ", \quad 20^{\circ} \mathrm{S} ., " 56^{\circ}$.

(3) Meridian Passage.-This is tabulated in mean time for each day at upper and lower transit on p. IV. of the month, in Greenwich astronomical time. It is the interval between the transit of the Sun and Moon. As the Earth rotates from W. to E., and the Moon is constantly changing her angular distance eastward from the Sun (about $12^{\circ}$ daily), it follows that this interval is less when the Moon crosses the meridian of a place in E. long., and greater for a place in W. long. than the time given in the "Nautical Almanac." The change for 24 hours is found by comparing with the following day for $\mathrm{W}$. long. and the preceding day for E. long. The proportion of this change for the "Longitude in Time" is the correction required, and gives the time at place of the transit across the meridian of the place; by applying "Longitude in Time" to this, we obtain the M.T.G. of the transit across the ship's meridian.

Note.-(a) It is usual to ask for the Mer. pass. on a given Civil Day; therefore, if the corrected time of Mer. pass. exceeds 12 hours, it must be taken out for the preceding day, but for the same day if under 12 hours.

(b) The "Lower" Mer. pass. is used only when the Moon is observed below the pole. 
(c) When two asterisks $\left({ }^{*}\right)$ are seen in the upper Mer. pass. column, it is New Moon, and therefore no observation can be made.

Examples.-August 25th find the M.T.G. of Moon's Mer. pass. in long. $78^{\circ} \mathrm{W}$.

Mer. pass. Aug. $25^{\mathrm{d}} 4^{\mathrm{h}} 39^{\mathrm{m}} \cdot 8$

Cor. for long. $\quad+11 \cdot 7$

M.T. at place $\overline{25^{\mathrm{d}} 4} 51 \cdot 5$

Long. +512

M.T.G. $\overline{25^{\mathrm{d}} 10 \quad 3 \cdot 5}$
Increase to following day because of West long. $54^{\mathrm{m}}$ long. in time $5 \cdot 2$

$$
24 \begin{cases}\frac{\overline{108}}{470} \overline{280 \cdot 8} & \overline{\frac{31,2}{5^{\mathrm{h}} 12^{\mathrm{m}}}} \\ \text { 6) } \overline{70 \cdot 2} & \end{cases}
$$

$11 \cdot 7$

August 11th find M.T.G. of Moon's Mer. pass. in long. $156^{\circ} \mathrm{E}$.

Since Mer. pass. on August 11th occurs at $17^{\mathrm{h}} 57^{\mathrm{m}} \cdot 0$, we use-

Mer. pass. Aug. $10^{\mathrm{d}} 17^{\mathrm{h}} 13^{\mathrm{m}} \cdot 3$

Cor. for long. $\quad-18.8$

M.T. at place $\overline{10^{\mathrm{d}} 16^{\mathrm{h}} 54 \cdot 5}$

Long. -1024

M.T.G. $10^{\mathrm{d}} \quad 6 \quad 30 \cdot 5$
Decrease to preceding day

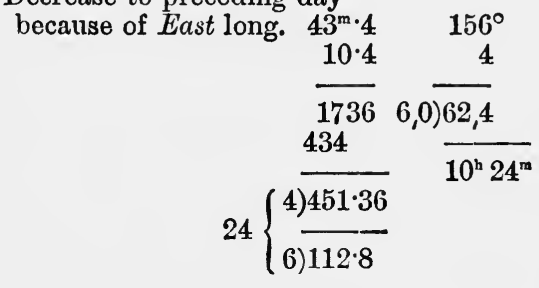

$18 \cdot 8$

\section{ExERCISES.}

Find the M.T.G. of the Moon's Mer. pass. under following conditions :-

1. August 1st in long. $172^{\circ} 20^{\prime} \mathrm{W}$.

2. ," 28th , 9625 W.

3. " 2nd ", 12525 E.

4., 27 th $", \quad 8945$ E.

5. , 4th , $17530 \mathrm{~W}$.

6. ", 15th ," 14248 E.

7. $\quad$ ", 9 th,$" 2430 \mathrm{E}$.

8., 7 th ", $5535 \mathrm{E}$.

(4 and 5.) The Moon's Right Ascension and Declination.-The Moon's path in the heavens is inclined to the Sun's at an approximate angle of $5^{\circ} 9^{\prime}$; and a great circle drawn through the direction of the Moon's motion at any time cuts the ecliptic in two opposite points called the nodes. At every revolution of the moon round the earth the nodes retrograde in the ecliptic, in a manner similar to the precession of the equinoxes; and are carried back $19^{\circ} 20^{\prime}$ in one year, therefore taking $18 \frac{1}{2}$ years to complete the circle. Her greatest latitude is therefore $5^{\circ} 9^{\prime}$; but her greatest declination varies from $23^{\circ} 27^{\prime}+5^{\circ} 9^{\prime}$ to $23^{\circ} 27^{\prime}-$ $5^{\circ} 9^{\prime}$. This causes very large changes in her right ascension and declination from day to day, as in addition her angular motion 
in her orbit is nearly $13^{\circ}$ per day; therefore it has been found necessary to tabulate these data for every hour of the day. This is done in the "Nautical Almanac," pp. V. to XII. of each month, and the variations are given for $10^{\mathrm{m}}$.

In reducing these elements, it is convenient to find the var. in $1^{\mathrm{m}}$ by moving the decimal point one place to the left, and then multiplying by the number of minutes and decimals of a minute in the M.T.G.

Fixample.--Correct the Moon's R.A. and Dec. for M.T.G. August 4th $12^{\mathrm{h}} 24^{\mathrm{n}} \cdot 8$.

$\begin{aligned} & \text { R.A. for } 4^{\mathrm{d}} 12^{\mathrm{h}} 21^{\mathrm{h}} 20^{\mathrm{m}} 56^{\mathrm{s}} \cdot 87 \\ & \text { Cor. for } 24^{\mathrm{m} \cdot 8} \cdot 8\end{aligned} \quad+58 \cdot 60$
Corrected R.A.

Dec. for $4^{\mathrm{a}} 12^{\mathrm{h}} 16^{\circ} 4^{\prime} 41^{\prime \prime} \cdot 9 \mathrm{~S}$.

Cor. for $24^{\mathrm{m}} \cdot 8-3^{\prime} 8 \cdot 1$

Corrected Dec. $16133 \cdot 8 \mathrm{~S}$.

$$
\begin{aligned}
& \text { Var. in } 1^{\mathrm{m}} 2^{\mathrm{s}} \cdot 363 \\
& 24 \cdot 8 \\
& 18904 \\
& 9452 \\
& 4726 \\
& 60688 \\
& 30344 \\
& 15172 \\
& 6,0 \longdiv { 1 8 , 8 \cdot 1 3 2 8 } \\
& 3^{\prime} 8^{\prime \prime} \cdot 1
\end{aligned}
$$

Using 2nd differences.

R.A. for $4^{\mathrm{d}} 12^{\mathrm{h}} 21^{\mathrm{h}} 20^{\mathrm{m}} 56^{\mathrm{s}} \cdot 87 \quad 12^{\mathrm{h}}$ Var. in $10^{\mathrm{m}}=23 \cdot 627 \quad$ Var. in $1^{\mathrm{m}} 2 \cdot 3616$ Cor. $+58.5713^{\mathrm{h}},, \quad=23.574$

Corrected R.A. $212155^{\circ} 44$ Change in $60^{\mathrm{m}}-.053$

$$
\begin{aligned}
& \frac{1}{2} \text { Int. } \frac{12 \cdot 4}{212} \\
& \frac{636}{60) \cdot 6572}
\end{aligned}
$$

188928

94464

47232

58.56768

\section{$\therefore$ Req. var. $=23 \cdot 616$}

Ch. $\cdot 011$

Dec. for $4^{\mathrm{d}} 12^{\mathrm{h}} 16^{\circ} 4^{\prime} 41 \cdot 9^{\prime \prime}$ S. $12^{\mathrm{h}}$ Var. in $10^{\mathrm{m}} 75 \cdot 86$ Cor. $\quad-3,8 \cdot 6$ 13

$$
\begin{array}{r}
\text { Ch. in } 60^{\mathrm{m}}+\frac{76 \cdot 75}{2} \\
\frac{1}{2} \text { Int. } \frac{12 \cdot 4}{356} \\
\frac{1068}{6,0) 1,1 \cdot 036} \\
\text { Ch. }
\end{array}
$$

Cor. Dec. $16 \quad 1 \quad 33.3$ S.

Var. in $1^{\mathrm{m}} 7 \cdot 604$

$24 \cdot 8$

$\overline{60832}$

30416

15208

$6,0) 18,8 \cdot 5792$

$\therefore$ Req. var. $=76.04$ 
Exercises.

Reduce the Moon's R.A. and Dec. to the following M. Times at Greenwich :-

$\begin{array}{lllllll}\text { 1. August } & 5^{\mathrm{d}} & 18^{\mathrm{h}} & 19^{\mathrm{m}} & 27^{\mathrm{s}} \\ \text { 2. } & \text { " } & 8 & 11 & 48 & 45 . \\ 3 . & , & 15 & 6 & 37 & 24 . \\ 4 . & \text { " } & 22 & 19 & 51 & 48 .\end{array}$

ART. 45. Planets' Elements.-The planetary elements used are(1) Right Ascension.

(2) Declination.

These are entered for Mean noon at Greenwich on each day; no variation is given; and the corrections are found by using the difference between two consecutive days as diff. for 24 hours, and thence by proportion determining the change for hours and decimals in M.T.G.

Example.-Find the R.A. and Dec. of Jupiter for August $9^{\mathrm{d}} 10^{\mathrm{h}} 15^{\mathrm{m}}$ M.T.G.

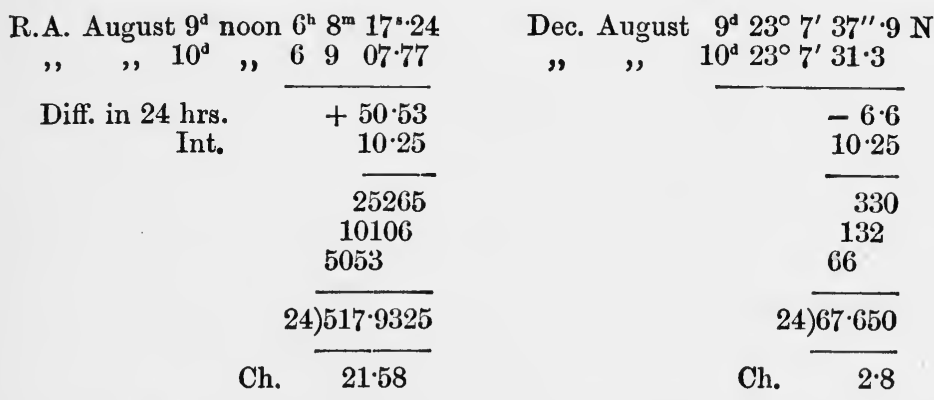

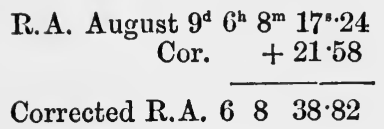

Dec. August $9^{\mathrm{d}} 23^{\circ} 7^{\prime} 37^{\prime \prime} \cdot 9 \mathrm{~N}$.

Cor. $\quad-2 \cdot 8$

Corrected Dec. $23 \quad 7 \quad 35 \cdot 1 \quad \mathrm{~N}$.

S(3) Semi-diameter.

(4) Horizontal Parallax.-These elements do not require correction, and are entered for mean noon at Greenwich. The S.D. is occasionally used in "Lunar" problems.

(5) Meridian Passage.-This column in the "Nautical Almanac" is consulted to obtain the time for observing the Mer. Alt. of a planet for the purpose of finding the latitude. It also determines whether a planet is east or west of the meridian at a given time.

The correction for longitude, when necessary, is similar to that of the Moon's Mer. Pass. 
Example.-Find the G.M.T. of Mer. Pass. of Jupiter on August 9th in long. $75^{\circ} \mathrm{E}$.

\begin{tabular}{|c|c|c|}
\hline $\begin{array}{l}\text { Mer. Pass. August } \\
\text { Cor. for long. }\end{array}$ & $\begin{aligned} 21^{\mathrm{h}} 0^{\mathrm{m} \cdot 4} \\
+\cdot 6\end{aligned}$ & $\begin{array}{c}\text { Ch. to preceding day } \\
\text { long. }\end{array}$ \\
\hline Long. in time & $\begin{array}{rl}21 & 1 \cdot 0 \\
5 & 0\end{array}$ & 24)1: \\
\hline
\end{tabular}

\section{EXERCISES.}

1. Correct the R.A. and Dec. of Jupiter for M.T.G. August $10^{\mathrm{d}} 14^{\mathrm{h}} 54^{\mathrm{m}}$, and find his Mer. Pass. in long. $120^{\circ} \mathrm{W}$.

2. Correct the R.A. and Dec. of Saturn for August $11^{\mathrm{d}} 8^{\mathrm{h}} 24^{\mathrm{m}}$ M.T.G., and find his Mer. Pass. in long. $150^{\circ} \mathrm{E}$.

ART. 46. Stars' Elements.-The only elements used in Navigation are Right Ascension and Declination; these do not require correction.

In the "Nautical Almanac" is a table giving the Mean Places of Stars where they are arranged in order of Right Ascension. The magnitudes are also stated by numbers, the smaller number denoting the brighter star. At the bottom of each page the proper name of the star is given; this may also be found in Table XIV., Norie. After the Mean Places, there is a very much extended table giving the Apparent Places of Stars for every 10 th day of the month.

Directions.-Find the star in the table of "Mean Places," and note the R.A. This R.A. is then used to find the star in the extended table of "Apparent Places." The R.A. and Dec. are then taken out for the nearest date.

Examples.-In our table in the Appendix we find-

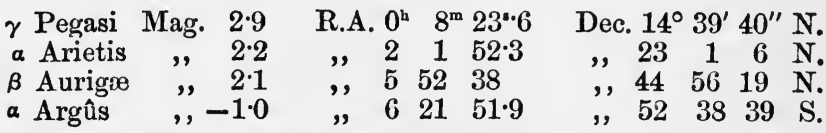

Stars like " $\alpha$ Argûs" whose mag. is prefixed by a " - " sign are brighter than those of mag. 0 ; and these increase in brightness as the negative number increases. Thus Sirius mag. $\mathbf{- 1 \cdot 4}$ is brighter than a Argûs. 


\section{CHAPTER XI.}

SIDEREAL AND SOLAR TIME.

ART. 47.-As a consequence of the Earth's rotation from W. to E., all Celestial bodies have an apparent motion from E. to W., but not all at the same rate. A star completes its apparent revolution in exactly the same time as the Earth takes to turn once on its axis, but the Sun, Moon, and Planets all change their positions with respect to the Stars. The Sun moves to the eastward about $1^{\circ}$ daily, and the Moon about $13^{\circ}$ daily, whilst a planet may have a motion to the E. or W., and sometimes stands still amongst the Stars.

The Apparent Motions of the Stars and the Sun are those used for measuring Time.

A Sidereal Day is the interval between two successive transits of a star over the Meridian of a place, and all Sidereal Days are equal.

A Solar Day is the interval between two successive transits of the Sun's centre, but Solar Days are not all equal, as they increase or decrease in length according to the time of the year. The Sun cannot therefore be a uniform time-keeper. Yet, as Day and Night depend on the Sun, it is the Natural Controller of time for ordinary purposes, and its position with respect to the Meridian marks Apparent Time, as indicated by a sun-dial.

To secure a Uniform Solar Time and Equal Solar Days, a Mean Sun is adopted, which gives Equal Days of 24 Equal Hours all the year round. Its position-sometimes to the E., sometimes to the W., and sometimes (four times in the year) coinciding in Right Ascension with the true Sun-marks Mean Time.

But on account of the progress Eastward (about $1^{\circ}$ daily) of this Mean Sun, it is evident that it will take a longer time to come round to the Meridian again than would a fixed Starnearly $4^{\mathrm{m}}$, in fact.

Hence the Mean Solar Day is nearly $4^{\mathrm{m}}$ longer than a Sidereal Day, but as both kinds of days are divided into 24 hours, it follows that Solar hours, minutes, and seconds are longer than the corresponding divisions of Sidereal Time. The exact relative values are given in two Tables in the "Nautical Almanac," on pp. 588 and 590, and in the Appendix. 
Any star would do to measure a Sidereal Day, but astronomers have made the Sidereal Day begin at the moment when the point where the Ecliptic cuts the Equator-corresponding to the Sun's position on March 21st, and named the "First point of Aries"-is on the Meridian of a place.

Right Ascension is also measured from this point (see Definition).

N.B.-An hour of any kind, whether of Right Ascension, Sidereal Time, or Solar Time, corresponds to an arc of $15^{\circ}$, because $24 \times 15^{\circ}=360^{\circ}$.

ArT. 48.-To find Sidereal Time.-When the Hour Angle and the Right Ascension of any Celestial Object are known, the Sidereal Time may be found as follows :-

(a) Hour Angle West.-Add the Hour Angle to the Right Ascension (rejecting 24 if the sum exceeds 24 hours).

(b) Hour Angle East.-Subtract the H.A. from the R.A. (adding 24 hours if necessary).

Illustration.- $\mathrm{PMP}_{1}$ is the Celestial Meridian of a place, and

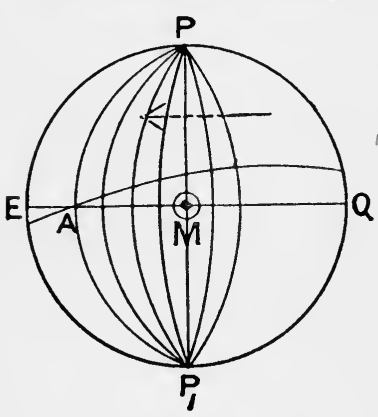

Fig. 98. the other projected semicircles from $P$ to $P_{1}$ are "Hour Circles" ( $15^{\circ}$ apart). $A$ is the "First point of Aries," and the Arc of the Equinoctial M.A. is the Sidereal Time (in this case, 4 hours). But the same Arc measured eastwards from A to $M$ is the R.A. of the Meridian ; therefore Sidereal Time and Right Ascension of Meridian are always equal.

Note.-The student must regard the Meridian and Hour Circles as fixed, and the "First Point of Aries," as well as all celestial objects, in motion from $\mathrm{E}$. to W. in the direction of the arrow.

Using the initials H.A. for Hour Angle, S.T. for Sidereal Time, R.A. for Right Ascension, and R.A.M. for Right Ascension of Meridian, the above rules may be stated concisely thus-

(a) H.A. West; S.T. or R.A.M. = R.A. + H.A.

(b) H.A. East; S.T. or R.A.M. = R.A. - H.A.

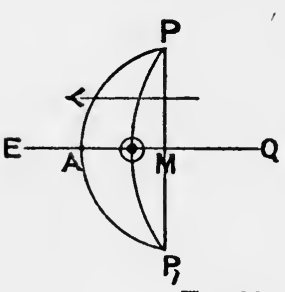

Fig. 99.

\section{Examples.-}

1. Given the Sun's H.A. $3^{\mathrm{h}} 10^{\mathrm{m}} 30^{\mathrm{s}} \mathrm{W}$. of the Meridian, and Sun's R.A. $14^{\mathrm{h}} 20^{\mathrm{m}} 40^{\mathrm{s}}$ : required the Sidereal Time.

Here S.T. = R.A. + H.A.

Sun's R.A. $14^{\mathrm{h}} 20^{\mathrm{m}} 40^{\mathrm{a}}$

Sun's H.A. $310 \quad 30$

S.T. $17 \quad 31 \quad 10$ 
2. Given the Moon's H.A. $4^{\mathrm{h}} 15^{\mathrm{m}} 50^{\circ}$ E. of Meridian, and Moon's R.A. $10^{\mathrm{h}} 19^{\mathrm{m}} 35^{\mathrm{s}}$ : required the S.T.

$$
\begin{aligned}
& \text { Here S.T. = R.A. - H.A. } \\
& \text { Moon's R.A. } 10^{\mathrm{h}} 19^{\mathrm{m}} 35^{\mathrm{s}} \\
& \text { Moon's H.A. } 4 \quad 15 \quad 50 \\
& \text { S.T. } \begin{array}{lll}
6 \quad 3 & 45
\end{array}
\end{aligned}
$$

3. Given a star's H.A. $6^{\text {h }} 50^{\mathrm{m}} 25^{\mathrm{s}}$ E., and its R.A. $2^{\mathrm{b}} 15^{\mathrm{m}} 45^{\mathrm{s}}$ : required the S.T.

$$
\begin{aligned}
& \text { Star's R.A. } 2^{\mathrm{h}} 15^{\mathrm{m}} 45^{\mathrm{s}}\left(\operatorname{add~} 24^{\mathrm{h}}\right) \\
& \text { Star's H.A. } 65025
\end{aligned}
$$

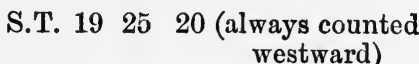

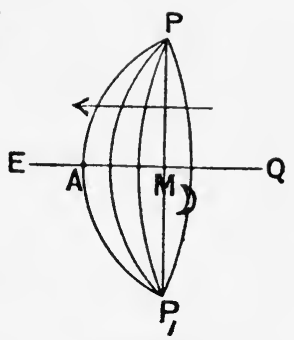

Fia. 100.

4. Given a Planet's H.A. $4^{\mathrm{h}} 12^{\mathrm{m}} 20^{\mathrm{s}}$ W., and its R.A. $22^{\mathrm{h}} 44^{\mathrm{m}} 14^{\mathrm{s}}$ : required the $\mathrm{S} . \mathrm{T}$.

Planet's R.A. $22^{\text {h }} 44^{\mathrm{m}} 14^{\mathrm{s}}$

Planet's H.A. $412 \quad 20$

S.T. $2 \quad 56 \quad 34$

Note.-The above calculation occurs in the "Lunar" and other problems, and should be clearly understood.

ART. 49. To find Sidereal Time from Solar Time.-Since Apparent Time is the Westerly Hour Angle of the Sun, and Mean Time is the Westerly Hour Angle of the Mean Sun, the formula for finding Sidereal Time from the Solar Time will be-

$$
\begin{aligned}
\text { S.T. } & =\text { R.A.M.S. + M.T.S. } \\
\text { or }, " & =\text { R.A.T.S. + A.T.S. }
\end{aligned}
$$

\begin{tabular}{|c|c|c|c|}
\hline $\begin{array}{l}\text { A.T.S. Aug. } 13^{\mathrm{d}} \\
\text { long. W. }+\end{array}$ & & $\begin{array}{l}20^{\mathrm{m}} 0^{\circ} \\
120\end{array}$ & $\begin{array}{c}78^{\circ} \\
4\end{array}$ \\
\hline A.T.G. Aug. $14^{d}$ & & 320 & $6,0) 31,2$ \\
\hline & & & $5^{\mathrm{h}} 12^{\mathrm{m}}$ \\
\hline $\begin{array}{c}\text { Sun's R.A. at noon } \\
\text { Cor. }\end{array}$ & $9^{\text {h }} 3$ & $\begin{array}{r}2^{\mathrm{m}} 39^{\mathrm{s}} \cdot 09 \\
14 \cdot 40\end{array}$ & $\begin{array}{l}\text { H.V } \\
9 \cdot 41\end{array}$ \\
\hline $\begin{array}{r}\text { Reduced R.A. } \\
\text { A.T.S. }\end{array}$ & $\begin{array}{rr}9 & 3 \\
20 & 2\end{array}$ & $\begin{array}{ll}32 & 53 \cdot 49 \\
20 & 0\end{array}$ & $\overline{2823}$ \\
\hline Sid. Time & 55 & $52 \quad 53 \cdot 49$ & 941 \\
\hline
\end{tabular}

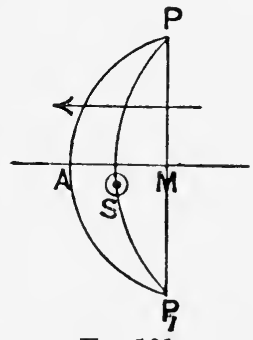

Fig. 101.

\section{Examples.-}

1. Given Apparent Time at ship in long. $78^{\circ}$ W., August 14th, at $8^{\mathrm{h}} 20^{\mathrm{m}}$ A.M. : required the Sidereal Time. 
2. Given Mean Time at ship in long. $84^{\circ} 35^{\prime}$ W., September 23rd, $4^{\text {h }} 36^{m}$ A.M. : required the Sidereal Time.

M.T.S. Sept. $22^{\mathrm{d}} 16^{\mathrm{h}} 36^{\mathrm{m}} 0^{\mathrm{s}}$

long. W. +53820

M.T.G. Sept. $22^{\mathrm{d}} 221420$

$$
\begin{array}{r}
84^{\circ} 35^{\prime} \\
\frac{4}{33,8 \quad 20} \\
\frac{5^{\mathrm{h}} 38^{\mathrm{m}} 20^{\prime}}{}
\end{array}
$$

R.A. Mean Sun at noon (or Sid. Time) $12^{\mathrm{h}} \quad 1^{\mathrm{m}} 44^{\mathrm{s}} \cdot 97$

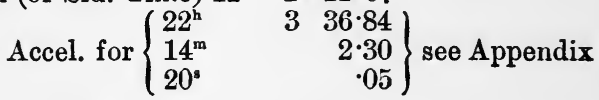

Red. M.S.R.A. $12 \quad 5 \quad 24 \cdot 16$

M.T.S. $1636 \quad 0$

R.A.M. or Sid. Time $44124 \cdot 16$

3. Given M.T.G. September $28^{\mathrm{d}} 20^{\mathrm{h}} 16^{\mathrm{m}} 50^{\mathrm{a}}$, long. $75^{\circ} 20^{\prime}$ E. : find S.T.

M.T.G. Sept. $28^{\mathrm{d}} 20^{\mathrm{h}} 16^{\mathrm{m}} 50^{\mathrm{s}}$ long. E. +5120

M.T.S. Sept. $29^{\mathrm{d}} 11810$

$$
\begin{array}{r}
75^{\circ} 20^{\prime} \\
\frac{4}{30,1 \quad 20} \\
5^{\mathrm{h}} 1^{\mathrm{m}} 20^{\circ}
\end{array}
$$

S.T. at noon or R.A.M.S. $12^{\text {h }} 25^{\mathrm{m}} 24^{\mathrm{s}} \cdot 28$

$$
\text { Accel. for }\left\{\begin{array}{lr}
20^{\mathrm{h}} & 317 \cdot 13 \\
16^{\mathrm{m}} & 2 \cdot 63 \\
50^{\mathrm{s}} & \cdot 14
\end{array}\right\} \text { see Appendix }
$$

Red. M.S.R.A. $12 \quad 28 \quad 44 \cdot 18$

M.T.S. 11810

\section{R.A.M. or Sid. Time $1346 \quad 54 \cdot 18$}

Note.-The Mean Sun's R.A. at noon is taken from the Sidereal Time column on p. II. of "Nautical Almanac," because the mean Sun being on the Meridian at Mean Noon, its R.A. at that moment is the same as the R.A.M. and the S.T. at Mean Noon.

\section{ExerCises.}

Compute the S.T. from the following data :-

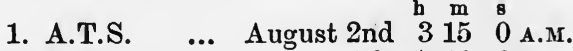

long.

2. M.T.S. $\quad \ldots \quad,, \quad 4$ th 710 P.M. 10545 E.

3. M.T.G. $\quad \ldots, \quad, \quad 8^{\mathrm{d}} 231442$

4. M.T.G. $\quad \ldots$ Sept. $1^{\text {d }} 51525$

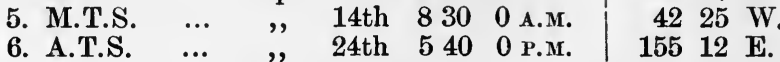

$3630 \mathrm{E}$.

$12437 \mathrm{~W}$. 
the Sidereal Time and the Right Ascension of a Celestial object are known, its Hour Angle can be found by subtracting one from the other, so as to obtain the least difference between them (borrowing 24 hours when necessary). The object is West of the Meridian when R.A. is less than S.T., and East when greater.

Illustration.-A is the first point of Aries. The are MA is the S.T. of observation, $A R_{1}$ is the R.A. of a star west of the Meridian; its H.A. (the arc $M_{1}$ ) is evidently = MA - AR , that is, S.T. star's R.A.

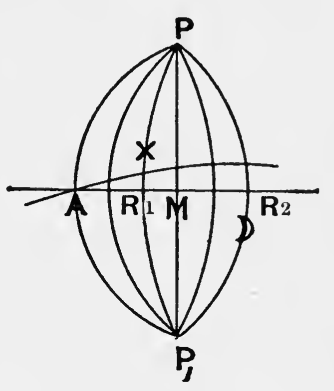

FIG. 102.

Again, $\mathrm{AR}_{2}$ is the R.A. of the Moon, and its H.A. (the are $\left.\mathrm{MR}_{2}\right)=\mathrm{AR}_{2}-\mathrm{MA}$, that is, Moon's R.A. - S.T., and it is East of the Meridian.

\title{
Examples.-
}

1. Given the S.T. $7^{\mathrm{h}} 42^{\mathrm{m}} 35^{\mathrm{s}}$, and the R.A. of a star $6^{\mathrm{h}} 40^{\mathrm{m}} 13^{\mathrm{a}}$ : required its H.A.

\author{
S.T. $7^{\mathrm{h}} 42^{\mathrm{m}} 35^{\mathrm{s}}$ \\ Star's R.A. $6 \quad 40 \quad 13$ \\ Star's H.A. 1222 W. of Mer.
} H.A.

2. Given S.T. $19^{\mathrm{h}} 10^{\mathrm{m}} 40^{\mathrm{s}}$, and R.A. of an object $1^{\mathrm{h}} 2^{\mathrm{m}} 50^{\mathrm{s}}$ : required its

$$
\begin{aligned}
& \text { S.T. } 19^{\mathrm{h}} 10^{\mathrm{m}} 40^{\mathrm{s}} \\
& \text { R.A. } 12250 \\
& \text { H.A. } 55210 \mathrm{E} \text {. of Mer. }
\end{aligned}
$$

Note.-In this example the Sidereal Time is subtracted from the R.A. (which is therefore the greater), because it gives a difference less than 12 hours, and no object can be farther from the Meridian than 12 hours.

ART. 51.-All the Celestial bodies are so related to each other in position that when the H.A. of one of them is known, the H.A. of any other can be found by means of their known Right Ascensions; because it was shown in Art. 46 that S.T. is equal to the sum or difference of the R.A. and H.A. of a given object, and now it has been shown that the H.A. is the difference between the S.T. and the R.A. of any given object.

Note. - The H.A. can also be computed from the Altitude, as will be seen hereafter. 


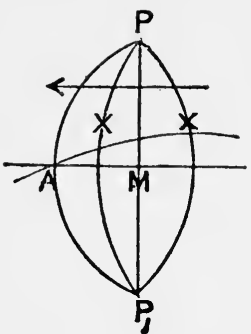

Fig. $10 \%$.

\section{Examples.-}

1. Given R.A. of Star Aldebaran $4^{\mathrm{h}} 30^{\mathrm{m}} 7^{\mathrm{*}}$, and its H.A. $2^{\mathrm{h}} 10^{\mathrm{m}} 25^{\mathrm{A}}$ west of Meridian : what is the H.A. of the Star Regulus whose R.A. is $10^{\mathrm{h}} 3^{\mathrm{m}} 0^{\mathrm{a}}$ ?

$$
\begin{aligned}
& \text { R.A. Star Aldebaran } 4^{\mathrm{h}} 30^{\mathrm{m}} 7^{\mathrm{s}} \\
& \text { H.A. , } 21025 \mathrm{~W} \text {. } \\
& \text { S.T. (or R.A.M.) } 64032 \\
& \text { R.A. Star Regulus } 10 \quad 3 \quad 0 \\
& \text { H.A. , } \\
& 32228 \text { E. of Mer. }
\end{aligned}
$$

2. Given R.A. of Star Achernar $1^{\mathrm{b}} 33^{\mathrm{m}} 57^{\mathrm{a}}$, and H.A. $4^{\mathrm{h}} 50^{\mathrm{m}} 47^{\mathrm{A}}$ east of Meridian : required the H.A. of the Moon when its R.A. is $18^{\mathrm{h}} 10^{\mathrm{m}} 25^{\mathrm{s}}$.

$$
\begin{aligned}
& \text { R.A. Star Achernar } 1^{\mathrm{h}} 33^{\mathrm{m}} 57^{\mathrm{s}} \\
& \text { H.A. " } \quad 4 \quad 50 \quad 47 \text { E. } \\
& \text { S.T. (or R.A.M.) } \overline{20 \quad 43 \quad 10} \\
& \text { R.A. of moon } 18 \quad 10 \quad 25 \\
& \text { H.A. " } 23245 \mathrm{~W} \text {. of Mer. }
\end{aligned}
$$

3. Given M.T.G. Aug. $16^{\mathrm{d}} 8^{\mathrm{h}} 14^{\mathrm{m}} 20^{\circ}$ in long. $80^{\circ}$ E. : find the Meridian Distance or Hour Angle of the Moon.

$$
\begin{gathered}
\text { M.T.G. Aug. } 16^{\mathrm{a}} 8^{\mathrm{h}} 14^{\mathrm{m}} 20^{\mathrm{*}} \\
\text { long. E. } 5 \quad 20 \quad 0
\end{gathered}
$$

M.T.S. Aug. $16^{\mathrm{d}} 133420$

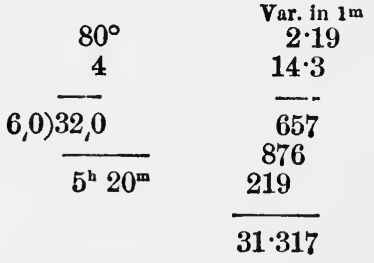

R.A. $16^{\mathrm{d}} 8^{\mathrm{h}}=7^{\mathrm{h}} 4^{\mathrm{m}} 7^{\mathrm{s}} \cdot 82$

Cor. $31 \cdot 32$

Red. R.A. $7 \longdiv { 4 \quad 3 9 \cdot 1 4 }$

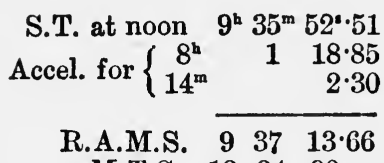

M.T.S. $13 \quad 34 \quad 20$

R.A.M. 231133.66

R.A. D $7 \quad 4 \quad 4 \quad 39 \cdot 14$

H.A. D $16 \quad 6 \quad 54.52 \mathrm{~W}$. of Mer. or $753 \quad 5.48 \mathrm{E}$. of Mer. Time.

ART. 52.-To find the Solar Time corresponding to given Sid.

\section{Examples.-} $7^{\mathrm{b}} 55^{\mathrm{m}} 20^{\mathrm{s}}$. 


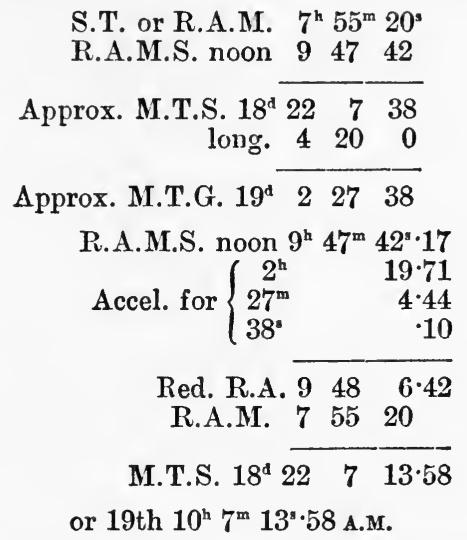

2. Find the M.T.S. in long. $82^{\circ}$ E. on Sept. 20th, when the S.T. is $19^{\mathrm{h}} 14^{\mathrm{m}} 35^{\mathrm{s}}$.

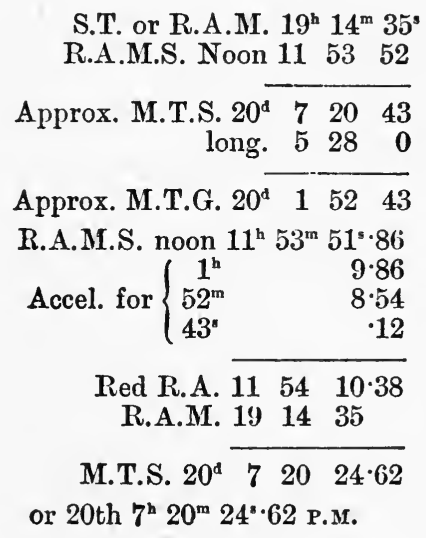

\section{Exercises.}

1. Find the hour angle of Altair at $8^{\mathrm{h}} 20^{\mathrm{m}}$ P.M. M.T.S. in long. $126^{\circ} 20^{\prime}$ E. on August 12th.

2. Find the hour angle of Capella at $7^{\mathrm{h}} 15^{\mathrm{m}}$ A.M. M.T.S. in long. $84^{\circ}$ $3 \tilde{5}^{\prime}$ W. on September 20th.

3. Find the hour angle of the Moon on August 22nd at $5^{\mathrm{h}} 26^{\mathrm{m}}$ P.M. M.T.S. in long. $34^{\circ} \mathrm{W}$.

4. Find the hour angle of Jupiter on August $8^{\mathrm{d}} 17^{\mathrm{h}} 15^{\mathrm{m}}$ M.T.G. in long. $56^{\circ} 25^{\prime} \mathrm{E}$.

5. Find the M.T.S. in long. $74^{\circ}$ E. on August 18th, when the S.T. is $6^{\text {b }}$ $14^{\mathrm{m}} 24^{\mathrm{s}}$.

6. Find the M.T.S. in long. $95^{\circ} \mathrm{W}$. on September 14th, when the S.T. is $18^{\mathrm{h}} 7^{\mathrm{m}} 36^{\mathrm{s}}$.

ART. 53.-To compute the Time when a given Star is on the Observer's Meridian. - When a star is on the meridian, the right 
ascension of the star is the same as the right ascension of the meridian, or Sidereal Time, hence the problem is the same as finding the M.T.S. or A.T.S. corresponding to a given Sid. Time.

\section{Examples.-}

1. Find the M.T.S. when the star Procyon is on the observer's meridian in long. $35^{\circ} \mathrm{W}$. on August 6 th.

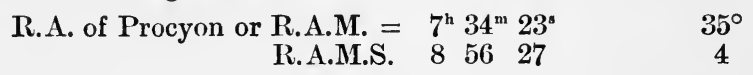

$$
\begin{aligned}
& \text { Approx. M.T.S. } 5^{\mathrm{d}} 2237 \quad 56 \\
& \text { Long. W. } 220 \quad 0 \\
& \text { Approx. M.T.G. } 6^{\mathrm{a}} \overline{0 \quad 57} \overline{56} \\
& \text { R.A.M.S. noon } 8^{\mathrm{h}} 56^{\mathrm{m}} 27^{\mathrm{s}} \\
& \text { Accel. for } 58^{\mathrm{m}} \quad 9 \\
& \text { Red. R.A. } 856 \quad 36 \\
& \text { R.A.* } 7 \quad 34 \quad 23 \\
& \text { M.T.S. } 5^{\mathrm{d}} 22 \quad 37 \quad 47 \\
& \text { or } 6 \text { th } 10^{\mathrm{h}} 37^{\mathrm{m}} 47^{\mathrm{s}} \text { A.M. } \\
& \frac{6,0 \longdiv { 1 4 , 0 }}{2^{\mathrm{h}} 20^{\mathrm{m}}}
\end{aligned}
$$

Care must be taken in dating the approx. M.T.S. If the hours, as in the example, exceed 12, the date is the day before the date in the question; if the hours are less than 12, the date is the same as the question. The passages are required for the civil day, and hence the $5^{\mathrm{d}} 22^{\mathrm{h}}$ (astro. time) corresponds to the 6th $10^{\mathrm{h}}$ A.M. (civil time).

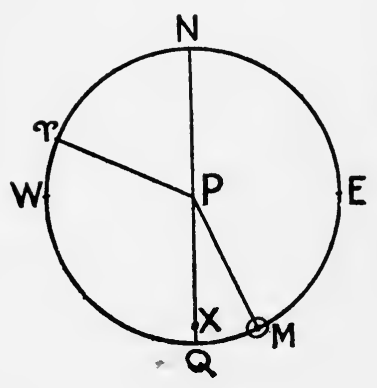

Fig. 104.

In Fig. 104, NEQW represents plane of equinoctial. NPQ is meridian, and the object $\mathrm{X}$ is always found between $\mathrm{P}$ and $\mathrm{Q}$, as this represents our upper meridian. Distance to measure QX is the declination north or south. Find position of $\Upsilon 1$ st point of Aries by measuring to the westward the R.A. of star, which since the star is on the meridian represents the R.A.M. and Sidereal Time ; then from $\Upsilon$ measure to the eastward the R.A. of Mean Sun, this gives M. Draw hour circles through $\Upsilon$ and $M$.

rWQ is R.A. of star and of meridian. TQM is R.A.M.S.

QWEM is westerly hour angle of $M$

$$
\begin{aligned}
& \text { is M.T.S. } \\
& =24^{\mathrm{h}}+r W Q-r Q M .
\end{aligned}
$$

2. Find the M.T.S. when Regulus is on the meridian in $94^{\circ} \mathbf{E}$. on August 4th. R.A. Regulus or R.A.M. $=10^{\mathrm{h}} \quad 3^{\mathrm{m}} 22^{\mathrm{s}}$
R.A.M.S. $8 \quad 48 \quad 34$

Approx. M.T.S. $4^{\mathrm{d}} \overline{114} \mathbf{1 4}$

Long. E. $-616 \quad 0$ 


\section{R.A.M.S. noon $8^{\mathrm{h}} 44^{\mathrm{m}} 37^{\mathrm{s}}$ Accel. for $\left\{\begin{array}{lrr}18^{\mathrm{h}} & 2 & 57 \\ 59^{\mathrm{m}} & & 10\end{array}\right.$ Red. R.A. $\overline{8 \quad 4744}$ R.A.* $10 \quad 3 \quad 22$ M.T.S. $4^{\mathrm{d}} \overline{\mathbf{1}} \overline{15 \quad 38}$ or 4 th $1^{\mathrm{b}} 15^{\mathrm{m}} 38^{\mathrm{s}}$ P.M.}

In Fig. 105, projected on plane of equinoctial, measure $Q W \Upsilon=10^{\mathrm{h}}$, then $\Upsilon W M$ $8^{\mathrm{h}} 48^{\mathrm{n}}$ for $M$.

QM is M.T.S. when $\mathrm{X}$ is on meridian $=r W Q-r W M$.

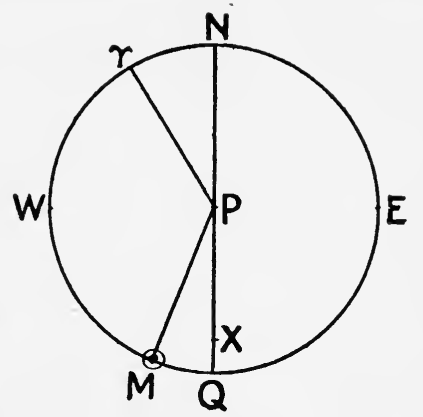

Fig. 105.

3. Find the A.T.S. when Arcturus is on the meridian in $100^{\circ} \mathrm{E}$. on September 2nd. Also by inspection.

R.A. Arcturus or R.A.M. $=14^{\mathrm{b}} 11^{\mathrm{m}} 22^{\mathrm{s}}$ App. R.A. page I. or P.A.T.S. 104244

$$
\begin{aligned}
& \text { Approx. A.T.S. } 2^{\text {d }} 328 \quad 38 \\
& \text { Long. E. - } 640 \quad 0 \\
& \text {, A.T.G. } 1^{\mathrm{d}} 2048 \quad 38
\end{aligned}
$$

App. R.A. noon $10^{\mathrm{h}} 42^{\mathrm{m}} 44^{\mathrm{s}}$

$$
\text { Cor. }
$$

29

Red. R.A. $\overline{10 \quad 42 \quad 15}$

R.A.* 141122

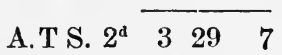

or 2nd $3^{\mathrm{h}} 29^{\mathrm{m}} 7^{\mathrm{s}}$ P.M.

$$
\begin{aligned}
& 100^{\circ} \\
& 4 \\
& 6,0 \longdiv { 4 0 , 0 } \\
& 6^{\mathrm{h}} 40^{\mathrm{m}} \\
& \text { H.v. } \\
& 9.06 \\
& 3 \cdot 2
\end{aligned}
$$

From Table xuIv., Norie, Mer. pass. Arcturus Sept. $1^{\mathrm{d}} \quad 3^{\text {h }} 26^{\mathrm{m}}$

$$
, 6 \quad 6 \quad 3 \quad 9
$$

Diff. in 5 days

," 1 day

17

Hence by inspection 2nd 323 or $2^{\text {nd }} 3^{\text {h }} 23^{\text {in }}$ P.M.

In Fig. 106

NEQW plane of equinoctical.

NPQ meridian.

$\mathrm{X}$ object. $\mathrm{P}$ pole. A true sun.

1st point of Aries. Draw hour circles as in Fig. 106.

$\Upsilon \mathrm{WWQ}=$ R.A.* and R.A.M.

$\Upsilon$ YWM $=$ R.A.T.S.

$\mathrm{QM}=$ Wly. H.A. of $\mathrm{A}^{\prime}$.

$$
\begin{aligned}
& =A . T . S . \\
& =\text { rWQ - rWM. }
\end{aligned}
$$

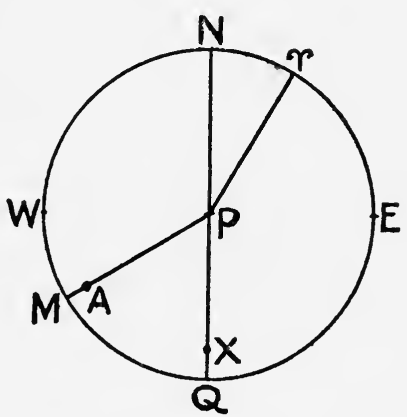

F1G. 106. 
EXERCISES.

Find the ship time when the given star is on the observer's meridian from the following data:-

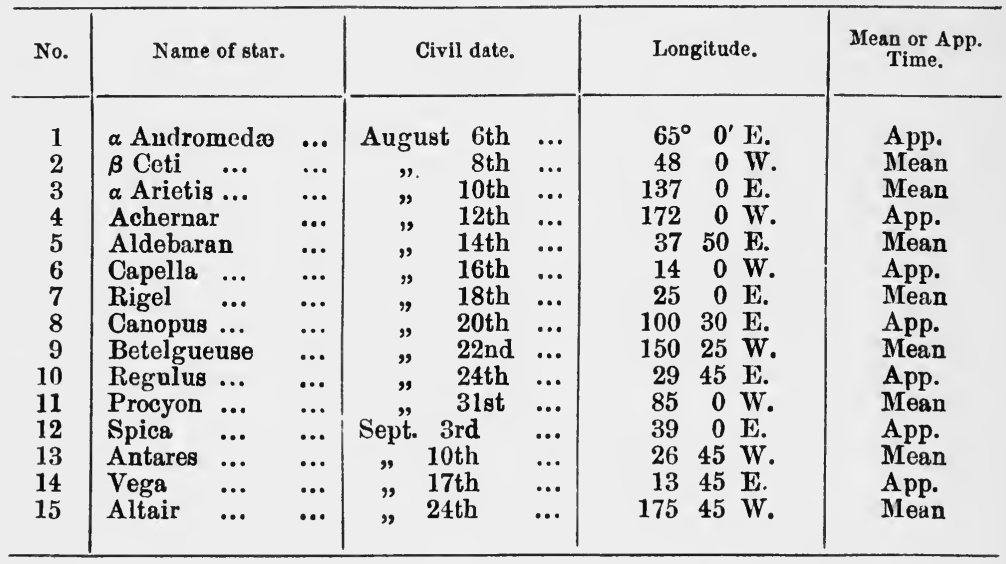

ART. 54.-Bright Stars and Planets.-Stars which may be considered as "bright," and suitable for Navigation purposes, are those of the first and second magnitudes. In the Table of "Mean Places of Stars" in the "Nautical Almanac," there are eighteen of the former and about twice as many of the latter, which gives the Navigator a choice of fifty-four objects suitable for observations, in addition to the Sun, Moon, and Planets.

It is not a work of much labour for the Student, by the help of a Star Atlas or a "Planisphere," to make himself familiar with most of the bright Stars and the Constellations to which they belong.

The Planets Venus, Mars, Jupiter, and Saturn are sometimes very conspicuous objects, and well adapted for observations, but they vary very much in brightness, according to their distance from the Earth. They may easily be recognized by their wanderings amongst the Stars, or by the times of their Meridian passage as given in the "Nautical Almanac."

With such an ample choice of objects, there is no excuse for the Navigator relying upon observations of the Sun only.

ART. 55.-To find what Bright Stars are near the Meridian, or within a given Hour Angle at a Stated Time.

Directions.-Find the S.T. corresponding to the given time, then look in the "Table of Mean Places" in the "Nautical Almanac" for the names of bright Stars whose Right Ascensions do not differ from the S.T. by more than the given Hour Angle. 
N.B.-The star is E. of Mer. when its R.A. is greater than the S.T. (or R.A.M.), and W. when less.

It is $\mathrm{N}$. of the observer when its Declination reads $\mathrm{N}$. of the latitude, and $\mathrm{S}$. when it reads $\mathrm{S}$.

Remark.-As the object in view is to find what stars would be suitable for finding the latitude by Meridian and Ex-Meridian Altitudes, or for finding the Time and Azimuth, in practice it will be sufficient to take the Sun's R.A. at the nearest noon at Greenwich, since the error would not amount to 2 minutes in any case; but for examination purposes the R.A.M. must be exactly determined.

\section{Examples.-}

1. What bright stars will cross the meridian of a place long. $48^{\circ} 30^{\prime} \mathrm{E}$., between the hours of 6 and 9 P.M. M.T.G. on September 30th.
G.M.T. Sept. $30^{\mathrm{d}} \quad 6^{\mathrm{h}} \quad 0^{\mathrm{m}} \quad 0^{\mathrm{s}}$ Long. E. $314 \quad 0$ Sept. $30^{\mathrm{d}} \quad 9^{\mathrm{h}} 0^{\mathrm{m}} \quad 0^{*}$

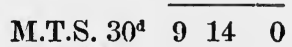
R.A.M.S. $12 \quad 33 \quad 17$
Accel. for $6^{\mathrm{h}}$
59
R.A.M. $2148 \quad 16$

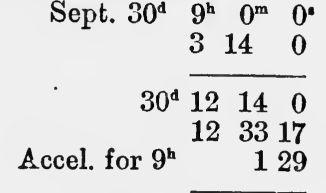
R.A.M. 244846

Hence all stars whose R.A.'s fall between $21^{\mathrm{h}} 48^{\mathrm{m}} 16^{\mathrm{s}}$ and $0^{\mathrm{h}} 48^{\mathrm{m}} 46^{\mathrm{s}}$ will cross the meridian during these times. These stars are $\alpha$ Gruis, $\beta$ Gruis, Fomalhaut, Alpheratz, and $\beta$ Ceti.

2. Sept. $20^{\mathrm{a}} 6^{\mathrm{h}} 19^{\mathrm{m}}$ M.T.G. in lat. $24^{\circ}$ S., long. $125^{\circ} 36^{\prime}$ E.; find what stars not less bright than $2 \cdot 2$ magnitude are within 2 hours $E$. and W. of the meridian, and above the horizon; state their meridian distances, and whether N. or S. of observer at transit.
M.T.G. Sept. $20^{\mathrm{d}} \quad 6^{\mathrm{h}} 19^{\mathrm{m}} \quad 0^{\mathrm{a}}$
Long. E. $\begin{array}{llll}8 & 22 & 24\end{array}$
$125^{\circ} 36$
M.T.S. $20^{\mathrm{d}} \overline{14 \quad 41 \quad 24}$
R.A.M.S. noon 115352
$\begin{array}{lll}6^{\mathrm{h}} & 59\end{array}$
Accel. for $19^{\mathrm{m}}$
3
R.A.M. $2 \quad 36 \quad 18$

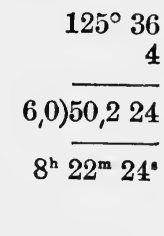

Hence limits of R.A. are from $0^{\mathrm{h}} 36^{\mathrm{m}} 18^{\mathrm{s}}$ to $4^{\mathrm{h}} 36^{\mathrm{m}} 18^{\mathrm{s}}$.

\begin{tabular}{|c|c|c|c|c|c|}
\hline \multicolumn{3}{|c|}{ Name of star. } & Magnitude. & Meridian distance. & Bearing at transit. \\
\hline 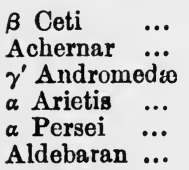 & $\begin{array}{l}\cdots \\
\cdots \\
\cdots \\
\cdots \\
\cdots\end{array}$ & $\begin{array}{l}\cdots \\
\cdots \\
\cdots \\
\cdots \\
\cdots\end{array}$ & $\begin{array}{l}2 \cdot 2 \\
0 \cdot 5 \\
2 \cdot 2 \\
2 \cdot 2 \\
1 \cdot 9 \\
1 \cdot 1\end{array}$ & $\begin{array}{lrrr}1^{\mathrm{h}} & 57^{\mathrm{m}} & 26^{\circ} & \mathrm{W} . \\
1 & 2 & 5 & \mathrm{~W} . \\
0 & 38 & 11 & \mathrm{~W} . \\
0 & 34 & 26 & \text { W. } \\
0 & 41 & 18 & \mathbf{E} . \\
1 & 54 & 14 & \mathbf{E .}\end{array}$ & $\begin{array}{l}\text { N. } \\
\text { S. } \\
\text { N. } \\
\text { N. } \\
\text { N. } \\
\text { N. }\end{array}$ \\
\hline
\end{tabular}




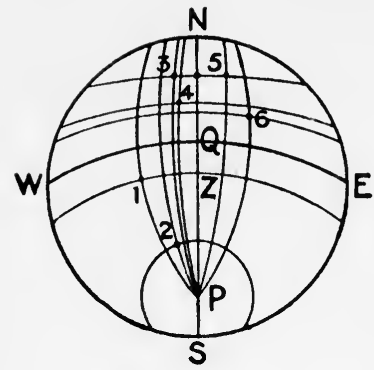

Fia. 107.
In Fig. 107, NESW is Ratl. horizon.

NZS is Meridian.

EQW is Equinoctial.

$\mathbf{P}$ pole; $\mathbf{Z}$ zenith.

$1,2,3,4,5,6$, the stars at the intersection of their respective hour circles and parallels of declination.

ZP1, ZP2, etc., are the hour angles or meridian distances of the stars.

\section{Exercises.}

From following data find names of stars which are visible, and state their hour angles and bearings at transit.

\begin{tabular}{|c|c|c|c|c|c|}
\hline No. & Time. & Limit. & Mag. & Longitude. & Latitude. \\
\hline $\begin{array}{l}1 \\
2 \\
3 \\
4 \\
5 \\
6\end{array}$ & 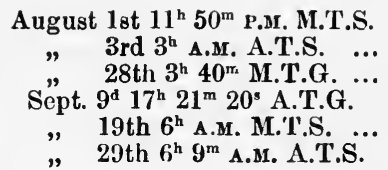 & $\begin{array}{l}1^{\text {th }} \text { E. and W. } \\
11 \text { E. and W. } \\
1 \text { E. and W. } \\
2 \text { F. and W. } \\
1 \text { W. of Mer. } \\
1 \text { E. of Mer. }\end{array}$ & $\begin{array}{l}2 \cdot 6 \\
2 \cdot 0 \\
1 \cdot 0 \\
2 \cdot 6 \\
2 \cdot 0 \\
1 \cdot 5\end{array}$ & $\begin{array}{rlll}48^{\circ} & 15 & \mathrm{~W} \\
56 & 45 & \mathrm{E} . \\
72 & 30 & \mathrm{E} . \\
87 & 50 & \mathrm{~W} . \\
96 & 45 & \mathrm{E} . \\
162 & 15 & \mathrm{~W} .\end{array}$ & $\begin{array}{rl}33^{\circ} & \mathrm{N} . \\
20 & \mathrm{~S} . \\
24 & \mathrm{~S} . \\
5 & \mathrm{~N} . \\
40 & \mathrm{~N} . \\
24 & \mathrm{~S} .\end{array}$ \\
\hline
\end{tabular}

7. On May 27 th at a place in long. $101^{\circ} \mathrm{W}$., time shown by a sidereal clock was $13^{\mathrm{h}} 27^{\mathrm{m}} 38^{\mathrm{s}}$, error of clock on local sidereal time being $2^{\mathrm{h}} 17^{\mathrm{m}} 47^{\mathrm{s}}$. Find local mean time at the instant having given sidereal time at mean noon $4^{\mathrm{h}} 20^{\mathrm{m}} 15^{\mathrm{s}}$.

8. Apparent R.A. Sun on page ii for mean noon is $20^{\mathrm{h}} 57^{\mathrm{m}} 47 \cdot 8^{\mathrm{s}}$, and sidereal time on same page is $20^{\mathrm{h}} 44^{\mathrm{m}} 33 \cdot 2^{\mathrm{s}}$. Find equation of time and show by diagram how it is to be applied to app. time.

9. Sun's app. R.A. on page $i$ for app. noon was $14^{\mathrm{h}} 35^{\mathrm{m}} 28 \cdot 91^{\mathrm{s}}$, and on page ii for mean noon was $14^{\mathrm{h}} 35^{\mathrm{m}} 31^{\circ} 6^{\mathrm{s}}$. Var. in R.A. for $1 \mathrm{hr}$. is $9.883^{\mathrm{s}}$. Find equation of time and show how it is to be applied to mean time. 


\section{CHAPTER XII.}

\section{CORRECTION OF ALTITUDES.}

ART. 56.-The altitudes of all objects, whether observed at sea or on shore in an artificial horizon, must be corrected to reduce them to the true geocentric altitudes. The corrections employed are for index error, or correction; height of eye, or dip; semi-diameter of the object; refraction; and parallax. The method of applying them may be understood from the following remarks.

(a) Index Error--This correction is due to an imperfection in the sextant used, by which the zero mark on the arc is placed out of position. As already explained, when the " 0 " on the vernier is in line with " 0 " on the arc, the index and horizon glasses should be parallel; if they (the zeros) are not in line an error is introduced; when the " 0 " on the vernier is to the left of the " 0 " on the arc (the glasses being parallel), it shows that the " 0 " on the arc is to the right of its true position, hence all angles will be in excess of their true value; the reading is "on" the arc and the error "subtractive." The "0" on the arc being to the left of its true position makes all angles smaller than their true value; the reading is "off" the arc and the error "additive."

The ind. err. is always applied according to the direction in the question.

(b) Height of Eye.-This correction allows for the depression or dip of the visible horizon below the sensible horizon; observed angles, being measured above the visible horizon, are too large, hence the correction is always subtractive. Its amount is found in Norie, Table v., or Raper, Table 30. Should a table not be handy, an approximate correction is found by taking the square root of the height of the eye in feet; this gives the "dip" in minutes of arc.

(c) Semi-diameter.-The altitude of an object's centre is the one required in the calculations, and in bodies which have a visible disc, like the sun and moon, it would be a matter of impossibility for an observer to say exactly where the centre is ; 
an observation of its limb or boundary is therefore taken. The limb nearer the horizon is called the lower limb, "L.L."; an observation of this limb is less in altitude than that of the centre; the S.D. is therefore added. The limb further from the horizon is called the upper limb, "U.L." ; an observation of this limb gives too great an altitude, and the S.D. is subtracted.

The amount for the Sun is entered for noon of each day on page II., "Nautical Almanac."

The amount for the Moon is entered for noon and midnight of each day on page III., "Nautical Almanac."

The limb observed is always stated in the questions. When the corrections $a, b, c$ are applied, the amount obtained is the Apparent altitude of the centre.

(d) Refraction.-Rays of light, in passing from a rarer to a denser medium, have their directions diverted towards the normal or perpendicular to the surface bounding the media. This is called the refraction or bending of the ray. Objects appear in the direction that the last portion of the rays enters the eye, and therefore, as the air is denser at the surface of the earth than higher up, the effect is to make all objects appear nearer the zenith than their true positions, hence the correction for refraction is always subtractive. Its amount is found in Norie, 'lable IV., or Raper, Table 31.

(e) Parallax.-Observations are of necessity made on the surface of the earth; these have to be reduced to the centre or rational horizon, which is below but parallel to the visible horizon; as all objects would appear higher in altitude at the centre than at the surface, the correction for parallax is always additive.

Its amount depends on the latitude of the observer, and the altitude and proximity of the object, and for the Sun is entered in Norie, Table vi., or Raper, Table 34.

In the case of the Moon the amount is entered in the "Nautical Almanac," page III., and must be corrected as before directed.

Refraction and parallax decrease as the altitude increases, and vanish when the object is in the zenith.

Norie, Table XVIII., gives the combined effect in the case of the Sun, and since Refraction is greater than Parallax, the amount found there is always subtractive.

Norie, Table xxx., and Raper, Table 39, give the amount of the Refraction and Parallax in altitude combined in the case of the Moon, and is additive, as the Parallax is more than the Refraction.

In practice the Refraction is taken out for the apparen: altitude of the limb observed, that is, after the index error and dip have been applied. 
When the Refraction and Parallax are applied to the apparent altitude, the true altitude is obtained.

\section{Examples.-}

1. September 23rd, the obs. alt. of the sun's L.L. was $46^{\circ} 25^{\prime} 40^{\prime \prime}$; height of eye, 24 feet; ind. cor. $+2^{\prime} 25^{\prime \prime}$. Find the true alt.

$$
\begin{aligned}
& \text { Obs. alt. } \odot 46^{\circ} 25^{\prime} 40^{\prime \prime} \\
& \text { Ind. cor. }+225 \\
& \longdiv { 4 6 2 8 \quad 5 } \\
& \text { Dip } \quad-4 \quad 48 \\
& 46 \quad 2317 \\
& \text { S.D. }+1558 \\
& \text { App. alt. } 46 \quad 3915 \\
& \text { Ref. } \quad-54 \\
& 463821 \\
& \text { Par. } \quad+6 \\
& \text { True alt. } 46 \quad 3827
\end{aligned}
$$

2. August 5th, the obs. alt. of the sun's U.L. was $14^{\circ} 38^{\prime} 20^{\prime \prime}$; height of eye, 32 feet; ind. cor. $-3^{\prime} 37^{\prime \prime}$. Find the true alt.

$$
\begin{aligned}
& \text { Obs. alt. } \odot 14^{\circ} 38^{\prime} 20^{\prime \prime} \\
& \text { Ind. cor. } \quad-337 \\
& 14 \quad 3443 \\
& \text { Dip } \quad-5 \quad 32 \\
& \begin{array}{lll}
14 \quad 29 & 11
\end{array} \\
& \text { S.D. } \quad-1548 \\
& \text { App. alt. } 141323 \\
& \text { Ref. } \quad-338 \\
& 14945 \\
& \text { Par. } \quad+9 \\
& \text { True alt. } 14 \quad 9 \quad 54
\end{aligned}
$$

The stars appearing merely as points of light have no S.D., and, as they are so far distant, no appreciable parallax.

3. August 6th, the obs. alt. of the star $a$ Trianguli Australis was $27^{\circ} 26^{\prime} 10^{\prime \prime}$ Find the true alt., ind. cor. $-5^{\prime} 27^{\prime \prime}$, eye 41 feet.

Obs. alt. $27^{\circ} 26^{\prime} 10^{\prime \prime}$

Ind. cor. $\quad-527$

$$
\text { Dip } \begin{array}{rr}
27 \quad 2043 \\
-6 \quad 6
\end{array}
$$

App. alt. $27 \quad 1427$

Ref. $\quad-150$

True alt. $\overline{27 \quad 12 \quad 37}$ 
4. August 19th, in lat. $46^{\circ} 25^{\prime}$ N., the obs. alt. of the Moon's L.L. was $42^{\circ} 19^{\prime} 30^{\prime \prime}$; ind. cor. $+3^{\prime} 11^{\prime \prime}$; height of eye, 27 feet ; M.T.G. $19^{d} 4^{\mathrm{h}} 23^{\mathrm{m}} 50^{\circ}$. Find the true alt.

The Par. in alt. is obtained from formula-

Par. in alt. = H.P. $\times$ cos app. alt.

or P.L. Par. in alt. = P.L. Hor. Par. + L. sec. app. alt.

\begin{tabular}{|c|c|c|}
\hline $\begin{array}{c}\text { Noon } \\
\text { Cor. }\end{array}$ & $\begin{array}{l}\text { S.D. } \\
5^{\prime} 28^{\prime \prime} \cdot 8 \\
+1 \cdot 8\end{array}$ & $\begin{array}{r}4^{\prime \prime} \cdot 8 \\
4 \cdot 4\end{array}$ \\
\hline Cab. D. & $\begin{array}{r}1530 \cdot 6 \\
+10 \cdot 4\end{array}$ & $\begin{array}{c}192 \\
192\end{array}$ \\
\hline & 1541 & 12) $21 \cdot 12$ \\
\hline
\end{tabular}

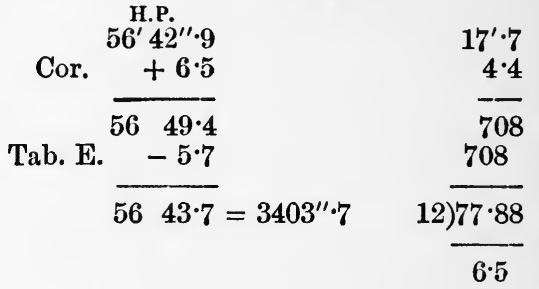

Obs. alt. I) $42^{\circ} 19^{\prime} 30^{\prime \prime}$

Ind. cor. $\quad+311$

$$
\begin{aligned}
& 422241 \\
& \text { Dip. } \quad \begin{array}{rr}
-5 \quad 5 \\
42 \quad 17 \quad 36
\end{array} \\
& \text { S.D. } \quad+1541 \\
& \text { App. alt. } 42 \quad 4317 \\
& \text { Ref. }-12 \\
& 42 \quad 32 \quad 15 \\
& \begin{array}{rr}
3403.7 \log =3 \cdot 531952 & \text { Or H P. P.L. }=5014 \\
\cos =9 \cdot 867250 & \text { sec }=1327
\end{array} \\
& 2507 \log =\overline{3 \cdot 399202} \quad 41^{\prime} 48^{\prime \prime} \text { P.L. }=\overline{6341} \\
& 6,0) 250,7 \\
& 41^{\prime} 47^{\prime \prime}
\end{aligned}
$$

Tab. xxx. $40^{\prime} 5^{\prime \prime}$

Cor. for $43^{\prime \prime}$ par. $\quad 32$

$$
\text { ," } \quad 3^{\prime} \text { alt. } 8
$$

Par. in alt. - ref. $=$ cor. $\overline{4045}$

5. August 9th, the obs. alt. of Jupiter's U.L. was $34^{\circ} 8^{\prime} 50^{\prime \prime}$; ind. cor. $+4^{\prime} 23^{\prime \prime}$; height of eye, 25 feet.

Obs. alt. $34^{\circ} 8^{\prime} 50^{\prime \prime}$

Ind. cor. +423

$$
\begin{aligned}
& 34 \quad 1313 \\
& \text { Dip } \quad-454 \\
& \text { S.D. } \begin{array}{lll}
34 & 819 \\
\hline
\end{array} \\
& \text { App. alt. } 34 \quad 8 \quad 3 \quad \text { H.P. }=1^{\prime \prime} .5 \text {; turn up Tab. } \\
& \text { Ref. }-124 \text { xuvir., which gives par. } \\
& \text { in alt. } 1^{\prime \prime} \text {. }
\end{aligned}
$$

$+1$


ART. 57.-The Artificial Horizon is a plane horizontal mirror, or reflecting surface, used for taking altitudes when the sea horizon is obscured, or not visible. The liquid used is mercury, but treacle, oil, or tar will do as well, and they all depend on the same law in optics, viz. "The angles of incidence and reflection

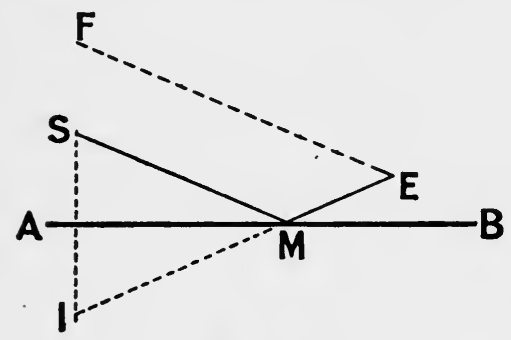

FıG. 108. are equal." AB is a plane horizontal mirror, $\mathrm{S}$ a celestial object; its image, $I$, is seen by an eye placed at $\mathrm{E}$ as far perpendicularly below the surface as $\mathrm{S}$ is above it. Join $\mathrm{EI}$, meeting $\mathrm{AB}$ in $\mathrm{M}$, and join SM. The object $S$ appears in the direction of the dotted line through $\mathrm{E}$, but because of the immense distance $\mathrm{S}$ is off, this line and MS may be considered parallel. The angle FEI is measured with the sextant, while SMA is the altitude of $\mathrm{S}$.

Now, observed angle FEI $=\pi-$ EMS

$$
\begin{aligned}
& =\text { SMA + EMB } \\
& =\text { SMA + AMI } \\
& =\text { twice altitude of S. }
\end{aligned}
$$

Hence, when an altitude is taken with an artificial horizon the index correction is first applied, and then the result halved; moreover, as the horizon is a portion of, or parallel to, the sensible horizon, no correction for dip is necessary.

\section{Example.-}

August 12th, the obs. alt. of the sun's L.L. in artificial horizon was $103^{\circ} 56^{\prime} 20^{\prime \prime}$; ind. cor. $-4^{\prime} 18^{\prime \prime}$; height of eye, $56 \mathrm{ft}$. Find the true alt.

$$
\begin{aligned}
& \text { Obs. alt. } \odot 103^{\circ} 56^{\prime} 20^{\prime \prime} \\
& \text { Ind. cor. } \quad-418 \\
& \text { 2) } 103 \quad 52 \quad 2 \\
& \begin{array}{lll}
51 & 56 & 1
\end{array} \\
& \text { S.D. } \quad+1549 \\
& \text { Ref. } 52 \quad 1150 \\
& \begin{array}{lll}
52 & 11 & 6
\end{array} \\
& \text { Par. } \quad+5 \\
& \text { True alt. } 52 \quad 1111
\end{aligned}
$$




\section{Exercises.}

1. August 16 th, the obs. alt. of the $\odot$ was $50^{\circ} 3^{\prime} 10^{\prime \prime}$; ind. cor. $-4^{\prime} 19^{\prime \prime}$; eye, $20 \mathrm{ft}$. Find true alt.

2. August 8 th, the obs. alt. of $\bar{\odot}$ was $21^{\circ} 13^{\prime} 20^{\prime \prime}$; ind. cor. $+6^{\prime} 17^{\prime \prime}$; eye, $15 \mathrm{ft}$. Find true alt.

3. September 1st, the obs. alt. of $\odot$ was $19^{\circ} 52^{\prime} 10^{\prime \prime}$; ind. cor. $-3^{\prime} 25^{\prime \prime}$; eye, $30 \mathrm{ft}$. Find true alt.

4. September 4 th, the obs. alt. of $\odot$ was $32^{\circ} 24^{\prime} 30^{\prime \prime}$; ind. cor. $+37^{\prime \prime}$; eye, $17 \mathrm{ft}$. Find true alt.

5. August 6 th, the obs. alt. of $\bar{\odot}$ was $47^{\circ} 19^{\prime} 50^{\prime \prime}$; ind. cor. $+4^{\prime} 29^{\prime \prime}$; eye, $24 \mathrm{ft}$. Find true alt.

6. September 27 th, the obs. alt. of $\odot$ was $12^{\circ} 17^{\prime} 20^{\prime \prime}$; ind. cor. $-1^{\prime} 57^{\prime \prime}$; eye, $50 \mathrm{ft}$. Find true alt.

7. August 13 th, at $13^{\mathrm{d}} 6^{\mathrm{h}} 9^{\mathrm{m}} 30^{\mathrm{s}}$ M.T.G. the obs. alt. of Moon's L.L. was $55^{\circ} 36^{\prime} 20^{\prime \prime}$, in lat. $24^{\circ} \mathrm{N}$. ; ind. cor. $+2^{\prime} 41^{\prime \prime}$; eye, $10 \mathrm{ft}$. Find true alt.

8. August 15 th, $6^{\text {h }} 14^{\mathrm{m}}$ A.M. M.T.S., in lat. $43^{\circ}$ S., long. $45^{\circ}$ E., the obs. alt. of Moon's U.L. was $15^{\circ} 13^{\prime} 10^{\prime \prime}$; ind. cor. $-3^{\prime} 17^{\prime \prime}$; eye, $32 \mathrm{ft}$. Find true alt.

9. August 17th, the obs. alt. of star Rigel was $29^{\circ} 17^{\prime} 20^{\prime \prime}$; eye, $50 \mathrm{ft}$. ; ind. cor. $+4^{\prime} 48^{\prime \prime}$. Find true alt.

10. August $28 \mathrm{th}$, the obs. alt. of star Altair was $47^{\circ} 29^{\prime} 30^{\prime \prime}$; eye, $35 \mathrm{ft}$. ; ind. cor. $-3^{\prime} 26^{\prime \prime}$. Find true alt.

11. August 12 th, the obs. alt. of Planet Saturn in lat. $51^{\circ} \mathrm{N}$. was $23^{\circ} 14^{\prime}$; ind. cor. $+2^{\prime} 27^{\prime \prime}$; eye, $36 \mathrm{ft}$. Find true alt.

12. August 8th, the obs. alt. of Planet Jupiter in lat. $42^{\circ} \mathrm{S}$. was $53^{\circ} 20^{\prime}$ $10^{\prime \prime}$; ind. cor. - $37^{\prime \prime}$; eye, $25 \mathrm{ft}$. Find true alt.

13. August $27 \mathrm{th}$, the obs. alt. of Sun's L.L. in artificial horizon was $78^{\circ}$ $14^{\prime} 20^{\prime \prime}$; ind. cor. $-3^{\prime} 36^{\prime \prime}$. Find true alt.

14. August 21st, the obs. alt. of Polaris in artificial horizon was $95^{\circ} 37^{\prime}$ $40^{\prime \prime}$; ind. cor. $+2^{\prime} 56^{\prime \prime}$; eye, $27 \mathrm{ft}$. Find true alt.

15. August 20th, when the M.T.S. was $4^{\mathrm{h}} 19^{\mathrm{m}} 32^{*}$ P.M., in lat. $37^{\circ} \mathrm{N}$., long. $147^{\circ} 30^{\prime}$ W., the obs. alt. of Moon's L.L. in artificial horizon was $102^{\circ}$ $21^{\prime} 30^{\prime \prime}$; ind. cor. 0 ; eye, $100 \mathrm{ft}$. Find true alt. 


\section{CHAPTER XIII.}

\section{LATITUDE BY MERIDIAN ALTITUDE.}

ART. 58.- Latitude is the angle at the earth's centre subtended by the arc of the meridian intercepted between the equator and the place. The arc of the declination circle intercepted between the observer's zenith and the equinoctial subtends the same angle; the latitude is therefore the declination of the observer's zenith, and may be determined easiest by meridian or ex-meridian observations.

The Altitude of the Pole is equal to the Latitude of the

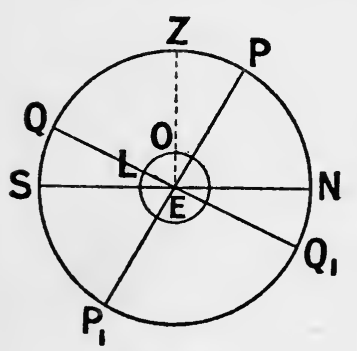

FIG. 109.

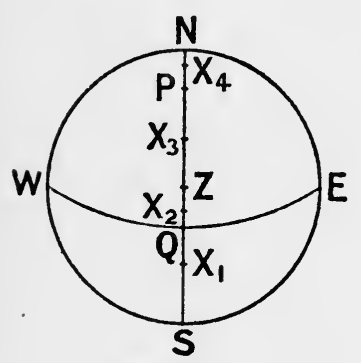

Fig. 110. Observer.-Let $\mathrm{ZSP}_{1} \mathrm{~N}$ represent the celestial meridian of the observer $O$. $\mathrm{Z}$ is the zenith, $\mathrm{QQ} \mathrm{Q}_{1}$ the equinoctial. $\mathrm{E}$ is the centre of earth. Angle OEL or latitude is subtended by arc LO or arc QZ. $\mathbf{P}$ is the elevated pole, $\mathrm{SN}$ the horizon. PEN is altitude of pole.

$$
\begin{aligned}
\text { Now, } \mathrm{PEN} & =90^{\circ}-\mathrm{PEZ} \\
& =\mathrm{ZEQ} \\
\text { or altitude of pole } & =\text { latitude. }
\end{aligned}
$$

ART. 59.-Proof of Latitude by Meridian Altitude.-Let NESW represent the plane of the horizon produced to meet the celestial concave. NPZS the celestial meridian of the observer. $\mathrm{P}$ the elevated pole, $\mathrm{Z}$ his zenith, EQW the equinoctial. Let $X_{1}$, $X_{2}, X_{3}$, and $X_{4}$ be the positions of four celestial objects. Then $\mathrm{QX}_{1}, \mathrm{QX}_{2}, \mathrm{QX}_{3}$ are the declinations of the first three, and $\mathrm{PX}_{4}$ the polar distance of the fourth. Object 1 has south declination, the others north.

$$
\begin{aligned}
\text { Lat. } & =\mathrm{QZ}=Z \mathrm{ZX}_{1}-\mathrm{QX}_{1} \\
& =\text { Mer. zen. dist. }- \text { dec. }
\end{aligned}
$$




$$
\begin{aligned}
\text { Lat. } & =\mathrm{QZ}=\mathrm{ZX}_{2}+\mathrm{QX}_{2} \\
& =\mathrm{Mer} \text {. zen. dist. }+ \text { dec. } \\
\text { Lat. } & =\mathrm{QZ}=\mathrm{QX}_{3}-\mathrm{ZX}_{3} \\
& =\text { Dec. }- \text { Mer. zen. dist. }
\end{aligned}
$$

From these the rules for finding lat. by mer. alt. may be deduced, viz. when dec. and zen. dist. are of same name the sum is the lat.; when dec. and zen. dist. are of contrary name the difference is the lat., which is of the name of the greater.

The zen. dist. is always of contrary name to the bearing.

$$
\begin{aligned}
\text { Lat. } & =\mathrm{NP}=\mathrm{PX}_{4}+\mathrm{NX}_{4} \\
& =\text { pol. dist. }+ \text { alt. }
\end{aligned}
$$

Hence when an object is observed on the meridian between the pole and the horizon, i.e. below the pole, the lat. is the sum of pol. dist. and alt.

Therefore, to find lat. by mer. alt. the process is as follows:-

Object above the Pole.-

(1) Find Greenwich date, correct declination.

(2) Correct altitude, and subtract from $90^{\circ}$ for zen. dist., which mark of contrary name to the bearing of the object.

(3) Dec. and zen. dist. of same name, add for lat.; dec. and zen. dist. of contrary name, subtract for lat., which is of same name as the greater.

Object below the Pole.-

(1) Find Greenwich date; in the case of the sun, the observation must be taken at midnight; in the case of the moon, use the lower mer. pass Correct declination, and subtract from $90^{\circ}$ for pol. dist.

(2) Correct altitude. as dec.

(3) Add pol. dist. to alt. for lat., which must be of same name

\section{Examples.-}

1. August 17 th, in long. $55^{\circ} 45^{\prime}$ W. the obs. mer. alt. of the Sun's L.L. was $35^{\circ} 10^{\prime} 30^{\prime \prime}$ bearing north; ind. cor. $-4^{\prime} 50^{\prime \prime}$; height of eye, $18 \mathrm{ft}$. Required the latitude.
A.T.S. August $17^{\mathrm{d}} 0^{\mathrm{h}} \quad 0^{\mathrm{m}} 0^{4}$
Long. W. $343 \quad 0$
Dec. $13^{\circ} 38^{\prime} 32^{\prime \prime} \cdot 5 \mathrm{~N}$.
H.V. $47^{\prime \prime} \cdot 59$

$$
\text { A.T.G. } 17^{\mathrm{a}} \overline{3430}
$$
Cor.
$1335 \quad 36.5 \mathrm{~N}$. 
Obs. alt. $\odot 35^{\circ} 10^{\prime} 30^{\prime \prime}$

Ind. cor. -450

$\begin{array}{lll}35 & 5 & 40\end{array}$

Dip. $\quad-4 \quad 9$

$\begin{array}{lll}35 & 1 & 31\end{array}$

S.D. +1550

351721

Ref. $\quad-120$

Par. $\begin{array}{r}35161 \\ \hline\end{array}$

True alt. $35168 \mathrm{~N}$. 90

M.Z.D. $544352 \mathrm{~S}$.

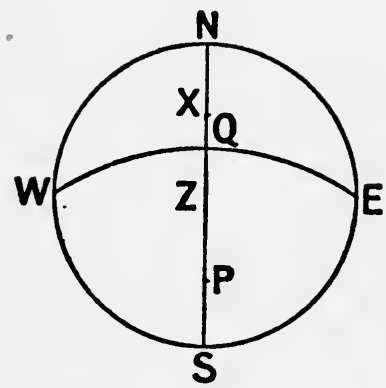

Fig. 111.

Dec. $133537 \mathrm{~N}$.

Lat. $41815 \mathrm{~S}$.

Construction.-Draw a circle NESW radius $\frac{9}{10}$ inch to represent rational horizon, centre point is the zenith $\mathrm{Z}$. The vertical diameter is the ship's meridian on which the sun is situated (Fig. 111). Since the sun bears north, measure $35^{\circ}$ to scale from the north point for position $X$ of sun. His declination is $14^{\circ} \mathrm{N}$., from $\mathrm{X}$ measure to scale $14^{\circ}$ to the south (contrary name to declination) for the point $Q$ where the equinoctial cuts the meridian. $\mathrm{E}$ and $\mathrm{W}$ are in the line through $\mathrm{Z}$ at right angles to the meridian. Through EQW draw an arc of circle for the equinoctial, the centre is somewhere on the meridian produced, and also on the perpendicular bisecting the line joining $\mathrm{EQ}$, and so is at their intersection. Measure $90^{\circ}$ from $Q$ for the position of the elevated pole $P$. The centres for circles of declination passing through objects whose declination is of the same name as the latitude lie between the centre for the equinoctial and $\mathbf{P}$, the greater the declination, the nearer $\mathbf{P}$ is the centre ; when declination is of contrary name to latitude, the centre is beyond this point.

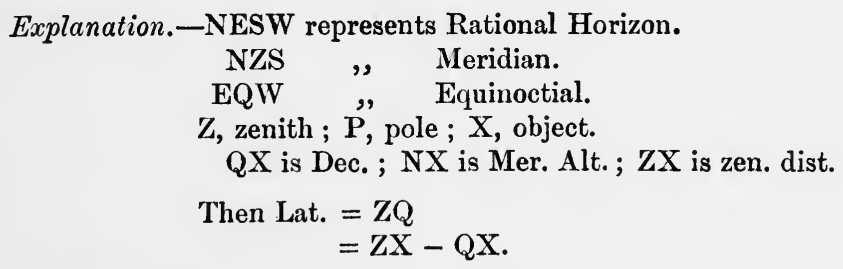

2. August 26th, in long. $87^{\circ} \mathrm{W}$., the obs. mer. alt. of the Sun's U.L. bearing south was $56^{\circ} 30^{\prime} 30^{\prime \prime}$; ind. cor., $+3^{\prime} 20^{\prime \prime}$; eye, $16 \mathrm{ft}$. Required the lat. 
A.T.S. August $26^{\mathrm{d}} 0^{\mathrm{h}} 0^{\mathrm{m}} 0^{\mathrm{s}}$ Long. 5480

A.T.G. $26^{\mathrm{d}} \overline{548 \quad 0}$
Dec. $10^{\circ} 39^{\prime} 5^{\prime \prime} \mathrm{N}$.

Cor.

51

$10344 \mathrm{~N}$.
H.V. $51^{\prime \prime} \cdot 92$

$$
\frac{\frac{5 \cdot 8}{41536}}{\frac{25960}{30,1 \cdot 136}} \frac{5^{\prime} 1^{\prime \prime}}{}
$$

Obs. alt. $\bar{\odot} 56^{\circ} 30^{\prime} 30^{\prime \prime}$

Ind. cor. +320

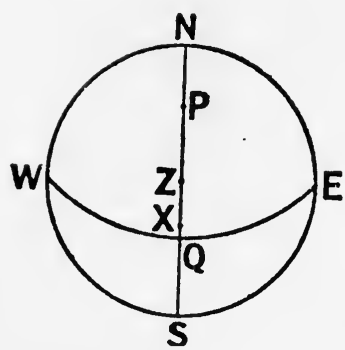

Fig. 112.

$$
\begin{aligned}
& \frac{+320}{56 \quad 3350} \\
& \text { Dip. } \quad-355 \\
& 56 \quad 2955 \\
& \text { S.D. }-1551 \\
& \text { Ref. } \quad-38 \\
& 56 \quad 13 \quad 26 \\
& \text { Par. } \\
& +5 \\
& \text { True alt. } 561331 \mathrm{~S} \text {. } \\
& 90 \\
& \text { M.Z.D. } 334629 \mathrm{~N} \text {. }
\end{aligned}
$$

Construction (Fig. 112).-Draw NESW and NZS, as before. For $\mathrm{X}$ measure $56^{\circ}$ from $S$, since sum bears south, and from $X$ measure $X Q$ to the south $10^{\circ}$. Draw EQW; put in $\mathbf{P}$ as explained.

Explanation.-NESW represents Rational Horizon.

$\begin{array}{cl}\text { NZS } & \text { Meridian. } \\ \text { EQW } & \text { Equinoctial. } \\ \text { Z, zenith; P, pole ; X, object. }\end{array}$

$\mathrm{QX}$ is Dec. ; SX is Mer. Alt. ; ZX is zen. dist.

$$
\text { Then Lat. } \begin{aligned}
& =\mathrm{ZQ} \\
& =\mathrm{ZX}+\mathrm{QX}
\end{aligned}
$$

3. August 1st, in long. $49^{\circ}$ E., the obs. mer. alt. of the sun's U.L. zenith south of sun was $76^{\circ} 54^{\prime} 40^{\prime \prime}$; eye, $25 \mathrm{ft}$.; ind. cor. $-5^{\prime} 10^{\prime \prime}$. Required the lat.

A.T.S. August $1^{\mathrm{d}} 0^{\mathrm{h}} 0^{\mathrm{m}} 0^{\mathrm{s}} \quad$ Dec. $18^{\circ} 11^{\prime} 45^{\prime \prime} \mathrm{N}$. Long. $\quad 3160$

A.T.G. July $31^{\mathrm{d}} 20440$

Cor.

H. V. $37^{\prime \prime} \cdot 26$

$$
\overline{181348} \mathrm{~N} \text {. }
$$

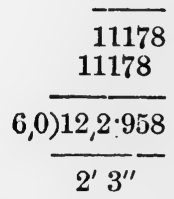




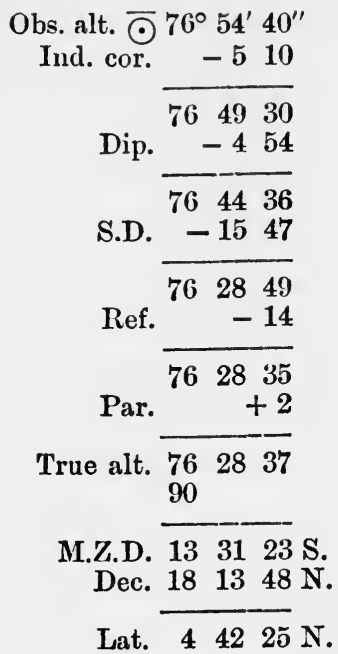

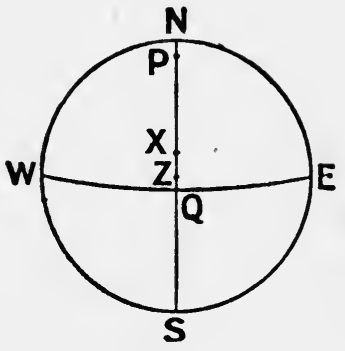

Fig. 113.

Construction (Fig. 113). -Draw NESIV and NZS as before.

Since zenith is south of sun, measure $77^{\circ}$ from $N$ to $X$, as sun must bear north. Complete figure.

Explanation.-As given to Fig. 111.

$$
\begin{aligned}
\text { Then Lat. } & =Z Q \\
& =Q X-Z X .
\end{aligned}
$$

\section{Exercises.}

1. August 3rd, in long. $51^{\circ} 45^{\prime}$ W., the obs. mer. alt. of the Sun's L.L. bearing north was $34^{\circ} 15^{\prime} 30^{\prime \prime}$; ind. cor. $-3^{\prime} 31^{\prime \prime}$; eye, $16 \mathrm{ft}$. Find the lat.

2. August 5th, in long. $33^{\circ} 30^{\prime}$ W., the obs. mer. alt. of the Sun's L.I., zenith north of sun was $50^{\circ} 1^{\prime} 20^{\prime \prime}$; ind. cor. $+4^{\prime} 14^{\prime \prime}$; eye, $18 \mathrm{ft}$. Find the lat.

3. August 7 th, in long. $60^{\circ}$ E., the obs. mer. alt. of the Sun's L. L. bearing north was $19^{\circ} 32^{\prime} 10^{\prime \prime}$; ind. cor. + $2^{\prime} 37^{\prime \prime}$; eye, $20 \mathrm{ft}$. Find the lat.

4. August 9th, in long. $97^{\circ} 30^{\prime} \mathrm{E}$., the obs. mer. alt. of the Sun's U.L. zenith south of sun was $69^{\circ} 47^{\prime} 40^{\prime \prime}$; ind. cor. $+1^{\prime} 10^{\prime \prime}$; eye, $17 \mathrm{ft}$. Find the lat.

5. August 11th, in long. $20^{\circ} 15^{\prime}$ W., the obs. mer. alt. of the Sun's U.L. bearing north was $64^{\circ} 4^{\prime} 50^{\prime \prime}$; ind. cor. $-1^{\prime} 43^{\prime \prime}$; eye, $19 \mathrm{ft}$. Find the lat.

6. August 13th, in long. $70^{\circ} 30^{\prime} \mathrm{E}$., the obs. mer. alt. of the Sun's U.L. zenith south of sun was $50^{\circ} 6^{\prime} 10^{\prime \prime}$; ind. cor. $-1^{\prime} 56^{\prime \prime}$; eye, $21 \mathrm{ft}$. Find the lat.

7. August 15 th, in long. $10^{\circ}$ E., the obs. mer. alt. of the Sun's L.L. bearing north was $78^{\circ} 36^{\prime} 30^{\prime \prime}$; ind. cor. $-2^{\prime} 59^{\prime \prime}$; eye, $25 \mathrm{ft}$. Find the lat.

Under the following conditions find the latitude by mer. alt. of the Sun :- 


\begin{tabular}{|c|c|c|c|c|c|c|c|}
\hline & Date. & Longitude. & Mer. alt. & Limb. & Bearing. & Ind. cor. & IIt. of eye. \\
\hline 8 & Aug. 17th & $12^{\circ} 0^{\prime} \mathrm{W}$. & $80^{\circ} 12^{\prime} \quad 0^{\prime \prime}$ & U. & N. & $-3^{\prime} 42^{\prime \prime}$ & 27 feet. \\
\hline 9 & 19th & $1800 \mathrm{~W}$. & $\begin{array}{llll}52 & 35 & 10\end{array}$ & L. & S. & -625 & 29 \\
\hline 10 & Sept. 30th & 5719 E. & $89 \quad 4 \quad 20$ & U: & S. & +538 & 30 \\
\hline 11 & , 23rd & $4845 \mathrm{~W}$. & $48 \quad 57 \quad 50$ & L. & s. & +320 & 32 \\
\hline 12 & , 23rd & $9730 \mathrm{~W}$. & $\begin{array}{lll}43 & 22 & 20\end{array}$ & L. & N. & -417 & 34 \\
\hline 13 & $\# 27$ th & 1325 E. & $\begin{array}{lll}58 & 44 & 40\end{array}$ & U. & S. & -234 & 22 \\
\hline 14 & 29 th & 914 W. & $\begin{array}{lll}36 & 36 & 30\end{array}$ & U. & N. & -241 & 45 \\
\hline 15 & 24th & $1650 \mathrm{E}$. & $\begin{array}{lll}67 \quad 14 & 10\end{array}$ & L. & S. & -358 & 36 \\
\hline 16 & 23rd & $10040 \overline{\mathrm{E}}$. & $\begin{array}{lll}52 & 19 & 30\end{array}$ & U. & S. & +215 & 34 \\
\hline 17 & 24th & $2450 \mathrm{~W}$. & $\begin{array}{lll}22 & 28 & 20\end{array}$ & L. & S. & -152 & 33 \\
\hline 18 & "24th & $\begin{array}{lll}38 & 20 & \mathrm{E}\end{array}$ & $\begin{array}{lll}30 & 31 & 0\end{array}$ & U. & N. & +329 & 49 \\
\hline
\end{tabular}

ART. 60.-Latitude by Meridian Altitude of a Star.

Example.-August 5th, the obs. mer. alt. of the star Canopus ( $a$ Argûs)

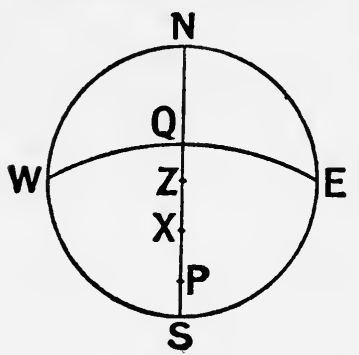

Fig. 114.

Given

Mer. alt. $=\mathbf{S X}$

Dec. $=\mathrm{QX}$

Req. lat. $=\mathbf{Z Q}$

$$
\begin{aligned}
& =\mathbf{Q X}-\mathbf{Z X} \\
& =\mathbf{Q}-(90-\mathbf{S X})
\end{aligned}
$$

bearing sou.th was $54^{\circ} 17^{\prime} 30^{\prime \prime}$; ind. cor., $-6^{\prime} 10^{\prime \prime}$;

eye, $24 \mathrm{ft}$ Required the lat.

Obs. alt. $54^{\circ} 17^{\prime} 30^{\prime \prime}$

Ind cor. $\quad-610$

$$
541120
$$

Dip. $\quad-4 \quad 48$

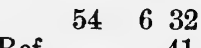

True alt. $54551 \mathrm{~S}$.

90

M.Z.D. $3554 \quad 9 \mathrm{~N}$.

Dec. $523839 \mathrm{~s}$.

Lat. $164430 \mathrm{~S}$.

\section{Exercises.}

1. The observed Mer. Alt. of Capella was $54^{\circ} 29^{\prime} 15^{\prime \prime}$ north of the observer; index error, $-3^{\prime} 10^{\prime \prime}$; height of eye, $20 \mathrm{ft}$. Required the latitude.

2. The observed Mer. Alt. of Rigel was $84^{\circ} 54^{\prime} 20^{\prime \prime}$ north of the observer; index error, $+1^{\prime} 10^{\prime \prime}$; height of eye, $21 \mathrm{ft}$. Required the latitude. 
3. The observed Mer. Alt. of Sirius, zenith north of star, was $45^{\circ} 30^{\prime} 30^{\prime \prime}$; index error, $+1^{\prime} 30^{\prime \prime}$; height of eye, $23 \mathrm{ft}$. Required the latitude.

4. The observed Mer. Alt. of Spica bearing south of observer was $36^{\circ}$ $25^{\prime} 20^{\prime \prime}$; index error, $-3^{\prime} 10^{\prime \prime}$; height of eye, $24 \mathrm{ft}$. Required the latitude.

5. The observed Mer. Alt. of Fomalhaut bearing south of the observer was $10^{\circ} 19^{\prime} 30^{\prime \prime}$; height of eye, $25 \mathrm{ft}$. Required the latitude.

6. The Mer. Alt. of Aldebaran bearing south was $56^{\circ} 23^{\prime}$; index correction, $+1^{\prime} 19^{\prime \prime}$; height of eye, $28 \mathrm{ft}$. Required the latitude.

7. The Mer. Alt. of Spica in an Artificial Horizon was $86^{\circ} 47^{\prime} 20^{\prime \prime}$; index correction, $-2^{\prime} 18^{\prime \prime}$; zenith north of the star. Find the latitude.

8. The Mer. Alt. of Markab bearing north was $30^{\circ} 59^{\prime} 10^{\prime \prime}$; index correction, $+4^{\prime} 2^{\prime \prime}$; height of eye, $33 \mathrm{ft}$. Find the latitude.

9. The Mer. Alt. of a Arietis bearing south was $75^{\circ} 18^{\prime} 40^{\prime \prime}$; index correction, $-4^{\prime} 9^{\prime \prime}$; height of eye, $19 \mathrm{ft}$. Required the latitude.

10. The Mer. Alt. of Algenib in an Artificial Horizon was $111^{\circ} 57^{\prime} 10^{\prime \prime}$; index correction, $+8^{\prime} 6^{\prime \prime}$; zenith south of the star. Find the latitude.

11. The Mer. Alt. of Regulus in an Artificial Horizon was $114^{\circ} 20^{\prime} 30^{\prime \prime}$; index correction, $-5^{\prime} 16^{\prime \prime}$; zenith north of the star. Find the latitude.

ART. 61. Latitude by Meridian Altitude of the Moon.-It is first necessary to find the M.T.G. when the Moon is on the observer's meridian, and then reduce the "Elements" as before directed.

Example.-August 16th, in long. $126^{\circ} 5^{\prime}$ E., the obs. mer. alt. of the Moon's L.L. bearing north was $42^{\circ} 26^{\prime} 20^{\prime \prime}$; ind. cor. $-3^{\prime} 30^{\prime \prime}$; height of eye, $16 \mathrm{ft}$. Find the latitude.

The time of mer. pass. on the 16 th is $21^{\mathrm{b}} 55^{\mathrm{m}} \cdot 3$, which is really about 10 o'clock on the morning of the 17 th, hence we use the passage for the $15 \mathrm{th}$, and since we are in E. long. work from that day towards the 14 th, as the transit occurs earlier.

Mer. pass. $15^{\mathrm{d}} 21^{\mathrm{h}} 4^{\mathrm{m}} \cdot 9$

Cor.

$-17 \cdot 2$

M.T.S. $\overline{15^{\mathrm{d}} 20} \overline{47 \cdot 7}$

Long. $\quad 8 \quad 24 \cdot 3$

M.T.G. $\overline{15^{\mathrm{d}} 12 \quad 23 \cdot 4}$
$49^{\mathrm{m}} \cdot 2\left(\right.$ for $\left.24^{\mathrm{h}}\right)$
$8 \cdot 4$
1968
3936

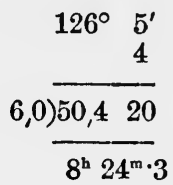
$8^{\mathrm{h}} 24^{\mathrm{m}} \cdot 3$

$\left\{\begin{array}{l}4 \longdiv { 4 1 3 \cdot 2 8 } \\ 6 \lcm{103 \cdot 32}\end{array}\right.$

$17 \cdot 2$

H.P.

S.D.

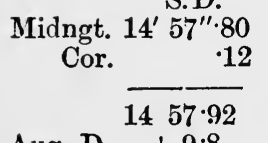

Aug. D. +9.8

$15 \quad 7 \cdot \% 2$ $54^{\prime} 49^{\prime \prime} \cdot 29$

$\cdot 44$

$54 \quad 49 \cdot 73$

12)1‘432 $\cdot 12$

Red. E. -2.4

$\overline{5447 \cdot 33}$ 


\begin{tabular}{|c|c|c|c|c|c|c|}
\hline Obs. alt. D & $42^{\circ} 26^{\prime} 20^{\prime \prime}$ & Dec. & & $11^{\prime} 20$ & $\mathrm{~N}$ & r. $1 \cdot 15$ \\
\hline Ind. cor. & -330 & Cor. & & +26 & & $23 \cdot 4$ \\
\hline Dip. & $\begin{array}{r}422250 \\
-355\end{array}$ & & 20 & 1147 & $\mathrm{~N}$ & $\begin{array}{c}460 \\
345\end{array}$ \\
\hline S.D. & $\begin{array}{r}421855 \\
+158\end{array}$ & & & & & 200 \\
\hline
\end{tabular}

App. alt. $\begin{array}{llllllll}42 & 34 & 3 & \text { Cos. } \quad \ldots & 9 \cdot 867167 & \text { Sec } & \ldots & 1328\end{array}$

$\begin{array}{llll}\text { Ref. } \quad-12 & 3287 \log =3.516800 \quad \text { H.P. P.L. } 5166\end{array}$

$\overline{42331} \quad \overline{2421 \log =3 \cdot 383967} \quad \overline{40^{\prime} 21^{\prime \prime} \text { P.L. } 6494}$

Par. $\quad+4021$

True alt. $431322 \mathrm{~N}$. 90

M.Z.D. $464638 \mathrm{~S}$. Dec. $201147 \mathrm{~N}$. Lat. $263451 \mathrm{~S}$.

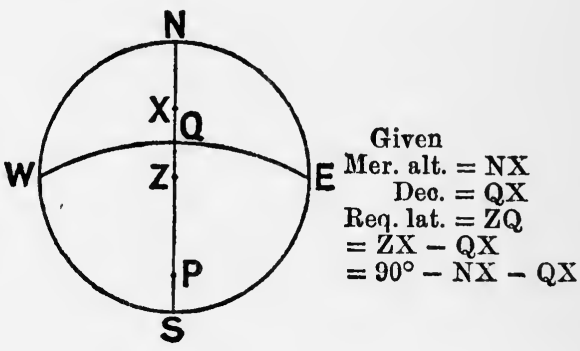

FiG. 115.

Exercises.

1. August 21st, in long. $48^{\circ} 30^{\prime}$ W., the obs. mer. alt. of the Moon's U.L. bearing north was $34^{\circ} 17^{\prime} 20^{\prime \prime}$; ind. cor. $+2^{\prime} 15^{\prime \prime}$; eye, $16 \mathrm{ft}$. Find the lat.

2. August 22nd, in long. $97^{\circ} 25^{\prime}$ W., the obs. mer. alt. of the Moon's L.L. bearing south was $53^{\circ} 26^{\prime} 10^{\prime \prime}$; ind. cor. $-3^{\prime} 20^{\prime \prime}$; eye, $17 \mathrm{ft}$. Find the lat.

3. August 30th, in long. $62^{\circ} 15^{\prime}$ E., the obs. mer. alt. of the Moon's U.L. zenith south of Moon was $61^{\circ} 34^{\prime} 40^{\prime \prime}$; ind. cor. $+5^{\prime} 46^{\prime \prime}$; eye, $18 \mathrm{ft}$. Find the lat.

4. August 31st, in long. $57^{\circ} 45^{\prime}$ E., the obs. mer. alt. of the Moon's L.L. zenith north of Moon was $24^{\circ} 46^{\prime} 50^{\prime \prime}$; ind. cor. $-4^{\prime} 27^{\prime \prime}$; eye, $20 \mathrm{ft}$. Find the lat.

5. August 31st, in long. $120^{\circ} \mathrm{W}$., the obs. mer. alt. of the Moon's L.L. zenith north of Moon was $68^{\circ} 57^{\prime} 30^{\prime \prime}$; ind. cor. $+3^{\prime} 33^{\prime \prime}$; eye, $23 \mathrm{ft}$. Find the lat.

Under the following conditions find the latitude by mer. alt. of the Moon :-

\begin{tabular}{|c|c|c|c|c|c|c|c|}
\hline & Date. & Longitude. & Mer. alt. & Limb. & Bearing. & Ind. cor. & Ilt. of eye. \\
\hline 6 & Aug. 4th & $178^{\circ} 30^{\prime} \mathrm{W}$ & $38^{\circ} 22^{\prime} 20^{\prime \prime}$ & L. & $\mathrm{N}$ & $-1^{\prime} 12^{\prime \prime}$ & 34 feet. \\
\hline 7 & "10th & $2130 \mathrm{E}$. & $42 \quad 3920$ & L. & S. & -219 & 36 " \\
\hline 8 & 11 th & $9415 \mathrm{E}$. & $\begin{array}{lll}46 & 17 & 10\end{array}$ & L. & S. & +35 & 43 \\
\hline 9 & 12 th & $12730 \mathrm{E}$. & $\begin{array}{lll}54 & 29 & 40\end{array}$ & U. & N. & -28 & 46 \\
\hline 10 & $14 \mathrm{th}$ & $13945 \mathrm{~W}$. & $\begin{array}{lll}75 & 16 & 40\end{array}$ & L. & N. & -457 & 49 \\
\hline 11 & $17 \mathrm{th}$ & $15824 \mathrm{E}$. & $\begin{array}{llll}73 & 56 & 10\end{array}$ & L. & N. & +235 & 54 \\
\hline 12 &.$\quad 25$ th & $8835 \mathrm{E}$. & $84 \quad 24 \quad 30$ & L. & S. & +124 & 56 \\
\hline
\end{tabular}




\section{ART. 62. Latitude by Meridian Altitude of a Planet.}

Example.-August 9th, in long. $90^{\circ} \mathrm{W}$., the obs. mer. alt. of the Planet Jupiter bearing north was $42^{\circ} 10^{\prime} 20^{\prime \prime}$; ind. cor. $+4^{\prime} 15^{\prime \prime}$; eye, $27 \mathrm{ft}$. Find lat.

As before explained, the G.M.T. of the Planet's mer. pass. across the observer's meridian must be first found, in a similar way to the Moon's.

Mer. pass. August $8^{\mathrm{d}} 21^{\mathrm{h}} 0^{\mathrm{m}} 4$

Ret.

$-8$

M.T.S. $8^{\mathrm{d}} \overline{20 \quad 59 \cdot 6}$

Long. +6

M.T.G. 9d $\overline{259 \cdot 6}$
Ret. in 24 hrs. $3^{\mathrm{m} \cdot 1}$

$$
\text { " } 6 \text { " } \frac{3.1 \times 6}{24}=8
$$

Dec. $23^{\circ} 7^{\prime} 37^{\prime \prime} \cdot 9 \mathrm{~N}$.

Cor.

$\frac{-8}{23737}$ N.

Diff. for 24 hours $6^{\prime \prime} \cdot 6$

3

Obs. alt. $42^{\circ} 10^{\prime} 20^{\prime \prime} \mathrm{N}$.

Ind. cor. +415

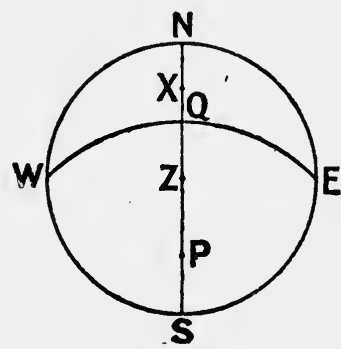

Fig. 116.

Given

Mer. alt. $=\mathrm{NX}$

Dec. $=Q X$

Req. lat. $=\mathrm{ZQ}$

$=\mathrm{ZX}-\mathrm{QX}$
$=90-\mathrm{NX}-\mathrm{QX}$

ArT. 63. Latitude by Meridian Altitude of an Object below the Pole.-An object whose Polar Distance is less than the elevation of the Pole above the horizon will never set, and will therefore be seen on the meridian below the Pole as well as above the Pole: when it has been proved that the lat. is found by adding together the Mer. Alt. and Pol. Dist.

Example.-August 10th, the obs. mer. alt. below the Pole in artificial horizon of the star a Ursæ Majoris was $33^{\circ} 1^{\prime} 10^{\prime \prime}$; ind. cor. $+3^{\prime} 26^{\prime \prime}$. Find the latitude. 


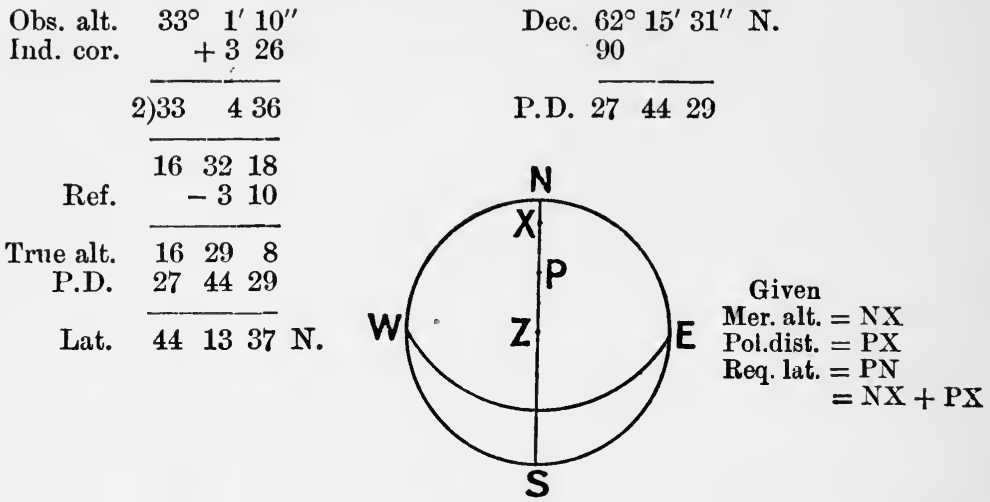

F1G. 117.

Exercises.

1. August 11th, in long. $48^{\circ} 30^{\prime} \mathrm{W}$., the obs. mer. alt. of the Planet Saturn bearing north was $55^{\circ} 16^{\prime} 40^{\prime \prime}$; ind. cor. $-3^{\prime} 27^{\prime \prime}$; eye, $30 \mathrm{ft}$. Find the lat.

2. September 19th, the obs. mer. alt. below the pole in artificial horizon of the star $\alpha^{\prime}$ Crucis was $42^{\circ} 8^{\prime} 50^{\prime \prime}$; ind. cor. $-4^{\prime} 36^{\prime \prime}$. Find the lat.

3. August 14th, the obs. mer. alt. below the pole in artificial horizon of the star a Cygni was $18^{\circ} 11^{\prime} 20^{\prime \prime}$; ind. cor. $+5^{\prime} 42^{\prime \prime}$. Find the lat.

4. August $29 \mathrm{th}$, in long. $135^{\circ} 45^{\prime}$ E., the obs. mer. alt. of the Moon's L.L. under the south pole was $13^{\circ} 27^{\prime} 50^{\prime \prime}$, taken in artificial horizon; ind. cor. $+3^{\prime} 24^{\prime \prime}$. Find the lat.

5. August 1st, in long. $94^{\circ} 25^{\prime} \mathrm{W}$., the obs. mer. alt. of the Sun's U.L. under the north pole in artificial horizon was $12^{\circ} 36^{\prime} 40^{\prime \prime}$; ind. cor. $-2^{\prime} 50^{\prime \prime}$. Find the lat.

6. September 9th, the obs. mer. alt. below the pole of $\beta$ Centauri was $20^{\circ} 47^{\prime} 10^{\prime \prime}$; ind. cor. $+45^{\prime \prime}$; height of eye, $37 \mathrm{ft}$. Find the lat.

ART. 64.-To find the Approximate Meridian Altitude of a Star, for setting the Sextant preparatory to observing the Meridian Altitude.

Referring to the Rule for finding the Latitude by a Meridian Altitude (Art. 59), it was shown that the Latitude is equal to the sum of the Meridian Zenith Distance and Declination when they are of the same name, and the difference when of different names.

Therefore it follows that the Meridian Zenith Distance is the difference of the Lat. and Dec. when they are of the same name, and the sum when of different names.

The Meridian Zenith distance subtracted from $90^{\circ}$ gives the Meridian Altitude.

\section{Examples.-}

1. Given lat. $25^{\circ} 30^{\prime} \mathrm{N}$., and a Star's Dec. $52^{\circ} 20^{\prime} \mathrm{N}$., required the Mer. Alt. of the Star. 
$\left.\begin{array}{lll}\text { Lat. } 25^{\circ} 30^{\prime} & \mathrm{N} . \\ \text { Dec. } 52 & 20 & \mathrm{~N}\end{array}\right\}$ Same name-subtract.

Mer. Zen. Dist. 2650 S.

$90 \quad 0$

Mer. Alt. 6310 North of observer.

Draw NESW and NZS as before. Lat. being north measure $\mathrm{ZQ} 25^{\circ}$ to south for $\mathrm{Q}$, draw EQW, and set off QX $52^{\circ}$ to north for X (Fig. 118).

$$
\begin{aligned}
& \text { Lat. }=\mathrm{ZQ} \\
& \text { Dec. }=\mathrm{QX}, \text { zen. dist. }=\mathrm{ZX} .1
\end{aligned}
$$

Then Mer. Alt. $=\mathrm{NX}=90-\mathrm{ZX}$

$$
=90-(Q X-Z Q) \text {. }
$$

2. Suppose the latitude to be $24^{\circ} 25^{\prime} \mathrm{S}$., and the Star's Dec. $32^{\circ} 10^{\prime}$ N., required its Mer. Alt.

Lat. $24^{\circ} 25^{\prime}$ S. ) Different names-

Dec. 3210 N. $\}$ add.

Mer. Zen. Dist $5635 \mathrm{~S}$.

900

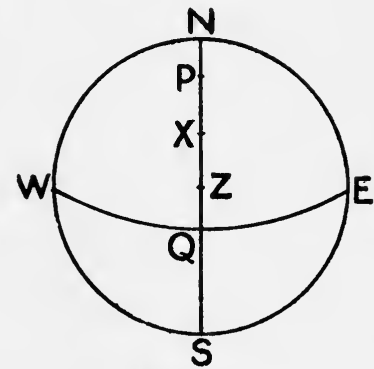

Fig. 118.

Mer. Alt. 3325 North of observer.

In Fig. 119, lat. being south, measure $Z Q=24^{\circ}$ to north for $Q$; make $\mathrm{QX}=32^{\circ}$ to north for $\mathrm{X}$. Lat. $=\mathbf{Z Q}$ Dec. $=\mathrm{QX}$, zen. dist. $=\mathrm{ZX}$.

Then Mer. Alt. $=\mathrm{NX}=90-\mathrm{ZX}$

$$
=90-(Q X+Z Q) \text {. }
$$

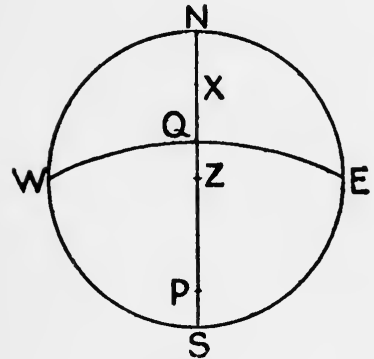

Frg. 119.

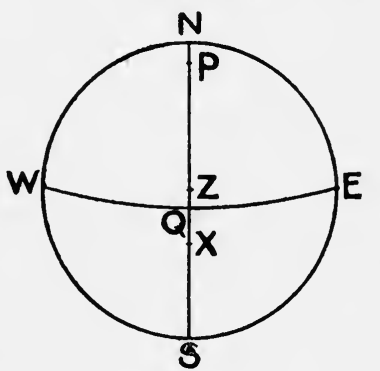

Fig. 120.

3. Given latitude of Ship $10^{\circ} 15^{\prime} \mathrm{N}$., what is the Mer. Alt. of a Star whose Dec. is $20^{\circ} 40^{\prime} \mathrm{S}$., and how does it bear from observer?

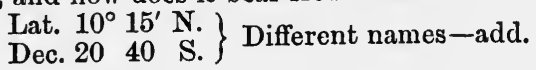

Mer. Zen. Dist. $\overline{3055} \mathrm{~N}$.

$90 \quad 0$

Mer. Alt. 595 N. South of observer.

Here Fig. 120. Mer. Alt. = SX

$$
\begin{aligned}
& =90-Z X \\
& =90-(Z Q+Q X) .
\end{aligned}
$$


N.B.-A Star is north or south of observer according as its Declination reads north or south of the latitude of observer.

If the corrections for Ref., Dip., etc., are applied to the true alt. to make an obs. alt., they must all be reckoned contrary to the manner indicated in the examples on the correction of altitudes.

\section{Exercises.}

Find the Meridian Altitudes of Stars from the following data, and state whether N. or S. of observer:-

\begin{tabular}{|c|c|c|c|}
\hline No. & Latitude. & Name of star. & Declination. \\
\hline $\begin{array}{r}1 \\
\mathbf{2} \\
\mathbf{3} \\
4 \\
\mathbf{5} \\
\mathbf{6} \\
7 \\
8 \\
\mathbf{9} \\
\mathbf{9} \\
10\end{array}$ & $\begin{array}{rcc}\circ & \prime \\
14 & 40 & \mathrm{~N} . \\
28 & 12 & \mathrm{~S} . \\
44 & 10 & \mathrm{~N} . \\
14 & 25 & \mathrm{~S} . \\
52 & 19 & \mathrm{~S} . \\
0 & 0 & \\
0 & 0 & \\
35 & 28 & \mathrm{~N} . \\
49 & 50 & \mathrm{~N} . \\
3 & 56 & \mathrm{~S} .\end{array}$ & $\begin{array}{l}a \text { Draconis } \\
\text { a Bootis } \\
\text { a Scorpii } \\
\beta \text { Gruis } \\
\text { a Piscis Aust. } \\
\text { Achernar } \\
\beta \text { Geminorum } \\
\text { Sirius } \\
\text { Polaris } \\
\text { a Ursø Majoris }\end{array}$ & \begin{tabular}{rrrr}
$\circ$ & \multicolumn{1}{c}{} \\
64 & 52 & $\mathrm{~N}$. \\
19 & 42 & $\mathrm{~N}$. \\
26 & 12 & $\mathrm{~S}$. \\
47 & 25 & $\mathrm{~S}$. \\
30 & 9 & $\mathrm{~S}$. \\
57 & 45 & $\mathrm{~S}$. \\
28 & 16 & $\mathrm{~N}$. \\
16 & 35 & $\mathrm{~S}$. \\
88 & 46 & $\mathrm{~N}$. \\
61 & 3 & $\mathrm{~N}$.
\end{tabular} \\
\hline
\end{tabular}




\section{CHAPTER XIV.}

\section{LATITUDE BY EX-MERIDIAN ALTITUDE.}

ART. 65.-Although the meridian altitude is the simplest method by which latitude may be determined, clouds or other causes may prevent an observation at the particular instant required; under these circumstances, the latitude is deduced from observations of the altitude taken when the object is near the meridian, that is, when its hour angle or meridian distance is small. There are two methods in use :-

(1) By calculating a correction which, when applied to the altitude out of the meridian, determines the object's altitude or zenith distance when on the meridian. This quantity is called a "Reduction," and the latitude by account is always used to determine its amount. The correctness of the result, therefore, depends on the accuracy with which the D.R. lat. is known.

(2) By direct spherics.

There are several variations of the first method, and the one we shall employ may be called the "log-rising" formula, which, according to Chauvenet, approximates more rapidly than the others.

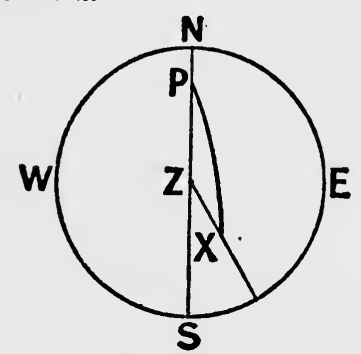

Fig. 121.

In figure, let $\mathrm{X}$ be object near the meridian; then in triangle $\mathrm{PZX} P X$ is Polar Distance, PZ colatitude, ZX zenith distance at time of observation, $P$ the hour angle.

From the fundamental equation.

$\operatorname{Cos} Z X=\cos P Z \cdot \cos P X+\sin P Z$. $\sin \mathrm{PX} \cdot \cos \mathrm{P}$.

Let " $a$ " denote the altitude, " $l$ " the latitude, " $h$ " the hour angle, and " $d$ " the declination.

Then above becomes-

$\operatorname{Sin} a=\sin l \cdot \sin d+\cos l \cdot \cos d \cdot \cos h$

$$
\begin{aligned}
& =\sin l \cdot \sin d+\cos l \cdot \cos d-\cos l \cdot \cos d\left(2 \cdot \sin ^{2} \frac{h}{2}\right) \\
& =\cos (l \sim d)-\cos l \cdot \cos d\left(2 \cdot \sin ^{2} \frac{h}{2}\right)
\end{aligned}
$$

$\therefore \cos (l \sim d)=\sin a+\cos l \cdot \cos d\left(2 \cdot \sin ^{2} \frac{h}{2}\right)$ 
The quantity $\log \left(2 \cdot \sin ^{2} \frac{h}{2}\right)$ is called the "log rising," and is tabulated in Norie, Table xxIx.

In practice the natural number corresponding to the second term on the right-hand side is found by adding together the L. cos. lat., L. cos dec., and log-rising hour angle; this number is added to the nat. sin of altitude; the nat. cos of sum is the zen. dist. when on the meridian; the lat. is then found as in meridian altitude.

ART. 66. Latitude by Ex-meridian Altitude. Direct Method.-

Given the hour angle $(h)$, the declina-

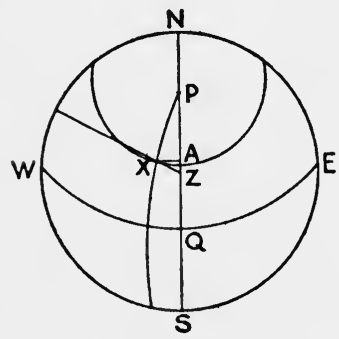

FIG. 122. tion $(\delta)$, and the true altitude $(a)$, to find the latitude.

In the figure $\mathrm{X}$ is the object, $\mathrm{PX}$ the polar distance, ZX the zenith distance, the angle $\mathrm{ZPX}(h)$ the hour angle, and $\mathrm{XA}$ an arc of a great circle at right angles to the meridian, EQW the equator.

Then QZ is the latitude, and is equal to the sum or difference of the ares $\mathrm{ZA}$ and QA.

In the right-angled spherical triangle PXA-

$$
\begin{aligned}
\cos h & =\cot p \cdot \tan \mathrm{PA} \\
& =\tan \delta \cdot \tan \mathrm{PA} \\
\therefore \tan \mathrm{PA} & =\cos h \cdot \cot \delta
\end{aligned}
$$

But QA (arc 1) is the complement of PA, because $\mathrm{PQ}=90^{\circ}$;

$$
\therefore \cot \operatorname{arc} 1=\cos h \cdot \cot \delta \text {. . . . . }
$$

Again, in the same triangle-

$$
\begin{aligned}
\cos p & =\cos \mathrm{PA} \cdot \cos \mathrm{XA} \\
i . e \cdot \sin \delta & =\sin \operatorname{arc} 1 \cdot \cos \mathrm{XA} \\
\therefore \cos \mathrm{XA} & =\sin \delta \cdot \operatorname{cosec} \operatorname{arc} 1 . .
\end{aligned}
$$

Also in the right-angled triangle $\mathrm{XZA}-$

$$
\begin{aligned}
\cos \mathrm{XZ} & =\cos \mathrm{XA} \cdot \cos \mathrm{ZA} \\
\text { i.e. } \sin \alpha & =\sin \delta \cdot \operatorname{cosec} \operatorname{arc} 1 \cdot \cos \mathrm{ZA}
\end{aligned}
$$

by substituting the value of $\cos \mathrm{XA}$ in (2)-

$$
\therefore \cos \mathrm{ZA}(\operatorname{arc} 2)=\frac{\sin a}{\sin \delta \cdot \operatorname{cosec} \operatorname{arc~} 1}
$$

or $\cos \operatorname{arc} 2=\sin a \cdot \operatorname{cosec} \delta \cdot \sin \operatorname{arc} 1$

Arc 1 is named the same as the dec., and arc 2 the same as the zenith distance, and the sum or difference, according as they 
are of the same or different names, gives the latitude as in the meridian altitude problem.

For computation the formulæ may be arranged as follows :-

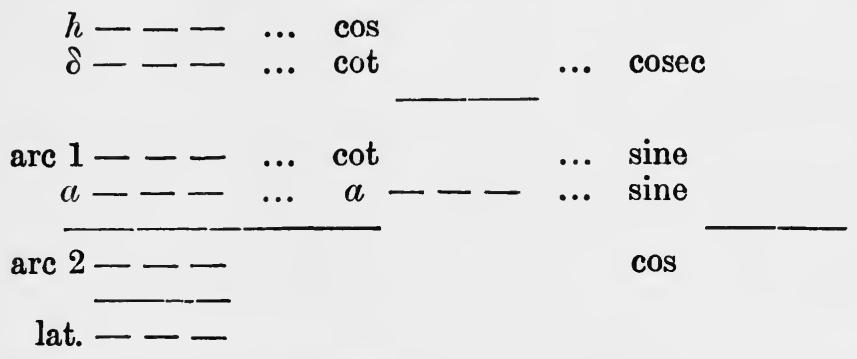

N.B.-When $\mathrm{X}$ is on the equinoctial (i.e. dec. $=0$ ), then the perpendicular $\mathrm{XA}$ coincides with the equinoctial $\mathrm{EQW}$ and are 1 disappears.

The lat. $Q Z$ is then found from the right-angled triangle $Z X Q$, in which QX measures the H.A., and ZX $=$ co-alt. or zenith distance.

$$
\begin{aligned}
\text { Then } \cos \mathrm{ZX} & =\cos Q \mathrm{QX} \times \cos \mathrm{QZ} \\
\therefore \cos \mathrm{QZ} & =\frac{\cos \mathrm{ZX}}{\cos \mathrm{QX}} \\
& =\cos \mathrm{ZX} \times \operatorname{ses} \mathrm{QX} \\
\text { i.e. } \cos \text { lat. } & =\text { sin alt. } \times \sec \mathrm{H} . \mathrm{A} .
\end{aligned}
$$

ART. 67.-Latitude by Ex-meridian Altitude of the Sun, Star, etc.-The hour angle of the Sun is the time from apparent noon.

The hour angle of any other celestial object is the difference between the R.A.M. and R.A. of object.

To allow for Run since determining error, it must be noticed that when the course has been to the eastward the ship is going to a place where the time is later; when to the westward, where time is earlier. Hence the diff. long. in time must be added for easterly, and subtracted for westerly run.

The process is as follows:-

(1) Find Greenwich time and hour angle.

(2) Correct declination and altitude.

(3) a. Log-rising Method.-Add L. cos lat., L. cos dec., and log-rising hour angle (Norie, Table xxIx.), increasing the index there found by " 1 "; reject 10's from sum and find natural number in Table xxiv.

Add this nat. no. to nat. sin true alt. in Table xxvi., and find in this same table nat. cos of sum ; this is the zen. dist., which mark of contrary name to bearing. The sum or difference of zen. dist. and dec. according as they are of same or different names gives the latitude.

b. Direct Method.-Add L. cos hour angle, and L. cot dec., take back L. cot of result, which call arc 1 , and name it the same as the dec. 
Then add L. cosec dec., L. $\sin$ arc 1, and L. sin alt., reject 10's, and take back $L$. cos of result for arc 2 , which name contrary to the bearing.

The sum of $\operatorname{arcs} 1$ and 2 when they are of the same name, or difference when they are of contrary names, gives the lat., which is of same name as the greater.

\section{ART. 68.-Latitude by Ex-meridian Altitude of Sun.}

Example.-August 7th A.M. at ship, in lat. by account $33^{\circ} 30^{\prime} \mathrm{N}$, long. $10^{\circ} 57^{\prime}$ W., the obs. alt. of the Sun's U.L. was $72^{\circ} 52^{\prime} 50^{\prime \prime}$; ind. cor. $+3^{\prime} 4^{\prime \prime}$; eye, $16 \mathrm{ft}$.; time by watch, $10^{\mathrm{h}} 57^{\mathrm{m}} 58^{\circ}$, which was slow of A.T.S. $44^{\mathrm{m}} 10^{\mathrm{*}}$; the d. long. made to the W. since the error was determined being $17 \frac{3}{4}$ miles. Find the latitude by ex-meridian; and supposing the course and distance to be S. by W. 4 miles since observation, find the latitude at noon.

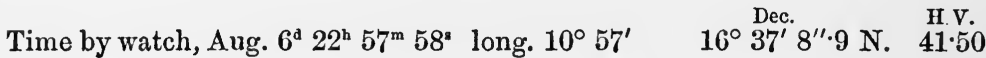

$$
\begin{aligned}
& \text { Slow }+4410 \quad 4 \text { Cor. }-16 \cdot 6 \text {. } \\
& \begin{array}{lllll}
6^{\mathrm{d}} \overline{2342} 8 & \overline{43^{\mathrm{m}} 48^{\mathrm{s}}} & \overline{163652 \cdot 3} & \overline{16 \cdot 600}
\end{array} \\
& \text { Run. W. } \quad-111 \quad \text { Obs. alt. } 72^{\circ} 52^{\prime} 50^{\prime \prime} \\
& \text { A.T.S. } 6^{\mathrm{d}} 23 \quad 40 \quad 57 \quad \text { Ind. cor. }+34 \\
& \text { Long. W. } \quad+4348 \\
& \text { A.T.G. } 7^{\mathrm{d}} \quad 0 \quad 24 \quad 45 \\
& 2760 \log =3 \cdot 440966
\end{aligned}
$$

First Method.

T.A. $72^{\circ} 35^{\prime} 57^{\prime \prime}$ nat. $\sin 954236$

$$
\begin{aligned}
\overline{956996} \text { N. cos. } & =16^{\circ} 51^{\prime} 51^{\prime \prime} \mathrm{N} . \\
\text { Dec. } & =163652 \mathrm{~N} . \\
\text { Obs. lat. } & =\overline{332843} \mathrm{~N} .
\end{aligned}
$$

Second Method.

E.H.A. $19^{\mathrm{m}} 3^{\mathrm{s}}$ Dec. $16^{\circ} 36^{\prime} 52^{\prime \prime}$

$$
\begin{aligned}
& \cos =9.998498 \\
& \cot =10.525219
\end{aligned}
$$

$\operatorname{cosec}=10 \cdot 543740$
Arc $116^{\prime} 40$
Arc $216 \quad 48 \quad 33$
8
Obs. lat. $\overline{3328} 41 \quad \mathrm{~N}$.
Run $354 \mathrm{~S}$.
Noon lat. $332447 \mathrm{~N}$.

$$
\begin{aligned}
& \sin =9 \cdot 457640 \\
& \sin =9.979656
\end{aligned}
$$
$\begin{array}{rrrr}\text { T.A. } 72^{\circ} 35^{\prime} 57^{\prime \prime} & \sin =9.979656 \\ \ldots & \ldots & \ldots & \cos =\overline{9.981036}\end{array}$
(Run S. by W. $4^{\prime}$ gives d. lat. $3^{\prime} \cdot 9$ to be applied to the S., as the abs. is taken before noon.) 


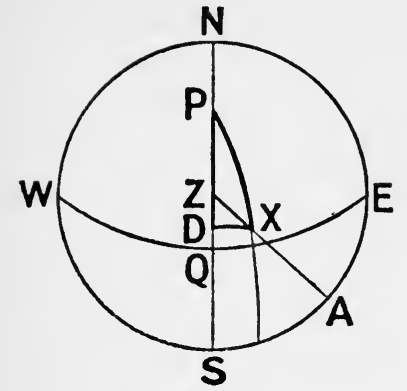

FIG. 123.

Third Method. Directly from figure.

$\mathrm{X}$ is position of object, $\mathrm{AX}$ its altitude, PX the pol. dist, $\mathrm{P}$ the hour angle, XD a perpendicular from $\mathrm{X}$ on the meridian.

In right-angled spherical triangle $\mathrm{PDX}$, $\mathrm{D}=90^{\circ}, \mathrm{P}$ the hour angle, $\mathrm{PX}$ the pol. dist. Find $\mathrm{PD}$ and $\mathrm{DX}$.

$\sin ($ co. $P)=\tan P D \cdot \tan ($ co. $P X)$

$\therefore \tan P D=\cos P \cdot \tan P X . . I$.

Again -

$$
\sin \mathrm{DX}=\cos (\cos \mathrm{P}) \cdot \cos (\operatorname{co} . \mathrm{PX})
$$

$$
=\sin \mathrm{P} \cdot \sin \mathrm{PX} . \text {. II. }
$$

$$
\mathrm{P}=19^{\mathrm{m}} 3^{\prime} \cos =9 \cdot 998498
$$

$\mathrm{PX}=73^{\circ} 23^{\prime} \quad 8^{\prime \prime} \tan =10.525219$

$$
\sin =8 \cdot 919209
$$

$\sin =9.981479$

$$
\mathrm{PD}=731952 \tan =\overline{10.523717} \quad \mathrm{DX}=4^{\circ} 33^{\prime} 48^{\prime \prime} \sin =\overline{8.900688}
$$

Then in right-angled triangle $\mathrm{ZDX}$, given $\mathrm{D}=90^{\circ}, \mathrm{ZX}$ zen. dist., and DX, find ZD

$$
\begin{aligned}
& \operatorname{Sin}(\operatorname{co} . \mathrm{ZX})=\cos \mathrm{ZD} \cdot \cos \mathrm{DX} \\
& \therefore \cos Z \mathrm{ZD}=\cos \mathrm{ZX} \text {. } \sec \mathrm{DX} \\
& \mathrm{DX}=4^{\circ} 33^{\prime} 48^{\prime \prime} \mathrm{sec}=10.001379 \\
& \mathrm{ZX}=17 \quad 24 \quad 3 \quad \cos =9.979656 \\
& \mathrm{ZD}=164834 \cos =\overline{\mathbf{9} 981035} \\
& \text { Lat. }=\mathrm{ZQ}=90-\mathrm{PZ}=90-(\mathrm{PD}-\mathrm{DZ}) \\
& =90-\left(73^{\circ} 19^{\prime} 52-16^{\circ} 48^{\prime} 34^{\prime \prime}\right) \\
& =90-563118 \\
& =33^{\circ} 28^{\prime} 42^{\prime \prime}
\end{aligned}
$$

\section{EXERCISES.}

1. August 1st P.M. at ship, in lat. by account $37^{\circ} 20^{\prime}$ S., long. $133^{\circ}$ E., the obs. alt. of the Sun's L.L., bearing north, was $33^{\circ} 55^{\prime} 20^{\prime \prime}$; ind. cor. $+2^{\prime}$ $5^{\prime \prime}$; eye, $30 \mathrm{ft}$.; time by watch, $3^{\mathrm{h}} 33^{\mathrm{m}} 1^{\mathrm{s}}$, which was found $8^{\mathrm{h}} 50^{\mathrm{m}}$ slow of A.T.S. the same morning; run since error was determined S. $38^{\circ}$ E., 23 miles. Find the latitude by ex-meridian, and if the run since noon was 3 miles on the same course, find lat. at noon.

2. August 6th A.M. at ship, in lat. by account $26^{\circ} 20^{\prime} \mathrm{N}$., long. $80^{\circ} 45^{\prime} \mathrm{W}$., the obs. alt. of the Sun's U.L., bearing south, was $78^{\circ} 9^{\prime} 20^{\prime \prime}$; ind. cor. $-3^{\prime} 16^{\prime \prime}$; eye, $19 \mathrm{ft}$. ; time by watch, $4^{\mathrm{h}} 50^{\mathrm{m}} 25^{\mathrm{s}}$, which had been found fast $5^{\mathrm{h}} 22^{\mathrm{m}} 18^{\mathrm{s}}$ of A.T.S. the same morning; since error was determined the diff. long. made westward was 24.5 miles. Find the lat. by ex-meridian.

3. August 9th P.M. at ship, in lat. by account $5^{\circ} 35^{\prime} \mathrm{S}$., long. $14^{\circ} \mathrm{W}$., the obs. alt. of the Sun's L.L. near the meridian, bearing north, was $67^{\circ} 10^{\prime}$ $10^{\prime \prime}$; ind. cor. $-2^{\prime} 18^{\prime \prime}$; eye, $35 \mathrm{ft}$. ; time by watch, $1^{\mathrm{h}} 23^{\mathrm{m}} 7^{\mathrm{s}}$, which was $58^{\mathrm{m}}$ fast of A.T.S.; diff. of long. made to the eastward since determining the error was $37 \frac{1}{4}$ miles. Find the latitude.

4. August 13th A.M. at ship, in lat. by account $53^{\circ} 15^{\prime} \mathrm{N}$., long. $168^{\circ} 47^{\prime} \mathrm{E}$., the obs. alt. of the Sun's L.L. near the meridian, bearing south, was $51^{\circ} 26^{\prime} 50^{\prime \prime}$; ind. cer. $+3^{\prime} 5^{\prime \prime}$; eye, $26 \mathrm{ft}$. ; time shown by chron., $12^{\mathrm{h}} 18^{\mathrm{m}}$ 44", which was $13^{\mathrm{m}} 20^{\mathrm{s}}$ slow of M.T.G. Find the latitude.

5. August 17 th P.M. at ship, in lat. by account $44^{\circ} 50^{\prime} \mathrm{S}$., long. $180^{\circ} \mathrm{W}$., 
the obs. alt. of the Sun's U.L. near the meridian, bearing north, was $31^{\circ} 57^{\prime} 50^{\prime \prime}$; ind. cor. $+48^{\prime \prime}$; eye, $23 \mathrm{ft}$.; time shown by watch, $1^{\mathrm{h}} 2^{\mathrm{m}} 5^{\mathrm{s}}$, which was $50^{\mathrm{m}} 54^{\text {s }}$ fast of M.T.G. Find the latitude.

6. August 22 nd A. M. at ship, in lat. by account $2^{\circ} 35^{\prime} \mathrm{S}$., long. $87^{\circ} 40^{\prime} \mathrm{F}$., the obs. alt. of the Sun's L.L. near the meridian, bearing north, was $72^{\circ}$ $1^{\prime} 20^{\prime \prime}$; ind. cor. $-3^{\prime} 11^{\prime \prime}$; eye, $31 \mathrm{ft}$.; time shown by chron., $5^{\text {h }} 18^{\mathrm{m}} 37^{\prime}$, which was $12^{\mathrm{m}} 40^{\circ}$ slow of G.M.T. Find the latitude at obs., and if the run to noon was S. $46^{\circ} \mathrm{E}$., 8 miles, find the lat. at noon.

7. August 26th P.M. at ship, in lat. by account $39^{\circ} 20^{\prime} \mathrm{N}$., long. meridian of Greenwich, the obs. alt. of the Sun's L.L. near the meridian, bearing south, was $60^{\circ} 45^{\prime} 20^{\prime \prime}$; ind. cor. $+4^{\prime} 18^{\prime \prime}$; eye, $17 \mathrm{ft}$.; time showu by chron. which had been found $14^{\mathrm{m}} 15^{\mathrm{s}}$ slow of G.M.T. was $12^{\mathrm{h}} 8^{\mathrm{m}} 14^{\mathrm{s}}$; run since error was determined, S. $52^{\circ}$ W., 29 miles. Find lat. at sights, and if the run was 4 miles on the same course since noon, find lat. at noon.

8. September 1st A.M. at slip, in lat. by account $43^{\circ} 22^{\prime} \mathrm{S}$., long. $93^{\circ} \mathrm{W}$., the obs. alt. of the Sun's U.L. near the meridian was $38^{\circ} 16^{\prime} 50^{\prime \prime}$; ind. cor. $+2^{\prime} 13^{\prime \prime}$; eye, $40 \mathrm{ft}$. ; time by watch, $5^{\mathrm{h}} 52^{\mathrm{m}} 37^{\circ}$, which was $6^{\mathrm{h}} 11^{\mathrm{m}} 40^{\circ}$ fast of A.T.S.; diff. long. made to the westward since determining the error, 25 miles. Find the latitude, and if the run to noon was $\mathrm{S} .65^{\circ} \mathrm{W}$., 5 miles, find lat. at noon.

9. September 29th P.M. at ship, in lat. by account $46^{\circ} 25^{\prime} \mathrm{N}$., long. $40^{\circ} 30^{\prime} \mathrm{W}$., the obs. alt. of the Sun's L.L. near the meridian was $40^{\circ} 45^{\prime} 20^{\prime \prime}$; ind. cor. 0 ; eye, $25 \mathrm{ft}$.; time shown by chron. $3^{\mathrm{h}} 30^{\mathrm{m}} 40^{\mathrm{s}}$, which was fast $28^{\mathrm{m}} 36^{\circ}$ of G.M.T.; run since determining the error, S. $42^{\circ}$ E., 18 miles. Find the latitude, and if the run since noon was 7 miles on the same course, find the lat. at noon.

10. September 24 th A.M. at ship, in lat. by account $15^{\circ} 38^{\circ} \mathrm{N}$., long. $93^{\circ} 26^{\prime}$ E., when a chron. estimated $10^{\mathrm{m}} 15^{\mathrm{s}}$ fast of G.M.T. showed $5^{\mathrm{h}} 25^{\mathrm{m}}$ 11', the obs. alt. of the Sun's L.L. was $73^{\circ} 5^{\prime} 30^{\prime \prime}$; ind. cor. $-2^{\prime} 5^{\prime \prime}$; eye, $18 \mathrm{ft}$. Find the latitude by ex-meridian.

11. September 23rd P.M. at ship, in lat. by D.R. $51^{\circ} 15^{\prime}$ N., long. $124^{\circ} 30^{\prime} \mathrm{W}$., when a watch showed $12^{\mathrm{h}} 5^{\mathrm{m}} 14^{\mathrm{s}}$, and had been found $6^{\mathrm{m}} 12^{\prime}$ slow of A.T.S., diff. long. made to the westward since determining the error was 19.5 miles; the obs. alt. of the Sun's U.L. was $39^{\circ} 5^{\prime} 40^{\prime \prime}$; ind. cor. $+2^{\prime} 9^{\prime \prime}$; eye, $22 \mathrm{ft}$. Find the latitude by ex-meridian. Run since noon S. by W. 4 miles. Find the lat. at noon.

12. September 23rd P. M. at ship, in D.R. lat. $40^{\circ} 18^{\prime} \mathrm{S}$., long. $165^{\circ} 54^{\prime} \mathrm{W}$., when a chron. showed $11^{\mathrm{h}} 18^{\mathrm{m}} 33^{\mathrm{s}}$, error on A.T.G. was $4^{\mathrm{m}} 15^{\mathrm{s}}$ slow; the obs. alt. of the Sun's L.L. near the meridian was $49^{\circ} 17^{\prime} 10^{\prime \prime}$; ind. cor. $-17^{\prime \prime}$; height of eye, $41 \mathrm{ft}$. Find the latitude at sights, and if the run since noon was $\mathrm{N}$. $35^{\circ} \mathrm{E}, 6$ miles, find lat. at noon.

\section{ART. 69.-Latitude by Ex-meridian Altitude of a Star.}

Example.-August 16th at ship, lat. $31^{\circ} 30^{\prime}$ S., long. $175^{\circ} 30^{\prime} 30^{\prime \prime} \mathrm{W}$. ; time by chron., $16^{\mathrm{d}}, 0^{\mathrm{h}} 0^{\mathrm{m}} 10^{\mathrm{a}}$, which was fast of M.T.G. $10^{\mathrm{a}}$; obs. alt. of $a$ Cygni bearing $N$. and W. of the observer, $11^{\circ} 37^{\prime} 50^{\prime \prime}$; ind. cor. $+2^{\prime} 30^{\prime \prime}$; height of eye, $26 \mathrm{ft}$. Find the latitude.

\begin{tabular}{|c|c|c|c|c|c|}
\hline$\underset{\text { Fast }}{\text { Time by chron. } 16^{\mathrm{d}}}$ & $0^{\mathrm{h}} \quad 0^{\mathrm{m}}$ & $\begin{array}{l}10^{\circ} \\
10\end{array}$ & $175^{\circ}$ & $30^{\prime}$ & $\begin{array}{c}30^{\prime \prime} \\
4\end{array}$ \\
\hline M.T.G. $16^{\mathrm{d}}$ & $\begin{array}{rr}0 & 0\end{array}$ & 0 & $6,0) 702$ & 2 & 0 \\
\hline
\end{tabular}

R.A.M.S. $9^{\text {h }} 35^{\mathrm{m}} 52^{*} 5$ M.T.S. $12 \quad 17 \quad 58$

R.A.M. $2153 \quad 50.5$

R.A.* $20 \quad 38 \quad 13 \cdot 6$

W.H.A.* $115 \quad 36.9$ 
First Method.

W.H.A. $1^{\mathrm{h}} 15^{\mathrm{m}} 37^{\mathrm{A}} \log$ ris. $=4 \cdot 731890$

Lat. $31^{\circ} 30^{\prime} \quad$ S. $\cos =9.930766$

Dec. $445639 \mathrm{~N} \cdot \cos =9 \cdot 849908$

T.A. $11^{\circ} 30^{\prime} 48^{\prime \prime}$ N.S. 199596

$$
32551 \log =\overline{4 \cdot 512564}
$$

232147 nat. $\cos Z \mathrm{ZD} 76^{\circ} 34^{\prime} 35^{\prime \prime} \mathrm{S}$.

Ref. $\quad-432$

Obs. alt. $11^{\circ} 37^{\prime} 50^{\prime \prime}$

I.C. +230

$$
114020
$$

Dip. $\quad-5 \quad 0$

113520

True alt. 113048

Second Method.

Lat. $313756 \mathrm{~S}$.

W.H.A. $1^{\mathrm{h}} 15^{\mathrm{m}} 37^{\mathrm{s}} \cos =9 \cdot 975919$

Dec. $44^{\circ} 56^{\prime} 39^{\prime \prime}$ N. cot $=10 \cdot 000846 \quad \operatorname{cosec}=10 \cdot 150939$

Arc $1463155^{\prime \prime}$ N. $\cot =\overline{9 \cdot 976765} \quad$ sin $=9 \cdot 860792$

$$
\text { T.A. } \overline{11^{\circ} 30^{\prime} 48} \quad \sin =9 \cdot 300150
$$

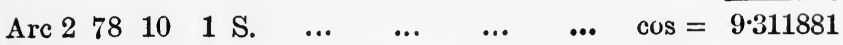

Lat. $3138 \quad 6 \mathrm{~S}$.

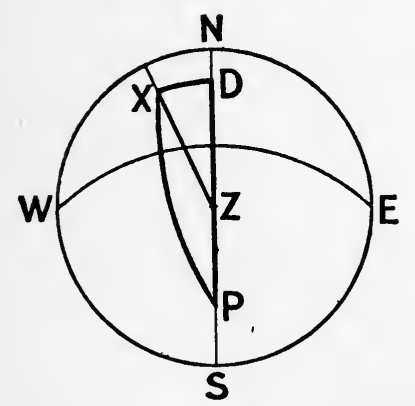

Third Method. From figure.

$\mathrm{X}$ is the star's position; $\mathrm{XD}$ a perpendicular on the meridian.

In triangle $\mathrm{PDX}, \mathrm{D}=90^{\circ}$; given Polar Dist. $=\mathrm{PX} ;$ Hour angle $=\mathrm{P}$. Find $\mathrm{PD}$ and DX.

$\operatorname{Sin}($ co. $\mathrm{P})=\tan ($ co. $\mathrm{PX}) \cdot \tan \mathrm{PD}$

$\therefore \tan \mathrm{PD}=\frac{\cos \mathrm{P}}{\cot \mathrm{PX}}=\cos \mathrm{P} \cdot \tan \mathrm{PX}$

Again-

$\sin \mathrm{DX}=\cos ($ co. $\mathrm{P}) \cdot \cos ($ co. $\mathrm{PX})$

$$
=\sin \mathrm{P} \cdot \sin \mathrm{PX}
$$

Fig. 124.

$$
\begin{aligned}
& \mathrm{P}=1^{\mathrm{b}} 15^{\mathrm{m}} 37^{\mathrm{*}} \quad \cos =9.975919 \\
& \mathrm{PX}=134^{\circ} 56^{\prime} 39^{\prime \prime} \quad \tan =10.000816 \\
& 43^{\circ} 28^{\prime} 5^{\prime \prime} . \quad \tan =\overline{9.976765} \\
& 180 \\
& \sin =9 \cdot 510526 \\
& \sin =9 \cdot 849908 \\
& 13^{\circ} \text { '́ó }^{\prime} 24^{\prime \prime} \sin =\overline{9 \cdot 360434}
\end{aligned}
$$$$
\mathrm{PD}=136 \quad 3155
$$$$
\mathrm{DX}=13^{\circ} 15^{\prime} 24^{\prime \prime}
$$

Now, in triangle $\mathrm{ZDX}, \mathrm{D}=90^{\circ}$; given zen. dist. $=\mathrm{ZX}$ and $\mathrm{DX}$, find $\mathrm{ZD}$. $\operatorname{Sin}(\cos \mathrm{ZX})=\cos \mathrm{ZD} \cdot \cos \mathrm{DX}$

$\therefore \cos Z \mathrm{D}=\frac{\cos \mathrm{ZX}}{\cos \mathrm{DX}}=\cos \mathrm{ZX} . \sec \mathrm{DX}$

$\mathrm{DX}=13^{\circ} 15^{\prime} 24^{\prime \prime}$ sec $=10 \cdot 011730$

$\mathrm{ZX}=78 \quad 29 \quad 12 \quad \cos =9 \cdot 300153$

$\mathrm{ZD}=78^{\circ} 10^{\prime} 1^{\prime \prime} \quad \cos =\overline{9 \cdot 311883}$

Lat. $=90^{\circ}-\mathrm{PZ}=90^{\circ}-(\mathrm{PD}-\mathrm{ZD})$

$=90^{\circ}-58^{\circ} 21^{\prime} 54^{\prime \prime}$

$=31^{\circ} 38^{\prime} 6^{\prime \prime} \mathrm{S}$. 


\section{Exercises.}

1. August 1st, about $10^{\text {h }}$ P.Mr. at ship, in lat. by account $38^{\circ} 52^{\prime}$ S., long. $10^{\circ} \mathrm{W}$., when a chron. showed $10^{\mathrm{h}} 45^{\mathrm{m}}$, and was fast $1^{\mathrm{m}} 48^{\circ}$ of G.M.'i'., the obs. alt. of Vega near the meridian, bearing north, was $12^{\circ} 30^{\prime} 40^{\prime \prime}$; ind. cor. + $2^{\prime} 54^{\prime \prime}$; eye, $20 \mathrm{ft}$. Find lat. by ex-meridian.

2. August 4 th, about $11^{\mathrm{h}} 15^{\mathrm{m}}$ P.M. at ship, in lat. by account $51^{\circ} 27^{\prime} \mathrm{N}$., long. $49^{\circ} 30^{\prime} \mathrm{W}$., when a chron. correct for A.T.G. showed $2^{\mathrm{h}} 36^{\mathrm{m}} 53^{\mathrm{s}}$, the obs. alt. of Altair near the meridian, bearing south, was $46^{\circ} 49^{\prime} 20^{\prime \prime}$; ind. cor. $+2^{\prime} 14^{\prime \prime}$; eye, $45 \mathrm{ft}$. Find lat. by ex-meridian.

3. August 8 th, about $10^{\mathrm{n}} 50^{\mathrm{m}}$ P.M. at ship, in lat. by D.R. $0^{\circ} 2^{\prime} \mathrm{N}$., long. $169^{\circ} 15^{\prime}$ E., when a chron. correct for M.T.G. showed $11^{\mathrm{b}} 35^{\mathrm{m}} 47^{\mathrm{e}}$, the obs. alt. of a Pavonis near the meridian, bearing S. $\frac{1}{2} \mathrm{E}$., was $32^{\circ} 56^{\prime} 30^{\prime \prime}$; ind. cor. - $37^{\prime \prime}$; eye, $39 \mathrm{ft}$. Required the lat.

4. A ugust 12 th, at $1^{\mathrm{h}} 5^{\mathrm{m}} 32^{\prime}$ A.M. apparent time at ship, in lat. by D.R. $42^{\circ} 30^{\prime} \mathrm{N}$., long. $174^{\circ} 18^{\prime} \mathrm{W}$., the obs. alt. of 'Fomalhaut near the meridian was $17^{\circ} 23^{\prime} 40^{\prime}$; ind. cor. $+1^{\prime} 11^{\prime \prime}$; eye, $42 \mathrm{ft}$. Find the lat.

5. August 17 th, about $2^{\text {h }} 45^{\circ}$ A.M. at ship, in lac. by account $17^{\circ} 15^{\prime} \mathrm{N}$., long. $57^{\circ} 12^{\prime}$ W., when a chron. correct for M.T.G. showed $6^{\mathrm{h}} 32^{\mathrm{m}} 38^{\mathrm{a}}$, the obs. alt. of a Andromedæ near the meridian, bearing north, was $77^{\circ} 59^{\prime} 10^{\prime \prime}$; ind. cor. $-2^{\prime} 7^{\prime \prime}$; eye, $50 \mathrm{ft}$. Required the lat.

6. August 26th, about $4^{\mathrm{h}} 10^{\mathrm{m}}$ A.M. at ship, in lat. by D.R. $8^{\circ} 45^{\prime}$ S., long $69^{\circ} 14^{\prime}$ E., when a watch which was $4^{\mathrm{h}} 38^{\mathrm{m}} 10^{\mathrm{s}}$ slow of A.T.S. showed $11^{\mathrm{h}} 29^{\mathrm{m}}$ $41^{\circ}$; the diff. long. made to the westward since determining the error was 18.5 miles; the obs. alt. of Achernar near the meridian, bearing south, was $40^{\circ} 11^{\prime} 30^{\prime \prime}$; ind. cor. $+3^{\prime} 17^{\prime \prime}$; height of eye, $38 \mathrm{ft}$. Find the lat.

7. September 4th, about $2^{\mathrm{h}} 50^{\mathrm{m}} \mathrm{A.M}$. at ship, in lat. by account $31^{\circ} 50^{\prime} \mathrm{S}$., long. $100^{\circ} 18^{\prime} \mathrm{E}$., when a chron., whose error on M.T.G. was $10^{\mathrm{m}} 57^{\mathrm{s}}$ slow, showed $7^{\mathrm{b}} 58^{\mathrm{m}} 14^{\mathrm{s}}$, the obs. alt. of $\alpha$ Arietis near the meridian was $34^{\circ} 58^{\prime}$ $40^{\prime \prime}$; ind. cor. $-1^{\prime} 6^{\prime \prime}$; height of eye, $41 \mathrm{ft}$. Required the lat. by exmeridian.

8. September 9 th, about $5^{\text {h }} 10^{\mathrm{m}}$ A.M. at ship, in lat. by D.R. $53^{\circ} 22^{\prime}$ N., long. $158^{\circ} 35^{\prime} \mathrm{E}$. ; when a watch, which had been found $10^{\mathrm{A}} 32^{\mathrm{m}} 10^{\mathrm{s}}$ slow of A.T.S., showed $6^{\mathrm{h}} 36^{\mathrm{m}} 15^{\mathrm{s}}$, the diff. long. made good to the eastward since determining the error was 32.5 miles ; the obs. alt. of Aldebaran near the meridian was $52^{\circ} 51^{\prime} 50^{\prime \prime}$; ind. cor. $+2^{\prime} 11^{\prime \prime}$; eye, $33 \mathrm{ft}$. Find the lat.

9. September 13 th, about $5^{\text {h }} 15^{\text {m }}$ A.M. at ship, in lat. by account $23^{\circ} 40^{\prime}$ S., long. $50^{\circ} 19^{\prime}$ W., when a chron., whose error on M.T.G. was $13^{\mathrm{m}} 15^{\circ}$ fast, showed $8^{\mathrm{h}} 49^{\mathrm{m}} 50^{\circ}$, the obs. alt. of Capella near the meridian was $20^{\circ}$ $22^{\prime} 50^{\prime \prime}$; ind. cor. $-2^{\prime} 9^{\prime \prime}$; eye, 46 feet. Find the lat. by ex-meridian.

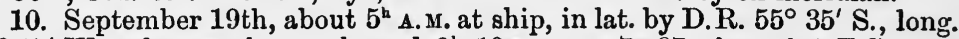
$60^{\circ} 15^{\prime}$ W., when a chron. showed $9^{\mathrm{h}} 10^{\mathrm{m}}$, error $7^{\mathrm{m}} 37^{\circ}$ fast of A.T G., the obs. alt. of Rigel near the meridian was $42^{\circ} 34^{\prime} 30^{\prime \prime}$; ind. cor. $+2^{\prime} 11^{\prime \prime}$; eye, $48 \mathrm{ft}$. Find the lat.

11. September 25 th, about $8^{\text {h }} 30^{\mathrm{m}}$ P.M. at ship, in lat. by D.R. $3^{\circ}$ N., long. $68^{\circ} 14^{\prime} \mathrm{E}$., the obs. alt. of $\alpha$ Cygni (Deneb) near the meridian was $48^{\circ}$ $16^{\prime} 10^{\prime \prime}$; ind. cor. $-2^{\prime} 3^{\prime \prime}$; height of eye, $50 \mathrm{ft}$. ; time by chron., $3^{\mathrm{h}} 57^{\mathrm{m}} 19^{\circ}$ correct M.T.G. Find the lat.

12. October 1st, about $9^{\text {h }}$ P.M. at ship, in lat. by account $20^{\circ} 10^{\prime}$ N., long. $137^{\circ} 46^{\prime} \mathrm{E}$., the obs. alt. of a Gruis, near the meridian, was $22^{\circ} 11^{\prime} 30^{\prime \prime}$; eye, $55 \mathrm{ft}$. ; no ind. cor. ; time by chron., $12^{\mathrm{b}}$, which was $8^{\mathrm{m}} 45^{\mathrm{s}}$ fast of A.T.G. Find the lat. by ex-meridian.

ART. 70. Latitude by the Pole Star.-On account of the proximity of the Pole Star to the North Pole, its azimuth is never large, and it is, therefore, a very suitable object for determining latitude by ex-meridian method at any time when 
visible. Special formula has, however, been devised for this purpose, and tables calculated from this formula are entered in the "Nautical Almanac."

Thus, if $l$ denote the latitude,

it may be shown that-

$$
\begin{array}{ll}
a & \quad " \quad \text { altitude, } \\
p & \quad \text { polar distance, } \\
h \quad " \quad \text { hour angle, }
\end{array}
$$

$$
l=a \pm p \cdot \cos h+\frac{1}{2} \sin 1^{\prime \prime} \cdot(p \sin h)^{2} \cdot \tan a
$$

$p . \cos h$ is found in Table I., calculated for different R.A.M.'s from $0^{\mathrm{h}}$ to $24^{\mathrm{h}}$; that is for different values of the hour angle and a constant value of the pol. dist.

The third term is found in Table II. and is always added; this is the second correction.

Table III. contains the third correction, always added, increased by $\mathbf{1}^{\prime}$ in order to make it so; this $\mathbf{1}^{\prime}$ is a constant to be subtracted from the true alt.; this correction in III. is an amount calculated for different dates to correct the mean values of R.A. and Dec. of Polaris used in constructing Tables I. and II.

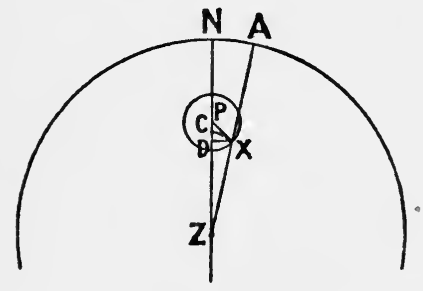

Fig. 125.

In figure, let $X$ be position of Pole Star; draw XD perpendicular on meridian; along $\mathrm{NZ}$ cut off $\mathrm{NC}$ $=\mathrm{AX}$ its altitude.

$\mathrm{PX}=$ pol. dist., $\mathrm{ZPX}=$ hour angle.

$$
\begin{aligned}
\text { Latitude } & =\mathrm{NP} \\
& =\mathrm{NC}-\mathrm{CP} \\
& =\mathrm{NC}-\mathrm{PD}+\mathrm{CD}
\end{aligned}
$$

If the hour angle had exceeded 6 hours-

$$
\text { latitude }=\mathrm{NC}+\mathrm{PD}+\mathrm{CD}
$$

$\mathrm{PD}$ is first correction, and considering the triangle PDX as a plane one-

$$
\begin{aligned}
\mathrm{PD} & =\mathrm{PX} \cdot \cos \mathrm{P} \\
\text { or 1st cor. } & =p \cdot \cos h
\end{aligned}
$$

and is added or subtracted according as the hour angle is greater or less than 6 hours.

$$
\text { 2nd cor. }=\mathrm{CD}
$$

In right-angled triangle $\mathrm{ZDX}$ -

$$
\begin{aligned}
\cos Z X & =\cos Z D \cdot \cos D X \\
\text { or } \cos Z C & =\cos Z D \cdot \cos D X \\
\therefore \cos (Z D+C D) & =\cos Z D \cdot \cos D X
\end{aligned}
$$

$\cos \mathrm{ZD} \cdot \cos \mathrm{CD}-\sin \mathrm{ZD} \cdot \sin \mathrm{CD}=\cos \mathrm{ZD} \cdot \cos \mathrm{DX}$ since $C D$ is very small, $\cos C D=1$ 
Hence $\cos Z D-\sin Z D \cdot \sin C D=\cos Z D \cdot \cos D X$ $\sin Z \mathrm{ZD} \cdot \sin \mathrm{CD}=\cos \mathrm{ZD}(1-\cos \mathrm{DX})$

$$
\text { or } \sin C D=\cot Z D \cdot\left(2 \sin ^{2} \frac{D X}{2}\right)
$$

As CD and DX are very small, we may write CD". $\sin 1^{\prime \prime}$ for $\sin \mathrm{CD}$ and $\frac{\mathrm{DX}^{\prime \prime}}{2} \cdot \sin 1^{\prime \prime}$ for $\sin \frac{\mathrm{DX}}{2}$; also $\mathrm{ZD}$ is very nearly $=\mathrm{ZX}$.

$$
\text { Hence } \begin{aligned}
\mathrm{CD}^{\prime \prime} \sin 1^{\prime \prime} & =\cot \mathrm{ZX} \cdot 2\left(\frac{\mathrm{DX}}{2}\right)^{2} \cdot\left(\sin 1^{\prime \prime}\right)^{2} \\
\text { i.e. } \mathrm{CD} & =\frac{1}{2} \sin 1^{\prime \prime} \cdot(\mathrm{DX})^{2} \cdot \cot \mathrm{ZX} \\
& =\frac{1}{2} \sin 1^{\prime \prime} \cdot(\mathrm{PX} \cdot \sin \mathrm{P})^{2} \cdot \cot \mathrm{ZX} .
\end{aligned}
$$

Hence approximately $l=a \pm p \cdot \cos h+\frac{1}{2} \sin 1^{\prime \prime} \cdot(p \sin h)^{2}$. $\tan a$

ART. 71.-The process is as follows :-

(1) Find Greenwich time, and sidereal time of observation, which is Right Ascension of Meridian.

(2) Correct altitude and subtract 1'.

(3) Apply first correction from Table I., as there directed.

(4) Add second and third corrections from respective tables for latitude.

Example.-August 24th, at $12^{\mathrm{h}} 12^{\mathrm{m}} 20^{\circ}$ mean time at ship, the obs. alt. of Polaris out of the meridian was $58^{\circ} 35^{\prime} 10^{\prime \prime}$, in longitude $28^{\circ} 15^{\prime} \mathrm{W}$.; ind. cor. $+2^{\prime} 13^{\prime \prime}$; height of eye, $27 \mathrm{ft}$. Find the latitude.
M.T.S. August $24^{\mathrm{d}} 12^{\mathrm{h}} 12^{\mathrm{m}} 20^{\mathrm{s}}$
Long. +1530

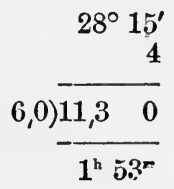
R.A.M.S. $10^{\mathrm{h}} \quad 7^{\mathrm{m}} 24^{\mathrm{s}} \cdot 9$ Accel. $\quad\left\{\begin{array}{rr}2 & 18 \cdot 0 \\ & 9\end{array}\right.$
$\begin{array}{lll}10 & 9 & 43 \cdot 8\end{array}$
M.T.G. August $24^{\mathrm{d}} 14 \quad 5 \quad 20$
${ }^{\mathrm{h}} \mathbf{5}^{\mathrm{x}}$
M.T.S. $12 \quad 12 \quad 20$

Obs. alt. $58^{\circ} 35^{\prime} 10^{\prime \prime}$

Ind. cor. +213

S.T. of obs. or R.A.M. $22 \quad 22 \quad 3 \cdot 8$

R.A. Polaris $\begin{array}{lll}26 & \mathbf{1 2} \cdot 9\end{array}$

E.H.A. $3 \quad 4 \quad 9 \cdot 1$

Dip. $\quad-5 \quad 5$

$58 \quad 32 \quad 18$

Ref.

$-34$

T.A. $58 \quad 3144$

Const. $\quad-10$

Red. A. 583044

1st cor. - 5015

$57 \quad 40 \quad 29$

Cor. for $22^{\mathrm{h}} 20^{\mathrm{m}}=0^{\circ} 49^{\prime} 48^{\prime \prime}$

,$\quad 22 \quad 30=0 \quad 52 \quad 1$

Diff. for $\quad 10=0 \quad 213$

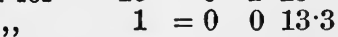

$" \quad 2=0 \quad 026 \cdot 6$

$\therefore$ 1st cor. $=05014^{\circ} 6$

2nd cor. $\quad+37$

3rd cor. +124

Lat. $57 \quad 4230$ 


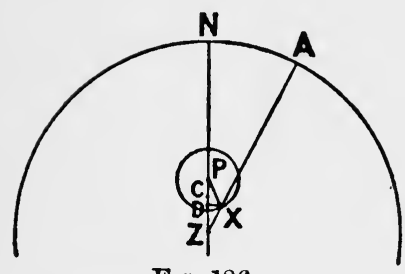

Fra. 126.

Given-

Alt. $=\mathbf{A X}=\mathrm{NC}$ by construction

Hour angle $=\mathrm{ZPX}$

Pol. dist. $=$ PX

1st cor. $=\mathrm{PD}$

2nd cor. = CD

Req. lat. $=\mathrm{NP}$

$$
=\mathrm{NC}-\mathrm{PD}+\mathrm{CD} \text {. }
$$

From formula-

$$
\text { Dec. }=88^{\circ} 48^{\prime} 9^{\prime \prime} \mathrm{N} \text {. }
$$

Pol. dist. $=11151$

$$
\begin{aligned}
& p=4311^{\prime \prime} \\
& h=3^{\mathrm{h}} 4^{\mathrm{m}} 9^{\mathrm{s}} \\
& a=58^{\circ} 31^{\prime} 44^{\prime \prime} .
\end{aligned}
$$

$p=4311^{\prime \prime} \quad \log =3 \cdot 634578$

$h=3^{\mathrm{n}} 4^{\mathrm{m}} 9^{\mathrm{s}} \quad \cos =9 \cdot 841476$

1st cor. $2993^{\prime \prime} \log =3 \cdot 476054$

$$
\begin{array}{ll}
p=4311^{\prime \prime} & \log =3 \cdot 634578 \\
h=3^{\text {h }} 4^{\mathrm{m}} 9^{\mathrm{s}} & \text { sin }=9 \cdot 857208
\end{array}
$$

$3 \cdot 491786$

$$
\begin{aligned}
(p \sin h)^{2} & =\overline{6.983572} \\
a=58^{\circ} 31^{\prime} 44^{\prime \prime} \tan & =10 \cdot 213172 \\
\frac{1}{2} \sin 1^{\prime \prime} & =4.384545
\end{aligned}
$$

2nd cor. $38^{\prime \prime} \cdot 13 \log =1 \cdot 581289$

True alt. $58^{\circ} 31^{\prime} 44^{\prime \prime}$

1st cor. -4953

2nd cor. $\begin{array}{r}57 \quad 4151 \\ +38 \\ \hline\end{array}$

Lat. $57 \quad 42 \quad 29$

\section{Exercises.}

1. August 28th, about $5^{\text {h }} 50^{\text {m }}$ A.M., in long. $48^{\circ} 30^{\prime}$ W.; when a chron. correct for M.T.G. showed $9^{\mathrm{h}} 2^{\mathrm{m}} 14^{\mathrm{s}}$; the obs. alt. of Polaris out of mer. was $36^{\circ} 47^{\prime} 20^{\prime \prime}$; ind. cor. $-2^{\prime} 17^{\prime \prime}$; eye, $26 \mathrm{ft}$. Find the latitude.

2. August 5th, about $1^{\mathrm{h}} 50^{\mathrm{m}}$ A.M., in long. $128^{\circ} 50^{\prime}$ E. ; when a chron., which was $10^{\mathrm{m}} 18^{\mathrm{s}}$ fast of A.T.G., showed $5^{\mathrm{h}} 15^{\mathrm{m}} 38^{\mathrm{s}}$; the obs. alt. of Polaris out of mer. was $46^{\circ} 12^{\prime} 30^{\prime \prime}$; ind. cor. $+3^{\prime} 46^{\prime \prime}$; eye, $32 \mathrm{ft}$. Find the latitude.

3. August 1st, about $4^{\mathrm{h}} 20^{\mathrm{m}}$ P.M., in long. $180^{\circ}$ E. ; when a chron. correct for M.T.G. showed $4^{\mathrm{b}} 19^{\mathrm{m}} 50^{\mathrm{s}}$; the obs. alt. of the Pole star out of mer. was $29^{\circ} 5^{\prime} 10^{\prime \prime}$; ind. cor. $-4^{\prime} 15^{\prime \prime}$; eye, $37 \mathrm{ft}$. Find the latitude.

4. August $2 \mathrm{nd}$, at $8^{\mathrm{h}} 10^{\mathrm{m}} 20^{\circ}$ P.M., apparent time at ship in long. $68^{\circ} 34^{\prime}$ W. ; the obs. alt. of a Urs. Min. out of mer. was $53^{\circ} 36^{\prime} 40^{\prime \prime}$; ind. cor. $+55^{\prime \prime}$; eye, $29 \mathrm{ft}$. Required the latitude.

5. September $30^{d} 8^{\mathrm{h}}$ M.T.G. ; when in long. $162^{\circ} 36^{\prime} 15^{\prime \prime}$ E. ; the obs. alt. of Polaris out of mer. was $23^{\circ} 14^{\prime} 50^{\prime \prime}$; ind. cor. $-1^{\prime} 8^{\prime \prime}$; eye, $42 \mathrm{ft}$. Find the latitude.

6. September 10th, about $8^{\mathrm{h}} 15^{\mathrm{m}}$ P.M., in long. of Greenwich; when a chron. correct for A.T.G. showed $8^{\mathrm{h}} 15^{\mathrm{m}} 38^{\mathrm{a}}$, the obs. alt. of the Pole star out of mer. was $32^{\circ} 26^{\prime} 40^{\prime \prime}$; ind. cor $+3^{\prime} 25^{\prime \prime}$; eye, $34 \mathrm{ft}$. Find the latitude.

7. September 1st A.M., at ship in long. $95^{\circ} 28^{\prime}$ E. ; when a chron. correct for M.T.G. showed $7^{\mathrm{h}} 3^{\mathrm{m}} 18^{\mathrm{s}}$; the obs. alt. of Polaris in artificial horizon out of mer. was $101^{\circ} 50^{\prime} 20^{\prime \prime}$; ind. cor. $+3^{\prime} 26^{\prime \prime}$. Find the latitude.

8. September 30th, about $7^{\text {h }} 20^{\mathrm{m}}$ A.M., in long. $179^{\circ} 45^{\prime} \mathrm{W}$.; when a chron. $12^{\mathrm{h}}$ slow of A.T.S. showed $7^{\mathrm{h}} 19^{\mathrm{m}} 32^{\mathrm{s}}$; the obs. alt. of $a$ Urs. Min. in artificial horizon out of mer. was $96^{\circ} 37^{\prime} 40^{\prime \prime}$; ind. cor. $-2^{\prime} 48^{\prime \prime}$. Find the latitude.

9. August 4th, at $9^{\mathrm{b}} 18^{\mathrm{m}} 10^{\mathrm{m}}$ P.M., mean time at ship in long. $127^{\circ} 16^{\prime} \mathrm{W}$.; the obs. alt. of Polaris in artificial horizon out of mer. was $61^{\circ} 15^{\prime} 10^{\prime \prime}$; ind. cor. $+2^{\prime} 42^{\prime \prime}$; eye, $50 \mathrm{ft}$. Find the latitude. 


\section{CHAPTER XV.}

\section{COMPASS ERROR BY AMPLITUDES.}

ART. 72.-Variation is the angle between the terrestrial and magnetic meridians. It shows how much the magnetic needle is disturbed from a true north and south direction by the action of the earth. It changes with the geographical position of the observer, and also with a lapse of time; the annual change is about $6^{\prime}$ annually. The amount of the variation for a particular year is entered on Admiralty charts.

Deviation is the angle the compass needle on a ship makes with the magnetic meridian. It shows how much the compass north is deflected from magnetic north by the action of iron in the ship or cargo. The amount varies with the direction of the ship's head, with the heel of the ship, and with her geographical position.

Compass Error is the angle the compass needle on a ship makes with the true meridian. It includes variation and deviation; and is the difference between the true and compass bearing of any object. The compass bearing of an object may be observed at any time, and one method of determining true bearings is by "Amplitude," which is the bearing of an object reckoned from east when rising, or from west when setting. Thus it is possible for the sun to be used for this purpose twice each day; and suitable stars can be selected continually at night.

ART. 73. Proof of Amplitude.-In the figure NESW is the horizon, $\mathrm{X}$ the position of an object on the horizon; the arc WX is its amplitude. In the right-angled triangle $\mathrm{PNX}$, $\mathrm{N}=90^{\circ} ; \mathrm{PN}=$ latitude $; \mathrm{PX}=$ pol. dist. or co. dec.; $\mathrm{NX}=$ co. amp.

$$
\begin{aligned}
\operatorname{Sin}(\operatorname{co} \cdot \mathrm{PX}) & =\cos \mathrm{PN} \cdot \cos \mathrm{NX} \\
\cos \mathrm{PX} & =\cos \mathrm{PN} \cdot \sin \mathrm{WX} \\
\text { since } \cos \mathrm{NX} & =\sin \mathrm{WX} \\
\therefore \sin \mathrm{WX} & =\frac{\cos \mathrm{PX}}{\cos \mathrm{PN}} \\
& =\cos \mathrm{PX} \cdot \sec \mathrm{PN}
\end{aligned}
$$

or $\sin$ amp. $=$ sin dec. . sec lat.

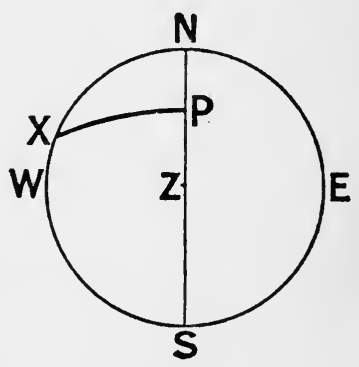

Fig. 127.

The equinoctial cuts the horizon in the east and west points, hence when an object is on the equinoctial, that is, has declination $=0^{\circ}$, it rises due east and sets due west. Again, when an 
observer is on the equator the formula becomes $\sin$ amp. $=\sin$ dec., since sec $0^{\circ}=1$; hence in this case amp. $=$ dec. It is also observed that when an object has north dec., it rises to the north of east, and sets to the north of west; if south dec., it rises south of east, and sets south of west; the name of the amplitude is therefore the same as the declination.

ART. 74. To find the Time of rising or setting of a Celestial Object.-In the figure the hour angle is ZPX, which is the supplement of NPX. Then from triangle NPX-

$$
\begin{aligned}
\sin (\operatorname{co} . \mathrm{P}) & =\tan \mathrm{PN} \cdot \tan (\cos \mathrm{PX}) \\
\cos \mathrm{P} & =\tan \mathrm{PN} \cdot \cot \mathrm{PX}
\end{aligned}
$$

hence $\cos$ H.A. = - tan lat. cot. pol. dist.

ART. 75.-The process for finding compass error by amplitude is as follows:-

(1) Find Greenwich time, and correct declination.

(2) To L. sin declination add L. sec latitude, reject 10 from index, and take back sin true amp., which reckon from $\mathbf{E}$. if A.M. at ship, and W. if P.M. at ship; and same name as declination. Under true amp. place comp., bearing reckoned from E. or W. like the true amp.

(3) When the true and comp. amps. are of the same name $\mathrm{N}$. or $\mathrm{S} .$, their difference is the comp.err.; when of contrary names, their sum is the comp. err. It is named E. or W. according as the true amp. reads to the right or left of the comp. amp.

(4) Under the comp. err. place the variation; if of same names subtract; if of contrary names add; this gives the deviation, which is to be named like the error, unless the error is subtracted from the variation, when it is of contrary name to error.

Examples.-

(1) September 28 th, at $5^{\text {h }} 53^{\mathrm{m}}$ A.M., mean time at ship in lat. $23^{\circ} 25^{\prime}$ S., long. $12^{\circ} 40^{\prime} \mathrm{W}$., the sun's compass bearing was E. $\frac{3}{4} \mathrm{~N}$. Find the comp. err. and deviation for the position of the ship's head, if the variation from

\begin{tabular}{|c|c|}
\hline 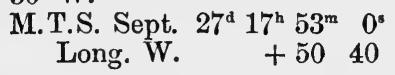 & $12^{\circ} 40^{\prime}$ \\
\hline M.T.G. Sept. $27^{\mathrm{d}} 1843 \quad 40$ & $6,0) 5,0 \quad 40$ \\
\hline $\begin{array}{c}\text { Dec. } 28 \text { th noon } 1^{\circ} 46^{\prime} 1^{\prime \prime} \cdot 4 \mathrm{~S} . \\
\text { Cor. } 58^{5}\end{array}$ & $\begin{array}{rr}50^{\mathrm{m}} 40^{\mathrm{a}} \\
\text { H.V. } \quad 58^{\prime \prime} \cdot 45 \\
5 \cdot 27\end{array}$ \\
\hline $14053.4 \mathrm{~S}$. & $\begin{array}{l}40915 \\
11690 \\
29225\end{array}$ \\
\hline & $6,0) 30,8 \cdot 0315$ \\
\hline & $5^{\prime} 8^{\prime \prime}$ \\
\hline
\end{tabular}
chart was $28^{\circ} 30^{\prime} \mathrm{W}$. 
Dec. $1^{\circ} 40^{\prime} \tilde{5} 3^{\prime \prime}$

Lat. 23250

True amp. E. $1^{\circ} 49^{\prime} 57^{\prime \prime} \mathrm{S}$. Comp. bearing E. $82615 \mathrm{~N}$.

Comp. err. 101612 E.

Var. $28 \quad 30 \quad 0 \quad$ W.

Dev. $\overline{38 \quad 4612}$ E.

In îgure $X$ is position of sun.

In triangle $\mathrm{SPX}, \mathrm{S}=90^{\circ}$.

Given -

$\mathbf{S P}=$ lat.

$P X=$ pol. dist. or co. dec.

Req. $\mathbf{S X}=$ co. amp.

Formula as proved above.

Sin amp. $=$ sin dec. sec lat. $\sin =8 \cdot 467483$

sec $=10.037328$

$\sin =8 \cdot 504811$

(Add because true and comp. amp. differ in name ; named $\mathrm{E}$, because true amp. reads to the right of the comp. amp.)

(Sum of comp. err. and variation because they are of different names; E. because comp. err. is $\mathrm{E}$.)

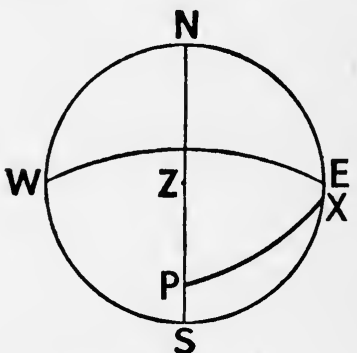

Fia. 128.

(2) August 1st, at $8^{\mathrm{h}} 35^{\mathrm{m}}$ P.M. apparent time at ship, in lat. $61^{\circ} 45^{\prime} \mathrm{S}$., long. $176^{\circ} 30^{\prime} \mathrm{E}$., the sun's compass bearing was N. $66^{\circ} 30^{\prime} \mathrm{W}$. If the variation from chart is $22^{\circ} 15^{\prime} \mathrm{E}$., find compass error and deviation.

A.T.S. Aug. $1^{\mathrm{d}} 8^{\mathrm{h}} 35^{\mathrm{m}} 0^{\circ}$

Long. E. - $1146 \quad 0$

A.T.G. July $31^{\text {d }} 2049 \quad 0$

Dec. 1st noon $18^{\circ} 11^{\prime} 45^{\prime \prime} \mathrm{N}$.

Cor. $\quad+159$

$181344 \mathrm{~N}$. $176^{\circ} 30^{\prime}$

4

$6,0 \lcm{70,60}$

$11^{\mathrm{h}} 46^{\mathrm{m}}$

II. V. $37^{\prime \prime} \cdot 26$

$3 \cdot 2$

7452

11178

$6,0 \longdiv { 1 1 , 9 \cdot 2 3 2 }$

$1^{\prime} 59^{\prime \prime}$
Dec. $18^{\circ} 13^{\prime} 44^{\prime \prime}$

Lat. 61450

$\sin =9 \cdot 495286$

$\sec =10 \cdot 324845$

True amp. W. 4122 5 N. $\quad \sin =\overline{9 \cdot 820131}$

Comp. ", W. $23300 \mathrm{~N}$.

Err. 17525 E.

Var. 22150 E.

Dev. 42255 W. 
The bearing in the question N. $66^{\circ} 30^{\prime} \mathrm{W}$. is subtracted from $90^{\circ}$ to reckon it from W., the same point as the true amp. Since true and comp. bearings are of same name $N$., they are subtracted for error, which is named E., because the true amp. reads to the right of the comp.; the difference of error and variation, because of same name $\mathbf{E}$., is the dev., which is of contrary name to error, because error is subtracted from variation.

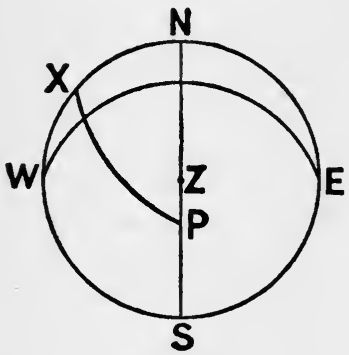

Fig. 129.
In figure $X$ is position of sun. In triangle $\mathrm{SPX}, \mathrm{S}=90^{\circ}$.

Given-

$\mathbf{S P}=$ lat.

PX $=$ pol. dist. or co. doo.

Req. $\mathrm{SX}=$ co. $\mathrm{amp}$.

\section{Fxercises.}

1. August 2 nd, at $7^{\mathrm{h}} 10^{\mathrm{m}}$ P.M. mean time at ship, in lat. $42^{\circ} 20^{\prime} \mathrm{S}$., long. $65^{\circ}$ E., the sun's comp. bearing was N.N.W. $\frac{3}{4}$ W., the variation being $28^{\circ}$ $30^{\prime}$ W. Find comp. err. and dev.

2. September 28th, at $5^{\text {h }} 50^{\mathrm{m}}$ A.M. mean time at ship, in lat. $50^{\circ} 25^{\prime} \mathrm{S}$., long. $81^{\circ} \mathrm{W}$., the sun rose by compass N. $64^{\circ} 30^{\prime} \mathrm{E}$. Find true amp. and comp. err. ; also if var. is $24^{\circ} 15^{\prime} \mathrm{E}$., find dev.

3. August 9 th, at $5^{\text {h }} 15^{\mathrm{m}}$ A.M. mean time at ship, in lat. $33^{\circ} 51^{\prime}$ N., long. $125^{\circ} \mathrm{W}$., the sun's comp. bearing was E. by N. $\frac{1}{4} \mathrm{~N}$. Find true amp. and comp. err.; and if var. is $11^{\circ} 20^{\prime} \mathrm{E}$., find dev.

4. September 30 th, at $6^{\mathrm{h}} 23^{\mathrm{m}}$ P.M. A.T.S., in lat. $48^{\circ} 19^{\prime}$ S., long. $76^{\circ}$ E., the sun set by compass W. $\frac{1}{2}$ S. Find true amp. and comp. err.; the var. being $29^{\circ} 45^{\prime} \mathrm{W}$., find the dev.

5. August 4th, at $5^{\text {h }} 6^{m}$ A.M., M.T.S., in lat. $37^{\circ} 15^{\prime}$ N., long. $20^{\circ} 30^{\prime}$ E., the sun's comp. bearing was E. by N. $\frac{1}{2}$ N. Find true amp., comp. err., and deviation, the var. being $11^{\circ} 30^{\prime} \mathrm{W}$.

6. September 26 th, at $6^{\text {h }} 5^{\mathrm{m}}$ P.M. M.T.S., in lat. $50^{\circ} 15^{\prime}$ N., long. $126^{\circ} 45^{\prime}$ W., the sun's comp. bearing was S. $69^{\circ} 30^{\prime}$ W. Find true amp., comp. err., and dev., the var. being $22^{\circ} 40^{\prime} \mathrm{E}$.

7. August 7 th, about $6^{\text {h }}$ A.M., in lat. $20^{\circ} 24^{\prime}$ S. long. $134^{\circ}$ W., when a chron. correct for M.T.G. showed $3^{\mathrm{h}} 20^{\mathrm{m}}$, the sun's comp. bearing was $\mathbf{E}$. Find the true amp., comp. err., and dev., the var. being $7^{\circ} 15^{\prime} \mathrm{E}$.

8. September 7 th, about $7^{\text {h }}$ P.M., in lat. $60^{\circ} 14^{\prime}$ N., long. $166^{\circ}$ W., when a chron. correct for M.T.G. showed $6^{\mathrm{h}} 4^{\mathrm{m}}$, the sun's comp. bearing was W. Find the true amp., comp. err., and dev., the var. being $12^{\circ} 20^{\prime} \mathrm{E}$.

9. August 3rd, about $3^{\mathrm{h}} 10^{\mathrm{m}}$ A.M., in lat. $65^{\circ} 22^{\prime} \mathrm{N}$., long. $170^{\circ} 15^{\prime} \mathrm{W}$., when a chron. correct for M.T.G. showed $2^{\mathrm{b}} 35^{\mathrm{m}}$, the sun's comp. bearing was N. $\frac{1}{4}$ W. Find the true amp., comp. err., and dev., the var. being $22^{\circ} 40^{\prime} \mathrm{E}$.

10. September 23rd, at $6^{\text {h }}$ A.M. A.T.S. at ship, in lat. $0^{\circ}$, long. $50^{\circ} \mathrm{W}$., the sun's comp. bearing was E. $10^{\circ} \mathrm{S}$. Find the true amp., comp. err., and dev., the var. being $0^{\circ}$.

11. September 25 th, at $6^{\mathrm{h}} 5^{\mathrm{m}}$ P.M. A.T.S. at ship, in lat. $13^{\circ} 15^{\prime} \mathrm{S}$, long. $95^{\circ} \mathrm{E}$., the sun's bearing by comp. was N. $76^{\circ} 30^{\prime} \mathrm{W}$. Find the true amp., comp. crr., and dev., the var. being $2^{\circ} \mathrm{W}$. 
12. September $23 \mathrm{rd}$, about $6^{\text {h }}$ P.M. at ship, in lat. $39^{\circ}$ N., long. $78^{\circ} 45^{\prime}$ W., when a chron. correct for M.T.G. showed $11^{\mathrm{h}} 15^{\mathrm{m}} 23^{\mathrm{s}}$, the sun's comp. bearing was S. $88^{\circ} \mathrm{W}$. Find true amp., comp. err., and dev., the var. being $6^{\circ} 30^{\prime} \mathrm{E}$.

13. August 30 th, at $5^{\mathrm{h}} 59^{\mathrm{m}}$ A.M., in lat. $0^{\circ}$, long. $180^{\circ} \mathrm{W}$., the sun's comp. bearing was N.E. by E. $\frac{1}{2}$ E. Find the true amp., comp. err., and dev., the var. being $9^{\circ} 30^{\prime} \mathbf{E}$.

14. September 24 th, about $6^{\text {h }}$ A.M., in lat. $2^{\circ} 20^{\prime}$ N., long. $101^{\circ} 11^{\prime}$ E., the sun's comp. bearing was E., when the chron. showed $11^{\mathrm{h}} 15^{\mathrm{m}} 14^{\mathrm{s}}$ correct M.T.G. Find the true amp., comp. err., and dev., the var. being $1^{\circ} 15^{\prime} \mathrm{E}$. long.

15. Find the time of sunrise on August 16th, in lat. $53^{\circ} 20^{\prime} \mathrm{N} ., 4^{\circ} \mathrm{W}$.

16. If a star in the equinoctial rises at $7^{\mathrm{h}} 12^{\mathrm{m}} 18^{\mathrm{s}}$ by chronometer, what should the chron. indicate when star is on meridian.

17. At a certain place the sun rose E. $25^{\circ} \mathrm{S}$. by compass, and set W. $15^{\circ}$ $\mathrm{N}$. by same compass. Find deviation, having given variation $22^{\circ} \mathrm{W}$.

18. At a certain place a star when on the prime vertical has its altitude equal to its amplitude when setting. Find lat.

19. Find the greatest amplitude the sun can have in lat. $53^{\circ} 20^{\prime} \mathrm{N}$.

20. In lat. $50^{\circ} \mathrm{S}$. when sun's declination is $18^{\circ} 40^{\prime} \mathrm{S}$.: find his altitude when on the prime vertical, and the approx. interval between then and setting. 


\section{CHAPTER XVI.}

\section{COMPASS ERROR BY AZIMUTHS.}

ART. 76.-Another method of finding compass error and deviation is by Azimuths; that is, by observing the bearing of any celestial object when out of the horizon. 'This method has the advantage of being available at all times of the day or night when the object is visible. When an altitude is observed for time, by taking the bearing very little extra trouble is involved in working the Azimuth from the altitude; generally, however, the time is accurately taken, and the Azimuth taken from tables calculated for the purpose. Burdwood's Tables are used for latitudes $30^{\circ}$ to $60^{\circ}$, and Davis's Tables for Latitudes $0^{\circ}$ to $30^{\circ}$; both for declinations from $0^{\circ}$ to $23^{\circ}$.

ART. 77.-The Azimuth of a Celestial Object-that is, its bearing reckoned from true North or South-is the angle at the Zenith between the Meridian of the observer and a vertical circle passing through the object, and is measured on the Horizon.

The Data required in the Calculation are the True Altitude, Latitude, and Polar Distance.

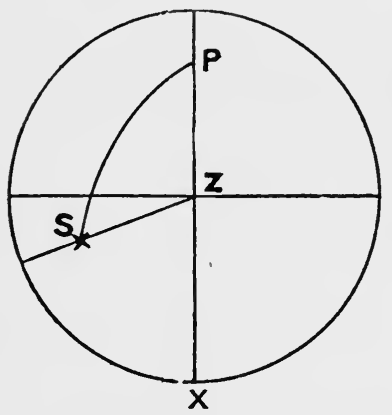

Fig. 130.

Let $\mathrm{S}$ be the object, $\mathrm{PS}$ its polar distance $(p)$, PZ the co-lat. $\left(90^{\circ}-l\right)$, ZS the zenith distance $\left(90^{\circ}-a\right)$. The angle PZS is the azimuth from N., and its supplement SZX is the azimuth from $S$.

PZS is a spherical triangle, of which the three sides are given to find an angle PZS.

The general formula is-

$$
\cos A=\frac{\cos a-\cos b \cdot \cos c}{\sin b \cdot \sin c}
$$

whence in the figure-

$\cos \mathrm{PZS}$ or $-\cos \mathrm{SZX}=\frac{\cos \mathrm{PS}-\cos \mathrm{ZS} \cdot \cos \mathrm{PZ}}{\sin \mathrm{ZS} \cdot \sin \mathrm{PZ}}$

Putting the letters $\mathrm{Z}, a, l, p$ for the azimuth, altitude, latitude, and polar distance respectively- 


$$
\begin{aligned}
-\cos Z & =\frac{\cos p-\cos \left(90^{\circ}-a\right) \cdot \cos \left(90^{\circ}-l\right)}{\sin \left(90^{\circ}-a\right) \cdot \sin \left(90^{\circ}-l\right)} \\
& =\frac{\cos p-\sin a \cdot \sin l}{\cos a \cdot \cos l}
\end{aligned}
$$

adding 1 to each side of the equation-

$$
\begin{aligned}
1-\cos Z & =1+\frac{\cos p-\sin a \cdot \sin l}{\cos a \cdot \cos l} \\
\therefore 2 \sin ^{2} \frac{Z}{2} & =\frac{(\cos a \cdot \cos l-\sin a \cdot \sin l)+\cos p}{\cos a \cdot \cos l} \\
& =\frac{\cos (a+l)+\cos p}{\cos a \cdot \cos l} \\
\sin ^{2} \frac{Z}{2} & =\frac{\cos \frac{1}{2}(a+l+p) \cos \frac{1}{2}(a+l-p)}{\cos a \cdot \cos l} \\
\therefore \sin ^{2} \frac{Z}{2} & =\frac{\cos s \cdot \cos (s-p)}{\cos a \cdot \cos l} \\
\text { where } s & =\frac{1}{2}(a+l+p) \\
\text { i.e. } \sin ^{2} \frac{Z}{2} & =\cos s \cdot \cos (s-p) \cdot \sec a \cdot \sec l \\
\text { or } \sin ^{\frac{Z}{2}} & =\sqrt{\cos s \cdot \cos (s-p) \cdot \sec a \cdot \sec l}
\end{aligned}
$$

from which is derived the rule for computing the azimuth of the opposite name to the latitude, namely, add together the $\log$ secants of the altitude and latitude, and the $\log$ cosines of the half-sum and remainder; divide by two to get the square root, which gives the log sine of half the azimuth.

ART. 78.-To find azimuth from altitude proceed as follows :-

(1) Find Greenwich time; correct declination and find polar distance.

(2) Correct altitude.

(3) Add altitude, latitude, and polar distance, divide by two for half-sum; difference between half-sum and polar distance is remainder.

(4) Add sec alt., sec lat., cos half-sum, and cos remainder; divide sum of logs by two, and take back sine; this angle multiplied by two is the true azimuth which mark contrary name to lat., E. if A.M. at ship, W. if P.M. at ship. If true and comp. azimuth are different in name $N$. or $S$., subtract true from $180^{\circ}$ to make of same name as comp. bearing.

(5) The difference of the true and comp. bearings when of same name E. or W., or their sum when of different names, gives the comp. error which is marked E. or W., according as the true reads to the right or left of the comp. bearing.

(6) Find deviation as in amplitude. 


\section{Example.-}

September 23rd, at $3^{\text {h }} 48^{\mathrm{m}} 27^{\prime}$ M.T.S. P.M., in lat. $56^{\circ} 20^{\prime}$ S., long. $67^{\circ}$ $35^{\prime}$ W., the obs. alt. of the Sun's U.L. was $16^{\circ} 54^{\prime} 30^{\prime \prime}$; ind. cor. $+1^{\prime} 1^{\prime \prime}$; height of eye, $27 \mathrm{ft}$. The Sun's comp. bearing was W. $\frac{1}{4} \mathrm{~S}$. Required the true azimuth, and comp. error; and, supposing the variation to be $22^{\circ} \mathrm{E}$., what is the deviation?

$$
\begin{aligned}
& \text { M.T.S. Sept. } 23^{\mathrm{d}} 3^{\text {h }} 48^{\mathrm{m}} 27^{\text {* }} \\
& \text { Long. W. }+43020 \\
& \text { M.T.G. } 23^{\mathrm{d}} \quad 8 \quad 18 \quad 47
\end{aligned}
$$$$
\begin{gathered}
67^{\circ} 35^{\prime} \\
\frac{4}{6,0)} \\
\frac{27,020}{4^{\mathrm{h}} 30^{\mathrm{m}} 20^{\circ}}
\end{gathered}
$$

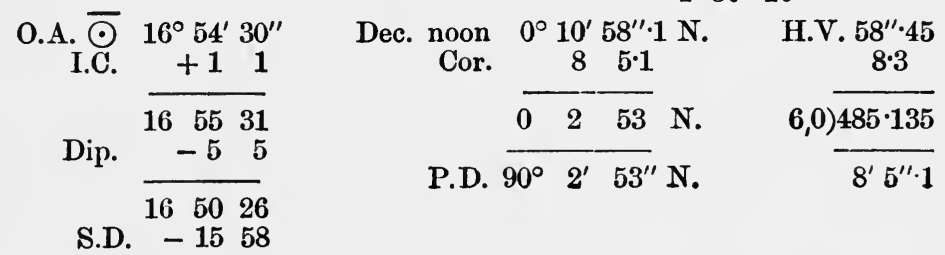

R. and $P . \quad \begin{array}{r}16 \quad 3428 \\ -258\end{array}$

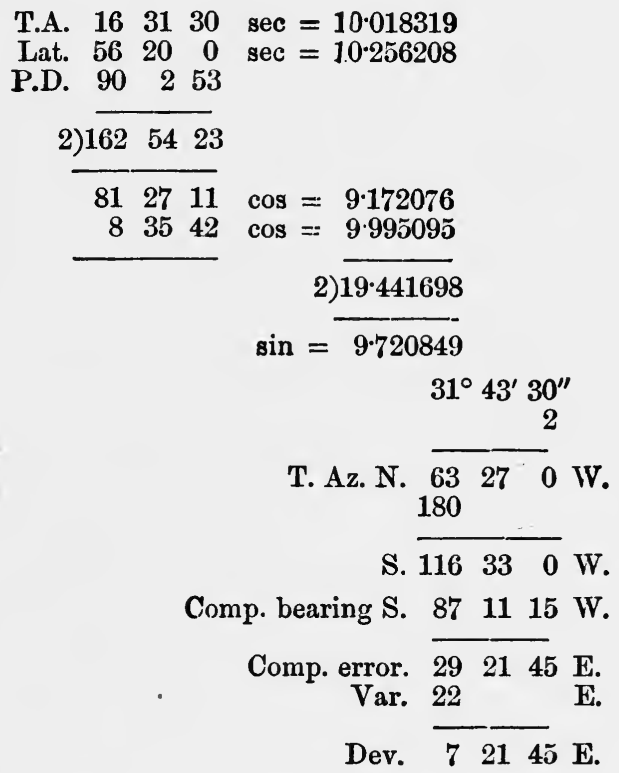

The true azimuth is marked $N$., contrary to name of lat., and W. since it is P.M. at ship. It is subtracted from $180^{\circ}$ to change the name to S., which reckons the angle from the same point as the comp. bearing; the difference is the error, since both are named W.; and the error is named $\mathrm{E}$., because the true reads to the right of the comp. bearing. 
Draw circle with $\frac{9}{10}$ inch radius to represent the rational horizon; NESW ; vertical diameter NZS represents meridian of observer.

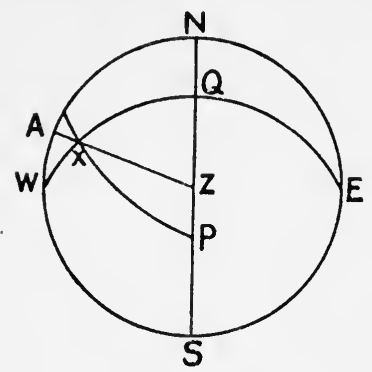

FiG. 131.

Mark off on scale $\mathrm{SP}=\mathrm{ZQ}=$ lat. $56^{\circ} 20^{\prime}$. Since declination is so small object may be considered as on the equinoctial EQW; with zenith distance as radius $=73^{\circ}$ describe an arc to westward cutting $\mathrm{EQW}$ in $\mathrm{X}$, the position of sun; through $X$ draw vertical circle ZXA, and hour circle PX to complete.

Then Alt. is AX ; Lat. is ZQ ; Pol. dist. is PX.

Hence azimuth is PZX, the formula employed gives its supplement NZX.

From the figure.

In figure $\mathrm{X}$ is position of object, very nearly on the equinoctial.

In triangle PZX.

$\begin{array}{rlllllllll}\text { Given co-lat. } & =\mathrm{PZ} \ldots & \ldots & \ldots & \ldots & \ldots & \ldots & 33^{\circ} & 40^{\prime} & 0^{\prime \prime} \\ \text { Pol. dist. } & =\mathrm{PX} \ldots & \ldots & \ldots & \ldots & \ldots & \ldots & 90 & 2 & 53 \\ \text { Zen. dist. } & =\mathrm{ZX} \ldots & \ldots & \ldots & \ldots & \ldots & \ldots & 73 & 28 & 30\end{array}$

Req. azimuth $=\mathrm{Z}$.

$$
\cos \frac{Z}{2}=\sqrt{\frac{\sin s \cdot \sin (s-\mathrm{PX})}{\sin \mathrm{PZ} \cdot \sin \mathrm{ZX}}}
$$

where $s=\frac{1}{2}(\mathrm{PX}+\mathrm{PZ}+\mathrm{ZX})$

PZ $\begin{array}{llll}33 & 40 & 0 & \operatorname{cosec}=10 \cdot 256208\end{array}$

ZX $73 \quad 2830 \quad \operatorname{cosec}=10 \cdot 018319$

2)197 $11 \quad 23$

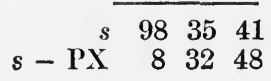

$\sin =9.995095$

$\sin =9 \cdot 172062$

2) $19 \cdot 441684$

$58 \quad 1634 \quad \cos =\overline{9 \cdot 720842}$

2

True az. S. $\overline{116 \quad 33} 8 \mathrm{~W}$.

Comp. bearing S. $871115 \mathrm{~W}$.

$\begin{array}{rlrrr}\text { Comp. error } & 29 & 21 & 53 \mathrm{E} . \\ \text { var. } & 22 & \mathrm{E} .\end{array}$

Dev. $72153 \mathrm{E}$.

\section{Exercises.}

1. August 4th, about $8^{\mathrm{h}} 30^{\mathrm{m}}$ A.M. , in lat. $38^{\circ} 47^{\prime}$ S., long. $92^{\circ} 12^{\prime}$ E. ; when a chron. correct for M.T.G. showed $2^{\mathrm{h}} 37^{\mathrm{m}} 35^{\mathrm{s}}$, the obs. alt. of Sun's L.I. was $16^{\circ} 42^{\prime} 10^{\prime \prime}$; ind.cor., + $2^{\prime} 15^{\prime \prime}$; eye, $29 \mathrm{ft}$. ; bearing by compass, N. $49^{\circ} 30^{\prime} \mathrm{E}$. Find the true azimuth, comp. error, and deviation, the variation being $18^{\circ} \mathrm{W}$.

2. August 19th, at $4^{\mathrm{h}} 25^{\mathrm{m}} 37^{\circ}$ P.M. A.T.S., in lat. $41^{\circ} 24^{\prime}$ N., long. $70^{\circ} 20^{\prime}$ W., the obs. alt. of the Sun's U.L. was $26^{\circ} 32^{\prime} 40^{\prime \prime}$; bearing by compass, W. ; ind. cor.. - $2^{\prime} 7^{\prime \prime}$; height of eye, $34 \mathrm{ft}$. Find the true azimuth and comp. error: also if the variation from chart is $9^{\circ} 30^{\prime} \mathrm{W}$., find the deviation. 
3. August 31st, about $9^{\text {h }} 20^{\mathrm{m}}$ A.M. , in lat. $52^{\circ} 25^{\prime}$ N., long. $3^{\circ} 17^{\prime} 30^{\prime \prime}$ W. ; when a chron., which was $38^{\mathrm{m}} 19^{\mathrm{a}}$ slow of M.T.G., showed $8^{\mathrm{h}} 57^{\mathrm{m}} 39^{\mathrm{s}}$, the obs. alt. of the Sun's U.L. was $36^{\circ} 26^{\prime} 10^{\prime \prime}$; bearing by compass S., $28^{\circ} 30^{\prime}$ E. ; ind. cor., $-26^{\prime \prime}$; eye, $41 \mathrm{ft}$. Find the true azimuth, comp. error., and deviation, the variation being $15^{\circ} 40^{\prime} \mathrm{W}$.

4. September 1st, A.M. at ship, in lat. $44^{\circ} 18^{\prime}$ N., long. $10^{\circ} 15^{\prime} \mathrm{W}$. ; when a chron. correct for M.T.G. indicated $9^{\mathrm{h}} 22^{\mathrm{m}} 37^{\mathrm{s}}$, the obs. alt. of Sun's U.L., $34^{\circ} 21^{\prime} 30^{\prime \prime}$; ind. cor., $+4^{\prime} 15^{\prime \prime}$; height of eye, $23 \mathrm{ft}$. ; bearing by compass, S.E. $\frac{1}{2}$ E. Required the true azimuth, and comp. error; and if variation from chart is $25^{\circ} \mathrm{W}$., what is the deviation?

5. September $22^{\mathrm{d}} 18^{\mathrm{h}} 29^{\mathrm{m}} 38^{\prime}$ (astronomical) M.T.G., in lat. $49^{\circ} 40^{\prime} \mathrm{S}$., long. $135^{\circ} 24^{\prime}$ E. ; the Sun's comp. bearing, N. $61^{\circ} 50^{\prime} \mathrm{W}$.; alt. of U.L., $22^{\circ}$ $18^{\prime} 50^{\prime \prime}$; height of eye, $20 \mathrm{ft}$. Find true azimuth, comp. error, and deviation, the variation being $0^{\circ}$.

6. September 30 th, about $3^{\text {h }} 15^{\mathrm{m}}$ P.M., in lat. $49^{\circ} 37^{\prime}$ S., long. $179^{\circ} 56^{\prime}$ E.; when a chron. showed $3^{\mathrm{b}} 20^{\mathrm{m}} 26^{\mathrm{a}}$ correct M.T.G., the obs. alt. of Sun's L.L., $25^{\circ} 3^{\prime} 20^{\prime \prime}$; ind. cor., $+3^{\prime} 14^{\prime \prime}$; height of eye, $37 \mathrm{ft}$.; bearing by compass, W.N.W. Find true azimuth, comp. error, and deviation, the variation from chart being $16^{\circ} 30^{\prime} \mathrm{E}$.

ART. 79. Time Azimuths of the Sun by the Tables.-When the Apparent Time at Ship, the Lat., and the Sun's Dec. are known, the Sun's 'True Azimuth can be found by inspection in Burdwood's or Davis's Tables.

The same Tables will give the true Azimuth of a Star, a Planet, or the Moon, provided the Hour Angle and Declination are within the limits of the Tables.

A description of one of the books suffices, as the only difference is that Burdwood is used with lats. $30^{\circ}$ to $60^{\circ}$, and Davis with lats. $0^{\circ}$ to $30^{\circ}$.

The azimuths are calculated and tabulated for each degree of lat. and dec., and at intervals of 4 mins. in time. Interpolations must be made for odd minutes of time, lat., and dec. The degrees of lat. are found at the top of the page, underneath which is a remark showing whether lat. and dec. are the same or contrary in name. The columns are headed with the degrees of dec. from $0^{\circ}$ to $23^{\circ}$ consecutively; $0^{\circ}$ to $11^{\circ}$ on left hand page, $12^{\circ}$ to $23^{\circ}$ on right; and at the sides the times are entered to every 4 mins. A.M. time on the left-hand side of the page, P.M. time on the right. The method of using the Tables will be illustrated, and the following rules must be observed:-

(1) Find the apparent time at ship (civil time).

(2) Correct Sun's declination.

(3) Open the tables at the degree of lat. in question, and observe whether dec. and lat. are of same or contrary names. Find in the A.M. or P.M. column the next less entry in point of time to the A.T.S. in question, and in this line under the degree of declination will be found the azimuth, which has to be corrected for odd minutes of time, declination, and latitude by proportion, for the true azimuth.

(4) The true azimuth must be named the same name as the latitude-E. if A.M. at ship, W. if P.M. at ship. 


\section{Example.-}

The apparent time at ship being $3^{\mathrm{h}} 56^{\mathrm{m}} 11^{\mathrm{A}}$ P.M., the correct declination $0^{\circ} 3^{\prime}$ N., and latitude $56^{\circ} 20^{\prime}$ S. Find true azimuth from "Tables."

$\begin{array}{llll}\text { A.T.S. } & \ldots & \ldots & 3^{\mathrm{b}} 56^{\mathrm{m}} \mathbf{1 1}^{\circ} \mathrm{P} . \mathrm{Mr} . \\ \text { Dec. } & \ldots & \ldots & 0^{\circ} 3^{\prime} \mathrm{N} . \\ \text { Lat. } & \ldots & \ldots & 56^{\circ} 20^{\prime} \mathrm{S} .\end{array}$

In Burdwood's Tables, with lat. $56^{\circ}$, contrary name to dec. opposite $3^{\text {h }}$ $56^{m}$, under dec. $0^{\circ}$, the Sun's azimuth is found to be $116^{\circ} 28^{\prime}$; this has to be corrected for $11^{\prime}$ of time, $3^{\prime}$ of dec., and $20^{\prime}$ of lat.

Az. for $3^{\text {h }} 56^{\mathrm{m}} 116^{\circ} 28^{\prime} \quad$ Az. for $0^{\circ}$ dec. $116^{\circ} 28^{\prime} \quad$ Az. for $56^{\circ}$ lat. $116^{\circ} 28^{\prime}$

$$
\begin{aligned}
& \text { " } 4 \quad 11535 \quad, 1 \quad 1 \quad 117 \quad 1 \quad \text {, } 57 \quad, 11644
\end{aligned}
$$

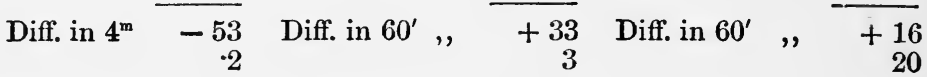

$$
\begin{aligned}
& \begin{array}{lll}
4 \longdiv { 1 0 \cdot 6 } & 6,0) 9,9 & 6,0) 32,0
\end{array} \\
& \text {, } 11^{\prime} \quad \overline{-2 \cdot 6} \quad, \quad 3^{\prime}, \quad \overline{+1 \cdot 6} \quad \text {, } 20^{\prime}, \quad \overline{+5 \cdot 3}
\end{aligned}
$$

Azimuth from Tables $116^{\circ} 28^{\prime}$

Correction $-2^{\prime} \cdot 6+1^{\prime} \cdot 6+5^{\prime} \cdot 3=+4 \cdot 3$

True azimuth S. $11632 \cdot 3 \mathrm{~W}$.

ArT. 80. Time Azimuth by Calculation.-Here the hour angle ZPS, the polar distance PS, and the co-latitude PZ are given to find the angle PZS, which is the azimuth of the same name as the latitude (Fig. 130).

This is a case of two sides and the included angle being given to find one of the angles at the base. From the general formulæ-

$$
\begin{aligned}
& \tan \frac{1}{2}(A+B)=\frac{\cos \frac{1}{2}(a-b)}{\cos \frac{1}{2}(a+b)} \cdot \cot \frac{1}{2} C \\
& \tan \frac{1}{2}(A-B)=\frac{\sin \frac{1}{2}(a-b)}{\sin \frac{1}{2}(a+b)} \cdot \cot \frac{1}{2} C
\end{aligned}
$$

by substituting the $Z$ and $S$ in the figure for $A$ and $B$, and the letters $h, p, l^{\prime}$ for the H.A., polar distance, and co-latitude respectively, we have-

$$
\begin{aligned}
& \tan \frac{1}{2}(\mathrm{Z}+\mathrm{S})=\frac{\cos \frac{1}{2}\left(p-l^{\prime}\right)}{\cos \frac{1}{2}\left(p+l^{\prime}\right)} \cot \frac{1}{2} h \\
& \tan \frac{1}{2}(\mathrm{Z}-\mathrm{S})=\frac{\sin \frac{1}{2}\left(p-l^{\prime}\right)}{\sin \frac{1}{2}\left(p+l^{\prime}\right)} \cot \frac{1}{2} h
\end{aligned}
$$

therefore, $\tan \frac{1}{2}(\mathrm{Z}+\mathrm{S})=\sec \frac{1}{2}\left(p+l^{\prime}\right) \cdot \cos \frac{1}{2}\left(p-l^{\prime}\right) \cdot \cot \frac{1}{2} h$ and $\tan \frac{1}{2}(Z-S)=\operatorname{cosec} \frac{1}{2}\left(p+l^{\prime}\right) \cdot \sin \frac{1}{2}\left(p-l^{\prime}\right) \cdot \cot \frac{\pi}{2} h$ whence the following form for computation :-

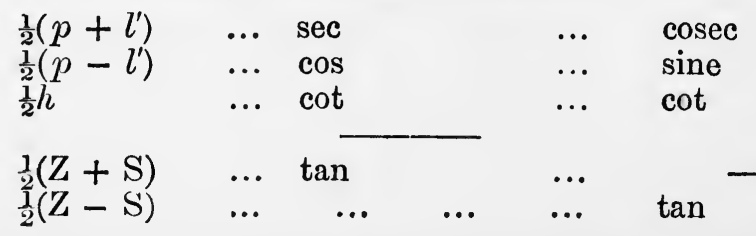


The sum of these angles is the greater of the two angles $\mathrm{Z}$ and $\mathrm{S}$, and the difference is the lesser angle; and since the greater angle is opposite to the greater side, the azimuth $\mathrm{Z}$ is the greater angle when $p$ is greater than $l^{\prime}$, and the smaller angle when $p$ is less than $l^{\prime}$.

NorE.-When $\frac{1}{2}\left(p+l^{\prime}\right)$ exceeds $90^{\circ}$, the sec is negative, and therefore $\tan \frac{1}{2}(Z+S)$ is negative, in which case the supplement must be taken for $\frac{1}{2}(Z+S)$.

\section{Example.-}

The apparent time at ship being $3^{\mathrm{h}} 56^{\mathrm{m}} 11^{\text {' }}$ P.M., correct dec. $0^{\circ} 3^{\prime} \mathrm{N}$., and lat. $56^{\circ} 20^{\prime} \mathrm{S}$., find true azimuth by calculation.

This figure is drawn similarly to Fig. 131, except that as the hour angle is given instead of the altitude, we must estimate an arc of the equinoctial equal to the hour angle $3^{\mathrm{h}} 56^{\mathrm{m}}$ to determine the point through which to draw the hour circle of the object : knowing that QW represents 6 hours : where this hour circle cuts the parallel of declination is the position of $\mathrm{X}$.

In triangle $\mathrm{PZX}-$

Given $\mathrm{P}=3^{\mathrm{h}} 56^{\mathrm{m}} 11^{\circ}=$ hour angle

$\mathrm{PZ}=33^{\circ} 40^{\prime}=$ co-lat.

$\mathrm{PX}=90^{\circ} 3^{\prime}=$ pol. dist.

Req. $Z=$ azimuth.

$$
\begin{array}{r}
\tan \frac{1}{2}(\mathrm{Z}+\mathrm{X})=\frac{\cos \frac{1}{2}(\mathrm{PX}-\mathrm{PZ})}{\cos \frac{1}{2}(\mathrm{PX}+\mathrm{PZ})} \cot \frac{\mathrm{P}}{2} \\
\tan \frac{1}{2}(\mathrm{Z}-\mathrm{X})=\frac{\frac{1}{2}(\mathrm{PX}-\mathrm{PZ})}{\sin \frac{1}{2}(\mathrm{PX}+\mathrm{PZ})} \\
\mathrm{PZ}=33^{\circ} 40^{\prime} \\
\mathrm{PX}=\frac{903}{2} \\
\mathrm{PX}+\mathrm{PZ}=12343
\end{array}
$$$$
\mathrm{PX}-\mathrm{PZ}=5623
$$

$$
\begin{aligned}
& \frac{\mathrm{P}}{2}=1^{\mathrm{h}} 58^{\mathrm{m}} 5^{\mathrm{s}} \cdot 5 \quad \cot =10 \cdot 246953 \quad \cot =10 \cdot 246953 \\
& \frac{1}{2}\left(\mathrm{PX}+\mathrm{P}^{\prime} \mathrm{Z}\right)=61^{\circ} 51^{\prime} 30^{\prime \prime} \quad \text { sec }=10 \cdot 326377 \quad \text { cosec }=10 \cdot 054638 \\
& \frac{1}{2}(\mathrm{PX}-\mathrm{PZ})=\begin{array}{lllll}
28 & 11 & 30 & \cos =9.945159 & \sin =9 \cdot 674331
\end{array} \\
& \frac{1}{2}(Z+X)=\overline{73 \quad 830} \quad \tan =\overline{10 \cdot 518489} \\
& \frac{1}{2}(Z-X)=\begin{array}{llllll}
43 & 24 & 30 & \ldots & \ldots & \ldots
\end{array} \quad \tan =\overline{9 \cdot 975922} \\
& \mathrm{Z}=116 \quad 33 \quad 0
\end{aligned}
$$

\section{EXERCISES.}

Under the following conditions find from the Tables or by calculation the True Azimuth, and hence the deviation :-

1. A.T.S. $2^{\text {h }} 48^{\text {m }}$ P.M. ; dec. $10^{\circ} 25^{\prime}$ S. ; lat. $40 \mathrm{~N}$.

2. A.T.S. $3^{\mathrm{h}} 19^{\mathrm{m}}$ P.M. ; dec. $14^{\circ} 33^{\prime}$ N. ; lat. $49^{\circ} \mathrm{N}$.

3. A.T.S. $9^{\mathrm{h}} 14^{\mathrm{m}}$ A.M. ; dec. $21^{\circ} 17^{\prime}$ N.; lat. $52^{\circ} 25^{\prime}$ S.

4. September 1st, M.T.G. $31^{\mathrm{d}} 15^{\mathrm{h}} 54^{\mathrm{m}} 42^{\mathrm{s}}$, in lat. $51^{\circ} 25^{\prime} \mathrm{S}$., long. $174^{\circ} 25^{\prime}$ E., the Sun's comp. bearing was W. $\frac{3}{4} \mathrm{~N}$. ; variation $30^{\circ} \mathrm{E}$.

5. August 12 , A.M. at ship, in lat. $0^{\circ}$, long. $12^{\circ} 50^{\prime}$ W.; when a chron. showed $8^{\mathrm{h}} 16^{\mathrm{m}} 20^{\mathrm{s}}$ M.T.G., the Sun's comp. bearing was E. $\frac{3}{4}$ N. ; var. $20^{\circ}$ $30^{\prime} \mathrm{W}$.

6. September 3rd, at $7^{\mathrm{h}} 57^{\mathrm{m}}$ A.M. M.T.S., in lat. $13^{\circ} 29^{\prime} \mathrm{N}$., long. $60^{\circ} 30^{\prime}$ E., the Sun's comp. bearing was E. by N. $\frac{3}{4}$ N. ; var. $1^{\circ} 10^{\prime} \mathrm{W}$. 
7. September 23 rd, about $3^{\mathrm{h}} 30^{\mathrm{m}}$ P.M. in lat. $49^{\circ} 40^{\prime}$ S., long. $135^{\circ} 24^{\prime}$ E. ; when a chron. showed $6^{\mathrm{h}} 29^{\mathrm{m}} 37^{\mathrm{s}}$, the Sun's comp. bearing was N. $61^{\circ} 50^{\prime} \mathrm{W}$.; var. $0^{\circ}$.

8. When the M.T.G. was August $31^{\mathrm{d}} 21^{\mathrm{b}} 22^{\mathrm{m}} 37^{\mathrm{B}}$, in lat. $44^{\circ} 18^{\prime}$ N., long. $10^{\circ} 15^{\prime} \mathrm{W}$. ; the Sun's comp. bearing was S.E. $\frac{1}{2} \mathrm{E}$. ; var. $25^{\circ} \mathrm{W}$.

9. About $4^{\mathrm{h}} 15^{\mathrm{m}}$ P.M. on September $23 \mathrm{rd}$, in lat. $0^{\circ} 15^{\prime}$ S., long. $150^{\circ} 15^{\prime} \mathrm{E}$.; when a chron. showed $6^{\mathrm{h}} 30^{\mathrm{m}}$ M.T.G., the Sun's comp. bearing was W.; var. $9^{\circ} \mathrm{E}$.

10. August 3rd, at $3^{\mathrm{h}} 50^{\mathrm{m}}$ P.M. A.T.S., in lat. $25^{\circ} 16^{\prime}$ S., long. $92^{\circ} 30^{\prime}$ E., the Sun bore by comp. N. $60^{\circ} \frac{1}{2} \mathrm{~W}$.; var. $8^{\circ} 15^{\prime} \mathrm{W}$.

11. August 5th at $8^{\mathrm{b}} 40^{\mathrm{m}}$ A.M. M.T.S., in lat. $30^{\circ} 21^{\prime} \mathrm{N}$., long. $51^{\circ} 15^{\prime}$ E., the Sun's comp. bearing was S.E. by E. $\frac{3}{4}$ E.; var. $2^{\circ} \mathrm{W}$.

12. August 9th at $4^{\mathrm{h}} 25^{\mathrm{m}}$ P.M. M.T.S., in lat. $37^{\circ} 27^{\prime}$ N., long. $20^{\circ} 14^{\prime}$ E., the Sun bore by comp. W. $\frac{1}{4} \mathrm{~N}$.; var. $21^{\circ} \mathrm{W}$.

13. August 23 rd about $9^{\mathrm{h}} 20^{\mathrm{m}}$ A.M., in lat. $52^{\circ} 49^{\prime}$ S., long. $53^{\circ} 17^{\prime} \mathrm{W}$.; when a chron. showed $1^{\mathrm{b}} 17^{\mathrm{m}} 12^{*}$ G.M.T., the Sun bore by comp. N.E. by E.; var. $15^{\circ} 30^{\circ} \mathrm{E}$.

14. August 24 th about $10^{\mathrm{h}} 40^{\mathrm{m}}$ A.M., in lat. $64^{\circ} 56^{\prime} \mathrm{N}$., long. $170^{\circ} \mathrm{W}$.; when a chron. correct for M.T.G. showed $10^{\mathrm{h}} 1^{\mathrm{m}} 30^{\mathrm{s}}$, the Sun's comp. bearing was S. $\frac{3}{4}$ W. ; var. $24^{\circ} \mathrm{E}$.

AR'r. 81. Star Time Azimuths.-As before noticed, providing the declination of the star is less than $23^{\circ}$, the Tables may be used for obtaining the true bearing. The Hour Angle of the star must, however, be calculated instead of the A.T.S., and always found in the P.M. column on the right-hand side of the page, otherwise the method is precisely the same.

\section{Example.-}

September 10 th at $1^{\mathrm{h}} 36^{\mathrm{m}} 20^{\circ}$ A.M. mean time at ship, in lat. $38^{\circ} 20^{\prime} \mathrm{N}$., long. $63^{\circ} 30^{\prime} \mathrm{W}$., the star $\alpha$ Orionis bore by compass E. by S. $\frac{1}{2} \mathrm{~S}$. Required the comp. error, and deviation, the variation being $9^{\circ} 15^{\prime} \mathrm{W}$.

\begin{tabular}{|c|c|c|c|c|c|}
\hline M.T.S. Sept. $9^{d} 13^{\text {h }} 36^{\mathrm{m}} 20^{\circ}$ & $63^{\circ} 30^{\prime}$ & R.A.M.S. noon & $11^{\mathrm{h}}$ & $10^{\mathrm{m}}$ & $29^{n} \cdot 8$ \\
\hline Long. W. +4140 & 4 & Accel. for $17^{\mathrm{h}}$ & & 2 & $47 \cdot 6$ \\
\hline M.T.G. Sept. $9^{d} 175020$ & $60) 254 \quad 0$ & & & & \\
\hline & & MI.T.G. & $\begin{array}{l}11 \\
13\end{array}$ & $\begin{array}{l}13 \\
36\end{array}$ & $\begin{array}{l}25 \cdot 6 \\
20\end{array}$ \\
\hline $\begin{array}{llll}\text { Dec. }{ }^{*} 7^{\circ} & 23^{\prime} & 34^{\prime \prime} & \mathrm{N} \\
\text { Lat. } 38 & 20 & \mathrm{~N}\end{array}$ & & $\begin{array}{l}\text { R.A.M. } \\
\text { R.A.* }\end{array}$ & $\begin{array}{l}0 \\
5\end{array}$ & $\begin{array}{l}49 \\
50\end{array}$ & $\begin{array}{r}45 \cdot 6 \\
4 \cdot 9\end{array}$ \\
\hline & & E.H.A & 4 & & \\
\hline
\end{tabular}

In Burdwood's Tables, with lat. $38^{\circ}$, same name as declination, under $7^{\circ}$ Dec., abreast $5^{\mathrm{h}}$ on the right-hand side (always find H.A. of star on righthand side), the star's' azimuth is entered as $93^{\circ} 43^{\prime}$, which requires correction for $19^{\prime}$ tirne, $24^{\prime}$ of Dec., and $20^{\prime}$ Lat.

Az. for $5^{\text {h }} \quad 93^{\circ} 43^{\prime}$ , $5^{\mathrm{h}} 4^{\mathrm{m}} 93 \quad 5$

Diff. for $4^{\mathrm{m}}-38$

$$
\text { Az. for } 7^{\circ} \text { dec. } 93^{\circ} 43^{\prime}
$$$$
\text { , } \quad 8^{\circ}, \text {, } 9253
$$

Diff. for $60^{\prime}$

$$
-50
$$$$
24
$$

Az. for $38^{\circ}$ lat. $93^{\circ} 43^{\prime}$

$$
\text { " } 39 \text {, } 940
$$

Diff. for $60^{\prime}+17$

$$
\begin{array}{rrrrr} 
& 4 \overline{11 \cdot 4} & & & 6,0) \overline{120,0} \\
\text { " } 19^{\prime} & -\overline{2 \cdot 3} & & & \\
& & 24^{\prime} & -20
\end{array}
$$$$
6,0) \overline{34,0}
$$$$
+\overline{5 \cdot 7}
$$ 


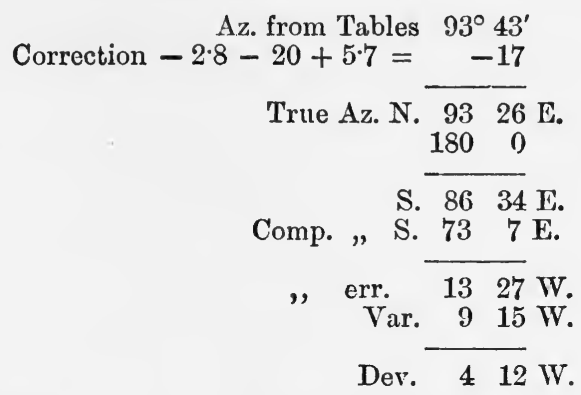

From the figure.

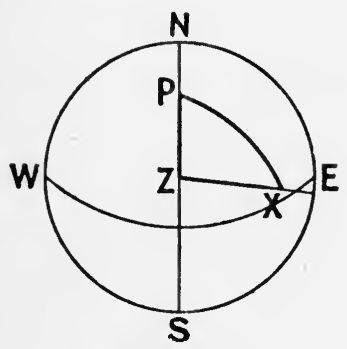

Fia. 133.

$$
\begin{aligned}
& \frac{\mathrm{P}}{2}=2^{\mathrm{h}} 30^{\mathrm{m}} 9.5^{\mathrm{s}} \\
& \frac{1}{2}(\mathrm{PX}+\mathrm{PZ})=67^{\circ} 8^{\prime} 15^{\prime \prime} \\
& \frac{1}{2}(\mathrm{PX}-\mathrm{PZ})=152815 \\
& \frac{1}{2}(\mathrm{Z}+\mathrm{X})=7247 \quad 18 \\
& \frac{1}{2}(Z-X)=2038 \quad 35 \\
& Z=93 \quad 25 \quad 53
\end{aligned}
$$

In triangle $\mathrm{PZX}$, where $\mathrm{X}$ is position of star ; given $\mathrm{PZ}=$ colat

$\mathrm{PX}=$ Pol. dist.

$\mathbf{P}=$ hour angle.

Req. $Z=$ azimuth.

$\operatorname{Tan} \frac{1}{2}(Z+X)=\frac{\cos \frac{1}{2}(P X-P Z)}{\cos \frac{1}{2}(P X+P Z)} \cdot \cot \frac{P}{2}$

$\operatorname{Tan} \frac{1}{2}(\mathrm{Z}-\mathrm{X})=\frac{\sin \frac{1}{2}(\mathrm{PX}-\mathrm{PZ})}{\sin \frac{1}{2}(\mathrm{PX}+\mathrm{PZ})} \cdot \cot \frac{\mathrm{P}}{2}$

$$
\begin{aligned}
& \mathrm{P}=5^{\mathrm{h}} 0^{\mathrm{m}} 19^{\text {s }} \quad \mathrm{PX}=82^{\circ} 36^{\prime} 30^{\prime \prime} \\
& \mathrm{PZ}=5140 \quad 0 \\
& \mathrm{PX}+\mathrm{PZ}=134 \quad 1630 \\
& \mathrm{PX}-\mathrm{PZ}=305630
\end{aligned}
$$

Cot $=10 \cdot 114398$

Cot $=10 \cdot 114398$

Sec $=10 \cdot 410586$

$\mathrm{Cos}=9 \cdot 983972$

Cosec $=10.035533$

Sin $=9 \cdot 426102$

$\operatorname{Tan}=10 \cdot 508956$

$\operatorname{Tan}=\overline{9.576033}$

Tr. Az. N. $93^{\circ} 25^{\prime} 53^{\prime \prime}$ E.

\section{Exercises.}

1. August 18th, about $1^{\mathrm{h}} 20^{\mathrm{m}}$ A. M., in lat. $37^{\circ} 50^{\prime} \mathrm{N}$., long. $50^{\circ}$ W., when a chron. showed $4^{\mathrm{h}} 37^{\mathrm{m}} 40^{\mathrm{s}}$ M.T.G., the comp. bearing of a Arietis was $\mathrm{E}$. Find the true azimuth from the "Tables ;" and if the variation is $14^{\circ} 45^{\prime} \mathrm{W}$., what is the dev.?

2. September 14th, at $2^{\mathrm{h}} 19^{\mathrm{m}}$ A Mr. M.T.S., in lat. $52^{\circ} 49^{\prime}$ S., long. $21^{\circ}$ $17^{\prime}$ W., the comp. bearing of Sirius was S.E. Find the true azimutl from the "'Tables;" and if var. from chart is $33^{\circ} 15^{\prime} \mathrm{W}$., find the dev.

3. September 6th, at $0^{\mathrm{h}} 15^{\mathrm{m}}$ A.M. M.T.S., in lat. $47^{\circ} 43^{\prime} \mathrm{N}$., long. $48^{\circ}$ $32^{\prime}$ W., the comp. bearing of Altair was N. $44^{\circ} 30^{\prime} \mathrm{W}$. Find the true azimuth from the "Tables;" and the var. being $34^{\circ} 40^{\prime} \mathrm{W}$., find the dev.

4. August 4th, at $11^{\mathrm{h}} 25^{\mathrm{m}}$ P.M. A.T.S., in lat. $38^{\circ} 49^{\prime}$ S., long. $56^{\circ} \mathrm{W}$., when the comp. bearing of Vega was N.N.W., calculate the true azimuth, comp. error, and dev., the var. being $17^{\circ} 10^{\prime} \mathrm{E}$.

5. August $2 \mathrm{nd}$, at $3^{\mathrm{h}} 27^{\mathrm{m}}$ A.M. A.T.S., in lat. $40^{\circ} 50^{\prime}$ N., long. $50^{\circ} 40^{\prime}$ W., 
the comp. bearing of a Orionis was E. $\frac{1}{2} \mathrm{~N}$. Using the "Tables," find the true azimuth, and comp. error ; and the var. being $20^{\circ} \mathrm{W}$., find the dev.

6. August 3rd, about $8^{\mathrm{b}} 20^{\mathrm{m}}$ P.M. , in lat. $57^{\circ} 19^{\prime}$ N., long. $3^{\circ} 14^{\prime}$ E., when a chron., whose error on A.T.G. was $14^{\mathrm{m}} 28^{\mathrm{s}}$ fast, showed $8^{\mathrm{b}} 44^{\mathrm{m}} 32^{\mathrm{s}}$, the comp. bearing of Arcturus was S. $65^{\circ} 30^{\prime} \mathrm{W}$. Find from "Tables" the true azimuth ; and var. being $25^{\circ} \mathrm{W}$., what is the dev. ?

7. September 11th, at $1^{\mathrm{h}} 45^{\mathrm{m}}$ A.M. M.T.S., in lat. $42^{\circ} 35^{\prime}$ S., long. $85^{\circ}$ $37^{\prime}$ E., the comp. bearing of Aldebaran was S. $50^{\circ}$ E. Find true azimuth, comp. error, and dev., the var. being $20^{\circ} \mathrm{W}$.

8. September 21st, when the M.T.G. by chron. was $20^{\mathrm{d}} 20^{\mathrm{h}} 38^{\mathrm{m}} 20^{\mathrm{s}}$, the comp. bearing of Fomalhaut, in lat. $14^{\circ} 10^{\prime} \mathrm{N}$., long. $94^{\circ} 50^{\prime} \mathrm{W}$., was S.W. $\frac{1}{2}$ S. Find true azimuth, comp. error, and dev., the var. from chart. being $8^{\circ} \mathrm{E}$.

9. September 21 st, at $4^{\mathrm{h}} 15^{\mathrm{m}}$ A.M. A.T.S., in lat. $21^{\circ} 17^{\prime}$ S., long. $87^{\circ} 40^{\prime}$ E., the comp. bearing of Pollux was N. $40^{\circ} 20^{\prime}$ E., var. $2^{\circ} 15^{\prime} \mathrm{W}$. Find true azimuth, comp. error, and dev.

10. September 21 st, about $11^{\text {h }} 30^{\mathrm{m}}$ P.M., in lat. $48^{\circ} 40^{\prime}$ S., long. $167^{\circ} 30^{\prime}$ W., when a chron., whose error on M.T.G. was $19^{\mathrm{m}} 24^{\mathrm{s}}$ fast, indicated $11^{\mathrm{h}}$ $17^{\mathrm{m}} 24^{\mathrm{s}}$, the comp. bearing of $a^{2}$ Centauri was S. $\frac{1}{2}$ E. Find true azimuth, comp. error, and dev., the var. being $19^{\circ} 20^{\prime} \mathrm{E}$.

11. August $2 \mathrm{nd}$, at $6^{\mathrm{h}} 40^{\mathrm{m}}$ P.M. A.T.S., in lat. $5^{\circ} 12^{\prime}$ S., long. $35^{\circ} \mathrm{W}$., the comp. bearing of Dubhe ( $\alpha$ Urs. Maj.) was N. $8^{\circ} 30^{\prime}$ E.. The var. being $11^{\circ} \mathrm{W}$., find true azimuth, comp. error, and dev.

12. August 1st, at $4^{\mathrm{b}} 30^{\mathrm{m}} 30^{\circ}$ A.M. M.T.S., in lat. $21^{\circ} 30^{\prime}$ S., long. $92^{\circ}$ $45^{\prime}$ E., the comp. bearing of Antares was S.W. by W. $\frac{1}{4}$ W. Find true azimuth, and comp. error ; also, if var. is $9^{\circ} \mathrm{W}$., what is the dev.?

13. If the declination of an object be greater than the latitude of the place, both being of the same name, find the greatest azimuth of the body, the time it will have its greatest azimuth, and its altitude.

14. In lat. of Greenwich $51^{\circ} 28^{\prime} 40^{\prime \prime} \mathrm{N}$., find greatest azimuth of $a$ Urs. Maj. dec. $62^{\circ} 16^{\prime} 50^{\prime \prime} \mathrm{N}$.

15. Altitude of star when on the prime vertical is $25^{\circ}$, altitude when on the six o'clock hour circle $15^{\circ}$. Find its declination, and latitude of observer. 


\section{CHAPTER XVII.}

\section{LONGITUDE BY CHRONOMETER.}

ART. 82. Longitude by Chronometer.-The time by chronometer when corrected for its original Error and accumulated Rate gives the time at Greenwich, whilst the time at ship can be calculated from an observed Altitude of a Celestial Object and the known Latitude. The difference converted into Arc is the Longitude.

The Longitude is E. when Greenwich time is less than ship time, and W. when greater.

The following are required in the Formula :-

(a) The true Altitude.

(b) The Polar Distance.

(c) The Latitude.

The Polar Distance is measured from the elevated Pole, which

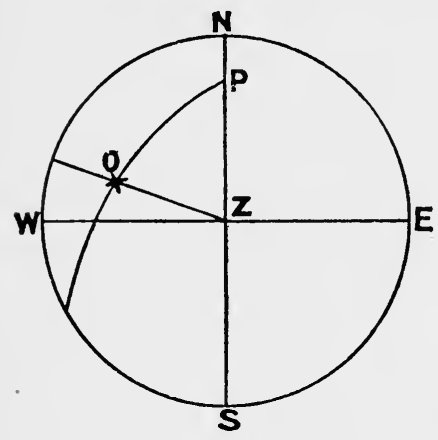

Fig. 134. is the N. Pole in N. Lat., and the $\mathrm{S}$. Pole in S. Lat. It is therefore $90^{\circ}$ - Dec. when the Dec. is of the same name as the Lat., and $90^{\circ}$ + Dec. when of a different name. ART. 83. To find the Hour Angle of a Celestial Object, the Altitude, Latitude, and Polar Distance being known.-Let $\mathrm{O}$ be the object, then $\mathrm{PO}$ is its polar distance $(p)$, $\mathrm{ZO}$ its zenith distance $\left(=90^{\circ}-a\right)$, and $\mathrm{PZ}$ the co-latitude $\left(=90^{\circ}-l\right)$; the angle $\mathrm{ZPO}$ is the hour angle. Therefore, in the spherical triangle $\mathrm{PZO}$, three sides are given to find an angle ZPO.

The general formula for finding an angle is-

$$
\cos A=\frac{\cos a-\cos b \cdot \cos c}{\sin b \cdot \sin c}
$$

which, applied to the figure, gives-

$$
\cos \mathrm{ZPO}=\frac{\cos \mathrm{ZO}-\cos \mathrm{PO} \cdot \cos \mathrm{PZ}}{\sin \mathrm{PO} \cdot \sin \mathrm{PZ}}
$$


Let the letters $a, l, p$, and $h$ stand for altitude, latitude, polar distance, and hour angle respectively;

$$
\text { then } \begin{aligned}
\cos h & =\frac{\cos \left(90^{\circ}-a\right)-\cos p \cdot \cos (90-l)}{\sin p \cdot \sin \left(90^{\circ}-l\right)} \\
& =\frac{\sin a-\cos p \cdot \sin l}{\sin p \cdot \cos l}
\end{aligned}
$$

Subtracting each side of the equation from 1-

$$
\begin{aligned}
1-\cos l & =1-\frac{\sin a-\cos p \cdot \sin l}{\sin p \cdot \cos l} \\
\text { i.e. } 2 \sin ^{2} \frac{l}{2} & =\frac{\sin p \cdot \cos l+\cos p \cdot \sin l-\sin a}{\sin p \cdot \cos l} \\
& =\frac{\sin (p+l)-\sin a}{\sin p \cdot \cos l} \\
& =\frac{2 \cos \frac{1}{2}(p+l+a) \cdot \sin \frac{1}{2}(p+l-a)}{\sin p \cdot \cos l}
\end{aligned}
$$

Now let $s=\frac{1}{2}(p+l+a)$, then $(s-a)=\frac{1}{2}(p+l-a)$;

therefore-

$$
\begin{aligned}
\sin ^{2} \frac{h}{2} & =\frac{\cos s \cdot \sin (s-a)}{\sin p \cdot \cos l} \\
& =\operatorname{cosec} p \cdot \sec l \cdot \cos s \cdot \sin (s-a) \\
\text { and } \sin \frac{h}{2} & =\sqrt{\operatorname{cosec} p \cdot \sec l \cdot \cos s \cdot \sin (s-a)}
\end{aligned}
$$

which is the formula used for computing the hour angle in the longitude by chronometer and other time problems.

ART. 84. To find the Time when the Sun or other Celestial Object is on the Prime Vertical.-Let $O$ be an object on the prime vertical; then $\mathrm{PO}$ is its polar distance, $\mathrm{PZ}$ is the co-latitude, and the angle $\mathrm{P}$ is the hour angle.

$\mathrm{PZO}$ is a spherical triangle, right angled at $Z$, of which the circular parts are $\mathrm{PZ}$ and $\mathrm{ZO}$, and

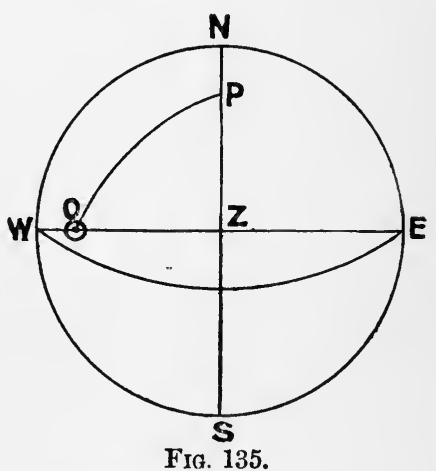
the complements of $\mathrm{PO}$ and the angles $\mathrm{P}$ and $\mathrm{O}$.

Taking complement of $\mathrm{P}$ as middle part, $\mathrm{PZ}$ and the complement of PO are adjacent parts : 


$$
\begin{aligned}
\text { then } \sin (\operatorname{comp} . \text { of } \mathrm{P}) & =\tan \mathrm{PZ} \times \tan (\text { comp. of } \mathrm{PO}) \\
\text { or } \cos \mathrm{P} & =\tan \mathrm{PZ} \times \cot \mathrm{PO} \\
\text { that is, } \cos \mathrm{H} . \mathrm{A} . & =\cot \text { lat. } \times \tan \text { dec. }
\end{aligned}
$$

In the case of the Sun, the H.A. is the interval from apparent noon.

For any other object, add its R.A. to its H.A. west to find the R.A. of meridian, from which subtract the sun's R.A. to find the time.

ART. 85.-The following rules must be observed in Sun chronometers:-

(1) Find the correct G.M.T. by applying the error when last found, and accumulated rate, to the time shown by chronometer. As in other problems, great care must be taken to make the time shown by the chronometer agree with the rough Greenwich time deduced from D.R. long. and ship time; both as regards the date and hours.

(2) Correct declination, equation of time, and altitude. Find polar distance ; and look at the heading of the equation of time column on page $I_{\text {., }}$ to see how it is to be applied.

(3) Add together true alt., lat., and pol. dist.; find the half sum, and from it subtract the alt.; this gives the chron. remainder. Add the secant lat., cosec pol. dist., cos half sum, and sin remainder, reject 10's, and look out result in Table xxxI., Norie; this is the hour angle.

Note 1.-Should the pol. dist. exceed $90^{\circ}$, use sec dec. for cosec pol. dist.

Note 2.-The lat. used must be the lat. at observation; if not given, it must be deduced from the lat. at noon.

(4) If P.M. at ship, the hour angle is the apparent time at ship of the same date as given in question.

If A.M. at ship subtract the hour angle from $24^{\mathrm{h}}$ and date the day before day in question for app. time at ship. To the A.T.S. apply equation of time for M.T.S.

(5) 'The difference between the M.T.S. and M.T.G. is the longitude in time, which must be expressed in arc, for long. at obs. named west when G.M.T. is best, and east when G.M.T. is least.

\section{Examples. -}

(1) August 8th, about $3^{\mathrm{h}} 50^{\mathrm{m}}$ P.M. at ship, in lat. $56^{\circ} 48^{\prime}$ N., long. D.R. $7^{\circ}$ W. ; when a chron. showed $4^{\mathrm{b}} 29^{\mathrm{m}} 34^{\mathrm{s}}$, the obs. alt. of the Sun's L.L. was $30^{\circ} 57^{\prime} 10^{\prime \prime}$; ind. cor., $-2^{\prime} 10^{\prime \prime}$; height of eye, $20 \mathrm{ft}$. Find the longitude, the chron. having been found $7^{\mathrm{m}} 46^{\circ} \cdot 2$ fast of G.M.T. on July $18 \mathrm{th}$, and losing daily $2^{*} \cdot 7$.

Approx. time at ship, Aug. $8^{\mathrm{d}} 3^{\mathrm{h}} 50^{\mathrm{m}}$ Long. W.

$$
\begin{aligned}
\text { elapsed time } & 21 \cdot 2 \text { days } \\
\text { rate } & 2 \cdot 7
\end{aligned}
$$$$
\text { , , Greenwich } 8^{\mathrm{d}} \overline{418}
$$

rate $\frac{2 \cdot 7}{1484}$
424


Time by chron., Aug. $8^{\mathrm{d}} 4^{\mathrm{h}} 29^{\mathrm{m}} 34^{\mathrm{s}}$ Fast.

acc. loss
Dec. $16^{\circ} 20^{\prime} 28^{\prime \prime} \cdot 7 \mathrm{~N}$

Cor.

$\frac{-3 \quad 5 \cdot 5}{161723 \cdot 2}$
90
II.V. $42 \cdot 16$ $4 \cdot 4$
M.T.G. $8 ^ { \mathrm { d } } \longdiv { 2 2 4 5 }$

Eq. T. $5^{\mathrm{m}} 33^{\mathrm{s} .2}$

Cor.

$$
\frac{-1.4}{531.8}
$$

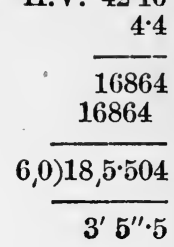

$$
\begin{aligned}
& \cdot 307^{8} \\
& 4.4 \\
& 1228 \\
& 1228
\end{aligned}
$$

Obs. alt. $30^{\circ} 57^{\prime} 10^{\prime \prime}$

I.C.

$$
-210^{\prime \prime}
$$

Dip.

$\begin{array}{lll}30 & 55 & 0\end{array}$

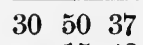

S.D. +1548

$$
\begin{array}{lll}
31 \quad 6 & 25
\end{array}
$$

R. and P. -127

T.A. $31 \quad 4 \quad 58$

Lat. $56 \quad 48 \quad 0$

P.D. $7342 \quad 37$

$$
\text { 2) } \overline{161 \quad 35 \quad 35}
$$

\begin{tabular}{rlll}
\cline { 2 - 4 } half sum & 80 & 47 & 47 \\
remainder & 49 & 42 & 49
\end{tabular}

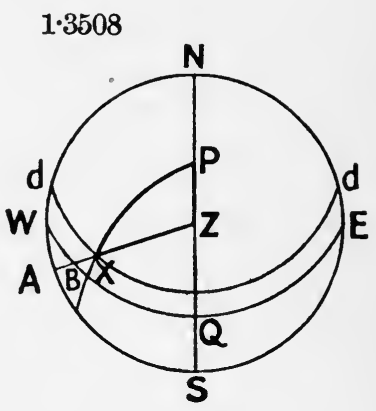

Fia. 136.

$$
\begin{aligned}
\sec & =10 \cdot 261566 \\
\operatorname{cosec} & =10 \cdot 017794
\end{aligned}
$$

$$
\begin{aligned}
& \cos =9 \cdot 203967 \\
& \sin =9 \cdot 882423
\end{aligned}
$$

W.H.A. $3^{\text {h }} 50^{\mathrm{m}} 26^{\mathrm{s}}$ XXXI. $=9 \cdot 365750$

A.T.S., Aug. $8^{\mathrm{d}} 3^{\mathrm{h}} 50^{\mathrm{m}} 26^{\mathrm{s}}$

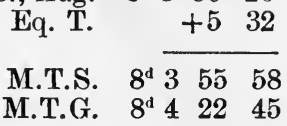

Long. in time

Long.

$$
\begin{aligned}
& 26 \quad 47 \\
& 6^{\circ} 41^{\prime} 45^{\prime \prime} \mathrm{W} \text {. }
\end{aligned}
$$

Construclion of Fig. 136.-Draw circle NESW repr"senting rational horizon, and NZS meridian. Measure $\mathrm{NP}=\mathrm{ZQ}=\tilde{5} 7^{\circ}$ lat.; set off dec. $=16$ to north, and draw EQW for equinoctial, and $d d$ parallel of declination. With centre $\mathrm{Z}$ and radius $=$ zen. dist. $=59^{\circ}$ draw an arc cutting $d d$ in $\mathrm{X}$ for position of sun, draw hour circle PXB, and vertical circle ZXA.

$$
\begin{array}{rr}
\mathrm{ZQ}=\text { lat. } & \mathrm{PZ}=\text { co. lat. } \\
\mathrm{AX}=\text { alt. } & \mathrm{ZX}=\text { zen. dist. } \\
\mathrm{BX}=\text { dec. } & \mathbf{P X}=\text { pol. dist. } \\
\mathrm{ZPX} & =\text { Hour angle. }
\end{array}
$$

To find H.A. from figure. 
In triangle $\mathrm{PZX}$; given $\mathrm{PZ}=$ co-lat., $\mathrm{PX}=$ pol. dist., $\mathrm{ZX}=$ zen. dist. Req. $\mathrm{P}=$ Hour angle.

where $s=\frac{1}{2}(\mathrm{PZ}+\mathrm{ZX}+\mathrm{PX})$.

$$
\operatorname{Cos} \frac{P}{2}=\sqrt{\frac{\sin s \cdot \sin (s-Z X)}{\sin P Z \cdot \sin P X}}
$$

$$
\begin{aligned}
& \mathrm{ZX}=58^{\circ} 55^{\prime} 2^{\prime \prime} \\
& \mathrm{PZ}=33 \quad 12 \quad 0 \quad \operatorname{cosec}=10 \cdot 261566 \\
& \mathrm{PX}=73 \quad 42^{\circ} 37 \quad \text { cosec }=10 \cdot 017794 \\
& \text { 2) } \overline{165 \quad 4939}
\end{aligned}
$$

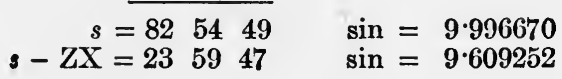

$$
\begin{aligned}
& \frac{\mathrm{P}}{2}=1^{\mathrm{h}} 55^{\mathrm{m}} 13^{\mathrm{s}} \quad \cos =\overline{9.942641} \\
& \text { W.H.A. } \overline{35026}
\end{aligned}
$$

(2) September 1st, about $9^{\text {h }} 15^{\mathrm{m}}$ A.M., in lat. at noon $46^{\circ} 1^{\prime} 30^{\prime \prime}$ S., D.R. long. $27^{\circ} \mathrm{E}$. ; when a chron. showed $7^{\mathrm{h}} 19^{\mathrm{m}} 43^{s}$, and had been found to be fast $3^{\mathrm{m}} 11^{s} \cdot 5$ on May $3 \mathrm{rd}$, and slow $12^{\mathrm{s}}$ on June $27 \mathrm{th}$, the alt. of Sun's L.L. was $24^{\circ} 14^{\prime} 40^{\prime \prime}$; ind. cor., $-3^{\prime} 15^{\prime \prime}$; eye, $29 \mathrm{ft}$. Find long. at sights ; and if run from obs. to noon was $\mathrm{S} .70^{\circ} \mathrm{E}$. 30 miles, find long. at noon.

Approx. time at ship, Aug. $31^{\mathrm{d}} 21^{\mathrm{h}} 15^{\mathrm{m}}$ Long. E. $\quad-148$

. $\quad$, Greenwich $31^{\mathrm{d}} \overline{1927}$
May 3rd, fast $3^{\mathrm{m}} 11^{* 5} 5$ June 27 th, slow 12

Loss in 55 days $\overline{323 \cdot 5}$

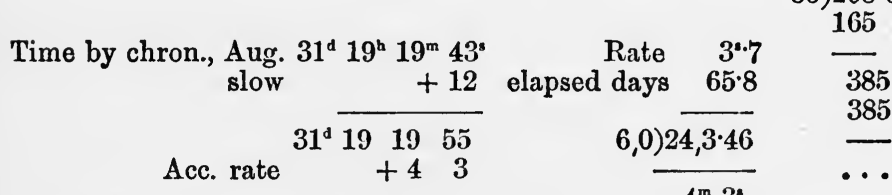
M.T.G. Aug. $\overline{31^{\mathrm{d}} 19} \overline{23 \quad 58}$

55) $203 \cdot 5\left(3^{4 \cdot 7}\right.$

$\begin{array}{rr}\begin{array}{r}\text { Rate } \\ \text { elapsed days }\end{array} & \begin{array}{r}3 \cdot 7 \\ 65 \cdot 8\end{array} \\ \frac{6,0) 24,3 \cdot 46}{385} \\ \frac{4^{\mathrm{m}} 3^{\mathrm{s}}}{385}\end{array}$

S.P.D. $98 \quad 3548$

$$
\begin{gathered}
\text { H.V. } 54 \cdot 19^{\prime \prime} \\
6,0 \frac{4 \cdot 6}{24,9 \cdot 274} \\
\frac{4^{\prime} 9^{\prime \prime}}{}
\end{gathered}
$$$$
\begin{array}{llll}
8 & 35 & 48 \cdot 1 & \mathrm{~N}
\end{array}
$$
90

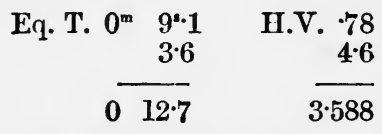

Lat. at noon $46^{\circ} 1^{\prime} 30^{\prime \prime} \mathrm{S}$. S. $70^{\circ}$ E., $30^{\prime}$ D. lat. $\quad 1018 \mathrm{~N}$.

Mid. Lat. $45^{\circ} 56^{\prime} 21^{\prime \prime} \quad$ sec $=10 \cdot 157752$

S. $70^{\circ}$ E., $30^{\prime}=$ dep. $28 \cdot 2 \quad \log =1.450249$

D. long. $40 \cdot 55 \log =1 \cdot 608001$ 
Obs. alt. $24^{\circ} 14^{\prime} 40^{\prime \prime}$

I.C. -315

241125

Dip. $\quad-516$

S.D. $\quad \begin{array}{rr}24 & 6 \\ +15 \quad 53\end{array}$

R. and $P . \quad-1 \quad 59$

T.A. $24 \quad 20 \quad 3$

Lat. $45 \quad 51 \quad 12$

P.D. $98 \quad 3548$

$$
\begin{aligned}
\sec & =10 \cdot 157080 \\
\operatorname{cosec} & =10 \cdot 004907
\end{aligned}
$$

2) $168 \quad 47 \quad 3$

half sum $8423 \quad 31.5 \quad \cos =8.989985$

remainder $\begin{array}{llll}60 & 328.5 & \sin =9.937784\end{array}$

E.H.A. $\overline{2^{\text {h }} 44^{\mathrm{m}} 13^{\mathrm{s}}} \mathrm{XXXI}=\overline{9.089756}$ 24

A.T.S. Aug. $31^{\mathrm{d}} 21^{\mathrm{h}} 15^{\mathrm{m}} 47^{\mathrm{s}}$

Eq. 'T.

$+13$

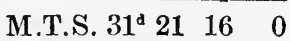

M.T.G. $31^{\text {d }} 19 \quad 23 \quad 58$

$\begin{array}{ll}152 & 2\end{array}$

4)112 2

Long. at obs.

D. long.

$28^{\circ} \overline{0^{\prime} 30^{\prime \prime}} \mathrm{E}$.

$4033 \mathrm{E}$.

Long. at noon $\quad \begin{array}{llll}28 & 41 & 3 & \text { E. }\end{array}$

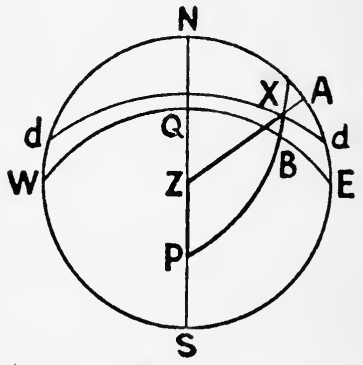

FIG. 137.

To find H.A. from figure.

In triangle $\mathrm{PZX}$, given $\mathrm{PZ}=$ co-lat., $\mathrm{PX}=$ pol. dist., $\mathrm{ZX}=$ zeı. dist. Req. $\mathbf{P}=$ Hour angle.

where $s=\frac{1}{2}(\mathrm{PZ}+\mathrm{ZX}+\mathrm{PX})$.

$$
\operatorname{Cos} \frac{P}{2}=\sqrt{\frac{\sin s \cdot \sin (s-\mathrm{ZX})}{\sin \mathrm{PZ} \cdot \sin \mathrm{PX}}}
$$

$$
\begin{aligned}
& \mathrm{ZX}=65^{\circ} 39^{\prime} 57^{\prime \prime} \\
& \mathrm{PZ}^{\prime}=\begin{array}{lrl}
44 & 848 \quad \operatorname{cosec}=10 \cdot 157080
\end{array} \\
& \mathrm{PX}=983548 \quad \operatorname{cosec}=10.004907 \\
& \text { 2) } 208 \quad 24 \quad 33 \\
& s=1041216.5 \quad \sin =9 \cdot 986515 \\
& s-\mathrm{ZX}=\cdot 383219 \cdot 5 \quad \text { sin }=9 \cdot 794518 \\
& \text { 2) } 19 \cdot 943020 \\
& \frac{\mathrm{P}}{2}=1^{\mathrm{h}} 22^{\mathrm{m}} 6^{\mathrm{s}} \cdot 5 \quad \cos =\overline{9 \cdot 971510}
\end{aligned}
$$


In Fig. 137, drawn as hefore explained.

$$
\begin{array}{ll}
\mathrm{ZQ}=\text { lat. } & \mathrm{PZ}=\text { co. lat. } \\
\mathrm{AX}=\text { alt. } & \mathrm{ZX}=\text { zen. dist. } \\
\mathrm{BX}=\text { dec. } & \mathrm{PX}=\text { pol. dist. } \\
\mathrm{ZIX}= & \text { Hour angle }
\end{array}
$$

Exercises.

1. August 4th, about $8^{\mathrm{k}} 40^{\mathrm{m}}$ A.M., in lat. at noon $38^{\circ} 15^{\prime}$ S., D.R. long. $92^{\circ}$ E. ; when a chron. showed $1^{\mathrm{b}} 15^{\mathrm{m}} 5^{\mathrm{s}}$, which had been found slow $1^{\mathrm{b}} 17^{\mathrm{m}} 9^{\mathrm{s}}$ on June 20th for G.M. noon, and slow $1^{\mathrm{h}} 18^{\mathrm{m}} 57^{\mathrm{a}}$ on July 5th, the obs. alt. of the Sun's L.L. was $16^{\circ} 42^{\prime} 10^{\prime \prime}$; ind.cor., $+2^{\prime} 15^{\prime \prime}$; eye, $29 \mathrm{ft}$. Find long. at obs. ; and if run since obs. was N. $24^{\circ}$, E. 35 miles, find long. at noon.

2. August 19 th, about $4^{\mathrm{h}} 30^{\mathrm{m}}$ P. M., in lat. at noon $42^{\circ} 3^{\prime}$ N., D. R. long. $70^{\circ}$ W.; when a chron. showed $8^{\mathrm{h}} 58^{\mathrm{m}} 5^{\mathrm{s}}$, which had been found slow $15^{\mathrm{m}} 8^{\mathrm{s}} \cdot 3$ on June 27th for G.M. noon, and slow $14^{\mathrm{m}} 22^{\mathrm{s}} \cdot 7$ on July 12th, the obs. alt. of the Sun's U.L. was $26^{\circ} 32^{\prime} 40^{\prime \prime}$; ind. cor., $-2^{\prime} 7^{\prime \prime}$; eye, $34 \mathrm{ft}$., run since noon, S. $32^{\circ}$ E. 46 miles. Find long. at obs. and noon.

3. August 31st, about $9^{\mathrm{h}} 20^{\mathrm{m}}$ A.M., in lat. at noon $52^{\circ} 36^{\prime}$ N., D.R. long. $3^{\circ} 15^{\prime}$ IV.; when a chron. showed $9^{\mathrm{h}} 47^{\mathrm{m}} 53^{\mathrm{s}}$, which had been found fast $12^{\mathrm{m}} 18^{\mathrm{s}} .8$ on August 1st for G.M. noon, and fast $12^{\mathrm{m}} 14^{\mathrm{s}}$ on August 7 th, the obs. alt. of the Sun's U.L. was $36^{\circ} 26^{\prime} 10^{\prime \prime}$; ind. cor., $-26^{\prime \prime}$; eye, $41 \mathrm{ft}$., run since obs. N. $64^{\circ}$ W. 25 miles. Find long. at obs. and noon.

4. September 1st, about $8^{\text {h }} 40^{\mathrm{m}}$ A.r., in lat. at noon $44^{\circ} 42^{\prime} \mathrm{N}$., long. $11^{\circ}$ W. ; when a chron. showed $9^{\text {h }} 34^{m} 3^{*}$, which was slow $4^{*}$ on April 17 th for G.M. noon, and on June 6th was $4^{\mathrm{m}} 8^{\mathrm{a}}$ fast; run since sights, N.W. $\frac{1}{2} \mathrm{~N} .31$ miles, the obs. alt. of Sun's U.L. was $34^{\circ} 21^{\prime} 30^{\prime \prime}$; ind. cor., $+4^{\prime} 15^{\prime \prime}$; eye, $23 \mathrm{ft}$. Find long. at sts. and noon.

5. September $23 \mathrm{rd}$, about $3^{\mathrm{h}} 38^{\mathrm{m}}$ P. M., lat. at noon $49^{\circ} 40^{\prime}$ S., long. $135^{\circ} \mathrm{E}$. ; ship becalmed ; obs. alt. of Sun's U.L. $22^{\circ} 18^{\prime} 50^{\prime \prime}$; eye, $20 \mathrm{ft}$. ; time by chron., $6^{\mathrm{b}} 27^{\mathrm{m}} 28^{\mathrm{a}}$, which was slow for G.M. noon on July 10 th $2^{\mathrm{m}} 10^{\mathrm{s}}$, and has since kept mean time ; course and distance since obs., nil. Find long. at obs. and noon.

6. September 30 th, about $3^{\mathrm{h}} 30^{\mathrm{m}}$ P.M., lat. at noon $49^{\circ} 30^{\prime} 12^{\prime \prime}$ S., long. $180^{\circ}$ E., the obs. alt. of Sun's L.L. was $25^{\circ} 3^{\prime} 20^{\prime \prime}$; ind. cor., $+3^{\prime} 14^{\prime \prime}$; eye, $37 \mathrm{ft}$. ; time by chron., $3^{\mathrm{h}} 54^{\mathrm{m}} 7^{\mathrm{s}}$, which had been found $8^{\mathrm{m}} 16^{\mathrm{s}} \cdot 4$ fast on May 6th, and fast $20^{\mathrm{m}} 24^{\mathrm{s}} 4$ on July 15 th for G.M. noon ; run since noon, S. $73^{\circ} \frac{1}{2}$ W. 24 miles. Find long. at obs. and noon.

AR'r. 86.-Rules for Longitude by Star Chronometers :-

(1) Find G.M.T. as before.

(2) Take out star's R.A. and Dec., find pol. dist., and correct altitude, and R.A.M.S. (sidereal time).

(3) Find H.A. as before.

(4) If H.A. is west, add H.A. to R.A. of star for R.A.M. If H.A. is east, subtract H.A. from R.A. of star for R.A.M. From the R.A.M. subtract the R.A.M.S., this gives the M.T.S., which is of same date as question if P.M. at ship, and the day before date of question if A.M. at ship.

(5) Finish as before for longitude.

Example.-August 1st, about $2^{\mathrm{h}} 39^{\mathrm{m}}$ A.Mr. at ship, in lat. $30^{\circ} 26^{\prime}$ N., long. $133^{\circ} \mathrm{E}$. by D.R. ; the obs. alt. of Vega was $33^{\circ} 38^{\prime} \tilde{50} 0^{\prime \prime}$; time by chron., $4^{\mathrm{h}} 41^{\mathrm{m}} 58^{\mathrm{a}}$, which was slow $1^{\mathrm{h}} 2^{\mathrm{m}} 53^{\mathrm{n}}$ of G.M. noon on June 26th, and losing $0^{\prime \prime} \cdot 4$ daily ; ind. cor., $-2^{\prime} 29^{\prime \prime}$; eye, $23 \mathrm{ft}$. Find the long.

Approx. ship time July $31^{\mathrm{d}} 14^{\mathrm{h}} 39^{\mathrm{m}}$

$$
\text { Long. E. }-852
$$

" Greenwich time July $31^{\mathrm{d}} 5 \mathbf{5} \quad 47$

Elapsed time $35 \cdot 2$

rate $\cdot 4$

$14 \cdot 08$ 
Time by chron., July $31^{\mathrm{d}} 4^{\mathrm{h}} 41^{\mathrm{m}} 58^{\mathrm{s}}$ slow +1253

Acc. loss

$31^{\mathrm{d}} 5 \quad 44 \quad 51$

M.T.G. $31^{\mathrm{d}} \overline{5} \quad \overline{45} \overline{5}$

R A. Vega $18^{\mathrm{h}} 33^{\mathrm{m}} 45^{\mathrm{s} \cdot 4}$
R.A.M.S. $8^{\mathrm{h}} 36^{\mathrm{m}} 44^{\mathrm{e}} \cdot 2$ for Aug. 1st. Cor. $\quad-2 \quad 59.9$

$8 \quad 23 \quad 44 \cdot 3$

Dec. $38^{\circ} 41^{\prime} 45^{\prime \prime} \mathrm{N}$. 90

N.P.D. $51 \quad 18 \quad 15$

In Fig. 138, constructed as before.

$$
\begin{array}{ll}
\mathrm{ZQ}=\text { lat. } & \mathrm{PZ}=\text { co. lat. } \\
\mathrm{AX}=\text { alt. } & \mathrm{ZX}=\text { zen. dist. } \\
\mathrm{BX}=\text { dec. } & \mathrm{PX}=\text { pol. dist. } \\
\mathrm{ZPX}= & \text { Hour angle. } \\
\mathrm{SZX}=\text { Azimuth. }
\end{array}
$$

Obs. alt. ${ }^{*} 33^{\circ} 38^{\prime} 50^{\prime \prime}$

I.C. $\quad-229$

$$
33 \quad 3621
$$

Dip. $\quad-442$

$$
33 \quad 3139
$$

\begin{tabular}{|c|c|}
\hline $\begin{array}{l}\text { half sum } \\
\text { remainder }\end{array}$ & $\begin{array}{rrr}57 & 37 & 14 \\
24 & 7 & 1\end{array}$ \\
\hline $\begin{array}{c}\text { W.H A.* } \\
\text { R.A.* }\end{array}$ & $\begin{array}{ccc}4^{\mathrm{h}} & 38^{\mathrm{m}} & 8^{\mathrm{s}} \\
18 & 33 & 45\end{array}$ \\
\hline $\begin{array}{l}\text { R.A.M. } \\
\text { R.A.M.S. }\end{array}$ & $\begin{array}{rrr}23 & 11 & 53 \\
8 & 33 & 44\end{array}$ \\
\hline \multirow[t]{3}{*}{$\begin{array}{l}\text { M.T.S. } 31^{\mathrm{d}} \\
\text { M.T.G. } 31^{\mathrm{d}}\end{array}$} & $\begin{array}{rl}14 & 38 \\
5 & 45\end{array}$ \\
\hline & $\begin{array}{l}853 \\
60\end{array}$ \\
\hline & 4)5ั53 4 \\
\hline
\end{tabular}

Ref. $\quad-126$

T.A. $\begin{array}{lll}33 & 30 & 13\end{array}$

Lat. $30 \quad 26 \quad 0$

P.D. $51 \quad 1815$

$$
\begin{aligned}
\text { sec } & =10 \cdot 064382 \\
\operatorname{cosec} & =10 \cdot 107641
\end{aligned}
$$

2)115 1428

$\cos =9 \cdot 728778$

$\sin =9 \cdot 611299$

XXXI. $=\overline{9.512100}$

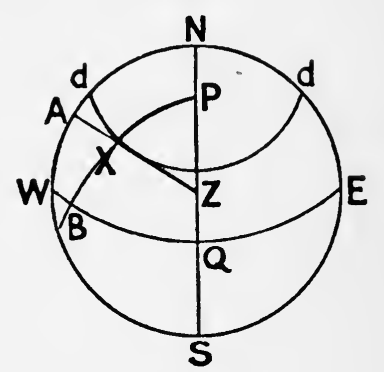

Fig. 138.

To find H.A. from figure.

In triangle $\mathrm{PZX}, \mathrm{X}$ is object, $\mathrm{PZ}=$ co-lat., $\mathrm{PX}=$ pol. dist., $\mathrm{ZX}=$ zen. dist. Req. $\mathbf{P}=$ Hour angle.

$$
\operatorname{Cos} \frac{P}{2}=\sqrt{\frac{\sin s \cdot \sin (s-\mathrm{ZX})}{\sin \mathrm{PZ} \cdot \sin \mathrm{PX}}}
$$

where $s=\frac{1}{2}(\mathrm{ZX}+\mathrm{PZ}+\mathrm{ZX})$. 


$$
\begin{aligned}
& Z X=56^{\circ} 29^{\prime} 47^{\prime \prime} \\
& \mathrm{PZ}=5934 \quad 0 \quad \operatorname{cosec}=10.064382 \\
& \mathrm{PX}=\begin{array}{lllll}
51 & 18 & 15 & \operatorname{cosec}=10 \cdot 107641
\end{array} \\
& \text { 2)167 } 22 \quad 2
\end{aligned}
$$

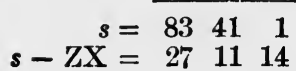

$$
\begin{aligned}
& \sin =9 \cdot 997355 \\
& \sin =\mathbf{9} \cdot 659820 \\
& \text { 2) } 19 \cdot 829198 \\
& \frac{\mathrm{P}}{2}=2^{\mathrm{h}} 19^{\mathrm{m}} 4^{\mathrm{s}} \\
& \text { W.H.A.* } 4388
\end{aligned}
$$

\section{Exercishes.}

1. September 10th, about $4^{\text {n }} 30^{\mathrm{m}}$ A.M., in lat. $35^{\circ} 47^{\prime} 30^{\prime \prime}$ S., long. D.R. $111^{\circ} \mathrm{E}$.; the obs. alt. of Achernar west of meridian was $59^{\circ} 28^{\prime} 40^{\prime \prime}$; ind. cor., $+2^{\prime} 12^{\prime \prime}$; eye, $35 \mathrm{ft}$. ; when a chron. showed $9^{\mathrm{h}} 7^{\mathrm{m}} 12^{\circ}$, which had been found fast $1^{\mathrm{m}} 3^{3}$ on May 12th of G.M. noon, and on August 20th was slow $40^{\circ}$. Find the long.

2. August 24th, about $4^{\text {h }} 40^{\mathrm{m}}$ A.M., in lat. $10^{\circ} 14^{\prime} 20^{\prime \prime}$ N., long. D.R. $75^{\circ}$ W.; the obs. alt. of Canopus east of the meridian was $12^{\circ} 15^{\prime} 40^{\prime \prime}$; ind. cor., $-3^{\prime} 13^{\prime \prime}$; height of eye, $48 \mathrm{ft}$; ; time shown by chron., $9^{\mathrm{h}} 21^{\mathrm{m}} 52^{\mathrm{s}}$, which had been found slow of G.M. noon $17^{\mathrm{m}} 52^{\mathrm{s} .7}$ on July 13th, and on July 31st was slow $17^{\mathrm{m}} 4^{\mathrm{s}} \cdot 1$. Find the long.

3. August 1st, P.M. at ship, in lat. $24^{\circ} 19^{\prime}$ S., long. by acct. $14^{\circ} 30^{\prime}$ E. ; when a chron. showed $8^{\mathrm{h}} 15^{\mathrm{m}} 4^{\prime}$, which had been found fast $28^{\mathrm{m}} 19^{\circ}$ on June 24th, and losing $1^{*} \cdot 2$ daily; the obs. alt. of Altair east of the meridian was $42^{\circ} 5^{\prime} 30^{\prime \prime}$; ind. cor., $+3^{\prime} 54^{\prime \prime}$; height of eye, $42 \mathrm{ft}$. Required the long.

4. September 11th, P.M. at ship, in lat. equator, long. of Greenwich; the obs. alt. of Vega west of the meridian was $26^{\circ} 18^{\prime}$; ind. cor., $-1^{\prime} 55^{\prime \prime}$; eye, $31 \mathrm{ft}$.; when a chron. showed $11^{\mathrm{b}} 10^{\mathrm{m}} 54^{\mathrm{*}}$, which had been found $12^{\mathrm{m}} 29^{\circ}$ fast of G.M. noon on July 15th, and on August 9th was $13^{\mathrm{m}} 29^{\circ}$ fast. Find the long.

5. September 21st, about $1^{\mathrm{h}} 30^{\mathrm{m}}$ A.M., in lat. $20^{\circ} 30^{\prime} \mathrm{N}$., long. by acct. $31^{\circ} \mathrm{W}$.; the obs. alt. of Capella east of meridian was $37^{\circ} 14^{\prime} 30^{\prime \prime}$; ind. cor., $+3^{\prime} 49^{\prime \prime}$; eye, $19 \mathrm{ft}$; ; when a chron. showed $3^{\mathrm{h}} 21^{\mathrm{m}} 26^{\circ}$, which had been found $3^{\text {s }}$ fast of G.M. noon on August 7th, and on August 31st was $3^{\mathrm{m}} 21^{\text {* }}$ slow. Find the long.

6. August 24 th, about $1^{\text {h }} 15^{\mathrm{m}}$ A.M., in lat. $18^{\circ} 12^{\prime} 30^{\prime \prime}$ N., long. D.R. $91^{\circ} \mathrm{E}$. ; when a chron. showed $9^{\mathrm{b}} 24^{\mathrm{m}} 17^{\circ}$, which had been found fast $11^{\mathrm{m}} 43^{\circ} \cdot 8$ on June 4th for G.M. noon, and on July 12th was fast $12^{\mathrm{m}} 18^{\mathrm{A}}$; the obs. alt. of Rigel east of meridian was $27^{\circ} 26^{\prime}$; ind. cor., $-3^{\prime} 5^{\prime \prime}$; eye, $46 \mathrm{ft}$. Find the long.

7. September 8th, about $5^{\text {h }}$ A.M., in lat. $43^{\circ} 24^{\prime}$ S., long. by acct. $110^{\circ} 45^{\prime}$ E. ; when a chron. showed $9^{\mathrm{h}} 41^{\mathrm{m}} 51^{\mathrm{O}}$, which had been found fast of G.M. noon $28 \cdot 8$ on August 23rd, and on August 31st showed G.M.T.; the obs. alt. of Procyon was $22^{\circ} 48^{\prime} 50^{\prime \prime}$; ind. cor., $+54^{\prime \prime}$; height of eye, $30 \mathrm{ft}$. Find the long.

8. August 30th, about $10^{\mathrm{h}}$ P.M., in lat. $35^{\circ} 15^{\prime}$ N., long. D.R. $169^{\circ} 30^{\prime}$ W.; when a chron. showed $9^{\mathrm{b}} 12^{\mathrm{m}} 34^{\circ}$, which had been found slow of G.M. noon on June 14th $6^{\mathrm{m}} 54^{\cdot \cdot 1}$, and on July 25 th was correct; the obs. alt. of Fomalhaut was $15^{\circ} 54^{\prime} 10^{\prime \prime}$; ind. cor., $-1^{\prime} 26^{\prime \prime}$; eye, $25 \mathrm{ft}$. Find the long.

9. September 2 nd, about $10^{\mathrm{h}} 15^{\mathrm{m}}$ P.M., in lat. $15^{\circ} 14^{\prime}$ S., long. D.R. $50^{\circ} \mathrm{E}$.; when a chron. showed $6^{\mathrm{h}} 50^{\mathrm{m}} 41^{\text {; }}$, which had been found correct for G.M. 
noon on July 4th, and on August 18 th was slow $3^{\mathrm{m}} 9^{\prime}$; the obs. alt. of Antares was $25^{\circ} 21^{\prime}$; no ind. cor.; eye, $27 \mathrm{ft}$. Find the long.

10. August 14 th, about $2^{\mathrm{h}}$ A.M., in lat. $40^{\circ} 27^{\prime} 15^{\prime \prime} \mathrm{N}$., long. by acct. $180^{\circ}$ W.; the obs. alt. of Aldebaran was $22^{\circ} 8^{\prime}$; ind. cor., $-22^{\prime \prime}$; eye, $38 \mathrm{ft}$.; when a chron. showed $2^{\mathrm{h}} 7^{\mathrm{m}} 58^{\mathrm{s}}$, which had been found slow $2^{\mathrm{m}} 33^{\mathrm{s}} \cdot 6$ on June 25 th, and on Aug. 4th was $4^{\mathrm{m}} 10^{\circ}$ fast. Find the long.

11. August 28th, P.M. at ship, in lat. by mer. alt. of a Ophiuchi in the art. horizon on shore, $15^{\circ} 55^{\prime} \mathrm{S}$., long. by cross-bearings $4^{\circ} 45^{\prime} \mathrm{W}$.; the obs. alt. of Arcturus west of the meridian was $35^{\circ}$; ind. cor., $-4^{\prime}$; height of eye, $15 \mathrm{ft}$.; time by chron., $5^{\mathrm{h}} 58^{\mathrm{m}} 9^{\mathrm{s}}$, which had been found slow of G.M. noon $1^{\mathrm{h}} 10^{\mathrm{m}} 15^{\mathrm{s}}$ on June 29th, and slow $1^{\mathrm{h}} 3^{\mathrm{m}} 33^{\mathrm{s}}$ on Aug. 8th. Find the long.

12. September $28 \mathrm{th}$, about 6 P. M., in lat. $50^{\circ} 17^{\prime} \mathrm{N}$. by mer. alt. of Vega, long. D.R. $161^{\circ}$ E. ; the obs. alt. of $\alpha$ Cygni was $68^{\circ} 30^{\prime}$; eye, $22 \mathrm{ft}$.; time by chron., $7^{\text {h }} 25^{\text {nn }} 21^{*} \cdot 2$, which was slow $2^{*} \cdot 4$ of G.M. noon on June 29 th, and fast $25^{8} \cdot 6$ on August 3rd. Find the long.

ART. 87. Longitude and Azimuth.-As the data used in the computation of Apparent Time at Ship and the Azimuth are the same, and 'the Formulæ very similar, it is most convenient to find the Azimuth at the same time as the longitude by chronometer.

\section{Example.-}

Using data as in star chronometer example (Fig. 138), the logs may be conveniently arranged for chron. az. as follows :-

True alt. $33^{\circ} 30^{\prime} 13^{\prime \prime}$ Lat. 30260 P.D. 511815

2) 1151428

573714

Chron. remdr. $24 \quad 7 \quad 1$

Az. remdr. $\quad 6 \quad 18 \quad 59$

W.H.A. $\overline{4^{\mathrm{h}} 38^{\mathrm{m}} 8^{\mathrm{a}}}$

$$
\begin{aligned}
\sec & =10 \cdot 064382 \\
\operatorname{cosec} & =10 \cdot 107641
\end{aligned}
$$

$$
\text { sec }=10 \cdot 078911
$$$$
\text { sec }=10.064382
$$

$$
\begin{array}{rlr}
\cos = & 9.728778 & \cos =9.728778 \\
\sin = & 9.611299 & \cos =9.997355 \\
\text { XXXI. }= & 9.512100 & 2) 19.869426 \\
& 59^{\circ} 21^{\prime} 52^{\prime \prime} & \sin =-\frac{9.934713}{2}
\end{array}
$$

True az. S. $\overline{1184344}$ W.

\section{Exercises.}

1. August 31st, about $5^{\text {h }}$ P.M., at ship in lat. at noon $0^{\circ} 21^{\prime}$ S., long. D.R $136^{\circ} \mathrm{W}$.; the obs. alt. of the Sun's L.L. was $13^{\circ} 13^{\prime} 40^{\prime \prime}$; ind. cor., + $7^{\prime} 21^{\prime \prime}$; eye, $17 \mathrm{ft}$.; bearing by compass W. $\frac{1}{4} \mathrm{~N}$.; time shown by chron., $2^{\mathrm{h}} 5^{\mathrm{m}} 44^{\mathrm{s}}$, which was slow $25^{\mathrm{m}} 19^{\mathrm{a}}$ on April 1.2th for G.M. noon, and on July 1st was $11^{\mathrm{m}} 55^{\mathrm{s}}$ slow. Find the long. at sights and noon, if the run since noon was N.E., 58 miles. Also find true azimuth, comp. error, and dev., the var. being $5^{\circ} 40^{\prime} \mathrm{E}$.

2. October 1st, about $7^{\text {h }} 15^{\mathrm{m}}$ A.M. at ship, in lat. $39^{\circ} 30^{\prime}$ S., long. by acct. $17^{\circ} \mathrm{W}$.; the obs. alt. of the Sun's L.L. was $16^{\circ} 40^{\prime} 30^{\prime \prime}$; ind. cor., + $6^{\prime} 12^{\prime \prime}$; 
eye, $20 \mathrm{ft}$; ; bearing by compass S.E. by E. $\frac{1}{4} \mathrm{E}$. ; time by chron., $8^{\mathrm{h}} 22^{\mathrm{m}} 40^{\circ} \cdot 4$, which had been found fast $1^{\mathrm{m}} 41^{*} \cdot 1$ for G.M. noon on March 30th, and on June 1st was $2^{\mathrm{m}} 25^{\cdot} \cdot 2$ fast. Find the long., true bearing, and dev., the var. being $12^{\circ} 15^{\prime} \mathrm{W}$.

3. September 1st, about $3^{\mathrm{h}} 30^{\mathrm{m}}$ P.M. at ship, in lat. at noon $51^{\circ} \mathrm{S}$., long. D.R. $175^{\circ}$ E. ; the obs. alt. of the Sun's L.L. was $14^{\circ} 52^{\prime} 20^{\prime \prime}$; ind. cor., $-7^{\prime}$ $10^{\prime \prime}$; eye, $15 \mathrm{ft}$. ; bearing by compass $\mathrm{N} .50^{\circ} 30^{\prime} \mathrm{W}$.; time shown by chron., $3^{\mathrm{h}} 44^{\mathrm{m}} 40^{\mathrm{s}}$, which had been found $13^{\mathrm{m}} 0^{\mathrm{s}} \cdot 3$ slow for G.M. noon on February $15 \mathrm{th}$, and on August 1st was $10^{\mathrm{m}} 30^{\circ}$ slow. Find long. at sights and noon, the run since noon being S.W. by W. $\frac{1}{2}$ W. 53 miles. Also find true bearing, comp. error, and dev., the var. being $16^{\circ} 10^{\prime} \mathrm{E}$.

4. September $23 \mathrm{rd}$, about $7^{\mathbf{h}}$ A.M. at ship, in lat. at noon $32^{\circ} \mathrm{S}$., long. D.R. $55^{\circ}$ E. ; the obs. alt. of the Sun's L.L. was $10^{\circ} 36^{\prime}$; ind. cor., $-2^{\prime} 10^{\prime \prime}$; eye, $19 \mathrm{ft}$. ; bearing by compass East; time shown by chron., $3^{\mathrm{b}} 0^{\mathrm{m}} 35^{\mathrm{c}}$, which had been found $5^{\mathrm{m}} 45^{\mathrm{A}} \cdot 5$ slow for G.M. noon on March 31st, and or. June 14th was slow $4^{\mathrm{m}} 45^{\circ} \cdot 5$; run since sights, N. $59^{\circ}$ W. 58 miles. Find long. at sights and noon. The var. from chart being $15^{\circ} 40^{\prime} \mathrm{W}$., find true bearing, comp. error, and dev.

5. September 1st, about $1^{\text {h }}$ P.M. at ship, in lat. $11^{\circ} 34^{\prime} 20^{\prime \prime}$ S., long. D.R. $144^{\circ}$ E. ; the obs. alt. of the Sun's L.L. was $65^{\circ} 2^{\prime}$; ind. cor., $-7^{\prime} 17^{\prime \prime}$; eye, $27 \mathrm{ft}$; ; bearing by compass $N_{.} 40^{\circ}$ W. ; time shown by chron., $2^{\mathrm{h}} 32^{\mathrm{m}} 48^{\mathrm{s}}$, which had been found slow $1^{\mathrm{h}} 0^{\mathrm{m}} 1^{\circ}$ for G.M. noon on April 1st, and on May 1st was $58^{\mathrm{m}} 40^{\prime \prime}$ slow. Find the long. and the var. being $5^{\circ} 45^{\prime}$ E., find comp. error and dev.

6. September 22 nd, about $8^{\mathrm{h}} 50^{\mathrm{m}}$ A.M., when the chron. showed $0^{\mathrm{s}} 20^{\mathrm{m}} 32^{\mathrm{s}}$; the obs. alt. of the Sun's U.L. was $30^{\circ} 59^{\prime} 30^{\prime \prime}$; ind. cor., $2^{\prime} 5^{\prime \prime}$ off the arc ; height of eye, $30 \mathrm{ft}$. ; bearing by compass S.E. $\frac{1}{4}$ E.; var., $11^{\circ} 30^{\prime} \mathrm{W}$.; lat. at obs., $42^{\circ} 16^{\prime} \mathrm{N}$.; long. by acct., $70^{\circ} 40^{\prime} \mathrm{W}$.; on June 16 th the chron. was slow $1^{\mathrm{h}} 14^{\mathrm{m}} 30^{\mathrm{a}}$ for G.M. noon, and on August 5th it was $1^{\mathrm{h}} 11^{\mathrm{m}} 8^{\mathrm{a}}$ slow. Required long., true azimuth, and dev.

7. September 23rd, about $1^{\mathrm{b}} 45^{\mathrm{m}}$ P.M., lat. at noon, $40^{\circ} 18^{\prime} \mathrm{S}$.; the obs. alt. of the Sun's L.L. was $42^{\circ} 55^{\prime} 40^{\prime \prime}$; eye, $7 \mathrm{ft}$.; long by acct., $148^{\circ} \mathrm{E}$.; time by chron., $3^{\mathrm{h}} 53^{\mathrm{m}} 29^{\mathrm{s}}$, which had been found fast $16^{\mathrm{m}} 20^{\circ}$ for G.M. noon on May 4th, and on August 2nd was $10^{\mathrm{m}} 47^{\circ}$ fast ; run from noon to obs., W.N.W. 21 miles ; the sun's comp. bearing was N.W., and the var. $10^{\circ} 45^{\prime} \mathrm{E}$. Find the long., true bearing, and dev. for the direction of the ship's head.

8. August 5th, about $2^{\mathrm{h}} 30^{\mathrm{m}}$ P.M., in lat. at noon $30^{\circ} 4^{\prime} 45^{\prime \prime}$ S., long. by acct. $94^{\circ}$ E. ; the obs. alt. of the Sun's U.L. was $31^{\circ} 32^{\prime}$; ind. cor., $-4^{\prime} 44^{\prime \prime}$; height of eye, $19 \mathrm{ft}$; ; bearing by compass, N.W. $\frac{1}{2} \mathrm{~N}$.; the chron. showed $8^{\mathrm{h}} 19^{\mathrm{m}} 41^{\mathrm{s}}$, and had been found to be fast of G.M.T. on May $23 \mathrm{rd} 7^{\mathrm{m}} 33^{\mathrm{s}}$, and losing daily $21^{\circ}$. Find the long. at sights and noon; and if the var. from chart was $14^{\circ} 20^{\prime} \mathrm{W}$., find true azimuth and dev. for the direction of the ship's head. Run since noon, S. $40^{\circ}$ E. 30 miles.

9. September 1st, about $4^{\mathrm{b}}$ P.M., in lat. $2^{\circ} 10^{\prime}$ N., long. D.R. $55^{\circ} 45^{\prime}$ E. ; the chron. showed $10^{\mathrm{h}} 57^{\mathrm{m}} 5^{\prime \prime}$; the obs. alt. of the Sun's U.L. was $29^{\circ} 11^{\prime} 40^{\prime \prime}$; ind. cor., $-50^{\prime \prime}$; eye, $22 \mathrm{ft}$. ; bearing by compass N. $88^{\circ} 30^{\prime} \mathrm{W}$.; on March 24 th the chron. was slow of G.M.T. $56^{m} 34^{\circ}$, and on May 4 th it was slow $1^{\mathrm{h}} 3^{\mathrm{m}} 27^{\circ}$. Find the long., true azimuth, and dev., the var. being $4^{\circ} 15^{\prime} \mathrm{W}$.

10. September 1st, about $4^{\mathrm{h}} 45^{\mathrm{m}}$ P.M., in lat. at noon $0^{\circ} 36^{\prime}$ N.; long. D.R. $93^{\circ} \mathrm{W}$.; the obs. alt. of the Sun's L.L. was $18^{\circ} 3^{\prime}$; height of eye, $32 \mathrm{ft}$. ; ind. cor., $-3^{\prime} 27^{\prime \prime}$; bearing by compass S. $87^{\circ} 15^{\prime}$ W. ; the chron. showed $10^{\mathrm{h}} 57^{\mathrm{m}}$ $27^{\circ}$, and had been found correct for M.T.G. on June 30th, and slow $4^{\mathrm{m}} 50^{\mathrm{a}}$ on July 27 th ; run from noon to obs., S. $35^{\circ} \mathrm{W}$. 44 miles. Find the long. at sights and noon; also if the var. is $2^{\circ} 30^{\prime} \mathrm{E}$., find true azimuth and dev.

11. August $20 \mathrm{th}$, about $8^{\mathrm{h}} 20^{\mathrm{m}}$ A.M., in lat. at noon $12^{\circ} 31^{\prime} \mathrm{S}$., long. by acct. $168^{\circ} \mathrm{W}$., when a chron. showed $7^{\mathrm{h}} 19^{\mathrm{m}} 19^{\mathrm{s}}$, which had been found $18^{\mathrm{m}} 19^{\mathrm{a}}$ slow for G.M. noon on June 8th, and gaining daily $9^{\circ}$; the obs. alt. of the Sun's L.L. was $29^{\circ} 46^{\prime} 10^{\prime \prime}$; ind. ccr., $-2^{\prime} 22^{\prime \prime}$; eye, $45 \mathrm{ft}$.; run since obs., 
S. $62^{\circ}$ W. 34 miles ; Sun's comp. bearing was N. $68^{\circ} 30^{\prime}$ E.; var., $9^{\circ} 15^{\prime} \mathrm{E}$. Find long. at obs. and noon, true azimuth, and dev.

12. September $23 r$ P.M., in lat. at noon $8^{\circ} 44^{\prime} \mathrm{N}$., long. by acct. $174^{\circ} \mathrm{W}$.; the obs. alt. of the Sun's U.L. was $53^{\circ} 29^{\prime} 20^{\prime \prime}$; ind. cor., $-3^{\prime} 19^{\prime \prime}$; eye, $41 \mathrm{ft}$.; bearing by compass|W. by S. $\frac{3}{4}$ S.; var., $8^{\circ} 40^{\prime}$ E. ; time by chron., $1^{\mathrm{h}} 47^{\mathrm{m}} 27^{\mathrm{s}}$, which had been found $1^{\mathrm{m}} 58^{\circ}$ slow for G.M. noon on August 18th, and losing daily $1^{\circ \cdot 1}$; run from noon to obs., N. $28^{\circ}$ E. 26 miles. Find long. at sights and noon, true azimuth, and dev. 


\section{CHAPTER XVIII.}

\section{SUMNER'S METHOD BY PROJECTION.}

ART. 88.-At any given moment the Sun is vertical over some place on the Earth's surface, and if a circle be drawn with this point as the centre, the Sun would have the same altitude from all points on the circumference of this circle.

Advantage is taken of this fact to find the Ship's Position by Projection on a chart.

Two points on the circumference of the circle can be found from the Sun's altitude, and two assumed latitudes; the projection on the chart of the arc of the circle of equal altitudes passing through these two positions would pass through the actual position of the ship.

After an interval of time another altitude is observed, and with the same assumed latitudes, two other points on a new circle of position are found, and projected on the chart in the same way. The intersection of the two projected lines gives the ship's position.

In practice, the longitudes computed are marked on Mercator's Chart on the parallels of assumed latitudes, and connected by straight lines called Lines of Position. The point of intersection of these lines gives the latitude and longitude of the ship.

The Sun's true bearing is at right angles to the line of position at each observation - towards the east if A.M., and towards the west if P.M.

If the ship changes place during the interval, the first line of position has to be moved (parallel to itself) according to the course and distance sailed.

Thus in figure, NESW is plane of observer's horizon, NZS the celestial meridian, $\mathrm{X}$ the position of object at first observation, and $\mathrm{Y}$ its position at second observation; $\mathrm{Z}$ the zenith, $\mathrm{ZX}$ and $\mathrm{ZY}$ the zenith distances of object. With $\mathrm{X}$ as centre and $\mathrm{XZ}$ as radius, describe a circle. This will be a circle of position for first observation, because the zenith of all places having the object at $\mathrm{X}$ would be situated on its circumference. Similarly, with $\mathrm{Y}$ as centre and $\mathrm{YZ}$ as radius, draw a second circle of 
position cutting the first in the points $\mathrm{Z}$ and $\mathrm{C}$. Hence either $\mathrm{Z}$ or $\mathrm{C}$ is the position of the observer. With suitably selected observations, these points are so wide apart that the true one may be chosen by comparison with the latitude by account. The lines ZXA, ZYB are portions of vertical circles, showing the bearings of the objects, and are seen to cut the circumferences of the circles of position at right angles, hence the bearing of the object is always at right angles to the line of position, which is a tangent to the circle of position at $Z$.

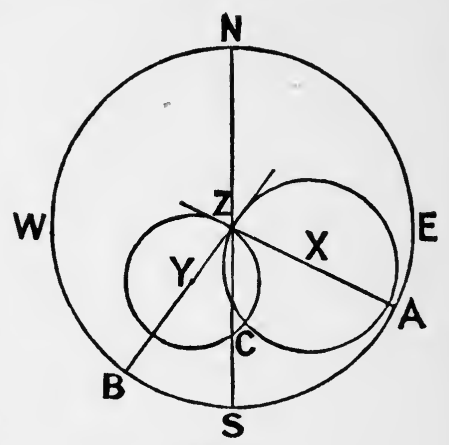

Fig. 139.

ART. 89. Rules for working Sumner problem-

(1) Find G.M.T.'s.

(2) Find correct declination for each time, and polar distances, correct observed altitudes.

(3) With the first altitude and polar distance, using the two assumed latitudes, work as in chronometer problem for two-hour angles, and hence two longitudes. These when projected on the chart and joined would give the first line of position.

With the second altitude and polar distance, using the two assumed latitudes, find as before two longitudes. These positions are projected on the chart and joined for the second line of position.

The direction of a line of position is taken from the chart, like a course, and may be named in either of the two ways the line trends.

The true bearings are at right angles to the lines of position, and are obtained by subtracting the direction of each line from $90^{\circ}$; and marked towards the east for E.H.A.'s; and towards the west for W.H.A.'s.

The run is laid off from any point of the first line, and where a parallel line to the first line, through the end of the run, cuts the second line is the position of the ship.

\section{Example.-}

August 5th, about $9^{\mathrm{h}} 15^{\mathrm{m}}$ A.M., in long. by account $55^{\circ} 15^{\prime} \mathrm{W}$. ; when a chron. correct for M.T.G. showed $1^{\mathrm{b}} 2^{\mathrm{m}} 21^{\circ}$, the obs. alt of the Sun's L. L. was $44^{\circ} 14^{\prime} 20^{\prime \prime}$; ind. cor., $-2^{\prime} 7^{\prime \prime}$; eye, $30 \mathrm{ft}$.; and again P.M. at ship on the same day, when the chron. showed $7^{\mathrm{h}} 5^{\mathrm{m}} 23^{\mathrm{s}}$, the obs. alt. of the Sun's L.L. was $39^{\circ} 21^{\prime} 25^{\prime \prime}$; run in the interval, S. $\frac{1}{2}$ W. 63 miles. Find the line of position and Sun's true bearing at the first obs., and position of the ship at the second obs. by Sumner's method, by projection, assuming lats. $47^{\circ}$ and $47^{\circ} 45^{\prime} \mathrm{N}$. 
First M.T.G., August $5^{d} 1^{\mathrm{h}} 2^{\mathrm{m}} 21^{\mathrm{s}}$. Second M.T.G., August $5^{\mathrm{d}} 7^{\mathrm{h}} 5^{\mathrm{m}} 23^{\mathrm{s}}$.

Dec. $17^{\circ} 9^{\prime} 52^{\prime \prime} \cdot 4$ N. H.V. $40 \cdot 14$ $41 \cdot 3$

\begin{tabular}{lll}
\hline 17 & 9 & 11 \\
90 & &
\end{tabular}

N.P.D. 725049

Eq. T. $5^{\mathrm{m}} 52^{\mathrm{a}} \cdot 6$

$$
\frac{\cdot 2}{552 \cdot 4}
$$

Obs. alt. $\odot 44^{\circ} 14^{\prime} 20^{\prime \prime}$

$$
\begin{aligned}
& \text { I.C. }-27 \\
& 44 \quad 12 \quad 13 \\
& \text { Dip } \frac{-522}{44 \quad 651} \\
& \text { S.D. }+1548 \\
& 44 \quad 22 \quad 39
\end{aligned}
$$

Cor. $\quad-53$

T.A. 442146

Lat. $\begin{array}{lll}47 & 0 & 0\end{array}$

P.D. $72 \quad 50 \quad 49$

1641235

Sum $\overline{82 \quad 618}$

Remdr. 374430

$$
\begin{array}{rr}
\text { Secs } & 10 \cdot 166217 \\
\text { Cosecs } & \mathbf{1 0} 019760 \\
\text { Cos } & 9 \cdot 137854 \\
\text { Sine } & 9 \cdot 786824 \\
& 9 \cdot 110655
\end{array}
$$

H.A.'s $2^{\mathrm{h}} 48^{\mathrm{m}} 24^{\prime}$ $44^{\circ} 21^{\prime} 46^{\prime \prime}$

$\begin{array}{lll}47 & 45 & 0\end{array}$

$\begin{array}{lll}72 & 50 & 49\end{array}$

$164 \quad 57 \quad 35$

$\begin{array}{lll}82 & 28 \quad 48\end{array}$

$\begin{array}{lll}38 & 7 & 0\end{array}$

$\overline{10 \cdot 172394}$

$10 \cdot 019760$

$\mathbf{9} \cdot 116849$

$9 \cdot 790471$

$9 \cdot 099474$

$2^{\mathrm{h}} 46^{\mathrm{m}} 9^{\mathrm{s}}$
A.T.S. $4^{\mathrm{d}} 211136 \quad 4^{\mathrm{d}} 211351$

Eq. T. $\quad+552$

$+552$

M.T.S. $4^{\mathrm{d}} \overline{21 \quad 17 \quad 28}$

M.T.G. $5^{\mathrm{d}} 1221$

$$
3 \quad 4453
$$

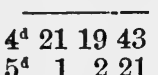

Dec. $17^{\circ} 9^{\prime} 52^{\prime \prime} \cdot 4$ N. H.V. $40 \cdot 14$ 445

\begin{tabular}{lll}
\hline 17 & 5 & 7
\end{tabular}

N.P.D. $72 \quad 5453$

$$
\begin{array}{rr}
\text { Eq. T. } 5^{\mathrm{m}} 52^{\prime} \cdot 6 & \text { H.V. } 23 \\
\hline 551 & \frac{7 \cdot 1}{1 \cdot 633}
\end{array}
$$

Obs. alt. $\odot 39^{\circ} 21^{\prime} 25^{\prime \prime}$

$$
\begin{aligned}
& \text { I.C. } \quad-27 \\
& \begin{array}{lll}
39 & 19 & 18
\end{array} \\
& \text { Dip } \quad-522 \\
& \begin{array}{lll}
39 & 13 \quad 56
\end{array} \\
& \text { S.D. }+1548 \\
& \begin{array}{lll}
39 & 29 & 44
\end{array} \\
& 392842 \quad 39^{\circ} 28^{\prime} 42^{\prime \prime} \\
& \begin{array}{llllll}
47 & 0 & 0 & 47 & 45 & 0
\end{array} \\
& \begin{array}{llllll}
72 & 54 & 53 & 72 & 54 & 53
\end{array}
\end{aligned}
$$

$\begin{array}{llllll}159 & 23 & 35 & 160 & 8 & 35\end{array}$

$$
\begin{aligned}
& \begin{array}{llllllll}
5^{d} & 3 & 19 & 8 & 5^{\text {d }} & 3 & 17 & 34
\end{array} \\
& +551+551 \\
& \begin{array}{lllll}
5^{\mathrm{d}} & \mathbf{3} \quad 24 \quad 59 & 5^{\mathrm{d}} 3 \quad 23 & 25
\end{array} \\
& \begin{array}{lllllll}
5^{\mathrm{d}} 7 & 5 & 23 & 5^{\mathrm{d}} 7 & 5 & 23
\end{array} \\
& \begin{array}{lllll}
34024 & 34158
\end{array}
\end{aligned}
$$

Long. (a) $56^{\circ} 13^{\prime} 15^{\prime \prime} \mathrm{W}$. ;

(b) $55^{\circ} 39^{\prime} 30^{\prime \prime} \mathrm{W}$.;

(c) $55^{\circ} 6^{\prime} 0^{\prime \prime} \mathrm{W}$. ;

(d) $55^{\circ} 29^{\prime} 30^{\prime \prime} \mathrm{W}$.

In Fig. 140 NESW is Ratl. Horizon.

NZS is Meridian.

EQW is Equinoctial.

$\mathrm{P}$, pole. $\mathrm{Z}$, zenith. $\mathrm{X}$ and $\mathrm{Y}$ positions of sun. Complete figure and 
also draw circles of position with $\mathrm{X}$ and $\mathrm{Y}$ as centres and $\mathrm{XZ}$ and $\mathrm{YZ}$ as radii.

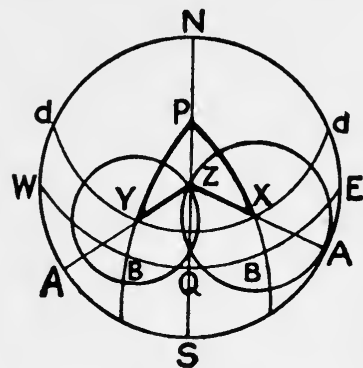

Fig. 140.

$\mathrm{AX}$ and $\mathrm{AY}$ are alts. $\mathrm{ZQ}$ is lat.

$\mathrm{BX}$ and $\mathrm{BY}$ are decs.

$P X$ and $P Y$ are pol. dist.

ZPX and ZPY are hour angles.

SZX and SZY are azimuths.

Projection.-Mark the longitudes $(a)$ and $(b)$ on their respective latitudes. The line $a b$ is the first line of positicn. Next set off 63 miles on a S. $\frac{1}{2}$ W. course from any point of this line, and through the end of the run draw a parallel line to $a b$. This is the corrected position of the first line in consequence of the ship's change of place during the interval. At the time of taking the second observation the ship was somewhere on this line.

Then mark the longitudes $(c)$ and $(d)$ on their latitudes; $c d$ is the second line of position, and at the time of taking the second observation the ship was somewhere on cd, consequently the intersection of $c d$ with the parallel line drawn before is the position of the ship.

To obtain the sun's bearing, take off the corresponding line of position, subtract from $90^{\circ}$, and mark.

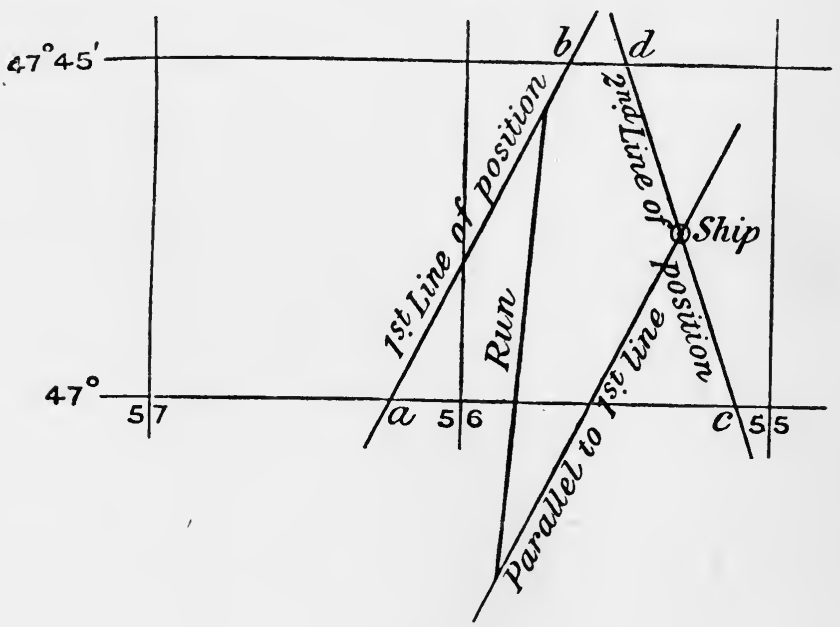

Fig. 141.

Ans. Direction of first line of position, N. $28^{\circ}$ E. or S. $28^{\circ}$ W. ; Sun's true bearing, S. $62^{\circ}$ E.; ship's position, lat. $47^{\circ} 23^{\prime}$ N., long. $55^{\circ} 18^{\prime} \mathrm{W}$. 


\section{Exercises.}

1. August 4th, about $8^{\mathrm{h}} 15^{\mathrm{m}}$ A.M. at ship, long. by account $64^{\circ}$ E. ; when a chron. showed $4^{\mathrm{h}} 11^{\mathrm{m}} 45^{\mathrm{s}}$, the obs. alt. of the Sun's L.L. was $36^{\circ} 15^{\prime} 40^{\prime \prime}$; and again P.M. at ship on the same day, when a chron. showed $10^{\mathrm{h}} 36^{\mathrm{m}} 45^{\mathrm{s}}$, the obs. alt. of the Sun's L.L. was $43^{\circ} 36^{\prime} 40^{\prime \prime}$; chron. correct for G.M.T. ; ind. cor., $+2^{\prime} 10^{\prime \prime}$; height of eye, $39 \mathrm{ft}$. ; the ship made a true course of W. $\frac{1}{2}$ S. for 32 miles during the interval. Find the first line of position, the Sun's true azimuth, and position of the ship at the time of taking the second observation, by Sumner's method by projection on the chart, assuming lats. $48^{\circ} 30^{\prime} \mathrm{N}$. and $49^{\circ} \mathrm{N}$.

2. August 9 th, about $8^{\mathrm{h}} 50^{\mathrm{m}}$ A.M. at ship, long. by account $4^{\circ} \mathrm{W}$.; when a chron. which was correct for M.T.G. showed $9^{\mathrm{h}} 8^{\mathrm{m}} 39^{\mathrm{s}}$, the obs. alt. of the Sun's U.L. was $38^{\circ} 47^{\prime} 10^{\prime \prime}$; and again P.M. of the same day, when the chron. showed $3^{\mathrm{h}} 16^{\mathrm{m}} 0^{\prime}$, the obs. alt. of the Sun's U.L. was $40^{\circ} 40^{\prime} 30^{\prime \prime}$; height of eye, $40 \mathrm{ft}$. ; ind. cor., $+2^{\prime} 17^{\prime \prime}$; the slip having made 72 miles $\mathrm{S}$. $60^{\circ} \mathrm{E}$. by compass, var. $20^{\circ} \mathrm{W}$., dev. $10^{\circ} \mathrm{W}$. in the interval. Find the lines of bearing and azimuths at both observations, also ship's position at second observation by Sumner's method by projection on the chart, assuming lats. $49^{\circ} 20^{\prime} \mathrm{N}$. and $50^{\circ} \mathrm{N}$.

3. August 24th, about $7^{\mathrm{b}} 40^{\mathrm{m}}$ A.M. at ship, long. Greenwich ; when a chron. $7^{\mathrm{m}} 40^{\mathrm{s}}$ slow of G.M.T. showed $7^{\mathrm{h}} 30^{\mathrm{m}} 4^{\mathrm{s}}$, the obs. alt. of the Sun's U.L. was $24^{\circ} 33^{\prime} 50^{\prime \prime}$; and again A.M. on the same day, when the same chron. showed $10^{\mathrm{h}} 54^{\mathrm{m}} 1^{\prime}$, the obs. alt. of the Sun's U.L. was $49^{\circ} 9^{\prime} 20^{\prime \prime}$; ind. cor., $-1^{\prime} 15^{\prime \prime}$; height of eye, $27 \mathrm{ft}$.; the ship's true course in the interval was W. by N., 47 miles. Required the line of position and Sun's azimuth at the first observation, and position of ship at the second observation, by Sumner's method, assuming lats. $49^{\circ} 50^{\prime} \mathrm{N}$. and $50^{\circ} 20^{\prime} \mathrm{N}$.

4. September 1st, long. by account $180^{\circ} \mathrm{E}$., with following observations find, by Sumner's method, the first line of position, the Sun's true bearing, and position of ship at second observation, assuming lats. $48^{\circ} 40^{\prime} \mathrm{N}$. and $49^{\circ} 20^{\prime} \mathrm{N}$.

Approx. ship time. Time by chron.
$0^{\mathrm{h}} 30^{\mathrm{m}}$ P.M.
$12^{\mathrm{h}} 42^{\mathrm{m}} 57^{\mathrm{s}}$
440 P.M.
$4 \quad 5020$
$\odot 48^{\circ} 51^{\prime} 0^{\prime \prime}$
ind. cor., $+1^{\prime} 10^{\prime \prime}$
$\odot 193020$
eye, $17 \mathrm{ft}$.

Run during interval W.S.W., $6 \frac{1}{2}$ knots per hour. The chron. was fast $5^{\mathrm{m}} 13^{\mathrm{s}}$ for G.M.T. on May 12th, and gaining daily $2^{\prime}$.

5. September $23 \mathrm{rd}$, about $8^{\mathrm{h}} 40^{\mathrm{m}}$ A.M., long. D.R. $60^{\circ}$ W.; when a chron. showed $12^{\mathrm{h}} 37^{\mathrm{m}} 55^{\mathrm{s}}$, the obs. alt. of the Sun's U.I. was $27^{\circ} 33^{\prime}$; and again P.M. on the same day, when a chron. showed $6^{\mathrm{b}} 29^{\mathrm{m}} 59^{\mathrm{s}}$, the obs. alt. of the Sun's U.L. was $32^{\circ} 53^{\prime} 40^{\prime \prime}$; ind. cor., $-3^{\prime} 57^{\prime \prime}$; eye, $25 \mathrm{ft}$. ; the ship having made 23 miles on a true W. by S. $\frac{3}{4} \mathrm{~S}$. course in the interval. Required the line of position and true bearing of the Sun at the first observation, and ship's position at second observation, by Sumner's method by projection on the chart, assuming lats. $46^{\circ} 10^{\prime} \mathrm{S}$. and $46^{\circ} 50^{\prime} \mathrm{S}$.

6. September 1st, about $8^{\mathrm{h}} 45^{\mathrm{m}}$ A.M., long. by account $110^{\circ}$ W. ; when a chron. showed $4^{\text {h }} 4^{\text {m }} 29^{n}$ G.M.T. ; the obs. alt. of the Sun's L.L. was $18^{\circ} 16^{\prime}$ $40^{\prime \prime}$; and again P.M. on the same day, when the chron. showed $9^{\mathrm{h}} 24^{\mathrm{m}} 43^{\mathrm{n}}$, the obs. alt. of the Sun's L.L. was $25^{\circ} 52^{\prime} 50^{\prime \prime}$; ind. cor., $+40^{\prime \prime}$; eye, $12 \mathrm{ft}$.; the ship having made 42 miles on a true S.E. by S. $\frac{1}{2}$ S. course in the interval. Find the line of position and sun's true bearing when the first altitude was taken, and ship's position at the second observation, by Sumner's method by projection on the chart, assuming lats. $49^{\circ} 15^{\prime} \mathrm{S}$. and $49^{\circ} 45^{\prime} \mathrm{S}$.

7. August 1st, about $5^{\text {b }} 30^{\mathrm{m}}$ A.M., long. by account $166^{\circ} \mathrm{E}$. ; when a chron. correct for G.M.T. showed $7^{\mathrm{h}} 39^{\mathrm{m}} 17^{\mathrm{s}}$, the obs. alt. of the Sun's L.L. was $20^{\circ}$ 
$59^{\prime} 40^{\prime \prime}$, and again $\mathrm{A.M.}$ on the same day, when the chron. showed $12^{\mathrm{h}} 7^{\mathrm{m}} 57^{\prime \prime}$, the obs. alt. of the Sun's L.L. was $57^{\circ} 6^{\prime} 10^{\prime \prime}$; ind. cor., $-3^{\prime} 7^{\prime \prime}$; eye, $36 \mathrm{ft}$. ; the ship having made a true $N$. by W. $\frac{1}{2}$ W. course 40 miles in the interval. Find the first line of position, the Sun's true bearing, and ship's position at the second observation by Sumner's method by projection on the chart, assuming lats. $49^{\circ} 50^{\prime} \mathrm{N}$. and $50^{\circ} 20^{\prime} \mathrm{N}$.

8. September 29 th, in long. by account $180^{\circ} \mathrm{E}$.; with following observations, assuming lats. $47^{\circ} \mathrm{N}$. and $47^{\circ} 50^{\prime} \mathrm{N}$., find by Sumner's method first line of position and Sun's true bearing; also position of ship at second observation.

Approx. ship time. Time by chron. Obs. alt. Sun's L.L. $7^{\mathrm{h}} 30^{\mathrm{m}}$ A.M.
$7^{\mathrm{b}} 29^{\mathrm{m}} 59^{\mathrm{s}}$
$10^{\circ} 53^{\prime} 20^{\prime \prime}$
264820
eye, $16 \mathrm{ft}$.
330 P.M.
$\begin{array}{lll}3 & 26 & 39\end{array}$
ind. cor., + $1^{\prime} 15^{\prime \prime}$

Run between observations, W. by S. $\frac{3}{4}$ S. 86 miles. The chron. was $22^{\mathrm{m}} 12^{\mathrm{s}}$ fast of G.M.T. on Sept. 1st, and gaining $2^{8} .5$ daily. 


\section{CHAPTER XIX.}

THE CHART.

ART. 90.-Charts used by Navigators are all constructed on Mercator's principle (except those of Harbours, Bays, etc.). Their characteristic is that the spaces between the Parallels of Latitude increase towards the Poles, whilst the Meridians of Longitude are also parallel instead of converging as they do on a globe. The reason for this construction is explained in Chap. I.

Latitudes are marked on the Graduated Meridians at the sides of the chart, and longitudes on the Graduated Parallels at the top and bottom.

Soundings in fathoms for Mean Low Water of Ordinary Spring Tides are given in small figures, and Roman numerals at various places give the Time of High Water, "Full and Change." The nature of the bottom is also shown by small letters and abbreviations.

Since 1911 the pattern of Compasses adopted on Admiralty Charts has been altered to show both Magnetic and True. The outer or true circle being graduated from $0^{\circ}$ to $360^{\circ}$. The inner or magnetic circle is divided into quadrants, each one reading from $0^{\circ}$ to $90^{\circ}$, and to quarter points. The variation is marked in the circle for a given indicated year, and its decrease per annum. True north is indicated by a star, magnetic north by a fleur de lis. Bearings are given both True and Magnetic, thus $161^{\circ}$ (S. $12^{\circ}$ E. mag.).

Variation Charts are charts of the oceans or of the globe with lines of equal variation drawn on them at intervals of one or two degrees. From these charts the variation at ship can be found, provided the latitude and longitude are known.

When out of sight of land, the ship's position is fixed by the latitude and longitude found from observation of heavenly bodies. Near the coasts the position can be obtained from soundings and from bearings of lights and other known objects.

ART. 91.-Using the following Deviation Tables it will now be shown how to convert the course from the chart into the corresponding compass course. 


\begin{tabular}{|c|c|c|}
\hline Ship's head by compass. & $\begin{array}{c}\text { Card A. } \\
\text { Deviation. }\end{array}$ & $\begin{array}{c}\text { Card B. } \\
\text { Deviation. }\end{array}$ \\
\hline N. & $11 \mathrm{E}$. & $36 \mathrm{w}$. \\
\hline N. by E. & $16 \mathrm{E}$. & $36 \mathrm{~W}$. \\
\hline N.N.E. & $21 \mathrm{E}$. & $30 \mathrm{~W}$. \\
\hline N.E. by N. & $27 \mathrm{E}$. & $27 \mathrm{~W}$. \\
\hline N.E. & $31 \mathrm{E}$. & $24 \mathrm{~W}$. \\
\hline N.E. by E. & $31 \mathrm{E}$. & $21 \mathrm{~W}$. \\
\hline E.N.E. & $28 \mathrm{E}$. & $17 \mathrm{~W}$. \\
\hline E. by N. & $26 \mathrm{E}$. & $12 \mathrm{~W}$. \\
\hline E. & $24 \mathrm{E}$. & $6 \mathrm{~W}$. \\
\hline E. by $\mathbf{S}$. & $20 \mathrm{E}$. & $2 \mathrm{E}$. \\
\hline E.S.E. & $15 \mathrm{E}$. & $6 \mathrm{E}$ \\
\hline S.E. by E. & $9 \mathrm{E}$. & $12 \mathrm{~F}$. \\
\hline S.E. & $4 \mathrm{E}$. & $17 \mathrm{E}$. \\
\hline S.E. by S. & $1 \mathrm{E}$. & $22 \mathrm{E}$. \\
\hline S.S.E. & $2 \mathrm{~W}$. & $27 \mathrm{E}$. \\
\hline S. by E. & $5 \mathrm{~W}$. & $32 \mathrm{E}$. \\
\hline S. & $8 \mathrm{~W}$. & $36 \mathrm{E}$. \\
\hline S. by w. & $11 \mathrm{~W}$. & 38 E. \\
\hline S.S.w. & $14 \mathrm{~W}$. & $37 \mathrm{E}$. \\
\hline S.W. by S. & $18 \mathrm{~W}$. & $35 \mathrm{E}$. \\
\hline S.W. & $21 \mathrm{~W}$. & $32 \mathrm{E}$. \\
\hline S.W. by W. & $24 \mathrm{~W}$. & $27 \mathrm{E}$. \\
\hline W.S.W. & $27 \mathrm{~W}$. & $20 \mathrm{E}$. \\
\hline W. by S. & $30 \mathrm{~W}$. & $12 \mathrm{E}$. \\
\hline W. & $26 \mathrm{~W}$. & 5 E. \\
\hline W. by N. & $23 \mathrm{~W}$. & $3 \mathrm{~W}$. \\
\hline W.N.W. & $21 \mathrm{~W}$. & $10 \mathrm{~W}$. \\
\hline N.W. by W. & $19 \mathrm{~W}$. & $16 \mathrm{~W}$. \\
\hline N.W. & $16 \mathrm{~W}$. & $22 \mathrm{~W}$. \\
\hline N.W. by N. & $11 \mathrm{~W}$. & $27 \mathrm{~W}$. \\
\hline N.N.W. & $4 \mathrm{~W}$ & $31 \mathrm{~W}$. \\
\hline N. by W. & $4 \mathrm{E}$. & $34 \mathrm{~W}$. \\
\hline
\end{tabular}

It is seen that the deviations are given for the compass directions of the ship's head; when the deviation is applied to the corresponding ship's head by compass; the magnetic direction of the ship's head is obtained: thus-

Card A. Comp. co. N.N.E. dev. $21^{\circ}$ E. gives mag. co. N. $44^{\circ} \mathrm{E}$.

Card B. $"$ N.N.E. " $30^{\circ} \mathrm{W}$. $, \quad, \quad$ N. $7^{\circ} \mathrm{W}$.

To obtain the deviation and compass course for a given magnetic course, two consecutive compass courses must be selected from the Table, so that when converted into magnetic 
courses, one will be greater and the other less than the given magnetic course, then by proportion the deviation, and hence the compass course may be obtained.

Thus using Card A: Find the Compass courses for mag. courses. (a) N. $70^{c}$ E. (b) S. $12^{\circ}$ W. (c) N. $15^{\circ}$ W.

Examples.

(a) N. $70^{\circ} \mathrm{E}$.

$$
\begin{array}{ccc}
\text { Comp.co. } & \text { Iev. } & \text { Mag. co. } \\
\text { N.E. by N. } & 27^{\circ} \text { E. } & \text { N. } 61^{\circ} \text { E. } \\
\text { N.E. } & 31 \text { E. } & \text { N. } 76 \text { E. }
\end{array}
$$

(Diff. of N. $61^{\circ}$ E. and N. $70^{\circ}$ E.) 9

15 (Diff. of courses)

15) $\overline{36}$

$$
\begin{aligned}
& 2^{\circ} \text { to add to } 27^{\circ} \mathrm{E} \text {. } \\
& \text { Hence deviation is } 29^{\circ} \mathrm{E} \text {. }
\end{aligned}
$$

Comp. co. N. $70^{\circ} \mathrm{E}$.

Dev. $29 \mathrm{E}$.

$$
\text { Mag. co. N. } \overline{41} 1^{\circ} \mathrm{E} \text {. }
$$

(b) S. $12^{\circ} \mathrm{W} . \quad$ Comp. co. Dev. Mag. co.

$$
\begin{array}{lll}
\text { S.S.W. } & 14^{\circ} \text { W. } & \text { S. } 9^{\circ} \text { W. } \\
\text { S.W. by S. } & \frac{18}{\text { W. }} & \text { S. } 16 \text { W. } \\
\text { (Diff. of dev.) } & \frac{4}{7} & \frac{7}{7} \text { (Diff. of courses) }
\end{array}
$$

(Diff. of S. $9^{\circ}$ W. and S. $12^{\circ} \mathrm{W}$ ) 3

$$
\frac{7 \overline{12}}{2^{\circ}} \text { to add to } 14^{\circ} \mathrm{W} \text {. }
$$

Mag. co. S. $12^{\circ} \mathrm{W}$.

$$
\text { Dev. } 16 \mathrm{~W} \text {. }
$$

Comp. S. $28^{\circ} \mathrm{W}$.

(c) N. $15^{\circ} \mathrm{W}$.

$$
\begin{aligned}
& \text { Comp. co. Dev. Mag. co. } \\
& \text { N.N.W. } \quad 4^{\circ} \text { W. } \quad \text { N. } 27^{\circ} \text { W. } \\
& \text { N. by W. } 4 \text { E. } \quad \text { N. } 7 \text { W. } \\
& \text { (Diff. of dev.) } 8 \\
& 20 \text { (Diff. of courses) }
\end{aligned}
$$

(Diff. of N. $27^{\circ}$ W. and N. $15^{\circ}$ W.) 12

$$
\begin{array}{ll} 
& \frac{20) 96}{5^{\circ}} \text { to subtract from } 4^{\circ} \mathrm{W} . \\
\begin{array}{l}
\text { Hence deviation is } 1^{\circ} \mathrm{E} . \\
\text { Mag. co. } \\
\text { dev. }
\end{array} & \quad \text { N. } 15^{\circ} \mathrm{W} . \\
\text { Comp. co. } \quad \text { N. } 16^{\circ} \mathrm{W} .
\end{array}
$$

Nore 1.-When the chart course is true, the variation must first be applied to find the magnetic course. The bearings must also be corrected for variation. 
Note 2.-The deviation can generally be found by inspection, as the difference of deviation between two adjacent points is usually small. In the tables the deviations are purposely increased to illustrate the method.

\section{EXERCISES.}

1. Using Card A. : find Comp. co. corresponding to following Mag. co. : (a) N. $79^{\circ}$ E. (b) East. (c) S.E. (d) S. $28^{\circ}$ E. (e) S. $85^{\circ}$ W.

2. Using Card B.: find the courses to steer by compass to make good following chart courses : (a) North. (b) East. (c) N. 83 W. (d) West.

ANSwers.

1. (a) N. $48^{\circ}$ E. (b) N. $60^{\circ}$ E. (c) S. 52 E. (d) S. 27 E. (e) N. $73^{\circ}$ W.

2. (a) N. $26^{\circ}$ E. (b) S. $86 \frac{1}{2}$ E. (c) N. 83 W. (d) S. $80^{\circ}$ W.

ART. 92.-When a vessel is steaming along a given course on the chart at a known rate, her estimated or expected D.R. position on that course can always be set down as the distance run is known, the observation position can be determined by station pointer, cross bearings, or two bearings and the run between, the course and distance from the D.R. to the obs. position is the set and drift of the current experienced. Thus in Fig. 142 vessel

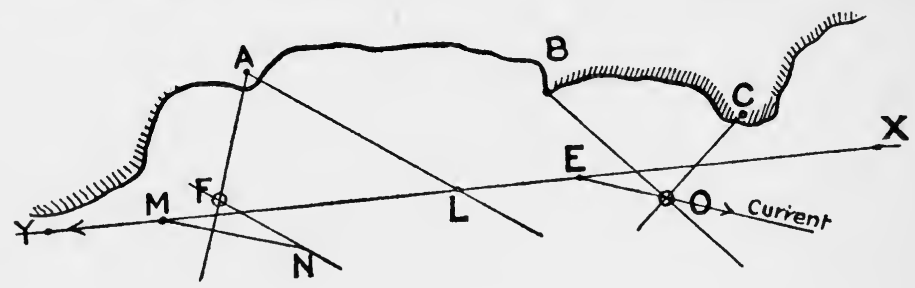

FiG. 142.

proceeding from $\mathrm{X}$ to $\mathrm{Y}$, at the end of a given time expects to be at $\mathrm{E} ; \mathrm{B}$ and $\mathrm{C}$ are two conspicuous objects, at this time the compass bearings of $\mathrm{B}$ and $\mathrm{C}$ are taken and corrected, and then laid on the chart in the directions $\mathrm{BO}$ and $\mathrm{CO}, \mathrm{O}$ the point of intersection of these bearings is the observed position of the ship, EO represents the set and drift of the current.

Again, at a given time let the bearing of an object $\mathrm{A}$ be taken, corrected and laid off as AL, after a known interval another bearing of $\mathrm{A}$ is taken, corrected and laid off as $\mathrm{AF}$, supposing the current found to be still acting, the position of the ship at the end of the time may be found thus: Measure LM along LY equal to the distance the ship steams in the interval, set off $M N$ in the direction of the current, and equal to the drift of the current in the interval, through $\mathrm{N}$ draw a parallel line to the first bearing, $\mathrm{AL}$ : to cut the second bearing in $\mathrm{F}$. $\mathrm{F}$ is the position of the ship allowing for the current. 
To set a course to counteract a given current is another problem of great importance to the navigator. In the previous paragraph the effect of a known current on the position of the ship at the end of the run has been considered; now it is required to find what course must be steered by a ship through a known current in order that she may make a given position.

In Fig. 143 the vessel is at $\mathrm{P}$ and wishes to get to $\mathrm{Q} 30.5$ miles away: her speed is 10 knots; the current sets in the direction $\mathrm{PR}$ at 3 knots. Measure 3-tenths inch along PR to $R$, and with $R$ as centre

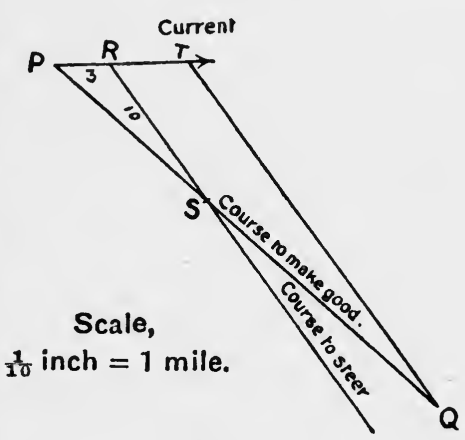

Fig. 143. and 10-tenths as radius cut the line $P Q$ in $S$, then $R S$ is the direction to steer to counteract the current, that is for the ship to get to point $\mathrm{S}$ on the line $\mathrm{PQ}$, and $\mathrm{PS}$ is the distance made good in one hour : this measured gives 11.8 miles.

Hence time taken to arrive at $Q=\frac{30.5}{11.8}$ hours

$$
=2.5 \text { hours. }
$$

Total distance for ship to steam $=2.5 \times 10$ miles

$$
=25 \text { miles. }
$$

Or by drawing a line through $\mathrm{Q}$ parallel to RS to cut direction of current in $\mathrm{T}$, and measuring $\mathrm{TQ}$, will also give total distance for ship to steam $=25.5$ miles.

The problem may be solved trigonometrically, as in triangle PRS are given $P R, R S$, and angle $S P R$, to find angle RSP by "rule of sines." This angle shows how much nearer south the course to steer is than the direction of $\mathrm{PQ}$.

N.B.-Find the deviation for the new course, and apply to it to obtain the compass course.

Again, in Fig. 144 let the vessel be going along the line $A B$, and at the end of a given time, say $1 \frac{1}{2}$ hours, finds her position to be at $C$, find the course

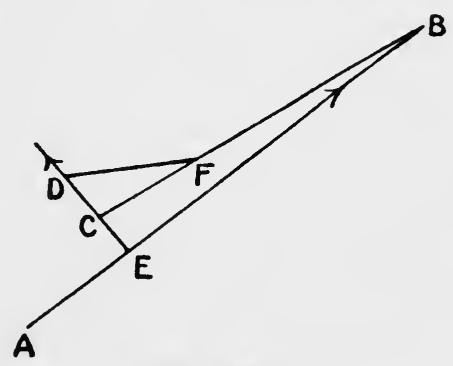

FIG. 144. she must steer to arrive at $B$. As the speed of the ship is known, her DR position would be at a fixed point on $A B$, say $E$, 
consequently the set and drift of the current acting is the direction and length of $\mathrm{EC}$ in $1 \frac{1}{2}$ hours. Join CB, this is the course required to be made good. Produce EC, make $\mathrm{CD}=\mathrm{CE}$, this represents the current for $1 \frac{1}{2}$ hours, with $D$ as centre, radius equal to $\mathrm{AE}$ the distance the ship steams in the same time, describe an arc cutting CB in F. Then the direction of $\mathrm{DF}$ is the required course, and $\mathrm{CF}$ is the distance made good in $1 \frac{1}{2}$ hours, whence by simple proportion, the time taken to arrive at $B$, or the distance towards $B$ made in any required time, may be found.

N.B.- When laying off a course to counteract a current, always allow the current to act, and the ship to steam for the same time, 1 hour, 2 hours, etc., as may be selected.

\section{Exercises.}

Using St. George's Channel Chart, Devia. Card B.

1. (a) Find the course to steer by compass from Bell Buoy, St. Tudwall Rds., to New Quay Lt. Also the deviation, variation, and distance.

(b) With the ship's head on the above compass course, Pengarn Mt. bore by compass N. $56^{\circ}$ E. and Aberdovey Lt. bore S. $84^{\circ} \mathrm{E}$. by the same compass. Find the ship's position, and set and drift experienced since course was set, ship steaming 6 knots and taking $2 \mathrm{~h} .40 \mathrm{~m}$. to reach position.

(c) With the ship's head as above, Aberystwith Lt. bore by compass S. $65^{\circ}$ E. and after continuing $3 \mathrm{~h} .10 \mathrm{~m}$. on the above-named course it bore N. $49^{\circ} \mathrm{E}$. by the same compass. Find the ship's position and distance from New Quay Lt., making allowance for current found in $(b)$.

$(d)$ Find the course to steer by compass from Bell buoy to New Quay in the current found in (b) vessel making 6 knots: and the distance she then makes good towards New Quay in 3 hours 50 minutes. How far would ship have to steam to reach New Quay?

(e) Horizontal angles, find position by station pointer: St. Tudwall Lt., $86 \frac{1}{2}^{\circ}$; Aberystwith Lt., $62^{\circ}$; New Quay Lt.

$(f)$ What do the small numbers indicate that are placed about the chart and at what time of tide?

(g) What do the Roman numerals indicate that are occasionally seen near the coast and in harböurs?

(h) How would you find approximately the time of high water at any place, the Admiralty tables not being at hand, nor any other special tables available?

2. (a) Find the courses to steer by compass and distance on each course from Dunmore Lt., Waterford Hr., to $Q$ off Sth. Arklow Lt. V. on G. line $3 \frac{1}{4}$ miles from Lt. V.

Note.-Alter course when Coningbeg Lt. bears $360^{\circ}$, distance 3 miles, and again when Tuskar Rk. Lt. bears $288^{\circ}$, distance 2 miles.

(b) With ship's head on the 2 nd compass course, Sth. Pt. S. Saltee bore by compass N. $61^{\circ} \mathrm{W}$, , and Carnsore Pt. bore N. $46^{\circ} \mathrm{E}$. by the same compass. Find the ship's position, set and drift experienced, if the expected position was with Barrel's Lt. V. bearing $251^{\circ}$, distance off 3 miles.

(c) With the ship's head on the 3rd compass course, Lucifer Lt. bore by compass $\mathrm{N} .17^{\circ} \mathrm{E}$., and after continuing 56 minutes on the above-named course, it bore $\mathrm{N}$. $62^{\circ} \mathrm{W}$. by the same compass. Find the ship's position and distance from Blackwater Lt., making due allowance for a current which set N.E. mag. 3 knots, vessel steaming 15 knots. 
(d) Find the courses to steer by compass from Dunmore Lt. to $\mathrm{Q}$ in a current which set east mag. $2 \frac{1}{2}$ knots, the vessel making $12 \mathrm{knots}$, and the distance she then makes good towards $Q$ in 3 hours 45 minutes.

(e) Horizontal angles, find position by station pointer, Hook Pt. Lt., $58^{\circ}$; Coningbeg Lt. V., $24 \frac{1}{2}^{\circ}$; Tuskar Lt.

3. (a) Set the courses to steer by compass from $\mathrm{X}$, lat. $51^{\circ} 35^{\prime} \mathrm{N}$. long. $5^{\circ} 18^{\prime} \mathrm{W}$., to $\mathrm{Y}$., lat. $52^{\circ} 2 \frac{1}{2}^{\prime} \mathrm{N}$. long. $5^{\circ} 2^{\prime} \mathrm{W}$., ship to pass 3 miles off S. Bishop Lt. ; then alter course to reach $Y$, with Cardigan Bay L.V. bearing $90^{\circ}$, distance $1 \frac{1}{4}$ miles; maintaining your distance of 3 miles from S. Bishop Lt., and give distance run on each course.

(b) With the ship's head on 1st compass course, St. Anne's Hd. Lt. bore by compass S. $17^{\circ} \mathrm{E}$., and Small's Lt. bore N. $58^{\circ} \mathrm{W}$. by the same compass. Find the ship's position, set and drift experienced, the ship having run 49 minutes on the course, steaning 11 knots.

(c) With ship's head on 2nd compass course, Strumble Hd. bore by compass S. $39^{\circ} \mathrm{E}$., and after continuing 1 hour 38 minutes on above course, it bore S. $31^{\circ} \mathrm{W}$. by same compass. Find the ship's position and distance from Cardigan Bay L.V., allowing for a current which set S. $63^{\circ} \mathrm{W}$. mag. $2 \frac{1}{2}$ knots, vessel steaming 11 knots.

(d) After running on second course $1 \mathrm{hr} .22$ mins., ship making 11 knots, her position was found to be lat. $52^{\circ} 2^{\prime} \mathrm{N}$., long $5^{\circ} 25^{\prime} \mathrm{W}$. Find course to steer by compass from this point to $\mathrm{Y}$, allowing for a similar current to that experienced during earlier part of run; and distance made good in 2 hrs. 50 mins. towards Y. How long would she take to reach Y. ? 


\section{CHAPTER XX.}

\section{USE OF NAPIER'S DIAGRAM.}

ART. 93.-In the list of questions proposed to candidates for Masters' Certificates in the Board of Trade Regulations, Nos. 11, 12,13 , and 14 refer to the use of Napier's Diagram.

of $\mathrm{S}.\} 70^{\circ}$ riugs

\& W. $\} 5$

ence 8) 65

g. $\}$ S. $8^{\circ} \mathrm{E}$.

. $3.79^{\circ} \mathrm{W}$.

$12 \mathrm{E}$.

S. 91 W

N. 89 W.

\} N. $8^{\circ} \mathrm{W}$.

$12^{\circ} \mathrm{E}$.

N. $\overline{4}$

\section{Example. -}

No. 11. Having taken the following compass bearings of a distant object, find its Correct Magnetic Bearing, and thence the deviation.

Correct magnetic bearing required: $\mathrm{S} .8^{\circ} \mathrm{E}$.

\begin{tabular}{|c|c|c|c|c|c|}
\hline $\begin{array}{l}\text { Ship's head by } \\
\text { standard } \\
\text { compass. }\end{array}$ & $\begin{array}{l}\text { Bearing of distant } \\
\text { object. }\end{array}$ & $\begin{array}{l}\text { Deviation } \\
\text { required. }\end{array}$ & $\begin{array}{l}\text { Ship's head by } \\
\text { standard } \\
\text { compass. }\end{array}$ & $\begin{array}{l}\text { Bearing of distant } \\
\text { object. }\end{array}$ & $\begin{array}{l}\text { Deviation } \\
\text { required. }\end{array}$ \\
\hline $\begin{array}{l}\text { N. } \\
\text { N.E. } \\
\text { E. } \\
\text { S.E. }\end{array}$ & $\begin{array}{l}\text { S. } 4^{\circ} \mathbf{E} . \\
\text { S. } \\
\text { S. } 4^{\circ} \mathrm{W} . \\
\text { S. } 1^{\circ} \mathrm{W} \text {. }\end{array}$ & $\begin{array}{l}4^{\circ} \mathrm{W} . \\
8^{\circ} \mathrm{W} . \\
12^{\circ} \mathrm{W} . \\
9^{\circ} \mathrm{W} .\end{array}$ & $\begin{array}{l}\text { S. } \\
\text { S. W. } \\
\text { W. } \\
\text { N.W. }\end{array}$ & $\begin{array}{l}\text { S. } 13^{\circ} \mathbf{E} . \\
\text { S. } 22^{\circ} \mathbf{E} . \\
\text { S. } 20^{\circ} \mathbf{E} . \\
\text { S. } 11^{\circ} \mathbf{E} .\end{array}$ & $\begin{aligned} 5^{\circ} \mathrm{E} \\
14^{\circ} \mathrm{E} \\
12^{\circ} \mathrm{E} \\
3^{\circ} \mathrm{E}\end{aligned}$ \\
\hline
\end{tabular}

No. 12. With the deviation as above, construct a curve of deviation on a Napier's Diagram, and give the courses you would steer by the Standard Compass to make the following correct magnetic courses :-

Magnetic courses: S.S.W. W.N.W. N.N.E. E.N.E. S.S.E.

Compass courses required : S. $14^{\circ}$ W. N. $77^{\circ}$ W. N. $29 \frac{1}{2}^{\circ}$ E. N. $79^{\circ}$ E. S. $20^{\circ} \frac{1}{2} \mathrm{E}$.

No. 13. Supposing you have steered the following courses by the Standard Compass, find the correct magnetic courses from the above curve of deviations :-

Compass courses: W.S.W. N.N.W. E.N.E. S.S.E.

Magnetic courses required: S. $82^{\circ}$ W. N. $23^{\circ}$ W. N. $57^{\circ}$ E. S. $25^{\circ}$ E.

No. 14. You have taken the following bearings of two distant objects by your Standard Compass as above, with the ship's head at W. $\frac{1}{2}$ S. by compass : find the correct magnetic bearings.

Bearings by compass : W. by S. N. $\frac{3}{4}$ W.

Magnetic bearings required: N. $89^{\circ} \mathrm{W} . \quad$ N. $3^{\circ} \mathrm{E}$.

Explanation.-In No. 11 the Correct Magnetic Bearing is the mean of the eight observed bearings.

(a) When the bearings all read one way from S. or N., the mean is found by adding the eight bearings together and dividing the sum by 8 . 
(b) When the bearings read different ways, viz. some towards E. and some towards W., then the mean is found by summing up the bearings of the same Name separately (as in the above example), and dividing the difference of the totals by 8 .

(c) The deviations are the differences between the correct magnetic bearing and each of the eight bearings by Compass, it being $\mathrm{E}$. dev. when the correct magnetic reads to the right of the compass bearing, and W. when to the left.

\section{ART. 94.-Napier's Diagram and Curve of Deviations.}

The deviations found for the eight equidistant courses are taken with a pair of dividers from the middle line, which is graduated like a compass card, and set off from the graduated line on the dotted lines for the given courses-to the left for W. dev., and to the right for E. dev. A curve is then drawn, as in the diagram (Fig. 145). The deviation for any course (compass or magnetic) may now be found by simply measuring the part of the line (dotted or plain) intercepted by the curve.

For No. 12, place one foot of the dividers on the given course, and extend the other on the plain line to the curve. Keeping one foot on the middle line, turn the other up or down according as the line inclines upwards or downwards, and read off the required compass course.

For No. 13, proceed exactly in the same way as in No. 12, except that the dotted lines only are to be used.

NotE. - The advantage of the diagram and curve is that it affords a ready mechanical way of changing magnetic courses to compass courses, and vice $v e r s \hat{a}$, and so avoids the risk of error in applying deviation by adding or subtracting.

For No. 14, find the Deviation for the given direction of ship's head, by measuring the part of the dotted line intercepted by the curve, and apply it in the usual way to the bearings by compass, viz. E. to right, and W. to left.

Example.-(a) Magnetic bearing required : S. $53^{\circ} 45^{\prime} \mathrm{W}$.

\begin{tabular}{|c|c|c|c|c|c|}
\hline $\begin{array}{l}\text { Ship's head by } \\
\text { compass. }\end{array}$ & $\begin{array}{l}\text { Bearing by } \\
\text { compass. }\end{array}$ & Deviation. & $\begin{array}{l}\text { Ship's head by } \\
\text { compass. }\end{array}$ & $\begin{array}{l}\text { Bearing by } \\
\text { compass. }\end{array}$ & Deviation. \\
\hline $\begin{array}{l}\text { N. } \\
\text { N.E. } \\
\text { E. } \\
\text { S.E. }\end{array}$ & $\begin{array}{l}\text { S. } 75^{\circ} \mathrm{WV} \text {. } \\
\text { S. } 64^{\circ} \mathrm{W} \text {. } \\
\text { S. } 56^{\circ} \mathrm{W} \text {. } \\
\text { S. } 50^{\circ} \mathrm{WV} \text {. }\end{array}$ & $\begin{array}{rr}21^{\circ} 15^{\prime} \mathrm{W} . \\
10^{\circ} 15^{\prime} \mathrm{W} . \\
2^{\circ} 15^{\prime} \mathrm{W} . \\
3^{\circ} 45^{\prime} \mathrm{E} .\end{array}$ & $\begin{array}{l}\text { S. } \\
\text { S.W. } \\
\text { W. } \\
\text { N.W. }\end{array}$ & $\begin{array}{l}\text { S. } 34^{\circ} \mathrm{W} \text {. } \\
\text { S. } 31^{\circ} \mathrm{W} \text {. } \\
\text { S. } 49^{\circ} \mathrm{W} \text {. } \\
\text { S. } 71^{\circ} \mathrm{W} \text {. }\end{array}$ & 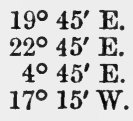 \\
\hline
\end{tabular}

NoTE. - The magnetic bearing required is the mean of all the bearings by compass, found by adding them and dividing by eight. The deviations are then marked on the dotted lines of a Napier's diagram, and a curve drawn.

(b) Magnetic courses : N.N.W. S.S.E. W.N.W. E.S.E.

Compass courses required : N. $1^{\circ}$ W. S. $31^{\circ}$ E. N. $53^{\circ}$ W. S. $68^{\circ}$ E. 
DIAGRAM.

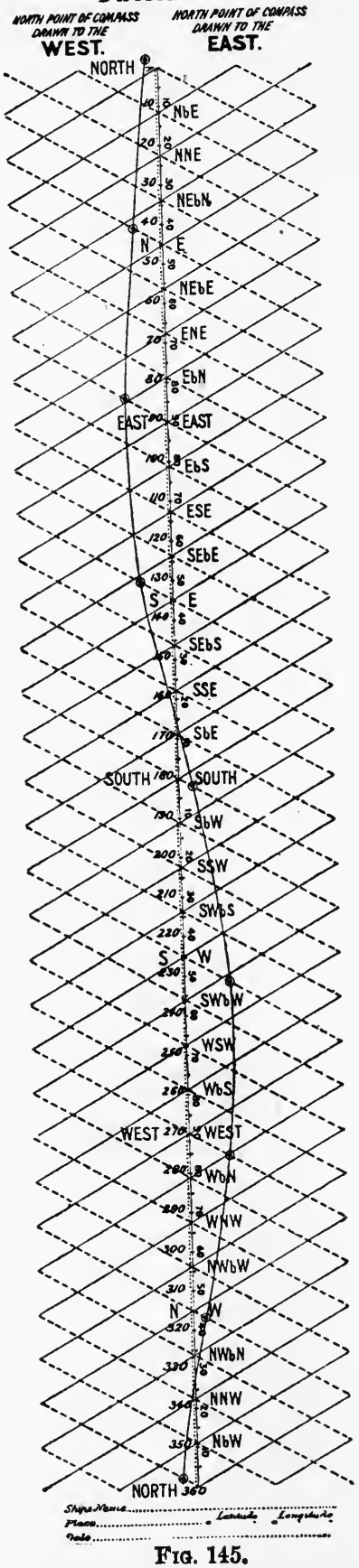


Explanation.-Place one leg of the compasses on the given course, and extend the other along the plain line to the curve, and turn upwards if the line tends upwards, but downwards if it tends down. wards, and read off the required course.

(c) Compass courses given : N.N.E. E.N.E. S.S.W. W.S.W. Magnetic courses required : N. $6^{\circ}$ E. N. $62^{\circ}$ E. S.W. S. $83^{\circ}$ W.

Explanation.-Place one leg of the compasses on the given course, and extend the other along the dotted lines to the curve, and turn up or down, as the line tends.

(d) Ship's head by compass : N.E. $\frac{1}{2}$ E.

Compass bearings : S.E. by S. N.N.W.

Magnetic bearings required: S. $44^{\circ}$ E. N. $32 \frac{1}{2}^{\circ} \mathrm{W}$.

Explanation.-Find the deviation on the given compass course from the dotted line, and apply it to both bearings (east to right, west to left).

\section{Exercises on Napier's Diagram and Curve.}

1. (a) Correct magnetic bearing required :-

\begin{tabular}{|c|c|c|c|c|c|}
\hline $\begin{array}{l}\text { Ship's head by } \\
\text { compass. }\end{array}$ & $\begin{array}{l}\text { Bearing of distant } \\
\text { object. }\end{array}$ & Deviation. & $\begin{array}{l}\text { Ship's head by } \\
\text { compass. }\end{array}$ & $\begin{array}{l}\text { Bearing of distant } \\
\text { object. }\end{array}$ & Deviation. \\
\hline $\begin{array}{l}\text { N. } \\
\text { N.E. } \\
\text { E. } \\
\text { S.E. }\end{array}$ & $\begin{array}{l}\text { N. } 83^{\circ} \mathrm{F} . \\
\text { S. } 86^{\circ} \mathrm{E} . \\
\text { E. } \\
\text { N. } 75^{\circ} \text { E. }\end{array}$ & & $\begin{array}{l}\text { S. } \\
\text { S.W. } \\
\text { W. } \\
\text { N.W. }\end{array}$ & $\begin{array}{l}\text { N. } 50^{\circ} \mathrm{E} . \\
\text { N. } 34^{\circ} \mathrm{E} . \\
\text { N. } 40^{\circ} \mathrm{E} . \\
\text { N. } 61^{\circ} \mathrm{E} .\end{array}$ & \\
\hline
\end{tabular}

Find the correct magnetic bearing and the deviations.

(b) Correct magnetic courses : N.E. $\frac{1}{2}$ E. E. by N. S.E. by S. $\frac{1}{2}$ S. N. $\frac{1}{2}$ W. Required courses to steer.

(c) Courses steered : N.W. $\frac{3}{4}$ W. S. E. by S. N. by E. Required correct magnetic courses.

(d) Ship's head by compass : W.S.W.

Bearings of distant object : S.S.W. and N.E.

Required the correct magnetic bearing.

2. (a) Correct magnetic bearing required :-

\begin{tabular}{|c|c|c|c|c|c|}
\hline $\begin{array}{l}\text { Ship's head by } \\
\text { compass. }\end{array}$ & $\begin{array}{l}\text { Bearing of distant } \\
\text { object. }\end{array}$ & Deviation. & $\begin{array}{l}\text { Ship's head by } \\
\text { compass. }\end{array}$ & $\begin{array}{l}\text { Bearing of distant } \\
\text { object. }\end{array}$ & Deviation. \\
\hline $\begin{array}{l}\text { N. } \\
\text { N.E. } \\
\text { E. } \\
\text { S.E. }\end{array}$ & $\begin{array}{l}\text { S. } 85^{\circ} \mathrm{W} . \\
\text { S. } 79^{\circ} \mathrm{W} \text {. } \\
\text { S. } 88^{\circ} \mathrm{W} . \\
\text { N. } 76^{\circ} \mathrm{W} .\end{array}$ & & $\begin{array}{l}\text { S. } \\
\text { S.W. } \\
\text { W. } \\
\text { N.W. }\end{array}$ & $\begin{array}{l}\text { N. } 73^{\circ} \mathrm{W} . \\
\text { N. } 68^{\circ} \mathrm{W} . \\
\text { N. } 74^{\circ} \mathrm{W} . \\
\text { N. } 79^{\circ} \mathrm{W} .\end{array}$ & \\
\hline
\end{tabular}

Required the correct magnetic bearing and the deviations.

(b) Correct magnetic courses : E. $\frac{1}{2}$ N. E.S.E. S. $\frac{3}{4}$ W. N.W. Required courses to steer.

(c) Courses steered : N. S.E. $\frac{3}{4}$ S. S.W. $\frac{1}{2}$ W. N. $35^{\circ}$ W. Required correct magnetic courses. 
(d) Ship's head S. $65^{\circ}$ E. Bearings by compass, W. $10^{\circ} \mathrm{S} . \quad$ N. $40^{\circ}$ E. Required the deviation and the correct magnetic bearings.

3. (a) Correct magnetic :-

\begin{tabular}{|c|c|c|c|c|c|}
\hline $\begin{array}{l}\text { Ship's head by } \\
\text { compass. }\end{array}$ & $\begin{array}{c}\text { Bearing of distant } \\
\text { object. }\end{array}$ & Deviation. & $\begin{array}{l}\text { Ship's head by } \\
\text { compass }\end{array}$ & $\begin{array}{l}\text { Basaring of distant } \\
\text { object. }\end{array}$ & Deviation. \\
\hline $\begin{array}{l}\text { N. } \\
\text { N.E. } \\
\text { E. } \\
\text { S.E. }\end{array}$ & $\begin{array}{l}\text { S. } 4^{\circ} \mathrm{W} . \\
\text { S. } 1^{\circ} \mathrm{E} \text {. } \\
\text { S. } \\
\text { S. } 22^{\circ} \mathrm{W} .\end{array}$ & & $\begin{array}{l}\text { S. } \\
\text { S.W. } \\
\text { W. } \\
\text { N.W. }\end{array}$ & $\begin{array}{l}\text { S. } 34^{\circ} \mathrm{W} . \\
\text { S. } 32^{\circ} \mathrm{W} \text {. } \\
\text { S. } 11^{\circ} \mathrm{W} \text {. } \\
\text { S. } 9^{\circ} \mathrm{W} \text {. }\end{array}$ & \\
\hline
\end{tabular}

(b) Correct magnetic courses : N. $\frac{1}{2}$ W. W. by S. $\frac{3}{4}$ S. S. $70^{\circ}$ E. E. $24^{\circ} \mathrm{N}$.

Courses to steer by compass.

(c) Courses steered by compass : W.N.W. $\frac{1}{2}$ N. N.E. $\frac{1}{4}$ N. S. $\frac{3}{4}$ E. N. $40^{\circ} \mathrm{W}$.

Correct magnetic courses.

(d) Ship's head at W. by N. by compass.

Bearings by compass (of distant objects) : S.W. $\frac{3}{4}$ W. N.W. by W. $\frac{1}{2}$ W. Correct magnetic bearings.

4. (a) Correct magnetic.

\begin{tabular}{|c|c|c|c|c|c|}
\hline $\begin{array}{l}\text { Ship's head by } \\
\text { compass. }\end{array}$ & $\begin{array}{l}\text { Bearing of distant } \\
\text { object. }\end{array}$ & Deviation. & $\begin{array}{l}\text { Ship's head by } \\
\text { compass. }\end{array}$ & $\begin{array}{l}\text { Bearing of distant } \\
\text { object. }\end{array}$ & Deviation. \\
\hline $\begin{array}{l}\text { N. } \\
\text { N.E. } \\
\text { E. } \\
\text { S.E. }\end{array}$ & $\begin{array}{l}\text { N. } 32^{\circ} \mathrm{W} . \\
\text { N. } 27^{\circ} \mathrm{W} . \\
\text { N. } 6^{\circ} \mathrm{E} . \\
\text { N. } 2^{\circ} \mathbf{E} .\end{array}$ & & $\begin{array}{l}\text { S. } \\
\text { S.W. } \\
\text { W. } \\
\text { N.W. }\end{array}$ & $\begin{array}{l}\text { N. } 4^{\circ} \mathrm{E} . \\
\text { N. } 4^{\circ} \mathrm{E} . \\
\text { N. } 10^{\circ} \mathrm{W} . \\
\text { N. } 15^{\circ} \mathrm{W} .\end{array}$ & \\
\hline
\end{tabular}

(b) Correct magnetic courses : S. $50^{\circ}$ W. N. E. $5^{\circ}$ S. E. by $\mathbf{N}$. Courses to steer by compass.

(c) Courses steered by compass : W. by S. N. by E. $\frac{1}{2}$ E. S.E. $\frac{3}{4}$ S. S. by W.

Correct magnetic courses.

(d) Ship's head at N.N.W. by compass.

Bearings by compass (of distant objects): W.N.W. S.S.W. Correct magnetic bearings.

5. (a) In the following table give the correct magnetic bearing, and thence the deviation.

Correct magnetic :-

\begin{tabular}{|c|c|c|c|c|c|}
\hline $\begin{array}{l}\text { Ship's head by } \\
\text { standard } \\
\text { compass. }\end{array}$ & $\begin{array}{l}\text { Bearing of distant } \\
\text { object by standard } \\
\text { compass. }\end{array}$ & $\begin{array}{l}\text { Deviation } \\
\text { required. }\end{array}$ & $\begin{array}{l}\text { Ship's head by } \\
\text { standard } \\
\text { compass. }\end{array}$ & $\begin{array}{l}\text { Bearing of distant } \\
\text { object by standard } \\
\text { compass. }\end{array}$ & $\begin{array}{l}\text { Deviation } \\
\text { required. }\end{array}$ \\
\hline $\begin{array}{l}\text { N. } \\
\text { N.E. } \\
\text { E. } \\
\text { S.E. }\end{array}$ & $\begin{array}{l}\text { N. } 62^{\circ} \text { E. } \\
\text { E. } 24^{\circ} \mathrm{N} . \\
\text { E. } 7^{\circ} \mathrm{N} . \\
\text { S. } 77^{\circ} \mathrm{E} .\end{array}$ & & $\begin{array}{l}\text { S. } \\
\text { S.W. } \\
\text { W. } \\
\text { N.W. }\end{array}$ & $\begin{array}{l}\text { E. } 15^{\circ} \mathrm{S} . \\
\text { S. } 81^{\circ} \mathrm{E} . \\
\text { E. } 5^{\circ} \mathrm{N} . \\
\text { N. } 67^{\circ} \mathrm{E} .\end{array}$ & \\
\hline
\end{tabular}


(b) With the deviations as above, give the courses you would steer by the Standard Compass to make the following courses correct magnetic :-

Magnetic courses : N.E. $\frac{1}{2}$ E. E. $\frac{1}{4}$ S. S. $\frac{1}{2}$ W. N. $\frac{1}{2}$ W.

Compass "

(c) Supposing you have steered the following courses by the Standard Compass, find the correct magnetic courses.

Compass courses: N.E. $\frac{1}{2}$ N. S.E. $\frac{1}{2}$ S. W. $\frac{1}{1}$ N. N.W. $\frac{1}{2}$ N.

Magnetic.

(d) You have taken the following bearings of two distant objects by your Standard Compass as above : with the ship's head at N. 1 W., find the bearings correct magnetic.

Compass bearings : S.S.E. $\frac{1}{4}$ E. E. $\frac{1}{2}$ N.

Correct magnetic.

6. (a) In the following table give the correct magnetic bearing of the distant object, and thence the deviation :-

Correct magnetic :-

\begin{tabular}{|c|c|c|c|c|c|}
\hline $\begin{array}{l}\text { Ship's head by } \\
\text { standard } \\
\text { compuss. }\end{array}$ & $\begin{array}{l}\text { Bearing of distant } \\
\text { object by standard } \\
\text { compass. }\end{array}$ & $\begin{array}{l}\text { Deviation } \\
\text { required. }\end{array}$ & $\begin{array}{l}\text { Ship's head by } \\
\text { standard } \\
\text { compass. }\end{array}$ & $\begin{array}{c}\text { Bearing of distant } \\
\text { object by standard } \\
\text { compass. }\end{array}$ & $\begin{array}{l}\text { Deviation } \\
\text { required. }\end{array}$ \\
\hline $\begin{array}{l}\text { N. } \\
\text { N.E. } \\
\text { E. } \\
\text { s.E. }\end{array}$ & $\begin{array}{lll}\text { S. } 32^{\circ} & 0^{\prime} & \text { E. } \\
\text { S. } 4^{\circ} & 45^{\prime} & \text { E. } \\
\text { S. } 16^{\circ} & 0^{\prime} & \text { W. } \\
\text { S. } 21^{\circ} & 30^{\circ} & \text { W. }\end{array}$ & & $\begin{array}{l}\text { S. } \\
\text { S.W. } \\
\text { W. } \\
\text { N.W. }\end{array}$ & 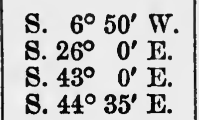 & \\
\hline
\end{tabular}

(b) With the deviations as above, give the courses you would steer by the Standard Compass to make the following courses correct magnetic :Magnetic: N. by E. $\frac{3}{4}$ E. E. $\frac{1}{2}$ N. S.S.W. $\frac{1}{4}$ W. N.W. $\frac{1}{2}$ W.

Courses to steer.

(c) Supposing you have steered the following courses by the Standard Compass, find the correct magnetic courses.

Standard : N.N.E. $\frac{3}{4}$ E. E. by N. $\frac{1}{2}$ N. S.S.E. $\frac{1}{4}$ E. N.W. $\frac{1}{4}$ N.

Magnetic.

(d) You have taken the following bearings of two distant objects by your Standard Compass as above : with the ship's head at S.E. $\frac{1}{2}$ S., find the bearings correct magnetic :-

Compass bearings : N.E. $\frac{1}{2}$ E. N. by W. $\frac{1}{6}$ W.

Correct magnetic.

7. (a) Magnetic bearing required-

\begin{tabular}{|c|c|c|c|c|c|}
\hline $\begin{array}{l}\text { Ship's head by } \\
\text { compass. }\end{array}$ & $\begin{array}{l}\text { Bearing by } \\
\text { compass. }\end{array}$ & Deviation. & $\begin{array}{l}\text { Ship's head by } \\
\text { compass. }\end{array}$ & $\begin{array}{l}\text { Bearing by } \\
\text { compass. }\end{array}$ & Deriation. \\
\hline $\begin{array}{l}\text { N. } \\
\text { N.E. } \\
\text { E. } \\
\text { S.E. }\end{array}$ & $\begin{array}{l}\text { N. } 56^{\circ} \mathrm{E} . \\
\text { N. } 48^{\circ} \mathrm{E} . \\
\text { N. } 45^{\circ} \mathrm{E} . \\
\text { N. } 49^{\circ} \mathrm{E} .\end{array}$ & & $\begin{array}{l}\text { S. } \\
\text { S.W. } \\
\text { W. } \\
\text { N.W. }\end{array}$ & $\begin{array}{l}\text { N. } 55^{\circ} \mathrm{E} . \\
\text { N. } 64^{\circ} \mathrm{E} . \\
\text { N. } 68^{\circ} \mathrm{E} . \\
\text { N. } 63^{\circ} \mathrm{E} .\end{array}$ & \\
\hline
\end{tabular}

(b) Magnetic courses : N. $\frac{1}{4}$ E. S. $70^{\circ}$ E. S. $55^{\circ}$ W. N. $8^{\circ}$ W. Compass courses required.

(c) Compass courses : S.S.W. N.W. $\frac{1}{2}$ W. N. S. $82^{\circ}$ E.

Magnetic courses required.

(d) Ship's head by compass: S.W.

Compass bearings: E. $\frac{1}{4}$ N. N. by E.

Maguetic bearings required. 
8. (a) Magnetic bearing required-

\begin{tabular}{c|c|c|c|c|c}
\hline $\begin{array}{c}\text { Ship's head by } \\
\text { compass. }\end{array}$ & $\begin{array}{c}\text { Bearing by } \\
\text { compass. }\end{array}$ & Deviation. & $\begin{array}{c}\text { Ship's head by } \\
\text { compass. }\end{array}$ & $\begin{array}{c}\text { Bearing by } \\
\text { compass. }\end{array}$ & Deviation. \\
\cline { 1 - 2 } N. & N. $44^{\circ}$ W. & & S. & S. $79^{\circ}$ W. \\
N.E. & N. $47^{\circ}$ W. & & S.W. & S. $89^{\circ}$ W. \\
E. & N. $80^{\circ}$ W. & & W. & N. $69^{\circ}$ W. \\
S.E. & S. $76^{\circ}$ W. & & N.W. & N. $52^{\circ}$ W. & \\
\hline
\end{tabular}

(b) Magnetic courses: S. $\frac{1}{2}$ E. S.W. $\frac{1}{4}$ S. N. $80^{\circ}$ W. N. $75^{\circ}$ E. Compass course required.

(c) Compass courses : N.N.W. $\frac{3}{4}$ W. W. by S. $\frac{1}{4}$ S. S. N. $80^{\circ}$ E. Magnetic courses required.

(d) Ship's head by compass : W.

Bearings by compass : E. $11^{\circ} \mathrm{N} . \quad$ N. $6^{\circ} \mathrm{W}$.

Magnetic bearings required.

9. (a) Magnetic bearing required-

\begin{tabular}{|c|c|c|c|c|c|}
\hline $\begin{array}{l}\text { Ship's head by } \\
\text { compass. }\end{array}$ & $\begin{array}{l}\text { Bearing by } \\
\text { compuss. }\end{array}$ & Deviation. & $\begin{array}{l}\text { Ship's head by } \\
\text { compass. }\end{array}$ & $\begin{array}{l}\text { Bearing by } \\
\text { compass. }\end{array}$ & Deviation. \\
\hline $\begin{array}{l}\text { N. } \\
\text { N.E. } \\
\text { E. } \\
\text { S.E. }\end{array}$ & $\begin{array}{l}\text { N. } 32^{\circ} \mathrm{W} . \\
\text { N. } 20^{\circ} \mathrm{W} . \\
\text { N. } 5^{\circ} \mathrm{E} . \\
\text { N. } 17^{\circ} \mathrm{E} .\end{array}$ & & $\begin{array}{l}\text { S. } \\
\text { S.W. } \\
\text { W. } \\
\text { N.W. }\end{array}$ & $\begin{array}{l}\text { N. } 20^{\circ} \mathrm{E} . \\
\text { N. } 9^{\circ} \mathrm{E} . \\
\text { N. } 15^{\circ} \mathrm{W} . \\
\text { N. } 31^{\circ} \mathrm{W} .\end{array}$ & \\
\hline
\end{tabular}

(b) Magnetic courses: S. $65^{\circ}$ W. N.W. N. $32^{\circ}$ E. E. Compass courses required.

(c) Compass courses: N. N.E. by N. E. by S. S.W. $\frac{1}{2}$ S. Magnetic courses required.

(d) Ship's head by compass E.

Bearings by compass : W. $\frac{1}{4} \mathrm{~N}$. S. by W. $\frac{3}{4} \mathrm{~W}$.

Magnetic bearings required.

10. (a) Magnetic bearing required-

\begin{tabular}{|c|c|c|c|c|c|}
\hline $\begin{array}{l}\text { Ship's head by } \\
\text { compass. }\end{array}$ & $\begin{array}{l}\text { Bearing by } \\
\text { compass. }\end{array}$ & Deviatime. & $\begin{array}{l}\text { Ship's head by } \\
\text { compass. }\end{array}$ & $\begin{array}{l}\text { Bearing by } \\
\text { compass. }\end{array}$ & Deviation. \\
\hline $\begin{array}{l}\text { N. } \\
\text { N.E. } \\
\text { E. } \\
\text { S.E. }\end{array}$ & $\begin{array}{l}\text { 8. } 43^{\circ} \mathrm{W} \text {. } \\
\text { S. } 50^{\circ} \mathrm{W} \text {. } \\
\text { S. } 65^{\circ} \mathrm{W} \text {. } \\
\text { S. } 80^{\circ} \mathrm{W} .\end{array}$ & & $\begin{array}{l}\text { S. } \\
\text { S.w. } \\
\text { W. } \\
\text { N.w. }\end{array}$ & $\begin{array}{l}\text { W. } \\
\text { S. } 83^{\circ} \mathrm{W} \text {. } \\
\text { S. } 65^{\circ} \mathrm{W} \text {. } \\
\text { S. } 45^{\circ} \mathrm{W} \text {. }\end{array}$ & \\
\hline
\end{tabular}

(b) Correct magnetic courses : S.E. by E. N.N.E. N.W. $\frac{1}{2}$ W. S. $10^{\circ} \mathrm{W}$.

Compass courses required.

(c) Compass courses : N.W. by W. N. by W. N.E. $\frac{1}{2}$ E. S. $50^{\circ}$ E. Magnetic courses required.

(d) Ship's head: E. $\frac{1}{2}$ N.

Bearings by compass : S.E. $\frac{3}{4}$ E. N.E. by N.

Magnetic bearings required. 
11. (a) Magnetic bearing required-

\begin{tabular}{|c|c|c|c|c|c|}
\hline $\begin{array}{l}\text { Ship's head by } \\
\text { compass. }\end{array}$ & $\begin{array}{l}\text { Bearing by } \\
\text { compass. }\end{array}$ & Deviation. & $\begin{array}{l}\text { Ship's head by } \\
\text { compass. }\end{array}$ & $\begin{array}{l}\text { Bearing by } \\
\text { compass. }\end{array}$ & Deviation. \\
\hline $\begin{array}{l}\text { N. } \\
\text { N.E. } \\
\text { E. } \\
\text { S.E. }\end{array}$ & $\begin{array}{l}\text { S. } 2^{\circ} \mathrm{W} . \\
\text { S. } 7^{\circ} \mathrm{W} . \\
\text { S. } 6^{\circ} \mathrm{E} . \\
\text { S. } 16^{\circ} \mathrm{E} .\end{array}$ & & $\begin{array}{l}\text { S. } \\
\text { S.W. } \\
\text { w. } \\
\text { N.W. }\end{array}$ & $\begin{array}{l}\text { S. } 29^{\circ} \mathrm{K} . \\
\text { S. } 26^{\circ} \mathrm{E} . \\
\text { S. } 15^{\circ} \mathrm{E} . \\
\text { S. } 3^{\circ} \mathrm{E} .\end{array}$ & \\
\hline
\end{tabular}

(b) Magnetic courses : W. N. $30^{\circ}$ E. S. $56^{\circ}$ E. S. $3^{\circ}$ W. Compass courses required.

(c) Compass courses : E. N.E. by N. $\frac{1}{4}$ N. N.W. by W. S. $3^{\circ}$ E: Magnetic courses required.

(d) Ship's head by compass: S.E.

Bearings by compass : N. E. by N. $\frac{3}{4} \mathrm{~N}$.

Magnetic bearings required.

12. (a) Magnetic bearing required-

\begin{tabular}{|c|c|c|c|c|c|}
\hline $\begin{array}{l}\text { Ship's hrad by } \\
\text { compass. }\end{array}$ & $\begin{array}{l}\text { Bearing by } \\
\text { compass. }\end{array}$ & Deviation. & $\begin{array}{l}\text { Ship's head by } \\
\text { compass. }\end{array}$ & $\begin{array}{l}\text { Bearing by } \\
\text { compass. }\end{array}$ & Deviation. \\
\hline $\begin{array}{l}\text { N. } \\
\text { N.E. } \\
\text { E. } \\
\text { S.E. }\end{array}$ & $\begin{array}{l}\text { N. } \\
\text { N. } 7^{\circ} \mathrm{E} . \\
\text { N. } 10^{\circ} \mathrm{W} . \\
\text { N. } 13^{\circ} \mathrm{W} .\end{array}$ & & $\begin{array}{l}\text { S. } \\
\text { S.W. } \\
\text { W. } \\
\text { N.W. }\end{array}$ & $\begin{array}{l}\text { N. } 21^{\circ} \mathrm{W} . \\
\text { N. } 17^{\circ} \mathrm{W} . \\
\text { N. } 18^{\circ} \mathrm{E} . \\
\text { N. } 16^{\circ} \mathrm{E} .\end{array}$ & \\
\hline
\end{tabular}

(b) Magnetic courses : E.S.E. S.S.E. W. by N. N.E. $\frac{1}{4}$ N. Compass courses required.

(c) Compass courses : N. $\frac{1}{2}$ W. W. $\frac{3}{4}$ N. N.E. $\frac{3}{4}$ N. E. Magnetic courses required.

(d) Ship's head by compass : N.E. Bearings by compass: S.W. $\frac{1}{4}$ S. S.E $\frac{3}{4}$ S. Magnetic bearings required. 


\section{CHAPTER XXI.}

\section{GREAT CIRCLE SAILING.}

ArT. 95.-A circle is really a plane surface bounded by a line called the circumference, but it is common to speak of this line as the circle.

A great circle of the globe is one which divides it in halves. Hence the Equator is a great circle, and as all great circles bisect one another, every other great circle must intersect the Equator in two opposite points (Fig. 146). A meridian of longitude cuts the Equator at right angles, but other great circles cross it more or less obliquely, and go to equal distances north and south. The two points on the Great Circle which are farthest from the Equator are called the Vertexes, and the meridian of longitude which passes through the Vertex is called the Meridian of Vertex.

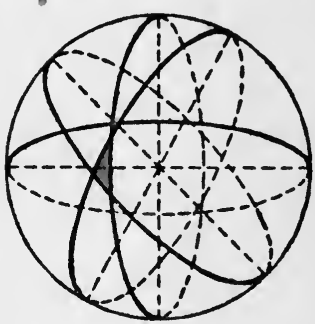

Fig. 146.

Now, the shortest distance between any two places on the globe is the arc of the Great Circle passing through them. Therefore, when this route is practicable, the navigator would save time in a sailing vessel, and coals as well as time in a steamship, by following the Great Circle track.

Illustration (Fig. 147).- - Let A be the starting-point, and B the destination, $A V B$ the arc of the Great Circle passing through the two places, $\mathrm{P}$ the north pole, $\mathrm{PA}$ and $\mathrm{PB}$ the meridians of longitude through $A$ and $B$, and $V$ the highest latitude reached on the parallel $\mathrm{LL}_{1}$ and meridian of vertex PVM; then-

The $\angle A P B$ is the Difference of Longitude of $A$ and $B$.

The $\angle \mathrm{PAB}$ is the Initial Course.

The $\angle$ PBA " Final Course.

$\mathrm{AB} "$ Distance on the

Great Circle.

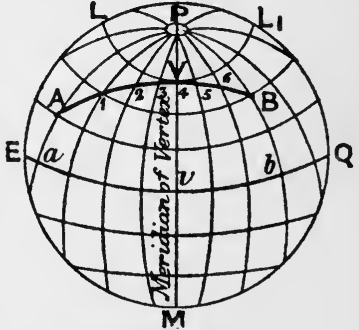

FIg 147.

$v \mathrm{~V}$ is the Latitude of Vertex.

The $\angle \mathrm{APV}$ (or arc $a v$ ) is the Longitude of A from Vertex. 
The $\angle \mathrm{BPV}$ (or arc $b v$ ) is the Longitude of $\mathrm{B}$ from Vertex. $\mathrm{PA}$ and $\mathrm{PB}$, Co-latitudes of $\mathrm{A}$ and $\mathrm{B}$.

PV, Co-latitude of Vertex.

$1,2,3,4,5,6$, points on the Great Circle.

N.B. - The Meridian of Vertex is at right angles to the Great Circle.

Inspection of the figure shows that the course from $\mathrm{A}$ would first be northerly until the Vertex is reached, where it would be due east, and then southerly to B. From B to A these directions would be reversed.

In proceeding along the Great Circle the course would change at each instant, but as this would not be possible in navigation, Great Circle sailing in practice consists in fixing the latitude and longitude of a number of points on the circle, and then shaping courses from point to point by Mercator's sailing. The greater the number of points chosen the nearer would the ship's track approximate to the Great Circle.

The co-latitudes PA and $\mathrm{PB}$ and the distance $\mathrm{AB}$ are three sides of a spherical triangle, of which two sides (the co-latitudes) and the included angle (difference of longitude) are known. From these data all the other details can be found by the principles of spherical trigonometry.

These details are-

(1) The initial and final courses.

(2) The distance on the Great Circle.

(3) The latitude and longitude of Vertex.

(4) The longitude from Vertex of A and B.

(5) The latitudes and longitudes of points on the Great Circle. point.

(6) The courses and distances by Mercator from point to

ART. 96. Great Circle Sailing (Fig. 148).-Let AB be the arc of a great circle from the startingpoint (A) to the destination (B), and $\mathrm{CA}, \mathrm{CB}$ arcs of meridians of longitude; then the angles $A$ and $B$ are the initial and final courses, the angle $\mathbf{C}$ is the difference of longitude, and $\mathrm{CA}, \mathrm{CB}$ the co-latitudes of $\mathrm{A}$ and $\mathrm{B}$.

Also, let the arc $\mathrm{CV}$ be drawn at right angles to $A B$; then $V$ is the vertex, and CV the co-latitude of vertex, putting the letters $a, b, c$ for the sides respectively opposite the angles $A, B, C$, and using the formulæ for oblique-

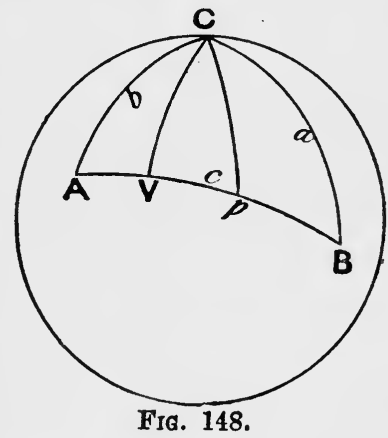
angled spherical triangles when two sides and included angle are known, we have- 


$$
\begin{aligned}
& \text { TEXT-BOOK ON NAVIGATION. } \\
& \text { Tan } \frac{1}{2}(\mathrm{~A}+\mathrm{B})=\frac{\cos \frac{1}{2}(a-b)}{\cos \frac{1}{2}(a+b)} \cdot \cot \frac{1}{2} \mathrm{C} \\
&=\frac{\sin \frac{1}{2}(a-b)}{\sin \frac{1}{2}(a+b)} \cdot \cot \frac{1}{2} \mathrm{C}
\end{aligned}
$$

The latitude of vertex, longitude from vertex, and the latitudes of points on the great circle are found by applying the rules for the solution of right-angled spherical triangles.

1. To find "Latitude of Vertex." - In the right-angled triangle $\mathrm{ACV}$ are known the angle $\mathrm{A}$ and the side $\mathrm{AC}$.

Taking CV (co-latitude of V) as middle part, the opposite parts are comp. of $\mathrm{A}$ and comp. of $\mathrm{AC}$;

$$
\text { therefore } \begin{aligned}
\sin \mathrm{CV} & =\cos (\operatorname{comp} . \text { of } \mathrm{A}) \times \cos (\mathrm{comp} . \text { of } \mathrm{AC}) \\
& =\sin \mathrm{A} \times \sin \mathrm{AC}
\end{aligned}
$$

2. To find "Longitude from Vertex" of A, viz. the angle $\mathrm{ACV}$.- In the same triangle, taking comp. of $\mathrm{AC}$ as middle part, comp. of ACV, and the comp. of A are adjacent parts ;

$$
\begin{aligned}
\therefore \sin (\text { comp. of } A C) & =\tan (\text { comp. of } A C V) \cdot \tan (\text { comp. of } A) \\
\text { Hence } \cos A C & =\cot A C V \cdot \cot A \\
\text { or } \cot A C V & =\cos A C \cdot \tan A
\end{aligned}
$$

Similarly, the latitude of $\mathrm{V}$ and "longitude from $\mathrm{V}$ " of $\mathrm{B}$ can be found from the triangle BCV.

The longitude of the vertex can be found by applying the "longitude from vertex" to the longitude of A or B.

3. To find the Latitude of a Point $(p)$ whose "Longitude from Vertex" (is assumed) (viz. the angle $p \mathrm{CV}$ ). - In the right-angled triangle $p \mathrm{VC}$, the side $\mathrm{CV}$ and the angle $p \mathrm{CV}$ being known-

$$
\begin{aligned}
\sin (\operatorname{comp} . \text { of } p \mathrm{CV}) & =\tan \mathrm{CV} \times \tan (\operatorname{comp} . \text { of } \mathrm{C} p) \\
\text { or } \cos p \mathrm{CV} & =\tan \mathrm{CV} \times \cot \mathrm{C} p \\
\text { transposing, } \cot \mathrm{C} p & =\frac{\cos p \mathrm{CV}}{\tan \mathrm{CV}}=\cos p \mathrm{CV} \times \cot \mathrm{CV}
\end{aligned}
$$

Similarly, the latitudes of other points on the great circle track can be found. The courses and distances from point to point are calculated as in Mercator's sailing.

ART. 97. Naming the Courses.-When the Vertex falls on the portion of the G.C. arc joining the two places, it is said to be "in;" when the Vertex is not situated on this arc, but on the arc produced, it is said to be "out." This can be decided 
when the initial and final courses have been computed; for if they are on the same side of $90^{\circ}$ the vertex is "in," but if one is greater and the other less than $90^{\circ}$ it is "out," and is in every case on the same side of the Equator as the greater latitude.

The first course is always of the same name, N. or S., as the Pole used in the calculation; the last course of contrary name to this; both are named E. or W. like a Mercator course.

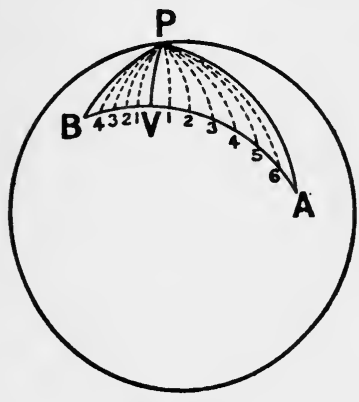

Fig. 149.

\section{Example.-Vertex "IN."}

Required the initial and final courses and the distance on the Great Circle from (A) San Lucas to (B) Yokohama; also the position of the Vertex, and position of points on G.C. differing $10^{\circ}$ in longitude.

A lat. $22^{\circ} 52^{\prime} \mathrm{N} . \therefore \mathrm{PA}=67^{\circ} 8^{\prime}$ long. $109^{\circ} 53^{\prime} \mathrm{W}$. $\mathrm{B},, 3526 \mathrm{~N} . \therefore \mathrm{PB}=5434,, 13939 \mathrm{E}$.

$$
\begin{aligned}
& \mathrm{PA}+\mathrm{PB}=12142 \quad 24932 \\
& \frac{1}{2}(\mathrm{PA}+\mathrm{PB})=6051 \quad 360 \quad 0 \\
& \mathrm{PA}-\mathrm{PB}=1234 \mathrm{P}=\overline{11028} \\
& \frac{1}{2}(\mathrm{PA}-\mathrm{PB})=617 \frac{\mathrm{P}}{2}=5514
\end{aligned}
$$

In triangle $\mathrm{PAB}$, given $\mathrm{PA}, \mathrm{PB}$, and $\mathrm{P}$, required $\mathrm{A}, \mathrm{B}$, and $\mathrm{AB}$.

$$
\begin{aligned}
\operatorname{Tan} \frac{B+A}{2} & =\frac{\cos \frac{1}{2}(P A-P B)}{\cos \frac{1}{2}(P A+P B)} \cdot \cot \frac{P}{2} \\
\operatorname{Tan} \frac{B-A}{2} & =\frac{\sin \frac{1}{2}(P A-P B)}{\sin \frac{1}{2}(P A+P B)} \cdot \cot \frac{P}{2} \\
\operatorname{Cos} \frac{A B}{2} & =\frac{\cos \frac{1}{2}(P A+P B)}{\cos \frac{1}{2}(B+A)} \cdot \sin \frac{P}{2}
\end{aligned}
$$

$$
\begin{aligned}
& \frac{1}{2}(\mathrm{PA}+\mathrm{PB})=60^{\circ} 51^{\prime} \quad \sec =10 \cdot 312384 \quad \operatorname{cosec}=10 \cdot 058813 \cos =9 \cdot 687616 \\
& \frac{1}{2}(\mathrm{PA}-\mathrm{PB})=\begin{array}{llll}
6 & 17 & \cos =9.997383 & \sin =9.039197
\end{array} \\
& \frac{\mathrm{P}}{2}=5514 \quad \cot =9 \cdot 841457 \quad \cot =9 \cdot 841457 \quad \sin =9 \cdot 914598
\end{aligned}
$$

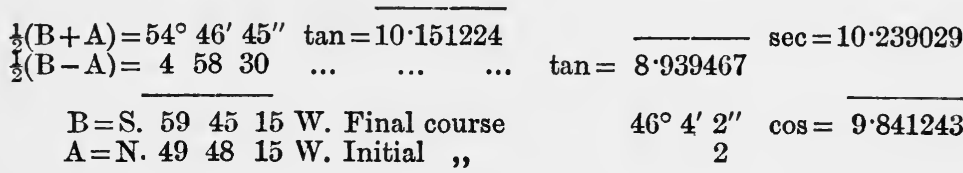

$$
\begin{aligned}
& \mathrm{AB}=928 \quad 4=5528 \cdot 1 \text { miles. }
\end{aligned}
$$

Since A and B are of same affection, vertex is "in."

To find position of vertex "V."

In triangle $\mathrm{PAV}, \mathrm{V}=90^{\circ}$. Given $\mathrm{PA}$ and $\mathrm{A}$, required $\mathrm{PV}=$ co-lat. $\mathrm{V}$, $\mathrm{P}=d$ long. of $\mathrm{V}$ from $\mathrm{A}$.

$\operatorname{Sin} \mathrm{PV}=\cos (\mathrm{co} . \mathrm{A}) \cdot \cos (\mathrm{co} . \mathrm{PA})$ and $\sin (\operatorname{co} . \mathrm{PA})=\tan ($ co. P) $\cdot \tan (\mathrm{co} . \mathrm{A})$ $=\sin \mathrm{A} \cdot \sin \mathrm{PA}$ or $\cos \mathrm{PA}=\cot \mathrm{P} . \cot \mathrm{A}$ $\therefore \cot P=\cos P A \cdot \tan A$ 


$$
\begin{aligned}
& A=49^{\circ} 48^{\prime} 15^{\prime \prime} \sin =9.883004 \quad \ldots \quad \ldots \quad \tan =10.073174 \\
& \begin{array}{llllll}
\mathbf{P A}=67 & 8 & \sin =9.964454 & \ldots & \ldots & \cos =9.589489
\end{array} \\
& \mathrm{PV}=44 \quad 44 \quad \sin =\overline{9.847458} \quad \ldots \quad 65^{\circ} 18^{\prime} \cot =\overline{9.662663} \\
& \therefore \text { Lat. } \mathrm{V}=45^{\circ} 16^{\prime} \mathrm{N} \text {. Long. A } 109^{\circ} 53^{\prime} \mathrm{W} \text {. }
\end{aligned}
$$$$
\therefore \text { Long. V } \overline{17511} \mathrm{~W} \text {. }
$$

To find "points" on the G.C. differing $10^{\circ}$ in long.-Since no particular neridian is stated in the question as the starting-point, the simplest way is so calculate from the vertex, using the angles at $\mathbf{P}$ or differences of long. as $10^{\circ}, 20^{\circ}, 30^{\circ}$, etc. As the total $d$ long. between $A$ and $V$ is $65^{\circ} 18^{\prime}$, the number of points will be $\frac{65}{10}=6$. The latitudes of points equally distant from the vertex are the same; hence, these lats. will do for either side of vertex.

Thus, if $1,2,3,4,5,6$ represent points, respectively $10^{\circ}, 20^{\circ}, 30^{\circ}, 40^{\circ}$, $50^{\circ}, 60^{\circ}$ from the vertex, there are a series of triangles, PV1, PV2, PV3, etc., to solve, all right angled at V; PV is co-lat. V, and angles at $\mathrm{P}$ are $10^{\circ}$, $20^{\circ}, 30^{\circ}$, etc., to find $\mathrm{P} 1, \mathrm{P} 2, \mathrm{P} 3$, etc. -

$$
\begin{aligned}
& \operatorname{Sin}(\cos \mathrm{P})=\tan \mathrm{PV} \cdot \tan (\operatorname{co} . \mathrm{P} 1) \\
& \therefore \cot P 1=\cos P \cdot \cot P V \text {. } \\
& \mathrm{PV}=44^{\circ} 44^{\prime} \quad \cot =10.004043 \quad \ldots \quad \ldots \quad \cot =10.004043 \\
& \mathbf{P}=10 \quad \cos =9.993351 \quad \ldots \quad \ldots 20^{\circ} \cos =\mathbf{9} \cdot 972986 \\
& 4510 \frac{1}{2} \cot =\overline{9.997394} \quad \ldots \quad 46^{\circ} 31^{\prime} \cot =\overline{9.977029} \\
& \mathrm{PV}=44^{\circ} 44^{\prime} \quad \cot =10.004043 \quad \ldots \quad \ldots \quad \quad \cot =10.004043 \\
& \mathrm{P}=30 \quad \cos =9.937531 \quad \ldots \quad \ldots 40^{\circ} \quad \cos =9.884254 \\
& 4850 \frac{1}{2}, \cot =\overline{9 \cdot 941574} \quad \ldots \quad 52^{\circ} 17 \frac{1}{2}^{\prime} \cot =\overline{9 \cdot 888297} \\
& \mathrm{PV}=44^{\circ} 44^{\prime} \quad \cot =10.004043 \quad \ldots \quad \ldots \quad \quad \ldots \quad \cot =10.004043 \\
& \mathrm{P}=50 \quad \cos =9.808067 \quad \ldots . \quad \ldots 60^{\circ} \quad \cos =9.698970 \\
& 57 \quad 1 \frac{1}{2} \cot =\overline{9 \cdot 812110} \quad \ldots \quad 63^{\circ} 13^{\prime}{ }^{\prime} \cot =\overline{9 \cdot 703013}
\end{aligned}
$$

These are the co-lats. of the points which may now be arranged in orcler from $A$ to $B$, thus-

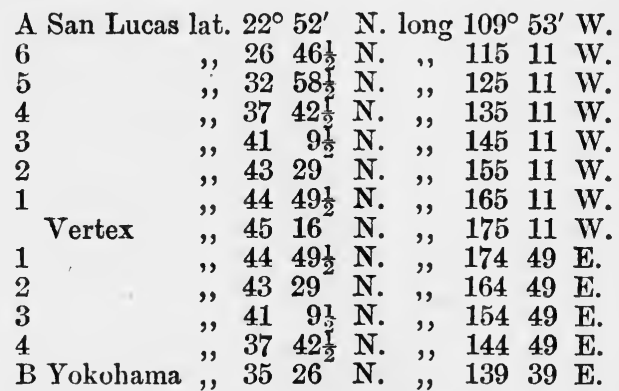

These positions set off on a chart and joined by a curve, give the G.C. track.

As it is impossible to keep a ship on the track, points are taken differing very little in long., say $2^{\circ}$, and courses steered from point to point by Mercator. Should a vessel be driven far from the track by stress of weather, the navigator should strike a new G.C. from the actual position of the ship, and not work back to the original one. 
Example. Vertex "out."

Required the initial and final courses, and distance on the G.C. from Start to Barbadoes; also position of the vertex, and position of a succession of points differing $5^{\circ}$ in long. commencing where the $5^{\circ} \mathrm{W}$. meridian cuts the track.

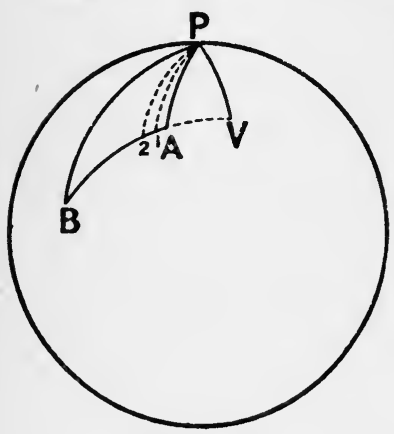

Fig. 150.

Start lat. $50^{\circ} 13^{\prime} \mathrm{N} . \mathrm{AP}=39^{\circ} 47^{\prime}$ long. $3^{\circ} 39^{\prime} \mathrm{W}$. Barb. , 133 N. BP $=7657$," $5737 \mathrm{~W}$.

$$
\begin{aligned}
& \mathrm{BP}+\mathrm{AP}=11644 \mathrm{P}=5358 \\
& \frac{1}{2}(\mathrm{BP}+\mathrm{AP})=58 \quad 22 \quad \frac{\mathrm{P}}{2}=2659 \\
& B P-A P=3710 \\
& \frac{1}{2}(B P-A P)=1835
\end{aligned}
$$

To solve triangle APB, having given PA, $\mathrm{PB}$, and $\mathrm{P}$.

$$
\begin{aligned}
\operatorname{Tan} \frac{1}{2}(A+B) & =\frac{\cos \frac{1}{2}(B P-A P)}{\cos \frac{1}{2}(B P+A P)} \cdot \cot \frac{P}{2} \\
\operatorname{Tan} \frac{1}{2}(A-B) & =\frac{\sin \frac{1}{2}(B P-A P)}{\sin \frac{1}{2}(B P+A P)} \cdot \cot \frac{P}{2} \\
\operatorname{Cos} \frac{A B}{2} & =\frac{\cos \frac{1}{2}(B P+A P)}{\cos \frac{1}{2}(A+B)} \cdot \sin \frac{P}{2}
\end{aligned}
$$

\begin{tabular}{rlrr}
$\frac{1}{2}(\mathrm{BP}+\mathrm{AP})=58^{\circ} 22^{\prime}$ & $\sec =10.280270$ & $\operatorname{cosec}=10.069855$ & $\cos =9.719730$ \\
$\frac{1}{2}(\mathrm{BP}-\mathrm{AP})=1835$ & $\cos =9.976745$ & $\sin =9.503360$ & \\
$\frac{\mathrm{P}}{2}=2659$ & $\cot =\underline{10.293146}$ & $\cot =10.293146$ & $\sin =\mathbf{9} .656799$ \\
$\frac{1}{2}(\mathrm{~A}+\mathrm{B})=74^{\circ} 15^{\prime} 57^{\prime \prime}$ & $\tan =10.550161$ & & $\sec =10.566751$ \\
\hline
\end{tabular}
$\frac{1}{2}(\mathrm{~A}-\mathrm{B})=361914$

$\tan =9 \cdot 866361$

$A=$ N. 1103511 W. or S. $69^{\circ} 24^{\prime} 49^{\prime \prime}$ W. 1st Co. $28^{\circ} 39^{\prime} \cos =9 \cdot 943280$ $\mathrm{B}=\mathrm{S}$. $\quad 375643 \mathrm{~W}$. Final Course.

Distance $5718=3438$ miles.

Since A and B are of contrary affection, vertex is "out."

To find position of vertex "V."

In triangle $A P V, V=90^{\circ}$. Given $A P$ and $A$, to find $P V$ and $P$.

$\operatorname{Sin} \mathrm{PV}=\cos ($ co. AP) $\cdot \cos (\operatorname{co} . \mathrm{A})$ and $\sin ($ co. AP) $=\tan ($ co. A) $\cdot \tan ($ co. P) $=\sin \mathrm{AP} \cdot \sin \mathrm{A}$

or $\cos A P=\cot A \cdot \cot P$

$\therefore \cot P=\cos A P \cdot \tan A$

$$
\begin{aligned}
& \mathrm{AP}=39^{\circ} 47^{\prime} \sin =9.806103 \\
& A=6925 \text { sin }=9.971351 \\
& \ldots \quad \ldots \quad \cos =9.885627 \\
& \ldots \quad \ldots \quad \tan =10.425340
\end{aligned}
$$

Lat. $\mathrm{V}=5312 \mathrm{~N}$.

Long. A $339^{2}$ W.

Long. V $2223 \frac{1}{2}$ E.

To find a succession of points.

First point where $5^{\circ} \mathrm{W}$. meridian cuts the track.

Long. from V of $1=22^{\circ} 23 \frac{1}{2}^{\prime}+5^{\circ}=27^{\circ} 23 \frac{1}{2}^{\prime}$

In triangle $\mathrm{PV} 1 ; \mathrm{V}=90^{\circ}$ given $\mathrm{PV}$ and $\mathrm{P}$; to find $\mathrm{P} 1$

$$
\begin{aligned}
\sin (\cos \mathrm{P}) & =\tan (\operatorname{co} . \mathrm{P} 1) \cdot \tan \mathrm{PV} \\
\text { or } \cos \mathrm{P} & =\cot \mathrm{P} 1 \cdot \tan \mathrm{PV} \\
\therefore \cot \mathrm{P} 1 & =\cos \mathrm{P} \cdot \cot \mathrm{PV}
\end{aligned}
$$




$$
\begin{aligned}
& \mathbf{P}=27^{\circ} 23 \frac{1}{2}^{\prime} \cos =9 \cdot 948355 \quad \ldots 32^{\circ} 23 \frac{1}{2}^{\prime} \cos =9 \cdot 926551 \\
& \mathrm{PV}=36 \quad 48 \quad \text { cot }=10 \cdot 126043 \quad \ldots \quad \ldots \quad \text { cot }=10 \cdot 126043 \\
& \mathrm{P} 1=407 \cot =10.074398 \mathrm{P} 2=4132 \frac{1}{2} \cot =10.052594 \\
& \text { Points.-1, lat. } 49^{\circ} 53^{\prime} \text { N. long. } 5^{\circ} \mathrm{W} \text {. } \\
& 2 \text {, , } 4827 \frac{1}{2} \text { N. ,, } 10 \text { W. } \\
& \text { and so on. }
\end{aligned}
$$

ART. 98. Composite Great Circle and Parallel Sailing.-When the Great Circle track would take the ship into too high a latitude, then a combination of Great Circle sailing and Parallel sailing is used to obtain the shortest route.

The highest practicable latitude is made the latitude of vertex for the arcs of two Great Circles, one passing through the starting-point, and the other through the destination. The route would then be along the first arc to the Vertex, next on

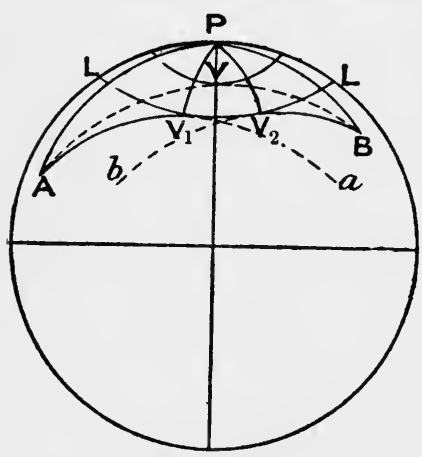

Fig. 151.

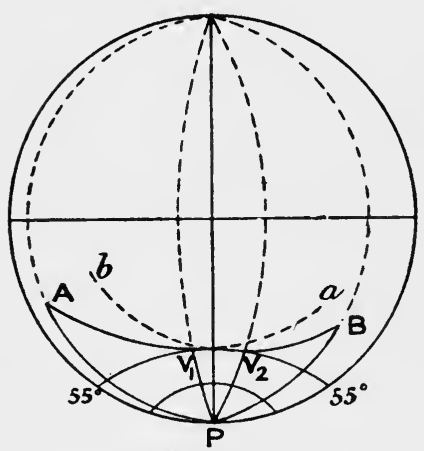

Fig. 152. the parallel of latitude to the Vertex of the other arc, and finally along this arc to the destination.

Illustration (Fig. 151). - Let A be the point of departure, and $B$ the destination, and AVB the arc of the Great Circle whose vertex is V. The parallel $\mathrm{LL}_{1}$ is assumed to be the highest practicable latitude. $A V_{1}$ and $B V_{2}$ are ares of two great circles touching the parallel, $\mathrm{V}_{\mathbf{1}} \mathrm{V}_{\mathbf{2}}$ is the arc of the parallel of latitude or meridian distance, $\mathrm{PV}_{1}$ and $\mathrm{PV}_{2}$ are arcs of the meridians of vertexes and make right angles with $\mathrm{AV}_{1}$ and $\mathrm{BV}_{2}$. The solutions, therefore, depend on right-angled spherical trigonometry and parallel sailing.

Example (Fig. 152).-Required the distance on the composite track from Rio to Cape Leeuwin, taking $55^{\circ}$ as the limit of S. latitude; also the initial and final courses.

\section{Lat. of Rio $23^{\circ} 4^{\prime} \mathrm{S}$.} Long. of Rio $43^{\circ} 8^{\prime} \mathrm{W}$.

Lat. of C. Leeuwin $34^{\circ} 19^{\prime} \mathrm{S}$.

Long. of C. Leeuwin $115^{\circ} 6^{\prime} \mathrm{E}$. $\mathrm{BV}_{2}$.

(1) To find the distances $A V_{1}$ and

In triangle $\mathrm{PAV}_{1}, \mathrm{~V}_{1}=90^{\circ}$ given $\mathrm{AP}$ and $\mathrm{PV}_{1}$

$$
\begin{aligned}
\sin (\cos A P) & =\cos A V_{1} \cdot \cos P_{1} \\
\therefore \cos A V_{1} & =\cos A P_{1} \cdot \sec P_{1}
\end{aligned}
$$

Similarly, $\cos \mathbf{B V}_{2}=\cos \mathrm{BP} \cdot \sec \mathbf{P V}_{2}$ 
Co-lat. of $\mathrm{A} \quad 66^{\circ} \tilde{5} 6^{\prime} \quad \ldots \quad \cos 9 \cdot 593067$

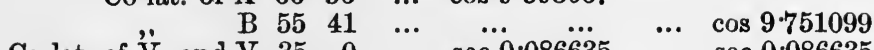

Co-lat. of $\ddot{v}_{1}$ and $\mathrm{V}_{2} 35 \quad 0 \quad \ldots \quad$ sec $0.086635 \quad \ldots \quad$ sec 0.086635

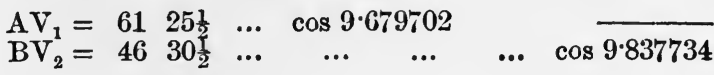

$$
\begin{aligned}
& \text { Sum } 10756 \\
& 60
\end{aligned}
$$

6476 geographical miles.

(2) To find the differences of long. $\mathrm{APV}_{1}$ and $\mathrm{BPV}_{2}$, or longitudes from Vertex.

$$
\begin{aligned}
\text { Sin }(\cos P) & =\tan \mathrm{PV}_{1} \cdot \tan (\cos \mathrm{AP}) \\
\therefore \cos \mathrm{P} & =\tan \mathrm{PV}_{1} \cdot \cot \mathrm{AP} \\
\text { and } \cos \mathrm{P} & =\tan \mathrm{PV}_{2} \cdot \cot \mathrm{BP}
\end{aligned}
$$

Co-lat. of $\mathrm{A} 66^{\circ} 56^{\prime} \quad \ldots \quad \cot 9 \cdot 62925 \overline{0}$

Co-lat. of $\mathrm{V}_{1}$ and $\mathrm{V}_{2} 35 \quad 0 \quad \ldots \quad \tan 9.845227 \quad \ldots \quad \tan 9.845227$

D. long of $A$ and $V_{1} 72 \quad 39 \quad \ldots \quad \cos 9 \cdot 474482$

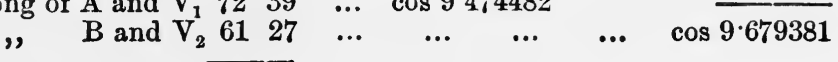

Sum $\overline{134 \quad \overline{6}}$

Total D. long 15814

D. long. $V_{1} V_{2} 248=1448$ geographical miles.

(3) To find the meridian distance between $V_{1}$ and $V_{2}$.

D. long. $1448 \quad \ldots \quad \ldots \quad \log 3 \cdot 160769$

Lat. $\quad 55^{\circ} \quad \ldots \quad \ldots \quad \cos 9 \cdot 758591$

Mer. dist. $830.5 \quad \ldots \quad \ldots \quad \log 2 \cdot 919360$

Arcs of Great Circles 6476

Total dist. $7306 \cdot 5$

Note.-The distance on the Great Circle between A and B is 7131 miles.

(4) To compute the initial and final courses.

$$
\begin{aligned}
\sin \mathrm{PV}_{1} & =\cos (\operatorname{co} \cdot \mathrm{AP}) \cdot \cos (c 0 . \mathrm{A}) \\
& =\sin \mathrm{AP} \cdot \sin \mathrm{A} \\
\therefore \sin \mathrm{A} & =\sin \mathrm{PV}_{1} \cdot \operatorname{cosec} \mathrm{AP} \\
\text { and } \sin \mathrm{B} & =\sin \mathrm{PV}_{2} \cdot \operatorname{cosec} \mathrm{BP}
\end{aligned}
$$

Co-lat. of $\mathrm{A} 66^{\circ} 56^{\prime} \quad \ldots \quad \operatorname{cosec} 0.036189$

Co-lat. "' $\begin{array}{rrrrrrrr}\text { B } & 55 & 41 & \ldots & \ldots & \ldots & \ldots & \operatorname{cosec} 0.083054\end{array}$

Initial co. S. $38 \quad 34 \mathrm{E} . . . \quad$ sine $\overline{9 \cdot 794780}$

Final co. N. $4359 \mathrm{E}$.... $\quad \ldots \quad \ldots \quad \ldots \quad$ sine $\overline{9 \cdot 841645}$

(5) To find the longitudes of $\mathrm{V}_{1}$ and $\mathrm{V}_{2}$.
Long. of A $43^{\circ} \quad 8^{\prime} \mathrm{W}$.
Long. of B $115^{\circ} 6^{\prime} \mathrm{E}$.

D. Long. to $V_{1} 7239$ E.

Long. of $V_{1} \overline{2931} \mathrm{E}$.

D. long. to $\mathrm{V}_{2} 6127 \mathrm{~W}$.

Long. of $\mathrm{V}_{2} 53 \quad 39 \mathrm{E}$. 
Various points on the arcs $A V_{1}$ and $B V_{2}$ can be fixed as in G.C.S. either by assuming intervals of longitude from $V_{1}$ towards $A$, and from $V_{2}$ towards $B$, or by working from a fixed meridian to destination.

AR'r. 99. Windward Great Circle Sailing.-What is called Windward Great Circle sailing applies only to sailing vessels, and consists in putting the ship on the tack on which her course would be nearest to the Great Circle track withont reference to the Rhumb or Chart course, which in some cases would differ four or five points or more from the former.

Illustration (Fig. 153).- - Let $\mathrm{O}$ be the starting-point, and

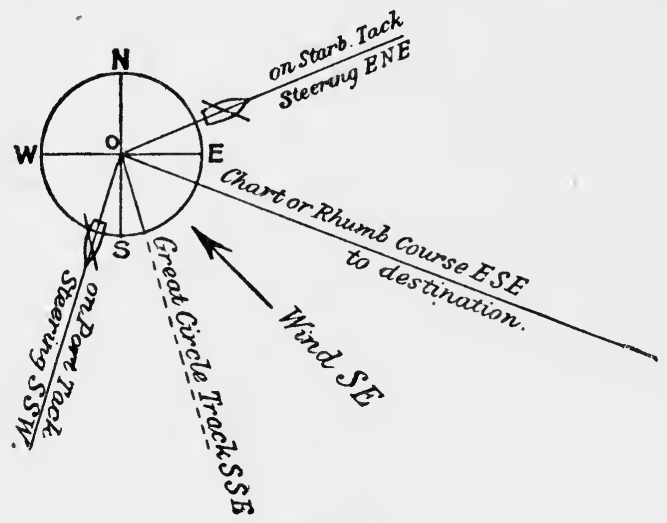

Fig. 153.

'suppose destination to bear E.S.E. by Chart, the Great Circle course from $\mathrm{O}$ being S.S.E.

With the wind at S.E., the course on the starboard tack would be E.N.E. and on the port tack S.S.W. It is evident that on the port tack the ship's head would only be four points off the shortest route, whilst on the starboard tack she would be steering at right angles to it. In sailing 100 miles on the former course the Traverse Table shows that she would make 70 miles towards her destination, but on the latter she would be no nearer to it, having sailed on a line at right angles to the direct route on the globe.

With the wind at S.E. by S., and steering S.W. by S. (apparently away from destination, according to chart), she would still gain 36 miles in 100 miles sailed, whilst on the starboard tack, steering E. by N., she would make good only 19 miles.

Other still more striking cases might be given, but the above are sufficient to show the advantage of the method.

All problems in Great Circle sailing, Composite sailing, and Windward Great Circle sailing can best be understood from a 
globe. A pair of 12-inch globes should be in every ship's equipment.

\section{Exercises.-Great Circle Sailina.}

1. Find the first and final courses from Cape of Good Hope, lat. $34^{\circ} 22^{\prime}$ S., long. $18^{\circ} 30^{\prime}$ E., to Rio Janeiro, lat. $22^{\circ} 55^{\prime} \mathrm{S}$., long. $43^{\circ} 9^{\prime} \mathrm{W}$.; also find the distance, latitude, and longitude of Vertex, and a succession of points for every five degrees of longitude.

2. Find the first and last courses, and distance from San Francisco, lat. $37^{\circ} 49^{\prime} \mathrm{N}$., long. $122^{\circ} 29^{\prime}$ W., to Yokohama, lat. $35^{\circ} 26^{\prime}$ N., long. $139^{\circ} 39^{\prime}$ E., the latitude and longitude of Vertex, and a succession of points for every twenty degrees of longitude.

3. Find the initial and final courses, distance on the Great Circle, latitude and longitude of Vertex, and a succession of points differing $10^{\circ}$ in longitude.

From A, lat. $33^{\circ} 51^{\prime}$ S., long. $151^{\circ} 16^{\prime} \mathrm{E}$.

To B, , 3747 N., ,, $12230 \mathrm{~W}$.

4. Find the initial and final courses, distance on the Great Circle, latitude and longitude of Vertex, and a succession of points differing $20^{\circ}$ in longitude.

From A, lat. $22^{\circ} 16^{\prime} \mathrm{N}$., long. $114^{\circ} 10^{\prime} \mathrm{E}$.

To B, ", $124 \mathrm{~S}$,, , $7716 \mathrm{~W}$.

5. Find the initial and final courses, distance on the Great Circle, latitude and longitude of Vertex, and a succession of points differing $5^{\circ}$ in longitude.

$$
\begin{gathered}
\text { From A, lat. } 52^{\circ} 12^{\prime} \mathrm{N} . \text {, long. } 6^{\circ} 12^{\prime} \mathrm{W} \text {. } \\
\text { To B, ,, } 137 \mathrm{~N} \text {., ,, } 5925 \mathrm{~W} \text {. }
\end{gathered}
$$

6. Find the initial and final courses, distance on the Great Circle, latitude and longitude of Vertex, in sailing.

$$
\begin{gathered}
\text { From R, lat. } 43^{\circ} 40^{\prime} \mathrm{N} \text {., long. } 150^{\circ} 37^{\prime} \mathrm{E} \text {. } \\
\text { To Q, , } 4340 \mathrm{~N} \text {., ,, } 15037 \mathrm{~W} \text {. }
\end{gathered}
$$

Also find latitude of point where the meridian of $155^{\circ}$ E. cuts the track, and a succession of points differing $5^{\circ}$ in longitude, from thence to destination.

7. Find the initial and final courses, distance on the Great Circle, position of Vertex, and a succession of points starting in long. $120^{\circ} \mathrm{W}$., and differing $5^{\circ}$ in longitude to Equator.

$$
\begin{gathered}
\text { From X., lat. } 38^{\circ} 27^{\prime} \mathrm{N} . \text {, long. } 100^{\circ} 26^{\prime} \mathrm{W} \text {. } \\
\text { To Y., ,, } 3827 \text { S., ,, } 15047 \mathrm{E} \text {. }
\end{gathered}
$$

8. A ship sails from Rio de Janeiro, lat. $22^{\circ} 54^{\prime} \mathrm{S}$., long. $43^{\circ} 6^{\prime} \mathrm{W}$., to Madeira, lat. $32^{\circ} 43^{\prime} \mathrm{N}$., long. $16^{\circ} 40^{\prime} \mathrm{W}$. Find longitude of point where the track crosses the Equator.

9. The point of "Maximum Separation in Latitude" on a Great Circle, is that point where the Great Circle course is the same as the Mercator course. Find the latitude of such a point in sailing from lat. $40^{\circ} 30^{\prime} \mathrm{N}$., long. $120 \mathrm{E}$., to lat. $45^{\circ} \mathrm{N}$., long. $172^{\circ} \mathrm{E}$.

10. One Vertex of a great circle is in lat. $50^{\circ} \mathrm{N} .70^{\circ} \mathrm{W}$.: what is position of the other Vertex? A ship sailing on a Great Circle crosses the Equator: show that the course at that time = complement lat. Vertex.

11. In sailing from lat. $34^{\circ} 51^{\prime} \mathrm{S}$., long. $20^{\circ} \mathrm{E}$., to lat. $34^{\circ} 19^{\prime} \mathrm{S}$., long. $115^{\circ} 6^{\prime} \mathrm{E}$., on a Great Circle arc, how far would the vessel be from Kerguelen island, lat. $49^{\circ} 54^{\prime} \mathrm{S}$., long. $70^{\circ} 12^{\prime} \mathrm{E}$., when upon same meridian as island?

12. A ship starts from A on the course N. $64^{\circ} 12^{\prime} \mathrm{E}$, , and sails on a Great Circle arc to $B$; she increases her distance from the Equator till she gets into long. $19^{\circ} 26^{\prime} 30^{\prime \prime} \mathrm{W}$. on parallel $51^{\circ} 50^{\prime} 30^{\prime \prime} \mathrm{N}$., and then diminishes it. Find lat. and long. of $\mathrm{A}$ and $\mathrm{B}$, their diff. long. being $43^{\circ} 34^{\prime}$. 


\section{Exercises.-Composite SaIlina.}

1. Find the first and last courses and distance from Bahia Blanca, lat. $38^{\circ} 59^{\prime}$ S., long. $61^{\circ} 39^{\prime} \mathrm{W}$., to Cape Lewin, lat. $34^{\circ} 31^{\prime}$ S., long. $115^{\circ} 6^{\prime} \mathbf{E}$. ; easting to be run on the parallel of $45^{\circ} \mathrm{S}$. Find also the longitudes of points of arrival at and departure from the parallel.

2. On a composite track from Cape S. Mary, lat. $16^{\circ} 40^{\prime}$ S., long. $50^{\circ} 4^{\prime} \mathrm{E}$., to Mont Video, lat. $34^{\circ} 43^{\prime} \mathrm{S}$., long. $56^{\circ} 16^{\prime} \mathrm{W}$., the westing to be run on the parallel of $40^{\circ} \mathrm{S}$. Required the first and last courses, total distance, and longitudes of points of arrival at and departure from the given parallel.

3. Find the first and last courses, distance, and longitudes of arrival at and departure from parallel of $50^{\circ} \mathrm{N}$. when sailing on a composite track from Yokohama, lat. $35^{\circ} 26^{\prime} \mathrm{N}$., long. $139^{\circ} 39^{\prime}$ E., to Cape Flattery, lat. $48^{\circ} 23^{\prime} \mathrm{N}$., long. $124^{\circ} 44^{\prime} \mathrm{W}$.

4. Find the first and last courses and distance when sailing on a composite track from Valparaiso, lat. $33^{\circ} 2^{\prime}$ S., long. $71^{\circ} 28^{\prime}$ W., to Port Lyttelton, lat. $43^{\circ} 36^{\prime} \mathrm{S}$., long. $172^{\circ} 50^{\prime}$ E., the westing being run on the latitude of Port Lyttelton ; also the position of a succession of points from long. $73^{\circ} \mathrm{W}$., and every $5^{\circ}$ to destination. 


\section{CHAPTER XXII.}

LATITUDE BY DOUBLE ALTITUDES.

ART. 100. Double Altitudes.-This is a problem for determining the latitude from-

(a) Two different altitudes of the same object (Sun, Moon, Star, or Planet).

(b) Simultaneous altitudes of two different objects.

The data required for the computation are-

(1) The polar angle.

(2) The two altitudes.

(3) The declination.

Definition. - The polar angle is the angle at the Pole between the hour circles passing through the two positions of the object or objects.

(1) For the Sun, the polar angle is the interval between the apparent times of observation; therefore, if mean times are given, the equation of time must be applied to each, or the change of equation of time applied to the mean time interval.

The rule for applying this correction is-

If Eq. of Time be additive to mean time and increasing add.

" " subtractive from mean time and decreasing add.

" " additive to mean time and decreasing subtract.

" " subtractive from mean time and increasing subtract.

Thus, if the mean interval on August 28th is $4^{\mathrm{h}} 30^{\mathrm{m}} 18^{\mathrm{s}}$, what is the apparent interval?

H.V. Eq. of T. $\cdot 72$

Int. $4: 5$

\begin{tabular}{lrr}
$\overline{360}$ & Mean Int. $4^{\mathrm{h}} 30^{\mathrm{m}} 18^{\mathrm{s}}$ \\
$\overline{288}$ & Change in Int. & $+3 \cdot 2$ \\
\hline $3 \cdot 240$ & App. Int. $\overline{45 \quad 21 \cdot 2}$
\end{tabular}

The change being added because the Eq. of Time is subtractive from mean time and decreasing.

(2) A Star's polar angle is the interval of sidereal time 
between the observations, and is found by accelerating the mean interval for the interval.

Thus, if the mean interval is $4^{\mathrm{h}} 30^{\mathrm{m}} 18^{\mathrm{s}}$, what is the sidereal interval ?

$$
\begin{aligned}
& \text { Mean Int. } 4^{\mathrm{h}} 30^{\mathrm{m}} 18^{\mathrm{s}} \\
& \text { Accel. for } \begin{cases}4^{\mathrm{h}} & 39 \cdot 4 \\
30^{\mathrm{m}} & 49 \\
18^{\mathrm{s}} & \cdot 1\end{cases} \\
& \text { Sid. Int. } \begin{array}{cc}
41 & 2 \cdot 4
\end{array}
\end{aligned}
$$

(3) When simultaneous altitudes of two stars are observed, the polar angle is the difference between their right ascensions.

(4) For the Moon or a Planet, the polar angle is the sidereal interval, increased or decreased by the change in right ascension during the elapsed mean time, according as the R.A. of the object is decreasing or increasing.

ART. 101. Correction for " Run."-Both altitudes are supposed to be observed at the same place; therefore, if a ship changes her position during the interval, a correction depending on the course and distance run and the bearing of the object must be applied to one of the altitudes, in order to make it what it would be at the place where the other altitude is observed.

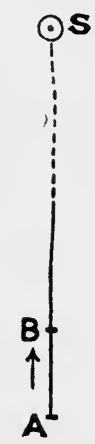

FIG. 154.

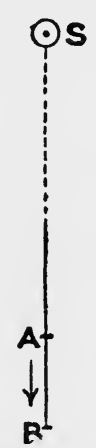

Fid. 155 .

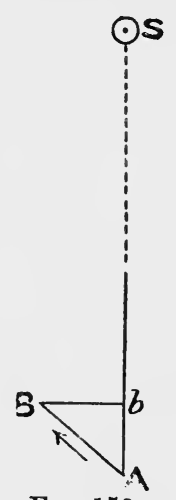

Fig. 156.

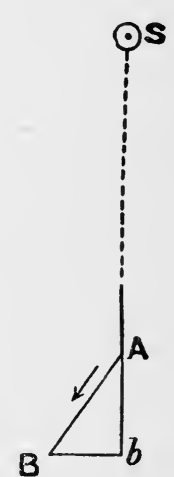

Fia. 157.

Thus, if the ship's course is the same as the bearing of the object at the first observation, that is, directly towards it, and the distance run ten miles, the first altitude would have to be increased by $10^{\prime}$; but if the course is opposite to the bearing, that is, directly away from the object, the first altitude will have to be decreased by $10^{\prime}$; whilst if the course were at right angles to the bearing, there would be no correction.

When the course is obliquely towards or from the object, the angle between the bearing and the course must be found. 
With this angle as a course in the Traverse Table and distance run in the Distance column, the correction will be found, in the Latitude column, and will be added to or subtracted from the first altitudes according as the course is towards or from the Sun.

Illustration.-Let A and B be the ship's positions at the first and second observations respectively, and $A S$ the direction of the object.

Fig. 154. Course directly towards the object; correction $=\mathrm{AB}+$

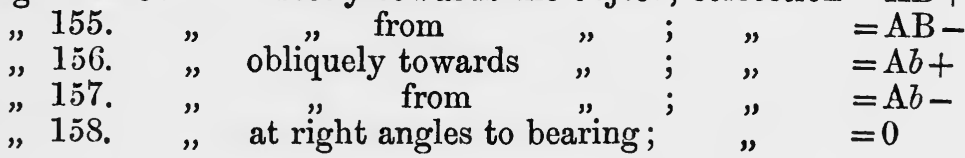

In Figs. 156 and 157 the angle at $A$ is the course, and $\mathrm{AB}$ the distance in the Traverse Table, and $\mathrm{A} b$ the latitude, since $\mathrm{B} b$ is a perpendicular upon AS.

When the bearing is given at the first observation, the computation gives the latitude at the second observation, and vice versâ.

Therefore, if the bearing at the second observation is given, the "correction for run" must be applied to the second altitude, reversing the rule for applying it; that is, if the run is towards the object, subtract the correction from the second altitude, and if from the object, add the correction. The latitude found is the latitude at the first observation.

Of the various methods for solving the problem, the best known is "Ivory's method," but the latitude found requires a correction for the change of declination in half the elapsed time.

AR'r. 102. Double Altitudes. Ivory's Method.-Let $S$ and $S_{1}$ be

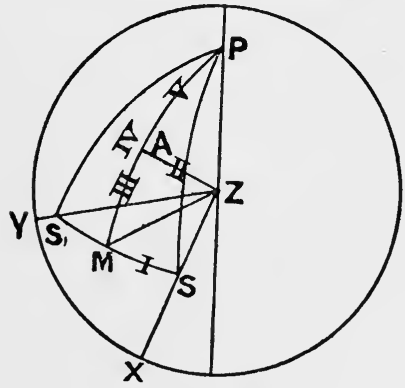

F1G. 159.

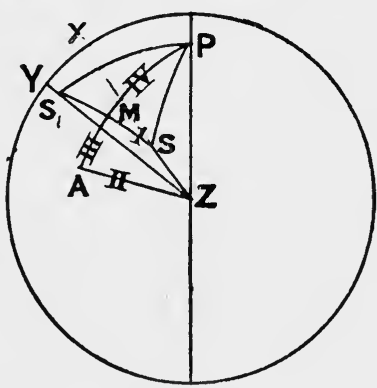

Fis. 160.

the two positions of the celestial body, and $\mathrm{SS}_{1}$ the arc of a great 
circle, bisected in $\mathrm{M}$; $\mathrm{PS}$ or $\mathrm{PS}_{1}$, the polar distance ; $\mathrm{ZS}$ and $\mathrm{ZS}_{1}$, the zenith distances; $\mathrm{PZ}$, the co-lat.; and $\mathrm{ZA}$, a perpendicular on PM. The angle MPS $=\frac{1}{2}$ elapsed time, or $\frac{1}{2}$ polar angle. $M S$ is $\operatorname{arc} 1, \mathrm{ZA}$ arc $2, \mathrm{AM}$ arc $3, \mathrm{PM}$ arc 4 , and $\mathrm{PA}$ arc 5 .

To find Arc 1 (MS).- In the right-angled triangle PMS are given PS (polar distance) and the angle MPS ( $\frac{1}{2}$ polar angle), to find MS.

Sin MS $=\cos ($ comp. of MPS $) \times \cos ($ comp. of PS $)$ or $\sin \mathrm{MS}=\sin \mathrm{MPS} \times \sin \mathrm{PS}$

that is, $\sin \operatorname{arc} 1=\sin \frac{1}{2}$ polar angle $\times \cos$ declination or cosec arc $1=\operatorname{cosec} \frac{1}{2}$ polar angle $\times$ sec declination

To find Arc 2 (ZA).-Applying the general formula to the triangle $\mathrm{ZMS}-$

$\cos \mathrm{ZS}=\cos \mathrm{ZMS} \cdot \sin \mathrm{ZM} \cdot \sin \mathrm{MS}+\cos \mathrm{ZM} \cdot \cos \mathrm{MS} \cdot$ Similarly, in the triangle $\mathrm{ZMS}_{1}-$

$\cos \mathrm{ZS}_{1}=-\cos \mathrm{ZMS} \cdot \sin \mathrm{ZM} \cdot \sin \mathrm{MS}+\cos \mathrm{ZM} \cdot \cos \mathrm{MS} \cdot$ (because $\mathrm{ZMS}_{1}$ is the supplement of $\mathrm{ZMS}$, and $\mathrm{MS}_{1}=\mathrm{MS}$ ). Subtracting (2) from (1) -

$\cos \mathrm{ZS}-\cos \mathrm{ZS}_{1}=2(\cos \mathrm{ZMS} \cdot \sin \mathrm{ZM} \cdot \sin \mathrm{MS})$

i.e. $\sin \mathrm{XS}-\sin \mathrm{YS}_{1}=2(\sin \mathrm{AMZ} . \sin \mathrm{ZM} . \sin \mathrm{MS})$ (because the alts. $\mathrm{XS}$ and $\mathrm{YS}_{1}$ and the angle $\mathrm{AMZ}$ are the complements of $\mathrm{ZS}, \mathrm{ZS}_{1}$, and $\mathrm{ZMS}$ ).

In the right-angled triangle $A M Z$ $\sin \mathrm{AZ}=\sin \mathrm{AMZ} \cdot \sin \mathrm{ZM}$

Substituting sin $\mathrm{AZ}$ in equation (3)-

$\sin \mathrm{XS}-\sin \mathrm{YS}_{1}=2 \sin \mathrm{AZ} \cdot \sin \mathrm{MS}$

$$
\begin{aligned}
\therefore 2 \sin \mathrm{AZ} & =\frac{\sin \mathrm{XS}-\sin \mathrm{YS}_{1}}{\sin \mathrm{MS}} \\
\sin \mathrm{AZ} & =\frac{\cos \frac{1}{2}\left(\mathrm{XS}+\mathrm{YS}_{1}\right) \cdot \sin \frac{1}{2}\left(\mathrm{XS}-\mathrm{YS}_{1}\right)}{\sin \mathrm{MS}}
\end{aligned}
$$

that is, $\sin \operatorname{arc} 2=\cos \frac{1}{2}$ sum of alt $\ldots$. $\sin \frac{1}{2}$ diff. of alts. . cosec arc 1

To find Arc 3 'AM).-Adding equations (1) and (2)-

$$
\cos \mathrm{ZS}+\cos \mathrm{ZS}_{1}=2 \cos \mathrm{ZM} \cdot \cos \mathrm{MS}
$$

But in the right-angled triangle $A M Z, \cos Z M=\cos A M \cdot \cos A Z$;

$\therefore \cos \mathrm{ZS}+\cos \mathrm{ZS}_{1}=2 \cos \mathrm{AM} \cdot \cos \mathrm{AZ} \cdot \cos \mathrm{MS}$

or $\sin \mathrm{XS}+\sin \mathrm{YS}_{1}=2 \cos \mathrm{AM} \cdot \cos \mathrm{AZ} \cdot \cos \mathrm{MS}$

$$
\begin{aligned}
\therefore \cos \mathrm{AM} & =\frac{\sin \mathrm{XS}+\sin \mathrm{YS}_{1}}{2 \cos \mathrm{AZ} \cdot \cos \mathrm{MS}} \\
& =\frac{\sin \frac{1}{2}\left(\mathrm{XS}+\mathrm{YS}_{1}\right) \cos \frac{1}{2}\left(\mathrm{XS}-\mathrm{YS}_{1}\right)}{\cos \mathrm{AZ} \cdot \cos \mathrm{MS}}
\end{aligned}
$$

that is, $\cos \operatorname{arc} 3=\sin \frac{1}{2}$ sum of alts. $\times \cos \frac{1}{2}$ diff. alts. $\times \sec$ arc $2 \times \sec$ arc 1 
To find Arc 4 (PM).--In the right-angled triangle PMS$\cos \mathrm{PS}=\cos \mathrm{MS} \cdot \cos \mathrm{PM}$

$$
\therefore \cos \mathrm{PM}=\frac{\cos \mathrm{PS}}{\cos \mathrm{MS}}=\cos \mathrm{PS} . \mathrm{sec} \mathrm{MS}
$$

that is, $\cos \operatorname{arc} 4=$ sin dec. $\times$ sec arc 1

To find Arc 5 (PA).-Arc 5 is the difference or the sum of 3 and 4 according to circumstances.

To find the Latitude.-In the right-angled triangle PZA-

$$
\cos \mathrm{PZ}=\cos \mathrm{PA} \cdot \cos \mathrm{ZA}
$$

that is, sin lat. $=\cos$ arc $5 . \cos$ arc 2

and therefore cosec lat. $=$ sec arc 5. sec arc 2

The foregoing formulæ are arranged for computation as follows :-

$\frac{1}{2}$ pol. angle $--\div \quad$ tcosec

Dec. - - - sec

$\sin$

Arc 1, - - $\quad$ cosec

$\frac{1}{2}$ sum alts. $-\ldots \quad \cos$

$\frac{1}{2}$ diff. , - -

$\sin$

sec

scc

Arc 2, - - $\quad$ tsin

Arc 3, - - -

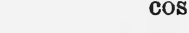

$\cos$

sec

$\cos$

Arc 4, - -

Arc 5, - -

Are 2, - - -

sec

${ }^{*} \sec$

Lat. - - c cosec

Logs marked thus * occur twice.

Logs marked thus $t$ are used again for finding correction to latitude.

The Ambiguous Case.-When the sum of arcs 3 and 4 is less than $90^{\circ}$, it may be doubtful whether they should be added or subtracted to find arc 5. But if the lat. be first found by adding, and the lat. by account is not given, the correctness of the answer may be tested by computing the hour angle at the middle time, and seeing if it agrees with the known hour angle. If not, then subtract 3 from 4, and again compute the latitude.

To compute the Hour Angle $\left(H_{1}\right)$ at the Middle Time.-In the right-angled triangle $\mathrm{PZA}-$

$$
\begin{aligned}
\sin \mathrm{AZ} & =\sin \mathrm{PZ} \cdot \sin \mathrm{ZPA} \\
\therefore \sin \mathrm{ZPA} & =\frac{\sin \mathrm{AZ}}{\sin \mathrm{PZ}}=\sin \mathrm{AZ} \cdot \operatorname{cosec} \mathrm{PZ}
\end{aligned}
$$

i.e. $\sin$ H.A. at mid. time $=\sin$ arc 2 . sec lat.

To correct the lat. found by "Ivory."

(1) Find change of declination in half elapsed time. 
(2) Add following logs:- -log change of dec., secant approx. lat., cosec half int., sine arc 2 , reject $10^{\prime}$, and take back log. This is the correction.

(3) When the second altitude is the greater.

Allow it $\mathrm{N}$, when the Sun is going $\mathrm{N}$.

Allow it $\mathrm{S}$, when the Sun is going $\mathrm{S}$.

Reverse this when the first altitude is the greater.

ART. 103.-Rule for finding latitude by "Ivory."

(1) Find polar angle as directed, and the declination for the Middle Greenwich time.

(2) Correct the altitudes, applying correction for "Run" to alt. for which bearing of object is given, as directed. Find half sum and half difference of alts.

(3) For Arc 1, add logs of cosecant half polar angle and secant dec.; this gives cosecant arc 1 .

For Arc 2, add logs cosecant arc 1, cosine half sum alts., sine half diff. alts.; this gives sine arc 2.

For Arc 3, add logs secant arc 1, sine half sum alts., cosine half diff. alts., secant arc 2 ; this gives cosine are 3 .

For Arc 4, add logs sine dec, and secant arc 1; this gives cosine arc 4.

For Arc 5. This arc is always the difference of arcs 3 and 4 when lat. and dec. are of different names, it can never exceed $90^{\circ}$, so should the sum of 3 and 4 be greater than $90^{\circ}$, their difference must also be used for 5 ; but if the sum is less than $90^{\circ}$, there may be some doubt, which can be decided by computing the H.A. at middle time from the formula

$$
\sin \text { H.A. = sine arc } 2 \times \text { sec lat. }
$$

and selecting that lat. which gives the known H.A. at middle time.

For lat. add logs secant arc 5 and secant arc 2 ; this gives cosecant lat. to be corrected as directed for true lat.

\section{Remarks.}

(1) When dec. is 0 , arc 4 is $90^{\circ}$, because $\sin 0=0$, and therefore $\cos \operatorname{arc} 4=0$.

(2) When alts. are equal, diff. $=0$, then arc $2=0$, and arc $5=$ co-lat.

(3) Arc 4 is of same affection as polar distance. Therefore when lat. and dec. are of different names supplement of angle found is arc 4 .

Example.-August 5th, lat. N., long. $55^{\circ} 17^{\prime} 30^{\prime \prime}$ W. With the following observations find the latitude at second observation-
A.T.S. $9^{\text {h }} 15^{\mathrm{m}} 19^{\text {a }}$ A.M.
Obs. alt.
$\odot 44^{\circ} 14^{\prime} 20^{\prime \prime}$
Ind. cor., $-2^{\prime} 7^{\prime \prime}$
, 31822 P.M.
, $\quad$ 392125
Eye, $30 \mathrm{ft}$.

Sun's bearing at first observation, S. $62^{\circ} \mathrm{E}$. ; run during the interval, S. $6^{\circ} \mathrm{W}$, 63 miles. 
First A.T.S. August $4^{\mathrm{d}} 21^{\mathrm{b}} 15^{\mathrm{m}} 19^{\mathrm{s}}$ Dec. $17^{\circ} 9^{\prime} 48^{\prime \prime} \cdot 4$ N. H.V. $40^{\prime \prime} \cdot 14$

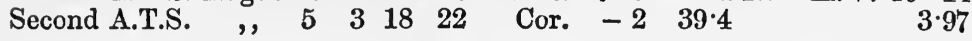

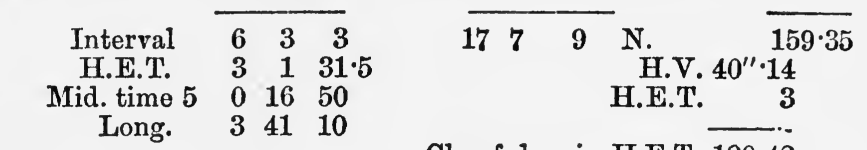

Mid. A.T.G. $5 \longdiv { 3 5 8 \quad 0 }$

Ch. of dec. in H.E.T. 120.42

Bearing S. $62^{\circ} \mathrm{E}$.

Inc. angle $\overline{68}$ dist. $63^{\prime}$

gives d. lat. $23 \cdot 6$

to be added to first alt., because angle is less than $90^{\circ}$.

First O.A. $44^{\circ} 14^{\prime} 20^{\prime \prime}$

I.C. -27

$$
\overline{4412} \overline{13}
$$

Dip $\quad-522$

$44 \quad 6 \quad 51$

S.D. +1548

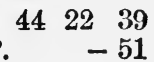

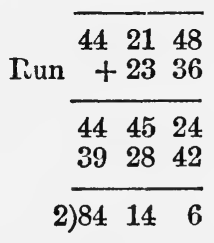

Half sum $\overline{42 \quad 7 \quad 3}$

H.E.T. $3^{\text {b }} 1^{\mathrm{m}} 31^{\mathrm{s}} 5 \quad$ cosec $10 \cdot 147644$

Dec. $17^{\circ} 7^{\prime} 9^{\prime \prime} \quad$ sec $10^{\circ} 019681$

Arc 1.42 5150

$\frac{1}{2}$ sum $42 \quad 7 \quad 3$

$\frac{1}{2}$ diff. 23821

Arc 2. 25241

cosec $10 \cdot 167325$

$\cos 9 \cdot 870270$

$\sin 8 \cdot 663191$

$\sin \overline{8 \cdot 700786}$

Arc 3. $2346 \quad 16$

Arc 4. 661919

Arc 5. $42 \quad 33 \quad 3$

Arc 2. 25241

$\sec 10 \cdot 132723$

$\sec 10.000548$
Second O.A. $39^{\circ} 21^{\prime} 25^{\prime \prime}$

$-27$

\begin{tabular}{rrr}
\hline 39 & 19 & 18 \\
-5 & 22 \\
\hline 39 & 13 & 56 \\
+15 & 48 \\
\hline 39 & 29 & 44 \\
& -1 & 2 \\
\hline 39 & 28 & 42 \\
44 & 45 & 24 \\
\hline 5 & 16 & 42
\end{tabular}

Half diff. $2 \quad 3821$

Approx. lat. $4722 \quad 13 \quad \operatorname{cosec} \overline{10 \cdot 133271} \ldots \quad \ldots \quad \sec 10 \cdot 169246$ $\sin 9 \cdot 468878$

sec $10 \cdot 134913 \quad \sec 10 \cdot 134913$

$\sin 9.826498$

cos 9.999539

sec 10.000548

$\cos 9.961498$

H.E.T. $\operatorname{cosec} 10 \cdot 147644$

... ... $\quad$ sin 8.700786

Ch. in dec. $120.4 \log 2 \cdot 080626$

Cor. $\quad+13 \quad \ldots \quad \ldots \quad \ldots \quad \ldots \quad 12.54 \log 1.098303$

True lat. $472226 \mathrm{~N}$. 
ART. 104. Direct Method.-In the triangle $\mathrm{PSS}_{1}$ are given the two sides $P S$ and $\mathrm{PS}_{1}$ and the included angle at $\mathrm{P}$, from which can be found the third side $\mathrm{SS}_{1}$ and the angles $\mathrm{PS}_{1} \mathrm{~S}$ and $\mathrm{PSS}_{1}$.

Then in the triangle $\mathrm{ZSS}_{1}$ with the three sides given, the angle $\mathrm{ZS}_{1} \mathrm{~S}$ can be found. Also the angle $\mathrm{PS}_{1} \mathrm{Z}$ $=\mathrm{PS}_{1} \mathrm{~S}-\mathrm{ZS}_{1} \mathrm{~S}$.

Lastly, in the triangle $\mathrm{PZS}_{1}$ the two sides $\mathrm{PS}_{1}$ and $\mathrm{ZS}_{1}$ and the included angle $\mathrm{PS}_{1} \mathrm{Z}$ are known, from which can be found the co-lat. PZ.

The latitude found by this method requires no correction for change of

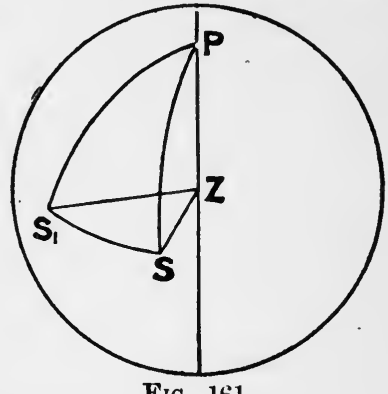

FIG. 161. declination, because the actual polar distances are used, but it is subject to the same ambiguity as Ivory's method when $\mathrm{SS}_{1}$ produced passes near the zenith. In the latter case the angle $\mathrm{PS}_{1} \mathrm{Z}$ may be either the difference or the sum of $\mathrm{PS}_{1} \mathrm{~S}$ and $\mathrm{ZS}_{1} \mathrm{~S}$.

Example.-The same problem as before worked from figuro.

In figure $\mathrm{X}$ and $\mathrm{Y}$ are the two positions of the sun. $P$ the polar angle $=6^{\mathrm{h}} 3^{\mathrm{m}} 3^{\mathrm{s}}$

\section{PX the 1st pol. dist. $=72^{\circ} 50^{\prime} 49^{\prime \prime}$ PY the 2nd , = 725453 ZX the 1st zen. dist. $=451436$ $\mathrm{ZY}$ the 2nd " = $50 \quad 3118$}

In triangle $\mathrm{PXY}$, given two sides $\mathrm{PX}$ and $P Y$, and included angle $P$, find $X$ and $X Y$.

$$
\begin{aligned}
\operatorname{Tan} \frac{1}{2}(X+Y) & =\frac{\cos \frac{1}{2}(P Y-P X)}{\cos \frac{1}{2}(P Y+P X)} \cdot \cot \frac{P}{2} \\
\operatorname{Tan} \frac{1}{2}(X-Y) & =\frac{\sin \frac{1}{2}(P Y-P X)}{\sin \frac{1}{2}(P Y+P X)} \cdot \cot \frac{P}{2} \\
\operatorname{Cos} \frac{X Y}{2} & =\frac{\cos \frac{1}{2}(P Y+P X)}{\cos \frac{1}{2}(X+Y)} \cdot \sin \frac{P}{2}
\end{aligned}
$$$$
\frac{\mathbf{P}}{\mathbf{2}}=3^{\mathrm{h}} 1^{\mathrm{m}} 31^{\mathrm{s}} \cdot \overline{\mathrm{j}} \quad \text { cot } 9.994220
$$$$
\frac{1}{2}(\mathrm{PY}+\mathrm{PX})=72^{\circ} 52^{\prime} 51^{\prime \prime}
$$$$
\frac{1}{2}(\mathrm{PY}-\mathrm{PX})=\begin{array}{lll}
0 & 2 & 2
\end{array}
$$$$
\frac{1}{2}(X+Y)=732324 \quad \tan \overline{10.525342}
$$
$\sec 10.531122$ $\cos 10.000000$

cot 9.994220 cosec $10 \cdot 019682$ $\sin 6.771935$

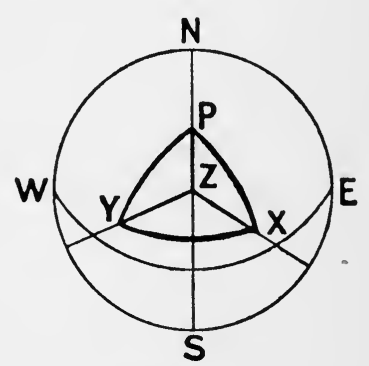

FIG. 162. $\tan \overline{6.785837}$ sec 10543854 $\sin 9 \cdot 852355$ $\cos 9.468878$

$$
\begin{aligned}
& \frac{1}{2}(X-Y)=\begin{array}{lll}
0 & 2 & 6
\end{array} \\
& X=73 \quad 2530
\end{aligned}
$$


In triangle $\mathrm{ZXY}$, given the three sides, to find $\mathrm{X}$.

$$
\cos \frac{X}{2}=\sqrt{\frac{\sin s \cdot \sin (s-Z Y)}{\sin Z X \cdot \sin X Y}}
$$

where $s=\frac{1}{2}(\mathrm{ZY}+\mathrm{ZX}+\mathrm{XY})$.

$$
\begin{aligned}
& \mathrm{ZY}=50^{\circ} 31^{\prime} 18^{\prime \prime} \\
& \mathrm{XY}=85 \quad 4342 \quad \operatorname{cosec} 10.001208 \\
& \mathrm{ZX}=45 \quad 1436 \quad \operatorname{cosec} 10 \cdot 148678
\end{aligned}
$$

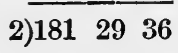

$$
\begin{aligned}
& s=90 \quad \overline{44} 48 \quad \sin 9.999963 \\
& 8-\mathrm{ZY}=40 \quad 13 \quad 30 \quad \sin 9 \cdot 810092 \\
& \text { 2)19.959941 } \\
& 17^{\circ} 16^{\prime} 4 \cdot 5^{\prime \prime} \cos \overline{9 \cdot 979970} \\
& \therefore \mathrm{ZXY}=34 \quad 32 \quad 9 \\
& \mathrm{PXY}=\begin{array}{llll}
73 & 25 & 30
\end{array} \\
& \text { Hence PXZ }=\overline{38 \quad 5321}
\end{aligned}
$$

Now in triangle PXZ, given two sides $\mathrm{PX}$ and $\mathrm{ZX}$, and included angle $\mathrm{PXZ}$, to find $\mathrm{PZ}=$ co-lat.

$$
\begin{aligned}
& \operatorname{Tan} \frac{1}{2}(Z+P)=\frac{\cos \frac{1}{2}(P X-Z X)}{\cos \frac{1}{2}(P X+Z X)} \cdot \cot \frac{X}{2} \\
& \operatorname{Cos} \frac{P Z}{2}=\frac{\cos \frac{1}{2}(P X+Z X)}{\cos \frac{1}{2}(Z+P)} \cdot \sin \frac{X}{2} \\
& \frac{\mathrm{X}}{2}=19^{\circ} 26^{\prime} 40^{\prime \prime} \quad \cot 10.452191 \quad \sin 9.522305 \\
& \frac{1}{2}(\mathrm{PX}+\mathrm{ZX})=59 \quad 242 \quad \sec 10 \cdot 288729 \quad \cos 9 \cdot 711271 \\
& \frac{1}{2}(\mathrm{PX}-\mathrm{ZX})=13 \quad 48 \quad 6 \quad \cos 9 \cdot 987276 \\
& \frac{1}{2}(Z+P)=732432 \quad \tan \overline{10 \cdot 728196} \quad \text { sec } 10735659
\end{aligned}
$$

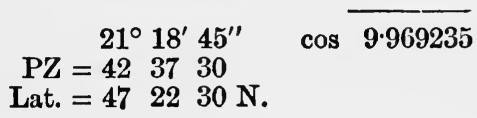

Art. 105. Simultaneous Altitudes.-The altitudes of two objects are observed at the same time; the problem may be worked either by Sumner's method, when the intersection of the two lines of position is the position of the ship, as there is no allowance for "Run," or by Direct Spherics.

\section{Example.}

September 9th, A.M. at ship in long. by account $128^{\circ}$ W., when the G.M.T. by chron. was $8^{\mathrm{d}} 20^{\mathrm{h}} 52^{\mathrm{m}} 15^{\mathrm{s}}$; obs. alt. of a Ceti east of meridian was $26^{\circ} 10^{\prime} 20^{\prime \prime}$; obs. alt of a Ophiuchi west of meridian was $9^{\circ} 59^{\prime} 30^{\prime \prime}$; ind. cor., $-2^{\prime} 18^{\prime \prime}$; height of eye, $30 \mathrm{ft}$. Required the ship's position, and true bearings of the stars, by Sumner's method, assuming lats. $51^{\circ}$ and $51^{\circ}$ $30^{\prime} \mathrm{N}$., or by any other method. 
M.T.G. Sept. $8^{\mathrm{d}} 20^{\mathrm{b}} 52^{\mathrm{m}} 15^{\mathrm{s}}$

S.T. at noon $11^{\mathrm{k}} 6^{\mathrm{m}} 33^{\mathrm{r}} \cdot 2$

Accel.

$\begin{array}{lll}3 & 17 \cdot 1\end{array}$

R.A.M.S. 11958.9

O.A. a Ceti $26^{\circ} 10^{\prime} 20^{\prime \prime}$

I.C. $\quad-218$

O.A. a Ophiuchi $9^{\circ} 59^{\prime} 30^{\prime \prime}$

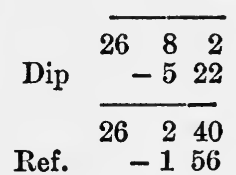

$$
\begin{array}{r}
-2 \quad 18 \\
\hline 95712 \\
-5 \quad 22 \\
\hline 95150
\end{array}
$$

T.A. $\quad 26 \quad 0 \quad 44$

Lat. $51 \quad 0 \quad 0$

P.D. $86 \quad 16 \quad 44$

$163 \quad 1728$

$\frac{1}{2}$ sum $81 \quad 3844$

$\begin{array}{llll}\text { remainder } & 55 & 38 & 0\end{array}$

Secs $10 \cdot 201128$

Cosecs $10 \cdot 000916$

Cos $\quad 9 \cdot 162256$

Sins $\quad \mathbf{9 \cdot 9 1 6 6 8 7}$

$$
\overline{9 \cdot 280987}
$$

E.H.A.'s $3^{\text {h }} 27^{\mathrm{m}} 18^{\circ}$

R.A.* $2 \quad 57 \quad 22$

R.A.M. $2 \longdiv { 3 0 \quad 4 }$

R.A.M.S. $11 \quad 9 \quad 59$

M.T.S. $8^{\mathrm{a}} \overline{1220 \quad 5}$

M.T.G. $8 \quad 20 \quad 52 \quad 15$

$\overline{832 \quad 10}$

$$
11
$$

$3^{\mathrm{h}} 25^{\mathrm{m}} 30^{\mathrm{s}}$

$\begin{array}{lll}2 & 57 & 22\end{array}$

$26^{\circ} 0^{\prime} 44^{\prime \prime}$

$-520$

$5130 \quad 0$

$86 \quad 16 \quad 44$

$9 \quad 46 \quad 30$

$9^{\circ} 46^{\prime} 30^{\prime \prime}$

$\begin{array}{lll}51 & 0 & 0\end{array}$

$\begin{array}{lll}77 \quad 22 & 20\end{array}$

$5130 \quad 0$

$\begin{array}{lll}77 \quad 22 & 20\end{array}$

$163 \quad 47 \quad 28$

$138 \quad 8 \quad 50$

$138 \quad 3850$

$81 \quad 53 \quad 44$

$\overline{69 \quad 4 \quad 25}$

$\begin{array}{lll}55 & 53 & 0\end{array}$

$\begin{array}{lll}59 & 17 & 55\end{array}$

$\begin{array}{lll}69 & 19 & 25\end{array}$

$\begin{array}{lll}59 & 32 & 55\end{array}$

$\overline{10 \cdot 205850}$

$10 \cdot 201128$

10.000916

$\mathbf{9} \cdot 149150$

9.917976

10.010635

9.552873

9.934417

$10 \cdot 205850$

10.010635

9.547885

9.935537

$\overline{9 \cdot 273892} \quad \overline{9 \cdot 699053}$

9.699907

$6^{\mathrm{h}} \quad 0^{\mathrm{m}} 30^{\mathrm{s}}$

$\begin{array}{llll}6^{\mathrm{h}} & 0^{\mathrm{m}} & 2^{\mathrm{a}}\end{array}$

$\begin{array}{lll}17 \quad 30 & 34\end{array}$

$\longdiv { 2 3 \longdiv { 5 1 5 2 } }$

$\begin{array}{lll}17 & 30 & 34\end{array}$

$\overline{2331 \quad 4}$

$\begin{array}{lll}11 & 9 & 59\end{array}$

$\begin{array}{lll}23 & 30 & 36\end{array}$

$\begin{array}{lll}11 & 9 & 59\end{array}$

$\begin{array}{llll}8^{\mathrm{d}} 12 & 21 & 53\end{array}$

$\begin{array}{llll}8 & 20 & 52 & 15\end{array}$

$\begin{array}{lll}11 & 9 & 59\end{array}$

$\begin{array}{llll}8^{\mathrm{s}} & 12 & 20 & 37\end{array}$

$\begin{array}{llll}8 & 20 & 52 & 15\end{array}$

$8^{\mathrm{a}} 12 \quad 21 \quad 5$

$\begin{array}{llll}8 & 20 & 52 & 15\end{array}$

$8 \quad 3022$

$8 \quad 3138$

$8 \quad 3110$

Long. (a) $128^{\circ} 2^{\prime} 30^{\prime \prime} \mathrm{W}$. (b) $127^{\circ} 35^{\prime} 30^{\prime \prime} \mathrm{W}$. (c) $127^{\circ} 54^{\prime} 30^{\prime \prime} \mathrm{W}$. (d) $127^{\circ} 47^{\prime} 30^{\prime \prime} \mathrm{W}$.

By projection on a chart these longs. give-

Bearing of $\alpha$ Ceti S. $59^{\circ} \mathrm{E}$.

Bearing by a Ophiuchi N. 81 W.

Lat. $51^{\circ} 12^{\prime} \mathrm{N}$. Long. $12751 \mathrm{~W}$.

Instead of projecting, the position of the ship may be found thus-

D. long. between " $a$ " and " $c$ " $=8$ ' E. ; call this A.

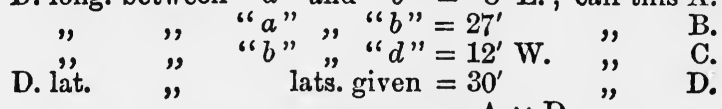

The cor. to lesser lat. $=\frac{A \times D}{A \pm C}$

$$
\text { , } \quad \operatorname{long}(a)=\frac{\mathrm{A} \times \mathrm{B}}{\mathrm{A} \pm \mathrm{C}}
$$


sum of $\mathbf{A}$ and $\mathbf{C}$ is taken when they are of contrary names (as in example) diff. of $\mathrm{A}, \mathrm{C}$

$$
\text { " }
$$

Cor. to lat. $=\frac{8 \times 30}{20}=12^{\prime}$

Lesser lat. $51^{\circ} 0^{\prime} \mathrm{N}$. Cor. 12

Lat. in $5112 \mathrm{~N}$. same ,,

Cor. to long $=\frac{8 \times 27}{20}=10^{\prime} 48^{\prime \prime}$

Long. " $a$ " $128^{\circ} 2^{\prime} 30^{\prime \prime} \mathrm{W}$. Cor. $\quad 1048 \mathrm{E}$.

Long. in 1275142 W.

The azimuths may be found from the Traverse Tables thus-

1st obs. D. lat. $=30^{\prime}$

D. long. $=27^{\prime}$

This gives dep. $=17$, hence co. " $a$ " to " $b$ " from traverse or first line of position is $\mathrm{N} .30^{\circ} \mathrm{E}$.

$\therefore$ bearing of $\alpha$ Ceti is $\mathrm{S} .60^{\circ} \mathrm{E}$.

2nd obs. D. lat. $=30^{\prime}$

D. long. $=\boldsymbol{7}^{\prime}$

This gives dep. $=4^{\prime} \cdot 4$, hence co. " $c$ " to " $d$ " from traverse or second line of position is N. $9^{\circ} \mathrm{E}$.

$$
\therefore \text { bearing of } \alpha \text { Ophiuchi is N. } 81^{\circ} \text {.W. }
$$

\section{From the figure.-}

In the figure $\mathrm{X}$ and $\mathrm{Y}$ are the positions of the two stars.

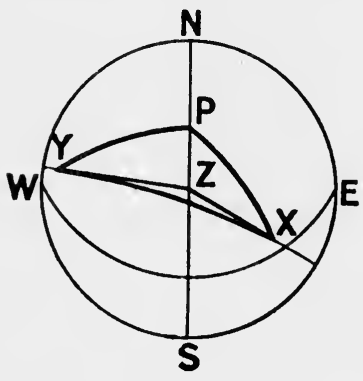

FIg. 163.

$\mathrm{PX}$ is pol. dist. of 1st star $=86^{\circ} 16^{\prime} 44^{\prime \prime}$

ZX is zen. ", , = $=635916$

PY is pol. " 2nd star $=772220$

$\mathrm{ZY}$ is zen. $, \quad, \quad=801330$

$P$ is diff. of R.A.'s " $=9^{\mathrm{b}} 26^{\mathrm{m}} 48^{\mathrm{s}}$

In triangle PXY, given two sides $\mathrm{PX}$ and $P Y$, and included angle $P$. Find $X$ and $X Y$.

$$
\begin{aligned}
\operatorname{Tan} \frac{1}{2}(\mathrm{Y}+\mathrm{X}) & =\frac{\cos \frac{1}{2}(\mathrm{PX}-\mathrm{PY})}{\cos \frac{1}{2}(\mathrm{PX}+\mathrm{PY})} \cdot \cot \frac{\mathrm{P}}{2} \\
\operatorname{Tan} \frac{1}{2}(\mathrm{Y}-\mathrm{X}) & =\frac{\sin \frac{1}{2}(\mathrm{PX}-\mathrm{PY})}{\sin \frac{1}{2}(\mathrm{PX}+\mathrm{PY})} \cdot \cot \frac{\mathrm{P}}{2} \\
\cos \frac{\mathrm{XY}}{2} & =\frac{\cos \frac{1}{2}(\mathrm{PX}+\mathrm{PY})}{\cos \frac{1}{2}(\mathrm{Y}+\mathrm{X})} \cdot \sin \frac{\mathrm{P}}{2}
\end{aligned}
$$

$$
\begin{aligned}
& \frac{\mathrm{P}}{2}=4^{\mathrm{h}} 43^{\mathrm{m}} 24^{\circ} \quad \cot 9.540653 \quad \cot 9.540653 \quad \sin 9 \cdot 975277 \\
& \frac{1}{s}(\mathrm{PX}+\mathrm{PY})=81^{\circ} 49^{\prime} 32^{\prime \prime} \quad \text { sec } 10 \cdot 847138 \quad \operatorname{cosec} 10 \cdot 004435 \text { cos } 9 \cdot 152862
\end{aligned}
$$

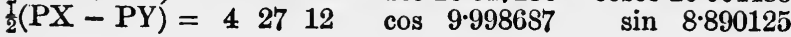

$$
\begin{aligned}
& \frac{1}{2}(\mathrm{Y}+\mathrm{X})=\overline{67 \quad 4020} \quad \tan \overline{10 \cdot 386478} \\
& \frac{1}{2}(\mathrm{Y}-\mathrm{X})=\begin{array}{lllll}
1 & 33 & 39 & \ldots & \ldots
\end{array} \quad \text { tan } \overline{8.435213} \\
& \mathrm{X}=\overline{66} \quad 6 \quad 41 \quad \ldots \quad \ldots \quad 69^{\circ} 17^{\prime} 41^{\prime \prime} \cos \overline{9 \cdot 548464} \\
& \mathrm{XY}=1383522
\end{aligned}
$$

In triangle $\mathrm{ZXY}$, given three sides $\mathrm{ZX}, \mathrm{ZY}$, and $\mathrm{XY}$, to find angles $\mathrm{Z}$ and $\mathrm{X}$. 


$$
\operatorname{Cos} \frac{Z}{2}=\sqrt{\frac{\sin s \cdot \sin (s-X Y)}{\sin Z X \cdot \sin Z Y}} \text { and } \cos \frac{X}{2}=\sqrt{\frac{\sin s \cdot \sin (s-Z Y)}{\sin Z X \cdot \sin X Y}}
$$

where $s=\frac{1}{2}(\mathrm{ZX}+\mathrm{ZY}+\mathrm{XY})$.

$$
\begin{aligned}
& \mathrm{XY}=138^{\circ} 35^{\prime} 22^{\prime \prime} \\
& \mathrm{ZY}=\begin{array}{llll}
80 & 13 & 30
\end{array} \\
& \mathrm{ZX}=\begin{array}{llll}
63 & 59 & 16
\end{array} \\
& \text { cosec } 10 \cdot 006351 \\
& \text { cosec } 10.04638 \tilde{0} \\
& \text { cosec } 10 \cdot 179503 \\
& \text { cosec } 10 \cdot 046385 \\
& \text { 2)282 } 48 \quad 8 \\
& s=141 \quad 24 \quad 4 \\
& s-\mathrm{XY}=24842 \\
& s-\mathrm{ZY}=611034
\end{aligned}
$$

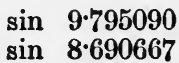

$$
\begin{aligned}
& \sin 9 \cdot 795090 \\
& \sin 9 \cdot 942555 \\
& \text { 2)18.538493 } \\
& \begin{array}{lll}
79 & 17 & 14
\end{array} \\
& Z=\begin{array}{llll}
158 & 34 & 28
\end{array} \\
& \cos \overline{9 \cdot 269246} \\
& \text { 2) } \overline{19 \cdot 963533} \\
& 16^{\circ} 29^{\prime} 13^{\prime \prime} \\
& \mathrm{ZXY}=\begin{array}{llll}
32 & 58 & 26
\end{array} \\
& \mathrm{PXY}=66 \quad 6 \quad 41 \\
& \therefore \mathrm{PXZ}=33 \quad 815
\end{aligned}
$$

In triangle PXZ, given two sides PX and ZX, and included angle $\mathrm{X}$; to find $P Z=$ co-lat., $P=$ H.A. 1st star, $Z=$ az. 1st star.

$$
\begin{aligned}
\text { Tan } \frac{1}{2}(Z+P) & =\frac{\cos \frac{1}{2}(P X-Z X)}{\cos \frac{1}{2}(P X+Z X)} \cdot \cot \frac{X}{2} \\
\text { Tan } \frac{1}{2}(Z-P) & =\frac{\sin \frac{1}{2}(P X-Z X)}{\sin \frac{1}{2}(P X+Z X)} \cdot \cot \frac{X}{2} \\
\operatorname{Cos} \frac{P Z}{2} & =\frac{\cos \frac{1}{2}(P X+Z X)}{\cos \frac{1}{2}(Z+P)} \cdot \sin \frac{X}{\frac{2}{2}}
\end{aligned}
$$

$\frac{\mathrm{X}}{2}=16^{\circ} 34^{\prime} 7^{\prime \prime} 5_{\text {_ }} \cot 10.526486 \quad \cot 10.526486 \sin 9 \cdot 455096$

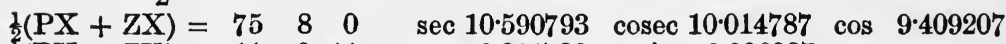
$\frac{1}{2}(\mathrm{PX}-\mathrm{ZX})=\begin{array}{lll}11 & 8 & 44\end{array}$

$$
\frac{1}{2}(Z+P)=\overline{8533 \quad 5} \quad \tan \overline{11 \cdot 109009}
$$
$\sec 11 \cdot 110320$

$$
\frac{1}{2}(Z-P)=335435
$$$$
\mathrm{Z}=11927 \quad 40
$$$$
\mathbf{P}=5138 \quad 30
$$
$\cos 9 \cdot 991730 \quad \sin 9 \cdot 286237$

$$
\tan \overline{9 \cdot 827510}
$$

$$
\begin{array}{lll}
19^{\circ} & 23^{\prime} & 45^{\prime \prime} \\
\mathrm{PZ}=38 & 47 & 30 \\
\therefore \text { lat. } 51 & 12 & 30 \mathrm{~N}
\end{array}
$$

$\therefore$ E.H.A. $3^{\mathrm{h}} 26^{\mathrm{m}} 34^{\circ}$

R.A.* 25722

R.A.M. $\overline{23 \quad 30 \quad 48}$

R.A.M.S. $11 \quad 959$

M.T.S. $8^{\mathrm{d}} \overline{12 \quad 20 \quad 49}$

M.T.G. $8^{\mathrm{d}} 20 \quad 52 \quad 15$

83126

Long. $127^{\circ} 51^{\prime} 30 \mathrm{~W}$. 
Azimuth of $\alpha$ Ceti $=\mathrm{Z}$, or N. $119^{\circ} 28^{\prime}$ E., which is S. $60^{\circ} 32^{\prime}$ E.

$$
\begin{aligned}
\text { SZX } & =60^{\circ} 32^{\prime} \\
\text { YZX } & =158 \quad 34 \frac{1}{2} \\
\text { Azimuth of } \alpha \text { Ophiuchi SZY } & =\overline{98} 2 \frac{1}{2}, \text { or N. } 81^{\circ} 57 \frac{1}{2}^{\prime} \text { W. }
\end{aligned}
$$

\section{EXERCISES.}

1. August 14th, in long. $73^{\circ} 14^{\prime}$ E., lat.S. ; with the following observations find the latitude at the second obs. :-

Approx. A.T.S., $9^{\mathrm{h}} 20^{\mathrm{m}}$ A.M. ; time by chron., $4^{\mathrm{b}} 26^{\mathrm{m}} 18^{\mathrm{s}}$; obs. alt. Sun's L.L., $30^{\circ} 21^{\prime} 50^{\prime \prime}$. Approx. A.T.S., $3^{\text {h }} 5^{\mathrm{m}}$ P.M. ; time by chron., $10^{\mathrm{h}} 12^{\mathrm{m}} 12^{*}$; obs. alt. Sun's L.L., $26^{\circ} 38^{\prime} 10^{\prime \prime}$.

Chron. showed correct A.T.G. ; ind. cor., $-3^{\prime} 16^{\prime \prime}$; height of eye, $30 \mathrm{ft}$.; Sun's bearing at first obs., N. $46^{\circ} 30^{\prime}$ E. ; run between sights, S. $57^{\circ} 30^{\prime} \mathrm{E}$. 8 knots per hour.

2. August 18th, lat. $\mathrm{N}$., long. $124^{\circ} 23^{\prime} \mathrm{W}$.; with the following observations find the latitude at the second obs. :-

Approx. A.T.S., $10^{\mathrm{h}} 0^{\mathrm{m}}$ A.M. ; chron., $6^{\mathrm{h}} 21^{\mathrm{m}} 46^{\mathrm{a}}$; obs. alt. $\odot, 50^{\circ} 32^{\prime} 50^{\prime \prime}$; ind. cor., $+1^{\prime} 39^{\prime \prime}$. Approx. A.T.S., $2^{\mathrm{b}} 50^{\mathrm{m}}$ P.M.; chron., $11^{\mathrm{b}} \mathbf{9}^{\mathrm{m}} 34^{\mathrm{B}}$; obs. alt. $\odot, 42^{\circ} 46^{\prime} 10^{\prime \prime}$; eye, $35 \mathrm{ft}$. ; chron. correct for M.T.G. ; Sun's bearing at first obs., S. $49^{\circ} 30^{\prime}$ E. ; run between obs., S. $67^{\circ} 30^{\prime}$ W. 10 knots per hour.

3. August 21st, lat. N., long. $130^{\circ} 21^{\prime} \mathrm{W}$.; with the following observations find the latitude at the second obs. :-

M.T.S., $9^{\text {h }} 21^{\text {m }} 42^{*}$ P.M. ; obs. alt. Vega, $75^{\circ} 47^{\prime} 27^{\prime \prime}$; bearing, S. $40^{\circ}$ W. M.T.S., $1^{\mathrm{h}} 52^{\mathrm{m}} 50^{\circ}$ A.M. ; obs. alt. Vega, $34^{\circ} 53^{\prime} 50^{\prime \prime}$; run, S. $50^{\circ}$ E. 9 knots per hour; ind. cor., $+2^{\prime} 58^{\prime \prime}$; eye, $29 \mathrm{ft}$.

4. August 27 th, lat. S., long. $84^{\circ} 27^{\prime} \mathrm{E}$. ; with the following observations find the latitude at the second obs. ; ind. cor., $+4^{\prime} 14^{\prime \prime}$; eye, $41 \mathrm{ft}$.

M.T.S., $2^{\mathrm{b}} 12^{\mathrm{m}} 19^{\mathrm{s}}$ A.M. ; obs. alt. Aldebaran, $18^{\circ} 10^{\prime} 50^{\prime \prime}$; bearing, N. $61^{\circ} \mathrm{E}$. M.T.S., $5^{\mathrm{h}} 12^{\mathrm{m}} 30^{\circ}$ A.M. ; obs. alt. Aldebaran, $45^{\circ} 40^{\prime} 10^{\prime \prime}$; run, S. $6^{\circ} \mathrm{E} .11$ knots per hour.

5. August 17th, about $11^{\mathrm{b}} 15^{\mathrm{m}}$ P.M. at ship; lat. by D.R. $48^{\circ} 15^{\prime} \mathrm{N}$., long. $179^{\circ} 30^{\prime}$ W.; when a chron. $8^{\mathrm{m}} 4^{\prime}$ fast of M.T.G. showed $11^{\mathrm{h}} 28^{\mathrm{m}} 17^{\prime}$, the obs. alt. of a Arietis was $27^{\circ} 15^{\prime} 40^{\prime \prime}$; ind. cor., $-1^{\prime} 13^{\prime \prime}$; at the same time the obs. alt. of Altair was $47^{\circ} 6^{\prime} 30^{\prime \prime}$; ind. cor., $+2^{\prime} 20^{\prime \prime}$; height of eye, $41 \mathrm{ft}$. Find the position of the ship and true bearings of the stars by Sumner's method, assuming lats. $15^{\prime}$ on each side of D.R. lat., or by any other method.

6. September $3 \mathrm{rd}$, in long. $50^{\circ} 25^{\prime}$ W., lat. N.; when the A.T.S. was $7^{\mathrm{h}} 14^{\mathrm{m}} 20^{\mathrm{s}}$ A.M., the obs. alt. of Sun's U.L. was $18^{\circ} 30^{\prime} 20^{\prime \prime}$; and again at $11^{\mathrm{b}} 0^{\mathrm{m}} 25^{\prime}$ A.M., A.T.S., the obs. alt. of Sun's U.L. was $47^{\circ} 26^{\prime} 20^{\prime \prime}$; ind. cor., $-2^{\prime} 11^{\prime \prime}$; eye, $28 \mathrm{ft}$. ; run between observations, N. $9^{\circ}$ E. 30 miles. If the Sun bore S. $81^{\circ} \mathrm{E}$. at first sight, find lat. at second sight.

7. August 16th, lat. $24^{\circ} \mathrm{N}$., long. $14^{\circ} \mathrm{W}$.; with the following observations of Fomalhaut ( $\alpha$ Pis. Aust.) find the lat. at second obs. :-

Approx. M.T.S., $9^{\mathrm{h}} 45^{\mathrm{m}}$ P.M. ; chron., $10^{\mathrm{h}} 42^{\mathrm{m}} 22^{\mathrm{s}}$; obs. alt., $15^{\circ} 8^{\prime} 50^{\prime \prime}$; bearing, East. Approx. M.T.S., $3^{\mathrm{h}} 15^{\mathrm{m}}$ A.M. ; chron., $4^{\mathrm{h}} 12^{\mathrm{m}} 25^{\mathrm{s}}$; obs. alt., $28^{\circ} 14^{\prime} 0^{\prime \prime}$; ind. cor., $+2^{\prime} 48^{\prime \prime}$. Run between sights, N. $64^{\circ} \mathrm{E} .10$ knots per hour; eye, $45 \mathrm{ft}$.

8. September 15th, lat. S., long. $123^{\circ} 34^{\prime} \mathrm{E}$., with the following observations find the lat. at second obs.; ind. cor., $-3^{\prime} 13^{\prime \prime}$; eye, $36 \mathrm{ft}$.:-

Approx. A.T.S., $0^{\mathrm{h}} 36^{\mathrm{m}}$ P.M.; chron., $4^{\mathrm{h}} 21^{\mathrm{m}} 12^{2}$ M.T.G.; obs. alt. Sun's L.L., $38^{\circ} 44^{\prime} 10^{\prime \prime}$. Approx. A.T.S., $4^{\mathrm{h}} 21^{\mathrm{m}}$ P.M. ; chron., $8^{\mathrm{h}} 6^{\mathrm{m}} 17^{\mathrm{s}}$ M.T.G. s obs. alt. Sun's L.L., $14^{\circ} 14^{\prime} 50^{\prime \prime}$. 
Bearing at first obs. N. by W.; run between sights, N. by W. 12 knots per hour.

9. September 21 st., lat. S., long. $94^{\circ} 26^{\prime}$ E.; with the following observations of Achernar ( $\alpha$ Eridani) find lat. at second obs.; ind.cor., $+2^{\prime} 34^{\prime \prime}$; eye, $33 \mathrm{ft}$ : :-

Approx. M.T.S., $10^{\mathrm{h}} 6^{\mathrm{m}}$ P.M. ; chron., $3^{\mathrm{h}} 40^{\mathrm{m}} 0^{\mathrm{s}}$; obs. alt., $55^{\circ} 53^{\prime} 50^{\prime \prime}$; bearing, S. $31^{\circ}$ E. Approx. M.T.S., $5^{\mathrm{h}} 46^{\mathrm{m}}$ A.M.; chron., $11^{\mathrm{h}} 20^{\mathrm{m}} 20^{\mathrm{s}}$; obs. alt., $49^{\circ} 13^{\prime} 30^{\prime \prime}$; run, N. $31^{\circ}$ W. 63 miles in the interval. The chron. was $8^{\mathrm{m}} 23^{\circ}$ slow of G.M.T.

10. A ugust 27 th, about $2^{\mathrm{h}} 35^{\mathrm{m}}$ A.M. at ship, in long. D.R. $156^{\circ}$ E.; when a chron. correct for M.T.G. showed $4^{\mathrm{h}} 11^{\mathrm{m}} 28^{\mathrm{a}}$; the obs. alt. of Aldebaran was $35^{\circ} 11^{\prime} 20^{\prime \prime}$; no ind. cor.; at the same time the obs. alt. of Markab was $47^{\circ} 49^{\prime} 40^{\prime \prime}$; ind. cor., nil ; eye, $45 \mathrm{ft}$. Find the position of the ship and true bearings of the stars by Sumner's method, assuming lat. $49^{\circ} 30^{\prime} \mathrm{N}$. and $50^{\circ} \mathrm{N}$, or by any other method.

11. September 10th, in long. $91^{\circ} 14^{\prime}$ E., lat. D.R. $27^{\circ} \mathrm{S}$.; with following observations find lat. at second obs. ; ind. cor., nil ; eye, $25 \mathrm{ft}$. :-

Approx. A.T.S., $10^{\mathrm{h}} 40^{\mathrm{m}}$ A.M. ; chron., $4^{\mathrm{h}} 28^{\mathrm{m}} 3^{\mathrm{s}}$; obs. alt. Sun's L.L., $51^{\circ} 52^{\prime}$ $10^{\prime \prime}$. Approx. A.T.S., $3^{\text {h }} 50^{\text {m }}$ P.M. ; chron., $9^{\text {h }} 38^{m} 8^{\text {c }}$; obs. alt. Sun's L.L., $26^{\circ} 25^{\prime} 40^{\prime \prime}$.

Bearing at 1st obs., N. $35^{\circ}$ E. ; run during interval, N. $80^{\circ}$ W. 12 knots per hour. The chron. was correct for G.M.T.

12. September 6th, lat. D.R. $13^{\circ}$ S., long. $30^{\circ} 25^{\prime}$ W.; with following observations of Altair, find lat. at second obs.; ind. cor., $+3^{\prime} 18^{\prime \prime}$; eye, $25 \mathrm{ft}$ : - -

Approx. M.T.S., $9^{\text {h }} 50^{\mathrm{m}}$ P.M. ; G.M.T., $11^{\mathrm{h}} 50^{\mathrm{m}} 2^{\mathrm{a}}$; obs. alt., $62^{\circ} 13^{\prime} 40^{\prime \prime}$; bearing, N. $36^{\circ}$ W. Approx. M.T.S., $1^{\mathrm{b}} 20^{\mathrm{m}}$ A.M. ; G.M.T., $3^{\mathrm{b}} 20^{\mathrm{m}} 15^{\mathrm{s}}$; obs. alt., $18^{\circ} 4^{\prime} 50^{\prime \prime}$.

Run during interval N. $36^{\circ} \mathrm{W} ., 14$ knots per hour.

13. September 16 th, about $4^{\mathrm{h}} 45^{\mathrm{m}}$ A.M., in long. by acct. $127^{\circ} 30^{\prime} \mathrm{E}$.; when a chron. which was $12^{\mathrm{m}} 24^{\mathrm{s}}$ fast of G.M.T. showed $8^{\mathrm{h}} 23^{\mathrm{m}} 12^{\mathrm{s}}$, the obs. alt. of Rigel was $49^{\circ} 28^{\prime} 10^{\prime \prime}$; ind. cor., $-3^{\prime} 15^{\prime \prime}$; and at the same time the obs. alt. of Fomalhaut was $27^{\circ} 25^{\prime} 50^{\prime \prime}$; ind. cor., $+2^{\prime} 11^{\prime \prime}$; height of eye, $27 \mathrm{ft}$. Find the position of the ship and true bearings of the stars by Sumner's method, assuming lats. $46^{\circ} 40^{\prime} \mathrm{S}$. and $47^{\circ} 20^{\prime} \mathrm{S}$., or by any other method.

14. September 28th, in lat. N., long. $6^{\circ} 15^{\prime} \mathrm{W}$.; with following observations of the Sun's L.L. find lat. at first obs.; ind. cor., $-2^{\prime} 12^{\prime \prime}$; eye, $30 \mathrm{ft}$. :-

Approx.A.T.S., $11^{\mathrm{b}} 10^{\mathrm{m}}$ A.M.; chron., $11^{\mathrm{l}} 10^{\mathrm{m}} 25^{\mathrm{s}}$; obs.alt., $34^{\circ} 29^{\prime} 10^{\prime \prime}$. Approx. A.T.S., $4^{\mathrm{b}} 0^{\mathrm{m}}$ P.M. ; chron., $3^{\mathrm{b}} 59^{\mathrm{m}} 49^{\mathrm{s}}$; obs. alt., $16^{\circ} 34^{\prime} 0^{\prime \prime}$; bearing, S. $50^{\circ}$ W.; run during interval, N. $60^{\circ}$ W. 10 knots per hour. The chron. was $14^{\mathrm{m}} 21^{\mathrm{s}}$ slow of G.M.T.

15. September 1st, in lat. N., long. $128^{\circ} 35^{\prime}$ W.; with following observations of a Cygni (Deneb) find lat. at first obs.; ind. cor., $+3^{\prime} 19^{\prime \prime}$; eye, $28 \mathrm{ft}$ : :-

Approx. M.T.S., $8^{\mathrm{h}} 0^{\mathrm{m}}$ P.M.; chron., $4^{\mathrm{h}} 40^{\mathrm{m}} 10^{\mathrm{s}}$; obs. alt., $66^{\circ} 5^{\prime} 20^{\prime \prime}$. Approx. M.T.S., $4^{\mathrm{h}} 10^{\mathrm{m}}$ A.M. ; chron., $12^{\mathrm{h}} 50^{\mathrm{m}} 20^{\mathrm{s}}$; obs. alt., $21^{\circ} 21^{\prime} 30^{\prime \prime}$; bearing, N. $20^{\circ} \mathrm{W}$. The chron. was $1^{\mathrm{m}} 20^{\circ}$ fast of M.T.G.; run during the interval, N. $34^{\circ}$ E. 12 knots per hour. 


\section{CHAPTER XXIII.}

FINDING ERROR OF CHRONOMETER.

AnT. 106. Error of Chronometer by a Single Altitude of the Sun or a Star.-For this purpose it is necessary to know the correct latitude and longitude of the place of observation. The altitude would therefore be usually observed in port, using an artificial horizon.

The computation of the hour angle is exactly the same as in the problem of finding the longitude by chronometer. Thence the mean time at place and mean time at Greenwich are found, and the error of chronometer determined.

Example.-August 30th, at $9^{\mathrm{h}} 3^{\mathrm{m}}$ A.M. M.T.S., in lat. $40^{\circ} 20^{\prime}$ N., long. $25^{\circ} 30^{\prime} \mathrm{W}$.; the obs. alt. of the Sun's L.L. in an artificial horizon was $79^{\circ} 10^{\prime} 20^{\prime \prime}$; ind. cor., $-3^{\prime} 18^{\prime \prime}$; time by chron., $10^{\mathrm{h}} 45^{\mathrm{m}} 15^{\circ}$. Required its error on M.T.G. and A.T.S.

M.T.S. Aug. $29^{\mathrm{d}} 21^{\mathrm{b}} 3^{\mathrm{m}} 0^{\text {s }}$

Long. +1420

$25^{\circ} 30^{\prime}$ Dec. $9^{\circ} 14^{\prime} 44^{\prime \prime} \cdot 3$ N. H.V. $53^{\prime \prime} \cdot 49$

M.T.G. $\overline{29^{\mathrm{d}} 22 \quad \overline{45} \quad 0}$

$$
6, \frac{\overline{10,20}}{1^{\mathrm{b}} 42^{\mathrm{m}}}
$$

Cor. $+1 \quad 6 \cdot 9$

$$
\frac{1}{1^{\mathrm{b}} 42^{\mathrm{m}}}
$$

N.P.D. 80448

\begin{tabular}{ccc}
\hline 9 & 15 & $51 \cdot 2$ \\
90 & & \\
\hline 80 & 44 & 8
\end{tabular}

26745

Obs. alt. $79^{\circ} 10^{\prime} 20^{\prime \prime}$

I.C. -318

$$
\begin{aligned}
& \text { Eq. T. } 0^{\mathrm{m}} \begin{array}{r}
45^{\circ} \cdot 9 \\
\text { Cor. } \\
+\cdot 9
\end{array} \\
& \hline 46 \cdot 8
\end{aligned}
$$

H.V. $\cdot 75$

$66 \cdot 8625$

$$
\begin{array}{rrr}
\hline \lcm{79} \quad 7 \quad 2 \\
\hline 39 \quad 33 \quad 31
\end{array}
$$

S.D. +1552

R. \& P. $-1 \quad 1$

$$
\overline{394923}
$$

T. A. 394822 


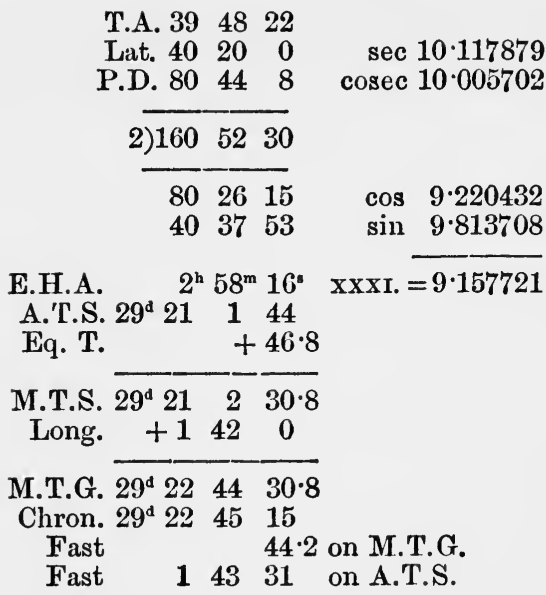

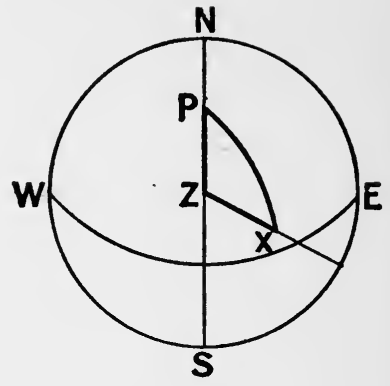

FIG. 164.

The H.A. might also have been determined, direct from the figure, as in the case of the chronometer. In the triangle $\mathbf{P Z X}$, the three sides are given to find angle $P$.

ArT. 107. Error of Chronometer by Equal Altitudes.-(a) Equal Altitudes of the Sun.-If the times by chronometer when the Sun has equal altitudes east and west of the meridian be noted, the mean of these times, with a correction on account of the change of declination during the interval, gives the time shown by the same chronometer when the Sun's centre crosses the meridian, that is, apparent noon. This affords a means of finding the error of the chronometer.

The observation can best be made on shore with an artificial horizon, the latitude and longitude of the place of observation being accurately known.

If there were nc change of declination, it is obvious that the hour angles $\mathrm{E}$. and $\mathrm{W}$. would be equal, and the mean of the times would be what the chronometer showed at apparent noon. But as the Sun's declination changes, the middle time would fall on one side or the other of apparent noon by a small interval called the "Equation of Equal Altitudes."

Thus, when the Sun's polar distance increases, the east H.A. would be greater than the west H.A., because it would take less time to fall to the same altitude, and the middle time would be a few seconds before apparent noon. Again, when the polar distance decreases, the west H.A. would be the greater, because it would take a longer time for the Sun to attain the same altitude, and so the middle time would then be a few seconds after apparent noon.

The object of the calculation is therefore to find the correction to be applied to the middle time to find the exact time by 
chronometer when the Sun's centre was on the meridian, and thence the error of the chronometer.

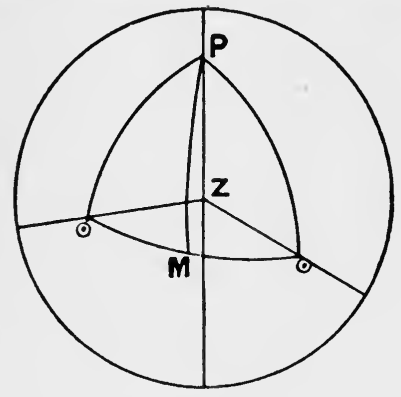

Fig. 165.

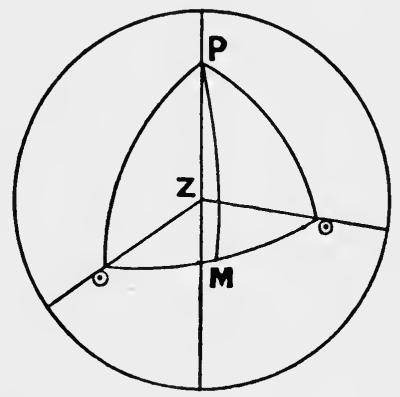

FIG. 166.

The working out of the formula gives the correction in two parts.

The first part is marked + or - according as the Sun's polar distance is increasing or decreasing.

The second part is marked + or - according as the declination is increasing or decreasing.

The algebraical sum of the two parts is the Equation of Equal Altitudes with the proper sign.

The elements required for the calculation are, the Time

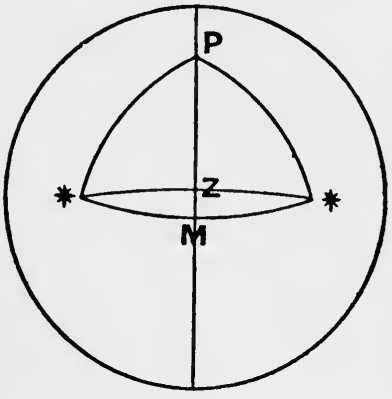

Fig. 167. Interval, the Sun's Declination, and the Equation of Time, with the latitude and longitude of the place of observation.

(b) Equal Altitudes of a Star.The intervals from the time when a star crosses the meridian to the times when it has equal altitude east and west of the meridian are exactly equal, because its declination does not change. Hence the middle time by chronometer would be the time of meridian passage, and as the time of meridian passage can be found independently, the error of the chronometer can be determined.

\section{Examples.}

(1) August 1st, at Valparaiso, lat. $33^{\circ} 2^{\prime}$ S., long. $71^{\circ} 42^{\prime}$ W., 'he sun had equal alts. at-

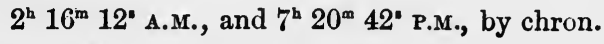

Find its error on M.T.G. and A.T.S. 

A.T.S. Aug. $1^{\mathrm{d}} 0^{\mathrm{m}} 0^{\mathrm{m}} 0^{\text {s }}$
Long. +44648
A.T.G. $\overline{1^{\mathrm{d}}} 4 \mathbf{4 6} 48$

First obs. $2^{\text {h }} 16^{\mathrm{m}} 12^{\prime}$ A.M. Second obs. 72042 P.M.

Int. $5 \quad 4 \quad 30$

$\frac{1}{2}$ Int. $2 \quad 32 \quad 15$

Mid. Time $4 \quad 48 \quad 27$

Dec. $18^{\circ} 11^{\prime} 45^{\prime \prime}$ N. H.V. $37^{\prime \prime} \cdot 26$ Eq.T. $6^{m} 10^{\prime} \cdot 22$ H.V. 13 Ch. of Dec.

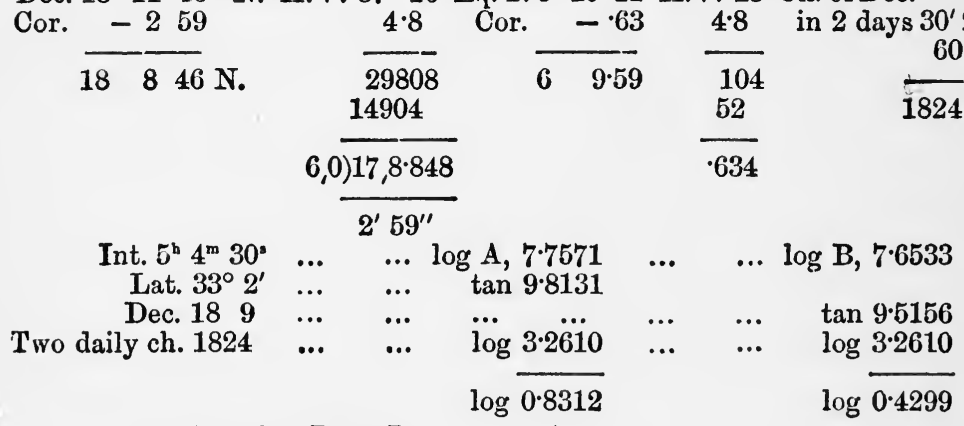

Pol. dist. dec. Part I. $\quad-6.78$

Dec. ,, ,, II. $\quad-2 \cdot 69$

Eq. of equal alts. $\quad-9.47$

Mid. time by chron. $4^{\mathrm{h}} 48^{\mathrm{m}} 27^{\mathrm{s}}$

A.T.G. $4^{\text {h }} 46^{\mathrm{m}} 48^{\text {* }}$

Eq. T. +69.59

M.T.G. $4 \quad 52 \quad 57 \cdot 59$

Watch $4 \quad 48 \quad 17 \cdot 53$

IVatch showed at approx. noon $4 \quad 48 \quad 17 \cdot 53$

Watch fast A.T.S. $4 \quad 48 \quad 17 \cdot 53 \quad$ Slow M.T.G. $4 \quad 40 \cdot 06$

(2) September 30th, the following times by chron. were noted in lat. $7^{\circ} 56^{\prime}$ S., long. $14^{\circ} 26^{\prime}$ W., when Markab had equal alts.
Star E. $7^{\text {h }} 34^{\mathrm{m}} 50^{\text {* }}$
Star W. $13^{\mathrm{h}} 3^{\mathrm{m}} 53^{\mathrm{a}}$

Find error of chron. on G.M.T.

$\begin{array}{cccc}\text { R.A. Markab } & 23^{\mathrm{h}} & 0^{\mathrm{m}} & 4^{\mathrm{s}} \cdot 66 \\ \text { R.A.M.S. } & 12 & 33 & 17 \cdot 38\end{array}$

Approx. M.T. transit $30^{\mathrm{d}} 10^{\mathrm{h}} 26^{\mathrm{m}} 47^{\mathrm{s} \cdot 28}$

$$
\begin{aligned}
& \text { Long. W. } \\
& +5744
\end{aligned}
$$

R.A.M.S. $12^{\mathrm{h}} 33^{\mathrm{m}} 17^{\mathrm{v}} \cdot 38$

Accel.

$148 \cdot 42$

$3 \cdot 94$

$\cdot 08$
First obs. $7^{\text {h }} 34^{\mathrm{m}} 50^{\text {生 }}$ Second obs. $13 \quad 3 \quad 53$

Int. $\begin{array}{lll}5 & 29 & 3\end{array}$

$\frac{1}{2}$ Int. $244 \quad 31.5$

Mid. time $10 \quad 19 \quad 21.5$

24 


\section{Exercises.}

1. August 4th, at $8^{\mathrm{h}} 40^{\mathrm{m}}$ A.M. A.T.S., in lat. $38^{\circ} 47^{\prime} \mathrm{S} .92^{\circ} 12^{\prime}$ E.; tl e obs. alt. of the Sun's L.L. was $16^{\circ} 42^{\prime} 10^{\prime \prime}$; ind. cor., $+2^{\prime} 15^{\prime \prime}$; eye, $29 \mathrm{ft}$., when a chron. showed $2^{\mathrm{h}} 45^{\mathrm{m}} 10^{\mathrm{s}}$. Find its error on M.T.G. and A.T.S.

2. August 31st, at $9^{\mathrm{h}} 22^{\mathrm{m}}$ A.M. A.T.S., in lat. $52^{\circ} 25^{\prime}$ N., long. $3^{\circ} 20^{\prime}$ W. ; the obs. alt. of the Sun's U.L. was $36^{\circ} 26^{\prime} 10^{\prime \prime}$; ind. cor., $-26^{\prime \prime}$; eye, $41 \mathrm{ft}$. ; if a chron. indicated $9^{\mathrm{h}} 20^{\mathrm{m}} 19^{\mathrm{s}}$, what was its error on M.T.G.

3. August 19th, at $4^{\mathrm{h}} 26^{\mathrm{m}}$ P.M. A.T.S., when a point in lat. $41^{\circ} 35^{\prime} 30^{\prime \prime}$ $\mathrm{N}$., long. $70^{\circ} 30^{\prime} 42^{\prime \prime} \mathrm{W}$., bore N. $35^{\circ} \mathrm{W}$., distant 14 miles ; the obs. alt. of the Sun's U.L. in artificial horizon was $52^{\circ} 53^{\prime} 10^{\prime \prime}$; ind. cor., $-3^{\prime} 30^{\prime \prime}$; if a chron. showed $9^{\mathrm{h}} 10^{\mathrm{m}}$, find its error on M.T.G.

4. September 30 th, at $3^{\mathrm{b}} 30^{\mathrm{m}}$ P.M. A.T.S., when a point in lat. $49^{\circ} 42^{\prime}$ S., long. $179^{\circ} 44^{\prime} 30^{\prime \prime} \mathrm{E}$., bore S. $56^{\circ}$ W., distant 9 miles ; the obs. alt. of the Sun's L. L. in artificial horizon was $49^{\circ} 57^{\prime} 10^{\prime \prime}$; ind. cor., $+3^{\prime} 56^{\prime \prime}$; eye, 50 ft. If a chron. showed $3^{\mathrm{h}} 15^{\mathrm{m}} 20^{\mathrm{s}}$, find its error on M.T.G.

5. August 16 th, at $9^{\text {h }} 45^{\mathrm{m}}$ P.M. M.T.S., when a point in lat. $24^{\circ} 17^{\prime} 12^{\prime \prime} \mathrm{N}$., long. $14^{\circ} 9^{\prime} 30^{\prime \prime} \mathrm{W}$., bore S. $27^{\circ} \mathrm{E}$., distant 11 miles ; the obs. alt. of Fomalhaut in artificial horizon was $31^{\circ} 46^{\prime} 20^{\prime \prime}$; ind. cor., $+2^{\prime} 12^{\prime \prime}$, when a chron. showed $11^{\text {h}}$. Find its error on M.T.G.

6. September 21 st, at $10^{\mathrm{h}} 6^{\mathrm{m}}$ P.M. M.T.S., in lat. $43^{\circ} 19^{\prime}$ S., long. $94^{\circ} 26^{\prime}$ E. ; the obs. alt. of Achernar was $54^{\circ} 50^{\prime} 50^{\prime \prime}$, when a chron. showed $3^{\mathrm{h}} 40^{\mathrm{m}}$; ind. cor., $+2^{\prime} 34^{\prime \prime}$; eye, $33 \mathrm{ft}$. Find error on M.T.S. and M.T.G.

7. August 22nd, at $1^{\mathrm{h}} 53^{\mathrm{m}}$ A.M. M.T.S., when a point in lat. $50^{\circ} 23^{\prime} 24^{\prime \prime} \mathrm{N}$., long. $130^{\circ} 6^{\prime} 30^{\prime \prime} \mathrm{W}$., bore N. $70^{\circ}$ E., distant 10 miles ; the obs. alt. of Vega in artificial horizon was $69^{\circ} 44^{\prime} 20^{\prime \prime}$; ind. cor., $-1^{\prime} 16^{\prime \prime}$; a chron. showed $10^{\mathrm{h}} 35^{\mathrm{m}}$, find its error on M.T.G.

8. August $22 \mathrm{nd}$, in lat. $27^{\circ} 10^{\prime} \mathrm{N}$., long. $56^{\circ} 17^{\prime}$ E., the following times were observed when the Sun had equal alts. Find the error of the chron. for A.T.S. and M.T.G.

$$
\begin{aligned}
& \text { A.M. } 4^{\text {h }} 19^{\mathrm{m}} 27^{\text {? }} \\
& 4 \quad 25 \quad 32 \\
& \text { P.x. } 0^{\mathrm{h}} \quad 7^{\mathrm{m}} 30^{\mathrm{s}} \\
& \begin{array}{lll}
0 & 12 \quad 15
\end{array}
\end{aligned}
$$




\section{CHAPTER XXIV.}

\section{CALCULATION OF ALTITUDES.}

ART. 108. Computing an Altitude. - In some problems of. Nautical Astronomy it is necessary to compute the altitude of a celestial object. Especially is this the case when setting questions, so that the altitude shall be consistent with the other data.

The data required to be known are the hour angle of the object and the latitude and longitude of the place.

The following method has the advantage of requiring only one table of logarithms.

In the figure, $\mathrm{S}$ is the object, PS the polar distance, the angle

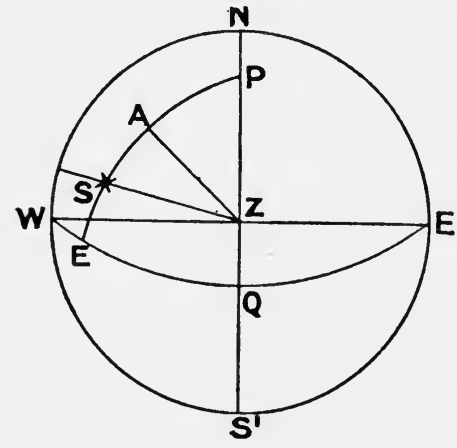

Fia. 168.

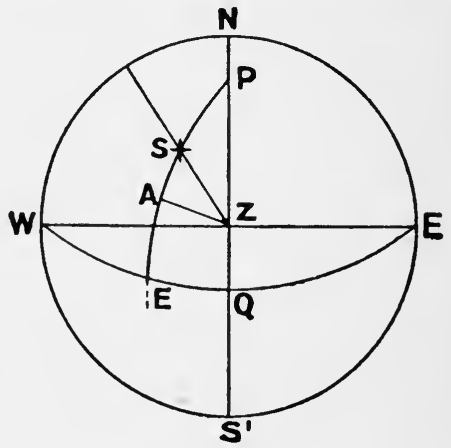

Fig. 169.

ZPS the hour angle, PZ the co-lat., and $\mathrm{ZA}$ an arc of a great circle perpendicular to PS.

Let $\mathrm{PA}=\boldsymbol{\theta}$;

$$
\text { then } \mathrm{SA}=(p \sim \theta)
$$

In the right-angled spherical triangle $\mathrm{PAZ}-$

$$
\begin{aligned}
\cos h & =\cot \mathrm{PZ} \cdot \tan \mathrm{PA} \\
& =\tan l \cdot \tan \theta \\
\therefore \tan \theta & =\cos h \cdot \cot l .
\end{aligned}
$$

In the same triangle-

$$
\begin{aligned}
\cos \mathrm{PZ} & =\cos \mathrm{PA} \cdot \cos \mathrm{AZ} \\
\text { i.e. } \sin l & =\cos \theta \cdot \cos \mathrm{AZ} \\
\therefore \cos \mathrm{AZ} & =\sin l \cdot \sec \theta .
\end{aligned}
$$


Also in the triangle SAZ-

$$
\begin{aligned}
\cos \mathrm{SZ} & =\cos \mathrm{AZ} \cdot \cos \mathrm{AS} \\
\text { i.e. } \sin a & =\sin l \cdot \sec \theta \cdot \cos (p \sim \theta)
\end{aligned}
$$

by substituting the value of $\cos \mathrm{AZ}$ from (2).

NotE. $-(p \sim \theta)$ signifies the difference between $p$ and $\theta$, because one or the other may be the greater according as the perpendicular ZA falls within or without the triangle PZS.

For computation the following arrangement is convenient ( $l=$ lat., $a=$ alt., $p=$ polar distance, $h=$ hour angle) :-

$\begin{array}{rrrrrr}h & \ldots & \cos & & & \\ l & \ldots & \cot & & \ldots & \sin \\ \theta & \ldots & \tan & & \ldots & \sec \\ \frac{p}{p \sim \theta} & \ldots & \ldots & \ldots & \ldots & \cos \\ a & \ldots & \ldots & \ldots & \ldots & \sin \end{array}$

The altitude may also be calculated by the log rising method, by transposing formula proved in the ex-meridian chapter, which becomes-

sin alt. $=\cos$ zen. dist. $-\cos$ lat. $\cos$ dec. log rising hour angle, or by direct spherics.

ART. 109.-The first method may be stated as follows :-

(1) Find the hour angle of the object.

(2) Correct declination, find polar distance.

(3) Add cos H.A. and cot lat.; this gives tan arc 1. Difference between arc 1 and pol. dist. gives arc 2: add sin lat., sec arc 1, and $\cos$ arc 2 ; the result is sin true alt.

(4) Apply refraction and parallax to true alt. for app. alt.

\section{Example.}

September 7 th, at $8^{\text {h }} 51^{\mathrm{m}} 32^{\mathrm{s}}$ A.M. apparent time at ship, in lat. $48^{\circ} 10^{\prime}$ N., long. $149^{\circ} 22^{\prime} 15^{\prime \prime}$ W. Find true and apparent altitudes of the Sun.
A.T.S. Sept. $6^{\mathrm{d}} 20^{\mathrm{h}} 51^{\mathrm{m}} 32^{\mathrm{s}}$
Long. W. +9 5729
$\begin{array}{llllll}\text { A.T.G. Sept. } 7^{\mathrm{d}} & \mathbf{6} 49 & 1 & 6,0) \overline{59,7} 29 & 0\end{array}$
$149^{\circ} 22^{\prime} 15^{\prime \prime}$
Dec. $6^{\circ} 19^{\prime} 18^{\prime \prime} \cdot 6 \mathrm{~N}$.
Cor. $\quad-622$
$9^{\mathrm{h}} 57^{\mathrm{m}} 29^{\mathrm{s}}$
H.V. $\begin{array}{r}56 \cdot 01 \\ 6 \cdot 82\end{array}$
N.P.D. $83 \quad \overline{47} 3$
$24^{\mathrm{h}} \quad 0^{\mathrm{m}} \quad 0^{\circ}$
$\begin{array}{lll}20 & 51 \quad 32\end{array}$
$6,0) 381.99$
E.H.A. $3 \quad 8 \quad 28$
$6^{\prime} 22^{\prime \prime}$ 


$$
\begin{aligned}
& \text { H.A. } 3^{\text {h }} \quad 8^{\mathrm{m}} 28^{\mathrm{s}} \quad \cos =9.832833 \\
& \text { Lat. } 48 \quad 10 \quad 0 \quad \cot =9.951896 \quad \sin =9.872208 \\
& \text { Arc 1, } 3120 \quad 53 \quad \tan =\overline{9 \cdot 784729} \quad \text { sec }=10.068 \tilde{5} 31 \\
& \text { P.D. } 8347 \quad 3 \\
& \operatorname{Arc} 2, \begin{array}{lllllll}
52 & 26 & 10 & \ldots & \ldots & \ldots & \cos =9 \cdot 785078
\end{array} \\
& \begin{array}{lllllll}
\text { True alt. } 32 & 7 & 58 & \ldots & \ldots & \ldots & \sin =\overline{9 \cdot 725817}
\end{array} \\
& \text { Par. } \\
& 32 \quad 750 \\
& \text { Ref. }+131 \\
& \text { App. alt. } \begin{array}{lll}
32 \quad 9 & 21
\end{array}
\end{aligned}
$$

Rules for log rising method.

(1) Find the hour angle of the object.

(2) Correct declination; find zenith distance by adding dec. and lat. if of contrary name, and subtracting them if of same name.

(3) Add cos lat., cos dec., and log rising hour angle, increasing index by 1 ; reject 10 's and take back log, Table xxIv.; this gives "Nat. No."

Subtract "Nat. No." from Nat. cos. zen. dist., and take back Nat. sin true alt.

(4) Apply ref. and par. for app. alt.

\section{Example.-}

$$
\begin{array}{rrrrrr}
\text { H.A. } & 3^{\mathrm{h}} & 8^{\mathrm{m}} & 28^{\mathrm{s}} & \text { log rising } & =5 \cdot 504460 \\
\text { Lat. } & 48^{\circ} & 10^{\prime} & 0 \mathrm{~N} . & \cos & =9 \cdot 824104 \\
\text { Dec. } 6 & 12 & 57 & \mathrm{~N} . & \cos & =9 \cdot 997440
\end{array}
$$

Z.D. $41^{\circ} 57^{\prime} 3^{\prime \prime} \quad$ N. $\cos 743718$

T.A. $32 \quad 7 \quad 57 \quad$ N. $\sin 531880$

R. and P. +123

$$
\text { A.A. } 32 \quad 920
$$

\section{From figure.}

In figure $\mathrm{X}$ is the position of the object, $\mathrm{AX}$ is alt. of object.

In triangle $\mathrm{PZX}$,

$$
\begin{aligned}
\text { Given co-lat. } & =\mathrm{PZ} \\
\text { Pol. dist. } & =\mathrm{PX} \\
\text { Hour angle } & =\mathrm{P}
\end{aligned}
$$

Required zen. dist. $=\mathrm{ZX}$

$$
\begin{aligned}
\operatorname{Tan} \frac{1}{2}(Z+X) & =\frac{\cos \frac{1}{2}(P X-P Z)}{\cos \frac{1}{2}(P X+P Z)} \cdot \cot \frac{P}{2} \\
\cos \frac{Z X}{2} & =\frac{\cos \frac{1}{2}(P X+P Z)}{\cos \frac{1}{2}(Z+X)} \cdot \sin \frac{P}{2}
\end{aligned}
$$

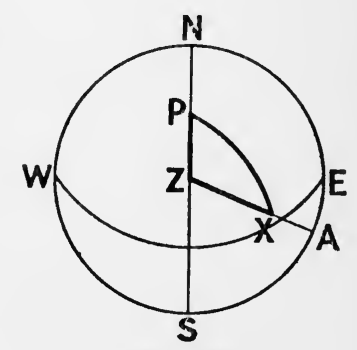

Fig. 170. 
$\mathrm{PX}=83^{\circ} 47^{\prime} 3^{\prime \prime}$

$\mathrm{PZ}=\begin{array}{lll}41 & 50 & 0\end{array}$

$$
\frac{\mathrm{P}}{2}=1^{\mathrm{h}} 34^{\mathrm{m}} 14^{\mathrm{e}} \quad \cot =10 \cdot 360490 \sin =9.601715
$$

$\mathrm{PX}+\mathrm{PZ}=\overline{125373} \frac{1}{2}(\mathrm{PX}+\mathrm{PZ})=62^{\circ} 48^{\prime} 32^{\prime \prime} \mathrm{sec}=10 \cdot 340122 \cos =9 \cdot 659878$

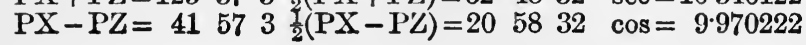

$\overline{775716} \tan =10 \cdot 670834$ sec $=10 \cdot 680503$

$$
\begin{aligned}
\mathrm{ZX} & =\frac{28^{\circ} 56^{\prime} 3^{\prime \prime} \quad \cos =\overline{9 \cdot 942096}}{5752 \quad 6} \\
\text { T.A. } & =\overline{32 \quad 754} \\
\text { R. and P. } & \frac{+123}{32 \quad 917} \\
\text { A.A. } &
\end{aligned}
$$

\section{EXERCISES.}

1. September 7 th, at $11^{\mathrm{b}} 14^{\mathrm{m}} 35^{\circ}$ A.M. apparent time at ship, in lat. $48^{\circ}$ $10^{\prime} \mathrm{N}$., long. $149^{\circ} 22^{\prime} 15^{\prime \prime} \mathrm{W}$. Find true and appar. alts. of Sun.

2. September 29th, at $4^{\text {h }} 32^{\mathrm{m}} 46^{\circ}$ P.M. M.T.S., in lat. $46^{\circ} 50^{\prime}$ N., long. $180^{\circ} \mathrm{W}$. Find true and appar. alts. of Sun.

3. August 2 nd, at $9^{\mathrm{h}} 15^{\mathrm{m}} 20^{\wedge}$ P.M. M.T.S., in lat. $23^{\circ} 12^{\prime}$ N., long. $62^{\circ} 35^{\prime}$ W. Find true and appar. alts. of Antares.

4. September 28 th, at $4^{\mathrm{h}} 5^{\mathrm{m}} 20^{\circ}$ A.M. M.T.S., in lat. $47^{\circ} 42^{\prime}$ S., long. $84^{\circ}$ $25^{\prime}$ E. Find true and appar. alts. of $a$ Hydræ.

5. August 10th at $8^{\mathrm{n}} 20^{\mathrm{m}} 41^{\circ}$ A.M. M.T.S., in lat. $37^{\circ} 14^{\prime}$ N., long. $14^{\circ}$ $26^{\prime}$ W. Find true and appar. alts. of the Moon.

6. August 12th, at $4^{\mathrm{h}} 58^{\mathrm{m}} 48^{\circ}$ A.M. M.T.S., in lat. $25^{\circ} 19^{\prime}$ S., long. $169^{\circ}$ $37^{\prime}$ E. Find true and appar. alts. of Saturn.

7. August 30th, at $8^{\mathrm{h}} 30^{\mathrm{m}} 25^{\mathrm{s}}$ P.M. M.T.S., in lat. $10^{\circ} 15^{\prime}$ S., long. $98^{\circ} 27^{\prime}$ $15^{\prime \prime}$ E. Find true and appar. alts. of the Moon.

8. August 9th, at $5^{\mathrm{h}} 4^{\mathrm{m}} 2^{3}$ A.M. M.T.S., in lat. $5^{\circ} 14^{\prime} \mathrm{N}$., long. $20^{\circ} 27^{\prime} \mathrm{W}$. Find true and appar. alts. of Jupiter. 


\section{CHAPTER XXV.}

\section{LONGITUDE BY LUNAR DISTANCES.}

ART. 110.-In a lunar observation the Greenwich time is found by measuring the distance between the moon and certain bright objects which lie in or near her path. The bodies chosen are the Sun, Venus, Mars, Jupiter, Saturn, and the bright stars a Arietis, Aldebaran, Pollux, Regulus, Spica, Antares, a Aquilæ, Fomalhaut, and $a$ Pegasi.

In the N.A., pp. XIII. to XVIII., are given for each day the distances east or west, between the moon and certain of these objects at intervals of three hours of M.T.G. These true distances are the angles between the centres of the Moon and object selected, as measured at the Earth's centre. The M.T.G. corresponding to any other distance may be found by proportion, but owing to the variation in the uniformity of the motion a correction for "second differences" found in the N.A. must be applied before the correct G.M.T. is known. Before the invention of chronometers the "Lunar Problem" was almost the only means available at sea for finding the Greenwich time, on which the determination of longitude depends. It may still be of great use in the event of chronometers "running down" or becoming unserviceable.

The proportion referred to may be worked by arithmetic, but the use of "Proportional Logarithms" is simpler and more general. These are found in Norie, Table xxxiv.

The proportional logarithm of a given quantity is the logarithm of the ratio of some constant greater than that quantity to the given quantity. In the N.A. the constant is 3 hours, or 10,800 seconds, and the prop. $\log$ (P.L.) for any other time, for instance, $1^{\mathrm{h}} 42^{\mathrm{m}} 11^{\mathrm{s}}$, is $=\log \frac{3^{\mathrm{h}}}{1^{\mathrm{h}} 42^{\mathrm{m}} 11^{\mathrm{s}}}$

$$
\begin{aligned}
& =\log 10800-\log 6131 \\
& =4 \cdot 033424-3 \cdot 787531 \\
& =0 \cdot 245893
\end{aligned}
$$

which is entered in tables as 2459 , the nearest fourth place only being used. This table facilitates the finding of a time corresponding to a true distance, as by it only two references are necessary, whereas by ordinary logs four entries are made before obtaining the result.

1 Discontinued since 1908. 
Suppose $x$ and $y$ the distances in the N.A. between which the true distance $d$ lies, and $t$ the number of hours elapsed since the time for which $x$ is tabulated.

Then-

$y-x$ is change in distance in three hours,

$d-\infty$

Hence-

$$
\begin{aligned}
y-x & : d-x:: 3: t \\
\text { or } \frac{3}{t} & =\frac{y-x}{d-x} \\
& =\frac{3}{d-x} \div \frac{3}{y-x}
\end{aligned}
$$

which is P.L. $t=$ P.L. $(d-x)-$ P.L. $(y-x)$

The quantity P.L. $(y-x)$ is tabulated in N.A. opposite the distance $x$.

In using these distances the instructions in the N.A. are-

"Take the difference between the reduced distance and the nearest distance preceding it, in order of time, in the ephemeris; from the P.L. of this difference subtract the P.L. in the ephemeris; the remainder will be the P.L. of a portion of time to be added to the hour answering to the nearest preceding distance, to obtain the approximate Greenwich mean time corresponding to the given distance."

When selecting a suitable object for observation, it must be remembered that those objects are most favourably situated from which the moon is receding, or to which the moon is approaching most rapidly, and this is shown by the smallness of the P.L. opposite to it; attention should also be paid to the object having as small a difference in declination from the moon as possible compared with their difference in right ascension.

\section{Examples.-}

(1) The true distance between the Moon and a Arietis on August 13th is $37^{\circ} 51^{\prime} 32^{\prime \prime}$. Find G.M.T.

Tr. dist. $37^{\circ} 51^{\prime} 32^{\prime \prime}$

N.A. " $372018 \quad$ P.L. $3493 \quad \ldots \quad$ Aug. $13^{\mathrm{d}} 12^{\text {h }} 0^{\mathrm{m}} 0^{\text {* }}$

$3114 \quad$ P.L. 7607

P.L. $4114 \quad \ldots \quad \ldots \quad \quad 1968$

P.L. 3527

Approx. M.T.G. $13^{\mathrm{d}} 13948$

" 3463

With diff. -32 of P.L.'s and

2)64 Int. $1^{\mathrm{h}} 10^{\mathrm{m}}$ cor. for 2 nd diffs. $=$ $+9$

Mean diff. 32

M.T.G. $13^{\mathrm{d}} 13 \quad 957$

(2) The true distance between the Moon and Spica on August 26th is $43^{\circ} 1^{\prime} 29^{\prime \prime}$. Find G.M.T. 
Tr. dist. $43^{\circ} 1^{\prime} 29^{\prime \prime}$

N.A. , $\frac{421122}{507}$

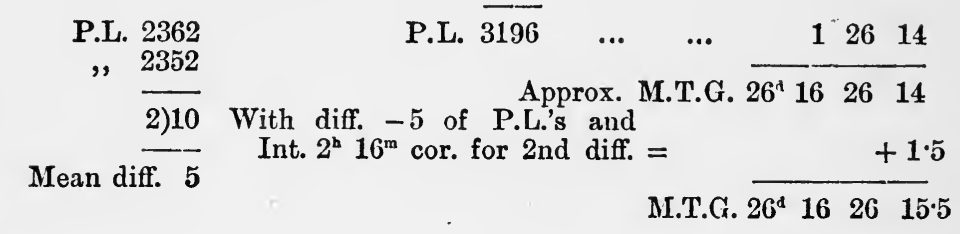

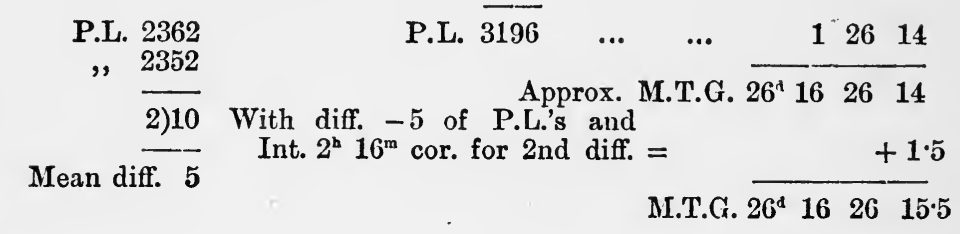

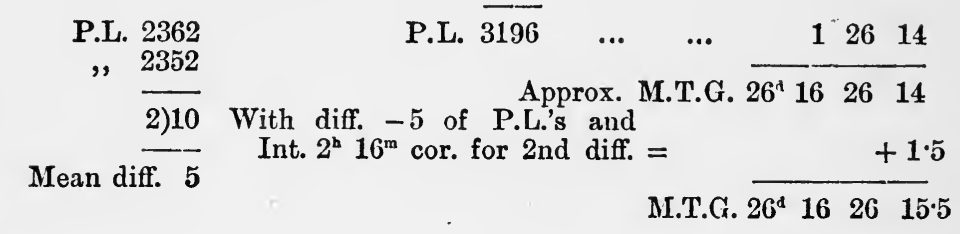

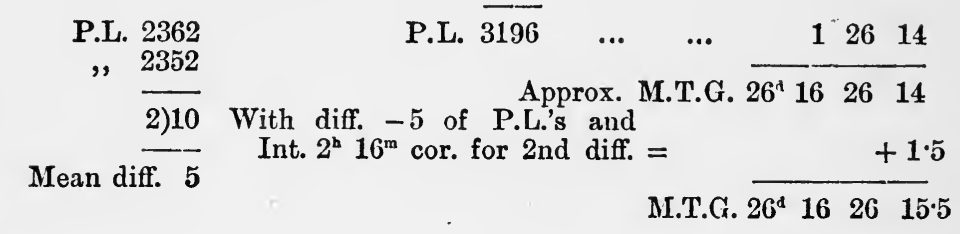

P.L. $2357 \quad \ldots \quad$ Aug. $26^{\text {d }} \quad 15^{\text {h }} 0^{m} \quad 0^{\text {a }}$

P.L. 5553

Exercises.

1. The true distance between the Moon and Aldebaran on August 6th is $80^{\circ} 29^{\prime} 7^{\prime \prime}$. Find G.M.T.

2. The true distance between the Moon and Jupiter on August 7 th is $89^{\circ} 21^{\prime} 12^{\prime \prime}$. Find G.M.T.

3. The true distance between the Moon and $\alpha$ Pegasi on August 12th is $69^{\circ} 40^{\prime} 15 .^{\prime \prime}$ Find G.M.T'.

4. The true distance between the Sun and Moon on August 22nd is $42^{\circ}$ $35^{\prime} 17^{\prime \prime}$. Find G.M.T.

5. The true distance between the Moon and Spica on August 28th is $65^{\circ}$ $32^{\prime}$ 11." Find G.M.T.

ART. 111. The Lunar.-Let ZX and ZY be two vertical circles passing through the apparent positions $\mathrm{M}^{\prime}$ and $\mathrm{S}^{\prime}$ of the Moon and another celestial object (Sun, Star, or Planet); the true positions M and $S$, as seen from the Earth's centre, will be on the same vertical circles, and differ from the apparent positions by the effects of refraction and parallax. The Moon's parallax exceeds the refraction, but the parallax of any other body is less than the refraction. Hence the Moon's apparent place is lower, and that of the other body higher,

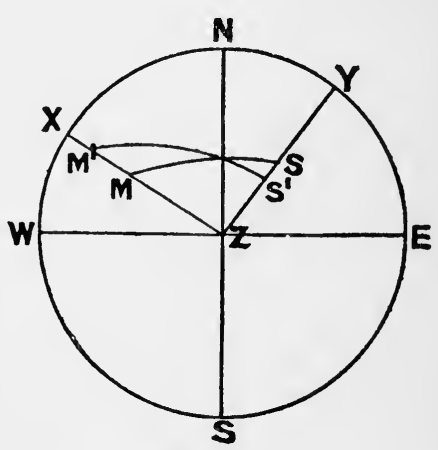

Fia. 171. than the true positions.

$\mathrm{M}^{\prime} \mathrm{S}^{\prime}$ and MS are arcs of two great circles, and represent the apparent and true distances.

$X M^{\prime}$ and $\mathrm{XM}$ are the apparent and true altitudes of the Moon, and YS' and YS the apparent and true altitudes of the other body.

The angle $\mathrm{Z}$ is common to the two triangles ZM'S' and ZMS.

The problem is to find the true distance MS, the apparent distance $\mathrm{M}^{\prime} \mathrm{S}^{\prime}$, and the true and apparent altitudes being given.

In the spherical triangle $\mathrm{ZM}^{\prime} \mathrm{S}^{\prime}$ are given the three sides, 
$\mathrm{ZM}^{\prime}, \mathrm{ZS}^{\prime}$, and $\mathrm{M}^{\prime} \mathrm{S}^{\prime}$, to find the angle $\mathrm{Z}$. Then in the triangle $Z M S$, the two sides $Z M$ and $Z S$ and the included single $Z$ being known, the third side MS or true distance can be found.

The problem can therefore be solved by simply applying the formulæ of Cases I. and II. of oblique-angled spherical trigonometry, but as this involves two separate computations, several methods have been devised for clearing the distance by a single logarithmic computation. The method most generally used is known as Borda's, which requires only one table of logarithms. It is obtained as follows :-

Applying the general formula, $\cos A=\frac{\cos a-\cos b \cdot \cos c}{\sin b \cdot \sin c}$

In the triangle $Z M^{\prime} S^{\prime}, \cos Z=\frac{\cos M^{\prime} S^{\prime}-\cos Z M^{\prime} \cdot \cos Z S^{\prime}}{\sin Z M^{\prime} \cdot \sin Z S^{\prime}}$

In the triangle ZMS, $\cos Z=\frac{\cos M S-\cos Z M \cdot \cos Z S}{\sin Z M I \cdot \sin Z S}$

Let $m$ and $m^{\prime}$ represent the Moon's true and apparent altitudes ;

$s$ and $s^{\prime}$ the true and apparent altitudes of the other body;

$d$ and $d^{\prime}$ the true and apparent distances ;

Then equation (1) becomes-

$$
\cos Z=\frac{\cos d^{\prime}-\sin m^{\prime} \cdot \sin s^{\prime}}{\cos m^{\prime} \cdot \cos s^{\prime}}
$$

and equation (2) becomes-

$$
\left.\begin{array}{rl}
\cos Z=\frac{\cos d-\sin m \cdot \sin s}{\cos m \cdot \cos s} \\
\therefore \frac{\cos d-\sin m \cdot \sin s}{\cos m \cdot \cos s}=\frac{\cos d^{\prime}-\sin m^{\prime} \cdot \sin s^{\prime}}{\cos m^{\prime} \cdot \cos s^{\prime}}
\end{array}\right\} \begin{aligned}
& \text { altitudes } \\
& \text { for zenith } \\
& \text { distances }
\end{aligned}
$$

by putting

Adding 1 to each side-

$$
1+\frac{\cos d-\sin m \cdot \sin s}{\cos m \cdot \cos s}=1+\frac{\cos d^{\prime}-\sin m \cdot \sin s^{\prime}}{\cos m^{\prime} \cdot \cos s^{\prime}}
$$

$\therefore \frac{\cos d+\cos m \cdot \cos s-\sin m \cdot \sin s}{\cos m \cdot \cos s}$

that is-

$$
=\frac{\cos d^{\prime}+\cos m^{\prime} \cdot \cos s^{\prime}-\sin m^{\prime} \cdot \sin s^{\prime}}{\cos m^{\prime} \cdot \cos s^{\prime}}
$$

$$
\begin{aligned}
\quad \frac{\cos d+\cos (m+s)}{\cos m \cdot \cos s} & =\frac{\cos d^{\prime}+\cos \left(m^{\prime}+s^{\prime}\right)}{\cos m^{\prime} \cdot \cos s^{\prime}} \\
\therefore \cos d+\cos (m+s) & =\frac{\cos m \cdot \cos s}{\cos m^{\prime} \cdot \cos s^{\prime}} \cdot\left\{\cos d^{\prime}+\cos \left(m^{\prime}+s^{\prime}\right)\right\}
\end{aligned}
$$


But $\cos d=1-2 \sin ^{2} \frac{d}{2}$, and $\cos (m+s)=2 \cos ^{2} \frac{m+s}{2}-1$

$\therefore 1-2 \sin ^{2} \frac{d}{2}+2 \cos ^{2} \frac{m+s}{2}-1=-2 \sin ^{2} \frac{d}{2}+2 \cos ^{2} \frac{m+s}{2}$

$=\frac{\cos m \cdot \cos s}{\cos m^{\prime} \cdot \cos s^{\prime}} \cdot\left\{\cos d^{\prime}+\cos \left(m^{\prime}+s^{\prime}\right)\right\}$

$=\frac{\cos m \cdot \cos s}{\cos m^{\prime} \cdot \cos s^{\prime}} \cdot 2 \cos \frac{m^{\prime}+s^{\prime}+d^{\prime}}{2} \cdot \cos \frac{m^{\prime}+s^{\prime}-d^{\prime}}{2}$

Dividing both sides by 2 , and putting $\sin ^{2} \theta$ for

$$
\frac{\cos m \cdot \cos s}{\cos m^{\prime} \cdot \cos s^{\prime}} \cdot \cos \frac{m^{\prime}+s^{\prime}+d^{\prime}}{2} \cdot \cos \frac{m^{\prime}+s^{\prime}-d^{\prime}}{2}
$$

we have-

$$
\begin{aligned}
&-\sin ^{2} \frac{d}{2}+\cos ^{2} \frac{m+s}{2}=\sin ^{2} 0 \\
& \therefore \sin ^{2} \frac{d}{2}=\cos ^{2} \frac{m+s}{2}-\sin ^{2} 0 \\
&=\frac{1}{2}\{1+\cos (m+s)\}-\frac{1}{2}(1-\cos 2 \theta) \\
&=\frac{1}{2}\{\cos (m+s)+\cos 2 \theta\} \\
&=\frac{1}{2}\left\{2 \cos \left(\frac{m+s}{2}+\theta\right) \cdot \cos \left(\frac{m+s}{2}-\theta\right)\right\} \\
& \therefore \sin \frac{d}{2}=\sqrt{\cos \left(\frac{m+s}{2}+\theta\right) \cdot \cos \left(\frac{m+s}{2}-\theta\right)}
\end{aligned}
$$

Form for Computation.

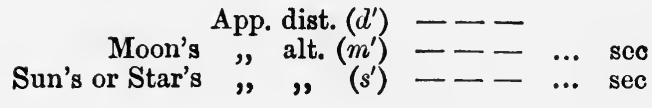

$$
\begin{aligned}
& \frac{1}{2} \operatorname{sum}=\left(\frac{m^{\prime}+s^{\prime}+d^{\prime}}{2}\right)-\ldots-\ldots \cos \\
& \frac{1}{2} \text { sum }-d^{\prime}=\left(\frac{m^{\prime}+s^{\prime}-d^{\prime}}{2}\right)--\ldots \quad \ldots \cos \\
& \text { Moon's true alt. }(m)-\ldots \quad \ldots \cos \\
& \text { Sun's or Star's ,, (s) } \quad \ldots \ldots \text { cos }
\end{aligned}
$$

$$
\begin{array}{r}
(m+s)=2)--- \\
\left(\frac{m+s}{2}\right)---
\end{array}
$$




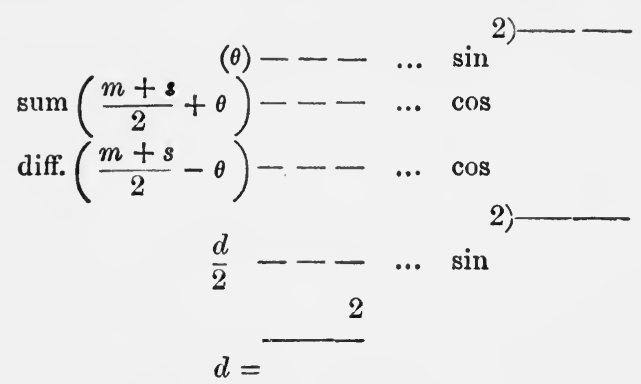

Remark.-It will be noticed that the first four logs are the same as in the alt.-azimuth problems, and that all other logs taken out are cosines, whilst the angles sought correspond to sines.

ART. 112. Rule for clearing the Distance by Borda.-Add together apparent distance, app. alt. of moon, and app. alt. of body observed for distance; find half sum, and the remainder, which is the difference between the app. dist. and half sum. Then add following logs : Sec app. alt. of moon, sec app. alt. of body, cos half sum, cos remainder, cos true alt. of moon, and cos true alt. of body; reject 40 from index, and divide by 2 , and look back sine of angle, which call B. Now find half sum of two true alts., which call A. Add together the cosines of the sum and difference of $\mathrm{A}$ and $\mathrm{B}$; divide sum by 2 , and look out sine of angle, which is half true distance.

\section{Example.-}

The apparent distance between the Sun and Moon's centre is $105^{\circ} 56^{\prime}$ $46^{\prime \prime}$; Moon's app. alt., $26^{\circ} 7^{\prime} 19^{\prime \prime}$, true alt., $26^{\circ} 55^{\prime} 26^{\prime \prime}$; Sun's app. alt., $14^{\circ}$ $24^{\prime} 27^{\prime \prime}$, true alt., $14^{\circ} 20^{\prime} 56^{\prime \prime}$. Find true distance.

App. dist. $105^{\circ} 56^{\prime} 46^{\prime \prime}$

Moon's A.A. $26 \quad 719$

Sun's A.A. $14 \quad 24 \quad 27$

2)146 $28 \quad 32$

$$
73 \quad 14 \quad 16
$$

$\begin{array}{lll}32 & 42 & 30\end{array}$

Moon's T.A. $26 \quad 5526$

Sun's T.A. $14 \quad 2056$

$$
\begin{aligned}
& \text { 2)41 } 16 \quad 22 \\
& \text { A } \quad 20 \quad 38 \quad 11 \\
& \text { B } 2924 \quad 14 \\
& A+B \quad 50 \quad 225 \\
& \mathrm{~B}-\mathrm{A} \quad 8 \quad 46 \quad 3
\end{aligned}
$$

$$
\begin{aligned}
& \begin{array}{llll}
52 & 49 & 0 & \sin \overline{9.901299} \\
2 &
\end{array} \\
& \text { 2) } \overline{19 \cdot 802598}
\end{aligned}
$$

sec $10 \cdot 046792$ sec $10 \cdot 013878$

$$
\begin{array}{rr}
\cos & \mathbf{9} \cdot \mathbf{4 5 9 9 9 7} \\
\cos & \mathbf{9 \cdot 9 2 5 0 1 9} \\
\cos & \mathbf{9 \cdot 9 5 0 1 7 4} \\
\cos \quad & 9 \cdot 986236 \\
& \\
\text { 2) } 19 \cdot 382096
\end{array}
$$

$$
\begin{array}{ll}
\sin & 9 \cdot 691048 \\
\cos & 9 \cdot 807703 \\
\cos & 9 \cdot 994895
\end{array}
$$


From the figure.

In the figure $\mathrm{AX}$ and $\mathrm{AN}$ are the truo and apparent alts. of the Sun. BY and BM are the true and app. alts. of the Moon. MN is the app. dist., and XY the true dist.

In the triangle $\mathrm{ZMN}$, given the three sides, ZM, Moon's a.z.d.: ZN, Sun's a.z.d. and $\mathrm{MN}$, to find $\mathrm{Z}$.

$$
\operatorname{Cos} \frac{Z}{2}=\sqrt{\frac{\sin s \cdot \sin (s-M N)}{\sin Z M \cdot \sin Z N}}
$$

where $s=\frac{1}{2}(Z M+Z N+M N)$.

$$
\begin{aligned}
& \mathrm{MN}=105^{\circ} 56^{\prime} 46^{\prime \prime} \\
& \mathrm{ZM}=\begin{array}{llll}
63 & 52 & 41 & \operatorname{cosec} 10.046792
\end{array} \\
& \mathrm{ZN}=\begin{array}{ll}
75 \quad 3533 \quad \operatorname{cosec} 10.013877
\end{array} \\
& \text { 2) } 245 \quad 25 \quad 0 \\
& s=122 \quad 42 \quad 30 \quad \sin 9.925019 \\
& 8-\mathrm{MN}=\begin{array}{llll}
16 & 45 & 44 & \text { sin } 9.459995
\end{array} \\
& \text { 2) } 19 \cdot 445683 \\
& \frac{Z}{2}=58 \quad 645 \quad \cos \overline{9 \cdot 722841}
\end{aligned}
$$

Now, in triangle ZXY, given two sides, ZY, Moon's t.z.d.; ZX, Sun's t.z.d., and included angle $Z$ (just found), find $X Y$, true dist.

$$
\begin{array}{rl}
\operatorname{Tan} \frac{1}{2}(Y+X) & =\frac{\cos \frac{1}{2}(Z X-Z Y)}{\cos \frac{1}{2}(Z X+Z Y)} \cdot \cot \frac{Z}{2} \\
\operatorname{Cos} \frac{X Y}{2} & =\frac{\cos \frac{1}{2}(Z X+Z Y)}{\cos \frac{1}{2}(Y+X)} \cdot \sin \frac{Z}{2} \\
Z X=75^{\circ} 39^{\prime} 4^{\prime \prime} & \frac{Z}{2}=58^{\circ} \quad 6^{\prime} 45^{\prime \prime} \cot 9 \cdot 793890 \sin 9 \cdot 928953 \\
Z Y=63434 & 434
\end{array}
$$

$\mathrm{ZX}+\mathrm{ZY}=\overline{138 \quad 43 \quad 38} \quad \frac{1}{2}(\mathrm{ZX}+\mathrm{ZY})=69 \quad 21 \quad 49 \quad \sec 10 \cdot 452920 \cos 9 \cdot 547080$ $Z X-Z Y=\begin{array}{llllllll}12 & 34 & 30 & \frac{1}{2}(Z X-Z Y)=6 & 17 & 15 & \cos & 9 \cdot 997379\end{array}$

$$
\begin{gathered}
\frac{1}{2}(Y+X)=\overline{601913} \cdot 5 \tan \overline{10 \cdot 244189} \sec 10 \cdot 305264 \\
52^{\circ} 49^{\prime} 1^{\prime \prime} \cos \overline{9 \cdot 781297} \\
\hline
\end{gathered}
$$

True dist. 105382

\section{Exercises.}

1. Given app. dist., $96^{\circ} 52^{\prime}$; Sun's app. alt., $36^{\circ} 18^{\prime} 7^{\prime \prime}$, true alt., $36^{\circ} 16^{\prime}$ 57"; Moon's app. alt., $24^{\circ} 17^{\prime} 14^{\prime \prime}$, true alt., $25^{\circ} 5^{\prime} 27^{\prime \prime}$. Find true dist.

2. Given app. dist., $107^{\circ} 35^{\prime} 18^{\prime \prime}$; Saturn's app. alt., $9^{\circ} 51^{\prime} 21^{\prime \prime}$, true alt., $9^{\circ} 46^{\prime} 2^{\prime \prime}$; Moon's app. alt., $38^{\circ} 43^{\prime}$, true alt., $39^{\circ} 27^{\prime} 20^{\prime \prime}$. Find true dist.

3. Given app. dist., $101^{\circ} 0^{\prime} 4^{\prime \prime}$; Mars' app. alt., $14^{\circ} 36^{\prime} 7^{\prime \prime}$, true alt., $14^{\circ} 32^{\prime}$ 35" ; Moon's app. alt., $48^{\circ} 10^{\prime} 5^{\prime \prime}$, true alt., $48^{\circ} 49^{\prime} 29^{\prime \prime}$. Find true dist.

4. Given app. dist., $56^{\circ} 14^{\prime} 32^{\prime \prime}$; Sun's app. alt., $65^{\circ} 15^{\prime} 36^{\prime \prime}$, true alt., $65^{\circ}$ $15^{\prime} 13^{\prime \prime}$; Moon's app. alt., $40^{\circ} 32^{\prime} 16^{\prime \prime}$, true alt., $41^{\circ} 15^{\prime} 48^{\prime \prime}$. Find true dist. 
ArT. 113,-Rules for Lunar Problem.

(1) Find the G.M.T.

(2) Correct the R.A.M.S., the Moon's R.A., Dec., S.D., and H.P. Correct the R.A., and Dec., of object observed for distance.

(3) Correct the obs. alt., finding app. and true alts., and calculate H.A. of object ; if both alts. are given, either may be chosen.

(4) With H.A. just found, calculate R.A.M. and H.A. of the other object, and thence its alts. true and app. (unless given).

(5) Correct observed distance for ind. cor. and S.D., adding for Near limbs, and subtracting for Far or remote limbs. In the case of a Sun Lunar, the enlightened limbs must be the near limbs.

(6) Clear the distance.

(7) Find corresponding G.M.T. and error of chronometer.

(8) From R.A.M. in (4) find M.T.S. and longitude.

\section{Example.-}

August 16th, P.M. at ship in lat. $20^{\circ} 29^{\prime}$ S., when the time by a chron. was $16^{\mathrm{d}} 2^{\mathrm{h}} 14^{\mathrm{m}} 50^{\mathrm{s}}$, which was estimated $2^{\mathrm{m}} 56^{\mathrm{s}}$ fast of M.T.G.; the obs. alt. of the Sun's L.L. was $48^{\circ} 1^{\prime} 20^{\prime \prime}$; ind. cor., $+2^{\prime} 12^{\prime \prime}$; height of eye, $27 \mathrm{ft}$.; observed distance between the enlightened limbs of Sun and Moon, $41^{\circ} 3^{\prime} 10^{\prime \prime}$; ind. cor., $-2^{\prime} 4^{\prime \prime}$. Find error of chron. for G.M.T. and longitude.

Time by chron. Aug. $16^{\mathrm{d}} 2^{\mathrm{h}} 14^{\mathrm{m}} 50^{\mathrm{s}}$ Fast $\quad-2 \quad 56$

M.T.G. $16^{\mathrm{d}} \overline{2 \quad 1154}$

S.D. $\begin{array}{lr}15^{\prime} 1^{\prime \prime} \cdot 4 \\ \text { Cor. } \begin{array}{r}+\cdot 7 \\ 15 \quad 2 \cdot 1\end{array}\end{array} \quad \begin{array}{r}4^{\prime \prime} \\ 2 \cdot 2\end{array}$
Aug. $\begin{array}{r}12) 8 \cdot 8 \\ \frac{15}{15} 5 \cdot 3\end{array}$

Moon's Dec. $20^{\circ} 17^{\prime} 41^{\prime \prime} \cdot 5$ N. Var. $\cdot 25$

Cor.

$$
\frac{-3}{201738} \mathrm{~N} \text {. }
$$

$11 \cdot 9$

$2 \cdot 97$

Sun's Dec. $13^{\circ} 57^{\prime} 31^{\prime \prime} \cdot 4 \mathrm{~N}$.

Cor. $\quad-1 \quad 43.4$

135548 N.

H.V. $47 \cdot 03$

$\frac{2 \cdot 2}{103 \cdot 46}$

O.A. $\odot 48^{\circ} 1^{\prime} 20^{\prime \prime}$

I. $\overline{\mathrm{C}} \quad+212$

48 332

Dip $-5 \quad 5$

$47 \quad 58 \quad 27$

S.D. +1549

$\odot$ 's A.A.

481416

R. \& P.

$-45$

$\odot$ 's T.A.

$\begin{array}{lll}48 & 13 & 31\end{array}$
R.A.M.S. $9^{\mathrm{h}} 35^{\mathrm{m}} 52^{\mathrm{s}} 5$

Accel.

$21 \cdot 7$

$936 \quad 14: 2$

H.P. $55^{\prime} 2^{\prime \prime} \cdot 4$

Cor. $\quad+2 \cdot 7$

$14^{\prime \prime} \cdot 6$

$2 \cdot 2$

12) $32 \cdot 12$

Red ${ }^{55}-1 \cdot 3$

$$
\overline{55 \quad 3 \cdot 8}
$$

$2 \cdot 7$

R.A. $6^{\mathrm{h}} 51^{\mathrm{m}} \quad 0^{\cdot} \cdot 6$

Cor. $\quad+25.9$

$6 5 1 \longdiv { 2 6 \cdot 5 }$

Var. $2 \cdot 18$

11.9

$25 \cdot 942$

H.V. 9·37

R.A. $9^{\text {h }} \quad 40^{\mathrm{m}} \quad 9^{\mathrm{s}} \cdot 1$

$2 \cdot 2$

$20 \cdot 592$ 
○'s T.A. $48 \quad 13 \quad 31$

Lat. $2029 \quad 0$

P.D. 1035548

sec $10 \cdot 028365$

cosec $10 \cdot 012964$

2)172 $38 \quad 19$

$\begin{array}{rrrrrr}86 & 19 & 10 & & \cos & 8 \cdot 807492 \\ 38 & 5 & 39 & & \sin 9 \cdot 790254\end{array}$

$\odot$ 's W.H.A. $\quad 1^{\text {h }} 36^{\mathrm{m}} 22^{\mathrm{s}} \cdot 5$ xxxi. $=\overline{8 \cdot 639075}$

$\odot$ 's R.A. $\quad 9 \quad 40 \quad 29 \cdot 7$

R.A.M. $11 \quad 16 \quad 52 \cdot 2$

D's R.A. $6 \quad 51 \quad 26.5$

D's W.H.A. $42525 \cdot 7$ log rising $5 \cdot 777405$

Lat. $\quad \ldots \quad 20^{\circ} 29^{\prime} \quad 0^{\prime \prime}$ S. $\cos 9.971635$

$\begin{array}{llllll}\text { Dec. } & \ldots & 20 & 17 & 38 & \text { N. } \cos 9.972169\end{array}$

Z.D. $40^{\circ} 46^{\prime} 38^{\prime \prime}$ Nat. cos 757255

$526271 \log 5 \cdot 721209$

D's T.A. $132118 \quad$ N. $\sin 230984$

Cor. $\quad-4933$

D's A.A. 123145

Obs. dist. $41^{\circ} 3^{\prime} 10^{\prime \prime}$

I.C. -2

$41 \quad 16$

$\odot$ 's S.D. $\quad 1549$

D's S.D. $\quad 15 \quad 5$

App. dist. $\overline{4132 \quad 0}$

D's A.A. 123145

$\odot$ 's A.A. $4814 \quad 16$

sec $10 \cdot 010468$

sec $10 \cdot 176498$

2) $102 \quad 18 \quad 1$

$\begin{array}{lllll}51 & 9 & 1 & \cos & 9 \cdot 797461\end{array}$

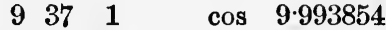

D's T.A. 132118

$\cos 9 \cdot 993854$
$\cos 9 \cdot 988094$

○'s T.A. 481331

$\cos \mathbf{9 \cdot 8 2 3 6 0 7}$

2) $6134 \quad 49$

A. $304724 \cdot 5$

2)19.789982

B. $514427 \cdot 5$

$\sin \mathbf{9 \cdot 8 9 4 9 9 1}$

A + B 823152

$\cos \overline{9 \cdot 113903}$

B - A $2057 \quad 3$

$\cos 9 \cdot 970295$

2)19.084198

$20 \quad 2326$

$\sin \mathbf{9} \mathbf{5 4 2 0 9 9}$

True dist. $40 \quad 46 \quad 52$ 
True dist. $40^{\circ} 46^{\prime} 52^{\prime}$
N.A. ,,

\begin{tabular}{lrr}
$41 \quad 49 \quad 2$ \\
\hline $1 \quad 2 \quad 10$
\end{tabular}
P.L. 3267
P.L. $\frac{4617}{1350}$
$\ldots \quad$ Aug. $16^{\mathrm{d}} 0^{\mathrm{h}} 0^{\mathrm{m}} 0^{\mathrm{a}}$
P.L. 1350
$\begin{array}{llllll}\ldots & \cdots & \ldots & 211 & 54 \cdot 5 \\ \text { Approx. M.T.G. } & 16^{\mathrm{a}} & \begin{array}{llll}2 & 11 & 54 \cdot 5\end{array}\end{array}$

Cor. for, -12 , Diff. P.L.'s, and Int. $2^{\mathrm{h}} 10^{\mathrm{m}}$ from N.A. $+3$

M.T.G. $16^{\mathrm{d}} \overline{21157 \cdot 5}$

Time by chron. $16^{\mathrm{d}} 2 \quad 14 \quad 50$

R.A.M. $11^{\mathrm{h}} 16^{\mathrm{m}} 52^{\mathrm{s} \cdot 2}$

Fast $252 \cdot 5$

R.A.M.S. $936 \quad 14 \cdot 2$

\begin{tabular}{cccc}
\cline { 2 - 4 } M.T.S. $16^{\mathrm{d}}$ & 1 & 40 & 38 \\
M.T.G. $16^{\mathrm{d}}$ & $\mathbf{2}$ & 11 & $57 \cdot 5$
\end{tabular}

$31 \quad 19 \cdot 5$

Long. $7^{\circ} 49^{\prime} 52^{\prime \prime} \mathrm{W}$.

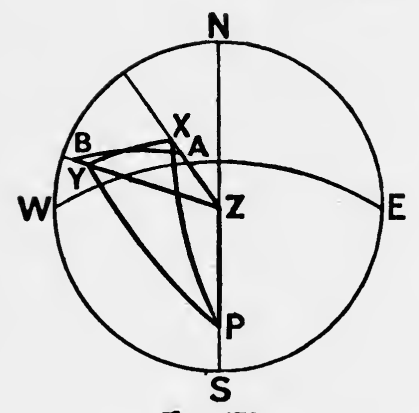

Fia. 173.

\section{From the figure.-}

In the figure $\mathrm{X}$ and $\mathrm{A}$ are true and app. positions of the Sun; $Y$ and $B$ are true and app. positions of the Moon.

First, to find Sun's H.A.-In triangle $\mathrm{PZX}$, given co-lat. $=\mathrm{PZ}$, Pol. dist.

$=\mathbf{P X}$, and zen. dist. $=\mathrm{ZX}$, to find $\mathbf{P}$.

$$
\operatorname{Cos} \frac{\mathrm{P}}{2}=\sqrt{\frac{\sin s \cdot \sin (s-\mathrm{ZX})}{\sin \mathrm{PX} \cdot \sin \mathrm{PZ}}}
$$

where $s=\frac{1}{2}\left(\mathrm{ZX}+\mathrm{PX}+\mathrm{P}^{\prime}\right)$.

$$
\begin{aligned}
& \mathrm{ZX}=41^{\circ} 46^{\prime} 29^{\prime \prime} \\
& \mathrm{PX}=1035548 \quad \text { cosec } 10.012964 \\
& \mathrm{PZ}=6931 \quad 0 \quad \text { cosec } 10.028365 \\
& \text { 2) } 2 1 5 \longdiv { 1 3 \quad 1 7 } \\
& s=\overline{107 \quad 3639} \quad \sin 9.979154 \\
& s-\mathrm{ZX}=655010 \quad \text { sin } 9.960174 \\
& \text { 2) } \overline{19 \cdot 980657} \\
& 0^{\text {h }} 48^{\text {m }} 11^{\text {s. }} 5 \quad \cos 9.990328
\end{aligned}
$$

$\odot$ 's W.H.A. 13623

$\odot$ 's R.A. $9 \quad 40 \quad 29 \cdot 7$

R.A.M. $11 \quad 16 \quad 52 \cdot 7$

D's R.A. $651 \quad 26.5$

D's H.A. $425 \quad 26 \cdot 2$ 
Second, to find Moon's True and Apparent Altitudes.

In triangle $\mathrm{PYZ}$, given $\mathrm{PZ}=$ co-lat., $\mathrm{PY}=$ D's Pol. dist. , $\mathrm{P}=$ Hour angle, to find $\mathrm{ZY}=\mathrm{D}$ 's true Z.D.

$$
\begin{aligned}
\operatorname{Tan} \frac{1}{2}(Z+Y) & =\frac{\cos \frac{1}{2}(P Y-P Z)}{\cos \frac{1}{2}(P Y+P Z)} \cdot \cot \frac{P}{2} \\
\operatorname{Cos} \frac{Z Y}{2} & =\frac{\cos \frac{1}{2}(P Y+P Z)}{\cos \frac{1}{2}(Z+Y)} \cdot \sin \frac{P}{2}
\end{aligned}
$$

$$
\begin{aligned}
& \mathrm{PY}=110^{\circ} 17^{\prime} 38^{\prime \prime} \\
& \mathrm{PZ}=\begin{array}{lll}
69 & 31 & 0
\end{array}
\end{aligned}
$$

$$
\frac{\mathrm{P}}{2}=2^{\mathrm{h}} 12^{\mathrm{m}} 43^{\mathrm{s}} \cdot 1 \cot 10 \cdot 184507 \sin 9 \cdot 738198
$$

$\mathrm{PY}+\mathrm{PZ}=1794838 \frac{1}{2}(\mathrm{PY}+\mathrm{PZ})=89^{\circ} 54^{\prime} 19^{\prime \prime}$ sec $12 \cdot 781671$ cos $7 \cdot 218329$ $\mathrm{PY}-\mathrm{PZ}=404638$ 采 $(\mathrm{PY}-\mathrm{PZ})=202319$ cos $9 \cdot 971902$

$89562 \cdot 2 \tan 12 \cdot 938080 \sec 12 \cdot 938080$

$$
38^{\circ} \overline{19^{\prime} 23^{\prime \prime} \cdot 5} \cos \overline{9 \cdot 894607}
$$

D's true Z.D. $=76 \quad 3847$

D's T.A. 132113

Cor. -4933

D's A.A. 123140

Third, to clear the Distance.

In triangle $\mathrm{ZAB}$, given $\mathrm{AB}=$ app. dist., $\mathrm{ZA}=\odot$ 's A.Z.D., $\mathrm{ZB}=\mathrm{D}^{\prime} \mathrm{s}$ A.Z.D. to find angle $Z$.

$$
\operatorname{Cos} \frac{Z}{2}=\sqrt{\frac{\sin s \cdot \sin (s-\mathrm{AB})}{\sin \mathrm{ZA} \cdot \sin \mathrm{ZB}}}
$$

where $8=\frac{1}{2}(\mathrm{AB}+\mathrm{ZA}+\mathrm{ZB})$.

$$
\begin{aligned}
& \mathrm{AB}=41^{\circ} 32^{\prime} \quad 0^{\prime \prime} \\
& \mathrm{ZA}=41 \quad 45 \quad 44 \quad \operatorname{cosec} 10 \cdot 176499 \\
& \mathrm{ZB}=77 \quad 2820 \quad \text { cosec } 10 \cdot 010466 \\
& \text { 2) } \longdiv { 6 0 \quad 4 6 \quad 4 } \\
& s=\begin{array}{llll}
80 & 23 & 2 & \text { sin } 9.993855
\end{array}
\end{aligned}
$$

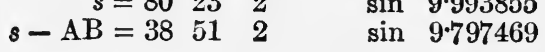

$$
\begin{aligned}
& \text { 2) } 19 \cdot 978289 \\
& \frac{\mathrm{Z}}{2}=1245 \quad 27 \cdot 5 \quad \cos \overline{9 \cdot 989144}
\end{aligned}
$$

Finally, in triangle ZXY, given ZX $=\odot$ 's true Z.D. , ZY = D's true Z.D, and angle $\mathrm{Z}$, to find $\mathrm{XY}=$ true dist.

$$
\begin{aligned}
\operatorname{Tan} \frac{1}{2}(X+Y) & =\frac{\cos \frac{1}{2}(Z Y-Z X)}{\cos \frac{1}{2}(Z Y+Z X)} \cdot \cot \frac{Z}{2} \\
\operatorname{Cos} \frac{X Y}{2} & =\frac{\cos \frac{1}{2}(Z Y+Z X)}{\cos \frac{1}{2}(X+Y)} \cdot \sin \frac{Z}{2}
\end{aligned}
$$




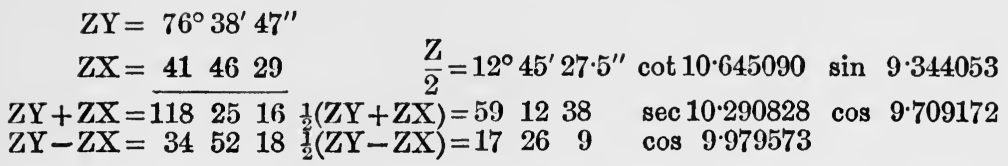

$\overline{83 \quad 425} \tan 10.915491 \sec 10.918672$

$20^{\circ} 2326^{\prime \prime} \cos \overline{9 \cdot 971897}$

Finish as before.

True dist. 404652

Remark.-Questions are sometimes set where it is not stated whether the object whose altitude is given is $\mathrm{E}$. or W. of the meridian, but this may be determined by noticing in the "Nautical Almanac" whether the other object is E. or W. of the Moon, and, taking the H.A. in conjunction with the distance, the wrong supposition would put one of the objects too near the horizon, or even below it.

\section{EXERCISES.}

1. August 13th, about $10^{\mathrm{h}} 30^{\mathrm{m}}$ A.M. at ship, in lat. $35^{\circ} 46^{\prime}$ S., long. D.R. $93^{\circ}$ E. ; when a chron. estimated $6^{\mathrm{m}}$ fast of G.M.T. showed $4^{\mathrm{h}} 20^{\mathrm{m}} 15^{\mathrm{s}}$, the obs. alt. of the Sun's L.L. was $34^{\circ} 13^{\prime} 30^{\prime \prime}$; ind. cor., $-1^{\prime} 44^{\prime \prime}$; height of eye, $30 \mathrm{ft}$. ; obs. dist. between near limbs of Sun and Moon, $78^{\circ} 22^{\prime} 50^{\prime \prime}$; no ind. cor. Find long. and error of chron. on G.M.T.

2. August 28 th , about $3^{\text {h }} 35^{m}$ P.M. at ship, in lat. $24^{\circ} 14^{\prime}$ N., long. by acct. $163^{\circ} 40^{\prime} \mathrm{W}$.; when a chron. whose supposed error on G.M.T. was $9^{\mathrm{m}} 18^{\mathrm{s}}$ slow showed $2^{\mathrm{h}} 20^{\mathrm{m}} 18^{\mathrm{s}}$, the obs. alt. of the Moon's U.I. was $14^{\circ} 27^{\prime} 40^{\prime \prime}$; ind. cor., $+1^{\prime} 11^{\prime \prime}$; eye, $35 \mathrm{ft}$; ; obs. dist. between enlightened limbs of Sun and Moon, $117^{\circ} 32^{\prime} 40^{\prime \prime}$; ind. cor., $+2^{\prime} 12^{\prime \prime}$. Find the error of chron. on G.M.T. and longitude.

3. August 10th, A.M. at ship, in lat. $37^{\circ} 50^{\prime}$ N.; when the M.T.G. by a chron. supposed correct was $9^{\mathrm{d}} 3^{\mathrm{h}} 49^{\mathrm{m}} 18^{\mathrm{s}}$, the obs. alt. of the Moon's L.L. E. of meridian was $53^{\circ} 11^{\prime} 20^{\prime \prime}$; ind. cor., $-3^{\prime} 21^{\prime \prime}$; eye, $31 \mathrm{ft}$; obs. dist. between Aldebaran and the Moon's near limb, $49^{\circ} 17^{\prime} 50^{\prime \prime}$; ind. cor., $+2^{\prime} 13^{\prime \prime}$. Find long. and error of chron. on G.M.T.

4. August 22 nd, about $6^{\mathrm{h}} 30^{\mathrm{m}}$ P.M. at ship, in lat. $29^{\circ} 45^{\prime}$ S., long. D.R. $34^{\circ} \mathrm{E}$. ; when a chron. estimated $10^{\mathrm{m}} 18^{\mathrm{s}}$ fast of G.M.T. showed $4^{\mathrm{n}} 20^{\mathrm{m}} 30^{\circ}$, the obs. alt. of a Aquilæ (Altair) was $28^{\circ} 21^{\prime} 50^{\prime \prime}$; ind. cor., $+2^{\prime} 16^{\prime \prime}$; eye, $40 \mathrm{ft}$; ; obs. dist. between Altair and the Moon's remote limb, $113^{\circ} 44^{\prime} 10^{\prime \prime}$; ind. cor., $-3^{\prime} 11^{\prime \prime}$. Find long. and error of chron. on G.M.T.

5. August 13th, about $2^{\text {h }}$ A.M. at ship, in lat. $30^{\circ} 27^{\prime}$ N., long. by acct., $41^{\circ}$ W.; when a chron. supposed correct for G.M.T. showed $4^{\mathrm{h}} 38^{\mathrm{m}} 12^{\mathrm{A}}$, the obs. alt. of the Moon's L.L. was $23^{\circ} 12^{\prime} 20^{\prime \prime}$; no ind. cor.; eye, $35 \mathrm{ft}$; ; obs. dist. between Saturn's centre and the Moon's further limb., $78^{\circ} 43^{\prime} 10^{\prime \prime}$; ind. cor., $-1^{\prime} 18^{\prime \prime}$. Find long. and error of chron. on G.M.T.

6. August 24 th, at $11^{\mathrm{h}} 23^{\mathrm{m}}$ A.M. at ship, in lat. $53^{\circ} 34^{\prime}$ N., long. $4^{\circ} 25^{\prime} \mathrm{E}$.; when a chron. which had run down and been set going indicated $11^{\mathrm{h}} 20^{\mathrm{m}}$, the following observations were taken for determining long. and error of chron. on G.M.T.; height of eye, $28 \mathrm{ft}$. :- 
Obs. alt. Sun's L.L. $46^{\circ} 53^{\prime} 40^{\prime \prime}$

1.C. +118
Obs. alt. Moon's U.L. $10^{\circ} 15^{\prime} 40^{\prime \prime}$
Obs. dist. Sun and Moon.

$$
56^{\circ} 24^{\prime} 10^{\prime \prime}
$$$$
\text { I.C. }-29
$$

7. August 29 th, at $8^{\text {h }}$ P.M. at ship, in lat. $48^{\circ} 43^{\prime}$ S., long. $30^{\circ} 49^{\prime} 45^{\prime \prime}$ W.; when a chron. which had run down and been set going showed $10^{\mathrm{h}} 15^{\mathrm{m}}$, the obs. alt. of Antares was $56^{\circ} 40^{\prime} 20^{\prime \prime}$; ind. cor., + $1^{\prime} 57^{\prime \prime}$; eye, $35 \mathrm{ft}$.; obs. dist. between Star and Moon's near limb was $35^{\circ} 57^{\prime} 20^{\prime \prime}$; ind. cor., $-3^{\prime} 33^{\prime \prime}$. Find the long. and error of chron. on G.M.T.

8. August 9 th, about $5^{\text {h }}$ A.M. at ship, in lat. $5^{\circ} 14^{\prime} \mathrm{N}$., long. by acct., $20^{\circ} 40^{\prime}$ W. ; when a chron. estimated correct for G.M.T. showed $6^{\mathrm{b}} 25^{\mathrm{m}} 48^{\mathrm{s}}$, the obs. alt. of Jupiter's centre was $30^{\circ} 30^{\prime} 20^{\prime \prime}$; ind. cor., $-2^{\prime} 16^{\prime \prime}$; obs. alt. of Moon's L.L. was $70^{\circ} 48^{\prime}$; ind. cor., + $2^{\prime} 9^{\prime \prime}$; eye, $32 \mathrm{ft}$. ; obs. dist. between Jupiter's centre and Moon's near limb, $78^{\circ} 3^{\prime} 50^{\prime \prime}$; ind. cor., $-2^{\prime} 15^{\prime \prime}$. Find long. and error of chron. on M.T.G.

9. September 1st, about $1^{\mathrm{b}} 30^{\mathrm{m}}$ A.M. at ship, in lat. equator, long. by acct., $43^{\circ}$ E.; when a chron. supposed to be $12^{\mathrm{m}} 10^{\circ}$ slow of G.M.T. indicated $10^{\mathrm{h}} 25^{\mathrm{m}} 32^{\prime}$, the obs. alt. of a Pegasi (Marcab) was $67^{\circ} 52^{\prime} 50^{\prime \prime}$; obs. dist. between Marcab and the Moon's remote limb, $44^{\circ} 55^{\prime} 20^{\prime \prime}$; ind. cor. for alt., $+1^{\prime} 31^{\prime \prime}$; for dist., $-2^{\prime} 17^{\prime \prime}$; height of eye, $31 \mathrm{ft}$. Find long. and error of chron. on M.T.G. 


\section{PART II.}

\section{CHAPTER XXVI.}

\section{CONSTRUCTION OF CHARTS.}

ART. 114.-Before proceeding to the actual drawing of a chart one or two matters must be considered. In the first place there are two geometrical problems which are continually in use : (1) To erect a perpendicular to a given straight line at a given point in the same. (2) To divide a given straight line into a required number of equal parts. There are several ways for performing each operation. Consider (1) when the given point is the end of the line. Let $\mathrm{AB}$ be line, through $\mathrm{B}$ draw a line perpendicular to $\mathrm{AB}$. Select any point $C$ above $A B$, with $C$ as centre and $\mathrm{CB}$ as radius describe an arc of a circle cutting $A B$ in $D$. $A$ line through DC cuts the arc again in $\mathrm{E}$, which is perpendicularly above $B$, since angle $\mathrm{DBE}$ is angle in a semicircle, and therefore a right angle.

For (2) the trial method will give as good results as any to any one

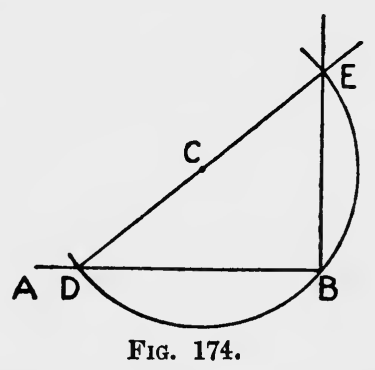
unaccustomed to use drawing instruments. Good practice in the above may be obtained by the construction of Diagonal Scales.

\section{Example.-}

Construct a diagonal scale of $1 \frac{1}{4}$ inch to $1^{\circ}$ long., to measure miles.

Draw a horizontal line, $\mathrm{AB}$, near the bottom of the drawing-paper, and supposing the scale to be $1 \frac{1}{4}$ inch to $1^{\circ}$ long., along it measure off distances $A 1,12,23$, each $=1 \frac{1}{4}$ inch; at $\mathrm{A}$ and 3 erect perpendiculars $\mathrm{AD}, 3 \mathrm{~F}$, and measure along these perpendiculars any ten equal parts-2, 4,6,8, show the even points; join these points by ten lines, which will be all parallel to $\mathrm{AB}$. On the upper one mark off points 1, 2 to correspond with the points 1,2 on $\mathrm{AB}$, and join 1 to 1 and 2 to 2. Through $\mathrm{D}$ draw a line $\mathrm{DO}$, making any angle with $\mathrm{DF}$, and on DO measure any six equal parts at $a, b, c, d, e, f$; lines 
drawn through $a, b, c, d$, and $e$ parallel to $f 1$ will divide D1 into six equal parts, and since D1 represents $1^{\circ}$, each part represents $10^{\prime}$ of long.; with these distances divide Al into six equal parts, and join up diagonally as shown in figure, by lines similar to $1 \mathrm{~g}$. Considering the triangles $1 \mathrm{hm}$ and $11 \mathrm{~g}$, these

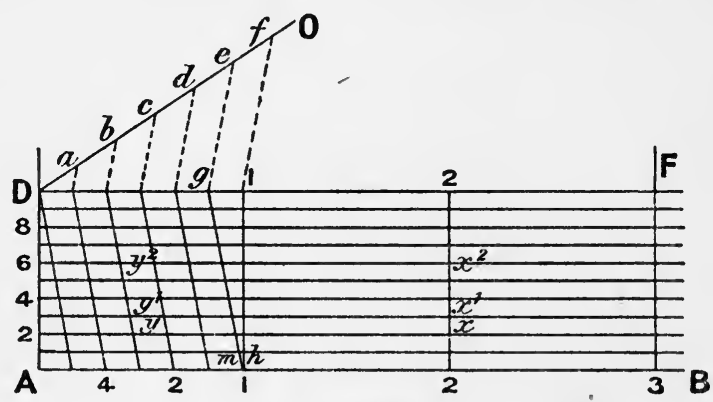

Fig. 175.

are seen to be similar, and since 11 is ten times $1 h$, therefore $1 g$ is ten times $h \mathrm{~m}$; but $1 \mathrm{~g}$ is $10^{\prime}$ of long., hence $\mathrm{hm}$ is $1^{\prime}$ of long.; that is, the portions of the lines intercepted between 11 and $1 g$ represent the single miles from 1 to 10 .

Angles may be set off (1) directly from a protractor ; (2) by using the scale of chords, marked Cho. On this scale the radius for describing the arc is the length to $60^{\circ}$, and the length of the chord subtending any required angle at the centre is the length of the scale to the angle; (3) by using the formula for finding the length of chord $(l)$ for any convenient radius $(r)$ to subtend angle (A) viz., $l=2 r \times \sin \frac{\mathrm{A}}{\overline{2}}$.

Thus for an angle of $37^{\circ}$ with radius $1.5 \mathrm{inch}-$

$$
\begin{aligned}
l & =2 \times 1.5 \times \sin 18 \frac{1}{2}^{\circ} \mathrm{inch} \\
& =3 \times .3173 \mathrm{inch}=.952 \text { inch. }
\end{aligned}
$$

On a plan is sometimes found a fraction in the title space thus $\frac{1}{10944}$, called the Natural Scale, which shows the ratio that the length of a certain unit on the plan bears to the real length of that unit on the earth's surface. Hence 1 inch represents 10944 inches.

$$
\begin{array}{ll} 
& \text { 20944 feet } \\
\prime & 912 \text {, } \\
" & 1.5 \text { cables. }
\end{array}
$$

Again, if 2 inches represent a nautical mile, the natural scale is-

$$
\frac{2}{6080 \times 12}=\frac{1}{36480} \text {. }
$$

When the scale for a minute of longitude is given the scale for a mile of latitude may be found, and vice versâ. On a Mercator Chart

Mile of latitude $=$ minute of long. $\times$ sec. lat. or min. of long. $=$ mile of lat. $\times$ cos. lat.

and so may be calculated, or found in traverse table. 
ART. 115.-Any straight line drawn in a circle and terminated at the circumference is called a chord, and the portions into which it divides the circle are called segments. When the line passes through the centre, the chord becomes a diameter, and the segments semicircles. The angle subtended by the chord at any point in the circumference of the circle is called the angle in the segment, and all angles in the same segment of a circle are equal to one another. When the segment is equal to a semicircle this angle is a right angle; when the segment is greater than a semicircle this angle is less than a right angle; when the segment is less than a semicircle this angle is obtuse. A segment of a circle may always be described on a given chord which contains an angle of a given size.

When the given angle is acute, the segment is greater than a semicircle, hence the centre for describing the arc and required arc are on the same side of the chord.

When the given angle is obtuse, the segment is less than a semicircle, hence the centre for describing the arc and required arc are on different sides of the chord.

To find the centre set off the complement of the given angle at each end of the chord, these lines will intersect in the centre.

Let $\mathrm{A}, \mathrm{B}$, and $\mathrm{C}$ be three conspicuous objects, $\mathrm{A}$ on the extreme left of the observer, $\mathrm{C}$ on his right, $\mathrm{B}$ the central object, the horizontal angle $\left(a^{\circ}\right)$ between $\mathrm{A}$ and $\mathrm{B}$ may be observed and the horizontal angle $\left(b^{\circ}\right)$ between $B$ and $C$. If now segments of circles be described on $\mathrm{AB}$ and $\mathrm{BC}$ as chords to contain angles of $a^{\circ}$ and $b^{\circ}$ respectively, the intersection of these ares will give the position of the observer. Care must be taken in the selection of the objects, or the cut of the two arcs is uncertain as to position. When the two arcs coincide it shows that the observer and the three points are on one circle, and there is no fix; to avoid this the central object should be chosen as nearly in a line as possible with the other two, or should be nearer the observer than the others. The station pointer performs the operation practically and the fix is tabulated thus: A. $a^{\circ}$ B. $b^{\circ} \mathrm{C}$.

ART. 116.-To construct a Mercator's Chart.-The advantages of such a chart are that all parallels of latitude are projected as parallel straight lines, and all meridians are projected as parallel straight lines cutting the parallels of latitude at right angles; a rhumb line projects as a straight line, since it cuts all meridians at the same angle, and all places of small area retain their proper form on the chart, but with increased area as the latitude increases.

Example 1 (Fig. 176).

Cunstruct a Mercator's chart on a scale of 1.9 inch to $1^{\circ}$ long., to extend from lat. $53^{\circ} \mathrm{N}$. to $54^{\circ} 30^{\prime} \mathrm{N}$., and from long. $3^{\circ} \mathrm{W}$. to $7^{\circ} \mathrm{W}$. Insert $a$ 
magnetic compass. Variation $17^{\circ} 20^{\prime} \mathrm{W}$., and the following positions. Chicken Rock $54^{\circ} 2^{\prime}$ N., $4^{\circ} 50^{\prime}$ W., Langness $54^{\circ} 3^{\prime}$ N., $4^{\circ} 37^{\prime}$ W., N.W. Lt. V. $53^{\circ} 31^{\prime}$ N., $3^{\circ} 31^{\circ} \mathrm{W}$.

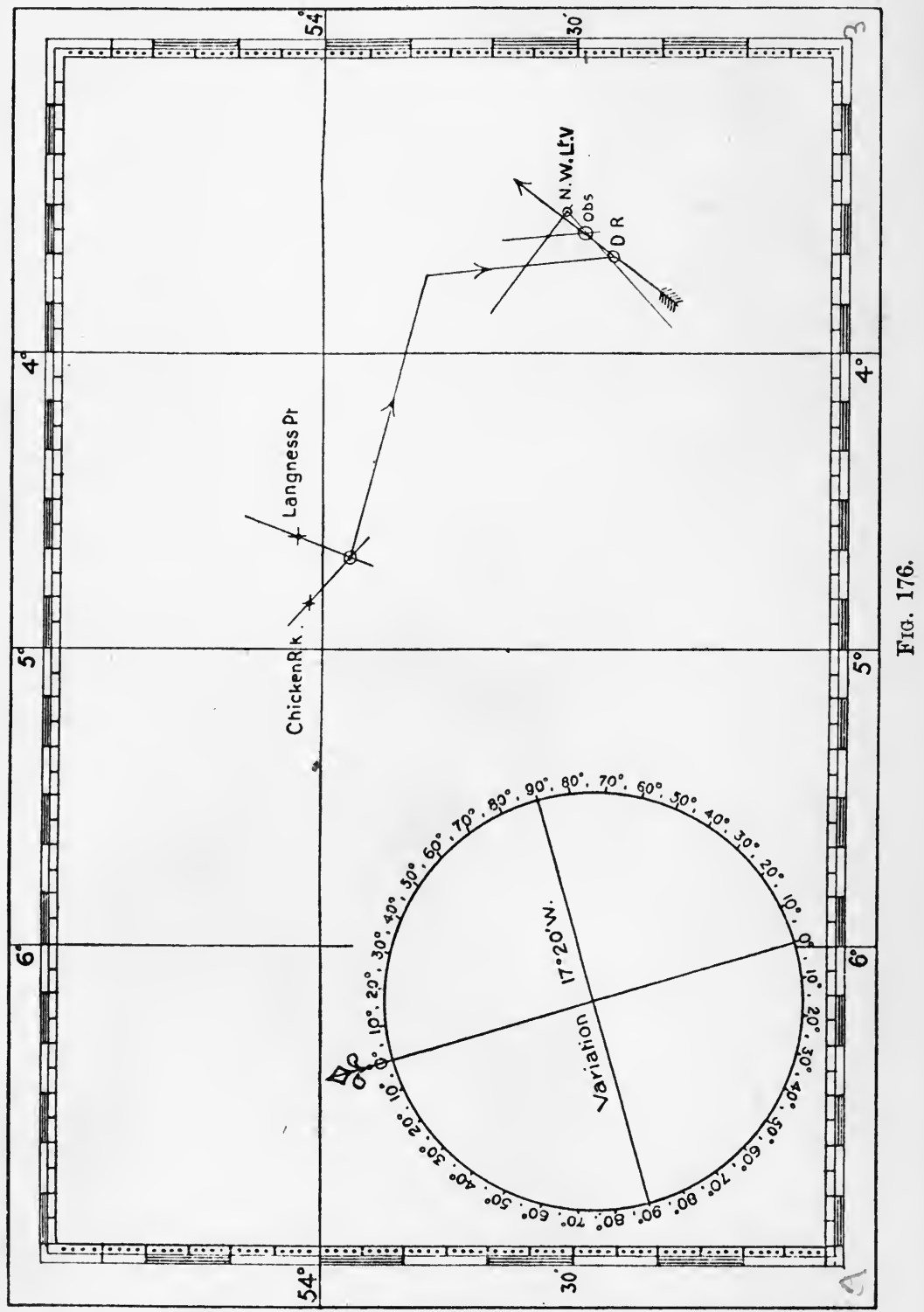

At $2^{\text {h }} 20^{\mathrm{m}}$ p.m. Chicken Rk. bore N. $32^{\circ} \mathrm{W}$, and Langness N. $39^{\circ} \mathrm{E}$. Shaped course S. $59^{\circ}$ E., 15 knots, and at $4^{\mathrm{h}} 40^{\mathrm{m}}$ p.m. altered course to S. 
$9^{\circ}$ W., at $5^{\text {h }} 50^{\mathrm{m}}$ p.m. N.W. Lt. V. bore S. $37^{\circ}$ E. ; and at $6^{\text {h }} 10^{\mathrm{m}}$ p.m. it bore N. $64^{\circ} \mathbf{E}$.; place courses on chart, find true and D. R. positions of ship at last observation, set and drift of current. Courses and bearings magnetic.

1st. To find the size of the chart.

As there are four degrees of long., $3^{\circ}$ to $7^{\circ} \mathrm{W}$., the breadth of the chart is $4 \times 1.9$ inches $=7.6$ inches.

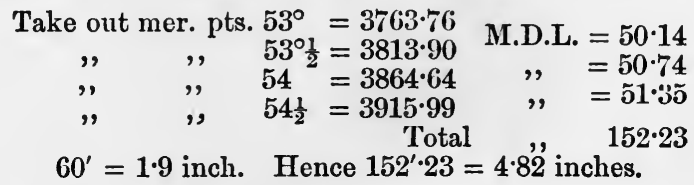

The height of the chart is 4.82 inches.

2nd. To draw the frame, meridians, and parallels.

Near the bottom of the paper draw a horizontal line 7.6 ins. long and divide into four equal parts, at each end set up perpendiculars as explained (Fig. 174). The lower line represents the parallel of $53^{\circ} \mathrm{N}$. Find the distances on the chart corresponding to M.D.L.'s, viz : $50.14=1.59$ inch, $50.74=1.61$ inch, $51.35=1.62$ inch. Now set these distances up on each perpendicular, and measure the distance between the perpendicular at the upper divisions to see if it corresponds with the base line $7 \cdot 6$ inches : if so join them and the frame is complete. Measure off the whole degrees on the top line, draw the parallel of $54^{\circ}$, and the meridian of $4^{\circ}, 5^{\circ}$, and $6^{\circ}$.

Draw around the frame two parallel lines for graduation purposes, graduate the degrees, and enclose in a thicker outside line.

3rd. To draw in the compass.

Select a portion of the chart clear away from the problem, and draw a circle of suitable radius. A diameter through the centre gives the true north and south line, measure the amount of the variation $17^{\circ} 20^{\prime} \mathrm{W}$. to the left of this diameter for magnetic north, draw the diameter and top it with a half fleur-de-lis. At right angles draw another diameter for the east and west line and graduate.

4. To complete the problem.

Insert the three given points from their lats. and longs., and from the compass set off the given bearings through Chicken Rk. and Langness, their intersection gives the point of departure. From this point set off the course S. 5 $9^{\circ}$ E. for 35 miles, the distance run between $2^{\mathrm{h}} 20^{\mathrm{m}} \mathrm{p} . \mathrm{m}$. and $4^{\mathrm{n}} 40^{\mathrm{m}} \mathrm{p} . \mathrm{m}$. ; here the course is altered to $\mathrm{S}$. $9^{\circ} \mathrm{W}$., which lay off for 22.5 miles, the distance run between $4^{\mathrm{h}} 40^{\mathrm{m}} \mathrm{p} . \mathrm{m}$. and $6^{\mathrm{h}} 10^{\mathrm{m}} \mathrm{p} . \mathrm{m}$. This gives the D.R. position which can be taken off. From the N.W. Lt. V. set off the two bearings observed, and fit in exactly the distance run by the ship between taking the observations (that is 5 miles run between $5^{\mathrm{h}} 50^{\mathrm{m}}$ p.m. and $6^{\mathrm{h}} 10^{\mathrm{m}}$ p.m.) on a line parallel to run made S. $9^{\circ} \mathrm{W}$., the point of cut on the 2nd bearing is the true position of the ship which can now be taken off.

Set and drift of current is the course and distance from $D$. $R$. to true position.

ANswer.-True pos. lat. $53^{\circ} 29^{\prime} \mathrm{N}$.

$$
\text { long. } 3^{\circ} 35^{\prime} \mathrm{W} \text {. }
$$

D.R. pos. lat. $53^{\circ} 26^{\prime} \mathrm{N}$. long. $3^{\circ} 40^{\prime} \mathrm{W}$.

Set N. $54^{\circ}$ E., $4 \frac{1}{2}$ miles.

Example 2 (Fig. 177).

Construct a plan $7^{\prime \prime}$ by $5^{\prime \prime}$. Scale $5^{\prime \prime}=1$ nautical mile : also scale of cables and 10ths. Insert compass showing $15^{\circ} \mathrm{E}$, variation. $\triangle$ to be $1^{\prime \prime}$ from bottom and left-hand corner. From $\triangle$, A bore N. $8^{\circ} \mathrm{W} ., 4 \cdot 2$ cables ; B bore N. $51^{\circ}$ E., 6.2 cables ; $C$ bore N. $61^{\circ} \mathrm{E}$., 10 cables ; all magnetic. 


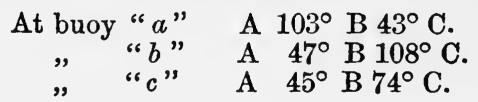

Plot buoys and give their bearings and distances from $\Delta$.

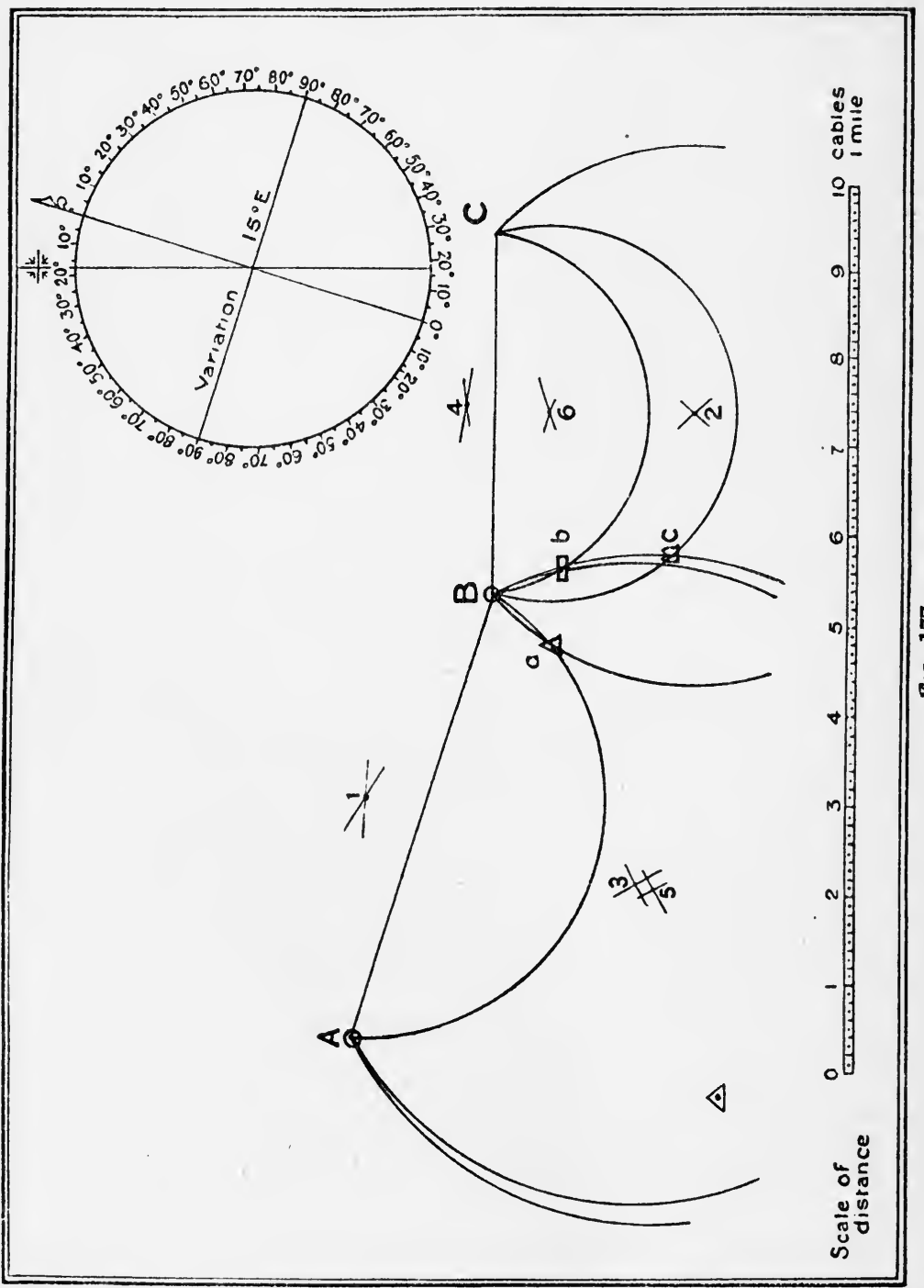

Draw a horizontal line $7^{\prime \prime}$ long at bottom of paper, and at each end erect perpendiculars as in Art. 114, and make them $5^{\prime \prime}$ long; measure to see if their extreme ends are $7^{\prime \prime}$ apart, if so join up and frame is complete. Inside the frame near the bottom draw scale of cables and 10ths as in 
diagram, and put in a compass with magnetic north and south inclined $15^{\circ}$ to sides of frame. Graduate compass.

Plot in $\triangle 1^{\prime \prime}$ from bottom and left-hand side; and from it set off bearings and distances from your scale and compass to plot positions of $A, B$, and $C$. Join $A B$ and $B C$.

For buoy " $a$ " it is noticed that $A$ is on the left, as seen from the buoy, and the angle between $\mathbf{A}$ and $\mathbf{B}$ is $103^{\circ}$, the arc is less than a semicircle, and the complement of $103^{\circ}$, that is $13^{\circ}$, is laid off at each end of $\mathbf{A}$ and $\mathbf{B}$, on the side away from where the fix is to be, the centre " 1 " in Fig. is the intersection of these lines, and the arc is drawn. Again the angle between B and $\mathrm{C}$ is $43^{\circ}$, so its complement $47^{\circ}$ is laid off at each end of $\mathrm{BC}$, on the same side as the fix is to be, and intersect in the centre " 2 "; where the former arc cuts this is buoy " $a$."

At buoy " $b$ " A is again on the left, since the angle between A and B is $47^{\circ}$, set off lines making $43^{\circ}$ with $\mathrm{AB}$ at each end to intersect in centre " 3 " on same side as fix, describe arc ; then set off lines making $18^{\circ}$ with $\mathrm{BC}$ at each end to intersect in centre " 4 ," on opposite side to fix, since angle between $\mathrm{B}$ and $\mathrm{C}$ is $108^{\circ}$; describe arc : these arcs cut at position of buoy " $b$."

For buoy " $e$ " it will be noticed that both angles being less than $90^{\circ}$, the centres " 5 " and " 6 ," determined as before, are both on the same side as the buoy.

Now take off the bearings and measure distances.

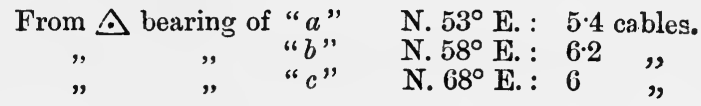

\section{Exercises in Construction of Mercator's Charts.}

1. Construct a Mercator's chart on a scale $2^{\prime \prime} \cdot 4$ to a degree of longitude, extending from lat. $56^{\circ} \mathrm{N}$. to $57^{\circ} 30^{\prime} \mathrm{N}$., and from long. $25^{\circ} \mathrm{W}$. to $28^{\circ} \mathrm{W}$. A ship from lat. $57^{\circ} 8^{\prime} \mathrm{N}$., long. $25^{\circ} 10^{\prime} \mathrm{W}$., sailed as follows by compass : S.W. by S. 50 miles, dev. $6^{\circ} 10^{\prime}$ W.; W.N.W. 53 miles, dev. $6^{\circ} 50^{\prime}$ W.; N.E. 40 miles, dev. $10^{\circ}$ E. ; N. by W. 52 miles, dev. $1^{\circ} 10^{\prime} \mathrm{E}$. The variation is two points W. Find latitude and longitude in.

2. Construct a Mercator's chart, scale $0.8^{\prime \prime}$ to $1^{\circ}$ long., extending from $63^{\circ} 30^{\prime} \mathrm{S}$. to $65^{\circ} 30^{\prime} \mathrm{S}$., and from $120^{\circ}$ to $123^{\circ} \mathrm{E}$., putting in parallels at each $1^{\circ}$. A ship leaves A, lat. $65^{\circ} 7^{\prime} \mathrm{S}$., long. $120^{\circ} 52^{\prime} \mathrm{E}$., and sails the following true courses and distances : N.E. 47 miles ; N.N.W. 63 miles ; S.W. by S. 42 miles; E. 27 miles. Find latitude and longitude in. The variation being $8^{\circ} 30^{\prime} \mathrm{W}$. , what is the magnetic bearing of A from ship?

3. Construct a Mercator's chart to extend from lat. $54^{\circ} 30^{\prime} \mathrm{N}$. to $56^{\circ} \mathrm{N}$., and long. $30^{\circ} \mathrm{W}$. to $33^{\circ} \mathrm{W}$., scale $1^{\prime \prime} \cdot 3$ to $1^{\circ}$ long. A point of land in lat. $54^{\circ} 32^{\prime}$ N., long. $32^{\circ} 56^{\prime}$ W., bears S.W. from the ship by compass, distant 7 miles; ship's head, E. $\frac{3}{4}$ N. ; dev. $9^{\circ} 55^{\prime} \mathrm{E}$. ; variation, $18^{\circ} \mathrm{W}$. Ship sailed as follows by compass : E. $\frac{3}{4}$ N. 90 miles, dev. $9^{\circ} 55^{\prime}$ E. ; N.N.W. $\frac{1}{4}$ W. 40 miles, dev. $2^{\circ} 20^{\prime}$ W.; W.S.W. 45 miles, dev. $7^{\circ} 50^{\prime}$ W.; N.E. ${ }^{\frac{3}{4}}$ E. 75 miles, dev. $10^{\circ} 35^{\prime} \mathrm{E}$. Find latitude and longitude in, true course, and distance made good.

4. Cunstruct a Mercator's chart to extend from lat. $54^{\circ} \mathrm{N}$. to $55^{\circ} 30^{\prime} \mathrm{N}$., and long. $3^{\circ}$ to $6^{\circ} \mathrm{W}$., scale $1^{\prime \prime} \cdot 75=1^{\circ}$ long. Insert following positions: Abbey Head, lat. $54^{\circ} 47^{\prime} \mathrm{N}$., long. $3^{\circ} 58^{\prime} \mathrm{W}$.; Little Ross, $54^{\circ} 46^{\prime} \mathrm{N}$., $4^{\circ} 5^{\prime}$ W. ; Burial Island, $54^{\circ} 29^{\prime}$ N., $5^{\circ} 25^{\prime}$ W.; South Rock, $54^{\circ} 22^{\prime}$ N., $5^{\circ} 26^{\prime}$ W. At the ship, Abbey Head bore N. $46^{\circ}$ E., and Little Ross, N. $37^{\circ} \mathrm{W}$.; she then steamed S. $63^{\circ} \mathrm{W}$. 12 knots for 4 hours, when her position was fixed by cross-bearings of Burial Island W. $8^{\circ} \mathrm{N}$., and South Rock S. $23^{\circ} \mathrm{W}$. Find true position of ship, set and drift of current.

5. Construct a Mercator's chart, scale $24^{\prime \prime}=1^{\circ}$ long., extending from 
lat. $68^{\circ}$ to $71^{\circ} \mathrm{N}$., and $6^{\circ}$ to $10^{\circ} \mathrm{E}$. long. A ship leaves $69^{\circ} 38^{\prime} \mathrm{N}$., $8^{\circ} 20^{\prime} \mathrm{E}$., and sails as follows by compass : N.E. $\frac{3}{4}$ E., $30^{\prime}$, dev. $12^{\circ}$ E. ; N.W. by W. $\frac{1}{2}$ W., $55^{\prime}$, dev. $8^{\circ} \mathrm{W}$. ; South, $80^{\prime}$, dev. $40^{\circ} \mathrm{W}$. ; variation, $20^{\circ} \mathrm{W}$. Find her latitude and longitude in, course, and distance made good.

6. Construct a Mercator's chart on a scale of 1.3 inch to $1^{\circ}$ long., extending from lat. $48^{\circ} 45^{\prime} \mathrm{S}$. to $52^{\circ} \mathrm{S}$., and long. $20^{\circ} \mathrm{E}$. to $26^{\circ} \mathrm{E}$. Position of lighthouse, lat. $51^{\circ} \mathrm{S}$., long. $25^{\circ} \mathrm{E}$. A peak lies 15 miles true North from Lt. Ho. Variation $20^{\circ} \mathrm{E}$. A ship steamed from $50^{\circ} \mathrm{S} ., 21^{\circ}$ E., as follows :-

$\begin{array}{lllcl}\text { Comp. Co. } & \text { Dev. } & \text { Dist. } & \text { Soundings. } & \text { Bottom. } \\ \text { S. } 32^{\circ} \mathrm{E} . & 2^{\circ} \mathrm{E} . & 120 \text { miles } & 100 \mathrm{ftms} & \text { coral. } \\ \text { N. } 6^{\circ} \mathrm{E} . & 4^{\circ} \mathrm{E} . & 180,, & 20 \% & \text { no bottom. } \\ \text { S. } 8^{\circ} \mathrm{E} . & 2^{\circ} \mathrm{W} . & 120, " & & \end{array}$

When the Lt. Ho. bore S. $45^{\circ}$ E. true with an angle of $75^{\circ}$ between it and the peak, give the lat. and long. of the position, amount of current experienced, and assuming the same rate of speed to have been maintained, plot the soundings in their correct positions.

7. Draw a plan on a scale 0.85 inch $=1$ mile; and insert following: $\mathrm{B}, \mathrm{C}, \mathrm{D}$ are three objects, the true bearings and distances of which from A are: B, S. $81^{\circ}$ E., $3 \frac{1}{2}$ miles; C, S. $85^{\circ}$ E., $6 \frac{1}{2}$ miles ; D, S.S.E. $\frac{1}{4}$ E., 3 miles. Fix the following soundings :-

A $\phi$ D $65^{\circ} 20^{\prime} \mathrm{C}$ (5 feet, mud).

A $41^{\circ} \mathrm{B} 65^{\circ} \mathrm{C}$ (3. fathoms, broken coral).

A $116^{\circ} \mathrm{B} 123^{\circ} \mathrm{D}$ (7 fathoms, sand and shells.

8. Construct a plan on a scale 0.8 inch to 1 mile lat., to extend from $52^{\circ} 3^{\prime} \mathrm{N}$. to $52^{\circ} 18^{\prime} \mathrm{N}$., $6^{\circ}$ to $6^{\circ} 25^{\prime} \mathrm{W}$. Insert a compass showing $21^{\circ} \mathrm{W}$. variation and graduate.

A ship steering east magnetic, observed a lighthouse lat. $52^{\circ} 12^{\prime} \mathrm{N}$., long. $6^{\circ} 7^{\prime} \mathrm{W}$., in transit with a buoy when the horizontal angle between light vessel, lat. $52^{\circ} 7^{\prime}$ N., long. $6^{\circ} 24^{\prime}$ W., and Lt. Ho. was $81^{\circ}$. After steering 1.5 miles on above course, the horizontal angle was observed to be $50^{\circ}$ between Lt. V. and Lt. Ho., and $22^{\circ}$ between buoy and Lt. Ho. Find position of buoy with reference to its charted position, which was at first S. $31^{\circ} \mathrm{W}$. of Lt. Ho. and 1.6 miles from it.

9. On a scale of 1.4 inch to 10 miles long, construct a Mercator's chart to extend from $55^{\circ} 15^{\prime} \mathrm{N}$., to $55^{\circ} 45^{\prime} \mathrm{N}$., and from $6^{\circ}$ to $7^{\circ} 30^{\prime} \mathrm{W}$., insert a magnetic compass variation $19^{\circ} 15^{\prime} \mathrm{W}$., graduate margins.

At $7^{\mathrm{h}} 30^{\mathrm{m}}$ a.m. a point $(\mathrm{P})$ bore $130^{\circ}$ from a ship proceeding on a magnetic course S. $80^{\circ}$ E., 10 knots, in a current setting N. $34^{\circ}$ E. magnetic. At $9^{\mathrm{h}} 45^{\mathrm{m}}$ a.m. it bore $206^{\circ}$, and at $10^{\mathrm{h}} 30^{\mathrm{m}}$ a.m. it bore $225^{\circ}$. P. lat. $55^{\circ} 14^{\prime} \mathrm{N}$., long. $6^{\circ} 39 \frac{1^{\prime}}{2} \mathrm{~W}$.

Find the ship's position and distance from $\mathbf{P}$ when the last bearing was taken, average drift of the current, course and distance made good. 


\section{CH.APTER XXVII.}

\section{LAWS OF STORMS.}

ART. 117.-The facts gathered from observations, and known as the Laws of Storms, apply more particularly to the violent Hurricanes, Cyclones, and Typhoons (which may be all classed under the name "Cyclone") met with between the parallels of $10^{\circ}$ and $35^{\circ}$ of latitude; but also in a modified degree to the strong winds, gales, and storms of higher latitudes.

These facts may be summarized as follows:-

1. The tropical Cyclones are never met with in the belt between $10^{\circ} \mathrm{N}$. and $10^{\circ} \mathrm{S}$. lat., but outside of $10^{\circ}$ they occur in the following regions:-

N. Atlantic: The western part near the West Indies.

N. Indian Ocean : The Bay of Bengal and Arabian Sea.

N. Pacific: The China and Java Seas.

S. Indian Ocean: The Western part, passing near Mauritius, and hence called "Mauritius Hurricanes."

S. Pacific : Eastern part.

2. Cyclones (as the name implies) have a rotatory motion round a centre, and a progressive motion, varying from three or four miles an hour to twelve or more.

Near their origin they cover only a small area, but afterwards expand to as much as a thousand or more miles in diameter.

3 . The barometer stands lowest at the centre (often 28 inches or less), and gradually increases in height towards the circumference, whilst the wind force is generally greater the nearer the centre.

4. The bearing of the centre from the ship may be inferred approximately by counting from the wind direction 8 or 10 points to the Right in the $\mathrm{N}$. Hemisphere, and the same number of points to the Left in the S. Hemisphere.

5. The path of the centre, or Line of Progression, divides the Storm Area into two semicircles, and by observing the change of wind it may be determined whether the ship is on the right- or left-hand side of the Line of Progression-a matter of great importance in the handling of the ship. Thus, if the wind changes to the Right, the ship is on the Right-hand side, but if to the left, she is in the Left-hand semicircle. 
If the wind is "steady," i.e. changes very slightly in direction, it indicates that the Ship is on the Line of Progression.

6. The Direction of Rotation in the N. Hemisphere is to the Left, and in the $\mathrm{S}$. Hemisphere to the Right.

7. The approach of a Cyclone is often indicated by well-marked signs, such as-

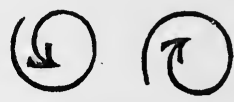

Fia, 178.

(a) An oppressive stillness, with threatening sky and much lightning.

(b) A long "ground swell."

(c) A dense cloud bank on the horizon.

(d) A rapid motion of the upper clouds.

8. When within the Storm Area, the approach of the centre is shown by-

(a) A rapidly falling barometer.

(b) Increase of wind, with heavy squalls, much lightning and rain, and general murkiness.

(c) Heavy and confused sea.

(d) Continuous "veering" or " backing " of the wind, except when on the Line of Progression.

The receding of the centre would be indicated by-

(a) Rising barometer.

(b) Wind becoming more "steady" and decreasing in force.

(c) Weather clearing, but the sea still confused and dangerous.

9. Vessels, especially steamships, sometimes overtake Hurricanes, because their speed is greater than the rate of progression of the Storm Centre. In this case, if the wind changes to the Left, the ship is on the Right-hand side of the storm, but if to the Right, she is in the Left-hand semicircle ; contrary to par. 5.

10. In entering the Central Area, which may be up to a hundred miles in diameter, the wind suddenly ceases, with glimpses of a clear sky and a general calm of perhaps hours' duration, interrupted by puffy squalls, whilst the sea is particularly confused and dangerous. After passing through the centre, the wind strikes the ship from the opposite point of the compass with renewed hurricane force.

11. The paths of Storm Centres follow the same general directions for the same regions of the Globe. The following are the usual tracks:-

(a) N. Atlantic: Having their origin near the Windward Islands, they first travel about W.N.W., then more northerly, and about $25^{\circ} \mathrm{N}$. to $30^{\circ} \mathrm{N}$. they recurve to the N.E. towards Mid-Atlantic.

(b) N. Pacific: The same general direction as in the $\mathrm{N}$. Atlantic.

(c) N. Indian Ocean, including Bay of Bengal and Arabian Seas: A general N. and W. direction. 
(d) China Scas: Between N.W. and W.S.W.

(e) Java Sea: Between N. and W.

(f) S. Indian Ocean : Starting from about $12^{\circ}$ South, they travel in a S.W. direction towards Mauritius, then more southerly, and recurve to the S.E. in $25^{\circ}$ to $30^{\circ} \mathrm{S}$. lat.

12. Seasons of Greatest Frequency of Cyclones. - The following Table of recorded Cyclones from Scott's Meteorology shows that Cyclones are most frequent in the $\mathrm{N}$. Indian Ocean at the Change of Monsoons, and in the other Cyclone Regions during the hottest months:-

\begin{tabular}{|c|c|c|c|c|c|c|c|c|c|c|c|c|c|c|}
\hline \multirow{2}{*}{ Cyclone region. } & \multicolumn{12}{|c|}{ Recorded cyclones for each mouth. } & \multirow{2}{*}{\begin{tabular}{|l|} 
Totals \\
of re- \\
corded \\
obser- \\
vations.
\end{tabular}} & \multirow{2}{*}{$\begin{array}{c}\text { Aver- } \\
\text { age } \\
\text { no. } \\
\text { per } \\
\text { annm }\end{array}$} \\
\hline & झ્ & 官 & 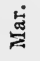 & $\frac{7}{4}$ & 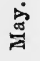 & 苛 & $\stackrel{\doteq}{\Xi}$ & $\frac{\dot{0}}{4}$ & 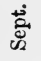 & ठ் & 宽 & 灾 & & \\
\hline $\begin{array}{l}\text { West Indies (in } 300 \text { yeurs) } \\
\text { S. Indian Ocean (39 years) } \\
\text { Bombay (25 years) ... } \\
\text { Bay of Bengal (139 years) } \\
\text { China Seas ( } 85 \text { years) }\end{array}$ & $\begin{array}{l}5 \\
9 \\
1 \\
2 \\
5\end{array}$ & $\begin{array}{r}7 \\
13 \\
1 \\
-1\end{array}$ & $\begin{array}{r}11 \\
10 \\
1 \\
2 \\
5\end{array}$ & $\begin{array}{l}6 \\
8 \\
5 \\
9 \\
5\end{array}$ & $\begin{array}{r}5 \\
4 \\
9 \\
21 \\
11\end{array}$ & $\begin{array}{l}\frac{10}{2} \\
10 \\
10\end{array}$ & $\begin{array}{r}\frac{42}{4} \\
3 \\
22\end{array}$ & $\begin{array}{r}96 \\
5 \\
4 \\
40\end{array}$ & $\begin{array}{r}80 \\
1 \\
8 \\
6 \\
58\end{array}$ & $\begin{array}{r}69 \\
1 \\
12 \\
31 \\
35\end{array}$ & $\begin{array}{r}17 \\
4 \\
9 \\
18 \\
16\end{array}$ & $\begin{array}{l}7 \\
3 \\
5 \\
9 \\
6\end{array}$ & $\begin{array}{r}355 \\
53 \\
62 \\
115 \\
214\end{array}$ & $\begin{array}{l}1 \cdot 18 \\
136 \\
2 \cdot 5 \\
0 \cdot 8 \\
2 \cdot 5\end{array}$ \\
\hline
\end{tabular}

The Table also shows that the most cyclone-infested regions of the globe are the W. Indies, Arabian Sea, and China Seas, and that the worst cyclone months in the various regions are-

(a) Bay of Bengal and Arabian Sea : May, June, October, and November.

(b) N. Atlantic: July to November.

(c) China and Java Seas: July to October.

(d) S. Indian Ocean : January to March.

The same rule would give for-

(e) N. Pacific: July to November.

$(f)$ S. Pacific : January to March.

13. The Rules of Action to be taken when a ship is caught in a Cyclone can be best understood by reference to the diagrams on p. 276.

These Rules may be summed up as follows:-

(1) If on the Line of Progression of an approaching Storm Centre, run or steam before the wind until clear of the track of the centre; then, in the N. Hemisphere, heave to on the Port Tack, but in the S. Hemisphere on the Starboard Tack. By so doing, the ship would always "come up" to the sea when hove to.

(2) In the Right-hand semicircle-

(a) Northern Hemisphere: Head reach or heave to on the Starboard Tack.

(b) Southern Hemisphere: Run with wind on Port Quarter, or heave to on Starboard Tack. 
(3) In the Left-hand Semicircle-

(a) Northern Hemisphere: Run, having the wind on Starboard Quarter, or heave to on the Port Tack.

(b) Southern Hemisphere: Head reach or heave to on the Port Tack.

(4) When overtaking a Cyclone, it is obvious that the ship should be stopped or her course altered so that she may not approach the centre.

14. General Remarks.-The most dangerous position for a ship is the track of the Centre of a Cyclone, which should be avoided if possible. This can generally be done, if there is sea room, by attention to the foregoing Rules.

Observations tend to show that a Storm Area is more circular in front than in the rear; so that the Rule for finding the bearing of the centre is most reliable in the most dangerous situation.

The same Rules may be applied when Heavy Gales are encountered in higher latitudes.

It is common to give the name of "Dangerous Semicircle" to the Right-hand Semicircle in N. Lat., and the Left-hand Semicircle in S. Lat., because the direction of the air-currents is towards the Line of Progression in front of the Storm Centre.

If it is suspected that the ship is overtaking a storm, the engines should be stopped, or the vessel "hove to," and the barometer carefully watched. Should the barometer begin to rise, it is a sure sign of overtaking; but if it continues to fall (although less rapidly), it is a case of meeting a storm.

As these storms have their origin in the hottest parts of the earth, their cause has been thought due to the rushing in of winds from the equatorial and polar regions to fill the partial vacuum caused by a vertical sun in rarefying the air and vaporizing the water. The path of a revolving storm is at first to the westward, but in consequence of the resistance due to meeting air carried round in an opposite direction by the rotation of the earth on its axis from W. to E., the storm trends to a place where there is less resistance, that is, in both hemispheres towards the poles. This is called the "Recurving" of the storm, and takes place in about $30^{\circ}$ latitude.

ART. 118.-

\section{LAW OF STORMS.}

Questions to be answered by candidates for Mates' and Masters' Certificates.

1. Suppose the wind in a cyclone to blow from probable bearing of the centre in the hemisphere. 2 . If the wind in the same cyclone changes to , on what
the line of progression is the ship, and what action would you take? , state what is the 
3. Under what circumstances would the change in the direction of the wind be the reverse of the above?

4. What are the usual indications that a ship is on the line of progression of the centre of a cyclone?

5. What are the usual indications that a ship is approaching the centre of a cyclone or receding from it?

6. State what are the usual tracks taken by cyclones in what season of the year do they most frequently occur in those regions?

\section{LAW OF STORMS.}

\section{Answers.}

1. In the Northern Hemisphere the centre bears about eight to ten points to the right, and in the Southern Hemisphere eight to ten points to the left, from the given direction of the wind.

2. If the wind changes to the right the ship is on the right-hand side of the line of progression, if to the left she is on the left-hand side. These rules apply to both hemispheres.

The action to take is as follows :-

Northern Hemisphere--

Right-Hand Side.-If possible, sail out on the starboard tack to a safer distance from the centre, or heave to on the starboard tack.

LEFT-HAND SIDE.-If possible, run with the wind on starboard quarter until in a safer position, or heave to on the port tack.

Southern Hemisphere-

Right-HAND SidE.-If possible, run with the wind on the port quarter until in a safer position, or heave to on the starboard tack.

IEFT-HAND SidE.-If possible, sail out on the port tack to a safer position, or heave to on the port tack.

3. The wind would change the reverse way if the ship were on the other side of the line of progression, also if she were overtaking the storm on the same side as before.

4. In advance of the centre the barometer falls more and more rapidly as the centre approaches, the wind continues to blow from the same quarter, but increases in violence, with frequent heavy squalls, a confused angry sea, a dense cloud bank, and general threatening appearances of weather.

In the central area the barometer is lowest, with a confused and dangerous sea, and calms varied by strong gusts.

In the rear of the centre the barometer rises, and the wind blows at first with great violence from the opposite quarter, afterwards moderating and the squalls becoming less frequent, the sea being heavy and confused, but the weather gradually clearing.

5. (a) When approaching the centre, not on the line of progression, there are the same barometer and weather indications as stated in the preceding answer, but the wind changes in direction as it increases in force, with heavy cross-seas.

(b) When receding from the centre the barometer rises, the wind becomes more steady, with less frequent squalls and less threatening appearance of weather, though the sea is still cross and dangerous.

6. North Atlantic (Tropical).-The cyclones, in this region, are supposed to take their rise near the Windward or Leeward Islands, and first travel about W.N.W. towards Florida, then more northerly, and on reaching the parallel of $30^{\circ}$ often recurve to the N.E. They occur most frequently from July to November; worst months, August and September.

South Atlantic (Tropical).--They travel first about W.S.W., then 
more southerly, and sometimes recurve to the S.E. They occur most frequently in the hottest months-December, January, and February.

South Indian Ocean (Tropical). - They are supposed to have their origin in the belt of calms, south of the Equator, often near Java, and travel first W.S.W., then more southerly towards the Mauritius, and sometimes recurve to the S.E. They occur from November to May, but most frequently in February and March.
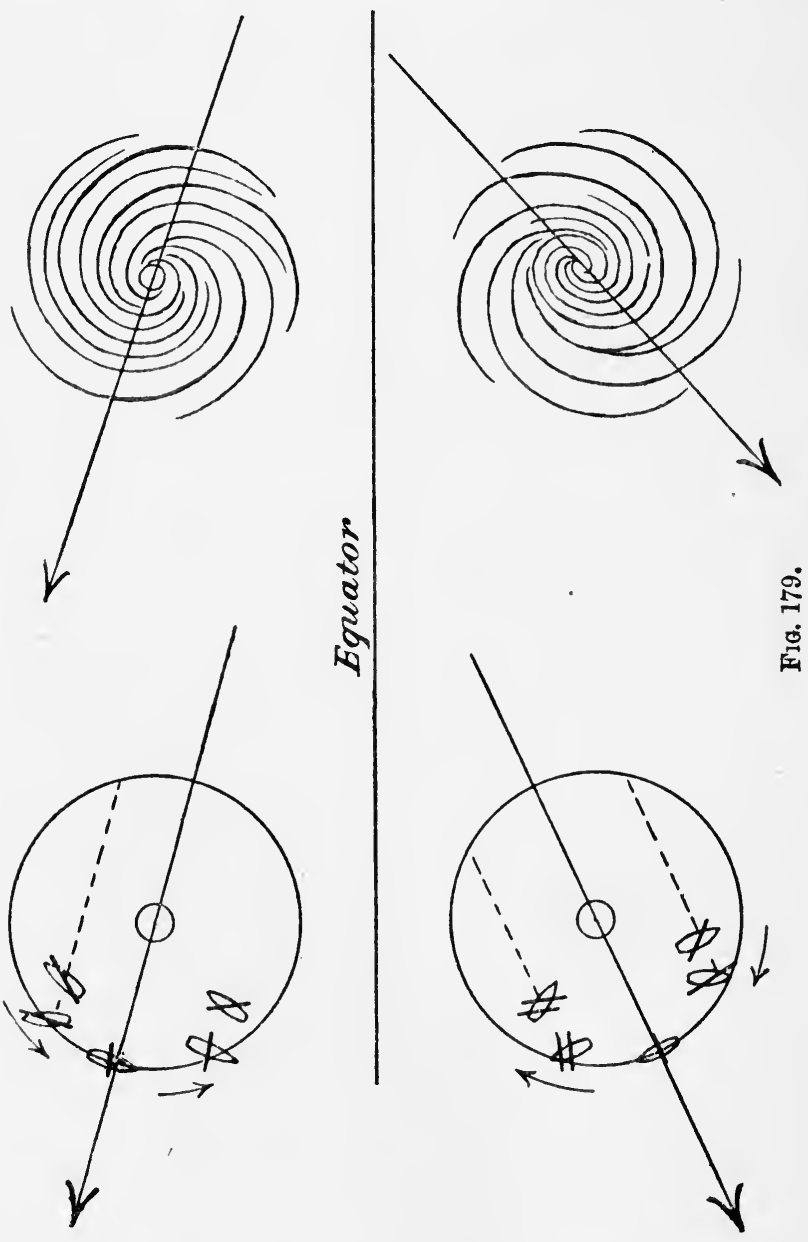

China Seas. - The storms take their origin near the Philippine Islands, and travel generally between W.N.W. and W.S.W. They occur most frequently from July to November; worst months, August and September.

Bay of Bengal. - The storms in this region begin in the neighbourhood of the Andaman and Nicobar Islands, and travel between W. and N.N.W. They occur most frequently in April to June, and September to November ; worst months, May, October, and November. 
Arabian Sea.-Between N. and W., and most frequent in May and October.

North Pacific (Tropical). - The cyclones of this region begin in about $10^{\circ} \mathrm{N}$., and travel first W.N.W., then more northerly, and finally recurve to the N.E. July, August, and September are the worst months.

South Pacific (Tropical).- The cyclones of this region first travel about W.S.W., then more southerly, and finally to the S.E. They occur most frequently from November to April.

Outside of lat. $30^{\circ}$, storms in the North Atlantic and North Pacific travel to N.E., and in the South Indian Ocean and South Pacific to the S.E.

Mauritius.-Storms occur from December to April, worst months being February and March ; they travel from S.S.W., recurving to S.S.I.. 


\section{CHAPTER XXVIII.}

\section{MAGNETISM AND DEVIATION OF THE COMPASS.}

ART. 119.-For a full and scientific discussion of the deviation of the compasses in iron ships, the student is referred to the "Admiralty Manual," or to the "Elementary Manual," edited and revised by Captain Creak, R.N. For general students Merrifield's "Magnetism and Deviation of the Compass" is recommended.

The purpose of the following remarks is to enable students to clearly understand the principles involved in the Board of Trade Syllabus of Questions dealing with the practical application of the laws of magnetism to the case of iron ships and their compasses.

Definition.-Magnetism is a property which may be acquired by masses of iron and steel, by virtue of which they attract or repel each other under certain circumstances.

Kinds of Magnets.-There are three kinds of magnets, viz. natural, artificial, and electro-magnets. The natural magnets are the Earth and pieces of magnetic iron ore or "lodestone." Artificial magnets are bars or "needles" of hard-tempered steel, which have been magnetized by rubbing contact with other magnets, or by the influence of an electric current. Electromagnets are elongated or horseshoe-shaped masses of soft iron wound round with copper wire, through which an electric current is passing. The strongest magnets are made in this way; but the magnetic properties disappear when the current ceases.

Degrees of Magnetism.-Magnetism may exist in three different states or degrees in steel or iron, viz. PERMANENT, SUB-PERMANENT, and TRANSIENT INDUCED.

A bar of hard-tempered steel receives magnetism slowly, but when once magnetized it retains its magnetic strength for an indefinite length of time, and is said to have permanent magnetism.

Iron or steel of a less degree of hardness is more easily magnetized, but is liable to lose a considerable portion of its magnetism with lapse of time, and is therefore said to have sub-permanent magnetism.

Soft or malleable iron becomes instantly magnetized by induction from any magnetic source, but loses it when the 
inducing cause is removed. This temporary magnetic condition is known as TRANSIENT INDUCED magnetism.

Saturation.-There is a limit to the magnetic strength which

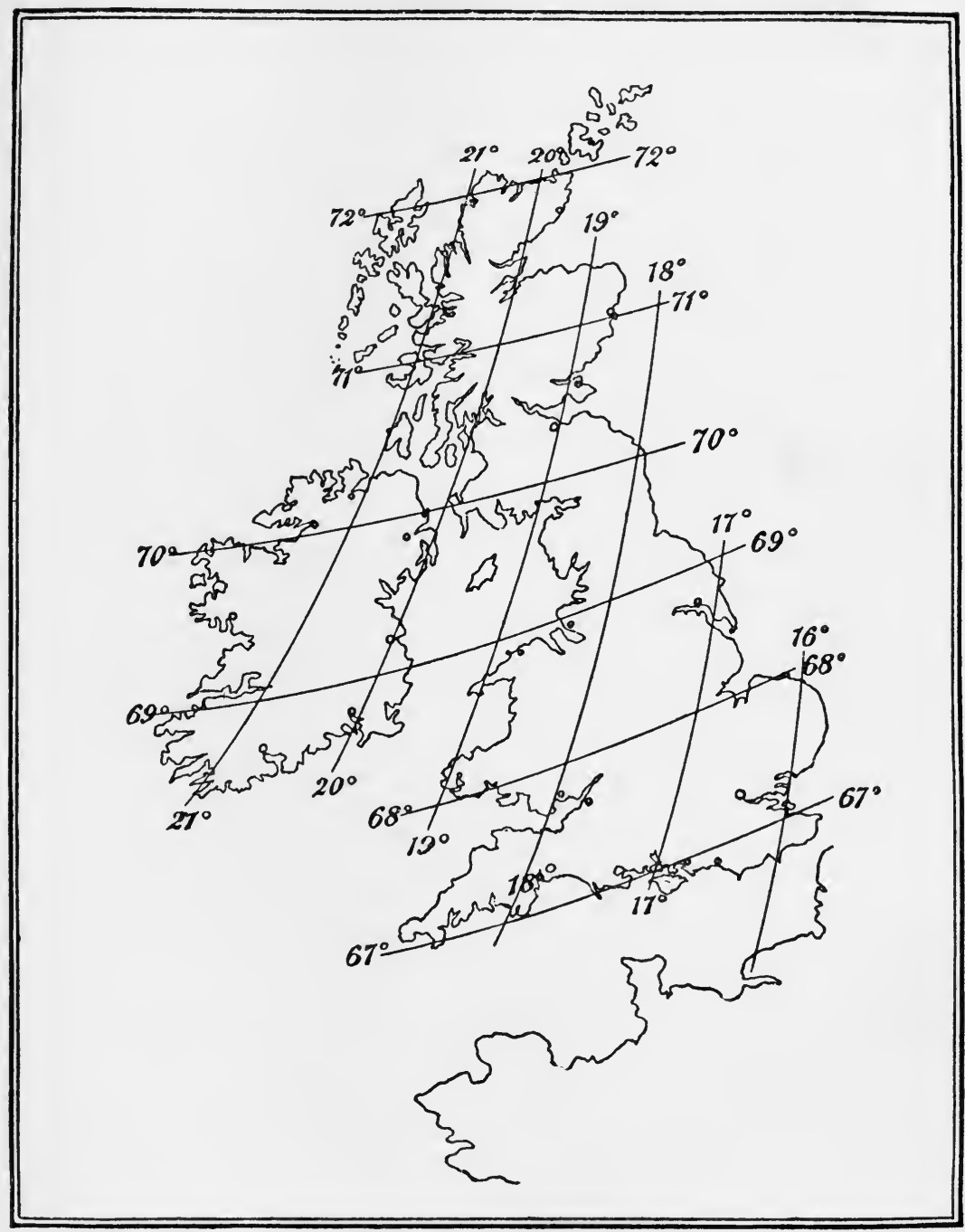

FIG. 180.-Variation chart of British Islands.

a piece of steel or iron can acquire, and when this limit is reached it is said to be saturated.

Magnetic Poles.-Every magnet has two POLES, or points 
where the greatest energy is concentrated, distinguished as RED and BLUE poles, because it is common to paint artificial magnets in these colours. The red pole of a permanent magnet is the one which would point north when the magnet is suspended at its centre and free to turn round. This end is also called the $\mathrm{N}$. or marked end. Therefore the end of a compass-needle which points $\mathrm{N}$. is the red pole.

ART. 120. First Law of Magnetism.-It is a well-known law of magnetism that like poles repel each other, and unlike poles attract each other. This can be proved on a compass-needle, for if the red pole of a magnet be brought near to the $\mathrm{N}$. or marked end, it will repel it, whilst the blue pole will attract it. Similarly, the S. end will be repelled by the blue pole, and attracted by the red. It follows from this experiment that the Earth's NORTH magnetic pole is BLUE, because the red pole of the needle is attracted towards it. The needle, if floating on water and free to move, would not, however, travel towards the $\mathrm{N}$. pole, because its length is as nothing compared with the distance from the Earth's pole, its blue end being as strongly repelled as the red end is attracted. It is the same with the action of the south magnetic pole. The only result is, therefore, to give the needle a north and south direction.

If a needle hundreds of miles in length could be supposed to be afloat in the North Atlantic, with its red pole towards north, no doubt it would travel bodily towards the N. pole of the Earth, because its red pole would then be attracted more strongly than the blue would be repelled.

Second Law.-It is another law of magnetism that the effect of a magnetic force (such as the pole of a magnet or an induced pole in soft iron) on a small magnet varies nearly in the inverse ratio of the cube of the distance; that is, at double the distance it is one-eighth $(2 \times 2 \times 2=8)$; at treble the distance it is only one twenty-seventh $(3 \times 3 \times 3=27)$, etc. Also-

Third Law.-A magnet placed end on to a pivoted needle causes twice the deflection that it would do if broadside on at the same distance between the centres of the magnet and needle.

These facts have a very important bearing on the effect of the magnetic forces in a ship on her compasses, and show the advantage of placing the compasses as far as practicable from masses of iron having magnetic properties, especially when end on.

ART. 121. Transient Induced Magnetism.-When either pole of a magnet is brought near to one end of an iron rod, it develops two magnetic poles in the iron, the near end being of the opposite name to that of the pole applied. The process may be repeated through a series of rods end on, so that the N. point of a compass-needle would be deflected by the last one in the same manner as by the magnet itself. 
The same fact may be illustrated by the familiar experiment of causing a number of soft iron bars or nails to hang on to the

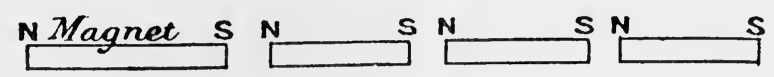

Fig. 181.

end of a strong magnet; but whether in contact or not, the effect is the same.

The above are examples of magnetic induction and the acquiring of transient induced magnetism.

Lines of Force.-The mysterious action of one magnet on

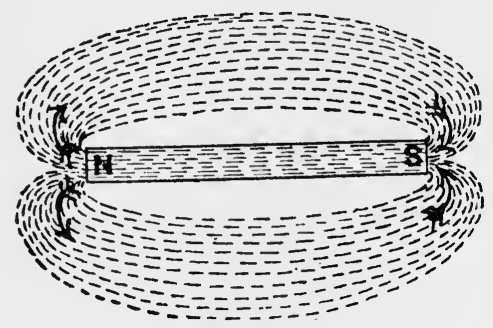

another at a distance, and the magnetization of iron with or without contact, are explained by the existence of lines of force, which issue from the red pole and return to the blue pole. These lines of force pass without interruption through all intervening non-magnetic substances, and it is the passing of

Fra. 182.

lines of force into iron which gives it magnetic properties. Their existence and direction can be shown by experiment (Fig. 182). If a sheet of white paper be laid on a magnet and iron filings sprinkled on the paper, the filings will arrange themselves in lines corresponding to

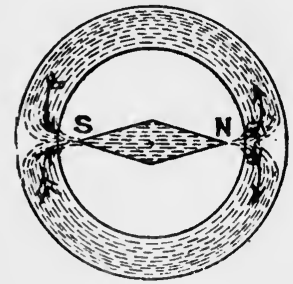

FiG. 183. the direction of the lines of force from one pole of the magnet to the other.

If a suspended magnetic needle were enclosed in a thick iron shell, the lines of force would follow round through the iron by preference to reach the blue pole, and the consequence would be that the needle would lose its directive power. This is the reason why compass-bowls are made of copper, and not of iron. Another reason is that poles would be induced in an iron bowl, which would oppose the Earth's directive action on the needle. Therefore a ship's compass which is closely surrounded by iron would have a weakened directive power.

The Earth's Magnetism.-The Earth itself acts as a magnet, having a blue pole towards the north and a red pole towards the south. Its action on a compass needle is merely to give a directive tendency, as before explained, but it is also a powerful inducing source. No iron can escape from its influence. Hence fireirons, knife-blades, needles, etc., are nearly always magnets with two fixed poles, as may be tested on a compass-needle, 
whilst bars or rods of soft iron have also induced poles from the same cause, which are not, however, fixed. A fairly strong magnet can be made by holding a bar of hardened steel in a N.-and-S. direction and tapping it with a hammer; the vibration quickens the process of magnetization by the Earth's induction.

A Ship's Induced Magnetism.-Even a ship becomes a huge magnet from the Earth's induction in the process of building, whilst the separate parts, such as beams, stanchions, davits, rudder and stern-posts, etc., become so many temporary magnets, liable to act separately and collectively in disturbing the compasses.

ART. 122. Variation.-The magnetic poles of the Earth do not coincide with the true geographical poles, the $\mathrm{N}$. or blue pole being in about lat. $70^{\circ} \mathrm{N}$., long. $90^{\circ} \mathrm{W}$., and the $\mathrm{S}$. or red pole was found by Lieut. Shackleton to be in lat. $722_{2}^{\circ} \mathrm{S}$., long. $154^{\circ} \mathrm{E}$. (from which it is seen they are not exactly opposite). This is the cause of the variation of the compass, which is the difference in direction between true $N$. and magnetic $N$. The amount of variation is stated on ordinary charts, and for the entire globe on special variation charts. The variation is not constant at any place, but changes at a known rate (in the United Kingdom now about $8^{\prime}$ or $9^{\prime}$ annually).

Previous to the year 1657 the variation was $\mathrm{E}$. in this country. In that year there was no variation at London, the compass pointing true $N$. Then it became westerly, and attained its maximum W. variation in 1816. Since then it has constantly decreased, and will again become 0 in 1977 ; then, becoming $\mathbf{E}$. again, it will reach its maximum in the year 2290. The explanation of this progressive change of variation is that the $\mathrm{N}$. magnetic pole describes a complete circle round the true N. pole in a period of about 640 years. Twice in the course of this period the compass would point true $\mathrm{N}$. at Greenwich, i.e. when the magnetic pole is on the meridian of Greenwich, and on the opposite meridian (Fig. 184). The annual change would evidently be greatest when the magnetic pole is at or near to the points 0 and $0_{1}$ in the

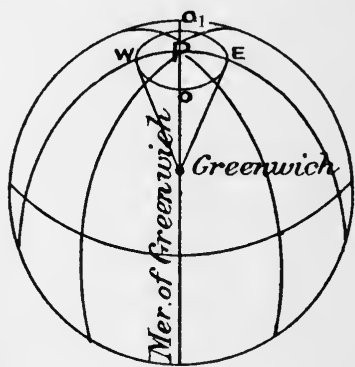

Fig. 184. figure, and slowest when near the points $W$ and $E$, when the direction of the needle is a tangent to the small circle. At present the magnetic poles are coming towards the meridian of Greenwich. The same remarks apply to other places. A line in the direction magnetic $N$. and $S$. at any place is called the magnetic meridian; hence variation may be defined as the 
angle between the true and magnetic meridians. An irregular line round the Earth, about midway between the poles, is the magnetic equator, which cuts the true geographical equator in two nearly opposite points about longs. $170^{\circ} \mathrm{E}$. and $12^{\circ} \mathrm{W}$.

Magnetic Dip.-A magnetized needle, poised at its centre so

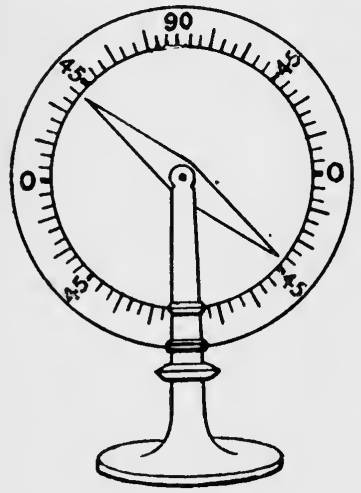

FiG. 185. as to be free to move in a vertical plane, and provided with a scale of degrees, is called a dipping-needle (Fig. 185).

At the magnetic equator, and placed in the plane of the magnetic meridian (i.e. pointing $\mathrm{N}$. and $\mathrm{S}$. magnetic), such a needle would lie horizontal; but if carried northwards the red pole would dip more and more, until the magnetic pole is reached, where it would stand upright, red pole downwards. South of the magnetic equator the blue pole would dip, and the needle would again assume an upright position at the $\mathrm{S}$. magnetic pole, blue pole downwards. At Greenwich the dip at the present time is $68^{\circ}$, but in the West Atlantic and Gulf of St. Lawrence it is much greater. Like the variation, the dip at Greenwich is decreasing annually, and will be least in the year 1977, when the variation will be 0 .

These are the results of observation. The explanation is that in N. magnetic latitude the red pole of the needle points

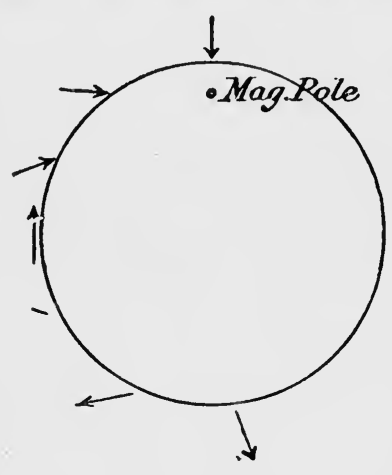

Fૈ̆IG. 186. direct to the N. magnetic pole, and in S. magnetic latitude the blue pole to the S. magnetic pole of the Earth, notwithstanding the mass of the Earth intervening, whilst the horizontal plane at any place is a tangent to the Earth's surface (see Fig. 186).

The dip at any place decreases when the magnetic pole, in making its circuit round the true pole, is approaching the meridian of the place, and increases when it is receding. Thus in the Fig. 184, the dip at Greenwich decreases when the magnetic pole is moving from $0_{1}$ to 0 , and increases from 0 to $0_{1}$, being greatest when the pole is at $0_{1}$, and least when at 0 . At present the dip at Greenwich is decreasing.

The position assumed by the dipping-needle may be con- 
sidered the natural one for any magnetized needle which is free to move, but the horizontal position of a compass needle is a forced one. The reason why the compass card lies horizontal under the circumstances is that the point of support is above the centre of gravity of the card and needles, and the dragging down force is not sufficient to overcome their weight. It is evident from the above that an ordinary compass would be of no use for steering purposes near the magnetic poles, and is at its best on the magnetic equator.

ART. 123. Parallelogram of Forces.-Before considering the magnetism of iron ships and its effects on their compasses, it is necessary to understand the principle of the parallelogram of forces.

It is a law in mechanics that if two adjacent sides of a parallelogram represent two given forces in direction and amount, then the diagonal from the point of meeting of these two sides will represent the resultant (or equivalent force) both

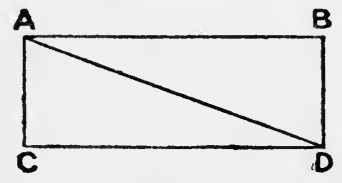

FiG. 187.

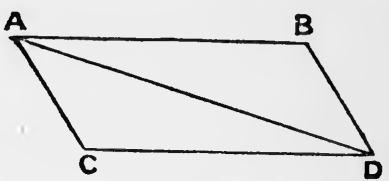

FIG. 188.

in direction and amount. Thus, if $\mathrm{AB}$ and $\mathrm{AC}$ in the parallelogram $A B C D$ represent two given forces, then the diagonal $A D$ will represent the joint effect or resultant. The sides of the triangle $\mathrm{ABD}$ represent equally well the forces and resultant.

A good illustration of this principle may be taken from the case of sailing in a current. For example, let the direction from A to B (Fig. 188) be the course steered, and the length of $A B$ the rate of sailing per hour; also let $\mathrm{AC}$ represent the "set" of the current and "drift" in one hour.

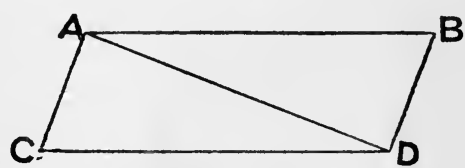

FIG 189. Draw $\mathrm{BD}$ parallel to $\mathrm{AC}$, and $\mathrm{CD}$ parallel to $\mathrm{AB}$, and join $\mathrm{AD}$; then AD will be the course and distance made good, and represents the resultant or joint effect of wind or steam and the current acting for the same length of time.

It is the same with any other kind of force, and it will be seen how the principle applies in dealing with the magnetic forces in a ship.

$\mathrm{AB}$ and $\mathrm{AC}$ are called components, and these can be found from the resultant, as well as the resultant from the components. The finding of the components is called "resolution," and of the resultant "composition." Thus, a force represented by AD is 
"resolved" into components represented by $\mathrm{AB}$ and AC. This expression will be frequently used hereafter.

ART. 124. Magnetic Condition of Iron Ships.-(a) Sub-permanent Magnetism.-It has been stated that the hull of an iron ship becomes a magnet from the Earth's induction. The effect of lying for a considerable time in one direction, and the hammering to which the iron is submitted, is to fix the acquired magnetism so that it becomes sub-permanent, i.e. less than permanent. After launching there is some reduction of the strength of this sub-permanent magnetism, but it can often be traced throughout the whole existence of the ship, showing that a portion of it is almost of a permanent character.

If the hull be supposed to be divided into halves as she lies on the stocks by a plane at right angles to the line of dip (q.v.), the half towards the $\mathrm{N}$. will have red polarity, and the other half blue.

Thus, if built in the United Kingdom, with head towards N., the line of dip being DP (Fig. 190) and EQ at right angles,

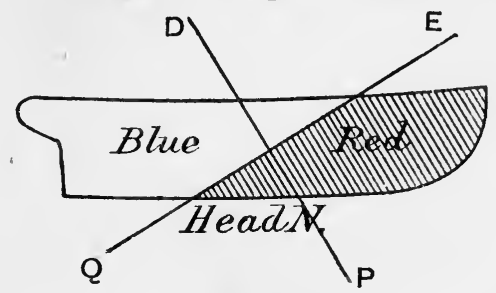

Fig. 190.

the ship would be an irregularly shaped magnet, red towards the bow, and blue towards the stern.

If built heading $S$., the red polarity would be at the stern, and blue at the bow.

If built heading E., the port side would be red, and the

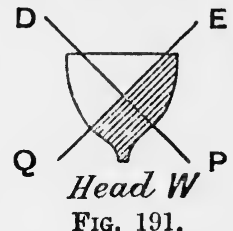

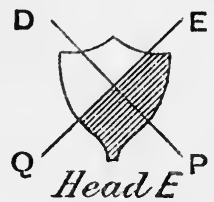

Fig. 192.

starboard side blue (Fig. 192) ; but if built head W., the starboard side would be red, and the port side blue (Fig. 191).

The magnetic poles or points of greatest concentration of magnetic strength might be supposed to be about the centre of the two halves. So that in all these cases the line joining the poles would be inclined, one pole being nearer the keel than the other (unless built on the magnetic equator). 
But it is only the horizontal component of the total force which causes deviation when the ship is upright. (The effect

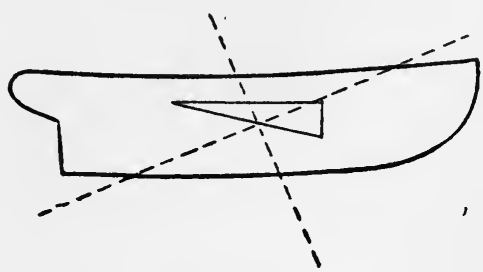

Fig. 193.

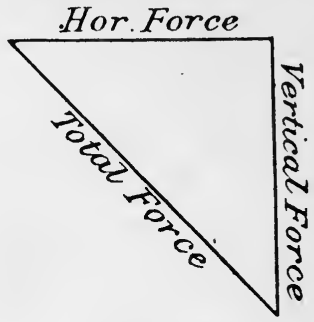

Fig. 194.

of the vertical component will be considered later.) The parallelogram (or triangle) of forces will show the relation of the horizontal to the total force (Fig. 194).

It is clear that the greater the dip the less will be the horizontal component of the ship's magnetic force, and vice versâ. Hence, other things being equal, a ship built in a high latitude

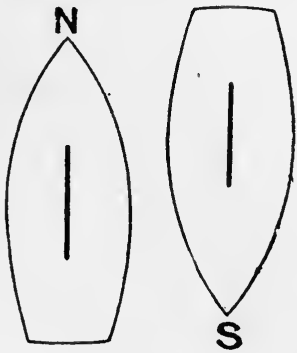

FIG. 195 .

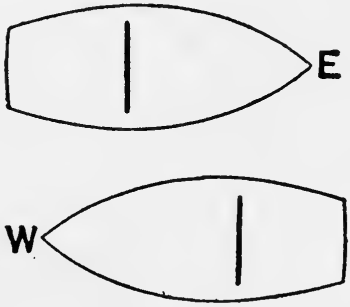

FIg. 196.

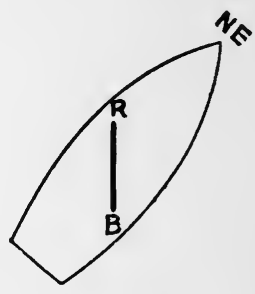

Fig. 197.

should cause less deviation from sub-permanent magnetism than one built in a low latitude, the ship being upright.

If a ship were built heading magnetic N. or S., the line representing the horizontal force of sub-permanent magnetism would be parallel to the keel (Fig. 195); if E. or W., it would be at right angles to the keel (Fig. 196); but if in any other direction it would lie obliquely (Fig. 197). In the latter case, the parallelogram of forces would again resolve the total horizontal force into two components-one represented by a line parallel to the keel, and the other at right angles to it.

Induction in Horizontal and Vertical Iron.-The effect of the Earth's induction on the horizontal and vertical iron of a ship may now be considered.

A bar of soft iron has the greatest magnetic strength from the Earth's induction when it lies in the line of dip, but is neutral when at right angles to it. 
Thus, in N. magnetic latitude the end B of the horizontal bar $\mathrm{AB}$ and the lower end of the vertical bar $\mathrm{CD}$ are red poles, because towards the N. dipping-pole (Fig. 198).

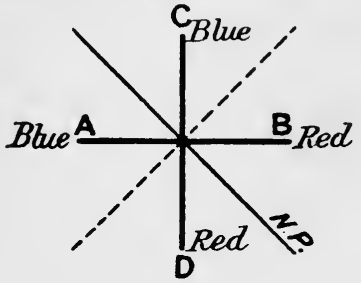

Fig. 198.

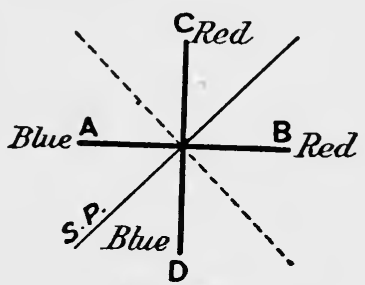

Fra. 199.

In S. magnetic latitude, the end A of the horizontal bar and the lower end of the vertical bar are blue, because towards the S. magnetic pole (Fig. 199).

A bar lying at right angles to the line of dip would be neutral.

This explains why the stern post, rudder post, and other vertical iron below the compass attract the $\mathrm{N}$. point of the compass when north of the magnetic equator and repel it when south, whilst they have no effect when the ship is on the magnetic equator. Also, why the ends of horizonal beams attract and repel alternately as the ship's head turns from one quadrant to another, but are neutral when her head is N. or S. magnetic.

Another inference is that the magnetic strength of vertical iron in a ship decreases on going towards the magnetic equator, and increases towards the poles, whilst that of a horizontal beam lying $\mathrm{N}$. and $\mathrm{S}$. increases towards the equator, and decreases towards the poles.

ART. 125. Coefficients.-The term Coefficients is used to represent the components of magnetic forces in a ship. It may be assumed that these forces have a mechanical value, although a very small one, and could be measured by the same standard as other mechanical forces; but in reference to a ship's compass they are estimated by the amount of deviation they produce when acting most effectively. This deviation itself is often called the coefficient.

The letters A, B, C, D, E name the coefficients, of whick B, $\mathrm{C}$, and $\mathrm{D}$ are the most important.

Coefficient B represents a magnetic force whose poles lie horizontally in the fore-and-aft midship line, and is a combination of the fore-and-aft component of sub-permanent magnetism and the induced magnetism of vertical iron before or abaft the compass. It is named $+\mathrm{B}$ if the combined effect is to attract the $\mathrm{N}$. point of the compass towards the bow, and $-\mathrm{B}$ if towards the stern. 
Coefficient $\mathrm{C}$ represents a force whose poles lie horizontally at right angles to the fore-and-aft midship line, and is the athwartship component of the sub-permanent magnetism only, for vertical iron is supposed to be evenly balanced towards the sides. It is named $+\mathrm{C}$ when the $\mathrm{N}$. point of the compass is attracted to the starboard side, and $-\mathrm{C}$ when to the port side.

The horizontal force of sub-permanent magnetism is therefore represented by coefficients $B$ and $C$, whose signs and relation to each other depend on the direction of ship's head during her construction, as illustrated in the following figures :-
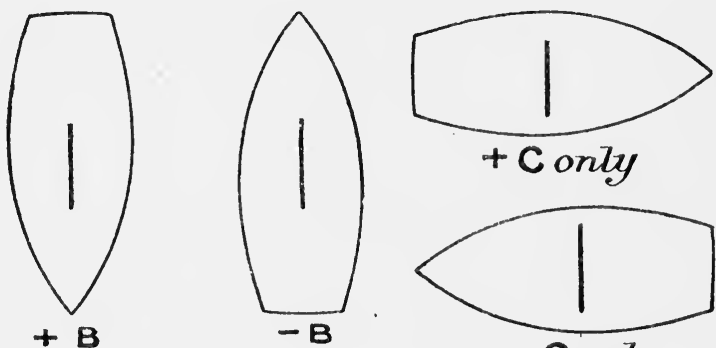

FIG. 200.
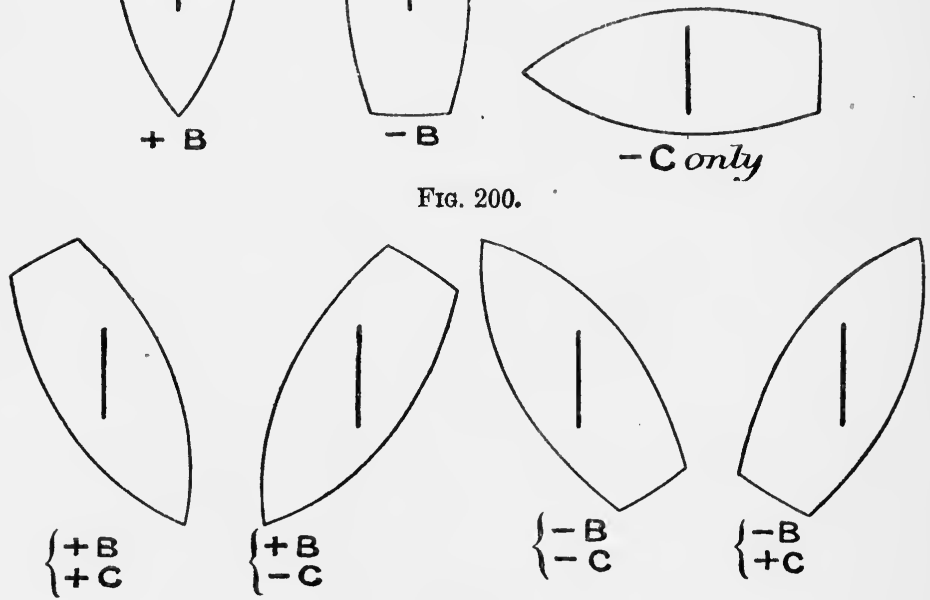

FIG. 201.

Semicircular Deviation.-The deviation due to coefficient B or coefficient $\mathrm{C}$ is called semicircular, because it is east on courses over one half of the compass, and west in the other half.

Coefficient $+B$ (blue pole forward) causes $E$. deviation when the ship's head is to the eastward, and W. deviation when to the westward; - $\mathrm{B}$ (blue pole aft) gives deviations of opposite name to the above. The maximum amount in both cases is found when the ship's head is E. or W. by compass.

Coefficient $+C$ gives E. deviation when the ship's head is to the northward, and W. deviation when to the southward; -C gives the opposite, the maximum amount being found when heading N. or S. by compass. B causes no deviation when ship's 
head is $\mathrm{N}$. or $\mathrm{S}$. by compass, and $\mathrm{C}$ causes no deviation when her head is E. or W., because in these cases the forces act in a line with the compass needle.

The kind of deviation due to coefficients $\mathrm{B}$ and $\mathrm{C}$ is seen at a glance in the following figures, where + stands for E. deviation, and - for W. deviation :-

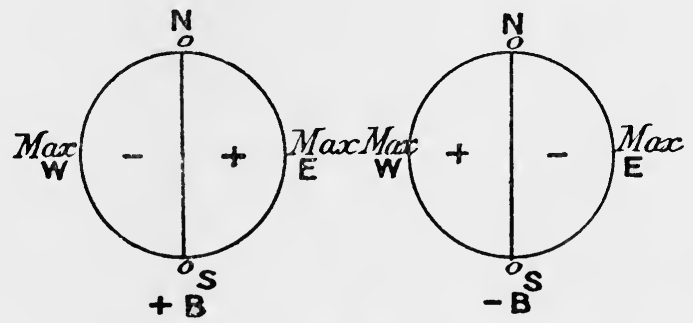

Fia. 202.
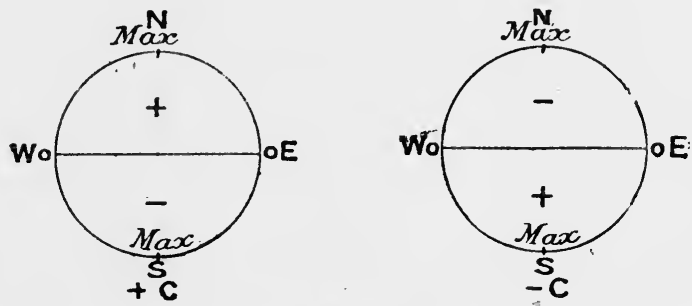

Fra. 203.

Transient Induced Magnetism in Ships.-The transient induced magnetism of horizontal iron is represented by coefficients $\mathrm{D}$ and E. Beams from side to side, and elongated iron lying fore-andaft end on to the compass, give coefficient $+\mathrm{D}$; athwartship beams end on and fore-and-aft iron extending beyond the compass both ways, gives -D (Fig. 204).

Horizontal stringers from starboard quarter towards port bow give $+\mathrm{E}$, and when extending from port quarter towards starboard bow they give - E. When end on to the compass, they give a coefficient of the opposite sign (Fig. 205).

Quadrantal Deviation: Coefficients $\mathbf{D}$ and $\mathbf{E}$.-The deviations caused by coefficients $\mathrm{D}$ and $\mathrm{E}$ are called quadrantal, because they change their signs with change of course from quadrant to quadrant.

Thus, $+\mathrm{D}$ gives $\mathrm{E}$. deviation between $\mathrm{N}$. and $\mathrm{E}$. and between S. and W., but W. deviation between $\mathrm{E}$. and S. and between W. and N. Also, + E gives E. deviation between N.W. and N.E. and between S.E. and S.W., but W. deviation between N.E. and S.E. 
and between S.W. and N.W. $-\mathrm{D}$ and $-\mathrm{E}$ give deviations of opposite sign.

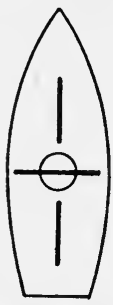

Iron Giving

$+D$.

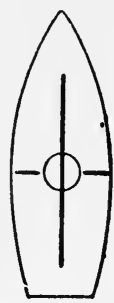

IronGiuing $-D$

FIG. 204.

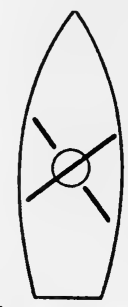

IronGiving

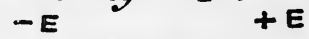

Fir. 205.

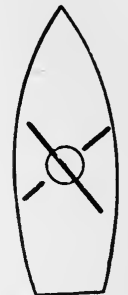

Iron Giving $+E$

It is an instructive exercise to prove the foregoing results by tracing the influence of one of these masses of horizontal iron on the compass as the ship's head is swung round.
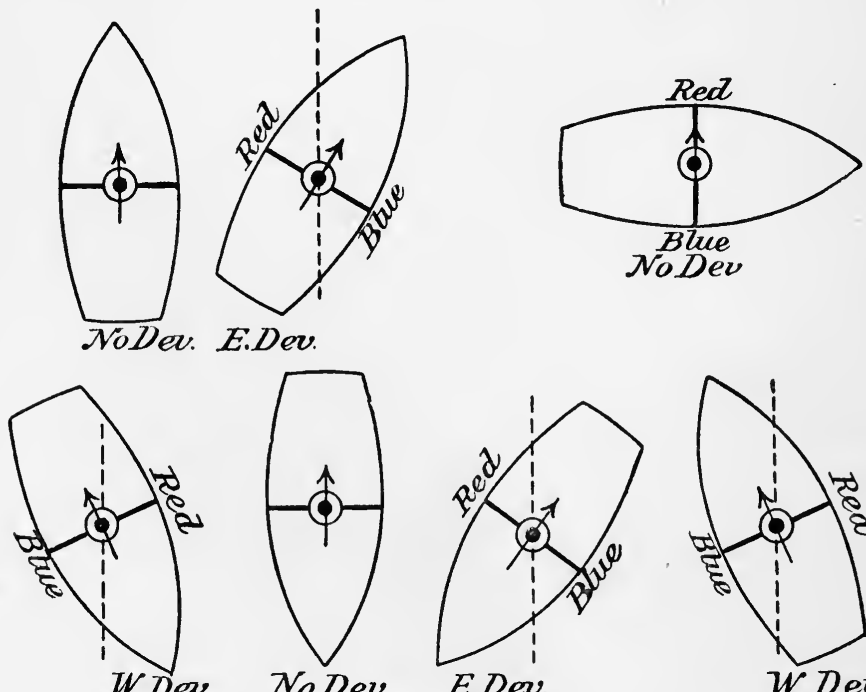

EDev.

Fig. 206.

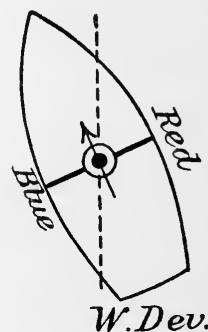

These figures show the magnetic polarity of a beam from side to side (giving coefficient $+\mathrm{D}$ ) and the deviation produced in each quadrant. The zero points (i.e. points on which there is no deviation) are N., E., S., and W., and the maximum deviation is on courses halfway between these points, namely, at N.E., S.E., S.W., and N.W.

Similarly, it can be shown that the zero points for coefficient 
$\mathrm{E}$ are N.E., S.E., S.W., and N.W., and the courses of maximum deviation N., E., S., and W.

The student should reason out for himself the effect of the various masses of horizontal iron as the ship is swung round the compass.

It is conceivable that the iron producing $+\mathrm{D}$ or $+\mathrm{E}$ might be exactly counterbalanced by iron causing $-\mathrm{D}$ or $-\mathrm{E}$, but if not, then the balance on the side of the greater is the coefficient.

The following figures show the quadrantal deviations due to coefficients D and E, and the zero and maximum points. The sign + stands for E. deviation, and - for W. deviation :-
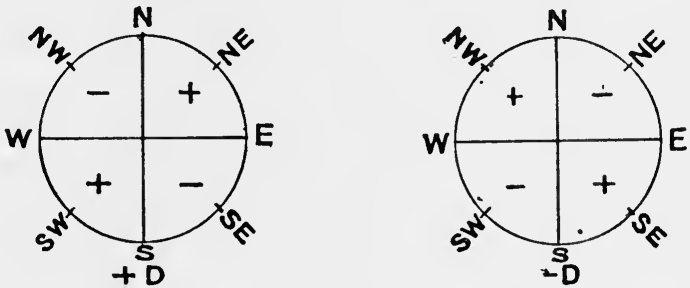

Fig. 207.
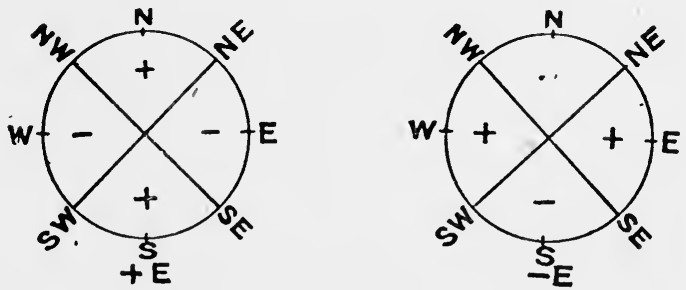

FIG. 208

Coefficient $\mathbf{A}$ and its Causes.-Coefficient $\mathbf{A}$ is of the nature of an index error, being of the same sign or name on all courses, and is often not due to magnetism at all. It may arise from any of the following causes:-

(a) The misplacing of the lubber line.

(b) The magnetic axis of the needles not coinciding in direction with the line through the $\mathrm{N}$. and $\mathrm{S}$. points of the card.

(c) An error in the correct magnetic bearing used in finding the deviations.

(d) Unsymmetrical arrangement of iron with respect to the compass.

(e) Retained magnetism during the process of "swinging" the ship.

The first three causes, if detected, could be removed, but the 
last two can scarcely be remedied. In any case the deviation from these causes is small, and is liable to be confounded with the deviation due to coefficient $\mathrm{E}$, which is also very small.

The existence of a coefficient $A$ is made evident in a table of deviations when the sum of the $\mathrm{E}$. deviations is not equal to the sum of the W. deviations. When the former is greater, $\mathrm{A}$ is + ; when the latter, it is -.

ART. 126. Analysis and Compensation.-The importance of making an analysis of the causes of deviation and of knowing how much is due to each, is that suitable methods of compensation may be employed, namely, to counterbalance the permanent magnetism by means of magnets, and the transient induced magnetism by iron correctors which themselves have the same kind of magnetism from the same source (the Earth), but act on the compass in the opposite sense.

Separation of Coefficients. - It is a fortunate circumstance that the effects of the various coefficients of forces can be sorted out from the observed deviations, as explained in the answer to Question 62, and a table can be made of the deviations due to each coefficient for every point of the compass (see answer to Question 62), which, being summed up algebraically, give the total deviation for each course.

The practical method of compensation is explained in answers to Question 40.

Compensation of Coefficient B.-The most troublesome coefficient to deal with is $B$, because it is a combination of subpermanent and transient induced magnetism, as before explained. When on the magnetic equator, it would be easy to compensate the former with a magnet, and then, on proceeding north or south, the amount of change in the deviation when the ship's head is E. or W. could be compensated by a "Flinders bar."

But since $\mathrm{B}$ and $\mathrm{C}$ of sub-permanent magnetism stand to each other in the relationship of difference of Latitude and Departure, the ship's head whilst building being the course, it is possible to find this B if that direction is known. For this purpose the ship's head should be steadied on N. or S. by compass, and the deviation from coefficient $\mathrm{C}$ observed. Then, with the direction of ship's head whilst being built as a course, and $\mathrm{C}$ in departure column (in the Traverse Table), the required B will be found in the latitude column. This is the amount to be compensated by the fore-and-aft magnet, and the balance of observed B with the Flinders bar, either before or abaft the compass as required.

Effect of Magnetic Forces on Different Compasses.-It may be remarked that although the same coefficients of magnetic forces in a ship disturb both steering and standard compasses, yet the measure of the coefficients as shown by the deviations will not be the same for both, because the forces act at different distances. 
Consequently, observations and corrections must be made for each compass separately.

It is explained in the answer to Question 63 how this can be done for several compasses simultaneously.

Compensation good for all Latitudes.-If the compensations are properly made when a ship is ready for sea, they should stand good for all latitudes, provided the sub-permanent magnetism does not change, for on this supposition the strength of the magnets and the coefficients of sub-permanent magnetism would always be in the same relation to each other, and no deviation would occur, although the directive power of the needle varies with change of latitude, whilst the horizontal force of transient induced magnetism and of the correctors would also remain in the same relation to each other.

Changes in Deviation.-But however carefully a compass may be compensated, changes may be expected with the lapse of time, and as these changes will be chiefly in the deviation due to sub-permanent magnetism, a readjustment of the magnets will be necessary from time to time. The effect of the vibration caused by the propeller, the buffeting of heavy seas, collisions, or stranding is to :considerably modify the magnetic condition of the ship when she left the builder's hands.

Retained Magnetism.-Another troublesome cause of change of deviation is what is called retained magnetism; that is, if a ship remains for a considerable time in one position in dock or on the same course at sea for several days, the induced magnetism from the earth is retained for a certain length of time, and causes a deviation when the course is altered. In sailor's language, the ship tends to follow her last course. For example, a steamer in crossing the Atlantic, bound for Liverpool, lays on an easterly course for several days together, and when on rounding Tuskar her course is changed to the northward, the retained red polarity on the port side (and blue on the starboard side) causes an $\mathrm{E}$. deviation, which tends to set her to the eastward of her proper course. To this cause is owing, no doubt, the fact that steamers from the westward, coming up Channel in thick weather, are apt to be found too near the Welsh coast, and steamers from the south, bound up the English Channel, too near the English coast.

ART. 127. Uncompensated Compasses.-An uncompensated compass having large deviations on some courses and very small deviations on others is very unsatisfactory for steering purposes, for two reasons :-

(1) The deviation will be subject to greater changes, because when a ship approaches the magnetic equator the directive force of the needle increases, and therefore the coefficients of subpermanent magnetism, which are assumed to remain nearly 
constant, will cause less deviation. On receding from the magnetic equator, the deviation would increase for the same reasons.

(2) The directive tendency of the needle would be much increased when a strong blue magnetism in the ship is towards the north from the compass, and correspondingly decreased when red is towards the north. The consequence would be that in some directions a considerable change of course would show only a small change in the compass course, and in other directions a small change of course would appear a large one by compass.

Horizontal Iron and Uncompensated Compass.-The deviation caused by horizontal iron would not be subject to these changes, because the horizontal component of transient induced force would vary in the same ratio as the directive force of the needle.

Diminution of Directive Force.-In an ordinary iron ship, the directive force is rarely more than six-sevenths of what it would be in a wooden ship or on shore, and in armoured war-ships not more than three-fourths, according to Captain Creak, R.N., who has had very large experience of such matters. The chief cause of this is the horizontal iron, for in most cases it has a red polarity to the north of the compass. Sub-permanent magnetism weakens the directive force on some courses, but strengthens it on others, according as a red pole is north or south of the compass, and so the mean effect all round is nil. These remarks apply to uncompensated compasses.

The consequence of a diminution of directive force is greater deviations, for the forces which cause deviation are acting on a weakened compass.

The object aimed at by compensating a compass is to secure a uniform directive force on all courses, so that if any deviations remain they will be small in amount and regular in their changes.

ART. 128. Heeling Error.-So far it has been assumed that the ship is upright, but when she has a list from the pressure of the wind, or shifting of cargo, or unequal trimming of bunker coals, further deviations-sometimes very large, and known as heeling error-occur on northerly and southerly courses, but disappear on east and west courses.

The Cause of Heeling Error.- (a) It has been already explained that there is a vertical component of sub-permanent magnetism as well as a horizontal. The upper pole of this force, nearest to the steering compass aft, is blue if the ship is built head north (Fig. 209), and red if built head south (Fig. 210), and so long as the ship is upright, it only tends to attract the $\mathbf{N}$. point of the needle downwards or repel it upwards, according as the upper pole is blue or red, without causing any deviation. The case is different when the ship heels, for then this upper pole is no longer in the vertical plane passing through the centre of the compass, but 
towards the higher side, deviating the $\mathrm{N}$. point of the compass towards the higher or lower side. This effect is evidently

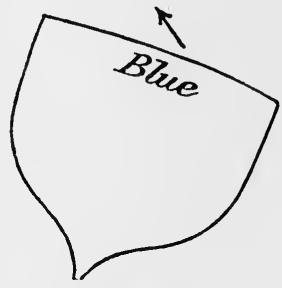

Fra. 209.

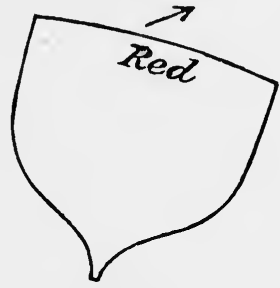

Fia. 210.

greatest on N. and S. courses, and nil on E. and W. courses, because in the former case the force acts at right angles to the needle, and in the latter case in the plane of the magnetic meridian.

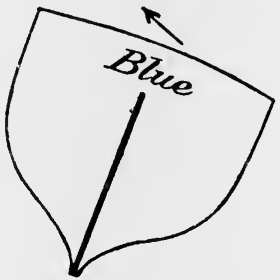

Fia. 211.

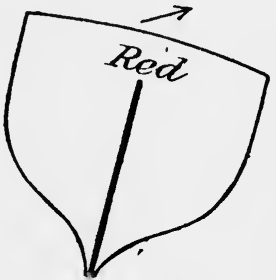

Fig. 212.

(b) The upper pole of vertical iron below the compass affects the compass in exactly the same way as the sub-permanent pole when the ship heels, only it must be remembered that vertical iron has the blue pole uppermost only in N. magnetic latitude, and red pole uppermost in S. magnetic latitude, being neutral on the magnetic equator. Therefore the heeling error from this cause decreases on sailing towards the magnetic equator, and. vice versâ.

(c) The athwartship iron, which gives coefficient D when the ship is upright, acquires a vertical component when she heels, which is of the same nature as the magnetism of vertical iron, and is subject to the same changes-the higher end being blue in $\mathrm{N}$. magnetic latitude, and red in $\mathrm{S}$. magnetic latitude.

It is evident that in some cases these three causes of heeling error would act together, and the heeling error would be large. In other cases the first would be opposed to the other two, and they would tend to neutralize each other, and give a small heeling error.

Their combined forces might be represented by a single force 
acting vertically under the centre of the compass, which would therefore be the resultant of-

(1) The vertical component of sub-permanent magnetism.

(2) The induced magnetism of vertical soft iron.

(3) The vertical component of the induced magnetism of transverse beams.

This resultant force is called + if the balance on the side of the greater is blue uppermost, and - if red. The total effect may be summed up by saying that a + vertical force causes a heeling error towards the higher side, and a - force a heeling error towards the lovver side (Figs. 213 and 214).

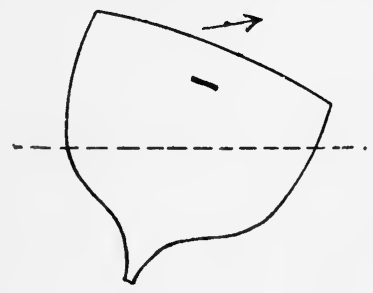

FiG. 213.

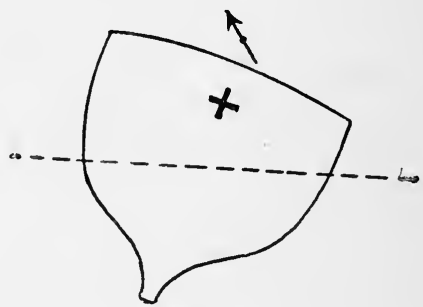

Fig. 214.

Experience shows that in the majority of sailing ships the force below the compass is + in N. latitude and - in S. latitude, with the result that $\mathrm{N}$. of the magnetic equator the ship is drawn to windward on northerly courses, and to leeward on southerly courses. South of the magnetic equator the rule would generally be reversed. The same rules apply to steam ships, if "higher side" is substituted for "windward," etc.

Navigators make a practical application of these facts by keeping "away" on northerly courses, and "closer" on southerly courses, when north of the magnetic equator, and the reverse when south of it.

Since the vertical force draws the $N$. point of the compass to one side or the other when the ship heels, it is called a coefficient $\mathrm{C}$, although it would be more logical to distinguish it in some way from the coefficient $\mathrm{C}$ already discussed, due to horizontal force, say by using $\mathrm{C}_{1}$ to represent it. ${ }^{1}$

Like coefficient $\mathrm{C}$ of horizontal sub-permanent force, the new coefficient $\mathrm{C}_{1}$ causes no deviation (heeling error) when the ship's head is E. or W. (magnetic), and the greatest deviation on $\mathrm{N}$. and S. courses, because in the former case it acts in the plane of the magnetic meridian, and in the latter at right angles to the needle.

ART. 129. Compensation.-The heeling error is usually

1 For a similar reason, the part of coefficient $B$ due to vertical iron before or abaft the compass might be distinguished as $B_{1}$. 
compensated by means of one or more magnets placed vertically under the compass, and capable of being moved up or down. There are two modes of procedure :-

(1) The ship's head being at N. or S. magnetic, she is caused to heel, say about $10^{\circ}$, and the error observed. Then the magnet is placed in position, and moved up or down, until the compass points correct magnetic $\mathrm{N}$.

(2) The card having been removed, and the ship upright, with her head E. or W. magnetic, a dipping needle, weighted so as to lie horizontal when in the plane of the magnetic meridian on shore, is placed on the pillar in the centre of the bowl, and lying $\mathrm{N}$. and S. Should the red end dip, showing a blue force below the compass, the red pole of the vertical magnet should be uppermost, and vice versâ, being moved up or down until the needle is again horizontal.

In either of these methods, what has been done is to counteract the force below the compass by a force of opposite name; by observation of the heeling error in the first case, and in the second case by observing the vertical action of the force below the compass on the dipping needle.

In a compensated compass the vertical force of the athwartship iron (producing coefficient D) is counterbalanced for moderate angles of heeling by a vertical force developed in the correctors; which leaves only the effects of vertical iron and the sub-permanent magnetism to be dealt with.

The Flinders bar increases the heeling error, for its upper pole is of the same name as that of the vertical iron it is intended to counteract when the ship is upright. Therefore the compensating magnet has to neutralize the combined vertical forces of sub-permanent magnetism, vertical iron, and Flinders bar. But as the two latter change with change of latitude, it is evident that this mode of compensation is effective only so long as the ship remains in the same latitude, and constant shifting of the magnet would be necessary as the ship proceeds north or south, and probably a reversal of the poles on the other side of the magnetic equator.

The only efficient compensation would be to use the magnet for the part due to sub-permanent magnetism only, and a vertical soft iron bar, having its lower end above the compass, to counteract the vertical force of soft iron below the compass. Some arrangement might possibly be made for the purpose in the construction of the binnacle.

It will now be understood that the principle of compensation is to counteract the existing magnetic forces in a ship by employing counter equal forces of the same kind, to act on the compass needles.

The order of procedure recommended in the "Elementary 
Manual " for ships of the Royal Navy, where the conditions are pretty constant, is-

1st. Coefficient D.

2nd. Heeling error.

3rd. Coefficients B and C.

But in the Merchant Service, where cargoes change every trip, and where the compensation is often hurriedly made when ready for sea, the "Tentative Method" of adjustment is usually carried out in the following order :-

1. Coefficient $\mathrm{C}$ (athwartship magnet).

2. Coefficient B. (1) Flinders bar, and (2) fore-and-aft magnet.

3. Coefficient D (soft-iron correctors).

4. Heeling error (vertical magnet).

Coefficient $\mathrm{E}$ is rarely compensated, although a counter $\mathrm{E}$ could be introduced by moving one of the D correctors forward, and the other a little aft. For $+\mathrm{E}$ the starboard corrector should be moved aft, and the port one as much forward; for $-\mathrm{E}$, the reverse.

A table of the remaining deviations is obtained by "swinging" the ship in dock or other convenient place.

Yet, however accurately the compensation may be made, changes in the deviation, from causes already explained, will occur during a voyage, and no careful navigator will place much reliance on "deviation cards." In fact, nothing can relieve him from the obligation to find the deviation from frequent observations, which is now happily made easy by Azimuth Tables. 


\title{
CHAPTER XXIX.
}

\author{
SYLLABUS.
}

\section{Questions on Deviation of the Compass for Ordinary Masters.}

THE applicant is to answer correctly at least 12 of such of the following questions as are marked with a cross by the examiner.

The examiner's attention is specially called to the importance of questions $11,12,13,14$, and 39 , which must be marked in all cases.

1. State briefly the essentials of an efficient compass.

2. State briefly the chief points to be considered when selecting a position for your compass on board ship, and what should be particularly guarded against.

3. What do you mean by deviation of the compass; and how is it caused?

4. Describe how you would determine the deviation of your compass : (1) by reciprocal bearings ; (2) by figures on the dock walls ; (3) by bearings of a distant object; (4) by the bearings of the sun or other celestial body.

5. Having determined the deviation with the ship's head on the various points of the compass, how do you know when it is easterly and when westerly?

6. Why is it necessary, in order to ascertain the deviations, to bring the ship's head in more than one direction?

7. For accuracy, what is the least number of points to which the ship's head should be brought for constructing a curve or table of deviations?

8. How would you find the deviation when sailing along a well-known coast?

9. Name some suitable objects by which you could readily obtain the deviation of the compass when sailing along the coasts of the Channel you have been accustomed to use.

10. Supposing you have no means of ascertaining the magnetic bearing of a distant object when swinging your ship for deviations, how could you find it approximately from equidistant compass bearings ; and at what distance, as a rule, should the object be from the ship?

11. Having taken the following compass bearings of a distant object, find the object's magnetic bearing, and thence the deviation.

Magnetic bearing required :-

\begin{tabular}{|c|c|c|c|c|c|}
\hline $\begin{array}{l}\text { Ship's head by } \\
\text { standard } \\
\text { compass. }\end{array}$ & $\begin{array}{l}\text { Bearing of distant } \\
\text { object by standard } \\
\text { compass. }\end{array}$ & $\begin{array}{l}\text { Deviation } \\
\text { required. }\end{array}$ & $\begin{array}{l}\text { Ship's head by } \\
\text { standard } \\
\text { compass. }\end{array}$ & $\begin{array}{l}\text { Bearing of distant } \\
\text { object by standard } \\
\text { compass. }\end{array}$ & $\begin{array}{l}\text { Deviation } \\
\text { required. }\end{array}$ \\
\hline $\begin{array}{l}\text { N. } \\
\text { N.E. } \\
\text { E. } \\
\text { S.E. }\end{array}$ & $\begin{array}{l}\text { S. } 4^{\circ} \mathrm{E} . \\
\text { S. } \\
\text { S. } 4^{\circ} \mathrm{W} . \\
\text { S. } 1^{\circ} \mathrm{W} .\end{array}$ & & $\begin{array}{l}\text { S. } \\
\text { S.W. } \\
\text { W. } \\
\text { N.W. }\end{array}$ & $\begin{array}{l}\text { S. } 13^{\circ} \mathrm{E} \text {. } \\
\text { S. } 23^{\circ} \mathrm{E} . \\
\text { S. } 21^{\circ} \mathrm{E} \text {. } \\
\text { S. } 11^{\circ} \mathrm{E} .\end{array}$ & \\
\hline
\end{tabular}


12. With the deviation as above, construct a curve of deviations on a Napier's diagram, and give the courses you would steer by the standard compass to make the following courses, correct magnetic :-
Magnetic courses : S.S.W
Compass courses required.
W.N.W. N.N.E. E.N.E. S.S.E.

13. Supposing you have steered the following courses by the standard compass, find the correct magnetic courses made from the above curve of deviations :-

Compass courses : W.S.W. N.N.W. E.N.E. S.S.E.

Magnetic courses required.

14. You have taken the following bearings of two distant objects by your standard compass as above; with the ship's head at W. $\frac{1}{2} \mathrm{~S}$., find the bearings, correct magnetic :-

Compass bearings : W. by S. and N. $\frac{3}{4}$ W.

Magnetic bearings required.

15. Do you expect the deviation to change? If so, state under what circumstances.

16. How often is it desirable to test the accuracy of your table of deviations?

17. What is meant by variation of the compass? What is it caused by ? And where can you find the variation for any given position?

18. The earth being regarded as a magnet, which is usually termed the blue, and which the red magnetic pole?

19. Which end of a magnet (or compass needle) is usually termed the red or "marked" end, and which the blue?

20. What effect has the pole of one magnet of either name on the poles of another magnet?

21. What is meant by transient induced magnetism ?

22. Which is the red and which is the blue pole of a mass of soft vertical iron, by induction, and what effect would the upper and lower ends of it have on the compass needle $(a)$ in the northern hemisphere, $(b)$ in the southern hemisphere, $(c)$ on the magnetic equator?

23. Describe what is usually termed the sub-permanent ${ }^{1}$ magnetism of an iron ship, and state when and how it is acquired, and which is the red and which is the blue pole, and why it is called sub-permanent magnetism.

24. Describe the meaning of the expression "coefficient A."

25. Describe the meaning of the expression " coefficient $B$," its signs and effects.

26. Describe the meaning of the expression "coefficient $C$," its signs and effects.

27. Describe the meaning of the expression "coefficient D," its signs and effects.

28. Describe the meaning of the expression "coefficient $\mathrm{E}$," its signs and effects.

29. Would you expect any change to be caused in the error of your compass by the ship' heeling over either from the effect of the wind or the cargo, etc. ?

30. The compasses of iron ships being more or less affected by what is termed the heeling error, on what courses is this error usually at its minimum, and on what courses at its maximum?

1 The term sub-permanent magnetism in these questions is used in the original ense as proposed by the late Sir G. B. Airy, to denote the character of the permanent magnetism of an iron ship as distinguished from the permanent magnetism of a magnetized steel bar. The terms "sub-permanent" and "permanent" throughout these questions may, therefore, be considered as synonymous. 
31. Describe clearly the three principal causes of the heeling error on board ship.

32. State to which side of the ship in the majority of cases is the north point of the compass drawn when the ship heels over in the northern hemisphere.

33. Under what conditions (that is, as regards position of ship whilst building, and the arrangement of iron in the ship) is the north point of the compass needle usually drawn to windward or the high side of the ship in the northern hemisphere; and if not allowed for, what effect has it on the assumed position of the ship when she is steering on northerly, also on southerly courses, in the northern hemisphere?

34. Under what conditions (as in Question 33) is the north point of the compass needle usually drawn to leeward or the low side of the ship in the northern hemisphere; and, if not allowed for, what effect would it have on the assumed position of the ship, when she is steering on northerly, also on southerly courses, in the northern hemisphere?

35. The effects being as you state, on what courses would you keep away, and on what courses would you keep closer to the wind in the northern hemisphere in order to make good a given compass course $(a)$ when north point of compass is drawn to windward or the high side of ship; and (b) when drawn to leeward or the low side?

36. Does the same rule hold good in both hemispheres with regard to the heeling error?

37. State clearly how that part of the heeling error due to the permanent part of the magnetism of the ship varies as the ship changes her position on the globe; and what is the reason of this.

38. State clearly how that part of the heeling error due to the induction in transverse iron (which was horizontal when ship was upright) and iron vertical to the ship's deck, varies as the ship changes her position on the globe.

39. Your steering compass having a large error, show by "Beall's Compass Deviascope" how you would correct it by compensating magnets and soft iron (as usually practised by compass adjusters in the Mercantile Marine) in order to reduce the error within manageable limits. Show also how the heeling error can be compensated.

40. As the coefficient B (capable of being corrected) usually consists of two parts, one due to the permanent magnetism of the ship, and the other to vertical induction in soft iron, how should each of the two parts, strictly speaking, be corrected when compensating the compass?

41. If the whole of coefficient $B$ be corrected by a permanent magnet, as is usually done, what is likely to ensue as the ship changes her magnetic latitude?

42. Provided the needles of your compass are not so long and powerful, and so near, as to cause the soft-iron correctors to become magnetized by induction, would the coefficient $\mathrm{D}$, if properly compensated, be likely to remain so in all magnetic latitudes and both hemispheres? If so, state the reason why.

43. State at what distance, as a general rule, the magnets and soft-iron correctors should be placed from the compass needles, and what will be the consequence if they are placed too near the needles.

44. Is it necessary that the magnets used for compensating coefficients $B$ and $\mathrm{C}$ should be placed on the deck? If not, state where they may also be placed, and the rules to be observed in placing them into position.

45. Can the compensation of the heeling error be depended upon when the ship changes her latitude? If not, state the reason. 


\section{Answeas to the Questions on Deviation of the Compass.}

1. The card should be light, accurately centred and divided, and the needles well magnetized, the magnetic axis coinciding with the $N$. and $S$. points of the card. The cap should be sound, and the pivot sharp and smooth. The point of the pivot should be level with the gimbals. The bowl should be of copper, and the mounting should not allow of any lateral play.

2. The standard compass should be in the midship line, and should afford a clear view all round for taking bearings, and not less than five feet from iron of any kind, especially vertical iron and any iron which is likely to change its position, such as derricks, cowls, davits, etc. Also as far as possible from a dynamo, if electric lighting is used. Steering compasses should be so placed that the card can be well seen by the steersman, and should be as far removed as possible from the influence of iron.

3. Deviation is the amount of deflection of the $N$. point of a compass from the correct magnetic $N$. caused by the magnetic influence of iron in the ship, whether in hull, equipment, or cargo.

4. (1) By reciprocal bearings: An observer is stationed at a compass on shore in a position free from local attraction, and another observer at the standard compass on board. Then, as the ship is swung round, bearings are taken of each compass by the other observer at the same time, whilst the ship's head is steadied on the required points. The difference between the bearing observed on board and the reversed shore bearing is the deviation. (2) By figures on the dock wall: These figures at Liverpool show the true bearings of the Vauxhall Chimney from the river, so that the figure in a line with the chimney as seen from the ship shows its true bearing from the observer's position. The difference between this and the bearing by the standard compass is the total error, from which the variation may be separated, and the result is the deviation. (3) By bearings of a distant object : When the correct magnetic bearing of a distant object is known, the difference between the bearing of it by compass on board, and the correct magnetic is the deviation. (4) By the bearings of a celestial object: The true azimuth of the object being found for a given moment, either by calculation or by tables, the bearing of the object at the same time is taken by compass ; the difference shows the error of compass for the actual position of ship's head, and the variation being known, the deviation may be found.

5. If the correct magnetic bearing reads to the right of the.compass bearing, the deviation is east; if to the left, it is west.

6. Because the deviation changes with every change of course.

7. Eight equidistant points, viz. N., N.E., E., S.E., S., S.W., W., N.W.

8. By comparing the bearing of two known objects when in one (or in line) with the known correct magnetic direction of one from the other obtained from a chart.

9. (a) English Channel : Bolt Head and Start Lighthouse, Prawle Point and Start Point, etc., (b) Irish Channel : Skerries and South Stack, Smalls and Bishop Lights, Wolf anc Longship. (c) North Sea: South Foreland Lights, Whitby Lights, and Tyne Harbour Lights.

10. The ship's head should be steadied on eight equidistant points in succession, and the bearing of a distant object observed when on each point. The mean of these may be taken as the correct magnetic. The object should be seven or eight miles distant, so that its bearing would not be sensibly affected by the swinging of the ship.

$11,12,13$, and 14 are practical.

15. Yes, the deviation may be expected to change: (a) From lapse of time; $(b)$ By keeping the ship's head for a considerable time in an opposite 
direction to that in which she was built; (c) By change of latitude ; $(d) \mathrm{By}$ shocks or strains from heavy seas ; (e) By being kept for a long time on one course, magnetism is induced which is retained on a change of course.

16. The deviation table should be tested at every opportunity.

17. Variation is the difference in direction between the magnetic north and true north, and is due to the fact that the earth's magnetic poles do not coincide with its geographical poles. The amount, together with the annual change, may be found on a magnetic chart.

18. The earth's north magnetic pole is the blue pole, and the south the red.

19. The end of a magnetized needle, freely suspended, which points north is the red pole, and the other the blue pole.

20. Poles of the same name repel each other, and poles of different names attract each other.

21. Transient induced magnetism is the magnetic condition of soft iron caused by the influence of a magnetic force in its neighbourhood or that of the earth itself.

22. North of the magnetic equator the upper end is the blue pole and the lower the red, but south of the magnetic equator this rule is reversed. (a) In the northern hemisphere the upper end would attract the north end of the compass needle, and the lower end repel it. (b) In the southern hemisphere the upper end would repel and the lower attract the north end of the needle. (c) On the magnetic equator the effect would be nil.

23. The sub-permanent magnetism of an iron ship is the magnetic condition of a more or less enduring character which she has when she is launched. It is acquired in the course of building, from the earth's inductive influence, aided by the vibration due to hammering, riveting, etc. The red pole is that which was towards the north, and the blue towards the south when the ship was on the stocks. It is called sub-permanent magnetism to distinguish it from the magnetism of a tempered steel bar, and because it is liable to be weakened or modified by circumstances and by lapse of time.

24. Coefficient $A$ is a deviation of the same amount and sign on all courses, usually due to a faulty or badly placed compass.

25. Coefficient $B$ represents a horizontal magnetic force, whose poles are in the fore-and-aft midship line. It is called $+B$ when the blue pole is towards the bow, and $-\mathrm{B}$ when towards the stern. $+\mathrm{B}$ causes $\mathrm{E}$. deviation on easterly courses, and W. deviation on westerly courses. -B causes W. deviation on easterly courses, and E. deviation on westerly courses. The effect is nil on $\mathbf{N}$. and S. courses, and greatest on $\mathbf{E}$. and W. courses.

26. Coefficient $\mathbf{C}$ represents a horizontal magnetic force, whose poles are in a line at right angles to the fore-and-aft midship line. It is called $+C$ when the blue pole is towards the starboard side, and $-\mathrm{C}$ when towards the port side. +C causes $\mathbf{E}$. deviation on northerly courses, and W. deviation on southerly courses. $-C$ causes $W$. deviation on northerly courses, and E. deviation on southerly courses. The effect is nil on E. and W. courses, and greatest on $\mathrm{N}$. and $\mathrm{S}$. courses.

27. Coefficient D represents the effect of transient induced magnetism in horizontal iron in fore-and-aft and athwartship directions. The deviation due to this cause changes its name in successive quadrants, and is thence called quadrantal. $+\mathrm{D}$ causes $\mathbf{E}$. deviation from $\mathrm{N}$. to $\mathrm{E}$. and $\mathrm{S}$. to $\mathrm{W}$. courses, and W. deviation from S. to $E$. and $N$. to $W$. $-D$ gives W. deviation from $\mathbf{N}$. to $\mathbf{E}$. and $\mathrm{S}$. to W. courses, and $\mathbf{E}$. deviation from $\mathbf{S}$. to $\mathbf{E}$. and $\mathrm{N}$. to IV. The deviation due to this cause is nil on the cardinal points and greatest on N.E., S.E., S.W., and N.W.

28. Coefficient $\mathbf{E}$ represents the effect on the compasses of induced magnetism in horizontal iron lying in a direction oblique to the fore-and-aft line. The deviation due to this cause is quadrantal, and is nil on N.E., S.E., S.IV., and N.W., and greatest on the cardinal points. +E gives $\mathbf{E}$. deviation 
from N.W. to N.E. and S.E. to S.W., and W. deviation from N.E. to S.E. and S.W. to N.W. - E gives W. deviation from N.W. to N.E. and S.E. to S.W., and E. deviation from N.E. to S.E. and S.W. to N.W.

29. Yes, because when the ship heels, horizontal athwartship iron acquires a vertical component, and besides, the upper poles of vertical iron and the poles of sub-permanent magnetism will then not be in the same vertical plane with the centre of the compass.

30. The heeling error is usually greatest on $\mathrm{N}$. and $\mathrm{S}$. courses, and least on E. and W. courses, because in the former case the force causing it acts at right angles to the compass needle, and in the latter case coincides with the direction of the needle.

31. The three principal causes of heeling error are : (1) Traverse iron acquires a vertical component. (2) The upper induced poles of vertical iron will not be in the same vertical plane with the centre of the compass. (3) The poles of the fore-and-aft component of the ship's sub-permanent magnetism fall to the right or left of the vertical plane, through the centre of the compass.

32. In the $\mathrm{N}$. hemisphere the $\mathrm{N}$. point is usually drawn towards the higher side.

33. In ships built with head northerly, compass aft, placed over continuous athwartship iron, the $N$. point of a steering compass will be attracted towards the higher side, and, if not allowed for, will draw the ship to windward on northerly courses, and to leeward on southerly courses.

34. In ships built with head towards south, with compass aft, placed over divided athwartship iron, the effect of the sub-permanent magnetism and soft iron would be to draw the $\mathrm{N}$. point of the compass to leeward, and if these exceeded the influence of the vertical soft iron, the $\mathrm{N}$. point of the compass would be drawn towards the lower side. If not allowed for, it would take the ship to leeward on northerly courses, and to windward on southerly courses.

35. (a) When the $\mathrm{N}$. point is drawn to windward, I would keep away on northerly courses, and closer to the wind on southerly courses. (b) When the N. point is drawn to leeward, I would keep closer to the wind on northerly courses, and keep away on southerly courses.

36. The rule for the northern hemisphere is generally reversed in the southern, especially in ships built heading south, for the poles of vertical induction are reversed, but in ships built heading north, the same rule may still obtain, that is, when the sub-permanent vertical force exceeds the induced.

37. It decreases on approaching the magnetic equator, and increases on receding from it, because the directive force of the compass changes as the magnetic latitude changes, being greatest at the magnetic equator and nil at the magnetic poles, whilst the sub-permanent magnetism of the ship is nearly constant.

38. The induced vertical force becomes weaker on approaching the magnetic equator, is nil at the equator and the poles are reversed on crossing it. Therefore the part of the heeling error due to this cause, drawing the $N$. point to windward in north mag. lat., disappears at the magnetic equator, and repels the $\mathrm{N}$. point to leeward in $\mathrm{S}$. mag. lat.

39. Practical.

40. The part of coefficient $B$ due to the sub-permanent magnetism should be compensated by means of a magnet, and the part due to vertical induction in soft iron by an upright bar of soft iron before or abaft the compass in the midship line.

41. It will be found to be over-compensated or under-compensated as the ship changes her mag. lat., for the part caused by vertical induction changes with change of latitude.

42. Yes, because the horizontal inductive force of the correctors will vary in the same ratio as that of the horizontal iron which produces coefficient $D$. 
in the same ratio as that of the horizontal iron which produces coefficient D.

43. The magnets used for compensating should not be nearer the centre of compass than twice their own length, and the soft-iron correctors should not be nearer than $1 \frac{1}{4}$ times the length of the needles. If the magnets are too near, the compensation which was made with the ship's head on the cardinal points would not be perfect on other points. If the soft-iron correctors are too near, the poles of the compass needles would have a tendency to induce opposite polarity in the correctors, rendering them useless.

44. The magnets used for compensating $\mathbf{B}$ and $\mathbf{C}$ need not be on the deck, but may be placed in any convenient position near the compass, in or outside the binnacle, provided the following conditions are complied with : (1) The ship should be upright and on even keel. (2) The fore-and-aft magnets should be parallel to the deck, and bisected by a vertical plane athwartships, passing through the centre of the compass. (3) The athwartship magnets should be parallel to the deck, and placed so as to be bisected by a fore-andaft vertical plane passing through the centre of the compass.

45. No, because a part of the heeling error is due to vertical induction in soft iron, which varies in force as the latitude changes. This part of the heeling error cannot be compensated by means of a permanent magnet fixed in position.

\section{Questions on Deviation of the Compass for Masters (Extra).}

1. Describe an artificial magnet, and how a steel bar or needle is usually magnetized.

2. Which end of the compass needle, or a magnet, is commonly termed the red, and which the blue pole?

3. Which is the red magnetic pole of the earth, and which the blue ? and give their geographical positions.

4. What effect has the pole of one magnet of either name on the pole of the same name of another magnet? and what would be the consequence of the pole of one magnet of either name being brought near enough to affect the pole of contrary name, if in these cases both magnets were freely suspended?

5. By applying this law to all magnets, natural as well as artificial, describe what would be the result on a magnetic bar or needle, freely suspended, but by weight or by the nature of its mounting constrained to preserve a horizontal position; and what would be the result, if so mounted, but free to move in erery direction, the earth being regarded as a natural magnet.

6. What is the cause of the variation of the compass?

7. What is meant by the deviation of the compass?

8. What is meant by the term "local attraction"? under what circumstances have ships' compasses, from recent careful investigation, been found to be affected by it? and name some of the localities in different parts of the world where this disturbance is to be found, and consequently where increased vigilance is nocessary (see page 22, "Creak's Elementary Manual," 1908).

9. What do you understand by the term "soft" iron; and what are its properties as regards acquiring and retaining magnetism?

10. What do you understand by the term "hard" iron; and what are its properties as regards acquiring and retaining magnetism?

11. Describe the meaning of the term "horizontal force" of the earth ; where is it the greatest, and where the least, and what effect has it in respect to the increase or decrease of the directive force of the compass needle?

12. Does the magnetic equator coincide with the geographical equator? if not, state clearly how it is situated. 
13. Where can the values of the magnetic dip, the earth's horizontal force, and the variation, be found?

14. State in what parts of the globe lying in the usual tracks of navigation the variation changes very rapidly, and what special precautions should be observed when navigating these localities; also why a "variation" chart is then very useful.

15. Why is a knowledge of the magnetic dip and the earth's horizontal force important in dealing with compass deviations?

16. Describe the meaning of the term "vertical force" of the earth; where is it the greatest, and where the least?

17. Would you expect a compass to be the more seriously affected by any given disturbing force when near the magnetic equator, or near the poles? and state the reason.

18. State briefly (a) the essentials of an efficient compass; and (b) what you would consider a good arrangement of the needles (that is, whether long or short, single or double, etc.) with the view to good compensation.

19. In stowing away spare compass cards or magnets, how would you place them with regard to each other, or what might be the probable consequence?

20. State briefly the chief points to be considered when selecting a position for your compass on board ship, and what should be particularly guarded against.

21. What is meant by transient induced magnetism?

22. Which is the red and which the blue pole of a mass of soft vertical iron (or indeed of any soft iron not in a horizontal position) by induction ; and what effect would the upper and lower ends of it have on a compass needle in the Northern hemisphere?

23. Which is the red and which the blue pole of a mass of soft vertical iron by induction; and what effect would the upper and lower ends of it have on the compass needle in the Southern hemisphere?

24. What effect would a bar of soft vertical iron have on the compass needle on the magnetic equator?

25. Describe what is usually termed the sub-permanent ${ }^{2}$ magnetism of an iron ship, and state when and how it is acquired, and which is the subpermanent red and which is the blue pole, and why it is called sub-permanent magnetism.

26. What is meant by "the composition of forces" and "the parallelogram of forces"? and show how the knowledge of these is valuable in ascertaining and compensating the sub-permanent magnetism of an iron ship.

27. Describe the nature of the coefficients B and $\mathrm{C}$, plus $(+)$ and minus $(-)$, and the different magnetic forces they represent; also why they are said to produce semicircular deviations.

28. Can semicircular deviations be produced by any other force than the sub-permanent magnetism of the ship? If so, by what?

29. On what points, by compass bearings of the ship's head, does $+B$ give westerly deviation, and on what points does it give easterly; also on what point does - B give westerly, and on what points easterly?

30. On what points does $+\mathbf{C}$ give westerly deviation, and on what points easterly; also on what points does $-C$ give westerly, and on what points easterly deviation?

31. The value of either coefficient $\mathbf{B}$ or $\mathbf{C}$ being given, also the magnetic direction of the ship's head while she was being built, determine by the Traverse Tables the approximate value of the other coefficient $\mathbf{C}$ or B ; and, 
the value of both these coefficients being given, determine approximately the direction by compass of the ship's head whilst being built, assuming, of course, that these coefficients resulted altogether from sub-permanent magnetism.

32. Would you expect the greatest disturbance of the needle from the effects of sub-permanent magnetism alone to take place when ship's head is in same direction as when building, or when her head is at right angles to that direction, and in what direction of the ship's head would you expect to find the least disturbance?

33. Describe quadrantal deviation, and state what coefficients represent it; also on what points of the ship's head, by compass, each of these coefficients gives the greatest amount of deviation, and why it is called quadrantal deviation.

34. On what points of the compass will each of the coefficients $D$ and $\mathrm{E},+$ and - give easterly, and on what points westerly, deviation?

35. What conditions of the iron of a ship will produce $+D$, and what $-\mathrm{D}$ ?

36. State clearly, then, which end of the horizontal iron running athwartship (such as beams, etc.), and of horizontal iron running fore and aft of a ship, acquires red and which blue polarity, by induction, when ship's head is at N.E., S.E., S.W., and N.W. respectively.

37. Describe the nature of the deviation represented by coefficients $+A$ and $-\mathbf{A}$, and describe the errors in the construction of the compass, and other causes, that frequently produce it.

38. What is the object of compensating the compass by magnets, etc.; and what are the general advantages of a compensated compass over an uncompensated one?

39. Before adjusting the compass of an iron ship, what is it desirable to do with the view to eliminating, as far as possible, what may be termed the unstable part of the magnetism of the ship?

40. Describe clearly the tentative method of compass adjustment (that is, the compensation of coefficients B, C, and D, with ship upright) as generally practised by compass adjusters in ships of the Mercantile Marine.

41. State at what distance, as a general rule, the magnets and soft-iron correctors should be placed from the compass needles, and what will be the consequence if they are placed too near the needles.

42. Is it necessary that the magnets used for compensating coefficients $\mathrm{B}$ and $\mathrm{C}$ should be placed on the deck? If not, state where they may also be placed, and the rules to be observed in placing them into position.

43. Does the B found on board ship usually arise altogether from subpermanent magnetism, or does part of it usually arise from some other cause or causes?

44. If the part of $B$ due to induced magnetism in vertical soft iron, as well as the part due to sub-permanent magnetism, are corrected by a magnet alone, as is generally the case, what is frequently the consequence on the ship changing her magnetic latitude and hemisphere?

45. How should each of these two parts of B then, strictly speaking, be compensated?

46. Assuming, for the sake of clearness, that your steering compass is unavoidably placed very near to the head of the stern-post (and other vertical iron at the stern), thereby causing a very large - B from induced magnetism, describe briefly any method by which the approximate position for the compensating vertical iron bar (Flinders' or Rundell's) could be estimated in order to reduce the error; describe also how you would proceed, in order to improve, if not to perfect, its position after observations have been made on the magnetic equator.

47. State if standard compasses, as well as steering compasses, are 
generally subject to this disturbance from induced magnetism in vertical iron; also whether the attraction in all cases is found to be towards the stern; and if not, state the conditions under which it might be toward the bow, and how the compensating soft-iron bar should then be placed.

48. Generally speaking, does the magnetism induced in vertical iron usually have any effect in producing the coefficient $\mathbf{C}$ (ship upright), or is it generally produced by sub-permanent magnetism alone? State also your reasons for saying so.

49. Provided the needles of your compass are not so long and powerful, and so near, as to cause the soft-iron correctors to become magnetized by induction, would the coefficient $D$, if properly compensated as you have described (Ans. 40), be likely to remain so in all latitudes and both hemispheres? If so, state the reason why.

50. Under what circumstances does the character of $\mathbf{A}$ and $\mathbf{E}$ so change as to render it desirable that these coefficients should be disregarded or modified?

51. Supposing your compasses were allowed to remain uncompensated, explain clearly what would be the probable changes (ship upright) in the deviations produced separately by (1) the sub-permanent magnetism of the ship alone, (2) by the induced magnetism in vertical soft iron, $(a)$ on reaching the equator, $(b)$ in the southern hemisphere.

52. Assuming you were able to arrive at the proper proportions to be corrected, and were then to exactly compensate the sub-permanent magnetism of the ship by means of a permanent magnet, and the induced magnetism in vertical iron by a soft-iron bar, would you expect any deviation to take place in your compass as the ship changed her latitude and hemisphere? And state your reasons for saying so.

53. Supposing the coefficient D from horizontal soft iron were allowed to remain uncompensated, would you, or would you not, expect the $D$ to differ in name or amount on the ship changing her magnetic latitude, and hemisphere? And state the reason.

54. Describe how you would determine the deviation of your compass, (1) by reciprocal bearings, (2) by figures on the dock walls, (3) by bearings of a distant object.

55. Describe, in detail, how you would determine the deviation of your compass by the bearings of the Sun. Also by a star or planet.

56. Describe the uses to which the Napier's diagram can be applied, and its special advantages.

57. Describe clearly how the Napier's diagram is constructed.

58. For accuracy, what is the least number of points to which the ship's head should be brought for constructing a complete curve of deviations, or a complete table of deviations ?

59. Nearing land, and being anxious to check your deviations on a few courses you may probably require to steer, what is the least number of points it would be necessary to steady the ship's head upon, if making use of a Napier's diagram, in order to ascertain the deviation on each of the points, say, in a quadrant of the compass? and describe clearly how you would do this at sea.

60. Supposing you have no means of ascertaining the magnetic bearing of the distant object when swinging your ship for deviations, how could you find it, approximately, from equidistant compass bearings; and how far, as a rule, should the object be from the ship when swinging, or steaming round?

61. Having taken the following equidistant compass bearings of a distant object, find the object's magnetic bearings, and thence the deviations :-

(a) Magnetic bearing required- 


\begin{tabular}{|c|c|c|c|c|c|}
\hline $\begin{array}{l}\text { Ship's head by } \\
\text { standard } \\
\text { compass. }\end{array}$ & $\begin{array}{l}\text { Bearing of distant } \\
\text { object by standard } \\
\text { compass. }\end{array}$ & Deriation. & $\begin{array}{l}\text { Ship's head by } \\
\text { standard } \\
\text { compass. }\end{array}$ & $\begin{array}{c}\text { Bearing of distant } \\
\text { object by standard } \\
\text { compass. }\end{array}$ & Deviation. \\
\hline $\begin{array}{l}\text { N. } \\
\text { N.E. } \\
\text { E. } \\
\text { S.E. }\end{array}$ & $\begin{array}{l}\text { S. } 75^{\circ} \mathrm{W} . \\
\text { S. } 64^{\circ} \mathrm{W} \text {. } \\
\text { S. } 56^{\circ} \mathrm{W} \text {. } \\
\text { S. } 50^{\circ} \mathrm{W} \text {. }\end{array}$ & & $\begin{array}{l}\text { S. } \\
\text { S.W. } \\
\text { W. } \\
\text { N.W. }\end{array}$ & $\begin{array}{l}\text { S. } 34^{\circ} \mathrm{W} . \\
\text { S. } 31^{\circ} \mathrm{W} \text {. } \\
\text { S. } 49^{\circ} \mathrm{W} \text {. } \\
\text { S. } 71^{\circ} \mathrm{W} .\end{array}$ & \\
\hline
\end{tabular}

(b) Construct a curve of deviations on a Napier's diagram, with the deviations as above, and give the courses you would steer by the standard compass to make the following courses, correct magnetic :-

Magnetic courses : N.N.W. S.S.E. W.N.W. E.S.E.

Compass courses required.

(c) Supposing you have steered the following courses by the standard compass, find the correct magnetic courses made from the above curve of deviations :-

Compass courses : N.N.E. E.N.E. S.S.W. W.S.W.

Magnetic courses required.

(d) You have taken the following bearings of two distant objects by your standard compass as above; with the ship's head at N.E. $\frac{1}{2}$ E., find the bearings, correct magnetic:-

Compass bearings : S.E. by S. and N.N.W.

Magnetic bearings required.

62. Assuming the deviations observed with the ship's head by compass to be as follows (or as in Question 61, whichever may be given), determine the value of the coefficients $A, B, C, D$, and $E$, and from them construct a complete table of deviations (or for as many points as the Examiner may direct).

$$
\begin{array}{rll}
\text { Deviation at N. } & \left(21^{\circ} \mathrm{W} .\right) & \text { S. } \\
\text { N.E. }\left(10^{\circ} \mathrm{W} .\right) & \text { S.W. }\left(23^{\circ} \mathrm{E} .\right) \\
\text { E. }\left(2^{\circ} \mathrm{W} .\right) & \text { W. }\left(5^{\circ} \mathrm{E} .\right) \\
\text { S.E. }\left(4^{\circ} \mathrm{E} .\right) & \text { N.W. }\left(17^{\circ} \mathrm{W} .\right)
\end{array}
$$

63. When swinging your ship, if it be required to construct Deviation Tables for two or more compasses situated in different parts of the vessel, describe the process, and how you would employ the Napier's diagram for this purpose.

64. State your rule for determining whether deviation is easterly or westerly.

65. Is a knowledge of the value of the various coefficients of any advantage? If so, state why?

66. Describe (a) what is commonly known by the term "retentive" or "retained" magnetism, and how the ship acquires it when in port and at sea; $(b)$ its effect on the compass needle whilst ship's head continues in the same direction; (c) the immediate consequence when the direction of the ship's head is altered; and $(d)$ the special precautions to be invariably observed at sea on the alteration of the ship's course.

67. Describe a "Dumb-card" or "Pelorus," and its use $(a)$ in compensating a compass, $(b)$ in determining the deviation.

68. If you determine the deviation by an azimuth or an amplitude of a heavenly body, it is then combined with variation, which together is sometimes called the correction for the compass. State when the deviation is the difference between the variation and the correction, and when the sum; and when it is of the same name as that of the correction, and when of the contrary name. 
69. In observing azimuths of heavenly bodies, the best method is by "time azimuths," since these can be observed without an altitude when the ship is in port, or when the horizon cannot be defined from any cause. Given the Sun's declination, the hour of the day, and the latitude, to find the true bearing of the Sun.1

70. By night, if it be desirable to observe the correction of the compass. Given the day of the year, and time at ship, also the latitude of the place, to determine what stars will be in good position for this purpose.

71. If your correcting magnets are so mounted that their positions can be altered, describe the process by which, on open sea, you can place the ship's head correct magnetic $\mathrm{N}$. (or S.), and correct magnetic E. (or W.), and can make the correction perfect.

72. Given the name of a star, the time, the place of ship, the variation of the compass, and the bearing of the star by compass, determine the deviation, and name it east or west.

73. Would you expect any change to be caused in the error of your compass by the ship heeling over, either from the effect of the wind or the cargo ?

74. Describe clearly the three principal causes of the heeling error on board an iron ship?

75. Towards which side of the ship would that part of magnetism induced in continuous transverse iron (which was horizontal while ship was upright) help to draw the north point of the needle when ship heels over, $(a)$ in the northern hemisphere, $(b)$ in the southern hemisphere ?

76. Supposing the compass were placed between the two parts of a divided beam or other athwartship iron, towards which side of the ship would iron so situated help to draw the north point of the needle when ship heels over, $(a)$ in the northern hemisphere, $(b)$ in the southern hemisphere?

77. Would you expect that part of the magnetism induced in iron exactly perpendicular to the ship's deck, such as stanchions, bulkheads, etc., if below the compass, to cause any part of the heeling error when ship heels over, and if so, towards which side of the ship, (a) in the northern hemisphere, (b) in the southern hemisphere?

78. If an ordinary standard compass placed higher than the iron top sides be compensated whilst the ship is upright, what coefficient will be affected by heeling?

79. Under what conditions (that is, as regards position whilst building and the arrangement of iron in the ship) is the north point of the compass needle usually drawn to windward, or the high side of the ship, in the northern hemisphere?

80. Under what conditions, as a rule, is the north point of the compass needle usually drawn to leeward, or the low side of the ship, in the northern hemisphere?

81. State to which side of the ship, in the majority of cases, is the north point of the compass drawn when ship heels over in the northern hemisphere ; and when this is the case, and it is not allowed for, what effect has it on the assumed position of the ship when she is steering on northerly, and also on southerly courses?

82. On what courses would you keep away, and on what courses would you keep closer to the wind in both the northern and southern hemispheres in order to make good a given compass course, $(a)$ when north point of compass is drawn to windward, or the high side of ship; and $(b)$ when drawn to leeward or the low side?

1 The process of finding time azimuths by the ordinary formulm of spherical trigonometry is tedious, and since on board an iron ship these observations should be often repeated, the candidate will be allowed to use any table or graphic or linear method that will solve the problem within a half of a degree, the altitude of the heavenly body not being given. 
83. If a ship is beating to windward, when she tacks, under what circumstances will the heeling error retain the same name, and under what circumstances will it take the contrary name?

84. If a ship is placed on the opposite tack by the change of wind, the ship's course being the same by compass, will the heeling error change its name?

85. In which direction of the ship's head does the heeling error attain its maximum value, and in which direction does it generally vanish?

86. Explain clearly how that part of the heeling error due to the permanent part of the magnetism of the ship varies as the ship changes her geographical position, and what is the reason of this?

87. Explain clearly how that part of the heeling error due to the induction in transverse iron (which was horizontal when ship was upright), and iron vertical to the ship's deck, varies as the ship changes her geographical position.

88. What, then, would be the probable nature of the heeling error, that is, whether to high or low side of the ship, and whether the error would be equal to the sum or difference, etc., of the forces-(1) in high north latitudes, (2) on magnetic equator, (3) in high south latitudes? Assuming the polarity of the sub-permanent magnetism of the ship under, and affecting, the compass to be as given below; the vertical induction in soft iron, of course, obeying the ordinary laws in the above geographical positions (1), (2), (3).

(a) In cases where the effect of red vertical sub-permanent magnetism is equal to that of the vertical induction in the soft iron of the ship.

(b) Where the effect of red vertical sub-permanent magnetism is greater than that of the vertical induction in the soft iron.

(c) Where the effect of red vertical sub-permanent magnetism is less than that of the vertical induction in the soft iron.

(d) Where the effect of blue vertical sub-permanent magnetism is equal to that of the vertical induction in the soft iron.

(e) Where the effect of blue vertical sub-permanent magnetism is greater than that of the vertical induction in the soft iron.

$(f)$ Where the effect of blue vertical sub-permanent magnetism is less than that of the vertical induction in the soft iron.

89. Can the heeling error be compensated? If so, state the means to be employed, and how the compensation may be effected.

90. Can the compensation of the heeling error be depended on in every latitude? If not, state the reason.

91. Do the soft-iron correctors used for compensating the coefficient $+D$ have any effect on the compass needle when the ship heels over? and, if so, do they draw the needle torwards the low or the high side of the ship, and do they counteract, or otherwise, the effect produced by the vertical induction in the soft iron, $(a)$ in the northern hemisphere, $(b)$ in the southern hemisphere; and what is the reason of this?

92. Given the heel, the direction of the ship's head by compass, and the heeling error observed, to find the approximate heeling error, with a greater or less given heel, and with the ship's head on some other named point of the compass, the ship's magnetic latitude being in both cases the same.

93. Describe any instrument to show the ship's heel (generally called a clinometer), and state how and where it should be fixed.

94. Should the clinometer be observed when the ship is swung to determine the deviation when the ship is upright? If so, state the reason why.

95. Would you expect the Table of Deviations supplied by the compass adjuster from observations made in swinging the ship to remain good during the voyage, or would you expect the deviations to change? If so, state under what circumstances.

96. Is it desirable that a record of your observations for deviations should 
be kept as a guide for any subsequent voyage, in case the ship should be in the same locality, or for further correction of the compass? If so, describe some suitable form for keeping such record.

97. Would you, under any circumstances, consider it a safe and proper procedure to place implicit confidence in your compasses, however skilfully they may have been adjusted? If not, what precautions is it your duty to take at all times?

\section{Answers to the Questions on Compass Deviation for Masters (Extra).}

1. An artificial magnet is a bar or needle of hard-tempered steel which has been magnetized by artificial means, and so distinguished from a loadstone or natural magnet.

Artificial magnets can be made in several ways :

(a) For small needles, it is sufficient to place either pole of a strong magnet on one end of the needle and draw it in contact to the other end, where it is taken off. If the pole used is the red pole, the end of the needle last in contact with it becomes a blue pole, and the other a red pole.

(b) The method of "separate touch." The bar to be magnetized is placed with its ends resting on opposite poles of two strong magnets; two other magnets are held, one in each hand, with opposite poles downwards, and brought together at the middle of the bar. The magnets are then inclined so as to make angles of about $30^{\circ}$ with the bar, and are moved in contact with it towards the ends, where they are taken off. This process should be repeated several times on both sides of the bar, taking care that a red pole is moved towards the end supported by a red pole, and the blue pole towards the end resting on a blue pole.

(c) By using an electro-magnet. One half of the bar is drawn from the middle to the end over one pole of a strong electro-magnet, and the other half over the other pole.

(d) By suspending the bar inside a solenoid and passing a strong electric current through the latter.

2. The end which points north when the magnet is freely suspended is named the red pole, and the other end the blue pole.

3. The south magnetic pole of the Earth is the red, and the north the blue pole. The north magnetic pole is situated about $70^{\circ} \mathrm{N}$. latitude and $97^{\circ} \mathrm{W}$. longitude, and the south magnetic pole about $72 \frac{1{ }^{\circ}}{2} \mathrm{~S}$. latitude and $154^{\circ}$ E. longitude.

4. Poles of the same name repel each other, whilst poles of different names attract each other. If freely suspended in the manner stated, they would assume a position of equilibrium determined by the Earth's directive force acting on the needles and the mutual attraction of their opposite poles.

5. In the first case, the needle would come to rest in the plane of the magnetic meridian, with its red pole pointing north; in the second case, the needle would still coincide with the magnetic meridian, but its red pole would dip in N. latitude, and its blue pole would dip in S. latitude at an angle from the horizontal depending on the magnetic latitude, the dip being 0 on the magnetic equator, and $90^{\circ}$ at the magnetic poles.

6. The variation of the compass is due to the fact that the Earth's marnetic poles do not coincide with the geographical poles.

7. Deviation of the compass is the angle of deflection of its nois point from magnetic north, caused by the disturbing influence of iron.

8. "Local attraction" is tho name given to the meotietic influences (causing a disturbance of the compast of the iucallty in which a ship may be found; for example, whe in dock tear to iron ships, iron pillars, cranes, etc., also in the neighbourhoou or spme volcanic islands, It is said that the following places have a disturbing effect on ships' compasses: Ascension, 
St. Helena, Cape St. Frances (Labrador), Cossack (North Australia), New Ireland, Solomon Islands, Tumbora, Sumbawa, coast of Madagascar, Iceland, Ile de Los (west coast of Africa), and Odessa Bay and Shoal.

3. Malleable iron and cast iron are termed "soft iron." Soft iron has the property of being instantaneously magnetized by induction from the magnetism of the Earth or of a natural or artificial magnet; also by passing an electric current round it. This induced magnetism is only transient in its character, and is lost in great part or entirely when the inducing cause is removed.

10. "Hard iron" is iron combined with a certain percentage of carbon, and is usually termed steel. Tempered hard iron has the property of acquiring slowly and retaining permanently, or nearly so, the magnetic polarity communicated to it.

11. "Horizontal force" is the horizontal component of the Earth's total magnetic force in the line of dip, and varies as the cosine of the magnetic latitude. It is greatest at the magnetic equator, and 0 at the magnetic poles, and therefore gives the greatest directive force to the compass needle in the former case, whilst there is no directive tendency in the latter.

12. The magnetic equator does not coincide with the geographical equator, but intersects it in two nearly opposite points situated in west longitude and east longitude. From the former point in the Pacific Ocean it runs nearly parallel to the Equator to about $100^{\circ}$ W. long., then bends to the south on approaching South America, and in crossing Brazil it recedes from the Equator as far as $16^{\circ} \mathrm{S}$. lat.; then it bends northwards and crosses the Equator in about $6^{\circ} \mathrm{W}$. long., whence it passes across the Gulf of Guinea and the African continent, receding to about $10^{\circ} \mathrm{N}$. lat., and then very gradually approaches the Equator to the other point of intersection.

13. The values of the dip, etc., may be found on charts prepared for the purpose.

14. The variation changes rapidly in the English Channel, the western portion of the North Atlantic, the South Atlantic near the coast of Brazil, the South Indian Ocean, the neighbourhood of Japan, and especially in the Gulf of St. Lawrence.

In navigating these localities, if the ship's course is across the magnetic meridians, the precaution should be taken of altering the courses steered by compass in accordance with the change of variation. A variation chart is useful to show what magnetic meridians are crossed and the amount of variation.

15. Because the vertical induced magnetism which causes "heeling error" depends on the dip, and the directive force of the needle depends on the Earth's horizontal force.

16. The "vertical force" is the vertical component of the Earth's total magnetic force in the direction of the dip. It is greatest at the magnetic poles, and least at the magnetic equator.

17. The needle would be least affected near the magnetic equator, because the Earth's horizontal force, and therefore the directive power of the needle, are there at their greatest.

18. (a) The card should be accurately centred and graduated, the magnetic axis of the needle (or the common axis, if more than one) coinciding with the north and south points of the card. There should be the least possible friction between the centre cap and the supporting pivot, the needles should have good directive power, the "lubber-point" should be exactly in the fore and aft midship line, and the deviation should be reduced by compensation to a small amount, say under $3^{\circ}$. The gimbals should have little friction, and should not allow any lateral play. When in position in the binnacle, the card and lubber-point should be in full view of the man at the wheel.

(b) It is generally agreed that two or more short needles parallel to each 
other in the same plane is the best arrangement for securing good compensation.

19. Care should be taken that the magnets are not stowed away with similar poles in contact, because in that position they would tend to weaken or demagnetize each other, or even reverse the poles.

20. A position should be chosen for the steering compass where it would not be near large elongated masses of iron, e.g. stern post, rudder post, tiller, stanchions, funnel, etc.

For a standard compass the same precautions are necessary, and the position chosen should be, if possible, symmetrical with regard to the various magnetic forces in the ship.

21. Transient induced magnetism is acquired by soft iron by induction from permanent magnets, from electric currents, or from the Earth. This polarity is retained only so long as the inducing cause is present.

22. The blue pole is uppermost in north magnetic latitudes when the cause of induction is the Earth's magnetism; therefore in the northern hemisphere the north end of the needle would be attracted by the upper end of a soft iron bar, and repelled by the lower end.

23. In south magnetic latitude the upper pole of soft iron by induction is red, and the lower end blue; therefore the north point of a compass needle would be repelled by the upper end, and attracted by the lower.

24. No effect.

25. The sub-permanent magnetism of an iron ship is the magnetic polarity acquired in the course of construction by induction from the Earth and retained after launching. It is liable, however, to a considerable reduction after the ship leaves the stocks, and is therefore termed "sub-permanent" to distinguish it from the fixed magnetism of tempered steel.

The red pole is that which was towards the north when the ship was being built, and the blue towards the south.

26. Composition of forces is the method of finding a single force which is equivalent to two or more forces of given amount and direction.

In the "Parallelogram of Forces," two adjacent sides represent in direction and units of amount two given forces acting at the point of meeting, and a diagonal from this point represents in direction and units of amount the equivalent force, or "resultant" of the composition of the two given forces.

A knowledge of this principle enables a compass adjuster to resolve the sub·permanent magnetic force in a ship into fore and aft, athwartship, and vertical components, and to compensate each independently of the others.

27. Coefficients $\mathbf{B}$ and $\mathbf{C}$ express the maximum deviations caused by magnetic forces acting horizontally in fore-and-aft and athwartship directions respectively; $+B$ represents a blue pole at the bow, and red at the stern; $-\mathrm{B}$ the reverse; $+\mathbf{C}$ represents a blue pole at the starboard side, and red at the port side; $-C$ the reverse. They are said to produce semicircular deviation, because the deviation due to each is easterly on one half of the compass, and westerly on the other half.

28 . Yes; it may be caused by vertical soft iron, because the induced poles remain the same whatever the direction of ship's head.

29. + B gives E. deviation on all courses from N. through E. to S., and W. deviation from $N$. through W. to $\mathrm{S}$. ; $-\mathrm{B}$ gives the opposite.

30 . $+C$ gives $\mathbf{E}$. deviation on all courses from W. through $\mathrm{N}$. to $\mathbf{E}$., and W. deviation from W. through S. to E. ; -C gives the opposite.

31. See page 296.

32. The greatest disturbance from sub-permanent magnetism would be found when the ship lay at right angles to the direction in which she was when being built, and least when in the same direction.

33. Quadrantal deviation is the effect of transient induced magnetism in horizontal iron; it is represented by coefficients $D$ and $E$. $D$ gives the 
greatest deviation on N.E., S.E., S.W., and N.W. courses, and E gives the greatest on N., E., S., and W. courses. It is termed quadrantal because it changes its name in successive quadrants.

34. + D gives E. deviation on courses from $\mathrm{N}$. to $\mathrm{E}$. and $\mathrm{S}$. to W., and W. deviation from E. to S. and W. to N.; $-\mathrm{D}$ gives the opposite.

+ E. gives E. deviation on courses from N.W. to N.E. and S.E. to S.W., and W. deviation from N.E. to S.E. and S.W. to N.W.; - E gives the opposite.

35. Continuous transverse iron produces $+D$, and continuous fore-and-aft iron - D ; but if end on to the compass, or when a beam is divided for a skylight and a compass placed between the parts, then the signs would be reversed.

36. The following table shows the results :-

\begin{tabular}{|c|c|c|c|}
\hline $\begin{array}{l}\text { Ship's } \\
\text { head. }\end{array}$ & Athwartship iron. & Fore-and-aft iron. & $\begin{array}{l}\text { Polarity } \\
\text { acquired. }\end{array}$ \\
\hline $\begin{array}{l}\text { N.E. } \\
\text { S.E. } \\
\text { S.W. } \\
\text { N.W. }\end{array}$ & $\begin{array}{l}\text { End to port. } \\
\quad \text { starboard. } \\
\quad " \quad \text { port. } \\
\text { " starboard. } \\
\text { " port. } \\
\text { " starboard. } \\
\text { " port. }\end{array}$ & $\begin{array}{cc}\text { End towards bow. } \\
" & \text { stern. } \\
" & \text { bow. } \\
" & \text { stern. } \\
" & \text { bow. } \\
" & \text { stern. }\end{array}$ & $\begin{array}{l}\text { Red. } \\
\text { Blue. } \\
\text { Red. } \\
\text { Blue. } \\
\text { Red. } \\
\text { Blue. } \\
\text { Red. } \\
\text { Blue. }\end{array}$ \\
\hline
\end{tabular}

37. Coefficient $A$ is a constant deviation of the same amount and sign on all courses, $+\mathbf{A}$ being easterly and $-\mathbf{A}$ westerly. It may be due to several causes-

(a) The magnetic axes of the needles not coinciding in direction with the N. and S. points of the card.

(b) The lubber-point not being correctly placed.

(c) Unsymmetrical arrangement of iron with respect to the compass.

(d) An error in the correct magnetic bearing used for finding the deviation.

(e) Retained magnetism when swinging the ship.

38. The object of compensating compasses is to reduce the deviations to the smallest possible amounts. An uncompensated compass having large deviations would be too "sensitive" on some courses, and too "sluggish" on others, so that its indications would not correspond to the actual changes of course; whilst a compass having its deviations reduced to a minimum by compensation would behave equally well on all courses.

39. When being equipped for sea, it is desirable that the ship's head should point the opposite way to the direction when building, the compensations being made just before sailing.

40. A common practice is to draw two lines on the deck where the binnacle stands-one fore and aft amidships, and the other at right angles, both passing through a point vertically under the centre of the compass; then, with the ship's head at correct magnetic N. or S., a bar magnet is laid on the deck at right angles to the fore-and-aft line, with its middle point on it and approached to the compass until the needle points correct magnetic $N$.

Next, the ship's head is steadied on correct magnetic E. or W., and another bar is laid on the deck at right angles to the athwartship line, with its middle point on that line, and moved to or from the compass until the needle again points correct magnetic $\mathrm{N}$. Both magnets are then fixed in position.

Next, the ship's head is steadied on N.E., S.E., S.W., or N.W. correct magnetic for the purpose of correcting the quadrantal deviation. This is 
done by placing two soft iron correctors on the supports attached to the binnacle, and moving them towards or from the compass until the deviation is compensated.

Lastly, the ship's head is brought to $\mathrm{N}$. or $\mathrm{S}$. by compass, and she is heeled over, say $10^{\circ}$, and the heeling error observed. Then a small bar magnet is placed vertically under the centre of the compass, and moved up or down in its groove until the error disappears.

N.B.-The red pole of the magnet must be uppermost when the deviation is towards the higher side, and vice versâ.

In Thompson's compass the magnets are inside the binnacle.

41. The magnets should not be nearer to the centre of the card than twice their own length, and the quadrantal correctors not nearer the needles than once and a quarter the length of the needles.

If the magnets are too near, they cause a new deviation called sextantal error, and if the correctors are too near they are liable to receive induced magnetic polarity from the needle, and attract either end indifferently.

42. No. They may be placed either above or below the compass, on a bulkhead, or in the binnacle itself, but parallel to the deck, provided the condition is observed that they are bisected at right angles by transverse and fore-and-aft planes passing through the centre of the compass.

43. Coefficient $B$ is partly due to sub-permanent magnetism and partly to induced magnetism in vertical iron before or abaft the compass.

44. The compass would be found to be over-compensated with respect to $B$ on going to a lower latitude, and on crossing the magnetic equator the part due to vertical induction would be reversed, which would necessitate the shifting or removal, or perhaps reversal, of the magnet.

45. One part should be compensated by a vertical soft iron bar amidships, either before or abaft the compass, as required, and the other by a bar magnet.

46. The ship's head being at E. or W., the deviation should be observed; then the Flinders bar should be moved into position before the compass, to correct, say, one-fourth of this deviation as a first approximation, the rest being compensated by a magnet. When on the magnetic equator the whole of coefficient $B$ is due to sub-permanent magnetism, and should be exactly compensated by the fore-and-aft magnet. Then, as the ship proceeds $\mathrm{N}$. or S., the change observed in the deviation due to coefficient $B$ would be the amount to be compensated by the Flinders bar.

A more correct method would be, when direction of ship's head whilst building is known, to enter the Traverse Table with direction of ship's head when building as a course, and coefficient $C$ in the dep. column, then $B$ will be found in the latitude column. This would be the part of $B$ to be compensated by the magnet, and the remainder by the Flinders bar.

47. Standard compasses are liable to be affected by the induced magnetism of vertical iron in the form of stanchions, pillars, funnels, or bulkheads near them. The attraction is not always towards the stern, because the disturbing masses of iron might be forward of the compass, in which case the Flinders bar should be abaft the compass.

48. Vertical iron could not cause any part of coefficient $C$, unless it was unsymmetrically placed with regard to the compass, therefore the whole of $\mathrm{C}$, when the ship is upright, is usually due to sub-permanent magnetism.

49. Yes; because the horizontal force of the correctors, the disturbing force, and the directive force of the needle would vary in the same ratio.

50 . When the joint effect is small, and when the constant deviation is $\mathrm{W}$. when the ship is swung to the right, and $\mathrm{E}$. when swung to the left, and consequently the effect of temporarily retained magnetism, they may be disregarded when compensating the compass.

51. (1) (a) It would be found to have decreased.

(b) It would increase again and tend to return to its original amount. 
(2) (a) It would become 0 .

(b) It would have a different sign.

52. No deviation would occur from the sub-permanent magnetism so long as it remained constant, because it is exactly counterbalanced by the correcting magnet; nor from the vertical induced magnetism, because it varies in the same ratio as that of the Flinders bar.

53. The deviation from this cause would not change its name and amount, because $(a)$ the red induced pole is towards the north in all latitudes, and $(b)$ the horizontal induced force changes in the same ratio as the directive force of the needle.

54. (1) A compass is set up on shore or in a boat at some distance from the ship, where it is not exposed to local attraction, and an observer stationed by it. The ship is then swung, and as her head comes to the desired points simultaneous bearings are taken by signal of each compass from the other. The bearings by shore compass reversed are correct magnetic, with which the bearings observed on board are compared, and the deviation found.

(2) Figures on dock walls show either the correct magnetic or the true bearings of a prominent distant object from the observer's position. When, therefore, the ship swings with the tide or is specially swung, the difference is noted between the figure on the wall in line with the object and the bearing of the same object by the compass on board, as the ship's head comes to each point on which the deviation is required. These differences are either "compass errors" or deviation, according as the figures on the wall are true or magnetic bearings.

(3) The correct magnetic bearings of the distant object may be found by means of a compass placed in a direct line with the ship and the object in a position free from local attraction. The deviation for the actual direction of the ship's head is the difference between the compass bearing of the object and the correct magnetic as before.

55. (a) By the sun: Take its bearing by compass and compute for the same time, or take from the Azimuth Tables its true azimuth. The difference is the compass error, from which the deviation may be found when the variation is known.

(b) By a star or planet: Find the hour angle of the body and compute, or take from the Azimuth Tables (when within their limits) its true azimuth, the difference between which and the observed bearing by compass at the time for which the calculation is made will be the compass error, whence the deviation as before.

56. Uses of Napier's diagram :-

(a) From known deviations on a few points, either correct magnetic or by compass, a curve showing the deviation on all points may be drawn.

(b) The curve so drawn may be used as a complete deviation table, from which may be found mechanically the compass course from the correct magnetic, and vice versâ. Its advantages are, that a complete curve of deviations may be drawn from the deviations observed on a few points, whether by compass or correct magnetic, and whether equidistant or not. It also gives a graphic record of the deviations which appeals to the eye, and gives a much better appreciation of the results of compensation than does an ordinary deviation table.

Again, if observations have been obtained of the deviations on two or three points of the quadrant in which the ship's course may lie, a curve will show the deviations on the other neighbouring points.

Further, the deviations obtained by drawing a curve are free from possible errors of observation and calculation.

57. The Napier's diagram consists of a vertical line graduated to points and degrees, with two sets of parallel lines drawn across it at angles of $60^{\circ}$, one set being continuous or plain, the other set broken or dotted, through 
each of the thirty-two marks representing the "points" of the compass. The $\mathrm{N}$. is at the top and bottom, the S. in the middle, and the E. and W. midway between the $\mathrm{N}$. and $\mathrm{S}$. marks, the other points following in order.

58. Eight equidistant points, viz. N., N.E., E., S.E., S., S.W., W., and N.W.

59. Two would be the least number, but three would be better, because a circle could be drawn through the three projected points.

Assuming that deviations had been observed on three compass courses in the quadrant in which my course would lie, I would project them on the dotted lines, and then draw a fair curve through the projected points, extending it to comprise the whole quadrant. The parts intercepted by the curve of the dotted lines through the other courses would give the required deviations, measured on the vertical line.

If only two observations were available, a straight line passing through the points of projection would show approximately the deviations on the intermediate courses.

N.B.-If the observations for deviation had been made on correct magnetic courses, the plain lines would be used instead of the dotted.

60. The mean of the equidistant bearings would be the correct magnetic bearing, nearly.

The object should be so far distant that its bearing by the compass on board would not be sensibly affected by the change of position in swinging the ship.

61. See page 208.

62. See page 322 .

63. An observer being stationed at each compass, bearings are taken simultaneously of a distant object as the ship's head is steadied on seven or eight points correct magnetic (by Pelorus) round the compass. Comparing these bearings with the known correct magnetic, the deviations for each compass are found, and are then marked on the plain lines of a Napier's diagram. A curve is then drawn through each set of projected marks, and from these curves a complete table of deviations on compass courses may be constructed by measuring the parts of the dotted lines intercepted by the curve.

64. If the correct magnetic bearing reads to the right of the compass bearing, the deviation is easterly ; if to the left, westerly.

65. A knowledge of the coefticients is of advantage, because-

(1) From the coefficients a oomplete table of deviations can be constructed.

(2) It shows how much of the deviation is due to each of the disturbing forces in a ship.

(3) It enables a compass adjuster to employ the proper means for compensating.

66. (a) "Retentive " or " retained " magnetism is the name given to the temporary magnetic polarity acquired by a ship whilst heading for a considerable time in one direction, and retained for a longer or shorter period after that direction is changed. It is induced by the Earth's magnetism whilst the ship is in dock or on a long-continued course at sea.

(b) It has no effect on the compass needle whilst the ship's head continues on the same course.

(c) A deviation will appear tending to make the ship follow the last course steered.

(d) Allowance should be made for this effect, and an observation for deviation should be made as soon as possible after the course is changed.

67. The "Pelorus" has the general appearance of an azimuth compass, but it has no magnets. The "card" is usually a metal disc, which can be turned about its centre and clamped in any position.

(a) Its use in compensating : First clamp the sight vanes to the known 
correct magnetic bearing of a distant object ; then turn the card round until the desired direction of ship's head is at the lubber-point, and clamp. Next swing the ship until the object is seen through the sight vanes, and place the magnet or corrector in position to effect the compensation.

(b) Its use to find the deviation : Clamp the sight vane to the known correct magnetic bearing of a distant object on land, or a celestial object, and turn the card round until the object is seen through the sight vanes. The course by "Pelorus" is the correct magnetic, the difference between which and the course by compass is the deviation for that course.

68. Deviation is the difference between the correction and variation when they, are of the same name, but the sum if of different names. It has the same name or sign as the correction in all cases except when the correction is less than variation of the same name.

69. See page 177.

70. See page 325 .

71. When on the magnetic equator, sea smooth, and ship upright, set a watch to show apparent time at ship. Bring the ship's head to near north (or south), and clamp the sight vanes of the Pelorus to the correct magnetic bearing of the Sun-found by taking out the true bearing from the tables for some minutes in advance, and applying the variation; also bring the (N. or S.) point of the Pelorus to the lubber-point. Then steer the ship so that the centre of the Sun's image is on the sight vanes at the moment for which the bearing was computed, and steady her on that course whilst the athwartship magnet is moved into position to make the compass indicate correct magnetic.

In a similar manner place and keep ship's head on correct magnetic east or west, and adjust the position of the fore-and-aft magnet.

72. See page 180.

73. Yes; a deviation appears which is known as the heeling error.

74. (1) When the ship heels, the vertical component of sub-permanent magnetism takes effect in producing deviation, the upper pole not being vertically under the centre of the compass.

(2) Iron which is horizontal when the ship is upright acquires a vertical component of induced magnetism.

(3) The upper ends of rudder post, stern post, or other vertical iron before or abaft the binnacle, are brought out to one side of a vertical plane passing through the centre of the compass.

75. (a) Towards the higher side.

(b) Towards the lower side.

76. (a) Towards the lower side.

(b) Towards the higher side.

77. Such iron would cause a heeling error.

(a) Towards the higher side.

(b) Towards the lower side.

78. Coefficient $\mathrm{C}$.

79. In the northern hemisphere, the N. point of the compass is generally drawn to windward in ships built head north, also in ships whose compasses have $+D$, and in others which have large masses of vertical iron below the compass.

80. In some shipe built head south, and ships having a large $-D$.

81. In the majority of cases the $\mathrm{N}$. point of the compass is drawn to windward. If not allowed for, the effect would be to draw the ship to windward on northerly courses, and to leeward on southerly.

82. (a) In $N$. latitude keep away by compass on either tack as the ship heels on northerly courses, and keep closer to the wind on either tack on southerly courses.

(b) In $\mathrm{N}$. latitude keep closer to the wind by compass on either tack on northerly courses, and keep away on southerly courses. 
This holds good in S. latitude.

83. If in tacking the ship's head is northerly on one tack, and southerly on the other, the heeling error retains the same name; but if on both tacks her head is either northerly or southerly, the error changes its name.

84. Yes.

85. The heeling error has its maximum value when heading north or south magnetic, and nearly vanishes at east and west.

86. It diminishes when the ship goes to a lower latitude, and increases when to a higher, because the directive force of the needle increases in the first case, and decreases in the second, whilst the vertical sub-permanent force is assumed to be constant.

87. It decreases on approaching the equator, and vice versâ, becomes 0 on the magnetic equator, and changes its sign after crossing; because the vertical force of induced magnetism decreases to 0 at the equator, and increases with increase of latitude, the uppermost poles being blue in north magnetic latitude, and red in south. The directive force of the needle also varies with change of latitude.

88.

\begin{tabular}{|c|c|c|c|}
\hline \multicolumn{2}{|r|}{ (1) High N. latitude. } & (2) Magnetic equator. & (3) High S. latitude. \\
\hline \multicolumn{2}{|c|}{ (a) Nil. } & $\begin{array}{l}\text { To low side, due to sub- } \\
\text { permanent only. }\end{array}$ & Sum to low side. \\
\hline \multicolumn{2}{|c|}{$\begin{array}{l}\text { (b) Difference to low side. } \\
\text { (c) bigh side. } \\
\text { (d) Sum to }\end{array}$} & $\begin{array}{l}\text { To high side, due to sub- } \\
\text { permanent only. }\end{array}$ & $"$ Nil. " \\
\hline $\begin{array}{l}(e) \\
(f)\end{array}$ & $"$ & $" \quad "$ & $\begin{array}{c}\text { Difference to high side. } \\
" \text { low } "\end{array}$ \\
\hline
\end{tabular}

89. Yes; for a given magnetic latitude, by means of a vertical magnet which can be moved up or down in a groove or tube. There are two ways of proceeding-

(1) Bring the ship's head to N. or S. by compass (assumed to be correct) and give her a list of, say, $10^{\circ}$; then slide the magnet up or down until the error disappears, and fix in position.

(2) Bring the ship's head to $\mathbf{E}$. or W. magnetic, ship upright ; remove the card and place on the supporting pillar a small dipping needle, which has been balanced by a sliding weight so as to show no dip when on shore; then place the magnet in its groove and move up or down until the needle is again perfectly level.

90. No; because the heeling error is partly due to vertical induced magnetism, which varies with change of latitude.

91. The soft iron correctors are found to correct the heeling error due to transverse iron for ordinary angles of heeling. (a) In the N. hemisphere they deflect the $\mathrm{N}$. point of the needle to the low side; $(b)$ in the $\mathrm{S}$. hemisphere, towards the high side. The reason is that they produce a coefficient $\mathbf{C}$ due to an induced vertical force in the correctors, which has a different sign from that of the $C$ caused by transverse iron when the ship heels.

92. See page 326 .

93. A clinometer consists of a graduated semicircle, which is fixed on a bulkhead with its diameter horizontal and arc downwards. The zero of the arc should coincide with a plumb-line from the middle of the diameter, so that when the ship heels the plumb-line or weighted index would show on the arc the exact degrees of inclination. 
94. Yes ; otherwise the deviations would be complicated with the heeling errors.

95. The deviations might be expected to change from several causes-

(1) The place where the ship is swung may have local attraction.

(2) The force of sub-permanent magnetism is liable to change from long continuance on one course, and from concussion and vibration.

(3) The compensation of coefficient $B$ can only be regarded as provisional, there being no certainty that the just proportions were assigned to the magnet and the Flinders bar.

(4) Allowance must be made for a want of scientific knowledge on the part of the adjuster, or a careless performance of his work.

(5) Loss of power in needles or magnets.

96. It is most necessary that such a record should be kept. The following form would serve the purpose :-

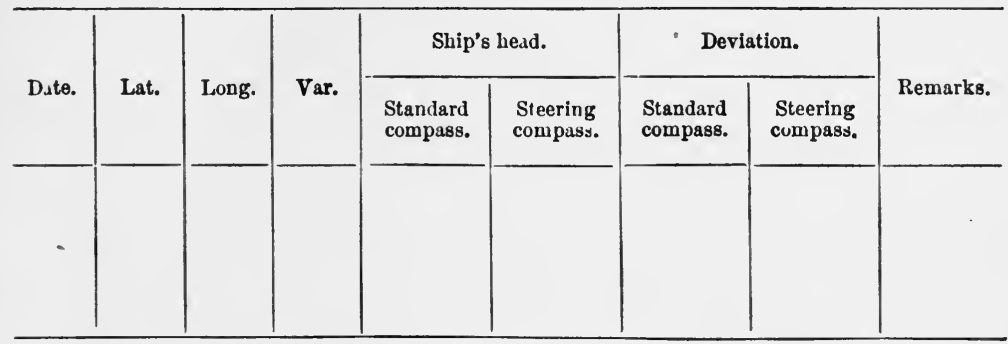

97. No, because considerable changes in the deviation may occur. Therefore it is necessary that frequent observations for deviation may be made, especially when the course is altered, or when rapidly changing latitude.

\section{Practical Questions in Syllabus of Deviation for Extra Masters.}

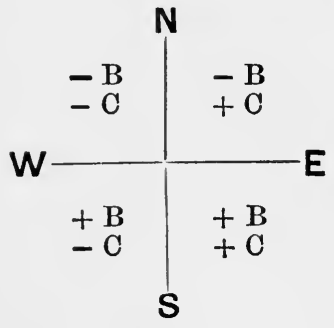

Fig. 215.

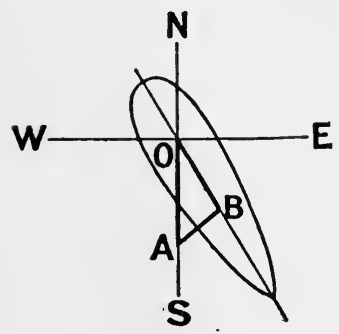

FiG. 216.
31. The values of $\mathrm{B}$ and $\mathrm{C}$ being given to determine the magnetic direction of ship's head whilst building, supposing coefficients due entirely to sub-permanent magnetism.

According to the direction of ship's head whilst building, the signs of $B$ and $C$ can be easily remembered from the adjoining figure.

Again, let a ship be built with her head in, say, the S.E. quadrant, OB being fore-andaft line. Then if $\mathrm{OA}$, in magnetic meridian, be taken as representing the horizontal component of the total magnetic force in the ship, it can be resolved into two forces at right angles, $\mathrm{OB}$ in a fore-and-aft direction, and $\mathrm{BA}$ in an athwartship direction.

OB represents coefficient $B$.

BA , ,,$\quad$ C.

AOB ", magnetic direction ship's head building. 


$$
\begin{aligned}
\therefore \cot \mathrm{AOB} & =\frac{\mathrm{OB}}{\mathrm{AB}} \\
\text { or } \cot \text { direction } & =\frac{\mathrm{B}}{\mathrm{C}}
\end{aligned}
$$

Hence in the Traverse Table, if the direction of ship's head whilst being built be taken as a course, the latitude and departure columns will give the relative values of $B$ and $C$. Therefore-

(1) With ship's head as a course and B in latitude column, $\mathbf{C}$ is found in departure column.

(2) Ship's head as course and $\mathbf{C}$ as departure give B in latitude column.

(3) $\mathrm{B}$ in latitude and $\mathrm{C}$ in departure columns give the direction of ship's head from $\mathrm{N}$. or $\mathrm{S}$.

\section{Examples.-}

1. Given the direction of ship's head whilst building N.E. by N., and coefticient $\mathrm{B}=-16^{\circ} \cdot 5$. Find coefficient $\mathrm{C}$.

Here the course 3 points and lat. $16 \cdot 5$, give dep. 11:1. Coefficient $C$ is therefore $+11^{\circ} \cdot 1$, because the ship's head was easterly.

2. Given ship's head S.S.W., and coefficient $\mathrm{C}=-3^{\circ} \cdot 6$. Required coefficient B.

Course 2 points and dep. 3.6 give lat. 8.7 ; therefore coefficient $B=+8^{\circ .7}$, because the ship's head was southerly.

3. Given coefficient $\mathrm{B}=+7^{\circ} \cdot 3$, and coefficient $\mathrm{C}=-10^{\circ} \cdot 7$. Required the direction of the ship's head when building.

Lat. $7^{\circ} .3$ and dep. 10.7 give the course $56^{\circ}$, which is $\mathrm{S} .56^{\circ} \mathrm{W}$., because $\mathrm{B}$ is + and $\mathrm{C}$ is - .

Exercises.-

1. Given coefficient $\mathrm{B}=-11^{\circ}$ and $\mathrm{C}=-8^{\circ} \cdot 5$. Find direction of ship's head whilst being built.

2. Given coefficient $+\mathrm{C}=12^{\circ} \cdot 5$, and $-\mathrm{B}=6^{\circ} \cdot 8$. Required the direction of ship's head.

3. Given $+\mathrm{B}=14^{\circ} \cdot 7$ and $+\mathrm{C}=8^{\circ} \cdot 7$. Required ship's head.

4. Given ship's head N. $65^{\circ}$ W., and $-B=5^{\circ} \cdot 4$. Required coefficient $\mathrm{C}$.

5. Given ship's head S. $14^{\circ} \mathrm{W}$., and $-\mathrm{C}=3^{\circ} \cdot 5$. Required coefficient B.

6. Given ship's head S.E. $\frac{3}{4}$ E., and coefficient $\mathrm{C}=+7^{\circ} 5$. Required coefficient B.

62. Example.-Assuming the deviations observed with the ship's head by compass to be as follows, determine the value of the coefficients $A, B, C$, $\mathrm{D}$, and $\mathrm{E}$, and from them construct a table of deviations.

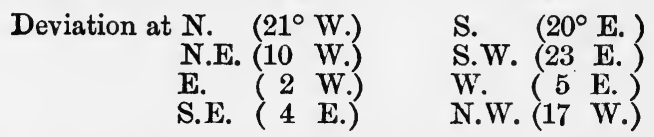

Nore.-In computing the coefticients, E. deviation is marked +, and W. deviation -.

To find coefficient A. by 4 .

Add (algebraically) the deviations on N., E., S., and W., and divide

$$
\begin{aligned}
& \text { Deviation on N. }-21^{\circ} \\
& \text { E. }-2 \\
& \text { S. }+20 \\
& \text { W. }+5 \\
& \text { 4) } \overline{2} \\
& {\overline{+1^{\circ}}}^{\circ}=\mathrm{A}, i \text { e. }+\mathrm{A}=\frac{1}{2}^{\circ}
\end{aligned}
$$


To find coefficient $B$.

Add (algebraically) the deviation on E. and W., after reversing the sign of the latter, and divide by 2 .

To find coefficient $\mathbf{C}$.

$$
\begin{aligned}
& \text { Deviation on E. }-2^{\circ} \\
& \text { W. }-5 \text { (reversed) } \\
& \begin{array}{l}
\frac{2)}{-7} \\
\frac{-3 \frac{1}{2}^{\circ}}{-7 . e .}-\mathrm{B}=3 \frac{1}{2}^{\circ}
\end{array}
\end{aligned}
$$

Add (algebraically) the deviations on $\mathrm{N}$. and S., after reversing the sign of the latter.

$$
\begin{aligned}
& \text { Deviation on N. }-21^{\circ} \\
& \text { S. }-20 \text { (reversed) } \\
& \begin{array}{l}
\text { 2) } \frac{-41}{-20 \frac{1}{2}^{\circ}} \text { i.e. }-\mathrm{C}=20 \frac{1}{2}^{\circ}
\end{array}
\end{aligned}
$$

To find coefficient $\mathrm{D}$.

Add (algebraically) the deviations on N.E., S.W., S.E., and N.W., after reversing the signs of the two latter, and divide by 4 .

$$
\begin{aligned}
& \text { Deviation on N.E. }-10^{\circ} \\
& \text { S.W. }+23 \\
& \text { S.E. - 4) } \\
& \text { N.W. } \left.+{ }_{17}^{4}\right\} \text { (reversed) } \\
& \text { 4) } \overline{+26} \\
& \overline{+6^{\circ} 30^{\prime}} \text { i.e. }+\mathrm{D}=6 \frac{1}{2}^{\circ}
\end{aligned}
$$

To find coefficient E.

Add (algebraically) the deviations on N., S., E., and W., after reversing the signs of the two latter, and divide by 4 .

$$
\begin{aligned}
& \text { Deviation on N. }-21^{\circ} \\
& \text { S. }+20 \\
& \left.\begin{array}{l}
\text { E. }+2 \\
\text { W. }-5
\end{array}\right\} \text { (reversed) } \\
& \text { 4) }-4 \\
& -1^{\circ} \text { i.e. }-\mathrm{E}=1^{\circ}
\end{aligned}
$$

The formula for obtaining the deviation for any point from the above coefficients is, where $d=$ deviation, and $Z=$ azimuth or direction of ship's head by compass-

$$
d=\mathrm{A}+\mathrm{B} \cdot \sin \mathrm{Z}+\mathrm{C} \cdot \cos \mathrm{Z}+\mathrm{D} \cdot \sin 2 \mathrm{Z}+\mathrm{E} \cdot \cos 2 \mathrm{Z}
$$

Here $A$ represents an amount constant in value and sign.

Here B $. \sin \mathrm{Z}+\mathrm{C} \cdot \cos \mathrm{Z}$ represents an amount depending on the azimuth for value and sign, and giving semicircular deviation.

Here $\mathrm{D} \cdot \sin 2 \mathrm{Z}+\mathrm{E} \cdot \cos 2 \mathrm{Z}$ represents an amount depending on twice the azimuth for value and sign, and giving quadrantal deviation. to $\mathrm{N}$.

In the following table the tirst column represents all the points from $N$.

Second column. Coefficient $A$, and is the same for every point.

Third column. All the values of B. $\sin Z$ that can be obtained either by multiplying the value of coefficient $B$ by the natural sine of azimuth; or from 
the Traverse Table, by taking the azimuth as "course," coefficient B as "dist.," and finding corresponding values in the "dep." column.

Fourth column. All the values of $C \cdot \cos Z$ that can be obtained either by multiplying coefficient $\mathbf{C}$ by the natural cosine of azimuth; or from the Traverse Table, by taking azimuth as "course," coefficient $\mathrm{C}$ as " dist.," and finding corresponding values in " $\mathrm{d}$. lat." column.

Fifth column. All the values of $\mathrm{D} \cdot \sin 2 \mathrm{Z}$ that can be obtained either by multiplying coefficient $D$ by the natural sine of twice the azimuth; or from Traverse Table, by taking twice the azimuth as "course," coefticient D in "dist." column, and finding corresponding values in "dep." column.

Sixth column. All the values of $\mathbf{E} \cdot \cos 2 Z$ that can be obtained either by multiplying coefficient $\mathrm{E}$ by the natural cosine of twice the azimuth; or from Traverse Table, by taking twice the azimuth as "course," coefficient $\mathbf{E}$ in "dist." column, and finding corresponding values in "d. lat." column.

Seventh column contains the amount obtained by adding across columns 2 to 6 algebraically.

In forming the table, use the coefficients expressed as degrees and decimals of a degree, and all entries to be made in the same manner from the Traverse Table. It is only necessary to convert the sums found in the seventh column to degrees and miles. Begin by inserting in each column the maximum and minimum values against the proper directions of the ship's head; when a deviation passes through " 0 " it changes in name.

\begin{tabular}{|c|c|c|c|c|c|c|}
\hline $\begin{array}{l}\text { Ship's head by } \\
\text { compass. }\end{array}$ & $\begin{array}{l}\text { Coefficient } A \\
=+0^{\circ} \cdot 5 .\end{array}$ & $\begin{array}{c}\text { Coefficient B } \\
=-3^{\circ} \cdot 5 .\end{array}$ & $\begin{array}{l}\text { Coefficient C } \\
=-20^{\circ} \cdot 5\end{array}$ & $\begin{array}{l}\text { Coefficient D } \\
=+6^{\circ} \cdot 5 .\end{array}$ & $\begin{array}{c}\text { Coefficient } \mathrm{E} \\
=-1^{\circ} .\end{array}$ & $\begin{array}{c}\text { Total } \\
\text { deviation. }\end{array}$ \\
\hline $\begin{array}{c}\text { North } \\
\text { N. by E. } \\
\text { N.N.E. } \\
\text { N.E. by N. } \\
\text { N.E. } \\
\text { N.E. by E. } \\
\text { E.N.E. } \\
\text { E. by N. } \\
\text { East } \\
\text { E. by S. } \\
\text { E.S.E. } \\
\text { S.E. by E. } \\
\text { S.E. } \\
\text { S.E. by S. } \\
\text { S.S.E. } \\
\text { S. by E. } \\
\text { South } \\
\text { S. by W. } \\
\text { S.S.W. } \\
\text { S.W. by S. } \\
\text { S.W. } \\
\text { S.W. by W. } \\
\text { W.S.W. } \\
\text { W. by S. } \\
\text { West } \\
\text { W. by N. } \\
\text { W.N.W. } \\
\text { N.W. by W. } \\
\text { N.W. } \\
\text { N.W. by N. } \\
\text { N.N.W. } \\
\text { N. by W. }\end{array}$ & $\begin{array}{l}0 \\
+\cdot 5 \\
+\cdot 5 \\
+\cdot 5 \\
+\cdot 5 \\
+\cdot 5 \\
+\cdot 5 \\
+\cdot 5 \\
+\cdot 5 \\
+\cdot 5 \\
+\cdot 5 \\
+\cdot 5 \\
+\cdot 5 \\
+\cdot 5 \\
+\cdot 5 \\
+\cdot 5 \\
+\cdot 5 \\
+\cdot 5 \\
+\cdot 5 \\
+\cdot 5 \\
+\cdot 5 \\
+\cdot 5 \\
+\cdot 5 \\
+\cdot 5 \\
+\cdot 5 \\
+\cdot 5 \\
+\cdot 5 \\
+\cdot 5 \\
+\cdot 5 \\
+\cdot 5 \\
+\cdot 5 \\
+\cdot 5 \\
+\cdot 5\end{array}$ & $\begin{array}{l}0 \\
0 \\
-0.68 \\
-1.34 \\
-1.94 \\
-2.47 \\
-2.91 \\
-3.23 \\
-3.43 \\
-3.50 \\
-3.43 \\
-3.23 \\
-2.91 \\
-2.47 \\
-1.94 \\
-1.34 \\
-0.68 \\
0 \\
+0.68 \\
+1.34 \\
+1.94 \\
+2.47 \\
+2.91 \\
+3.23 \\
+3.43 \\
+3.50 \\
+3.43 \\
+3.23 \\
+2.91 \\
+2.47 \\
+1.94 \\
+1.34 \\
+0.68\end{array}$ & 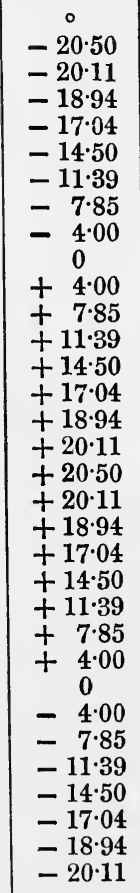 & $\begin{array}{c}0 \\
0 \\
+2 \cdot 49 \\
+4.60 \\
+6.01 \\
+6.50 \\
+6.01 \\
+4.60 \\
+2.49 \\
0 \\
-2.49 \\
-4.60 \\
-6.01 \\
-6.50 \\
-6.01 \\
-4.60 \\
-2.49 \\
0 \\
+2.49 \\
+4.60 \\
+6.01 \\
+6.50 \\
+6.01 \\
+4.60 \\
+2.49 \\
0 \\
-2.49 \\
-4.60 \\
-6.01 \\
-6.50 \\
-6.01 \\
-4.60 \\
-2.49\end{array}$ & $\begin{array}{l}0 \\
-1 \\
-0.92 \\
-0.71 \\
-0.38 \\
0 \\
+0.38 \\
+0.71 \\
+0.92 \\
+1 \\
+0.92 \\
+0.71 \\
+0.38 \\
0 \\
-0.38 \\
-0.71 \\
-0.92 \\
-1 \\
-0.92 \\
-0.71 \\
-0.38 \\
0 \\
+0.38 \\
+0.71 \\
+0.92 \\
+1 \\
+0.92 \\
+0.71 \\
+0.38 \\
0 \\
-0.38 \\
-0.71 \\
-0.92\end{array}$ & $\begin{array}{rrr} & 0 & \\
-21 & 0 \\
-18 & 43 \\
-15 & 53 \\
-12 & 51 \\
- & 9 & 58 \\
- & 7 & 25 \\
- & 5 & 16 \\
- & 3 & 31 \\
- & 2 & 0 \\
- & 0 & 30 \\
+ & 1 & 14 \\
+ & 3 & 21 \\
+ & 6 & 2 \\
+ & 9 & 13 \\
+12 & 47 \\
+16 & 31 \\
+20 & 0 \\
+22 & 52 \\
+24 & 40 \\
+2 & 75 \\
+23 & 58 \\
+21 & 11 \\
+16 & 53 \\
+ & 11 & 20 \\
+ & 5 & 0 \\
- & 1 & 38 \\
- & 8 & 1 \\
- & 13 & 37 \\
-18 & 2 \\
-21 & 0 \\
-22 & 25 \\
-22 & 20\end{array}$ \\
\hline
\end{tabular}


Exercises.-

1. From the following deviations on ship's head by compass, find the coefficients A, B, C, D, E, and construct a table of deviations from W. by N. to N.E. by E. :-

$\begin{array}{rlll}\text { Deviation at N. }\left(291^{\circ}\right. & \text { W. }) & \text { S. }\left(271^{\circ}\right. & \text { E. }) \\ \text { N.E. }\left(26 \frac{1}{2}\right. & \text { W. }) & \text { S.W. }\left(17 \frac{1}{2}\right. & \text { E. }) \\ \text { E. }\left(6 \frac{1}{2}\right. & \text { E. }) & \text { W. }\left(4 \frac{1}{2}\right. & \text { W. }) \\ \text { S.E. }\left(30 \frac{1}{2}\right. & \text { E. }) & \text { N.W. }\left(21 \frac{1}{2}\right. & \text { W. })\end{array}$

2. From deviations found on ship's head by compass as follows, find the coefficients A, B, C, D, E, and construct a table of deviations from E. to W. through S. :-

$\begin{aligned} \text { Deviation at N. }\left(22^{\circ} \text { E. }\right) & \text { S. }\left(25^{\circ} \text { W. }\right) \\ \text { N.E. }(15 \text { E. }) & \text { S.W. }(18 \text { W. }) \\ \text { E. }(0) & \text { W. }(0) \\ \text { S.E. }(15 \text { W. }) & \text { N.W. }(20 \text { E. })\end{aligned}$

3. From the following deviations on ship's head by compass, find the coefficients A, B, C, D, E, and make a table of deviations for all points from E.N.E. to S. :-

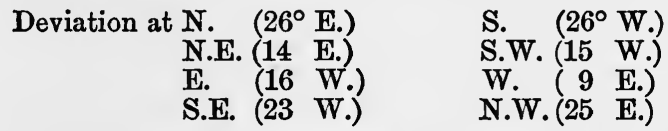

4. Given the following deviations on ship's head by compass, required the coefficients A, B, C, D, E, and make a table of deviations for all points from N. through W. to S. :-

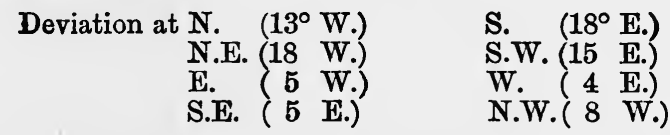

5. Given the following deviations on ship's head correct magnetic, construct a Napier's curve, find the coefficients B, C, D, and make a table of deviations for all points from N.N.W. to S.W. by S. :-

Deviation at N. by E. (mag.) ( $6^{\circ}$ E.)

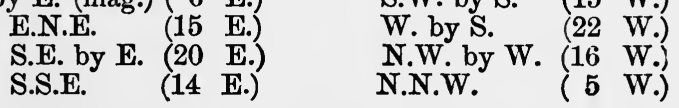

70. Remark. - In the short time available at an examination, it would be troublesome to find, by direct calculation, what stars would satisfy the conditions as to altitude and hour angle to render them suitable for azimuths. Therefore it is better to make use of tables, where the work is already done.

Table IV. in "Towson's Deviation" will answer the purpose, the sidereal time and latitude being known.

Example.-

August 10 th, at $11^{\mathrm{h}} 30^{\mathrm{m}}$ P.M. mean time at ship, in lat. $50^{\circ} 50^{\prime} \mathrm{N}$., long. $62^{\circ} \mathrm{W}$., what stars would be in a good position for determining the correction of the compass?

To find the sidereal time-

M.T.S. Aug. $10^{\mathrm{d}} 11^{\mathrm{h}} 30^{\mathrm{m}}$ Long. $62^{\circ} \mathrm{W} .=4^{\mathrm{h}} 8^{\mathrm{m}}$

M.T.G. 


\section{$\begin{array}{cccc}\text { Sid. time at noon } & 9^{\mathrm{h}} & 12^{\mathrm{m}} & 13^{\mathrm{*}} \\ \text { Acceleration }\left(15^{\mathrm{h}}\right) & 2 & 28 \\ \left(38^{\mathrm{m}}\right) & & 6 \\ \text { M.T.S. } 11 & 30 & 0\end{array}$ \\ Sid. time of observation $\begin{array}{lll}20 & 44 & 47\end{array}$}

Entering Table IV. (Towson) with the nearest hour of sidereal time and the nearest latitude, the suitable stars are found to be-

$$
\begin{array}{lllll}
\text { East of meridian } & & 2 & \\
\text { West }, & 7 & 8 & 9
\end{array}
$$

Referring to map (p. 44, Towson), these numbers correspond to-

Capella (east of meridian).

a Urs. Maj., $\gamma$ Urs. Maj., Arcturus (west of meridian).

In Fig. 217 NESW represents plane of horizon, NZS meridian, EQW equinoctial ; $A$ and $B$ are circles of altitude drawn parallel to horizon, and

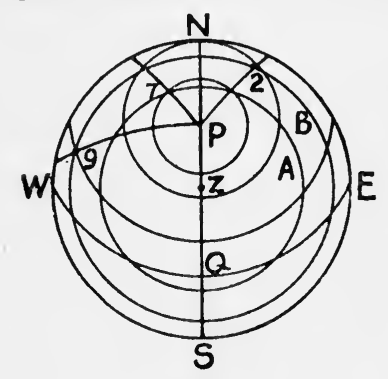

Fig. 217. distance $30^{\circ}$ and $10^{\circ}$ from it. Stars given in Towson which are suitable fall in the space between these circles of altitude. Set off the declination parallels of the stars 2,7 , and 9 ; and where the hour circles cut these parallels, give the positions of the stars as shown at 2,7 , and 9.

$$
\begin{array}{cccc}
\text { Hour angle of } 2 \text { Capella } & 9^{\mathrm{h}} 23^{\mathrm{m}} \mathrm{E} . \\
,, \quad, \quad 7 \text { Dubhe } & 9^{\mathrm{h}} 49^{\mathrm{m}} \mathrm{W} \\
, & , \quad 9 \text { Arcturus } 6^{\mathrm{h}} 34^{\mathrm{m}} \mathrm{W} .
\end{array}
$$

\section{Exercises.-}

1. August 15 th, $2^{\mathrm{h}} 30^{\mathrm{m}}$ A.M. at ship, in lat. $38^{\circ} \mathrm{S}$., long. $25^{\circ} \mathrm{E}$. What stars would be suitable for azimuths?

2. August 20th, $1^{\text {b }} 16^{\mathrm{m}}$ A.M. apparent time at ship, in lat. $42^{\circ} 30^{\prime} \mathrm{N}$., long. $130^{\circ} \mathrm{W}$.

3. August 1st, $2^{\mathrm{h}} 15^{\mathrm{m}}$ A.M. mean time at ship, in lat. $21 \mathrm{~S}$., long. $93^{\circ} 30^{\prime} \mathrm{E}$. Give the names of suitable stars for determining the correction of the compass.

4. September 20 th, $11^{\mathrm{h}} 48^{\mathrm{m}}$ P.M. mean time at ship, in lat. $49^{\circ} \mathrm{S}$, long. $168^{\circ} 15^{\prime} \mathrm{W}$. Name some stars which would be suitable for finding the correction of the compass.

5. September $23 \mathrm{rd}, 11^{\text {h }} 58^{\mathrm{m}}$ P.M. mean time at ship, in lat. $35^{\circ} \mathrm{N}$., long. $44^{\circ} 36^{\prime} \mathrm{W}$. Give the names of stars suitable for finding the correction of the compass.

6. September 10th, $1^{\text {h }} 45^{\mathrm{m}}$ P.M. apparent time at ship, in lat. $55^{\circ} \mathrm{S}$, long. $135^{\circ} \mathrm{W}$. Find what stars are suitable for azimuths.

92. Example.-Given the angle of heeling $15^{\circ}$, the course N.N.E. on the port tack, and the heeling error $-12^{\circ}$, required the error when steering W.S.W. on the starboard tack and heeling $12^{\circ}$.

Since the amount of the heeling error varies directly as the heel, draw two concentric circles, whose radii $\mathrm{CA}$ and $\mathrm{CB}$ are in the ratio of the angles of heel, i.e. CA : CB :: $15: 12$,

$$
\text { . or } \mathrm{CB}=\frac{12}{15} \mathrm{CA} \text {. }
$$

Draw CP, making with CA an angle equal to first direction of ship's head 
(N.N.E.) ; and CX (W.S.W.) second direction of ship's head, X being on its own circle. Draw $P(2$ and $X Y$ perpendiculars on AC. Then CQ represents the first heeling error $12^{\circ}$, and $C Y$ represents the second heeling error.

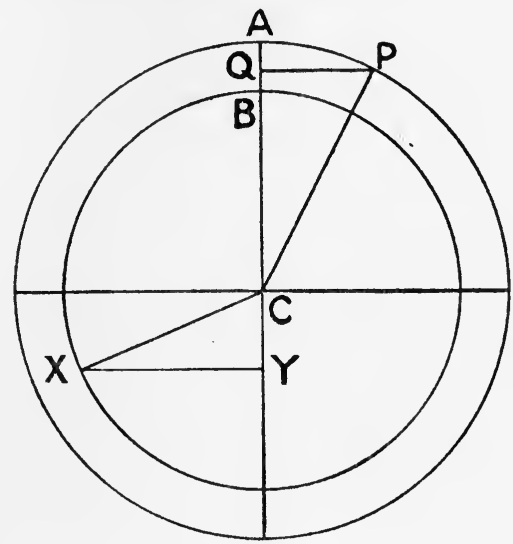

Fig. 218.

$$
\text { Then } \begin{aligned}
C Y & =C X \cdot \cos X C Y \\
& =C B \cdot \cos \mathrm{XCY} \\
& =\frac{12}{15} \cdot \mathrm{CA} \cdot \cos \mathrm{XCY} \\
& =1 \frac{1}{15} \cdot \mathrm{CP} \cdot \cos \mathrm{XCY} \\
& =15 \cdot \mathrm{CQ} \cdot \mathrm{Sec} \mathrm{PCQ} \cdot \cos \mathrm{XCY} \\
& =\frac{12 \cdot \cos \mathrm{XCY} \cdot \mathrm{CQ}}{15 \cdot \cos \mathrm{PCQ}}
\end{aligned}
$$

This is expressed in a formula by-

$$
\begin{aligned}
& \text { New error }=\frac{\text { new heel } \times \cos \text { new co. } \times \text { old error }}{\text { old heel } \times \cos \text { old co. }} \\
& \cdot 8 \\
& \text { \& } \\
& =\frac{78 \times \cos 6 \text { pts. } \times 12}{75 \times \cos 2 \text { pts. }} \\
& =9.6 \times \cos 6 \text { pts } \times \sec 2 \text { pts. } \\
& \text { apply logs. } \\
& 9 \cdot 6 \log =0.982271 \\
& 6 \text { pts. L. } \cos =9 \cdot 582840 \\
& 2 \text { pts. L. } \sec =10.034385 \\
& 3.977 \log =0.599496
\end{aligned}
$$

The name changes with a change of tack, and also when the course is changed from the northern to the southern semicircle, or vice versâ.

A change of either changes the name.

A change in both does not change the name.

Here we have a change in hemisphere and tack, consequently the name remains the same $(-)$.

$$
\text { New error }=-4^{\circ}
$$




\section{Exer CISES.}

1. Given $20^{\circ}$ heel on the starboard tack, steering N.W. by N., and observed heeling error $+15^{\circ}$, required the error when steering W. by S. on the same tack, and heeling $17^{\circ}$.

2. Given $12^{\circ}$ heel on the port tack, steering S.W. $\frac{1}{2}$ W., and observed heeling error $+9^{\circ} 30^{\prime}$, required the error when steering S.W. by W. $\frac{3}{4} \mathrm{~W}$. on the starboard tack, and heeling $14^{\circ}$.

3. Given $25^{\circ}$ heel on the starboard tack, steering E. by N. $\frac{1}{2}$ N., and observed heeling error $+5^{\circ} 30^{\prime}$, required the error when steering $\mathrm{S}$. by W. $\frac{1}{4} \mathrm{~W}$. on the port tack, and heeling $16^{\circ}$.

4. A ship steering S.E. $\frac{1}{2}$ E., with the wind at S.S.W., and heeling $9^{\circ}$, the observed heeling error was $+4^{\circ}$; the wind changes to W.N.W. in a squall, and the ship now lays S.W. $\frac{1}{2}$ S., heeling $19^{\circ}$. Required the new heeling error.

5. Course N., wind E.N.E., heel $13^{\circ}$, and error observed $+18^{\circ}$. Required the error when the ship is put on the other tack by change of wind, laying N.N.E., with a list of $20^{\circ}$.

6. Steering S.W. $\frac{3}{4}$ W., wind S.S.E., heel $12^{\circ}$, and observed heeling error $-6^{\circ}$. Required the error when the wind changes to S.W., and the ship lays N.W. by W. $\frac{1}{2}$ W., heeling $15^{\circ}$.

7. Steering N.W. $\frac{3}{4}$ N., heeling $12^{\circ}$, wind W.S.W., and error observed $-7^{\circ} 12^{\prime}$. Required the error when the course is changed to $\mathrm{S}$., and heel $15^{\circ}$, with no change of wind.

8. Steering S. by E. $1 \frac{1}{2}$ E., heeling $20^{\circ}$ to starboard, heeling error observed $-13^{\circ} 30^{\prime}$. Required the error when steering $\mathrm{E}$. on the same tack and heeling $18^{\circ}$.

9. Course N., wind W., the error observed when heeling $14^{\circ}$ was $12^{\circ} 30^{\prime}$. Required the error when on the other tack steering $S$. and heeling $16^{\circ}$.

10. Given heel $8 \frac{1}{2}^{\circ}$, course N.W. by W. on the starboard tack, heeling error observed $-2^{\circ}$, required the error when the wind veers so as to allow the ship to lay N. by W. on the same tack, heeling $8 \frac{1}{2}^{\circ}$ by clinometer.

11. Steering E. by S. $\frac{3}{4}$ S. on the port tack, and heeling $19^{\circ}$, the observed heeling error was $+4^{\circ} 40^{\prime}$. Required the error when steering S.S.W. on the same tack, the clinometer showing $13_{2}^{10}$.

12. Heeling $23^{\circ}$ when steering E. by $\mathrm{N}$. $\frac{1}{4} \mathrm{~N}$., and wind at N. by E., the heeling error observed was $+4 \frac{1}{2}{ }^{\circ}$. Required the error when steering N.W. by W. $\frac{3}{4}$ W. on the starboard tack and heeling $17 \frac{1}{2}^{\circ}$.

\section{DESCRIPTION AND USE OF BEALL'S DEVIASCOPE.}

This is a model representing the after-deck of a ship, with its binnacle and steering compass. A soft-iron bar at right angles to the deck represents the stern-post, and two soft-iron bars under the deck, the athwartship beams. These bars are to give the vertical and horizontal iron effects. To imitate the effects of sub-permanent magnetism in a ship, thin steel magnets are placed in grooves in the deck, which run fore and aft, athwartship, and at intermediate angles. By this means a counterpart of a ship built with her head in any given direction may be obtained. A "Pelorus" stands on the deck. The model has horizontal and heeling motions, with clamping screws, and a clinometer on the binnacle for showing the angle of heeling. 
On the sides of the binnacle are jointed brass supports for the spherical soft-iron correctors. Under the binnacle is a tube for holding a small brass case, having holes for the reception of small round magnets for the compensation of heeling error. Other flat magnets are provided for compensating coefficients B and C, and a "Flinders" bar and dipping needle complete the outfit.

To explain, by the aid of the Deviascope, the ordinary "tentative" method of compensating a ship's compass-

The deck being horizontal by clinometer, the iron bars representing the stern-post and beams in position, and the magnets in one of the grooves, the sight vanes of the Pelorus should be clamped to the assumed correct magnetic bearing of an object as far removed as possible.

1. To compensate coefficient $C$.

Turn the Pelorus card round until the N. or S. point is at the lubber line, then turn the model until the object is seen through the sight vanes. This represents ship's head N. or S. correct magnetic. Now take up one of

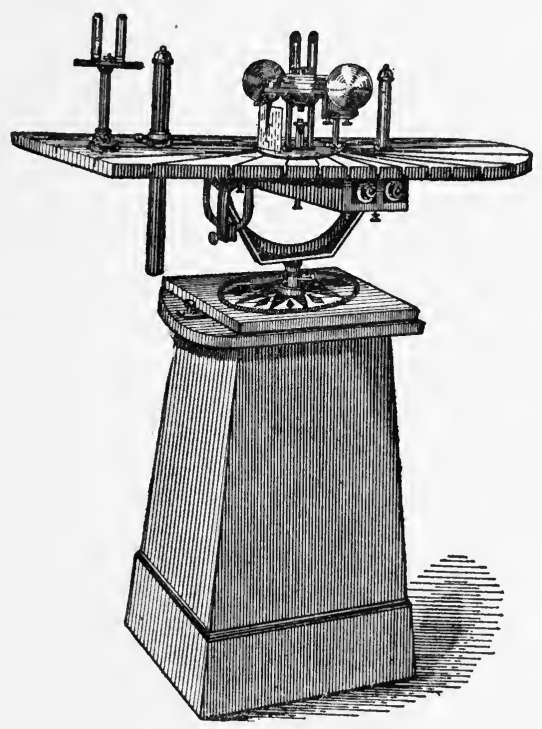

Beall's Deviascope.

the compensating magnets and place it on the deck before or abaft the binnacle, at right angles to the midship groove, and move it towards or from the compass until the deviation disappears. Of course, the red end of the magnet must be towards the side which attracts the N. point of the compass.

2. To compensate coefficient $\mathrm{B}$.

Bring the E. or W. point of the Pelorus card to the lubber line, and turn the model until the sight vanes are again directed to the object. Now place the "Flinders" bar on the fore side of the compass (because the vertical iron is abaft), and move it nearer until a part of the deviation is corrected (say one-half for the purpose of illustration); then place a magnet on the deck on either side of the binnacle at right angles to the athwartship groove, and move it towards or from the compass until the balance of the deviation from coefficient $\mathrm{B}$ is corrected.

3. To compensate coefficient $D$. 
Turn the Pelorus card until the N.E. point is at the lubber line, and then turn the model until the object is seen through the sight vanes. If the deviation is $\mathbf{E}$. on this course, it shows a coefficient $+\mathrm{D}$; but if $\mathrm{W}$., a-D. The soft-iron correctors are then placed in position on their supports, and brought near enough to the compass to correct the deviation. For $+\mathrm{D}$ the correctors must be at the sides, and for $-\mathrm{D}$ they are moved round to the fore-and-aft line.

The joints in the brass supporting arms are to allow the correctors to be moved a little forward on one side, and aft on the other, for compensating coefficient E.

4. To compensate the vertical force producing heeling error.

(1) By heeling the model and observing the heeling error-

Bring the model's bow to $\mathrm{N}$. or S. by compass (which will now show correct magnetic), and incline the deck (say $10^{\circ}$ by clinometer), and observe the deviation. If the $\mathrm{N}$. point is drawn to the higher side (which is usually the case), place the small vertical magnet underneath, with the red pole up, and move it up or down until the deviation is corrected; but if the $\mathrm{N}$. point goes towards the lower side, the blue pole of the magnet must be uppermost.

(2) By dipping needle-

Bring the model's head to E. or W. magnetic, and, after removing the compass card and pivot, place the dipping needle ${ }^{1}$ on the pillar in the bowl, with its red pole pointing $\mathrm{N}$. If the needle dips, it shows a blue or + force below the compass; but if it rises, it shows the force is red or -. In the former case the red pole of the magnet must be uppermost, and in the latter the blue pole. It should then be moved up or down until the needle is horizontal.

1 The dipping needle is weighted to counterbalance the natural dip, so that it is horizontal when not on the model. 


\section{CHAPTER XXX.}

\section{MISCELLANEOUS PROBLEMS.}

ART. 130. Freights and Commissions.-Freight is money paid to the owner of a ship for the carriage and safe delivery of goods, and its gross amount is reckoned at so much per ton. The gross freight is subject to additions and deductions, which are calculated at so much per cent., or per $£ 100$; and when made the net freight is the result. Primage is a charge paid by the shipper, over and above the freight, to the owner towards expenses of wharfage, pilotage, light dues, tug expenses, and other port charges. Commission and Brokerage are charges paid by the owner for expeditious loading of cargo, and for obtaining the contract.

Example.-Find the net freight on 5500 tons at 45 francs per ton. Brokerage $2 \frac{1}{2} \%$; primage $6 \%$; exchange, 1 franc $=9 \frac{3}{4} d$.

Gross freight $=5500 \times 45=247,500$ francs.

Brokerage and primage $\left(6-2 \frac{1}{2}\right) \%=3 \frac{1}{2} \%=\frac{247,500 \times 7}{2 \times 100}=8662.5$,

Net freight $=256,162 \cdot 5$,

$=2,497,584 \cdot 375 d$.

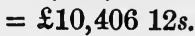

Since the brokerage is a deduction from, and the primage an addition to the gross freight, the difference between them, $6-2 \frac{1}{2}=3 \frac{1}{2} \%$, must be added to obtain the net amount.

ART. 131. Areas, Volumes, Weights.-The area of any surface is expressed in square measure, which in a rectangle is the product of the length and breadth, both dimensions being expressed in the same unit-feet, inches, etc.-when the area is expressed as square feet or square inches, etc.

For a triangle the area is half the product of base and the perpendicular height.

For a trapezoid, that is a four-sided figure having two sides parallel, the area is half the sum of the parallel sides multiplied by the perpendicular distance between them.

The circumference of a circle is given by $\pi d$.

The area of a circle by $\frac{\pi d^{2}}{4}$

$$
\text { where } \pi=3 \cdot 1416 \text {. }
$$


For the area of an irregular figure bounded on one side by a curve, such as the half-section of a boat or ship, Simpson's rules are employed; or by multiplying the area of the circumscribing rectangle by a constant called the coefficient of fineness of the plane. This constant varies in value from 7 to $\cdot 85$.

\section{Examples.-}

1. The circumference of an engine-room ventilator is $13 \mathrm{ft}$. $6 \mathrm{in}$, find its diameter and sectional area.

$$
\begin{aligned}
\text { Circ. } & =13.5 \mathrm{ft} . \\
\pi d & =13.5 \\
\therefore d & =\frac{13 \cdot 5}{3 \cdot 1416} \mathrm{ft} . \\
& =4.3 \mathrm{ft} .
\end{aligned}
$$

$$
\begin{aligned}
\text { Area } & =\frac{\pi d^{2}}{4} \\
& =\frac{3 \cdot 1416 \times(4 \cdot 3)^{2}}{4} \text { sq. ft. }
\end{aligned}
$$$$
=14 \cdot 52 \mathrm{sq} . \mathrm{ft} \text {. }
$$

2. $A B C D$ is a quadrilateral, $A B$ is $20 \mathrm{ft}$., $A D$ at right angles to $A B$ is $12 \mathrm{ft}$., $D C$ parallel to $A B$ is $30 \mathrm{ft}$. Fiud its area.

$$
\begin{aligned}
\text { Area } & =\frac{1}{2}(\mathrm{AB}+\mathrm{CD}) \cdot \mathrm{AD} \\
& =\frac{1}{2}(30+20) \cdot 12 \\
& =300 \text { sq. ft. } \\
\text { Draw } & \text { BE perpr. on CD. }
\end{aligned}
$$

Then area $\mathrm{ABCD}=$ area $\mathrm{ABED}+$

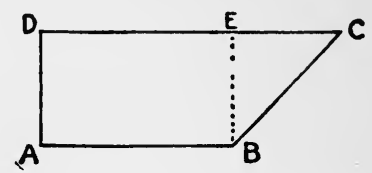
area $\mathrm{BCE}$

$$
\begin{aligned}
& =\mathrm{AB} \cdot \mathrm{BE}+\frac{1}{2} \mathrm{BE} \cdot \mathrm{EC} \\
& =20 \times 12+\frac{1}{2} \cdot 12 \times 10=240+60=300 \mathrm{sq} . \mathrm{ft} .
\end{aligned}
$$

The volume of a rectangular block is the product of its length, breadth, and thickness or depth, and is expressed in cubic feet or cubic inches as case may be according to the unit used.

$$
\begin{aligned}
\mathrm{L} \times \mathrm{B} \times \mathrm{D} & =\text { Vol., and since } \mathrm{L} \times \mathrm{B}=\text { area } \\
\therefore \text { area } \times \mathrm{D} & =\text { Vol., } \\
\text { and } \mathrm{D} & =\frac{\text { Vol. }}{\text { area }}, \text { or area }=\frac{\text { Vol. }}{\mathrm{D}}
\end{aligned}
$$

The ratio of the volumes of displacement and of a block having same length, breadth, and draught as a vessel is called its block coefficient of fineness.

The volume of a cylinder or pipe is its sectional area multiplied by its length

$$
=\frac{\pi d^{2} . l}{4}
$$

The volume of a sphere $=\frac{\pi d^{3}}{6}$

When the volume of a solid is ascertained, its weight may be found from its specific gravity (S.G.), or in the case of a floating 
body by finding the number of cubic feet of water displaced, allowing 35 cubic feet of salt water to weigh one ton. A cubic foot of fresh water weighs 1000 ounces, and contains $6 \frac{1}{4}$ gallons approx. Hence taking the S.G. of cast iron as $7 \cdot 207$, the weight of a cubic foot would be $7 \cdot 207 \times 1000$ ounces $=7207$ ounces.

\section{Examples.-}

1. The displacement of a ship of 15,300 tons. Her dimensions are $462 \mathrm{ft}$. long, $45 \mathrm{ft}$. beam, and $32 \mathrm{ft}$. draught : find the coefficient of fineness.

$$
\begin{aligned}
\text { Coefft. } & =\frac{\text { Displacement }}{\text { Contents of block }} \\
& =\frac{1700, \frac{17}{45}, 300 \times \frac{25}{452} \times 45 \times 32}{66 \quad 0} \\
& =8 .
\end{aligned}
$$

2. The area of the water plane of a vessel is $21,000 \mathrm{sq}$. $\mathrm{ft}$. ; what are the tons per inch immersion at that plane, and how much will 300 tons of bunkers sink her?

When she sinks 1 in. or $\frac{1}{12} \mathrm{ft}$.

$$
\begin{aligned}
\text { The vol. displaced } & =\frac{21,000}{12} \text { cubic ft. } \\
\text { hence tons } & =\frac{21,000}{12 \times 35}=50 \\
\text { or ton per inch immersion } & =50 \\
\text { and } 300 \text { tons will put her down } \frac{300}{50} \text { ins. } & =6 \text { ins. }
\end{aligned}
$$

3. Allowing 45 cubic $\mathrm{ft}$. of coal to a ton, how long must a bunker be made to contain 250 tons bunkers, beam ship $51 \mathrm{ft}$., height 'tween decks $6 \mathrm{ft} .6$ in. ?

Coal will occupy $45 \times 250$ cubic $\mathrm{ft}$. Area end of bunker $51 \times 6 \frac{1}{2} \mathrm{sq}$. $\mathrm{ft}$.

$$
\begin{aligned}
\text { Hence length } & =\frac{\text { volume }}{\text { area }} \\
& =\frac{45 \times 250}{51 \times 6.5} \mathrm{ft} . \\
& =33.94 \mathrm{ft} .
\end{aligned}
$$

4. Find the weight of a balk of timber $31 \mathrm{ft}$. long, 30 ins. wide, and 20 ins. deep, S.G. being $\cdot 72$.

$$
\text { Volume }=31 \times 2 \frac{1}{2} \times 1 \frac{2}{3} \text { cubic ft. }
$$

$$
\begin{aligned}
& \text { Weight of } 1 \mathrm{c} . \mathrm{ft} .=72 \times 1000=720 \mathrm{oz} \text {. } \\
& =45 \mathrm{lbs} \text {. } \\
& \text { Hence weight of } \log =\frac{31 \times 5 \times 5 \times 45}{2 \times 3} \mathrm{lbs} \text {. } \\
& =5812.5 \mathrm{lbs} \text {. }
\end{aligned}
$$


5. How many gallons of oil will a cylindrical tank $4 \mathrm{ft}$. in diameter and $6 \mathrm{ft}$. long hold? What weight will the oil be, S.G. $\cdot 9$ ?

$$
\begin{aligned}
\text { Volume tank } & =\frac{4^{2} \times 3 \cdot 1416 \times 6}{4} \text { cubic ft. } \\
& =75 \cdot 4 \text { cubic ft. }
\end{aligned}
$$

each cubic ft. holds $6 \frac{1}{4}$ gallons.

$$
\text { Hence No. galls. in tank } \begin{aligned}
& =75.4 \times 6 \frac{1}{4} \\
& =471 \frac{1}{4} .
\end{aligned}
$$

One gallon of water weighs $10 \mathrm{lbs}$, so the weight of 1 gallon of oil is $10 \times 9=9 \mathrm{lbs}$.

$$
\begin{aligned}
\therefore \text { Weight of oil in tank } & =9 \times 471 \frac{1}{4} \text { lbs. } \\
& =4241 \frac{1}{4} \mathrm{lbs} .
\end{aligned}
$$

ART. 132. Strength of Chain, Rope, and Wire.-Chains may either be of open link or stayed link pattern, the former used for crane work, and the latter in cables. The relative strengths when of same iron may be taken as 6 to 9 . For mentally estimating the safe working load in tons of chains, a simple rule is to square the number of eighths of an inch in the diameter, and divide by 10 : thus for a chain $\frac{1}{2}$ inch diameter the safe working load would be $\frac{4^{2}}{10}=1 \cdot 6$ tons.

The strength of ropes depends greatly on the quality of the hemp fibre of which it is made, and its ultimate strength is usually taken to be 6,400 lbs. per square inch of sectional area, the proof strength is one-half of the ultimate strength, and the safe working load may be considered to be one-fifth of the ultimate strength. The size of rope is measured by its circumference, and its strength deteriorates rapidly by age and use. The safe working load of a rope in tons is found by squaring the circumference and dividing by 7 . Consider a rope $\mathrm{C}^{\prime \prime}$ in circumference, its sectional area is $\frac{\mathrm{C}^{2}}{4 \pi}$ sq. inches;

$$
\begin{aligned}
\text { ultimate strength } & =\frac{\mathrm{C}^{2} \times 6400}{4 \pi \times 2240} \text { tons, } \\
\text { taking } \pi & =\frac{22}{7} \\
& =\frac{\mathrm{C}^{2} \times 7 \times 6400}{4 \times 22 \times 2240} \text { tons, } \\
& =\frac{\mathrm{C}^{2}}{4 \cdot 4} \text { tons, }
\end{aligned}
$$

which for a 6 -inch rope would work out to about $8 \cdot 2$ tons.

Anderson, in his "Strength of Materials," says that from experiment the tenacity of this size rope is from 14 to 17 tons, 
from which it seems that the ultimate strength is more than 6400 lbs. per sq. in. The rule given estimates the safe working load at $\frac{36}{7}$ tons $=5 \cdot 2$ tons approximately and appears to be rather excessive.

The safe working strain of a wire may be considered to be two-fifths of the square of the circumference in tons; which for a 3 -inch wire would give $\frac{2 \times 3^{2}}{5}$ tons

$$
=\frac{18}{5}=3 \cdot 6 \text { tons. }
$$

The above rules may also be used to estimate the size rope or wire to carry a certain load.

For rope, multiply the load in tons by 7 and extract the square root.

For wire, multiply the load in tons by 5 , divide by 2 , and extract the square root.

When the size rope or wire to be used with a given purchase to take out a known weight has to be determined, first find the load on the hauling part, then the size to carry that load. To find the load on the haul, add one-tenth of the weight to be lifted for each sheave in the purchase, to the weight, and divide by the number of strings at the moving block. Thus to take out a 20-ton weight with a treble purchase and leading block: there are 7 sheaves: hence

$$
\begin{aligned}
\text { Load on haul } & =\frac{\frac{7 \times 20}{10}+20}{7} \text { tons } \\
& =\frac{34}{7} \text { tons } \\
\text { Rope to lift this load } & =\sqrt{\frac{34}{7} \times 7} \\
& =\sqrt{34} \\
& =6 \text { inches nearly; } \\
\text { or, Wire to lift this load } & =\sqrt{\frac{34}{7} \times \frac{5}{2}} \\
& =\sqrt{ } 12 \\
& =3 \frac{1}{2} \text { inches nearly. }
\end{aligned}
$$

Again, to find what weight can be lifted with a given purchase and a known rope or wire : first find the load such rope or wire will carry, multiply this load by the number of parts in the moving block, and allow one quarter of the result off for friction, etc. Thus using a 6 -inch rope and treble purchase :

$$
\text { Safe load for } 6 \text {-inch rope }=\frac{6^{2}}{7}=\frac{36}{7} \text { tons. }
$$

There are 7 parts in moving block, hence total weight it can lift $=\frac{36}{7} \times 7=36$ tons; allow one quarter or 9 tons for friction, and remainder is 27 tons; or, using a $3 \frac{1}{2}$ inch wire: 


$$
\begin{aligned}
\text { Safe load } & =\frac{2}{5} \times\left(\frac{7}{2}\right)^{2}=\frac{2 \times 49}{5 \times 4} \text { tons } \\
& =4.9 \text { tons. } \\
\text { Total lift } & =7 \times 4.9 \text { tons } \\
& =34.3 \text { tons. }
\end{aligned}
$$

For friction allow $\frac{1}{4}=8 \cdot 6$

Remainder $=25 \cdot 7$ tons to be safely lifted.

These rules evidently do not give similar results, but it must be remembered they are all approximations : to make them tally $\frac{9}{16}$ would certainly be a better multiplier than $\frac{3}{4}$; that is, the allowance for friction, etc., should be rather $\frac{7}{16}$ of the total lift.

ART. 133. Speed, Consumption, and Displacement.-When a screw turns in a solid bed, each complete turn advances the screw by an amount equal to the pitch; hence, if " $N$ " be the number of revolutions per minute made, and " $P$ " be the pitch of the screw in feet, the number of nautical miles per hour is $\frac{60 . \mathrm{NP}}{6080}$.

Since the water in which the screw of a ship turns is not solid, the actual speed over the ground, as determined by trial on measured miles, is less than this amount; the difference between the engine and actual speeds is called the "slip," and may be expressed as a percentage on the engine speed. Thus in a ship where the number of revolutions per minute is 57 , the pitch 18 feet, determine the percentage of slip, if the trials give a speed of 9.5 knots.

$$
\begin{aligned}
& \text { Engine speed }=\frac{60 \times 57 \times 18}{6080} \text { knots } \\
&=10 \cdot 1 \text { knots. } \\
& \text { Actual speed }=9 \cdot 5 \\
& \text { Slip }=\cdot 6 \\
& \text { As } 10 \cdot 1: 100:: \cdot 6:-
\end{aligned}
$$

Hence percentage of slip $=6 \%$ roughly.

The moving power in the ship is supplied by the burning of the coal, and it may be seen that the total consumption must depend on the speed, the time occupied, and the weight moved. From various experiments made it has been found that in the same ship, under the same conditions, the consumption varies as the cube of the speed obtained, if $\mathrm{C}$ represents consumption in tons, $s$ the speed in knots, and $t$ the time in hours:

$$
\begin{aligned}
& \mathrm{C} \text { varies as } s^{3} \times t \text {, and since } s \times t=\text { distance " } d \text { " } \\
& \mathrm{C} \text { varies as } s^{2} \times d \text {; }
\end{aligned}
$$


hence if the time is constant

Consumption varies as cube of speed;

if the distance is constant

Consumption varies as square of speed.

From observation it is found that in modern engines, with good coal, the consumption varies from 1.2 to $1.7 \mathrm{lbs}$. per hour per I.H.P., say $1 \frac{1}{2} \mathrm{lbs}$., and since the speed of the ship varies directly as the number of revolutions made per minute, hence the I.H.P. varies as cube of revolutions in a given time.

Example.-The daily consumption for a speed of 8.5 knots is 30 tons, what would it be for a speed of 10.5 knots?

Since the time is the same, consumption varies as cube of speed.

$$
\begin{aligned}
& \text { As } 8 \cdot 5^{3}: 10 \cdot 5^{3}:: 30: x \\
& x=\frac{10 \cdot 5^{3} \times 30}{8 \cdot 5^{3}}=\begin{array}{c}
34,728 \cdot 75 \\
614 \cdot 125
\end{array} \\
& =56 \cdot 5 \text { tons. }
\end{aligned}
$$

Again, if in above ship the consumption is reduced to 20 tons per day, what speed would be developed?

$$
\begin{aligned}
& \text { As } 30: 20:: 8.5^{3}: x^{3} \\
& \quad x^{3}=\frac{20 \times 8.5^{3}}{30}=409 \cdot 4 \\
\sqrt[3]{409 \cdot 4} \log & =\frac{2.612148}{3} \quad \therefore x=\sqrt[3]{409 \cdot 4}=7.42 \text { knots. } \\
& =0.870716 \\
& =7.425 \mathrm{log} .
\end{aligned}
$$

Again, if the ship has to make a voyage of 3570 miles, what would be the total consumption at the second speed?

As the distance is the same, consumption varies as square of speed.

$$
\begin{aligned}
& \text { Number of days taken at } 8 \cdot 5 \text { knots }=\frac{3570}{8 \cdot 5 \times 24}=17 \cdot 5 \\
& \text { Total consumption }=17 \cdot 5 \times 30=525 \text { tons. } \\
& \text { As } 8 \cdot 5^{2}: 10 \cdot 5^{2}:: 525: x \\
& x=\frac{10 \cdot 5^{2} \times 525}{8 \cdot 5^{2}}=\frac{57,881 \cdot 25}{72 \cdot 25} \\
& =801 \text { tons. }
\end{aligned}
$$

Number of days taken at 10.5 knots $=\frac{3570}{10.5 \times 25}=14 \frac{1}{6}$

$\therefore$ Total consumption at 56.5 tons per day $=14 \frac{1}{6} \times 56.5$

$$
=800 \cdot 5 \text { tons, }
$$

agreeing with amount obtained directly.

From the above example it is seen that 801 tons of coal will drive the ship 8570 miles at 10.5 knots, but if her speed is reduced to 8.5 knots the distance will be increased. 
For 801 tons will be consumed in $\frac{801}{30}$ days at $8 \cdot 5$ knots ;

$$
\begin{aligned}
\text { Hence distance } & =\frac{801 \times 204}{30} \text { miles } \\
& =5446.8 \text { miles. }
\end{aligned}
$$

Again, if in the above ship, where the speed is 8.5 knots for a daily consumption of 30 tons, it is found that three days' coal are left at that speed when 1000 miles from port, to what speed must she be reduced to reach port?

Consumption varies as square of speed multiplied by distance.

$$
\text { As } \begin{aligned}
s^{2} \times 1000: & 8 \cdot 5^{2} \times 204:: 90: 30 \\
\text { Hence } s^{2} & =\frac{8 \cdot 5^{2} \times 204 \times \because 0}{50 \times 1000} \\
& =44.217 \\
\therefore s & =6.65 \text { knots. }
\end{aligned}
$$

It is evident that the more deeply a ship is laden the more power is required to drive her through the water at the same speed, and it is found that the consumption or I.H.P. varies as the ${ }_{3}^{2} \mathrm{rd}$ power of the displacement, that is as the cube root of the square of the displacement. Thus if in a ship of 5000 tons displacement, 4000 tons are taken on at one port, and it is found that the consumption per day is 50 tons to drive her at a speed of 9 knots, what would the consumption be per day when the 1000 tons are taken on at another port to make the same speed?

$$
\begin{aligned}
& \text { As } \sqrt[3]{4000^{2}}: \sqrt{5000^{2}}:: 50: x \\
& x=\frac{50 \times \sqrt[3]{5000^{2}}}{\sqrt[3]{4000^{2}}} \\
& \therefore \log x=\log 50+\frac{2}{3} \log 5000-\frac{2}{3} \log 4000 \\
& =\log 50+\frac{2}{3}(\log 5000-\log 4000) \\
& 5000 \log =3 \cdot 698970 \\
& 4000 \mathrm{log}=3 \cdot 602060 \\
& \overline{0.096910} \\
& 2 \\
& \text { 3) } 0 \cdot 193820 \\
& \frac{3}{3}(\log 5000-\log 4000)=\overline{0.064607} \\
& 50 \log =1 \cdot 698970 \\
& 58 \cdot 02 \log =\overline{1 \cdot 763577} \\
& \text { or } x=58 \cdot 02 \text { tons per day. }
\end{aligned}
$$

\section{EXERCISES.}

1. Find net freight on 2400 tons at 17 s. $6 d$. per ton, after allowing $6 \%$ loading commission and $8 \%$ primage.

2. Find the net freight of 5600 tons at 6 dollars per ton, allowing $5 \%$ loading commission and $7 \%$ primage, exchange being 4.85 dollars to $£ 1$.

3 . Calculate net freight on 2700 tons at $22 \mathrm{~s}$. $6 d$. per ton, if primage is $7 \frac{1}{2} \%$ and loading commission $3 \%$. 
4. Convert $£ 683610$ s. to dollars if $£ 1=4.66$ dollars. Convert 567832.5 francs to $£$ 's. if $£ 1=28 \cdot 4$ francs.

5. Wine costs 3.5 francs per litre, how much is this per gallon. The price of meat is 4 francs per kilogramme, how many pence per lb. ?

6. Find displacement of a ship in tons whose dimensions are: Length $465 \mathrm{ft}$., breadth $50 \mathrm{ft}$., draught $28 \mathrm{ft}$., coefficient of fineness $\cdot 84$.

7. Taking the height of a mercurial barometer to be 30 ins. when a water barometer reads $34 \mathrm{ft}$., find S.G. of mercury.

8. The sectional area at load water-level is $5600 \mathrm{sq}$. $\mathrm{ft}$., how much will 320 tons of bunkers sink her?

9. Find coefficient of displacement of a liner $525 \mathrm{ft}$. long by $51 \mathrm{ft}$. broad by $25 \mathrm{ft}$. draught, her displacement being 15,300 tons.

10. A lifeboat is $24 \mathrm{ft}$. long, by $7 \mathrm{ft}$. 3 ins. wide, and $3 \mathrm{ft}$. 6 ins. deep : how many people will it carry, and what air-tight space must be allowed?

N.B.-Use $\cdot 6$ as multiplier for finding cubical contents, and allow 10 cub. ft. per person, of which 1 cub. ft. must be air-tight.

11. How long must a bunker be made to contain 250 tons coal, allowing $42 \mathrm{cub}$. $\mathrm{ft}$. to the ton, beam of ship $56 \mathrm{ft}$., height 'tween decks $6 \mathrm{ft}$. 6 ins.

12. The length of a rectangular field is to its breadth as 3 to 2 , and its area is 11,094 sq. metres. Find the cost of surrounding it with a fence at $2 \cdot 25$ francs per metre length of boundary.

13. If 648 boxes are stowed close together on board a ship, find the total cost of freightage at 1s. $2 d$. per cub. yard, when each box measures $4 \frac{1}{2} \mathrm{ft}$. long, $3 \mathrm{ft}$. wide, and $2 \frac{1}{4} \mathrm{ft}$. deep.

14. A rectangular tank $8 \mathrm{ft}$. long and $7 \mathrm{ft}$. wide holds when full $6 \frac{1}{4}$ tons of water : find its depth.

15. If gold is worth 3 francs 10 centimes per gramme, find its value per ounce in English money, taking a franc as equal to $9 \frac{3}{4} d$,, and a gramme as $15 \cdot 43$ grains.

16. How many tons of coal will a bunker $10 \mathrm{ft} .3$ ins. deep, $42 \mathrm{ft} .6$ ins. long, and breadth at two ends $8 \mathrm{ft} .6$ ins., and in middle $10 \mathrm{ft}$, , hold ?

17. How many persons will a lifeboat hold whose length is $22 \mathrm{ft} .6$ ins., breadth $6 \mathrm{ft} .6$ ins., inside depth $3 \mathrm{ft} .6$ ins., and what number of cubic feet of air-tight space should it contain?

18. A supposed cubical iceberg is 100 feet above level of sea, S.G. of ice .921 , sea water 1.026 : find total height of berg.

19. If the displacement of a ship is 6800 tons, her length $340 \mathrm{ft}$., breadth $35 \mathrm{ft}$., and draught $22 \mathrm{ft}$., find coefficient of fineness.

20 . If 150 , tons of bunker sink a ship 5 ins., find her area at that water level.

21. Taking S.G. of iron as 7.7, find weight in pounds of a plate $20^{\prime} \times 2^{\prime}$ $\times 1 \frac{1}{2}^{\prime \prime}$.

22. Length of ship $525 \mathrm{ft}$., beam $55 \mathrm{ft}$., coefficient of fineness $\cdot 9:$ how many tons per "inch" immersion?

23. Find approx. the daily consumption in a vessel of 5000 I.H.P.

24. Find safe working loads for chains of $\frac{3}{4}$ in., $1 \frac{1}{2}$ in., and $\frac{7}{8}$ in. diameter.

25 . When chains are weakened by having been in use for a time, how is strength restored?

26. Find safe working strain of manilla ropes of $3 \frac{1}{2}$ ins., 5 ins., and $6 \frac{1}{2}$ ins. circumference.

27 . Find the safe working strain of wires 1 in., $2 \frac{1}{2}$ ins., and 5 ins. circumference.

28. How many parts of a 3 -in. rope will be equal in strength to a 6 -in. rope?

29. What weight will a $3 \frac{1}{2}$-in. rope hang, when rove as a tackle having 6 parts at the travelling block?

30 . What weight will a $2 \frac{1}{2}$-in. wire raise, using a double purchase? 
31. What size rope or wire would you use to get out a 15-ton weight with a fourfold purchase and leading block?

32. What size rope and wire would be required to take out a 14-ton weight with a treble block ?

33. If the breaking strain of a 2 -in. chain is 72 tons, what is it of a 3-in. chain?

34. Mercury is 10,574 times as heavy as air, the S.G. of mercury is 13.597 : find the weight in grains of $1 \mathrm{cub}$. $\mathrm{ft}$. of air.

35. From Glazebrook's experiments the S.G. of air at $15^{\circ}$ C. and 760 $\mathrm{mm}$. pressure when $\frac{1}{4}$ saturated was 0012 . Find weight in grains of $1 \mathrm{cub}$. $\mathrm{ft}$. of this air.

36. Taking the composition of air to be $77 \%$ of nitrogen, $21 \%$ of oxygen, and the remainder carbonic acid gas, and Ganot's estimates that 1 litre of nitrogen at $0^{\circ} \mathrm{C}$. and $760 \mathrm{~mm}$. weighs 1.2561 grammes, of oxygen 1.4298 grammes, of carbonic acid 1.9774 grammes, find weight in grains of $1 \mathrm{cub}$. $\mathrm{ft}$.

37 . At $32^{\circ} \mathrm{F}$. the velocity of sound is $1090 \mathrm{ft}$. per second, and the increase is at the rate of $10 \mathrm{ft}$. per second for each $9^{\circ} \mathrm{F}$. rise in temperature.

You see the flash of a gun, and 6 seconds after hear the report, temperature $68^{\circ} \mathrm{F}$.: how far away is the gun?

38 . If the velocity of light be reckoned at 299,860 kilometres per sec., how many miles per sec. is this?

39. The pitch of a propeller is $15 \mathrm{ft}$., and it makes 60 revolutions per minute, allowing $5 \%$ slip : find actual speed.

40. The pitch of a propeller is $16 \mathrm{ft}$., revolutions per minute 57, and time for measured mile is 7 minutes : find slip \%.

41. The speed on the trials is 9.5 knots, propeller pitch $19 \mathrm{ft}$., revolutions per minute 56 , find slip \%.

42. For a speed of 10 knots, the daily consumption is 25 tons : what would the consumption be for speeds of 12 knots and 8 knots?

43. The daily consumption for a speed of 19 knots is 150 tous : what amount would be necessary for speeds of 21 and 15 knots?

44. For a daily consumption of 55 tons, the speed is 13 knots: what speed would be developed on consumption of 30 and 80 tons per day?

45. On a daily consumption of 84 tons, the speed is 15 knots : what would it be for consumptions of $2 \cdot 5$ and 5 tons per hour?

46. In a ship $16 \frac{2}{3}$ tons of fuel are consumed per hour for a speed of 24 knots: how many tons will be required for a voyage of $4 \frac{1}{2}$ days if the speed is increased 1 knot?

47. The total consumption for a certain distance at 9 knots is 240 tons : what would it be for same distance if speed is increased to $13.5 \mathrm{knots}$ ?

48. A ship steams 10 knots on 23 tons daily : how much coal will be required to steam 3036 miles in 11 days, and have 100 tons in reserve?

49. At 60 revolutions per minute the I.H.P. developed was 3500 , what would the I.H.P. be when revolutions were increased to 75 per minute? How much coal per day is consumed under the two conditions?

50. For 1800 miles at $10 \mathrm{knots}$, the consumption is 500 tons : how much will be required for 2500 miles at 12 knots?

51. The consumption per day for a speed of 12 knots is found to have been 51 tons. There are 150 tons of coal left in bunkers, and 1152 miles to port, speed is reduced to 10 knots, how much will there be at the end of the voyage?

52. On a daily consumption of 80 tons, the vessel makes 15 knots; with only one day's coal left at this speed and 1000 miles to go, at what speed must she proceed to reach port?

53. There are 20 days' coal on board, when steaming at 9 knots on 35 tons per day, and 100 tons reserve. When 12 days out, owing to bad weather, it is found that 45 tons daily have been consumed: at what speed must she proceed to arrive with 50 tons in bunkers? 
54. A vessel with a displacement of 3000 tons consumes 25 tons daily : what would consumption be at displacernent of 2000 and 4000 tons?

55. A ship of 10,800 tons displacement burns 100 tons of coal daily, for a speed of 13.5 knots : what would be the effect on the consumption of taking in 300 tons extra cargo, and increasing speed $\frac{1}{2}$ knot?

56. A vessel of 8000 tons displacement has 7000 tons on board at one port, and develops a speed of 12 knots on 50 tons per day : what consump. tion will she have to make a speed of $13 \mathrm{knots}$, when the extra 1000 tons is taken in? 



\section{A P PENDIX}

CONTAINING EXTRACTS FROM

\section{TIDE TABLES}

AND

\section{NAUTICAL ALMANAC}

FOR THE SOLUTION OF ALL PROBLEMS IN THIS BOOK USEFUL TABLES

AND

EXAMINATION PAPERS 
AUGUST.

AT APPARENT NOON.

\begin{tabular}{|c|c|c|c|c|c|c|c|c|}
\hline \multirow{2}{*}{\multicolumn{2}{|c|}{ Date. }} & \multicolumn{4}{|c|}{ THE SUN'S } & \multirow{3}{*}{ 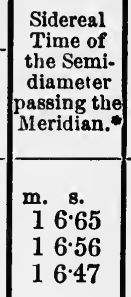 } & \multirow{3}{*}{$\begin{array}{c}\begin{array}{c}\text { Equation } \\
\text { of Time, } \\
\text { to be } \\
\text { added to } \\
\text { Apparent } \\
\text { Time. }\end{array} \\
\begin{array}{cc}\text { m. } \\
6 & 10 \cdot 22 \\
6 & 6 \cdot 74 \\
6 & 2.64\end{array}\end{array}$} & \multirow{2}{*}{$\begin{array}{c}\text { Var. } \\
\text { in } \\
1 \text { hour. }\end{array}$} \\
\hline & & & & & & & & \\
\hline $\begin{array}{l}\text { Wed. } \\
\text { Thur. } \\
\text { Frid. }\end{array}$ & $\begin{array}{l}1 \\
2 \\
3\end{array}$ & $\begin{array}{lcc}\text { h. } \mathrm{m} . & \text { s. } \\
8 & 42 & 55 \cdot 43 \\
8 & 46 & 48 \cdot 49 \\
8 & 50 & 40 \cdot 93\end{array}$ & $\begin{array}{c}\text { s. } \\
9 \cdot 724 \\
9 \cdot 698 \\
9 \cdot 672\end{array}$ & \begin{tabular}{ccc}
$\circ$ & \multicolumn{1}{c}{} & \multicolumn{1}{c}{} \\
N. 18 & 11 & $45 \cdot 0$ \\
17 & 56 & $41 \cdot 9$ \\
17 & 41 & $21 \cdot 2$
\end{tabular} & $\begin{array}{c}\prime \prime \\
37 \cdot 26 \\
38 \cdot 00 \\
38 \cdot 72\end{array}$ & & & $\begin{array}{c}\text { s. } \\
0.132 \\
0.158 \\
0.184\end{array}$ \\
\hline $\begin{array}{l}\text { Sat. } \\
\text { Sun. } \\
\text { Mon. }\end{array}$ & $\begin{array}{l}4 \\
5 \\
6\end{array}$ & $\begin{array}{lrl}8 & 54 & 32 \cdot 76 \\
8 & 58 & 23 \cdot 99 \\
9 & 2 & 14 \cdot 61\end{array}$ & $\begin{array}{l}9 \cdot 647 \\
9 \cdot 622 \\
9 \cdot 597\end{array}$ & 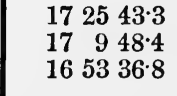 & $\begin{array}{l}39 \cdot 43 \\
40 \cdot 14 \\
40 \cdot 82\end{array}$ & & & $\begin{array}{l}0.209 \\
0.234 \\
0.258\end{array}$ \\
\hline $\begin{array}{l}\text { 'Tues. } \\
\text { Wed. } \\
\text { 'Thur. }\end{array}$ & $\begin{array}{l}7 \\
8 \\
9\end{array}$ & $\begin{array}{rrr}9 & 6 & 4 \cdot 66 \\
9 & 9 & 54 \cdot 13 \\
9 & 13 & 43 \cdot 02\end{array}$ & $\begin{array}{l}9 \cdot 573 \\
9 \cdot 549 \\
9 \cdot 525\end{array}$ & $\begin{array}{rrrr}16 & 37 & 8 \cdot 9 \\
16 & 20 & 24 \cdot 9 \\
16 & 3 & 25 \cdot 0\end{array}$ & $\begin{array}{l}41 \cdot 50 \\
42 \cdot 16 \\
42 \cdot 82\end{array}$ & & & $\begin{array}{l}0.282 \\
0.307 \\
0.330\end{array}$ \\
\hline $\begin{array}{l}\text { Frid. } \\
\text { Sat. } \\
\text { Sun. }\end{array}$ & $\begin{array}{l}10 \\
11 \\
12\end{array}$ & $\begin{array}{llr}9 & 17 & 31 \cdot 34 \\
9 & 21 & 19 \cdot 10 \\
9 & 25 & 6 \cdot 31\end{array}$ & $\begin{array}{l}9 \cdot 502 \\
9 \cdot 479 \\
9 \cdot 456\end{array}$ & $\begin{array}{rrrr}15 & 46 & 9 \cdot 5 \\
15 & 28 & 38 \cdot 9 \\
15 & 10 & 53 \cdot 3\end{array}$ & $\begin{array}{l}43 \cdot 46 \\
44 \cdot 09 \\
44 \cdot 70\end{array}$ & $\begin{array}{l}15.87 \\
15.79 \\
15.71\end{array}$ & $\begin{array}{rr}5 & 17 \cdot 28 \\
5 & 8 \cdot 51 \\
4 & 59 \cdot 19\end{array}$ & $\begin{array}{l}0.354 \\
0.377 \\
0.400\end{array}$ \\
\hline $\begin{array}{l}\text { Mon. } \\
\text { Tues. } \\
\text { Wed. }\end{array}$ & $\begin{array}{l}13 \\
14 \\
15\end{array}$ & $\begin{array}{lll}9 & 28 & 52 \cdot 97 \\
9 & 32 & 39 \cdot 09 \\
9 & 36 & 24 \cdot 68\end{array}$ & $\begin{array}{l}9 \cdot 433 \\
9 \cdot 411 \\
9 \cdot 389\end{array}$ & $\begin{array}{llll}14 & 52 & 53 \cdot 1 \\
14 & 34 & 38 \cdot 6 \\
14 & 16 & 10 \cdot 1\end{array}$ & $\begin{array}{l}45 \cdot 31 \\
45 \cdot 90 \\
46 \cdot 47\end{array}$ & & & $\begin{array}{l}0.422 \\
0.445 \\
0.466\end{array}$ \\
\hline $\begin{array}{l}\text { Thur. } \\
\text { Frid. } \\
\text { Sat. }\end{array}$ & $\begin{array}{l}16 \\
17 \\
18\end{array}$ & $\begin{array}{rrrr}9 & 40 & 9 \cdot 75 \\
9 & 43 & 54 \cdot 30 \\
9 & 47 & 38 \cdot 34\end{array}$ & $\begin{array}{l}9 \cdot 367 \\
9 \cdot 346 \\
9 \cdot 325\end{array}$ & $\begin{array}{lll}13 & 57 & 28 \cdot 0 \\
13 & 38 & 32 \cdot 5 \\
13 & 19 & 23 \cdot 9\end{array}$ & $\begin{array}{l}47 \cdot 03 \\
47 \cdot 59 \\
48 \cdot 12\end{array}$ & & $\begin{array}{rr}4 & 16 \cdot 54 \\
4 & 4 \cdot 57 \\
3 & 52 \cdot 09\end{array}$ & $\begin{array}{l}0.488 \\
0.509 \\
0.530\end{array}$ \\
\hline $\begin{array}{l}\text { Sun. } \\
\text { Mon. } \\
\text { Tues. }\end{array}$ & $\begin{array}{l}19 \\
20 \\
21\end{array}$ & $\begin{array}{lll}9 & 51 & 21 \cdot 88 \\
9 & 55 & 4 \cdot 92 \\
9 & 58 & 47 \cdot 48\end{array}$ & $\begin{array}{l}9 \cdot 304 \\
9 \cdot 283 \\
9 \cdot 263\end{array}$ & $\begin{array}{rrrr}13 & 0 & 2 \cdot 6 \\
12 & 40 & 28 \cdot 9 \\
12 & 20 & 43 \cdot 1\end{array}$ & $\begin{array}{l}48 \cdot 65 \\
49 \cdot 16 \\
49 \cdot 65\end{array}$ & & $\begin{array}{l}339 \cdot 11 \\
325 \cdot 64 \\
311 \cdot 68\end{array}$ & $\begin{array}{l}0.551 \\
0.571 \\
0.591\end{array}$ \\
\hline $\begin{array}{l}\text { Wed. } \\
\text { 'Thur. } \\
\text { Frid. }\end{array}$ & $\begin{array}{l}22 \\
23 \\
24\end{array}$ & $\begin{array}{lll}10 & 2 & 29 \cdot 56 \\
10 & 6 & 11 \cdot 17 \\
10 & 9 & 52 \cdot 32\end{array}$ & $\begin{array}{l}9 \cdot 244 \\
9 \cdot 224 \\
9 \cdot 205\end{array}$ & $\begin{array}{rrr}12 & 0 & 45 \cdot 7 \\
11 & 40 & 36 \cdot 8 \\
11 & 20 & 16 \cdot 9\end{array}$ & $\begin{array}{l}50 \cdot 13 \\
50 \cdot 60 \\
51 \cdot 05\end{array}$ & & $\begin{array}{ll}2 & 57 \cdot 25 \\
2 & 42 \cdot 34 \\
2 & 26 \cdot 98\end{array}$ & $\begin{array}{l}0.611 \\
0.631 \\
0.649\end{array}$ \\
\hline $\begin{array}{l}\text { Sat. } \\
\text { Sun. } \\
\text { Mon. }\end{array}$ & $\begin{array}{l}25 \\
26 \\
27\end{array}$ & $\begin{array}{lll}10 & 13 & 33 \cdot 02 \\
10 & 17 & 13 \cdot 28 \\
10 & 20 & 53 \cdot 12\end{array}$ & $\begin{array}{l}9 \cdot 187 \\
9 \cdot 169 \\
9 \cdot 151\end{array}$ & $\begin{array}{rrrr}10 & 59 & 46 \cdot 2 \\
10 & 39 & 5 \cdot 2 \\
10 & 18 & 14 \cdot 1\end{array}$ & $\begin{array}{l}51 \cdot 49 \\
51 \cdot 92 \\
52 \cdot 33\end{array}$ & $\begin{array}{ll}1 & 4.76 \\
1 & 4.70 \\
1 & 4.64\end{array}$ & $\begin{array}{ll}2 & 11 \cdot 17 \\
1 & 54 \cdot 92 \\
1 & 38 \cdot 25\end{array}$ & $\begin{array}{l}0.668 \\
0.686 \\
0.703\end{array}$ \\
\hline $\begin{array}{l}\text { Tues. } \\
\text { Wed. } \\
\text { Thur. } \\
\text { Frid. }\end{array}$ & $\begin{array}{l}28 \\
29 \\
30 \\
31\end{array}$ & $\begin{array}{lll}10 & 24 & 32 \cdot 55 \\
10 & 28 & 11 \cdot 58 \\
10 & 31 & 50 \cdot 24 \\
10 & 35 & 28.55\end{array}$ & $\begin{array}{l}9 \cdot 135 \\
9 \cdot 119 \\
9 \cdot 104 \\
9 \cdot 089\end{array}$ & $\begin{array}{lrr}9 & 57 & 13 \cdot 2 \\
9 & 36 & 3 \cdot 0 \\
9 & 14 & 43 \cdot 6 \\
8 & 53 & 15 \cdot 5\end{array}$ & $\begin{array}{l}52 \cdot 73 \\
53 \cdot 12 \\
53 \cdot 49 \\
53 \cdot 85\end{array}$ & $\begin{array}{ll}1 & 4.58 \\
1 & 4.53 \\
1 & 4.48 \\
1 & 4.43\end{array}$ & $\begin{array}{rr}1 & 21 \cdot 17 \\
1 & 3 \cdot 70 \\
0 & 45 \cdot \times 6 \\
0 & 27 \cdot 66\end{array}$ & $\begin{array}{l}0.720 \\
0.736 \\
0.751 \\
0.765\end{array}$ \\
\hline Sat. & 32 & 10396.52 & $9 \cdot 075$ & N. 83138.9 & $54 \cdot 19$ & $14 \cdot 38$ & $\begin{array}{ll}0 & 9 \cdot 13\end{array}$ & 0.779 \\
\hline
\end{tabular}

* Mean Time of the Semidiameter passing may be found by subtracting 0 - $\cdot 18$ from the Sidereal Time. 
II.

AUGUST.

AT MEAN NOON.

\begin{tabular}{|c|c|c|c|c|c|c|}
\hline & & & THE SUN'S & & & \\
\hline Da & & $\begin{array}{c}\text { Apparent. } \\
\text { Right Ascension. }\end{array}$ & $\begin{array}{c}\text { Apparent } \\
\text { Declination. }\end{array}$ & Semidiameter.* & $\begin{array}{l}\text { from Mean } \\
\text { Time. }\end{array}$ & Sidereal Time. \\
\hline $\begin{array}{l}\text { Wed. } \\
\text { Thur. } \\
\text { Frid. }\end{array}$ & $\begin{array}{l}1 \\
2 \\
3\end{array}$ & $\begin{array}{lcc}\text { h. } & \text { m. } & \text { s. } \\
8 & 42 & 54 \cdot 43 \\
8 & 46 & 47 \cdot 50 \\
8 & 50 & 39 \cdot 96\end{array}$ & $\begin{array}{rcc}\circ & \prime & \prime \prime \\
\text { N. } 18 & 11 & 48 \cdot 8 \\
17 & 56 & 45 \cdot 8 \\
17 & 41 & 25 \cdot 1\end{array}$ & $\begin{array}{cc}\prime & \prime \prime \\
15 & 47 \cdot 14 \\
15 & 47 \cdot 27 \\
15 & 47 \cdot 40\end{array}$ & \begin{tabular}{lr} 
m. & \multicolumn{1}{c}{ s. } \\
6 & $10 \cdot 24$ \\
6 & $6 \cdot 75$ \\
6 & $2 \cdot 66$
\end{tabular} & $\begin{array}{lcc}\text { h. } & \text { m. } & \text { s. } \\
8 & 36 & 44 \cdot 19 \\
8 & 40 & 40 \cdot 75 \\
8 & 44 & 37 \cdot 30\end{array}$ \\
\hline $\begin{array}{l}\text { Sat. } \\
\text { Sun. } \\
\text { Mon. }\end{array}$ & $\begin{array}{l}4 \\
5 \\
6\end{array}$ & $\begin{array}{rrr}8 & 54 & 31 \cdot 81 \\
8 & 58 & 23 \cdot 05 \\
9 & 2 & 13 \cdot 70\end{array}$ & $\begin{array}{rrr}17 & 25 & 47 \cdot 2 \\
17 & 9 & 52 \cdot 4 \\
16 & 53 & 40 \cdot 8\end{array}$ & $\begin{array}{ll}15 & 47 \cdot 53 \\
15 & 47 \cdot 67 \\
15 & 47 \cdot 81\end{array}$ & $\begin{array}{ll}5 & 57 \cdot 95 \\
5 & 52 \cdot 64 \\
5 & 46 \cdot 73\end{array}$ & $\begin{array}{lll}8 & 48 & 33 \cdot 86 \\
8 & 52 & 30 \cdot 41 \\
8 & 56 & 26.97\end{array}$ \\
\hline $\begin{array}{l}\text { Tues. } \\
\text { Wed. } \\
\text { Thur. }\end{array}$ & $\begin{array}{l}7 \\
8 \\
9\end{array}$ & $\begin{array}{rrr}9 & 6 & 3 \cdot 76 \\
9 & 9 & 53 \cdot 25 \\
9 & 13 & 42 \cdot 16\end{array}$ & $\begin{array}{rrr}16 & 37 & 12 \cdot 8 \\
16 & 20 & 28 \cdot 7 \\
16 & 3 & 28 \cdot 8\end{array}$ & $\begin{array}{ll}15 & 47 \cdot 95 \\
15 & 48 \cdot 09 \\
15 & 48 \cdot 24\end{array}$ & $\begin{array}{ll}5 & 40 \cdot 24 \\
5 & 33 \cdot 17 \\
5 & 25 \cdot 52\end{array}$ & $\begin{array}{lll}9 & 0 & 23 \cdot 52 \\
9 & 4 & 20 \cdot 08 \\
9 & 8 & 16 \cdot 63\end{array}$ \\
\hline $\begin{array}{l}\text { Frid. } \\
\text { Sat. } \\
\text { Sun. }\end{array}$ & $\begin{array}{l}10 \\
11 \\
12\end{array}$ & $\begin{array}{llr}9 & 17 & 30 \cdot 50 \\
9 & 21 & 18 \cdot 29 \\
9 & 25 & 5 \cdot 52\end{array}$ & $\begin{array}{lll}15 & 46 & 13 \cdot 4 \\
15 & 28 & 42 \cdot 7 \\
15 & 10 & 57 \cdot 0\end{array}$ & $\begin{array}{ll}15 & 48 \cdot 39 \\
15 & 48 \cdot 54 \\
15 & 48 \cdot 69\end{array}$ & $\begin{array}{lr}5 & 17 \cdot 32 \\
5 & 8 \cdot 55 \\
4 & 59 \cdot 23\end{array}$ & $\begin{array}{rrr}9 & 12 & 13 \cdot 19 \\
9 & 16 & 9 \cdot 74 \\
9 & 20 & 6 \cdot 29\end{array}$ \\
\hline $\begin{array}{l}\text { Mon. } \\
\text { Tues. } \\
\text { Wed. }\end{array}$ & $\begin{array}{l}13 \\
14 \\
15\end{array}$ & $\begin{array}{lll}9 & 28 & 52 \cdot 22 \\
9 & 32 & 38 \cdot 37 \\
9 & 36 & 23 \cdot 98\end{array}$ & $\begin{array}{lll}14 & 52 & 56 \cdot 8 \\
14 & 34 & 42 \cdot 2 \\
14 & 16 & 13 \cdot 6\end{array}$ & & $\begin{array}{ll}4 & 49 \cdot 37 \\
4 & 38 \cdot 96 \\
4 & 28 \cdot 02\end{array}$ & $\begin{array}{rrr}9 & 24 & 2 \cdot 85 \\
9 & 27 & 59 \cdot 40 \\
9 & 31 & 55 \cdot 96\end{array}$ \\
\hline $\begin{array}{l}\text { Thur. } \\
\text { Frid. } \\
\text { Sat. }\end{array}$ & $\begin{array}{l}16 \\
17 \\
18\end{array}$ & $\begin{array}{rrr}9 & 40 & 9 \cdot 08 \\
9 & 43 & 53 \cdot 66 \\
9 & 47 & 37 \cdot 74\end{array}$ & $\begin{array}{lll}13 & 57 & 31 \cdot 4 \\
13 & 38 & 35 \cdot 7 \\
13 & 19 & 27 \cdot 0\end{array}$ & $\begin{array}{ll}15 & 49 \cdot 36 \\
15 & 49 \cdot 54 \\
15 & 49 \cdot 72\end{array}$ & $\begin{array}{rr}4 & 16 \cdot 57 \\
4 & 4 \cdot 60 \\
3 & 52 \cdot 12\end{array}$ & $\begin{array}{lll}9 & 35 & 52 \cdot 51 \\
9 & 39 & 49 \cdot 07 \\
9 & 43 & 45 \cdot 62\end{array}$ \\
\hline $\begin{array}{l}\text { Sun. } \\
\text { Mon. } \\
\text { Tues. }\end{array}$ & $\begin{array}{l}19 \\
20 \\
21\end{array}$ & $\begin{array}{rrrr}9 & 51 & 21 \cdot 31 \\
9 & 55 & 4 \cdot 39 \\
9 & 58 & 46.99\end{array}$ & $\begin{array}{rrr}13 & 0 & 5 \cdot 5 \\
12 & 40 & 31 \cdot 7 \\
12 & 20 & 45 \cdot 8\end{array}$ & $\begin{array}{ll}15 & 49 \cdot 90 \\
15 & 50 \cdot 09 \\
15 & 50 \cdot 29\end{array}$ & $\begin{array}{ll}3 & 39 \cdot 14 \\
3 & 25 \cdot 67 \\
3 & 11 \cdot 71\end{array}$ & $\begin{array}{lll}9 & 47 & 42 \cdot 17 \\
9 & 51 & 38 \cdot 73 \\
9 & 55 & 35 \cdot 28\end{array}$ \\
\hline $\begin{array}{l}\text { Wed. } \\
\text { Thur. } \\
\text { Frid. }\end{array}$ & $\begin{array}{l}22 \\
23 \\
24\end{array}$ & $\begin{array}{lll}10 & 2 & 29 \cdot 11 \\
10 & 6 & 10 \cdot 76 \\
10 & 9 & 51 \cdot 95\end{array}$ & $\begin{array}{rrr}12 & 0 & 48 \cdot 1 \\
11 & 40 & 39 \cdot 0 \\
11 & 20 & 18 \cdot 9\end{array}$ & $\begin{array}{ll}15 & 50 \cdot 49 \\
15 & 50 \cdot 69 \\
15 & 50.90\end{array}$ & $\begin{array}{ll}2 & 57 \cdot 28 \\
2 & 42 \cdot 37 \\
2 & 27 \cdot 00\end{array}$ & $\begin{array}{rrrr}9 & 59 & 31 \cdot 83 \\
10 & 3 & 28 \cdot 39 \\
10 & 7 & 24 \cdot 94\end{array}$ \\
\hline $\begin{array}{l}\text { Sat. } \\
\text { Sun. } \\
\text { Mon. }\end{array}$ & $\begin{array}{l}25 \\
26 \\
27\end{array}$ & $\begin{array}{lll}10 & 13 & 32 \cdot 69 \\
10 & 17 & 12 \cdot 99 \\
10 & 20 & 52 \cdot 87\end{array}$ & $\begin{array}{rrr}10 & 59 & 48 \cdot 1 \\
10 & 39 & 6 \cdot 8 \\
10 & 18 & 15 \cdot 5\end{array}$ & $\begin{array}{ll}15 & 51 \cdot 11 \\
15 & 51 \cdot 32 \\
15 & 51 \cdot 54\end{array}$ & $\begin{array}{ll}2 & 11 \cdot 19 \\
1 & 54 \cdot 94 \\
1 & 38 \cdot 27\end{array}$ & $\begin{array}{lll}10 & 11 & 21 \cdot 50 \\
10 & 15 & 18 \cdot 05 \\
10 & 19 & 14 \cdot 60\end{array}$ \\
\hline $\begin{array}{l}\text { Tues. } \\
\text { Wed. } \\
\text { Thur. } \\
\text { Frid. }\end{array}$ & $\begin{array}{l}28 \\
29 \\
30 \\
31\end{array}$ & $\begin{array}{lll}10 & 24 & 32 \cdot 34 \\
10 & 28 & 11 \cdot 42 \\
10 & 31 & 50 \cdot 13 \\
10 & 35 & 28 \cdot 48\end{array}$ & $\begin{array}{rrr}9 & 57 & 14 \cdot 4 \\
9 & 36 & 3 \cdot 9 \\
9 & 14 & 44 \cdot 3 \\
8 & 53 & 15 \cdot 9\end{array}$ & $\begin{array}{ll}15 & 51 \cdot 76 \\
15 & 51 \cdot 99 \\
15 & 52 \cdot 21 \\
15 & 52 \cdot 44\end{array}$ & $\begin{array}{rr}1 & 21 \cdot 19 \\
1 & 3 \cdot 71 \\
0 & 45 \cdot 87 \\
0 & 27 \cdot 67\end{array}$ & $\begin{array}{rrr}10 & 23 & 11 \cdot 15 \\
10 & 27 & 7 \cdot 71 \\
10 & 31 & 4 \cdot 26 \\
10 & 35 & 0 \cdot 81\end{array}$ \\
\hline Sat. & 32 & $1039 \quad 6 \cdot 49$ & N. $83139 \cdot 1$ & $1552 \cdot 67$ & $\begin{array}{ll}0 & 9 \cdot 13\end{array}$ & $1038 \quad 57 \cdot 37$ \\
\hline
\end{tabular}

* The Semidiameter for Apparent Noon may be assumed the same as that for Mean Noon. 
AUGUST.

III.

MEAN TIME.

\begin{tabular}{|c|c|c|c|c|c|c|c|c|}
\hline \multirow{3}{*}{ ay. } & \multicolumn{2}{|c|}{$\begin{array}{c}\text { THE SUN'S } \\
\text { Apparent }\end{array}$} & \multirow{2}{*}{$\begin{array}{l}\text { Logarithm } \\
\text { of the } \\
\text { Radius } \\
\text { Vector of } \\
\text { the Earth. }\end{array}$} & \multirow{3}{*}{$\begin{array}{c}\text { Transit of } \\
\text { the First } \\
\text { Point of } \\
\text { Aries. }\end{array}$} & \multicolumn{4}{|c|}{ THE MOON'S } \\
\hline & Longitude. & Latitude. & & & \multicolumn{2}{|c|}{ Semidiameter. } & \multicolumn{2}{|c|}{ Horizontal Parallax. } \\
\hline & Noon. & Noon. & Noon. & & Noon. & Midnight. & Noon. & Midnight. \\
\hline $\begin{array}{l}1 \\
2 \\
3\end{array}$ & $\begin{array}{ccc}\circ & \prime & \prime \prime \\
128 & 18 & 11 \cdot 6 \\
129 & 15 & 35 \cdot 7 \\
130 & 13 & 0 \cdot 6\end{array}$ & 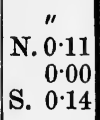 & $\begin{array}{r}0.0063890 \\
\cdot 0063306 \\
\cdot 0062709\end{array}$ & $\begin{array}{lll}\text { h. } & \text { m. } & \text { s. } \\
15 & 20 & 44 \cdot 55 \\
15 & 16 & 48 \cdot 64 \\
15 & 12 & 52 \cdot 73\end{array}$ & $\begin{array}{cc}\prime & \prime \prime \\
16 & 20 \cdot 78 \\
16 & 18 \cdot 62 \\
16 & 13 \cdot 34\end{array}$ & \begin{tabular}{cc}
$\prime$ & \multicolumn{1}{c}{} \\
16 & $20 \cdot 09$ \\
16 & $16 \cdot 37$ \\
16 & $9 \cdot 57$
\end{tabular} & $\begin{array}{cc}\prime & \prime \prime \\
59 & 53 \cdot 36 \\
59 & 45 \cdot 45 \\
59 & 26.08\end{array}$ & $\begin{array}{cc}\prime \prime & \prime \prime \\
59 & 50 \cdot 83 \\
59 & 37 \cdot 19 \\
59 & 12 \cdot 27\end{array}$ \\
\hline $\begin{array}{l}4 \\
5 \\
6\end{array}$ & $\begin{array}{rrr}131 & 10 & 26 \cdot 3 \\
132 & 7 & 53 \cdot 0 \\
133 & 5 & 20 \cdot 7\end{array}$ & $\begin{array}{l}0.28 \\
0.42 \\
0.55\end{array}$ & $\begin{array}{r}0 \cdot 0062101 \\
\cdot 0061481 \\
\cdot 0060850\end{array}$ & $\begin{array}{rrr}15 & 8 & 56.83 \\
15 & 5 & 0.92 \\
15 & 1 & 5.01\end{array}$ & $\begin{array}{rr}16 & 5 \cdot 12 \\
15 & 54 \cdot 56 \\
15 & 42 \cdot 52\end{array}$ & $\begin{array}{rr}16 & 0.09 \\
15 & 48 \cdot 67 \\
15 & 36 \cdot 24\end{array}$ & $\begin{array}{lll}58 & 55 \cdot 98 \\
58 & 17 \cdot 30 \\
57 & 33 \cdot 14\end{array}$ & $\begin{array}{lll}58 & 37 \cdot 55 \\
57 & 55 \cdot 68 \\
57 & 10 \cdot 13\end{array}$ \\
\hline $\begin{array}{l}7 \\
8 \\
9\end{array}$ & $\begin{array}{rrr}134 & 2 & 49 \cdot 6 \\
135 & 0 & 19 \cdot 8 \\
135 & 57 & 51 \cdot 3\end{array}$ & $\begin{array}{l}0.67 \\
0.76 \\
0.83\end{array}$ & $\begin{array}{r}0.0060207 \\
\cdot 0059551 \\
\cdot 0058881\end{array}$ & $\begin{array}{rrr}14 & 57 & 9 \cdot 10 \\
14 & 53 & 13 \cdot 19 \\
14 & 49 & 17 \cdot 28\end{array}$ & $\begin{array}{rr}15 & 29 \cdot 96 \\
15 & 17 \cdot 90 \\
15 & 7 \cdot 18\end{array}$ & $\mid \begin{array}{rr}15 & 23 \cdot 81 \\
15 & 12 \cdot 33 \\
15 & 2 \cdot 53\end{array}$ & $\begin{array}{rr}56 & 47 \cdot 15 \\
56 & 2 \cdot 95 \\
55 & 23 \cdot 65\end{array}$ & $\begin{array}{rr}56 & 24 \cdot 62 \\
55 & 42 \cdot 51 \\
55 & 6 \cdot 64\end{array}$ \\
\hline $\begin{array}{l}10 \\
11 \\
12\end{array}$ & $\begin{array}{lll}136 & 55 & 24 \cdot 1 \\
137 & 52 & 58 \cdot 3 \\
138 & 50 & 33 \cdot 9\end{array}$ & $\begin{array}{l}0.88 \\
0.91 \\
0.90\end{array}$ & $\begin{array}{r}0.0058197 \\
\cdot 0057498 \\
\cdot 0056782\end{array}$ & $\begin{array}{lll}14 & 45 & 21 \cdot 37 \\
14 & 41 & 25 \cdot 46 \\
14 & 37 & 29 \cdot 55\end{array}$ & & & & \\
\hline $\begin{array}{l}13 \\
14 \\
15\end{array}$ & $\begin{array}{lll}139 & 48 & 11 \cdot 0 \\
140 & 45 & 49 \cdot 6 \\
141 & 43 & 29 \cdot 6\end{array}$ & $\begin{array}{l}0.86 \\
0.80 \\
0.71\end{array}$ & $\begin{array}{r}0.0056050 \\
.0055300 \\
.0054531\end{array}$ & $\begin{array}{lll}14 & 33 & 33 \cdot 64 \\
14 & 29 & 37 \cdot 74 \\
14 & 25 & 41 \cdot 83\end{array}$ & & & & \\
\hline $\begin{array}{l}16 \\
17 \\
18\end{array}$ & $\begin{array}{lll}142 & 41 & 11 \cdot 1 \\
143 & 38 & 54 \cdot 1 \\
144 & 36 & 38 \cdot 5\end{array}$ & $\begin{array}{l}0.61 \\
0.49 \\
0.36\end{array}$ & $\begin{array}{r}0.0053744 \\
.0052936 \\
.0052108\end{array}$ & $\begin{array}{lll}14 & 21 & 45 \cdot 92 \\
14 & 17 & 50 \cdot 01 \\
14 & 13 & 54 \cdot 11\end{array}$ & $\begin{array}{rr}15 & 1 \cdot 38 \\
15 & 9 \cdot 70 \\
15 & 19 \cdot 06\end{array}$ & $\begin{array}{rr}15 & 5 \cdot 37 \\
15 & 14 \cdot 30 \\
15 & 23 \cdot 93\end{array}$ & $\begin{array}{rr}55 & 2 \cdot 42 \\
55 & 32 \cdot 91 \\
56 & 7 \cdot 22\end{array}$ & \\
\hline $\begin{array}{l}19 \\
20 \\
21\end{array}$ & $\begin{array}{rrr}145 & 34 & 24 \cdot 4 \\
146 & 32 & 11 \cdot 7 \\
147 & 30 & 0 \cdot 4\end{array}$ & $\begin{array}{rr} & 0.23 \\
\text { S. } & 0.09 \\
\text { N. } & 0.03\end{array}$ & $\begin{array}{r}0.0051260 \\
.0050390 \\
.0049500\end{array}$ & $\begin{array}{rrr}14 & 9 & 58 \cdot 20 \\
14 & 6 & 2 \cdot 29 \\
14 & 2 & 6 \cdot 38\end{array}$ & & & $\begin{array}{|ll|}56 & 42 \cdot 94 \\
57 & 17 \cdot 80 \\
57 & 49 \cdot 84\end{array}$ & $\begin{array}{rr}57 & 0 \cdot 61 \\
57 & 34 \cdot 29 \\
58 & 4 \cdot 29\end{array}$ \\
\hline $\begin{array}{l}22 \\
23 \\
24\end{array}$ & $\begin{array}{lll}148 & 27 & 50 \cdot 4 \\
149 & 25 & 41 \cdot 7 \\
150 & 23 & 34 \cdot 2\end{array}$ & $\begin{array}{l}0.13 \\
0.20 \\
0.24\end{array}$ & $\begin{array}{r}0.0048589 \\
\cdot 0047659 \\
\cdot 0046710\end{array}$ & $\begin{array}{lll}13 & 58 & 10 \cdot 48 \\
13 & 54 & 14 \cdot 57 \\
13 & 50 & 18.66\end{array}$ & $\begin{array}{rr}15 & 54 \cdot 63 \\
16 & 0 \cdot 78 \\
16 & 5 \cdot 45\end{array}$ & $\begin{array}{rr}15 & 57 \cdot 89 \\
16 & 3 \cdot 30 \\
16 & 7 \cdot 25\end{array}$ & & $\begin{array}{rr}58 & 29 \cdot 47 \\
58 & 49 \cdot 32 \\
59 & 3 \cdot 76\end{array}$ \\
\hline $\begin{array}{l}25 \\
26 \\
27\end{array}$ & $\begin{array}{lll}151 & 21 & 28 \cdot 0 \\
152 & 19 & 23 \cdot 0 \\
153 & 17 & 19 \cdot 2\end{array}$ & $\begin{array}{l}0.26 \\
0.26 \\
0.21\end{array}$ & $\begin{array}{r}0.0045743 \\
\cdot 0044761 \\
\cdot 0043765\end{array}$ & $\begin{array}{lll}13 & 46 & 22 \cdot 75 \\
13 & 42 & 26 \cdot 85 \\
13 & 38 & 30 \cdot 94\end{array}$ & $\begin{array}{rr}16 & 8 \cdot 68 \\
16 & 10.55 \\
16 & 11.08\end{array}$ & $\begin{array}{rr}16 & 9 \cdot 78 \\
16 & 10 \cdot 98 \\
16 & 10.85\end{array}$ & $\left|\begin{array}{rr}59 & 9 \cdot 02 \\
59 & 15 \cdot 85 \\
59 & 17 \cdot 81\end{array}\right|$ & $\begin{array}{lll}59 & 13.05 \\
59 & 17 \cdot 45 \\
59 & 16.95\end{array}$ \\
\hline $\begin{array}{l}28 \\
29 \\
30 \\
31\end{array}$ & $\begin{array}{rrr}154 & 15 & 16 \cdot 7 \\
155 & 13 & 15 \cdot 5 \\
156 & 11 & 15 \cdot 6 \\
157 & 9 & 17 \cdot 1\end{array}$ & $\begin{array}{r}0.13 \\
\text { N. } 0.03 \\
\text { S. } 0.10 \\
0.23\end{array}$ & $\begin{array}{r}0.0042756 \\
\cdot 0041736 \\
\cdot 0040708 \\
\cdot 0039672\end{array}$ & $\mid \begin{array}{lll}13 & 34 & 35 \cdot 03 \\
13 & 30 & 39 \cdot 12 \\
13 & 26 & 43 \cdot 22 \\
13 & 22 & 47 \cdot 31\end{array}$ & $\begin{array}{rr}16 & 10 \cdot 26 \\
16 & 7 \cdot 97 \\
16 & 4.07 \\
15 & 58 \cdot 48\end{array}$ & $\begin{array}{rr}16 & 9 \cdot 30 \\
16 & 6 \cdot 23 \\
16 & 1 \cdot 49 \\
15 & 55.06\end{array}$ & $\mid \begin{array}{rr}59 & 14 \cdot 80 \\
59 & 6 \cdot 40 \\
58 & 52 \cdot 12 \\
58 & 31 \cdot 65\end{array}$ & \begin{tabular}{|rr}
59 & $11 \cdot 29$ \\
59 & $0 \cdot 02$ \\
58 & $42 \cdot 66$ \\
58 & $19 \cdot 13$
\end{tabular} \\
\hline 32 & $158720 \cdot 1$ & S. 0.36 & 0.0038629 & $131851 \cdot 40$ & $1551 \cdot 25$ & $1547 \cdot 09$ & $58 \quad 5 \cdot 16$ & 5749.88 \\
\hline
\end{tabular}


AUGUST.

MEAN TIME.

\begin{tabular}{|c|c|c|c|c|c|c|c|}
\hline \multirow{3}{*}{ Day. } & \multicolumn{7}{|c|}{ THE MOON'S } \\
\hline & \multicolumn{2}{|c|}{ Longitude. } & \multicolumn{2}{|c|}{ Latitude. } & \multirow{2}{*}{$\frac{\text { Age. }}{\text { Noon. }}$} & \multicolumn{2}{|c|}{ Meridian Passage. } \\
\hline & Noon. & Midnight. & Noon. & Midnight. & & Opper. & Lower. \\
\hline $\begin{array}{l}1 \\
\mathbf{2} \\
\mathbf{3}\end{array}$ & \begin{tabular}{crc}
$\circ$ & \multicolumn{1}{c}{} & $\prime \prime$ \\
267 & 36 & $27 \cdot 5$ \\
282 & 5 & $51 \cdot 2$ \\
296 & 28 & $14 \cdot 8$
\end{tabular} \mid & $\begin{array}{ccc}\circ & \prime & \prime \prime \\
274 & 51 & 41 \cdot 4 \\
289 & 18 & 15 \cdot 8 \\
303 & 35 & 10 \cdot 3\end{array}$ & $\begin{array}{ccc}\circ & \prime & \prime \prime \\
\text { N. } 3 & 40 & 55 \cdot 7 \\
2 & 36 & 59 \cdot 9 \\
1 & 23 & 35 \cdot 1\end{array}$ & \begin{tabular}{rrr}
$\circ$ & 1 & \multicolumn{1}{c}{} \\
N. 3 & 10 & $27 \cdot 6$ \\
2 & 1 & $9 \cdot 3$ \\
N. 0 & 44 & $57 \cdot 9$
\end{tabular} & \begin{tabular}{c|} 
d. \\
$10 \cdot 96$ \\
$11 \cdot 96$ \\
$12 \cdot 96$
\end{tabular} & $\begin{array}{rc}\text { h. } & \text { m. } \\
9 & 36 \cdot 2 \\
10 & 36 \cdot 3 \\
11 & 35 \cdot 3\end{array}$ & $\begin{array}{cl}\text { b. } & \text { m. } \\
22 & 6 \cdot 3 \\
23 & 6 \cdot 1 \\
* & *\end{array}$ \\
\hline $\begin{array}{l}4 \\
5 \\
6\end{array}$ & $\left|\begin{array}{rrr}310 & 38 & 27 \cdot 3 \\
324 & 32 & 7 \cdot 9 \\
338 & 6 & 16 \cdot 1\end{array}\right|$ & $\begin{array}{lll}317 & 37 & 34 \cdot 9 \\
331 & 21 & 46 \cdot 3 \\
344 & 45 & 29 \cdot 9\end{array}$ & $\begin{array}{rrr}\text { N. } 0 & 5 & 58.7 \\
\text { S. } 1 & 10 & 30.5 \\
2 & 21 & 11.7\end{array}$ & $\begin{array}{rrr}\text { S. } 0 & 32 & 43 \cdot 1 \\
1 & 46 & 50 \cdot 0 \\
2 & 53 & 10 \cdot 2\end{array}$ & & & $\begin{array}{rr}0 & 3.8 \\
0 & 58.5 \\
1 & 49.8\end{array}$ \\
\hline $\begin{array}{l}7 \\
8 \\
9\end{array}$ & $\begin{array}{rrr}351 & 19 & 26 \cdot 2 \\
4 & 11 & 50 \cdot 1 \\
16 & 45 & 7 \cdot 5\end{array}$ & $\begin{array}{rrr}357 & 48 & 9 \cdot 6 \\
10 & 30 & 42 \cdot 7 \\
22 & 55 & 27 \cdot 9\end{array}$ & $\begin{array}{lll}3 & 22 & 24 \cdot 8 \\
4 & 11 & 39 \cdot 6 \\
4 & 47 & 28 \cdot 8\end{array}$ & $\begin{array}{rrr}3 & 48 & 38 \cdot 9 \\
4 & 31 & 18 \cdot 2 \\
5 & 0 & 7 \cdot 9\end{array}$ & & $\begin{array}{rr}15 & 1 \cdot 2 \\
15 & 46 \cdot 1 \\
16 & 29 \cdot 9\end{array}$ & $\begin{array}{lr}2 & 38 \cdot 1 \\
3 & 23 \cdot 9 \\
4 & 8 \cdot 1\end{array}$ \\
\hline $\begin{array}{l}10 \\
11 \\
12\end{array}$ & $\begin{array}{llr}29 & 2 & 10 \cdot 7 \\
41 & 6 & 43 \cdot 5 \\
53 & 3 & 4 \cdot 6\end{array}$ & $\begin{array}{rrr}35 & 5 & 45 \cdot 3 \\
47 & 5 & 38 \cdot 5 \\
58 & 59 & 36 \cdot 3\end{array}$ & $\begin{array}{rrr}5 & 9 & 14 \cdot 3 \\
5 & 16 & 53 \cdot 0 \\
5 & 10 & \mathbf{4 3} \cdot 5\end{array}$ & $\begin{array}{rrr}5 & 14 & 48 \cdot 8 \\
5 & 15 & 30 \cdot 0 \\
5 & 2 & 38 \cdot 3\end{array}$ & & & $\begin{array}{ll}4 & 51 \cdot 6 \\
5 & 35 \cdot 0 \\
6 & 19 \cdot 2\end{array}$ \\
\hline $\begin{array}{l}13 \\
14 \\
15\end{array}$ & $\begin{array}{llll}64 & 55 & 48 \cdot 3 \\
76 & 49 & 30 \cdot 6 \\
88 & 48 & 34 \cdot 1\end{array}$ & $\begin{array}{llr}70 & 52 & 15 \cdot 3 \\
82 & 48 & 6 \cdot 6 \\
94 & 51 & 21 \cdot 6\end{array}$ & $\begin{array}{lrr}4 & 51 & 19 \cdot 2 \\
4 & 19 & 25 \cdot 5 \\
3 & 36 & 1 \cdot 4\end{array}$ & $\begin{array}{llr}4 & 36 & 52 \cdot 7 \\
3 & 59 & 5 \cdot 3 \\
3 & 10 & 24 \cdot 4\end{array}$ & & $\begin{array}{rr}19 & 27 \cdot 9 \\
20 & 15 \cdot 7 \\
21 & 4 \cdot 9\end{array}$ & $\begin{array}{rr}7 & 4 \cdot 7 \\
7 & 51 \cdot 6 \\
8 & 40 \cdot 1\end{array}$ \\
\hline $\begin{array}{l}16 \\
17 \\
18\end{array}$ & $\begin{array}{lll}100 & 56 & 55 \cdot 5 \\
113 & 17 & 53 \cdot 5 \\
125 & 53 & 57 \cdot 0\end{array}$ & $\begin{array}{rrr}107 & 5 & 39 \cdot 4 \\
119 & 33 & 55 \cdot 0 \\
132 & 18 & 8 \cdot 7\end{array}$ & $\begin{array}{rrr}242 & 26 \cdot 5 \\
1 & 4027 \cdot 0 \\
\text { S. } 032 & 24 \cdot 6\end{array}$ & $\begin{array}{rrr}2 & 12 & 21 \cdot 8 \\
\text { S. } 1 & 7 & 0 \cdot 9 \\
\text { N. } 0 & 2 & 57 \cdot 9\end{array}$ & & $\begin{array}{ll}21 & 55 \cdot 3 \\
22 & 46 \cdot 2 \\
23 & 37 \cdot 1\end{array}$ & $\begin{array}{rr}9 & 30 \cdot 0 \\
10 & 20 \cdot 7 \\
11 & 11 \cdot 7\end{array}$ \\
\hline $\begin{array}{l}19 \\
20 \\
21\end{array}$ & $\begin{array}{lll}138 & 46 & 35 \cdot 5 \\
151 & 56 & 14 \cdot 0 \\
165 & 22 & 11 \cdot 8\end{array}$ & $\begin{array}{|lll|}145 & 19 & 18 \cdot 4 \\
158 & 37 & 15 \cdot 4 \\
172 & 10 & 48 \cdot 4\end{array}$ & $\begin{array}{rrr}\text { N. } 0 & 38 & 40.6 \\
1 & 49 & 11.5 \\
2 & 55 & 4.4\end{array}$ & $\begin{array}{lll}1 & 14 & 15 \cdot 3 \\
2 & 22 & 58 \cdot \tilde{5} \\
3 & 24 & 57 \cdot 6\end{array}$ & $\begin{array}{r}28 \cdot 96 \\
0.44 \\
1.44\end{array}$ & $\begin{array}{cc}* & * \\
0 & 27 \cdot 7 \\
1 & 17 \cdot 7\end{array}$ & $\begin{array}{rr}12 & 2 \cdot 5 \\
12 & 52 \cdot 7 \\
13 & 42 \cdot 5\end{array}$ \\
\hline $\begin{array}{l}22 \\
23 \\
24\end{array}$ & $\begin{array}{rrr}\mathbf{1 7 9} & \mathbf{2} & \mathbf{4 8} \cdot 8 \\
\mathbf{1 9 2} & \mathbf{5 5} & \mathbf{4 1} \cdot 3 \\
206 & \mathbf{5 7} & \mathbf{5 7} \cdot 0\end{array}$ & $\begin{array}{rrr}185 & 57 & 53 \cdot 6 \\
199 & 55 & 50 \cdot 1 \\
214 & 1 & 40 \cdot 0\end{array}$ & $\begin{array}{rrr}3 & 52 & 7 \cdot 6 \\
4 & 36 & 25 \cdot 7 \\
5 & 4 & 45 \cdot 0\end{array}$ & $\begin{array}{rrr}4 & 16 & 5 \cdot 7 \\
4 & 52 & 45 \cdot 1 \\
5 & 12 & 11 \cdot 2\end{array}$ & $\begin{array}{l}2 \cdot 44 \\
3 \cdot 44 \\
4 \cdot 44\end{array}$ & $\begin{array}{rr}2 & 7 \cdot 4 \\
2 & 57 \cdot 2 \\
3 & 47 \cdot 8\end{array}$ & $\begin{array}{ll}14 & 32 \cdot 2 \\
15 & 22 \cdot 4 \\
16 & 13 \cdot 6\end{array}$ \\
\hline $\begin{array}{l}25 \\
26 \\
27\end{array}$ & $\begin{array}{rrr}221 & 6 & 36 \cdot 7 \\
235 & 18 & 48 \cdot 9 \\
249 & 31 & 58 \cdot 6\end{array}$ & $\left|\begin{array}{lll}228 & 12 & 26 \cdot 4 \\
242 & 25 & 25 \cdot 6 \\
256 & 38 & 10 \cdot 7\end{array}\right|$ & $\begin{array}{rrr}\mathbf{5} & \mathbf{1 4} & 54 \cdot 0 \\
\mathbf{5} & \mathbf{5} & 56 \cdot 9 \\
4 & 38 & 19 \cdot 2\end{array}$ & $\begin{array}{lll}5 & 12 & 49 \cdot 1 \\
4 & 54 & 23 \cdot 5 \\
4 & 17 & 59 \cdot 5\end{array}$ & $\begin{array}{l}5 \cdot 44 \\
6 \cdot 44 \\
7 \cdot 44\end{array}$ & $\begin{array}{ll}4 & 39 \cdot 8 \\
5 & 33 \cdot 8 \\
6 & 29 \cdot 9\end{array}$ & $\begin{array}{rr}17 & 6 \cdot 6 \\
18 & 1 \cdot 6 \\
18 & 58 \cdot 6\end{array}$ \\
\hline $\begin{array}{l}28 \\
29 \\
30 \\
31\end{array}$ & $\begin{array}{rrr}263 & 43 & 46 \cdot 1 \\
277 & 52 & 2 \cdot 9 \\
291 & 54 & 41 \cdot 0 \\
305 & 49 & 27 \cdot 6\end{array}$ & $\begin{array}{lll}270 & 48 & 28 \cdot 8 \\
284 & 54 & 12 \cdot 5 \\
298 & 53 & 11 \cdot 9 \\
312 & 43 & 10 \cdot 9\end{array}$ & $\begin{array}{rrr}3 & 53 & 44 \cdot 3 \\
2 & 55 & 7 \cdot 5 \\
1 & 46 & 20 \cdot 8 \\
\text { N. } 0 & 31 & 55 \cdot 2\end{array}$ & $\begin{array}{rrr}3 & 25 & 57 \cdot 9 \\
2 & 21 & 44 \cdot 1 \\
\text { N. } 1 & 9 & 32 \cdot 5 \\
\text { S. } 0 & 5 & 55 \cdot 3\end{array}$ & $\begin{array}{r}8 \cdot 44 \\
9 \cdot 44 \\
10 \cdot 44 \\
11 \cdot 44\end{array}$ & $\begin{array}{rr}7 & 27 \cdot 6 \\
8 & 26 \cdot 1 \\
9 & 24 \cdot 0 \\
10 & 20 \cdot 2\end{array}$ & $\begin{array}{ll}19 & 56 \cdot 8 \\
20 & 55 \cdot 2 \\
21 & 52 \cdot 4 \\
22 & 47 \cdot 3\end{array}$ \\
\hline 32 & $\begin{array}{lll}319 & 34 & 4.8\end{array}$ & $326 \quad 2152 \cdot 0$ & S. 04323.4 & S. 11955.5 & $12 \cdot 44$ & $1113 \cdot 7$ & $2339 \cdot 4$ \\
\hline
\end{tabular}

The Moon's Longitude and Latitude are from Hansen's Tables; the Right Ascension and Declination contain Newcoms's corrections. 
AUGUST.

MEAN TIME.

THE MOON'S RIGHT ASCENSION AND DECLINATION.

\begin{tabular}{|c|c|c|c|c|c|c|c|c|c|}
\hline : & $\begin{array}{c}\text { Right } \\
\text { Ascension. }\end{array}$ & $\begin{array}{l}\text { Var. } \\
\text { in } 10 \mathrm{~m} .\end{array}$ & Declination. & $\begin{array}{l}\text { Var. } \\
\text { in } 10 \mathrm{~m} .\end{array}$ & 它 & $\underset{\text { Ascension. }}{\text { Right }}$ & $\begin{array}{l}\text { Var. } \\
\text { in } 10 \mathrm{~m} .\end{array}$ & Declination. & $\begin{array}{l}\text { Var. } \\
\text { in } 10 \mathrm{~m} .\end{array}$ \\
\hline
\end{tabular}

\begin{tabular}{l|l|l|l|l|l|}
0 & 1749 & 48.87 & 25.622 & S. 1944 & 44.6
\end{tabular}

$1 \quad 175222 \cdot 65 \quad 25 \cdot 638$

$2175456 \cdot 52 \quad 25 \cdot 653$

$31757 \quad 30 \cdot 48 \quad 25 \cdot 667$

$\begin{array}{lllll}4 & 18 & 0 & 4.52 & 25.679\end{array}$

$5 \quad 18 \quad 2 \quad 38 \cdot 63 \quad 25 \cdot 692$

$6 \begin{array}{llllll}18 & 5 & 12 \cdot 82 & 25 \cdot 703\end{array}$

$\begin{array}{llllll} & 18 & 7 & 47 \cdot 07 & 25 \cdot 713\end{array}$

$\begin{array}{lllllll}8 & 18 & 10 & 21 \cdot 38 & 25 \cdot 723\end{array}$

$9 \quad 1812 \quad 55 \cdot 74 \quad 25 \cdot 731$

$10 \quad 1815 \quad 30 \cdot 15 \quad 25 \cdot 738$

$11 \quad \begin{array}{lllll}18 & 18 & 4 \cdot 60 & 25 \cdot 744\end{array}$

$\begin{array}{llllll}12 & 18 & 20 & 39 \cdot 08 & 25 \cdot 749\end{array}$

$\begin{array}{llllll}13 & 18 & 23 & 13.59 & 25 \cdot 753\end{array}$

$\begin{array}{lllll}14 & 18 & 25 & 48 \cdot 12 & 25 \cdot 756\end{array}$

$\begin{array}{lllll}15 & 18 & 28 & 22 \cdot 66 & 25 \cdot 758\end{array}$

$\begin{array}{llllll}16 & 18 & 30 & 57 \cdot 21 & 25 \cdot 758\end{array}$

\begin{tabular}{lllll|l}
17 & 18 & 33 & $31 \cdot 76$ & $25 \cdot 758$
\end{tabular}

$\begin{array}{llllll}18 & 18 & 36 & 6 \cdot 31 & 25 \cdot 757\end{array}$

$\begin{array}{lllllll}19 & 18 & 38 & 40 \cdot 84 & 25 \cdot 754\end{array}$

$\begin{array}{llllll}20 & 18 & 41 & 15 \cdot 36 & 25 \cdot 752\end{array}$

$\begin{array}{llllll}21 & 18 & 43 & 49 \cdot 86 & 25 \cdot 747\end{array}$

$\begin{array}{llllll}22 & 18 & 46 & 24 \cdot 32 & 25 \cdot 741\end{array}$

\begin{tabular}{l|lll|l}
23 & 18 & 48 & $58 \cdot 75$ & $25 \cdot 734$
\end{tabular}

\section{Thursday 2.}

0|18 $5133.13|25 \cdot 726|$ S. 201734.5

$1 \quad$\begin{tabular}{lll|l}
18 & 54 & $7 \cdot 46$ & $25 \cdot 717$
\end{tabular}

$\begin{array}{lllllll}1 & 18 & 56 & 41 \cdot 73 & 25 \cdot 707\end{array}$

$\begin{array}{llllll}3 & 18 & 59 & 15.94 & 25.695\end{array}$

$\begin{array}{llllll}4 & 19 & 1 & 50.07 & 25 \cdot 683\end{array}$

$\begin{array}{llllll}5 & 19 & 4 & 24 \cdot 13 & 25 \cdot 670\end{array}$

$6 \begin{array}{llllll}6 & 19 & 6 & 58 \cdot 11 & 25 \cdot 656\end{array}$

$\begin{array}{llllll}7 & 19 & 9 & 32 \cdot 00 & 25 \cdot 640\end{array}$

$\begin{array}{llllll}8 & 19 & 12 & 5 \cdot 79 & 25 \cdot 623\end{array}$

$\begin{array}{llllll}8 & 19 & 14 & 39 \cdot 48 & 25 \cdot 606\end{array}$

\begin{tabular}{r|rrr|r}
10 & 19 & 17 & 13.06 & 25.588
\end{tabular}

$11 \quad 191946.53 \quad 25 \cdot 568$

\begin{tabular}{llll|l}
12 & 19 & 22 & $19 \cdot 88$ & $25 \cdot 548$
\end{tabular}

$\begin{array}{llllll}13 & 19 & 24 & 53 \cdot 10 & 25 \cdot 526\end{array}$

$\begin{array}{llllll}14 & 19 & 27 & 26 \cdot 19 & 25.503\end{array}$

$\begin{array}{llllll}15 & 19 & 29 & 59 \cdot 13 & 25 \cdot 478\end{array}$

$\begin{array}{llllll}16 & 19 & 32 & 31 \cdot 93 & 25 \cdot 454\end{array}$

\begin{tabular}{llll|l}
17 & 19 & 35 & 4.58 & 25.429
\end{tabular}

$18193737.08 \quad 25 \cdot 402$

\begin{tabular}{llll|l}
19 & 19 & 40 & $9 \cdot 41$ & $25 \cdot 374$
\end{tabular}

$\begin{array}{llllll}20 & 19 & 42 & 41 \cdot 57 & 25 \cdot 346\end{array}$

$\begin{array}{llllll}21 & 19 & 45 & 13.56 & 25 \cdot 317\end{array}$

$\begin{array}{llllll}22 & 19 & 47 & 45 \cdot 37 & 25 \cdot 287\end{array}$

$\begin{array}{llllll}23 & 19 & 50 & 17.00 & 25 \cdot 255\end{array}$

$241952 \quad 48 \cdot 43 \quad 25 \cdot 223$
$194742 \cdot 9$

195033.0

195314.8

$195548 \cdot 3$

$1958 \quad 13.5$

$\begin{array}{lll}20 & 0 & 30.4\end{array}$

$\begin{array}{lll}20 & 239 \cdot 0\end{array}$

$20 \quad 4392$

20631.0

$\begin{array}{llll}20 & 8 & 14.4\end{array}$

$\begin{array}{lll}20 & 9 & 49 \cdot 4\end{array}$

$2011 \quad 15 \cdot 9$

$201234 \cdot 0$

$2013 \quad 43 \cdot 7$

$2014 \quad 44 \cdot 9$

$201537 \cdot 7$

$201622 \cdot 0$

$201657 \cdot 8$

$201725 \cdot 1$

$201743 \cdot 9$

$201754 \cdot 3$

$201756 \cdot 2$

S. $201749 \cdot 6$

$201711 \cdot 0$

$201639 \cdot 1$

$201558 \cdot 7$

201510.0

$2014 \quad 12 \cdot 8$

$\begin{array}{llll}20 & 13 & 7 \cdot 3\end{array}$

$201153 \cdot 4$

$201031 \cdot 2$

$\begin{array}{lll}20 & 9 & 0.6\end{array}$

$20721 \cdot 8$

$20 \quad 534 \cdot 7$

$20339 \cdot 4$

$\begin{array}{lll}20 & 1 & 35 \cdot 9\end{array}$

$195924 \cdot 2$

$1957 \quad 4 \cdot 3$

$195436 \cdot 3$

$\begin{array}{lll}19 & 52 & 0.3\end{array}$

$194916 \cdot 2$

$194624 \cdot 1$

$194324 \cdot 1$

$1937 \quad 0.3$

$193336 \cdot 6$

S. $1930 \quad 5.1$
$194016 \cdot 1$
$30 \cdot 39$

$29 \cdot 03$

$27 \cdot 66$

$26 \cdot 28$

$24 \cdot 89$

\begin{tabular}{ll|lll|l}
5 & 20 & 5 & 22.57 & 25.050
\end{tabular}

\begin{tabular}{ll|lll|l}
$22 \cdot 13$ & 6 & 20 & 7 & $52 \cdot 76$ & $25 \cdot 013$
\end{tabular}

\begin{tabular}{lll|llll}
20.73 & 7 & 20 & 10 & 22.72 & 24.975
\end{tabular}

\begin{tabular}{ll|lll|l}
19.33 & 8 & 20 & 12 & 52.46 & 24.937
\end{tabular}

\begin{tabular}{ll|lll|l}
$17 \cdot 93$ & 9 & 20 & 15 & $21 \cdot 96$ & $24 \cdot 898$
\end{tabular}

\begin{tabular}{ll|lllll}
16.53 & 10 & 20 & 17 & $51 \cdot 23$ & $24 \cdot 858$
\end{tabular}

\begin{tabular}{ll|lll|l}
$15 \cdot 13$ & 11 & 20 & 20 & $20 \cdot 25$ & $24 \cdot 817$
\end{tabular}

\begin{tabular}{ll|lll|l|l|}
13.72 & 12 & 20 & 22 & 49.03 & 24.776
\end{tabular}

\begin{tabular}{ll|lll|l}
$12 \cdot 32$ & 13 & 20 & 25 & $17 \cdot 56$ & $24 \cdot 733$
\end{tabular}

\begin{tabular}{l|l|lll|l}
$10 \cdot 91$ & 14 & 20 & 27 & $45 \cdot 83$ & $24 \cdot 690$
\end{tabular}

\begin{tabular}{lll|lll|l}
$9 \cdot 50$ & 15 & 20 & 30 & $13 \cdot 84$ & $24 \cdot 647$
\end{tabular}

\begin{tabular}{ll|lll|l}
8.09 & 16 & 20 & 32 & 41.59 & 24.603
\end{tabular}

\begin{tabular}{ll|lll|l|l}
$6 \cdot 68$ & 17 & 20 & 35 & $9 \cdot 07$ & 24.558
\end{tabular}

\begin{tabular}{ll|lll|l}
$5 \cdot 26$ & 18 & 20 & 37 & $36 \cdot 29$ & $\mathbf{2 4} \cdot 513$
\end{tabular}

\begin{tabular}{ll|lll|l|}
3.84 & 19 & 20 & 40 & 3.23 & 24.467
\end{tabular}

\begin{tabular}{ll|lll|l}
2.43 & 20 & 20 & 42 & $29 \cdot 89$ & $24 \cdot 420$
\end{tabular}

\begin{tabular}{l|l|lll|l|}
1.03 & 21 & 20 & 44 & $56 \cdot 28$ & $24 \cdot 375$
\end{tabular}

\begin{tabular}{l|llll|l}
0.39 & 22 & 20 & 47 & $22 \cdot 39$ & 24.328
\end{tabular}

\begin{tabular}{l|l|lll|l}
$1 \cdot 81$ & 23 & 20 & 49 & $48 \cdot 21$ & $24 \cdot 279$
\end{tabular}

\section{Saturday 4.}

\begin{tabular}{ll|lll|l|l|l|l|l|}
3.22 & 0 & 20 & 52 & $13 \cdot 74$ & $24 \cdot 231$ & S. 172852.5
\end{tabular}

\begin{tabular}{ll|lll|l}
4.62 & 1 & 20 & 54 & 38.98 & $24 \cdot 183$
\end{tabular}

$\begin{array}{lllllll}6 \cdot 03 & 2 & 20 & 57 & 3 \cdot 93 & 24 \cdot 133\end{array}$

\begin{tabular}{ll|lll|l}
$7 \cdot 43$ & 3 & 20 & 59 & $28 \cdot 58$ & $24 \cdot 084$
\end{tabular}

\begin{tabular}{ll|lll|l}
8.83 & 4 & 21 & 1 & 52.94 & 24.035
\end{tabular}

\begin{tabular}{ll|lll|l}
$10 \cdot 23$ & 5 & 21 & 4 & $17 \cdot 00$ & 23.985
\end{tabular}

\begin{tabular}{ll|llll|l}
11.62 & 6 & 21 & 6 & 40.76 & 23.934
\end{tabular}

\begin{tabular}{l|l|lll|l}
13.01 & 7 & 21 & 9 & 4.21 & 23.883
\end{tabular}

\begin{tabular}{l|l|llll|l}
$14 \cdot 40$ & 8 & 21 & 11 & $27 \cdot 36$ & $23 \cdot 833$
\end{tabular}

\begin{tabular}{ll|llllll}
15.78 & 9 & 21 & 13 & $50 \cdot 20$ & 23.781
\end{tabular}

\begin{tabular}{l|r|rrr|r}
$17 \cdot 16$ & 10 & 21 & 16 & $12 \cdot 73$ & $23 \cdot 729$
\end{tabular}

\begin{tabular}{ll|lll|l}
18.53 & 11 & 21 & 18 & 34.95 & 23.678
\end{tabular}

\begin{tabular}{ll|lll|l}
$19 \cdot 90$ & 12 & 21 & 20 & $56 \cdot 87$ & 23.627
\end{tabular}

\begin{tabular}{ll|lll|l}
$21 \cdot 27$ & 13 & 21 & 23 & $18 \cdot 47$ & 23.574
\end{tabular}

\begin{tabular}{ll|lll|l}
$22 \cdot 63$ & 14 & 21 & 25 & $39 \cdot 76$ & 23.522
\end{tabular}

\begin{tabular}{ll|lll|l}
23.99 & 15 & 21 & 28 & 0.73 & 23.468
\end{tabular}

\begin{tabular}{ll|llll|l}
$25 \cdot 33$ & 16 & 21 & 30 & $21 \cdot 38$ & $23 \cdot 416$
\end{tabular}

\begin{tabular}{ll|llll|l}
26.68 & 17 & 21 & 32 & $41 \cdot 72$ & $23 \cdot 364$
\end{tabular}

\begin{tabular}{ll|lll|l}
28.02 & 18 & 21 & 35 & 1.75 & 23.311
\end{tabular}

\begin{tabular}{l|l|lll|l}
$29 \cdot 34$ & 19 & 21 & 37 & $21 \cdot 45$ & $23 \cdot 257$
\end{tabular}

\begin{tabular}{l|l|lll|l}
$30 \cdot 67$ & 20 & 21 & 39 & $40 \cdot 83$ & $23 \cdot 204$
\end{tabular}

\begin{tabular}{ll|lll|l}
31.98 & 21 & 21 & 41 & $59 \cdot 90$ & $23 \cdot 152$
\end{tabular}

$\begin{array}{llllll}33.29 & 22 & 21 & 44 & 18.65 & 23.098\end{array}$

\begin{tabular}{ll|llll|l}
34.60 & 23 & 21 & 46 & $37 \cdot 07$ & 23.044
\end{tabular}

$172224 \cdot 5$

$1715 \quad 50 \cdot 3$

$\begin{array}{lll}17 & 9 & 9.9\end{array}$

17223.5

$165531 \cdot 1$

$164832 \cdot 7$

$164128 \cdot 4$

$163418 \cdot 4$

$\begin{array}{lll}16 & 27 & 2.7\end{array}$

$16 \quad 1941.3$

$161214 \cdot 4$

$\begin{array}{lll}16 & 4 & 41 \cdot 9\end{array}$

$\begin{array}{lll}15 & 57 & 4.1\end{array}$

154920.9

154132.5

153338.9

$152540 \cdot 2$

$151736 \cdot 5$

$\begin{array}{lll}15 & 9 & 27 \cdot 9\end{array}$

$\begin{array}{lll}15 & 1 & 14: 3\end{array}$

$145256 \cdot 0$

144432.9

$\begin{array}{lll}14 & 36 & 5\end{array}$

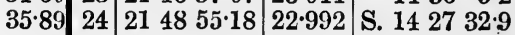

$35 \cdot 89$

$37 \cdot 18$

$38 \cdot 46$

$39 \cdot 73$

40.98

$42 \cdot 24$

43.48

$44 \cdot 72$

45.94

$47 \cdot 15$

$48 \cdot 36$

$49 \cdot 56$

$50 \cdot 74$

$51 \cdot 93$

53.09

$54 \cdot 24$

$55 \cdot 38$

56.53

$57 \cdot 65$

$58 \cdot 75$

$59 \cdot 86$

60.95

62.03

63.09

64.14

$65 \cdot 18$

66.22

$67 \cdot 23$

68.23

69.23

70.23

$71 \cdot 19$

$72 \cdot 14$

73.09

74.03

74.95

$75 \cdot 86$

$76 \cdot 75$

$77 \cdot 63$

78.50

$79 \cdot 36$

$80 \cdot 20$

81.03

$81 \cdot 85$

82.66

83.45

$84 \cdot 23$

85.00

85.75 


\section{MEAN TIME.}

THE MOON'S RIGH'T ASCENSION AND DECLINATION.

\begin{tabular}{c|c|c|c|c|c|c|c|c}
\hline \multirow{0}{*}{$\begin{array}{c}\text { Right } \\
\text { Ascension. }\end{array}$} & $\begin{array}{c}\text { Var. } \\
\text { in 10m. }\end{array}$ & Declination. & $\begin{array}{c}\text { Var. } \\
\text { in 10m. }\end{array}$ & $\begin{array}{c}\text { Right } \\
\text { Ascension. }\end{array}$ & $\begin{array}{c}\text { Var. } \\
\text { in 10m. }\end{array}$ & Declination. & $\begin{array}{c}\text { Var. } \\
\text { in 10m. }\end{array}$ \\
\hline
\end{tabular}

h. m. 8 . Sunday 5.

\begin{tabular}{l|lll|c|}
0 & 21 & 48 & $55^{\circ} 18$ & $22 \cdot 99$
\end{tabular}

\begin{tabular}{l|lll|l} 
& 21 & 51 & $12 \cdot 97$ & $22 \cdot 938$
\end{tabular}

$\begin{array}{llllll} & 21 & 53 & 30.43 & 22.884\end{array}$

\begin{tabular}{l|lll|l}
3 & 21 & 55 & $47 \cdot 58$ & $22 \cdot 832$
\end{tabular}

4 \begin{tabular}{lll|l}
4 & 58 & $4 \cdot 41$ & $22 \cdot 778$
\end{tabular}

$\begin{array}{llllll}5 & 22 & 0 & 20.92 & 22.725\end{array}$

$6 \quad \begin{array}{lllll}22 & 2 & 37 \cdot 11 & 22.672\end{array}$

\begin{tabular}{l|lll|l}
7 & 22 & 4 & $52 \cdot 98$ & 22.619
\end{tabular}

\begin{tabular}{l|lll|l}
8 & 22 & 7 & 8.54 & 22.567
\end{tabular}

\begin{tabular}{r|rrr|r}
9 & 22 & 9 & 23.78 & 22.513
\end{tabular}

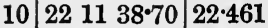

$1122 \quad 13 \quad 53 \cdot 31 \quad 22 \cdot 408$

\begin{tabular}{l|lll|l}
12 & 22 & 16 & $7 \cdot 60$ & $22 \cdot 356$
\end{tabular}

$13 \quad 22 \quad 18 \quad 21 \cdot 58 \quad 22.304$

$14 \quad 22 \quad 20 \quad 35 \cdot 25 \quad 22 \cdot 253$

$15 \mid \begin{array}{llllll}152 & 22 & 48 \cdot 61 & 22.200\end{array}$

\begin{tabular}{l|lll|l}
16 & 22 & 25 & $1 \cdot 65$ & $22 \cdot 148$
\end{tabular}

\begin{tabular}{l|lll|l}
17 & 22 & 27 & 14.39 & 22.098
\end{tabular}

\begin{tabular}{lllll|l}
18 & 22 & 29 & 26.82 & 22.047
\end{tabular}

\begin{tabular}{l|lll|l}
19 & 22 & 31 & 38.95 & 21.997
\end{tabular}

\begin{tabular}{l|llll}
20 & 22 & 33 & 50.78 & 21.946
\end{tabular}

\begin{tabular}{llll|l}
21 & 22 & 36 & 2.30 & $21 \cdot 895$
\end{tabular}

$\begin{array}{lllll}22 & 22 & 38 & 13 \cdot 52 & 21 \cdot 845\end{array}$

$23|224024 \cdot 44| 21 \cdot 796 \mid$ Monday 6.
$0|224235 \cdot 07| 21 \cdot 747 \mid$

0
1
2
5
6
7
10
11
13
14
15
16
18
19
20
21
22
23
2

$1 \quad 22 \begin{array}{lllll}45 \cdot 40 & 21 \cdot 698\end{array}$

$2 \quad 22 \quad 4655 \cdot 44 \quad 21 \cdot 649$

\begin{tabular}{l|llr|l}
3 & 22 & 49 & $5 \cdot 19$ & $21 \cdot 600$
\end{tabular}

\begin{tabular}{l|lll|l}
4 & 22 & 51 & 14.64 & $21 \cdot 552$
\end{tabular}

5 \begin{tabular}{l|lll|l}
52 & 53 & $23 \cdot 81$ & $21 \cdot 505$
\end{tabular}

$6 \quad 2255 \quad 32 \cdot 70 \quad 21 \cdot 458$

\begin{tabular}{l|llll|l}
7 & 22 & 57 & $41 \cdot 30$ & $21 \cdot 410$
\end{tabular}

$8 \begin{array}{lllll} & 22 & 59 & 49 \cdot 62 & 21 \cdot 363\end{array}$

\begin{tabular}{l|lll|l}
9 & 23 & 1 & $57 \cdot 66$ & $21 \cdot 318$
\end{tabular}

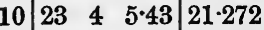

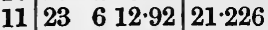

\begin{tabular}{l|lll|l}
12 & 23 & 8 & $20 \cdot 14$ & $21 \cdot 181$
\end{tabular}

\begin{tabular}{l|lll|l}
13 & 23 & 10 & $27 \cdot 09$ & $21 \cdot 137$
\end{tabular}

\begin{tabular}{llll|l}
14 & 23 & 12 & $33 \cdot 78$ & $21 \cdot 093$
\end{tabular}

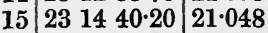

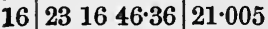

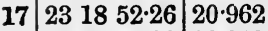

\begin{tabular}{l|lll|l}
18 & 23 & 20 & $57 \cdot 90$ & $20 \cdot 919$
\end{tabular}

\begin{tabular}{l|lll|l}
19 & 23 & 23 & $3 \cdot 29$ & $20 \cdot 878$
\end{tabular}

\begin{tabular}{l|lll|l}
20 & 23 & 25 & $8 \cdot 43$ & $20 \cdot 836$
\end{tabular}

\begin{tabular}{llll|l}
21 & 23 & 27 & $13 \cdot 32$ & $20 \cdot 795$
\end{tabular}

\begin{tabular}{lllll|l}
22 & 23 & 29 & $17 \cdot 97$ & $20 \cdot 755$
\end{tabular}

\begin{tabular}{llll|l}
23 & 23 & 31 & $22 \cdot 38$ & $20 \cdot 714$
\end{tabular}

\begin{tabular}{l|lll|l}
24 & 23 & 33 & 26.54 & 20.674
\end{tabular}
142732.9

$141856 \cdot 2$

141015.0

$14 \quad 129 \cdot 5$

$135239 \cdot 8$

134345.9

$133447 \cdot 8$

$132545 \cdot 8$

$1316 \quad 39 \cdot 8$

$\begin{array}{lll}13 & 7 & 29.9\end{array}$

$125816 \cdot 2$

$124858 \cdot 8$

$123937 \cdot 7$

$1230 \quad 13 \cdot 1$

$122044 \cdot 9$

$1211 \quad 13.4$

$12 \quad 138.5$

$\begin{array}{lll}11 & 52 & 0.3\end{array}$

114218.9

$113234 \cdot 4$

$112246 \cdot 8$

$111256 \cdot 3$

$\begin{array}{lll}11 & 3 & 2.8\end{array}$

S. 10536.5

,

85.75

86.49

$87 \cdot 22$

$87 \cdot 93$

88.63

$89 \cdot 33$

$90 \cdot 01$

$90 \cdot 67$

91.33

91.97

$2351 \quad 53 \cdot 71 \quad 20 \cdot 338$

\begin{tabular}{ll|lll|l}
92.59 & 10 & 23 & 53 & $55 \cdot 63$ & $20 \cdot 303$
\end{tabular}

\begin{tabular}{ll|lll|l}
$93 \cdot 21$ & 11 & 23 & 55 & $57 \cdot 35$ & $20 \cdot 270$
\end{tabular}

\begin{tabular}{ll|lll|l|l|}
$\mathbf{9 3} \cdot 81$ & 12 & 23 & 57 & $58 \cdot 87$ & $20 \cdot 236$
\end{tabular}

\begin{tabular}{ll|rrr|r|}
$\mathbf{9 4 . 4 0}$ & 13 & 0 & 0 & 0.18 & $\mathbf{2 0 . 2 0 3}$
\end{tabular}

\begin{tabular}{ll|lll|l}
94.98 & 14 & 0 & 2 & 1.30 & $20 \cdot 170$
\end{tabular}

\begin{tabular}{ll|lll|l}
95.53 & 15 & 0 & 4 & $2 \cdot 22$ & $20 \cdot 138$
\end{tabular}

\begin{tabular}{ll|lll|l}
96.09 & 16 & 0 & 6 & 2.95 & $20 \cdot 106$
\end{tabular}

\begin{tabular}{ll|lll|l}
96.63 & 17 & 0 & 8 & 3.49 & 20.075
\end{tabular}

\begin{tabular}{ll|lll|l|}
$97 \cdot 16$ & 18 & 0 & 10 & $3 \cdot 85$ & $20 \cdot 044$
\end{tabular}

\begin{tabular}{ll|lll|l}
$97 \cdot 68$ & 19 & 0 & 12 & 4.02 & 20.014
\end{tabular}

\begin{tabular}{ll|lll|l}
$98 \cdot 18$ & 20 & 0 & 14 & 4.02 & 19.984
\end{tabular}

\begin{tabular}{l|l|lll|l}
$\mathbf{9 8} \cdot 67$ & 21 & 0 & 16 & 3.83 & $\mathbf{1 9} \cdot 954$
\end{tabular}

\begin{tabular}{l|l|lll|l}
$99 \cdot 15$ & 22 & 0 & 18 & 3.47 & 19.927
\end{tabular}

$99 \cdot 62$

$\begin{array}{ll}0 & 18 \\ 0 & 20\end{array}$

$2 \cdot 95 \mid 19 \cdot 899$

\section{Wednesday 8.}

\begin{tabular}{lll|l}
10 & 33 & 5.6 & 100.52
\end{tabular}

\begin{tabular}{lll|l}
10 & 23 & 1.2 & 100.94
\end{tabular}

$101254 \cdot 3 \quad 101 \cdot 37$

$\begin{array}{lllll}10 & 2 & 44.8 & 101 \cdot 78\end{array}$

\begin{tabular}{lll|l}
952 & 52.9 & $102 \cdot 18$
\end{tabular}

$94218 \cdot 7 \quad 102 \cdot 56$

$\begin{array}{llll}9 & 32 & 2.2 & 102.93\end{array}$

$\begin{array}{lllll}9 & 21 & 43.5 & 103.30\end{array}$

$\begin{array}{llll}9 & 1122.6 & 103.65\end{array}$

$\begin{array}{lrrr}9 & 0 & 59 \cdot 7 & 103.99\end{array}$

$\begin{array}{llll}850 & 34.7 & 104 \cdot 33 & 11\end{array}$

\begin{tabular}{lll|l|l}
8 & 40 & $7 \cdot 8$ & $104 \cdot 64$ & 12
\end{tabular}

$\begin{array}{llll}829 & 39 \cdot 0 & 104.95 & 13\end{array}$

\begin{tabular}{lll|l|l}
8 & 19 & $8 \cdot 4$ & $105 \cdot 24$ & 14
\end{tabular}

$\begin{array}{llllll}8 & 8 & 36.1 & 105.53 & 15\end{array}$

\begin{tabular}{lll|l|l}
7 & 58 & $2 \cdot 1$ & $105 \cdot 81$ & 16
\end{tabular}

$\begin{array}{lllll}74726.4 & 106 \cdot 08 & 17\end{array}$

$\begin{array}{lllll}7 & 36 & 49 \cdot 2 & 106 \cdot 33 & 18\end{array}$

$\begin{array}{lllll}726 & 10.5 & 106.57 & 19\end{array}$

$\begin{array}{lllll}715 & 30 \cdot 4 & 106 \cdot 81 & 20\end{array}$

$\begin{array}{lllll}7 & 4 & 48.8 & 107.03 & 21\end{array}$

\begin{tabular}{lll|l|l}
6 & 54 & 6.0 & $107 \cdot 24$ & 22
\end{tabular}

\begin{tabular}{lll|l|l}
6 & 43 & 21.9 & $107 \cdot 44$ & 23
\end{tabular}

S. $63236 \cdot 7 \quad 107 \cdot 63 \mid 2$ \begin{tabular}{lll|l|l|l|l|}
0 & 22 & $2 \cdot 26$ & $19 \cdot 872$
\end{tabular}

\begin{tabular}{lll|l}
0 & 24 & 1.41 & 19.844
\end{tabular}

$\begin{array}{llll}0 & 26 & 0.39 & 19.818\end{array}$

$\begin{array}{lllll}0 & 27 & 59 \cdot 22 & 19 \cdot 792\end{array}$

$\begin{array}{lllll}0 & 29 & 57 \cdot 89 & 19 \cdot 767\end{array}$

$\begin{array}{llll}0 & 31 & 56.42 & 19 \cdot 743\end{array}$

\begin{tabular}{lll|l}
0 & 33 & 54.80 & $19 \cdot 718$
\end{tabular}

$\begin{array}{llll}0 & 35 & 53.03 & 19.693\end{array}$

$\begin{array}{llll}0 & 37 & 51 \cdot 12 & 19 \cdot 671\end{array}$

\begin{tabular}{ll|l}
0 & $3949 \cdot 08$ & $\mathbf{1 9} 648$
\end{tabular}

\begin{tabular}{lll|l}
0 & 41 & 46.90 & $19 \cdot 626$
\end{tabular}

$\begin{array}{lllll}0 & 43 & 44.59 & 19 \cdot 604\end{array}$

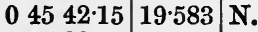

$\begin{array}{llll}0 & 47 & 39.59 & 19.563\end{array}$

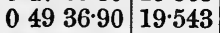

$05134 \cdot 10 \quad 19.524$

$05331 \cdot 19 \quad 19 \cdot 505$

$05528 \cdot 16 \quad 19 \cdot 487$

$\begin{array}{llll}0 & 5725.03 & 19.469\end{array}$

$\begin{array}{lllll}0 & 59 & 21 \cdot 79 & 19 \cdot 451\end{array}$

$\begin{array}{lllll}1 & 1 & 18 \cdot 44 & 19 \cdot 434\end{array}$

$1315.00 \quad 19.419$

$\begin{array}{lllll}1 & 5 & 11 \cdot 47 & 19 \cdot 403\end{array}$

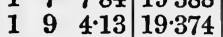

$\begin{array}{llll}1 & 7 & 7 \cdot 84 & 19.388\end{array}$

\section{7.}

$63236 \cdot 7 \mid 107 \cdot 63$

$\begin{array}{llll}621 & 50.3 & 107 \cdot 82\end{array}$

$\begin{array}{llll}6 & 11 & 2.9 & 107 \cdot 99\end{array}$

$\begin{array}{lllll}6 & 0 & 14.4 & 108 \cdot 16\end{array}$

$54925 \cdot 0 \quad 108 \cdot 31$

$\begin{array}{llll}538 & 34.7 & 108 \cdot 46\end{array}$

$\begin{array}{llll}5 & 27 & 43.5 & 108.59\end{array}$

$\begin{array}{llll}5 & 16 & 51 \cdot 6 & 108 \cdot 72\end{array}$

$\begin{array}{lllll}5 & 5 & 58.9 & 108.84\end{array}$

$\begin{array}{llll}455 & 5.5 & 108.94\end{array}$

\begin{tabular}{l}
$44411 \cdot 6 \quad 109 \cdot 04$ \\
\hline
\end{tabular}

$\begin{array}{llll}433 & 17 \cdot 0 & 109 \cdot 13\end{array}$

$42222.0 \quad 109 \cdot 21$

$41126 \cdot 5 \quad 109 \cdot 28$

$\begin{array}{lllll}4 & 0 & 30.6 & 109.34\end{array}$

$\begin{array}{llll}34934 & 109 \cdot 40\end{array}$

$\begin{array}{llll}338 & 37.8 & 109 \cdot 45\end{array}$

$\begin{array}{llll}327 & 41 \cdot 0 & 109 \cdot 48\end{array}$

$\begin{array}{lllll}3 & 16 & 44.0 & 109.52\end{array}$

$\begin{array}{llll}3 & 5 & 46.8 & 109 \cdot 53\end{array}$

$25449.6109 \cdot 54$

$24352 \cdot 3 \quad 109.56$

$23254^{\circ}$ 109.55

S. $22157 \cdot 7 \mid 109.53$ 
AUGUST.

VII.

MEAN TIME.

THE MOON'S RIGHT ASCENSION AND DECLINATION.

\begin{tabular}{c|c|c|c|c|c|c|c|c}
\hline \multirow{2}{*}{} & $\begin{array}{c}\text { Right } \\
\text { Ascension. }\end{array}$ & $\begin{array}{c}\text { Var. } \\
\text { in } 10 \mathrm{~m} .\end{array}$ & Declination. & $\begin{array}{c}\text { Var. } \\
\text { in 10m. }\end{array}$ & $\begin{array}{c}\text { 完 } \\
\text { Ascension. }\end{array}$ & $\begin{array}{c}\text { Var. } \\
\text { in 10m. }\end{array}$ & Declination. & $\begin{array}{c}\text { Var. } \\
\text { in 10m. }\end{array}$ \\
\hline
\end{tabular}

b. m. s. Thursday 9.

\begin{tabular}{l|lll|l|l|l|l|l|l}
0 & 1 & 9 & $4 \cdot 13$ & $19 \cdot 374$ & N. 2 & 9 & 22.2 & $106 \cdot 78$
\end{tabular}

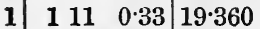

$2 \quad 11256 \cdot 45 \quad 19 \cdot 346$

$\begin{array}{llllll} & & 1 & 14 & 52 \cdot 48 & 19 \cdot 333\end{array}$

$11648 \cdot 44 \times 19 \cdot 321$

$11844 \cdot 33 \quad 19 \cdot 309$

$6 \quad 120 \quad 40 \cdot 15 \quad 19 \cdot 298$

\begin{tabular}{l|lll|l}
7 & 1 & 22 & $35 \cdot 90$ & $19 \cdot 287$
\end{tabular}

$\begin{array}{llllll}8 & 1 & 24 & 31 \cdot 59 & 19 \cdot 277\end{array}$

$9 \begin{array}{llllll}8 & 1 & 26 & 27 \cdot 22 & 19 \cdot 267\end{array}$

\begin{tabular}{l|lll|l}
10 & 1 & 28 & $22 \cdot 79$ & $19 \cdot 257$
\end{tabular}

\begin{tabular}{llll|l}
11 & 1 & 30 & $18 \cdot 30$ & $19 \cdot 248$
\end{tabular}

\begin{tabular}{llll|l}
12 & 1 & 32 & 13.76 & $19 \cdot 240$
\end{tabular}

\begin{tabular}{llll|l}
13 & 1 & 34 & $9 \cdot 18$ & $19 \cdot 233$
\end{tabular}

$14 \quad 136 \quad 4.55 \quad 19 \cdot 225$

$\begin{array}{llllll}15 & 1 & 37 & 59 \cdot 88 & 19 \cdot 218\end{array}$

\begin{tabular}{llll|l}
16 & 1 & 39 & $55 \cdot 17$ & $19 \cdot 212$
\end{tabular}

$17 \quad \begin{array}{llll}1 & 41 & 50 \cdot 42 & 19.207\end{array}$

$18 \quad 143 \quad 45 \cdot 65 \quad 19 \cdot 202$

\begin{tabular}{l|lll|l}
19 & 1 & 45 & $40 \cdot 84$ & $19 \cdot 196$
\end{tabular}

$\begin{array}{lllll}20 & 1 & 47 & 36.00 & 19 \cdot 192\end{array}$

$21 \quad 1 \quad 4931 \cdot 14 \quad 19 \cdot 189$

\begin{tabular}{l|lll|l}
22 & 1 & 51 & $26 \cdot 27$ & $19 \cdot 186$
\end{tabular}

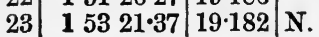

\section{Friday 10.}

\begin{tabular}{r|}
0 \\
1 \\
2 \\
3 \\
4 \\
5 \\
6 \\
7 \\
8 \\
9 \\
10 \\
11 \\
12 \\
13 \\
14 \\
15 \\
16 \\
17 \\
18 \\
19 \\
20 \\
21 \\
22 \\
23 \\
24
\end{tabular}

$15516 \cdot 45|19 \cdot 180| \mathrm{N}$.

$\begin{array}{llll}1 & 57 & 11 \cdot 53 & 19 \cdot 178\end{array}$

$\begin{array}{lllll}1 & 59 & 6.59 & 19 \cdot 177\end{array}$

$\begin{array}{lllll}2 & 1 & 1.65 & 19 \cdot 177\end{array}$

$\begin{array}{lllll}2 & 2 & 56 \cdot 71 & 19 \cdot 177\end{array}$

$\begin{array}{lllll}2 & 4 & 51 \cdot 77 & 19 \cdot 177\end{array}$

$\begin{array}{llll}2 & 6 & 46 \cdot 83 & 19 \cdot 177\end{array}$

$\begin{array}{lllll}2 & 8 & 41 \cdot 89 & 19 \cdot 178\end{array}$

$\begin{array}{lllll}2 & 10 & 36 \cdot 97 & 19 \cdot 180\end{array}$

$\begin{array}{llll}2 & 12 & 32.05 & 19 \cdot 182\end{array}$

$\begin{array}{llll}2 & 14 & 27 \cdot 15 & 19 \cdot 184\end{array}$

$\begin{array}{lllll}2 & 16 & 22 \cdot 26 & 19 \cdot 187\end{array}$

2 \begin{tabular}{ll|l}
2 & $17 \cdot 40$ & $19 \cdot 192$
\end{tabular}

$22012 \cdot 56 \quad 19 \cdot 195$

$\begin{array}{lllll}2 & 22 & 7 \cdot 74 & 19 \cdot 199\end{array}$

$\begin{array}{lllll}2 & 24 & 2.95 & 19 \cdot 203\end{array}$

$\begin{array}{llll}2 & 25 & 58 \cdot 18 & 19 \cdot 208\end{array}$

$22753 \cdot 45 \quad 19 \cdot 215$

$\begin{array}{lllll}2 & 29 & 48.76 & 19 \cdot 222\end{array}$

$\begin{array}{lllll}2 & 31 & 44 \cdot 11 & 19 \cdot 228\end{array}$

$\begin{array}{llll}233 & 39.50 & 19 \cdot 235\end{array}$

$23534.93 \quad 19 \cdot 243$

$\begin{array}{llll}2 & 37 & 30 \cdot 41 & 19 \cdot 251\end{array}$

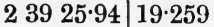

$\begin{array}{llll}2 & 41 & 21 \cdot 52 & 19 \cdot 268\end{array}$

\begin{tabular}{lll|l}
2 & 20 & 2.3 & 106.58
\end{tabular}

$\begin{array}{llll}2 & 30 & 41 \cdot 2 & 106 \cdot 38\end{array}$

$\begin{array}{llll}2418 \cdot 9 & 106 \cdot 18\end{array}$

$25155 \cdot 3 \quad 105 \cdot 96$

$\begin{array}{lllll}3 & 2 & 30 \cdot 4 & 105.73\end{array}$

$\begin{array}{llll}3.13 & 4 \cdot 1 & 105 \cdot 50\end{array}$

$\begin{array}{llll}323 & 36 \cdot 4 & 105 \cdot 26\end{array}$

$\begin{array}{llll}3 & 34 & 7 \cdot 2 & 105.02\end{array}$

$\begin{array}{llll}344 & 36 \cdot 6 & 104 \cdot 78\end{array}$

$\begin{array}{llll}3 & 55 & 4.5 & 104 \cdot 52\end{array}$

$\begin{array}{llll}4 \quad 530 \cdot 8 & 104 \cdot 26\end{array}$

$\begin{array}{lll}415 & 55 \cdot 6 & 103 \cdot 99\end{array}$

$\begin{array}{lllll}426 & 18.7 & 103 \cdot 72\end{array}$

$\begin{array}{llll}4 & 47 & 0.0 & 103 \cdot 15\end{array}$

$\begin{array}{llll}457 & 18 \cdot 0 & 102 \cdot 86\end{array}$

\begin{tabular}{lll|l}
5 & $734: 3$ & 102.57
\end{tabular}

$\begin{array}{llll}5 & 17 & 48.8 & 102 \cdot 27\end{array}$

\begin{tabular}{lll|l}
5 & 28 & 1.5 & 101.96
\end{tabular}

$\begin{array}{llll}5 & 38 & 12.3 & 101 \cdot 65\end{array}$

$54821 \cdot 3 \quad 101 \cdot 33$

$55828 \cdot 3 \quad 101 \cdot 00$

\begin{tabular}{ll|l}
6 & 839.3 & $100 \cdot 68$
\end{tabular}

$61836 \cdot 4 \mid 100 \cdot 34$ $\begin{array}{ll}62837.4 & 99.99\end{array}$ $\begin{array}{lll}63836.3 & 99 \cdot 65\end{array}$

$\begin{array}{llll}6 & 48 & 33.2 & 99.30\end{array}$

$\begin{array}{lll}65827 \cdot 9 & 98.94\end{array}$

$\begin{array}{lll}7 & 8 & 20.5\end{array}$

98.58

71810.8

72758.9

$73744 \cdot 8$

74728.4

$\begin{array}{lll}7 & 57 & 9.7\end{array}$

$\begin{array}{lrr}8 & 6 & 48.7\end{array}$

$81625 \cdot 2$

$82559 \cdot 3$

$83531 \cdot 0$

$845 \quad 0.3$

$85427 \cdot 0$

$9 \quad 351 \cdot 2$

91312.8

$92231 \cdot 8$

93148.2

$\begin{array}{lll}9 & 41 & 1.9\end{array}$

95012.9

$95921 \cdot 2$

$98 \cdot 20$

$97 \cdot 83$

$97 \cdot 46$

$92 \cdot 95$

$90 \cdot 69$
$43640 \cdot 2 \quad 103 \cdot 44$

\section{Saturday 11.}

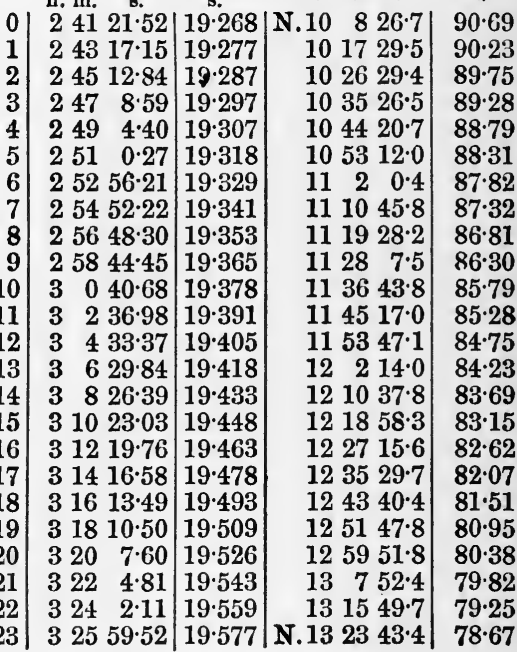

Sunday 12.

$97 \cdot 08$

$96 \cdot 6910$

$96 \cdot 2911$

$95 \cdot 8812$

$95 \cdot 4813$

$9 5 . 0 8 \longdiv { 1 4 }$

$94 \cdot 67 \mid 15$

$94 \cdot 2416$

$93 \cdot 8217$

93.3818

92.5120

$92 \cdot 06$

$91 \cdot 6122$

$91 \cdot 15 \quad 23$

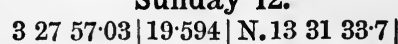
$32954 \cdot 65 \quad 19 \cdot 613$ $33152 \cdot 38 \quad 19 \cdot 631$

$33350 \cdot 22 \quad 19 \cdot 649$

$33548 \cdot 17 \quad 19 \cdot 668$

$\begin{array}{llll}3 & 376 \cdot 24 & 19 \cdot 688\end{array}$

$\begin{array}{llll}3394.42 & 19 \cdot 707\end{array}$

$\begin{array}{llll}3 & 41 & 42 \cdot 72 & 19 \cdot 727\end{array}$

$\begin{array}{llll}343 & 41 \cdot 14 & 19 \cdot 747\end{array}$

\begin{tabular}{ll|l}
345 & $39 \cdot 68$ & $19 \cdot 767$
\end{tabular}

$\begin{array}{llll}3478 \cdot 34 & 19 \cdot 787\end{array}$

$\begin{array}{llll}349 & 37 \cdot 12 & 19 \cdot 808\end{array}$

$\begin{array}{llll}3 & 51 & 36 \cdot 03 & 19 \cdot 829\end{array}$

353 35.07' $19 \cdot 850$

$\begin{array}{lll}355 & 34.23 & 19 \cdot 872\end{array}$

\begin{tabular}{ll|l}
$35733 \cdot 53$ & $19 \cdot 894$
\end{tabular}

\begin{tabular}{ll|l}
359 & 32.96 & $19 \cdot 916$
\end{tabular}

\begin{tabular}{lll|l}
4 & 1 & 32.52 & $19 \cdot 938$
\end{tabular}

$\begin{array}{llll}4 & 3 & 32 \cdot 21 & 19 \cdot 960\end{array}$

\begin{tabular}{llll|l}
4 & 5 & 32.04 & $19 \cdot 983$
\end{tabular}

$\begin{array}{lllll}4 & 732.01 & 20.007\end{array}$

\begin{tabular}{lll|l}
4 & $1132 \cdot 36$ & $20 \cdot 052$
\end{tabular}

\begin{tabular}{ll|l}
41332.74 & 20.076
\end{tabular}

133920.5

$\begin{array}{lll}13 & 47 & 3.7\end{array}$

$135443 \cdot 3$

$\begin{array}{lll}14 & 2 & 19.3\end{array}$

$\begin{array}{lll}14 & 9 & 51 \cdot 7\end{array}$

141720.4

$1424 \quad 45.4$

$\begin{array}{lll}14 & 32 & 6.7\end{array}$

$143924 \cdot 3$

$144638 \cdot 0$

145348.0

$\begin{array}{lll}15 & 0 & 54 \cdot 1\end{array}$

$15756 \cdot 3$

$151454 \cdot 6$

$152839 \cdot 4$

$153525 \cdot 8$

$154846 \cdot 5$

155520.7

$\begin{array}{lll}16 & 1 & 50 \cdot 8\end{array}$

$\begin{array}{lll}16 & 8 & 16 \cdot 7\end{array}$

161438.4

\begin{tabular}{ll|l|lll}
4 & $1533 \cdot 27$ & $20 \cdot 100$ & $N_{.} 16$ & 20 & $56 \cdot 0$
\end{tabular} \begin{tabular}{lll|l}
4 & 9 & $32 \cdot 12$ & $20 \cdot 029$
\end{tabular}

$152149 \cdot 0$

$1542 \quad 8 \cdot 2$
78.09

$77 \cdot 50$

76.90

$76 \cdot 30$

$75 \cdot 70$

$75 \cdot 09$

$74 \cdot 48$

$73 \cdot 86$

$73 \cdot 24$

72.61

71.98

$71 \cdot 34$

$70 \cdot 69$

$70 \cdot 04$

69.39

68.73

68.07

$67 \cdot 40$

66.73

66.04

$65 \cdot 36$

$64 \cdot 67$

63.97

$63 \cdot 28$

62.58 
THE MOON'S RIGHT ASCENSION AND IECLINATIUN.

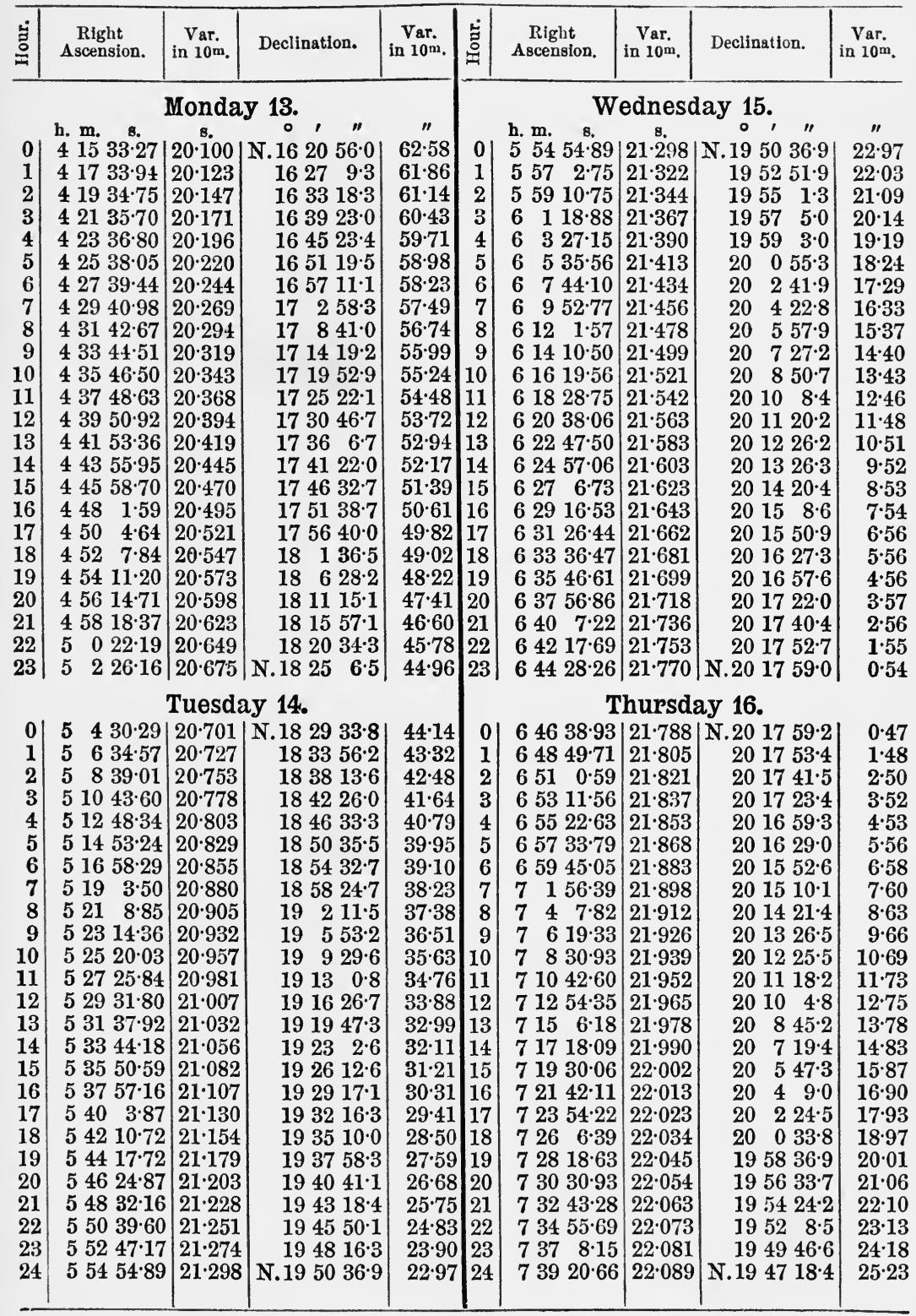




\section{MEAN TIME.}

THE MOON'S RIGHT ASCENSION AND DECLINATION.

\begin{tabular}{|c|c|c|c|}
\hline & $\begin{array}{c}\text { Right } \\
\text { Ascension. }\end{array}$ & $\begin{array}{l}\text { Var. } \\
\text { in } 10^{\mathrm{m}} \text {. }\end{array}$ & Declination. \\
\hline & \multicolumn{3}{|c|}{ Friday 17.} \\
\hline 0 & $\begin{array}{l}\text { h. m. } \\
739 \text {. } \\
20 \cdot 66\end{array}$ & 22.089 & $\begin{array}{ccc}0 & \prime \prime \\
N .19 & 47 & 18.4\end{array}$ \\
\hline 1 & $74133 \cdot 22$ & $22 \cdot 098$ & 194444.0 \\
\hline 2 & $74345 \cdot 83$ & $22 \cdot 105$ & $1942 \quad 3 \cdot 3$ \\
\hline 3 & 74558.48 & $22 \cdot 112$ & 193916.4 \\
\hline 4 & $74811 \cdot 17$ & $22 \cdot 118$ & $193623 \cdot 2$ \\
\hline 5 & 75023.90 & $22 \cdot 125$ & $193323 \cdot 8$ \\
\hline 6 & 75236.67 & $22 \cdot 131$ & $19 \quad 30 \quad 18 \cdot 2$ \\
\hline 7 & $7.5449 \cdot 47$ & $22 \cdot 136$ & $19 \quad 27 \quad 6.4$ \\
\hline 8 & $\begin{array}{lll}757 & 2 \cdot 30\end{array}$ & $22 \cdot 141$ & $192348 \cdot 3$ \\
\hline 9 & $75915 \cdot 16$ & $22 \cdot 146$ & $192024 \cdot 0$ \\
\hline 10 & $8 \quad 128.05$ & $22 \cdot 151$ & 191653.5 \\
\hline 11 & $8 \quad 340.97$ & $22 \cdot 154$ & 191316.8 \\
\hline 12 & $8 \quad 553.90$ & $22 \cdot 158$ & 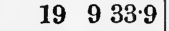 \\
\hline 13 & $\begin{array}{lll}8 & 8 & 6.86\end{array}$ & $22 \cdot 162$ & $544 \cdot 8$ \\
\hline 14 & $\begin{array}{llll}8 & 10 & 19 \cdot 84\end{array}$ & $22 \cdot 164$ & $19 \quad 149 \cdot 6$ \\
\hline 15 & $81232 \cdot 83$ & $22 \cdot 167$ & $185748 \cdot 1$ \\
\hline 16 & $81445 \cdot 84$ & $22 \cdot 168$ & 185340.5 \\
\hline 17 & 81658.85 & $22 \cdot 170$ & 184926.8 \\
\hline 18 & $81911 \cdot 88$ & $22 \cdot 172$ & $1845 \quad 6.9$ \\
\hline 19 & 82124.92 & $22 \cdot 173$ & 184040.9 \\
\hline 20 & 82337.96 & $22 \cdot 173$ & $\begin{array}{lll}18 & 36 & 8 \cdot 7\end{array}$ \\
\hline 21 & $82551 \cdot 00$ & $22 \cdot 174$ & $183130 \cdot 5$ \\
\hline 22 & $828 \quad 4.05$ & $22 \cdot 175$ & 182646.2 \\
\hline & $\begin{array}{llll}830 & 17 \cdot 10\end{array}$ & & 100 \\
\hline
\end{tabular}

\section{Saturday 18.}

0| 832 30.14|22.173|N.18 16 59.4

$1 \quad 8 \quad 34 \quad 43 \cdot 18 \mid 22 \cdot 173$

\begin{tabular}{l|lll|l} 
& 8 & 36 & $56 \cdot 21$ & $22 \cdot 171$
\end{tabular}

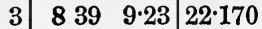

\begin{tabular}{l|llll}
4 & 8 & 41 & $22 \cdot 25$ & $22 \cdot 168$
\end{tabular}

\begin{tabular}{l|llll}
5 & 8 & 43 & $35 \cdot 25$ & $22 \cdot 165$
\end{tabular}

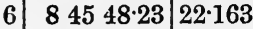

\begin{tabular}{l|lll|l}
7 & 8 & 48 & $1 \cdot 20$ & $22 \cdot 161$
\end{tabular}

\begin{tabular}{l|lll|l}
8 & 8 & 50 & $14 \cdot 16$ & $22 \cdot 158$
\end{tabular}

\begin{tabular}{l|llll}
9 & 8 & 52 & $27 \cdot 09$ & $22 \cdot 153$
\end{tabular}

$10 \quad 85440 \cdot 00 \mid 22 \cdot 150$

$11 \quad 85652 \cdot 89 \quad 22 \cdot 147$

$12 \quad 859 \quad 5 \cdot 76 \quad 22 \cdot 143$

$\begin{array}{lllllll}13 & 9 & 1 & 18 \cdot 60 & 22 \cdot 138\end{array}$

$14 \quad 9 \quad 3 \quad 31 \cdot 41 \quad 22 \cdot 133$

$150 \quad 9 \quad 5 \quad 44 \cdot 20 \quad 22 \cdot 128$

\begin{tabular}{llll|l}
16 & 9 & 7 & $56 \cdot 95$ & $22 \cdot 123$
\end{tabular}

17 \begin{tabular}{lll|l}
9 & 10 & $9 \cdot 67$ & $22 \cdot 118$
\end{tabular}

$18 \quad 9 \quad 12 \quad 22 \cdot 36 \quad 22 \cdot 113$

$199 \begin{array}{lllll}9 & 14 & 35 \cdot 02 & 22 \cdot 107\end{array}$

$\begin{array}{lllllll}20 & 9 & 16 & 47 \cdot 64 & 22 \cdot 100\end{array}$

\begin{tabular}{lllll|l}
21 & 9 & 19 & 0.22 & 22.093
\end{tabular}

$\begin{array}{llllll}22 & 9 & 21 & 12.76 & 22.088\end{array}$

$\begin{array}{llllll}23 & 9 & 23 & 25 \cdot 27 & 22 \cdot 082\end{array}$

24
$181156 \cdot 9$

$\begin{array}{lll}18 & 6 & 48.4\end{array}$

$\begin{array}{lll}18 & 1 & 33.9\end{array}$

175613.4

$175047 \cdot 0$

$\begin{array}{llll}17 & 45 & 14.7\end{array}$

173936.4

$173352 \cdot 2$

$\begin{array}{lll}17 & 28 & 2.2\end{array}$

$1722 \quad 6 \cdot 3$

$17 \quad 16 \quad 4.6$

$\begin{array}{lll}17 & 9 & 57 \cdot 1\end{array}$

$\begin{array}{lll}17 & 3 & 43.8\end{array}$

$165724 \cdot 8$

$1651 \quad 0.0$

164429.5

$163753 \cdot 4$

$1631 \quad 11 \cdot 7$

$162424 \cdot 3$

$161731 \cdot 4$

161032.9

$16 \quad 328 \cdot 9$

$155619 \cdot 4$

N. $1549 \quad 4.5$

in $10 \mathrm{~m}$.

(1)

\begin{tabular}{c|c|c|c|c} 
Right & $\begin{array}{c}\text { Var. } \\
\text { in } 10 \mathrm{~m} .\end{array}$ & Declination. & $\begin{array}{c}\text { Var. } \\
\text { in } 10 \mathrm{~m} .\end{array}$ \\
\hline
\end{tabular}

"

$25 \cdot 23$

26.26

$27 \cdot 30$

$28 \cdot 34$

$29 \cdot 38$

30.42

$31 \cdot 45$

$32 \cdot 49$

33.53

34.57

35.60

$36 \cdot 63$

$37 \cdot 67 \quad 12$

$38 \cdot 6913$

$39 \cdot 7314$

\begin{tabular}{l|l|rrr|r}
$40 \cdot 76$ & 15 & 9 & 58 & $39 \cdot 32$ & 21.957 \\
41.78 & 16 & 10 & 0 & 51.03 & 21.948
\end{tabular}

\begin{tabular}{rl|lll|l}
$42 \cdot 80$ & 17 & 10 & 3 & $\mathbf{2} \cdot 70$ & $\mathbf{2 1} \cdot \mathbf{9 4}$
\end{tabular}

\begin{tabular}{ll|lllll}
43.83 & 18 & 10 & 5 & $14 \cdot 31$ & 21.931
\end{tabular}

\begin{tabular}{ll|lll|l}
44.85 & 19 & 10 & 7 & $25 \cdot 87$ & $21 \cdot 922$
\end{tabular}

\begin{tabular}{ll|llll|l}
45.87 & 20 & 10 & 9 & $37 \cdot 37$ & $21 \cdot 913$
\end{tabular}

\begin{tabular}{ll|llll}
46.88 & 21 & 10 & 11 & $48 \cdot 83$ & $21 \cdot 905$
\end{tabular}

\begin{tabular}{ll|lll|l}
$47 \cdot 89$ & 22 & 10 & 14 & 0.23 & $21 \cdot 896$
\end{tabular}

\begin{tabular}{ll|lll|l}
48.90 & 23 & 10 & 16 & $11 \cdot 58$ & $21 \cdot 888$
\end{tabular}
Sunday 19.

h. m. 8. 8, " " "

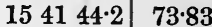

$\begin{array}{llll}15 & 34 & 18 \cdot 5 & \mathbf{7 4} \cdot 73\end{array}$

$\begin{array}{llll}15 & 26 & 47 \cdot 4 & \mathbf{7 5} \cdot 62\end{array}$

\begin{tabular}{ll|l}
15 & $1911 \cdot 0$ & 76.50
\end{tabular}

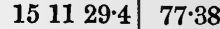

$\begin{array}{lllll}15 & 3 & 42.5 & 78 \cdot 25\end{array}$

\begin{tabular}{l|l}
$145550 \cdot 4$ & $79 \cdot 12$
\end{tabular}

\begin{tabular}{ll|l}
14 & $4753 \cdot 1$ & $79 \cdot 98$
\end{tabular}

\begin{tabular}{l|l}
$143950 \cdot 7$ & $80 \cdot 82$
\end{tabular}

\begin{tabular}{ll|l}
1431 & $43 \cdot 3$ & $81 \cdot 66$
\end{tabular}

$\begin{array}{lll}1423 & 30.8 & 82.51\end{array}$

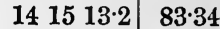

\begin{tabular}{lll|l}
14 & $6 \cdot 50 \cdot 7$ & $84 \cdot 16$
\end{tabular}

\begin{tabular}{ll|l}
1358 & $23 \cdot 3$ & 84.98
\end{tabular}

\begin{tabular}{ll|l}
$134951 \cdot 0$ & $85 \cdot 78$
\end{tabular}

\begin{tabular}{lll|l}
13 & 41 & $13 \cdot 9$ & 86.58
\end{tabular}

\begin{tabular}{ll|l}
1332 & $32 \cdot 0$ & $87 \cdot 38$
\end{tabular}

\begin{tabular}{ll|l}
1323 & $45 \cdot 3$ & $88 \cdot 18$
\end{tabular}

\begin{tabular}{lll|l}
13 & 14 & $53 \cdot 9$ & 88.95
\end{tabular}

\begin{tabular}{lll|l}
13 & 5 & $57 \cdot 9$ & $89 \cdot 72$
\end{tabular}

$\begin{array}{llll}12 & 5657 \cdot 3 & \mathbf{9 0} \cdot 48\end{array}$

$124752 \cdot 1 \quad 91 \cdot 24$

N.12 $3842.4 \quad 91.98$

\section{Monday 20.}

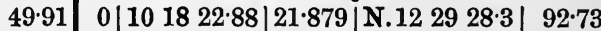
\begin{tabular}{ll|lll|ll|l|l|l}
50.92 & 1 & 10 & 20 & $34 \cdot 13$ & $21 \cdot 870$ & 12 & 20 & 9.7 & 93.47
\end{tabular} \begin{tabular}{ll|lll|llll|l}
$51 \cdot 92$ & 2 & 10 & 22 & $45 \cdot 32$ & $21 \cdot 862$ & 12 & 10 & $46 \cdot 7$ & $94 \cdot 19$
\end{tabular}

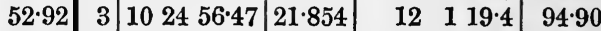

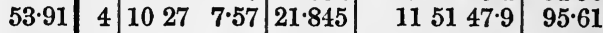

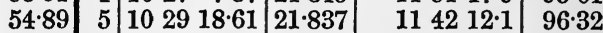
\begin{tabular}{ll|lll|lllll}
55.88 & 6 & 10 & 31 & $29 \cdot 61$ & $21 \cdot 828$ & 11 & 32 & $32 \cdot 1$ & $97 \cdot 01$
\end{tabular} \begin{tabular}{l|l|lll|l}
$56 \cdot 87$ & 7 & 10 & 33 & 40.55 & $21 \cdot 820$
\end{tabular} \begin{tabular}{ll|lll|l}
$57 \cdot 85$ & 8 & 10 & 35 & $51 \cdot 45$ & $21 \cdot 812$
\end{tabular} \begin{tabular}{l|l|lll|l}
58.83 & 9 & 10 & 38 & $2 \cdot 29$ & $21 \cdot 803$
\end{tabular} \begin{tabular}{ll|l|llll|l}
$59 \cdot 80$ & 10 & 10 & 40 & 13.09 & $21 \cdot 796$
\end{tabular} \begin{tabular}{ll|l|lll|l}
$60 \cdot 77$ & 11 & 10 & 42 & $23 \cdot 84$ & $21 \cdot 788$
\end{tabular} \begin{tabular}{ll|llll}
$61 \cdot 73$ & 12 & 10 & 44 & $34 \cdot 55$ & $21 \cdot 781$
\end{tabular} \begin{tabular}{ll|lllll}
62.69 & 13 & 10 & 46 & $45 \cdot 21$ & $21 \cdot 773$
\end{tabular} \begin{tabular}{ll|lll|l}
$63 \cdot 65$ & 14 & 10 & 48 & $55 \cdot 82$ & $21 \cdot 765$
\end{tabular} \begin{tabular}{ll|lll|l}
64.61 & 15 & 10 & 51 & $6 \cdot 39$ & $21 \cdot 758$
\end{tabular} \begin{tabular}{ll|l|lll|l}
65.55 & 16 & 10 & 53 & $16 \cdot 92$ & $21 \cdot 751$
\end{tabular} \begin{tabular}{ll|lllll}
$66 \cdot 48$ & 17 & 10 & 55 & $27 \cdot 40$ & $21 \cdot 744$
\end{tabular} \begin{tabular}{ll|l|lll|l}
$67 \cdot 43$ & 18 & 10 & 57 & $37 \cdot 85$ & $21 \cdot 738$
\end{tabular} \begin{tabular}{ll|lll|l}
$68 \cdot 36$ & 19 & 10 & 59 & $48 \cdot 25$ & $21 \cdot 730$
\end{tabular} \begin{tabular}{l|l|lll|l}
$69 \cdot 28$ & 20 & 11 & 1 & $58 \cdot 61$ & $21 \cdot 723$
\end{tabular} \begin{tabular}{ll|lll|l}
$70 \cdot 21$ & 21 & 11 & 4 & 8.93 & $21 \cdot 718$
\end{tabular} \begin{tabular}{ll|llll|}
$71 \cdot 13$ & 22 & 11 & 6 & $19 \cdot 22$ & $21 \cdot 712$
\end{tabular} \begin{tabular}{ll|lll|l}
$72 \cdot 03$ & 23 & 11 & 8 & $29 \cdot 47$ & $21 \cdot 705$
\end{tabular} \begin{tabular}{l|l|lll|lll}
$72 \cdot 93$ & 24 & 11 & 10 & $39 \cdot 68$ & $21 \cdot 699$ & N. $82738 \cdot 2$ & $107 \cdot 93$
\end{tabular}

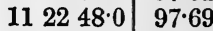
$\begin{array}{llll}11 & 12 & 59 \cdot 8 & 98 \cdot 37\end{array}$ \begin{tabular}{lll|l}
11 & 3 & $7 \cdot 6$ & $99 \cdot 03$
\end{tabular} $105311 \cdot 4 \quad 99 \cdot 69$ $104311 \cdot 3 \quad 100 \cdot 34$ $\begin{array}{llll}10 & 33 & 7 \cdot 3 & 100 \cdot 98\end{array}$

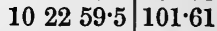
$1012 \quad 48 \cdot 0 \quad 102 \cdot 23$ $\begin{array}{lllll}10 & 2 & 32.8 & 102 \cdot 84\end{array}$ $95213.9 \quad 103.45$ $94151 \cdot 4 \quad 104.04$ $93125 \cdot 4 \quad 104 \cdot 63$ $92055 \cdot 9 \quad 105 \cdot 20$ $\begin{array}{llllll}9 & 10 & 23.0 & 105 \cdot 77\end{array}$ $\begin{array}{lllll}859 & 46.7 & 106.33\end{array}$ $\begin{array}{llllll}8 & 49 & 7 \cdot 1 & 106.88\end{array}$ $83824 \cdot 2 \quad 107 \cdot 41$ 
X.

AUGUST.

MEAN TIME.

THE MOON'S RIGH'T ASCENSION AND DECLINATION.

\begin{tabular}{|c|c|c|c|c|c|c|c|c|c|}
\hline 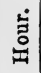 & $\begin{array}{c}\text { Right } \\
\text { Ascension. }\end{array}$ & $\begin{array}{l}\text { Var. } \\
\text { in } 10 \mathrm{~m} .\end{array}$ & Declination. & $\begin{array}{l}\text { Var. } \\
\text { in } 10 \mathrm{~m} \text {. }\end{array}$ & 岂 & $\begin{array}{c}\text { Right } \\
\text { Ascension. }\end{array}$ & $\begin{array}{l}\text { Var. } \\
\text { in 10m. }\end{array}$ & Declination. & $\begin{array}{l}\text { Var. } \\
\text { in 10m. }\end{array}$ \\
\hline
\end{tabular}

\section{Tuesday 21.}

b. $\mathrm{m}$

$111 \quad 1249 \cdot 86 \quad 21 \cdot 694$

$\begin{array}{llllll}2 & 11 & 15 & 0.01 & 21 \cdot 689\end{array}$

$\begin{array}{lllllll} & 11 & 17 & 10 \cdot 13 & 21 \cdot 683\end{array}$

$4 \begin{array}{lllll}11 & 19 & 20 \cdot 21 & 21 \cdot 678\end{array}$

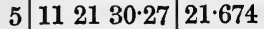

$6 \quad 1123 \quad 40 \cdot 30 \quad 21 \cdot 670$

$7 \begin{array}{llllll}11 & 25 & 50 \cdot 31 & 21 \cdot 667\end{array}$

\begin{tabular}{l|lll|l}
8 & 11 & 28 & 0.30 & $21 \cdot 663$
\end{tabular}

\begin{tabular}{l|lll|l}
9 & 11 & 30 & $10 \cdot 26$ & $21 \cdot 658$
\end{tabular}

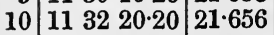

$11 \quad 1134 \quad 30 \cdot 13 \quad 21 \cdot 653$

\begin{tabular}{l|lllll}
12 & 11 & 36 & $40 \cdot 03$ & $21 \cdot 649$
\end{tabular}

\begin{tabular}{l|lll|l}
13 & 11 & 38 & $49 \cdot 92$ & $21 \cdot 648$
\end{tabular}

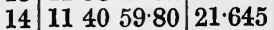

\begin{tabular}{l|lll|l}
15 & 11 & 43 & $9 \cdot 66$ & $21 \cdot 643$
\end{tabular}

\begin{tabular}{l|lll|l}
16 & 11 & 45 & $19 \cdot 52$ & $21 \cdot 643$
\end{tabular}

\begin{tabular}{l|lll|l}
17 & 11 & 47 & $29 \cdot 37$ & $21 \cdot 641$
\end{tabular}

\begin{tabular}{llll|l}
18 & 11 & 49 & $39 \cdot 21$ & $21 \cdot 640$
\end{tabular}

\begin{tabular}{l|lll|l}
19 & 11 & 51 & $49 \cdot 05$ & $21 \cdot 640$
\end{tabular}

\begin{tabular}{l|lll|l}
20 & 11 & 53 & $58 \cdot 89$ & $21 \cdot 640$
\end{tabular}

\begin{tabular}{l|lll|l}
21 & 11 & 56 & 8.73 & $21 \cdot 640$
\end{tabular}

\begin{tabular}{lllll|l}
22 & 11 & 58 & 18.57 & $21 \cdot 640$
\end{tabular}

$23|120028 \cdot 41| 21 \cdot 641 \mid N$

\section{Wednesday 22.}

0|12 $238.26|21 \cdot 643|$ N. $35551 \cdot 7 \mid 117 \cdot 55$

$1 \quad 12 \quad 4 \quad 48 \cdot 12 \quad 21 \cdot 644$

$\begin{array}{llllll}2 & 12 & 6 & 57 \cdot 99 & 21 \cdot 646\end{array}$

\begin{tabular}{llll|l|l}
3 & 12 & 9 & $7 \cdot 87$ & $21 \cdot 648$
\end{tabular}

$4 \quad 12 \quad 11 \quad 17 \cdot 77 \quad 21 \cdot 651$

5 $1213 \quad 27 \cdot 68 \quad 21 \cdot 653$

$6 \quad 12 \quad 15 \quad 37 \cdot 61 \mid 21 \cdot 657$

$7 \quad \begin{array}{llllll}12 & 17 & 47 \cdot 56 & 21 \cdot 661\end{array}$

$8 \quad 1219 \quad 57 \cdot 54 \quad 21 \cdot 666$

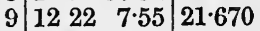

$10 \quad 12 \quad 24 \quad 17 \cdot 58 \quad 21 \cdot 674$

$11 \quad 12 \quad 26 \quad 27 \cdot 64 \quad 21 \cdot 679$

\begin{tabular}{l|lll|l}
12 & 12 & 28 & $37 \cdot 73$ & $21 \cdot 685$
\end{tabular}

\begin{tabular}{l|lllll}
13 & 12 & 30 & $47 \cdot 86$ & $21 \cdot 692$
\end{tabular}

\begin{tabular}{l|lllll}
14 & 12 & 32 & 58.03 & 21.698
\end{tabular}

\begin{tabular}{l|lll|l}
15 & 12 & 35 & 8.24 & 21.705
\end{tabular}

\begin{tabular}{l|lll|l}
16 & 12 & 37 & $18 \cdot 49$ & $21 \cdot 712$
\end{tabular}

\begin{tabular}{l|lll|l}
17 & 12 & 39 & 28.78 & $21 \cdot 720$
\end{tabular}

\begin{tabular}{l|lll|l}
18 & 12 & 41 & $39 \cdot 13$ & $21 \cdot 728$
\end{tabular}

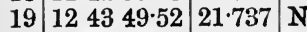

\begin{tabular}{llllll|l}
20 & 12 & 45 & $59 \cdot 97$ & $21 \cdot 746$ & $\mathrm{~S}$.
\end{tabular}

\begin{tabular}{lllll|l}
21 & 12 & 48 & 10.47 & 21.756
\end{tabular}

\begin{tabular}{l|llll|l}
22 & 12 & 50 & 21.04 & 21.766
\end{tabular}

$\begin{array}{lllll}23 & 12 & 52 & 31 \cdot 66 & 21 \cdot 775\end{array}$

$\begin{array}{llllll}24 & 12 & 54 & 42 \cdot 34 & 21 \cdot 786 & \text { S. }\end{array}$

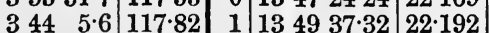

$\begin{array}{lllllllll}3 & 32 & 17.9 & 118.08 & 2 & 13 & 51 & 50.54 & 22.213\end{array}$

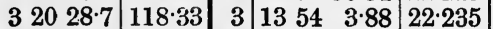

\begin{tabular}{lll|lll|lll|l}
3 & 8 & $38 \cdot 0$ & $118 \cdot 56$ & 4 & 13 & 56 & $17 \cdot 36$ & $22 \cdot 258$
\end{tabular}

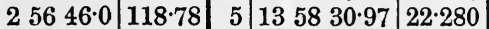

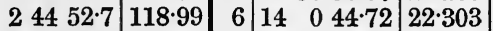

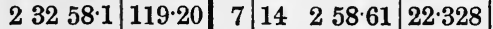

\begin{tabular}{lll|l|l|lll|l}
2 & 21 & $2 \cdot 3$ & 119.39 & 8 & 14 & 5 & 12.65 & 22.352
\end{tabular}

\begin{tabular}{lll|l|l|lll|l}
2 & 9 & 5.4 & 119.57 & 9 & 14 & 7 & 26.83 & 22.375
\end{tabular}

\begin{tabular}{lll|l|l|lll|l}
1 & 57 & $7 \cdot 5$ & $119 \cdot 73$ & 10 & 14 & 9 & $41 \cdot 15$ & $22 \cdot 400$
\end{tabular}

\begin{tabular}{lll|l|l|lll|l}
145 & 8.6 & 119.88 & 11 & 14 & 11 & 55.63 & 22.425 \\
\hline
\end{tabular}

\begin{tabular}{lll|l|l|lll|l}
1 & 33 & 8.9 & 120.03 & 12 & 14 & 14 & 10.25 & 22.450
\end{tabular}

\begin{tabular}{lll|l|l|llll}
1 & 21 & 8.3 & $120 \cdot 17$ & 13 & 14 & 16 & 25.03 & 22.476
\end{tabular}

\begin{tabular}{lll|l|l|lll|l}
1 & 9 & 6.9 & 120.29 & 14 & 14 & 18 & 39.96 & 22.503
\end{tabular}

\begin{tabular}{lll|l|l|lll|l}
0 & 57 & 4.8 & 120.41 & 15 & 14 & 20 & 55.06 & 22.529
\end{tabular}

$\begin{array}{llllllllll}0 & 45 & 2 \cdot 0 & 120.51 & 16 & 14 & 23 & 10.31 & 22.555\end{array}$

\begin{tabular}{lll|l|l|lll|l}
0 & 32 & 58.7 & 120.59 & 17 & 14 & 25 & 25.72 & 22.583
\end{tabular}

\begin{tabular}{lll|l|l|llll|l}
0 & 20 & 54.9 & 120.67 & 18 & 14 & 27 & 41.30 & 22.610
\end{tabular}

\begin{tabular}{lll|l|l|lll|l}
0 & 8 & 50.7 & $120 \cdot 73$ & 19 & 14 & 29 & 57.04 & 22.638
\end{tabular} \begin{tabular}{llllllll|l}
0 & 3 & 13.9 & 120.79 & 20 & 14 & 32 & 12.95 & 22.666
\end{tabular} \begin{tabular}{lll|l|l|lll|l|l|}
0 & 15 & 18.8 & 120.83 & 21 & 14 & 34 & 29.03 & 22.694 \\
\hline
\end{tabular}

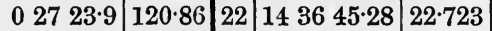

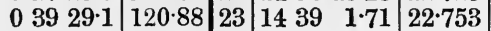

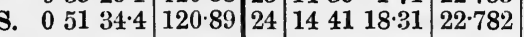

23.

$34 \cdot 4 \mid 120 \cdot 89$

\begin{tabular}{lll|l}
1 & 3 & $39 \cdot 8$ & $\mathbf{1 2 0} 89$
\end{tabular}

$11545 \cdot 1 \quad 120.87$

12750.2120 .84

$13955 \cdot 2 \quad 120 \cdot 81$

$15159 \cdot 9 \quad 120 \cdot 76$

\begin{tabular}{lll|l}
2 & 4 & $4 \cdot 3$ & $120 \cdot 70$
\end{tabular}

$\begin{array}{llll}2 & 16 & 8.3 & 120.63\end{array}$

\begin{tabular}{lll|l}
2 & 28 & 11.8 & 120.53
\end{tabular}

$\begin{array}{llll}2 & 40 & 14.7 & 120 \cdot 43\end{array}$

$25217 \cdot 0 \quad 120 \cdot 33$

$\begin{array}{lllll}3 & 4 & 18.7 & 120.21\end{array}$

$\begin{array}{lllll}3 & 16 & 19.5 & 120.07\end{array}$

$\begin{array}{llll}328 & 19.5 & 119.93\end{array}$

$34018: 6 \quad 119 \cdot 78$

$\begin{array}{llll}3 & 52 & 16.8 & 119 \cdot 61\end{array}$

\begin{tabular}{lll|l}
4 & 4 & 13.9 & $119 \cdot 42$
\end{tabular}

\begin{tabular}{lll|l}
4 & 16 & $9 \cdot 8$ & $119 \cdot 23$
\end{tabular}

$428 \quad 4.6 \quad 119.03$

$\begin{array}{llll}4 & 3958 \cdot 1 & 118 \cdot 81\end{array}$

$\begin{array}{llll}45150 \cdot 3 & 118.58\end{array}$

$\begin{array}{lllll}5 & 3 & 41 \cdot 1 & 118 \cdot 34\end{array}$

\begin{tabular}{lll|l}
5 & 15 & 30.4 & 118.08
\end{tabular}

S. $52718 \cdot 1 \mid 117 \cdot 82$ 
AUGUST.

MEAN TIME.

THE MOON'S RIGHT ASCENSION AND DECLINATION.

\begin{tabular}{|c|c|c|c|c|c|c|c|c|c|}
\hline 宫 & $\begin{array}{c}\text { Right } \\
\text { Ascension. }\end{array}$ & $\begin{array}{l}\text { Var. } \\
\text { in } 10 \mathrm{~m} .\end{array}$ & Declination. & \begin{tabular}{|} 
Var. \\
in $10^{\mathrm{m}}$
\end{tabular} & 容 & $\underset{\text { Ascension. }}{\text { Right }}$ & $\begin{array}{l}\text { Var. } \\
\text { in } 10^{\mathrm{m}} \text {. }\end{array}$ & Declination. & $\begin{array}{l}\text { Var. } \\
\text { in } 10^{\mathrm{m}}\end{array}$ \\
\hline
\end{tabular}

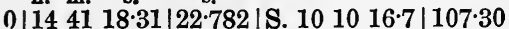

$1 \quad 144335 \cdot 0922 \cdot 811$

$2144552.04 \quad 22 \cdot 841$

\begin{tabular}{l|lllll}
3 & 14 & 48 & $9 \cdot 18$ & $22 \cdot 871$
\end{tabular}

$\begin{array}{llllll} & 14 & 50 & 26 \cdot 49 & 22 \cdot 901\end{array}$

$5145243.9922 \cdot 932$

$6 \quad 1455 \quad 1 \cdot 67 \mid 22 \cdot 963$

$\begin{array}{llllll}7 & 14 & 57 & 19.54 & 22.994\end{array}$

$8145937 \cdot 60 \quad 23.025$

$9 \begin{array}{llllll}15 & 1 & 55.84 & 23.056\end{array}$

\begin{tabular}{r|rrrr}
10 & 15 & 4 & $14 \cdot 27$ & $23 \cdot 088$
\end{tabular}

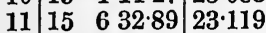

$\begin{array}{llllll}12 & 15 & 8 & 51 \cdot 70 & 23 \cdot 151\end{array}$

\begin{tabular}{l|lllll}
13 & 15 & 11 & $10 \cdot 70$ & $23 \cdot 183$
\end{tabular}

$\begin{array}{llllll}14 & 15 & 13 & 29 \cdot 90 & 23 \cdot 216\end{array}$

$\begin{array}{llllll}15 & 15 & 15 & 49 \cdot 29 & 23 \cdot 248\end{array}$

$\begin{array}{llllll}16 & 15 & 18 & 8 \cdot 88 & 23 \cdot 281\end{array}$

$\begin{array}{llllll}17 & 15 & 20 & 28 \cdot 66 & 23 \cdot 313\end{array}$

$18 \quad 1522 \quad 48 \cdot 63 \quad 23 \cdot 346$

\begin{tabular}{llll|l}
19 & 15 & 25 & $8 \cdot 81$ & $23 \cdot 379$
\end{tabular}

$201527 \quad 29 \cdot 18 \quad 23 \cdot 412$

$21 \quad 1529 \quad 49 \cdot 75 \mid 23.444$

$22 \quad 1532 \quad 10.51 \quad 23.478$

\begin{tabular}{lllll|l}
23 & 15 & 34 & $31 \cdot 48$ & $23 \cdot 511$
\end{tabular}

\section{Sunday 26.}

$0|153652.64| 23.543 \mid$ S. $14 \quad 836.5$

$1153914.00 \quad 23.578$

$\begin{array}{llllll}1 & 15 & 41 & 35 \cdot 57 & 23 \cdot 611\end{array}$

$\begin{array}{llllll}3 & 15 & 43 & 57 \cdot 33 & 23 \cdot 643\end{array}$

$\begin{array}{llllll}4 & 15 & 46 & 19 \cdot 29 & 23.676\end{array}$

$\begin{array}{lllllll}5 & 15 & 48 & 41 \cdot 44 & 23 \cdot 709\end{array}$

$6 \begin{array}{llllll}5 & 15 & 51 & 3.80 & 23.743\end{array}$

\begin{tabular}{l|lll|l}
7 & 15 & 53 & $26 \cdot 36$ & $23 \cdot 776$
\end{tabular}

$\begin{array}{lllllll}8 & 15 & 55 & 49 \cdot 11 & 23 \cdot 808\end{array}$

$\begin{array}{llllll}9 & 15 & 58 & 12.06 & 23 \cdot 842\end{array}$

\begin{tabular}{llll|l}
10 & 16 & 0 & $35 \cdot 21$ & $23 \cdot 874$
\end{tabular}

$\begin{array}{lllll}11 & 16 & 2 & 58.55 & 23.907\end{array}$

$\begin{array}{lllll}12 & 16 & 5 & 22.09 & 23.939\end{array}$

$\begin{array}{llllll}13 & 16 & 7 & 45 \cdot 82 & 23 \cdot 972\end{array}$

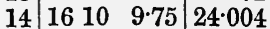

$\begin{array}{llllll}15 & 16 & 12 & 33.87 & 24.035\end{array}$

\begin{tabular}{l|lll|l}
16 & 16 & 14 & $58 \cdot 17$ & $24 \cdot 067$
\end{tabular}

$17 \quad 16 \quad 17 \quad 22 \cdot 67 \quad 24 \cdot 099$

\begin{tabular}{l|lll|l}
18 & 16 & 19 & $47 \cdot 36$ & $24 \cdot 130$
\end{tabular}

$19 \begin{array}{lllll}16 & 22 & 12 \cdot 23 & 24 \cdot 161\end{array}$

$\begin{array}{llllll}20 & 16 & 24 & 37 \cdot 29 & 24 \cdot 192\end{array}$

$\begin{array}{llllll}21 & 16 & 27 & 2.53 & 24.223\end{array}$

\begin{tabular}{lllll|l}
22 & 16 & 29 & $27 \cdot 96$ & $24 \cdot 253$
\end{tabular}

\begin{tabular}{lllll|l}
23 & 16 & 31 & 53.56 & $24 \cdot 283$
\end{tabular}

$\begin{array}{llllll}24 & 16 & 34 & 19 \cdot 35 & 24 \cdot 313\end{array}$
$102058 \cdot 8 \quad 106 \cdot 73$

$103137 \cdot 4 \quad 106 \cdot 13$

$1042 \quad 12.4 \quad 105.53$

$1052 \quad 43.7 \quad 104.92$

$\begin{array}{lllll}11 & 3 & 11 \cdot 4 & 104 \cdot 29\end{array}$

$11 \quad 1335.2 \quad 103.65$

$112355 \cdot 2$ 103.01

$\begin{array}{llll}11 & 34 & 11.3 & 102.35\end{array}$

$114423.4 \quad 101.68$

$115431 \cdot 4 \quad 100.98$

$\begin{array}{lllll}12 & 4 & 35 \cdot 2 & 100 \cdot 29\end{array}$

121434.9

122430.3

$123421 \cdot 3$

$\begin{array}{lll}12 & 44 & 7 \cdot 9\end{array}$

$125349 \cdot 9$

$\begin{array}{lll}13 & 3 & 27 \cdot 4\end{array}$

$\begin{array}{llll}13 & 13 & 0.3\end{array}$

132228.5

$133151 \cdot 9$

$1341 \quad 10.5$

$135024 \cdot 2$

. 135932.9

91.03
141735.0

$142628 \cdot 4$

143516.5

$144359 \cdot 3$

145236.7

$\begin{array}{lll}15 & 1 & 8.7\end{array}$

$\begin{array}{lll}15 & 9 & 35 \cdot 2\end{array}$

$151756 \cdot 1$

152611.3

$153420 \cdot 9$

$154224 \cdot 7$

155022.7

155814.8

$\begin{array}{llll}16 & 6 & 0.9\end{array}$

161341.0

$162115 \cdot 1$

$\begin{array}{llll}16 & 28 & 43 \cdot 1\end{array}$

$\begin{array}{lll}16 & 36 & 4.8\end{array}$

$164320 \cdot 3$

165029.5

165732.3

\begin{tabular}{lll}
$17 \quad 428 \cdot 6$ \\
\hline
\end{tabular}

171118.5
S. $17 \quad 18 \quad 1.9$ h. m. s. s.

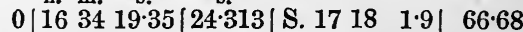

$\begin{array}{llllll} & 16 & 36 & 45 \cdot 31 & 24 \cdot 342\end{array}$

$\begin{array}{llllll}2 & 16 & 39 & 11 \cdot 45 & 24 \cdot 371\end{array}$

$\begin{array}{lllll}3 & 16 & 41 & 37 \cdot 76 & 24 \cdot 399\end{array}$

$\begin{array}{lllll}4 & 16 & 44 & 4 \cdot 24 & 24 \cdot 428\end{array}$

5 16 $46 \begin{array}{lll}30 \cdot 89 & 24 \cdot 456\end{array}$

$6 \quad \begin{array}{lllll}16 & 48 & 57 \cdot 71 & 24 \cdot 483\end{array}$

$\begin{array}{llllll}7 & 16 & 51 & 24.68 & 24.509\end{array}$

$\begin{array}{lllllll}8 & 16 & 53 & 51 \cdot 82 & 24.537\end{array}$

$\begin{array}{llllll}9 & 16 & 56 & 19 \cdot 12 & 24.563\end{array}$

$\begin{array}{lllll}10 & 16 & 58 & 46.57 & 24: 588\end{array}$

$\begin{array}{llllll}11 & 17 & 1 & 14 \cdot 17 & 24 \cdot 613\end{array}$

$\begin{array}{lllllll}99.59 & 12 & 17 & 3 & 41 \cdot 92 & 24 \cdot 638\end{array}$

\begin{tabular}{ll|lll|l}
$98 \cdot 87$ & 13 & 17 & 6 & $9 \cdot 82$ & $24 \cdot 662$
\end{tabular}

\begin{tabular}{ll|lll|l}
$98 \cdot 13$ & 14 & 17 & 8 & $37 \cdot 86$ & $24 \cdot 686$
\end{tabular}

\begin{tabular}{ll|lll|l}
$97 \cdot 38$ & 15 & 17 & 11 & $6 \cdot 05$ & $24 \cdot 709$
\end{tabular}

\begin{tabular}{ll|lll|l}
96.63 & 16 & 17 & 13 & $34 \cdot 37$ & $24 \cdot 731$
\end{tabular}

\begin{tabular}{ll|lll|l}
95.87 & 17 & 17 & 16 & 2.82 & 24.753
\end{tabular}

\begin{tabular}{ll|lllll}
$95 \cdot 09$ & 18 & 17 & 18 & $31 \cdot 40$ & $24 \cdot 774$
\end{tabular}

\begin{tabular}{ll|lll|l}
94.30 & 19 & 17 & 21 & $0 \cdot 11$ & $24 \cdot 795$
\end{tabular}

\begin{tabular}{ll|lll|l}
93.50 & 20 & 17 & 23 & 28.94 & $24 \cdot 816$
\end{tabular}

\begin{tabular}{ll|lllll}
92.69 & 21 & 17 & 25 & 57.90 & 24.836
\end{tabular}

\begin{tabular}{ll|llll|l}
91.87 & 22 & 17 & 28 & 26.97 & 24.853
\end{tabular} \begin{tabular}{ll|l}
$172438 \cdot 7$ & $65 \cdot 58$
\end{tabular}

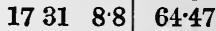

$173732 \cdot 3 \quad 63 \cdot 35$

\begin{tabular}{ll|l}
$174349 \cdot 0$ & $62 \cdot 22$
\end{tabular}

\begin{tabular}{ll|l}
174958.9 & $61 \cdot 08$
\end{tabular}

$\begin{array}{llll}17 & 56 & 2.0 & 59 \cdot 93\end{array}$

\begin{tabular}{lll|l}
18 & 1 & $58 \cdot 1$ & $58 \cdot 78$
\end{tabular}

$\begin{array}{lllll}18 & 7 & 47 \cdot 3 & 57 \cdot 62\end{array}$

$181329.5 \quad 56.45$

$\begin{array}{llll}18 & 19 & 4.7 & 55 \cdot 27\end{array}$

\begin{tabular}{ll|l}
18 & 2432.7 & 54.08
\end{tabular}

\begin{tabular}{ll|l}
1829 & 53.6 & $52 \cdot 88$
\end{tabular}

$\begin{array}{llll}18 & 35 & 7 \cdot 3 & 51 \cdot 68\end{array}$

$\begin{array}{llll}18 & 40 & 13.8 & 50 \cdot 48\end{array}$

$\begin{array}{llll}18 & 45 & 13 \cdot 0 & 49 \cdot 26\end{array}$

\begin{tabular}{lll|l}
18 & 50 & 4.9 & 48.04
\end{tabular}

\begin{tabular}{ll|l}
1854 & $49 \cdot 5$ & $46 \cdot 81$
\end{tabular}

\begin{tabular}{ll|l}
1859 & $26 \cdot 6$ & $45 \cdot 57$
\end{tabular}

\begin{tabular}{lll|l}
19 & 3 & $56 \cdot 3$ & $44 \cdot 33$
\end{tabular}

\begin{tabular}{lll|l}
19 & 8 & 18.6 & 43.08
\end{tabular}

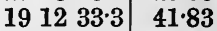

$\begin{array}{llll}19 & 16 & 40.5 & 40.57\end{array}$

S. $192040 \cdot 1 \quad 39 \cdot 29$

\section{Tuesday 28.}

$90 \cdot 18$

$89 \cdot 33$

\begin{tabular}{ll|lllll}
88.46 & 2 & 17 & 38 & $24 \cdot 31$ & 24.923
\end{tabular}

87.58

$86.68 \quad 4 \quad 1740$ 23.58 24.939

$85 \cdot 78$

84.88

83.95

83.01

82.07

\begin{tabular}{l|llll|l}
10 & 17 & 58 & 23.30 & 25.027
\end{tabular}

\begin{tabular}{ll|lll|l}
$80 \cdot 15$ & 11 & 18 & 0 & 53.49 & 25.037
\end{tabular}

\begin{tabular}{lllll|l}
$79 \cdot 18$ & 12 & 18 & 3 & 23.74 & 25.046
\end{tabular}

$\begin{array}{lllllll}78 \cdot 18 & 13 & 18 & 5 & 54 \cdot 04 & 25 \cdot 053\end{array}$

\begin{tabular}{ll|lll|l}
$77 \cdot 18$ & 14 & 18 & 8 & $24 \cdot 38$ & $25 \cdot 060$
\end{tabular}

\begin{tabular}{ll|lll|l}
$76 \cdot 18$ & 15 & 18 & 10 & $54 \cdot 76$ & $25 \cdot 067$
\end{tabular}

$\begin{array}{lllllll}\mathbf{7 5} \cdot 17 & 16 & 18 & 13 & 25 \cdot 18 & 25 \cdot 073\end{array}$

\begin{tabular}{ll|lll|l}
$74 \cdot 14$ & 17 & 18 & 15 & $55 \cdot 63$ & $25 \cdot 077$
\end{tabular}

\begin{tabular}{ll|llll|l}
$73 \cdot 10$ & 18 & 18 & 18 & $26 \cdot 10$ & $25 \cdot 081$
\end{tabular}

\begin{tabular}{ll|llll}
72.06 & 19 & 18 & 20 & 56.60 & 25.084
\end{tabular}

$\begin{array}{lllllll}71 \cdot 00 & 20 & 18 & 23 & 27 \cdot 11 & 25 \cdot 087\end{array}$

\begin{tabular}{lllll|l}
69.93 & 21 & 18 & 25 & $57 \cdot 64$ & $25 \cdot 088$
\end{tabular}

\begin{tabular}{ll|lll|l}
$68 \cdot 85$ & 22 & 18 & 28 & $28 \cdot 17$ & $25 \cdot 088$
\end{tabular}

\begin{tabular}{ll|lllll}
$67 \cdot 78$ & 23 & 18 & 30 & $58 \cdot 70$ & $25 \cdot 088$
\end{tabular}

\begin{tabular}{ll|lll|l}
$66 \cdot 68$ & 24 & 18 & 33 & $29 \cdot 23$ & $25 \cdot 088$
\end{tabular}

S. 192432.0

$192816 \cdot 3$

$193153 \cdot 0$

$193521 \cdot 9$

$1938 \quad 43 \cdot 1$

194156.5

$\begin{array}{llll}19 & 45 & 2 \cdot 1\end{array}$

194759.9

195049.9

195332.0

$\begin{array}{lll}19 & 56 & 6.2\end{array}$

195832.5

$\begin{array}{lll}20 & 0 & 50.9\end{array}$

$\begin{array}{lll}20 & 3 & 1.3\end{array}$

$\begin{array}{lll}20 & 5 & 3.8\end{array}$

$20 \quad 658.3$

$20 \quad 8 \quad 44.9$

$201023 \cdot 4$

201153.9

$2013 \quad 16 \cdot 4$

201430.9

$201537 \cdot 3$

201635.7

201726.0

38.02

$36 \cdot 75$

35.47

$34 \cdot 18$

$32 \cdot 88$

31.58

$30 \cdot 28$

28.98

$27 \cdot 68$

$26 \cdot 36$

$25 \cdot 04$

23.72

$22 \cdot 40$

21.08

$19 \cdot 75$

18.43

$17 \cdot 09$

$15 \cdot 75$

$14 \cdot 42$

13.08

$11 \cdot 74$

$10 \cdot 40$

$9 \cdot 06$

$7 \cdot 71$

6.37 
XII.

AUGUST.

MEAN TIME.

THE MOON'S RIGHT ASCENSION AND DECLINATION.

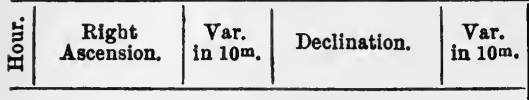

Wednesday 29.

h. m. 8. 8 .

$0|183329 \cdot 23| 25 \cdot 088 \mid$ S. $2018 \quad 8 \cdot 2 \mid$

$1 \quad 1835 \quad 59 \cdot 75 \quad 25 \cdot 085$

21838 30.25 25.083

$\begin{array}{llllll}3 & 18 & 41 & 0.74 & 25.079\end{array}$

$4 \quad 18 \quad 43 \quad 31 \cdot 20 \quad 25 \cdot 074$

\begin{tabular}{l|lll|l}
5 & 1846 & 1.63 & 25.069
\end{tabular}

$6 \quad 1848 \quad 32 \cdot 03 \quad 25 \cdot 063$

$\begin{array}{llllll}7 & 18 & 51 & 2.38 & 25.055\end{array}$

\begin{tabular}{l|lllll}
8 & 18 & 53 & $32 \cdot 69$ & $25 \cdot 048$
\end{tabular}

9 \begin{tabular}{l|lll|l}
18 & 56 & 2.95 & 25.039
\end{tabular}

$10185833 \cdot 16 \quad 25 \cdot 030$

$11 \quad$\begin{tabular}{lll|l}
19 & 1 & 3.31 & 25.018
\end{tabular}

\begin{tabular}{llll|l}
12 & 19 & 3 & $33 \cdot 38$ & $25 \cdot 007$
\end{tabular}

\begin{tabular}{l|lll|l}
13 & 19 & 6 & $3 \cdot 39$ & 24.995
\end{tabular}

\begin{tabular}{l|lll|l}
14 & 19 & 8 & $33 \cdot 32$ & 24.982
\end{tabular}

$\begin{array}{llllll}15 & 19 & 11 & 3 \cdot 17 & 24 \cdot 968\end{array}$

$\begin{array}{llllll}16 & 19 & 13 & 32 \cdot 93 & 24 \cdot 953\end{array}$

$17 \quad 19 \quad 16 \quad 2 \cdot 60 \mid 24 \cdot 938$

$181918 \quad 32 \cdot 18 \quad 24 \cdot 921$

\begin{tabular}{llll|l|l}
19 & 19 & 21 & $1 \cdot 65$ & $24 \cdot 903$
\end{tabular}

\begin{tabular}{llll|l}
20 & 19 & 23 & $31 \cdot 02$ & $24 \cdot 886$
\end{tabular}

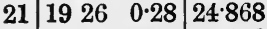

$\begin{array}{llllll}22 & 19 & 28 & 29 \cdot 43 & 24 \cdot 848\end{array}$

$23|193058 \cdot 45| 24 \cdot 827 \mid$

\section{Thursday 30.}

0|1933 27.35|24.806

$11935 \quad 56 \cdot 12 \quad 24 \cdot 784$

$\begin{array}{llllll}1 & 19 & 38 & 24 \cdot 76 & 24.761\end{array}$

$\begin{array}{llllll}3 & 19 & 40 & 53 \cdot 25 & 24 \cdot 737\end{array}$

$4 \mathbf{1 9} 4321 \cdot 60 \mid 24 \cdot 713$

$\begin{array}{llllll}5 & 19 & 45 & 49 \cdot 81 & 24 \cdot 689\end{array}$

$\begin{array}{lllllll}6 & 19 & 48 & 17 \cdot 87 & 24 \cdot 663\end{array}$

$7 \mathbf{1 9} 50 \quad 45 \cdot 76 \quad 24 \cdot 636$

$8 \begin{array}{llllll} & 19 & 53 & 13 \cdot 50 & 24 \cdot 609\end{array}$

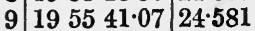

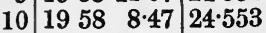

$11 \quad 20 \quad 0 \quad 35 \cdot 70 \quad 24 \cdot 523$

\begin{tabular}{l|lll|l}
12 & 20 & 3 & 2.75 & 24.493
\end{tabular}

\begin{tabular}{l|lll|l}
13 & 20 & 5 & $29 \cdot 62$ & $24 \cdot 463$
\end{tabular}

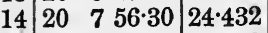

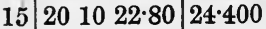

$16 \quad 20 \begin{array}{lllll}12 & 49 \cdot 10 & 24 \cdot 367\end{array}$

\begin{tabular}{l|lll|l}
17 & 20 & 15 & $15 \cdot 20$ & $24 \cdot 334$
\end{tabular}

$18 \quad 20 \quad 17 \quad 41 \cdot 11 \quad 24 \cdot 301$

19 \begin{tabular}{lll|l}
20 & 20 & $6 \cdot 81$ & $24 \cdot 266$
\end{tabular}

$20 \quad 2022 \quad 32 \cdot 30 \quad 24 \cdot 232$

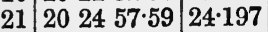

\begin{tabular}{l|lll|l}
22 & 20 & 27 & $22 \cdot 66$ & $24 \cdot 161$
\end{tabular}

\begin{tabular}{llll|l}
23 & 20 & 29 & $47 \cdot 52$ & $24 \cdot 124$
\end{tabular}

$\begin{array}{lllll}24 & 20 & 32 & 12 \cdot 15 & 24 \cdot 087\end{array}$

1952

$194941 \cdot 1$

$194649 \cdot 6$

194350.5

194043.9

$193729 \cdot 7$

$1934 \quad 8.0$

193038.9

$\begin{array}{lll}19 & 27 & 2.3\end{array}$

192318.4

$191927 \cdot 2$

$191528 \cdot 7$

$191122 \cdot 9$

$\begin{array}{lll}19 & 7 & 9.9\end{array}$

$\begin{array}{lll}19 & 2 & 49.8\end{array}$

$185822 \cdot 6$

$185348 \cdot 3$

$1849 \quad 7 \cdot 0$

$1844 \quad 18.7$

183923.5

183421.5

182912.6

$182357 \cdot 0$

S. 181834.7

\begin{tabular}{|c|c|c|c|c|}
\hline : & $\begin{array}{c}\text { Right } \\
\text { Ascension. }\end{array}$ & $\begin{array}{c}\text { Var: } \\
\text { in } 10 \mathrm{~m}\end{array}$ & Declination. & $\begin{array}{c}\text { Var. } \\
\text { in } 10^{\mathrm{m}} .\end{array}$ \\
\hline
\end{tabular}

h. m. s. s. , " "

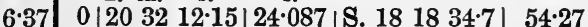

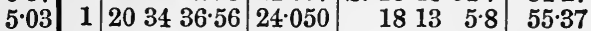
\begin{tabular}{lllll|lllll}
3.68 & 2 & 20 & 37 & 0.75 & 24.013 & 18 & 730.3 & 56.47
\end{tabular} \begin{tabular}{l|l|lll|lllll|l}
$2 \cdot 34$ & 3 & 20 & 39 & $24 \cdot 71$ & $23 \cdot 974$ & 18 & 1 & $48 \cdot 2$ & $57 \cdot 56$
\end{tabular}

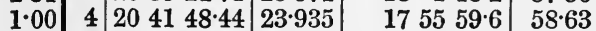

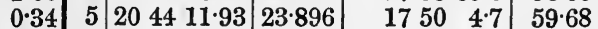

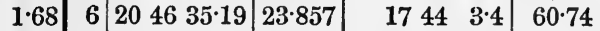
\begin{tabular}{l|l|lll|l|lll|l}
3.03 & 7 & 20 & 48 & $58 \cdot 21$ & 23.817 & 17 & 37 & 55.8 & $61 \cdot 79$
\end{tabular}

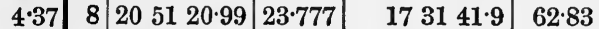

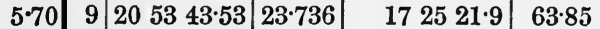
\begin{tabular}{ll|lll|l}
$7 \cdot 03$ & 10 & 20 & 56 & $5 \cdot 82$ & $23 \cdot 695$
\end{tabular} \begin{tabular}{l|l|lll|l}
$8 \cdot 36$ & 11 & 20 & 58 & $27 \cdot 87$ & $23 \cdot 654$
\end{tabular} \begin{tabular}{ll|lll|l|l}
$\mathbf{9} \cdot 69$ & 12 & 21 & 0 & $49 \cdot 67$ & $23 \cdot 613$
\end{tabular} \begin{tabular}{ll|lll|l}
11.02 & 13 & 21 & 3 & $11 \cdot 22$ & 23.570
\end{tabular} \begin{tabular}{l|l|lll|l}
$12 \cdot 35$ & 14 & 21 & 5 & 32.51 & 23.528
\end{tabular} \begin{tabular}{ll|lll|l}
13.67 & 15 & 21 & 7 & 53.55 & 23.486
\end{tabular} \begin{tabular}{ll|llll}
14.98 & 16 & 21 & 10 & 14.34 & $23 \cdot 443$
\end{tabular} \begin{tabular}{ll|lll|l}
$16 \cdot 30$ & 17 & 21 & 12 & $34 \cdot 87$ & $23 \cdot 399$
\end{tabular} \begin{tabular}{ll|lllll}
$17 \cdot 61$ & 18 & 21 & 14 & $55 \cdot 13$ & $23 \cdot 356$
\end{tabular} \begin{tabular}{ll|lll|l}
$18 \cdot 92$ & 19 & 21 & 17 & $15 \cdot 14$ & $23 \cdot 313$
\end{tabular} \begin{tabular}{ll|lll|l}
$20 \cdot 22$ & 20 & 21 & 19 & $34 \cdot 88$ & $23 \cdot 268$
\end{tabular}

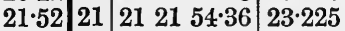
\begin{tabular}{ll|lll|l}
$22 \cdot 82$ & 22 & 21 & 24 & 13.58 & $23 \cdot 181$
\end{tabular} \begin{tabular}{l|l|lll|l}
$24 \cdot 11$ & 23 & 21 & 26 & $32 \cdot 53$ & $23 \cdot 136$
\end{tabular}

\begin{tabular}{ll|l}
17 & $1855 \cdot 7$ & $64 \cdot 87$
\end{tabular} \begin{tabular}{ll|l}
1712 & 23.5 & 65.87
\end{tabular} \begin{tabular}{lll|l}
17 & 5 & $45 \cdot 3$ & $66 \cdot 87$
\end{tabular} \begin{tabular}{lll|l}
16 & 59 & $1 \cdot 1$ & $67 \cdot 85$
\end{tabular} \begin{tabular}{lll|l}
16 & 52 & $11 \cdot 1$ & $68 \cdot 82$
\end{tabular} $\begin{array}{lllll}16 & 45 & 15 \cdot 3 & 69 \cdot 78\end{array}$ \begin{tabular}{l|l}
163813.7 & $70 \cdot 73$
\end{tabular}

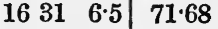
\begin{tabular}{ll|l}
16 & 2353.6 & $72 \cdot 61$
\end{tabular} \begin{tabular}{ll|l}
16 & $1635 \cdot 2$ & 73.53
\end{tabular} \begin{tabular}{lll|l}
16 & 9 & $11 \cdot 3$ & 74.43
\end{tabular} \begin{tabular}{lll|l}
16 & 1 & $42 \cdot 0$ & $75 \cdot 33$
\end{tabular} \begin{tabular}{lll|l}
15 & 54 & $7 \cdot 4$ & $76 \cdot 21$
\end{tabular} S. $154627 \cdot 5 \mid 77 \cdot 08$

Saturday, SEPT. 1.

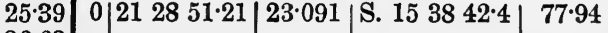
$26 \cdot 68$ $27 \cdot 95$ $29 \cdot 22$ 30.48 $31 \cdot 73$ 32.99 34.23 35.47 $36 \cdot 71$ 37.93 $39 \cdot 14$ 40.36 41.57 $42 \cdot 76$ 43.94 $45^{\circ} 13$ $46 \cdot 30$ $47 \cdot 47$

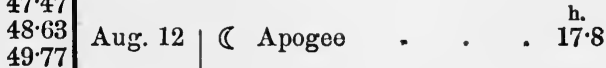
50.91 52.04 $53 \cdot 16$ $54 \cdot 27$
PHASES OF THE MOON.

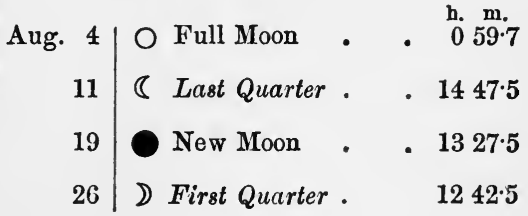
26 \& Perigee $\quad . \quad . \quad 21.5$ 
AUGUST.

MEAN TIME.

LUNAR DISTANCES.

\begin{tabular}{|c|c|c|c|c|c|c|c|c|c|c|}
\hline Day. & \multicolumn{2}{|c|}{$\begin{array}{l}\text { Star's Name } \\
\text { and } \\
\text { Position. }\end{array}$} & Noon. & $\begin{array}{l}\text { P.I. } \\
\text { of } \\
\text { diff. }\end{array}$ & III ${ }^{\mathrm{b}}$. & $\begin{array}{l}\text { P.I. } \\
\text { of } \\
\text { diff. }\end{array}$ & VIh. & $\begin{array}{c}\text { P.L. } \\
\text { of } \\
\text { diff. }\end{array}$ & IX $\mathrm{h}^{\mathrm{s}}$ & $\begin{array}{c}\text { P.L. } \\
\text { of } \\
\text { diff. }\end{array}$ \\
\hline \multirow{5}{*}{1} & & & 0,11 & " & $\circ, 11$ & & 0,11 & & 0,11 & \\
\hline & Spica & W. & $\begin{array}{llll}65 & 16 & 56\end{array}$ & 2222 & 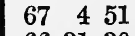 & 2221 & $\begin{array}{lll}68 & 52 & 47\end{array}$ & 2220 & $70 \quad 40 \quad 44$ & 222 \\
\hline & Fomalhaut & E. & & 2476 & 663130 & 2485 & 644955 & 2495 & $\begin{array}{lll}63 & 8 & 34\end{array}$ & \\
\hline & Saturn & E. & $7635 \quad 21$ & 2167 & $74 \quad 46 \quad 3$ & 2168 & $\begin{array}{llll}72 & 56 & 47\end{array}$ & 2168 & $\begin{array}{lll}71 & 7 & 31\end{array}$ & 216 \\
\hline & a Pegasi & E. & $8340 \quad 36$ & 2541 & $\begin{array}{lll}82 & 0 & 20\end{array}$ & 2545 & $\begin{array}{lll}80 & 20 & 9\end{array}$ & 2550 & $\begin{array}{lll}78 & 40 & 4\end{array}$ & 255 \\
\hline \multirow[t]{5}{*}{2} & Spica & W. & $\begin{array}{llll}79 & 40 & 6\end{array}$ & 2231 & $\begin{array}{lll}81 & 27 & 48\end{array}$ & 2235 & $\begin{array}{lll}83 & 15 & 24\end{array}$ & 2239 & $85 \quad 255$ & \\
\hline & Anta & W. & $\begin{array}{lll}34 & 21 & 41\end{array}$ & 2372 & 36556 & 2363 & $\begin{array}{lll}37 & 50 & 24\end{array}$ & 2355 & $\begin{array}{llll}39 & 35 & 4\end{array}$ & 2 \\
\hline & Sat & E. & $\begin{array}{lll}62 & 1 & 48\end{array}$ & 2181 & $\begin{array}{lll}60 & 12 & 52\end{array}$ & 2185 & $\begin{array}{lll}58 & 24 & 1\end{array}$ & 2189 & $\begin{array}{llll}56 & 35 & 17\end{array}$ & 219 \\
\hline & $\alpha \mathrm{Pe}$ & E. & $\begin{array}{lll}70 & 22 & 16\end{array}$ & 2603 & $\begin{array}{rr}68 & 4325\end{array}$ & 2618 & $67 \quad 454$ & 2634 & 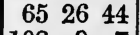 & \\
\hline & a Arietis & E. & $\begin{array}{lll}113 & 2120\end{array}$ & 2380 & 1113716 & 2379 & $\begin{array}{lll}109 & 53 & 11\end{array}$ & 2380 & $\begin{array}{lll}108 & 9 & 7\end{array}$ & 238 \\
\hline \multirow[t]{5}{*}{3} & Spice & W. & $93 \quad 58 \quad 30$ & 2274 & $\begin{array}{lll}95 & 45 & 8\end{array}$ & 2282 & 3134 & 2290 & 48 & $25+2+3$ \\
\hline & & W. & & 2342 & $50 \quad 450$ & 2344 & 514945 & 2348 & & 235 \\
\hline & Saturn & E. & 473338 & 2225 & $\begin{array}{lll}45 & 45 & 47\end{array}$ & 2233 & $\begin{array}{lll}43 & 58 & 8\end{array}$ & 2241 & 41 & 2249 \\
\hline & $a \mathrm{Pe}_{8}$ & E. & $\begin{array}{lll}57 & 22 & 37\end{array}$ & 2768 & $\begin{array}{llll}55 & 47 & 27\end{array}$ & 2798 & $54 \quad 1256$ & 2831 & $\begin{array}{lll}52 & 39 & 8\end{array}$ & 2868 \\
\hline & a Arietis & & $\begin{array}{lll}99 & 29 & 37\end{array}$ & 2400 & $9746 \quad 2$ & 2406 & $\begin{array}{lll}96 & 2 & 36\end{array}$ & 2413 & $94 \quad 1920$ & 2421 \\
\hline \multirow[t]{4}{*}{4} & Spica & W. & $\begin{array}{lll}108 & 5 & 27\end{array}$ & 2351 & $\begin{array}{lll}109 & 50 & 12\end{array}$ & 2363 & 1113440 & 2375 & $\mid \begin{array}{lll}113 & 18 & 50\end{array}$ & \\
\hline & & W. & $62 \quad 1645$ & 2387 & $\begin{array}{lll}64 & 0 & 39\end{array}$ & 2395 & 654 & 2405 & 749 & 241 \\
\hline & & E. & $\begin{array}{llll}33 & 16 & 47\end{array}$ & 2298 & $\begin{array}{lll}31 & 30 & 45\end{array}$ & 2309 & $\begin{array}{lll}29 & 44 & 59\end{array}$ & 2321 & 2759 & 233 \\
\hline & $\begin{array}{l}a \text { Arietis } \\
\text { Aldebaran }\end{array}$ & E. & 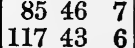 & 2471 & $\begin{array}{rrr}84 & 4 & 13 \\
15 & 57 & 29\end{array}$ & 2483 & $\begin{array}{rrr}82 & 22 & 36 \\
14 & 12 & 8\end{array}$ & 2496 & \begin{tabular}{rrr|}
80 & 41 & 17 \\
112 & 27 & 3
\end{tabular} & $\begin{array}{l}250 \\
234\end{array}$ \\
\hline \multirow{3}{*}{5} & Antare & W. & & 2473 & 7 & 486 & $7924 \quad 40$ & 2499 & & 2513 \\
\hline & $\alpha$ Ari & E. & & 2586 & $\begin{array}{llll}70 & 40 & 24\end{array}$ & 2600 & $\begin{array}{lll}69 & 1 & 34\end{array}$ & 2622 & 6723 & 2640 \\
\hline & Aldebaran & E. & 103464 & 2413 & 102248 & 2427 & 1001952 & 2441 & $\begin{array}{lll}98 & 37 & 15\end{array}$ & 245 \\
\hline \multirow[t]{5}{*}{6} & $n$ ta & W. & & 586 & $\begin{array}{lll}91 & 6 & 25\end{array}$ & 601 & 92 & 2616 & & 632 \\
\hline & $\infty$ & W. & & 3623 & & 3584 & & 3550 & 51 & 352 \\
\hline & & $\mathbf{E}$. & 591 & 2745 & $\begin{array}{lll}57 & 41 & 59\end{array}$ & 2769 & 650 & 2793 & $\begin{array}{ll}32 & 12\end{array}$ & 281 \\
\hline & & E. & 90 & 2530 & 8328 & 2544 & 8648 & 2559 & 845 & 257 \\
\hline & upiter & E. & $\begin{array}{lll}113 & 11 & 10\end{array} \mid$ & 2600 & $\begin{array}{lll}111 & 32 & 15\end{array} \mid$ & 2616 & $10953 \quad 42$ & 2632 & $\begin{array}{llll}108 & 15 & 30\end{array}$ & 264 \\
\hline \multirow[t]{5}{*}{7} & Anta & W. & $\begin{array}{lll}102 & 31 & 12\end{array}$ & 2713 & 735 & 2729 & 10543 & 2746 & $\begin{array}{lll}107 & 19 & 15\end{array}$ & 2762 \\
\hline & e & W. & & 3430 & & 3421 & 61 & 3413 & 62 & 408 \\
\hline & & E. & 45 & 2962 & $\begin{array}{lll}45 & 16 & 45\end{array}$ & 2996 & 434 & 3031 & $42 \quad 1653$ & 306 \\
\hline & A & E. & 452 & 2653 & $75 \quad 17$ & 2668 & 733 & 2684 & 244 & 269 \\
\hline & Jupiter & E. & $\begin{array}{lll}100 & 9 & 43\end{array}$ & 2725 & $98 \quad 33 \quad 36$ & 2741 & $\begin{array}{llll}96 & 57 & 51\end{array}$ & 2756 & $\begin{array}{lll}95 & 22 & 25\end{array}$ & 2772 \\
\hline \multirow[t]{6}{*}{8} & $\infty$ & W. & , 693354 & 3402 & 7056 & 3405 & $\begin{array}{lll}72 & 18 & 20\end{array}$ & 3408 & $\begin{array}{llll}73 & 40 & 27\end{array}$ & 3412 \\
\hline & & W. & & 2755 & & 769 & 235 & 84 & 54 & 797 \\
\hline & $\operatorname{ran}$ & E. & 64240 & 2775 & 739 & & 605 & 2802 & 591 & 817 \\
\hline & & E. & $\begin{array}{llll}87 & 30 & 19\end{array}$ & 2847 & 855652 & 2862 & 842 & 2876 & 825 & 289] \\
\hline & ollu & E. & $\begin{array}{lll}108 & 4 & 3\end{array}$ & 2826 & $10630 \quad 9$ & 2839 & $104 \quad 56 \quad 32$ & 2852 & 1032 & 86 \\
\hline & & E. & $\begin{array}{lll}130 & 41 & 2\end{array}$ & 3114 & $\begin{array}{lll}129 & 13 & 9\end{array}$ & 3129 & 1274535 & 3144 & $\begin{array}{lll}126 & 18 & 19\end{array}$ & 3160 \\
\hline \multirow[t]{6}{*}{9} & uilæ & W. & $\begin{array}{lll}80 & 29 & 35\end{array}$ & 3445 & 8151 & 3453 & $\begin{array}{lll}83 & 12 & 19\end{array}$ & 3461 & $\begin{array}{lll}84 & 33 & 27\end{array}$ & 3470 \\
\hline & & $W$ & & 62 & & & 3620 & 2886 & 37 & 2897 \\
\hline & & E. & & & $\begin{array}{lll}49 & 58 & 16\end{array}$ & & 482551 & 2908 & 465 & 2919 \\
\hline & & E. & $\begin{array}{lll}75 & 11 & 16\end{array}$ & 8 & $\begin{array}{llll}73 & 40 & 11\end{array}$ & 2970 & $\begin{array}{llll}72 & 9 & 21\end{array}$ & 2982 & $\begin{array}{llll}70 & 38 & 46\end{array}$ & 299 \\
\hline & & E. & $\begin{array}{llll}95 & 40 & 47\end{array}$ & 2930 & $\begin{array}{lll}94 & 9 & 6\end{array}$ & 2942 & 923741 & 2954 & 91 & 296 \\
\hline & Sun & E. & $\begin{array}{lll}119 & 6 & 30\end{array}$ & 3232 & $\begin{array}{llll}117 & 40 & 59\end{array}$ & 3245 & $\begin{array}{lll}116 & 15 & 43\end{array}$ & 3258 & $\begin{array}{lll}114 & 50 & 42\end{array}$ & 3270 \\
\hline
\end{tabular}


XIV.

AUGUST.

MEAN TIME.

LUNAR DISTANCES.

\begin{tabular}{|c|c|c|c|c|c|c|c|c|c|c|}
\hline Day. & \multicolumn{2}{|c|}{$\begin{array}{l}\text { Star's Name } \\
\text { and } \\
\text { Position. }\end{array}$} & Midnight. & $\begin{array}{c}\text { P.L. } \\
\text { of } \\
\text { diff. }\end{array}$ & XVh. & $\begin{array}{c}\text { P.L. } \\
\text { of } \\
\text { diff. }\end{array}$ & XVIII'b. & $\begin{array}{c}\text { P.L. } \\
\text { of } \\
\text { diff. }\end{array}$ & XXIh. & $\begin{array}{l}\text { P.L. } \\
\text { of } \\
\text { diff. }\end{array}$ \\
\hline & & & 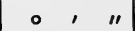 & & $0, " 1$ & & 0,11 & & 0,1 & \\
\hline \multirow[t]{4}{*}{1} & Spica & W. & $\begin{array}{lll}72 & 28 & 41\end{array}$ & 2222 & $\begin{array}{llll}74 & 16 & 36\end{array}$ & 2223 & 429 & 2225 & $\begin{array}{lll}77 & 52 & 19\end{array}$ & 2228 \\
\hline & Fomalhaut & E. & $\begin{array}{lll}61 & 27 & 29\end{array}$ & 2519 & $\begin{array}{llll}59 & 46 & 42\end{array}$ & 2533 & $\begin{array}{lll}58 & 6 & 15\end{array}$ & 2549 & $\begin{array}{llll}56 & 26 & 10\end{array}$ & 2568 \\
\hline & Saturn & E. & $\begin{array}{lll}69 & 18 & 16\end{array}$ & 2170 & $\begin{array}{llr}67 & 29 & 4\end{array}$ & 2172 & 653955 & 2175 & $\begin{array}{lll}63 & 50 & 49\end{array}$ & 2178 \\
\hline & a Pegasi & E. & $\begin{array}{lll}77 & 0 & 8\end{array}$ & 2562 & $\begin{array}{llll}75 & 20 & 21\end{array}$ & 2570 & $\begin{array}{lll}73 & 40 & 45\end{array}$ & 2580 & $\begin{array}{lll}72 & 1 & 23\end{array}$ & 2591 \\
\hline \multirow[t]{5}{*}{2} & Spica & W. & $\begin{array}{lll}86 & 50 & 19\end{array}$ & 2248 & $\begin{array}{lll}88 & 37 & 35\end{array}$ & 2254 & $90 \quad 24 \quad 43$ & 2260 & $\begin{array}{lll}92 & 11 & 41\end{array}$ & 2267 \\
\hline & Antares & W. & 411953 & 2344 & $\begin{array}{ll}43 \quad 48 \\
\end{array}$ & 2341 & $44 \quad 4948$ & 2339 & 463450 & 2340 \\
\hline & Saturn & E. & $\begin{array}{ll}54 & 46 \quad 40\end{array}$ & 2199 & $\begin{array}{llll}52 & 58 & 11\end{array}$ & 2205 & $\begin{array}{lll}51 & 9 & 51\end{array}$ & 2211 & $\begin{array}{lll}49 & 21 & 40\end{array}$ & 2217 \\
\hline & a Pegasi & E. & $\begin{array}{ll}63 & 48 \quad 58\end{array}$ & 2670 & $\begin{array}{llll}62 & 11 & 38\end{array}$ & 2690 & 603445 & 2713 & $\begin{array}{lll}58 & 58 & 23\end{array}$ & 2740 \\
\hline & $\alpha$ Arietis & E. & $\begin{array}{lll}106 & 25 & 4\end{array}$ & 2383 & 104415 & 2386 & $\begin{array}{lll}10257 & 10\end{array}$ & 2389 & 1011320 & 2394 \\
\hline \multirow[t]{5}{*}{3} & Spica & W. & $\begin{array}{lll}101 & 3 & 49\end{array}$ & 2309 & $\begin{array}{llll}102 & 49 & 36\end{array}$ & 2319 & 104358 & 2329 & $106 \quad 20 \quad 25$ & 2340 \\
\hline & Antares & W. & $\begin{array}{llll}55 & 19 & 19\end{array}$ & 2358 & $\begin{array}{lll}57 & 355\end{array}$ & 2364 & $\begin{array}{lll}58 & 48 & 22\end{array}$ & 2371 & $\begin{array}{lll}60 & 32 & 39\end{array}$ & 2379 \\
\hline & Saturn & E. & $\begin{array}{lll}40 & 2326\end{array}$ & 2258 & $\begin{array}{lll}38 & 36 & 25\end{array}$ & 2268 & $\begin{array}{lll}36 & 49 & 38\end{array}$ & 2277 & $\begin{array}{lll}35 & 3 & 5\end{array}$ & 2287 \\
\hline & a Pegasi & E. & $\begin{array}{lll}51 & 6 & 8\end{array}$ & 2908 & 493359 & 2952 & $48 \quad 246$ & 3000 & 463233 & 3053 \\
\hline & a Arietis & & 923615 & 2429 & $\begin{array}{lll}90 & 5322\end{array}$ & 2439 & $\begin{array}{lll}89 & 10 & 43\end{array}$ & 2449 & 872818 & 2459 \\
\hline \multirow[t]{5}{*}{4} & Spica & W. & $\begin{array}{lll}115 & 2 & 42\end{array}$ & 2401 & 1164615 & 2416 & 11829 & 2430 & $\begin{array}{lll}120 & 12 & 19\end{array}$ & 2444 \\
\hline & Ant & W. & $\begin{array}{lll}69 & 11 & 2\end{array}$ & 2426 & $\begin{array}{lll}70 & 54 & 0\end{array}$ & 2437 & 7236 & 2449 & $\begin{array}{lll}74 & 19 & 7\end{array}$ & 2460 \\
\hline & Saturn & E. & 261418 & 2345 & $24 \quad 2924$ & 2358 & 224449 & 2371 & 21033 & 2384 \\
\hline & $\alpha$ Arietis & E. & $\begin{array}{lll}79 & 0 & 16\end{array}$ & 2523 & $77 \quad 1935$ & 2538 & $75 \quad 3915$ & 2553 & $\begin{array}{llll}73 & 59 & 16\end{array}$ & 2569 \\
\hline & Aldebaran & E. & $\begin{array}{lll}110 & 42 & 15\end{array}$ & 2362 & 1085745 & 2374 & $107 \quad 13 \quad 33$ & 2387 & $105 \quad 2939$ & 2400 \\
\hline \multirow[t]{3}{*}{5} & Antares & W. & 8246 & 2527 & 8427 & 2541 & $\begin{array}{lll}86 & 7 & 40\end{array}$ & 2556 & 874736 & 2571 \\
\hline & a Arietis & E. & & 2660 & & 2681 & 623028 & 2701 & $\begin{array}{lll}60 & 53 & 49\end{array}$ & 2722 \\
\hline & Aldebaran & E. & & 2470 & $\begin{array}{lll}95 & 13 & 3\end{array}$ & 2485 & 933128 & 2499 & 915014 & 2514 \\
\hline \multirow[t]{5}{*}{6} & Antares & W. & $96 \quad 2$ & 2649 & $\begin{array}{lll}97 & 39 & 52\end{array}$ & 2665 & $\begin{array}{lll}99 & 17 & 20\end{array}$ & 2681 & 1005426 & 2696 \\
\hline & $a \mathrm{~A}$ & w. & $53 \quad 13$ & 3496 & 543333 & 3475 & $\begin{array}{lll}55 & 5425\end{array}$ & 3457 & $\begin{array}{lll}57 & 15 & 37\end{array}$ & 3442 \\
\hline & a Arietis & E. & $\begin{array}{lll}52 & 58 & 8\end{array}$ & 2844 & $\begin{array}{lll}5124 & 37\end{array}$ & 2872 & $\begin{array}{lll}49 & 51 & 42\end{array}$ & 2901 & $\begin{array}{llll}48 & 19 & 24\end{array}$ & 2931 \\
\hline & Aldebaran & E. & $\begin{array}{lll}83 & 29 & 16\end{array}$ & 2591 & $\begin{array}{lll}81 & 50 & 8\end{array}$ & 2607 & $\begin{array}{llll}80 & 11 & 22\end{array}$ & 2622 & 257 & 2637 \\
\hline & Jupiter & E. & 1063739 & 2663 & 1050 & 2678 & 1032259 & 2694 & 1014611 & 2709 \\
\hline \multirow[t]{5}{*}{7} & Antares & W. & 1085433 & 2779 & $\begin{array}{lll}110 & 29 & 29\end{array}$ & 2795 & $\begin{array}{lll}112 & 4 & 4\end{array}$ & 2811 & $\begin{array}{lll}113 & 38 & 17\end{array}$ & 2828 \\
\hline & Aquilæ & W. & & 3404 & 6527 & 3401 & $\begin{array}{llll}66 & 49 & 20\end{array}$ & 3400 & $\begin{array}{lll}68 & 11 & 37\end{array}$ & 3400 \\
\hline & Arietis & E. & $\begin{array}{llll}40 & 48 & 6\end{array}$ & 3110 & $\begin{array}{lll}39 & 20 & 8\end{array}$ & 3153 & $\begin{array}{lll}37 & 53 & 1\end{array}$ & 3199 & $\begin{array}{lll}36 & 26 & 50\end{array}$ & 3249 \\
\hline & Aldebaran & E. & $\begin{array}{lll}70 & 26 & 3\end{array}$ & 2715 & $\begin{array}{lll}68 & 49 & 43\end{array}$ & 2729 & $\begin{array}{lll}67 & 13 & 42\end{array}$ & 2744 & $\begin{array}{lll}65 & 38 & 1\end{array}$ & 2760 \\
\hline & Jupiter & E. & 934720 & 2787 & 921235 & 2802 & $90 \quad 3810$ & 2818 & $\begin{array}{lll}89 & 4 & 5\end{array}$ & 2832 \\
\hline \multirow[t]{6}{*}{8} & a Aquilø & W. & 75 & 3418 & $\begin{array}{llll}76 & 24 & 27\end{array}$ & 3424 & 77 & 3430 & 59 & 3437 \\
\hline & & W. & $\begin{array}{lll}26 & 59 & 26\end{array}$ & 2811 & & 2824 & & 2836 & $\begin{array}{lll}31 & 41 & 18\end{array}$ & 2849 \\
\hline & $\operatorname{aran}$ & E. & $\begin{array}{ll}57 & 44 \quad 25\end{array}$ & 2831 & $\begin{array}{lll}56 & 10 & 37\end{array}$ & 2844 & $\begin{array}{lll}54 & 37 & 7\end{array}$ & 2857 & $\begin{array}{lll}53 & 353\end{array}$ & 2870 \\
\hline & $\mathrm{Ju}$ & E. & $\begin{array}{lll}81 & 18 & 25\end{array}$ & 2905 & $\begin{array}{llll}79 & 46 & 12\end{array}$ & 2919 & $\begin{array}{llll}78 & 14 & 17\end{array}$ & 2931 & $76 \quad 42 \quad 38$ & 2945 \\
\hline & Pollux & E. & 1015010 & 2879 & 1001725 & 2892 & 984 & 2905 & $\begin{array}{llll}97 & 12 & 44\end{array}$ & 2917 \\
\hline & SuN & E. & 1245122 & 3175 & $123 \quad 2443$ & 3190 & $12158 \quad 22$ & 3204 & 1203218 & 3218 \\
\hline \multirow[t]{6}{*}{9} & $\alpha$ Aquilø & W. & 855425 & 3479 & $\begin{array}{llll}87 & 15 & 13\end{array}$ & 3488 & $\begin{array}{lll}88 & 35 & 50\end{array}$ & 3498 & 5617 & 3508 \\
\hline & & W. & $\begin{array}{llll}39 & 25 & 41\end{array}$ & 2908 & & 2919 & $\begin{array}{lll}42 & 29 & 44\end{array}$ & 2929 & $44 \quad 125$ & 2939 \\
\hline & Aldebaran & E. & $\begin{array}{lll}45 & 21 & 47\end{array}$ & 2931 & $\begin{array}{lll}43 & 50 & 7\end{array}$ & 2942 & $\begin{array}{lll}42 & 18 & 41\end{array}$ & 2952 & $40 \quad 4728$ & 2962 \\
\hline & Jupiter & E. & $\begin{array}{lll}69 & 8 & 26\end{array}$ & 3006 & $\begin{array}{lll}67 & 38 & 21\end{array}$ & 3018 & $\begin{array}{lll}66 & 8 & 30\end{array}$ & 3028 & $6438 \quad 52$ & 3039 \\
\hline & Pollux & E. & $\begin{array}{llll}89 & 35 & 35\end{array}$ & 2977 & $\begin{array}{lll}88 & 4 & 54\end{array}$ & 2988 & $\begin{array}{lll}86 & 34 & 26\end{array}$ & 2999 & $\begin{array}{lll}85 & 4 & 12\end{array}$ & 3009 \\
\hline & SUN & E. & 1132556 & 3283 & 112125 & 3295 & $\begin{array}{lll}110 & 37 & 8\end{array}$ & 3306 & $\begin{array}{lll}109 & 13 & 4\end{array}$ & 3317 \\
\hline
\end{tabular}


AUGUST.

MEAN TIME.

LUNAR DISTANCES.

\begin{tabular}{|c|c|c|c|c|c|c|c|c|c|c|}
\hline Day. & $\begin{array}{c}\text { Star's Nam } \\
\text { and } \\
\text { Position. }\end{array}$ & & Noon. & $\begin{array}{c}\text { P.L. } \\
\text { of } \\
\text { diff. }\end{array}$ & IIIt. & $\begin{array}{c}\text { P.L. } \\
\text { of } \\
\text { diff. }\end{array}$ & VIb. & $\begin{array}{c}\text { P.I. } \\
\text { of } \\
\text { diff. }\end{array}$ & LX'b. & $\begin{array}{l}\text { P.L. } \\
\text { of } \\
\text { diff. }\end{array}$ \\
\hline & & & - , " & & $\circ, " 1$ & & 011 & & - ' " & \\
\hline \multirow[t]{8}{*}{10} & a Aquilø & & $91 \quad 1632$ & 3519 & $92 \quad 36 \quad 35$ & 3529 & $\begin{array}{lll}93 & 56 & 27\end{array}$ & 3540 & 9516 & 3551 \\
\hline & Fomalhaut & W. & 565654 & 3327 & $\begin{array}{lll}58 & 20 & 34\end{array}$ & 3324 & $\begin{array}{lll}59 & 44 & 17\end{array}$ & 3323 & 618 & 3322 \\
\hline & Saturn & W. & 453254 & 2949 & $\begin{array}{lll}47 & 4 & 10\end{array}$ & 2958 & $48 \quad 35 \quad 15$ & 2967 & $\begin{array}{lll}50 & 6 & 9\end{array}$ & 2976 \\
\hline & a Pegasi & W. & $43 \quad 47 \quad 13$ & 3765 & 252 & 3733 & 46194 & 3705 & 473546 & 3680 \\
\hline & Aldebaran & E. & $\begin{array}{lll}39 & 16 & 28\end{array}$ & 2972 & $\begin{array}{llll}37 & 45 & 41\end{array}$ & 2981 & & 2990 & $34 \quad 44 \quad 40$ & 299 \\
\hline & Jupiter & E. & $\begin{array}{lll}63 & 9 & 27\end{array}$ & 3049 & $\begin{array}{lll}61 & 40 & 15\end{array}$ & 3058 & $\begin{array}{lll}60 & 11 & 14\end{array}$ & 3067 & $\begin{array}{lll}58 & 42 & 24\end{array}$ & 3076 \\
\hline & Pollux & E. & $\begin{array}{lll}83 & 34 & 10\end{array}$ & 3019 & $\begin{array}{lll}82 & 4 & 21\end{array}$ & 3029 & $\begin{array}{llll}80 & 34 & 45\end{array}$ & 3039 & $\begin{array}{lll}79 & 5 & 20\end{array}$ & 3047 \\
\hline & Sun & E. & 1074912 & 3328 & 1062533 & 3338 & 10526 & 3348 & $103 \quad 3850$ & 3358 \\
\hline \multirow[t]{8}{*}{11} & $\alpha$ Aquilæ & W. & $\begin{array}{lll}101 & 51 & 17\end{array}$ & 3611 & $\begin{array}{lll}103 & 9 & 39\end{array}$ & 3624 & $104 \quad 2748$ & 3637 & $\begin{array}{lll}105 & 45 & 42\end{array}$ & 3651 \\
\hline & Foma & W. & $\begin{array}{lll}68 & 6 & 56\end{array}$ & 3321 & $\begin{array}{lll}69 & 30 & 43\end{array}$ & 3322 & 7054 & 3321 & $\begin{array}{llll}72 & 18 & 16\end{array}$ & 332 \\
\hline & Saturn & W. & $\begin{array}{lll}57 & 38 & 12\end{array}$ & 3010 & $\begin{array}{lll}59 & 8 & 12\end{array}$ & 3017 & $6038 \quad 4$ & 3022 & 62750 & 302 \\
\hline & & W. & $\begin{array}{lll}54 & 5 & 7\end{array}$ & 3587 & $\begin{array}{lll}55 & 23 & 55\end{array}$ & 3573 & $\begin{array}{lll}56 & 42 & 59\end{array}$ & 3560 & 217 & 3549 \\
\hline & Aldebaran & E. & $\begin{array}{lll}27 & 15 & 7\end{array}$ & 3035 & 254538 & 3042 & 241 & 3047 & $\begin{array}{lll}22 & 47 & 2\end{array}$ & 3052 \\
\hline & Jupiter & E. & $\begin{array}{lll}51 & 20 & 48\end{array}$ & 3114 & 495255 & 3120 & $\begin{array}{lll}48 & 2510\end{array}$ & 3126 & 465732 & 3131 \\
\hline & Pollux & E. & 49 & 3086 & $\begin{array}{lll}70 & 12 & 23\end{array}$ & 3093 & $\begin{array}{lll}68 & 44 & 5\end{array}$ & 3100 & 55 & 310 \\
\hline & Sun & E. & 964458 & 3396 & $\begin{array}{lll}95 & 22 & 37\end{array}$ & 3403 & $\begin{array}{lll}94 & 0 & 24\end{array}$ & 3408 & 817 & 3413 \\
\hline \multirow[t]{6}{*}{12} & alhaut & W. & 7917 & 3322 & $\begin{array}{lll}80 & 40 & 53\end{array}$ & 3322 & 439 & 3321 & 826 & 3321 \\
\hline & Satu & W. & 23 & 3043 & $71 \quad 4 \quad 43$ & 3045 & 72 & 3046 & & 3047 \\
\hline & si & W. & 140 & 3501 & $\begin{array}{lll}66 & 2 & 3\end{array}$ & 3494 & $67 \quad 2234$ & 3486 & $\begin{array}{lll}68 & 43 & 14\end{array}$ & 3478 \\
\hline & Jup & E. & 48 & 3151 & $\begin{array}{lll}38 & 13 & 41\end{array}$ & 3154 & $\begin{array}{lll}36 & 46 & 37\end{array}$ & 3157 & $\begin{array}{llll}35 & 19 & 36\end{array}$ & 315 \\
\hline & Pollu & E. & 46 & 3130 & 582 & 3134 & $\begin{array}{lll}57 & 1 & 46\end{array}$ & 3138 & 422 & 3142 \\
\hline & Sun & E. & 854858 & 3432 & $\begin{array}{lll}84 & 27 & 18\end{array}$ & 3434 & $\begin{array}{lll}83 & 5 & 40\end{array}$ & 3436 & $8144 \quad 4$ & 3437 \\
\hline \multirow[t]{7}{*}{13} & Fomalhaut & W. & $\begin{array}{lll}90 & 27 & 33\end{array}$ & 3316 & $91 \quad 51 \quad 26$ & 3314 & 21 & 3313 & $94 \quad 39 \quad 18$ & 3311 \\
\hline & $\mathbf{S}$ & W. & & 3044 & 49 & 3042 & 84 & 3039 & & 3037 \\
\hline & & W. & $75 \quad 2835$ & 3444 & $\begin{array}{ll}0 & 1\end{array}$ & 3438 & 78 & 3431 & $\begin{array}{lll}79 & 33 & 16\end{array}$ & 3425 \\
\hline & & W. & $\begin{array}{lll}32 & 5 & 5\end{array}$ & 3652 & 243 & 3606 & 34 & 3565 & 024 & 3527 \\
\hline & & E. & 55 & 3167 & 16 & 3168 & 29 & 3168 & 23 & 3169 \\
\hline & $\operatorname{llux}$ & E. & 322 & 3155 & 465 & 3158 & 45 & 3160 & 723 & 3163 \\
\hline & SUN & E. & 745610 & 3434 & 73 & 3432 & 72 & 3430 & $\begin{array}{llll}70 & 51 & 9\end{array}$ & 3427 \\
\hline \multirow[t]{6}{*}{14} & laut & W. & 36 & 3301 & $103 \quad 3 \quad 47$ & 3299 & 104 & 3296 & 105 & 3294 \\
\hline & & W. & 33 & 3016 & $\begin{array}{lll}94 & 55 & 26\end{array}$ & 3011 & 962 & 3005 & 97 & 2998 \\
\hline & & W & 28 & 3394 & $\begin{array}{llll}87 & 45 & 52\end{array}$ & 3388 & 22 & 3382 & 90 & 3376 \\
\hline & & W. & & 3382 & $\begin{array}{lll}44 & 8 & 20\end{array}$ & 3359 & 453123 & 3337 & 52 & 3316 \\
\hline & & E. & 36 & 3180 & $\begin{array}{lll}35 & 16 & 58\end{array}$ & 3185 & $\begin{array}{lll}33 & 50 & 31\end{array}$ & 3192 & 412 & 3200 \\
\hline & SUN & E. & $\begin{array}{lll}64 & 1 & 33\end{array}$ & 3405 & 623922 & 3399 & $\begin{array}{lll}61 & 17 & 4\end{array}$ & 3393 & 595 & 3386 \\
\hline \multirow[t]{4}{*}{15} & & W. & 10 & 2962 & 1065 & 2954 & 108 & 2946 & 110 & 2936 \\
\hline & & $\mathrm{u}$ & & 3347 & & 3342 & 28 & 3337 & 101 & 3332 \\
\hline & & W. & 535 & 3224 & & 3207 & $\begin{array}{ll}56 & 49\end{array}$ & 3190 & $\begin{array}{lll}58 & 16 & 2\end{array}$ & 3174 \\
\hline & & E. & & 3347 & $\begin{array}{lll}51 & 37 & 13\end{array}$ & 3338 & $\begin{array}{lll}50 & 13 & 45\end{array}$ & 3328 & $\begin{array}{lll}4850 & 6\end{array}$ & 3319 \\
\hline \multirow[t]{2}{*}{16} & $\alpha$ Ari & W. & $\begin{array}{lll}65 & 32 & 28\end{array}$ & 3098 & 040 & 3083 & $\begin{array}{lll}68 & 29 & 10\end{array}$ & 3069 & 695758 & 3055 \\
\hline & & E. & & 3267 & $\begin{array}{lll}40 & 24 & 12\end{array}$ & 3255 & $\begin{array}{lll}38 & 59 & 8\end{array}$ & 3244 & $\begin{array}{lll}37 & 33 & 51\end{array}$ & 3233 \\
\hline \multirow[t]{2}{*}{17} & Arietis & W. & 77 & 2985 & 785 & 2972 & 802 & 2958 & $\begin{array}{ll}58 & 42\end{array}$ & 2945 \\
\hline & Sun & L. & & 3173 & $\begin{array}{lll}28 & 57 & 18\end{array}$ & 3161 & 273022 & 3148 & $\begin{array}{lll}26 & 3 & 11\end{array}$ & 3137 \\
\hline 22 & Sun & W. & $\begin{array}{lll}30 & 47 & 40\end{array}$ & 2723 & $\begin{array}{lll}32 & 23 & 49\end{array}$ & 2716 & 34 & 2709 & 353635 & 2702 \\
\hline
\end{tabular}




\section{XVI.}

\section{AUGUST.}

\section{MEAN TIME.}

LUNAR DISTANCES.

\begin{tabular}{|c|c|c|c|c|c|c|c|c|c|c|}
\hline Day. & $\begin{array}{c}\text { Star's Nam } \\
\text { and } \\
\text { Position. }\end{array}$ & & Midnight. & $\begin{array}{c}\text { P.L. } \\
\text { of } \\
\text { diff. }\end{array}$ & $\mathbf{X V h}$. & $\begin{array}{c}\text { P.L. } \\
\text { of } \\
\text { diff. }\end{array}$ & XVIIIb. & $\begin{array}{c}\text { P.L. } \\
\text { of } \\
\text { diff. }\end{array}$ & XXIb. & $\begin{array}{c}\text { P.L. } \\
\text { of } \\
\text { diff. }\end{array}$ \\
\hline & & & 0 , ' & & $\circ$ ' & & $\circ, 11$ & & 0,1 & \\
\hline \multirow[t]{8}{*}{10} & $\alpha$ Aquilæ & W. & 963535 & 3563 & $97 \quad 54 \quad 50$ & 3575 & $\begin{array}{lll}99 & 13 & 52\end{array}$ & 3587 & $\begin{array}{llll}100 & 32 & 41\end{array}$ & 3598 \\
\hline & Fomalhaut & W. & 623148 & 3322 & 635534 & 3321 & $\begin{array}{lll}65 & 19 & 21\end{array}$ & 3321 & $\begin{array}{lll}66 & 43 & 8\end{array}$ & 3320 \\
\hline & Saturn & W. & $\begin{array}{lll}51 & 36 & 52\end{array}$ & 2984 & $\begin{array}{lll}53 & 725\end{array}$ & 2991 & $54 \quad 3749$ & 2997 & 568 & 3004 \\
\hline & $\alpha$ Pegasi & W. & 485254 & 3657 & $\begin{array}{lll}50 & 10 & 27\end{array}$ & 3637 & $\begin{array}{lll}51 & 28 & 21\end{array}$ & 3619 & $5246 \quad 35$ & 3602 \\
\hline & Aldebaran & E. & $\begin{array}{lll}33 & 14 & 26\end{array}$ & 3008 & $\begin{array}{lll}31 & 44 & 23\end{array}$ & 3015 & $\begin{array}{lll}30 & 14 & 29\end{array}$ & 3022 & $\begin{array}{llll}28 & 44 & 44\end{array}$ & 3029 \\
\hline & Jupiter & E. & $\begin{array}{lll}57 & 13 & 45\end{array}$ & 3085 & $\begin{array}{llll}55 & 45 & 17\end{array}$ & 3093 & $54 \quad 1658$ & 3101 & $\begin{array}{lll}52 & 48 & 49\end{array}$ & 3107 \\
\hline & Pollux & E. & $7736 \quad 5$ & 3056 & $\begin{array}{lll}76 & 7 & 1\end{array}$ & 3065 & $\begin{array}{lll}74 & 38 & 8\end{array}$ & 3072 & $\begin{array}{lll}73 & 9 & 24\end{array}$ & 3079 \\
\hline & Sun & E. & 1021545 & 3366 & 1005250 & 3374 & $99 \begin{array}{lll}90 & 4\end{array}$ & 3382 & $\begin{array}{lll}98 & 7 & 27\end{array}$ & 3389 \\
\hline \multirow[t]{8}{*}{11} & $\alpha$ Aquilæ & W. & $107 \quad 322$ & 3665 & $108 \quad 2046$ & 3679 & 1093755 & 3694 & $11054 \quad 48$ & 3709 \\
\hline & Fomalhaut & W. & $\begin{array}{lll}73 & 42 & 3\end{array}$ & 3322 & $\begin{array}{lll}75 & 5 & 49\end{array}$ & 3322 & $76 \quad 2935$ & 3322 & 775321 & 3322 \\
\hline & Saturn & W. & $\begin{array}{ll}63 & 3730\end{array}$ & 3030 & $\begin{array}{lll}65 & 7 & 4\end{array}$ & 3034 & 663634 & 3037 & $\begin{array}{lll}68 & 6 & 0\end{array}$ & 3040 \\
\hline & $\alpha$ Pegasi & W. & $\begin{array}{llll}59 & 21 & 47\end{array}$ & 3538 & $\begin{array}{lll}60 & 41 & 29\end{array}$ & 3528 & $\begin{array}{lll}62 & 1 & 22\end{array}$ & 3518 & $\begin{array}{lll}63 & 21 & 26\end{array}$ & 3509 \\
\hline & Aldebaran & E. & 211754 & 3056 & $\begin{array}{lll}19 & 48 & 51\end{array}$ & 3061 & $\begin{array}{lll}18 & 19 & 54\end{array}$ & 3065 & $\begin{array}{lll}1651 & 2\end{array}$ & 3069 \\
\hline & Jupiter & E. & $\begin{array}{lll}45 & 30 & 0\end{array}$ & 3136 & $44 \quad 235$ & 3140 & $\begin{array}{llll}42 & 35 & 15\end{array}$ & 3144 & $41 \quad 759$ & 3148 \\
\hline & Pollux & E. & 654752 & 3111 & 641956 & 3117 & $\begin{array}{lll}62 & 52 & 7\end{array}$ & 3122 & $\begin{array}{lll}61 & 24 & 24\end{array}$ & 3126 \\
\hline & SUN & E. & $91 \quad 1615$ & 3418 & $89 \quad 54 \quad 19$ & 3422 & $88 \quad 32 \quad 28$ & 3426 & $\begin{array}{lll}87 & 10 & 41\end{array}$ & 3429 \\
\hline \multirow[t]{6}{*}{12} & Fomalhaut & W. & $84 \quad 52 \quad 13$ & 3320 & $\begin{array}{lll}86 & 16 & 1\end{array}$ & 3319 & 873950 & 3318 & 341 & 3317 \\
\hline & Saturn & W. & $\begin{array}{llll}75 & 32 & 31\end{array}$ & 3047 & $\begin{array}{lll}77 & 1 & 45\end{array}$ & 3047 & $\begin{array}{lll}78 & 30 & 59\end{array}$ & 3046 & 014 & 3045 \\
\hline & $\alpha$ Pegasi & W. & $\begin{array}{lll}70 & 4 & 3\end{array}$ & 3471 & $\begin{array}{lll}71 & 24 & 59\end{array}$ & 3464 & $\begin{array}{lll}72 & 46 & 3\end{array}$ & 3457 & $74 \quad 715$ & 3450 \\
\hline & Jupiter & E. & $\begin{array}{lll}33 & 52 & 38\end{array}$ & 3161 & $\begin{array}{lll}32 & 25 & 42\end{array}$ & 3163 & $\begin{array}{lll}30 & 58 & 48\end{array}$ & 3164 & 293156 & 3165 \\
\hline & Poillux & E. & $\begin{array}{lll}54 & 7 & 3\end{array}$ & 3145 & $\begin{array}{lll}52 & 39 & 48\end{array}$ & 3148 & $51 \quad 1236$ & 3150 & $\begin{array}{lll}49 & 45 & 27\end{array}$ & 3153 \\
\hline & SuN & $\mathbf{E}$. & $\begin{array}{lll}80 & 22 & 29\end{array}$ & 3438 & $\begin{array}{llll}79 & 0 & 55\end{array}$ & 3438 & $\begin{array}{lll}77 & 39 & 21\end{array}$ & 3437 & 761746 & 3436 \\
\hline \multirow[t]{7}{*}{13} & Fomalhaut & W. & $\begin{array}{lll}96 & 3 & 17\end{array}$ & 3309 & $\begin{array}{lll}97 & 27 & 18\end{array}$ & 3307 & $\begin{array}{lll}98 & 51 & 22\end{array}$ & 3305 & 10015 & 3303 \\
\hline & Satur & W. & $\begin{array}{lll}87 & 27 & 0\end{array}$ & 3034 & $\begin{array}{lll}88 & 56 & 31\end{array}$ & 3030 & $\begin{array}{lll}90 & 26 & 6\end{array}$ & 3026 & 915546 & 3021 \\
\hline & $\alpha$ Pegasi & W. & $8055 \quad 4$ & 3419 & $\begin{array}{lll}82 & 16 & 59\end{array}$ & 3412 & $\begin{array}{lll}83 & 39 & 2\end{array}$ & 3406 & $\begin{array}{lll}85 & 1 & 12\end{array}$ & 3400 \\
\hline & a Arietis & W. & $\begin{array}{lll}37 & 20 & 18\end{array}$ & 3493 & $\begin{array}{lll}38 & 40 & 50\end{array}$ & 3463 & $\begin{array}{lll}40 & 1 & 56\end{array}$ & 3434 & $4123 \quad 34$ & 3407 \\
\hline & Jupiter & E. & 221756 & 3171 & $\begin{array}{lll}20 & 51 & 12\end{array}$ & 3173 & $\begin{array}{lll}19 & 24 & 31\end{array}$ & 3177 & 175754 & 3182 \\
\hline & Pollux & E. & 423030 & 3166 & $\begin{array}{lll}41 & 3 & 40\end{array}$ & 3169 & $\begin{array}{lll}39 & 36 & 53\end{array}$ & 3172 & $\begin{array}{lll}38 & 10 & 10\end{array}$ & 3176 \\
\hline & SuN & E. & $\begin{array}{lll}69 & 29 & 23\end{array}$ & 3423 & $\begin{array}{lll}68 & 7 & 33\end{array}$ & 3419 & $\begin{array}{llll}66 & 45 & 38\end{array}$ & 3415 & $\begin{array}{lll}65 & 23 & 38\end{array}$ & 3410 \\
\hline \multirow[t]{6}{*}{14} & Fomalhaut & W. & 1071635 & 3292 & $\begin{array}{lll}108 & 40 & 56\end{array}$ & 3290 & $\begin{array}{lll}110 & 5 & 19\end{array}$ & 3288 & $\begin{array}{lll}111 & 29 & 45\end{array}$ & 3286 \\
\hline & Satu & W. & & 2992 & $\begin{array}{lll}100 & 56 & 9\end{array}$ & 2985 & $\begin{array}{lll}102 & 26 & 40\end{array}$ & 2978 & 1035720 & 2970 \\
\hline & $\alpha \mathrm{Peg}$ & W. & $\begin{array}{lll}91 & 53 & 43\end{array}$ & 3370 & $\begin{array}{llll}93 & 16 & 34\end{array}$ & 3364 & \begin{tabular}{|lll}
94 & 39 & 32
\end{tabular} & 3358 & $\begin{array}{lll}96 & 2 & 36\end{array}$ & 3352 \\
\hline & a Arietis & W. & $\begin{array}{llll}48 & 18 & 45\end{array}$ & 3296 & $\begin{array}{lll}49 & 43 & 1\end{array}$ & 3277 & $\begin{array}{lll}51 & 7 & 39\end{array}$ & 3259 & $\begin{array}{lll}52 & 32 & 39\end{array}$ & 3241 \\
\hline & Pollux & E. & $\begin{array}{lll}30 & 58 & 2\end{array}$ & 3209 & $\begin{array}{lll}29 & 32 & 3\end{array}$ & 3221 & $\begin{array}{lll}28 & 6 & 19\end{array}$ & 3236 & $2640 \quad 52$ & 3253 \\
\hline & SUN & E. & $\begin{array}{lll}58 & 32 & 6\end{array}$ & 3379 & $\begin{array}{lll}57 & 9 & 25\end{array}$ & 3372 & 554636 & 3364 & 542338 & 3355 \\
\hline \multirow[t]{4}{*}{15} & Saturn & W. & 1113314 & 2927 & 458 & 2918 & $\begin{array}{llll}114 & 36 & 54\end{array}$ & 2908 & $\begin{array}{lll}116 & 9 & 3\end{array}$ & 2898 \\
\hline & & W. & $\begin{array}{lll}102 & 59 & 32\end{array}$ & 3327 & $104 \quad 2313$ & 3323 & 1054658 & 3319 & $\begin{array}{lll}107 & 10 & 48\end{array}$ & 3314 \\
\hline & $\alpha$ Arietis & W. & $\begin{array}{lll}59 & 42 & 42\end{array}$ & 3158 & $\begin{array}{lll}61 & 9 & 41\end{array}$ & 3143 & $\begin{array}{lll}62 & 36 & 58\end{array}$ & 3128 & $64 \quad 4 \quad 34$ & 3113 \\
\hline & Sun & E. & $\begin{array}{lll}472617\end{array}$ & 3310 & $\begin{array}{lll}46 & 2 & 17\end{array}$ & 3299 & $4438 \quad 4$ & 3288 & $\begin{array}{lll}43 & 13 & 39\end{array}$ & 3278 \\
\hline \multirow[t]{2}{*}{16} & $\alpha$ Arietis & W. & $\begin{array}{lll}71 & 27 & 3\end{array}$ & 3041 & $7256 \quad 25$ & 3026 & 74265 & 3012 & $\begin{array}{lll}75 & 56 & 2\end{array}$ & 2998 \\
\hline & SUN & E. & $\begin{array}{lll}36 & 8 & 21\end{array}$ & 3221 & & 3209 & $\begin{array}{lll}33 & 16 & 39\end{array}$ & 3198 & $\begin{array}{lll}31 & 50 & 27\end{array}$ & 3185 \\
\hline \multirow[t]{2}{*}{17} & $\alpha$ Arietis & W. & $\begin{array}{lll}83 & 30 & 4\end{array}$ & 2933 & & 2920 & $\begin{array}{lll}86 & 33 & 35\end{array}$ & 2907 & $\begin{array}{llll}88 & 5 & 45\end{array}$ & 2894 \\
\hline & Sun & E. & 243546 & 3124 & $\begin{array}{lll}23 & 8 & 6\end{array}$ & 3112 & $\begin{array}{lll}21 & 40 & 11\end{array}$ & 3101 & $\begin{array}{lll}20 & 12 & 2\end{array}$ & 3088 \\
\hline 22 & Sun & W. & $\begin{array}{lll}37 & 13 & 13\end{array}$ & 2695 & $\begin{array}{lll}38 & 49 & 59\end{array}$ & 2689 & 402654 & 2683 & $42 \quad 358$ & 2677 \\
\hline
\end{tabular}


AUGUST.

XVII.

MEAN TIME.

LUNAR DISTANCES

\begin{tabular}{|c|c|c|c|c|c|c|c|c|c|c|}
\hline Day. & $\begin{array}{c}\text { Star's Name } \\
\text { and } \\
\text { Position. }\end{array}$ & & Noon. & $\begin{array}{c}\text { P.I. } \\
\text { of } \\
\text { diff. }\end{array}$ & III'b. & $\begin{array}{l}\text { P.L. } \\
\text { of } \\
\text { diff. }\end{array}$ & VIb. & $\begin{array}{l}\text { P.I. } \\
\text { of } \\
\text { diff. }\end{array}$ & $\mathrm{IX}^{\mathrm{b}}$. & $\begin{array}{c}\text { P.I. } \\
\text { of } \\
\text { diff. }\end{array}$ \\
\hline 22 & $\alpha$ Aquilø & E. & $\begin{array}{ccc}0 & \prime \prime \\
114 & 52 & 11\end{array}$ & 3081 & $\begin{array}{rrr}0 & \prime & \prime \prime \\
113 & 23 & 38\end{array}$ & 3057 & $\begin{array}{ccc}0 & \prime & \prime \prime \\
111 & 54 & 36\end{array} \mid$ & 3035 & $\begin{array}{ccc}0 & \prime & \prime \prime \\
110 & 25 & 7\end{array}$ & 3015 \\
\hline 23 & $\begin{array}{l}\text { Sun } \\
\alpha \text { Aquilæ }\end{array}$ & $\begin{array}{l}\text { W. } \\
\text { E. }\end{array}$ & $\begin{array}{rrr}43 & 41 & 9 \\
102 & 51 & 54\end{array}$ & $\begin{array}{l}2671 \\
2935\end{array}$ & \begin{tabular}{rrr|}
45 & 18 & 28 \\
101 & 20 & 19
\end{tabular} & $\begin{array}{l}2666 \\
2922\end{array}$ & $\begin{array}{lll}46 & 55 & 53 \\
99 & 48 & 28\end{array}$ & $\begin{array}{l}2660 \\
2912\end{array}$ & $\begin{array}{lll}48 & 33 & 26 \\
98 & 16 & 24\end{array}$ & $\begin{array}{l}2655 \\
2903\end{array}$ \\
\hline 24 & $\begin{array}{l}\text { SuN } \\
\alpha \text { Aquilæø }\end{array}$ & $\begin{array}{l}\text { W. } \\
\text { E. }\end{array}$ & $\begin{array}{lll}56 & 42 & 45 \\
90 & 33 & 31\end{array}$ & $\begin{array}{l}2635 \\
2872\end{array}$ & $\begin{array}{rrr}58 & 20 & 53 \\
89 & 0 & 36\end{array}$ & $\begin{array}{l}2631 \\
2869\end{array}$ & $\begin{array}{llr}59 & 59 & 6 \\
87 & 27 & 37\end{array}$ & $\begin{array}{l}2627 \\
2867\end{array}$ & $\begin{array}{lll}61 & 37 & 24 \\
85 & 54 & 36\end{array}$ & $\begin{array}{l}2624 \\
2867\end{array}$ \\
\hline 25 & $\begin{array}{l}\text { SuN } \\
\alpha \text { Aquilæ } \\
\text { Fomalhaut }\end{array}$ & $\begin{array}{l}\text { W. } \\
\text { E. }\end{array}$ & $\begin{array}{rrr}69 & 49 & 55 \\
78 & 9 & 50 \\
111 & 52 & 35\end{array}$ & $\begin{array}{l}2610 \\
2881 \\
2588\end{array}$ & $\begin{array}{rrr}71 & 28 & 36 \\
76 & 37 & 7 \\
110 & 13 & 24\end{array}$ & $\begin{array}{l}2608 \\
2887 \\
2580\end{array}$ & $\begin{array}{|rrr|}73 & 7 & 20 \\
75 & 4 & 32 \\
108 & 34 & 2\end{array} \mid$ & $\begin{array}{l}2606 \\
2895 \\
2573\end{array}$ & \begin{tabular}{rrr|}
74 & 46 & 7 \\
73 & 32 & 7 \\
106 & 54 & 30
\end{tabular} & $\begin{array}{l}2604 \\
2905 \\
2566\end{array}$ \\
\hline 26 & $\begin{array}{l}\text { Sun } \\
\text { Spica } \\
\alpha \text { Aquilø } \\
\text { Fomalhaut } \\
\text { Saturn } \\
\text { a Pegasi }\end{array}$ & $\begin{array}{l}\text { W. } \\
\text { W. } \\
\text { E. } \\
\text { E. } \\
\text { E. } \\
\text { E. }\end{array}$ & $\begin{array}{rrr}83 & 0 & 34 \\
33 & 30 & 38 \\
65 & 53 & 38 \\
98 & 34 & 46 \\
107 & 10 & 29 \\
113 & 16 & 54\end{array}$ & $\begin{array}{l}2597 \\
2393 \\
2975 \\
2542 \\
2267 \\
2708\end{array}$ & $\left|\begin{array}{rrr|}84 & 39 & 33 \\
35 & 14 & 23 \\
64 & 22 & 54 \\
96 & 54 & 31 \\
105 & 23 & 41 \\
111 & 40 & 25\end{array}\right|$ & $\begin{array}{l}2596 \\
2384 \\
2995 \\
2539 \\
2266 \\
2697\end{array}$ & $\begin{array}{|rrr|}86 & 18 & 33 \\
36 & 58 & 21 \\
62 & 52 & 35 \\
95 & 14 & 12 \\
103 & 36 & 52 \\
110 & \mathbf{3} & \mathbf{4 1}\end{array}$ & $\begin{array}{l}2596 \\
2375 \\
3017 \\
2537 \\
2265 \\
2687\end{array}$ & $\begin{array}{|rrr|}87 & 57 & 34 \\
38 & 42 & 31 \\
61 & 22 & 43 \\
93 & 33 & 50 \\
101 & 50 & 1 \\
108 & 26 & 44\end{array}$ & $\begin{array}{l}2595 \\
2368 \\
3041 \\
2535 \\
2264 \\
2679\end{array}$ \\
\hline 27 & $\begin{array}{l}\text { Sun } \\
\text { Spica } \\
\text { a Aquilæ } \\
\text { Fomalhaut } \\
\text { Saturn } \\
\text { a Pegasi }\end{array}$ & $\begin{array}{l}\text { W. } \\
\text { W. } \\
\text { E. } \\
\text { E. } \\
\text { E. } \\
\text { E. }\end{array}$ & $\begin{array}{rrr}96 & 12 & 53 \\
47 & 25 & 35 \\
54 & 2 & 2 \\
85 & 11 & 41 \\
92 & 55 & 33 \\
100 & 19 & 27\end{array}$ & $\begin{array}{l}2593 \\
2344 \\
3209 \\
2536 \\
2262 \\
2649\end{array}$ & $\begin{array}{rrr}97 & 51 & 58 \\
49 & 10 & 30 \\
52 & 36 & 3 \\
83 & 31 & 17 \\
91 & 8 & 38 \\
98 & 41 & 38\end{array}$ & \begin{tabular}{|l|}
2594 \\
2341 \\
3255 \\
2538 \\
2263 \\
2645
\end{tabular} & $\begin{array}{rrr}99 & 31 & 1 \\
50 & 55 & 30 \\
51 & 10 & 59 \\
81 & 50 & 56 \\
89 & 21 & 44 \\
97 & 3 & 44\end{array}$ & $\begin{array}{l}2594 \\
2339 \\
3305 \\
2540 \\
2264 \\
2643\end{array}$ & $\begin{array}{|rrr|}101 & 10 & 5 \\
52 & 40 & 34 \\
49 & 46 & 53 \\
80 & 10 & 38 \\
87 & 34 & 51 \\
95 & 25 & 47\end{array}$ & $\begin{array}{l}2594 \\
2337 \\
3360 \\
2543 \\
2263 \\
2640\end{array}$ \\
\hline 28 & $\begin{array}{l}\text { Sow } \\
\text { Spica } \\
\text { Fomalhaut } \\
\text { Saturn } \\
\text { a Pegasi }\end{array}$ & $\begin{array}{l}\text { W. } \\
\text { W. } \\
\text { E. } \\
\text { E. } \\
\text { E. }\end{array}$ & $\begin{array}{rrr}109 & 25 & 9 \\
61 & 26 & 25 \\
71 & 50 & 31 \\
78 & 40 & 32 \\
87 & 15 & 46\end{array} \mid$ & $\begin{array}{l}2599 \\
2332 \\
2569 \\
2267 \\
2643\end{array}$ & \begin{tabular}{rrr|}
111 & $\mathbf{4}$ & $\mathbf{5}$ \\
63 & $\mathbf{1 1}$ & $\mathbf{3 8}$ \\
70 & 10 & 53 \\
76 & 53 & 44 \\
85 & 37 & 50
\end{tabular} & $\begin{array}{l}2601 \\
2331 \\
2577 \\
2268 \\
2647\end{array}$ & \begin{tabular}{|rrr}
112 & 42 & 59 \\
64 & 56 & 52 \\
68 & 31 & 26 \\
75 & 6 & 58 \\
83 & 59 & 59
\end{tabular} & $\begin{array}{l}2602 \\
2332 \\
2585 \\
2270 \\
2651\end{array}$ & $\begin{array}{|rrr|}114 & 21 & 51 \\
66 & 42 & 5 \\
66 & 52 & 11 \\
73 & 20 & 14 \\
82 & 22 & 13\end{array}$ & $\begin{array}{l}2604 \\
2332 \\
2594 \\
2272 \\
2655\end{array}$ \\
\hline 29 & $\begin{array}{l}\text { Sun } \\
\text { Spica } \\
\text { Antares } \\
\text { Fomalhaut } \\
\text { Saturn } \\
\text { a Pegasi } \\
\text { a Arietis }\end{array}$ & $\begin{array}{l}\text { W. } \\
\text { W. } \\
\text { W. } \\
\text { E. } \\
\text { E. } \\
\mathbf{E .} \\
\text { E. }\end{array}$ & $\begin{array}{rll}122 & 35 & 24 \\
75 & 27 & 49 \\
30 & 18 & 55 \\
58 & 39 & 37 \\
64 & 27 & 17 \\
74 & 15 & 18 \\
117 & 25 & 13\end{array}$ & $\begin{array}{l}2618 \\
2340 \\
2525 \\
2660 \\
2283 \\
2692 \\
2499\end{array}$ & $\begin{array}{|rrr|}124 & 13 & 55 \\
77 & 12 & 51 \\
31 & 59 & 34 \\
57 & 2 & 2 \\
62 & 40 & 52 \\
72 & 38 & 27 \\
115 & 43 & 59\end{array}$ & $\begin{array}{l}2621 \\
2342 \\
2507 \\
2677 \\
2285 \\
2702 \\
2497\end{array}$ & $\begin{array}{|rrr|}125 & 52 & 22 \\
78 & 57 & 49 \\
33 & 40 & 37 \\
55 & 24 & 51 \\
60 & 54 & 31 \\
71 & 1 & 49 \\
114 & 2 & 42\end{array}$ & $\begin{array}{l}2624 \\
2344 \\
2493 \\
2696 \\
2288 \\
2713 \\
2495\end{array}$ & $\begin{array}{rrr}127 & 30 & 45 \\
80 & 42 & 44 \\
35 & 22 & 0 \\
53 & 48 & 6 \\
59 & 8 & 14 \\
69 & 25 & 26 \\
112 & 21 & 22\end{array}$ & $\begin{array}{l}2628 \\
2347 \\
2481 \\
2716 \\
2291 \\
2726 \\
2494\end{array}$ \\
\hline 30 & $\begin{array}{l}\text { Spica } \\
\text { Antares } \\
\text { Saturn } \\
\text { a Pegasi } \\
\text { a Arietis }\end{array}$ & $\begin{array}{l}\text { W. } \\
\text { W. } \\
\text { E. } \\
\text { E. } \\
\text { E. }\end{array}$ & $\begin{array}{rrr}89 & 26 & 6 \\
43 & 52 & 12 \\
50 & 18 & 7 \\
61 & 28 & 22 \\
103 & 54 & 30\end{array}$ & $\begin{array}{l}2366 \\
2450 \\
2311 \\
2810 \\
2497\end{array}$ & $\begin{array}{rrr}91 & 10 & 30 \\
45 & 34 & 36 \\
48 & 32 & 23 \\
59 & 54 & 7 \\
102 & 13 & 12\end{array}$ & $\begin{array}{l}2371 \\
2448 \\
2315 \\
2831 \\
2499\end{array}$ & $\begin{array}{rrr}92 & 54 & 46 \\
47 & 17 & 3 \\
46 & 46 & 46 \\
58 & 20 & 20 \\
100 & 31 & 58\end{array}$ & $\begin{array}{l}2376 \\
2446 \\
2320 \\
2855 \\
2502\end{array}$ & $\begin{array}{rrr}94 & 38 & 56 \\
48 & 59 & 32 \\
45 & 1 & 16 \\
56 & 47 & 4 \\
98 & 50 & 48\end{array}$ & $\begin{array}{l}2381 \\
2445 \\
2325 \\
2882 \\
2506\end{array}$ \\
\hline 31 & $\begin{array}{l}\text { Spica } \\
\text { Antares } \\
\text { Saturn } \\
\text { a Pegasi } \\
\text { a Arietis } \\
\text { Aldebaran }\end{array}$ & $\begin{array}{l}\text { W. } \\
\text { W. } \\
\text { E. } \\
\text { E. } \\
\text { E. } \\
\text { E. }\end{array}$ & $\begin{array}{rrr}103 & 17 & 40 \\
57 & 31 & 39 \\
36 & 15 & 45 \\
49 & 10 & 8 \\
90 & 26 & 27 \\
122 & 33 & 24\end{array}$ & $\begin{array}{l}2412 \\
2456 \\
2355 \\
3054 \\
2532 \\
2379\end{array}$ & $\begin{array}{rrr}105 & 0 & 57 \\
59 & 13 & 54 \\
34 & 31 & 6 \\
47 & 41 & 2 \\
88 & 45 & 58 \\
120 & 49 & 19\end{array}$ & $\begin{array}{l}2420 \\
2460 \\
2362 \\
3099 \\
2539 \\
2385\end{array}$ & $\begin{array}{rrr}106 & \mathbf{4 4} & \mathbf{3} \\
60 & 56 & \mathbf{3} \\
\mathbf{3 2} & 46 & 36 \\
46 & 12 & \mathbf{5 1} \\
\mathbf{8 7} & \mathbf{5} & 39 \\
119 & \mathbf{5} & 23\end{array}$ & $\begin{array}{l}2427 \\
2465 \\
2368 \\
3149 \\
2546 \\
2392\end{array}$ & $\begin{array}{rrr}108 & 26 & 59 \\
62 & 38 & 6 \\
31 & 2 & 16 \\
44 & 45 & 40 \\
85 & 25 & 30 \\
117 & 21 & 37\end{array}$ & $\begin{array}{l}2435 \\
2470 \\
2376 \\
3204 \\
2554 \\
2399\end{array}$ \\
\hline
\end{tabular}


XVIII.

AUGUST.

MEAN TIME.

LUNAR DISTANCES.

\begin{tabular}{|c|c|c|c|c|c|c|c|c|c|c|}
\hline Day. & $\begin{array}{c}\text { Star's Nam } \\
\text { and } \\
\text { Position. }\end{array}$ & & Midnight. & $\begin{array}{c}\text { P.I. } \\
\text { of } \\
\text { diff. }\end{array}$ & $\mathrm{XVh}$. & $\begin{array}{l}\text { P.L. } \\
\text { of } \\
\text { diff. }\end{array}$ & XVIII'b. & $\begin{array}{l}\text { P.L. } \\
\text { of } \\
\text { diff. }\end{array}$ & $\mathrm{XXIh}$. & $\begin{array}{l}\text { P.L. } \\
\text { of } \\
\text { diff. }\end{array}$ \\
\hline 22 & a Aquilø & E. & $\begin{array}{ccc}\circ & \prime \prime \\
108 & 55 & 13\end{array}$ & 2996 & $\begin{array}{ccc}0 & \prime & \prime \prime \\
107 & 24 & 55\end{array}$ & 2978 & $\begin{array}{ccc}\circ & \prime & \prime \prime \\
105 & 54 & 14\end{array}$ & 2962 & ' & 294 \\
\hline 23 & $\begin{array}{l}\text { Sun } \\
\text { a Aquilæ }\end{array}$ & $\begin{array}{l}\text { W. } \\
\text { E. }\end{array}$ & $\begin{array}{lll}50 & 11 & 6 \\
96 & 44 & 8\end{array}$ & $\begin{array}{l}2651 \\
2894\end{array}$ & $\begin{array}{lll}51 & 48 & 52 \\
95 & 11 & 41\end{array}$ & $\begin{array}{l}2646 \\
2887\end{array}$ & $\begin{array}{rrr}53 & 26 & 44 \\
93 & 39 & 5\end{array}$ & $\begin{array}{l}2642 \\
2881\end{array}$ & $\begin{array}{lll}55 & 4 & 42 \\
92 & 6 & 21\end{array}$ & $\begin{array}{l}2638 \\
2876\end{array}$ \\
\hline 24 & $\begin{array}{l}\text { Son } \\
\alpha \text { Aquilæ }\end{array}$ & $\begin{array}{l}\text { W. } \\
\text { E. }\end{array}$ & $\begin{array}{lll}63 & 15 & 47 \\
84 & 21 & 35\end{array}$ & $\begin{array}{l}2621 \\
2867\end{array}$ & $\begin{array}{lll}64 & 54 & 13 \\
82 & 48 & 34\end{array}$ & $\begin{array}{l}2618 \\
2869\end{array}$ & $\begin{array}{lll}66 & 32 & 43 \\
81 & 15 & 35\end{array}$ & $\begin{array}{l}2615 \\
2872\end{array}$ & $\begin{array}{lll}68 & 11 & 17 \\
79 & 42 & 40\end{array}$ & $\begin{array}{l}261 \\
287\end{array}$ \\
\hline 25 & $\begin{array}{l}\text { SoN } \\
\text { a Aquilø } \\
\text { Fomalhaut }\end{array}$ & $\begin{array}{l}\text { W. } \\
\text { E. } \\
\text { E. }\end{array}$ & $\begin{array}{rrr}76 & 24 & 56 \\
71 & 59 & 54 \\
105 & 14 & 49\end{array}$ & $\begin{array}{l}2603 \\
2915 \\
2560\end{array}$ & $\begin{array}{rrr}78 & 3 & 47 \\
70 & 27 & 54 \\
103 & 34 & 59\end{array}$ & $\begin{array}{l}2601 \\
2927 \\
2554\end{array}$ & $\begin{array}{rrr}79 & 42 & 41 \\
68 & 56 & 10 \\
101 & 55 & 1\end{array}$ & $\begin{array}{l}2599 \\
2942 \\
2549\end{array}$ & $\begin{array}{rrr}81 & 21 & 37 \\
67 & 24 & 44 \\
100 & 14 & 56\end{array}$ & $\begin{array}{l}259 \\
295 \\
254\end{array}$ \\
\hline 26 & $\begin{array}{l}\text { Sux } \\
\text { Spica } \\
\text { a Aquilæ } \\
\text { Fomalhaut } \\
\text { Saturn } \\
\text { a Pegasi }\end{array}$ & $\begin{array}{l}\text { W. } \\
\text { W. } \\
\text { E. } \\
\text { E. } \\
\text { E. } \\
\text { E. }\end{array}$ & $\begin{array}{|rrr|}89 & 36 & 37 \\
40 & 26 & 52 \\
59 & 53 & 21 \\
91 & 53 & 25 \\
100 & 3 & 9 \\
106 & 49 & 36\end{array}$ & $\begin{array}{l}2594 \\
2362 \\
3068 \\
2534 \\
2264 \\
2671\end{array}$ & $\begin{array}{rrr}91 & 15 & 40 \\
42 & 11 & 22 \\
58 & 24 & 32 \\
90 & 12 & 59 \\
98 & 16 & 16 \\
105 & 12 & 17\end{array}$ & $\begin{array}{l}2593 \\
2357 \\
3099 \\
2534 \\
2263 \\
2663\end{array}$ & $\begin{array}{rrrr}92 & \mathbf{5 4} & \mathbf{4 4} \\
\mathbf{4 3} & \mathbf{5 5} & \mathbf{5 9} \\
\mathbf{5 6} & \mathbf{5 6} & \mathbf{2 1} \\
\mathbf{8 8} & \mathbf{3 2} & \mathbf{3 3} \\
\mathbf{9 6} & 29 & \mathbf{2 2} \\
103 & \mathbf{3 4} & \mathbf{4 8}\end{array}$ & $\begin{array}{l}2593 \\
2352 \\
3132 \\
2534 \\
2263 \\
2657\end{array}$ & $\begin{array}{rrr}94 & 33 & 48 \\
45 & 40 & 44 \\
55 & 28 & 50 \\
86 & 52 & 7 \\
94 & 42 & 28 \\
101 & 57 & 11\end{array}$ & $\begin{array}{l}259 \\
234 \\
316 \\
253 \\
226 \\
265\end{array}$ \\
\hline 27 & $\begin{array}{l}\text { Son } \\
\text { Spica } \\
\alpha \text { Aquilø } \\
\text { Fomalhaut } \\
\text { Saturn } \\
\text { a Pegasi . }\end{array}$ & $\begin{array}{l}\text { W. } \\
\text { W. } \\
\text { E. } \\
\text { E. } \\
\text { E. } \\
\text { E. }\end{array}$ & $\begin{array}{rrr}102 & 49 & 8 \\
54 & 25 & 40 \\
48 & 23 & 51 \\
78 & 30 & \mathbf{2 4} \\
85 & 47 & 57 \\
93 & 47 & 47\end{array}$ & $\begin{array}{l}2595 \\
2335 \\
3422 \\
2547 \\
2264 \\
2640\end{array}$ & \begin{tabular}{|rrr}
104 & 28 & 10 \\
56 & 10 & 49 \\
47 & 1 & 59 \\
76 & 50 & 15 \\
84 & 1 & 4 \\
92 & 9 & 46
\end{tabular} & $\begin{array}{l}2596 \\
2334 \\
3491 \\
2551 \\
2264 \\
2640\end{array}$ & $\left|\begin{array}{rrr}106 & 7 & 11 \\
57 & 55 & 59 \\
45 & 41 & 25 \\
75 & 10 & 13 \\
82 & 14 & 12 \\
90 & 31 & 45\end{array}\right|$ & $\begin{array}{l}2596 \\
2333 \\
3568 \\
2556 \\
2265 \\
2640\end{array}$ & \begin{tabular}{|rrr}
107 & 46 & 11 \\
59 & 41 & 12 \\
44 & 22 & 16 \\
73 & 30 & 18 \\
80 & 27 & 21 \\
88 & 53 & 45
\end{tabular} & $\begin{array}{l}2598 \\
2332 \\
3653 \\
2562 \\
2266 \\
2641\end{array}$ \\
\hline 28 & $\begin{array}{l}\text { UN } \\
\text { pica } \\
\text { omalhaut } \\
\text { aturn } \\
\text { Pegasi }\end{array}$ & $\begin{array}{l}\text { W. } \\
\text { W. } \\
\text { E. } \\
\text { E. } \\
\text { E. }\end{array}$ & $\begin{array}{rrr}116 & 0 & 40 \\
68 & 27 & 18 \\
65 & 13 & 8 \\
71 & 33 & 33 \\
80 & 44 & 33\end{array}$ & $\begin{array}{l}2607 \\
2333 \\
2605 \\
2274 \\
2660\end{array}$ & $\begin{array}{rrr}117 & 39 & 26 \\
70 & 12 & 29 \\
63 & 34 & 19 \\
69 & 46 & 54 \\
79 & 7 & 0\end{array}$ & $\begin{array}{l}2609 \\
2335 \\
2617 \\
2276 \\
2667\end{array}$ & $\begin{array}{|rrr|}119 & 18 & 9 \\
71 & 57 & 38 \\
61 & 55 & 47 \\
68 & 0 & 19 \\
77 & 29 & 36\end{array} \mid$ & $\begin{array}{l}2612 \\
2336 \\
2630 \\
2278 \\
2675\end{array}$ & $\begin{array}{rrr}120 & 56 & 48 \\
73 & 42 & 45 \\
60 & 17 & 32 \\
66 & 13 & 46 \\
75 & 52 & 21\end{array}$ & $\begin{array}{l}2615 \\
2338 \\
2644 \\
2280 \\
2683\end{array}$ \\
\hline 29 & $\begin{array}{l}\text { SuN } \\
\text { Spica } \\
\text { Antares } \\
\text { Fomalhaut } \\
\text { Saturn } \\
\text { a Pegasi } \\
\text { a Arietis }\end{array}$ & $\begin{array}{l}\text { W. } \\
\text { W. } \\
\text { W. } \\
\text { E. } \\
\text { E. } \\
\text { E. } \\
\text { E. }\end{array}$ & $\begin{array}{rrr}129 & 9 & 2 \\
82 & 27 & 35 \\
37 & 3 & 40 \\
52 & 11 & 48 \\
57 & 22 & 2 \\
67 & 49 & 21 \\
110 & 40 & 0\end{array}$ & $\begin{array}{l}2632 \\
2351 \\
2471 \\
2740 \\
2295 \\
2740 \\
2493\end{array}$ & \begin{tabular}{|rrr}
130 & 47 & 13 \\
84 & 12 & 21 \\
38 & 45 & 34 \\
50 & 36 & 1 \\
55 & 35 & 55 \\
66 & 13 & 34 \\
108 & 58 & 37
\end{tabular} & $\begin{array}{l}2636 \\
2355 \\
2464 \\
2766 \\
2298 \\
2755 \\
2493\end{array}$ & $\begin{array}{|rrr|}132 & 25 & 19 \\
85 & 57 & 1 \\
40 & 27 & 39 \\
49 & 0 & 48 \\
53 & 49 & 53 \\
64 & 38 & 7 \\
107 & 17 & 14\end{array} \mid$ & $\begin{array}{l}2641 \\
2358 \\
2458 \\
2794 \\
2302 \\
2772 \\
2493\end{array}$ & \begin{tabular}{|rrr}
134 & 3 & 19 \\
87 & 41 & 36 \\
42 & 9 & 52 \\
47 & 26 & 12 \\
52 & 3 & 57 \\
63 & 3 & 3 \\
105 & 35 & 51
\end{tabular} & $\begin{array}{l}2646 \\
2362 \\
2453 \\
2825 \\
2307 \\
2790 \\
2495\end{array}$ \\
\hline 30 & $\begin{array}{l}\text { Spica } \\
\text { Antares } \\
\text { Saturn } \\
\text { a Pegasi } \\
\text { a Arietis }\end{array}$ & $\begin{array}{l}\text { W. } \\
\text { W. } \\
\text { E. } \\
\text { E. } \\
\text { E. }\end{array}$ & $\begin{array}{rrr}96 & 22 & 58 \\
50 & 42 & 2 \\
43 & 15 & 53 \\
55 & 14 & 22 \\
97 & 9 & 42\end{array}$ & $\begin{array}{l}2387 \\
2447 \\
2331 \\
2910 \\
2510\end{array}$ & $\begin{array}{rrr}98 & 6 & 52 \\
52 & 24 & 30 \\
41 & 30 & 38 \\
53 & 42 & 16 \\
95 & 28 & 42\end{array}$ & $\begin{array}{l}2393 \\
2448 \\
2337 \\
2941 \\
2515\end{array}$ & $\begin{array}{rrr}\mathbf{9 9} & 50 & 37 \\
\mathbf{5 4} & \mathbf{6} & \mathbf{5 6} \\
\mathbf{3 9} & \mathbf{4 5} & 32 \\
\mathbf{5 2} & \mathbf{1 0} & 49 \\
93 & \mathbf{4 7} & \mathbf{5 0}\end{array}$ & $\begin{array}{l}2399 \\
2450 \\
2342 \\
2975 \\
2520\end{array}$ & $\begin{array}{rrr}101 & 34 & 13 \\
55 & 49 & 19 \\
38 & 0 & 34 \\
50 & 40 & 5 \\
92 & 7 & 5\end{array}$ & $\begin{array}{l}2405 \\
2453 \\
2348 \\
3013 \\
2525\end{array}$ \\
\hline 31 & $\begin{array}{l}\text { Spica } \\
\text { Antares } \\
\text { Saturn } \\
\text { a Pegasi } \\
\text { a Arietis } \\
\text { Aldebaran }\end{array}$ & $\begin{array}{l}\text { W. } \\
\text { W. } \\
\text { E. } \\
\text { E. } \\
\text { E. } \\
\text { E. }\end{array}$ & $\begin{array}{rrr}110 & 9 & 44 \\
64 & 20 & 3 \\
29 & 18 & 7 \\
43 & 19 & 35 \\
83 & 45 & 32 \\
115 & 38 & 1\end{array}$ & $\begin{array}{l}2444 \\
2476 \\
2383 \\
3265 \\
2563 \\
2407\end{array}$ & $\begin{array}{rrr}111 & 52 & 17 \\
66 & 1 & 52 \\
27 & 34 & 8 \\
41 & 54 & 42 \\
82 & 5 & 46 \\
113 & 54 & 36\end{array}$ & $\begin{array}{l}2453 \\
2481 \\
2391 \\
3333 \\
2572 \\
2415\end{array}$ & $\begin{array}{rrr}113 & 34 & 37 \\
67 & 43 & 32 \\
25 & 50 & 21 \\
40 & 31 & 7 \\
80 & 26 & 12 \\
112 & 11 & 22\end{array}$ & $\begin{array}{l}2461 \\
2488 \\
2399 \\
3408 \\
2582 \\
2423\end{array}$ & $\begin{array}{rrr}115 & 16 & 45 \\
69 & 25 & 2 \\
24 & 6 & 45 \\
39 & 8 & 59 \\
78 & 46 & 51 \\
110 & 28 & 19\end{array}$ & $\begin{array}{l}2470 \\
2494 \\
2408 \\
3492 \\
2592 \\
2431\end{array}$ \\
\hline
\end{tabular}


SEPTEMBER.

AT APPARENT NOON.

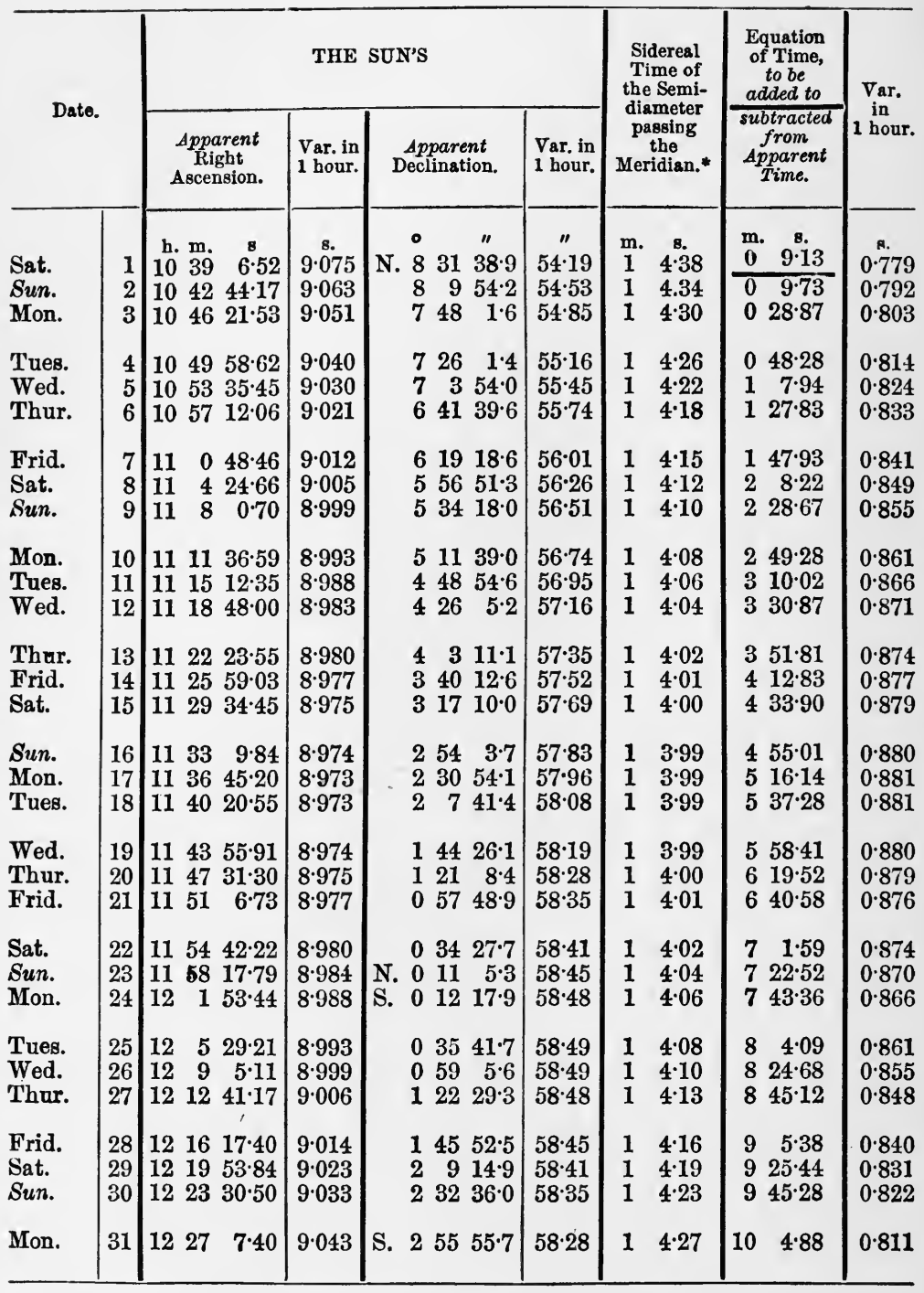

* Mean Time of the Semidiameter passing may be found by subtracting 0 s.18 from the Sidereal Time. 
SEPTEMBER.

AT MEAN NOON.

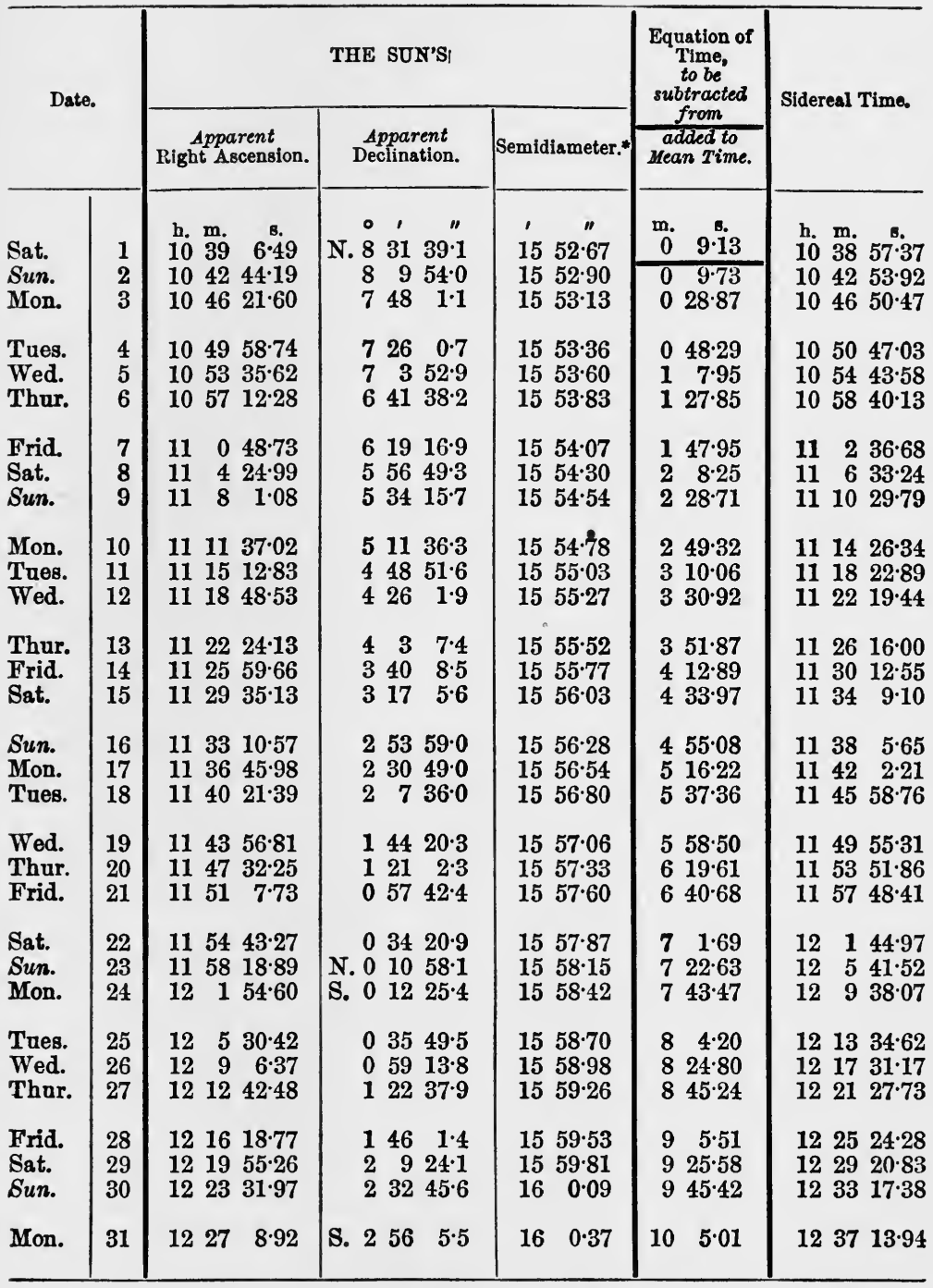

* The Semidiameter for Apparent Noon may be assumed the same as that for Mean Noon. 
SEPTEMBER.

III.

MEAN TIME.

\begin{tabular}{|c|c|c|c|c|c|c|c|c|}
\hline \multirow{3}{*}{ Day. } & \multicolumn{2}{|c|}{$\begin{array}{c}\text { THE SUN'S } \\
\text { Apparent }\end{array}$} & \multirow{3}{*}{$\begin{array}{c}\begin{array}{c}\text { Logarithm } \\
\text { of the } \\
\text { Radius } \\
\text { Vector of } \\
\text { the Earth. }\end{array} \\
\text { Noon. }\end{array}$} & \multirow{3}{*}{$\begin{array}{l}\text { Transit of } \\
\text { the First } \\
\text { Point of } \\
\text { Aries. }\end{array}$} & \multicolumn{4}{|c|}{ THE MOON'S } \\
\hline & Longitude. & Latitude. & & & \multicolumn{2}{|c|}{ Semidiameter. } & \multicolumn{2}{|c|}{ Horizontal Parallax. } \\
\hline & Noon. & Noon. & & & Noon. & Midnight. & Noon. & Midnight. \\
\hline $\begin{array}{l}\mathbf{1} \\
\mathbf{2} \\
\mathbf{3}\end{array}$ & \begin{tabular}{ccc}
$\circ$ & \multicolumn{1}{c}{} & " \\
158 & 7 & $20 \cdot 1$ \\
159 & 5 & $24 \cdot 6$ \\
160 & 3 & $30 \cdot 7$
\end{tabular} & $\begin{array}{cc} & \prime \prime \\
\text { S. } 0.36 \\
0.50 \\
0.62\end{array}$ & $\begin{array}{r}0.0038629 \\
\cdot 0037580 \\
\cdot 0036526\end{array}$ & $\begin{array}{|ccc|}\text { h. } & \text { m. } & \text { s. } \\
13 & 18 & 51 \cdot 40 \\
13 & 14 & 55 \cdot 50 \\
13 & 10 & 59 \cdot 59\end{array}$ & $\begin{array}{cc}\prime & \prime \prime \\
15 & 51 \cdot 25 \\
15 & 42 \cdot 60 \\
15 & 32 \cdot 92\end{array}$ & $\begin{array}{cc}\prime & \prime \prime \\
15 & 47 \cdot 09 \\
15 & 37 \cdot 85 \\
15 & 27 \cdot 88\end{array}$ & $\begin{array}{cc}\prime & \prime \prime \\
58 & 5 \cdot 16 \\
57 & 33 \cdot 43 \\
56 & 57 \cdot 98\end{array}$ & $\begin{array}{cc}\prime & \prime \prime \\
57 & 49 \cdot 88 \\
57 & 16 \cdot 04 \\
56 & 39 \cdot 53\end{array}$ \\
\hline $\begin{array}{l}4 \\
5 \\
6\end{array}$ & $\begin{array}{rrr}161 & 1 & 38 \cdot 6 \\
161 & 59 & 48 \cdot 4 \\
162 & 58 & 0 \cdot 0\end{array}$ & $\begin{array}{l}0.72 \\
0.81 \\
0.86\end{array}$ & $\begin{array}{r}0.0035466 \\
.0034402 \\
.0033332\end{array}$ & $\begin{array}{ccc}13 & 7 & 3 \cdot 68 \\
13 & 3 & 7 \cdot 78 \\
12 & 59 & 11 \cdot 87\end{array}$ & \begin{tabular}{rr|}
15 & $22 \cdot 80$ \\
15 & $12 \cdot 94$ \\
15 & $3 \cdot 99$
\end{tabular} & \begin{tabular}{rr|}
15 & $17 \cdot 79$ \\
15 & 8.31 \\
15 & 0.06
\end{tabular} \mid & $\begin{array}{|ll|}56 & 20 \cdot 93 \\
55 & 44 \cdot 75 \\
55 & 11 \cdot 96\end{array}$ & $\begin{array}{rr}56 & 2 \cdot 58 \\
55 & 27 \cdot 79 \\
54 & 57 \cdot 57\end{array}$ \\
\hline $\begin{array}{l}7 \\
8 \\
9\end{array}$ & $\begin{array}{l}1635613.5 \\
1645429 \cdot 0 \\
1655246.6\end{array}$ & $\begin{array}{l}0.88 \\
0.88 \\
0.85\end{array}$ & $\begin{array}{r}0.0032256 \\
.0031173 \\
.0030082\end{array}$ & $\mid \begin{array}{lll}12 & 55 & 15 \cdot 96 \\
12 & 51 & 20 \cdot 05 \\
12 & 47 & 24 \cdot 15\end{array}$ & & & & \\
\hline $\begin{array}{l}10 \\
11 \\
12\end{array}$ & $\begin{array}{rrr}166 & 51 & 6 \cdot 2 \\
167 & 49 & 27 \cdot 9 \\
168 & 47 & 51 \cdot 7\end{array}$ & $\begin{array}{l}0.81 \\
0.74 \\
0.63\end{array}$ & $\begin{array}{r}0.0028984 \\
.0027877 \\
.0026761\end{array}$ & $\mid \begin{array}{lll}12 & 43 & 28 \cdot 24 \\
12 & 39 & 32 \cdot 34 \\
12 & 35 & 36 \cdot 43\end{array}$ & & $\begin{array}{|cc|}14 & 49 \cdot 37 \\
14 & 53.52 \\
15 & 0.36\end{array}$ & & \\
\hline $\begin{array}{l}13 \\
14 \\
15\end{array}$ & $\begin{array}{lll}169 & 46 & 17 \cdot 6 \\
170 & 44 & 45 \cdot 5 \\
171 & 43 & 15 \cdot 6\end{array}$ & $\begin{array}{l}0.51 \\
0.38 \\
0.25\end{array}$ & $\begin{array}{r}0.0025635 \\
.0024498 \\
.0023349\end{array}$ & $\left|\begin{array}{lll}12 & 31 & 40 \cdot 52 \\
12 & 27 & 44 \cdot 62 \\
12 & 23 & 48 \cdot 71\end{array}\right|$ & $\left|\begin{array}{rr}15 & 4 \cdot 68 \\
15 & 14 \cdot 83 \\
15 & 26 \cdot 42\end{array}\right|$ & $\begin{array}{rr}15 & 9.53 \\
15 & 20.49 \\
15 & 32.51\end{array}$ & & \\
\hline $\begin{array}{l}16 \\
17 \\
18\end{array}$ & $\begin{array}{lll}172 & 41 & 47 \cdot 8 \\
173 & 40 & 21 \cdot 9 \\
174 & 38 & 58 \cdot 1\end{array}$ & $\mid \begin{array}{r}\text { S. } 0 \cdot 12 \\
0 \cdot 00 \\
\text { N. } 0 \cdot 11\end{array}$ & $\begin{array}{r}0.0022189 \\
.0021016 \\
.0019830\end{array}$ & $\left|\begin{array}{rrr}12 & 19 & 52.80 \\
12 & 15 & 56.90 \\
12 & 12 & 0.99\end{array}\right|$ & & $\begin{array}{rr}15 & 44 \cdot 70 \\
15 & 56 \cdot 08 \\
16 & 5 \cdot 75\end{array}$ & & \\
\hline $\begin{array}{l}19 \\
20 \\
21\end{array}$ & $\begin{array}{lll}175 & 37 & 36 \cdot 2 \\
176 & 36 & 16 \cdot 2 \\
177 & 34 & 57 \cdot 9\end{array}$ & $\begin{array}{l}0.19 \\
0.24 \\
0.28\end{array}$ & $\begin{array}{r}0.0018631 \\
.0017419 \\
.0016196\end{array}$ & $\left|\begin{array}{rrr}12 & 8 & 5 \cdot 09 \\
12 & 4 & 9 \cdot 18 \\
12 & 0 & 13 \cdot 27\end{array}\right|$ & \begin{tabular}{|rr}
16 & $9 \cdot 70$ \\
16 & $15 \cdot 50$ \\
16 & $18 \cdot 37$
\end{tabular} & & & \\
\hline $\begin{array}{l}22 \\
23 \\
24\end{array}$ & $\begin{array}{lll}178 & 33 & 41 \cdot 5 \\
179 & 32 & 26 \cdot 7 \\
180 & 31 & 13 \cdot 6\end{array}$ & $\begin{array}{l}0.27 \\
0.24 \\
0.17\end{array}$ & $\begin{array}{r}0.0014963 \\
\cdot 0013721 \\
.0012471\end{array}$ & $\mid \begin{array}{lll}11 & 56 & 17 \cdot 37 \\
11 & 52 & 21 \cdot 46 \\
11 & 48 & 25 \cdot 55\end{array}$ & & $\begin{array}{rr}16 & 17 \cdot 52 \\
16 & 14 \cdot 15 \\
16 & 9 \cdot 15\end{array}$ & & \\
\hline $\begin{array}{l}25 \\
26 \\
27\end{array}$ & $\begin{array}{rrr}181 & 30 & 2 \cdot 2 \\
182 & 28 & 52 \cdot 6 \\
183 & 27 & 44 \cdot 6\end{array}$ & $\begin{array}{r}\text { N. } 0.06 \\
\text { S. } 0.05 \\
0.18\end{array}$ & $\begin{array}{r}0.0011216 \\
.0009957 \\
.0008696\end{array}$ & $\mid \begin{array}{llll}11 & 44 & 29 \cdot 65 \\
11 & 40 & 33 \cdot 74 \\
11 & 36 & 37 \cdot 84\end{array}$ & $\begin{array}{rr}16 & 6 \cdot 22 \\
15 & 59 \cdot 72 \\
15 & 52 \cdot 61\end{array} \mid$ & $\begin{array}{rr}16 & 3 \cdot 07 \\
15 & 56 \cdot 22 \\
15 & 48 \cdot 89\end{array} \mid$ & $\mid \begin{array}{rr}59 & 0 \cdot 01 \\
58 & 36 \cdot 18 \\
58 & 10 \cdot 13\end{array}$ & $\begin{array}{ll}58 & 48 \cdot 45 \\
58 & 23 \cdot 38 \\
57 & 56 \cdot 50\end{array}$ \\
\hline $\begin{array}{l}28 \\
29 \\
30\end{array}$ & $\begin{array}{llll}184 & 26 & 38 \cdot 3 \\
185 & 25 & 33 \cdot 8 \\
186 & 24 & 31 \cdot 2\end{array}$ & $\begin{array}{l}0.31 \\
0.43 \\
0.55\end{array}$ & $\begin{array}{r}0.0007434 \\
.0006174 \\
.0004917\end{array}$ & $\mid \begin{array}{lll}11 & 32 & 41 \cdot 93 \\
11 & 28 & 46 \cdot 02 \\
11 & 24 & 50 \cdot 12\end{array}$ & $\begin{array}{ll}15 & 45 \cdot 09 \\
15 & 37 \cdot 22 \\
15 & 29 \cdot 13\end{array}$ & $\begin{array}{l}15 \quad 41 \cdot 19 \\
15 \quad 33 \cdot 20 \\
15 \quad 25 \cdot 03\end{array}$ & $\begin{array}{ll}57 & 42 \cdot 55 \\
57 & 13 \cdot 75 \\
56 & 44 \cdot 11\end{array}$ & $\begin{array}{ll}57 & 28 \cdot 28 \\
56 & 59 \cdot 02 \\
56 & 29 \cdot 09\end{array}$ \\
\hline 31 & $1872330 \cdot 5$ & S. 0.66 & 0.0003662 & $112054: 21$ & 1520.93 & 1516.85 & 5614.06 & $5559 \cdot 11$ \\
\hline
\end{tabular}


MEAN TIME.

\begin{tabular}{|c|c|c|c|c|c|c|c|}
\hline \multirow{3}{*}{ Day. } & \multicolumn{7}{|c|}{ THE MOON'S } \\
\hline & \multicolumn{2}{|c|}{ Longitude. } & \multicolumn{2}{|c|}{ Latitude. } & \multirow{2}{*}{$\frac{\text { Age. }}{\text { Noon. }}$} & \multicolumn{2}{|c|}{ Meridian Passage. } \\
\hline & Noon. & Midnight. & Noon. & Midnight. & & Upper. & Lower. \\
\hline $\begin{array}{l}\mathbf{1} \\
\mathbf{2} \\
\mathbf{3}\end{array}$ & \begin{tabular}{ccr}
$\circ$ & \multicolumn{1}{c}{} & \multicolumn{1}{c}{} \\
319 & 34 & $4 \cdot 8$ \\
333 & 6 & $17 \cdot 3$ \\
346 & 24 & $7 \cdot 0$
\end{tabular} & \begin{tabular}{ccr}
$\circ$ & $\prime$ & \multicolumn{1}{c}{} \\
326 & 21 & $52 \cdot 0$ \\
339 & 47 & $6 \cdot 2$ \\
352 & 57 & $10 \cdot 5$
\end{tabular} & \begin{tabular}{rcr}
$\circ$ & $\prime$ & \multicolumn{1}{c}{} \\
S. 0 & 43 & $23 \cdot 4$ \\
1 & 55 & $0 \cdot 4$ \\
2 & 58 & $57 \cdot 2$
\end{tabular} & \begin{tabular}{ccc}
$\circ$ & $\prime$ & \multicolumn{1}{c}{} \\
S.1 & 19 & $55 \cdot 5$ \\
2 & 28 & $9 \cdot 3$ \\
3 & 27 & $2 \cdot 8$
\end{tabular} & $\begin{array}{c}\text { d. } \\
12 \cdot 44 \\
13 \cdot 44 \\
14 \cdot 44\end{array}$ & $\begin{array}{lr}\text { h. } & \text { m. } \\
11 & 13 \cdot 7 \\
12 & 4 \cdot 4 \\
12 & 52 \cdot 4\end{array}$ & $\begin{array}{cc}\text { h. } & \text { m. } \\
23 & 39 \cdot 4 \\
* & * \\
0 & 28 \cdot 7\end{array}$ \\
\hline $\begin{array}{l}4 \\
5 \\
6\end{array}$ & $\begin{array}{rrr}359 & 26 & 10 \cdot 6 \\
12 & 11 & 54 \cdot 8 \\
24 & 41 & 49 \cdot 2\end{array}$ & $\begin{array}{rrr}\mathbf{5} & \mathbf{5 1} & 4 \cdot 7 \\
18 & 28 & 46 \cdot 4 \\
30 & 51 & 17 \cdot 0\end{array}$ & $\begin{array}{rrr}3 & 52 & 8 \cdot 3 \\
4 & 32 & 28 \cdot 0 \\
4 & 58 & 48 \cdot 6\end{array}$ & $\begin{array}{rrr}4 & 14 & 0 \cdot 1 \\
4 & 47 & 25 \cdot 4 \\
5 & 6 & 36 \cdot 7\end{array}$ & $\begin{array}{l}15 \cdot 44 \\
16 \cdot 44 \\
17 \cdot 44\end{array}$ & $\begin{array}{rr}13 & 38 \cdot 4 \\
14 & 23 \cdot 0 \\
15 & 6 \cdot 9\end{array}$ & $\begin{array}{rr}1 & 15 \cdot 6 \\
2 & 0 \cdot 8 \\
2 & 45 \cdot 0\end{array}$ \\
\hline $\begin{array}{l}7 \\
8 \\
9\end{array}$ & $\begin{array}{rrr}36 & 57 & 28 \cdot 0 \\
49 & 1 & 28 \cdot 5 \\
60 & 57 & 22 \cdot 2\end{array}$ & $\begin{array}{rrr}43 & 0 & 43 \cdot 4 \\
55 & 0 & 11 \cdot 2 \\
66 & 53 & 34 \cdot 6\end{array}$ & $\begin{array}{rrr}5 & 10 & 50 \cdot 7 \\
5 & 8 & 49 \cdot 7 \\
4 & 53 & 24 \cdot 9\end{array}$ & $\begin{array}{rrr}5 & 11 & 33 \cdot 6 \\
5 & 2 & 44 \cdot 6 \\
4 & 40 & 57 \cdot 5\end{array}$ & $\begin{array}{l}18 \cdot 44 \\
19 \cdot 44 \\
20 \cdot 44\end{array}$ & $\begin{array}{ll}15 & 50 \cdot 9 \\
16 & 35 \cdot 4 \\
17 & 21 \cdot 0\end{array}$ & $\begin{array}{ll}3 & 28 \cdot 9 \\
4 & 13 \cdot 0 \\
4 & 58 \cdot 0\end{array}$ \\
\hline $\begin{array}{l}10 \\
11 \\
12\end{array}$ & $\begin{array}{lll}72 & 49 & 23.5 \\
84 & 42 & 15 \cdot 9 \\
96 & 40 & 56.5\end{array}$ & $\begin{array}{rrr}78 & 45 & 24 \cdot 8 \\
90 & 40 & 33 \cdot 9 \\
102 & 44 & 0 \cdot 3\end{array}$ & $\begin{array}{lll}4 & 25 & 30 \cdot 2 \\
3 & 46 & 10 \cdot 5 \\
2 & 56 & 41 \cdot 7\end{array}$ & $\begin{array}{rrr}4 & 7 & 11 \cdot 6 \\
3 & 22 & 36 \cdot 9 \\
2 & 28 & 36 \cdot 9\end{array}$ & $\begin{array}{l}21 \cdot 44 \\
22 \cdot 44 \\
23 \cdot 44\end{array}$ & $\begin{array}{rr}18 & 7 \cdot 8 \\
18 & 56 \cdot 1 \\
19 & 45 \cdot 6\end{array}$ & $\begin{array}{ll}5 & 44 \cdot 2 \\
6 & 31 \cdot 8 \\
7 & 20 \cdot 7\end{array}$ \\
\hline $\begin{array}{l}13 \\
14 \\
15\end{array}$ & $\begin{array}{rrr}108 & 50 & 20 \cdot 4 \\
121 & 15 & 0 \cdot 1 \\
133 & 58 & 41 \cdot 9\end{array}$ & $\begin{array}{rrr}115 & 0 & 30 \cdot 2 \\
127 & 34 & 16 \cdot 6 \\
140 & 28 & 33 \cdot 0\end{array}$ & $\begin{array}{rrr}1 & 58 & 36 \cdot 2 \\
\text { S.0 } & 53 & 50 \cdot 5 \\
\text { N.0 } & 15 & 5 \cdot 3\end{array}$ & $\begin{array}{|rrr|}1 & 26 & 54 \cdot 8 \\
\text { S.0 } & 19 & 42 \cdot 8 \\
\text { N.0 } & 50 & 9 \cdot 1\end{array}$ & $\begin{array}{l}24 \cdot 44 \\
25 \cdot 44 \\
26 \cdot 44\end{array}$ & $\begin{array}{ll}20 & 35 \cdot 9 \\
21 & 26 \cdot 7 \\
22 & 17 \cdot 5\end{array}$ & $\begin{array}{rr}8 & 10 \cdot 7 \\
9 & 1 \cdot 3 \\
9 & 52 \cdot 1\end{array}$ \\
\hline $\begin{array}{l}16 \\
17 \\
18\end{array}$ & $\begin{array}{rrr}147 & 4 & 0 \cdot 7 \\
160 & 31 & 53 \cdot 3 \\
174 & 21 & 18 \cdot 1\end{array}$ & $\begin{array}{rrr}153 & 45 & 8 \cdot 8 \\
167 & 24 & 2 \cdot 8 \\
181 & 23 & 11 \cdot 4\end{array}$ & $\begin{array}{rrr}1 & 25 & 0.4 \\
2 & 32 & 3 \cdot 7 \\
3 & 31 & 54 \cdot 3\end{array}$ & $\begin{array}{rrr}1 & 59 & 9 \cdot 3 \\
3 & 3 & 10 \cdot 0 \\
3 & 57 & 43 \cdot 6\end{array}$ & $\begin{array}{l}27 \cdot 44 \\
28 \cdot 44 \\
29 \cdot 44\end{array}$ & $\begin{array}{rr}23 & 8 \cdot 2 \\
23 & 58 \cdot 8 \\
* & *\end{array}$ & $\begin{array}{ll}10 & 42 \cdot 9 \\
11 & 33 \cdot 5 \\
12 & 24 \cdot 2\end{array}$ \\
\hline $\begin{array}{l}19 \\
20 \\
21\end{array}$ & $\begin{array}{rrr}188 & 29 & 9 \cdot 2 \\
202 & 50 & 33 \cdot 3 \\
217 & 19 & 28 \cdot 7\end{array}$ & $\begin{array}{|rrr|}195 & 38 & 31 \cdot 2 \\
210 & 4 & 28 \cdot 5 \\
224 & 34 & 47 \cdot 9\end{array}$ & $\begin{array}{rrr}4 & 20 & 6 \cdot 4 \\
4 & 52 & 45 \cdot 0 \\
5 & 7 & 2 \cdot 2\end{array}$ & $\begin{array}{rrr}4 & 38 & 35 \cdot 0 \\
5 & 2 & 18 \cdot 2 \\
5 & 6 & 50 \cdot 6\end{array}$ & \begin{tabular}{l|l}
0.98 \\
1.98 \\
2.98
\end{tabular} & $\begin{array}{ll}0 & 49 \cdot 8 \\
1 & 41 \cdot 4 \\
2 & 34 \cdot 3\end{array}$ & $\begin{array}{rr}13 & 15 \cdot 5 \\
14 & 7 \cdot 7 \\
15 & 1 \cdot 4\end{array}$ \\
\hline $\begin{array}{l}22 \\
23 \\
24\end{array}$ & $\begin{array}{lll}231 & 49 & 42 \cdot 0 \\
246 & 15 & 43 \cdot 0 \\
260 & 33 & 24 \cdot 3\end{array}$ & $\begin{array}{rrr}239 & 3 & 31 \cdot 8 \\
253 & 25 & 47 \cdot 8 \\
267 & 38 & 16 \cdot 8\end{array}$ & $\begin{array}{rrr}5 & 1 & 44 \cdot 1 \\
4 & 37 & 19 \cdot 7 \\
3 & 55 & 50 \cdot 2\end{array}$ & $\begin{array}{lll}4 & 51 & 49 \cdot 6 \\
4 & 18 & 32 \cdot 6 \\
3 & 29 & 38 \cdot 8\end{array}$ & $\begin{array}{l}3 \cdot 98 \\
4 \cdot 98 \\
5 \cdot 98\end{array}$ & $\begin{array}{ll}3 & 28 \cdot 9 \\
4 & 25 \cdot 2 \\
5 & 22 \cdot 9\end{array}$ & $\begin{array}{ll}15 & 56 \cdot 9 \\
16 & 53 \cdot 9 \\
1.7 & 52 \cdot 0\end{array}$ \\
\hline $\begin{array}{l}25 \\
26 \\
27\end{array}$ & $\begin{array}{rrr}274 & 40 & 14 \cdot 8 \\
288 & 35 & 8 \cdot 1 \\
302 & 17 & 56 \cdot 0\end{array}$ & $\begin{array}{|rrr|}281 & 39 & 12 \cdot 6 \\
295 & 28 & 1 \cdot 6 \\
309 & 4 & 54 \cdot 0\end{array}$ & $\begin{array}{rrr}3 & 0 & 26 \cdot 7 \\
1 & 55 & 4 \cdot 5 \\
\text { N.0 } & 43 & 59 \cdot 9\end{array}$ & $\begin{array}{rrr}2 & 28 & 44 \cdot 7 \\
1 & 19 & 58 \cdot 7 \\
\text { N.0 } & 7 & 40.4\end{array}$ & $\begin{array}{l}6 \cdot 98 \\
7 \cdot 98 \\
8 \cdot 98\end{array}$ & $\begin{array}{ll}6 & 21 \cdot 1 \\
7 & 18 \cdot 5 \\
8 & 14 \cdot 3\end{array}$ & $\begin{array}{ll}18 & 50 \cdot 0 \\
19 & 46 \cdot 7 \\
20 & 41 \cdot 2\end{array}$ \\
\hline $\begin{array}{l}28 \\
29 \\
30\end{array}$ & $\begin{array}{rrr}315 & 48 & 59 \cdot 0 \\
329 & 8 & 39 \cdot 7 \\
342 & 17 & 6 \cdot 2\end{array}$ & $\begin{array}{rrr}322 & 30 & 13 \cdot 6 \\
335 & 44 & 17 \cdot 4 \\
348 & 47 & 4 \cdot 4\end{array}$ & $\begin{array}{|rrr|}\text { S. } 0 & 28 & 28 \cdot 3 \\
1 & 38 & 14 \cdot 1 \\
2 & 41 & 36 \cdot 4\end{array}$ & $\begin{array}{rrr}\text { S. } 1 & 3 & 56.0 \\
2 & 10 & 55.7 \\
3 & 9 & 54.8\end{array}$ & $\begin{array}{r}9 \cdot 98 \\
10 \cdot 98 \\
11 \cdot 98\end{array}$ & $\begin{array}{rr}9 & 7 \cdot 5 \\
9 & 58 \cdot 0 \\
10 & 46 \cdot 1\end{array}$ & $\begin{array}{lr}21 & 33 \cdot 1 \\
22 & 22 \cdot 4 \\
23 & 9 \cdot 4\end{array}$ \\
\hline 31 & $\begin{array}{lll}355 & 14 & 9 \cdot 2\end{array}$ & $13818 \cdot 0$ & S. $3 \quad 3531 \cdot 3$ & S. $358 \quad 10.3$ & $12 \cdot 98$ & $1132 \cdot 3$ & $2354: 8$ \\
\hline
\end{tabular}

The Moon's Longitude and Latitude are from Hansen's Tables; the Right Ascension and Declination contain Newcomb's corrections. 


\section{JUPITER'S ELEMENTS.}

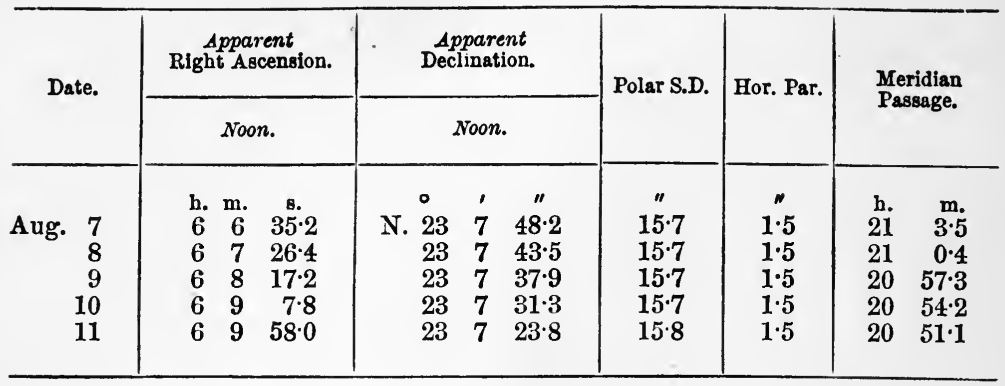

SATURN'S ELEMENTS.

\begin{tabular}{|c|c|c|c|c|c|c|c|c|c|}
\hline Aug. $\begin{array}{r}9 \\
10 \\
11 \\
12 \\
13\end{array}$ & $\begin{array}{rr}\text { h. } & \text { m. } \\
23 & 2 \\
23 & 2 \\
23 & 2 \\
23 & 1 \\
23 & 1\end{array}$ & $\begin{array}{r}\text { 8. } \\
32 \cdot 3 \\
18.4 \\
4.3 \\
50 \cdot 0 \\
35.5\end{array}$ & $\begin{array}{r}\circ \\
\text { S. } \\
8 \\
8 \\
8 \\
8\end{array}$ & $\begin{array}{l} \\
21 \\
22 \\
24 \\
26 \\
27\end{array}$ & \begin{tabular}{r}
\multicolumn{1}{c}{$10 \cdot 0$} \\
$46 \cdot 9$ \\
$24 \cdot 9$ \\
$4 \cdot 0$ \\
$44 \cdot 1$
\end{tabular} & $\begin{array}{l}\prime \prime \\
8 \cdot 7 \\
8 \cdot 8 \\
8 \cdot 8 \\
8 \cdot 8 \\
8 \cdot 8\end{array}$ & $\begin{array}{l}11 \\
1 \cdot 0 \\
1 \cdot 0 \\
1 \cdot 0 \\
1 \cdot 0 \\
1 \cdot 0\end{array}$ & $\begin{array}{l}\text { h. } \\
13 \\
13 \\
13 \\
13 \\
13\end{array}$ & $\begin{array}{r}\mathrm{m} . \\
51 \cdot 9 \\
47 \cdot 7 \\
43 \cdot 5 \\
39 \cdot 4 \\
35 \cdot 2\end{array}$ \\
\hline
\end{tabular}

MEAN PLACES OF STARS.

\begin{tabular}{|c|c|c|c|c|c|c|c|}
\hline \multicolumn{2}{|l|}{ Star's Name. } & $\begin{array}{c}\text { Mag. } \\
2 \cdot 1\end{array}$ & \multicolumn{2}{|c|}{ Right Ascension. } & \multicolumn{3}{|c|}{ Declination. } \\
\hline 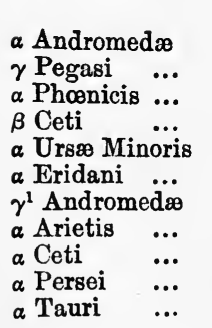 & $\begin{array}{l}\cdots \\
\cdots \\
\cdots \\
\cdots \\
\cdots \\
\cdots \\
\cdots \\
\cdots \\
\cdots \\
\cdots\end{array}$ & $\begin{array}{l}2 \cdot 1 \\
2.9 \\
2 \cdot 4 \\
2 \cdot 2 \\
2 \cdot 1 \\
0 \cdot 5 \\
2 \cdot 2 \\
2 \cdot 2 \\
2 \cdot 8 \\
1 \cdot 9 \\
1 \cdot 1\end{array}$ & $\begin{array}{rr}\text { h. } & \text { m. } \\
0 & 3 \\
0 & 8 \\
0 & 21 \\
0 & 38 \\
1 & 25 \\
1 & 34 \\
1 & 58 \\
2 & 1 \\
2 & 57 \\
3 & 17 \\
4 & 30\end{array}$ & $\begin{array}{r}\text { s. } \\
31 \cdot 6 \\
23 \cdot 6 \\
38 \cdot 4 \\
52 \cdot 3 \\
8 \cdot 2 \\
12 \cdot 8 \\
7 \cdot 5 \\
52 \cdot 3 \\
21 \cdot 9 \\
36 \cdot 4 \\
31 \cdot 5\end{array}$ & $\begin{array}{l}\quad \circ \\
\text { N. } 28 \\
\text { N. } 14 \\
\text { S. } 42 \\
\text { S. } 18 \\
\text { N. } 88 \\
\text { S. } 57 \\
\text { N. } 41 \\
\text { N. } 23 \\
\text { N. } 3 \\
\text { N. } 49 \\
\text { N. } 16\end{array}$ & $\begin{array}{r}1 \\
34 \\
39 \\
48 \\
30 \\
48 \\
42 \\
52 \\
1 \\
43 \\
31 \\
19\end{array}$ & \begin{tabular}{r}
\multicolumn{1}{ll}{} \\
$17 \cdot 3$ \\
$39 \cdot 6$ \\
$59 \cdot 3$ \\
$8 \cdot 6$ \\
$18 \cdot 9$ \\
$51 \cdot 3$ \\
$44 \cdot 3$ \\
$5 \cdot 7$ \\
$16 \cdot 4$ \\
$37 \cdot 6$ \\
$14 \cdot 8$
\end{tabular} \\
\hline
\end{tabular}


MEAN PLACES OF STARS (continued).

\begin{tabular}{|c|c|c|c|c|c|c|c|c|c|}
\hline Star's & Name. & & Mag. & Righ & $t \mathrm{Asc}$ & onsion. & Decl & natio & \\
\hline & & & 0.2 & h. & & s.. & $\begin{array}{l}\circ \\
\mathbf{4 5}\end{array}$ & $\therefore$ & $"$ \\
\hline a Aurigæ & $\cdots$ & $\cdots$ & $\begin{array}{l}0.2 \\
0.3\end{array}$ & $\begin{array}{l}0 \\
5\end{array}$ & $\begin{array}{r}9 \\
10\end{array}$ & $\begin{array}{r}44 \cdot 6 \\
1 \cdot 2\end{array}$ & N. 45 & 54 & $10 \cdot 8$ \\
\hline B Orionis & $\cdots$ & $\cdots$ & 1.7 & 5 & 20 & $5 \cdot 3$ & & 18 & $35 \cdot 3$ \\
\hline$\gamma$ Orionis & $\cdots$ & $\cdots$ & $1 \cdot 8$ & 5 & 20 & & N. 6 & 15 & $53 \cdot 8$ \\
\hline B Tauri & ... & $\cdots$ & & 3 & 20 & 20.9 & N. 28 & 31 & $42 \cdot 8$ \\
\hline$\epsilon$ Orionis & $\ldots$ & $\cdots$ & $1 \cdot 7$ & 5 & 31 & $26 \cdot 6$ & S. 1 & 15 & $41 \cdot 4$ \\
\hline$\alpha$ Orionis & $\cdots$ & ... & var. & 5 & 50 & $4 \cdot 9$ & N. 7 & 23 & $24 \cdot 0$ \\
\hline B Aurigæ & $\cdots$ & $\cdots$ & $\begin{array}{l}2 \cdot 1 \\
0 \cdot 0\end{array}$ & 5 & 52 & $38 \cdot 0$ & N. 44 & 56 & $18 \cdot 6$ \\
\hline B Canis Ma & joris & ... & 20 & 6 & 18 & $33 \cdot 6$ & S. 17 & 54 & $31 \cdot 7$ \\
\hline a Argûs & ... & ... & $-1 \cdot 0$ & 6 & 21 & $51 \cdot 9$ & S. 52 & 38 & $39 \cdot 0$ \\
\hline$\gamma$ Geminorv & & .. & 1.9 & 6 & 32 & 16.9 & N. 16 & 28 & $47 \cdot 9$ \\
\hline a Canis Ma & joris & $\cdots$ & $-1 \cdot 4$ & 6 & 41 & $\begin{array}{r}0.2 \\
55 \cdot 0\end{array}$ & S. 16 & 35 & $12 \cdot 2$ \\
\hline$\epsilon$ Canis Ma & joris & •.. & $1 \cdot 6$ & 6 & 54 & $55 \cdot 9$ & S. 28 & 50 & $37 \cdot 6$ \\
\hline$\delta$ Canis $\mathrm{Ma}$ & joris & .. & $2 \cdot 0$ & 7 & 4 & $34 \cdot 1$ & S. 26 & 14 & 36.9 \\
\hline a Geminor & um & $\cdots$ & $\begin{array}{l}2.0 \\
0.5\end{array}$ & $\begin{array}{l}7 \\
7\end{array}$ & 28 & $\begin{array}{l}36.2 \\
22 \cdot 9\end{array}$ & $\begin{array}{l}\text { N. } 32 \\
\text { N. } 5\end{array}$ & $\begin{array}{r}5 \\
97\end{array}$ & 43.4 \\
\hline a Canis Mir & ooris & .... & $\begin{array}{l}0.5 \\
1.2\end{array}$ & $\begin{array}{l}7 \\
7\end{array}$ & $\begin{array}{l}34 \\
39\end{array}$ & $\begin{array}{l}22 \cdot 9 \\
33 \cdot 9\end{array}$ & $\begin{array}{l}\text { N. } 5 \\
\text { N. } 28\end{array}$ & $\begin{array}{l}27 \\
15\end{array}$ & $\begin{array}{l}57 \cdot 3 \\
13 \cdot 3\end{array}$ \\
\hline $\begin{array}{l}\beta \text { Geminoru } \\
\epsilon \text { Argus }\end{array}$ & im & & 1.7 & 8 & $\begin{array}{l}39 \\
20\end{array}$ & $\begin{array}{l}33 \cdot 9 \\
35 \cdot 1\end{array}$ & $\begin{array}{l}\text { S. } 20 \\
\text { S. } 59\end{array}$ & $\begin{array}{l}15 \\
12\end{array}$ & $\begin{array}{l}13 \cdot 3 \\
24 \cdot 6\end{array}$ \\
\hline $\begin{array}{l}\epsilon \text { Argûs } \\
\delta \text { Argûs }\end{array}$ & $\ldots$ & ... & $2 \cdot 0$ & 8 & 42 & $6 \cdot 3$ & S. 54 & 21 & $\begin{array}{l}24.0 \\
49.9\end{array}$ \\
\hline$\beta$ Argûs & ... & ... & $1 \cdot 7$ & 9 & 12 & $10 \cdot 3$ & S. 69 & 19 & $47 \cdot 8$ \\
\hline$\alpha$ Hydræ & ... & ... & $2 \cdot 2$ & 9 & 22 & $58 \cdot 1$ & S. 8 & 15 & 2.9 \\
\hline$\alpha$ Leonis & $\ldots$ & ... & $1 \cdot 3$ & 10 & 3 & $22 \cdot 0$ & N. 12 & 25 & $36 \cdot 7$ \\
\hline$\alpha$ Ursæ Maj & joris & ... & $2 \cdot 0$ & 10 & 57 & $56 \cdot 1$ & N. 62 & 15 & $31 \cdot 0$ \\
\hline$\alpha^{1}$ Crucis & $\ldots$ & ... & $1 \cdot 0$ & 12 & 21 & $21 \cdot 8$ & S. 62 & 35 & 41.5 \\
\hline$\alpha^{2}$ Crucis & ... & ... & 1采 & $\Delta \alpha$ & + & 0.6 & $\Delta \delta$ & - & $3 \cdot 1$ \\
\hline$\gamma$ Crucis & ... & ... & $1 \cdot 6$ & 12 & 25 & $56 \cdot 7$ & S. 56 & 35 & $12 \cdot 3$ \\
\hline B Crucis & $\cdots$ & ... & $1 \cdot 5$ & 12 & 42 & $13 \cdot 4$ & S. 59 & 10 & $30 \cdot 1$ \\
\hline$\epsilon$ Ursæ Maj & joris & ... & $1 \cdot 8$ & 12 & 49 & $53 \cdot 8$ & N. 56 & 28 & $11 \cdot 9$ \\
\hline$\alpha$ Virginis & $\cdots$ & ... & $1 \cdot 2$ & 13 & 20 & $14 \cdot 4$ & S. 10 & 40 & $14 \cdot 8$ \\
\hline$\eta$ Ursæ Maj & joris & ... & $1 \cdot 9$ & 13 & 43 & $50 \cdot 3$ & N. 49 & 46 & $56 \cdot 0$ \\
\hline $\boldsymbol{\beta}$ Centauri & $\ldots$ & $\ldots$ & 0.8 & 13 & 57 & $11 \cdot 0$ & S. 59 & 55 & $11 \cdot 0$ \\
\hline$\alpha$ Boötis . & ... & ... & 0.3 & 14 & 11 & $22 \cdot 4$ & N. 19 & 40 & $17 \cdot 6$ \\
\hline$\alpha^{2}$ Centauri & ... & $\ldots$ & 1 & 14 & 33 & $13 \cdot 2$ & S. 60 & 26 & $43 \cdot 3$ \\
\hline$\alpha$ Scorpii & $\ldots$ & $\ldots$ & $1 \cdot 3$ & 16 & 23 & 38.5 & S. 26 & 13 & $25 \cdot 7$ \\
\hline$\alpha$ Trianguli & Austra & lis & $1 \cdot 9$ & 16 & 38 & $42 \cdot 2$ & S. 68 & 51 & 20.9 \\
\hline$\lambda$ Scorpii & ... & ... & $1 \cdot 8$ & 17 & 27 & 13.5 & S. 37 & 2 & $8 \cdot 2$ \\
\hline a Ophiuchi & $\ldots$ & ... & $2 \cdot 1$ & 17 & 30 & $34 \cdot 2$ & N. 12 & 37 & $40 \cdot 7$ \\
\hline$\in$ Sagittarii & ... & ... & $1 \cdot 9$ & 18 & 17 & $56 \cdot 0$ & S. 34 & 25 & $45 \cdot 8$ \\
\hline a Lyræ & $\ldots$ & ... & $0 \cdot 1$ & 18 & 33 & $45 \cdot 4$ & N. 38 & 41 & $45 \cdot 0$ \\
\hline$\alpha$ Aquilø & ... & ... & 0.9 & 19 & 46 & $11 \cdot 8$ & N. 8 & 37 & $10 \cdot 6$ \\
\hline$\alpha$ Pavonis & 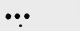 & ... & $2 \cdot 0$ & 20 & 18 & $12 \cdot 9$ & S. 57 & 2 & $12 \cdot 3$ \\
\hline$\gamma$ Cygni & $\therefore$ & $\ldots$ & $2 \cdot 3$ & 20 & 18 & $51 \cdot 3$ & N. 39 & 57 & $19 \cdot 7$ \\
\hline$\alpha$ Cygni & ... & $\ldots$ & $1 \cdot 3$ & 20 & 38 & $13 \cdot 6$ & N. 44 & 56 & 38.9 \\
\hline$\alpha$ Cephei & $\ldots$ & ... & $2 \cdot 6$ & 21 & 16 & $20 \cdot 2$ & N. 62 & 11 & $13 \cdot 7$ \\
\hline є Pegasi & ... & ... & $2 \cdot 5$ & 21 & 39 & $34 \cdot 1$ & N. 9 & 26 & $37 \cdot 5$ \\
\hline$\alpha$ Gruis & $\cdots$ & & 1.9 & 22 & 2 & $18 \cdot 7$ & S. 47 & 24 & $59 \cdot 7$ \\
\hline$\beta$ Gruis & $\ldots$ & $\ldots$ & $2 \cdot 1$ & 22 & 37 & $3 \cdot 5$ & S. 47 & 22 & $35 \cdot 0$ \\
\hline$\alpha$ Piscis Au & stralis & ... & $1 \cdot 3$ & 22 & 52 & $27 \cdot 5$ & S. 30 & 7 & $14 \cdot 2$ \\
\hline$\alpha$ Pegasi & $\cdots$ & $\cdots$ & $2 \cdot 6$ & 23 & 0 & $4 \cdot 7$ & N. 14 & 41 & $57 \cdot 8$ \\
\hline
\end{tabular}


THE CORRECTION FOR SECOND DIFFERENCES, IN FINDING THE GREENWICH TIME CORRESPONDING TO A REDUCED LUNAR DISTANCE.

Arguments :-Interval and Mean difference of Proportional Logarithms.

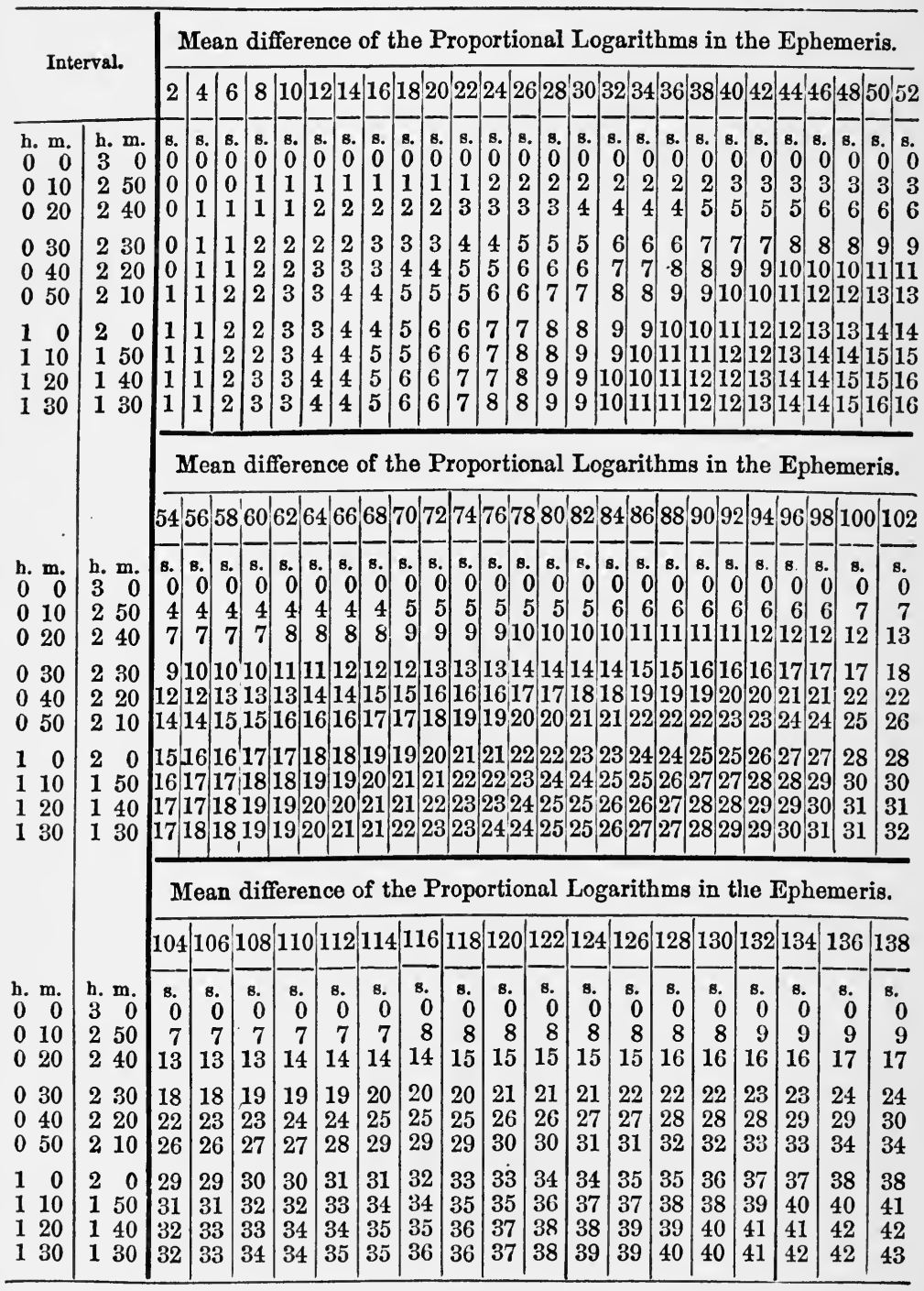

The Correction is to be added to the approximate Greenwich Time when the Proportional Logarithms in the Ephemeris are decreasing, and sultracted when they are increasing. 
TABLES USED IN DETERMINING THE LATITUDE BY OBSERVATIONS OF THE POLE STAR OUT OF THE MERIDIAN.

\section{TABLE I.}

Containing the First Correction.

Arguments :-Sidereal Time of Observation.

\begin{tabular}{|c|c|c|c|c|c|}
\hline $\begin{array}{l}\text { Sidereal } \\
\text { Time. }\end{array}$ & Correction. & $\begin{array}{c}\text { Sideresl } \\
\text { Time. }\end{array}$ & $\begin{array}{c}\text { Sidereal } \\
\text { Time. }\end{array}$ & Correction. & $\begin{array}{c}\text { Sidereal } \\
\text { Time. }\end{array}$ \\
\hline 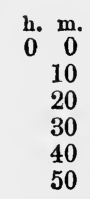 & $\begin{array}{rrr}0 & 1 & \prime \prime \\
-1 & 7 & 6 \\
1 & 8 & 11 \\
1 & 9 & 7 \\
1 & 9 & 56 \\
1 & 10 & 37 \\
1 & 11 & 10\end{array}$ & $\begin{array}{rr}\text { h. m. } & \text {. } \\
12 \\
10 \\
20 \\
30 \\
40 \\
50\end{array}$ & 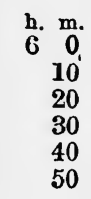 & $\begin{array}{rrr}0 & 1 & \prime \prime \\
-0 & 26 & 5 \\
0 & 23 & 8 \\
0 & 20 & 9 \\
0 & 17 & 7 \\
0 & 14 & 3 \\
0 & 10 & 57\end{array}$ & 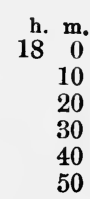 \\
\hline $\begin{array}{r}10 \\
10 \\
20 \\
30 \\
40 \\
50\end{array}$ & $\begin{array}{lll}1 & 11 & 35 \\
1 & 11 & 51 \\
1 & 11 & 59 \\
1 & 11 & 59 \\
1 & 11 & 51 \\
1 & 11 & 35\end{array}$ & $13 \begin{array}{r}0 \\
10 \\
20 \\
30 \\
40 \\
50\end{array}$ & $\begin{array}{r}70 \\
10 \\
20 \\
30 \\
40 \\
50\end{array}$ & 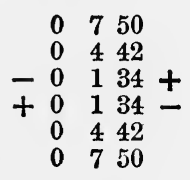 & 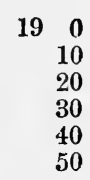 \\
\hline $\begin{array}{rr}2 & 0 \\
10 \\
20 \\
30 \\
40 \\
50\end{array}$ & $\begin{array}{rrr}1 & 11 & 10 \\
1 & 10 & 37 \\
1 & 9 & 56 \\
1 & 9 & 7 \\
1 & 8 & 11 \\
1 & 7 & 6\end{array}$ & $14 \begin{array}{r}0 \\
10 \\
20 \\
30 \\
40 \\
50\end{array}$ & $\begin{array}{r}80 \\
10 \\
20 \\
30 \\
40 \\
50\end{array}$ & $\begin{array}{llr}0 & 10 & 57 \\
0 & 14 & 3 \\
0 & 17 & 7 \\
0 & 20 & 9 \\
0 & 23 & 8 \\
0 & 26 & 5\end{array}$ & $\begin{array}{rr}20^{\circ} 0 \\
10 \\
20 \\
30 \\
40 \\
50\end{array}$ \\
\hline $\begin{array}{r}30 \\
10 \\
20 \\
30 \\
40 \\
50\end{array}$ & $\begin{array}{rrr}1 & 5 & 54 \\
1 & 4 & 34 \\
1 & 3 & 7 \\
1 & 1 & 33 \\
0 & 59 & 52 \\
0 & 58 & 4\end{array}$ & $15 \begin{array}{r}0 \\
10 \\
20 \\
30 \\
40 \\
50\end{array}$ & $\begin{array}{r}90 \\
10 \\
20 \\
30 \\
40 \\
50\end{array}$ & $\begin{array}{llr}0 & 29 & 0 \\
0 & 31 & 51 \\
0 & 34 & 38 \\
0 & 37 & 21 \\
0 & 40 & 0 \\
0 & 42 & 34\end{array}$ & $\begin{array}{r}210 \\
10 \\
20 \\
30 \\
40 \\
50\end{array}$ \\
\hline $\begin{array}{r}4 \quad 0 \\
10 \\
20 \\
30 \\
40 \\
50\end{array}$ & $\begin{array}{lrr}0 & 56 & 9 \\
0 & 54 & 8 \\
0 & 52 & 1 \\
0 & 49 & 48 \\
0 & 47 & 29 \\
0 & 45 & 4\end{array}$ & $16 \begin{array}{r}0 \\
10 \\
20 \\
30 \\
40 \\
50\end{array}$ & 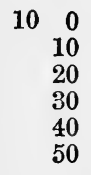 & $\begin{array}{rrr}0 & 45 & 4 \\
0 & 47 & 29 \\
0 & 49 & 48 \\
0 & 52 & 1 \\
0 & 54 & 8 \\
0 & 56 & 9\end{array}$ & $\begin{array}{r}220 \\
10 \\
20 \\
30 \\
40 \\
50\end{array}$ \\
\hline $\begin{array}{rr}5 & 0 \\
10 \\
20 \\
30 \\
40 \\
50\end{array}$ & $\begin{array}{rrr}0 & 42 & 34 \\
0 & 40 & 0 \\
0 & 37 & 21 \\
0 & 34 & 38 \\
0 & 31 & 51 \\
0 & 29 & 0\end{array}$ & 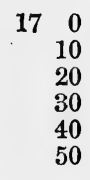 & $11 \begin{array}{r}0 \\
10 \\
20 \\
30 \\
40 \\
50\end{array}$ & $\begin{array}{rrr}0 & 58 & 4 \\
0 & 59 & 52 \\
1 & 1 & 34 \\
1 & 3 & 7 \\
1 & 4 & 34 \\
1 & 5 & 54\end{array}$ & $\begin{array}{r}230 \\
10 \\
20 \\
30 \\
40 \\
50\end{array}$ \\
\hline 60 & $-0265+$ & 180 & 120 & $+176-$ & 240 \\
\hline
\end{tabular}


TABLE II.

Containing the Second Correction (always to be added).

Arguments :-Sidereal Time and Altitude.

\begin{tabular}{|c|c|c|c|c|c|c|c|c|c|c|c|c|c|c|c|c|}
\hline \multirow{2}{*}{$\begin{array}{c}\text { Sidereal } \\
\text { Time. }\end{array}$} & \multicolumn{15}{|c|}{ Altitude. } & \multirow{2}{*}{$\begin{array}{l}\text { Sidereal } \\
\text { Time. }\end{array}$} \\
\hline & \multicolumn{2}{|c|}{$0^{\circ}$} & \multicolumn{2}{|c|}{$5^{\circ}$} & \multicolumn{2}{|c|}{$10^{\circ}$} & \multicolumn{2}{|c|}{$15^{\circ}$} & \multicolumn{2}{|c|}{$20^{\circ}$} & \multicolumn{2}{|c|}{$25^{\circ}$} & \multicolumn{2}{|c|}{$30^{\circ}$} & $35^{\circ}$ & \\
\hline h. $\mathrm{m}$. & & $"{ }_{1}$ & & " & & " & & " & & & & & & & , I & h. $\mathrm{m}$ \\
\hline $\begin{array}{ll}0 & 0\end{array}$ & & 0 & 0 & 1 & & & & & & & 0 & & 0 & & $\begin{array}{ll}0 & 4\end{array}$ & 120 \\
\hline 30 & & 0 & 0 & 0 & & 0 & & 1 & & & & & 0 & & 02 & 30 \\
\hline 10 & 0 & 0 & 0 & 0 & 0 & 0 & 0 & 0 & & 0 & 0 & & 0 & & $\begin{array}{ll}0 & 0\end{array}$ & 130 \\
\hline 30 & 0 & 0 & 0 & 0 & 0 & 0 & 0 & 0 & & & 0 & & 0 & & 00 & 30 \\
\hline 20 & 0 & 0 & 0 & 0 & & 0 & 0 & 0 & & & 0 & & 0 & & $\begin{array}{ll}0 & 1\end{array}$ & 140 \\
\hline 30 & 0 & 0 & 0 & 0 & 0 & 1 & 0 & 1 & & 1 & 0 & 2 & 0 & & 03 & 30 \\
\hline 30 & 0 & 0 & 0 & 1 & 0 & $\overline{1}$ & 0 & 2 & 0 & 3 & 0 & & 0 & & 05 & 150 \\
\hline 30 & 0 & 0 & 0 & 1 & & 2 & & 3 & & & 0 & & & & $\begin{array}{ll}0 & 9\end{array}$ & 30 \\
\hline 40 & 0 & 0 & 0 & 2 & 0 & 3 & 0 & 5 & & 6 & 0 & & 01 & & $\begin{array}{ll}0 & 12\end{array}$ & 160 \\
\hline 30 & 0 & 0 & 0 & 2 & 0 & 4 & & 6 & & 9 & 01 & & 01 & & 017 & 30 \\
\hline 50 & 0 & 0 & 0 & 3 & 0 & 5 & 0 & 8 & 01 & 11 & 01 & & 01 & & 021 & 170 \\
\hline 30 & 0 & 0 & 0 & 3 & 0 & 6 & & 9 & & 13 & 01 & & 02 & & 024 & 30 \\
\hline 60 & 0 & 0 & 0 & 3 & 0 & 7 & & 11 & & 14 & 01 & & 02 & & 028 & 180 \\
\hline 30 & & 0 & 0 & 4 & 0 & 7 & & 11 & & 16 & 02 & & 02 & & 030 & 30 \\
\hline 70 & 0 & 0 & 0 & 4 & 0 & 8 & & 12 & & 16 & 02 & 21 & 02 & & 031 & 190 \\
\hline 30 & 0 & 0 & 0 & 4 & 0 & 8 & & 12 & 01 & 16 & 02 & 1 & 02 & & 032 & 30 \\
\hline 80 & 0 & 0 & 0 & 4 & 0 & 8 & & 12 & & 16 & $0 \overline{2}$ & & 02 & & 031 & 200 \\
\hline 30 & 0 & 0 & 0 & 4 & 0 & 7 & & 11 & & 15 & 01 & & 02 & & $\begin{array}{ll}0 \quad 29\end{array}$ & 30 \\
\hline 90 & 0 & 0 & 0 & 3 & 0 & 7 & & 10 & & 14 & 01 & 18 & 02 & & 027 & 210 \\
\hline 30 & 0 & 0 & 0 & 3 & 0 & 6 & 0 & 9 & & 12 & 01 & & 01 & & 023 & 30 \\
\hline 100 & 0 & 0 & 0 & 2 & 0 & 5 & 0 & 7 & & 10 & 01 & 13 & 01 & & $\begin{array}{ll}0 & 19\end{array}$ & 220 \\
\hline 30 & 0 & 0 & 0 & 2 & 0 & 4 & 0 & 6 & 0 & 8 & 01 & 0 & 01 & & 015 & 30 \\
\hline 110 & 0 & 0 & 0 & $\overline{1}$ & 0 & 3 & 0 & 4 & 0 & 6 & 0 & 7 & 0 & & 011 & 230 \\
\hline 30 & 0 & 0 & 0 & 1 & 0 & 2 & 0 & 3 & 0 & 4 & 0 & 5 & 0 & & $\begin{array}{ll}0 & 7\end{array}$ & 30 \\
\hline 120 & 0 & 0 & 0 & 0 & 0 & 1 & 0 & 2 & 0 & 2 & 0 & & 0 & & 0 & 240 \\
\hline
\end{tabular}

TABLE III.

Containing the Third Correction (always to be added). Arguments:-Sidereal Time and Date.

\begin{tabular}{|c|c|c|c|c|c|c|c|}
\hline $\begin{array}{c}\text { Sidereal } \\
\text { Time. }\end{array}$ & Jan. 1. & Feb. 1. & March 1. & April 1. & May 1. & June 1. & July 1. \\
\hline h. & , " & , " & , " & , " & , " & " & , " \\
\hline 0 & 135 & 131 & 124 & 115 & 17 & & 3 \\
\hline 2 & 130 & 132 & 129 & 121 & 112 & 4 & 10 \\
\hline 4 & 117 & 124 & 126 & 121 & 114 & 5 & 057 \\
\hline 6 & 10 & 110 & 115 & 116 & 112 & & 054 \\
\hline 8 & 043 & 053 & 11 & 17 & 17 & 2 & 053 \\
\hline 10 & 030 & 038 & 047 & 056 & $\begin{array}{ll}1 & 0\end{array}$ & 10 & 054 \\
\hline 12 & 025 & $\begin{array}{ll}029 \\
\end{array}$ & 036 & 045 & 053 & 058 & 057 \\
\hline 14 & 030 & 028 & 031 & 039 & 048 & 056 & 10 \\
\hline 16 & $\begin{array}{ll}043 \\
0\end{array}$ & 036 & 034 & 039 & 046 & 055 & 1 \\
\hline 18 & 10 & 050 & 045 & 044 & 048 & 056 & $\overline{1}$ \\
\hline 20 & 117 & 17 & 059 & 053 & 053 & 058 & 1 \\
\hline 22 & 130 & 122 & 113 & 14 & 10 & 10 & 1 \\
\hline 24 & 135 & 131 & 124 & $11 \overline{5}$ & 17 & 2 & I 3 \\
\hline
\end{tabular}


TABLE II.

Containing the Second Correction (always to be added). Arguments :-Sidereal Time and Altitude.

\begin{tabular}{|c|c|c|c|c|c|c|c|c|c|}
\hline \multirow{2}{*}{$\begin{array}{l}\text { Sidereal } \\
\text { Time. }\end{array}$} & \multicolumn{8}{|c|}{ Altitude. } & \multirow{2}{*}{$\begin{array}{l}\text { Sidereal } \\
\text { Time. }\end{array}$} \\
\hline & $35^{\circ}$ & $40^{\circ}$ & $45^{\circ}$ & $50^{\circ}$ & $55^{\circ}$ & $60^{\circ}$ & $65^{\circ}$ & $70^{\circ}$ & \\
\hline h. $\mathrm{m}$. & , " & , " & , " & , " & , " & , " & , " & - " & h. m. \\
\hline $\begin{array}{cc}\text { n. } \\
0\end{array}$ & $\begin{array}{ll}0 & 4\end{array}$ & 05 & 06 & $\begin{array}{ll}0 & 7\end{array}$ & 08 & 010 & 013 & $\begin{array}{ll}0 & 16\end{array}$ & 120 \\
\hline 30 & & & $\begin{array}{ll}0 & 3\end{array}$ & & & $\begin{array}{ll}0 & 4\end{array}$ & 05 & 07 & 30 \\
\hline 10 & 0 & 0 & 01 & & & 01 & 01 & 01 & 130 \\
\hline 30 & & 0 & 00 & & 0 & $\begin{array}{ll}0 & 0\end{array}$ & 00 & 00 & 30 \\
\hline 20 & & & 01 & & & $\begin{array}{ll}0 & 2\end{array}$ & 02 & $\begin{array}{ll}0 & 3\end{array}$ & 140 \\
\hline 30 & 0 & 0 & 04 & 4 & 05 & 06 & 08 & 010 & 30 \\
\hline 30 & & & $0 \overline{7}$ & & 010 & 013 & 016 & $\begin{array}{ll}020 \\
0\end{array}$ & 150 \\
\hline 30 & $\begin{array}{ll}0 & 9\end{array}$ & 010 & 012 & 014 & 017 & 021 & 026 & 034 & 30 \\
\hline 40 & $\begin{array}{ll}0 & 12\end{array}$ & 015 & 018 & 021 & 025 & 031 & 038 & $\begin{array}{ll}049 \\
\end{array}$ & 160 \\
\hline 30 & 017 & 020 & 024 & 028 & 034 & 041 & 051 & & 30 \\
\hline 50 & 021 & 025 & 029 & 035 & 042 & 051 & 13 & 121 & 170 \\
\hline 30 & 024 & 029 & 035 & 041 & 050 & 10 & 114 & 136 & 30 \\
\hline 60 & 028 & 033 & 039 & 047 & 056 & 18 & 124 & 148 & 180 \\
\hline 30 & 030 & 036 & $\begin{array}{ll}043 \\
\end{array}$ & 051 & 11 & 114 & 131 & 157 & 30 \\
\hline 70 & 031 & 038 & 045 & 053 & i 4 & 117 & 136 & 23 & 190 \\
\hline 30 & 032 & 038 & 045 & 054 & 15 & 118 & 137 & 24 & 30 \\
\hline 80 & $03 \overline{1}$ & 037 & 044 & 053 & 1 3 & 116 & 135 & 22 & 200 \\
\hline 30 & 029 & 035 & 042 & 050 & 10 & 112 & 129 & 155 & 30 \\
\hline 90 & 027 & 032 & 038 & 045 & 054 & 16 & 121 & 144 & 210 \\
\hline 30 & $\begin{array}{ll}023 \\
\end{array}$ & 028 & 033 & 039 & 047 & $\begin{array}{ll}0 & 57\end{array}$ & 111 & 131 & 30 \\
\hline 100 & 019 & 023 & $0: 28$ & 033 & 039 & $\begin{array}{ll}0 & 48\end{array}$ & 059 & 116 & 220 \\
\hline 30 & 015 & 018 & 022 & 026 & 031 & 037 & 046 & 059 & 30 \\
\hline 110 & 011 & 013 & 016 & 019 & 023 & 027 & 034 & 043 & 230 \\
\hline 30 & 07 & $\begin{array}{ll}0 & 9\end{array}$ & 010 & 012 & 015 & 018 & 022 & $\begin{array}{ll}029 \\
\end{array}$ & 30 \\
\hline 120 & 04 & 05 & 06 & 07 & 08 & 010 & 013 & 016 & 240 \\
\hline
\end{tabular}

TABLE III.

Containing the Third Correction (always to be added). Arguments :-Sidereal Time and Date.

\begin{tabular}{|c|c|c|c|c|c|c|c|}
\hline $\begin{array}{l}\text { Sidereal } \\
\text { Time. }\end{array}$ & July 1. & Aug. 1. & Sept. 1. & Oct. 1. & Nov. 1. & Dec. 1. & Dec. 31. \\
\hline $\begin{array}{r}\text { h. } \\
0 \\
2 \\
4 \\
6 \\
8 \\
10 \\
12 \\
14 \\
16 \\
18 \\
20 \\
22 \\
24\end{array}$ & $\begin{array}{rr}0 & n \\
1 & 3 \\
1 & 0 \\
0 & 57 \\
0 & 54 \\
0 & 53 \\
0 & 54 \\
0 & 57 \\
1 & 0 \\
1 & 3 \\
1 & 6 \\
1 & 7 \\
1 & 6 \\
1 & 3\end{array}$ & \begin{tabular}{rr}
1 & \multicolumn{1}{c}{} \\
1 & 10 \\
1 & 2 \\
0 & 53 \\
0 & 46 \\
0 & 43 \\
0 & 45 \\
0 & 50 \\
0 & 58 \\
1 & 7 \\
1 & 14 \\
1 & 17 \\
1 & 15 \\
1 & 10
\end{tabular} & \begin{tabular}{rr}
1 & \multicolumn{1}{c}{} \\
1 & 20 \\
1 & 8 \\
0 & 54 \\
0 & 41 \\
0 & 33 \\
0 & 33 \\
0 & 40 \\
0 & 52 \\
1 & 6 \\
1 & 19 \\
1 & 27 \\
1 & 27 \\
1 & 20
\end{tabular} & $\begin{array}{rr}1 & \prime \prime \\
1 & 31 \\
1 & 17 \\
0 & 58 \\
0 & 40 \\
0 & 27 \\
0 & 23 \\
0 & 29 \\
0 & 43 \\
1 & 2 \\
1 & 20 \\
1 & 33 \\
1 & 37 \\
1 & 31\end{array}$ & $\begin{array}{lr}1 & 1 " \\
1 & 42 \\
1 & 28 \\
1 & 7 \\
0 & 44 \\
0 & 25 \\
0 & 15 \\
0 & 18 \\
0 & 32 \\
0 & 53 \\
1 & 16 \\
1 & 35 \\
1 & 45 \\
1 & 42\end{array}$ & \begin{tabular}{rr} 
& \multicolumn{1}{c}{} \\
1 & 50 \\
1 & 39 \\
1 & 17 \\
0 & 51 \\
0 & 27 \\
0 & 12 \\
0 & 10 \\
0 & 21 \\
0 & 43 \\
1 & 9 \\
1 & 33 \\
1 & 48 \\
1 & 50
\end{tabular} & $\begin{array}{lr}1 & \prime \prime \\
1 & 53 \\
1 & 47 \\
1 & 28 \\
1 & 1 \\
0 & 34 \\
0 & 14 \\
0 & 7 \\
0 & 13 \\
0 & 32 \\
0 & 59 \\
1 & 26 \\
1 & 46 \\
1 & 53\end{array}$ \\
\hline
\end{tabular}


For converting Intervals of Mean Solar Time into Equivalent Intervals of Sidereal Time.

\begin{tabular}{|c|c|c|c|c|c|c|c|c|c|}
\hline \multicolumn{2}{|r|}{ HOURS. } & \multicolumn{4}{|c|}{ MINUTES. } & \multicolumn{4}{|c|}{ SECONDS. } \\
\hline 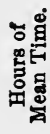 & $\begin{array}{c}\begin{array}{c}\text { Equivalents } \\
\text { in }\end{array} \\
\text { Sidereal Time. }\end{array}$ & 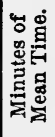 & $\begin{array}{c}\text { Equivalents } \\
\text { in } \\
\text { Sidereal } \\
\text { Time. }\end{array}$ & 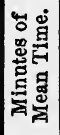 & $\begin{array}{c}\text { Equivalents } \\
\text { in } \\
\text { Sidereal } \\
\text { Time. }\end{array}$ & 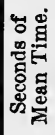 & $\begin{array}{l}\text { Equiva- } \\
\text { lents in } \\
\text { Sidereal } \\
\text { Time. }\end{array}$ & 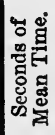 & $\begin{array}{l}\text { Equiva- } \\
\text { lents in } \\
\text { Sldereal } \\
\text { Time. }\end{array}$ \\
\hline $\begin{array}{l}1 \\
2 \\
3\end{array}$ & \begin{tabular}{lllr} 
h. & m. & \multicolumn{1}{c}{ s. } \\
1 & 0 & $9 \cdot 8565$ \\
2 & 0 & $19 \cdot 7130$ \\
3 & 0 & $29 \cdot 5694$
\end{tabular} & $\begin{array}{l}1 \\
2 \\
3\end{array}$ & $\begin{array}{cc}\text { m. } & \text { s. } \\
1 & 0.1643 \\
2 & 0.3286 \\
3 & 0.4928\end{array}$ & $\begin{array}{l}31 \\
32 \\
33\end{array}$ & $\begin{array}{lc}\text { m. } & \text { s. } \\
31 & 5 \cdot 0925 \\
32 & 5 \cdot 2568 \\
33 & 5 \cdot 4211\end{array}$ & $\begin{array}{l}1 \\
2 \\
3\end{array}$ & $\begin{array}{c}\text { s. } \\
1 \cdot 0027 \\
2 \cdot 0055 \\
3 \cdot 0082\end{array}$ & $\begin{array}{l}31 \\
32 \\
33\end{array}$ & $\begin{array}{c}\text { s. } \\
31 \cdot 0849 \\
32 \cdot 0876 \\
33 \cdot 0904\end{array}$ \\
\hline $\begin{array}{l}4 \\
5 \\
6\end{array}$ & $\begin{array}{lll}4 & 0 & 39 \cdot 4259 \\
5 & 0 & 49 \cdot 2824 \\
6 & 0 & 59 \cdot 1388\end{array}$ & $\begin{array}{l}4 \\
5 \\
6\end{array}$ & $\begin{array}{ll}4 & 0.6571 \\
5 & 0.8214 \\
6 & 0.9857\end{array}$ & $\begin{array}{l}34 \\
35 \\
36\end{array}$ & $\begin{array}{ll}34 & 5 \cdot 5853 \\
35 & 5 \cdot 7496 \\
36 & 5 \cdot 9139\end{array}$ & $\begin{array}{l}4 \\
5 \\
6\end{array}$ & $\begin{array}{l}4 \cdot 0110 \\
5 \cdot 0137 \\
6 \cdot 0164\end{array}$ & $\begin{array}{l}34 \\
35 \\
36\end{array}$ & $\begin{array}{l}34 \cdot 0931 \\
35 \cdot 0958 \\
36 \cdot 0986\end{array}$ \\
\hline $\begin{array}{l}7 \\
8 \\
9\end{array}$ & $\begin{array}{llr}7 & 1 & 8 \cdot 9953 \\
8 & 1 & 18 \cdot 8518 \\
9 & 1 & 28 \cdot 7083\end{array}$ & $\begin{array}{l}7 \\
8 \\
9\end{array}$ & $\begin{array}{ll}7 & 1 \cdot 1499 \\
8 & 1 \cdot 3142 \\
9 & 1 \cdot 4785\end{array}$ & $\begin{array}{l}37 \\
38 \\
39\end{array}$ & $\begin{array}{ll}37 & 6 \cdot 0782 \\
38 & 6 \cdot 2424 \\
39 & 6 \cdot 4067\end{array}$ & $\begin{array}{l}7 \\
8 \\
9\end{array}$ & & $\begin{array}{l}37 \\
38 \\
39\end{array}$ & $\begin{array}{l}37 \cdot 1013 \\
38 \cdot 1040 \\
39 \cdot 1068\end{array}$ \\
\hline $\begin{array}{l}10 \\
11 \\
12\end{array}$ & $\begin{array}{lll}10 & 1 & 38 \cdot 5647 \\
11 & 1 & 48 \cdot 4212 \\
12 & 1 & 58 \cdot 2777\end{array}$ & $\begin{array}{l}10 \\
11 \\
12\end{array}$ & $\begin{array}{ll}10 & 1 \cdot 6428 \\
11 & 1 \cdot 8070 \\
12 & 1 \cdot 9713\end{array}$ & $\begin{array}{l}40 \\
41 \\
42\end{array}$ & $\begin{array}{ll}40 & 6 \cdot 5710 \\
41 & 6 \cdot 7353 \\
42 & 6 \cdot 8995\end{array}$ & $\begin{array}{l}10 \\
11 \\
12\end{array}$ & & $\begin{array}{l}40 \\
41 \\
42\end{array}$ & $\begin{array}{l}40 \cdot 1095 \\
41 \cdot 1123 \\
42 \cdot 1150\end{array}$ \\
\hline $\begin{array}{l}13 \\
14 \\
15\end{array}$ & $\begin{array}{rrr}13 & 2 & 8 \cdot 1342 \\
14 & 2 & 17 \cdot 9906 \\
15 & 2 & 27 \cdot 8471\end{array}$ & $\begin{array}{l}13 \\
14 \\
15\end{array}$ & $\begin{array}{ll}13 & 2 \cdot 1356 \\
14 & 2 \cdot 2998 \\
15 & 2 \cdot 4641\end{array}$ & $\begin{array}{l}43 \\
44 \\
45\end{array}$ & $\begin{array}{ll}43 & 7 \cdot 0638 \\
44 & 7 \cdot 2281 \\
45 & 7 \cdot 3924\end{array}$ & $\begin{array}{l}13 \\
14 \\
15\end{array}$ & $\begin{array}{l}13 \cdot 0356 \\
14 \cdot 0383 \\
15 \cdot 0411\end{array}$ & $\begin{array}{l}43 \\
44 \\
45\end{array}$ & $\begin{array}{l}43 \cdot 1177 \\
44 \cdot 1205 \\
45 \cdot 1232\end{array}$ \\
\hline $\begin{array}{l}16 \\
17 \\
18\end{array}$ & $\begin{array}{lll}16 & 2 & 37 \cdot 7036 \\
17 & 2 & 47 \cdot 5600 \\
18 & 2 & 57 \cdot 4165\end{array}$ & $\begin{array}{l}16 \\
17 \\
18\end{array}$ & $\begin{array}{ll}16 & 2 \cdot 6284 \\
17 & 2 \cdot 7927 \\
18 & 2 \cdot 9569\end{array}$ & $\begin{array}{l}46 \\
47 \\
48\end{array}$ & $\begin{array}{ll}46 & 7 \cdot 5566 \\
47 & 7 \cdot 7209 \\
48 & 7 \cdot 8852\end{array}$ & $\begin{array}{l}16 \\
17 \\
18\end{array}$ & $\begin{array}{l}16 \cdot 0438 \\
17 \cdot 0465 \\
18 \cdot 0493\end{array}$ & $\begin{array}{l}46 \\
47 \\
48\end{array}$ & $\begin{array}{l}46 \cdot 1259 \\
47 \cdot 1287 \\
48 \cdot 1314\end{array}$ \\
\hline $\begin{array}{l}19 \\
20 \\
21\end{array}$ & $\begin{array}{rrr}19 & 3 & 7 \cdot 2730 \\
20 & 3 & 17 \cdot 1295 \\
21 & 3 & 26 \cdot 9859\end{array}$ & $\begin{array}{l}19 \\
20 \\
21\end{array}$ & $\begin{array}{ll}19 & 3 \cdot 1212 \\
20 & 3 \cdot 2855 \\
21 & 3 \cdot 4498\end{array}$ & $\begin{array}{l}49 \\
50 \\
51\end{array}$ & $\begin{array}{ll}49 & 8 \cdot 0495 \\
50 & 8 \cdot 2137 \\
51 & 8 \cdot 3780\end{array}$ & $\begin{array}{l}19 \\
20 \\
21\end{array}$ & $\begin{array}{l}19 \cdot 0520 \\
20 \cdot 0548 \\
21 \cdot 0575\end{array}$ & $\begin{array}{l}49 \\
50 \\
51\end{array}$ & $\begin{array}{l}49 \cdot 1342 \\
50 \cdot 1369 \\
\mathbf{5 1} \cdot 1396\end{array}$ \\
\hline $\begin{array}{l}22 \\
23 \\
24\end{array}$ & $\begin{array}{lll}22 & 3 & 36 \cdot 8424 \\
23 & 3 & 46 \cdot 6989 \\
24 & 3 & 56.5554\end{array}$ & $\begin{array}{l}22 \\
23 \\
24\end{array}$ & $\begin{array}{ll}22 & 3 \cdot 6140 \\
23 & 3 \cdot 7783 \\
24 & 3 \cdot 9426\end{array}$ & $\begin{array}{l}52 \\
53 \\
54\end{array}$ & $\begin{array}{ll}52 & 8 \cdot 5423 \\
53 & 8 \cdot 7066 \\
54 & 8 \cdot 8708\end{array}$ & $\begin{array}{l}22 \\
23 \\
24\end{array}$ & $\begin{array}{l}22 \cdot 0602 \\
23 \cdot 0630 \\
24 \cdot 0657\end{array}$ & $\begin{array}{l}52 \\
53 \\
54\end{array}$ & $\begin{array}{l}\mathbf{5 2} \cdot 1424 \\
\mathbf{5 3} \cdot 1451 \\
\mathbf{5 4} \cdot 1479\end{array}$ \\
\hline & & $\begin{array}{l}25 \\
26 \\
27 \\
28 \\
29 \\
30\end{array}$ & $\begin{array}{ll}25 & 4 \cdot 1069 \\
26 & 4 \cdot 2711 \\
27 & 4 \cdot 4354 \\
& \\
28 & 4 \cdot 5997 \\
29 & 4 \cdot 7640 \\
30 & 4 \cdot 9282\end{array}$ & $\begin{array}{l}55 \\
56 \\
57 \\
\\
58 \\
59 \\
60\end{array}$ & $\begin{array}{ll}55 & 9 \cdot 0351 \\
56 & 9 \cdot 1994 \\
57 & 9 \cdot 3637 \\
& \\
58 & 9 \cdot 5279 \\
59 & 9 \cdot 6922 \\
60 & 9 \cdot 8565\end{array}$ & $\begin{array}{l}25 \\
26 \\
27\end{array}$ & $\begin{array}{l}25 \cdot 0685 \\
26 \cdot 0712 \\
27 \cdot 0739 \\
\\
28 \cdot 0767 \\
29 \cdot 0794 \\
30 \cdot 0821\end{array}$ & $\begin{array}{l}\mathbf{5 5} \\
56 \\
57 \\
\\
58 \\
59 \\
60\end{array}$ & $\begin{array}{l}55 \cdot 1506 \\
56 \cdot 1533 \\
57 \cdot 1561\end{array}$ \\
\hline
\end{tabular}




\section{SUMMARY OF USEFUL FORMULA.}

\section{Plane Trigonometry.}

1. $\operatorname{Sin} A=\frac{1}{\operatorname{cosec} A}, \cos A=\frac{1}{\sec A}, \tan A=\frac{1}{\cot A}$

$\operatorname{Cosec} A=\frac{1}{\sin A}, \sec A=\frac{1}{\cos A}, \cot A=\frac{1}{\tan A}$

2. $\operatorname{Tan} A=\frac{\sin A}{\cos A}, \cot A=\frac{\cos A}{\sin A}$

3. $\operatorname{Sir}^{2} A+\cos ^{2} A=1$ whence, $\sin ^{2} A=1-\cos ^{2} A$, and $\cos ^{2} A=1-\sin ^{2} A$

4. $\operatorname{Sec}^{2} A=1+\tan ^{2} A$, and therefore $\tan ^{2} A=\sec ^{2} A-1$

$\operatorname{Cosec}^{2} A=1+\cot ^{2} A$, and therefore $\cot ^{2} A=\operatorname{cosec}^{2} A-1$

5. $\operatorname{Sin} A=\cos \left(90^{\circ}-A\right)=\sin \left(180^{\circ}-A\right)$

$\operatorname{Cos} A=\sin \left(90^{\circ}-A\right)=-\cos \left(180^{\circ}-A\right)$

6. $\sin (A+B)=\sin A \cdot \cos B+\cos A \cdot \sin B$

$\operatorname{Sin}(A-B)=\sin A \cdot \cos B-\cos A \cdot \sin B$

$\operatorname{Cos}(A+B)=\cos A \cdot \cos B-\sin A \cdot \sin B$

$\operatorname{Cos}(A-B)=\cos A \cdot \cos B+\sin A \cdot \sin B$

7. $\operatorname{Tan}(A+B)=\frac{\tan A+\tan B}{1-\tan A \cdot \tan B}$

$\operatorname{Tan}(A-B)=\frac{\tan A-\tan B}{1+\tan A \cdot \tan B}$

$\operatorname{Cot}(A+B)=\frac{\cot A \cdot \cot B-1}{\cot A+\cot B}$

$\operatorname{Cot}(A-B)=\frac{\cot A \cdot \cot B+1}{\cot B-\cot A}$

8. $\operatorname{Sin} A+\sin B=2 \sin \frac{1}{2}(A+B) \cdot \cos \frac{1}{2}(A-B)$

$\operatorname{Sin} A-\sin B=2 \cos \frac{1}{2}(A+B) \cdot \sin \frac{1}{2}(A-B)$

$\left.\operatorname{Cos} A+\cos B=2 \cos \frac{1}{2}(A+B) \cdot \cos \frac{1}{2}(A-B)\right\}$

$\operatorname{Cos} A-\cos B=2 \sin \frac{1}{2}(A+B) \cdot \sin \frac{1}{2}(B-A)$

9. $\operatorname{Sin} 2 \mathrm{~A}=2 \sin \mathrm{A} \cdot \cos \mathrm{A}$

10. $\operatorname{Cos} 2 A=\cos ^{2} A-\sin ^{2} A$

$$
\begin{aligned}
& =1-2 \sin ^{2} \mathrm{~A} \\
& =2 \cos ^{2} \mathrm{~A}-1
\end{aligned}
$$

$\operatorname{Cos} A=2 \cos ^{2} \frac{1}{2} A-1$

$$
=1-2 \sin ^{2} \frac{1}{2} A
$$

$\operatorname{Cos}^{2} 1 \mathrm{~A}=\frac{1}{2}(1+\cos \mathrm{A})$

$\operatorname{Sin}^{2} \frac{1}{2} A=\frac{1}{2}(1-\cos A)$

Note.-These formulæ are equally true of the angles of spherical triangles.

Relations of sides and angles of a plane triangle whose angles are A, B, C, and opposite sides $a, b, c$.

11. $\mathrm{A}+\mathrm{B}+\mathrm{C}=180^{\circ}$.

12. $\frac{\operatorname{Sin} A}{a}=\frac{\sin B}{b}=\frac{\sin O}{c}$ 
13. $\operatorname{Cos} \mathrm{A}=\frac{b^{2}+c^{2}-a^{2}}{2 b c}$

14. $\operatorname{Cos} \frac{1}{2} \mathrm{~A}=\sqrt{\frac{s \cdot(s-a)}{b c}}$

$\operatorname{Sin} \frac{1}{2} \mathrm{~A}=\sqrt{\frac{(s-b) \cdot(s-c)}{b c}}$ where $s=\frac{1}{2}(a+b+c)$

$\operatorname{Tan} \frac{1}{2} \mathrm{~A}=\sqrt{\frac{(s-b) \cdot(s-c)}{s \cdot(s-a)}}$

15. $\operatorname{Cot} \frac{1}{2} \mathrm{~A}=\frac{b+c}{b-c} \cdot \tan \frac{1}{2}(\mathrm{~B}-\mathrm{C})$

\section{Spherical Trigonometry.}

Relations of sides and angles of an oblique-angled spherical triangle.

1. Cos $\mathrm{A}=\frac{\cos a-\cos b \cdot \cos c}{\sin b \cdot \sin c}$

$\operatorname{Cos} a=\cos b \cdot \cos c+\sin b \cdot \sin c \cdot \cos A$

2. $\frac{\operatorname{Sin} A}{\sin a}=\frac{\sin \mathrm{B}}{\sin b}=\frac{\sin \mathrm{C}}{\sin c}$

3. $\operatorname{Sin} \frac{1}{2} A=\sqrt{\frac{\sin (8-b) \cdot \sin (s-c)}{\sin b \cdot \sin c}}$ $\operatorname{Cos} \frac{1}{2} \mathrm{~A}=\sqrt{\frac{\frac{\sin 8 \cdot \sin (s-a)}{\sin b \cdot \sin c}}{\sin (s-b) \cdot \sin (s-c)}}$
$\operatorname{Tan} \frac{1}{2} \mathrm{~A}=\sqrt{\frac{\sin s \cdot \sin (s-a)}{a}}$$\quad$ where $s=\frac{1}{2}(a+b+c)$

4. $\operatorname{Tan} \frac{1}{2}(A+B)=\frac{\cos \frac{1}{2}(a-b)}{\cos \frac{1}{2}(a+b)} \cdot \cot \frac{1}{2} \mathrm{C}$ Tan $\left.\frac{1}{2}(A-B)=\frac{\sin \frac{1}{2}(a-b)}{\sin \frac{1}{2}(a+b)} \cdot \cot \frac{1}{2} C\right\}$

5. $\operatorname{Tan} \frac{1}{2}(a+b)=\frac{\cos \frac{1}{2}(A-B)}{\cos \frac{1}{2}(A+B)} \cdot \tan \frac{1}{2} c$ $\left.\operatorname{Tan} \frac{1}{2}(a-b)=\frac{\sin \frac{1}{2}(\mathrm{~A}-\mathrm{B})}{\sin \frac{1}{2}(\mathrm{~A}+\mathrm{B})} \cdot \tan \frac{1}{2} c\right\}$

6. $\left.\operatorname{Sin} \frac{1}{2} c=\frac{\sin \frac{1}{2}(a+b)}{\cos \frac{1}{2}(A+B)} \cdot \sin \frac{1}{2} \mathrm{C}\right)$ $\left.\cos \frac{1}{2} c=\frac{\cos \frac{1}{2}(a+b)}{\cos \frac{1}{2}(\mathrm{~A}+\mathrm{B})} \cdot \sin \frac{1}{2} \mathrm{C}\right\}$ 


\section{WEIGHTS AND MEASURES.}

Angular.

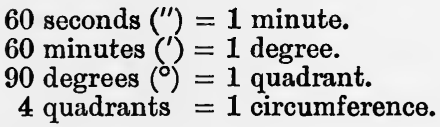

Apothecaries' (dry).

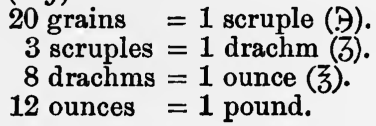

Apothecaries' (wet).

60 minims or drops $=1 \mathrm{drachm}$.

8 drachms $=1$ ounce (oz.).

20 ounces

8 pints

$=1$ pint.

4 drachms

$=1$ gallon.

2 ounces

$=1$ tablespoonful.

3 ounces

$=1$ wineglassful.

$=1$ teacupful.

Avoirdupois.

16 drachms (dr.) = 1 ounce (oz.).

16 ounces $=1$ pound (lb.).

28 pounds $\quad=1$ quarter (qr.).

4 quarters $\quad=1$ hundredweight (cwt.).

20 hundredweights $=1$ ton.

Troy.

$$
\begin{aligned}
24 \text { grains (gr.) } & =1 \text { pennyweight (dwt.). } \\
20 \text { pennyweights } & =1 \text { ounce (oz.). } \\
12 \text { ounces } & =1 \text { pound. } \\
7000 \text { grains Troy } & =1 \text { lb. Avoirdupois. }
\end{aligned}
$$

Lineal.

$$
\begin{aligned}
& 12 \text { inches (in.) =1 foot (ft.). } \\
& 3 \text { feet }=1 \text { yard (yd.). } \\
& 5 \frac{1}{2} \text { yards } \quad=1 \text { rod, pole, or perch (po.). } \\
& 40 \text { poles } \quad=1 \text { furlong (fur.). } \\
& 8 \text { furlongs }=1 \text { mile (m.). }
\end{aligned}
$$

Square.

144 square inches (sq. in.) $=1$ square foot (sq. ft.).

9 square feet

301 square yards

40 poles

4 roods

640 acres
$=1$ square yard (sq. yd.).

$=1$ square rod, pole or perch (sq. po.).

$=1 \operatorname{rood}(\mathrm{rd}$.).

$=1$ acre (ac.).

$=1$ square mile (sq. m.). 
Cubic or solid.

1728 cubic inches (cub. in.) = 1 cubic foot (cub. ft.).

27 cubic feet $\quad=1$ cubic yard (cub. yd.).

Capacity or dry.

$$
\begin{aligned}
& 4 \text { gills (gi.) }=1 \text { pint (pt.). } \\
& 2 \text { pints }=1 \text { quart (qt.). } \\
& 4 \text { quarts }=1 \text { gallon (gal.). } \\
& 2 \text { gallons }=1 \text { peck (pk.). } \\
& 4 \text { pecks }=1 \text { bushel (bush.). } \\
& 8 \text { bushels }=1 \text { quarter (qr.). } \\
& 36 \text { bushels }=1 \text { chaldron (chal.). }
\end{aligned}
$$

Wine or Ale.

$$
\begin{array}{ll}
4 \text { noggins } & =1 \text { pint. } \\
2 \text { pints } & =1 \text { quart. } \\
4 \text { quarts } & =1 \text { gallon. }
\end{array}
$$

9 gallons $=1$ firkin (fir.).

18 gallons $=1$ kilderkin (kil.) ale.

36 gallons $\quad=1$ runlet (run.) spir.

54 gallons $=1$ hogshead (hhd.) ale.

2 barrels $=1$ puncheon (pun.) ale.

3 barrels $=1$ butt (ale).

42 gallons $=1$ Tierce (wine).

\begin{tabular}{|c|c|c|c|c|}
\hline Dek: & leans & & $\operatorname{Ime}$ & \\
\hline Hekto & ", & 100 & , & \\
\hline Kilo & $"$ & 1000 & ", & \\
\hline Myria & , & 10,000 & ," & \\
\hline
\end{tabular}

63 gallons $=1$ hogshead (wine).

84 gallons $=1$ puncheon (wine).

126 gallons $=1$ pipe.

Pipes of wine vary in quantity.

$$
252 \text { gallons }=1 \text { tun. }
$$

Metric system derives its name from the metre which is the unit of length in the system, and is equal to a ten-millionth part of the distance from the equator to the pole, or $39 \cdot 3708$ inches.

To indicate multiples of the unit Greek prefixes are used thus-

To indicate sub-multiples Latin prefixes are used thus-

$$
\begin{aligned}
& \text { Deci means } \frac{1}{10} \text { of unit } \\
& \text { Centi ", 100 , } \\
& \text { Milli " } \frac{1}{1000},
\end{aligned}
$$

Unit of weight is gramme $\{=1 \mathrm{cu}$. centimetre of water at $4^{\circ} \mathrm{C}$. $\quad\{=15.43$ grains

Unit of capacity is litre $=1 \mathrm{cu}$. decimetre

$$
=1.76 \text { pints }
$$

1 litre of water weighs 1 kilogram $=2 \cdot 2 \mathrm{lbs}$.

$\begin{array}{ll}10 \text { millimetres make } & 1 \text { centimetre } \\ 10 \text { centimetres ,, } & 1 \text { decimetre } \\ 10 \text { decimetres ", } & 1 \text { metre } \\ 10 \text { metres } & \text { 1 dekametre } \\ 10 \text { dekametres ," } & 1 \text { hektometre } \\ 10 \text { hektometres ," } & 1 \text { kilometre } \\ 10 \text { kilometres ," } & 1 \text { myriametre. }\end{array}$


Specific gravity of solids at zero as compared with distilled water at $4^{\circ} \mathrm{C}$.

\begin{tabular}{|c|c|c|c|c|c|}
\hline Platinum & & . . & & & \\
\hline Gold . & . & . . & . & . & \\
\hline Silver & . & & . & . & \\
\hline Steel . & & & & • & \\
\hline Cast iron & & & & . & \\
\hline Marble. & & . & . & . & \\
\hline Common & salt & & & . & \\
\hline Sugar . & 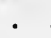 & . & • & . & \\
\hline Ice. & . & . & . & . & \\
\hline Beech . & . & . & . & . & \\
\hline Oak & & & & . & \\
\hline Elm & . & . & . & . & \\
\hline Pine & . & & . & . & \\
\hline Cork & & & & & \\
\hline Snow & & & & & \\
\hline
\end{tabular}

Specific gravity of liguids under same conditions-

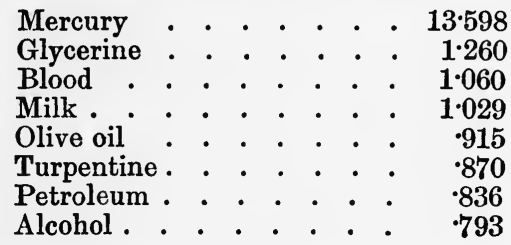

Vapour density under same conditions-

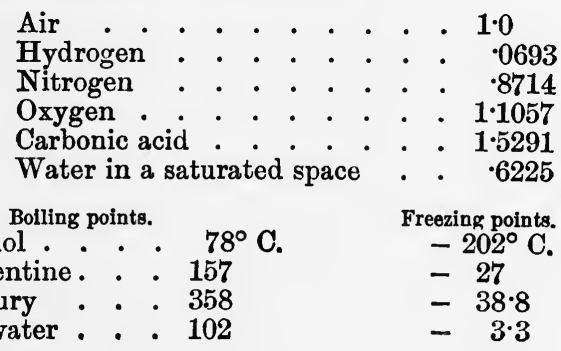

Alcohol . . . $78^{\circ} \mathrm{C}$.

Turpentine. . 157

Mercury . . 358

Salt water . . 102
Freezing points.

$-202^{\circ} \mathrm{C}$.

$-38 \cdot 8$

$-\quad 3 \cdot 3$ 


\section{EXAMINATION PAPERS.}

\section{PAPER I.}

1. Multiply 142.07 by 0.00347 , by logs.

2. Divide 0.0004629 by 0.00000542, by logs.

3.

\begin{tabular}{|c|c|c|c|c|c|c|c|}
\hline Hour. & Courses. & Knts. & 10 ths. & Winds. & $\begin{array}{l}\text { Lee- } \\
\text { way. }\end{array}$ & $\begin{array}{c}\text { Devia- } \\
\text { tion. }\end{array}$ & Remarks. \\
\hline $\begin{array}{l}1 \\
2 \\
3 \\
4\end{array}$ & s. & $\begin{array}{l}7 \\
7 \\
6 \\
6\end{array}$ & $\begin{array}{l}2 \\
2 \\
9 \\
7\end{array}$ & W.s.W. & $\begin{array}{c}\text { Pts. } \\
\frac{8}{4}\end{array}$ & $3^{\circ} \mathrm{W}$. & \multirow{6}{*}{$\begin{array}{l}\text { point in lat. } \\
50^{\circ} 44^{\prime} \mathrm{N} ., \text { long. } \\
0^{\circ} 13^{\prime} \mathrm{E} \text {.; bear } \\
\text { ing by compass } \\
\text { N.E. } \frac{3}{4} \mathrm{E} . ; \text { ship's } \\
\text { head, W. by } \mathrm{S} . \\
\text { S.; deviation as } \\
\text { per log, dis- } \\
\text { tant } 12 \text { miles. } \\
\text { Variation, } 18^{\circ} \text { W. }\end{array}$} \\
\hline $\begin{array}{l}5 \\
6 \\
7 \\
8\end{array}$ & W. by S. $\frac{1}{2} \mathrm{~S}$. & $\begin{array}{l}6 \\
7 \\
8 \\
6\end{array}$ & $\begin{array}{l}8 \\
3 \\
4 \\
5\end{array}$ & s. & $\frac{1}{2}$ & $8^{\circ} \mathrm{W}$. & \\
\hline $\begin{array}{r}9 \\
10 \\
11 \\
12\end{array}$ & S.W. by W. $\frac{1}{2}$ W. & $\begin{array}{l}8 \\
7 \\
7 \\
7\end{array}$ & $\begin{array}{c}\overline{2} \\
7 \\
1\end{array}$ & N.W. & 1 & $7^{\circ} \mathrm{W}$ & \\
\hline $\begin{array}{l}\mathbf{1} \\
\mathbf{2} \\
\mathbf{3}\end{array}$ & N.E. $\frac{1}{2}$ N. & $\begin{array}{l}6 \\
6 \\
7\end{array}$ & $\begin{array}{l}2 \\
5 \\
3\end{array}$ & N.N.W. & $1 \frac{3}{4}$ & - & \\
\hline $\begin{array}{l}4 \\
5 \\
6 \\
7 \\
8\end{array}$ & W. by N. $\frac{1}{2} \mathrm{~N}$. & $\begin{array}{l}7 \\
7 \\
6 \\
6 \\
6\end{array}$ & $\begin{array}{l}8 \\
6 \\
9 \\
4 \\
3\end{array}$ & N. & 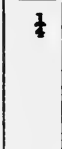 & $7^{\circ} \mathrm{W}$ & \\
\hline $\begin{array}{r}9 \\
10 \\
11 \\
12\end{array}$ & N.E. $\frac{1}{2}$ E. & $\begin{array}{l}7 \\
6 \\
6 \\
6\end{array}$ & $\begin{array}{l}\mathbf{4} \\
5 \\
\mathbf{3} \\
\mathbf{8}\end{array}$ & N. $\frac{1}{2} \mathrm{~W}$. & $1 \frac{1}{4}$ & $2^{\circ} \mathrm{E}$ & \\
\hline
\end{tabular}

By observation the lat. and long. of the ship was $49^{\circ} 30^{\prime} \mathrm{N} ., 0^{\circ} 45^{\prime} \mathrm{W}$. Find set and drift of the current.

4. August 3rd, in long. $68^{\circ} 45^{\prime}$ E., the observed mer. alt. of the Sun's L.L. bearing S. was $58^{\circ} 14^{\prime} 40^{\prime \prime}$; ind. err. $-3^{\prime} 25^{\prime \prime}$, height of eye, $27 \mathrm{ft}$. Required the latitude.

5. In lat. $51^{\circ} 30^{\prime} \mathrm{S}$., long. $37^{\circ} \mathrm{E}$., the departure made good eastward was 306.5 miles. Required the long. in by parallel sailing.

6. Required the compass course and distance by Mercator's sailingFrom A, lat. $30^{\circ} 27^{\prime} \mathrm{N}$. To $\mathrm{B}$, , $1045 \mathrm{~S}$. Variation, 13 15 W. Deviation, 2430 W.

7. January 19th, find the M.T.G. times of high water at Rotterdam. 
8. August 5th, at ship, in lat. $38^{\circ} 24^{\prime} \mathrm{S}$., long. $130^{\circ} 45^{\prime} \mathrm{E}$., when the time shown by chron. correct for G.M.T. was $10^{\mathrm{b}} 13^{\mathrm{m}}$; the Sun's bearing by compass at rising was N. $64^{\circ} 30^{\prime} \mathrm{E}$. Required the true amplitude, and error of the compass; and supposing the variation to be $6^{\circ} 15^{\prime} \mathrm{W}$., required the deviation of the compass for the position of the ship's head.

9. August 7th, about $9^{\mathrm{h}} 15^{\mathrm{m}}$ A.M. at ship, in lat. at noon $39^{\circ} 31^{\prime} 40^{\prime \prime} \mathrm{N}$.; long. by account $31^{\circ} \mathrm{W}$.; the obs. alt. of Sun's L.L. was $53^{\circ} 53^{\prime} 10^{\prime \prime}$; ind. err. $+3^{\prime}$, height of eye, $29 \mathrm{ft}$. ; time by chron. $12^{\mathrm{b}} 0^{\mathrm{m}} 9^{\mathrm{a}}$ which was slow $10^{\mathrm{s}}$ for G.M. noon, on January 9 th, and on April 29 th was correct ; run since obs. W. 25 miles. Required the long. at sight, also brought up to noon. The sun's compass bearing was S. $30^{\circ}$ E., var. $28^{\circ} 15^{\prime}$ W., find the true azimuth, comp. error, and deviation.

10. September 2 nd, about $3^{\text {h }} 30^{\text {m }}$ P.M. at ship, in lat. $51^{\circ} 25^{\prime}$ S., long. $174^{\circ} 25^{\prime} \mathrm{E}$. ; when the time shown by chron. was $3^{\mathrm{h}} 54^{\mathrm{m}} 42^{2}$, the Sun's bearing by compass N. $81^{\circ} 30^{\prime}$ W., the error of the chron. on G.M.T. was $15^{m} 12^{\circ}$ slow. Required the true azimuth and error of the compass by the Tables; and supposing the variation to be $30^{\circ} 15^{\prime} \mathrm{E}$., required the deviation for the position of the ship's head.

11. August 25 th, about $3^{\text {h }} 5^{\text {m }}$ A.M. at ship, lat. by account $26^{\circ} 16^{\prime} \mathrm{S}$.,

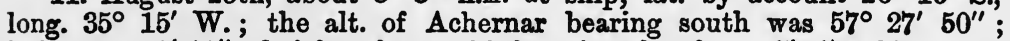
ind. err. $+2^{\prime} 11^{\prime \prime}$; height of eye, $26 \mathrm{ft}$; t time by chron. $5^{\mathrm{h}} 17^{\mathrm{m}} 32^{\prime}$, which had been found to be $21^{\mathrm{m}} \mathrm{7}^{\circ}$ fast of G.M.T. Required the lat. by reduction to the meridian.

12. September 23rd, A.M. at ship. If at sea and uncertain of my position when the chron. showed $23^{d} 9^{b} 51^{\mathbf{m}} 1^{\prime}$ G.M.T.; the alt. of the Sun's L.L. $32^{\circ} 50^{\prime} 30^{\prime \prime}$; again P.M. on the same day, when the chron. showed $23^{\mathrm{d}} 13^{\mathrm{b}} 51^{\mathrm{m}} 9^{\circ}$ G.M.T.; the alt. of the Sun's L.L. $32^{\circ} 54^{\prime} 10^{\prime \prime}$; ind. err. $-1^{\prime} 20^{\prime \prime}$; height of eye, $17 \mathrm{ft}$; the ship becalmed heading east in the interval between the observations. Required the line of position when the first alt. was taken, the Sun's true azimuth when the second alt. was taken, and the position of the ship when the second alt. was observed by "Sumner's method " by projection on the chart, assuming the lats. $51^{\circ} 15^{\prime}$ and $51^{\circ} 45^{\prime} \mathrm{S}$.

13. August 14th, in long. $159^{\circ} 15^{\prime} \mathrm{W}$., find the mean time of transit of a Arietis across the meridian.

14. On August 14th at $4^{\mathrm{k}} \mathbf{1 5}^{\mathrm{m}}$ A.M. M.T.S., find what stars not less bright than the second magnitude are within two hours east of the meridian in lat. $32^{\circ} 14^{\prime} \mathrm{N}$., long. $159^{\circ} 15^{\prime} \mathrm{W}$, above the horizon and pole. Give their meridian distances, and state bearing $N$. or S.; also find the approx. mer. alt. for setting the sextant of a Persei ; ind. cor. $-4^{\prime} 29^{\prime \prime}$; eye, $40 \mathrm{ft}$.

15. August 31st, about $6^{\text {b }}$ P.M. at ship, in lat. $24^{\circ} 19^{\prime}$ S., long. by account $180^{\circ}$ E., when a chron. showed $6^{\mathrm{b}} 4^{\mathrm{m}} 3^{\circ}$, which was slow on June $16 \mathrm{th}$, $1^{\mathrm{m}} 53^{\circ} \cdot 5$; and was fast $1^{\mathrm{m}} 29^{\circ} \cdot 5$ on Aug. 5th, for G.M.T.; the obs. alt. of Vega was $21^{\circ} 29^{\prime} 10^{\prime \prime}$; ind. cor. $-2^{\prime} 15^{\prime \prime}$; eye, $28 \mathrm{ft}$. Find the long.

16. August 24th, when the M.T.S. was $2^{\mathrm{h}} 15^{\mathrm{m}}$ A.M. in lat. equator, long. Greenwich, Rigel bore by compass S. $85^{\circ} 30^{\prime}$ E. Find the true azimuth, and deviation, the variation being $20^{\circ} 15^{\prime} \mathrm{W}$.

17. September 12th, when the M.T.S. was $4^{\mathrm{h}} 40^{\mathrm{m}} 15^{\mathrm{s}}$ A.M., in long. $136^{\circ} 24^{\prime} \mathrm{E}$., the obs. alt. of Polaris out of the meridian was $39^{\circ} 15^{\prime} 40^{\prime \prime}$; ind. cor. $-3^{\prime} 48^{\prime \prime}$; eje, $27 \mathrm{ft}$. Find the lat.

18. August 7th, in long. $90^{\circ} 45^{\prime} \mathrm{E}$., the obs. mer. alt. of the Moon's L.L. was $49^{\circ} 56^{\prime} 20^{\prime \prime}$ bearing south, ind. cor. $+2^{\prime} 45^{\prime \prime}$; eye, $36 \mathrm{ft}$. Find the lat.

State where tables giving the approx. time of most of the principal stars passing the meridian are to be found, the numbers of the tables, and whether given in mean or apparent time.

Can the approx. mer. pass. of a planet and its approx. alt. be found in the same way as in the case of a star?

State where the times of the mer. pass. of the principal planets may be found. Is the time given mean or apparent? 
19. August 12th, the obs. mer. alt. of the star a Arietis was $38^{\circ} 47^{\prime} 40^{\prime \prime}$ bearing north ; ind. err. $-5^{\prime} 25^{\prime \prime}$; height of eye, $32 \mathrm{ft}$. Required the lat.

20.

\begin{tabular}{|c|c|c|c|c|c|}
\hline $\begin{array}{l}\text { Ship's head by } \\
\text { standard } \\
\text { compass. }\end{array}$ & $\begin{array}{l}\text { Bearings of distant } \\
\text { object by standard } \\
\text { compass. }\end{array}$ & $\begin{array}{l}\text { Deviation } \\
\text { required. }\end{array}$ & $\begin{array}{l}\text { Ship's head by } \\
\text { standard } \\
\text { compass. }\end{array}$ & $\begin{array}{c}\text { Bearings of distant } \\
\text { object by standard } \\
\text { compass. }\end{array}$ & $\begin{array}{l}\text { Deviation } \\
\text { required. }\end{array}$ \\
\hline $\begin{array}{l}\text { N. } \\
\text { N.E. } \\
\text { E. } \\
\text { S.E. }\end{array}$ & $\begin{array}{l}\text { N. } 7^{\circ} \mathrm{W} . \\
\text { N. } 27^{\circ} \mathrm{W} . \\
\text { N. } 21^{\circ} \mathrm{W} . \\
\text { N. }\end{array}$ & & $\begin{array}{c}\text { S. } \\
\text { S.W. } \\
\text { W. } \\
\text { N.W. }\end{array}$ & $\begin{array}{l}\text { N. } 10^{\circ} \mathrm{E} . \\
\text { N. } 25^{\circ} \mathrm{E} . \\
\text { N. } 30^{\circ} \mathrm{E} . \\
\text { N. } 20^{\circ} \mathrm{E} .\end{array}$ & \\
\hline
\end{tabular}

Find correct magnetic bearing; construct a Napier curve.

With magnetic courses : E. W.S.W. S.E. by S. N.N.W.

Required compass courses.

With compass courses : N.W. N.E. by N. $\frac{1}{2}$ N. S.S.W. E.S.E.

Required magnetic courses.

With ship's head at W.S. W. by compass, the compass bearings of distant objects were W. by S. and N. Find magnetic bearings.

21. On October 11th, at $7^{\mathrm{h}} 40^{\mathrm{m}}$ A.M. M.T.S., being off Fowey by reckoning, took a cast of the lead. Required the correction to be applied to the depth obtained by the lead-line, before comparing it with the depth marked on the chart.

22. August 1st, P.M. at ship in lat. $34^{\circ} 28^{\prime}$ S., when a chron. showed $7^{\mathrm{h}} 20^{\mathrm{m}} 35^{\mathrm{s}}$, estimated error, $6^{\mathrm{m}} 15^{\mathrm{s}}$ fast of G.M.T., approx. long. $66^{\circ} \mathrm{E}$.; the following observations were taken for finding long. and error of chron., Observed alt. of a Pegasi $27^{\circ} 16^{\prime} 20^{\prime \prime}$, ind. cor. + $4^{\prime} 13^{\prime \prime}$, eye, $44 \mathrm{ft}$. ; observed distance between the star and Moon's remote limb, was $80^{\circ} 14^{\prime} 40^{\prime \prime}$, ind. cor. $-2^{\prime} 27^{\prime \prime}$.

23. September 23rd, lat. N., long. $82^{\circ} 30^{\prime}$ E. With the following observations of the Sun's L.L. find the lat. by double alts. at second obs.
A.T.S. $9^{\text {h }} 30^{\mathrm{m}} 10^{\mathrm{s}}$ A.M. ," 23020 P.M.
Obs. alt. $32^{\circ} 13^{\prime} 10^{\prime \prime}$.
Ind. cor. $-2^{\prime} 8^{\prime \prime}$. , 321310
Eye, $28 \mathrm{ft}$.

Sun's bearing at first obs. S. $46^{\circ}$ E.; course and distance during interval, N. $60^{\circ} \mathrm{E}$.; rate $5.8 \mathrm{knots}$ per hour.

24. August 30th, about $9^{\text {h }}$ A.M. M.T.S., a point in lat. $40^{\circ} 28^{\prime} \mathrm{N}$., long. $25^{\circ} 24^{\prime} \cdot 5$ W., bore $N .27^{\circ}$ E. from a ship, distant 9 miles; the obs. alt. of Sun's L.L. in an artificial horizon was $79^{\circ} 10^{\prime} 20^{\prime \prime}$; ind. cor. $-3^{\prime} 18^{\prime \prime}$. Time by chron. $10^{\mathrm{h}} 30^{\mathrm{m}}$, estimated slow $15^{\mathrm{m}} 15^{\mathrm{h}}$ of M.T.G. Find error on M.T.G.

25. Find the first course and distance on a G.C. from Wolf Rock, lat. $49^{\circ} 57^{\prime} \mathrm{N}$., long. $5^{\circ} 48^{\prime} \mathrm{W}$., to Charleston lat. $32^{\circ} 45^{\prime} \mathrm{N}$., long. $79^{\circ} 52^{\prime} \mathrm{W}$.; also position of Vertex, lat. of points $5^{\circ}, 10^{\circ}, 15^{\circ}, 20^{\circ}$ from Wolf ; and lat. at which the 61st W. mer. cuts the G.C. arc.

26. In a triangle $\mathrm{PQR}, \mathrm{Q}=90^{\circ}, \mathrm{PR}=364, \mathrm{P}=28^{\circ} 45^{\prime}$. Find $\mathrm{PQ}$.

27. In triangle $\mathrm{PQR}, \mathrm{PQ}=417, \mathrm{PR}=243, \mathrm{P}=58^{\circ} 26^{\prime}$. Find $\mathrm{R}$.

28. In spherical triangle $\mathrm{ABC}, \mathrm{A}=36^{\circ} 38^{\prime}, \mathrm{B}=101^{\circ} 42^{\prime}, \mathrm{C}=90^{\circ}$. Find $\mathrm{AB}$.

29. In spherical triangle, $\mathrm{A}=90^{\circ}, \mathrm{B}=104^{\circ} 25^{\prime}, \mathrm{AC}=107^{\circ} 39^{\prime}$. Find $\mathrm{BC}$.

30. Coefficient $\mathrm{B}=-15^{\circ} 36^{\prime}, \mathrm{C}=+9^{\circ} 24^{\prime}$. Find direction of ship's head whilst building.

Direction of ship's head whilst building S. $49^{\circ}$ W., coefficient $B=$ $+20^{\circ} 15^{\prime}$. Find $\mathrm{C}$.

31. September 20 th, $11^{\mathrm{h}} 48^{\mathrm{m}}$ P.M. M.T.S.; in lat. $49^{\circ}$ S., long. $168^{\circ} 15^{\prime} \mathrm{W}$. Name some stars which would be suitable for finding the correction of the compass. 
32. Given deviations with ship's head by compass at
$\mathrm{N}$.
N.E.
E.
S.E.
S.
S.W.
W. N.W. to be $17^{\circ} \mathrm{W} .28^{\circ} \mathrm{W} .24^{\circ} \mathrm{W} .9^{\circ} \mathrm{W} . \quad 16^{\circ} \mathrm{E}, \quad 32^{\circ} \mathrm{E} . \quad 26^{\circ} \mathrm{E} . \quad 5^{\circ} \mathrm{E}$. find coefficients $A, B, C, D$, and $E$, and construct a table of deviations for all points from $\mathrm{N}$ to $\mathrm{S}$, through $\mathrm{W}$.

33. With a ship steering N.E. by N. on the port tack, heeling $12^{\circ}$; the heeling error was $-15^{\circ}$. Required the error when steering E.S.E. on the port tack, and heeling $10^{\circ}$.

34. Construct a Mercator's chart, scale $1^{\prime \prime} \cdot 5=1^{\circ}$ long., extending from lat. $58^{\circ}$ to $61^{\circ} \mathrm{N}$., and $6^{\circ}$ to $10^{\circ} \mathrm{E}$. long. Graduate a degree of lat. and long. and place on it a magnetic compass showing points, variation $20^{\circ} \mathrm{W}$.

PaPer II.

1. Multiply 47290 by 0.0045 , by logs.

2. Divide $4765 \cdot 07$ by $32406 \cdot 5$, by logs.

3.

\begin{tabular}{|c|c|c|c|c|c|c|c|}
\hline Hrs. & Courses. & Knts. & 10ths. & Winds. & $\begin{array}{l}\text { Lee- } \\
\text { way. }\end{array}$ & $\begin{array}{l}\text { Devia- } \\
\text { tion. }\end{array}$ & Remarks. \\
\hline $\begin{array}{l}1 \\
2 \\
3 \\
4 \\
5\end{array}$ & S.E. by E. $\frac{1}{\text { E. }}$ & $\begin{array}{r}10 \\
11 \\
9 \\
11 \\
11\end{array}$ & $\begin{array}{l}7 \\
3 \\
9 \\
1 \\
-\end{array}$ & S.S.W. & $\begin{array}{r}\text { Pts. } \\
\frac{8}{8}\end{array}$ & $25^{\circ} \mathrm{W}$ & \multirow{2}{*}{$\begin{array}{l}\text { A point in lat. } \\
25^{\circ} 15^{\prime} \mathrm{S} . \text {, long. } \\
47^{\circ} 20^{\prime} \mathrm{W} \text {.; bear- } \\
\text { ing by compass } \\
\text { N.N.E. } \frac{1}{2} \mathrm{E} . \text {; } \\
\text { ship's head, S.E. } \\
\text { by E. } \frac{1}{4} \mathrm{E} . \text {; devi- } \\
\text { ation as per log, } \\
\text { distant } 15 \text { miles. } \\
\text { Variation, } 20^{\circ} \mathrm{W} \text {. }\end{array}$} \\
\hline $\begin{array}{r}6 \\
7 \\
8 \\
9 \\
10\end{array}$ & E. by S. $\frac{3}{2}$ S. & $\begin{array}{r}10 \\
9 \\
10 \\
9 \\
9\end{array}$ & $\begin{array}{l}4 \\
7 \\
5 \\
8 \\
6\end{array}$ & S. & $1 \frac{1}{4}$ & $24^{\circ} \mathrm{W}$. & \\
\hline $\begin{array}{r}11 \\
12 \\
1 \\
2\end{array}$ & S.E. by $\mathbf{~ S . ~}$ & $\begin{array}{r}9 \\
10 \\
10 \\
11\end{array}$ & $\begin{array}{l}7 \\
2 \\
4 \\
7\end{array}$ & S.W. & 1 & $18^{\circ} \mathrm{W}$. & \multirow{4}{*}{$\begin{array}{l}\text { A current set } \mathrm{N} \text {. } \\
14^{\circ} \mathrm{W} \text {. true, } 54 \\
\text { miles during the } \\
\text { day. }\end{array}$} \\
\hline $\begin{array}{l}3 \\
4 \\
5\end{array}$ & S.W. by S. & $\begin{array}{r}9 \\
10 \\
11\end{array}$ & $\begin{array}{l}6 \\
2 \\
2\end{array}$ & S.S.E. & $1 \frac{1}{2}$ & $25^{\circ} \mathrm{E}$. & \\
\hline $\begin{array}{l}6 \\
7 \\
8\end{array}$ & S. & $\begin{array}{r}9 \\
10 \\
9\end{array}$ & $\begin{array}{l}5 \\
7 \\
8\end{array}$ & E.S.E. & $1 \frac{1}{4}$ & $5^{\circ} \mathrm{E}$ & \\
\hline $\begin{array}{r}9 \\
10 \\
11 \\
12\end{array}$ & S. by E. $\frac{3}{4}$ E. & $\begin{array}{r}10 \\
11 \\
10 \\
9\end{array}$ & $\begin{array}{l}4 \\
3 \\
9 \\
4\end{array}$ & E. & 1 & $9^{\circ} \mathrm{W}$. & \\
\hline
\end{tabular}

Find the course and distance made good ; lat. and long. of the ship.

4. September 23rd, in long. $28^{\circ} 45^{\prime}$ W., the obs. mer. alt. of the Sun's L.L. bearing north, was $64^{\circ} 53^{\prime} 10^{\prime \prime}$; ind. err. $-4^{\prime} 26^{\prime \prime}$; height of eye, $37 \mathrm{ft}$. Required the latitude.

5. From lat. $40^{\circ} 30^{\prime} \mathrm{N}$., long. $39^{\circ} 43^{\prime} \mathrm{W}$., the departure made good was 89 miles to the west. Required long. in by parallel sailing. 
6. Required the compass course and distance by Mercator's sailing

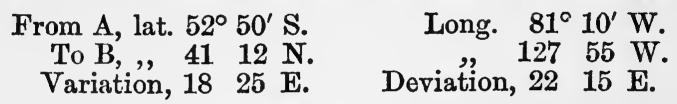

7. January 30th. Find the M.T.G. of high water at Dungeness.

8. September 29 th, about $6^{\mathrm{h}} 5^{\mathrm{m}}$ P.M. at ship, in lat. $42^{\circ} 10^{\prime} \mathrm{N}$., long. $146^{\circ} 58^{\prime}$ E., when a chron. correct for M.T.G. showed $8^{\mathrm{h}} 2^{\mathrm{m}} 33^{\mathrm{s}}$, the Sun's bearing by compass was $\mathrm{N} .84^{\circ} 30^{\prime} \mathrm{W}$. Required the true amplitude, and error of the compass; and supposing the variation to be 0 , required the deviation of the compass for the position of the ship's head.

9. August 4th, about $7^{\mathrm{h}} 15^{\mathrm{m}}$ A.M. at ship, in lat. at noon $15^{\circ} 22^{\prime} \mathrm{N}$., long. by account $37^{\circ} 30^{\prime} \mathrm{E}$.; the obs. alt. of sun's L.L. was $22^{\circ} 31^{\prime} 10^{\prime \prime}$; ind. err. $-1^{\prime} 30^{\prime \prime}$; height of eye, $25 \mathrm{ft}$. ; time shown by chron. $4^{\text {h }} 42^{\text {m }} 11^{\text {' }}$, which was $9^{\mathrm{m}} 44^{\mathrm{e}} \cdot 2$ slow for G.M. noon on April 20th, and on June $3 \mathrm{rd}$ was $10^{\mathrm{m}} 15^{\star}$ slow ; run since sights, S. $67^{\circ} \mathrm{E}$. 46 miles. Required the long. at sight, also brought up to noon ; and if the compass bearing be $\mathrm{N} .87^{\circ} 30^{\prime} \mathrm{E}$., find true azimuth and deviation, the variation being $5^{\circ} \mathrm{W}$.

10. September 1st, about $4^{\text {h }}$ P.M. at ship, in lat. $44^{\circ} 23^{\prime}$ S., long. $145^{\circ} 17^{\prime}$ E.; when a chron. correct for G.M.T. showed $6^{\mathrm{h}} 24^{\mathrm{m}} 35^{\mathrm{s}}$, the Sun's bearing by compass W. $\frac{1}{2}$ N. Required the true azimuth and error of the compass by the tables; and supposing the variation to be $10^{\circ} 15^{\prime} \mathrm{E}$., required the deviation for the position of the ship's head.

11. August 7th, A.M. at ship, lat. by account $33^{\circ} 15^{\prime} \mathrm{N}$., long. $10^{\circ} 57^{\prime} \mathrm{W}$.; the alt. of the Sun's U.L. $72^{\circ} 53^{\prime}$; ind. err. $+3^{\prime}$; height of eye, $16 \mathrm{ft}$.; time by watch $10^{\mathrm{h}} 57^{\mathrm{m}} 58^{\mathrm{s}}$, which had been found to be $44^{\mathrm{m}} 10^{\mathrm{a}}$ slow of A.T.S.; the diff. long. made westward $17 \frac{3}{4}$ miles after the error was determined. Required the lat. by reduction to the meridian, and if the run since observation was S. $11^{\circ}$ W., 4 miles, find the lat. at noon.

12. September 29 th about $1^{\mathrm{b}} 20^{\mathrm{m}}$ P.M. at ship. If in long. by account $125^{\circ} 30^{\prime}$ W., when the chron. showed $9^{\mathrm{h}} 26^{\mathrm{m}} 12^{\circ}$ G.M.T.; the alt. of the Sun's L.L. $36^{\circ} 33^{\prime} 40^{\prime \prime}$; again P.M. on the same day, when the chron. showed $12^{\mathrm{h}} 2^{\mathrm{m}} 10^{\circ}$ G.M.T.; the alt. of the Sun's L.L. $18^{\circ} 39^{\prime} 20^{\prime \prime}$; ind. err. $-2^{\prime} 5^{\prime \prime}$; height of eye, $34 \mathrm{ft}$. ; the ship having made 43 miles on a true E. $\frac{1}{4} \mathrm{~N}$. course in the interval between the observations. Required the line of /position when the first alt. was taken, the Sun's true azimuth and the position of the ship when the second alt. was observed by "Sumner's method" by projection on the chart, assuming the lats. $48^{\circ}$ and $48^{\circ} 30^{\prime} \mathrm{N}$.

13. On Sept. 28th. At what apparent ship time will Capella cross the meridian of a place in long. $73^{\circ} 48^{\prime}$ E. ? Also by inspection?

14. What stars of brightness not less than 1.5 will be within 2 hours of the meridian of a place above the horizon and pole in lat. $30^{\circ} 55^{\prime} \mathrm{S}$., long. $73^{\circ} 48^{\prime}$ E., on September 28 th at $5^{\mathrm{h}} 27^{\mathrm{m}}$ A.M. M.T.S. ? Give meridian distances, and if ind. cor. be $3^{\prime} 47^{\prime \prime}$ to add, eye $35 \mathrm{ft}$., find approx. mer. alt. of Rigel for placing on sextant.

15. September 7 th, about $7^{\text {h }}$ P.M. at ship, in lat. $35^{\circ} 20^{\prime}$ N., long. by account $165^{\circ}$ W., when a chron. showed $7^{\mathrm{h}} 54^{\mathrm{m}} 50^{\mathrm{s}}$, which was fast $1^{\mathrm{h}} 58^{\mathrm{m}} 5^{\mathrm{a}} \cdot 4$ on June 29 th, and was fast $2^{\mathrm{h}} 3^{\mathrm{m}} 13^{\mathrm{n}} \cdot 4$ on A ugust 3rd for G.M. noon, the obs. alt. of Altair was $53^{\circ} 1^{\prime} 40^{\prime \prime}$; ind. cor. $+1^{\prime} 11^{\prime \prime}$; eye, $29 \mathrm{ft}$. Find the longitude.

Are you acquainted with any maps, diagrams, or any other means for facilitating the recognition of the fixed stars and planets? If so, give a short description of the one you prefer, and how you use it.

16. August 27 th at $1^{\mathrm{h}} 15^{\mathrm{m}}$ A.M. A.T.S. in lat. $47^{\circ} 24^{\prime} \mathrm{N}$., long. $68^{\circ} 19^{\prime} \mathrm{W}$., the compass bearing of Altair was S. $81^{\circ} \mathrm{W}$. Find the true azimuth from the "tables," compass error, and deviation, supposing the variation to be $14^{\circ} 30^{\prime} \mathrm{W}$.

17. September 7th, when the G.M.T. was noon in long. $125^{\circ} 40^{\prime}$ E., the 
obs. alt. of Polaris out of the meridian in an artificial horizon was $58^{\circ} 37^{\prime} 20^{\prime \prime}$, ind. cor. $-5^{\prime} 40^{\prime \prime}$. Required the latitude.

18. August 30th, in long. $49^{\circ} 36^{\prime} \mathrm{W}$., the obs. mer. alt. of the Moon's L.L. was $58^{\circ} 57^{\prime} 50^{\prime \prime}$; zenith south of moon; ind. cor. $+6^{\prime} 24^{\prime \prime}$; eye, $29 \mathrm{ft}$. Required the latitude.

19. September 19th, the obs. mer. alt. of the star $\beta$ Argûs was $50^{\circ} 26^{\prime} 40^{\prime \prime}$ bearing south; ind. err. $-7^{\prime} 46^{\prime \prime}$; height of eye, $56 \mathrm{ft}$. Required the latitude.

20.

\begin{tabular}{|c|c|c|c|c|c|}
\hline $\begin{array}{l}\text { Ship's head by } \\
\text { standard } \\
\text { compass. }\end{array}$ & $\begin{array}{l}\text { Bearings of distant } \\
\text { object by standard } \\
\text { compass. }\end{array}$ & $\begin{array}{l}\text { Deviation } \\
\text { required. }\end{array}$ & $\begin{array}{l}\text { Ship's head by } \\
\text { standard } \\
\text { compass. }\end{array}$ & $\begin{array}{l}\text { Bearings of distant } \\
\text { object by standard } \\
\text { compass. }\end{array}$ & $\begin{array}{l}\text { Deviarion } \\
\text { required. }\end{array}$ \\
\hline $\begin{array}{c}\text { N. } \\
\text { N.E. } \\
\text { E. } \\
\text { S.E. }\end{array}$ & $\begin{array}{l}\text { S. } 43^{\circ} \mathrm{W} \text {. } \\
\text { S. } 50^{\circ} \mathrm{W} . \\
\text { S. } 65^{\circ} \mathrm{W} . \\
\text { S. } 80^{\circ} \mathrm{W} .\end{array}$ & & $\begin{array}{l}\text { S. } \\
\text { S.W. } \\
\text { W. } \\
\text { N. } .\end{array}$ & $\begin{array}{l}\text { W. } \\
\text { S. } 83^{\circ} \mathrm{W} \text {. } \\
\text { S. } 65^{\circ} \mathrm{W} . \\
\text { S. } 45^{\circ} \mathrm{W} .\end{array}$ & \\
\hline
\end{tabular}

Find correct magnetic bearing, and construct a curve.

Given magnetic courses : S.E. by E. N.N.E. N.W. $\frac{1}{2}$ W. S. $10^{\circ}$ W. Find compass courses.

Given compass courses : N.W. by W. N. by W. N.E. $\frac{1}{2}$ E. S. $50^{\circ}$ E. Find magnetic courses.

With ship's head at E. $\frac{1}{2} \mathrm{~N}$. by compass, the comp. bearings of distant objects were S.E. $\frac{3}{4}$ E. and N.E. by N. Find magnetic bearings.

21. On December 15th, at $11^{\mathrm{h}} 36^{\mathrm{m}}$ P.M. M.T.G., being off Ardrossan by reckoning, took a cast of the lead. Required the correction to be applied to the depth obtained by the lead-line, before comparing it with the depth marked on the chart.

22. August 2 nd, at $9^{\mathrm{h}} 20^{\mathrm{m}}$ P.M. M.T.S., in lat. $25^{\circ} 14^{\prime}$ N., long. by account, $100^{\circ} 37^{\prime} 30^{\prime \prime} \mathrm{W}$.; the following observations were taken for determining the error of a chron. which had run down, and set going on G.M.T. and showed $4^{\mathrm{h}}$; obs. alt. of the Moon's L.I., $39^{\circ} 8^{\prime} 30^{\prime \prime}$; ind. cor. $-4^{\prime} 12^{\prime \prime}$; height of eye, 17 feet; obs. distance between Spica and the Moon's near limb, $88^{\circ} 59^{\prime} 40^{\prime \prime}$; ind. cor. $+7^{\prime} 43^{\prime \prime}$.

23. September 29th, in long. $125^{\circ} 35^{\prime}$ W., lat. N. With following observations, find lat. at time of taking second obs. :-
A.T.S. $1^{\mathrm{h}} 13^{\mathrm{m}} 40^{\mathrm{a}}$ P.M.$$
\text { " } 34940 \text {," }
$$
Alt. Sun's L.L. $36^{\circ} 33^{\prime} 40^{\prime \prime}$, bearing S. $23^{\circ} \mathrm{W}$.

The ship's true course, N. $87^{\circ}$ E., 16.5 knots per hour during the interval ; ind. cor. $-2^{\prime} 3^{\prime \prime}$; height of eye, 34 feet.

24. September $23 \mathrm{rd}, 2^{\mathrm{h}} 49^{\mathrm{m}}$ P.M. M.T.S., at a place in lat. $23^{\circ} 28^{\prime}$ S., long. $158^{\circ} 35^{\prime} \mathrm{E}_{\text {. ; }}$; the obs. alt. of Sun's U.L., $41^{\circ} 32^{\prime} 10^{\prime \prime}$; ind. cor. $-2^{\prime} 25^{\prime \prime}$; eye, 34 feet; the chron. shows $4^{\mathrm{b}} 17^{\mathrm{m}} 7^{\mathrm{*}}$. Find its error on M.T.G.

25. Find initial and final courses, and distance, easting to be run down on parallel of $55^{\circ} \mathrm{S}$., from lat. $42^{\circ} 53^{\prime} \mathrm{S}$., long. $147^{\circ} 21^{\prime} \mathrm{E}$., to $33^{\circ} 2^{\prime} \mathrm{S}$., iong. $71^{\circ} 38^{\prime} \mathrm{W}$. Find latitudes of points where the meridians $160^{\circ} \mathrm{E}$., $170^{\circ} \mathrm{E}$., $90^{\circ} \mathrm{W}$., and $80^{\circ} \mathrm{W}$. cut the track.

26. In triangle $\mathrm{ABC}, \mathrm{A}=90^{\circ}, \mathrm{C}=68^{\circ} 40^{\prime}, \mathrm{AC}=37 \cdot 2$. Find $\mathrm{AB}$.

27. In triangle $\mathrm{OST}, \mathrm{OS}=379, \mathrm{OT}=325, \mathrm{ST}=85$. Find $\mathrm{T}$.

28. In spherical triangle $\mathrm{ABC}, \mathrm{C}=90^{\circ}, \mathrm{B}=103^{\circ} 20^{\prime}, \mathrm{BC}=75^{\circ}$. Find $\mathrm{AB}$.

29. $", \quad \mathrm{PQR}, \mathrm{P}=90^{\circ}, \mathrm{RQ}=98^{\circ} 56^{\prime}, \mathrm{R}=72^{\circ} 45^{\prime}$. Find $\mathrm{Q}$.

30. If coefficient $\dddot{B}^{\prime}=+16^{\circ} 54^{\prime}$, coefficient $\mathrm{C}=-18^{\circ} 36^{\prime}$, find direction of ship's head whilst building.

Coefficient $\mathbf{C}=-20^{\circ} 30^{\prime}$; direction ship's head building, S. $39^{\circ} \mathrm{W}$. Find B. 
31. In lat. $45^{\circ} \mathrm{N}$., long. $58^{\circ} \mathrm{W}$., find what stars are suitable for finding compass error by azimuth on September 7th at $2^{\mathrm{h}} 30^{\mathrm{m}}$ A.M.

32. The deviations with ship's head by compass at N., N.E., E., S.E., S., S.W., W., and N.W. being $5^{\circ}$ E., $5^{\circ}$ E., $2^{\circ}$ W., $13^{\circ} \mathrm{W}^{\circ}$., $15^{\circ}$ W., $3^{\circ}$ W., $13^{\circ}$ E., $8^{\circ}$ E., find the coefficients A, B, C, D, E, and construct a table of deviations for every alternate point of the compass, starting from North.

33. With the wind at S.E., the ship heads N.E. by E. $\frac{1}{2}$ E., having a heel of $14^{\circ}$, and heeling error $-21^{\circ}$. Find what the error will be when heeling $15^{\circ}$ with her head S.S.W., wind in same direction.

Paper III.

1. Multiply 0.0765 by 0.000006201 , by logs.

2. Divide 0.00652 by 0.9876 , by logs.

3.

\begin{tabular}{|c|c|c|c|c|c|c|c|}
\hline Hour & Courses. & Knts. & 10th. & Winds. & $\begin{array}{l}\text { Lee- } \\
\text { way. }\end{array}$ & $\begin{array}{l}\text { Devia- } \\
\text { tion. }\end{array}$ & Remarks. \\
\hline $\begin{array}{l}1 \\
2 \\
3 \\
4\end{array}$ & w. & $\begin{array}{l}7 \\
7 \\
7 \\
7\end{array}$ & & N.N.W. & Pts. & $10^{\circ} \mathrm{W}$ & \multirow{3}{*}{$\begin{array}{l}\text { Departure taken } \\
\text { from \& point in } \\
\text { lat. } 60^{\circ} 45^{\prime} \mathrm{N} \text {., } \\
\text { long. } 4^{\circ} 43^{\prime} \mathrm{E} \text {.; } \\
\text { bearing by com- } \\
\text { pass, , W.; ship's } \\
\text { head, W.; devi- } \\
\text { ation as per log, } \\
\text { distant } 15 \text { miles. } \\
\text { Variation, } 17^{\circ} \mathrm{W} \text {. }\end{array}$} \\
\hline $\begin{array}{l}5 \\
6 \\
7 \\
8\end{array}$ & N.W. & $\begin{array}{l}7 \\
7 \\
7 \\
7\end{array}$ & $\begin{array}{l}5 \\
5 \\
5 \\
5\end{array}$ & N.N.E. & $\frac{1}{4}$ & $20^{\circ} \mathrm{W}$ & \\
\hline $\begin{array}{r}9 \\
10 \\
11 \\
12\end{array}$ & W. by N. $\frac{3}{4} \mathrm{~N}$. & $\begin{array}{l}9 \\
9 \\
9 \\
9\end{array}$ & & S.W. by S. & $\frac{3}{4}$ & $13^{\circ} \mathrm{W}$ & \\
\hline $\begin{array}{l}1 \\
2 \\
3 \\
4\end{array}$ & W.S.W. & $\begin{array}{l}10 \\
10 \\
10 \\
10\end{array}$ & & S. & $\frac{1}{2}$ & $7^{\circ} \mathrm{W}$. & \multirow{3}{*}{$\begin{array}{l}\text { A current set } \\
\text { N.N.E. correct } \\
\text { magnetic all day } \\
\text { at mile per } \\
\text { hour. }\end{array}$} \\
\hline $\begin{array}{l}5 \\
6 \\
7 \\
8\end{array}$ & S.W. & $\begin{array}{l}10 \\
10 \\
10 \\
10\end{array}$ & $\begin{array}{l}5 \\
5 \\
5 \\
5\end{array}$ & W.N.W. & $\frac{1}{4}$ & - & \\
\hline $\begin{array}{r}9 \\
10 \\
11 \\
12\end{array}$ & W. by $\mathrm{S}$. & $\begin{array}{l}8 \\
8 \\
8 \\
8\end{array}$ & & S. by W. & $1 \frac{1}{4}$ & $8^{\circ} \mathrm{W}$. & \\
\hline
\end{tabular}

Find the course' and distance made good ; lat. and long. of the ship.

4. August 1st, in long. $124^{\circ} 27^{\prime}$ E., the obs. mer. alt. of the Sun's U.L. bearing north was $81^{\circ} 27^{\prime} 10^{\prime \prime}$; ind. err. $-1^{\prime} 25^{\prime \prime}$; height of eye, $33 \mathrm{ft}$. Required the latitude.

5. In lat. $54^{\circ} 37^{\prime} \mathrm{N}$., the diff. long. made good was $5^{\circ} 47^{\prime}$. Required the distance sailed by parallel sailing.

6. Required the compass course and distance by Mercator's sailing. From A, lat. $50^{\circ} 10^{\prime} \mathrm{N}$. To B, , $4750 \mathrm{~N}$. Long. $13^{\circ} 25^{\prime} \mathrm{W}$. 'Deviation, 2030 E. Variation, 250 W. 
7. November 5th. Find the M.T.G. of high water at Bridlington.

8. August 5th, about $5^{\mathrm{h}} 40^{\mathrm{m}}$ A.M., in lat. $31^{\circ} 14^{\prime}$ S., long. $157^{\circ} 20^{\prime}$ E., when the chron. showed correct G.M.T., $7^{\mathrm{h}} 11^{\mathrm{m}} 40^{\mathrm{s}}$, the Sun's bearing by compass was $\mathrm{N}$. $75^{\circ} 30^{\prime} \mathrm{E}$. Required the true amplitude and error of the compass ; and supposing the variation to be $6^{\circ} 20^{\prime}$ E., required the deviation of the compass for the position of the ship's head.

9. August 17th, about $8^{\text {h }}$ A.M. at ship, in lat. at noon $35^{\circ} 48^{\prime} \mathrm{N}$., long. by account $36^{\circ} \mathrm{W}$., the obs. alt. of Sun's L.L. was $30^{\circ} 25^{\prime} 50^{\prime \prime}$; ind. err. $+2^{\prime} 14^{\prime \prime}$; height of eye, $30 \mathrm{ft}$. ; time by chron. $10^{\mathrm{h}} 39^{\mathrm{m}} 14^{\mathrm{s}}$, which was fast $20^{\mathrm{m}} 12^{\mathrm{s}}$ for G.M. noon, on June 9th and on July 19 th was fast $19^{\mathrm{m}} 40^{\circ}$; run since sights, S. $25^{\circ}$ E. 43 miles. Required the long. at sight, also brought up to noon ; and if the compass bearing was $\mathrm{S}$. $80^{\circ} 30^{\prime} \mathrm{E}$., and variation $23^{\circ} 30^{\prime} \mathrm{W}$., find the true azimuth and deviation.

10. August 4th, about $10^{\mathrm{h}} 14^{\mathrm{m}}$ A.M., in lat. $38^{\circ} 27^{\prime} \mathrm{N}$., long. $84^{\circ} 20^{\prime} \mathrm{W}$., when a chron. supposed $15^{\mathrm{m}} 12^{\mathrm{s}}$ fast of M.T.G. showed $4^{\mathrm{b}} 7^{\mathrm{m}} \mathbf{4 7}^{\mathrm{s}}$, the Sun's bearing by compass $\mathrm{S} .52^{\circ} 30^{\prime} \mathrm{E}$. Required the true azimuth and error of the compass by the tables; and supposing the variation to be $7^{\circ} 30^{\prime} \mathrm{E}$., required the deviation for the position of the ship's head.

11. August 19th, P.M. at ship, lat. by account, $17^{\circ} 10^{\prime}$ S., long. $177^{\circ} 30^{\prime}$ E., the alt. of the Sun's L.L. $57^{\circ} 15^{\prime} 20^{\prime \prime}$; ind. err. $+1^{\prime} 18^{\prime \prime}$; height of eye, $18 \mathrm{ft}$. ; time by chron. $12^{\mathrm{h}} 51^{\mathrm{m}} 39^{\mathrm{a}}$, which had been found to be slow $11^{\mathrm{h}} 55^{\mathrm{m}}$ of A.T.S.; the course and dist. were S. $54^{\circ}$ E., $23^{\prime}$ since the error was determined. Required the lat. by reduction to the meridian; and if the run from noon to obs. on the same course was 3 miles, find the lat. at noon.

12. September 7th, about $9^{\text {b }}$ A.M. at ship. If in lat. by account $48^{\circ} 5^{\prime} \mathrm{N}$., long. $149^{\circ} 30^{\prime} \mathrm{W}$., chron. showed $6^{\mathrm{h}} 47^{\mathrm{m}} 8^{\circ}$ G.M.T. ; the alt. of the Sun's U.L. $32^{\circ} 26^{\prime} 50^{\prime \prime}$; again A.xr. on the same day, when the chron. showed $9^{\mathrm{h}} 10^{\mathrm{m}} 9^{\circ}$ G.M.T.; the alt. of the Sun's U.L. $47^{\circ} 20^{\prime} 30^{\prime \prime}$; ind. err. $-3^{\prime} 13^{\prime \prime}$; height of eye, $35 \mathrm{ft}$. ; the ship having made 23 miles on a true N. $49^{\circ} \mathrm{E}$. course in the interval between the observations; required the line of position, the Sun's true azimuth, and the position of the ship when the second alt. was observed by "Sumner's method" by projection on the chart, assuming the lats. $47^{\circ} 30^{\prime} \mathrm{N}$. and $48^{\circ} \mathrm{N}$.

13. Find the A.T.S. of the meridian passage of $\alpha$ Cygni in long. $96^{\circ} 45^{\prime} \mathrm{E}$. on September 7 th ; also by inspection.

14. What stars not less than magnitude 2 are within 1 hour east of the meridian of a place in lat. $20^{\circ} 30^{\prime} \mathrm{S}$., long. $80^{\circ} 40^{\prime} \mathrm{E}$., above the horizon and pole at $7^{\text {h }}$ P.M. M.T.S. on August 7 th ?

15. Calculate the mer. alt. of a Pavonis for placing on the sextant ind. cor. $-2^{\prime} 13^{\prime \prime}$; eye, $27 \mathrm{ft}$. in lat. $12^{\circ} 40^{\prime} \mathrm{N}$.

16. September 26 th, in lat. $36^{\circ} 32^{\prime}$ S., long. $125^{\circ} 40^{\prime}$ W., at $1^{\text {b }} 35^{\mathrm{m}}$ A.M. M.T.S. ; the compass bearing of Aldebaran was N. $40^{\circ} \mathrm{E}$. Find from the tables the true azimuth; and if the variation be $9^{\circ} \mathrm{E}$., find the deviation.

17. September 28 th, about $4^{\text {h }}$ A.x. at ship, in lat. $47^{\circ} 42^{\prime}$ S., long. by account, $84^{\circ} 15^{\prime}$ E., the obs. alt. of a Hydræ was $17^{\circ} 15^{\prime} 20^{\prime \prime}$; no ind. cor. ; eye, $29 \mathrm{ft}$; t time by chron., $9^{\mathrm{h}} 13^{\mathrm{m}} 25^{*}$, which was slow $1^{\mathrm{h}} 16^{\mathrm{m}} 12^{\mathrm{s}}$ of G.M. noon on September 2 nd, and gaining $4^{\prime} \cdot 6$ daily. Find the longitude.

18. August 12th, when the G.M. 'I'. was $12^{\mathrm{d}} 11^{\mathrm{b}} 36^{\mathrm{m}} 31^{\text {, }}$, in long. $23^{\circ} 49^{\prime} \mathrm{W}$.; the obs. alt. of Polaris out of the meridian was $42^{\circ} 17^{\prime} 50^{\prime \prime}$; ind. cor. $-3^{\prime} 11^{\prime \prime}$; eye, $28 \mathrm{ft}$. Find the latitude.

19. August 17th, in long. $33^{\circ} 45^{\prime} \mathrm{E}$. ; the obs. meridian alt. of the Moon's L.L. bearing north was $80^{\circ} 37^{\prime} 40^{\prime \prime}$; ind. cor. $-1^{\prime} 20^{\prime \prime}$; eye, $35 \mathrm{ft}$. Find the latitude.

20. September 19th, the obs. meridian alt. of the star $\beta$ Tauri was $53^{\circ} 25^{\prime} 10^{\prime \prime}$ bearing north; ind. err. $-3^{\prime} 17^{\prime \prime}$; height of eye, $24 \mathrm{ft}$. Required the latitude. 
21.

\begin{tabular}{|c|c|c|c|c|c|}
\hline $\begin{array}{l}\text { Ship's head by } \\
\text { standard } \\
\text { compass. }\end{array}$ & $\begin{array}{l}\text { Bearings of distant } \\
\text { object by standard } \\
\text { compass. }\end{array}$ & $\begin{array}{l}\text { Deviation } \\
\text { required. }\end{array}$ & $\begin{array}{l}\text { Ship's head by } \\
\text { standard } \\
\text { compass. }\end{array}$ & $\begin{array}{c}\text { Bearings of distant } \\
\text { object by standard } \\
\text { compass. }\end{array}$ & $\begin{array}{l}\text { Deviation } \\
\text { required. }\end{array}$ \\
\hline $\begin{array}{l}\text { N. } \\
\text { N.E. } \\
\text { E. } \\
\text { S.E. }\end{array}$ & $\begin{array}{l}\text { N. } 41^{\circ} \mathrm{E} . \\
\text { N. } 30^{\circ} \mathrm{E} . \\
\text { N. } 11^{\circ} \mathrm{E} . \\
\text { N. } 12^{\circ} \mathrm{W} .\end{array}$ & & $\begin{array}{c}\text { S. } \\
\text { S.W. } \\
\text { W. } \\
\text { N.W. }\end{array}$ & $\begin{array}{l}\text { N. } 33^{\circ} \mathrm{W} . \\
\text { N. } 27^{\circ} \mathrm{W} . \\
\text { N. } \\
\text { N. } 28^{\circ} \mathrm{E} .\end{array}$ & \\
\hline
\end{tabular}

Find correct magnetic bearing ; construct a Napier's curve.

With mag. courses : N. by E. $\frac{1}{2}$ E. E. $\frac{3}{4}$ S. S.S.W. N.W. by N. $\frac{1}{4}$ N. Find comp. courses.

Given comp. courses : N. $\frac{1}{2}$ E. E.N.E. S.E. by E. $\frac{1}{4}$ E. S.W. $\frac{3}{4}$ W. Find mag. courses.

With ship's head at E. $\frac{3}{4}$ S. by compass, the comp. bearings of distant objects were E.S.E. and W. by N. $\frac{3}{4}$ N. Find magnetic bearings.

22. On October 13th, at $2^{\text {h }} 47^{\mathrm{m}}$ A.M. M.T.S., being off Fleetwood by reckoning, took a cast of the lead. Required the correction to be applied to the depth obtained by the lead-line, before comparing it with the depth marked on the chart.

23. August 10th, about $8^{\mathrm{h}} 15^{\mathrm{m}}$ A.M , in lat. $37^{\circ} 14^{\prime}$ N., long. by account $14^{\circ} \mathrm{W}$., when a chron. estimated $5^{\mathrm{m}} 25^{\mathrm{s}}$ slow of G.M.T. showed $9^{\mathrm{h}} 13^{\mathrm{m}}$; the following observations were taken for determining long. and chron. error : obs. alt. of Moon's L.L. $29^{\circ} 38^{\prime} 20^{\prime \prime}$; ind. cor. + $3^{\prime} 14^{\prime \prime}$; height of eye, $30 \mathrm{ft}$. ; obs. distance between enlightened limbs of Sun and Moon, $109^{\circ} 17^{\prime} 50^{\prime \prime}$; ind. cor. $-2^{\prime} 35^{\prime \prime}$.

24. August 2nd, about $9^{\text {h }}$ P.M. in lat. $23^{\circ} 15^{\prime}$ N., approx. long. $62^{\circ} 20^{\prime}$ W., when a chron. showed $1^{\mathrm{h}} 25^{\mathrm{m}} 40^{\mathrm{s}}$ correct M.T.G. ; the obs. alt. of Antares was $35^{\circ} 42^{\prime} 40^{\prime \prime}$; and at the same time the obs. alt. of Spica was $14^{\circ} 18^{\prime} 20^{\prime \prime}$; ind. cor. $-3^{\prime} 18^{\prime \prime}$; eye, $35 \mathrm{ft}$. Find the true bearings of the stars and ship's position, either by "Sumner's method," assuming lats. $15^{\prime}$ on each side of lat. by account, or by direct spherics.

25. August 5th, at $2^{\mathrm{b}} 30^{\mathrm{m}}$ P.M. M.T.S. in lat. $30^{\circ} 27^{\prime} 45^{\prime \prime}$ S., long. $93^{\circ} 55^{\prime} \mathbf{E}$. ; the obs. alt. of Sun's U.L. in artificial horizon was $62^{\circ} 50^{\prime} 50^{\prime \prime}$; ind. cor. $-4^{\prime} 44^{\prime \prime}$; eye, $19 \mathrm{ft}$. If the chron. showed $8^{\mathrm{b}} 19^{\mathrm{m}} 41^{\mathrm{s}}$, required its error on M.T.G.

26. Find the first and last courses and distance on a G.C. arc from lat. $11^{\circ} 51^{\prime} \mathrm{N}$., long. $51^{\circ} 16^{\prime} \mathrm{E}$., to lat. $52^{\circ} 33^{\prime}$ S., long. $169^{\circ} 9^{\prime} \mathrm{E}$., position of vertex, and latitudes of intersection of meridians of $60^{\circ} \mathrm{E}$., $70^{\circ} \mathrm{E}$., $80^{\circ} \mathrm{E}$., $90^{\circ}$ E., and $160^{\circ} \mathrm{E}$. with the track.

27. In triangle $\mathrm{ABC}, \mathrm{A}=90^{\circ}, \mathrm{AC}=1950, \mathrm{C}=1^{\circ} 3^{\prime}$. Find $\mathrm{BC}$.

28. In triangle $\mathrm{XYZ}, \mathrm{XY}=210, \mathrm{X}=47^{\circ} 48^{\prime}, \mathrm{Y}=67^{\circ} 26^{\prime}$. Find $\mathrm{XZ}$.

29. In spherical triangle, $\mathrm{R}=90^{\circ}, \mathrm{QR}=119^{\circ} 8^{\prime}, \mathrm{PR}=168^{\circ} 20^{\prime}$. Find $\mathbf{P}$ and $\mathbf{P Q}$.

30. The deviations with ship's head by compass, on N., N.E., E., S.E., S., S.W., W., and N.W. are $20^{\circ}$ W., $16^{\circ}$ W., $5^{\circ}$ E., $12^{\circ}$ E., $12^{\circ}$ E., $9^{\circ}$ E., $2^{\circ}$ E., $4^{\circ} \mathrm{W}$. Find coefficients $\mathrm{A}, \mathrm{B}, \mathrm{C}, \mathrm{D}$, and $\mathrm{E}$, and compute deviations for points from $\mathrm{E}$. to $\mathrm{W}$. through north.

31. With ship steering $\mathrm{N}$. $35^{\circ} \mathrm{E}$., and heeling $14^{\circ}$ to port, the heeling error is $-15^{\circ}$. Find the amount when steering N. $70^{\circ} \mathrm{W}$., and heeling $18^{\circ}$ to starboard. 


\section{Paper IV.}

1. Multiply 300.07 by 0.0246 , by logs.

2. Divide $5623 \cdot 87$ by $48960 \cdot 02$, by lorgs.

3.

\begin{tabular}{|c|c|c|c|c|c|c|c|}
\hline Hour. & Cuurses. & Knts. & 10ths. & Winds. & $\begin{array}{l}\text { Lee- } \\
\text { way. }\end{array}$ & $\begin{array}{l}\text { Devia- } \\
\text { tion. }\end{array}$ & Remarks. \\
\hline $\begin{array}{l}1 \\
2 \\
3 \\
4 \\
5\end{array}$ & W.S.W. & $\begin{array}{l}12 \\
13 \\
12 \\
11 \\
11\end{array}$ & $\begin{array}{r}8 \\
1 \\
5 \\
6 \\
-\end{array}$ & N.W. & $\begin{array}{c}\text { Pts. } \\
1 \stackrel{j}{4}\end{array}$ & $26^{\circ} \mathrm{E}$. & \multirow{3}{*}{$\begin{array}{l}\text { Departure taken } \\
\text { from a point in } \\
\text { lat. } 37^{\circ} 3^{\prime} \mathrm{N} \text {., } \\
\text { long. } 4^{\circ} 25^{\prime} \mathrm{E} \text {; } \\
\text { bearing by com- } \\
\text { pass } \mathrm{E} \text {. by N.; } \\
\text { ship's head S.W.; } \\
\text { deviation } 29^{\circ} \mathrm{E} \text {., } \\
\text { distant } 20 \text { miles. } \\
\text { Variation } 21^{\circ} \mathrm{W} \text {. }\end{array}$} \\
\hline $\begin{array}{l}6 \\
7 \\
8 \\
9\end{array}$ & W. & $\begin{array}{l}12 \\
13 \\
12 \\
12\end{array}$ & $\frac{9}{8}$ & N.N.W. & 2 & $19 !_{2}^{\prime \circ} \mathrm{E}$ & \\
\hline $\begin{array}{l}10 \\
11 \\
12\end{array}$ & W. $\frac{1}{2} \mathrm{~N}$. & $\begin{array}{l}12 \\
12 \\
12\end{array}$ & $\begin{array}{l}2 \\
7 \\
1\end{array}$ & N. & $1 ! \frac{1}{2}$ & $17^{\circ} \mathrm{E}$. & \\
\hline $\begin{array}{l}1 \\
2 \\
3 \\
4 \\
5\end{array}$ & W. by S. & $\begin{array}{l}11 \\
11 \\
11 \\
11 \\
11\end{array}$ & $\begin{array}{l}9 \\
8 \\
9 \\
8 \\
6\end{array}$ & N.N.W. & $\frac{3}{4}$ & $23^{\circ} \mathrm{E}$ & \multirow{3}{*}{$\begin{array}{l}\text { A current set } \\
\mathrm{S} .21^{\circ} \mathrm{E} \text {. true, } 42 \\
\text { miles during the } \\
\text { day. }\end{array}$} \\
\hline $\begin{array}{l}6 \\
7 \\
8 \\
9\end{array}$ & W. $\frac{1}{1} \mathrm{~S}$. & $\begin{array}{l}11 \\
12 \\
12 \\
12\end{array}$ & $\begin{array}{l}5 \\
9 \\
8 \\
8\end{array}$ & N.N.W. & $1 \frac{1}{4}$ & $20^{\circ} \mathrm{E}$ & \\
\hline $\begin{array}{l}10 \\
11 \\
12\end{array}$ & W.N.W. & $\begin{array}{l}13 \\
13 \\
13\end{array}$ & $\begin{array}{l}1 \\
6 \\
3\end{array}$ & N. & 1 & $11^{\circ} \mathrm{E}$ & \\
\hline
\end{tabular}

Find the course and distance made good ; lat. and long. of the ship.

4. August 4th, in long. $82^{\circ} 35^{\prime} \mathrm{E}$., the observed meridian altitude of the Sun's L.L. zenith south of Sun was $15^{\circ} 32^{\prime} 30^{\prime \prime}$; ind. err. $-3^{\prime} 4^{\prime \prime}$; height of eye, 35 feet. Required the latitude.

5. How far due east must a vessel sail on the parallel of $39^{\circ} 27^{\prime} \mathrm{S}$. to change her longitude $1^{\circ} 29^{\prime}$ ?

6. Required the compass course and distance by Mercator's sailing-

$$
\begin{aligned}
& \text { From A, lat. } 42^{\circ} 35^{\prime} \mathrm{N} \text {. Long. } 71^{\circ} 18^{\prime} \mathrm{W} \text {. } \\
& \text { To B, ,, } 5322 \mathrm{~N} \text {. „, } 1230 \text { W. } \\
& \text { Variation, } 430 \text { W. Deviation, } 1920 \text { E. }
\end{aligned}
$$

7. July 24th. Find the M.T.S. of high water at Limerick.

8. September 8th P.M. at ship, in lat. $23^{\circ} 40^{\prime}$ S., long. $65^{\circ} 50^{\prime} \mathrm{E}$., when the A.T.S. was $5^{\mathrm{h}} 50^{\mathrm{m}} 20^{\circ}$, the Sun's bearing by compass was W. $\frac{1}{4} \mathrm{~S}$. Required the true amplitude, and error of the compass ; and supposing the variation to be $10^{\circ} 30^{\prime} \mathrm{W}$., required the deviation of the compass for the position of the ship's head.

9. August 10th, about $8^{\mathrm{h}} 15^{\mathrm{m}}$ A.M. at ship, in lat. at noon $37^{\circ} 29^{\prime}$ N., long. by account $14^{\circ} 30^{\prime}$ W., the obs. alt. of the Sun's L.L. was $36^{\circ} 6^{\prime} 40^{\prime \prime}$; ind. 
err. 0 ; height of eye, 30 feet; time by chron. $9^{\text {h }} 20^{\mathrm{m}} 53^{4}$, which was slow $1^{\mathrm{m}} 12^{\mathrm{a}}$ for G.M. noon on June 25th, and on July 10 th was correct; run between obs. and noon, N.E. by E. 27 miles. Required the long. at sight, also brought up to noon; also, if the compass bearing was East and variation $21^{\circ} 15^{\prime} \mathrm{W}$., find true azimuth and deviation.

10. September $2 \mathrm{nd}$, about $4^{\text {h }} 20^{\mathrm{m}}$ P.M. at ship, in lat. $43^{\circ} 16^{\prime}$ S., long. $14^{\circ} 5^{\prime}$ W.; when the correct G.M.T. by chron. was $5^{\text {h }} 25^{\mathrm{m}} 10^{\text {s }}$, the Sun's bearing by compass $\mathrm{N}$. $65^{\circ} 15^{\prime} \mathrm{W}$. Required the true azimuth and error of the compass by the tables; and supposing the variation to be $14^{\circ} \mathrm{W}$., required the deviation for the position of the ship's head.

11. September 25 th P.M. at ship, lat. by account $29^{\circ} 10^{\prime}$ S., long. $7^{\circ} 29^{\prime}$ E. ; the alt. of Algenib bearing $N$. was $46^{\circ} 5^{\prime} 50^{\prime \prime}$; ind. err. $-2^{\prime} 8^{\prime \prime}$; height of eye, $19 \mathrm{ft}$; time by watch $11^{\mathrm{h}} 25^{\mathrm{m}} 4^{\mathrm{s}}$, which had been found to be fast of M.T.S. $2^{\mathrm{m}} 22^{\prime}$; the diff. long. made eastward was $127^{\prime}$ after the error was determined. Required the lat. by reduction to the meridian.

12. September 1st, about $0^{\text {h }} 33^{\mathrm{m}}$ P.M. at ship. In lat. by account $49^{\circ} \mathrm{N}$., long. $180^{\circ} \mathrm{E}$, when the chron. showed $12^{\mathrm{h}} 42^{\mathrm{m}} 57^{\mathrm{s}}$, and was fast $8^{\mathrm{m}} 55^{\mathrm{s}}$ of G.M.T.; the alt. of the Sun's L.I. $48^{\circ} 51^{\prime}$; again P.N. on the same day, when the chron. showed $4^{\mathrm{h}} 50^{\mathrm{m}} 20^{\prime}$; the alt. of the Sun's U.L. $19^{\circ} 30^{\prime} 20^{\prime \prime}$; ind. err. $+1^{\prime} 10^{\prime \prime}$; height of eye, $17 \mathrm{ft}$. ; the ship having made $6 \frac{1}{2}$ knots per hour on a true E.N.E. course in the interval between the observations. Required the line of position, the Sun's true azimuth, and the position of the ship when the second alt. was observed by "Sumner's method" by projection on the chart, assuming the lats. $20^{\prime}$ on each side of lat. by account.

13. In long. $127^{\circ} 45^{\prime} \mathrm{E}$., find the mean time of transit of Fomalhaut on Sept. 14th.

14. What stars not less bright than mag. 2.5 are within 1 hour $\mathbf{E}$. and W. of the meridian, above the horizon of a place in lat. $45^{\circ} \mathrm{N}$., long. $95^{\circ} \mathrm{W}$. on Sept. 8th at $9^{\mathrm{h}}$ P.M. M.T.S. Give their meridian distances and bearings.

15. Calculate for placing on the sextant the mer. alt. of $\alpha$ Gruis in lat. $30^{\circ} 24^{\prime} \mathrm{S}$., ind. cor. $+1^{\prime} 17^{\prime \prime}$; eye, $30 \mathrm{ft}$.

16. August 16th, midnight mean time at ship in lat. $30^{\circ} 20^{\prime} \mathrm{N}$., long. $64^{\circ} 20^{\prime} \mathrm{W}$., the compass bearing of a Arietis was E. $\frac{1}{2} \mathrm{~S}$. Find true bearing from the "tables;" and if the variation was $6^{\circ} \mathrm{W}$., required the deviation.

17. August 2 nd, about $9^{\mathrm{h}} 30^{\mathrm{m}}$ P.M. in lat. $25^{\circ} 14^{\prime} \mathrm{N}$., long. $97^{\circ} 15^{\prime} \mathrm{W}$., the obs. alt. of Spica was $12^{\circ} 19^{\prime} 20^{\prime \prime}$; ind. cor. $-4^{\prime} 12^{\prime \prime}$; eye, $17 \mathrm{ft}$.; when a chron. showed $3^{\mathrm{h}} 55^{\mathrm{m}} 58^{\mathrm{s}} \cdot 5$, and had been found slow $3^{\mathrm{m}} 31^{\mathrm{s}} \cdot 5$ on April $29 \mathrm{th}$ of G.M. noon, and fast $2^{\mathrm{m}} 15^{\mathrm{A}}$ on June $23 \mathrm{rd}$. Find the longitude.

18. September 8 th, A.M. at ship, about $3^{\mathrm{h}}$ in long. $157^{\circ} \mathrm{E}$., when the A.T.G. was $4^{\mathrm{h}} 36^{\mathrm{m}} 26$, the obs. alt. of Polaris out of the meridian was $29^{\circ} 26^{\prime} 40^{\prime \prime}$; ind. cor. $+6^{\prime} 4^{\prime \prime}$; height of eye, $41 \mathrm{ft}$. Find the latitude.

19. August 15 th, in long. $136^{\circ} 15^{\prime}$ E., the obs. alt. of the Moon's L.L. bearing north was $46^{\circ} 19^{\prime} 10^{\prime \prime}$; ind. cor. $+2^{\prime} 28^{\prime \prime}$; height of eye, $34 \mathrm{ft}$. Required the latitude.

20. August 22nd, the observed meridian alt. of the star $\beta$ Canis Majoris was $51^{\circ} 19^{\prime} 20^{\prime \prime}$ bearing north; ind. err. $-4^{\prime} 37^{\prime \prime}$; height of eye, $35 \mathrm{ft}$. Required the latitude.

21.

\begin{tabular}{|c|c|c|c|c|c|}
\hline $\begin{array}{l}\text { Ship's head by } \\
\text { standard } \\
\text { comprass. }\end{array}$ & $\begin{array}{l}\text { Bearings of distant } \\
\text { object by standard } \\
\text { compass. }\end{array}$ & $\begin{array}{l}\text { Deviation } \\
\text { required. }\end{array}$ & $\begin{array}{l}\text { Ship's hearl by } \\
\text { standard } \\
\text { compass. }\end{array}$ & $\begin{array}{l}\text { Bearings of distant } \\
\text { object by standard } \\
\text { compass. }\end{array}$ & $\begin{array}{l}\text { Deviation } \\
\text { required. }\end{array}$ \\
\hline $\begin{array}{l}\text { N. } \\
\text { N.E. } \\
\text { E. } \\
\text { S.E. }\end{array}$ & $\begin{array}{l}\text { N. } 32^{\circ} \mathrm{W} . \\
\text { N. } 20^{\circ} \mathrm{W} . \\
\text { N. } 5^{\circ} \mathrm{E} . \\
\text { N. } 17^{\circ} \mathrm{E} .\end{array}$ & & $\begin{array}{l}\text { S. } \\
\text { S.W. } \\
\text { W. } \\
\text { N.W. }\end{array}$ & $\begin{array}{l}\text { N. } 20^{\circ} \mathrm{E.} \\
\text { N. } 9^{\circ} \mathrm{E.} \\
\text { N. } 15^{\circ} \mathrm{W} . \\
\text { N. } 31^{\circ} \mathrm{W} .\end{array}$ & \\
\hline
\end{tabular}


Find correct magnetic bearing; construct a curre.

Given mag. courses : S.E. $\frac{1}{2}$ E. N.E. by N. W. by N. $\frac{1}{2}$ N. S. $72^{\circ}$ W.

Find comp. courses.

Given comp. courses : E. by N. $\frac{1}{4}$ N. $\quad$ S.E. $\frac{3}{4}$ S. S.S.W. W. $15^{\circ}$ N.

Find mag. courses.

With ship's head at E.S.E. by compass, comp. bearings of distant objects were $\mathrm{S} .50^{\circ} \mathrm{W}$. and $\mathrm{S} .35^{\circ} \mathrm{E}$. Find magnetic bearings.

22. On September 7th, at $5^{\text {h }}$ A.M. M.T.S., being off Wicklow by reckoning, took a cast of the lead. Required the correction to be applied to the depth obtained by the lead-line before comparing it with the depth marked on the chart.

23. August 11th, at $4^{\text {h }} 6^{\text {ma }}$ A.M. M.T.S., in lat. $40^{\circ} 17^{\prime}$ N., long. by account $21^{\circ} 39^{\prime} 45^{\prime \prime} \mathrm{W}$., when a chron. which had run down and been set going showed $5^{\mathrm{h}} 30^{\mathrm{m}}$, the following observations were taken for finding the long. and error of chron. for G.M.T.: obs. alt. of Moon's L.L., $54^{\circ} 33^{\prime} 50^{\prime \prime}$; ind. cor. $-2^{\prime} 2^{\prime \prime}$; height of eye, $27 \mathrm{ft}$. ; obs. dist. between Jupiter's centre and the Moon's near limb, $54^{\circ} 16^{\prime} 10^{\prime \prime}$; ind. cor. $-3^{\prime} 3^{\prime \prime}$.

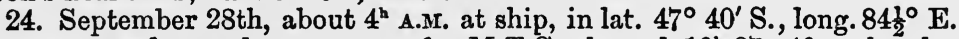
by account; when a chron. correct for M.T.G. showed $10^{\mathrm{h}} 27^{\mathrm{m}} 40^{\mathrm{a}}$; the obs. alt. of $\epsilon$ Orionis was $41^{\circ} 42^{\prime} 20^{\prime \prime}$; and at the same time the obs. alt. of Alphard was $17^{\circ} 15^{\prime} 20^{\prime \prime}$; eye, $29 \mathrm{ft}$. Find the true bearings of the stars, and position of ship, either by "Sumner's method" assuming lats. $47^{\circ}$ and $47^{\circ} 40^{\prime}$ S., or by direct spherics.

25. September 22nd, at $2^{\mathrm{h}} 17^{\mathrm{m}} 27^{\mathrm{S}}$ P.M. at ship, from which a place in lat. $9^{\circ} 12^{\prime} \mathrm{N}$., long. $173^{\circ} 44^{\prime} \mathrm{W}$., bore N. $33^{\circ} \mathrm{W}$., distant 6 miles; the obs. alt. of Sun's L.L. was $53^{\circ} 29^{\prime} 20^{\prime \prime}$; ind. cor. $-3^{\prime} 19^{\prime \prime}$; height of eye, $21 \mathrm{ft}$. If a chron. showed $1^{\mathbf{k}} 47^{\mathrm{m}} 27^{\mathbf{3}}$, find its error on G.M.T.

26. Find the initial course and distance on a Great Circle, and position of vertex in sailing from lat. $34^{\circ} 36^{\prime} \mathrm{S}$., long. $58^{\circ} 22^{\prime}$ '. W., to lat. $33^{\circ} 56^{\prime} \mathrm{S}$., long. $18^{\circ} 29^{\prime} \mathbf{E}$. ; and lat. of place where meridian of Greenwich cuts the track.

27. $A B$ is a horizontal line $1300 \mathrm{ft}$. long. ; a vertical line is drawn from $B$ upwards, and in it two points $P$ and $Q$ are taken such that $B Q=3 B P$, $\mathrm{BAP}=10^{\circ} 30^{\prime} 20^{\prime \prime}$. Find $\mathrm{BP}$ and $\mathrm{BAQ}$.

28. $\mathrm{XY}$ is $2000 \mathrm{ft}$. long; $\mathrm{Y}$ is due east of $\mathrm{X}$; at $\mathrm{Y}$ a point $\mathrm{Z}$ bears N. $46^{\circ} 20^{\prime}$ W., at $X$ it bears N. $8^{\circ} 45^{\prime} \mathrm{E}$. Find $\mathrm{XZ}$.

29. Two places, $A$ and $B$, are on the same parallel $35^{\circ} \mathrm{N}$., and their difference of longitude is $85^{\circ}$. Find the distance between them on the G.C., also lat. of vertex.

30. From a rock $7 \mathrm{ft}$. above high water, the angle of elevation to the summit of a cliff distant $5320 \mathrm{ft}$. in a horizontal direction is $1^{\circ} 30^{\prime}$; height of eye, $\mathbf{5} \mathrm{ft}$. Find height of cliff above high water.

31. September 12th, in lat. $25^{\circ} 17^{\prime}$ S., long. $100^{\circ} 14^{\prime}$ E. at $8^{\mathrm{h}} 30^{\mathrm{m}}$ P.M. M.T.S., the compass bearing of $\gamma$ Crucis was S. $28^{\circ} 30^{\prime}$ W. Find the deviation, the variation being $8^{\circ} 15^{\prime} \mathrm{W}$.

32. Coefficient $\mathrm{B}=-18^{\circ} 30^{\prime}$, coefficient $\mathrm{C}=+27^{\circ} 48^{\prime}$. Find direction ship's head.

Ship's head S. $74^{\circ} \mathrm{W}$., coefficient $\mathrm{B}=+5^{\circ} \cdot 7$. Find coefficient C.

33. Ship's head by compass N.; N.E., E., S.E., S., S.W., W., N.W.

Deviations $10^{\circ} \mathrm{W} ., 15^{\circ} \mathrm{W} ., 14^{\circ} \mathrm{W} ., 8^{\circ} \mathrm{E} ., 20^{\circ} \mathrm{E} ., 18^{\circ} \mathrm{E} ., 3^{\circ} \mathrm{W} ., 5^{\circ} \mathrm{W}$.

Find coefficients A, B, C, D and E, and thence compute a table of deviations from $\mathbf{E}$. to W. through $\mathrm{S}$.

34. When steering S. $28^{\circ}$ E., and heeling to port $15^{\circ}$, the error was $-10^{\circ}$. Find its amount when steering west and heeling $12^{\circ}$ to starboard. 
Paper V.

1. Multiply 1.0009 by $62 \cdot 7014$, by logs.

2. Divide $7 \cdot 5$ by 1000 , by logs.

3.

\begin{tabular}{|c|c|c|c|c|c|c|c|}
\hline IIrs. & Courses. & Kints. & 10ths. & Winds. & $\begin{array}{c}\text { Lee- } \\
\text { way. }\end{array}$ & $\begin{array}{l}\text { Devia- } \\
\text { tiun. }\end{array}$ & Remarks. \\
\hline $\begin{array}{r}1 \\
1 \\
2 \\
3 \\
4 \\
5 \\
6 \\
7 \\
8 \\
9 \\
10 \\
11 \\
12 \\
1 \\
2 \\
3 \\
4 \\
5 \\
6 \\
7 \\
8 \\
9 \\
10 \\
11 \\
12\end{array}$ & N.E. by E. $\frac{1}{2}$ E. & $\begin{array}{l}10 \\
10 \\
10 \\
10 \\
10 \\
10 \\
10 \\
10 \\
11 \\
11 \\
11 \\
11 \\
11 \\
11 \\
11 \\
11 \\
12 \\
12 \\
12 \\
12 \\
11 \\
11 \\
11 \\
11\end{array}$ & $\begin{array}{l}5 \\
5 \\
5 \\
5 \\
.\end{array}$ & $\begin{array}{l}\text { S.S.E. } \\
\text { E.S.E. }\end{array}$ & $\begin{array}{r}\text { I'ts. } \\
\frac{1}{4}\end{array}$ & $\begin{array}{l}16^{\circ} \mathrm{E} . \\
18^{\circ} \mathrm{E} .\end{array}$ & $\begin{array}{l}\text { Departure taken } \\
\text { from a point in } \\
\text { lat. } 62^{\circ} 30^{\prime} \mathrm{N} \text {., } \\
\text { long. } 178^{\circ} 54^{\prime} \mathbf{E} \text {.; } \\
\text { bearing by com- } \\
\text { pass W.N.W.; } \\
\text { sh i p's h e a d } \\
\text { N.N.E.; devia- } \\
\text { tion 5 } 5^{\circ} \text { E., dis- } \\
\text { tant } 20 \text { miles. } \\
\text { Variation, } 15^{\circ} \mathrm{E} \text {. }\end{array}$ \\
\hline
\end{tabular}

Find the course and distance made good; lat. and long. of the ship.

4. August 6 th, in long. $19^{\circ} 17^{\prime} \mathrm{W}$.; the obs. mer. alt. of the Sun's U.L., $78^{\circ} 16^{\prime} 50^{\prime \prime}$, zenith south of object; ind. err., $-5^{\prime} 11^{\prime \prime}$; height of eye, $37 \mathrm{ft}$. Required the latitude.

5. In lat. $45^{\circ} 50^{\prime} \mathrm{N}$. What is the departure made good to cause a change of $800^{\prime}$ of long. by sailing due east?

6. Required the compass course and distance by Mercator's sailing; var. $30^{\circ} \mathrm{W}$. ; dev. $10 \frac{1}{2}^{\circ} \mathrm{E}$. -

$$
\begin{aligned}
& \text { From A, lat. } 33^{\circ} 24^{\prime} \mathrm{S} \text {. long. } 20^{\circ} 15^{\prime} \mathrm{E} \text {. } \\
& \text { To B, „ } 5340 \mathrm{~S} \text {. "63 } 37 \mathrm{~W}
\end{aligned}
$$

7. August 15th. Find the M.T.S. of high water at Seal Cove. N.B.

8. August 15th, about $5^{\text {h }}$ P.M. at ship, in lat. $44^{\circ} 29^{\prime}$ S., long. $129^{\circ} 35^{\prime}$ E., when a chron. known to be $15^{\mathrm{m}} 50^{\circ}$ slow of M.T.G. showed $7^{\mathrm{h}} 56^{\mathrm{m}} 50^{\circ}$, the Sun's bearing by compass was S. $88^{\circ} 30^{\prime} \mathrm{W}$. Required the true amplitude, and error of the compass ; and supposing the variation to be $2^{\circ} 20^{\prime} \mathrm{W}$., required the deviation of the compass for the position of the ship's head.

9. September 29th, about $4^{\mathrm{b}} 45^{\mathrm{m}}$ P.M. at ship, in lat. at noon $46^{\circ} 23^{\prime} \mathrm{N}$., long. by account $179^{\circ} 50^{\prime}$ W., the obs. alt. of Sun's L.L. was $11^{\circ} 12^{\prime}$; ind. err., nil ; height of eye, $25 \mathrm{ft}$. ; time by chron., $4^{\mathrm{h}} 43^{\mathrm{m}} 46^{\mathrm{s}}$, which was fast $13^{\mathrm{m}} 47^{\mathrm{s}}$ for G.M. noon on August 10th, and losing $3^{a} \cdot 3$ per day. The run since noon, N. $50^{\circ}$ W. 42 miles. Required the long. at sight, also brought up to noon ; and if the compass bearing was W. $\frac{1}{4} \mathrm{~N}$., variation $13^{\circ} 15^{\prime} \mathrm{E}$., find the deviation. 
10. August 14 th, about $9^{\text {h }}$ A.M. in lat. $58^{\circ} 49^{\prime}$ N., long. $32^{\circ} 56^{\prime}$ W., when a chron. correct for G.M.T. showed $11^{\mathrm{b}} 22^{\mathrm{m}} 38^{\mathrm{s}}$; the sun's bearing by compass, $\mathrm{S} .5^{\circ} 30^{\prime} \mathrm{E}$. Required the true azimuth and error of the compass by the "Tables;" and supposing the rariation to be $50^{\circ} \mathrm{W}$., required the deviation for the position of the ship's head.

11. August 19 th P.M. at ship, lat. by account $30^{\circ} 22^{\prime} \mathrm{S}$., long. $170^{\circ} 48^{\prime} \mathrm{E}$.; the alt. of the Sun's L.L., $45^{\circ} 47^{\prime} 50^{\prime \prime}$; ind. err., $+3^{\prime} 55^{\prime \prime}$; height of eye, $19 \mathrm{ft}$.; time by chron., $1^{\mathrm{h}} 16^{\mathrm{m}} 58^{\mathrm{s}}$, which had been found to be fast $10^{\mathrm{m}} 6^{\mathrm{a}}$ of M.T.G.; the run was S. $48^{\circ}$ W. 35 miles after the error was determined. Require the lat. by reduction to the meridian; and if the run since noon was 4 miles on the same course, find the lat. at noon.

12. September 29 th, about $0^{\mathrm{h}} 30^{\mathrm{m}}$ P.M. at ship, lat. by account $46^{\circ} 55^{\prime} \mathrm{N}$., long. $179^{\circ} 50^{\prime}$ W., when the chron. showed $12^{\mathrm{h}} 20^{\mathrm{m}} 39^{\mathrm{s}}$ G.M.T.; the alt. of the Sun's L.L., $40^{\circ} 30^{\prime} 40^{\prime \prime}$; again P.M. on the same day, when the chron. showed $4^{\mathrm{h}} 32^{\mathrm{m}} 46^{\circ}$ G.M.T.; the alt. of the Sun's L L., $11^{\circ} 7^{\prime}$; ind. err., $+5^{\prime}$; height of eye, $25 \mathrm{ft}$.; the ship having made 42 miles on a true $\mathrm{N}$. $45^{\circ} \mathrm{W}$. course in the interval between the observations. Required the line of position when the first alt. was taken, the sun's true azimuth and position of the ship when the second alt. was observed by "Sumner's method" by projection on the chart, assuming the lats. $46^{\circ}$ and $46^{\circ} 40^{\prime} \mathrm{N}$.

13. Find the apparent time of transit of Markab across the meridian of a place long. $121^{\circ} 45^{\prime} \mathrm{E}$. on September 21st; also by inspection.

14. Find what bright stars of at least 2 nd mag. are within 1 hour $\mathbf{E}$. and W. of mer., above horizon and pole, on August 14th at $1^{\mathrm{h}} 30^{\mathrm{m}}$ A.M. A.T.S. in lat. $29^{\circ} \mathrm{N}$., long. $130^{\circ} \mathrm{E}$., and state their hour angles.

15. Calculate mer. alt. of $a$ Cephei for placing on sextant in lat. $12^{\circ} 15^{\prime} \mathrm{N}$.; ind. cor., $-4^{\prime} 26^{\prime \prime}$; height of eye, $35 \mathrm{ft}$.

16. August $2 \mathrm{nd}$, about $9^{\mathrm{h}}$ P.M. at ship, in lat. $23^{\circ} 12^{\prime} \mathrm{N}$., long. $62^{\circ} 30^{\prime} \mathrm{W}$. ; the obs. alt. of Antares was $35^{\circ} 37^{\prime} 10^{\prime \prime}$; ind. cor., $+2^{\prime} 14^{\prime \prime}$; eye, $35 \mathrm{ft}$. ; when a chron. sliowed $1^{\mathrm{b}} 13^{\mathrm{m}} 21^{\mathrm{s}}$, which was slow $15^{\mathrm{m}} 47^{\mathrm{s}}$ on May 2 nd, and slow $14^{\mathrm{m}} 17^{\mathrm{s}}$ on June 11th for G.M. noon. Required the longitude.

17. August 26th, at $3^{\text {h }} 42^{\mathrm{m}}$ A. M. A.T.S., in lat. $42^{\circ} 18^{\prime}$ S., long. $91^{\circ} 14^{\prime}$ W.; the compass bearing of Markab was N.W. $\frac{1}{4} \mathrm{~N}$., the variation being $18^{\circ} 45^{\prime} \mathrm{E}$. Find true azimuth from "Tables," and deviation.

18. September 18 th, about $5^{\mathrm{h}} 15^{\mathrm{m}}$ A.M. at ship, in long. $148^{\circ} 15^{\prime} \mathrm{W}$., when a chron. which showed G.M.T. indicated $3^{\mathrm{h}} 14^{\mathrm{m}} 12^{\mathrm{s}}$, the obs. alt. of Polaris out of the meridian was $51^{\circ} 7^{\prime} 20^{\prime \prime}$; ind. cor., $-5^{\prime} 37^{\prime \prime}$; eye, $19 \mathrm{ft}$. Required the latitude.

19. August 10 th, in long. $29^{\circ} 30^{\prime} \mathrm{W}$. ; the obs. mer. alt. of the Moon's U.L. was $48^{\circ} 13^{\prime} 20^{\prime \prime}$; zenith north of Moon; ind. cor., $-3^{\prime} 16^{\prime \prime}$; height of eye, $32 \mathrm{ft}$. Find latitude.

20. The obs. mer. alt. of the star $\beta$ Argûs under the South Pole was $30^{\circ} 47^{\prime} 50^{\prime \prime}$; ind. err., $+5^{\prime} 26^{\prime \prime}$; height of eye, $12 \mathrm{ft}$. Required the latitude. 21.

\begin{tabular}{c|c|c|c|c|c}
\hline $\begin{array}{c}\text { Ship's bead by } \\
\text { standard } \\
\text { compass. }\end{array}$ & $\begin{array}{c}\text { Bearings of distant } \\
\text { object by standard } \\
\text { compass. }\end{array}$ & $\begin{array}{c}\text { Deviation } \\
\text { required. }\end{array}$ & $\begin{array}{c}\text { Ship's head by } \\
\text { standard } \\
\text { compass. }\end{array}$ & $\begin{array}{c}\text { Bearings of distant } \\
\text { object by standard } \\
\text { compass. }\end{array}$ & $\begin{array}{c}\text { Deviation } \\
\text { required. }\end{array}$ \\
\cline { 1 - 2 } N. & N. $56^{\circ}$ E. & & S. & N. $56^{\circ}$ E. & \\
N.E. & N. $48^{\circ}$ E. & & S.W. & N. $63^{\circ}$ E. \\
E. & N. $45^{\circ}$ E. & & W. $68^{\circ}$ E. \\
S.E. & N. $49^{\circ}$ E. & & N.W. & N. $64^{\circ}$ E. & \\
\hline
\end{tabular}

Find correct magnetic bearing; construct a curve.

Given magnetic courses : E. by N. S.E. by E. W.S.W. N.N.W.

Find compass courses. 
Given compass courses: S. $79^{\circ}$ W. S. $23^{\circ}$ E. N. $34^{\circ}$ E. N. W. Find magnetic courses.

With ship's head at E.N.E. by compass, the compass bearings of distant objects were S. by W. $\frac{1}{2}$ W., and S. $59^{\circ}$ E. Find magnetic bearings.

22. On August 6th, at $6^{\text {h }}$ P.M. M.T.S., being off Tenby by reckoning, took a cast of the lead. Required the correction to be applied to the depth obtained by the lead-line, before comparing it with the depth marked on the chart.

23. August 17 th, about $8^{\text {h }}$ A.M. at ship, in lat. $36^{\circ} 27^{\prime}$ N., loug. by account, $36^{\circ}$ W., when a chron. estimated $12^{\mathrm{m}} 10^{\mathrm{s}}$ fast on G.M.T. showed $10^{\mathrm{h}} 31^{\mathrm{m}} 40^{\mathrm{*}}$; the obs. alt. of the Sun's L.L. was $30^{\circ} 25^{\prime} 50^{\prime \prime}$; ind. cor., $+2^{\prime} 14^{\prime \prime}$; height of eye, $30 \mathrm{ft}$; ; obs. distance between the enlightened limbs of Sun and Moon, $30^{\circ} 12^{\prime} 40^{\prime \prime}$; ind. cor., $+3^{\prime} 16^{\prime \prime}$. Find the true and apparent altitudes of the Moon, long. of ship, and error of chron. on G.M.T.

24. September 7 th, in lat. N., long. $149^{\circ} 30^{\prime} \mathrm{W}$., the following observations were made for finding latitude by "Ivory" or "Direct," at second obs. :-

App. times ship nearly.

G.M.T. by chron.

$\begin{array}{rrr}8^{\mathrm{h}} & 50^{\mathrm{m}} & \text { A.M. } \\ 11 & 15 & \text { A.M. }\end{array}$

$6^{\mathrm{h}} 47^{\mathrm{m}} 7^{*}$

Obs. alts. Sun's L.L.

9108

$32^{\circ} 26^{\prime} 50^{\prime \prime}$

472030

Bearing at first obs., S. $60^{\circ} \frac{1}{2}$ E. ; run between obs., N. $48 \frac{1}{2}^{\circ}$ E., $9.5 \mathrm{knots}$ per hour ; ind. cor., $-3^{\prime} 13^{\prime \prime}$; eye, $35 \mathrm{ft}$.

25. September 4 th, at $4^{\mathrm{b}} 30^{\mathrm{m}}$ P.M., when Cape Farewell in lat. $40^{\circ} 29^{\prime} 50^{\prime \prime} \mathrm{S}$., long. $172^{\circ} 40^{\prime} 6^{\prime \prime}$ E., bore from ship west 13 miles distant, the obs. alt. of Sun's U.L. in artificial horizon was $24^{\circ} 0^{\prime} 30^{\prime \prime}$; ind. cor., $-2^{\prime} 8^{\prime \prime}$; time shown by chron., $4^{\mathrm{b}} 37^{\mathrm{m}}$. Find its error on M.T.G.

26. Find the initial and final courses from lat. $34^{\circ} 21^{\prime}$ S., long. $18^{\circ} 30^{\prime} \mathrm{E}$., to lat. $38^{\circ} 18^{\prime} \mathrm{S}$., long. $144^{\circ} 39^{\prime} \mathrm{E}$., by composite sailing; easting to be run on the parallel of $46^{\circ} \mathrm{S}$. Also find total distance, and lats. where meridians of $50^{\circ} \mathrm{E}$. and $140^{\circ} \mathrm{E}$. cut the track.

27. From a boat the angle of elevation of the truck, known to be $165 \mathrm{ft}$. above the water-level, was found to be $9^{\circ} 17^{\prime}$. Find distance of observer from ship.

28. A vessel sails S.S.E. $\frac{1}{4}$ E., 137 miles by $\log$, but by observation she is known to be 101 miles S. $\frac{1}{4} \mathrm{~W}$. of her former position. Find the set and drift of the current.

29. In a right-angled spherical triangle, hyp. $=105^{\circ} 20^{\prime}$; one angle is $35^{\circ} 4^{\prime}$. Find side opposite given angle, and remaining angle.

30. Coefficient $\mathrm{B}=-3^{\circ} 12$; coefficient $\mathrm{C}=+8^{\circ} 48^{\prime}$. Find direction of ship's head on stocks. With ship's head at building S. $14^{\circ} \mathrm{W}$. , and coefficient $\mathrm{C}=-1^{\circ} \cdot 47$, find $\mathrm{B}$.

31. Using deviations found in question 21 , find coefficients A, B, C, D, and $\mathbf{E}$; and construct a table of deviations for quadrants N. to $\mathbf{E}$ and $\mathrm{S}$. to W.

32. Steering S. W. by IV., heeling $14^{\circ}$, wind N.N.W., obs. heeling error, $-15^{\circ}$. Required the error when course is changed to $\mathbf{E}$. by N., heeling $10^{\circ}$. 
PAPER VI.

1. Multiply .00483506 by $100 \cdot 0706$ by logs.

2. Divide 6789 by 78900 by logs.

3.

\begin{tabular}{|c|c|c|c|c|c|c|c|}
\hline IIrs. & Courses. & Knts. & 10 ths. & Winds. & $\begin{array}{l}\text { Lee- } \\
\text { way. }\end{array}$ & $\begin{array}{c}\text { Devia- } \\
\text { tion. }\end{array}$ & Remarks. \\
\hline $\begin{array}{l}1 \\
2 \\
3 \\
4 \\
5\end{array}$ & N.E. $\frac{1}{2}$ E. & $\begin{array}{l}14 \\
14 \\
13 \\
14 \\
14\end{array}$ & $\begin{array}{l}6 \\
8 \\
9 \\
3 \\
4\end{array}$ & N.W. $\frac{1}{2} \mathrm{~W}$. & 1 & $20^{\circ} \mathrm{E}$ & $\begin{array}{l}\text { Departure taken } \\
\text { from a point in } \\
\text { lat. } 37^{\circ} 45^{\prime} \mathrm{S} \text {., } \\
\text { long. } 178^{\circ} 32^{\prime} \mathrm{E} \text {.; } \\
\text { bearing by com- }\end{array}$ \\
\hline $\begin{array}{l}6 \\
7 \\
8\end{array}$ & E.N.E. & $\begin{array}{l}14 \\
14 \\
13\end{array}$ & $\begin{array}{l}9 \\
5 \\
6\end{array}$ & W.N.W. & $\frac{1}{4}$ & $21^{\circ} \mathrm{E}$ & $\begin{array}{l}\text { ship's head, } \\
\text { N.E. } \frac{1}{2} \text { E.; devia- } \\
\text { tion as per log, }\end{array}$ \\
\hline $\begin{array}{r}9 \\
10 \\
11 \\
12\end{array}$ & E. by N. $\frac{1}{4} \mathrm{~N}$. & $\begin{array}{l}13 \\
13 \\
14 \\
14\end{array}$ & $\begin{array}{r}9 \\
8 \\
3 \\
-\end{array}$ & W. & - & $22^{\circ} \mathrm{E}$. & Variation, $14^{\circ} \mathrm{E}$. \\
\hline $\begin{array}{l}1 \\
2 \\
3 \\
4\end{array}$ & E. by S. $\frac{1}{2} \mathrm{~S}$. & $\begin{array}{l}14 \\
13 \\
14 \\
14\end{array}$ & $\begin{array}{l}7 \\
6 \\
3 \\
4\end{array}$ & S.W. & $1 \frac{1}{4}$ & $19^{\circ} \mathrm{E}$ & \\
\hline $\begin{array}{l}5 \\
6 \\
7 \\
8\end{array}$ & E.S.E. & $\begin{array}{l}14 \\
13 \\
14 \\
13\end{array}$ & $\begin{array}{l}2 \\
3 \\
1 \\
9\end{array}$ & S.S.IV. & 1 & $18^{\circ} \mathrm{E}$ & 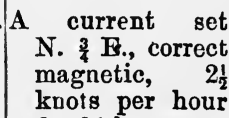 \\
\hline $\begin{array}{r}9 \\
10 \\
11 \\
12\end{array}$ & E.N.E. & $\begin{array}{l}14 \\
14 \\
13 \\
13\end{array}$ & $\begin{array}{l}2 \\
1 \\
9 \\
8\end{array}$ & S.S.W. & $\frac{1}{2}$ & $14^{\circ} \mathrm{E}$ & \\
\hline
\end{tabular}

Find the course and distance made good; lat. and long. of the ship.

4. September 23rd, in long. $8^{\circ} 45^{\prime} \mathrm{W}$., the obs. mer. alt. of the Sun's L.L. bearing north was $47^{\circ} 4^{\prime} 20^{\prime \prime}$; ind. err., $+4^{\prime} 32^{\prime \prime}$; height of eye, $39 \mathrm{ft}$. Required the latitude.

5. Along what parallel is a vessel sailing when for a distance sailed due west of 76 miles she alters her long. $1^{\circ} 30^{\prime}$ ?

6. Required the compass course and distance by Mercator's sailing-

From A, lat. $55^{\circ} 13^{\prime} \mathrm{S}$.

To B, „ $1019 \mathrm{~S}$.

Variation, $3640 \mathrm{~W}$. Deviation, $1410 \mathrm{~W}$.

7. July 13th. Find the M.T.G. of high water at Quaco. 
8. September 18th, in lat. $35^{\circ} 18^{\prime}$ N., long. $156^{\circ} 17^{\prime}$ W., when the A.T.S. (civil time) was $5^{\mathrm{h}} \mathbf{5 4}^{\mathrm{m}}$ A.M., the Sun's bearing by compass was E.N.E. Required the true amplitude, and error of the compass; and supposing the variation to be $14^{\circ} 20^{\prime} \mathrm{E}$., required the deviation of the compass for the position of the ship's head.

9. September 7 th, about $8^{\text {h }} 50^{\mathrm{m}}$ A.M. at ship, in lat. at noon $48^{\circ} 37^{\prime} \mathrm{N}$., approx. long. $149^{\circ} 30^{\prime}$ W., the obs. alt. of Sun's U.L. was $32^{\circ} 35^{\prime} 20^{\prime \prime}$; ind. err., $-4^{\prime} 19^{\prime \prime}$; height of eye, $35 \mathrm{ft}$. ; time by chron., $6^{\mathrm{h}} 41^{\mathrm{m}} 30^{\mathrm{s}}$, which was fast $3^{\mathrm{m}} 10^{\circ} \cdot 6$ for G.M. noon on July 19th, and on August 8th was slow $19^{\circ} \cdot 4$; run since obs. N. $50^{\circ}$ E. 42 miles. Required the long. at sight, also brought up to noon; and if the compass bearing was N. $84^{\circ} 30^{\prime} \mathrm{E}$., and variation $22^{\circ} 15^{\prime} \mathrm{E}$., find true azimuth and deviation.

10. September 12 th, about $2^{\mathrm{h}} 15^{\mathrm{m}}$ P.M., in lat. $35^{\circ} 33^{\prime}$ S., long. $43^{\circ} 27^{\prime}$ E., when a chron. correct for G.M.T. showed $11^{\mathrm{h}} 21^{\mathrm{m}} 21^{\mathrm{s}}$, the Sun's bearing by compass, N. $8^{\circ} 30^{\prime}$ W. Required the true azimuth and error of the compass by the "Tables; " and supposing the variation to be $23^{\circ} 30^{\prime}$.W., required the deviation for the position of the ship's head.

11. September 17 th, about $5^{\mathrm{h}} 15^{\mathrm{m}}$ A.M. at ship, lat. by account $40^{\circ} 35^{\prime} \mathrm{S}$., long. $88^{\circ} 16^{\prime} \mathrm{W}$., the alt. of Aldebaran bearing north was $32^{\circ} 58^{\prime} 40^{\prime \prime}$; ind. err., $-4^{\prime} 18^{\prime \prime}$; height of eye, $37 \mathrm{ft}$. ; time by watch, $10^{\mathrm{h}} 42^{\mathrm{m}} 24^{\circ}$, which had been found to be $24^{\mathrm{m}} 7^{\mathrm{s}}$ slow of M.T.G. ; the diff. long. to the westward 17 miles after the error was determined. Required the lat. by reduction to the meridian.

12. September 23rd, about $9^{\mathrm{h}} 30^{\mathrm{m}}$ A.M. at ship, in lat. $47^{\circ} 30^{\prime} \mathrm{N}$., long. $82^{\circ} 20^{\prime}$ E. by D.R., when the chron. showed $3^{\mathrm{h}} 52^{\mathrm{m}} 39^{\prime}$ G.M.T.; the alt. of the Sun's L.L., $32^{\circ} 13^{\prime} 10^{\prime \prime}$; again P.M. on the same day, when the chron. showed $8^{\mathrm{h}} 52^{\mathrm{m}} 46^{\mathrm{s}}$ G.M.T. ; the alt. of the Sun's L.L., $32^{\circ} 13^{\prime} 10^{\prime \prime}$; ind. err., $-2^{\prime} 8^{\prime \prime}$; height of eye, $28 \mathrm{ft}$.; the ship having made 21 miles on a true N. $60^{\circ}$ E. course in the interval between the observations. Required the line of position when the first alt. was taken, and the Sun's true azimuth; also the position of the ship when the second alt. was observed by "Sumner's mothod" by projection on the chart, assuming the lats. 20 miles on each side of D.R. lat.

13. Find the mean time of passage of Arcturus across the meridian of $38^{\circ} 15^{\prime}$ W. on September 28th.

14. September 28th. What bright stars not less than 2nd mag. are within 2 hours of the meridian, above the horizon and pole in lat. $30^{\circ} \mathrm{S}$., long. $140^{\circ}$ W., at $2^{\mathrm{h}} 15^{\mathrm{m}}$ A.M. M.T.S. ? State their mer. distances and bearings.

15. Calculate for placing on the sextant the mer. alt. of $\gamma$ Cygni in lat. $24^{\circ} 12^{\prime} \mathrm{S}$. ; ind. cor., $+3^{\prime} 27^{\prime \prime}$; eye, $32 \mathrm{ft}$.

16. September 16 th, at $0^{\mathrm{h}} 15^{\mathrm{m}}$ A.s. A.T.S., in lat. $38^{\circ} 47^{\prime} \mathrm{N}$., long. $14^{\circ} 29^{\prime} \mathrm{W}$., the compass bearing of Altair was West. Find from the "Tables" the true azimuth; and if the variation be $23^{\circ} 30^{\prime} \mathrm{W}$., find the deviation.

17. August 5th, about $9^{\mathrm{h}} 30^{\mathrm{m}}$ P.M. at ship, in lat. $48^{\circ} 30^{\prime} \mathrm{N}$., long. by account $50^{\circ} \mathrm{W}$., the obs. alt. of a Cygni, $67^{\circ} 14^{\prime} 30^{\prime \prime}$; ind. cor., $-3^{\prime} 13^{\prime \prime}$; eye, $39 \mathrm{ft}$.; when a chron. showed $11^{\mathrm{h}} 57^{\mathrm{m}} 25^{\mathrm{A}}$, which had been found to be $45^{\mathrm{m}} 32^{\mathrm{s}}$ slow of G.M. noon on June 6 th, and $48^{\mathrm{m}} 13^{\mathrm{s}}$ slow on June $26 \mathrm{th}$. Find the longitude.

18. August 26 th, at $9^{\mathrm{h}} 14^{\mathrm{m}} 23^{\prime}$ P.M. M.T.S., in long. $64^{\circ} 45^{\prime} \mathrm{W}$., the obs. alt. of the Pole star out of the meridian was $38^{\circ} 29^{\prime} 20^{\prime \prime}$; ind. cor., $+2^{\prime} 25^{\prime \prime}$; eye, $37 \mathrm{ft}$. Find the latitude.

19. August $7 \mathrm{th}$, in long. $48^{\circ} 45^{\prime} \mathrm{W}$., the obs. mer. alt. of the Moon's L.L. was $32^{\circ} 17^{\prime} 50^{\prime \prime}$ bearing north ; ind. cor., $-5^{\prime} 5^{\prime \prime}$, height of eye, $48 \mathrm{ft}$. Required the latitude.

20. August 13th, the obs. mer. alt. of the star a Ursæ Majoris was $62^{\circ} 15^{\prime} 30^{\prime \prime}$ zenith south of star; ind. err., $-4^{\prime} 45^{\prime \prime}$; height of eye, $36 \mathrm{ft}$. Required the latitude. 
21.

\begin{tabular}{c|c|c|c|c|c}
\hline $\begin{array}{c}\text { Ship's bead by } \\
\text { standard } \\
\text { compass. }\end{array}$ & $\begin{array}{c}\text { Bearings of distant } \\
\text { object by standard } \\
\text { compass. }\end{array}$ & $\begin{array}{c}\text { Deviation } \\
\text { required. }\end{array}$ & $\begin{array}{c}\text { Ship's head by } \\
\text { standard } \\
\text { compass. }\end{array}$ & $\begin{array}{c}\text { Bearings of distant } \\
\text { object by standard } \\
\text { compass. }\end{array}$ & $\begin{array}{c}\text { Deviation } \\
\text { required. }\end{array}$ \\
\cline { 1 - 2 } N. & S. $5^{\circ} \mathrm{W}$. & & S. & S. $10^{\circ} \mathrm{E}$. \\
N.E. & S. $6^{\circ} \mathrm{E}$. & & S.W. & S. $7^{\circ} \mathrm{W}$. \\
E. & S. $18^{\circ} \mathrm{E}$. & & W. & $18^{\circ} \mathrm{W}$. \\
S.E. & S. $17^{\circ} \mathrm{E}$. & & N.W. & S. $21^{\circ} \mathrm{W}$. & \\
\hline
\end{tabular}

Find correct magnetic bearing, and construct a curve.

Given magnetic courses : N. by W. W. $\frac{3}{4}$ S. S.E. $\frac{1}{4}$ E. N. $32^{\circ}$ E. Find compass courses.

Given compass courses : E. by S. $\frac{1}{2}$ S. S.W. $\frac{3}{4}$ S. W. $\frac{1}{2}$ N. N. $8^{\circ}$ W. Find magnetic courses.

With ship's head at E. by S. by compass, the compass bearings of distant objects were N.W. $\frac{1}{4}$ W. and S.W. $\frac{3}{4}$ W. Find magnetic bearings.

22. On January 10th, at $8^{\text {h }} 15^{\mathrm{m}}$ A.M. M.T.M., being off Beachy Head by reckoning, took a cast of the lead. Required the correction to be applied to the depth obtained by the lead-line, before comparing it with the depth marked on the chart.

23. August 30th, at $8^{\mathrm{h}} 29^{\mathrm{m}} 30^{\circ}$ P.M. at ship, in lat. $10^{\circ} 15^{\prime}$ S., long by D.R. $98^{\circ} 14^{\prime}$ E., when a chron. which had stopped and been set going showed $1^{\mathrm{b}} 4 \tilde{\sigma}^{\mathrm{m}}$, the obs. alt. of the Moon's L.L. was $76^{\circ} 38^{\prime} 40^{\prime \prime}$; obs. alt. of Antares was $49^{\circ} 33^{\prime} 50^{\prime \prime}$; ind. cor. to alts., $-2^{\prime} 15^{\prime \prime}$; height of eye, $40 \mathrm{ft}$. ; obs. distance between the Star and Moon's near limb, $44^{\circ} 44^{\prime} 30^{\prime \prime}$; ind. cor., $+2^{\prime} 47^{\prime \prime}$. Find longitude and error of chron. on M.T.G.

24. August 19th, in lat. $48^{\circ} 30^{\prime}$ S., long. $157^{\circ}$ E. by D.R., the following obs. were made for finding lat. at second obs. by "Ivory" or "Direct" method :-

\begin{tabular}{|c|c|c|}
\hline $\begin{array}{l}\text { Mean ship times. } \\
8^{\mathrm{h}} 13^{\mathrm{m}} \text { P.M. } \\
1233\end{array}$ & $\begin{array}{l}\text { G.M.T. by chron. } \\
9^{\text {h }} 42^{\mathrm{m}} 40^{\mathrm{s}} \\
2 \quad 2 \quad 40\end{array}$ & $\begin{array}{l}\text { Obs. alt. } \text { al Crucis. }^{\prime} \text { Cru } \\
44^{\circ} 19^{\prime} 30^{\prime \prime} \text { bearing S. } 40 \frac{1}{2} \text { W. } \\
233850\end{array}$ \\
\hline
\end{tabular}

Run between obs. N. $20 \frac{1}{2}^{\circ}$ W., 12 knots per hour ; ind. cor., $-2^{\prime} 12^{\prime \prime}$; eye, $36 \mathrm{ft}$.

25. September 4th, at $2^{\text {h }}$ A.M. A.T.S., Cape Lobos in lat. $18^{\circ} 45^{\prime}$ S., long. $70^{\circ} 24^{\prime}$ W., bore S. $40^{\circ} \mathrm{E}$., distant 17 miles; the obs. alt. of a Gruis in artificial horizon was $79^{\circ} 34^{\prime} 40^{\prime \prime}$; ind. cor., $+4^{\prime} 16^{\prime \prime}$. If a chron. showed $6^{\mathrm{h}} 40^{\mathrm{m}}$, find its error on M.T.G.

26. Find initial course and distance on a composite track, highest lat. $50^{\circ} \mathrm{S}$., and lats. of points where meridians of $120^{\circ} \mathrm{W}$. and $180^{\circ} \mathrm{W}$. cut the track一

$$
\begin{aligned}
& \text { From lat. } 33^{\circ} 3^{\prime} \mathrm{S} \text {, long. } 71^{\circ} 38^{\prime} \mathrm{W} \text {. } \\
& \text { To ,, } 41 \quad 16 \mathrm{~S} \text {,, , } 174 \quad 53 \mathrm{E} \text {. }
\end{aligned}
$$

27. In the triangle $\mathrm{ABC}, \mathrm{C}=90^{\circ}, \mathrm{AC}=15,866 \mathrm{ft}$., $\mathrm{BC}=13,000 \mathrm{ft}$. Find the angles, and length of line drawn from $\mathrm{B}$ to $\mathrm{AC}$, bisecting angle ABC.

28. The elevation of a tower at $\mathrm{A}$ is $28^{\circ} 17^{\prime}$; at $\mathrm{B}$, in the same horizontal plane and $155 \mathrm{ft}$. nearer the tower, the elevation is $62^{\circ} 37^{\prime}$. Find height of tower.

29. A vessel sails for 18 hours S.E. by S. 95 miles by the log, in a current setting S. by W. $\frac{1}{2}$ W. 2 knots per hour. What is the course and distance made good?

30. Using deviations from question 21 , find coefficients $A, B, C, D$, and $E$, 
and construct a table showing deviations for each point from N.N.E. to S.E. through east.

31. The Sun's declination being $18^{\circ} 30^{\prime} \mathrm{N}$., and his true bearing at rising N.E. by E. $\frac{3}{4}$ E., find the lat. and hour angle at rising.

32. Construct a Mercator's chart, scale $1.8 \mathrm{in}$. to $1^{\circ}$ long, extending from $59^{\circ}$ to $61^{\circ} \mathrm{S}$, and $28^{\circ} 30^{\prime} \mathrm{W}$. to $31^{\circ} 30^{\prime} \mathrm{W}$. A ship sails by compass from lat. $59^{\circ} 40^{\prime}$ S., long. $30^{\circ} 30^{\prime}$ W., as follows : S.E. by S., 57 miles (deviation $3^{\circ}$ W.) ; W., 25 miles (dev. $8^{\circ} 30^{\prime}$ E.) ; variation, $10^{\circ} \mathrm{E}$. Find position of ship, course, and dist. made good.

33. Steering W. $\frac{1}{4}$ N., on the port tack, heeling $12^{\circ}$; the error obs. was $-1^{\circ}$. Find the amount when steering south on the starboard tack, and heeling $15^{\circ}$.

\section{Paper VII.}

1. Multiply $13 \cdot 5426$ by 51400 , by logs.

2. Divide 7560009 by $387 \cdot 003$, by logs.

3.

\begin{tabular}{|c|c|c|c|c|c|c|c|}
\hline Hrs. & Courses. & Knts. & 10th8. & Winds. & $\begin{array}{l}\text { Lee- } \\
\text { way. }\end{array}$ & $\begin{array}{c}\text { Devia- } \\
\text { tion. }\end{array}$ & Remarks. \\
\hline $\begin{array}{r}1 \\
2 \\
3 \\
4 \\
5 \\
6 \\
7 \\
8 \\
9 \\
10 \\
11 \\
12 \\
1 \\
2 \\
3 \\
4 \\
5 \\
6 \\
7 \\
8 \\
9 \\
10 \\
11 \\
12\end{array}$ & $\begin{array}{c}\text { N.W. } \\
\text { N.N.W. } \\
\text { W.S.W. } \\
\text { N.N.W. } \frac{1}{2} \text { W. }\end{array}$ & $\begin{array}{l}10 \\
10 \\
11 \\
11 \\
12 \\
12 \\
11 \\
11 \\
11 \\
11 \\
12 \\
12 \\
12 \\
12 \\
12 \\
12 \\
12 \\
12 \\
12 \\
12 \\
12 \\
12 \\
12 \\
12\end{array}$ & $\begin{array}{l}\mathbf{5} \\
\mathbf{5} \\
\mathbf{5} \\
\mathbf{5}\end{array}$ & $\begin{array}{c}\text { W.S.W. } \\
\text { W. } \\
\text { N.W. } \\
\text { W. }\end{array}$ & $\begin{array}{l}1 \\
\frac{1}{4} \\
\frac{3}{4} \\
0\end{array}$ & $\begin{array}{l}10^{\circ} \mathrm{E} . \\
15^{\circ} \mathrm{E} . \\
8^{\circ} \mathrm{W} . \\
15^{\circ} \mathrm{E} .\end{array}$ & $\begin{array}{l}\text { Departure taken } \\
\text { from a point in } \\
\text { lat. } 50^{\circ} 10^{\prime} \mathrm{S} \text {., } \\
\text { long. } 110^{\circ} 15^{\prime} \mathrm{W} \text {. } \\
\text { Variation, } 20^{\circ} \mathrm{E} \text {. } \\
\\
\text { Position by obser- } \\
\text { vation at end of } \\
\text { run, lat. } 46^{\circ} 10^{\prime} \mathrm{S} \text {., } \\
\text { long. } 110^{\circ} 30^{\prime} \mathrm{W} \text {. }\end{array}$ \\
\hline
\end{tabular}

Find the set and drift of the current.

4. September 30th, in long. $124^{\circ} 26^{\prime}$ E., the obs. mer. alt. of the Sun's U.L. bearing south was $88^{\circ} 56^{\prime} 40^{\prime \prime}$; ind. err., + $1^{\prime} 44^{\prime \prime}$; height of eye, $41 \mathrm{ft}$. Required the latitude.

5. From lat. $51^{\circ} 23^{\prime}$ N., long. $9^{\circ} 36^{\prime} \mathrm{W}$., the distance sailed due west was 250 miles. Required present position.

6. Required the compass course and distance by Mercator's sailing-

From A, lat. $38^{\circ} 13^{\prime} \mathrm{S}$.

To B, \#, $5210 \mathrm{~N}$.

Variation, $130 \mathrm{E}$.

Long. $178^{\circ} 43^{\prime} \mathrm{W}$.

Deviation, $\begin{array}{r}165 \\ 5\end{array}$ 
7. September 28th. Find the M.T.S. of H.W. at Port Carlisle.

8. August 25 , in lat. $48^{\circ} 30^{\prime}$ S., long. $49^{\circ} 35^{\prime}$ E., when the M.T.S. was $6^{\mathrm{h}} 50^{\mathrm{m}}$ A.M., the Sun's bearing by compass was E. by S. $\frac{1}{4} \mathrm{~S}$. Required the true amplitude and error of the compass ; and supposing the variation to be $33^{\circ} 20^{\prime} \mathrm{W}$., required the deviation of the compass for the position of the ship's head.

9. September 24th, about $2^{\text {h }} 45^{\mathrm{m}}$ P.M. at ship, in lat. $23^{\circ} 28^{\prime} \mathrm{S}$., long. $158^{\circ} 30^{\prime}$ E., the obs. alt. of Sun's U.L. was $41^{\circ} 32^{\prime} 20^{\prime \prime}$; ind. err., $-2^{\prime} 35^{\prime \prime}$; height of eye, $34 \mathrm{ft}$.; time shown by chron., $3^{\mathrm{h}} 58^{\mathrm{m}} 53^{\mathrm{a}}$, which was slow $21^{\mathrm{m}} 41^{\circ}$ for G.M. noon on April 11th, and on July 20 th was slow $18^{\mathrm{m}} 14^{*}$; the compass bearing was W.N.W. Required the long., compass error, and deviation, the variation being $6^{\circ} 30^{\prime} \mathrm{E}$.

10. August 24 th, about $8^{\mathrm{h}} 30^{\mathrm{m}}$ A.m. in lat. $44^{\circ} 17^{\prime} \mathrm{S}$., long. $15^{\circ} 45^{\prime} \mathrm{W}$., when a chron. which was $8^{\mathrm{m}} 43^{\mathrm{a}}$ slow of G.M.T. showed $9^{\mathrm{h}} 29^{\mathrm{m}} 32^{\mathrm{a}}$; the Sun's bearing by compass N.F. $\frac{3}{4}$ E. Required the true azimuth and error of the compass by the "Tables;" and supposing the variation to be $12^{\circ} 40^{\prime} \mathrm{W}$., required the deviation for the position of the ship's head.

11. September 29 th, A.M. at ship, lat. by account $44^{\circ} 15^{\prime} \mathrm{N}$., long. $47^{\circ} 42^{\prime}$ W.; the alt. of the Sun's L.L., $43^{\circ} 0^{\prime} 30^{\prime \prime}$; ind. err., $-3^{\prime} 3^{\prime \prime}$; height of eye, $32 \mathrm{ft}$; time by chron., $2^{\mathrm{h}} 33^{\mathrm{m}} 56^{\mathrm{a}}$, which had been found to be $3^{\mathrm{h}} 2^{\mathrm{m}} 38^{\mathrm{a}}$ fast of A.T.S.; the run was N. $34^{\circ} \mathrm{E} .25$ miles, after the error was determined. Required the lat. by reduction to the meridian ; and if the run on the same course was 4 miles, find the lat. at noon.

12. August 4 th, about $8^{\mathrm{h}} 15^{\mathrm{m}}$ A.M. at ship, in lat. $47^{\circ} 20^{\prime}$ S., long. Greenwich when the chron. showed $8^{\mathrm{b}} 20^{\mathrm{m}} 51^{*}$ G.M.T. ; the alt. of the Sun's U.L., $9^{\circ} 9^{\prime} 20^{\prime \prime}$; again P.M. on the same day, when the chron. showed $2^{\mathrm{h}} 22^{\mathrm{m}} 42^{\mathrm{z}}$ G.M.T. : the alt. of the Sun's U.L., $18^{\circ} 45^{\prime}$; ind. err., $-2^{\prime} 23^{\prime \prime}$; height of eye, $23 \mathrm{ft}$.; the ship having made 48 miles on a true S.W. $\frac{3}{4} \mathrm{~W}$. course in the interval between the observations. Required the line of position, the Sun's true azimuth, and the position of the ship when the second alt. was observed by "Sumner's method" by projection on the chart, assuming the lats. $46^{\circ} 50^{\prime}$ and $47^{\circ} 20^{\prime} \mathrm{S}$.

13. Find the apparent time of the meridian passage of Castor on August 23rd in long. $49^{\circ} 30^{\prime} \mathrm{E}$. ; also by inspection.

14. Calculate the meridian alt. of $\in$ Sagittarii for placing on the sextant in lat. $24^{\circ} 30^{\prime} \mathrm{N}$.; ind. cor., $-5^{\prime} 14^{\prime \prime}$; eye, $40 \mathrm{ft}$.

15. Find what stars of not less than second mag. are within 2 hours east of the meridian of a place lat. $40^{\circ} \mathrm{N}$., long. $150^{\circ} \mathrm{E}$., above the horizon and pole on August 21 st at $5^{\mathrm{h}} 50^{\mathrm{m}}$ A.M. M.T.S., and state their meridian distances.

16. August 12 th, about $11^{\text {b }}$ P.M. at ship, lat. $54^{\circ} 26^{\prime}$ S., long. $160^{\circ} 25^{\prime} \mathrm{E}$., when a chron. correct for M.T.G. showed $12^{\mathrm{h}} 48^{\mathrm{m}} 20^{\mathrm{z}}$, the compass bearing of $\alpha$ Ophiuchi was N.W. $\frac{1}{4}$ W. The variation being $17^{\circ}$ E., find from the "Tables" the true bearing, and thence the deviation.

17. August 30 th, about $8^{\mathrm{h}} 30^{\mathrm{m}}$ P.M. at ship, in lat. $10^{\circ} 15^{\prime} \mathrm{S}$., long. $98 \frac{1}{2}^{\circ} \mathrm{E}$. by D.R., the obs. alt. of Antares was $49^{\circ} 33^{\prime} 50^{\prime \prime}$; ind. cor., $-2^{\prime} 15^{\prime \prime}$; eye, $40 \mathrm{ft}$. ; when a chron. showed $11^{\mathrm{h}} 34^{\mathrm{m}} 24^{\mathrm{s}}$, which was $2^{\mathrm{h}} 17^{\mathrm{m}} 38^{\mathrm{a}}$ slow on June 21st, and slow $2^{\mathrm{h}} 19^{\mathrm{m}} 44^{\mathrm{s}}$ on July 21 st for G.M.T. Find the longitude.

18. September 25 th, at $11^{\mathrm{h}} 30^{\mathrm{m}} 50^{\circ}$ P.M. A.T.S., in long. $129^{\circ} 19^{\prime}$ E., the obs. alt. of Polaris out of the meridian was $21^{\circ} 24^{\prime} 50^{\prime \prime}$; ind. cor., $+1^{\prime} 14^{\prime \prime}$; eye, $38 \mathrm{ft}$. Find the latitude.

19. August $30 \mathrm{th}$, in long. $14^{\circ} 55^{\prime}$ E., the obs. mer. alt. of the Moon's upper limb zenith north of Moon was $29^{\circ} 46^{\prime} 40^{\prime \prime}$; ind. cor., $+2^{\prime} 29^{\prime \prime}$; eye, $51 \mathrm{ft}$. Find the latitude.

20. August 10th, the obs. mer. alt. of the star Arcturus was $37^{\circ} 50^{\prime} 20^{\prime \prime}$ bearing south ; ind. err., $-4^{\prime} 37^{\prime \prime}$; height of eye, $39 \mathrm{ft}$. Required the latitude. 
21.

\begin{tabular}{|c|c|c|c|c|c|}
\hline $\begin{array}{l}\text { Ship's head by } \\
\text { standard } \\
\text { compass. }\end{array}$ & $\begin{array}{l}\text { Bearings of distant } \\
\text { object by standard } \\
\text { compass. }\end{array}$ & $\begin{array}{l}\text { Deviation } \\
\text { required. }\end{array}$ & $\begin{array}{l}\text { Ship's head by } \\
\text { standard } \\
\text { compass. }\end{array}$ & $\begin{array}{l}\text { Bearings of distant } \\
\text { object by standard } \\
\text { compass. }\end{array}$ & $\begin{array}{l}\text { Deviation } \\
\text { required. }\end{array}$ \\
\hline $\begin{array}{l}\text { N. } \\
\text { N.E. } \\
\text { E. } \\
\text { S.E. }\end{array}$ & $\begin{array}{l}\text { N. } 44^{\circ} \mathrm{W} . \\
\text { N. } 47^{\circ} \mathrm{W} . \\
\text { N. } 80^{\circ} \mathrm{W} . \\
\text { S. } 76^{\circ} \mathrm{W} .\end{array}$ & & $\begin{array}{c}\text { S. } \\
\text { S.W. } \\
\text { W. } \\
\text { N.W. }\end{array}$ & $\begin{array}{l}\text { S. } 79^{\circ} \mathrm{W} \text {. } \\
\text { S. } 89^{\circ} \mathrm{W} \text {. } \\
\text { N. } 69^{\circ} \mathrm{W} . \\
\text { N. } 52^{\circ} \mathrm{W} .\end{array}$ & \\
\hline
\end{tabular}

Find correct magnetic bearing, and construct a curve.

Given magnetic courses : N. $30^{\circ}$ W. S. $55^{\circ}$ E. S. $66^{\circ}$ W. N. $35^{\circ}$ E. Find compass courses.

Given compass courses : E. $\frac{3}{4}$ S. S.S.W. $\frac{1}{4}$ W. W. $\frac{1}{4}$ N. N.W. by W. Find magnetic courses.

With ship's head at N. $\frac{1}{2}$ E. by compass, the compass bearings of distant objects were S. $55^{\circ}$ W. and N. $32^{\circ}$ W. Find magnetic bearings.

22. On September 21st, at $1^{\text {h }}$ P.M. M.T.S., being off Torbay by reckoning, took a cast of the lead. Required the correction to be applied to the depth obtained by the lead-line, before comparing it with the depth marked on the chart.

23. August 12th, A.M. at ship, in lat. $25^{\circ} 19^{\prime} \mathrm{S}$., when the time by a chron. estimated $10^{\mathrm{m}} 30^{\mathrm{s}}$ fast of M.T.G. was $11^{\mathrm{d}} 5^{\mathrm{h}} 50^{\mathrm{m}} 50^{\mathrm{s}}$; the obs. alt. of Saturn was $41^{\circ} 1^{\prime}$; ind. cor., $+2^{\prime} 14^{\prime \prime}$; height of eyc, $29 \mathrm{ft}$.; observed distance between Saturn's centre and the Moon's remote limb was $61^{\circ} 2^{\prime} 10^{\prime \prime}$; ind. cor., $-3^{\prime} 15^{\prime \prime}$. Find the true and apparent alts. of the moon, longitude, and error of chron. for G.M.T.

24. September 29th, P.M. at ship, in lat. N., long. $180^{\circ} \mathrm{W}$., with the following observations, find the lat. at second obs. by "Ivory" or "Direct" method :-
Approx. A.T.S.
$0^{\mathrm{b}} 30^{\mathrm{m}}$ P.M.
M.T.G. by chron.
$0^{\mathrm{h}} 20^{\mathrm{m}} 39^{\mathrm{x}}$
43246
Obs. alt. Sun's L.L.
$40^{\circ} 35^{\prime} 40^{\prime \prime} \quad$ No ind. cor.
442 P.M.
11120 Height of eye,

Sun's bearing at first obs., S. $10^{\circ}$ W. ; run between obs., N. $45^{\circ}$ W. 42 miles.

25. September 28th, at $1^{\text {h }} 30^{\mathrm{m}}$ A.M., M.T.S. when Cape San Roque, lat. $5^{\circ} 29^{\prime}$ S., long. $35^{\circ} 15^{\prime} \mathrm{W}$., bore N. $64^{\circ} \mathrm{W}$. distant 16 miles ; the obs. alt. of Capella in artificial horizon was $45^{\circ} 20^{\prime} 30^{\prime \prime}$; ind. cor., $+1^{\prime} 16^{\prime \prime}$. If a chron. showed $4^{\mathrm{b}} 10^{\mathrm{m}} 5^{\mathrm{s}}$, find its error on M.T.G.

26. Find the first and last courses on a great circle, from Tarifa, lat. $36^{\circ} 0^{\prime} \mathrm{N}$., long. $5^{\circ} 37^{\prime} \mathrm{W}$., to Monte Video, lat. $34^{\circ} 57^{\prime}$ S., long. $55^{\circ} 55^{\prime} \mathrm{W}$., position of vertex, distance, the course to steer crossing the equator, and the long. to cross the equator.

27. The summit of a spire is vertically over the middle point of a horizontal square enclosure whose side is $1000 \mathrm{ft}$. long; the shadow of the spire reaches a corner of the square when the sun has an altitude of $27^{\circ} 29^{\prime} 48^{\prime \prime}$. Required the height of the summit of the spire above the level of the square.

28. An island bears from a cape S.E. $\frac{1}{2}$ E. 35 miles; a ship bound to the island meets a tide running to the eastward, and finds herself after some time 28 miles from the island, and 40 miles from the cape. Required the bearing of the island and set of the tide.

29. Calculate angle $\mathrm{A}$ and side $\mathrm{AC}$ of a spherical triangle, having given $\mathrm{C}=90^{\circ}, \mathrm{AB}=74^{\circ} 49^{\prime}$, and $\mathrm{BC}=30^{\circ}$.

30. Taking the deviations as found in question 21, find coefficients $\mathrm{A}, \mathrm{B}, \mathrm{C}, \mathrm{D}$, and $\mathrm{E}$; and thence calculate a table of deviations for each point from $W$. to $E$. through south. 
31. Steering N.W. $\frac{1}{2}$ W., heeling $10^{\circ}$ to port, the heeling error was found to be $-15^{\circ}$. What will be the amount when steering E. $\frac{1}{2} \mathrm{~N}$., and heeling $20^{\circ}$ to starboard?

32. August 26th, about $5^{\text {h }}$ A.M., in lat. $5^{\circ} 30^{\prime}$ S., long. $40^{\circ} 30^{\prime}$ W., the obs. compass bearing of a Persei was North, the variation being $6^{\circ} 15^{\prime} \mathrm{W}$. Find the deviation, when a chron. correct for G.M.T. showed $7^{\mathrm{h}} 45^{\mathrm{m}}$.

\section{Paper VIII.}

1. Multiply $\cdot 0043$ by $\cdot 00025$, by logs.

2. Divide 9999.99 by 100,000 , by logs.

3.

\begin{tabular}{|c|c|c|c|c|c|c|c|}
\hline Hrs. & Courses. & Knts. & 10tha. & Winds. & $\begin{array}{l}\text { Lee- } \\
\text { way. }\end{array}$ & $\begin{array}{l}\text { Devia- } \\
\text { tion. }\end{array}$ & Remarks. \\
\hline $\begin{array}{r}1 \\
2 \\
3 \\
4 \\
5 \\
6 \\
7 \\
8 \\
9 \\
10 \\
11 \\
12\end{array}$ & 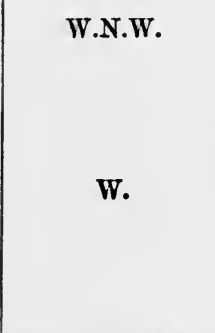 & $\begin{array}{l}12 \\
12 \\
12 \\
12 \\
13 \\
13 \\
13 \\
13 \\
14 \\
14 \\
14 \\
14\end{array}$ & & N.N.W. & $\begin{array}{c}\text { pts. } \\
\frac{1}{6}\end{array}$ & $35^{\circ} \mathrm{W}$. & $\begin{array}{l}\text { Departure taken } \\
\text { from a point in } \\
\text { lat. } 59^{\circ} 49^{\prime} \mathrm{N} \text {, } \\
\text { long. } 43^{\circ} 54^{\prime} \mathrm{W} \text {.; } \\
\text { bearing by com- } \\
\text { pass, E. by N.; } \\
\text { ship } \mathrm{W} \text {, head, } \\
\mathrm{N} . \mathrm{W} . \frac{1}{2} \mathrm{~N} . \text {; de- } \\
\text { viation as per } \\
\text { log, distant } 30 \\
\text { miles. }\end{array}$ \\
\hline $\begin{array}{r}1 \\
2 \\
3 \\
4 \\
5 \\
6 \\
7 \\
8 \\
9 \\
10 \\
11 \\
12\end{array}$ & 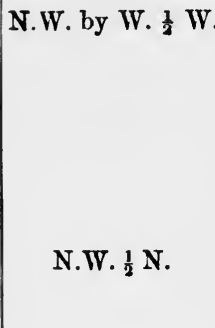 & $\begin{array}{l}14 \\
14 \\
12 \\
12 \\
15 \\
15 \\
15 \\
15 \\
15 \\
15 \\
15 \\
15\end{array}$ & & N.E. by $\mathbf{N}$. & $\frac{1}{4}$ & $21^{\circ} \mathrm{W}$. & $\begin{array}{l}\text { Variation : first } 8 \\
\text { hours, } 51^{\circ} \mathrm{W} \text {; ; } \\
\text { second } 8 \text { hours, } \\
49^{\circ} \mathrm{W} . ; \text { third } 8 \\
\text { hours, } 47^{\circ} \mathrm{W} \text {. } \\
\text { A current set true } \\
\text { S. } 65^{\circ} \text { W., } 10 \\
\text { miles for the } 24 \\
\text { hours. }\end{array}$ \\
\hline
\end{tabular}

Find the course and distance made good; lat. and long. of the ship.

4. September $24 \mathrm{th}$, in long. $172^{\circ} 15^{\prime} \mathrm{E}$., the obs. mer. alt. of the Sun's L.L. zenith south of Sun was $56^{\circ} 42^{\prime} 10^{\prime \prime}$; ind. err., $-2^{\prime} 23^{\prime \prime}$.; height of eye, $43 \mathrm{ft}$. Required the latitude.

5. At noon the lat. is $51^{\circ} 20^{\prime} \mathrm{S}$. ; by morning sights the long. was found to be $85^{\circ} 40^{\prime} \mathrm{W}$.; run since sights, East 76 miles. Find noon longitude.

6. Required the compass course and distance by Mercator's sailing-

From A, lat. $35^{\circ} \quad 7^{\prime} \mathrm{N}$. Long. $141^{\circ} 6^{\prime} \mathrm{E}$. To B, ," $5453 \mathrm{~S}$. $\quad,, 7535 \mathrm{~W}$. Variation, 120 E. Deviation, $1840 \mathrm{~W}$. 
7. September 13th. Find the M.T.S. of high water at Dartmouth.

8. September 28 th, about $6^{\text {h }}$ P.M., in lat. $50^{\circ} 5^{\prime}$ N., long. $175^{\circ} 30^{\prime}$ W., when a chron. correct for M.T.G. showed $5^{\text {h }} 43^{\mathrm{m}} 24^{\mathrm{s}}$, the Sun's bearing by compass was N. $84^{\circ} 30^{\prime} \mathrm{W}$. Required the true amplitude, and error of the compass; and supposing the variation to be $18^{\circ} 20^{\prime} \mathrm{E}$., required the deviation of the compass for the position of the ship's head.

9. August 4th, about $8^{\mathrm{h}} 20^{\mathrm{m}}$ A.M. at ship, in lat. $47^{\circ} 24^{\prime}$ S., long. Greenwich, the obs. alt. of Sun's U.L. was $8^{\circ} 16^{\prime} 30^{\prime}$; ind. err., + $3^{\prime} 12^{\prime \prime}$; height of eye, $28 \mathrm{ft}$.; time by cliron., $8^{\mathrm{h}} 18^{\mathrm{m}} 59^{\mathrm{s}}$, which was $3^{\mathrm{m}}$ fast for G.M. noon on May 31st, and on July 10 th was correct. Find the long.; also, if the compass bearing was $\mathrm{N}$. $50^{\circ} 30^{\prime} \mathrm{E}$. and variation $10^{\circ} 30^{\prime} \mathrm{W}$., find the deviation.

10. September 22nd, about $5^{\text {b }}$ P.M., in lat. $57^{\circ} 11^{\prime} \mathrm{N}$., long. $169^{\circ} 28^{\prime} \mathrm{E}$., when a chron. correct for M.T.G. showed $5^{\text {h }} 42^{\mathrm{m}} 23^{\mathrm{s}}$, the Sun's bearing by compass, S. $60^{\circ} \mathrm{W}$. Required the true azimuth and error of the compass by the "Tables;" and supposing the variation to be $10^{\circ} 40^{\prime} \mathrm{E}$., required the deviation for the position of the ship's head.

11. September 21 st, about $10^{\mathrm{b}} 20^{\mathrm{m}}$ P.M. at ship ; lat. by account $43^{\circ} 30^{\prime} \mathrm{N}$., long. $146^{\circ} 27^{\prime}$ E. ; the alt. of Fomalhaut, $16^{\circ} 5^{\prime} 40^{\prime \prime}$; ind. err., $-4^{\prime} 11^{\prime \prime}$; height of eye, $27 \mathrm{ft}$. ; time shown by chron., $12^{\mathrm{h}} 12^{\mathrm{m}} 54^{\mathrm{*}}$, which had been found to be $16^{\mathrm{m}} 44^{\circ}$ slow of M.T.G. Required the latitude by reduction to the meridian.

12. October 1st, about $11^{\mathrm{b}} 30^{\mathrm{m}}$ A.x. at ship, in lat. $49^{\circ} 20^{\prime} \mathrm{N}$., long. $179^{\circ} 50^{\prime}$ E. by D.R., when the chron. showed $11^{\mathrm{h}} 21^{\mathrm{m}} 24^{\circ}$ G.M.T., the alt. of the Sun's L.L., $37^{\circ} 30^{\prime} 50^{\prime \prime}$; again P.Mr. on the same day, when the chron. showed $3^{\mathrm{h}} 4^{\mathrm{m}} 26^{\mathrm{a}}$ G.M.T. ; the alt. of the Sun's L.L. $23^{\circ} 6^{\prime} 30^{\prime \prime}$; ind. err., $-2^{\prime} 9^{\prime \prime}$; height of eye, $32 \mathrm{ft}$.; the ship having made 50 miles on a true $\mathrm{S} .81^{\circ} \mathrm{W}$. course in the interval between the observations. Required the line of position when the first alt. was taken, the Sun's true azimuth, and the position of the ship when the second alt. was observed by "Sumner's method" by projection on the chart, assuming the lats. $48^{\circ} 40^{\prime} \mathrm{N}$. and $49^{\circ} 20^{\prime} \mathrm{N}$.

13. Find the mean time of transit of Sirius across the meridian of $62^{\circ} 15^{\prime} \mathrm{W}$. on August 30th.

14. Find what bright stars up to mag. $2 \cdot 5$ are within 1 hour E. and W. of the meridian, above the horizon and pole, in lat. $35^{\circ} \mathrm{S}$., long. $160 \mathrm{~W}$., at $4^{\mathrm{b}} 30^{\mathrm{m}}$ A.M. A.T.S. on September 23rd. State their hour angles, and bearings when on meridian.

15. Calculate the mer. alt. for placing on sextant of $\alpha$ Ophiuchi in lat. $55^{\circ} 30^{\prime} \mathrm{N}$. ; ind. cor., $5^{\prime} 14^{\prime \prime}$ on the arc ; eye, $40 \mathrm{ft}$.

16. September 14th, about $9^{\mathrm{h}}$ P.M., in lat. $35^{\circ} 37^{\prime}$ N., long. $74^{\circ} 20^{\prime} \mathrm{W}$., when a chron. showed $2^{\mathrm{h}} 12^{\mathrm{m}} 10^{\mathrm{a}}$ G.M.T., the compass bearing of $\gamma$ Pegasi was $\mathbf{E}$. by N. Find from the "Tables" the true azimuth; and if the variation was $5^{\circ} 15^{\prime} \mathrm{W}$., find the deviation.

17. August 20th, about $0^{\mathrm{h}} 30^{\mathrm{m}}$ A.M., in lat. $48^{\circ} 20^{\prime} \mathrm{S}$., long. $157^{\circ} \mathrm{E}$. by D.R., the obs. alt. of $a^{1}$ Crucis W. of mer. was $23^{\circ} 38^{\prime} 50^{\prime \prime}$; ind. cor., $-2^{\prime} 8^{\prime \prime}$; eye, $36 \mathrm{ft}$. ; time shown by chron., $2^{\mathrm{h}} 11^{\mathrm{m}} 9^{\prime}$, which had been found fast $7^{\mathrm{m}} 29^{\circ}$ of G.M. noon on June 5 th, and fast $8^{\mathrm{m}} 13^{\mathrm{a}}$ on July 30 th. Find the longitude.

18. August 30 th at $2^{\mathrm{h}} 47^{\mathrm{m}} 23^{\mathrm{s}}$ A.M. M.T.S., in long. $165^{\circ} 15^{\prime} \mathrm{W}$, the obs. alt. of Polaris out of the meridian was $30^{\circ} 2^{\prime} 10^{\prime \prime}$; ind. cor., $-2^{\prime} 16^{\prime \prime}$; eye, $25 \mathrm{ft}$. Required the latitude.

19. September 1st, in long. $174^{\circ} 30^{\prime}$ E., the obs. mer. alt. of the Moon's L.L. was $81^{\circ} 11^{\prime} 24^{\prime \prime}$, zenith north of Moon; ind. cor., $-4^{\prime} 15^{\prime \prime}$; eye, $27 \mathrm{ft}$. Required the latitude.

20. September 20th. The obs. mer. alt. of the star $\lambda$ Scorpii was $41^{\circ} 13^{\prime} 10^{\prime \prime}$ bearing south; ind. err., $-1^{\prime} 49^{\prime \prime}$; height of eye, $25 \mathrm{ft}$. Required the latitude. 
21.

\begin{tabular}{|c|c|c|c|c|c|}
\hline $\begin{array}{l}\text { Ship's head by } \\
\text { standard } \\
\text { compass. }\end{array}$ & $\begin{array}{l}\text { Bearings of distant } \\
\text { object by standard } \\
\text { compass. }\end{array}$ & $\begin{array}{l}\text { Deviation } \\
\text { required. }\end{array}$ & $\begin{array}{l}\text { Ship's head by } \\
\text { standard } \\
\text { compuss. }\end{array}$ & $\begin{array}{l}\text { Bearings of distant } \\
\text { object by standard } \\
\text { cumpass. }\end{array}$ & $\begin{array}{l}\text { Deviation } \\
\text { required. }\end{array}$ \\
\hline $\begin{array}{l}\text { N. } \\
\text { N.E. } \\
\text { E. } \\
\text { S.E. }\end{array}$ & $\begin{array}{l}\text { N. } \\
\text { N. } 7^{\circ} \mathrm{E} . \\
\text { N. } 10^{\circ} \mathrm{W} . \\
\text { N. } 13^{\circ} \mathrm{W} .\end{array}$ & & $\begin{array}{l}\text { S. } \\
\text { s.W. } \\
\text { W. } \\
\text { N.W. }\end{array}$ & $\begin{array}{l}\text { N. } 21^{\circ} \mathrm{W} . \\
\text { N. } 17^{\circ} \mathrm{W} . \\
\text { N. } 18^{\circ} \mathrm{E} . \\
\text { N. } 16^{\circ} \mathrm{E} .\end{array}$ & \\
\hline
\end{tabular}

Find correct magnetic bearing; construct a curve.

Given magnetic courses : N. $\frac{1}{4}$ E. S.E. by E. $\frac{1}{2}$ E. W.S.W. W. $12^{\circ} \mathrm{N}$.

Find compass courses.

Given compass courses : E. $\frac{3}{4}$ N. N.W. $\frac{1}{2}$ W. S. $65^{\circ}$ W. S. $32^{\circ}$ E.

Find magnetic courses.

With ship's head at E. $\frac{1}{2}$ S. by compass, the compass bearings of distant objects were S. by W. $\frac{1}{4}$ W., and S.E. by E. Find magnetic bearings.

22. On September 5th, at $0^{\mathbf{h}} 30^{\mathrm{m}}$ A.M. M.T.G., being off Fowey by reckoning, took a cast of the lead. Required the correction to be applied to the depth obtained by the lead-line before comparing it with the depth marked on the chart.

23. August 15th, about $1^{\text {h }} 25^{\mathrm{m}}$ P.M. at ship, in lat. $23^{\circ} 27^{\prime} \mathrm{N}$., long. by account, $170^{\circ} 30^{\prime}$ W., when a chron. estimated $7^{\mathrm{m}}$ slow of G.M.T. showed $12^{\mathrm{b}} 40^{\mathrm{m}}$, the alt. of the Sun's L.L. was $68^{\circ} 37^{\prime} 10^{\prime \prime}$; ind. cor., $+4^{\prime} 9^{\prime \prime}$; height of eye, $28 \mathrm{ft}$.; obs. distance between the enlightened limbs of the Sun and Moon, $47^{\circ} 22^{\prime} 40^{\prime \prime}$; ind. cor., $-3^{\prime} 17^{\prime \prime}$. Find the true and apparent alts. of the Moon, longitude, and error of chron. on G.M.T.

24. August 5 th, in lat. $48^{\circ} \mathrm{N}$., long. $50^{\circ} \mathrm{W}$., with following observations, find lat. at second obs. by "Ivory" or "Direct" method :-

M.T.S. nearly. Time shown by chron. Obs. alts. of a Cygni.

$\begin{array}{lcccc}\text { 5th } 9^{\mathrm{h}} 30^{\mathrm{m}} \text { P.M. } & 12^{\mathrm{h}} 46^{\mathrm{m}} 4^{\mathrm{s}} & 67^{\circ} 21^{\prime} 40^{\prime \prime} & \text { Ind. cor., }+2^{\prime} 12^{\prime \prime} \\ 6 \text { th } 148 \text { A.M. } & 5 & 359 & 682640 & \text { Eye, } 39 \mathrm{ft} .\end{array}$

The chron. was $5^{\mathrm{m}}$ slow of M.T.G.; bearing at first obs., N. $86^{\circ}$ E.; run between obs., S. $13^{\circ} \mathrm{W}$., 10 knots per hour.

25. September 9th, at $9^{\mathrm{h}} \mathbf{1 5}^{\mathrm{m}}$ A.M. A.T.S., when Cape Comino, lat. $40^{\circ} 31^{\prime} 30^{\prime \prime} \mathrm{N}$., long. $9^{\circ} 50^{\prime} 30^{\prime \prime} \mathrm{E}$., bore N. $35^{\circ} \mathrm{E}$. dist. 14 miles, the obs. alt. of Sun's L.L. in artificial horizon was $77^{\circ} 51^{\prime} 10^{\prime \prime}$; ind. cor., + $3^{\prime} 18^{\prime \prime}$; time shown by chron., $8^{\mathrm{b}} 43^{\mathrm{m}}$. Find its error on M.T.G.

26. Find the initial course and distance on a composite track, easting run on parallel of $42^{\circ} \mathrm{S}$., from lat. $33^{\circ} 56^{\prime} \mathrm{S}$., long. $18^{\circ} 29^{\prime} \mathrm{E}$., to lat. $35^{\circ} 2^{\prime} \mathrm{S}$., long. $117^{\circ} 54^{\prime} \mathrm{E}$.; and lats. of points in which meridians of $50^{\circ} \mathrm{E}$., $90^{\circ} \mathrm{E}$., and $100^{\circ} \mathrm{E}$. cut the track.

27. If the diff. lat. is $224 \cdot 6 \mathrm{~N}$., and dep. $157 \cdot 9$ miles E., find course and distance by calculation.

28. In triangle $\mathrm{PQR}, \mathrm{PQ}=137, \mathrm{PR}=257, \mathrm{R}=30^{\circ} 40^{\prime}$. Find $\mathrm{QR}$.

29. The angular elevation of a tower at $A$ is $30^{\circ}$, at $B$ in the same horizontal plane, and $100 \mathrm{ft}$. nearer the tower, the elevation is $60^{\circ}$. Find height of the tower.

30. In spherical triangle $\mathrm{PQR}, \mathrm{P}=90^{\circ}, \mathrm{Q}=68^{\circ} 30^{\prime}, \mathrm{PQ}=101^{\circ} 20^{\prime}$. Find $R$ and $R Q$.

31. In spherieal triangle $\mathrm{ABC}, \mathrm{C}=90^{\circ}, \mathrm{AC}=43^{\circ} 45^{\prime}, \mathrm{BC}=81^{\circ} 27^{\prime}$. Find $\mathrm{A}$ and $\mathrm{AB}$.

32. Construct a Mercator chart, scale $1^{\prime \prime} \cdot 2=1^{\circ}$ long., extending from $67^{\circ}$ to $70^{\circ} \mathrm{N}$, and $2^{\circ} \mathrm{W}$. to $2^{\circ} \mathrm{E}$. A ship sails from $69^{\circ} 30^{\prime} \mathrm{N}$., $0^{\circ} 30^{\prime} \mathrm{E}$., the following true courses: S.W. by S. $30^{\prime}$; E. by S. $40^{\prime}$; S.S.W. $56^{\prime}$; W. by N. $25^{\prime}$. Find her latitude and longitude in. 
33. Given coefficient $\mathrm{B}=-15^{\sim} \cdot 7$, coefficient $\mathrm{C}=-14^{\circ} \cdot 5$. Find direction of ship's head at building.

34. Using deviations found in question 21 , find coefficients $A, B, C, D$, and $\mathrm{E}$; and construct a table of deviations for every alternate point of the compass, starting at $\mathrm{N}$.

35. Steering N.W. $\frac{1}{2} \mathrm{~N}$., heeling $16^{\circ}$ on the port tack, the error was observed to be $-14^{\circ} \cdot 5$. Find its amount when steering east on the starboard tack and heeling $20^{\circ}$.

36. August 17 th, at $11^{\mathrm{b}} 35^{\mathrm{m}} 20^{\circ}$ P.M. M.T.S., in lat. $5^{\circ} 24^{\prime}$ N., long. $68^{\circ} 30^{\prime} \mathrm{E}$., the compass bearing of $\beta$ Gruis was S.S.E. Find the true bearing; and if the variation is $1^{\circ} 15^{\prime} \mathrm{W}$., find the deviation. 


\title{
ANSWERS.
}

\author{
CHAPTER III.
}

LOGARITHMS.

1. 0.477121 $1 \cdot 672098$

$1 \cdot 698970$

$2 \cdot 000000$

$2 \cdot 439333$

3.922206

$1 \cdot 758079$

$2 \cdot 563173$

0.000389

$4 \cdot 876391$

$1 \cdot 797278$

$2 \cdot 243058$

$4 \cdot 361779$

$2 \cdot 215643$

$4 \cdot 333447$

4.370328

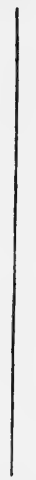

\author{
0.532627 \\ 0.875061 \\ $2 \cdot 213385$ \\ $2 \cdot 847579$ \\ $4 \cdot \tilde{5} 13697$ \\ 9.698970 \\ $8 \cdot 690196$ \\ $7 \cdot 556302$ \\ $7 \cdot 080626$ \\ $7 \cdot 827886$ \\ $6 \cdot 447794$ \\ 5.876795 \\ $8 \cdot 539087$ \\ $8 \cdot 878545$ \\ $9 \cdot 564667$
}

Numbers.

2. 1598

$139 \cdot 9$

$50 \cdot 15$

$5 \cdot 199$

$1 \cdot 010$

$48026 \cdot 9$

490000

1408961

10969874

63980

\section{$149899 \cdot 7$ \\ $3400015 \cdot 6$ \\ $10010023 \cdot 1$ \\ 230100 \\ 11000 \\ 1121000 \\ 1.001 \\ $4679 \cdot 01$ \\ $18880043 \cdot 5$ \\ 239901-1}

Multiplication by Logs.

1. 19639

2. 23360

3. 279088

4. 358900

5. $709 \cdot 3934$

6. $47 \cdot 808$

7. $2110 \cdot 41$

8. $288 \cdot 651$

9. $3540707 \cdot 3$

10. $5 \cdot 9585$

11. $\cdot 0000081005$

12. $6 \cdot 4831$
13. $\cdot 0000129$

14. $\cdot 000259$

15. $\cdot 5$

16. $24951 \cdot 6$

17. 100000

18. $20 \cdot 42$

19. $\cdot 2303$

20. 001795

21. $1267 \cdot 618$

22. 229500

23. $18 \cdot 16$

24. $143 \cdot 21$ 
Division BY Logs.
1. $46 \cdot 3572$
2. $293 \cdot 6$
3. 9040
4. $176020 \cdot 7$
5. $4 \cdot 613$
6. $24 \cdot 7069$
7. $1328856 \cdot 7$
8. $1026 \cdot 903$
9. $1 \cdot 424$
10. $142199 \cdot 67$
11. $1 \cdot 02217$
12. $\cdot 00001029$

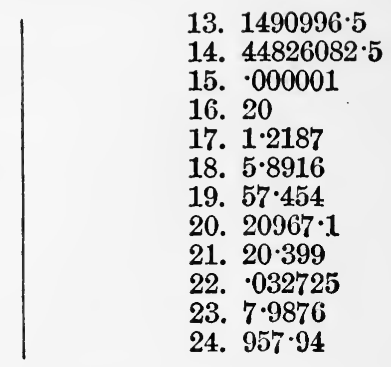

Involution By Logs.
1. $547 \cdot 56$
2. $6 \cdot 602$
3. $\cdot 000005797$
4. $\cdot 000000001411$
5. $\cdot 000002191$

Evolution By Logs.
1. $17 \cdot 5$
2. $3 \cdot 6$
3. $\cdot 30012$
4. 230
5. $\cdot 08$

Additional Exercises.

1. $143 \cdot 8,27 \cdot 74,360 \cdot 8$

2. 891.9 and 9754.5

3. $172974 \cdot 6, \cdot 03528$

4. $1 \cdot 439$

\section{CHAPTER IV.}

Right-angled Plane Triangles.

1. $\mathrm{A}=44^{\circ} 47^{\prime} 10^{\prime \prime} ; \mathrm{B}=45^{\circ} 12^{\prime} 50^{\prime \prime} ; \mathrm{BC}=354.3$.

2. $\mathrm{P}=28^{\circ} 48^{\prime} 30^{\prime \prime} ; \mathrm{R}=61^{\circ} 11^{\prime} 30^{\prime \prime} ; \mathrm{PR}=423 \cdot 4$.

3. $\mathrm{B}=10^{\circ} 25^{\prime} 30^{\prime \prime} ; \mathrm{P}=79^{\circ} 34^{\prime} 30^{\prime \prime} ; \mathrm{OB}=683.5$.

4. $\mathrm{AC}=443 \bullet 4 ; \mathrm{BC}=937 \cdot 4$.

5. $\mathrm{AB}=1095 ; \mathrm{AC}=617$.

6. $\mathrm{A}=52^{\circ} 6^{\prime} 11^{\prime \prime} ; \mathrm{B}=37^{\circ} 53^{\prime} 49^{\prime \prime} ; \mathrm{AC}=90.3$.

7. $\mathrm{PR}=5227 ; \mathrm{QR}=2864$.

8. $\mathrm{A}=54^{\circ} 15^{\prime} 30^{\prime \prime} ; \mathrm{B}=35^{\circ} 44^{\prime} 30^{\prime \prime} ; \mathrm{AB}=1208.5$.

9. Height, $91.55 \mathrm{ft}$.

10. Course, S. $42^{\circ} 22^{\prime}$ W. ; dist. $320 \cdot 1$ miles.

11. Height, $15 \mathrm{ft} .7$ in.

12. First dist. 9.08 miles; second dist. 5.75 miles.

13. $6^{\circ} 151^{\prime}$.

14. $113 \cdot 8 \mathrm{ft}$. 


\section{Orlique-angled Plane Triangles.}

1. $\mathrm{A}=47^{\circ} 7^{\prime} 8^{\prime \prime} ; \mathrm{B}=14^{\circ} 25^{\prime} 32^{\prime \prime} ; \mathrm{C}=118^{\circ} 27^{\prime} 20^{\prime \prime}$.

2. $\mathrm{A}=42^{\circ} 16^{\prime} 41^{\prime \prime} ; \mathrm{B}=23^{\circ} 38^{\prime} 38^{\prime \prime} ; \mathrm{C}=114^{\circ} 4^{\prime} 41^{\prime \prime}$.

3. $\mathrm{A}=83^{\circ} 25^{\prime} 54^{\prime \prime} ; \mathrm{B}=55^{\circ} 52^{\prime} 48^{\prime \prime} ; \mathrm{C}=40^{\circ} 41^{\prime} 18^{\prime \prime}$.

4. $\mathrm{C}=67^{\circ} 41^{\prime} 0^{\prime \prime} ; b=164 ; c=157 \cdot 5$.

5. $\mathrm{A}=64^{\circ} 27^{\prime} 0^{\prime \prime} ; a=1078 \cdot 7 ; c=1172 \cdot 8$.

6. $\mathrm{B}=32^{\circ} 10^{\prime} 0^{\prime \prime} ; a=20.62 ; b=11.08$.

7. $\mathrm{A}=96^{\circ} 16^{\prime} 25^{\prime \prime} ; \mathrm{B}=44^{\circ} 3^{\prime} 35^{\prime \prime} ; c=4466$.

8. $\mathrm{A}=45^{\circ} 31^{\prime} 53^{\prime \prime} ; \mathrm{C}=65^{\circ} 42^{\prime} 7^{\prime \prime} ; b=348 \cdot 7$.

9. $\mathrm{B}=46^{\circ} 50^{\prime} 2^{\prime \prime} ; \mathrm{C}=35^{\circ} 51^{\prime} 58^{\prime \prime} ; a=82.95$.

10. $\mathrm{B}=42^{\circ} 50^{\prime} 18^{\prime \prime} ; \mathrm{C}=84^{\circ} 43^{\prime} 42^{\prime \prime} ; c=1086$.

11. $\mathrm{A}=19^{\circ} 4^{\prime} 29^{\prime \prime} ; \mathrm{B}=121^{\circ} 51^{\prime} 31^{\prime \prime} ; a=180{ }^{\circ} \tilde{5}$; or $82^{\circ} 47^{\prime} 31^{\prime \prime}$; or $58^{\circ} 8^{\prime} 29^{\prime \prime}$; or $547 \cdot 8$.

12. $\mathrm{B}=90^{\circ} 30^{\prime} 11^{\prime \prime} ; \mathrm{C}=39^{\circ} 53^{\prime} 49^{\prime \prime} ; b=1398 \cdot 4$.

13. $\mathrm{B}=35^{\circ} 4^{\prime} 5^{\prime \prime} ; \mathrm{C}=123^{\circ} 32^{\prime} 55^{\prime \prime} ; \mathrm{c}=1342$; or $144^{\circ} 55^{\prime} 55^{\prime \prime}$; or $13^{\circ} 41^{\prime} 5^{\prime \prime}$; or 380.9 .

14. $\mathrm{A}=48^{\circ} 11^{\prime} 22^{\prime \prime} ; \mathrm{B}=58^{\circ} 24^{\prime} 42^{\prime \prime} ; \mathrm{C}=73^{\circ} 23^{\prime} 56^{\prime \prime}$.

15. $\mathrm{A}=27^{\circ} 7^{\prime} 36^{\prime \prime} ; \mathrm{B}=22^{\circ} 19^{\prime} 54^{\prime \prime} ; \mathrm{C}=130^{\circ} 32^{\prime} 30^{\prime \prime}$.

16. $\mathrm{A}=44^{\circ} 24^{\prime} 54^{\prime \prime} ; \mathrm{B}=57^{\circ} 7^{\prime} 20^{\prime \prime} ; \mathrm{C}=78^{\circ} 27^{\prime} 46^{\prime \prime}$.

17. $\mathrm{C}=11^{\circ} 40^{\prime} 0^{\prime \prime} ; a=6291 ; c=4044$.

18. $\mathrm{B}=61^{\circ} 25^{\prime} 0^{\prime \prime} ; a=206 \cdot 3 ; b=184.7$.

19. $\mathrm{B}=88^{\circ} 30^{\prime} 1^{\prime \prime} ; \mathrm{C}=33^{\circ} 30^{\prime} 59^{\prime \prime} ; a=201 \cdot 2$.

20. $\mathrm{A}=48^{\circ} 41^{\prime} 9^{\prime \prime} ; \mathrm{C}=73^{\circ} 1^{\prime} 51^{\prime \prime} ; b=2015$.

21. $\mathrm{A}=46^{\circ} 35^{\prime} 31^{\prime \prime} ; \mathrm{B}=16^{\circ} 13^{\prime} 31^{\prime \prime} ; c=1591 \cdot 8$.

22. $\mathrm{B}=62^{\circ} 31^{\prime} 25^{\prime \prime} ; \mathrm{C}=102^{\circ} 17^{\prime} 35^{\prime \prime} ; \mathrm{c}=5919$; or $117^{\circ} 28^{\prime} 35^{\prime \prime}$; or $47^{\circ} 20^{\prime} 25^{\prime \prime}$; or 4455 .

23. $\mathrm{B}=59^{\circ} 57^{\prime} 53^{\prime \prime} ; \mathrm{C}=84^{\circ} 47^{\prime} 7^{\prime \prime} ; \mathrm{c}=345 \cdot 1$;

24. $212 \mathrm{ft}$. or $120^{\circ} 2^{\prime} 7^{\prime \prime}$; or $24^{\circ} 42^{\prime} 53^{\prime \prime}$; or 144.9 .

25. $134 \cdot 7 \mathrm{ft}$.

\section{Miscellaneous Problems.}

1. $56^{\circ} 18^{\prime} 36^{\prime \prime}$ and $33^{\circ} 41^{\prime} 24^{\prime \prime}$.

2. 610.5 yards.

3. N. $36^{\circ} 12^{\prime} 15^{\prime \prime} \mathrm{W}$.

4. $71 \cdot 36 \mathrm{ft}$.

5. Height $74 \mathrm{ft}$. Width $47 \cdot 7 \mathrm{ft}$.

6. $367 \cdot 9 \mathrm{ft}$.

7. $4^{\circ} 57 \frac{1^{\prime}}{}$.
8. $1628 \cdot 7 \mathrm{ft}$.

9. S. $53^{\circ} 11^{\prime} 24^{\prime \prime} \mathrm{W}$.

10. S. $80^{\circ} \mathrm{W}$.

11. $115 \mathrm{ft}$.

12. S. $52^{\prime \prime}, 1^{\prime} 36^{\prime \prime} \mathrm{E}$.

13. $578.5 \mathrm{ft}$., $818^{\circ} 5 \mathrm{ft}$., $54^{\circ} 39^{\prime} 28^{\prime \prime}$.

14. $64^{\circ} 26^{\prime} 30^{\prime \prime}$. 29.66 yards.

\section{CHAPTER $\nabla$.}

\section{Right-angled Spherical Triangles.}

1. $\mathrm{A}=54^{\circ} 15^{\prime} 52^{\prime \prime} ; \mathrm{B}=70^{\circ} 5^{\prime} 36^{\prime \prime} ; \mathrm{AB}=74^{\circ} 53^{\prime} 52^{\prime \prime}$.

2. $\mathrm{BC}=71^{\circ} 20^{\prime} 56^{\prime \prime} ; \mathrm{AC}=38^{\circ} 18^{\prime} 16^{\prime \prime} ; \mathrm{AB}=75^{\circ} 27^{\prime} 57^{\prime \prime}$.

3. $\mathrm{A}=62^{\circ} 17^{\prime} ; \mathrm{B}=79^{\circ} 8^{\prime} 34^{\prime \prime} ; \mathrm{AC}=77^{\circ} 42^{\prime} 53^{\prime \prime}$.

4. $\mathrm{B}=77^{\circ} 2^{\prime} 15^{\prime \prime} ; \mathrm{BC}=50^{\circ} 17^{\prime} 53^{\prime \prime} ; \mathrm{AC}=73^{\circ} 20^{\prime} 39^{\prime \prime}$.

5. $\mathrm{A}=45^{\circ} 40^{\prime} 14^{\prime \prime} ; \mathrm{AC}=39^{\circ} 6^{\prime} 20^{\prime \prime} ; \mathrm{AB}=49^{\circ} 18^{\prime} 54^{\prime \prime}$.

6. $\mathrm{B}=139^{\circ} 26^{\prime} 36^{\prime \prime}$, or $40^{\circ} 33^{\prime} 24^{\prime \prime} ; \mathrm{AC}=145^{\circ} 5^{\prime} 45^{\prime \prime}$, or $34^{\circ} 54^{\prime} 15^{\prime \prime}$;

$\mathrm{AB}=118^{\circ} 21^{\prime} 6^{\prime \prime}$, or $61^{\circ} 38^{\prime} 54^{\prime \prime}$.

7. $\mathrm{C}=70^{\circ} 55^{\prime} 17^{\prime \prime} ; \mathrm{A}=101^{\circ} 55^{\prime} 44^{\prime \prime} ; \mathrm{AC}=94^{\circ} 11^{\prime} 25^{\prime \prime}$.

8. $\mathrm{C}=110^{\circ} 3^{\prime} 55^{\prime \prime} ; \mathrm{A}=98^{\circ} 13^{\prime} 51^{\prime \prime} ; \mathrm{AC}=86^{\circ} 58^{\prime} 17^{\prime \prime}$.

9. $\mathrm{AB}=117^{\circ} 2^{\prime} 58^{\prime \prime} ; \mathrm{BC}=65^{\circ} 5^{\prime} 37^{\prime \prime} ; \mathrm{AC}=101^{\circ} 2^{\prime} 29^{\prime \prime}$.

10. $\mathrm{AB}=92^{\circ} 52^{\prime} 13^{\prime \prime} ; \mathrm{BC}=118^{\circ} 45^{\prime} 49^{\prime \prime} ; \mathrm{AC}=88^{\circ} 37^{\prime} 9^{\prime \prime}$

11. $\mathrm{C}=78^{\circ} 10^{\prime} 28^{\prime \prime} ; \mathrm{A}=144^{\circ} 52^{\prime} 34^{\prime \prime}: \mathrm{BC}=146^{\circ} 41^{\prime}$. 
12. $\mathrm{C}=96^{\circ} 57^{\prime} 4^{\prime \prime} ; \mathrm{A}=101^{\circ} 19^{\prime} 54^{\prime \prime} ; \mathrm{AB}=97^{\circ} 5^{\prime} 24^{\prime \prime}$.

13. $\mathrm{B}=55^{\circ} 2^{\prime} 52^{\prime \prime} ; \mathrm{C}=96^{\circ} 0^{\prime} 20^{\prime \prime} ; \mathrm{AC}=54^{\circ} 49^{\prime} 36^{\prime \prime}$.

14. $\mathrm{B}=144^{\circ} 52^{\prime} 47^{\prime \prime} ; \mathrm{AC}=148^{\circ} 4^{\prime} 7^{\prime \prime} ; \mathrm{AB}=62^{\circ} 23^{\prime} 2^{\prime \prime}$.

15. $\mathrm{B}=129^{\circ} 14^{\prime} 9^{\prime \prime} ; \mathrm{AC}=129^{\circ} 43^{\prime} 36^{\prime \prime} ; \mathrm{AB}=100^{\circ} 40^{\prime} 35^{\prime \prime}$.

16. $\mathrm{C}=95^{\circ} 41^{\prime} 50^{\prime \prime} ; \mathrm{AC}=76^{\circ} 8^{\prime} 49^{\prime \prime} ; \mathrm{BC}=91^{\circ} 24^{\prime} 9^{\prime \prime}$.

17. $\mathrm{B}=106^{\circ} 24^{\prime} 22^{\prime \prime} ; \mathrm{AB}=94^{\circ} 18^{\prime} 33^{\prime \prime} ; \mathrm{BC}=88^{\circ} 47^{\prime}$.

18. $\mathrm{B}=49^{\circ} 37^{\prime}$, or $130^{\circ} 23^{\prime} ; \mathrm{AC}=46^{\circ} 57^{\prime} 45^{\prime \prime}$, or $123^{\circ} 2^{\prime} 15^{\prime \prime}$; $\mathrm{BC}=106^{\circ} 21^{\prime} 15^{\prime \prime}$, or $73^{\circ} 38^{\prime} 45^{\prime \prime}$.

\section{Oblique-angled Spherical Triangles.}

1. $\mathrm{A}=82^{\circ} 42^{\prime} 30^{\prime \prime} ; \mathrm{B}=90^{\circ} 9^{\prime} 16^{\prime \prime} ; \mathrm{C}=104^{\circ} 19^{\prime} 36^{\prime \prime}$.

2. $\mathrm{A}=153^{\circ} 7^{\prime} 14^{\prime \prime} ; \mathrm{B}=41^{\circ} 22^{\prime} 24^{\prime \prime} ; \mathrm{C}=43^{\circ} 50^{\prime} 32^{\prime \prime}$.

3. $\mathrm{A}=116^{\circ} 19^{\prime} 7^{\prime \prime} ; \mathrm{B}=104^{\circ} 58^{\prime} 43^{\prime \prime} ; \mathrm{AB}=137^{\circ} 29^{\prime} 6^{\prime \prime}$.

4. $\mathrm{BC}=91^{\circ} 29^{\prime} 30^{\prime \prime}$.

5. $\mathrm{A}=119^{\circ} 15^{\prime} ; \mathrm{C}=73^{\circ} 59^{\prime}$.

6. $\mathrm{A}=91^{\circ} 30^{\prime} 10^{\prime \prime}$.

7. $24^{\circ} 20^{\prime} 38^{\prime \prime}$.

8. $249^{\circ} 51^{\prime} 15^{\prime \prime} .29^{\circ} 37^{\prime} 12^{\prime \prime} \mathrm{N}$.

10. $41^{\circ} 0^{\prime} 20^{\prime \prime} \mathrm{N}$. $42^{\circ} 36^{\prime} 50^{\prime \prime} \mathrm{W}$.

\section{CHAPTER VI. \\ Parallel Sailing.}

1. $174^{\prime} \cdot 8$.

2. $116^{\prime} \cdot 7$.

3. $373^{\prime} \cdot 1$.

4. $70^{\circ} 31^{\prime} 44^{\prime \prime}$.

5. $12^{\prime} \cdot 01$.

6. $57^{\circ} 52^{\prime} \mathrm{N}$. $41^{\circ} 52^{\prime} \mathrm{S}$. Diff. lat. 5984 miles.

7. $34^{\circ} 44^{\prime} \mathrm{W}$.

8. $45^{\circ} 20^{\prime}$ N. Dep. $210 \cdot 9$.

9. 13.09 .

10. $38^{\circ} 8^{\prime} \mathrm{S}$.

11. 1266.

12. $60^{\circ}$.

13. $136^{\circ} 49^{\prime} 24^{\prime \prime} \mathrm{E}$.

14. $44^{\circ} 21^{\prime} 18^{\prime \prime} \mathrm{E}$.

15. $96 \cdot 24$.

16. $50^{\circ} 44^{\prime}$.

17. $92 \cdot 99$.

18. $41^{\circ} 242_{2}^{\prime}$.

\section{DAYs' WORKS.}

1. N. $31^{\circ}$ W., $49^{\prime} ;$ N. $34^{\circ}$ W., $61^{\prime} ;$ N. $17^{\circ}$ E., $63^{\prime} ;$ N. $60^{\circ}$ W., 55'; N. $15^{\circ}$ W., $57^{\prime} ;$ S. $27^{\circ}$ W., $62^{\prime}$; S. $25^{\circ}$ E., $57^{\prime}$; S. $30^{\circ}$ E., $4^{\prime}$; D. lat. $125^{\prime} \cdot 0$, dep. $105^{\prime} \cdot 3$; lat. in $1^{\circ} 31^{\prime} \mathrm{N}$.; long. in $2^{\circ} 2^{\prime}$ W. Course, N. $40^{\circ}$ W., dist. $163^{\prime}$.

2. N. $37^{\circ}$ W., $7^{\prime}$; S. $81^{\circ}$ W., $99^{\prime} \cdot 6$; S. $79^{\circ}$ W., $49^{\prime} \cdot 4$; S. $80^{\circ}$ W., $47^{\prime} \cdot 2$; S. $78^{\circ}$ W., $96^{\prime} \cdot 8$; S. $56^{\circ}$ E., $18^{\prime}$; S. $58^{\circ}$ E., $18^{\prime}$; S. $60^{\circ}$ E., $18^{\prime}$; D. lat. $76^{\prime} \cdot 4$, dep. $246^{\circ} \cdot 5$. Course, S. $73^{\circ} \mathrm{W}$.; dist. 258 ; lat. in $53^{\circ} 57^{\prime} \cdot 6 \mathrm{~N}$.; long. in $15^{\circ} 25^{\prime} \cdot 5 \mathrm{~W}$. 
3. N. $41^{\circ}$ W., $19^{\prime} ;$ N. $38^{\circ}$ E., $37^{\prime} ;$ S. $87^{\circ}$ E., $25^{\prime} ;$ S. $78^{\circ}$ E., $23^{\prime}$; S. $88^{\circ}$ W., $21^{\prime}$; S. $9^{\circ}$ W., $34^{\prime}$; N. $62^{\circ}$ E., $40^{\prime}$; S. $22^{\circ}$ E., $15^{\prime}$; D. lat. $8^{\prime} \cdot 0$, dep. $72^{\prime} \cdot 4$. Course, N. $83^{\circ}$ E., $73^{\prime}$; lat. in $18^{\circ} 51^{\prime}$ S. ; long. in $178^{\circ} 36^{\prime} \mathrm{W}$. 4. S. $14^{\circ}$ E., $60^{\prime}$; S. $31^{\circ}$ W., $53^{\prime} ;$ N. $82^{\circ}$ W., $51^{\prime} ;$ S. $64^{\circ}$ W., $58^{\prime}$; N. $44^{\circ}$ E., $49^{\prime}$; N. $26^{\circ}$ E. , $65^{\prime}$; S. $84^{\circ}$ W., $21^{\prime}$; N. $75^{\circ}$ W., $39^{\prime}$; D. lat. $20^{\prime} \cdot 4$, dep. $111^{\prime} \cdot 5$. Course, S. $80^{\circ}$ W., $113^{\prime}$; lat. in $58^{\circ} 50^{\prime} \mathrm{S}$. ; long. in $68^{\circ} 28^{\prime} \mathrm{W}$.

5. S. $23^{\circ}$ W., $15^{\prime} ;$ N. $49^{\circ}$ W., $12^{\prime}$; S. $37^{\circ}$ E., $13^{\prime} ;$ S. $16^{\circ}$ W., $25^{\prime}$; N. $34^{\circ}$ E., $20^{\prime}$; N. $78^{\circ}$ W., $15^{\prime}$; N. $15^{\circ}$ E., $27^{\prime}$; D.R. lat. $30^{\circ} 4^{\prime} \cdot 5$ N. ; long. $132^{\circ} 41 \frac{3}{4}$ E. Set N. $46^{\circ}$ E. ; drift $30^{\prime}$.

6. S. $33^{\circ}$ E., $8^{\prime} ;$ S. $6^{\circ}$ W., $49^{\prime} ;$ N. $24^{\circ}$ E., $53^{\prime}$; S. $65^{\circ}$ E., $49^{\prime}$; S. $30^{\circ}$ E., $44^{\prime}$; S. $25^{\circ}$ W., $54^{\prime}$; S. $66^{\circ}$ E., $52^{\prime}$; D.R. lat. $52^{\circ} 6^{\prime} \cdot 1$ N.; long. $178^{\circ} 26^{\prime} \cdot 9$ W. Set S. $62 \frac{1}{2}^{\circ}$ E. ; drift $15^{\prime}$.

\section{Mercator Sailing.}

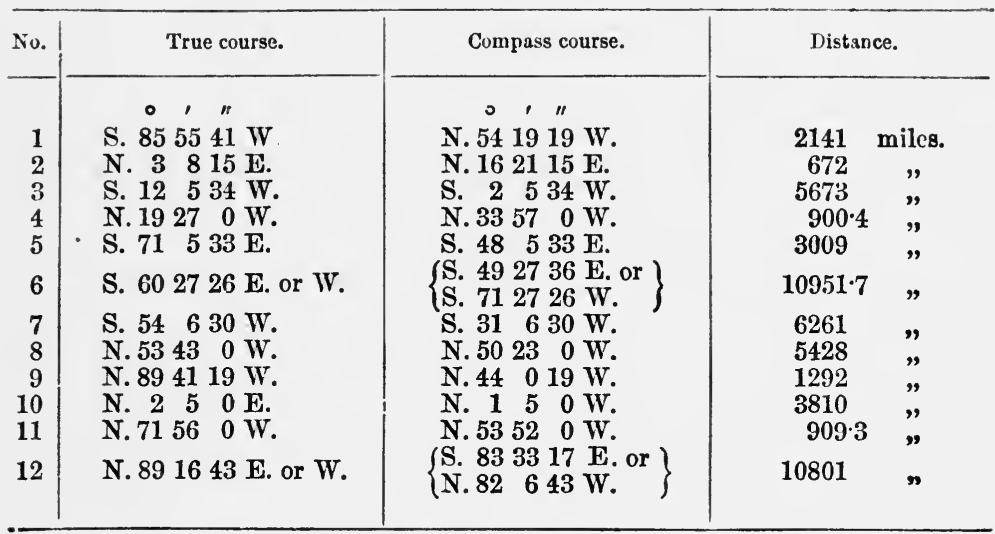

\section{Miscellaneous Exercises.}

1. $244 \cdot 7$ miles.

2. $39^{\circ} 16^{\prime \prime}$.

3. Lat. $35^{\circ} 20^{\prime}$ N., long. $30^{\circ} 17^{\prime} \cdot \check{\mathrm{o}} \mathrm{W}$.

4. $36 \cdot 2$ hours.

5. N. $7^{\circ} 54^{\prime}$ W., $44 \cdot 8$ miles.

6. $6^{\mathrm{h}} 33^{\mathrm{m}}$.

7. Cliff, $131 \cdot 6 \mathrm{ft}$; lighthouse, $107 \cdot 2 \mathrm{ft}$.

8. $315 \cdot 3 \mathrm{ft}$.

9. S. $60^{\circ} 9^{\prime}$ W., $13 \cdot 36$ miles.

10. $116 \cdot 82$ miles.

11. N. $56^{\circ} 13^{\prime}$ E., 116.9 miles.

12. S. $7^{\circ} 50^{\prime} \mathrm{W}$., $5 \cdot 6$ miles.

13. $6^{\mathrm{b}} 45^{\mathrm{m}}$.

14. $12 \cdot 34$ miles.

15. S. $63^{\circ} 20^{\prime}$ E. ; $7 \cdot 38$ miles.

16. N. $71^{\circ} 15 \frac{1}{2}^{\prime}$ E. ; $7 \cdot 27$ miles. 
CHAPTER VII.

Tuves.

\begin{tabular}{|c|c|c|c|c|c|}
\hline No. & \multicolumn{2}{|c|}{ A.M. } & \multicolumn{3}{|c|}{ P.M. } \\
\hline 1 & $\begin{array}{r}\text { h. } \\
6 \\
10 \\
0 \\
11 \\
11\end{array}$ & $\begin{array}{l}\mathrm{m} . \\
48 \\
31 \\
13 \\
53 \\
35\end{array}$ & $\begin{array}{r}\text { h. } \\
7 \\
10 \\
0 \\
11\end{array}$ & $\begin{array}{l}\mathrm{m} . \\
15 \\
58 \\
49 \\
- \\
57\end{array}$ & $\begin{array}{c}\text { I.T.G. } \\
\text { ", } \\
" \\
\text { ", }\end{array}$ \\
\hline 2 & $\begin{array}{r}4 \\
5 \\
11 \\
11 \\
1 \\
2 \\
\text { Midn } \\
0 \\
11 \\
0\end{array}$ & $\begin{array}{c}42 \\
18 \\
8 \\
47 \\
8 \\
20 \\
\text { ight } \\
32 \\
45 \\
4\end{array}$ & $\begin{array}{r}5 \\
5 \\
11 \\
1 \\
2 \\
0 \\
0 \\
0\end{array}$ & $\begin{array}{r}0 \\
36 \\
28 \\
-\quad \\
46 \\
50 \\
23 \\
54 \\
-\quad 26\end{array}$ & $\begin{array}{c}\text { I.T.S. } \\
", \\
" \\
" \\
" \\
" \\
" \\
"\end{array}$ \\
\hline 3 & $\begin{array}{l}9 \\
4 \\
1 \\
1\end{array}$ & $\begin{array}{r}1 \\
3 ! 1 \\
28 \\
6\end{array}$ & $\begin{array}{l}9 \\
5 \\
1 \\
1\end{array}$ & $\begin{array}{l}32 \\
10 \\
49 \\
27\end{array}$ & $\begin{array}{l}\text { I.I.G. } \\
\text { IT.S. } \\
\text { I.T.G. } \\
\text { I.S.S. }\end{array}$ \\
\hline 4 & $\left\{\begin{array}{l}11 \\
0 \\
1\end{array}\right.$ & $\begin{array}{r}34 \\
1 \\
38\end{array}$ & $\left\{\begin{array}{r}11 \\
0 \\
1\end{array}\right.$ & $\begin{array}{l}54 \\
18 \\
55\end{array}$ & $\begin{array}{c}\text { 1.'I.G. } \\
\text { ", }\end{array}$ \\
\hline
\end{tabular}

CHAPTER VIII.

\begin{tabular}{|c|c|c|}
\hline & Interval. & Angle. \\
\hline $\begin{array}{l}1 \\
2 \\
3 \\
4 \\
5 \\
6\end{array}$ & 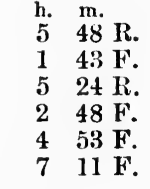 & $\begin{array}{r}174 \\
48 \\
162 \\
86 \\
117 \\
175\end{array}$ \\
\hline & N.T.L. & H.D.R. \\
\hline & ft. ins. & ft. ins. \\
\hline 1 & $10 \quad 0$ & $2 \quad 11$ \\
\hline 2 & $\begin{array}{ll}5 & 11\end{array}$ & $6 \quad 6$ \\
\hline 8 & $8 \quad 1$ & $\begin{array}{ll}6 & 10\end{array}$ \\
\hline 4 & $\begin{array}{l}11 \quad 2 \mathrm{R} . \\
11 \quad 0 \mathrm{~F} .\end{array}$ & $\begin{array}{rr}\mathbf{5} & 8 \\
5 & 10\end{array}$ \\
\hline 5 & $125 \mathrm{R}$. & 126 \\
\hline & $12 \quad 2 \mathrm{~F}$. & 12 \\
\hline 6 & $1011 \mathrm{R}$. & 9 \\
\hline & $112 \mathrm{~F}$. & 9 \\
\hline 7 & $87 \mathrm{R}$. & 3 \\
\hline & $85 \mathrm{~F}$. & $\begin{array}{ll}3 & 11\end{array}$ \\
\hline 8 & $110 \mathrm{R}$. & 110 \\
\hline
\end{tabular}




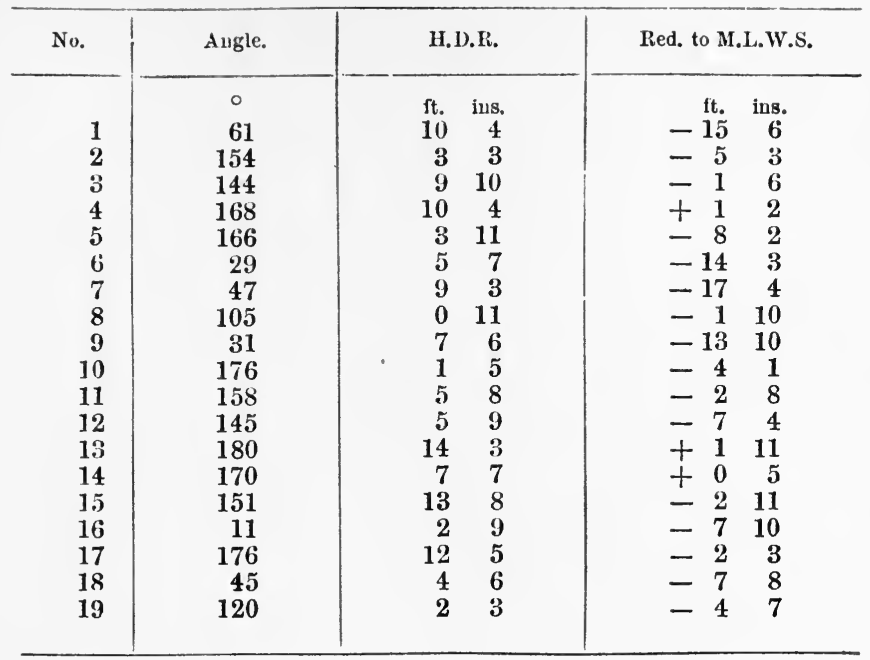

20. $26 \mathrm{ft} .10$ ins.

21. $5^{\mathrm{h}} 8^{\mathrm{m}}$ p.m.

22. $22 \mathrm{ft} .8$ ins.

23. depth $34 \mathrm{ft} .9$ ins.; under $9 \mathrm{ft} .9$ ins.

24. $7^{\mathrm{h}} 33^{\mathrm{m}}$ a.m.

\section{CHAPTER IX.}

Time Equivalents.

$11^{\mathrm{m}} 58^{\mathrm{s}} ; 11^{\mathrm{b}} 56^{\mathrm{m}} 3^{\mathrm{s}} ; 1^{\mathrm{h}} 0^{\mathrm{m}} 1^{\mathrm{s}} ; 4^{\mathrm{h}} 31^{\mathrm{m}} 31^{\mathrm{s}} \cdot 6 ; 1^{\mathrm{m}} 9^{\mathrm{s}} \cdot 3 ; 41^{\mathrm{m}} 18^{\mathrm{s}} \cdot 6 ;$ $10^{\mathrm{h}} 20^{\mathrm{m}} 46^{\mathrm{s}} 4 ; 6^{\mathrm{h}} 12^{\mathrm{m}} 3^{\mathrm{s}} ; 7^{\mathrm{h}} 50^{\mathrm{m}} 34^{\mathrm{s}} ; 9^{\mathrm{h}} 39^{\mathrm{m}} 36^{\mathrm{s}} ; 11^{\mathrm{h}} 46^{\mathrm{m}} 38^{\mathrm{c}} \cdot 3 ; 13^{\mathrm{s}} \cdot 53$; $3^{\mathrm{m}} 59^{\mathrm{s}} ; 1^{\mathrm{s}} ; 1^{\mathrm{m}} ; 3^{\mathrm{m}} 12^{\mathrm{s}} ; 11^{\mathrm{h}} 12^{\mathrm{m}} 36^{\mathrm{s}} ; 4^{\mathrm{h}} 17^{\mathrm{m}} 15^{\mathrm{s}}$.

\section{Arc Equivalents.}

$18^{\circ} 7^{\prime} 30^{\prime \prime} ; 154^{\circ} 58^{\prime} 45^{\prime \prime} ; 120^{\circ} 2^{\prime} 30^{\prime \prime} ; 104^{\circ} 49^{\prime} 30^{\prime \prime} ; 179^{\circ} 59^{\prime} 30^{\prime \prime}$; $45^{\circ} 4^{\prime} 45^{\prime \prime} ; 89^{\circ} 50^{\prime} 30^{\prime \prime} ; 135^{\circ} 24^{\prime} 15^{\prime \prime} ; 3^{\circ} 48^{\prime} 45^{\prime \prime} ; 36^{\circ} 1^{\prime} ; 2^{\circ} 38^{\prime} 45^{\prime \prime}$; $11^{\prime} 15^{\prime \prime} ; 36^{\circ} 11^{\prime} ; 165^{\circ} 4^{\prime} 45^{\prime \prime} ; 168^{\circ} 22^{\prime} 30^{\prime \prime} ; 75^{\circ} 1^{\prime} 15^{\prime \prime} ; 127^{\circ} 13^{\prime} ; 150^{\circ} 3^{\prime}$; $3^{\prime} ; 25^{\prime}$.

\section{Differeyce of Times.}

$41^{\mathrm{m}} 20^{\mathrm{s}}$ less; $1^{\mathrm{h}} 11^{\mathrm{m}}$ more; $7^{\mathrm{h}} 21^{\mathrm{m}} 8^{\mathrm{s}}$ more; $11^{\mathrm{h}} 50^{\mathrm{m}} 24^{\mathrm{s}}$ less $; 6^{\mathrm{h}} 41^{\mathrm{m}} 5^{\mathrm{s}}$ more; $6^{\mathrm{h}} 0^{\mathrm{m}} 19^{\mathrm{s}}$ less; $29^{\mathrm{s}}$ more; $11^{\mathrm{b}} 59^{\mathrm{m}} 47^{\mathrm{s}}$ less; $4^{\mathrm{m}} 9^{\mathrm{s}}$ less ; $7^{\mathrm{h}} 40^{\mathrm{m}} 2^{\mathrm{s}}$ more ; $11^{\text {' more }} 111^{\mathrm{h}} 0^{\mathrm{m}} 1^{\mathrm{t}}$ less. 
LoNGitudes.
1. $96^{\circ} 25^{\prime} 45^{\prime \prime} \mathrm{E}$.
2. $106 \quad 50 \quad 15 \quad \mathrm{~W}$.
3. $11050 \quad \mathrm{~W}$.
4. $122 \quad 27 \quad 30 \quad$ E.
5. $78 \quad 48 \quad 45 \quad W$.
6. $117 \quad 5830 \quad \mathrm{E}$.
7. $0 \begin{array}{llll} & 345 & \mathrm{E} \text {. }\end{array}$

8. $9^{\circ} 7^{\prime} 30^{\prime \prime} \mathrm{E}$.

9. $0 \begin{array}{llll} & 35 & 0 & \mathrm{~W}\end{array}$

10. $174 \quad 145$. W.

11. $22 \quad 9 \quad 45 \quad$ W.

12. $167 \quad 0 \quad 0 \quad \mathrm{E}$.

$\begin{array}{llllll}\text { 13. } & 80 & 17 & 30 & \mathrm{~W} .\end{array}$

14. $17920 \quad \mathrm{~W}$.

\section{Greenwich Tmes.}

1. $16^{\mathrm{d}} \quad 7^{\mathrm{h}} \quad 9^{\mathrm{m}} 36^{\mathrm{s}}$.

$\begin{array}{lllll}2 . & 1 & 2 & 13 & 41.3 .\end{array}$

3. $12 \quad 20 \quad 5036$.

4. $30 \quad 6 \quad 4 \quad 56$.

5. $31 \quad 21 \quad 3641$.

6. $17 \quad 124226$.
7. $28^{\mathrm{d}} 5^{\text {h }} 48^{\mathrm{m}} 17^{\mathrm{s}}$.

8. $2021 \quad 9 \quad 34$.

9. $31 \quad 15 \quad 5034$.

$\begin{array}{lllll}10 . & 10 & 0 & 16 & 34 .\end{array}$

11. $22758 \quad 15$.

12. $29 \quad 162520$.

Ship Times.

1. October 15th, $5^{\text {h }} 29^{\mathrm{m}} 14^{\mathrm{e}}$ A.M.

2. May 6th, 114346 A.M.

3. August 31st, $7 \quad 333$ P.м.
4. June 3rd,

4. June 3rd, $52^{\text {n }} 18^{\circ}$ A.M.

5. October 19th, 113747 P.M.

6. May 1st, 4496 P.M.

\section{Chronometer Rates and G.M.T.}

1. Rate $2^{8 \cdot 7}$ losing.

2. ,, $5 \cdot 3$ gaining.

3. ,, 10.05 gaining.

4. ," 5 gaining.

5.,$\quad .5$ losing.

6. ", $5 \cdot 4$ gaining.

$7 ., \quad 9$ gaining.

8. ,, 10.05 losing.
9. G.M.T. Nov. $26^{\mathrm{d}} 13^{\mathrm{h}} 45^{\mathrm{m}} 45^{\mathrm{s}}$. 10.,$\quad$ Oct. $31 \quad 101747$. 11. " $\quad$ Mar. $20 \quad 8 \quad 1849$.

12. $\quad$ Dec. $10 \quad 12 \quad 57 \quad 36$.

13. ," July $323 \quad 5822$.

14. " Nov. $26 \quad 1923 \quad 52$.

15. ", Dec. $14 \quad 52324$.

16. ,, May $1 \quad 0 \quad 2410$.

17. ", April $15 \quad 1917 \quad 16$.

\section{CHAPTER $\mathrm{X}$.}

Sun's Elements.

1. Dec. $17^{\circ} 37^{\prime} 36^{\prime \prime} \cdot 2$ N. Eq. of Time $6^{\mathrm{m}} 1^{\mathrm{s} \cdot 73}$ R.A. $8^{\mathrm{h}} 51^{\mathrm{m}} 37^{\mathrm{a}} \cdot 01$.

2. ,, $16 \quad 30 \quad 16.8 \mathrm{~N}$

3. ,, $142325 \cdot 7 \mathrm{~N}$.

4. $\quad, \quad 3 \quad 3030 \quad 9.9$ N.

5. ," $\quad 0 \quad 4 \quad 55.7 \mathrm{~N}$.

6. ", $0 \quad 0 \quad 14 \cdot 1 \mathrm{~S}$.

7. " $\quad 0 \quad 3 \quad 47 \cdot 9$ S.

8. , $01112 \cdot 3 \mathrm{~S}$.

9., $22710 \mathrm{~S}$.

10. A.T.S. Aug. $20^{\mathrm{d}} 20^{\mathrm{h}} 18^{\mathrm{m}} 13^{\mathrm{s}} \cdot 6$.

\begin{tabular}{|c|c|c|c|c|c|c|}
\hline & & & & & & \\
\hline & & 20.22 & $"$ & & 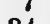 & 5920. \\
\hline " & & $32 \cdot 33$ & ," & 9 & 34 & 56.38. \\
\hline ", & 4 & 22 & " & 11 & 27 & 33.02 . \\
\hline$"$ & $\gamma$ & 2801 & ", & 11 & 59 & $14 \cdot 6$. \\
\hline$"$ & 7 & 32.62 & ", & 12 & 0 & $2 \cdot 2$ \\
\hline "' & $\gamma$ & 50 & ", & 12 & U & 351. \\
\hline " & 7 & $42 \cdot 39$ & " & 12 & & $43^{\circ} 4$. \\
\hline & 9 & $40 \cdot 69$ & ", & 12 & 22 & 40.04 \\
\hline
\end{tabular}

11. M.T.S. Sept. $292134 \quad 7 \cdot 4$.

12. M.T.G. Sept. $24 \quad 93413$. 
Sidereal Time or R.A.M.S.
1. $9^{\text {h }} 50^{\mathrm{m}} 41^{\mathrm{*}} \cdot 32$.
3. $10^{\mathrm{h}} 57^{\mathrm{m}} 10^{\mathrm{n}} \cdot 48$.
2. $10 \quad 23 \quad 41.51$.
4. $122948 \cdot 66$.

Moon's S.D. AND H.P.
1. S.D. $15^{\prime} 33^{\prime \prime}$
2. , $1524 \cdot 9$
3. , $16 \quad 20.5$
4. ,, $16 \quad 10.5$

H.P. $56^{\prime} 28^{\prime \prime} \cdot 6$.

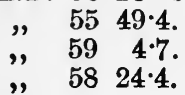

Moon's Meridian Passagz.

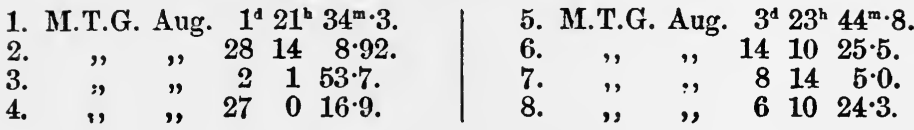

Moon's R.A. AND Dec.
1. R.A. $22^{\mathrm{h}} 30^{\mathrm{m}} \quad 9^{\mathrm{s}} \cdot 7$
2. , 0 45 20
$\begin{array}{lllll}3 . & , & 6 & 9 & 4 \cdot 27\end{array}$
$\begin{array}{rrrrr}\text { 4. } & \text {, } & 12 & 45 & 42 \cdot 13\end{array}$

Dec. $11^{\circ} 39^{\prime} 9^{\prime \prime} \cdot 8 \mathrm{~S}$. $\begin{array}{lrrrr}\text { " } & 0 & 2 & 2 \cdot 1 & \mathrm{~S} \\ \text { ", } & 20 & 3 & 45 \cdot 9 & \mathrm{~N} \\ & 0 & 1 & 34 \cdot 8 & \mathrm{~S}\end{array}$

Planet's Elements.

1. R. A. Jupiter $6^{\mathrm{h}} 9^{\mathrm{m}} 38^{\mathrm{s}} \cdot 94$ Dec. $23^{\circ} 7^{\prime} 26^{\prime \prime} \cdot 6 \mathrm{~N}$. Mer. Pass. $10^{\mathrm{d}} 4^{\mathrm{h}} 56^{\mathrm{m}} \cdot 27$. 2. "Saturn $23159 \cdot 32$ " $82459.6 \mathrm{~S}$. " 11345.3.

CHAPTER XI.

Sidereal Time or R.A.M.
1. $0^{\mathrm{h}} 2^{\mathrm{m}} \quad 8^{\mathrm{s}} \cdot 66$.
2. $1558 \quad 34 \cdot 45$.
3. $10 \quad 48 \quad \tilde{51}: 2$.
4. $7^{\mathrm{h}} 36^{\mathrm{m}} 46^{\mathrm{a}} \cdot 18$
5. $800 \quad 5 \cdot 93$.
6. $17 \quad 41 \quad 11 \cdot 29$.

Hour Angles.

1. E.H.A. $2^{\mathrm{h}} 6^{\mathrm{m}} \quad 6^{\mathrm{s}} \cdot 41$.

2. W.H.A. $15916 \cdot 02$.

3. W.H.A. $3729 \cdot 19$.
4. E.H.A. $0^{\mathrm{h}} \quad 0^{\mathrm{m}} 12^{\mathrm{s}} \cdot 84$.

5. M.T.S. Aug. $17^{\mathrm{d}} 20^{\mathrm{h}} 32^{\mathrm{m}} 1^{\mathrm{*}} 49$.

6. M.T.S. Sept. $1463515 \cdot 75$.

Star's Meridian Passage.

1. A.T.S. $3^{\mathrm{h}} 3^{\mathrm{m}} 25^{\mathrm{s}}$ A.M.

2. M.T.S. 33523 A.M.

3. M.T.S. 45220 A.M.

4. A.T.S. 4833 A.M.

5. M.T.S. 7346 A.м.

6. A.T.S. 7309 A.M.

7. M.T.S. 72717 А.м.

8. A.T.S. 82822 A.M.
9. M.T.S. $7^{\text {h }} 49^{\mathrm{m}} 35^{\mathrm{n}}$ A.M. 10. A.T.S. 115349 A.M. 11. M.T.S. 85856 A.M. 12. A.T.S. 23353 P.M. 13. M.T.S. 585 5.M. 14. A.T.S. 656 6 P.N. 15. M.T.S. 73323 P.M. 
Bright Stars near Meridian.

1. Altair $43^{m} \quad 1^{*} \mathrm{~W}$. and $\mathrm{S}$. y Cygni 1011 W. ,, N. Deneb 91 E. ", N. a Cephei $47 \quad 7$ E. " N.

2. Fomalhaut $56^{\mathrm{m}} 8^{\mathrm{s}} \mathrm{W}$. and $\mathrm{S}$.

3. Vega $20^{\text {m }} 2^{3} \mathrm{WV}$. and $\mathrm{N}$. Altair 5225 E. " N.

4. $a$ Cephei $1^{\mathrm{h}} 24^{\mathrm{m}} 17^{\mathrm{b}} \mathrm{W}$. and $\mathrm{N}$. $\epsilon$ Pegasi $114 \mathrm{~W}$. , N. $\begin{array}{llllll}\alpha \text { Gruis } & 0 & 38 & 18 \mathrm{~W} \text {. , S. }\end{array}$ B Gruis $\quad 0 \quad 3 \quad 34$ W. ," S. Fomalhaut 01150 E. ," S. Markab 01928 E. ", N. Alpheratz 12255 E. " N. B Cassiopeiæ 12332 E. " N. a Phœnicis 141 1 E. ", S. B Ceti 158 15 E. ,, S.

5. Capella $0^{\mathrm{h}} 38^{\mathrm{m}} \quad 7^{\mathrm{s}} \mathrm{W}$. and $\mathrm{N}$. Rigel $0 \begin{array}{lllll} & 37 & 51 & \mathrm{~W} . & \text {, S. }\end{array}$ Bellatrix 027 48 W. ," S. B Tauri $0 \begin{array}{lllll} & 27 & 31 & \text { W. ,, S. }\end{array}$ є Orionis $01626 \mathrm{~W}$. ,, $\mathrm{S}$.

6. Sirius $0^{\mathrm{h}} 11^{\mathrm{m}} 21^{\mathrm{B}} \mathrm{E}$. and $\mathrm{N}$.

7. $11^{\mathrm{h}} 22^{\mathrm{m}} 11^{\mathrm{s}}$.

8. $+13^{\mathrm{m}} 14 \cdot 6^{\mathrm{s}}$.

9. $+16^{\mathrm{m}} 25 \cdot 9^{\circ}$.

\section{CHAPTER XIT.}

Altitudes.

1. $50^{\circ} 9^{\prime} 35^{\prime \prime}$

2. 205744

3. 195646

4. 323536

5. $47 \quad 2 \quad 57$

6. $12 \quad 2015$

7. $56 \quad 2043$

8. $15 \quad 3828$

9. $29 \quad 13 \quad 31$

10. $47 \quad 19 \quad 24$

11. $23 \quad 8 \quad 22$

12. $53 \quad 13 \quad 51$

13. $3920 \quad 11$

14. $47 \quad 49 \quad 27$

15. $52 \quad 147$
S.D. $15^{\prime} 0^{\prime \prime}$ H.P. 54' $13^{\prime \prime}$ Cor. $29^{\prime} 47^{\prime \prime}$

,, $1457 \quad$," $5426 \quad$ " 494

S.D. $15^{\prime} 56^{\prime \prime}$ H.P. $57^{\prime} 33^{\prime \prime}$ Cor. $35^{\prime} 6^{\prime \prime}$ 


\section{CHAPTER XIII.}

Latitude by Sun's Merinian Altitude.

\begin{tabular}{|c|c|c|c|}
\hline No. & Declination. & True altitude. & Latitude. \\
\hline $\begin{array}{r}1 \\
2 \\
3 \\
4 \\
5 \\
6 \\
7 \\
8 \\
9 \\
10 \\
11 \\
12 \\
13 \\
14 \\
15 \\
16 \\
17 \\
18\end{array}$ & $\begin{array}{rrrl}\circ & \prime & \prime \prime \\
17 & 39 & 10 & \mathrm{~N} . \\
17 & 8 & 20 & \mathrm{~N} . \\
16 & 39 & 55 & \mathrm{~N} . \\
16 & 8 & 3 & \mathrm{~N} . \\
15 & 27 & 39 & \mathrm{~N} . \\
14 & 53 & 16 & \mathrm{~N} . \\
14 & 6 & 41 & \mathrm{~N} . \\
13 & 37 & 54 & \mathrm{~N} . \\
12 & 50 & 19 & \mathrm{~N} . \\
2 & 28 & 54 & \mathrm{~S} . \\
0 & 7 & 55 & \mathrm{~N} . \\
0 & 4 & 45 & \mathrm{~N} . \\
1 & 21 & 36 & \mathrm{~S} . \\
2 & 9 & 50 & \mathrm{~S} . \\
0 & 1 & 35 & \mathrm{~S} . \\
0 & 17 & 37 & \mathrm{~N} . \\
0 & 13 & 55 & \mathrm{~S} . \\
0 & 9 & 48 & \mathrm{~S} .\end{array}$ & $\begin{array}{rrr}\circ & \prime & \prime \prime \\
34 & 22 & 44 \\
50 & 16 & 30 \\
19 & 43 & 40 \\
69 & 28 & 41 \\
63 & 42 & 38 \\
49 & 43 & 13 \\
78 & 50 & 4 \\
79 & 47 & 14 \\
52 & 38 & 40 \\
88 & 48 & 35 \\
49 & 10 & 53 \\
43 & 27 & 24 \\
58 & 21 & 2 \\
36 & 10 & 5 \\
67 & 19 & 57 \\
51 & 59 & 25 \\
22 & 34 & 39 \\
30 & 10 & 10\end{array}$ & $\begin{array}{rccc}\circ & \prime & \text { " } \\
37 & 58 & 6 & \mathrm{~S} . \\
56 & 51 & 50 & \mathrm{~N} . \\
53 & 36 & 25 & \mathrm{~S} . \\
4 & 23 & 16 & \mathrm{~S} . \\
10 & 49 & 43 & \mathrm{~S} . \\
25 & 23 & 31 & \mathrm{~S} . \\
3 & 6 & 45 & \mathrm{~N} \\
3 & 25 & 8 & \mathrm{~N} \\
50 & 11 & 39 & \mathrm{~N} \\
1 & 17 & 29 & \mathrm{~S} . \\
40 & 57 & 2 & \mathrm{~N} \\
46 & 27 & 51 & \mathrm{~S} . \\
30 & 17 & 22 & \mathrm{~N} \\
55 & 59 & 45 & \mathrm{~S} . \\
22 & 38 & 28 & \mathrm{~N} \\
38 & 18 & 12 & \mathrm{~N} . \\
67 & 11 & 26 & \mathrm{~N} \\
59 & 59 & 38 & \mathrm{~S} .\end{array}$ \\
\hline
\end{tabular}

Latitude by Star's Meridian Altitude.
1. $10^{\circ} 15^{\prime} 12^{\prime \prime} \mathrm{N}$.
2. 132739 S.
3. $275826 \mathrm{~N}$.
4. $43 \quad 340 \mathrm{~N}$.
5. $494318 \mathrm{~N}$.
6. $50 \quad 0 \quad 45 \mathrm{~N}$.

$\begin{array}{rrrrr}\text { 7. } & 35^{\circ} & 58^{\prime} & 14^{\prime \prime} & \mathrm{N} \\ \text { 8. } & 44 & 22 & 3 & \mathrm{~S} . \\ 9 . & 37 & 51 & 6 & \mathrm{~N} \\ \text { 10. } & 19 & 18 & 20 & \mathrm{~S} \\ 11 . & 45 & 18 & 37 & \mathrm{~N}\end{array}$

Latitude by Moon's Meridian Altitude.

\begin{tabular}{|c|c|c|c|c|c|c|}
\hline No. & M.T.G. & S.D. & H.P. & Declination. & True alt. & Latitude. \\
\hline $\begin{array}{r}1 \\
2 \\
3 \\
4 \\
5 \\
6 \\
7 \\
8 \\
9 \\
10 \\
11 \\
12\end{array}$ & \begin{tabular}{rrr} 
d. & h. & \multicolumn{1}{c}{ m. } \\
21 & 4 & $38 \cdot 4$ \\
22 & 8 & $50 \cdot 6$ \\
30 & 5 & $5 \cdot 0$ \\
31 & 6 & $20 \cdot 2$ \\
31 & 18 & $38 \cdot 0$ \\
3 & 23 & $57 \cdot 2$ \\
9 & 15 & $1 \cdot 3$ \\
10 & 10 & $44 \cdot 9$ \\
11 & 9 & $11 \cdot 5$ \\
14 & 5 & $5 \cdot 5$ \\
16 & 10 & $59 \cdot 1$ \\
24 & 22 & $32 \cdot 7$
\end{tabular} & \begin{tabular}{rr}
1 & \multicolumn{1}{c}{} \\
15 & 58 \\
16 & 10 \\
16 & 17 \\
16 & 4 \\
16 & 8 \\
16 & 16 \\
15 & 11 \\
15 & 3 \\
15 & 4 \\
15 & 5 \\
15 & 19 \\
16 & 25
\end{tabular} & $\begin{array}{lc}\prime & \prime \prime \\
57 & 49 \\
58 & 22 \\
58 & 42 \\
58 & 19 \\
58 & 11 \\
58 & 46 \\
54 & 56 \\
54 & 34 \\
54 & 21 \\
54 & 24 \\
55 & 16 \\
59 & 8\end{array}$ & $\begin{array}{rccc}\circ & \prime & \text { " } \\
7 & 37 & 1 & \mathrm{~N} . \\
2 & 10 & 58 & \mathrm{~N} . \\
19 & 40 & 28 & \mathrm{~S} . \\
17 & 42 & 1 & \mathrm{~S} . \\
16 & 19 & 18 & \mathrm{~S} . \\
17 & 29 & 13 & \mathrm{~S} . \\
4 & 47 & 13 & \mathrm{~N} . \\
8 & 4 & 24 & \mathrm{~N} . \\
11 & 29 & 47 & \mathrm{~N} . \\
18 & 50 & 58 & \mathrm{~N} . \\
20 & 11 & 19 & \mathrm{~N} . \\
9 & 54 & 37 & \mathrm{~S} .\end{array}$ & $\begin{array}{rrr}\circ & \prime & \prime \prime \\
34 & 46 & 16 \\
54 & 8 & 55 \\
61 & 47 & 40 \\
25 & 44 & 55 \\
69 & 32 & 47 \\
39 & 16 & 31 \\
43 & 25 & 36 \\
47 & 5 & 35 \\
54 & 37 & 2 \\
75 & 33 & 28 \\
74 & 21 & 44 \\
84 & 40 & 30\end{array}$ & \begin{tabular}{rrrr}
\multicolumn{1}{c}{} & $\prime$ & \multicolumn{1}{c}{} \\
47 & 36 & 43 & $\mathrm{~S}$. \\
38 & 2 & 3 & $\mathrm{~N}$. \\
47 & 52 & 48 & $\mathrm{~S}$. \\
46 & 33 & 4 & $\mathrm{~N}$. \\
4 & 7 & 55 & $\mathrm{~N}$. \\
68 & 12 & 42 & $\mathrm{~S}$. \\
51 & 21 & 37 & $\mathrm{~N}$ \\
50 & 58 & 50 & $\mathrm{~N}$. \\
23 & 53 & 11 & $\mathrm{~S}$. \\
4 & 24 & 26 & $\mathrm{~N}$ \\
4 & 33 & 3 & $\mathrm{~N}$. \\
4 & 35 & 7 & $\mathrm{~S}$.
\end{tabular} \\
\hline
\end{tabular}


Latitude by Meridian Altitude below Pole.

1. M.T.G. $10^{\mathrm{d}} 17^{\mathrm{h}} 1^{\mathrm{m} \cdot} 1$. Dec. $8^{\circ} 23^{\prime} 56^{\prime \prime}$ S. Lat. $43^{\circ} 16^{\prime} 44^{\prime \prime}$ S.

2. $48^{\circ} 23^{\prime} 59^{\prime \prime} \mathrm{S}$.

3. $54^{\circ} 6^{\prime} 9^{\prime \prime} \mathrm{N}$.

4. M.T.G. $28^{\mathrm{d}} 10^{\mathrm{b}} 31^{\mathrm{m}} \cdot 9$. S.D. $16^{\prime} 12^{\prime \prime}$. H.P. $59^{\prime} 1^{\prime \prime}$. Dec. $19^{\circ} 57^{\prime} 26^{\prime \prime}$ S. True Alt. $7^{\circ} 53^{\prime} 4^{\prime \prime}$. Lat. $77^{\circ} 55^{\prime} 38^{\prime \prime} \mathrm{S}$.

5. Dec. $18^{\circ} 0^{\prime} 19^{\prime \prime}$ N. True Alt. $5^{\circ} 53^{\prime} 11^{\prime \prime}$. Lat. $77^{\circ} 52^{\prime} 52^{\prime \prime} \mathrm{N}$.

6. $50^{\circ} 44^{\prime} 17^{\prime \prime} \mathrm{S}$.

Star's calculated Altitudes.
1. $39^{\circ} 48^{\prime}$
2. 426
3. 1938
4. 570
5. 6750

6. $32^{\circ} 15^{\prime}$

7. 6144

8. $37 \quad 57$

9. 514

10. 251

\section{CHAPTER XIV.}

Latitude by Ex-Meridian Altitude of the Sun.

\begin{tabular}{|c|c|c|c|c|c|c|}
\hline No. & Hour angle. & Nat. No. & Arc I. & Arc II. & Latitude sights. & Latitude at noon. \\
\hline $\begin{array}{r}1 \\
2 \\
3 \\
4 \\
5 \\
6 \\
7 \\
8 \\
9 \\
10 \\
11 \\
12\end{array}$ & 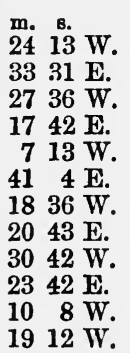 & $\begin{array}{r}4213 \\
9161 \\
6927 \\
1725 \\
342 \\
15638 \\
2503 \\
2932 \\
6173 \\
5134 \\
611 \\
2675\end{array}$ & \begin{tabular}{rrr}
0 & $\prime$ & \multicolumn{1}{c}{} \\
18 & 22 & 46 \\
17 & 0 & 56 \\
16 & 9 & 4 \\
15 & 4 & 6 \\
& - & \\
12 & 17 & 42 \\
10 & 40 & 49 \\
8 & 28 & 25 \\
2 & 13 & 34 \\
0 & 5 & 53 \\
0 & 2 & 41
\end{tabular} & 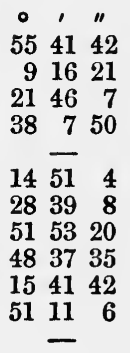 & 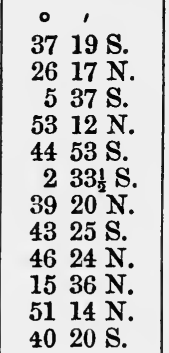 & 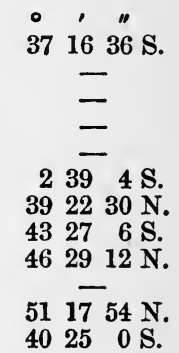 \\
\hline
\end{tabular}

Latitude by Ex-Meridian Altitude of a Star.

\begin{tabular}{|c|c|c|c|c|c|}
\hline No. & Hour angle. & Nat. No. & Arc I. & Arc II. & Latitude. \\
\hline $\begin{array}{r}1 \\
2 \\
3 \\
4 \\
5 \\
6 \\
7 \\
8 \\
9 \\
10 \\
11 \\
12\end{array}$ & $\begin{array}{rr}\text { m. } & \mathbf{s .} \\
7 & 56 \cdot 5 \\
29 & 35 \cdot 0 \\
21 & 9 \cdot 7 \\
21 & 42 \cdot 6 \\
19 & 13 \cdot 7 \\
47 & 43 \cdot 0 \\
23 & 18 \cdot 4 \\
14 & 32 \cdot 4 \\
28 & 43 \cdot 0 \\
25 & 8 \cdot 7 \\
6 & 15 \cdot 0 \\
32 & 53 \cdot 7\end{array}$ & $\begin{array}{r}365 \\
5126 \\
2318 \\
2861 \\
2950 \\
11403 \\
4037 \\
1152 \\
5000 \\
3365 \\
264 \\
6532\end{array}$ & \begin{tabular}{rrr}
$\circ$ & \multicolumn{1}{c}{} & \multicolumn{1}{c}{} \\
38 & 42 & 45 \\
8 & 41 & 27 \\
57 & 8 & 54 \\
30 & 13 & 56 \\
28 & 39 & 23 \\
58 & 16 & 35 \\
23 & 7 & 31 \\
16 & 21 & 7 \\
46 & 7 & 42 \\
8 & 21 & 34 \\
44 & 57 & 15 \\
47 & 42 & 46
\end{tabular} & \begin{tabular}{rrr}
$\circ$ & \multicolumn{1}{c}{} & \multicolumn{1}{c}{} \\
77 & 34 & 45 \\
42 & 45 & 50 \\
57 & 8 & 55 \\
72 & 40 & 57 \\
11 & 25 & 19 \\
49 & 34 & 31 \\
54 & 59 & 32 \\
37 & 3 & 44 \\
69 & 43 & 43 \\
47 & 12 & 24 \\
41 & 53 & 0 \\
67 & 51 & 30
\end{tabular} & \begin{tabular}{rrrr}
0 & \multicolumn{1}{c}{} & \multicolumn{1}{c}{} \\
38 & 52 & 0 & $\mathrm{~S}$. \\
51 & 27 & 17 & $\mathrm{~N}$. \\
0 & 0 & 1 & $\mathrm{~N}$. \\
42 & 27 & 1 & $\mathrm{~N}$. \\
17 & 14 & 4 & $\mathrm{~N}$. \\
8 & 42 & 4 & $\mathrm{~S}$. \\
31 & 52 & 1 & $\mathrm{~S}$. \\
53 & 24 & 51 & $\mathrm{~N}$. \\
23 & 36 & 1 & $\mathrm{~S}$. \\
55 & 33 & 58 & $\mathrm{~S}$. \\
3 & 4 & 16 & $\mathrm{~N}$. \\
20 & 8 & 44 & $\mathrm{~N}$.
\end{tabular} \\
\hline
\end{tabular}


Latitude by Pole Star.

\begin{tabular}{|c|c|c|c|c|c|}
\hline No. & R.A.M. & First cor. & Second cor. & Third cor. & Latitude. \\
\hline $\begin{array}{l}1 \\
2 \\
3 \\
4 \\
5 \\
6 \\
7 \\
8 \\
9\end{array}$ & $\begin{array}{rcc}\text { h } & \text { m. } & \text { s. } \\
4 & 10 & 55 \cdot 9 \\
22 & 36 & 2 \\
12 & 55 & 19 \\
16 & 59 & 12 \\
7 & 25 & 1 \\
19 & 28 & 29 \\
0 & 1 & 21 \\
7 & 44 & 9 \\
18 & 9 & 40\end{array}$ & \begin{tabular}{rrr}
$\circ$ & $\prime$ & \multicolumn{1}{l}{} \\
-0 & 53 & 56 \\
-0 & 53 & 17 \\
+1 & 11 & 23 \\
+0 & 42 & 49 \\
0 & 0 & 0 \\
-0 & 1 & 6 \\
-1 & 7 & 15 \\
+0 & 5 & 59 \\
+0 & 23 & 13
\end{tabular} & $\begin{array}{rr} & 1 \\
0 & 15 \\
0 & 22 \\
0 & 0 \\
0 & 40 \\
0 & 19 \\
0 & 28 \\
0 & 7 \\
0 & 51 \\
0 & 24\end{array}$ & $\begin{array}{cc}1 & \prime \prime \\
0 & 53 \\
1 & 16 \\
0 & 54 \\
1 & 10 \\
0 & 31 \\
1 & 27 \\
1 & 20 \\
0 & 28 \\
1 & 15\end{array}$ & \begin{tabular}{rrr}
$\circ$ & \multicolumn{1}{c}{} & \multicolumn{1}{c}{} \\
35 & 44 & 59 \\
45 & 17 & 10 \\
30 & 4 & 31 \\
54 & 15 & 16 \\
23 & 4 & 59 \\
32 & 22 & 41 \\
49 & 49 & 19 \\
48 & 22 & 55 \\
31 & 1 & 12
\end{tabular} \\
\hline
\end{tabular}

CHAPTER XV.

Compass Error by Amplitude.

\begin{tabular}{|c|c|c|c|c|}
\hline No. & Declination. & True amplitude. & Compass error. & Deviation. \\
\hline $\begin{array}{r}1 \\
2 \\
3 \\
4 \\
5 \\
6 \\
7 \\
8 \\
9 \\
10 \\
11 \\
12 \\
13 \\
14\end{array}$ & $\begin{array}{rccc}\circ & \prime & \text { " } \\
17 & 55 & 0 & \mathrm{~N} . \\
1 & 45 & 17 & \mathrm{~S} . \\
16 & 2 & 20 & \mathrm{~N} . \\
2 & 33 & 52 & \mathrm{~S} . \\
17 & 31 & 14 & \mathrm{~N} . \\
1 & 13 & 23 & \mathrm{~S} . \\
16 & 34 & 56 & \mathrm{~N} . \\
6 & 2 & 21 & \mathrm{~N} . \\
17 & 39 & 44 & \mathrm{~N} . \\
0 & 13 & 43 & \mathrm{~N} . \\
0 & 35 & 35 & \mathrm{~S} . \\
0 & 0 & 0 \\
9 & 9 & 23 & \mathrm{~N} . \\
0 & 0 & 0\end{array}$ & 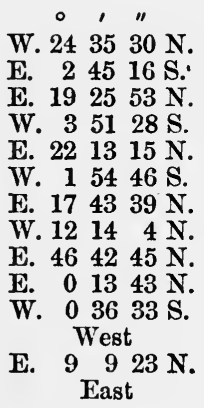 & $\begin{array}{rrrr}\circ & \prime & \prime \prime \\
34 & 28 & 30 & \mathrm{~W} . \\
28 & 15 & 16 & \mathrm{E} . \\
5 & 22 & 8 & \mathrm{~W} . \\
1 & 46 & 2 & \mathrm{E} . \\
5 & 20 & 45 & \mathrm{~W} . \\
18 & 35 & 14 & \mathrm{E} . \\
17 & 43 & 39 & \mathrm{~W} . \\
12 & 14 & 4 & \mathrm{E} . \\
46 & 6 & 0 & \mathrm{E} . \\
10 & 13 & 43 & \mathrm{~W} . \\
14 & 6 & 33 & \mathrm{~W} . \\
2 & 0 & 0 & \mathrm{E} . \\
18 & 58 & 7 & \mathrm{E} . \\
0 & 0 & 0\end{array}$ & $\begin{array}{rrrl}0 & \prime & \prime \prime \\
5 & 58 & 30 & \mathrm{~W} . \\
4 & 0 & 16 & \mathrm{E} . \\
16 & 42 & 8 & \mathrm{~W} . \\
31 & 31 & 2 & \mathrm{E} . \\
6 & 9 & 15 & \mathrm{E} . \\
4 & 4 & 46 & \mathrm{~W} . \\
24 & 58 & 39 & \mathrm{~W} . \\
0 & 5 & 56 & \mathrm{~W} . \\
23 & 26 & 0 & \mathrm{E} . \\
10 & 13 & 43 & \mathrm{~W} . \\
12 & 6 & 33 & \mathrm{~W} . \\
4 & 30 & 0 & \mathrm{~W} . \\
9 & 28 & 7 & \mathrm{E} . \\
1 & 15 & 0 & \mathrm{~W} .\end{array}$ \\
\hline
\end{tabular}

15. $4^{\mathrm{h}} 41^{\mathrm{m}} 30^{\mathrm{s}}$ A.M.

16. $1^{\mathrm{h}} 11^{\mathrm{m}} 17^{\circ}$.

17. $2^{\circ} \mathrm{E}$,
18. $45^{\circ}$.

19. $41^{\circ} 49^{\prime}$.

20. $24^{\circ} 42^{\prime}$

$2^{\text {h }} 40^{\text {m }} 50^{\text {e. }}$

\section{CHAPTER XVI.}

Compass Error by Alt. Azimuth.

\begin{tabular}{|c|c|c|c|c|c|}
\hline No. & Polar distance. & True altítude. & True azimuth. & Compass error. & Deviation. \\
\hline $\begin{array}{l}1 \\
2 \\
3 \\
4 \\
5 \\
6\end{array}$ & \begin{tabular}{rrr}
0 & 1 & \multicolumn{1}{c}{} \\
107 & 31 & 58 \\
77 & 7 & 20 \\
81 & 4 & 35 \\
81 & 26 & 0 \\
90 & 16 & 20 \\
87 & 35 & 42
\end{tabular} & $\begin{array}{rrc}\circ & \prime & \prime \prime \\
16 & 51 & 58 \\
26 & 7 & 13 \\
36 & 2 & 26 \\
34 & 3 & 54 \\
21 & 56 & 18 \\
25 & 14 & 42\end{array}$ & \begin{tabular}{lcccc} 
& 0 & \multicolumn{1}{c}{} & \multicolumn{1}{c}{} \\
N. & 49 & 39 & 6 & $\mathrm{E}$. \\
S. & 84 & 10 & 50 & $\mathrm{~W}$. \\
S. & 50 & 53 & 8 & $\mathrm{E}$. \\
S. & 65 & 53 & 0 & $\mathbf{E}$. \\
N. & 61 & 9 & 54 & W. \\
N. & 61 & 8 & 10 & W.
\end{tabular} & 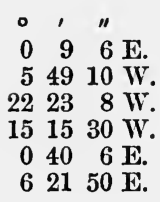 & \begin{tabular}{rrrr}
\multicolumn{1}{c}{} & \multicolumn{1}{c}{} & \multicolumn{1}{c}{} \\
18 & 9 & 6 & $\mathbf{E}$. \\
3 & 40 & 50 & $\mathbf{E}$. \\
6 & 43 & 8 & $\mathrm{~W}$. \\
9 & 44 & 30 & $\mathbf{E}$. \\
0 & 40 & 6 & $\mathbf{E}$ \\
10 & 8 & 10 & $\mathrm{~W}$.
\end{tabular} \\
\hline
\end{tabular}


Compass Error by Tine Azimuth of Sun.

\begin{tabular}{|c|c|c|c|c|}
\hline No. & A.T.S. & Corrections. & True azimuth. & Deviation. \\
\hline $\begin{array}{r}1 \\
2 \\
3 \\
4 \\
5 \\
6 \\
7 \\
8 \\
9 \\
10 \\
11 \\
12 \\
13 \\
14\end{array}$ & $\begin{array}{rrrr}\text { h. m. } & \text { s. } \\
2 & 48 & 0 & \text { P.M. } \\
3 & 19 & 0 & \text { P.M. } \\
9 & 14 & 0 & \text { A.M. } \\
3 & 32 & 0 & \text { P.M. } \\
7 & 20 & 0 & \text { A.M. } \\
7 & 57 & 22 & \text { A.M. } \\
3 & 38 & 31 & \text { P.M. } \\
8 & 41 & 26 & \text { A.M. } \\
4 & 38 & 18 & \text { P.M. } \\
3 & 50 & 0 & \text { P.M. } \\
8 & 34 & 6 & \text { A.M. } \\
4 & 19 & 35 & \text { P.M. } \\
9 & 41 & 21 & \text { A.M. } \\
10 & 39 & 9 & \text { A.M. }\end{array}$ & $\begin{array}{c}\prime \prime 16 \\
+14-25 \\
+25+7+2 \\
+21+5 \\
-14 \\
+4+5+17 \\
-33+10+14 \\
+19-27+11 \\
-17+6 \\
-18+37+5 \\
+17-18+18 \\
+4-1+15 \\
+19+16+11 \\
82^{\circ} 59^{\prime}+72^{\circ} 45^{\prime}\end{array}$ & 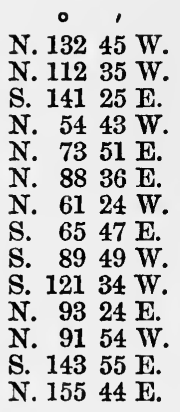 & $\begin{array}{rrr}3 & 9 & \mathrm{~W} . \\
12 & 47 & \mathrm{E} . \\
19 & 27 & \mathrm{E} . \\
0 & 26 & \mathrm{E} . \\
9 & 51 & \mathrm{E} . \\
9 & 11 & \mathrm{~W} . \\
10 & 19 & \mathrm{E} . \\
19 & 55 & \mathrm{~W} . \\
16 & 18 & \mathrm{E} . \\
35 & 40 & \mathrm{~W} . \\
56 & 43 & \mathrm{~W} .\end{array}$ \\
\hline
\end{tabular}

Compass Error by Time Azimuth op Stars.

\begin{tabular}{|c|c|c|c|c|}
\hline No. & Hour angle. & Corrections. & True azimuth. & Deviation. \\
\hline $\begin{array}{r}1 \\
2 \\
3 \\
4 \\
5 \\
6 \\
7 \\
8 \\
9 \\
10 \\
11 \\
12\end{array}$ & $\begin{array}{rrrr}\text { h. } & \text { m. } & \text { s. } \\
3 & 1 & 39 & \mathrm{E} . \\
4 & 53 & 9 & \mathrm{E} . \\
3 & 26 & 4 & \mathrm{~W} . \\
1 & 48 & 14 & \mathrm{~W} . \\
5 & 37 & 7 & \mathrm{E} . \\
3 & 23 & 41 & \mathrm{~W} . \\
3 & 29 & 46 & \mathrm{E} . \\
3 & 23 & 47 & \mathrm{~W} . \\
3 & 35 & 29 & \mathrm{E} . \\
9 & 16 & 22 & \mathrm{~W} . \\
4 & 30 & 20 & \mathrm{~W} . \\
8 & 41 & 20 & \mathrm{~W} .\end{array}$ & 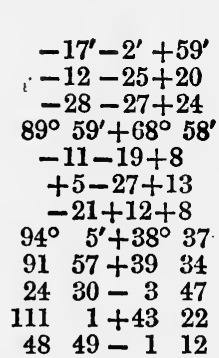 & \begin{tabular}{lrrr} 
& \multicolumn{1}{c}{ ' } \\
N. & 97 & 37 & $\mathrm{E}$. \\
S. & 92 & 51 & $\mathrm{E}$. \\
N. & 114 & 36 & $\mathrm{~W}$. \\
S. & 158 & 57 & $\mathrm{~W}$. \\
N. & 88 & 5 & $\mathrm{E}$. \\
N. & 113 & 30 & $\mathrm{~W}$. \\
S. & 128 & 24 & $\mathrm{E}$. \\
N. & 132 & 42 & $\mathrm{~W}$. \\
S. & 131 & 31 & $\mathrm{E}$. \\
S. & 20 & 43 & $\mathrm{~W}$. \\
S. & 154 & 23 & $\mathrm{~W}$. \\
S. & 47 & 37 & $\mathrm{~W}$.
\end{tabular} & $\begin{array}{rrr}0 & 1 \\
22 & 22 & \mathrm{E} . \\
14 & 42 & \mathrm{~W} . \\
35 & 26 & \mathrm{~W} . \\
15 & 43 & \mathrm{~W} . \\
23 & 43 & \mathrm{E} . \\
26 & 0 & \mathrm{E} . \\
21 & 36 & \mathrm{E} . \\
0 & 5 & \mathrm{~W} . \\
10 & 25 & \mathrm{E} . \\
7 & 1 & \mathrm{E} . \\
23 & 10 & \mathrm{~W} . \\
2 & 26 & \mathrm{~W} .\end{array}$ \\
\hline
\end{tabular}

14. N. $48^{\circ} 20^{\prime}$ E.

15. Dec. $19^{\circ} 19^{\prime} \mathrm{N}$.; Lat. $51^{\circ} 30^{\prime} \mathrm{N}$.

\section{CHAPTER XVII.}

Longitude bX Sun Chronometer.

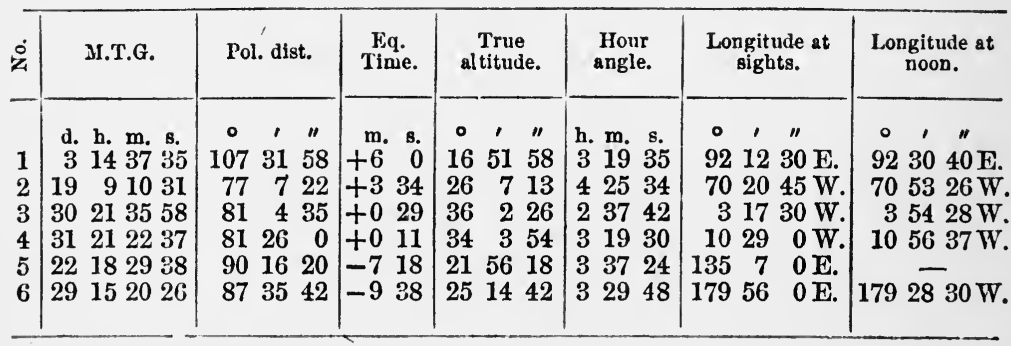


ANSWERS.

Longitude by Star Chronometer.

\begin{tabular}{|c|c|c|c|c|c|}
\hline No. & M.T.G. & R.A.M.S. & True altitude. & Hour angle. & Longitude. \\
\hline $\begin{array}{r}1 \\
2 \\
3 \\
4 \\
5 \\
6 \\
7 \\
8 \\
9 \\
10 \\
11 \\
12\end{array}$ & $\begin{array}{rrrr}\text { d. } & \text { h. } & \text { m. } & \text { s. } \\
9 & 9 & 8 & 13 \\
23 & 21 & 37 & 52 \\
1 & 7 & 47 & 31 \\
11 & 10 & 56 & 5 \\
20 & 15 & 27 & 42 \\
23 & 9 & 11 & 21 \\
7 & 9 & 42 & 18 \\
30 & 21 & 6 & 21 \\
2 & 6 & 54 & 54 \\
14 & 2 & 2 & 6 \\
28 & 6 & 58 & 18 \\
27 & 19 & 24 & 11\end{array}$ & \begin{tabular}{rrr}
\multicolumn{1}{c}{} & m. & s. \\
11 & 12 & 0 \\
10 & 7 & 2 \\
8 & 38 & 1 \\
11 & 20 & 11 \\
11 & 56 & 24 \\
10 & 4 & 59 \\
11 & 4 & 12 \\
10 & 34 & 32 \\
10 & 44 & 2 \\
9 & 28 & 19 \\
10 & 24 & 20 \\
12 & 24 & 39
\end{tabular} & \begin{tabular}{ccc}
$\circ$ & $\prime$ & \multicolumn{1}{c}{} \\
59 & 24 & 30 \\
12 & 1 & 18 \\
42 & 2 & 0 \\
26 & 8 & 42 \\
37 & 12 & 48 \\
27 & 14 & 27 \\
22 & 42 & 6 \\
15 & 44 & 30 \\
25 & 13 & 55 \\
21 & 59 & 16 \\
34 & 50 & 51 \\
68 & 25 & 1
\end{tabular} & $\begin{array}{lrrr}\text { h. } & \text { m. } & \text { s. } \\
2 & 9 & 2 & \mathrm{~W} . \\
3 & 36 & 40 & \mathrm{E} . \\
2 & 22 & 59 & \mathrm{E} . \\
3 & 42 & 30 & \mathrm{~W} . \\
3 & 48 & 43 & \mathrm{E} . \\
3 & 50 & 37 & \mathrm{E} . \\
3 & 25 & 33 & \mathrm{E} . \\
2 & 29 & 43 & \mathrm{E} . \\
4 & 36 & 0 & \mathrm{~W} . \\
4 & 59 & 0 & \mathrm{E} . \\
2 & 51 & 28 & \mathrm{~W} . \\
2 & 5 & 9 & \mathrm{E} .\end{array}$ & $\begin{array}{rrrr}0 & \prime & \prime \prime \\
110 & 45 & 30 & \mathrm{E} . \\
74 & 55 & 15 & \mathrm{~W} . \\
14 & 25 & 15 & \mathrm{E} . \\
0 & 0 & 0 & \\
30 & 46 & 15 & \mathrm{~W} . \\
90 & 46 & 0 & \mathrm{E} . \\
110 & 35 & 0 & \mathrm{E} . \\
169 & 32 & 15 & \mathrm{~W} . \\
50 & 10 & 45 & \mathrm{E} . \\
179 & 43 & 30 & \mathrm{~W} . \\
4 & 56 & 45 & \mathrm{~W} . \\
161 & 3 & 45 & \mathrm{E} .\end{array}$ \\
\hline
\end{tabular}




\begin{tabular}{|c|c|c|c|c|c|c|c|c|c|c|c|c|}
\hline 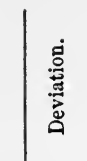 & $\begin{array}{rl} & \dot{\theta} \\
= & \infty \\
- & \overrightarrow{0} \\
- & \vec{N} \\
0 & 0\end{array}$ & 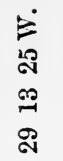 & $\begin{array}{l}\text { ह } \\
\text { \% } \\
0 \\
\text { ㄱ. }\end{array}$ & 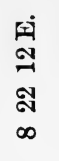 & $\begin{array}{l}0 \\
0 \\
0 \\
N\end{array}$ & 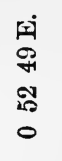 & $\begin{array}{l}\text { 国 } \\
0 \\
\text { ๓ } \\
\text { N }\end{array}$ & 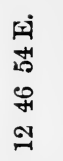 & $\begin{array}{l}\mathbf{9} \\
0 \\
0 \\
\approx \\
\approx \\
=\end{array}$ & $\begin{array}{l}\text { 里 } \\
0 \\
\text { o } \\
0\end{array}$ & $\begin{array}{l}\dot{0} \\
0 \\
\circ \\
0 \\
\circ\end{array}$ & \begin{tabular}{l} 
E \\
\multirow{2}{*}{} \\
ส \\
-1
\end{tabular} \\
\hline 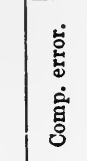 & 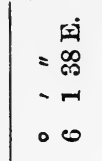 & 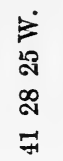 & $\begin{array}{l}\dot{0} \\
\infty \\
\infty \\
\infty \\
\infty \\
\infty\end{array}$ & 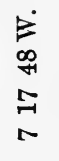 & 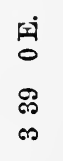 & \begin{tabular}{l}
$\vec{E}$ \\
$=$ \\
\multirow{6}{0}{} \\
0
\end{tabular} & 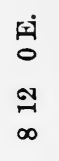 & 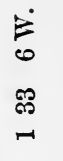 & $\begin{array}{l}\text { ri } \\
0 \\
- \\
N \\
N\end{array}$ & $\begin{array}{l}\text { ⿷匚 } \\
0 \\
\text { कొ } \\
=1\end{array}$ & $\begin{array}{l}\dot{0} \\
0 \\
i n \\
\text { in } \\
0\end{array}$ & 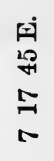 \\
\hline 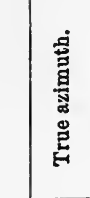 & $\begin{aligned} & \overrightarrow{0} \\
&= \infty \\
&-\infty \\
&-\infty \\
& 0 \\
& 0 \\
& \infty \\
& \\
& \dot{\infty}\end{aligned}$ & 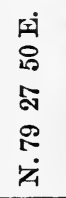 & 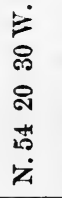 & 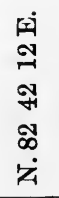 & $\begin{array}{l}\dot{E} \\
0 \\
\vec{A} \\
0 \\
\ddot{n} \\
\dot{z}\end{array}$ & 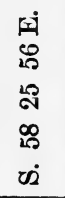 & 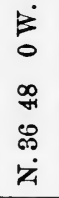 & 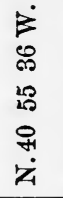 & 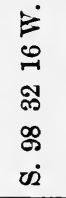 & 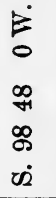 & 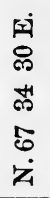 & $\begin{array}{l}\dot{E} \\
8 \\
0 \\
0 \\
\hat{N} \\
\dot{R}\end{array}$ \\
\hline 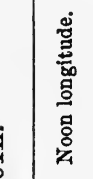 & $\begin{array}{l}\dot{\hat{\sigma}} \\
=0 \\
-\infty \\
0 \\
0\end{array}$ & 1 & 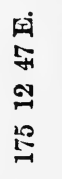 & 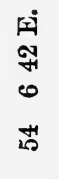 & 1 & 1 & 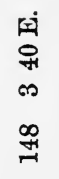 & $\begin{array}{l}\text { 정 } \\
0 \\
\text { के } \\
\text { ஜ̊ }\end{array}$ & 1 & 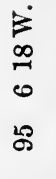 & 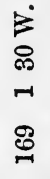 & 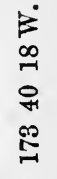 \\
\hline 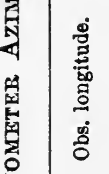 & 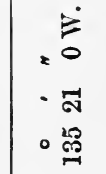 & 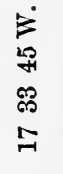 & 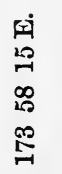 & $\begin{array}{l}\text { 19 } \\
8 \\
8 \\
\text { 40 } \\
\text { ผn }\end{array}$ & 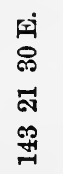 & $\begin{array}{l}30 \\
0 \\
-1 \\
E\end{array}$ & 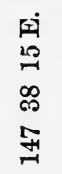 & 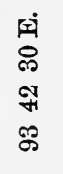 & $\begin{array}{l}\text { 国 } \\
20 \\
-10 \\
\infty \\
\infty\end{array}$ & 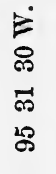 & 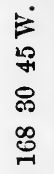 & 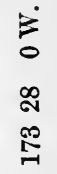 \\
\hline 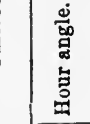 & 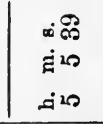 & $\begin{array}{l}\vec{N} \\
F \\
H\end{array}$ & $\begin{array}{l}\text { ని } \\
\text { లి } \\
\text { లో }\end{array}$ & 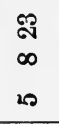 & 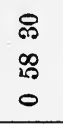 & $\begin{array}{l}\infty \\
\infty \\
\infty \\
\infty\end{array}$ & $\begin{array}{l}F \\
F \\
\text { F } \\
-1\end{array}$ & $\begin{array}{l}\text { is } \\
\text { 跑 } \\
\text { ov }\end{array}$ & $\begin{array}{l}H \\
H \\
H\end{array}$ & $\begin{array}{l}9 \\
\text { I } \\
\text { o } \\
\text { H }\end{array}$ & $\begin{array}{l}\text { is } \\
\text { of } \\
\text { of }\end{array}$ & $\begin{array}{l}\infty \\
\stackrel{\infty}{1} \\
\Re \\
\stackrel{N}{N} \\
\sim\end{array}$ \\
\hline 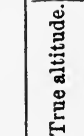 & $\begin{array}{l}=\infty \\
-\mathscr{N} \\
-\infty \\
0\end{array}$ & $\begin{array}{l}0 \\
2 \\
20 \\
20 \\
0 \\
0\end{array}$ & 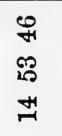 & 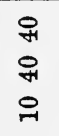 & $\begin{array}{l}1 \\
20 \\
28\end{array}$ & $\begin{array}{l}\infty \\
\sim \\
\infty \\
\infty \\
\infty\end{array}$ & $\begin{array}{l}\infty \\
\infty \\
\not{F}\end{array}$ & $\begin{array}{l}\text { जे } \\
\text { म0 } \\
\text { ले }\end{array}$ & 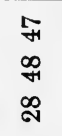 & $\begin{array}{l}\infty \\
\sim \\
\infty\end{array}$ & $\begin{array}{l}\ddot{1} \\
\overrightarrow{10} \\
\text { बे }\end{array}$ & $\begin{array}{l}\infty \\
\text { m } \\
\text { if }\end{array}$ \\
\hline 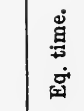 & $\begin{array}{l}\text { किज } \\
\dot{\text { घं }} \\
+\end{array}$ & $\begin{array}{l}\boldsymbol{N} \\
\stackrel{\circ}{1}\end{array}$ & $\begin{array}{l}20 \\
0 \\
+\end{array}$ & $\frac{20}{2}$ & $\begin{array}{l}0 \\
0 \\
+\end{array}$ & in & $\underset{1}{2}$ & $\begin{array}{l}\text { i⿱ } \\
\text { in } \\
+\end{array}$ & $\begin{array}{l}0 \\
0 \\
+\end{array}$ & $\begin{array}{l}0 \\
0\end{array}$ & $\begin{array}{l}\text { N } \\
\infty \\
+\end{array}$ & $\frac{1}{1}$ \\
\hline $\begin{array}{l}\dot{\vec{m}} \\
\dot{\vec{g}} \\
\dot{\overrightarrow{0}}\end{array}$ & 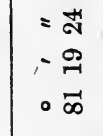 & 旤 & $\begin{array}{l}\infty \\
20 \\
\infty \\
\infty \\
\infty \\
\infty\end{array}$ & $\begin{array}{l}\infty \\
\infty \\
9 \\
\stackrel{8}{8}\end{array}$ & $\begin{array}{l}10 \\
\stackrel{2}{ } \\
\mathbb{m} \\
\infty \\
\infty\end{array}$ & $\begin{array}{l}20 \\
\text { ล } \\
\infty\end{array}$ & $\begin{array}{l}0 \\
9 \\
\stackrel{1}{8} \\
8\end{array}$ & 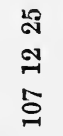 & 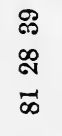 & $\begin{array}{l}\text { A } \\
\infty \\
\infty \\
\infty\end{array}$ & 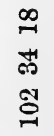 & $\begin{array}{l}\overrightarrow{6} \\
\sigma \\
8\end{array}$ \\
\hline 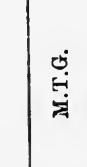 & 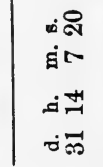 & 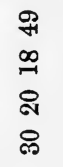 & 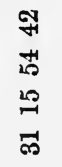 & $\begin{array}{l}0 \\
H \\
\stackrel{2}{1} \\
\text { న్ }\end{array}$ & $\begin{array}{l}\text { จิ } \\
\text { เి } \\
\text { 12 } \\
\vec{~}\end{array}$ & $\begin{array}{l}\text { జ } \\
\text { జ } \\
-1 \\
\text { สิ }\end{array}$ & 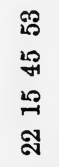 & 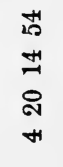 & $\begin{array}{l}\text { 아 } \\
\text { \& } \\
0 \\
-1\end{array}$ & $\begin{array}{l}\text { I } \\
\infty \\
\Rightarrow \\
\Rightarrow \\
-1\end{array}$ & 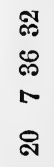 & 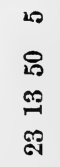 \\
\hline$\dot{\Delta}$ & & $\mathbf{N}$ & & $H$ & 10 & 0 & 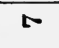 & $\infty$ & $\theta$ & 잉 & $\approx$ & $\underset{工}{ }$ \\
\hline
\end{tabular}




\section{CHAPTER XVIII.}

\section{Sumner's Method.}

1. First observation : T.A. $36^{\circ} 26^{\prime} 20^{\prime \prime}$; P.D. $72^{\circ} 29^{\prime} 5^{\prime \prime}$; eq. time, $+6^{\mathrm{m}} 0^{\mathrm{s}}$; H.A.'s, $3^{\mathrm{h}} 37^{\mathrm{m}} 17^{\mathrm{s}}$ and $3^{\mathrm{h}} 36^{\mathrm{m}} 25^{\mathrm{s}}$; longs., $(a), 64^{\circ} 14^{\prime} 30^{\prime \prime} \mathrm{E}$.; (b), $64^{\circ} 27^{\prime} 30^{\prime \prime} \mathrm{E}$.

Second observation : T.A. $43^{\circ} 47^{\prime} 38^{\prime \prime}$; P.D. $72^{\circ} 33^{\prime} 18^{\prime \prime}$; eq. time, $+5^{\mathrm{m}} 58^{\prime}$;

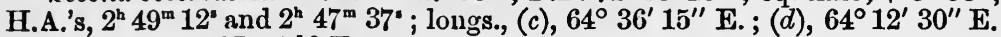

First line: $\left\{\begin{array}{l}\text { N. } 151^{\circ} \\ \text { S. } 15 \frac{1}{2}^{\circ} \\ \mathrm{W} .\end{array}\right\}$; second azimuth, S. $63^{\circ}$ W. ; lat. $49^{\circ} 27^{\prime}$ N. ; long. $63^{\circ} 52^{\prime} \mathrm{E}$.

2. First observation: T.A. $38^{\circ} 26^{\prime} 23^{\prime \prime}$; P.D. $73^{\circ} 54^{\prime} 28^{\prime \prime}$; eq. time, $+5^{\mathrm{m}} 26^{\mathrm{s}}$; H.A.'s, $3^{\mathrm{h}} 15^{\mathrm{m}} 40^{\prime \prime}$ and $3^{\mathrm{h}} 13^{\mathrm{m}} 56^{\text {s }}$; longs., $(a), 4^{\circ} 43^{\prime} 15^{\prime \prime}$ W.; (b) $4^{\circ} 17^{\prime} 15^{\prime \prime} \mathrm{W}$.

Second observation: T.A. $40^{\circ} 19^{\prime} 48^{\prime \prime}$; P.D. $73^{\circ} 58^{\prime} 52^{\prime \prime}$; eq. time, $+5^{\mathrm{m}} 24^{\mathrm{s}} ;$ H.A.'s, $3^{\mathrm{h}} 2^{\mathrm{m}} 35^{\mathrm{s}}$ and $3^{\mathrm{h}} 0^{\mathrm{m}} 34^{\mathrm{s}}$; longs., (c), $2^{\circ} 0^{\prime} 1^{\prime \prime}$ W.; (d), $2^{\circ} 30^{\prime} 30^{\prime \prime} \mathrm{W}$.

First line : $\left\{\begin{array}{l}\text { N. } 23^{\circ} \mathrm{E} . \\ \text { S. } 23^{\circ} \text { W. }\end{array}\right\}$; azimuth, S. $67^{\circ}$ E. ; second line : $\left\{\begin{array}{l}\text { N. } 25^{\circ} \mathrm{W} . \\ \text { S. } 25^{\circ} \text { E. }\end{array}\right\}$; lat. $50^{\circ} 0^{\prime} \mathrm{N}$. ; long. $2^{\circ} 30^{\prime} 30^{\prime \prime} \mathrm{W}$.

3. First observation: T.A. $24^{\circ} 9^{\prime} 42^{\prime \prime}$; P.D. $78^{\circ} 35^{\prime} 56^{\prime \prime}$; eq. time, $+2^{\mathrm{m}} 30^{\mathrm{s}}$; H.A.'s, $4^{\mathrm{h}} 23^{\mathrm{m}} 33^{\mathrm{s}}$ and $4^{\mathrm{h}} 22^{\mathrm{m}} 57^{\mathrm{s}}$; longs., $(a), 0^{\circ} 18^{\prime} 15^{\prime \prime}$ E.; (b), $0^{\circ} 27^{\prime} 15^{\prime \prime} \mathrm{E}$.

Second observation: T.A. $48^{\circ} 46^{\prime} 26^{\prime \prime}$; P.D. $78^{\circ} 38^{\prime} 51^{\prime \prime}$; eq. time, $+2^{\mathrm{m}} 28^{\mathrm{s}} ;$ H.A.'s, $1^{\mathrm{h}} 11^{\mathrm{m}} 42^{\mathrm{s}}$ and $1^{\mathrm{h}} 5^{\mathrm{m}} 19^{\mathrm{s}}$; longs., (c), $2^{\circ} 43^{\prime} 45^{\prime \prime} \mathrm{W}$.; (d), $1^{\circ} 8^{\prime} 0^{\prime \prime} \mathrm{W}$.

First line: $\left\{\begin{array}{l}\text { N. } 11^{\circ} \mathrm{E} . \\ \text { S. } 11^{\circ} \mathrm{W} .\end{array}\right\}$; azimuth, S. $79^{\circ}$ E.; lat. $50^{\circ} 28^{\prime} \mathrm{N}$. ; long. $0^{\circ} 41^{\prime} 30^{\prime \prime} \mathrm{W}$.

4. First observation: T.A. $48^{\circ} 31^{\prime} 31^{\prime \prime}$; P.D. $81^{\circ} 18^{\prime} 3^{\prime \prime}$; eq. time, $+0^{\mathrm{m}} 18^{\mathrm{a}}$; H. A.'s, $0^{\mathrm{h}} 52^{\mathrm{m}} 40^{\circ}$ and $0^{\mathrm{h}} 39^{\mathrm{m}} 41^{\prime}$; longs., $(a), 175^{\circ} 15^{\prime} 45^{\prime \prime}$ W.; (b), $178^{\circ} 30^{\prime} 30^{\prime \prime} \mathrm{W}$.

Second observation : T.A. $19^{\circ} 9^{\prime} 3^{\prime \prime}$; P.D. $81^{\circ} 21^{\prime} 45^{\prime \prime}$; eq. time, + $0^{\mathrm{m}} 15^{\mathrm{s}}$; H.A.'s, $4^{\text {b }} 43^{\mathrm{m}} 0^{\mathrm{s}}$ and $4^{\mathrm{h}} 42^{\mathrm{m}} 21^{\text {' }}$; longs., (c), $179^{\circ} 32^{\prime} 15^{\prime \prime} \mathrm{W}$. ; $(d), 179^{\circ} 42^{\prime} 0^{\prime \prime}$ W.

First line: $\left\{\begin{array}{c}\text { N. } 72^{\circ} \text { W. } \\ \text { S. } 72^{\circ} \text { E. }\end{array}\right\}$; second azimuth, S. $81^{\circ}$ W.; lat. $49^{\circ} 17^{\prime}$ N.; long. $179^{\circ} 40^{\prime} \mathrm{W}$.

5. First observation: T.A. $27^{\circ} \cdot 6^{\prime} 30^{\prime \prime}$; P.D. $90^{\circ} 10^{\prime} 21^{\prime \prime}$; eq. time, $-7^{\mathrm{m}} 23^{\mathrm{s}} ;$ H.A.'s, $3^{\mathrm{h}} 14^{\mathrm{m}} 28^{\mathrm{s}}$ and $3^{\mathrm{h}} 11^{\mathrm{m}} 57^{\mathrm{s}}$; longs., $(a), 59^{\circ} 56^{\prime} 30^{\prime \prime}$ W.; (b), $59^{\circ} 18^{\prime} 45^{\prime \prime} \mathrm{W}$.

Second observation : T.A. $32^{\circ} 27^{\prime} 30^{\prime \prime}$; P.D. $90^{\circ} 4^{\prime} 38^{\prime \prime}$; eq. time, $-7^{\mathrm{m}} 28^{\prime}$; H.A.'s, $2^{\mathrm{h}} 36^{\mathrm{m}} 18^{\mathrm{s}}$ and $2^{\mathrm{h}} 32^{\mathrm{m}} 46^{\text {s }}$; longs., (c), $60^{\circ} 17^{\prime} 15^{\prime \prime} \mathrm{W}$. ; (d), $61^{\circ} 10^{\prime} 15^{\prime \prime} \mathrm{W}$.

First line : $\left\{\begin{array}{l}\text { N. } 33^{\circ} \mathrm{W} . \\ \text { S. } 33^{\circ} \mathrm{E} .\end{array}\right\}$; azimuth, N. $57^{\circ} \mathrm{E}$. ; lat. $46^{\circ} 18^{\prime} \mathrm{S}$. ; long. $60^{\circ} 27^{\prime} \mathrm{W}$.

6. First observation: T.A. $18^{\circ} 27^{\prime} 6^{\prime \prime}$; P.D. $98^{\circ} 27^{\prime} 58^{\prime \prime}$; eq. time, $+0^{\mathrm{m}} 6^{\mathrm{s}}$; H.A.'s, $3^{\text {h }} 13^{\mathrm{m}} 54^{\prime}$ and $3^{\mathrm{h}} 11^{\mathrm{m}} 24^{\text {' }}$; longs., (a), $109^{\circ} 34^{\prime} 15^{\prime \prime} \mathrm{W}$.; (b), $108^{\circ} 56^{\prime} 45^{\prime \prime} \mathrm{W}$. Second observation: T.A. $26^{\circ} 4^{\prime} 10^{\prime \prime}$; P.D. $98^{\circ} 23^{\prime} 10^{\prime \prime}$; eq. time, + $0^{\mathrm{m}} 2^{\prime \prime}$; H.A.'s, $2^{\mathrm{h}} 6^{\mathrm{m}} 27^{\circ}$ and $2^{\mathrm{h}} 2^{\mathrm{m}} 0^{\mathrm{s}}$; longs., (a), $109^{\circ} 33^{\prime} 30^{\prime \prime} \mathrm{W}$.; (d), $110^{\circ} 40^{\prime} 15^{\prime \prime} \mathrm{W}$. First line : $\left\{\begin{array}{l}\text { N. } 41^{\circ} \mathrm{W} . \\ \text { S. } 41^{\circ} \mathrm{E} .\end{array}\right\}$; azimuth, N. $49^{\circ} \mathrm{E}$.; lat. $49^{\circ} 21^{\prime}$ S.; long. $109^{\circ} 45^{\prime} \mathrm{W}$.

7. First observation: T.A. $21^{\circ} 4^{\prime} 7^{\prime \prime}$; P.D. $71^{\circ} 38^{\prime} 7^{\prime \prime}$; eq. time, + $6^{\mathrm{m}} 12^{\prime \prime}$; H.A.'s, $5^{\mathrm{h}} 15^{\mathrm{m}} 16^{\prime \prime}$ and $5^{\mathrm{h}} 15^{\mathrm{m}} 29^{\mathrm{s}}$; longs. , (a), $167^{\circ} 54^{\prime} 45^{\prime \prime}$ E. ; (b), $167^{\circ} 51^{\prime} 30^{\prime \prime}$ E. Second observation: T.A. $57^{\circ} 12^{\prime} 25^{\prime \prime}$; P.D. $71^{\circ} 40^{\prime} 18^{\prime \prime}$; eq. time, $+6^{\mathrm{m}} 12^{\prime \prime}$; H.A.'s, $0^{\mathrm{h}} 45^{\mathrm{m}} 14^{\mathrm{s}}$ and $0^{\mathrm{h}} 35^{\mathrm{m}} 36^{\prime}$; longs., (c), $168^{\circ} 15^{\prime} 15^{\prime \prime}$ E. ; (d), $170^{\circ} 39^{\prime} 45^{\prime \prime} \mathrm{E}$.

First line: $\left\{\begin{array}{l}\text { N. } 6^{\circ} \mathrm{W} . \\ \text { S. } 6^{\circ} \mathrm{E} .\end{array}\right\}$; second azimuth, S. $73^{\circ}$ E. ; lat. $49^{\circ} 44^{\prime} \mathrm{N}$. long. $166^{\circ} 13^{\prime} \mathrm{E}$. 
8. First observation: T.A. $11^{\circ} 1^{\prime} 58^{\prime \prime}$; P.D. $91^{\circ} 52^{\prime} 56^{\prime \prime}$; eq. time, $-9^{\mathrm{m}} 12^{2}$; H.A.'s, $4^{\mathrm{h}} 46^{\mathrm{m}} 19^{\mathrm{s}}$ and $4^{\mathrm{h}} 45^{\mathrm{m}} 0^{\mathrm{s}}$; longs., $(a), 179^{\circ} 27^{\prime} 30^{\prime \prime} \mathrm{E}$.; (b), $179^{\circ} 47^{\prime} 15^{\prime \prime} \mathrm{E}$. Second observation: T.A. $26^{\circ} 59^{\prime} 56^{\prime \prime}$; P.D. $92^{\circ} 0^{\prime} 41^{\prime \prime}$; eq. time, $-9^{\mathrm{m}} 18^{\circ}$; H.A.'s, $3^{\text {h }} 1^{\mathrm{m}} 6^{\mathrm{s}}$ and $2^{\mathrm{h}} \tilde{5} 7^{\mathrm{m}} 16^{\mathrm{s}}$; longs., (a), $177^{\circ} 7^{\prime} 30^{\prime \prime}$ E.; (d), $176^{\circ} 10^{\prime} 0^{\prime \prime} \mathbf{E}$.'

First line : $\left\{\begin{array}{l}\text { N. } 15^{\circ} \mathrm{E} . \\ \text { S. } 15^{\circ} \text { W. }\end{array}\right\}$; azimuth, S. $75^{\circ}$ W. ; lat. $46^{\circ} 40^{\prime}$ N.; long. $17731^{\prime}$ E.

\section{CHAPTER XIX.}

\section{Chart.}

1. (a) S. $17^{\circ}$ E., $30^{\circ}$ E., $18^{\circ}$ W. ; $35 \frac{1}{4}$ miles.

(b) Lat. $52^{\circ} 35^{\prime}{ }^{\prime} \mathrm{N}$.; long. $4^{\circ} 17^{\prime} \mathrm{W}$.; ; set N. $70^{\circ} \mathrm{E}$. ; dist. $5 \frac{1}{2}$ miles.

(c) Lat. $52^{\circ} 20 \frac{1^{\prime}}{} \mathrm{N}^{\prime}$; ; long. $4^{\circ} 17 \frac{1}{2}^{\prime} \mathrm{W}$. ; dist. $7 \frac{3}{4}$ miles.

(d) S. $5^{\circ}$ E. ; dist. 20 miles ; she steams 40 miles.

(e) Lat. $52^{\circ} 24 \frac{1}{2}^{\prime} \mathrm{N}$. . long. $4^{\circ} 31^{\prime} \mathrm{W}$.

2. (a) Comp. Co. S. $49^{\circ}$ E. ; dev. $15^{\circ}$ E. ; var. $18^{\circ}$ W.; dist. $15 \frac{1}{2}$ miles. , N. $85^{\circ}$ E. ; dev. $7^{\circ} \mathrm{W}$.; var. $18^{\circ} \mathrm{W}$.; dist. 23 miles. , N. $58^{\circ}$ E. ; dev. $21^{\circ} \mathrm{W}$. ; var. $18^{\circ} \mathrm{W}$.; dist. $31 \frac{1}{2}$ miles.

(b) Lat. $52^{\circ} 6 \frac{1}{2}^{\prime} \mathrm{N}$.; long. $6^{\circ} 24 \frac{1}{2}^{\prime} \mathrm{W}$.; ; set S. $80^{\circ} \mathrm{W}$.; dist. $3 \frac{1}{2}$ miles.

(c) Lat. $52^{\circ} 23 \frac{1}{2} \mathrm{~N}$. ; long. $5^{\circ} 51_{4}^{\prime}{ }^{\prime} \mathrm{W}$.; dist. $10 \frac{1}{2}$ miles.

(d) Comp. Co. S. $42^{\circ}$ E.; N. $87^{\circ}$ E. ; N. $49^{\circ}$ E.; dist. 52 miles.

(e) Lat. $51^{\circ} 56_{4}^{\prime \prime} \mathrm{N}$. ; long. $6^{\circ} 44 \frac{1}{2}^{\prime} \mathrm{W}$.

3. (a) Comp. Co. N. $23^{\circ}$ E. ; dev. $30^{\circ}$ W. ; var. $18^{\circ}$ W. ; dist. $17 \frac{3}{4}$ miles.

(b) Lat. " $51^{\circ} 45_{\frac{3^{\prime}}{4}}$ N. $63^{\circ}$ E. ; long. $5^{\circ} 26^{1} \mathrm{~W}$.; ; set $\mathrm{N} .14^{\circ} \mathrm{W}$. ; dist. 3 miles.

(c) Lat. $52^{\circ} 17^{\prime} \mathrm{N}$. ; long. $5^{\circ} 6^{\prime} \mathrm{W}$.; dist $8 \frac{1}{2}$ miles.

(d) Comp. Co. N. $71^{\circ}$ E. ; dist. made good 22 miles.

Total dist. steamed $32 \frac{1}{2}$ miles.

\section{CHAPER XX.}

\section{NAPIER'S Curve.}

1. Correct magnetic bearing: N. $66^{\circ} \mathrm{E}$.

Deviations: $17^{\circ} \mathrm{W} .28^{\circ} \mathrm{W} .24^{\circ} \mathrm{W} .9^{\circ} \mathrm{W} .16^{\circ} \mathrm{E} .32^{\circ} \mathrm{E} .26^{\circ} \mathrm{E}$. $5^{\circ} \mathrm{E}$.

Compass coúrses : N. $76^{\circ}$ E. S. $80^{\circ}$ E. S. $28^{\circ}$ E. N. $16^{\circ} \mathrm{E}$.

Magnetic courses: N. $44^{\circ}$ W. S. $16^{\circ}$ W. N. $79 \frac{1}{2}^{\circ}$ E. N. $9^{\circ}$ W.

Deviation: $31^{\circ} \mathrm{E}$.

Bearings: S. $53^{\circ}$ W. N. $76^{\circ}$ E.

2. Correct magnetic bearing: N. $82 \frac{1}{2}^{\circ} \mathrm{W}$.

Deviations: $12 \frac{1}{2}^{\circ} \mathrm{E} .18 \frac{1}{2}^{\circ} \mathrm{E} .9_{2}^{\circ} \mathrm{E} .6 \frac{1}{2}^{\circ} \mathrm{W} .9 \frac{1}{2}^{\circ} \mathrm{W} .14 \frac{1}{2}^{\circ} \mathrm{W}$. $8 \frac{1}{2}^{\circ} \mathrm{W}$. $3 \frac{1}{2}^{\circ} \mathrm{W}$.

Compass courses: N. $71^{\circ}$ E. S. $69^{\circ}$ E. S. $20^{\circ}$ W. N. $42^{\circ}$ W.

Correct magnetic bearings : N. $12 \frac{1}{2}^{\circ}$ E. S. $44^{\circ}$ E. S. $37^{\circ}$ W. N. $35^{\circ}$ W. Deviation: 0 .

Correct bearings: S. $80^{\circ}$ W. N. $40^{\circ}$ E. 
3. Correct magnetic bearing : S. $14^{\circ} \mathrm{W}$.

Deviations : $10^{\circ} \mathrm{E} .15^{\circ} \mathrm{E} .14^{\circ} \mathrm{E} .8^{\circ} \mathrm{W} .20^{\circ} \mathrm{W} .18^{\circ} \mathrm{W} .3^{\circ} \mathrm{E}$. $5^{\circ} \mathrm{E}$.

Compass courses : N. $16^{\circ}$ W. S. $75^{\circ}$ W. S. $75 \frac{1}{2}^{\circ}$ E. N. $51^{\circ}$ E.

Correct magnetic courses : N. $56^{\circ}$ W. N. $56^{\circ}$ E. S. $27^{\circ}$ E. N. $33^{\circ}$ W. Deviation : $4^{\circ} \mathrm{E}$.

Correct bearings : S. $57^{\circ}$ W. N. $58^{\circ} \mathrm{W}$.

4. Correct magnetic bearing: N. $81^{\circ} \mathrm{W}$.

Deviations: $23 \frac{1}{2}^{\circ} \mathrm{E}$. $18 \frac{1}{2}^{\circ} \mathrm{E}$. $14 \frac{1}{2}^{\circ} \mathrm{W} .10 \frac{1}{2}^{\circ} \mathrm{W} .12 \frac{1}{2}^{\circ} \mathrm{W} .12 \frac{1}{2}^{\circ} \mathrm{W}$. $1 \frac{1}{2} \circ \mathrm{E}$. $6 \frac{10}{2} \mathrm{E}$.

Compass courses : S. $57^{\circ}$ W. N. $18 \frac{1}{2}^{\circ}$ W. S. $73^{\circ}$ E. S, $88^{\circ}$ E.

Correct magnetic courses: S. $80^{\circ}$ W. N. $40^{\circ}$ E. S. $45^{\circ}$ E. S. $1^{\circ}$ E.

Deviation : $16^{\circ} \mathrm{E}$.

Bearings: N. $52^{\circ}$ W. S. $39^{\circ}$ W.

5. Correct magnetic bearing : N. $83^{\circ}{ }^{\circ} \mathrm{E}$.

Deviations : $21^{\circ} 45^{\prime} \mathrm{E} .17^{\circ} 45^{\prime} \mathrm{E} .00^{\circ} 45^{\prime}$ E. $19^{\circ} 15^{\prime} \mathrm{W} .21^{\circ} 15^{\prime} \mathrm{W}$. $15^{\circ} 15^{\prime} \mathrm{W} .1^{\circ} 15^{\prime} \mathrm{W} .16^{\circ} 45^{\prime} \mathrm{E}$.

Compass courses : N. $29^{\circ}$ E. S. $86^{\circ}$ E. S. $25^{\circ}$ W. N. $26^{\circ}$ W.

Correct magnetic courses : N. $581^{\circ}$ E. S. $61^{\circ}$ E. N. $871^{\circ}$ W. N. $21^{\circ}$ W. Deviation : $22^{\circ}$ E. Bearings : S. $3 \frac{1}{4}^{\circ}$ E. S. $73 \frac{1}{2}^{\circ} \mathrm{E}$.

6. Correct magnetic bearing: S. $13 \frac{1}{4} \mathrm{~K}$.

Deviations : $18 \frac{3}{4}^{\circ} \mathrm{E}$. $8 \frac{1}{2}^{\circ} \mathrm{W} .29^{\circ} \mathrm{W} .343^{\circ} \mathrm{W} .20^{\circ} 5^{\prime} \mathrm{W} .12 \frac{3}{4}^{\circ} \mathrm{E}$. $293^{\circ} \mathrm{E}$. $31^{\circ} 20^{\prime} \mathrm{E}$.

Compass courses : N. $2 \frac{1}{2}^{\circ}$ E. S. $60 \frac{1}{2}^{\circ}$ E. S. $26^{\circ}$ W. N. $811^{\circ} \mathrm{WV}$.

Correct magnetic courses : N. $32^{\circ}$ E. N. $50^{\circ}$ E. S. $46 \frac{1}{2}^{\circ}$ E. N. $11^{\circ} \mathrm{W}$. Deviation : $35^{\circ} \mathrm{W}$.

Correct bearings: N. $15^{\circ} 38^{\prime}$ E. N. $49^{\circ} 4^{\prime}$ W.

7. (a) Magnetic bearing, N. $56^{\circ} \mathrm{E}$.

(b) N. $\frac{1}{4}$ E., S. $80^{\circ}$ E., S. $66^{\circ}$ W., N. $7^{\circ}$ W.

(c) S. $19^{\circ}$ W., N. $59^{\circ}$ W., N., S. $71^{\circ}$ E.

(d) E. $11^{\circ}$ N., N. $3^{\circ}$ E.

8. (a) N. $73 \frac{1}{2}^{\circ} \mathrm{W}$.

(b) S. $37^{\circ}$ E., S. $18^{\circ}$ W., N. $65^{\circ}$ W., N. $78^{\circ}$ E.

(c) N.W. by W., W. by S., S. $28^{\circ}$ W., N. $80^{\circ}$ E.

(d) N. $74 \frac{1}{2}^{\circ}$ E., N. $10 \frac{1}{2}^{\circ} \mathrm{W}$.

9. (a) N. $6^{\circ} \mathrm{W}$.

(b) W.S.W., N. $65^{\circ}$ W., N. $7^{\circ}$ E., S. $75^{\circ}$ E.

(c) N. $26^{\circ}$ E., N. $51^{\circ}$ E., N. $87^{\circ}$ E., S. $21^{\circ}$ W.

(d) S. $78^{\circ}$ W., S. $5^{\circ} \mathrm{W}$.

10. (a) S. $65^{\circ} \mathrm{W}$.

(b) S. $40^{\circ}$ E., N., N. $63^{\circ}$ W., S. $21^{\circ}$ W.

(c) N. $40^{\circ}$ W., N. $10^{\circ}$ E., N. $64^{\circ}$ E., S. $63^{\circ}$ E.

(d) S. $51^{\circ}$ E., N. $36^{\circ}$ E.

11. (a) S. $11^{\circ} \mathrm{E}$.

(b) S. $84^{\circ}$ W., N. $48^{\circ}$ E., S. $58^{\circ}$ E., S. $11^{\circ}$ E.

(c) N. $85^{\circ}$ E., N. $13^{\circ}$ E., N. $61^{\circ}$ W., S. $14^{\circ}$ W.

(d) N. $5^{\circ}$ E., N. $75^{\circ}$ E.

12. (a) N. $21^{\circ} \mathrm{W}$.

(b) S. $76^{\circ}$ E., S. $35^{\circ}$ E., N. $58^{\circ}$ W., N. $50^{\circ}$ E.

(c) N. by W., S. $76^{\circ}$ W., N. $27^{\circ}$ E., S. $82 \frac{1}{2}^{\circ}$ E.

(d) S. $32 \frac{1}{2}^{\circ}$ W., S. $46^{\circ}$ E. 


\section{CHAPTER XXI.}

\section{Great Circle Samling.}

1. First course, S. $84^{\circ} 44^{\prime} 50^{\prime \prime}$ W. ; last course, N. $63^{\circ} 10^{\prime} 40^{\prime \prime}$ W. ; lat. of vertex, $34^{\circ} 43^{\prime}$ S., long. $9^{\circ} 15^{\prime} \mathrm{E}$. ; distance, 3269 miles.

\begin{tabular}{|c|c|c|}
\hline Points. & Longitude. & Latitude. \\
\hline $\begin{array}{c}\text { Long. from } \mathrm{V} \text {. } \\
9 \text { 15 } \\
5 \\
5 \\
0 \\
5 \\
10 \\
15 \\
20 \\
25 \\
30 \\
35 \\
40 \\
45 \\
50 \\
52 \\
44\end{array}$ & $\begin{array}{rcc}\circ & \prime \\
18 & 30 & \mathrm{E} . \\
14 & 15 & \mathrm{E} . \\
9 & 15 & \mathrm{E} . \\
4 & 15 & \mathrm{E} . \\
0 & 45 & \mathrm{~W} . \\
5 & 45 & \mathrm{~W} . \\
10 & 45 & \mathrm{~W} . \\
15 & 45 & \mathrm{~W} . \\
20 & 45 & \mathrm{~W} . \\
25 & 45 & \mathrm{~W} . \\
30 & 45 & \mathrm{~W} . \\
35 & 45 & \mathrm{~W} . \\
40 & 45 & \mathrm{~W} . \\
43 & 9 & \mathrm{~W} .\end{array}$ & $\begin{array}{lcl}\circ & , \\
34 & 22 & \mathrm{~S} . \\
34 & 37 & \mathrm{~S} . \\
34 & 43 & \mathrm{~S} . \\
34 & 37 & \mathrm{~S} . \\
34 & 19 & \mathrm{~S} . \\
33 & 47 \frac{1}{2} & \mathrm{~S} . \\
33 & 4 & \mathrm{~S} . \\
32 & 7 \frac{1}{2} & \mathrm{~S} . \\
30 & 57 \frac{1}{2} & \mathrm{~S} . \\
29 & 34 \frac{1}{2} & \mathrm{~S} . \\
27 & 57 \frac{1}{2} \mathrm{~S} . \\
26 & 6 \frac{1}{2} \mathrm{~S} . \\
24 & 0 \frac{1}{2} \mathrm{~S} . \\
22 & 55 \mathrm{~S} .\end{array}$ \\
\hline
\end{tabular}

2. Initial course, N. $56^{\circ} 54^{\prime}$ W. ; final course, S. $54^{\circ} 18^{\prime}$ W. ; distance, 4469 miles ; lat. and long. of vertex, $48^{\circ} 34^{\prime} \mathrm{N}$., $169^{\circ} 14^{\prime} \mathrm{W}$.

Points 1. $40^{\circ} 57 \frac{1}{2}^{\prime} \mathrm{N}$., $129^{\circ} 14^{\prime} \mathrm{W}$.

$\begin{array}{llllll}\text {, } & \text { 2. } 46 & 47 \frac{1}{2} & \text { N., } 149 & 14 & \text { W. } \\ \text { " } & \text { 3. } 48 & 34 & \text { N., } 169 & 14 & \text { W. } \\ \text {, } & 4.46 & 47 \frac{1}{2} & \text { N., } 170 & 46 & \text { E. } \\ \text {, } & \text { 5. } 40 & 57 \frac{1}{2} & \text { N., } 150 & 46 & \text { E. }\end{array}$

3. Courses, N. $55^{\circ} 43^{\prime}$ E., and N. $60^{\circ} 15^{\prime}$ E. ; dist. C441 miles ; vertex, lat. $46^{\circ} 40^{\prime} \mathrm{N}$., long. $79^{\circ} 29^{\prime} \mathrm{W}$.

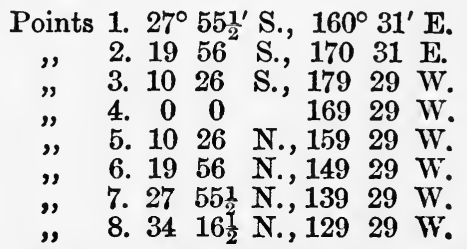

4. Courses, N. $48^{\circ} 47 \frac{1}{2}^{\prime}$ E. , and S. $45^{\circ} 23 \frac{1}{2}^{\prime}$ E. ; dist. 9904 miles ; vertex, lat. $45^{\circ} 52 \frac{1}{2}^{\prime} \mathrm{N}$., long. $179^{\circ} 14^{\prime} \mathrm{W}$.

Points $1.27^{\circ} 16^{\prime}$ N., $120^{\circ} 46^{\prime}$ E.

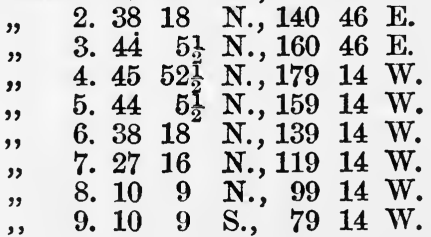


5. Courses, S. $67^{\circ} 35 \frac{1}{2}^{\prime}$ W., and S. $35^{\circ} 34 \frac{1}{2}$ W. ; dist. 3452 miles ; vertex, lat. $55^{\circ} 29^{\prime}$ N., long. $21^{\circ} 21_{\frac{1}{2}}^{\prime} \mathrm{E}$.

\begin{tabular}{|c|c|c|}
\hline Points & 6109 & \\
\hline oints & 5133 & \\
\hline & 59 & ., 13 \\
\hline & 3. 48 & N., 18 \\
\hline & 4. $45 \quad 48$ & 23 \\
\hline & 43 & 28 \\
\hline & 50 & 33 \\
\hline , & $1_{2}^{1}$ & N., 38 \\
\hline " & $34_{2}^{1}$ & N., \\
\hline , & $26 \frac{1}{2}$ & N., \\
\hline & $37 \frac{1}{2}$ & N., 53 \\
\hline & - 1410 & N., 5838 \\
\hline
\end{tabular}

6. Courses, N. $68^{\circ} 45^{\prime}$ E., and S. $68^{\circ} 45^{\prime}$ E. ; dist. 2494.6 miles ; vertex, lat. $47^{\circ} 36_{\frac{1}{\prime}}^{\prime}$ N., long. $180^{\circ} \mathrm{E}$.

$$
\begin{aligned}
& \text { Points 1. } 44^{\circ} 47 \frac{1}{2}^{\prime} \text { N., } 155^{\circ} \mathrm{E} \text {. } \\
& \text {, 2. } 4549 \frac{3}{4} \mathrm{~N} \text {., } 160 \mathrm{E} \text {. } \\
& \text {, 3. } 4637^{\text {N., }} 165 \mathrm{E} \text {. } \\
& \text { ", 4. } 4710 \text { N., } 170 \text { E. } \\
& \text {,, 5. } 4730 \text { N., } 175 \text { E. } \\
& \text { " 6. Vertex. } \\
& \text {, 7. } 4730 \text { N., } 175 \text { W., etc. }
\end{aligned}
$$

7. Courses, S. $66^{\circ}$ W., and S. $66^{\circ}$ W.; dist. 7544.6 miles; vertex, lat. $44^{\circ} 19 \frac{1}{2}^{\prime}$ N., long. $64^{\circ} \cdot 49 \frac{1}{2}^{\prime} \mathrm{W}$.

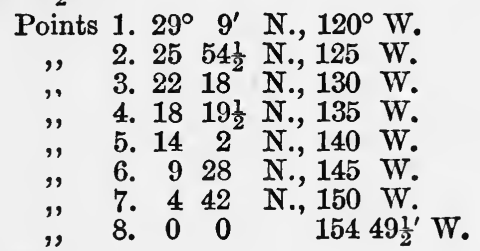

8. Long. $32^{\circ} 391^{\prime} \mathrm{W}$.

\begin{tabular}{|c|c|c|c|c|c|}
\hline No. & First course. & Last course. & Distance. & $\begin{array}{l}\text { Longitude } \\
\text { arrival. }\end{array}$ & $\begin{array}{l}\text { Longitude } \\
\text { departure. }\end{array}$ \\
\hline $\begin{array}{l}1 \\
2 \\
3\end{array}$ & \begin{tabular}{ccc} 
& $\circ$ & \multicolumn{1}{c}{} \\
S. 65 & $27 \frac{1}{2}$ & E. \\
S. 53 & $5 \frac{1}{2}$ & W. \\
N. 52 & 5 & F.
\end{tabular} & \begin{tabular}{cccc} 
& $\circ$ & \multicolumn{1}{c}{} \\
N. 59 & $6 \frac{1}{2}$ & E. \\
N. 68 & $44 \frac{1}{2}$ & W. \\
S. & 75 & 26 & E.
\end{tabular} & $\begin{array}{l}7832 \cdot 4 \\
5600 \cdot 6 \\
4096 \cdot 1\end{array}$ & $\begin{array}{ccc}\circ & 1 & \\
25 & 40 \frac{1}{2} & \text { W. } \\
19 & 1 \frac{1}{2} & \text { W. } \\
167 & 1 & \text { W. }\end{array}$ & $\begin{array}{ccc}0 & \text { ' } & \\
68 & 32 \frac{1}{2} & \mathrm{E} . \\
21 & 55 \frac{1}{2} & \text { W. } \\
143 & 54 & \text { W. }\end{array}$ \\
\hline
\end{tabular}

9. Lat. $45^{\circ} 52 \frac{1}{2}^{\prime} \mathrm{N}$.

10. $50^{\circ} \mathrm{S} ., 110^{\circ} \mathrm{E}$.

11. 119 miles north.

12. A. Iat. $46^{\circ} 40^{\prime} \mathrm{N}$. ; long. $53^{\circ} 3^{\prime} \mathrm{W}$.

B. Lat. $51^{\circ} 25^{\prime} \mathrm{N}$. ; long. $9^{\circ} 29^{\prime} \mathrm{W}$.

Conposite Tracks.

4. Courses, S. $59^{\circ} 45^{\prime}$ W., and West ; longs. $118^{\circ} 24^{\prime}$ W. , and $172^{\circ} \tilde{0} 0^{\prime}$ E. ; dist. $2988+2266 \cdot 2=5254 \cdot 2$ miles.

$$
\begin{aligned}
& \text { Points } 1.33^{\circ} 46^{\prime} \text { S., } 73^{\circ} \mathrm{W} \text {. } \\
& \text {, 2. } 3557 \text { S., } 78 \text { W. } \\
& \text { " } 3.3749 \text { S., } 83 \text { W. } \\
& \text { ") 4. } 3924 \text { S., } 88 \text { W. }
\end{aligned}
$$




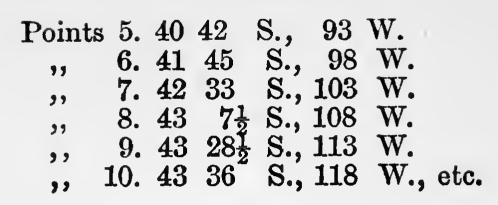

CHAPTER XXII.

Latitude by Double Altitudes.

1. H.E.T. $2^{\mathrm{h}} 52^{\mathrm{m}} 57^{\mathrm{s}}$; mid. dec. $14^{\circ} 38^{\prime} 13^{\prime \prime} \mathrm{N}$. ; cor. for run, $+11^{\prime} 6^{\prime \prime}$; first alt. $30^{\circ} 38^{\prime} 37^{\prime \prime}$; second alt. $26^{\circ} 43^{\prime} 34^{\prime \prime} ; \mathrm{XY}=83^{\circ} 1^{\prime} 34^{\prime \prime} ; \mathrm{X}_{1}$ $=103^{\circ} 19^{\prime} 32^{\prime \prime} ; \mathrm{X}_{2}=63^{\circ} 0^{\prime} 32^{\prime \prime}$. Cor. for lat. $+12^{\prime \prime}$. Lat. $30^{\circ} 21^{\prime} 30^{\prime \prime} \mathrm{S}$.

2. H.E.T. $2^{\mathrm{b}} 23^{\mathrm{m}} 55^{\mathrm{A}} 5$; mid. dec. $13^{\circ} 12^{\prime} 25^{\prime \prime}$ N. ; cor. for run, $-21^{\prime} 48^{\prime \prime}$; first alt. $50^{\circ} 22^{\prime} 0^{\prime \prime}$; second alt. $42^{\circ} 57^{\prime} 0^{\prime \prime}$; $\mathrm{XY}=69^{\circ} 46^{\prime} 30^{\prime \prime} ; \mathrm{X}_{1}$ $=80^{\circ} 37^{\prime} 38^{\prime \prime} ; \mathrm{X}_{2}=46^{\circ} 5^{\prime} 30^{\prime \prime}$. Cor. for lat. $=21^{\prime \prime}$. Lat. $43^{\circ} 27^{\prime} 45^{\prime \prime} \mathrm{N}$.

3. H.E.T. $2^{\mathrm{h}} 15^{\mathrm{m}} 56^{\mathrm{a}} \cdot 7$; dec. $38^{\circ} 41^{\prime} 45^{\prime \prime} \mathrm{Y}$.; cor. for run, 0 ; first alt. $75^{\circ} 44^{\prime} 55^{\prime \prime}$; second alt. $34^{\circ} 50^{\prime} 11^{\prime \prime} ; \mathrm{XY}=51^{\circ} 43^{\prime} 52^{\prime \prime} ; \mathrm{Y}_{1}=67^{\circ} 8^{\prime} 50^{\prime \prime}$; $\mathrm{Y}_{2}=17^{\circ} 14^{\prime} 56^{\prime \prime}$. Lat. $50^{\circ} 20^{\prime} \mathrm{N}$.

4. H.E.T. $1^{\text {h }} 30^{\mathrm{m}} 20^{\mathrm{s}} \cdot 3$; dec. $16^{\circ} 19^{\prime} 15^{\prime \prime} \mathrm{N}$. ; cor. for run, $-12^{\prime} 54^{\prime \prime}$; first alt. $17^{\circ} 53^{\prime} 0^{\prime \prime}$; second alt. $45^{\circ} 37^{\prime} 12^{\prime \prime} ; \mathrm{XY}=43^{\circ} 15^{\prime} 18^{\prime \prime} ; \mathrm{Y}_{1}=96^{\circ} 40^{\prime} 1^{\prime \prime}$; $\mathrm{Y}_{2}=41^{\circ} 9^{\prime}$. Lat. $25^{\circ} 31^{\prime} 8^{\prime \prime} \mathrm{S}$.

5. R.A.M.S. $9^{\text {h }} 43^{\mathrm{m}} 39^{\prime}$; T.A. a Arietis, $27^{\circ} 6^{\prime} 20^{\prime \prime}$; longs., (a) $179^{\circ} 57^{\prime}$ W.; (b) $179^{\circ} 59^{\prime}$ E. Bearing, N. $85^{\circ} 6^{\prime}$ E. T.A. Altair, $47^{\circ} 1^{\prime} 41^{\prime \prime}$; longs., (c) $179^{\circ} 4^{\prime} 30^{\prime \prime}$ W.; (d) $179^{\circ} 35^{\prime} 15^{\prime \prime}$ E. Bearing, S. $28^{\circ} 50^{\prime}$ W. XY $=90^{\circ} 12^{\prime} 41^{\prime \prime} ; \mathrm{X}_{1}=80^{\circ} 32^{\prime} 23^{\prime \prime} ; \mathrm{X}_{2}=34^{\circ} 32^{\prime} 3^{\prime \prime}$. Lat. $48^{\circ} 21^{\prime} 0^{\prime \prime} \mathrm{N}$; long. $180^{\circ} \mathrm{W}$.

6. H.E.T. $1^{\mathrm{h}} 53^{\mathrm{m}} 2^{\mathrm{r}} \cdot 5$; mid. dec. $7^{\circ} 47^{\prime} 35^{\prime \prime} \mathrm{N}$.; run, 0 ; first alt. $18^{\circ} 4^{\prime} 22^{\prime \prime}$; second alt. $47^{\circ} 2^{\prime} 15^{\prime \prime} ; \mathrm{XY}=55^{\circ} 57^{\prime} 8^{\prime \prime} ; \mathrm{X}_{1}=85^{\circ} 53^{\prime} 6^{\prime \prime} ; \mathrm{X}_{2}=44^{\circ} 53^{\prime}$. Cor. for lat. $-2^{\prime} 30^{\prime \prime}$. Lat. $48^{\circ} 51^{\prime} \mathrm{N}$.

7. H.E.T. $2^{\text {h }} 45^{\mathrm{m}} 28^{\prime \prime} 6$; run, $+49^{\prime} 24^{\prime \prime}$; first alt. $15^{\circ} 50^{\prime} 58^{\prime \prime}$; second alt. $28^{\circ} 8^{\prime} 24^{\prime \prime} ; \mathrm{XY}=69^{\circ} 44^{\prime \prime} ; \mathrm{X}_{1}=113^{\circ} 50^{\prime} 32^{\prime \prime} ; \mathrm{X}_{2}=65^{\circ} 18^{\prime} 15^{\prime \prime}$. Lat. $24^{\circ} 27^{\prime} \mathrm{N}$.

8. H.E.T. $1^{\text {h }} 52^{\mathrm{m}} 34^{\circ}$; mid. dec. $3^{\circ} 22^{\prime} 34^{\prime \prime}$ N.; run, $+45^{\prime}$; first alt. $39^{\circ} 34^{\prime} 56^{\prime \prime}$; second alt. $14^{\circ} 18^{\prime} 3^{\prime \prime} ; \mathrm{XY}=56^{\circ} 10^{\prime} 39^{\prime \prime} ; \mathrm{Y}_{1}=91^{\circ} 51^{\prime} 40^{\prime \prime}$; $\mathrm{Y}_{2}=51^{\circ} 37^{\prime} 54^{\prime \prime}$. Lat. $46^{\circ} 23^{\prime} 48^{\prime \prime} \mathrm{S}$.

9. H.E.T. $3^{\mathrm{h}} 50^{\mathrm{m}} 47^{\mathrm{s}} \cdot 8$; run, $-1^{\circ} 3^{\prime} 0^{\prime \prime}$; first alt. $54^{\circ} 47^{\prime} 7^{\prime \prime}$; second alt. $49^{\circ} 9^{\prime} 37^{\prime \prime} ; \mathrm{XY}=53^{\circ} 40^{\prime} 42^{\prime \prime} ; \mathrm{Y}_{1}=36^{\circ} 47^{\prime} 22^{\prime \prime} ; \mathrm{Y}_{2}=45^{\circ} 33^{\prime} 48^{\prime \prime}$. Lat. $43^{\circ} 19^{\prime} 6^{\prime \prime} \mathrm{S}$.

10. R.A.M.S. $10^{\mathrm{h}} 15^{\mathrm{m}} 59^{\mathrm{r}}$; T.A. Aldebaran, $35^{\circ} 3^{\prime} 22^{\prime \prime}$; longs., $(a)$ $156^{\circ} 7^{\prime} 30^{\prime \prime}$ E. ; (b) $156^{\circ} 22^{\prime}$ E. Bearing, S. $72^{\circ} 9^{\prime}$ E. T.A. Markab, $47^{\circ} 42^{\prime} 15$; longs., (c) $157^{\circ} 39^{\prime} 45^{\prime \prime}$ E. ; (d) $156^{\circ} 52^{\prime}$ E. Bearing, S. $43^{\circ} \mathrm{W}$. $\mathrm{XY}=79^{\circ} 0^{\prime} 30^{\prime \prime} ; \mathrm{X}_{1}=77^{\circ} 43^{\prime} 59^{\prime \prime} ; \mathrm{X}_{2}=38^{\circ} 21^{\prime} 14^{\prime \prime}$. Lat. $50^{\circ} 14^{\prime} \mathrm{N}$. ; long. $156^{\circ} 29^{\prime} \mathrm{E}$.

11. H.E.T. $2^{\mathrm{h}} 35^{\mathrm{m}} 4^{\mathrm{s}} \cdot 5$; mid. dec. $5^{\circ} 16^{\prime} 18^{\prime \prime}$ N.; run, $-26^{\prime} 12^{\prime \prime}$; first alt. $51^{\circ} 36^{\prime} 17^{\prime \prime}$; second alt. $26^{\circ} 34^{\prime} 54^{\prime \prime} . \quad X Y=77^{\circ} 8^{\prime} 54^{\prime \prime} ; Y_{1}=94^{\circ} 16^{\prime} 13^{\prime \prime}$; $\mathrm{Y}_{2}=38^{\circ} 18^{\prime} 8^{\prime \prime}$. Cor. for lat. $-1^{\prime} 7^{\prime \prime}$. Lat. $27^{\circ} 14^{\prime} \mathrm{S}$.

12. H.E.T. $1^{\text {b }} 45^{\mathrm{m}} 23^{\prime \prime} \cdot 8$; run, $+49^{\prime} 0^{\prime \prime}$; first alt. $63^{\circ} 0^{\prime} 37^{\prime \prime}$; second alt. $18^{\circ} 37^{\prime} 27^{\prime \prime} . \mathrm{XY}=52^{\circ} 3^{\prime} 28^{\prime \prime} ; \mathrm{Y}_{1}=94^{\circ} 14^{\prime} 43^{\prime \prime} ; \mathrm{Y}_{2}=21^{\circ} 37^{\prime} 35^{\prime \prime}$. Lat. $13^{\circ} 25^{\prime} \mathrm{S}$. 
13. R.A.M.S. $11^{\text {h }} 35^{\mathrm{m}} 30^{\circ}$; T. A. Rigel, $49^{\circ} 19^{\prime} 1^{\prime \prime}$; longs., (a) $125^{\circ} 4^{\prime} 30^{\prime \prime}$ E. ; (b) $127^{\circ} 25^{\prime} 15^{\prime \prime}$ E. Bearing, N. $23^{\circ}$ E. T.A. Fomalhaut, $27^{\circ} 21^{\prime} 6^{\prime \prime}$; longs., (c) $127^{\circ} 23^{\prime} 15^{\prime \prime}$ E. ; (d) $127^{\circ} 39^{\prime} 45^{\prime \prime}$ E. Bearing, S. $74^{\circ} 30^{\prime}$ W. XY $=89^{\circ} 35^{\prime} 57^{\prime \prime} ; \mathrm{Y}_{1} ; 80^{\circ} 36^{\prime} 55^{\prime \prime} ; \mathrm{Y}_{2}=31^{\circ} 45^{\prime} 47^{\prime \prime}$. Lat. $47^{\circ} 24^{\prime} 30^{\prime \prime} \mathrm{S}$.; long. $127^{\circ} 41^{\prime} 30^{\prime \prime} \mathrm{E}$.

14. H.E.T. $2^{\text {h }} 24^{\mathrm{m}} 44^{\mathrm{s}}$; mid. dec. $1^{\circ} 47^{\prime} 48^{\prime \prime}$ S. ; first alt. $34^{\circ} 36^{\prime} 15^{\prime \prime}$; run, $-16^{\prime} 24^{\prime \prime}$; second alt. $16^{\circ} 22^{\prime} 59^{\prime \prime} ; \mathrm{XY}=72^{\circ} 19^{\prime} 30^{\prime \prime} ; \mathrm{Y}_{1}=91^{\circ} 15^{\prime} 47^{\prime \prime}$; $\mathrm{Y}_{2}=58^{\circ} 9^{\prime} 30^{\prime \prime}$. Cor. for lat. $-1^{\prime} 25^{\prime \prime}$. Lat. $52^{\circ} 35^{\prime} \mathrm{N}$.

15. H.E.T. $4^{\text {h }} 5^{\mathrm{m}} 45^{\mathrm{s}} \cdot 2$; first alt. $66^{\circ} 3^{\prime} 3^{\prime \prime}$; run, $-57^{\prime} 36^{\prime \prime}$; second alt. $20^{\circ} 19^{\prime} 39^{\prime \prime} . \quad \mathrm{XY}=76^{\circ} 53^{\prime} 45^{\prime \prime} ; Y_{1}=37^{\prime} 37^{\prime \prime} ; Y_{2}=23^{\circ} 52^{\prime} 18^{\prime \prime}$. Lat. $34^{\circ} 12^{\prime} 32^{\prime \prime} \mathrm{N}$.

\section{CHAPTER XXIII.}

Error of Chronometer by Single Autitude.

1. Fast M.T.G. $7^{\mathrm{m}} 35^{\mathrm{s}}$; slow A.T.S. $5^{\mathrm{h}} 55^{\mathrm{m}} 13^{\mathrm{s}}$.

2. Slow $15^{\mathrm{m}} 39^{\mathrm{s}}$.

3. Slow $31^{\mathrm{s}}$.

4. Slow $5^{\mathrm{m}} 6^{\mathrm{s}}$.

5. Fast $17^{\mathrm{m}} 38^{\mathrm{a}}$.

6. Slow $8^{\mathrm{m}} 23^{\mathrm{s}}$.

7. Fast $46^{\circ}$.

8. Slow A.T.S. $3^{\text {h }} 43^{m} 43^{\text {s }}$; fast M.G.T. $18^{\text {s. }}$.

\section{CHAPTER XXIV.}

Calculation of Autitudes.

1. E.H.A. $0^{\text {h }} 45^{\mathrm{m}} 25^{\mathrm{s}}$; dec. $6^{\circ} 10^{\prime} 42^{\prime \prime}$ N.; T.A. $46^{\circ} 54^{\prime} 43^{\prime \prime}$; A.A. $46^{\circ} 55^{\prime} 30^{\prime \prime}$.

2. W.H.A. $4^{\text {h }} 42^{\mathrm{m}} 25^{\mathrm{s}}$; dec. $2^{\circ} 25^{\prime} 30^{\prime \prime}$ S.; T.A. $11^{\circ} 18^{\prime} 30^{\prime \prime} ;$ A.A. $11^{\circ} 23^{\prime} 6^{\prime \prime}$.

3. W.H.A. $1^{\text {h }} 34^{\mathrm{m}} 34^{\mathrm{s}} \cdot 6$; T.A. $35^{\circ} 32^{\prime} 16^{\prime \prime}$; A.A. $35^{\circ} 33^{\prime} 36^{\prime \prime}$.

4. E.H.A. $4^{\mathrm{b}} 54^{\mathrm{m}} 27^{\mathrm{s}} \cdot 3$; T.A. $17^{\circ} 6^{\prime} 1^{\prime \prime}$; A.A. $17^{\circ} 9^{\prime} 4^{\prime \prime}$.

5. W.H.A. $3^{\text {h }} 42^{\mathrm{m}} 21^{\prime} \cdot 3$; H.P. $54^{\prime} 51^{\prime \prime}$; dec. $5^{\circ} 51^{\prime} 28^{\prime \prime}$ N.; T.A. $30^{\circ} 37^{\prime} 13^{\prime \prime}$; A.A. $29^{\circ} 51^{\prime} 19^{\prime \prime}$.

6. W.H.A. $3^{\text {h }} 13^{\mathrm{m}} 52^{\circ} \cdot 6$; dec. $8^{\circ} 24^{\prime} 48^{\prime \prime}$; T.A. $40^{\circ} 56^{\prime} 54^{\prime \prime} ;$ A.A. $10^{\circ} 57^{\prime} 58^{\prime \prime}$.

7. E.H.A. $0^{\mathrm{h}} 36^{\mathrm{m}} 28^{\circ}$; H.P. $58^{\prime} 50^{\prime \prime}$; dec. $19^{\circ} 49^{\prime} 51^{\prime \prime}$ S. ; T.A. $76^{\circ} 59^{\prime} 48^{\prime \prime}$; A.A. $76^{\circ} 46^{\prime} 33^{\prime \prime}$.

8. E.H.A. $3^{\text {h }} 56^{m} 40^{\prime} .9$; dec. $23^{\circ} 7^{\prime} 40^{\prime \prime}$ N.; T.A. $30^{\circ} 20^{\prime} 56^{\prime \prime}$; A.A. $30^{\circ} 22^{\prime} 32^{\prime \prime}$.

\section{CHAPTER XXV.}

Longitude by Lunar Distance.

\section{G.M.T.}

1. $6^{\mathrm{d}} 17^{\mathrm{b}} 27^{\mathrm{m}} 36^{\mathrm{s}} \cdot 5$.

2. $7^{\mathrm{d}} 20^{\mathrm{h}} 27^{\mathrm{m}} 13^{\mathrm{s}}$.

3. $12^{\mathrm{d}} 11^{\mathrm{h}} 7^{\mathrm{m}} 1^{\mathrm{o}} \cdot 5$.

4. $22^{\mathrm{d}} 21^{\mathrm{h}} 58^{\mathrm{m}} 2^{\mathrm{a}}$.

5. $28^{d} 7^{\mathrm{h}} 0^{\mathrm{m}} 25^{\mathrm{s}}$. 


\section{True Distance.}

1. $\mathrm{Z}=119^{\circ} 37^{\prime} 16^{\prime \prime} ; \mathrm{B}=25^{\circ} 26^{\prime} 45^{\prime \prime}$; true dist. $=96^{\circ} 18^{\prime} 32^{\prime \prime}$.

2. $\mathrm{Z}=122^{\circ} 9^{\prime} 50^{\prime \prime} ; \mathrm{B}=24^{\circ} 56^{\prime} 56^{\prime \prime}$; true dist. $107^{\circ} 17^{\prime} 39^{\prime \prime}$.

3. $Z=125^{\circ} 55^{\prime} 28^{\prime \prime} ; \mathrm{B}=21^{\circ} 16^{\prime} 40^{\prime \prime}$; true dist. $100^{\circ} 39^{\prime} 17^{\prime \prime}$.

4. $\mathrm{Z}=96^{\circ} 14^{\prime} 22^{\prime \prime} ; \mathrm{B}=21^{\circ} 59^{\prime} 24^{\prime \prime}$; true dist. $55^{\circ} 37^{\prime} 4^{\prime \prime}$.

\section{Longitudes ANd ERrors.}

1. Sun's elements: Dec. $14^{\circ} 58^{\prime} 51^{\prime \prime}$ N. ; R.A. $9^{\text {h }} 27^{\text {m }} 39^{\text {s }}$; R.A.M.S. $9^{\text {h }} 22^{\mathrm{m}} 46^{\mathrm{s}} \cdot 3$; A.A. $34^{\circ} 22^{\prime} 13^{\prime \prime}$; T.A. $34^{\circ} 20^{\prime} 57^{\prime \prime}$; E.H.A. $1^{\text {h }} 36^{\mathrm{m}} 32^{\mathrm{s}}$.

Moon's elements : R.A. $4^{\text {h }} 0^{\text {m }} 1^{\text {s. }} 3$; dec. $15^{\circ} 30^{\prime} 16^{\prime \prime}$ N.; H.P. $54^{\prime} 9^{\prime \prime} \cdot 1$; S.D. $14^{\prime} 51^{\prime \prime} \cdot 6$; W.H.A. $3^{\text {h }} 51^{\text {m }} 6^{\text {s }}$; T.A. $15^{\circ} 6^{\prime} 45^{\prime \prime}$; A.A. $14^{\circ} 17^{\prime} 56^{\prime \prime}$; app. dist. $78^{\circ} 53^{\prime} 30^{\prime \prime} ; \mathrm{B}=40^{\circ} 41^{\prime} 23^{\prime \prime} ; \mathrm{Z}=86^{\circ} 11^{\prime} 1^{\prime \prime}$; true dist. $78^{\circ} 27^{\prime} 16^{\prime}$; error, $6^{\mathrm{m}}$ fast; long. $93^{\circ} 31^{\prime} 45^{\prime \prime} \mathrm{E}$.

2. Sun's elements: R.A. $10^{\mathrm{h}} 26^{\mathrm{m}} 44^{\prime \prime} 8$; dec. $9^{\circ} 44^{\prime} 29^{\prime \prime}$ N. ; R.A.M.S. $10^{\mathrm{h}} 25^{\mathrm{m}} 34^{\mathrm{e}}$; W.H.A. $3^{\mathrm{h}} 34^{\mathrm{m}} 17^{\mathrm{s}} \cdot 2$; T.A. $37^{\circ} 5^{\prime} 42^{\prime \prime}$; A.A. $37^{\circ} 6^{\prime} 51^{\prime \prime}$.

Moon's elements : R.A. $18^{\mathrm{h}} 9^{\mathrm{m}} 38^{\mathrm{s}} \cdot 7$; dec. $20^{\circ} 6^{\prime} 2^{\prime \prime}$ S. ; S.D. $16^{\prime} 13^{\prime \prime}$; H.P. $59^{\prime} 8^{\prime \prime} \cdot 3$; E.H.A. $4^{\text {b }} 8^{\mathrm{m}} 36^{8} \cdot 7$; A.A. $14^{\circ} 6^{\prime} 50^{\prime \prime}$; T.A. $15^{\circ} 0^{\prime} 27^{\prime \prime}$; app. dist. $118^{\circ} 6^{\prime} 57^{\prime \prime} ; \mathrm{B}=16^{\circ} 7^{\prime} 49^{\prime \prime} ; \mathrm{Z}=143^{\circ} 5^{\prime} 37^{\prime \prime}$; true dist. $117^{\circ} 22^{\prime} 44^{\prime \prime}$; error, $9^{\mathrm{m}} 18^{\mathrm{s}}$ slow ; long. $163^{\circ} 32^{\prime} 0^{\prime \prime} \mathrm{W}$.

3. Star's elements: R.A. $4^{\mathrm{b}} 30^{\mathrm{m}} 31^{\mathrm{s}} \cdot 5$; dec. $16^{\circ} 19^{\prime} 15^{\prime \prime}$ N. ; R.A.M.S. $9^{\text {h }} 8^{\mathrm{m}} 54^{\mathrm{s}} \cdot 3$; E.H.A. $3^{\text {h }} 53^{\mathrm{m}} 49^{\mathrm{s}}$; T.A. $34^{\circ} 40^{\prime} 39^{\prime \prime}$; A.A. $34^{\circ} 42^{\prime} 0^{\prime \prime}$.

Moon's elements: R.A. $1^{\mathrm{h}} 16^{\mathrm{m}} 27^{\circ} \cdot 6$; dec. $2^{\circ} 50^{\prime} 3^{\prime \prime}$ N.; S.D. $15^{\prime} 17^{\prime \prime} \cdot 7$; H.P. $55^{\prime} 14^{\prime \prime} \cdot 5$; A.A. $53^{\circ} 17^{\prime} 50^{\prime \prime}$; T.A. $53^{\circ} 50^{\prime} 9^{\prime \prime}$; E.H.A. $0^{\mathrm{h}} 39^{\mathrm{m}} 45^{\mathrm{s}}$; app. dist. $49^{\circ} 35^{\prime} 21^{\prime \prime} ; \mathrm{B}=35^{\circ} 30^{\prime} 39^{\prime \prime} ; \mathrm{Z}=67^{\circ} 1^{\prime} 7^{\prime \prime}$; true dist. $49^{\circ} 32^{\prime} 54^{\prime \prime}$; error, $3^{\circ}$ slow ; long. $174^{\circ} 36^{\prime} 53^{\prime \prime} \mathrm{E}$.

4. Star's elements : R.A. $19^{\mathrm{h}} 46^{\mathrm{m}} 11^{\mathrm{s}} 8$; dec. $8^{\circ} 37^{\prime} 11^{\prime \prime}$ N. ; R.A.M.S. $10^{\mathrm{h}} 0^{\mathrm{m}} 12^{\mathrm{s}} \cdot 9$; A.A. $28^{\circ} 17^{\prime} 54^{\prime \prime}$; T.A. $28^{\circ} 16^{\prime} 8^{\prime \prime} ;$ E.H.A. $3^{\mathrm{h}} 21^{\mathrm{m}} 18^{\mathrm{s}} \cdot 9$.

Moon's elements: R.A. $12^{\mathrm{h}} 11^{\mathrm{m}} 39^{\mathrm{s}} \cdot 9$; dec. $3^{\circ} 6^{\prime} 37^{\prime \prime}$ N.; S.D. $16^{i} 1^{\prime \prime} \cdot 7$; H.P. $58^{\prime} 19^{\prime \prime}$; W.H.A. $4^{\text {b }} 13^{\mathrm{m}} 13^{\mathrm{s}}$; T.A. $21^{\circ} 15^{\prime} 24^{\prime \prime}$; A.A. $20^{\circ} 23^{\prime} 17^{\prime \prime}$; app. dist. $113^{\circ} 24^{\prime} 57^{\prime \prime} ; \mathrm{B}=21^{\circ} 11^{\prime} 29^{\prime \prime} ; \mathrm{Z}=132^{\circ} 58^{\prime} 10^{\prime \prime}$; true dist. $112^{\circ} 48^{\prime} 56^{\prime \prime}$; error, $10^{\mathrm{m}} 14^{\circ} \cdot 5$ fast; long. $33^{\circ} 36^{\prime} 7^{\prime \prime} \mathrm{E}$.

5. Planet's elements: R.A. $23^{\mathrm{h}} 1^{\mathrm{m}} 40^{\mathrm{s}}$; dec. $8^{\circ} 27^{\prime} 13^{\prime \prime}$ S. ; R.A.M.S. $9^{\text {h }} 22^{\mathrm{m}} 50^{\mathrm{s}} \cdot 3$; W.H.A. $0^{\text {h }} 15^{\mathrm{m}} 59^{\mathrm{s}} \cdot 3$; 'T.A. $50^{\circ} 54^{\prime} 27^{\prime \prime}$; A.A. $50^{\circ} 55^{\prime} 12^{\prime \prime}$.

Moon's elements : R.A. $4^{\mathrm{h}} 0^{\mathrm{m}} 49^{\mathrm{s}}$; dec. $15^{\circ} 32^{\prime} 59^{\prime \prime}$ N. ; S.D. $14^{\prime} 54^{\prime \prime}$; H.P. 54' $11^{\prime \prime}$; A.A. $23^{\circ} 21^{\prime} 26^{\prime \prime}$; T.A. $24^{\circ} 8^{\prime} 58^{\prime \prime}$; E.H.A. $4^{\text {h }} 43^{\mathrm{m}} 10^{\text {s }}$; app. dist. $78^{\circ} 26^{\prime} 58^{\prime \prime} ; \mathrm{B}=28^{\circ} 56^{\prime} 47^{\prime \prime} ; \mathrm{Z}=100^{\circ} 42^{\prime} 28^{\prime \prime}$; true dist. $77^{\circ} 50^{\prime} 26^{\prime \prime}$; error, $3^{\circ}$ fast; long. $40^{\circ} 50^{\prime} \mathrm{W}$.

6. Sun's elements: R.A. $10^{\text {h }} 9^{\mathrm{m}} 42^{\mathrm{s}} \cdot 7$; dec. $11^{\circ} 21^{\prime} 4^{\prime \prime}$ N. ; R.A.M.S. $10^{\mathrm{h}} 7^{\mathrm{m}} 16^{\mathrm{s}}$; A.A. $47^{\circ} 5^{\prime} 38^{\prime \prime}$; T.A. $47^{\circ} 4^{\prime} 51^{\prime \prime}$; E.H.A. $38^{\mathrm{m}} 45^{\mathrm{a} \cdot} \cdot 7$.

Moon's elements : R.A. $13^{\mathrm{b}} 45^{\mathrm{m}} 23^{\circ} \cdot 2$; dec. $5^{\circ} 28^{\prime} 21^{\prime \prime}$ S. ; S.D. $16^{\prime} 8^{\prime \prime} \cdot 3$; H.P. $58^{\prime} 49^{\prime \prime}$; A.A. $9^{\circ} 52^{\prime} 3^{\prime \prime}$; T.A. $10^{\circ} 44^{\prime} 41^{\prime \prime}$; E.H.A. $4^{\text {h }} 14^{\mathrm{m}} 26^{\mathrm{s}} \cdot 2$; app. dist. $56^{\circ} 54^{\prime} 0^{\prime \prime} ; \mathrm{B}=47^{\circ} 32^{\prime} 25^{\prime \prime} ; \mathrm{Z}=51^{\circ} 10^{\prime} 2^{\prime \prime}$; true dist. $56^{\circ} 13^{\prime} 1^{\prime \prime}$; error, $14^{\mathrm{m}} 35^{\mathrm{s}}$ fast ; long. $4^{\circ} 34^{\prime} \mathrm{E}$.

7. Star's elements: R.A. $16^{\mathrm{h}} 23^{\mathrm{m}} 38^{\mathrm{s}} \cdot 5$; dec. $26^{\circ} 13^{\prime} 26^{\prime \prime}$ S. ; R.A.M.S. $10^{\text {h }} 28^{\mathrm{m}} 46^{\circ} \cdot 8$; A.A. $56^{\circ} 36^{\prime} 29^{\prime \prime}$; T.A. $56^{\circ} 35^{\prime} 52^{\prime \prime}$; W.H.A. $2^{\text {h }} 7^{\text {m }} 23^{s} \cdot 5$.

Moon's elements : R.A. $18^{\mathrm{h}} 58^{\mathrm{m}} 41^{\circ} \cdot 5$; dec. $20^{\circ} 17^{\prime} 4 \tilde{5}^{\prime \prime}$ S. ; S.D. $16^{\prime} 21^{\prime \prime} \cdot 5$; H.P. $58^{\prime} 54^{\prime \prime}$; E.H.A. $0^{\mathrm{h}} 27^{\mathrm{m}} 39^{\mathrm{s} \cdot 7}$; T.A. $61^{\circ} 2^{\prime} 31^{\prime \prime}$; A.A. $60^{\circ} 34^{\prime} 6^{\prime \prime}$; app. dist. $36^{\circ} 10^{\prime} 9^{\prime \prime} ; \mathrm{B}=24^{\circ} 33^{\prime} 36^{\prime \prime} ; \mathrm{Z}=72^{\circ} 46^{\prime} 12^{\prime \prime}$; true dist. $35^{\circ} 57^{\prime} 44^{\prime \prime}$; error, $11^{\mathrm{m}} 41^{\prime}$ fast ; long. $30^{\circ} 16^{\prime} \mathrm{W}$.

8. Planet's elements: R.A. $6^{\text {h }} 8^{\text {m }} 5^{8} \cdot 6$; dec. $23^{\circ} 7^{\prime} 40^{\prime \prime}$ N.; R.A.M.S. $9^{\text {h }} 7^{\mathrm{m}} 21^{\circ \cdot} \cdot 7$; A.A. $30^{\circ} 22^{\prime} 32^{\prime \prime}$; T.A. $30^{\circ} 20^{\prime} 56^{\prime \prime}$; E.H.A. $3^{\text {h }} 56^{\mathrm{m}} 39^{\mathrm{s}}$.

Moon's elements: R.A. $0^{\mathrm{h}} 58^{\mathrm{m}} 15^{\mathrm{s}} \cdot 5$; dec. $1^{\circ} 9^{\prime} 37^{\prime \prime}$ N.; S.D. $15^{\prime} 23^{\prime \prime}$; H.P. $55^{\prime} 33^{\prime \prime}$; W.H.A. $1^{\text {b }} 13^{\mathrm{m}} 9^{\text {s }}$; T.A. $71^{\circ} 17^{\prime} 45^{\prime \prime}$; A.A. $71^{\circ}{D^{\prime}}^{\prime \prime}$; app. dist. $78^{\circ} 16^{\prime} 58^{\prime \prime} ; \mathrm{B}=3^{\circ} 4^{\prime} 32^{\prime \prime} ; \mathrm{Z}=168^{\circ} 17^{\prime} 36^{\prime \prime} ;$ true dist $78^{\circ} 1^{\prime} 6^{\prime \prime}$; error, $4^{s}$ slow ; long. $20^{\circ} 26^{\prime} 52^{\prime \prime} \mathrm{W}$. 
9. Star's elements: R.A. $23^{\mathrm{h}} 0^{\mathrm{m}} 4^{\mathrm{s} \cdot 7}$; dec. $14^{\circ} 41^{\prime} 58^{\prime \prime}$ N. ; R.A.M.S. $10^{\mathrm{h}} 36^{\mathrm{m}} 4 \tilde{0}^{\mathrm{s}} \cdot 6$; A.A. $67^{\circ} 48^{\prime} 54^{\prime \prime}$; T.A. $67^{\circ} 48^{\prime} 31^{\prime \prime}$; W.H.A. $1^{\mathrm{h}} 7^{\mathrm{m}} 15^{\mathrm{s}}$.

Moon's elements : R.A. $20^{\mathrm{h}} 57^{\mathrm{m}} 35^{\mathrm{s}}$; dec. $17^{\circ} 14^{\prime} 51^{\prime \prime}$ S. ; S.D. $16^{\prime} 6^{\prime \prime}$; H.P. $58^{\prime} 21^{\prime \prime}$; W.H.A. $3^{\text {h }} 9^{\mathrm{m}} 44^{\prime} \cdot 5$; T.A. $40^{\circ} 14^{\prime} 27^{\prime \prime}$; A.A. $39^{\circ} 30^{\prime} 36^{\prime \prime}$; app. dist. $44^{\circ} 36^{\prime} 57^{\prime \prime} ; \mathrm{B}=26^{\circ} 54^{\prime} 48^{\prime \prime} ; \mathrm{Z}=65^{\circ} 5^{\prime} 14^{\prime \prime}$; true dist. $43^{\circ} 58^{\prime} 42^{\prime \prime}$; error, $12^{\mathrm{m}} 24^{\mathrm{s}}$ slow ; long. $43^{\circ} 9^{\prime} 30^{\prime \prime} \mathrm{E}$.

\section{CHAPTER XXVI.}

\section{Mercator's Charts.}

1. Lat. $57^{\circ} 31 \frac{1}{2}^{\prime} \mathrm{N}$., long. $27^{\circ} 5 \frac{1}{2}^{\prime} \mathrm{W}$.

2. Lat. $64^{\circ} 10 \frac{1}{2}^{\prime} \mathrm{S}$., long. $121^{\circ} 22^{\prime} \mathrm{E}$., magnetic bearing S. $22^{\circ} \mathrm{W}$.

3. Lat. $55^{\circ} 51^{\prime} \frac{1}{2}^{\prime} \mathrm{N}$., long. $30^{\circ} 24^{\prime} \mathrm{W}$.

True course, $\mathrm{N} .47^{\circ}$ E. ; distance, 110 miles.

4. Obs. lat. $54^{\circ} 29^{\prime} \mathrm{N}$., long. $5^{\circ} 21^{\prime}{ }^{\prime} \mathrm{W}$.

D.R. lat. $54^{\circ} 22 \frac{1}{2}^{\prime} \mathrm{N}^{\prime}$, long. $5^{\circ} 15^{\prime} \mathrm{W}$.

Current, N. $28^{\circ}$ W. $7 \frac{3}{4}$ miles.

5. Lat. $69^{\circ} 19^{\prime} \mathrm{N}$., long. $10^{\circ} 1_{\frac{1}{4}}^{\prime \prime}$ E. ; course, S. $61^{\circ}$ E. ; distance, 39.5 miles.

6. Lat. $50^{\circ} 50^{\prime} \mathrm{S}$., long. $24^{\circ} 45^{\prime} \mathrm{E}$.

1st sounding, lat. $51^{\circ} 40^{\prime}$ S., long. $21^{\circ} 55^{\prime}$ E.

2nd sounding, lat. $49^{\circ} 3^{\prime}$ S., long. $24^{\circ} 53^{\prime} \mathrm{E}$.

7. Bearing and distance from $\mathrm{A}$ of 1 st S. $26^{\circ}$ E., 6.85 miles.

2nd S. $57 \frac{1}{2}$ E., 5.8 miles.

8. N. $84^{\circ}$ E. (mag.), 75 miles.

3rd S. $49^{\circ}$ E., $2 \cdot 1$ miles.

9. Lat. $55^{\circ} 33^{\prime}$ N., long. $6^{\circ} 3 \frac{1}{2}^{\prime} \mathrm{W}$., dist. 30 miles.

3.4 knots. Mag. co. $\mathrm{N} .86^{\circ} \mathrm{E}$., dist. $35 \frac{1}{2}$ miles.

\section{CHAPTER XXIX.}

SYLLABUS.

\section{Coefficients.}

31. 1. N. $37^{\circ}$ W. 2. N. $61^{\circ}$ E. 3. S. $31^{\circ}$ E. 4. $-11^{\circ} 6 . \quad 5 .+14^{\circ} \cdot 1$. $6 .+5^{\circ} .5$.

\section{Deviations from Tables.}

62. 1. A, $0 ; \mathrm{B},+5 \frac{1}{2} ; \mathrm{C},-28 \frac{1}{2} ; \mathrm{D},-4 \frac{1}{2} ; \mathrm{E},-1$. $-820,-127,-1550,-1932,-23,-2558,-2812,-2930$, $-2920,-286,-2512,-2046,-152$.

2. $\mathrm{A},-045 ; \mathrm{B}, 0 ; \mathrm{C},+2330 ; \mathrm{D},-2 ; \mathrm{E},-045$. $0,-351,-749,-1138,-1522,-1840,-21 \frac{1}{2},-2330,-25$, $-2518,-2424,-2228,-1922,-1526,-1037$, $-527,0$.

3. $\mathrm{A},=-1 \frac{3}{4} ; \mathrm{B},=-12 \frac{1}{2} ; \mathrm{C},=+26 ; \mathrm{D},=-\frac{3}{4} ; \mathrm{E},=+1 \frac{3}{4}$. $-57,-1051,-16,-2025,-2358,-2634,-2813,-2857$, $-2817,-2747,-26$.

4. $\mathrm{A},+1 ; \mathrm{B},-4 \frac{1}{2} ; \mathrm{C},-15 \frac{1}{2} ; \mathrm{D}, 0 ; \mathrm{E},+1 \frac{1}{2}$. $-13,-1156,-1032,-849,-637,-427,-150,+11,+4$, +72 , +102, +1247, +159, +16 57, +18 6, +18 28, + 18 .

5. $\mathrm{B},+21 ; \mathrm{C},+3 ; \mathrm{D},+3$. $-8,-14,-18,-20,-21,-21 \frac{1}{2},-21,-20,-18,-16,-14$. -11 . 


\section{Stars in Good Position.}

70. 1. E $\beta$ Argûs, $a$ Argûs, Rigel.
W. a Centauri, Altair.

2. E. Aldebaran, Capella.

3. $\mathrm{E}$. W. Vega, Altair.

W. Altair.

4. E. Rigel.

W. a Crucis, a Centauri, Marcab.

5. E. Aldebaran, a Orionis.

W. Vega, Altair.

6. None.

Heeling Error.

92. 1. $-3^{\circ}$. 2. $7^{\circ} 15^{\prime} .3 .+11^{\circ} 48^{\prime} . \quad 4 .+10^{\circ} 18^{\prime} . \quad 5 . \quad-25^{\circ} 30^{\prime}$. 6. $+5^{\circ} 54^{\prime} .7$. $-11^{\circ} 15^{\prime}$. 8. 0. 9. $-14^{\circ} 18^{\prime}$. 10. $-3^{\circ} 30^{\prime}$. 11. $+9^{\circ} 12^{\prime}$. 12. $-5^{\circ} 56^{\prime}$.

\section{CHAPTER XXX.}

Miscellaneous Problems.

1. £2142.

2. $£ 7066^{\circ} 5$.

3. £3174 9s.

4. $\$ 33,157 \cdot 025$. $£ 19,994$.

5. 13s. per gall.; $17 \frac{3}{4} d$. per lb.

6. 15,624 tons.

7. $13 \cdot 6$.

8. 2 feet.

9. 8 .

10. 49 .

11. 29 feet.

12. $967 \cdot 5$ francs.

13. $£ 42$ 10s. $6 d$.

14. 4 feet.

15. 78.35 shillings.

16. 92 tons.

17. $30 \cdot 6$.

18. 977 feet.

19. $\cdot 91$.

20. 12,600 sq. ft.

21. $2406 \cdot 25$ lbs.

22. 62 tons.

23. 80.3 tons.

24. 3.6 tons, 14.4 tons, 4.9 tons.

26. $1 \frac{3}{4}$ tons, $3 \frac{4}{7}$ tons, 6 tons.

27. 8 cwt., $2 \frac{1}{2}$ tons, 10 tons.

28. 4.

29. 8 tons nearly.

30. $7 \frac{1}{2}$ tons.

31. $4 \frac{1}{2}$ " rope ; $23^{3 \prime}$ wire.

32 . $5^{\prime \prime}$ rope ; $3^{\prime \prime}$ wire.

33. 162 tons.

34. 562 grains.

35. 525 grains.

36. 566 grains.

37. $1 \cdot 76$ nautical miles. 
38. 186,324 miles.

39. $8 \cdot 44$ knots.

40. $8 \%$.

41. $10 \%$.

42. 43.2 tons; 12.8 tons.

43. $202 \cdot 6$ tons; 73.9 tons.

44. $10 \cdot 62 \mathrm{kts}$; $14.73 \mathrm{kts}$.

45. 13.4 kts. ; 16.9 kts.

46. $2034 \cdot 5$ tons.

47. 540 tons.

48. $484 \cdot 8$ tons.

49. $6836 ; 56.4$ tons; $101 \cdot 4$ tons.

50. 1000 tons.

51. $8 \cdot 3$ tons.

52. 9 knots.

53. $6 \cdot 84$ knots.

54. 19.03 tons ;'30.28 tons.

55. Increase 12 tons.

56. 69 tons.

\section{PAPer I.}

1. $.49298 \log =9 \cdot 692831$.

2. $85.406 \log =1.931488$.

3. S. $27^{\circ}$ W., $12^{\prime}$; S. $29^{\circ}$ E., $28^{\prime}$; S. $50^{\circ}$ W., $29^{\prime}$; S. $34^{\circ}$ W., $30^{\prime}$; N. $41^{\circ}$ E., $20^{\prime} ;$ S. $79^{\circ} \mathrm{W}, 35^{\prime}$; N. $49^{\circ}$ E., $27^{\prime}$; D.R. lat. $49^{\circ} 51^{\prime} 4$ N. ; long. $0^{\circ} 36^{\prime} \cdot 6^{\circ} \mathrm{W}$. Set S. $14^{\circ} \mathrm{W}$. ; drift, 22 miles.

4. Dec. $17^{\circ} 44^{\prime} 18^{\prime \prime}$ N.; T.A. $58^{\circ} 21^{\prime} 26^{\prime \prime}$; lat. $49^{\circ} 22^{\prime} 52^{\prime \prime} \mathrm{N}$.

5. Long. $45^{\circ} 12^{\prime} \cdot 4 \mathrm{E}$.

6. D. lat. 2472 , M.D.L. 2569 , D. long. 876 ; true comp. S. $18^{\circ} 49 \frac{1}{2}^{\prime}$ W. ; comp. course, S. $56^{\circ} 34 \frac{1}{2}^{\prime} \mathrm{W}$. ; dist. 2612 miles.

7. $4^{\mathrm{h}} 24^{\mathrm{m}}$ A.Mr. ; $4^{\mathrm{h}} 42^{\mathrm{m}}$ P.M.

8. Dec. $17^{\circ} 19^{\prime} 5^{\prime \prime}$ N. ; true amp. E. $22^{\circ} 191^{\prime}$ N. ; dev. $9^{\circ} 25 \frac{1}{2}^{\prime}$ E.

9. M.T.G. Aug. $7^{\mathrm{d}} 0^{\mathrm{h}} 0^{\mathrm{m}} 0^{\circ}$; Dec. $16^{\circ} 37^{\prime} 13^{\prime \prime}$ N.; eq. time, $+5^{\mathrm{m}} 40^{\circ}$; T.A. $54^{\circ} 6^{\prime} 6^{\prime \prime}$; H.A. $2^{\mathrm{h}} 7^{\mathrm{m}} 17^{\prime}$; st. long. $30^{\circ} 24^{\prime} 15^{\prime \prime}$ W. ; noon long. $30^{\circ} 56^{\prime} 40^{\prime \prime}$ W. ; true azi. S. $59^{\circ} 30^{\prime}$ E. ; dev. $1^{\circ} 15^{\prime} \mathrm{W}$.

10. A.T.S. $3^{\mathrm{h}} 47^{\mathrm{m}} 38^{\prime}$ P.M. ; dec. $8^{\circ} 17^{\prime} 0^{\prime \prime}$ N. ; cor., $-46+10+5$; true azi. S. $121^{\circ} 43^{\prime} \mathrm{W}$. ; dev. $7^{\circ} 2^{\prime} \mathrm{W}$.

11. H.A. $48^{\mathrm{m}} 35^{\mathrm{s}}$; R.A.M.S. $10^{\mathrm{h}} 10^{\mathrm{m}} 12^{\mathrm{s}}$; T.A. $57^{\circ} 24^{\prime} 25^{\prime \prime}$; nat. no. 10729. Arc. I. $58^{\circ} 17^{\prime} 50^{\prime \prime}$; Arc II. $32^{\circ} 0^{\prime} 58^{\prime \prime}$; lat. $26^{\circ} 16^{\prime} 52^{\prime \prime} \mathrm{S}$.

12. First dec. $0^{\circ} 1^{\prime} 22^{\prime \prime}$ N.; T.A. $32^{\circ} 59^{\prime} 45^{\prime \prime}$; eq. time, $\left.-7^{m}\right] 31^{\prime}$; long. (a), $179^{\circ} 9^{\prime} 45^{\prime \prime} \mathrm{W}$.; (b), $178^{\circ} 1^{\prime} 30^{\prime \prime} \mathrm{W}$.; second dec. $0^{\circ} 2^{\circ} 32^{\prime \prime} \mathrm{S}$. ; T.A. $33^{\circ} 3^{\circ} 25^{\prime \prime}$; eq. time, $-7^{m} 35$; long. (c), $179^{\circ} 47^{\prime} 45^{\prime \prime}$ E.; $(d)$, $178^{\circ} 39^{\prime} 15^{\prime \prime} \mathrm{E}$.

First line: $\left\{\begin{array}{ll}\mathrm{N} .57^{\circ} \mathrm{W} . \\ \mathrm{S} .57^{\circ} & \mathrm{E} .\end{array}\right\}$; second azi. N. $33 \frac{1}{2}^{\circ} \mathrm{W} . ;$ lat. $51^{\circ} 2^{\prime}$ S. ; long. $179^{\circ} 40^{\prime} \mathrm{W}$.

13. $4^{\text {t }} 33^{\mathrm{m}} 22^{\prime}$ A.Mr.

14. a Persei, N. $1^{\text {h }} 34^{\mathrm{m}} 9^{\circ}$ E. Alt. $72^{\circ} 53^{\prime} 20^{\prime \prime}$.

15. M.T.G. Aug. $30^{d} 18^{\mathrm{h}} 0^{\mathrm{m}} 49^{\prime}$; R.A.M.S. $10^{\mathrm{h}} 34^{\mathrm{m}} 2^{\prime \prime}$; T.A. $21^{\circ} 19^{\prime} 19^{\prime \prime}$;

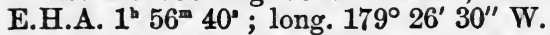

16. E.H.A. $4^{\text {b }} 49^{\mathrm{m}} 12^{\circ}$; cor. $+1-20+0$; true ari. S. $81^{\circ} 17^{\prime}$ E.; dev. $24^{\circ} 28^{\prime} \mathrm{E}$.

17. R.A.M. $3^{\text {h }} 59^{m} 53^{\prime \prime}$; first cor., $-56^{\prime} 10^{\prime \prime}$; lat. $38^{\circ} 9^{\prime} 37^{\prime \prime}$ N.

18. M.T.G. $6^{\text {d }} 7^{\text {h }} 58^{\mathrm{m}} \cdot 8$; S.D. $15^{\prime} 50^{\prime \prime}$; H.P. $57^{\prime} 15^{\prime \prime}$; dec. $9^{\circ} 21^{\prime} 57^{\prime \prime}$ S. ; A.A. $50^{\circ} 9^{\prime} 2^{\prime \prime}$; T.A. $50^{\circ} 44^{\prime} 55^{\prime \prime}$; lat. $29^{\circ} 53^{\prime} 8^{\prime \prime} \mathrm{N}$.

19. Lat. $28^{\circ} 23^{\prime} 22^{\prime \prime} \mathrm{S}$.

20. Mag. bearing, N. $33^{\circ}$ E. ; comp. course, N. $59^{\circ}$ E., N. $86^{\circ}$ W., 
S. $37^{\circ}$ E., N. $21^{\circ}$ W. ; mag. course, N. $61^{\circ}$ W., N. $52^{\circ}$ E., S. $9^{\circ}$ W., S. $53^{\circ}$ E. ; mag. bearings, S. $54^{\circ}$ W., N. $25^{\circ} \mathrm{W}$.

21. Red, -7 ft. 10 ins. $23^{\mathrm{h}} 0^{\mathrm{m}} 4^{\prime \cdot 7}$; dec. $14^{\circ} 41^{\prime} 58^{\prime \prime}$ N. ; R.A.M.S. $8^{\mathrm{h}} 37^{\mathrm{m}} 55^{\mathrm{a}} .5$; A.A. $27^{\circ} 14^{\prime} 3^{\prime \prime}$; T.A. $27^{\circ} 12^{\prime} 12^{\prime \prime}$; E.H.A. $2^{\text {h }} 44^{\mathrm{m}} 29^{\prime \prime}$.

Moon's elements: R.A. $18^{\text {h }} 8^{\mathrm{m}} 23^{\mathrm{s}} \cdot 8$; dec. $20^{\circ} 3^{\prime} 9^{\prime \prime}$ S. ; S.D. $16^{\prime} 35^{\prime \prime}$; H.P. $59^{\prime} 48^{\prime \prime}$; W.H.A. $2^{\mathrm{h}} 7^{\mathrm{m}} 12^{\prime \prime}$; T.A. $58^{\circ} 27^{\prime} 37^{\prime \prime}$; A.A. $57^{\circ} 56^{\prime} 27^{\prime \prime}$; app. dist. $79^{\circ} 55^{\prime} 38^{\prime \prime} ; \mathrm{B}=20^{\circ} 56^{\prime} 4^{\prime \prime} ; \mathrm{Z}=116^{\circ} 49^{\prime} 30^{\prime \prime}$; true dist. $79^{\circ} 38^{\prime} 49^{\prime \prime}$; error $6^{\mathrm{m}} 15^{\prime \prime}$ fast ; long. $65^{\circ} 50^{\prime} \mathrm{E}$.

23. First dec. $0^{\circ} 18^{\prime} 53^{\prime \prime} \mathrm{N}$.; run, $+8^{\prime}$; alt. $32^{\circ} 28^{\prime} 27^{\prime \prime}$; second dec. $0^{\circ} 1^{\prime} 1^{\prime \prime}$ N.; alt. $32^{\circ} 20^{\prime} 27^{\prime \prime}$; H.E.T. $2^{\mathrm{h}} 30^{\mathrm{m}} 5^{\mathrm{s}} ; \mathrm{XY}=75^{\circ} 2^{\prime} 26^{\prime \prime}$; $\mathrm{X}_{1}=89^{\circ} 50^{\prime} 32^{\prime \prime} ; \mathrm{X}_{2}=60^{\circ} 54^{\prime} 2^{\prime \prime}$; lat. $47^{\circ} 50^{\prime} 38^{\prime \prime} \mathrm{N}$.

24. Dec. $9^{\circ} 15^{\prime} 51^{\prime \prime}$ N. ; T.A. $39^{\circ} 48^{\prime} 21^{\prime \prime} ;$ H.A. $2^{\mathrm{h}} 58^{\mathrm{m}} 16^{\mathrm{a}}$; error $14^{\mathrm{m}} 31^{\circ}$ slow.

25. First course, N. $78^{\circ} 3^{\prime} \mathrm{W}$.; dist. 3346 miles ; vertex lat., $50^{\circ} 59^{\prime} \mathrm{N}$. ; long. $21^{\circ} 16^{\prime} \mathrm{W}$.; $5^{\circ} \mathrm{W}$. of Wolf, lat. $50^{\circ} 31^{\prime} \mathrm{N}$.; $10^{\circ} \mathrm{W}$. of Wolf, $50^{\circ} 51_{2}^{\prime \prime} \mathrm{N}_{\text {.; }}$; $15^{\circ} \mathrm{W}, 50^{\circ} 59 \frac{1}{2}^{\prime} \mathrm{N}$.; $20^{\circ}, 50^{\circ} 53 \frac{1}{2} \mathrm{~N} . ; 61^{\circ} \mathrm{W} ., 43^{\circ} 30 \frac{1}{2}^{\prime} \mathrm{N}$.

26. $319 \cdot 1$.

27. $86^{\circ} 1^{\prime} 21^{\prime \prime}$.

28. $106^{\circ} 10^{\prime} 16$.

29. $100^{\circ} 17^{\prime} 28^{\prime \prime}$, or $79^{\circ} 42^{\prime} 32^{\prime \prime}$.

30. N. $31^{\circ} 41_{2}^{\prime}$ E.; C, $-23^{\circ} 18^{\prime}$.

31. R.A.M. $23^{\mathrm{h}} 45^{\mathrm{m}} 39^{\mathrm{s}}$; E., Rigel ; W. $a^{1}$ Crucis, $a^{2}$ Centauri, Markab.

32. $\mathrm{A}+25 ; \mathrm{B}-25^{\circ} ; \mathrm{C}-16^{\circ} .5 ; \mathrm{D}+2^{\circ} ; \mathrm{E}-75$. Deviations, North, $17^{\circ}$ W. ; $12^{\circ} 29^{\prime}$ W.; $7^{\circ} 22^{\prime}$ W.; $1^{\circ} 43^{\prime}$ W. ; $4^{\circ} 15^{\prime}$ E.; $10^{\circ} 19^{\prime}$ E. ; $16^{\circ} 10^{\prime}$ E. ; $21^{\circ} 28^{\prime}$ E.; West, $26^{\circ}$ E.; $29^{\circ} 26^{\prime}$ E. ; $31^{\circ} 36^{\prime}$ E.; $32^{\circ} 21^{\prime}$ E.; $31^{\circ} 36^{\prime}$ E.; $29^{\circ} 25^{\prime}$ E. ; $25^{\circ} 58^{\prime}$ E. ; $21^{\circ} 24^{\prime}$ E. ; South, $16^{\circ}$ E.

33. $5^{\circ} 45^{\prime} \mathrm{E}$.

\section{Paper II.}

1. $212 \cdot 8 \log =2 \cdot 327982$.

2. $\cdot 147 \log =9 \cdot 167437$.

3. S. $17^{\circ}$ E., $15^{\prime} ;$ N. $67 \frac{10}{2}$ E., $54^{\prime} ;$ N. $52^{\circ}$ E., $50^{\prime}$; S. $83^{\circ}$ E., $42^{\prime}$; S. $56^{\circ}$ W., $31^{\prime}$; S. $1^{\circ}$ E., $30^{\prime}$; S. $37^{\circ}$ E., $42^{\prime} ;$ N. $14^{\circ}$ W.. $54^{\prime}$; D. lat. $3^{\prime} \cdot 2$ N., dep. $122^{\prime} 6$ E.; course, N. $88^{\circ}$ E. ; dist. $123^{\prime}$; lat. in $25^{\circ} 12^{\prime}$ S. ; long. $45^{\circ} 4 \frac{1}{2}^{\prime} \mathrm{W}$.

4. Dec. $0^{\circ} 9^{\prime} 13^{\prime \prime}$ N. ; T.A. $64^{\circ} 58^{\prime} 19^{\prime \prime}$; lat. $24^{\circ} 52^{\prime} 28^{\prime \prime}$ S.

5. $41^{\circ} 40^{\prime} \mathrm{W}$.

6. D. lat. 5642 ; M.D.L. 6465 ; D. long. 2805 ; true course, N. $23^{\circ} 27 \frac{1}{2}^{\prime}$ W. ; comp. course, N. $64^{\circ} 7 \frac{1}{2}^{\prime}$ W. ; dist. 6150 miles.

7. $5^{\text {h }} 40^{\text {m }}$ A.M., $6^{\text {h }} 23^{\text {m }}$ P.M.

8. Dec. $2^{\circ} 5^{\prime} 33^{\prime \prime} \mathrm{S}$. ; true amp. W. $2^{\circ} 49^{\prime} 25^{\prime \prime} \mathrm{S}$. ; dev. $8^{\circ} 19^{\prime} 30^{\prime \prime} \mathrm{W}$.

9. M.T.G. $3^{\mathrm{d}} 16^{\mathrm{h}} 53^{\mathrm{m}} 9^{\mathrm{s}}$; dec. $17^{\circ} 30^{\prime} 27^{\prime \prime}$ N. ; eq. time, $+5^{\mathrm{m}} 59^{4}$; T.A. $22^{\circ} 38^{\prime} 24^{\prime \prime}$; E.H.A. $4^{\mathrm{h}} 42^{\mathrm{m}} 44^{\mathrm{s}}$; st. long. $37^{\circ} 31^{\prime} 30^{\prime \prime}$ E. ; noon long. $38^{\circ} 15^{\prime} 30^{\prime \prime}$ E. ; true azi. S. $102^{\circ} 48^{\prime}$ E. ; error $10^{\circ} 18^{\prime} \mathrm{W}$.; dev. $5^{\circ} 18^{\prime} \mathrm{W}$.

10. W.H.A. $4^{\mathrm{h}} 5^{\mathrm{m}} 30^{\mathrm{a}}$; dec. $8^{\circ} 36^{\prime} 43^{\prime \prime}$ N.; cor. $-17+26+6$; true azi. S. $116^{\circ} 50^{\prime}$ W. ; dev. $10^{\circ} 57^{\prime} \mathrm{E}$.

11. E.H.A. $19^{m} 3^{s}$; dec. $16^{\circ} 36^{\prime} 52^{\prime \prime}$ N. ; T.A. $72^{\circ} 36^{\prime} 2^{\prime \prime}$; nat. no., 2767. Arc. I. $16^{\circ} 40^{\prime} 9^{\prime \prime}$; Árc. II. $16^{\circ} 48^{\prime} 17^{\prime \prime}$; st. lat. $33^{\circ} 28^{\prime} 26^{\prime \prime} \mathrm{N}$.; noon, $33^{\circ} 24^{\prime} 40^{\prime \prime} \mathrm{N}$.

12. First dec. $2^{\circ} 18^{\prime} 36^{\prime \prime}$ S. ; T.A. $36^{\circ} 40^{\prime} 42^{\prime \prime}$; eq. time, $-9^{\mathrm{m}} 33^{\prime}$; long. (a), $123^{\circ} 41^{\prime} 30^{\prime \prime} \mathrm{W}$.; (b), $125^{\circ} 20^{\prime} 30^{\prime \prime} \mathrm{W}$. ; second dec. $2^{\circ} 21^{\prime} 7^{\prime \prime} \mathrm{S}$.; T.A. $18^{\circ} 44^{\prime} 50^{\prime \prime}$; eq. time, $-9^{\mathrm{m}} 35^{\mathrm{s}}$; long. (c), $124^{\circ} 41^{\prime} 45^{\prime \prime} \mathrm{W}$.; (d), $125^{\circ} 4^{\prime} 15^{\prime \prime} \mathrm{W}$.

First line: $\left\{\begin{array}{c}\mathrm{N} .65^{\circ} \mathrm{W} \\ \mathrm{S} .65^{\circ} \mathrm{E} .\end{array}\right\}$; second azi. S. $63^{\circ}$ W. ; lat. $48^{\circ} 52^{\prime}$ N. ; long. $125^{\circ} 20^{\prime} \mathrm{W}$. 
13. Inspection $4^{\mathrm{h}} 46^{\mathrm{m}}$ A.M. ; $28 \mathrm{th}, 4^{\mathrm{h}} 55^{\mathrm{m}} 15^{\mathrm{A}}$ A.M.

14. R.A.M. $5^{\mathrm{h}} 50^{\mathrm{m}} 30^{\mathrm{s}}$; Aldebaran, N. $1^{\mathrm{h}} 19^{\mathrm{m}} 59^{\mathrm{s}}$ W. ; Capella, N. $40^{\mathrm{m}} 45^{\mathrm{s}}$ W. Rigel, N. $40^{\mathrm{m}} 29^{\mathrm{s}}$ W.; Canopus, S. $31^{\mathrm{m}} 22^{\mathrm{s}}$ E. ; Sirius, N. $50^{\mathrm{m}} 30^{\mathrm{s}}$ E. ; Procyon, N. $1^{\mathrm{h}} 43^{\mathrm{m}} 53^{\mathrm{s}}$ E. ; Pollux, N. $1^{\mathrm{h}} 49^{\mathrm{m}} 4^{\mathrm{s}}$ E. Approx. alt. $67^{\circ} 26^{\prime}$.

15. M.T.G. $7^{\mathrm{d}} 17^{\mathrm{h}} 46^{\mathrm{m}} 22^{\mathrm{s}}$; R.A.M.S. $11^{\mathrm{h}} 5^{\mathrm{m}} 32^{\mathrm{a}}$; E.H.A. $1^{\mathrm{h}} 52^{\mathrm{m}} 28^{\mathrm{s}}$; long. $164^{\circ} 32^{\prime} 30^{\prime \prime} \mathrm{W}$.

16. W.H.A. $3^{\text {h }} 48^{\mathrm{m}} 44^{\mathrm{s}}$; cor. $-9-27+12$; true azi. N. $109^{\circ} 26^{\prime}$ W. ; dev. $4^{\circ} 4^{\prime} \mathrm{E}$.

17. R.A.M. $19^{\mathrm{h}} 25^{\mathrm{m}} 17^{\mathrm{s}}$; first cor. $-5^{\prime \prime}$; second, $+26^{\prime \prime}$; third, $+1^{\prime} 23^{\prime \prime}$; lat. $29^{\circ} 14^{\prime} 50^{\prime \prime} \mathrm{N}$.

18. M.T.G. $30^{d} 12^{\text {h }} 50^{\mathrm{m} \cdot 1}$; S.D. $16^{\prime} 15^{\prime \prime}$; H.P. $58^{\prime} 36^{\prime \prime}$; dec. $19^{\circ} 12^{\prime} 4^{\prime \prime}$ S. ; cor. $29^{\prime} 29^{\prime \prime}$; T.A. $59^{\circ} 44^{\prime} 36^{\prime \prime}$; lat. $49^{\circ} 27^{\prime} 28^{\prime \prime} \mathrm{S}$.

19. Lat. $29^{\circ} 30^{\prime} 38^{\prime \prime} \mathrm{S}$.

20. S. $65^{\circ}$ W. ; comp. course, S. $40^{\circ}$ E. ; N., N. $65^{\circ}$ W. ; S. $32^{\circ}$ W. ; mag. course, N. $40^{\circ}$ W. ; N. $12^{\circ}$ E. ; N. $64^{\circ}$ E. ; S. $64^{\circ}$ E. ; mag. bearings, S. $51^{\circ} \mathrm{E}$., and N. $36^{\circ} \mathrm{E}$.

21. Red, $-3 \mathrm{ft} .9$ ins.

22. Star's elements: R.A. $13^{\text {h }} 20^{m} 14^{\text {s }}$; dec. $10^{\circ} 40^{\prime} 15^{\prime \prime}$ S. ; R.A.M.S. $8^{\mathrm{h}} 43^{\mathrm{m}} 19^{\mathrm{s}}$; A.A. $12^{\circ} 10^{\prime} 46^{\prime \prime}$; T.A. $12^{\circ} 6^{\prime} 26^{\prime \prime}$; W.H.A. $4^{\mathrm{h}} 44^{\mathrm{m}} 12^{\mathrm{s}}$.

Moon's elements : R.A. $19^{\mathrm{h}} 32^{\mathrm{m}} 38^{\prime}$; dec. $19^{\circ} 54^{\prime} 30^{\prime \prime}$ S. ; S.D. $16^{\prime} 26^{\prime \prime}$; H.P. $59^{\prime} 31^{\prime \prime}$; E.H.A. $1^{\text {h }} 28^{m} 12^{\text {s }}$; T.A. $40^{\circ} 1^{\prime} 36^{\prime \prime}$; A.A. $39^{\circ} 16^{\prime} 42^{\prime \prime}$; app. dist. $89^{\circ} 23^{\prime} 49^{\prime \prime} ; \mathrm{B}=34^{\circ} 2^{\prime} 53^{\prime \prime} ; \mathrm{Z}=99^{\circ} 21^{\prime} 32^{\prime \prime}$; true dist. $89^{\circ} 14^{\prime} 47^{\prime \prime}$; error, $2^{\mathrm{m}} 29^{\prime}$ slow ; long. $100^{\circ} 20^{\prime} 45^{\prime \prime} \mathrm{W}$.

23. H.E.T. $1^{\mathrm{h}} 18^{\mathrm{m}} 0^{\mathrm{\prime}}$; mid. dec. $2^{\circ} 19^{\prime} 52^{\prime \prime}$ S. ; run $-18^{\prime} 48^{\prime \prime}$; first alt. $36^{\circ} 21^{\prime} 56^{\prime \prime}$; second alt. $18^{\circ} 44^{\prime} 52^{\prime \prime} ; \mathrm{XY}=38^{\circ} 58^{\prime} 0^{\prime \prime} ; \mathrm{X}_{1}=90^{\circ} 45^{\prime} 52^{\prime \prime}$; $\mathrm{X}_{2}=54^{\circ} 49^{\prime} 40^{\prime \prime}$; lat. $48^{\circ} 50^{\prime} 20^{\prime \prime} \mathrm{N}$.

24. W.H.A. $2^{\mathrm{h}} 56^{\mathrm{m}} 1^{\mathrm{s}} \cdot 5$; eq. time, $-7^{\mathrm{m}} 16^{\mathrm{s}}$; error, $2^{\mathrm{m}} 41^{\mathrm{s}} \cdot 8$ fast.

25. First course, S. $51^{\circ} 31^{\prime}$ E. ; final N. $43^{\circ} 10^{\prime}$ E. ; dist. 5913 miles ; vertex long. $163^{\circ} 13^{\prime} \mathrm{W}$., and $134^{\circ} 33^{\prime} \mathrm{W}$.; points $48^{\circ} 50^{\prime}$ S., $160^{\circ}$ E. ; $51^{\circ} 53 \frac{1}{2}^{\prime}$ S., $170^{\circ}$ E. ; $45^{\circ} 30^{\prime}$ S., $90^{\circ}$ W. ; $39^{\circ} 38^{\prime}$ S., $80^{\circ}$ W.

26. $95 \cdot 25$.

27. $123^{\circ} 52^{\prime} 10^{\prime \prime}$.

28. $93^{\circ} 32^{\prime} 10^{\prime \prime}$.

29. $116^{\circ} 34^{\prime} 11^{\prime \prime}$.

30. S. $47^{\circ} 44^{\prime}$ W. ; $\mathrm{B}=+25^{\circ} 18^{\prime}$.

31. E., Castor, Betelgueuse ; W., Vega, Altair.

32. $\mathrm{A}=+.25^{\circ} ; \mathrm{B}=-7^{\circ} .5 ; \mathrm{C}=+10^{\circ} ; \mathrm{D}=+1^{\circ} .75 ; \mathrm{E}=-5^{\circ .25}$. Deviations, North, $+5^{\circ} ;+4^{\circ} 9^{\prime} ;+3^{\circ} 46^{\prime} ;+2^{\circ} 3^{\prime} ;$ East, $-2^{\circ} ;-8^{\circ} 2^{\prime}$; $-13^{\circ} 52^{\prime} ;-16^{\circ} 45^{\prime}$; South, $-15^{\circ} ;-8^{\circ} 35^{\prime} ;+0^{\circ} 14^{\prime} ;+8^{\circ} 18^{\prime}$; West, $+13^{\circ} ;+13^{\circ} 30^{\prime} ;+10^{\circ} 52^{\prime} ;+7^{\circ} 25^{\prime}$.

33. $-44^{\circ} 6^{\prime}$.

\section{Paper III.}

1. $00000047438 \log =3 \cdot 676123$.

2. $\cdot 0066019 \log =7 \cdot 819667$.

3. N. $18^{\circ}$ E., $15^{\prime}$; S. $63^{\circ}$ W., $28^{\prime}$; N. $85^{\circ}$ W., $30^{\prime}$; S. $88^{\circ}$ W., $36^{\prime}$; S. $49^{\circ}$ W., $40^{\prime}$; S. $25^{\circ}$ W., $42^{\prime}$; S. $68^{\circ}$ W., $32^{\prime} ;$ N. $6^{\circ}$ E., $18^{\prime}$; D. lat. 55.5 S. ; dep. $161 \cdot 9$ W. ; course, S. $71^{\circ}$ W. ; dist. 171 miles ; lat. $59^{\circ} 49^{\prime} \cdot 5$ N. ; long. $0^{\circ} 43^{\prime} \cdot 6 \mathrm{~W}$.

4. Dec. $18^{\circ} 16^{\prime} 54^{\prime \prime}$ N. ; T.A. $81^{\circ} 4^{\prime} 12^{\prime \prime}$; lat. $9^{\circ} 21^{\prime} 6^{\prime \prime}$ N.

5. 201 miles.

6. True course, S. $85^{\circ} 51^{\prime} 48^{\prime \prime} \mathrm{W}$.; compass course, N. $89^{\circ} 38^{\prime} 12^{\prime \prime} \mathrm{W}$.; dist. 1941 miles.

7. No. A.M.; $0^{\mathrm{h}} 41^{\mathrm{m}}$ P.M.

8. True amp. E. $20^{\circ} 24 \frac{1}{2}^{\prime}$ N. ; error, $5^{\circ} 541^{\prime}$ W. ; dev. $12^{\circ} 14 \frac{1}{2}^{\prime}$ W.

9. M.T.G. $16^{\mathrm{d}} 22^{\mathrm{h}} 19^{\mathrm{m}} 57^{\mathrm{s}}$; st. lat. $36^{\circ} 27^{\prime}$ N.; P.D. $76^{\circ} 20^{\prime} 3^{\prime \prime}$; E.H.A. 
$4^{\text {h }} 7^{\mathrm{m}} 20^{\prime}$; st. long. $35^{\circ} 48^{\prime}$ W. ; noon long. $35^{\circ} 25^{\prime} 28^{\prime \prime}$ W. ; true azi. S. $84^{\circ} 30^{\prime}$ E.; dev. $19^{\circ} 30^{\prime} \mathrm{E}$.

10. Corr. $+20-30+35$; true azi. N. $123^{\circ} 13^{\prime} \mathrm{E}$. ; dev. $11^{\circ} 47^{\prime} \mathrm{W}$.

11. W.H.A. $47^{\mathrm{m}} 57^{\mathrm{s}}$; nat. no. 20290 . Arc I. $13^{\circ} 25^{\prime} 58^{\prime \prime}$; Arc II. $30^{\circ} 35^{\prime} 19^{\prime \prime}$. Lat. sights $17^{\circ} 9^{\prime} 19^{\prime \prime} \mathrm{S}$. ; noon, $17^{\circ} 7^{\prime} 31^{\prime \prime} \mathrm{S}$.

12. First T.A. $32^{\circ} 0^{\prime} 31^{\prime \prime}$; P.D. $83^{\circ} 47^{\prime} 4^{\prime \prime}$; long. (a), $150^{\circ} 10^{\prime}$ W. ; (b), $149^{\circ} 44^{\prime} 15^{\prime \prime}$ W. ; second T.A. $46^{\circ} 54^{\prime} 48^{\prime \prime}$; P.D. $83^{\circ} 49^{\prime} 18^{\prime \prime}$; long. (c), $152^{\circ} 16^{\prime} 45^{\prime \prime} \mathrm{W}$. ; $(d), 150^{\circ} 10^{\prime} 30^{\prime \prime} \mathrm{W}$.

Second line: $\left\{\begin{array}{l}\text { N. } 70^{\circ} \mathrm{E} . \\ \text { S. } 70^{\circ} \mathrm{W} .\end{array}\right\}$; second azi. S. $20^{\circ}$ E. ; lat. $48^{\circ} 12^{\prime}$ N. ; long. $149^{\circ} 21^{\prime} \mathrm{W}$.

13. $9^{\mathrm{h}} 36^{\mathrm{m}} 57^{\text {' }}$ P.M. ; by inspection, $9^{\mathrm{h}} 31^{\mathrm{m}}$ P.M.

14. R.A.M. $16^{\mathrm{h}} 0^{\mathrm{m}} 39^{\mathrm{s}}$; Antares, S. $0^{\mathrm{h}} 23^{\mathrm{m}}$ E. ; $\alpha$ Triang. Aust. S. $0^{\mathrm{h}} 38^{\mathrm{m}}$ E.

15. Alt. $20^{\circ} 27^{\prime} 40^{\prime \prime}$.

16. E.H.A. $2^{\text {h }} 38^{\text {m }} 20^{\circ}$; cor. $-26+12+10$; true azi. S. $137^{\circ} 32^{\prime}$ E. ; dev. $6^{\circ} 32 \mathrm{~W}$.

17. M.T.G. $27^{\mathrm{a}} 10^{\mathrm{h}} 27^{\mathrm{m}} 40^{\text {s }}$; R.A.M.S. $12^{\mathrm{h}} 23^{\mathrm{m}} 11^{\text {' }}$; E.H.A. $4^{\mathrm{h}} 54^{\mathrm{m}} 21^{\text {' }}$; long. $84^{\circ} 26^{\prime \prime} \mathrm{E}$.

18. Cor. $+33^{\prime \prime},+41^{\prime \prime},+1^{\prime} 17^{\prime \prime}$; lat. $42^{\circ} 9^{\prime} 56^{\prime \prime} \mathrm{N}$.

19. M.T.G. $16^{\mathrm{d}} 19^{\mathrm{h}} 35^{\mathrm{m}} \cdot 6$; S.D. $15^{\prime} 22^{\prime \prime}$; H.P. $55^{\prime} 27^{\prime \prime}$; dec. $19^{\circ} 57^{\prime} 25^{\prime \prime}$ N.; T.A. $80^{\circ} 54^{\prime} 39^{\prime \prime}$; lat. $10^{\circ} 52^{\prime} 4^{\prime \prime} \mathrm{N}$.

20. Lat. $8^{\circ} 11^{\prime} 54^{\prime \prime} \mathrm{S}$.

21. Mag. bearing, N. $4^{\circ} 45^{\prime}$ E. ; comp. course, N. $43^{\circ}$ E., S. $81^{\circ}$ E., S. $11^{\circ}$ E., N. $7^{\circ}$ E. ; mag. course, N. $30^{\circ}$ W., N. $50^{\circ}$ E., S. $49^{\circ}$ E., S. $81^{\circ}$ W. ; mag. bearings, S. $68 \frac{1}{2}^{\circ} \mathrm{E}$., and N. $71^{\circ} \mathrm{W}$.

22. Red, $-14 \mathrm{ft} .8$ ins.

23. Sun's elements : R.A. $9^{\text {h }} 17^{\mathrm{m}} 4^{\mathrm{a}} \cdot 9$; dec. $15^{\circ} 48^{\prime} 11^{\prime \prime}$ N. ; R.A.M.S. $9^{\text {h }} 11^{\mathrm{m}} 46^{\mathrm{s}} \cdot 7$; E.H.A. $3^{\mathrm{h}} 44^{\mathrm{m}} 37^{\mathrm{s}}$; T.A. $36^{\circ} 15^{\prime} 56^{\prime \prime}$; A.A. $36^{\circ} 17^{\prime} 6^{\prime \prime}$.

Moon's elements: R.A. $1^{\mathrm{b}} 50^{\mathrm{m}} 6^{\mathrm{s}} 4$; dec. $5^{\circ} 51^{\prime} 28^{\prime \prime}$ N. ; S.D. $15^{\prime} 7^{\prime \prime}$; H.P. 54' $51^{\prime \prime}$; A.A. $29^{\circ} 51^{\prime} 19^{\prime \prime}$; T.A. $30^{\circ} 37^{\prime} 13^{\prime \prime}$; W.H.A. $3^{\mathrm{b}} 42^{\mathrm{m}} 21^{\prime \prime}$; app. dist., $109^{\circ} 46^{\prime} 10^{\prime \prime} ; \mathrm{B}=10^{\circ} 25^{\prime} 56^{\prime \prime} ; \mathrm{Z}=154^{\circ} 49^{\prime} 24^{\prime \prime}$; true dist. $109^{\circ} 4^{\prime} 27^{\prime \prime}$; error, $5^{\mathrm{m}} 29^{\circ}$ slow ; long. $14^{\circ} 27^{\prime} \mathrm{W}$.

24. Antares H.A.'s $1^{\mathrm{h}} 36^{\mathrm{m}} 20^{\mathrm{s}}$, and $1^{\mathrm{h}} 31^{\mathrm{m}} 53^{\mathrm{s}}$; long. (a), $62^{\circ} 8^{\prime} 45^{\prime \prime} \mathrm{W}$., (b), $63^{\circ} 15^{\prime} 30^{\prime \prime}$ W. ; Spica H.A.''s $4^{\mathrm{h}} 38^{\mathrm{m}} 15^{\mathrm{a}}$, and $4^{\mathrm{h}} 37^{\mathrm{m}} 32^{\mathrm{s}}$; long. (c), $62^{\circ} 31^{\prime} \mathrm{W}$., (d), $62^{\circ} 41^{\prime} 45^{\prime \prime} \mathrm{W}$.; bearings $\mathrm{S} .26^{\circ} \mathrm{W}$, and $\mathrm{S}$. $72^{\circ} \mathrm{W}$.; lat. $23^{\circ} 12^{\prime} \mathrm{N}$.; ; long. $62^{\circ} 35^{\prime} 15^{\prime \prime} \mathrm{W}$.; $\mathrm{Y}_{1}=116^{\circ} 19^{\prime} 47^{\prime \prime} ; \mathrm{Y}_{2}=53^{\circ} 45^{\prime} 30^{\prime \prime}$; $\mathrm{XY}=45^{\circ} 54^{\prime} 16^{\prime \prime}$; bearings S. $26^{\circ} 14^{\prime}$ W., and S. $71^{\circ} 37^{\prime}$ W.; lat. $23^{\circ} 12^{\prime} 6^{\prime \prime}$ N.; long. $62^{\circ} 35^{\prime} 7^{\prime \prime} \mathrm{W}$.

25. W.H.A. $2^{\mathrm{h}} 23^{\mathrm{m}} 50^{\mathrm{s}} \cdot 5$; error, $5^{\mathrm{m}} 37^{\mathrm{\prime}}$ fast.

26. First course, S. $36^{\circ} 48^{\prime}$ E. ; final, N. $74^{\circ} 35^{\prime}$ E. ; dist. 6971 miles ; vertex lat. $54^{\circ} 6 \frac{1}{2}^{\circ} \mathrm{S}$. ; long. $150^{\circ} \mathrm{E}$. ; points : lats. $0^{\circ}, 13^{\circ} 30^{\prime} \mathrm{S} ., 25^{\circ} 18^{\prime} \mathrm{S}$., $34^{\circ} 38^{\prime} \mathrm{S}$., $53^{\circ} 42^{\prime} \mathrm{S}$.

27. $1950 \cdot 33$.

28. $214 \cdot 37$.

29. $\mathrm{P}=96^{\circ} 25^{\prime} 50^{\prime \prime}$; P.Q. $=61^{\circ} 31^{\prime} 28^{\prime \prime}$.

30. $\mathrm{A}=-25^{\circ} ; \mathrm{B}=+1^{\circ} .5 ; \mathrm{C}=-16^{\circ} ; \mathrm{D}=-3^{\circ} .75 ; \mathrm{E}=-3^{\circ .75}$.

Deviations, East, $+5^{\circ} ;+0^{\circ} 8^{\prime}$ E. ; $-4^{\circ} 58^{\prime} ;-9^{\circ} 55^{\prime} ;-14^{\circ} 14 ;-17^{\circ} 37^{\prime}$; - $19^{\circ} 47^{\prime} ;-20^{\circ} 34^{\prime} ;$ North, $-20^{\circ} ;-18^{\circ} 16^{\prime} ;-15^{\circ} 37^{\prime} ;-12^{\circ} 22^{\prime}$; $-8^{\circ} 52^{\prime} ;-5^{\circ} 30^{\prime} ;-2^{\circ} 26^{\prime} ;+0^{\circ} \overline{0}^{\prime} ;$ West, $+2^{\circ}$.

31. $+8^{\circ} 3^{\prime}$.

\section{PAPER IV.}

1. $7 \cdot 382 \log =0 \cdot 868158$.

2. $\cdot 1149 \log =9 \cdot 060194$.

3. S. $87^{\circ}$ W., $20^{\prime}$; S. $53^{\circ}$ W., $61^{\prime}$; S. $66^{\circ}$ W., $51^{\prime}$; S. $75^{\circ}$ W., $37^{\prime}$, S. $72^{\circ}$ W., $59^{\prime}$; S. $69^{\circ}$ W., $50^{\prime}$; N. $89^{\circ}$ W., $40^{\prime}$; S. $21^{\circ}$ E., $42^{\prime}$; D. lat. 
142.6 S. ; dep. $278 \cdot 7$ W. ; course, S. $63^{\circ}$ W. ; dist. 313 miles; lat. $34^{\circ} 40^{\prime} \mathrm{N}$.; ; long. $1^{\circ} 19^{\prime} \mathrm{W}$.

4. Dec. $17^{\circ} 29^{\prime} 20^{\prime \prime}$ N. ; lat. $56^{\circ} 54^{\prime} 31^{\prime \prime} \mathrm{S}$.

5. $68 \cdot 73$ miles.

6. True course, N. $74^{\circ} 36 \frac{1^{\prime}}{2}$ E. ; compass course, N. $59^{\circ} 46 \frac{1^{\prime}}{2}$ E. ; dist. 2433 miles.

7. $10^{\mathrm{h}} 49^{\mathrm{m}}$ A.M. ; $11^{\mathrm{h}} 26^{\mathrm{m}}$ P.M.

8. True amp. W. $6^{\circ} 28^{\prime}$ N.; error, $9^{\circ} 17^{\prime}$ E. ; dev. $19^{\circ} 47^{\prime}$ E.

9. M.T.G. $9^{\mathrm{d}} 21^{\mathrm{h}} 18^{\mathrm{m}} 25^{\mathrm{c}}$; st. lat. $37^{\circ} 14^{\prime}$ S. ; E.H.A. $3^{\mathrm{h}} 44^{\mathrm{m}} 36^{\mathrm{s}}$; st. long. $14^{\circ} 25^{\prime} 45^{\prime \prime}$ W. ; noon long. $13^{\circ} 57^{\prime} 34^{\prime \prime}$ W. ; true azi. S. $82^{\circ} 20^{\prime} 20^{\prime \prime}$ E. ; dev. $28^{\circ} 54^{\prime} 40^{\prime \prime} \mathrm{E}$.

10. Cor. $-11+4+2$; true azi. S. $111^{\circ} 47^{\prime}$ W. ; dev. $11^{\circ} 2^{\prime} \mathrm{E}$.

11. E.H.A. $29^{m} 29^{\circ}$; nat. no. 6980 . Arc. I. $14^{\circ} 46^{\prime} 41^{\prime \prime}$; Arc. II. $43^{\circ} 33^{\prime} 38^{\prime \prime}$; lat. $28^{\circ} 46^{\prime} 57^{\prime \prime} \mathrm{S}$.

12. First T.A. $49^{\circ} 3^{\prime} 18^{\prime \prime}$; P.D. $81^{\circ} 18^{\prime} 3^{\prime \prime}$; H.A.'s $0^{\mathrm{h}} 42^{\mathrm{m}} 16^{\prime \prime}$, and $0^{\mathrm{h}} 24^{\mathrm{m}} 3^{\circ}$; long. (a), $177^{\circ} 52^{\prime}$ W. ; (b), $177^{\circ} 34^{\prime} 45^{\prime \prime}$ E. ; second T.A. $19^{\circ} 9^{\prime} 3^{\prime \prime}$; P.D. $81^{\circ} 21^{\prime} 45^{\prime \prime}$; H.A.'s $4^{\mathrm{h}} 43^{\mathrm{m}} 0^{\mathrm{s}}$, and $4^{\mathrm{h}} 42^{\mathrm{m}} 21^{\circ}$; long. (c), $179^{\circ} 32^{\prime} 30^{\prime \prime}$ W. ; (d), $179^{\circ} 42^{\prime} 15^{\prime \prime} \mathrm{W}$.

Second line: $\left\{\begin{array}{c}\text { N. } 9^{\circ} \text { W. } \\ \text { S. } 9^{\circ} \text { E. }\end{array}\right\}$; azi. S. $81^{\circ}$ W ; lat. $49^{\circ} 11^{\prime}$ N. ; long. $179^{\circ} 40^{\prime} \mathrm{W}$.

13. $11^{\mathrm{b}} 21^{\mathrm{m}} 47^{\circ}$ P.M.

14. Altair, S. $0^{\mathrm{h}} 22^{\mathrm{m}} 52^{\circ}$ W. ; $\gamma$ Cygni, S. $0^{\mathrm{h}} 9^{\mathrm{m}} 47^{\circ}$ E. ; Deneb, S. $0^{\mathrm{h}} 29^{\prime} 10^{\prime \prime} \mathrm{E}$.

15. Alt. $73^{\circ} 3^{\prime} 20^{\prime \prime}$.

16. E.H.A. $4^{\mathrm{b}} 23^{\mathrm{m}} 19^{\mathrm{a}}$; cor. $-19-1+13$; true azi. N. $80^{\circ} 5^{\prime}$ E. ; dev. $9^{\circ} 33^{\prime} \mathrm{W}$.

17. M.T.G. $2^{\mathrm{d}} 15^{\mathrm{h}} 49^{\mathrm{m}} 27^{\mathrm{s}}$; W.H.A. $4^{\mathrm{h}} 44^{\mathrm{m}} 10^{\mathrm{s}} \cdot 5$; R.A.M.S. $8^{\mathrm{h}} 43^{\mathrm{m}} 17^{\mathrm{a}}$; long. $97^{\circ} 5^{\prime} 15^{\prime \prime} \mathrm{W}$.

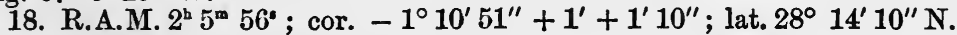

19. M.T.G. $14^{\text {d }} 10^{\text {h }} 52^{\text {m }} 6$; S.D. $15^{\prime} 2^{\prime}$; H.P. $54^{\prime} 26^{\prime \prime}$; dec. $19^{\circ} 12^{\prime} 35^{\prime \prime}$ N. ; T. A. $47^{\circ} 7^{\prime} 32^{\prime \prime}$; lat. $23^{\circ} 39^{\prime} 55^{\prime \prime} \mathrm{S}$.

20. Lat. $56^{\circ} 46^{\prime} 23^{\prime \prime} \mathrm{S}$.

21. Mag. bearing, N. $6^{\circ}$ W. ; comp. course, S. $27 \frac{10}{2}$ E., N. $10^{\circ}$ E., N. $84^{\circ}$ W., S. $75^{\circ}$ W. ; mag. course, N. $74^{\circ}$ E., S. $61^{\circ}$ E., S., N. $60^{\circ}$ W.; mag. bearings, S. $30^{\circ}$ W., and S. $54^{\circ} \mathrm{E}$.

22. Red, $-5 \mathrm{ft} .1$ in.

23. Jupiter's elements : R.A. $6^{\mathrm{b}} 9^{\mathrm{m}} 44^{\mathrm{s}} \cdot 5$; dec. $23^{\circ} 7^{\prime} 26^{\prime \prime}$ N. ; R.A.M.S. $9^{\text {h }} 15^{\mathrm{m}} 6^{\prime \prime} \cdot 2$; E.H.A. $4^{\text {h }} 50^{\mathrm{m}} 39^{\circ} \cdot 5$; T.A. $27^{\circ} 34^{\prime} 42^{\prime \prime}$; A.A. $27^{\circ} 36^{\prime} 29^{\prime \prime}$.

Moon's elements : R.A. $2^{\text {h }} 28^{m} 56^{\circ} \cdot 1$; dec. $9^{\circ} 8^{\prime} 57^{\prime \prime}$ N.; S.D. $15^{\prime} 6^{\prime \prime}$; H.P. $54^{\prime} 30^{\prime \prime}$; A.A. $54^{\circ} 41^{\prime} 48^{\prime \prime}$; T.A. $55^{\circ} 12^{\prime} 37^{\prime \prime}$; E.H.A. $1^{\mathrm{b}} 9^{\mathrm{m}} 51^{\circ}$; app. dist. $54^{\circ} 28^{\prime} 13^{\prime \prime} ; \mathrm{B}=36^{\circ} 27^{\prime} 21^{\prime \prime} ; \mathrm{Z}=66^{\circ} 39^{\prime} 32^{\prime \prime}$; true dist. $54^{\circ} 30^{\prime} 24^{\prime \prime}$; error, $2^{\mathrm{m}} 36^{\circ} \cdot 5$ slow ; long. $22^{\circ} 9^{\prime} 15^{\prime \prime} \mathrm{W}$.

24. $€$ Orionis : E.H.A.'s $1^{\mathrm{h}} 12^{\mathrm{m}} 41^{\prime}$, and $1^{\mathrm{h}} 3^{\mathrm{m}} 26^{\prime}$; long. (a), $81^{\circ} 58^{\prime} 30^{\prime \prime}$ E., (b), $84^{\circ} 17^{\prime} 30^{\prime \prime} \mathrm{E}$.

Alphard: E.H.A.'s $4^{\mathrm{h}} 54^{\mathrm{m}} 50^{\mathrm{s}}$, and $4^{\mathrm{h}} 54^{\mathrm{m}} 23^{\mathrm{s}}$; long. (c), $84^{\circ} 19^{\prime} 30^{\prime \prime}$ E.,

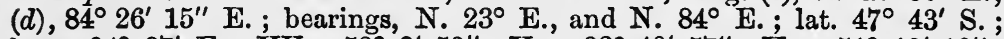
long. $84^{\circ} 27^{\prime} \mathrm{E}$.; $\mathrm{XY}=58^{\circ} 2^{\prime} 52^{\prime \prime} ; \mathrm{X}_{1}=93^{\circ} 40^{\prime} 57^{\prime \prime} ; \mathrm{X}_{2}=51^{\circ} 12^{\prime} 10^{\prime \prime}$; bearings N. $21^{\circ} 13^{\prime}$ E., and N. $83^{\circ} 22^{\prime}$ E.; lat. $47^{\circ} 42^{\prime} 48^{\prime \prime}$ S. ; long. $84^{\circ} 26^{\prime} 30^{\prime \prime} \mathrm{E}$.

25. Eq. time $-7^{\mathrm{m}} 13^{\mathrm{u}} .8$; P.D. $89^{\circ} 39^{\prime} 10^{\prime \prime} ;$ H.A. $2^{\mathrm{h}} 21^{\mathrm{m}} 54^{\circ}$; error, $1^{\text {m }} 55^{\mathrm{s}} \cdot 8$ slow.

26. First course, S. $66^{\circ} 261^{\prime}$ E. ; dist. 3708 miles ; vertex, $41^{\circ} 1^{\prime}$ S. ; long. $20^{\circ} 51^{\prime}$ W. Point, lat. $39^{\circ} 6 \frac{1}{2}^{4} \mathrm{~N}$. ; long. $0^{\circ}$.

27. $\mathrm{BP}=241 \cdot 1 \mathrm{ft}$.; $\mathrm{BAQ}=29^{\circ} 5^{\prime} 30^{\prime \prime}$.

28. $\mathrm{XZ}=1684 \mathrm{ft}$.

29. Dist. 4032 miles ; lat. $43^{\circ} 31^{\prime} 30^{\prime \prime} \mathrm{N}$.

30. $151 \cdot 3 \mathrm{ft}$. 
31. W.H.A. $7^{\text {h }} 26^{\mathrm{m}} 40^{\circ} .5$; true azi. $44^{\circ} 56^{\prime}-13^{\circ} 38^{\prime}=$ S. $31^{\circ} 18^{\prime}$ W. ; dev. $11^{\circ} 3^{\prime} \mathrm{E}$.

32. N. $56^{\circ} 22^{\prime}$ E. ; $\mathrm{C}=-19^{\circ} 53^{\prime}$.

33. $\mathbf{A}=-1^{0.75 ;} \mathbf{B}=-5^{\circ .5} ; \quad \mathbf{C}=-15^{\circ} ; \quad \mathrm{D}=0 ; \quad \mathbf{E}=+6^{0.75}$; Deviations, East, - $14^{\circ} ;-10^{\circ} 29^{\prime} ;-5^{\circ} 54^{\prime} ;-0^{\circ} 36^{\prime} ;+4^{\circ} 56^{\prime} ;+10^{\circ} 16^{\prime}$; $+14^{\circ} 49^{\prime} ;+18^{\circ} 10^{\prime} ;$ South, $+20^{\circ} ;+20^{\circ} 16^{\prime} ;+19^{\circ} 2^{\prime} ;+16^{\circ} 23^{\prime}$; $+12^{\circ} 44^{\prime} ;+8^{\circ} 35^{\prime} ;+4^{\circ} 16^{\prime} ;+0^{\circ} 18^{\prime} ;$ West, $-3^{\circ}$.

34. 0 .

\section{Paper V.}

1. $62 \cdot 7577 \log =1 \cdot 797667$.

2. $0 \cdot 0075 \log =7 \cdot 875091$.

3. S. $48^{\circ}$ E., $20^{\prime}$; E. $40^{\prime}$; S. $82^{\circ}$ E., $42^{\prime}$; N. $64^{\circ}$ E., $44^{\prime}$; N. $88^{\circ}$ E., $46^{\prime}$; S. $80^{\circ}$ E., $48^{\prime}$; E. $46^{\prime}$; N. $83^{\circ}$ E., $54^{\prime}$; D. lat. 0, dep. 328.9 E. ; course E., dist. 329 miles ; lat. $62^{\circ} 30^{\prime} \mathrm{N}$. ; long. $169^{\circ} 13^{\prime} \cdot 7 \mathrm{~W}$.

4. Dec. $16^{\circ} 52^{\prime} 44^{\prime \prime}$ N. ; T.A. $77^{\circ} 49^{\prime} 43^{\prime \prime}$; lat. $4^{\circ} 42^{\prime} 27^{\prime \prime}$ N.

5. $557 \cdot 4$ miles.

6. True course, S. $71^{\circ} 18^{\prime}$ W. ; compass course, N. $89^{\circ} 12^{\prime}$ W. ; dist. 3793 miles.

7. No. A.M. ; $0^{\mathrm{h}} 4^{\mathrm{m}}$ P.M.

8. Dec. $14^{\circ} 19^{\prime} 10^{\prime \prime}$ N.; true amp. W. $20^{\circ} 17^{\prime}$ N. ; error, $21^{\circ} 47^{\prime}$ E. ; dev. $24^{\circ} \boldsymbol{7}^{\prime} \mathbf{E}$.

9. M.T.G. $29^{\mathrm{d}} 16^{\mathrm{h}} 32^{\mathrm{m}} 46^{\mathrm{s}}$; P.D. $92^{\circ} 25^{\prime} 31^{\prime \prime}$; eq. time, $-9^{\mathrm{m}} 39^{\mathrm{s}}$; st. lat. $46^{\circ} 50^{\prime}$; W.H.A. $4^{\mathrm{h}} 42^{\mathrm{m}} 25^{\mathrm{s}}$; sight long. $180^{\circ}$ W. ; noon $179^{\circ} 13^{\prime} 40^{\prime \prime}$ W.; true azi. S. $73^{\circ} 57^{\prime} 42^{\prime \prime} \mathrm{W}$. ; dev. $32^{\circ} 6^{\prime} \mathrm{W}$.

10. Cor. $+36-19+28$; true azi. N. $125^{\circ} 17^{\prime}$ E. ; dev. $0^{\circ} 47^{\prime} \mathrm{E}$.

11. W.H.A. $24^{\mathrm{m}} 19^{\circ}$; nat. no. 4724 . Arc I. $13^{\circ} 13^{\prime} 14^{\prime \prime}$; Arc. II. $43^{\circ} 38^{\prime} 22^{\prime \prime}$; sight lat. $30^{\circ} 25^{\prime} 5^{\prime \prime} \mathrm{S}$. ; noon $30^{\circ} 22^{\prime} 23^{\prime \prime} \mathrm{S}$.

12. First P.D. $92^{\circ} 21^{\prime} 23^{\prime \prime}$; eq. time, $-9^{\mathrm{m}} 36^{\circ}$; H.A.'s $0^{\mathrm{h}} 20^{\mathrm{m}} 48^{\circ}$ and $0^{\mathrm{h}} 41^{\mathrm{m}} 53^{\mathrm{e}}$; long. (a), $177^{\circ} 38^{\prime} 15^{\prime \prime}$ E.; $(b), 177^{\circ} 5^{\prime} 30^{\prime \prime}$ W. ; second P.D. $92^{\circ} 25^{\prime} 28^{\prime \prime}$; eq. time, $-9^{\mathrm{m}} 39^{\mathrm{s}}$; W.H.A.'s $4^{\mathrm{h}} 42^{\mathrm{m}} 43^{\mathrm{s}}$ and $4^{\mathrm{b}} 43^{\mathrm{m}} 48^{\mathrm{a}}$; long. (c), $179^{\circ} 55^{\prime} 30^{\prime \prime}$ W. ; (d), $179^{\circ} 39^{\prime} 15^{\prime \prime} \mathrm{W}$.

First line: $\left\{\begin{array}{l}\text { N. } 80^{\circ} \text { W. } \\ \text { S. } 80^{\circ} \text { E. }\end{array}\right\}$; second azi. S. $74^{\circ} \mathrm{W}$; lat. $46^{\circ} 45 \frac{1}{2}^{\prime}$ N. ; long. $179^{\circ} 58^{\prime} \mathrm{W}$.

13. A.T.S. $11^{\mathrm{h}} 8^{\mathrm{m}} 31^{\mathrm{s}}$ P.M. ; inspection, $11^{\mathrm{b}} 1^{\mathrm{m}}$ P.M.

14. $\alpha$ Gruis S. $57^{\mathrm{m}} 20^{\mathrm{*}}$ W. ; Fomalhaut, S. $7^{\mathrm{m}} 10^{\mathrm{s}} \mathrm{W}$.

15. Alt. $40^{\circ} 15^{\prime} 10^{\prime \prime}$.

16. M.T.G. $2^{d} 13^{\text {h }} 25^{\mathrm{m}} 40^{\text {a }}$; W.H.A. $1^{\mathrm{h}} 34^{\mathrm{m}} 35^{\mathrm{s}}$; R.A.M.S. $8^{\mathrm{h}} 42^{\mathrm{m}} 53^{\text {s }}$; long. $62^{\circ} 35^{\prime} \mathrm{W}$.

17. W.H.A. $2^{\text {h }} 58^{\mathrm{m}} 48^{\mathrm{s}}$; cor. $-35+24+5$; true azi. S. $133^{\circ} 43^{\prime}$ W. ; dev. $22^{\circ} 51^{\prime} \mathrm{W}$.

18. Cor. $-40^{\prime} 35^{\prime \prime},+37^{\prime \prime}$, $+50^{\prime \prime}$; lat. $50^{\circ} 16^{\prime} 33^{\prime \prime} \mathrm{N}$.

19. M.T.G. $9^{\mathrm{d}} 18^{\mathrm{h}} 31^{\mathrm{m}} \cdot 5$; dec. $5^{\circ} 23^{\prime} 11^{\prime \prime}$ N. ; S.D. $15^{\prime} 11^{\prime \prime}$; H.P. $54^{\prime} 51^{\prime \prime}$; T.A. $48^{\circ} 25^{\prime} 19^{\prime \prime}$; lat. $46^{\circ} 57^{\prime} 52^{\prime \prime}$.

20. Lat. $51^{\circ} 28^{\prime} 29^{\prime \prime} \mathrm{S}$.

21. Mag. bearing, N. $56^{\circ}$ E. ; compass course, N. $68^{\circ}$ E., S. $67^{\circ}$ E., S. $79^{\circ}$ W., N. $19^{\circ}$ W. ; mag. course, S. $68^{\circ}$ W., S. $18^{\circ}$ E., N. $40^{\circ}$ E., N. $53^{\circ}$ W. ; mag. bearings, S. $21^{\circ}$ W., and S. $49^{\circ}$ E.

22 . $-8 \mathrm{ft} .5$ ins.

23. Sun's elements: R.A. $9^{\mathrm{h}} 43^{\mathrm{m}} 37^{\mathrm{s}} 8$; dec. $13^{\circ} 39^{\prime} 57^{\prime \prime}$ N. ; R.A.M.S. $9^{\text {b }} 39^{\mathrm{m}} 32^{\mathrm{s}} \cdot 5$; A.A. $30^{\circ} 38^{\prime} 31^{\prime \prime}$; T.A. $30^{\circ} 37^{\prime} 1^{\prime \prime}$; F.H.A. $4^{\text {h }} 7^{\mathrm{m}} 20^{\mathrm{s}}$.

Moon's elements: R.A. $7^{\text {h }} 35^{\mathrm{m}} 38^{\circ} \cdot 5$; dec. $19^{\circ} 51^{\prime} 24^{\prime \prime}$ N. ; S.D. $15^{\prime} 22^{\prime \prime}$; H.P. $55^{\prime} 27^{\prime \prime}$; E.H.A. $1^{\text {b }} 59^{\mathrm{m}} 21^{\mathrm{s}}$; T.A. $59^{\circ} 6^{\prime} 1^{\prime \prime}$; A.A. $58^{\circ} 37^{\prime} 44^{\prime \prime}$; app. dist. $30^{\circ} 47^{\prime} 7^{\prime \prime} ; \mathrm{B}=40^{\circ} 59^{\prime} 0^{\prime \prime} ; \mathrm{Z}=18^{\circ} 49^{\prime} 30^{\prime \prime}$; true dist. $31^{\circ} 12^{\prime} 20^{\prime \prime}$; error, $12^{\mathrm{m}} 15^{\circ}$ fast ; long. $35^{\circ} 40^{\prime} \mathrm{W}$.

24. H.E.T. $1^{\mathrm{h}} 11^{\mathrm{m}} 31^{\mathrm{s}} \cdot 5$; mid. dec. $6^{\circ} 11^{\prime} 49^{\prime \prime}$; cor. run $+7^{\prime} 25^{\prime \prime}$; first 
alt. $32^{\circ} 39^{\prime} 46^{\prime \prime}$; second alt. $47^{\circ} 26^{\prime} 36^{\prime \prime} ; \mathrm{XY}=35^{\circ} 32^{\prime} 54^{\prime \prime} ; \mathrm{X}_{1}=88^{\circ} 3^{\prime}$ $46^{\prime \prime} ; \mathrm{X}_{2}=52^{\circ} 34^{\prime} 2^{\prime \prime}$; lat. correction, $-1^{\prime} 47^{\prime \prime}$; lat. $47^{\circ} 42^{\prime} 53^{\prime \prime} \mathrm{N}$.

25. P.D. $97^{\circ} 32^{\prime} 29^{\prime \prime}$; eq. time, $-0^{\mathrm{m}} 42^{\mathrm{s}} \cdot 7$; W.H.A. $4^{\text {h }} 30^{\mathrm{m}} 26^{\mathrm{s}}$; error, $20^{\mathrm{m}} 54^{\mathrm{s}} \cdot 4$ slow.

26. First course, S. $57^{\circ} 17^{\prime} 30^{\prime \prime}$ E. ; final, N. $62^{\circ} 17^{\prime} 30^{\prime \prime}$ E. ; first long. $67^{\circ} 12^{\prime} \mathrm{E}$. ; second long. $104^{\circ} 21^{\prime} \mathrm{E}$. ; dist. $=2300+1549+1830=5679$ miles ; points : lat. $44^{\circ} 41^{\prime} \frac{1}{2}^{\prime} \mathrm{S}$., long. $50^{\circ} \mathrm{E}$., lat. $40^{\circ} 4 \frac{3}{4}^{\prime} \mathrm{S}$., $140^{\circ} \mathrm{E}$.

27. 1009.

28. N. $70^{\circ} 7^{\prime} 25^{\prime \prime} \mathrm{W}$. ; drift $67 \cdot 55$ miles.

29. Side $33^{\circ} 38^{\prime} 50^{\prime \prime}$; angle $100^{\circ} 30^{\prime} 56^{\prime \prime}$.

30. N. $70^{\circ}$ E. ; $B=+5^{\circ} \cdot 86$.

31. $\mathrm{A}=-\cdot 25^{\circ} ; \mathrm{B}=+11^{\circ} \cdot 5 ; \mathrm{C}=0 ; \mathrm{D}=+\cdot 5^{\circ} ; \mathrm{E}=+25^{\circ} ;$ Deviations, North, $0+2^{\circ} 25^{\prime} ;+4^{\circ} 41^{\prime} ;+6^{\circ} 42^{\prime} ;+8^{\circ} 23^{\prime} ;+9^{\circ} 40^{\prime} ;+10^{\circ} 33^{\prime} ;$ $+10^{\circ} 59^{\prime}$; East, $+11^{\circ}$; South, 0 ; $-2^{\circ} 4^{\prime} ;-4^{\circ} 7^{\prime} ;-6^{\circ} 5^{\prime} ;-7^{\circ} 53^{\prime}$; $-9^{\circ} 27^{\prime} ;-10^{\circ} 43^{\prime} ;-11^{\circ} 34^{\prime} ;$ West, $-12^{\circ}$.

32. $-3^{\circ} 45^{\prime}$.

\section{PAPER VI.}

1. $\cdot 4839 \log =9 \cdot 684706$.

2. $\cdot 08604 \log =8 \cdot 934729$.

3. N. $62^{\circ}$ W., $17^{\prime}$; S. $84^{\circ}$ E., $72^{\prime}$; S. $75^{\circ}$ E., $43^{\prime}$; S. $68^{\circ}$ E., $56^{\prime}$; S. $54^{\circ}$ E., $57^{\prime}$; S. $47^{\circ}$ E., $56^{\prime}$; E. $56^{\prime}$; N. $22^{\circ}$ E., $60^{\prime}$; D. lat. $47 \cdot 7$; dep. 315.6 ; course, S. $81 \frac{1}{2}^{\circ} \mathrm{E}$. ; dist. 318 miles ; lat. $38^{\circ} 33^{\prime} \mathrm{S}$. ; long. $174^{\circ} 47^{\prime} \mathrm{W}$.

4. Dec. $0^{\circ} 10^{\prime} 30^{\prime \prime}$ N. ; T.A. $47^{\circ} 17^{\prime} 56^{\prime \prime}$; lat. $42^{\circ} 31^{\prime} 34^{\prime \prime} \mathrm{S}$.

5. $32^{\circ} 23^{\prime}$.

6. True course, N. $53^{\circ} 48^{\prime}$ E. ; compass course, S. $75^{\circ} 22^{\prime}$ E. ; dist. 4561 miles.

7. $1^{\text {h }} 8^{\mathrm{m}}$ A.M. ; $1^{\mathrm{h}} 54^{\mathrm{m}}$ P.M.

8. Dec. $2^{\circ} 3^{\prime} 32^{\prime \prime}$ N.; true amp. E. $2^{\circ} 31 \frac{1}{2}$ N.; dev. $5^{\circ} 38^{\prime} 37^{\prime \prime}$ E.

9. M.T.G. $7^{\mathrm{d}} 6^{\mathrm{h}} 47^{\mathrm{m}} 7^{\mathrm{s}}$; P.D. $83^{\circ} 47^{\prime} 4^{\prime \prime}$; st. lat. $48^{\circ} 10^{\prime}$; eq. time, $-1^{\mathrm{m}} \tilde{5} 4^{\mathrm{s}}$; T.A. $32^{\circ} 7^{\prime} 56^{\prime \prime}$; E.H.A. $3^{\mathrm{b}} 8^{\mathrm{m}} 28^{\mathrm{s}}$; st. long, $149^{\circ} 22^{\prime} 15^{\prime \prime}$ W.; noon, $148^{\circ} 33^{\prime} 45^{\prime \prime} \mathrm{W}$. ; true azi. S. $59^{\circ} 20^{\prime} 20^{\prime \prime} \mathrm{E}$. ; dev. $13^{\circ} 54^{\prime} 40^{\prime \prime} \mathrm{E}$.

10. W.H.A. $2^{\text {h }} 18^{\mathrm{m}} 39^{\mathrm{s}}$; cor. $-41+21+20$; true azi. S. $133^{\circ} 36^{\prime}$ W. ; dev. $14^{\circ} 24^{\prime} \mathrm{W}$.

11. W.H.A. $23^{m} 41^{\prime}$; nat. no. 3884 . Arc I. $16^{\circ} 24^{\prime} 13^{\prime \prime}$; Arc II. $57^{\circ} 2^{\prime} 9^{\prime \prime}$; lat. $40^{\circ} 37^{\prime} 56^{\prime \prime} \mathrm{S}$.

12. First P.D. $89^{\circ} 41^{\prime} 9^{\prime \prime}$; eq. time, $-7^{\mathrm{m}} 16^{\mathrm{s}}$; T.A. $32^{\circ} 20^{\prime} 25^{\prime \prime}$; H.A.'s $2^{\mathrm{h}} 34^{\mathrm{m}} 37^{\mathrm{s}}$ and $2^{\mathrm{h}} 30^{\mathrm{m}} 56^{\mathrm{s}}$; long. $(a), 81^{\circ} 22^{\prime} \mathrm{E}$. ; $(b), 82^{\circ} 17^{\prime} 15^{\prime \prime}$ E. ; second P.D. $89^{\circ} 46^{\prime} 1^{\prime \prime}$; eq. time, $-7^{\mathrm{m}} 20^{\mathrm{s}}$; T.A. $32^{\circ} 20^{\prime} 25^{\prime \prime}$; H.A.'s $2^{\mathrm{h}} 34^{\mathrm{m}} 3^{\mathrm{s}}$ and $2^{\mathrm{h}} 30^{\mathrm{m}} 21^{\mathrm{s}}$; long. (c), $83^{\circ} 29^{\prime} 15^{\prime \prime}$ E. ; $(d), 82^{\circ} 33^{\prime} 45^{\prime \prime}$ E.

First line: $\left\{\begin{array}{l}\text { N. } 43^{\circ} \mathrm{E} . \\ \text { S. } 43^{\circ} \mathrm{W} .\end{array}\right\}$; first azi. S. $47^{\circ} \mathrm{E} ;$ lat. $47^{\circ} 51^{\prime} \mathrm{N}$. ; long. $82^{\circ} 32^{\prime} \mathrm{E}$.

13. M.T.S. $1^{\text {h }} 45^{\mathrm{m}} 15^{\mathrm{s}}$ P.M.

14. Achernar, S. $1^{\text {h }} 6^{\mathrm{m}}, 7^{\circ}$ W. ; a Persei, N. $37^{\mathrm{m}} 16^{\mathrm{s}}$ E. ; Aldebaran, N. $1^{\mathrm{h}} 50^{\mathrm{m}} 12^{\mathrm{s}} \mathrm{E}$.

15. Alt. $25^{\circ} 54^{\prime} 40^{\prime \prime}$.

16. W.H.A. $4^{\mathrm{h}} 0^{\mathrm{m}} 20^{\mathrm{s}}$; cor. $-5-33+25$; true azi. N. $102^{\circ} 36^{\prime}$ W. ; dev. $10^{\circ} 54^{\prime} \mathrm{E}$.

17. M.T.G. $5^{\mathrm{a}} 12^{\mathrm{h}} 51^{\mathrm{m}} 4^{\mathrm{s}}$; E.H.A. $2^{\mathrm{h}} 13^{\mathrm{m}} 13^{\mathrm{s}}$; R.A.M.S. $8^{\mathrm{h}} 54^{\mathrm{m}} 37^{\mathrm{s}}$; long. $50^{\circ} 10^{\prime} \mathrm{W}$.

18. Cor. $-2^{\prime} 12^{\prime \prime},+35^{\prime \prime},+1^{\prime} 25^{\prime \prime}$; lat. $38^{\circ} 23^{\prime} 24^{\prime \prime} \mathrm{N}$.

19. M.T.G. $6^{\text {d }} 17^{\text {h }} 35^{\mathrm{m}} \cdot 6$; S.D. $15^{\prime} 42^{\prime \prime}$; H.P. $56^{\prime} 50^{\prime \prime}$; dec. $7^{\circ} 41^{\prime} 9^{\prime \prime}$ S.; cor. + $46^{\prime} 30^{\prime \prime}$; T.A. $33^{\circ} 8^{\prime} 9^{\prime \prime}$; lat. $64^{\circ} 33^{\prime} 0^{\prime \prime} \mathrm{S}$.

20. Lat. $34^{\circ} 19^{\prime} 53^{\prime \prime} \mathrm{N}$.

21. Mag. bearings, South ; comp. course, N. $3^{\circ}$ W., N. $80^{\circ}$ W., S. $66^{\circ}$ E., 
N. $31^{\circ}$ E. ; mag. course, S. $55^{\circ}$ E., S. $30^{\circ}$ W., S. $77^{\circ}$ W., N. $19^{\circ}$ W. ; mag. bearings, N. $30^{\circ}$ W., S. $72^{\circ} \mathrm{W}$.

22. Red, -2 ft. 9 ins.

23. Star's elements: R.A. $16^{\text {h }} 23^{\mathrm{m}} 38^{\circ} 5$; dec. $26^{\circ} 13^{\prime} 26^{\prime \prime}$ S. ; R.A.M.S. $10^{\mathrm{h}} 31^{\mathrm{m}} 23^{\mathrm{s}} \cdot 5$; A.A. $49^{\circ} 25^{\prime} 23^{\prime \prime}$; T.A. $49^{\circ} 24^{\prime} 34^{\prime \prime}$; W.H.A. $2^{\mathrm{h}} 38^{\mathrm{m}} 10^{\mathrm{s}}$.

Moon's elements : R.A. $19^{\mathrm{h}} 38^{\mathrm{m}} 16^{\mathrm{s}} 3$; dec. $19^{\circ} 49^{\prime} 51^{\prime \prime}$ S. ; S.D. $16^{\prime} 20^{\prime \prime}$; H.P. $58^{\prime} 50^{\prime \prime}$; A.A. $76^{\circ} 46^{\prime} 33^{\prime \prime}$; T.A. $76^{\circ} 59^{\prime} 48^{\prime \prime}$; E.H.A. $36^{m} 28^{\circ}$; app. dist. $45^{\circ} 3^{\prime} 37^{\prime \prime} ; \mathrm{B}=13^{\circ} 48^{\prime} 1^{\prime \prime} ; \mathrm{Z}=102^{\circ} 49^{\prime} 30^{\prime \prime}$; true dist. $44^{\circ} 58^{\prime} 32^{\prime \prime}$; error, $11^{\mathrm{m}} 38^{\circ}$ slow ; long. $98^{\circ} 26^{\prime} 45^{\prime \prime} \mathrm{E}$.

24. H.E.T. $2^{\mathrm{h}} 10^{\mathrm{m}} 21^{\circ} \cdot 5$; run cor. $-25^{\prime} 12^{\prime \prime}$; first T.A. $43^{\circ} 45^{\prime} 14^{\prime \prime}$; second $23^{\circ} 28^{\prime} 34^{\prime \prime} ; \mathrm{XY}=28^{\circ} 43^{\prime} 33^{\prime \prime} ; \mathrm{X}_{1}=60^{\circ} 25^{\prime} 42^{\prime \prime} ; \mathrm{X}_{2}=126^{\circ} 49^{\prime} 36^{\prime \prime}$; lat. $48^{\circ} 20^{\prime} \mathrm{S}$.

25. Ship $18^{\circ} 32^{\prime}$ S. ; $70^{\circ} 35^{\prime} \cdot 5$ W. ; W.H.A. $3^{\mathrm{b}} 22^{\mathrm{m}} 54^{\mathrm{s}}$; error, $37^{\mathrm{m}} 40^{\circ}$ slow.

26. First course, S. $50^{\circ} 41_{2}^{\prime \prime}$ W. ; final, N. $58^{\circ} 46 \frac{1}{2}^{\prime}$ W. ; longs. $128^{\circ} 32 \frac{1}{2}$ W., $142^{\circ} 32^{\prime} \mathrm{W}$. ; dist. $5050 \cdot 1$ miles ; lat. $49^{\circ} 41^{\prime} \mathrm{S}$. ; long. $120^{\circ} \mathrm{W}$. ; lat. $43^{\circ} 24 \frac{1}{2} \mathrm{~S}$.; long. $180^{\circ} \mathrm{W}$.

27. $\mathrm{B}=50^{\circ} 140^{\prime} 12^{\prime \prime} ; \mathrm{A}=39^{\circ} 19^{\prime} 48^{\prime \prime} ; \mathrm{BD}=14383 \mathrm{ft}$.

28. $115 \cdot 6 \mathrm{ft}$.

29. Course, S. $78^{\circ} 30^{\prime}$ E. ; dist. 92 miles.

30. $\mathrm{A}=+1^{\circ} \cdot 25 ; \mathrm{B}=+18^{\circ} ; \mathrm{C}=-7^{\circ} \cdot 5 ; \mathrm{D}=+\cdot 75^{\circ} ; \mathrm{E} .=+1^{\circ} .25$; Deviations, $+2^{\circ} 37^{\prime} ;+6^{\circ} 11^{\prime} ;+9^{\circ} 26^{\prime} ;+12^{\circ} 16^{\prime} ;+14^{\circ} 40^{\prime} ;+16^{\circ} 34^{\prime}$; East, $+18^{\circ} ;+18^{\circ} 55^{\prime} ;+19^{\circ} 20^{\prime} ;+19^{\circ} 13^{\prime} ;+18^{\circ} 32^{\prime}$.

31. Lat. $42^{\circ} 5^{\prime} ;$ H.A. $7^{\mathrm{h}} 10^{\mathrm{m}} 21^{\circ} \cdot 5$.

32. Lat. $60^{\circ} 22^{\prime}$ S. ; long. $30^{\circ} 26^{\prime}$ W. ; course S. $3^{\circ}$ E. ; dist. 43 miles.

33. $-25^{\circ} 30^{\prime}$.

\section{Paper VII.}

1. $696090 \cdot 3 \log =5 \cdot 842665$.

2. $19534 \cdot 82 \mathrm{log}=4 \cdot 290809$.

3. N. $12^{\circ}$ W., $20^{\prime}$; N. $15^{\circ}$ E. $22^{\prime}$; S. $71^{\circ}$ W., $24^{\prime}$; N. $7^{\circ}$ E., $214^{\prime}$; D. lat. $245^{\prime} \cdot 5$; dep. 4.9 ; D.R. lat. $46^{\circ} 4^{\prime}{ }^{\prime} 5$ S. ; long. $110^{\circ} 7^{\prime} 40^{\prime \prime}$ W.; set S. $70^{\circ}$ W.; drift $16 \frac{1}{2}$ miles.

4. Dec. $2^{\circ} 24^{\prime} 32^{\prime \prime}$ S. ; T.A. $88^{\circ} 36^{\prime} 7^{\prime \prime}$. Lat. $1^{\circ} 0^{\prime} 39^{\prime \prime}$ S,

5. $51^{\circ} 23^{\prime}$ N. ; $16^{\circ} 16^{\prime} 30^{\prime \prime} \mathrm{W}$.

6. Compass course, N. $16^{\circ} 22^{\prime}$ W.; dist. 5489 miles.

7. Midnt.; $0^{\text {h }} 23$ P.M.

8. True amp., E. $16^{\circ} 55^{\prime} \mathrm{N}$. ; dev. $2^{\circ} 21^{\prime} \mathrm{E}$.

9. M.T.G. $23^{\mathrm{a}} 16^{\mathrm{h}} 14^{\mathrm{m}} 51^{\mathrm{s}}$; P.D. $89^{\circ} 55^{\prime} 8^{\prime \prime}$; H.A. $2^{\mathrm{h}} 57^{\mathrm{m}} 0^{\mathrm{s}}$; long. $158^{\circ} 38^{\prime}$ E. ; true azi. N. $67^{\circ} 51^{\prime} 28^{\prime \prime}$ W. ; dev. $6^{\circ} 51^{\prime} 28^{\prime \prime}$ W.

10. A.T S. $8^{\mathrm{b}} 33^{\mathrm{m}} 13^{\mathrm{s}}$ A.M. ; cor. $+21+14+5$; true azi. S. $126^{\circ} 15^{\prime}$ E. ; dev. $12^{\circ} 59^{\prime} \mathrm{E}$.

11. E.H.A. $27^{\mathrm{m}} 24^{\mathrm{s}}$; nat. no. 5109. Arc. I. $2^{\circ} 12^{\prime} 50^{\prime \prime}$; Arc. II. $46^{\circ} 29^{\prime} 45^{\prime \prime}$. Lat. st. $44^{\circ} 16^{\prime} 55^{\prime \prime} \mathrm{N}$.; noon, $44^{\circ} 20^{\prime} 13^{\prime \prime} \mathrm{N}$.

12. First P.D. $107^{\circ} 28^{\prime} 11^{\prime \prime}$; T.A. $8^{\circ} 40^{\prime} 49^{\prime \prime}$; eq. time, $+5^{\mathrm{m}} 59^{\prime \prime}$; H.A.'s $3^{\mathrm{h}} 41^{\mathrm{m}} 54^{\mathrm{s}}$ and $3^{\mathrm{h}} 39^{\mathrm{m}} 39^{\mathrm{s}}$; long. $(a), 0^{\circ} 49^{\prime}$ E. ; $(b), 1^{\circ} 22^{\prime} 15^{\prime \prime}$ E. ; second P.D. $107^{\circ} 24^{\prime} 12^{\prime \prime}$; T.A. $18^{\circ} 19^{\prime} 28^{\prime \prime}$; eq. time, +5 $57^{\circ}$; H.A.'s $2^{\mathrm{b}} 21^{\mathrm{m}} 22^{\mathrm{s}}$ and $2^{\mathrm{h}} 17^{\mathrm{m}} 9^{\mathrm{s}}$; long. $(c), 1^{\circ} 9^{\prime} 30^{\prime \prime}$ E. ; $(d), 0^{\circ} 6^{\prime}$ E.

Second line: $\left\{\begin{array}{l}\text { S. } \\ \text { N. } 55^{\circ} \text { W. } \\ 55^{\circ}\end{array}\right\}$; second azi. N. $35^{\circ}$ W. ; lat. $47^{\circ} 25^{\prime}$ S. : long. $0^{\circ} 3^{\prime} \mathrm{W}$.

13. A.T.S. $9^{\mathrm{h}} 23^{\mathrm{m}} 19^{\mathrm{e}}$ A.M.

14. Alt. $31^{\circ} 17^{\prime} 20^{\prime \prime}$.

15. Aldebaran, S. $47^{\mathrm{m}} 36^{\mathrm{s}}$ E. ; Capella, N. $1^{\text {t }} 26^{\mathrm{m}} 49^{\mathrm{s}}$ E. ; Rigel, S. $1^{\text {th }} 27^{\mathrm{m}} 5^{\mathrm{s}}$ E. ; Bellatrix, S. $1^{\mathrm{h}} 37^{\mathrm{m}} 9^{\circ}$ E. ; $\beta$ Tauri, S. $1^{\text {h }} 37^{\mathrm{m}} 25^{\mathrm{s}}$ E. ; $\epsilon$ Orionis, S. $1^{\text {h }} 48^{\mathrm{m}} 31^{\mathrm{s}} \mathrm{E}$.

16. W.H.A. $3^{\text {h }} 19^{\mathrm{m}} 40^{\mathrm{a}}$; cor. $-49+18+4$ : true azi. S. $130^{\circ} 32^{\prime}$ W. ; dev. $18^{\circ} 39^{\prime}$ W. 
17. M.T.G. $30^{\mathrm{d}} 1^{\mathrm{h}} 56^{\mathrm{m}} 56^{\mathrm{s}}$; W.H.A. $2^{\mathrm{h}} 38^{\mathrm{m}} 10^{\mathrm{s}}$; R.A.M.S. $10^{\mathrm{h}} 31^{\mathrm{m}} 24^{\mathrm{s}}$; long. $98^{\circ} 22^{\prime} 15^{\prime \prime} \mathrm{E}$.

18. Cor. $-1^{\circ} 4^{\prime} 5^{\prime \prime},+2^{\prime \prime},+1^{\prime} 25^{\prime \prime}$. ; lat. $20^{\circ} 14^{\prime} 2^{\prime \prime} \mathrm{N}$.

19. M.T.G. $30^{\mathrm{d}} 8^{\mathrm{h}} 21^{\mathrm{m} .9}$; S.D. $16^{\prime} 11^{\prime \prime}$; H.P. $58^{\prime} 41^{\prime \prime}$; dec. $19^{\circ} 29^{\prime} 21^{\prime \prime}$ S. ; T.A. $30^{\circ} 15^{\prime} 24^{\prime \prime}$; lat. $40^{\circ} 15^{\prime} 15^{\prime \prime} \mathrm{N}$.

20. Lat. $72^{\circ} 1^{\prime} 56^{\prime \prime} \mathrm{N}$.

21. Mag. bearing, N. $73^{\circ} 30^{\prime} \mathrm{W}$. ; comp. course, N. $2^{\circ}$ W., S. $74^{\circ}$ E., S. $82^{\circ}$ W., N. $55^{\circ}$ E. ; mag. course, S. $67^{\circ}$ E., S. $20^{\circ}$ W., S. $86^{1 \circ}$ W., N. $74^{\circ} \mathrm{W}$.; mag. bearings, S. $25 \frac{1}{2}^{\circ} \mathrm{W}$., and N. $61^{\circ} 30^{\prime} \mathrm{W}$.

22. $-9 \mathrm{ft} .5 \mathrm{ins}$.

23. Planet's elements : R.A. $23^{\text {h }} 2^{\text {m }} 1^{\text {s }}$; dec. $8^{\circ} 24^{\prime} 48^{\prime \prime}$ S. ; R.A.M.S. $9^{\text {h }} 17^{\mathrm{m}} 5^{\mathrm{s}} \cdot 6$; A.A. $40^{\circ} 57^{\prime} 58^{\prime \prime}$; T.A. $40^{\circ} 56^{\prime} 54^{\prime \prime}$; W.H.A. $3^{\mathrm{h}} 13^{\mathrm{m}} 54^{\mathrm{s}}$.

Moon's elements: R.A. $2^{\mathrm{h}} 52^{\mathrm{m}} 18^{\mathrm{s}} \cdot 1$; dec. $10^{\circ} 59^{\prime} 8^{\prime \prime}$ N.; S.D. $15^{\prime} 3^{\prime \prime}$; H.P. $54^{\prime} 23^{\prime \prime}$; E.H.A. $36^{m} 23^{\circ}$; T.A. $52^{\circ} 37^{\prime} 46^{\prime \prime}$; A.A. $52^{\circ} 5^{\prime} 6^{\prime \prime}$; app. dist. $60^{\circ} 43^{\prime} 53^{\prime \prime} ; \mathrm{B}=27^{\circ} 38^{\prime} 28^{\prime \prime} ; \mathrm{Z}=93^{\circ} 30^{\prime} 2^{\prime \prime}$; true dist. $60^{\circ} 28^{\prime} 13^{\prime \prime}$; error, $10^{\mathrm{m}} 34^{\circ} \cdot 5$; long. $169^{\circ} 38^{\prime} 30^{\prime \prime} \mathrm{E}$.

24. H.E.T. $2^{\mathrm{h}} 6^{\mathrm{m}} 5^{\mathrm{s}}$; mid. dec. $2^{\circ} 23^{\prime} 28^{\prime \prime}$ S. ; run cor., $-24^{\prime} 6^{\prime \prime}$; first alt. $40^{\circ} 21^{\prime} 10^{\prime \prime}$; second alt. $11^{\circ} 18^{\prime} 30^{\prime \prime} ; \mathrm{XY}=62^{\circ} 58^{\prime} 56^{\prime \prime} ; \mathrm{X}_{1}=91^{\circ} 31^{\prime} 18^{\prime \prime}$; $\mathrm{X}_{2}=98^{\circ} 18^{\prime} 12^{\prime \prime}$; lat. cor., + $2^{\prime} 28^{\prime \prime}$; lat. $46^{\circ} 50^{\prime} 30^{\prime \prime} \mathrm{N}$.

25. Ship lat. $5^{\circ} 36^{\prime}$ S. ; long. $35^{\circ} 0^{\prime} 32^{\prime \prime}$ W. ; E.H.A. $3^{\text {h }} 15^{\mathrm{m}} 41^{\text {s }}$; error, $20^{\mathrm{m}} 3^{\mathrm{s}}$ fast.

26. First course, S. $39^{\circ} 16 \frac{1}{2}^{\prime}$ W. ; final S. $38^{\circ} 40 \frac{1}{2}^{\prime}$ W. ; vertex lat. $59^{\circ} 11 \frac{1}{2}^{\prime}$, N. ; long. $58^{\circ} 43 \frac{1}{2}^{\prime}$ E. ; dist. 5101 miles ; course at equator, S. $31^{\circ} \mathrm{W}$.; in long. $31^{\circ} 16_{2}^{\prime} \mathrm{W}$.

27. $368 \mathrm{ft}$.

28. Bearing S. $27^{\circ} 19^{\prime} 49^{\prime \prime}$ W. ; set E. $3^{\circ} 49^{\prime} 42^{\prime \prime}$ N.

29. $\mathrm{A}=31^{\circ} 12^{\prime} 14^{\prime \prime} ; \mathrm{AC}=72^{\circ} 23^{\prime} 48^{\prime \prime}$.

30. $\mathrm{A}=0 ; \mathrm{B}=+5^{\circ} 5 ; \mathrm{C}=-28^{\circ} .5 ; \mathrm{D}=-4^{\circ} .5 ; \mathrm{E}=-1^{\circ}$. Deviations, West, $-4^{\circ} 30^{\prime} ;-0^{\circ} 38^{\prime} ;+3^{\circ} 22^{\prime} ;+7^{\circ} 29^{\prime} ;+11^{\circ} 46^{\prime} ;+16^{\circ} 6^{\prime}$; $+20^{\circ} 20^{\prime} ;+24^{\circ} 14^{\prime} ;$ South, $+27^{\circ} 30^{\prime} ;+29^{\circ} 49^{\prime} ;+30^{\circ} 55^{\prime} ;+30^{\circ} 32^{\prime}$; $+28^{\circ} 32^{\prime} ;+24^{\circ} 56^{\prime} ;+19^{\circ} 53^{\prime} ;+13^{\circ} 35^{\prime} ;$ East, $+6^{\circ} 30^{\prime}$.

31. $+4^{\circ} 38^{\prime}$.

32. H.A. 0 ; dev. $6^{\circ} 15^{\prime} \mathrm{E}$.

\section{Paper VIII.}

1. $\cdot 000001075 \log =4 \cdot 031408$.

2. $\cdot 1 \log =9 \cdot 000000$.

3. S. $3^{\circ}$ W., $30^{\prime} ;$ S. $34^{\circ}$ W., $74^{\prime}$; S. $1^{\circ}$ W., $26^{\prime} ;$ S. $3^{\circ}$ W., $56^{\prime}$; S. $54^{\circ}$ W., $52^{\prime}$; S. $56^{\circ}$ W., $75^{\prime}$; S. $71^{\circ}$ W., $45^{\prime}$; S. $65^{\circ}$ W., $10^{\prime}$; D. lat. $264 \cdot 3$, dep. $204 \cdot 9$; course, S. $37^{\circ} 47^{\prime}$ W. ; dist. $334 \cdot 5$ miles ; lat. $55^{\circ} 24^{\prime} 42^{\prime \prime} \mathrm{N}$.; long. $50^{\circ} 16^{\prime} 30^{\prime \prime} \mathrm{W}$.

4. Dec. $0^{\circ} 1^{\prime} 5^{\prime \prime}$ S. ; T.A. $56^{\circ} 48^{\prime} 49^{\prime \prime} ;$; lat. $33^{\circ} 12^{\prime} 16^{\prime \prime}$ S.

5. Noon long, $83^{\circ} 38^{\prime} \cdot 4 \mathrm{~W}$.

6. True course, S. $54^{\circ} 10^{\prime}$ E. ; compass course, S. $36^{\circ} 50^{\prime}$ E. ; dist. 9224 miles.

7. $6^{\mathrm{h}} 54^{\mathrm{m}}$ A.M. ; $7^{\mathrm{h}} 15^{\mathrm{m}}$ A.M.

8. Dec. $2^{\circ} 3^{\prime} 16^{\prime \prime} \mathrm{S}$.; true amp. W. $3^{\circ} 12^{\prime} 10^{\prime \prime} \mathrm{S}$.; dev. $27^{\circ} 2^{\prime} 10^{\prime \prime} \mathrm{W}$.

9. M.T.G. $3^{\mathrm{d}} 20^{\mathrm{h}} 20^{\mathrm{m}} 51^{\mathrm{s}}$; P.D. $107^{\circ} 28^{\prime} 12^{\prime \prime}$; eq. time, $+5^{\mathrm{m}} 59^{\mathrm{s}}$; T.A. $7^{\circ} 52^{\prime} 33^{\prime \prime}$; E.H.A. $3^{\mathrm{h}} 45^{\mathrm{m}} 18^{\circ}$; long. $0^{\circ} 2^{\prime} 30^{\prime \prime}$ W. ; true azi. N. $53^{\circ} 16^{\prime}$ E. ; dev. $13^{\circ} 16^{\prime} \mathrm{E}$.

10. A.T.S. $5^{\text {h }} 7^{\mathrm{m}} 10^{\circ}$ P.M. ; cor. $-41-22+1$; true azi. N. $100^{\circ} 47^{\prime}$ W. ; dev. $8^{\circ} 33^{\prime} \mathrm{E}$.

11. E.H.A. $39^{\mathrm{m}} 8^{\circ}$; nat. no. 9125 . Arc I. $30^{\circ} 29^{\prime} 10^{\prime \prime}$; Arc. II. $73^{\circ} 56^{\prime} 9^{\prime \prime}$. Lat. $43^{\circ} 26^{\prime} 59^{\prime \prime} \mathrm{N}$.

12. First T.A. $37^{\circ} 38^{\prime} 2^{\prime \prime}$; P.D. $92^{\circ} 43^{\prime} 47^{\prime \prime}$; eq. time, $-9^{\mathrm{m}} 55^{\circ}$; H.A.'s $0^{\mathrm{h}} 46^{\mathrm{m}} 6^{\mathrm{s}}$ and $0^{\mathrm{h}} 25^{\mathrm{m}} 57^{\circ}$; long. (a), $170^{\circ} 38^{\prime} 45^{\prime \prime}$ E. ; $(b), 179^{\circ} 19^{\prime}$ W. ; second 
T.A. $23^{\circ} 12^{\prime} 42^{\prime \prime}$; P.D. $92^{\circ} 47^{\prime} 27^{\prime \prime}$; eq. time, $-9^{\mathrm{m}} 58^{\mathrm{s}} ;$ H.A.'s $3^{\mathrm{h}} 16^{\mathrm{m}} 57^{\circ}$ and $3^{\mathrm{h}} 14^{\mathrm{m}} 6^{\mathrm{s}}$; long. $(c), 179^{\circ} 21^{\prime} 45^{\prime \prime}$ W. ; $(d), 179^{\circ} 55^{\prime} 30^{\prime \prime} \mathrm{E}$.

First line: $\left\{\begin{array}{l}\text { N. } 79^{\circ} \mathrm{E} . \\ \text { S. } 79^{\circ} \mathrm{W} .\end{array}\right\}$; second azi. S. $55^{\circ} \mathrm{W}$; lat. $49^{\circ} 16 \frac{1^{\prime}}{} \mathrm{N}^{\circ}$; long. $179^{\circ} 591^{\prime \prime} \mathrm{E}$.

13. M.T.S. $8^{\mathrm{h}} 9^{\mathrm{m}} 53^{\mathrm{s}}$ A.M.

14. Aldebaran, N. $1^{\mathrm{m}} 44^{\mathrm{s}}$ E. ; Capella, N. $40^{\mathrm{m}} 58^{\circ} \mathrm{E}$; ; Rigel, N. $41^{\mathrm{m}} 14^{\mathrm{s}} \mathrm{E}$. ; Bellatrix, N. $51^{\mathrm{m}} 18^{\mathrm{s}}$ E. ; $\beta$ Tauri, N. $51^{\mathrm{m}} 34^{\mathrm{s}}$ E.

15. Alt. $47^{\circ} 20^{\prime}$.

16. E.H.A. $3^{\text {h }} 21^{\mathrm{m}} 1^{\prime}$; cor., $-11-43+31$; true azi. N. $101^{\circ} 43^{\prime}$ E. ; dev. $28^{\circ} 13^{\prime} \mathrm{E}$.

17. M.T.G. $19^{\mathrm{d}} 2^{\mathrm{h}} 2^{\mathrm{m}} 40^{\mathrm{s}}$; W.H.A. $9^{\mathrm{h}} 59^{\mathrm{m}} 20^{\mathrm{s}}$; R.A.M.S. $9^{\mathrm{h}} 48^{\mathrm{m}} 2^{\mathrm{s}}$; long. $157^{\circ} 30^{\prime} \mathrm{E}$.

18. Cor., $-1^{\circ} 11^{\prime} 58^{\prime \prime},+0,+1^{\prime} 12^{\prime \prime}$; lat. $28^{\circ} 41^{\prime} 36^{\prime \prime} \mathrm{N}$.

19. M.T.G. $31^{\mathrm{d}} 23^{\mathrm{h}} 9^{\mathrm{m}} \cdot 9$; S.D. $16^{\prime} 8^{\prime \prime}$; H.P. $58^{\prime} 6^{\prime \prime}$; dec. $15^{\circ} 45^{\prime} 11^{\prime \prime}$ S. ; cor. + $8^{\prime} 37^{\prime \prime}$; T.A. $81^{\circ} 26^{\prime} 50^{\prime \prime}$; lat. $7^{\circ} 12^{\prime} 2^{\prime \prime} \mathrm{S}$.

20. Lat. $11^{\circ} 52^{\prime} 30^{\prime \prime} \mathrm{N}$.

21. Mag. bearing, N. $21_{2}^{\circ}$ W. ; comp. course, N. $8^{\circ}$ E., S. $71^{\circ}$ E., S. $79^{\circ}$ W., N. $57^{\circ}$ W.; mag. course, N. $85^{\circ}$ E., N. $72^{\circ}$ W., S. $65^{\circ}$ W., S. $20^{\circ}$ E. ; mag. bearings, S. $20^{\circ}$ W., and S. $50^{\circ}$ E.

22. -2 ft. 9 ins.

23. Sun's elements: R.A. $9^{\mathrm{h}} 38^{\mathrm{m}} 24^{\mathrm{s}} \cdot 2$; dec. $14^{\circ} 6^{\prime} 19^{\prime \prime}$ N.; R.A.M.S. $9^{\text {h }} 34^{\mathrm{m}} 2^{\mathrm{s}}$; A.A. $68^{\circ} 51^{\prime} 57^{\prime \prime}$; T.A. $68^{\circ} 51^{\prime} 38^{\prime \prime}$; W.H.A. $1^{\text {h }} 20^{\mathrm{m}} 17^{\mathrm{s}}$.

Moon's elements : R.A. $6^{\mathrm{h}} 22^{\mathrm{m}} 19^{\circ} 5$; dec. $20^{\circ} 12^{\prime} 13^{\prime \prime}$ N. ; S.D. $15^{\prime} 4^{\prime \prime}$; H.P. 54' $48^{\prime \prime}$; W.H.A. $4^{\text {h }} 36^{\mathrm{m}} 21^{\mathrm{s}}$; T.A. $26^{\circ} 24^{\prime} 26^{\prime \prime}$; A.A. $25^{\circ} 36^{\prime} 59^{\prime \prime}$; app. dist. $47^{\circ} 50^{\prime} 16^{\prime \prime} ; \mathrm{B} 32^{\circ} 52^{\prime} 29^{\prime \prime} ; \mathrm{Z}=34^{\circ} 29^{\prime} 14^{\prime \prime}$; true dist. $47^{\circ} 4^{\prime} 21^{\prime \prime}$; error, $7^{\mathrm{m}} 3^{\circ}$ slow ; long. $170^{\circ} 36^{\prime} \mathrm{W}$.

24. H.E.T. $2^{\mathrm{b}} 9^{\mathrm{m}} 18^{\mathrm{s}} 7$; run cor., $-12^{\prime} 36^{\prime \prime}$; first alt. $67^{\circ} 4^{\prime} 46^{\prime \prime}$; second alt. $68^{\circ} 22^{\prime} 20^{\prime \prime} ; \mathrm{XY}=44^{\circ} 28^{\prime} 55^{\prime \prime} ; \mathrm{X}_{1}=65^{\circ} 54^{\prime} 45^{\prime \prime} ; \mathrm{X}_{2}=3^{\circ} 12^{\prime} 0^{\prime \prime}$; lat. $48^{\circ} 29^{\prime} 42^{\prime \prime} \mathrm{N}$.

25. P.D. $84^{\circ} 22^{\prime} 30^{\prime \prime}$; eq. time, $-2^{\mathrm{m}} 25^{\mathrm{s}} .8$; E.H.A. $2^{\mathrm{h}} 45^{\mathrm{m}} 48^{\mathrm{s}}$; error, $9^{\mathrm{m}} 53^{\circ} \cdot 7$ fast.

26. First course, S. $63^{\circ} 36^{\prime}$ E. ; longs. $60^{\circ} 8^{\prime}$ E., and $79^{\circ} 2^{\prime}$ E. ; dist. 4705.6 miles ; lat. $41^{\circ} 33^{\prime}$; long. $50^{\circ} \mathrm{E}$. ; lat. $41^{\circ} 28^{\prime} 30^{\prime \prime} \mathrm{S}$.; long. $90^{\circ} \mathrm{E}$. ; lat. $40^{\circ} 3^{\prime} 30^{\prime \prime} \mathrm{S}$. ; long. $100^{\circ} \mathrm{E}$.

27. N. $35^{\circ} 61_{2}^{\prime}$ E. ; dist. $274 \cdot 5$ miles.

28. $\mathrm{QR}=260.9$ or $181 \cdot 2$.

29. $86^{\circ} 6 \mathrm{ft}$.

30. $\mathrm{R}=100^{\circ} 32^{\prime} 7^{\prime \prime} ; \mathrm{RQ}=94^{\circ} 12^{\prime} 4^{\prime \prime}$.

31. $\mathrm{A}=84^{\circ} 4^{\prime} 12^{\prime \prime} ; \mathrm{AB}=83^{\circ} 50^{\prime} 5^{\prime \prime}$.

32. Lat. $68^{\circ} 10^{\prime} 30^{\prime \prime} \mathrm{N}$. ; long. $0^{\circ} 34^{\prime} \mathrm{W}$.

33. N. $42^{\circ} 43^{\prime} 30^{\prime \prime} \mathrm{W}$.

34. $\mathrm{A}=+75^{\circ} ; \mathrm{B}=+14^{\circ} ; \mathrm{C}=-10^{\circ} .5 ; \mathrm{D}=+3^{\circ} .25 ; \mathrm{E}=+7^{\circ} \cdot 25$. Deviations, North: $-2^{\circ} 30^{\prime} ;+3^{\circ} 50^{\prime} ;+6^{\circ} 29^{\prime} ;+6^{\circ} 50^{\prime} ;$ East, $+7^{\circ} 30^{\prime}$; $+10^{\circ} 16^{\prime} ;+14^{\circ} 49^{\prime} ;+18^{\circ} 38^{\prime} ;$ South, $+18^{\circ} 30^{\prime} ;+12^{\circ} 31^{\prime} ;+1^{\circ} 31^{\prime}$;

$-10^{\circ} 59^{\prime} ;$ West, $-20^{\circ} 30^{\prime}$; $-23^{\circ} 38^{\prime} ;-19^{\circ} 49^{\prime} ;-11^{\circ} 29^{\prime}$.

35. 0.

36. E.H.A. $1^{\mathrm{h}} 20^{\mathrm{m}} 45^{\circ}$; true azi. $94^{\circ} 4^{\prime}+69^{\circ} 30^{\prime}=$ N. $163^{\circ} 34^{\prime}$ E. ; dev. $7^{\circ} 19^{\prime} \mathrm{E}$. 
PRINTED IN GREAT BRITAIN BY WILLIAM CLOWES AND SONS, LIMITED, BECCLES. 

INDEX FOR TIDAL EXERCISES. 


\section{INDEX FOR TIDAL EXERCISES.}

\section{Showng Standabd Ports in Syall Capttals.}

$\quad$ Name.
ABU SHA HR
Al Basra
Annan Foot
Ardrishaig
Ardrossan
Ayr
Beachy Head
Beaumaris
Bridlington
Carlisle Port
Clydebank
Crinan
Dartmouth
DEAL
DEvoNPorT
Dingle
Donaghadee
DovER
Dangeness
Exmouth
Fuetwood
Fowey
Foynes Island
GaLway
GreENock
Grimsby
Hastings
Henjam Island
Hilbre Island
HoLL

Standard Port
page (12)
Abu Shahr
Liverpool
Greenock
Greenock
Dover
Liverpool
Hull
Liverpool
Greenock
Greenock
Devonport
page (4)
page (3)
Galway
Kingstown
page (4)
Dover
Devonport
page (7)
Devonport
Galway

page (10)

page (6)

Hull

Dover

Abu Shahr

Liverpool

page (5)
Name.

Kivgstow

Knweit

Lamlash

Limerick

LIVERPOOL

Llanelly

Mellon

Pembroke Dock

Quaco

Ramsgate

Rotterdam

Rye Bay

St. Andrews

ST. JоH N, N.B.

St. Mary's

Seal Cove

South Rock

Spurn Point

Strangford Quay.

Tenby

Tor Bay

Valentia

Warren Point

Welchpool

Whitehaven

Wicklow

Workington
Standard Port.

page (9)

Abu Shahr

Greenock

Galway

page (7)

Pembroke Dock

Galway

page (8)

St. John

Dover

Dover

Dover

St. John page (11)

Devonport

St. John

page (9)

Hull

Kingstown

Pembroke Dock

Devonport

Galway

Kingstown

St. John

Liverpool

Kingstown

Liverpool 
H. W. F, \& C. $\left\{\mathrm{XI}^{\mathrm{H}} \cdot 12^{\mathrm{M}}\right.$. (Local mean time). XI. 7. (Standard time).
Lat. $51^{\circ} 7^{\prime} \mathrm{N}$. Long. $1^{\circ} 19^{\prime} \mathrm{E}$.

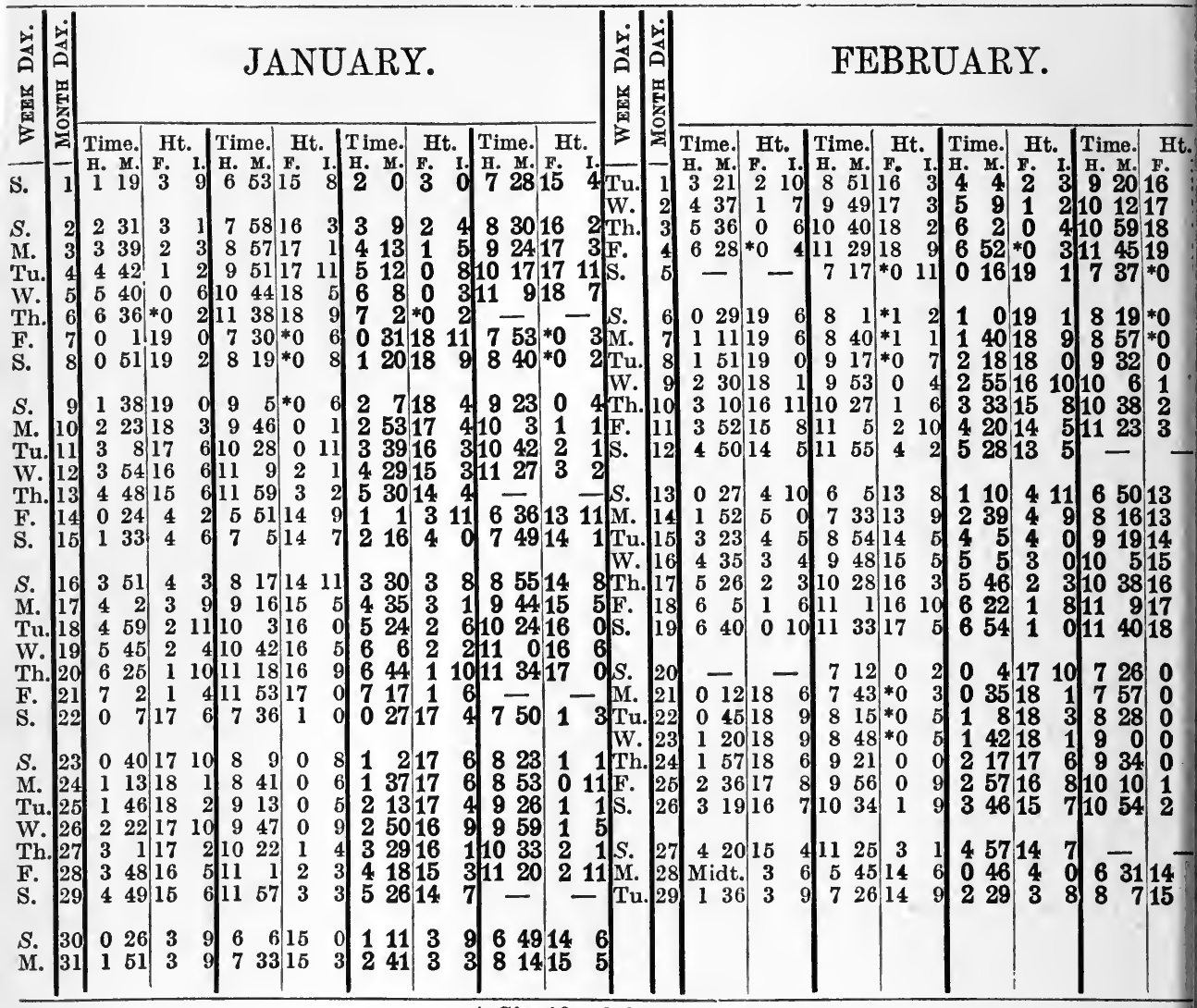

* Signifies below Datum.

The tides are placed in order of occurrence, p.m. times and heights being printed in large bloc type. A comparison of consecutive heights will indicate whether it is high or low water.

The times given are STANDARD, or mean time of the meridian of Greenwich. To obtain loce mean time add 5 minutes.

TIDAL DATUM, Eтc.

The zero of the predictions, which is also the datum of the Admiralty chart of Dover, is 8.42 fet below Ordnance datum, and is 0.15 foot above the level of mean low water spring tides.

TIDAL DIFFERENCES ON DOVER.

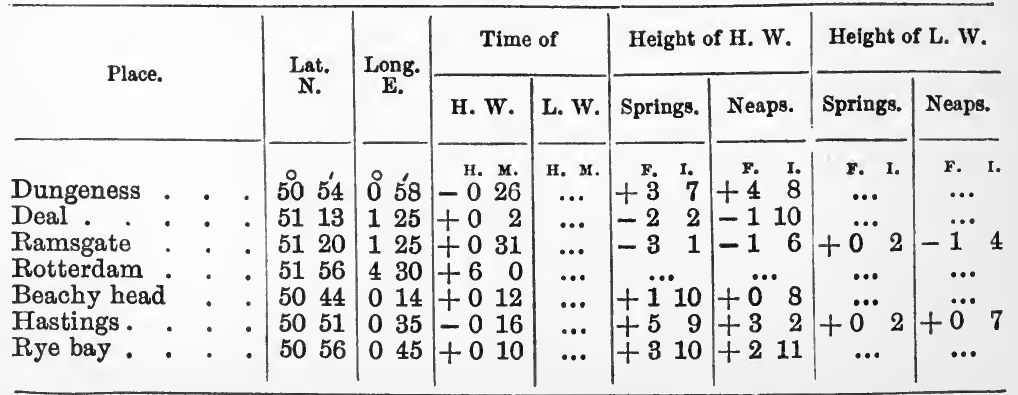


ENGLAND, EAST COAST-HULL.

H. W. F. \& O. $\left\{\right.$ VIH. $29^{\mathrm{M}}$. (Local mean time).

VI. 30 (Standard time).

Lat. $53^{\circ} 44^{\circ} \mathrm{N}$. Long. $0^{\circ} 19^{\prime} \mathrm{W}$.

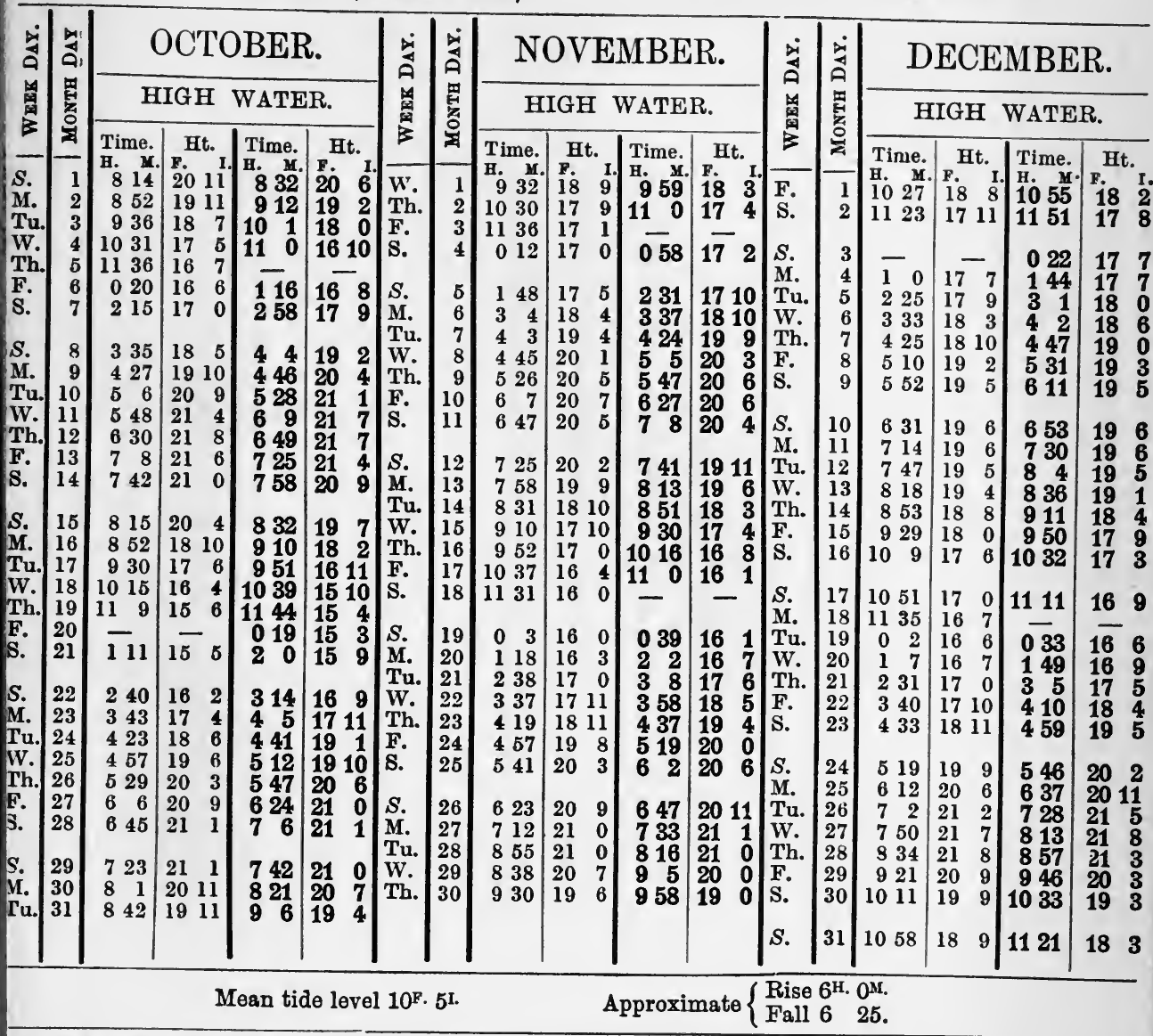

P.M. times and heights are printed in large block type.

The times given are STANDARD, or mean time of the meridian of Greenwich. To obtain local mean ime subtract 1 minute.

The zero of the predictions, which is also the datum of the Admiralty chart of Hull, is 10.07 feet selow Ordnance datum, and is the level of mean low water spring tides.

TIDAL DIFFERENCES ON HULL.

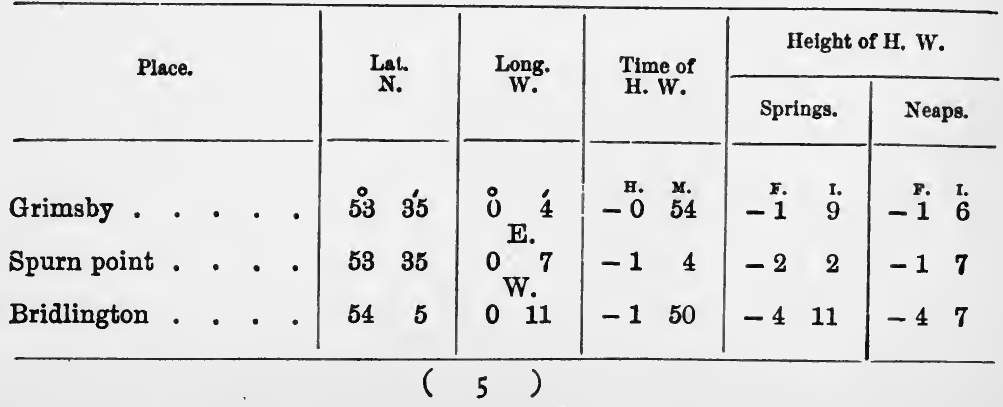


H. W. F. \& C. $\left\{\begin{array}{l}\text { XIIH. 5M. } \\ \text { XII, } 24 .\end{array}\right.$ (Local mean time).

Lat. $55^{\circ} 27^{\prime} \mathrm{N}$. Long. $4^{\circ} 46^{\prime} \mathrm{W}$.

\section{NOVEMBER.}

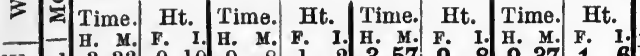

\section{ค่}

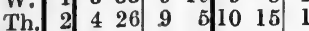

F. 3 \begin{tabular}{lllll|lll|l}
5 & 30 & 8 & 1 & 1 & 11 & 44 & 2
\end{tabular}

S. \begin{tabular}{lllllllll|llll|l}
$S$. & 5 & 1 & 50 & 2 & 0 & 8 & 19 & 8 & 10 & 2 & 24 & 1
\end{tabular}

$\begin{array}{llllllllllllll}\text { M. } & 6 & 2 & 48 & 1 & 6 & 9 & 26 & 9 & 2 & 3 & 13 & 1\end{array}$

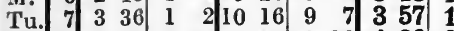

\begin{tabular}{llllll|llllllll} 
W. & 8 & 4 & 18 & 0 & 10 & 10 & 55 & 9 & 10 & 4 & 36 & 0
\end{tabular}

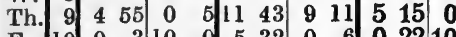

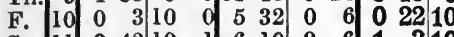

\begin{tabular}{llll|ll|ll|ll|ll|l} 
S. & 11 & 0 & 42 & 10 & 1 & 6 & 10 & 0 & 6 & 1 & 3 & 10
\end{tabular}

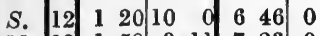

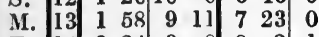

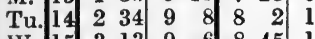

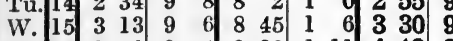

Th. $16 \begin{array}{llllllllllll}3 & 50 & 9 & 4 & 9 & 30 & 1 & 11 & 4 & 12 & 9\end{array}$

F. $\quad$\begin{tabular}{llllll|ll|l}
17 & 4 & 33 & 8 & 10 & 10 & 31 & 2
\end{tabular}

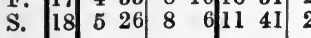

\begin{tabular}{ll|ll|ll|ll|l}
$S$. & 19 & 0 & 18 & 2 & 6 & 6 & 37 & 8
\end{tabular}

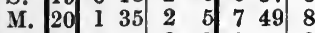

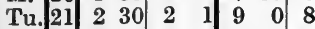

\begin{tabular}{ll|ll|ll|ll|l} 
W. & 22 & 3 & 15 & 1 & 8 & 9 & 48 & 9
\end{tabular}

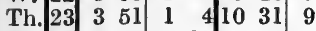

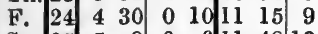

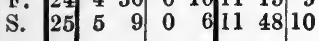

\begin{tabular}{ll|ll|l}
$S$. & 26 & 0 & 18 & 10
\end{tabular}

M. $27 \quad 1 \quad 6 \mid 10$

Tu. 28 1 $154 \quad 10$

W. $\mid$\begin{tabular}{llll|l}
29 & 2 & 41 & 10
\end{tabular}

\begin{tabular}{ll|ll|l} 
Th. & 30 & 3 & 43 & 10
\end{tabular}

1) 5 48 0

$\begin{array}{llllllll}3 & 6 & 32 & 0 & & 0 & 41 & 10\end{array}$

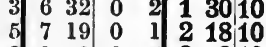

\begin{tabular}{lllll|lll}
2 & 8 & 8 & 0 & 5 & 3 & 9 & 10
\end{tabular}

8937 i 6 F.

\begin{tabular}{|l|l|l|l|l|}
\hline Time. Ht. & Time. & Ht. & Time. Ht. Time. & Ht.
\end{tabular} H. M. F. I. H. M. F. I. H. M. F. I. H. M. F.

\section{\begin{tabular}{lllll|rr|rr}
2 & 4 & 55 & 8 & 7 & 10 & 1 & 2 & 5
\end{tabular}} $\begin{array}{lllll}6 & 6 & 2 & 8\end{array}$

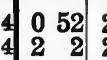

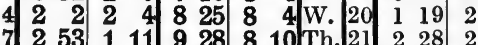

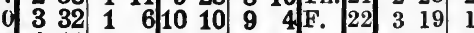

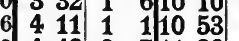

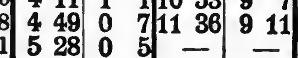

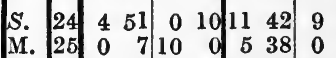

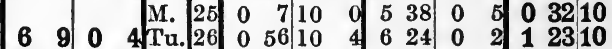

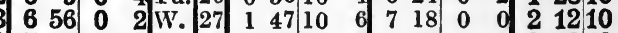

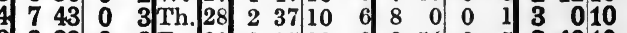

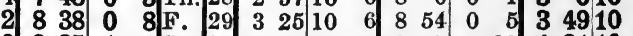
$\begin{array}{lllllllllllllllllllll}9 & 35 & 1 & 1 & \mathrm{~S} . & 30 & 4 & 11 & 10 & 4 & 9 & 47 & 0 & 11 & 4 & 31 & 10 & 1 & 10 & 12 & 1\end{array}$ \begin{tabular}{l|l|ll|ll|ll|ll|ll|ll|ll|l}
$S$. & 31 & 4 & 54 & 9 & 10 & 10 & 42 & 1 & 2 & 5 & 17 & 9 & 7 & 11 & 15 & 1
\end{tabular}

* Signifies below Datum.

The tides are placed in order of occurrence, p.m. times and heights being printed in large block type A comparison of consecutive heights will indicate whether it is high or low water.

The times given are STANDARD, or mean time of the meridian of Greenwich. To obtain local mear time subtract 19 minutes.

TIDAL DIFEERENCES ON GREENOCK.

\begin{tabular}{|c|c|c|c|c|c|c|c|c|c|}
\hline \multirow{2}{*}{ Place. } & & \multirow{2}{*}{$\begin{array}{l}\text { Lat. } \\
\text { N. }\end{array}$} & \multirow{2}{*}{$\begin{array}{l}\text { Long. } \\
\text { W. }\end{array}$} & \multicolumn{2}{|c|}{ Time of } & \multicolumn{2}{|c|}{ Height of H. W. } & \multicolumn{2}{|c|}{ Height of L. W. } \\
\hline & & & & H. W. & L. W. & Springs. & Neaps. & Springs. & Neaps. \\
\hline $\begin{array}{l}\text { Crinan. } \\
\text { Lamlash } \\
\text { Ardrossan. } \\
\text { Ayr } \\
\text { Clydebank }\end{array}$ & $\begin{array}{l}\dot{\bullet} \\
\dot{.} \\
\dot{ }\end{array}$ & $\begin{array}{rr}56 & 5 \\
55 & 48 \\
55 & 38 \\
55 & 28 \\
\ldots & \end{array}$ & $\begin{array}{ll}\stackrel{0}{5} & 30 \\
4 & 52 \\
4 & 50 \\
4 & 39 \\
& \ldots\end{array}$ & $\begin{array}{r}\text { H. } 3 . \\
+512 \\
-015 \\
-016 \\
-016 \\
\ldots\end{array}$ & $\begin{array}{c}\text { н. м. } \\
\ldots \\
\ldots \\
\ldots \\
\ldots \\
\ldots\end{array}$ & $\begin{array}{rr}\text { F. } & \text { I. } \\
-4 & 3 \\
-0 & 3 \\
-0 & 3 \\
-1 & 6 \\
+0 & 44\end{array}$ & $\begin{array}{rr}\text { F. } & \text { I. } \\
-4 & 3 \\
-1 & 3 \\
-0 & 9 \\
-1 & 0 \\
+0 & 20\end{array}$ & $\begin{array}{c}\text { F. } \mathbf{~} \\
\ldots \\
\ldots \\
\ldots \\
\ldots \\
\ldots\end{array}$ & $\begin{array}{c}\text { F. } \mathbf{~} \\
\ldots \\
\ldots \\
\ldots \\
\ldots \\
\ldots\end{array}$ \\
\hline
\end{tabular}

The zero of the predictions, which is also the datum of the Admiralty chart of the River Clyd entrance at Greenock, is 6.08 feet below Ordnance datum, and is 0.24 foot below the level of mean lor
water spring tides. 
ENGLAND, WEST COAST-LIVERPOOL.

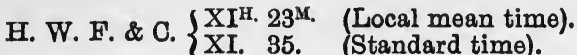

Lat. $53^{\circ} 24^{\prime} \mathrm{N}$. Long. $3^{\circ} 0^{\prime} \mathrm{W}$.

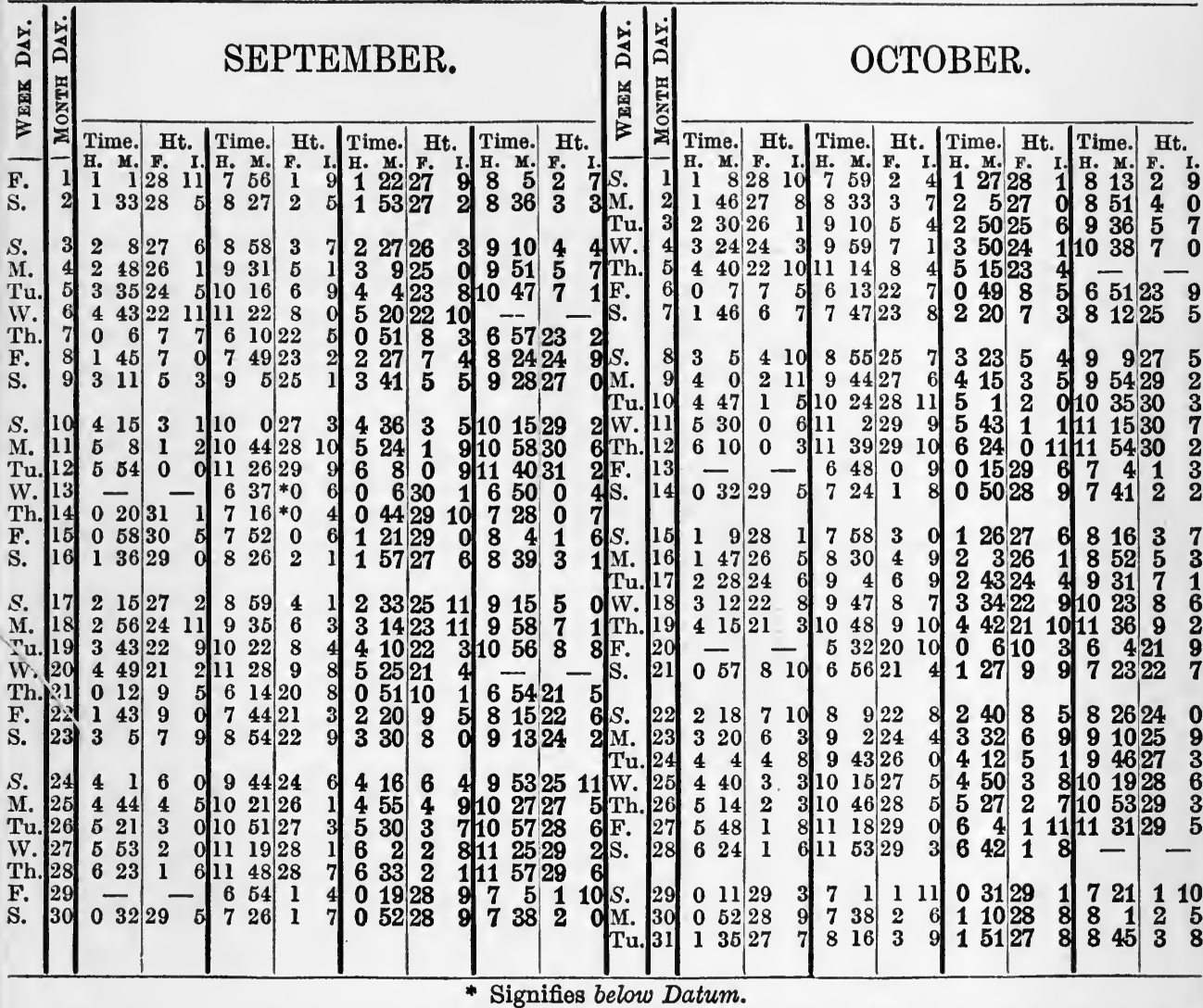

The tides are placed in order of occurrence, p.m. times and heights being printed in large block type. A comparison of consecutive heights will indicate whether it is high or low water.

The times given are STANDARD or mean time of the meridian of Greenwich. To obtain local mean time subtract 12 minutes.

TIDAL DIFEERENCES ON LIVERPOOL.

\begin{tabular}{|c|c|c|c|c|c|c|c|c|}
\hline \multirow{2}{*}{ Place. } & \multirow{2}{*}{$\begin{array}{l}\text { Lat. } \\
\text { N. }\end{array}$} & \multirow{2}{*}{$\begin{array}{l}\text { Long. } \\
\text { w. }\end{array}$} & \multicolumn{2}{|c|}{ Time of } & \multicolumn{2}{|c|}{ Height of $\mathrm{H}$. W. } & \multicolumn{2}{|c|}{ Height of L. W. } \\
\hline & & & H. W. & L. W. & Springs. & Neaps. & Springs. & Neaps. \\
\hline Port Carlisle & $545^{\prime}$ & 310 & $\begin{array}{r}\text { H. M. } \\
+048\end{array}$ & н. м. & $\begin{array}{l}\text { r. } 1 . \\
\text {... }\end{array}$ & $\begin{array}{l}\text { ₹. } 1 . \\
\text {... }\end{array}$ & $\begin{array}{ll}\text { P. } & \text { I. } \\
\ldots & \end{array}$ & $\begin{array}{l}\text { F. } 1 . \\
\ldots .\end{array}$ \\
\hline Annan foot & 5458 & 316 & +043 & $\ldots$ & -0 & -32 & ... & $\ldots$ \\
\hline Workington & $54 \quad 39$ & 334 & $\begin{array}{ll}-0 & 1\end{array}$ & $\ldots$ & -3 & $\begin{array}{ll}-3 & 2\end{array}$ & $\ldots$ & $\ldots$ \\
\hline Whitehaven & 5433 & 336 & $\begin{array}{ll}-0 & 7\end{array}$ & ... & $\begin{array}{ll}-3 & 2\end{array}$ & -411 & +11 & +010 \\
\hline $\begin{array}{l}\text { Fleetwood, } \\
\text { Wyre lighthouse }\end{array}$ & 5357 & 32 & -012 & ... & $\begin{array}{ll}-1 & 5\end{array}$ & -18 & +03 & $\begin{array}{ll}-0 & 1\end{array}$ \\
\hline Hilbre island. & 5323 & 313 & -022 & ... & -1 & $\begin{array}{ll}0 & 0\end{array}$ & $\begin{array}{ll}-0 & 2\end{array}$ & $\begin{array}{ll}-0 & 1\end{array}$ \\
\hline Beaumaris . & 5316 & 45 & -049 & ... & $-\begin{array}{ll}-5 & 8\end{array}$ & -68 & ... & ... \\
\hline
\end{tabular}

The zero of the prediotions, which is also the datum of the Admiralty chart of Liverpool, is 14.66 feet below Ordnance datum, and is 1.40 feet below the level of mean low water spring tides. 


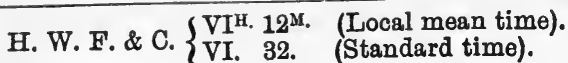

Lat. $51^{\circ} 42^{\prime} \mathrm{N}$. Long. $4^{\circ} 57^{\prime} \mathrm{W}$.

\begin{tabular}{|c|c|c|c|c|c|c|c|c|c|c|c|c|c|c|c|c|c|c|}
\hline \multirow{3}{*}{ 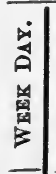 } & \multirow{3}{*}{ 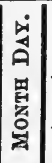 } & \multicolumn{4}{|c|}{ JULY. } & \multirow{3}{*}{ 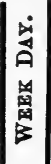 } & \multirow{3}{*}{ 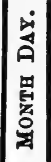 } & \multicolumn{5}{|c|}{ AUGUST. } & & \multirow{3}{*}{ 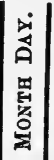 } & \multicolumn{4}{|c|}{ SEPTEMBER. } \\
\hline & & \multicolumn{2}{|c|}{ HIGH } & \multicolumn{2}{|c|}{ WATER. } & & & \multicolumn{2}{|c|}{ HIGH } & \multicolumn{2}{|c|}{ WATER. } & & & & \multicolumn{2}{|c|}{ HIGH } & \multicolumn{2}{|c|}{ WATER. } \\
\hline & & Time. & & Time. & & & & & & & & & & & Time. & & Time. & \\
\hline S. & 1 & H. $\begin{array}{r}\text { M. } \\
\text { I }\end{array}$ & $\begin{array}{ll}\text { F. } & \text { I. } \\
20 & 2\end{array}$ & $\begin{array}{rl}\text { H. } & \text { M. } \\
7 & 20\end{array}$ & $20 \stackrel{3}{3}$ & $\begin{array}{l}\text { Tu. } \\
\text { W. }\end{array}$ & $\begin{array}{l}1 \\
2\end{array}$ & $\begin{array}{rr}\mathbf{H .}_{\mathbf{7}} & \mathbf{M} \\
8 & \mathbf{4 5} \\
8 & 15\end{array}$ & $\begin{array}{ll}F .1 & 1 . \\
21 & 4 \\
21 & 5\end{array}$ & $\mid$\begin{tabular}{rr|}
$H_{8}$ & M. \\
8 & 0 \\
8 & 31
\end{tabular} & $\begin{array}{ll}\mathbf{F} & 1 \\
21 & 5 \\
21 & 5\end{array}$ & & . & $\begin{array}{l}1 \\
2\end{array}$ & $\begin{array}{rr}r_{8} & M . \\
8 & 17 \\
8 & 52\end{array}$ & $\begin{array}{ll}f . & 1 . \\
22 & 2 \\
21 & 6\end{array}$ & $\begin{array}{r}8 \\
8 \\
9\end{array} \frac{M}{34}$ & \\
\hline & 2 & 735 & 20 & 751 & 20 & Th. & 3 & 848 & 214 & & 213 & & & & & & & \\
\hline & 3 & & & & 20 & F. & 4 & $\begin{array}{lll}9 & 23\end{array}$ & 2010 & 0 & 20 & & i. & 3 & $\begin{array}{r}927 \\
106\end{array}$ & $\begin{array}{l}20 \\
19\end{array}$ & 946 & \\
\hline & 4 & 841 & 204 & 859 & 203 & s. & 5 & 957 & 201 & 101 & 198 & & & $\begin{array}{l}\mathbf{4} \\
5\end{array}$ & $\begin{array}{l}1056 \\
1056\end{array}$ & $\begin{array}{l}19 \\
18\end{array}$ & 1124 & \\
\hline & $\begin{array}{l}5 \\
6\end{array}$ & & $\begin{array}{ll}20 & 2 \\
19 & 9\end{array}$ & 5 & 1911 & $S$. & 6 & 1034 & $\begin{array}{ll}19 & 3\end{array}$ & & 1 & $8 \mid \mathrm{h}$ & & 6 & 1159 & 1611 & & \\
\hline & $\begin{array}{l}6 \\
7\end{array}$ & $\begin{array}{r}923 \\
1029\end{array}$ & $\begin{array}{l}19 \\
19\end{array}$ & & 1811 & M. & 7 & 19 & 181 & & 17 & & Th. & 7 & 044 & & 136 & 17 \\
\hline & $\dot{8}$ & & 187 & 11 & 182 & Tu. & 8 & & $17-1$ & & 17 & & . & 8 & $\begin{array}{ll}220 \\
3 & \end{array}$ & 17 & & 18 \\
\hline : & 9 & & 1710 & & & $\begin{array}{l}\text { W. } \\
\text { Th. }\end{array}$ & 10 & $\begin{array}{lll}0 & 53 \\
2 & 3 & 3\end{array} \mid$ & $\begin{array}{ll}17 & 1 \\
17 & 9\end{array} \mid$ & 14 & $\begin{array}{l}17 \\
18\end{array}$ & & & 9 & & & & 20 \\
\hline i. & 10 & & 178 & $\overline{047}$ & 178 & F. & 11 & $\begin{array}{lll}3 & 55\end{array}$ & $\begin{array}{ll}19 & 6\end{array}$ & 432 & 20 & & s. & 10 & 449 & 21 & 6 & \\
\hline & i & & 178 & & 1711 & S. & 12 & $\begin{array}{ll}5 & 5\end{array}$ & $\begin{array}{ll}21 & 4\end{array}$ & 534 & $\overline{22}$ & & M. & 11 & 542 & & & \\
\hline V. & 12 & $\begin{array}{ll}2 & 49\end{array}$ & 18 & 32 & 190 & & & & & & & & & 2 & 626 & 2311 & & \\
\hline & & & & & 206 & $S$. & 13 & & 2210 & 62 & & $6 \mathrm{~V}$ & & 13 & & & 2 & \\
\hline S. & 14 & 514 & 21 & 54 & 2111 & M. & 14 & & 2310 & 3 & 2 & & a. & 14 & 743 & & & \\
\hline S. & 15 & & 226 & 64 & 231 & Tu. & $\begin{array}{l}15 \\
16\end{array}$ & \begin{tabular}{ll|}
7 & 33 \\
8 & 14
\end{tabular} & $\begin{array}{ll}24 & 2 \\
23 & 9\end{array}$ & 3 & 24 & & & $\begin{array}{l}15 \\
16\end{array}$ & & $\begin{array}{l}22 \\
21\end{array}$ & & \\
\hline & 16 & & & 730 & 23 & Th. & 17 & 852 & $22 \quad 11$ & & 22 & & & & & & & \\
\hline & 1 & & & & & F. & 18 & $\begin{array}{l}930 \\
\end{array}$ & 217 & 7 & 20 & & s. & 17 & 933 & 19 & & \\
\hline & 1 & 840 & 23 & & 2211 & $S$. & 19 & 107 & 1911 & 1025 & 19 & & & 18 & 10 & & & \\
\hline V. & 19 & 924 & 22 & & 21 & & & & & & & & & 19 & 1054 & 16 & 4 & \\
\hline & 20 & 103 & 213 & 102 & & $S$. & 20 & 042 & 18 & 113 & 17 & 4 & N. & 20 & - & & & \\
\hline & 21 & 1043 & 1911 & 3 & 193 & M. & 21 & 1128 & 166 & & & & Th. & & 041 & 15 & & \\
\hline & 22 & 1124 & 185 & 1144 & 177 & Tu. & 22 & \begin{tabular}{lr|}
0 & 1 \\
1 & 20
\end{tabular} & 1510 & $\begin{array}{lll}0 & 36 \\
2 & 8\end{array}$ & $\begin{array}{l}15 \\
15\end{array}$ & & E. & $\begin{array}{l}22 \\
23\end{array}$ & $\begin{array}{lll}2 & 13 \\
3 & 30\end{array}$ & $\begin{array}{l}15 \\
17\end{array}$ & $\begin{array}{l}8 \\
0\end{array}$ & \\
\hline & 23 & & - & 8 & 17 & Th. & 24 & 253 & 160 & $3 \mathbf{3 1}$ & 16 & 7 & & & & & & \\
\hline & 2 & 0 & & & 16 & F. & 25 & & 17 & & & & & 24 & 22 & & & \\
\hline & 2 & & 162 & 24 & 16 & & 26 & 457 & $\begin{array}{ll}18 & 8\end{array}$ & 517 & & & & & & & & \\
\hline & 2 & & 1610 & & 17 & & & & & & & & & & $\begin{array}{ll}539 \\
\end{array}$ & & & \\
\hline & 2 & 4 & 179 & 4 & 18 & $S$. & 27 & $5 \quad 37$ & & & & 6 & W. & & 61 & & & \\
\hline & 28 & 521 & 1810 & & 19 & & & & & 62 & & & & 2 & 644 & & & \\
\hline & 29 & $\begin{array}{ll}6 & 5\end{array}$ & 198 & 625 & 200 & $T$ & 29 & $\begin{array}{lll}6 & 46 \\
7 & 10\end{array}$ & 2110 & 2 & 22 & & & 29 & 717 & 22 & & 22 \\
\hline & 3 & & & & 20 & Th. & $\begin{array}{l}30 \\
31\end{array}$ & 746 & $\begin{array}{ll}22 & 3 \\
22 & 4\end{array} \mid$ & 82 & & & & & & & & \\
\hline & 31 & & 210 & & 212 & & & & & & & & & & & & & \\
\hline
\end{tabular}

Mean tide level $12^{\text {P. }}$. r.

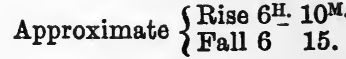

P.M. times and heights are printed in large block type.

The times given are STANDARD, or mean time of the meridian of Greenwich. To obtain local mean time subtract 20 minutes.

\section{TIDAL DIFFERENCES ON PEMBROKE DOCK.}

The Tidal observation station was at H.M. dockyard.

The zero of the predictions, which is also the datum of the Admiralty charts of Milford Haven, is 11.82 feet below Ordnance datum, and is 1.50 feet below the level of mean low water spring tides.

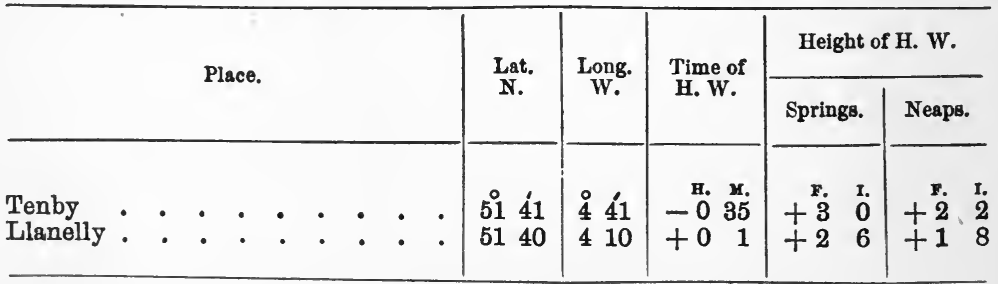


IRELAND, EAST COAST-KINGSTOWN.

H. W. F. \& C. $\left\{\begin{array}{l}\text { XIH. 12M. (Local mean time) } \\ \text { XI. } 11 .\end{array}\right.$

Lat. $53^{\circ} 18^{\prime} \mathrm{N}$. Long. $6^{\circ} 7^{\prime} \mathrm{W}$.

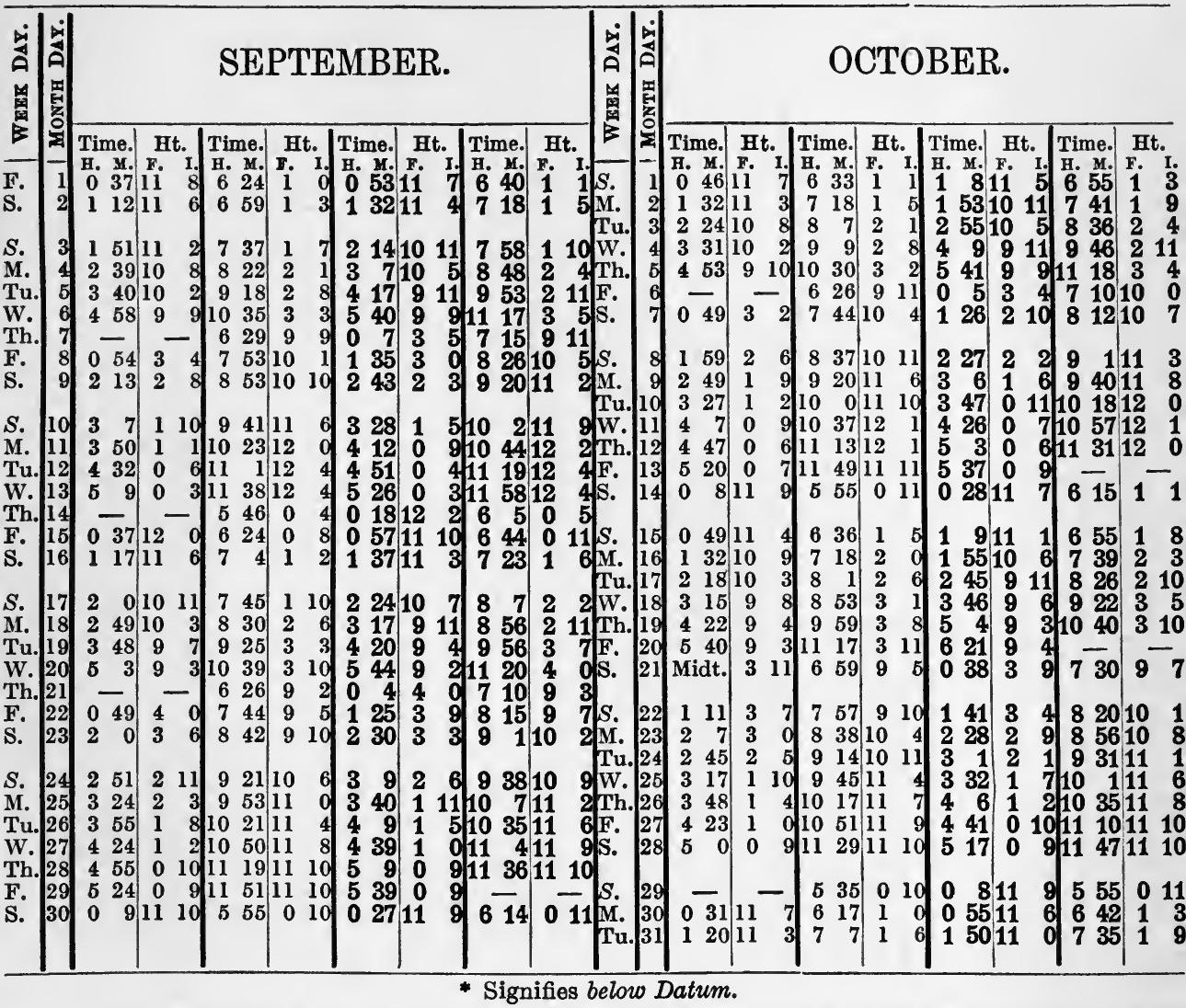

The tides are placed in order of occurrence, p.m. times and heights being printed in large block type. A comparison of consecutive heights will indicate whether it is high or low water.

The times given are STANDARD, or mean time of the meridian of Dublin, or $6^{\circ} 20^{\circ} \mathrm{W}$. from Greenwich. To obtain local mean time add 1 minute.

The zero of the predictions, which is also the datum of the Admiralty chart of Kingstown, is 1.75 feet above Ordnance datum, and is 0.84 foot below the level of mean low water spring tides.

TIDAL DIFFERENCES ON KINGSTOWN.

\begin{tabular}{|c|c|c|c|c|c|c|c|c|}
\hline \multirow{2}{*}{ Place. } & \multirow{2}{*}{$\begin{array}{l}\text { Lat. } \\
\text { N. }\end{array}$} & \multirow{2}{*}{$\begin{array}{l}\text { Long. } \\
\text { w. }\end{array}$} & \multicolumn{2}{|c|}{ Time of } & \multicolumn{2}{|c|}{ Height of $\mathrm{H}$. W. } & \multicolumn{2}{|c|}{ Height of $L . W$. } \\
\hline & & & H. W. & L. W. & Springs. & Neaps. & Springs. & Neaps. \\
\hline $\begin{array}{l}\text { Wicklow } \\
\text { Warren point. } \\
\text { Strangford quay } \\
\text { South rock } \\
\text { Donaghadee : }\end{array}$ & $\begin{array}{rr}52 & 59 \\
54 & 6 \\
54 & 22 \\
54 & 24 \\
54 & 38\end{array}$ & $\left|\begin{array}{rr}\circ & 2 \\
6 & 2 \\
6 & 15 \\
5 & 33 \\
5 & 25 \\
5 & 32\end{array}\right|$ & $\begin{array}{rr}\text { H. } & \text { м. } \\
-0 & 43 \\
-0 & 2 \\
+1 & 16 \\
-0 & 17 \\
-0 & 2\end{array}$ & $\begin{array}{l}\text { н. } \text { м. } \\
\ldots . \\
\ldots \\
\ldots \\
\ldots \\
\ldots\end{array}$ & $\begin{array}{rr}\mathbf{F} . & \mathbf{1} \\
-2 & 9 \\
+4 & 0 \\
-1 & 5 \\
+1 & 3 \\
+0 & 6\end{array}$ & $\begin{array}{rr}\mathbf{F} & 1 \\
-3 & 4 \\
+1 & 7 \\
-1 & 3 \\
+1 & 0 \\
+0 & 5\end{array}$ & $\begin{array}{rl} & \text { F. } 1 . \\
& \cdots \\
+0 & 2 \\
-0 & 10 \\
-0 & 10 \\
-0 & 10\end{array}$ & $\begin{array}{rr} & \text { r. } \\
+ & \text {. } \\
+2 & 1 \\
-1 & 8 \\
-1 & 1 \\
-0 & 11\end{array}$ \\
\hline
\end{tabular}


IRELAND, WEST COAST-GALWAY.

H. W. F. \& C. $\left\{\right.$ IVH. $35^{\mathrm{M} .}$ (Local mean time).

Lat. $53^{\circ} 16^{\prime} \mathrm{N}$. Long. $9^{\circ} 3^{\prime} \mathrm{W}$.

\begin{tabular}{|c|c|c|c|c|c|c|c|c|c|c|c|c|c|c|c|c|c|}
\hline \multirow{3}{*}{ 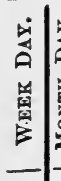 } & \multirow{2}{*}{ 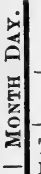 } & \multicolumn{4}{|c|}{ JULY. } & \multirow{2}{*}{ 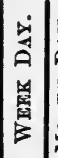 } & \multirow{2}{*}{ 氙 } & \multicolumn{4}{|c|}{ AUGUST. } & \multirow{2}{*}{ 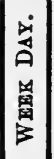 } & \multirow{2}{*}{ 甫 } & \multicolumn{4}{|c|}{ SEPTEMBER. } \\
\hline & & \multicolumn{2}{|c|}{ HIGH V } & \multicolumn{2}{|c|}{ WATER. } & & & \multicolumn{2}{|c|}{ HIGH V } & \multicolumn{2}{|c|}{ WATER. } & & & \multicolumn{2}{|c|}{ HIGH } & \multicolumn{2}{|c|}{ WATER. } \\
\hline & 지 & 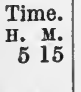 & $\begin{array}{l}\text { Ht. } \\
\text { F. I. } \\
13 \text { il }\end{array}$ & $\left|\begin{array}{cc}\text { Time. } \\
{ }_{\mathbf{H}} & \mathbf{M} \\
\mathbf{5} & \mathbf{3 4}\end{array}\right|$ & \begin{tabular}{ll}
\multicolumn{2}{c}{ Ht. } \\
F. & I. \\
14 & 1
\end{tabular} & $\begin{array}{l}\text { Tu. } \\
\text { W. }\end{array}$ & & 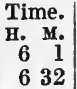 & $\begin{array}{c}\text { Ht. } \\
\text { F. } \\
14 \\
14 \\
14 \\
11\end{array}$ & $\left|\begin{array}{rr}\text { Time. } \\
\mathrm{H} . & \mathrm{M} \\
\mathbf{6} & 16 \\
6 & 48\end{array}\right|$ & $\begin{array}{l}\text { Ht. } \\
\text { F. } 14 \\
1411 \\
1411\end{array}$ & $\begin{array}{l}\text { F. } \\
\text { S. }\end{array}$ & $\frac{1}{2}$ & $\begin{array}{rr}\text { Time. } \\
\mathbf{B} . & \text { M. } \\
6 & 34 \\
7 & 10\end{array}$ & $\begin{array}{l}\text { Ht. } \\
\text { F. } \\
15 \\
14 \\
14 \\
11\end{array}$ & 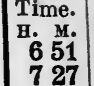 & $\begin{array}{l}\text { Ht. } \\
{ }_{15}{ }^{1} \\
14\end{array}$ \\
\hline$S$. & 2 & 550 & 141 & $\begin{array}{ll}6 & 7\end{array}$ & 14 & Th. & 3 & $\begin{array}{ll}7 & 5 \\
7 & 1\end{array}$ & $\begin{array}{ll}14 & 9 \\
1\end{array}$ & 721 & & & & & & & \\
\hline $\begin{array}{l}\text { M. } \\
\text { Tu. }\end{array}$ & 3 & $\begin{array}{ll}62 \\
62\end{array}$ & $\begin{array}{ll}14 & 1 \\
14 & 1\end{array}$ & $\begin{array}{ll}6 & 41 \\
7 & 17\end{array}$ & & F. & $\begin{array}{l}4 \\
5\end{array}$ & 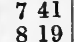 & $\begin{array}{rr}14 & 5 \\
13 & 10\end{array} \mid$ & $\begin{array}{ll}8 & 0 \\
8 & 41\end{array}$ & $\begin{array}{ll}14 & 2 \\
13 & 5\end{array}$ & $\begin{array}{l}S . \\
\text { M. }\end{array}$ & $\begin{array}{l}3 \\
4 \\
\end{array}$ & $\begin{array}{lll}7 & 47 \\
8 & 32\end{array}$ & $\begin{array}{ll}14 & 3 \\
13 & 2\end{array}$ & $\begin{array}{ll}8 & 9 \\
9 & 0\end{array}$ & 3 \\
\hline $\begin{array}{l}\text { Tu. } \\
\text { W. }\end{array}$ & $\begin{array}{l}4 \\
5\end{array}$ & $\begin{array}{l}658 \\
736\end{array}$ & $\begin{array}{ll}14 & 1 \\
13 & 10\end{array}$ & 755 & 13 & s. & & & & 021 & 150 & Tu. & 5 & 931 & 12 & 108 & 11 \\
\hline Th. & 6 & $\begin{array}{lll}8 & 16\end{array}$ & & $\begin{array}{lll}8 & 37 \\
0 & 0\end{array}$ & 13 & $s$ & 6 & $\begin{array}{ll}9 & 3\end{array}$ & $\begin{array}{ll}13 & 0 \\
10 & 3\end{array}$ & 927 & 12 & W. & 6 & 1050 & 11 & 1142 & \\
\hline F. & 7 & $\begin{array}{lll}8 & 57 \\
9 & 44\end{array} \mid$ & $\begin{array}{l}13 \\
12\end{array}$ & $\begin{array}{r}920 \\
108\end{array}$ & 4 & M. & 7 & $\begin{array}{r}956 \\
15\end{array}$ & $\begin{array}{rr}12 & 3 \\
11 & 10\end{array}$ & 1029 & & Th. & 8 & $\overline{112}$ & & $\begin{array}{ll}0 & 30 \\
1 & 0\end{array}$ & 1111 \\
\hline & & & 12 & & & $\begin{array}{l}\text { Iu. } \\
\text { W. }\end{array}$ & $\begin{array}{l}8 \\
9\end{array}$ & 118 & 1110 & $\left|\begin{array}{rl|}11 & 52 \\
0 & 36\end{array}\right|$ & $12^{1}$ & S. & 8 & $\begin{array}{lll}1 & 12 & 2 \\
2 & 20\end{array}$ & $\begin{array}{ll}12 & 5 \\
13 & 9\end{array}$ & $\begin{array}{l}150 \\
249\end{array}$ & 13 \\
\hline i. & 9 & 1037 & 12 & 1111 & 122 & Th. & 10 & $\begin{array}{ll}1 & 17\end{array}$ & 125 & $\begin{array}{lll}1 & 53 \\
0 & 50\end{array}$ & 1211 & & & & & & \\
\hline & 10 & $\begin{array}{rr}11 & 45 \\
0 & 19\end{array}$ & $\begin{array}{ll}12 & 3 \\
12 & 4\end{array}$ & & 127 & F. & 11 & $\begin{array}{ll}2 & 27 \\
3 & 29\end{array}$ & $\begin{array}{rr}13 & 7 \\
14 & 10\end{array}$ & 259 & 142 & S. & $\begin{array}{l}10 \\
11\end{array}$ & \begin{tabular}{ll|}
3 & 14 \\
3 & 59
\end{tabular} & $\begin{array}{ll}15 & 0 \\
16 & 1\end{array}$ & $\begin{array}{l}336 \\
41\end{array}$ & \\
\hline u. & $\begin{array}{l}11 \\
12\end{array}$ & $\begin{array}{ll}0 & 19 \\
1 & 32\end{array}$ & $\begin{array}{ll}12 & 4 \\
12 & 11\end{array}$ & $\begin{array}{ll}0 & 56 \\
2 & 3\end{array}$ & $\begin{array}{ll}12 & 7 \\
13 & 4\end{array}$ & s. & 12 & 329 & 1410 & 303 & 154 & Tu. & 12 & $\begin{array}{ll}4 & 09 \\
4 & 40\end{array}$ & 16 & 459 & $\begin{array}{l}10 \\
1611\end{array}$ \\
\hline h. & 13 & 237 & 139 & & 143 & $S$. & 13 & 419 & 1511 & 443 & & w. & 13 & 519 & 17 & & \\
\hline F. & 14 & 336 & 14 & 4 & 15 & M. & 14 & & $\begin{array}{ll}16 & 9\end{array}$ & 527 & & Th. & 14 & 55 & & 19 & 16 \\
\hline & 15 & 431 & 15 & 45 & 16 & Tu. & $\left|\begin{array}{l}15 \\
16\end{array}\right|$ & $\begin{array}{ll}5 & 48 \\
6 & 31\end{array}$ & $\begin{array}{ll}17 & 0 \\
16 & 8\end{array}$ & 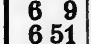 & $\begin{array}{ll}16 & 11 \\
16 & 4\end{array}$ & F. & $\begin{array}{l}15 \\
16\end{array}$ & & $\begin{array}{l}1510 \\
1410\end{array}$ & & \\
\hline$S$. & 16 & 520 & 16 & 545 & 16 & Th. & 17 & 710 & 160 & 729 & & & & & & & \\
\hline I. & 17 & & 16 & 63 & & F. & 18 & 749 & 1411 & $\begin{array}{ll}8 & 9 \\
0 & 9\end{array}$ & & $S$. & 17 & $\begin{array}{lll}7 & 55 \\
0 & 50\end{array}$ & 136 & 815 & \\
\hline Tu. & 18 & $\begin{array}{ll}6 & 57 \\
7 & 42\end{array}$ & $\begin{array}{ll}16 & 3 \\
15 & 8\end{array}$ & 81 & $\begin{array}{l}1511 \\
15\end{array}$ & S. & 19 & 832 & 138 & & & M. & $\left|\begin{array}{l}18 \\
19\end{array}\right|$ & $\mid$\begin{tabular}{ll|}
8 & 39 \\
9 & 32
\end{tabular} & $\begin{array}{ll}12 & 1 \\
10 & 11\end{array}$ & $\begin{array}{rr}9 & 5 \\
10 & 12\end{array}$ & \\
\hline h. & 20 & 825 & 14 & & 142 & s. & 20 & 914 & 12 & & & W. & 20 & 1053 & & 10 & \\
\hline F. & 21 & $\begin{array}{lll}9 & 12\end{array}$ & 13 & 93 & 13 & M. & 21 & 1012 & 11 & 1053 & 109 & Th. & 21 & & & & 10 \\
\hline S. & 22 & $\begin{array}{ll}10 & 1\end{array}$ & 125 & 103 & 120 & Tu. & $\begin{array}{l}22 \\
23\end{array}$ & $\begin{array}{rr}11 & 33 \\
0 & 17\end{array}$ & $\begin{array}{ll}10 & 8 \\
10 & 8\end{array}$ & $\overline{0} 59$ & $\overline{1010}$ & F. & $\left|\begin{array}{l}22 \\
23\end{array}\right|$ & $\begin{array}{ll}1 & 2 \\
2 & 7\end{array}$ & 1011 & & 11. \\
\hline 8 & 23 & $\begin{array}{ll}11 & 1\end{array}$ & 11 & 1137 & 115 & Th. & 24 & 137 & 111 & 29 & 116 & & & & & & \\
\hline I. & 24 & & & 014 & 11 & F. & 25 & 236 & 1111 & & 125 & $S$. & 24 & $\begin{array}{ll}2 & 50 \\
2 & 2\end{array}$ & 1211 & & 13 \\
\hline Cu. & 25 & $\begin{array}{lll}0 & 51 \\
2 & 3\end{array}$ & $\begin{array}{ll}11 & 3 \\
11 & 8\end{array}$ & 12 & \begin{tabular}{|rr}
11 & 5 \\
11 & 11
\end{tabular} & S. & 26 & 324 & 1210 & 340 & & M. & 25 & 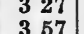 & 134 & & \\
\hline & 27 & 258 & 123 & 32 & 127 & $s$. & 27 & 357 & & 41 & & W. & 27 & 429 & 15 & & \\
\hline & 28 & 345 & 1211 & 4 & 132 & M. & 28 & 430 & & 4 & 1411 & Th. & 28 & 459 & 1511 & & \\
\hline s. & & 422 & 136 & & & Tu. & 29 & $\begin{array}{lr}5 & 0 \\
5 & 33\end{array}$ & 15 & $\mathbf{5}$ & & F. & 29 & $\begin{array}{lll}5 & 32 \\
6 & 9\end{array}$ & 16 & & \\
\hline s. & 30 & 457 & 14 & 513 & 14 & Th. & 31 & $\begin{array}{ll}6 & 2\end{array}$ & 158 & 619 & 157 & & & & & & \\
\hline 1. & 31 & 529 & & & & & & & & & & & & & & & \\
\hline & & & & & & & & & & & & & & & & & \\
\hline
\end{tabular}

P.M. times and heights are printed in large block type.

The times given are STANDARD, or mean time of the meridian of Dublin, or $6^{\circ} 20^{\prime} \mathrm{W}$. from Greenwich. To obtain local mean time subtract 11 minutes.

The zero of the predictions, which is also the datum of the Admiralty chart of Galway, is 1.30 feet above Ordnance datum, and is 0.75 foot below the level of mean low-water spring tides.

TIDAL DIFFERENCES ON GALWAY.

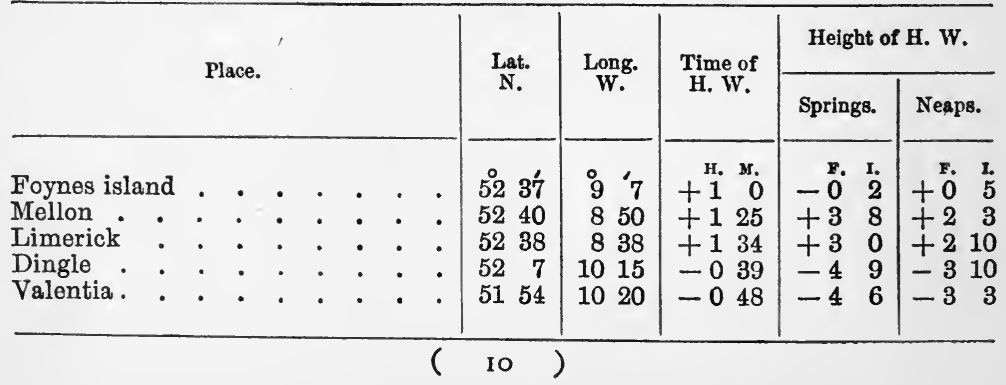


CANADA, ATLANTIC COAST-ST. $\mathcal{F O H N , ~ N . B . ~}$

H. W. F. \& C. $\begin{cases}\mathrm{XI} \\ \text { XI. } 21^{\mathrm{M}} . & \text { (Local mean time). }\end{cases}$

Lat. $45^{\circ} 16^{\prime} \mathrm{N}$. Long. $66^{\circ} 3^{\prime} \mathrm{W}$.

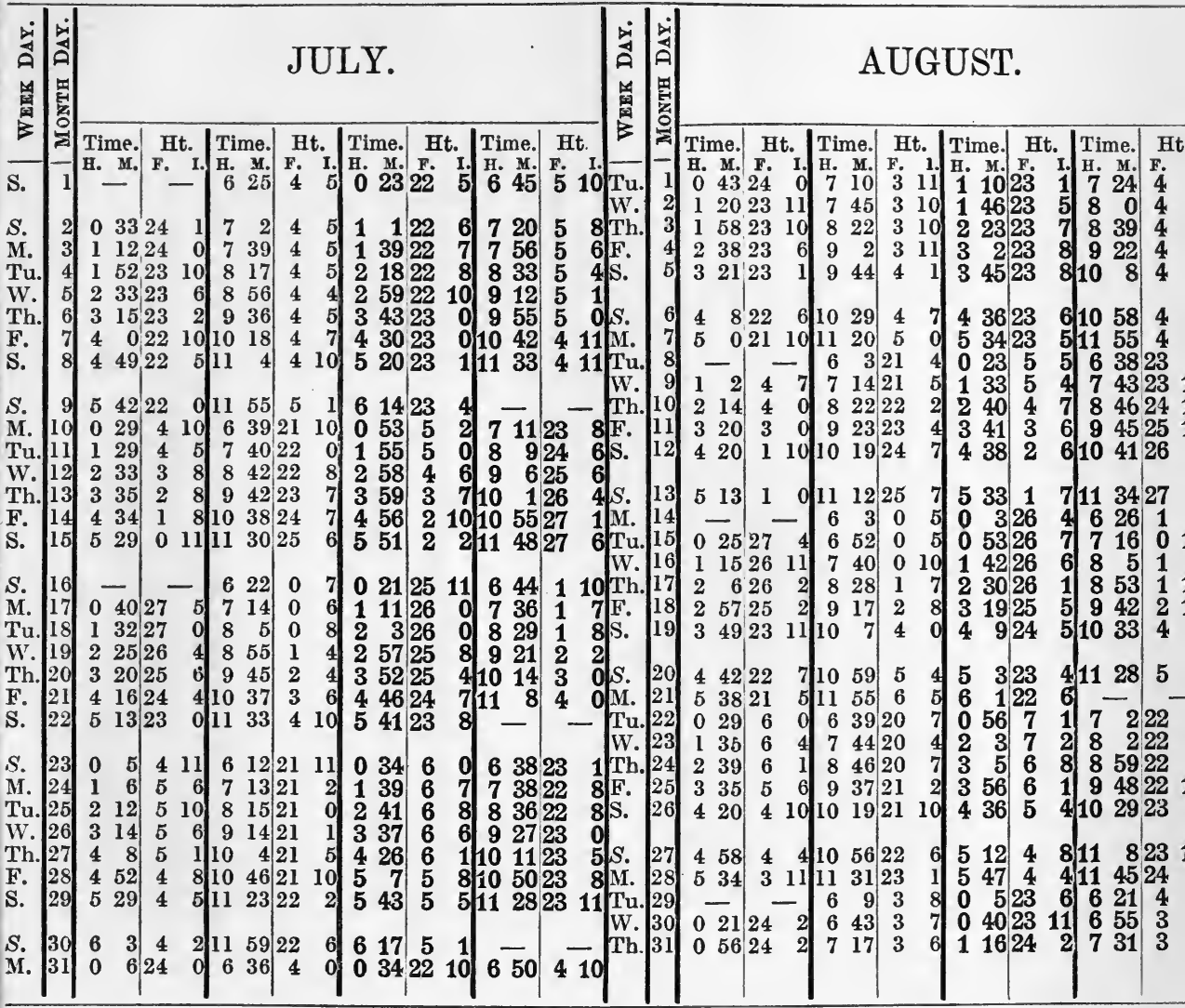

* Signifies below Datum.

The tides are placed in order of occurrence, p.m. times and heights being printed in large block typ A comparison of consecutive heights will indicate whether it is high or low water.

The times given are STANDARD, or mean time of the meridian of $60^{\circ} \mathrm{W}$. from Greenwich. obtain local mean time subtract 24 minutes.

\section{TIDAL DIFFERENCES ON ST. JOHN.}

The zero of the predictions, which is also the datum of the Admiralty chart of St. John, is 55.63 fe below a bench mark near the south-east corner of the Custom House, and is approximately $2 \frac{1}{4}$ fe below the level of mean low water spring tides.

\begin{tabular}{|c|c|c|c|c|c|c|c|c|c|c|}
\hline \multirow{2}{*}{ Place. } & & \multirow{2}{*}{$\begin{array}{l}\text { Lat. } \\
\text { N. }\end{array}$} & \multirow{2}{*}{$\begin{array}{l}\text { Long. } \\
\text { w. }\end{array}$} & \multicolumn{2}{|c|}{ Time of } & \multicolumn{3}{|c|}{ Height of H. W. } & \multicolumn{2}{|c|}{ Height of L.W. } \\
\hline & & & & H. w. & L. W. & Springs. & Neaps & & Springs. & Neaps. \\
\hline $\begin{array}{l}\text { Seal Cove } \\
\text { Welchpool } \\
\text { St. Andrews. } \\
\text { Quaco . }\end{array}$ & & $\begin{array}{rr}44 & 37 \\
44 & 53 \\
45 & 4 \\
45 & 20\end{array}$ & $\begin{array}{rr}66 & 51 \\
66 & 58 \\
67 & 3 \\
65 & 32\end{array}$ & $\begin{array}{rr}\text { स. } & \text { M. } \\
-0 & 22 \\
+0 & 2 \\
+0 & 8 \\
+0 & 12\end{array}$ & $\begin{array}{c}\text { н. м. } \\
+\ldots \\
+010 \\
+018 \\
\ldots\end{array}$ & $\begin{array}{rr}\text { F. } & \text { I. } \\
-5 & 6 \\
-2 & 0 \\
-0 & 6 \\
+4 & 6\end{array}$ & $\begin{array}{r}F \\
-6 \\
-1 \\
0 \\
0 \\
+3\end{array}$ & $\begin{array}{l}\text { I. } \\
6 \\
6 \\
0 \\
6\end{array}$ & $\begin{array}{l}\text { F. } \quad \text {. } \\
\ldots \\
\ldots \\
\ldots \\
\ldots\end{array}$ & $\begin{array}{l}\text { F. } \text { I. } \\
\ldots \\
\ldots \\
\ldots \\
\ldots\end{array}$ \\
\hline
\end{tabular}


PERSIAN GULF-ABU SHAHR (BUSHIRE).

H. W. F. \& C. VIIH. $43^{M}$.

Lat. $28^{\circ} 54^{\prime} \mathrm{N}$. Long. $50^{\circ} 43^{\prime} \mathrm{E}$.

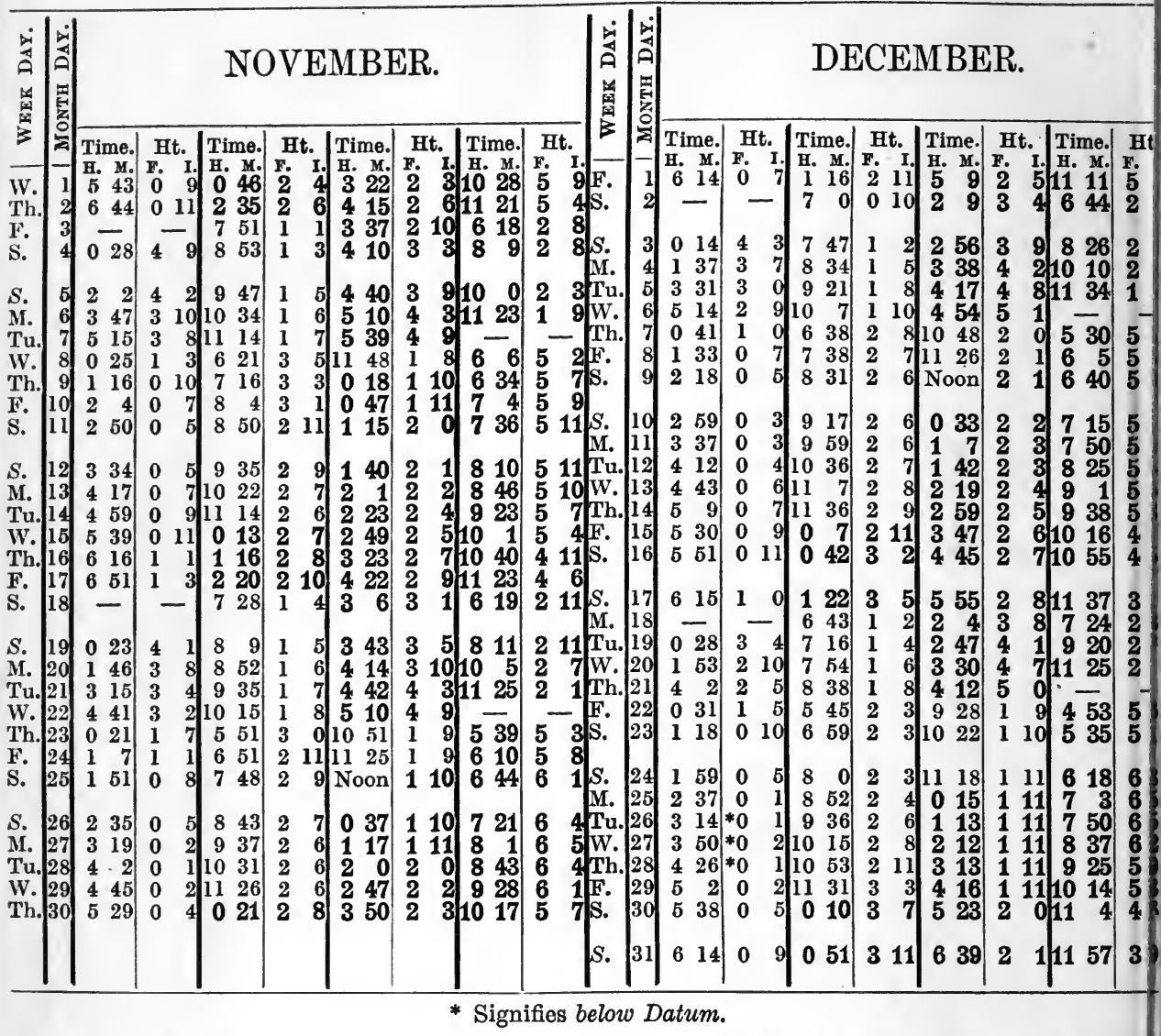

The tides are placed in order of occurrence, p.m. times and heights being printed in large blok type. A comparison of consecutive heights will indicate whether it is high or low water.

The times given are LOCAL MEAN TIME.

PERSIAN GULF.

\begin{tabular}{|c|c|c|c|c|c|c|c|}
\hline \multirow{2}{*}{ Place. } & \multicolumn{3}{|c|}{ Position. } & \multicolumn{2}{|c|}{ H. W. F. \& C. } & \multicolumn{2}{|c|}{ Rise. } \\
\hline & $\begin{array}{l}\text { Lati- } \\
\text { tude. }\end{array}$ & $\begin{array}{c}\text { Longi- } \\
\text { tude. }\end{array}$ & $\begin{array}{l}\text { Long. } \\
\text { in Time. }\end{array}$ & $\begin{array}{l}\text { M. T. } \\
\text { Place. }\end{array}$ & G. M. T. & Springs. & Neaps. \\
\hline $\begin{array}{l}\text { Kuweit } \\
\text { Shatt al Arab: Al Basra } \\
\text { ABU SHAHR or BusHIRE } \\
\text { Henjam island anchorage }\end{array}$ & $\begin{array}{lr}29 \\
29 & 22 \\
30 & 30 \\
29 & 0 \\
26 & 41\end{array}$ & $\begin{array}{lr}\text { E. } \\
48 & 0 \\
47 & 53 \\
50 & 43 \\
55 & 54\end{array}$ & $\begin{array}{rl}\text { H. } & \text { M. } \\
3 & 12 \\
3 & 12 \\
3 & 23 \\
3 & 44\end{array}$ & $\begin{array}{rr}\text { н. } & 3 . \\
0 & 13 \\
6 & 0 \\
7 & 43 \\
11 & 30\end{array}$ & $\begin{array}{lr}\text { н. } & \text { м. } \\
9 & 1 \\
2 & 48 \\
4 & 20 \\
7 & 46\end{array}$ & $\begin{array}{c}\text { Feet. } \\
11 \frac{1}{2} \\
9 \\
6 \\
101\end{array}$ & $\begin{array}{l}\text { Feet. } \\
8 \\
\dddot{5} \\
7 \ddagger\end{array}$ \\
\hline
\end{tabular}





\section{RETURN CIRCULATION DEPARTMENT}

TO $\rightarrow 202$ Main Library

\begin{tabular}{l|l|l}
\hline $\begin{array}{l}\text { LOAN PERIOD 1 } \\
\text { HOME USE }\end{array}$ & 2 & 3 \\
\hline 4 & 5 & 6 \\
\hline
\end{tabular}

ALL BOOKS MAY BE RECALLED AFTER 7 DAYS

Renewals and Recharges may be made 4 days prior to the due date.

Books may be Renewed by calling 642-3405.

\section{DUE AS STAMPED BELOW}

\begin{tabular}{l|l|l}
\hline APR 04 1988 & & \\
\hline & & \\
\hline & & \\
\hline & & \\
\hline & & \\
\hline & & \\
\hline & & \\
\hline & & \\
\hline FORM NO. DD6, & & BNIVERELEY, CA 94720 \\
\hline
\end{tabular}


2354 senerg

\section{YC 03276}

\section{U.C. BERKELEY LIBRARIES}

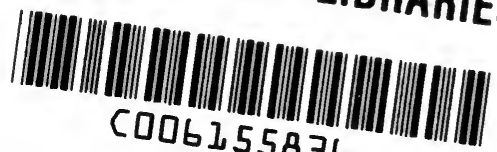

C006155836

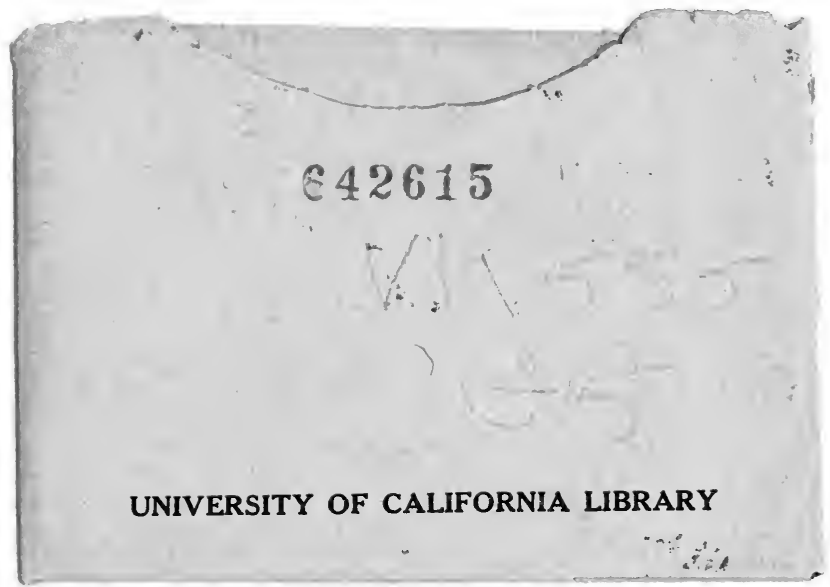




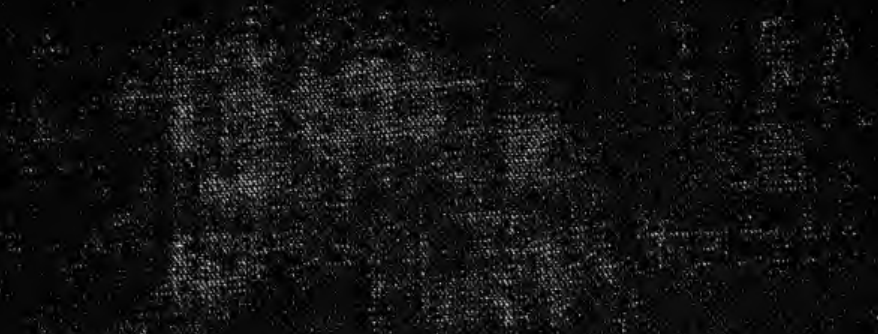

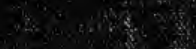
的

(2)

-

(2)

(

x.

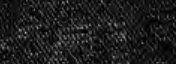

2 . 98

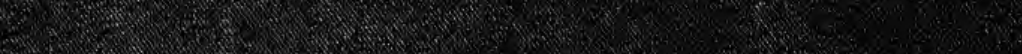

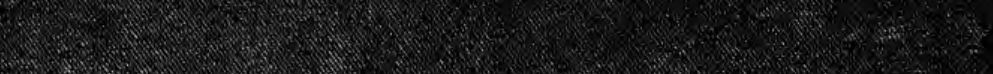

.

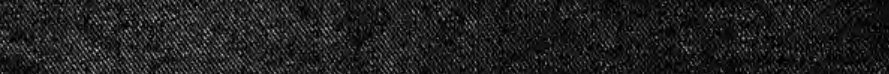

. . . . . . . . . . . . . . . . . . . . .

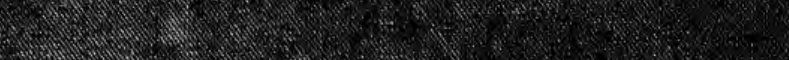

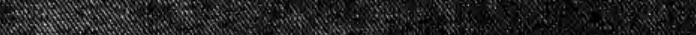

$\ldots \ldots \ldots$ 